\section{Francho Nagore Laín}

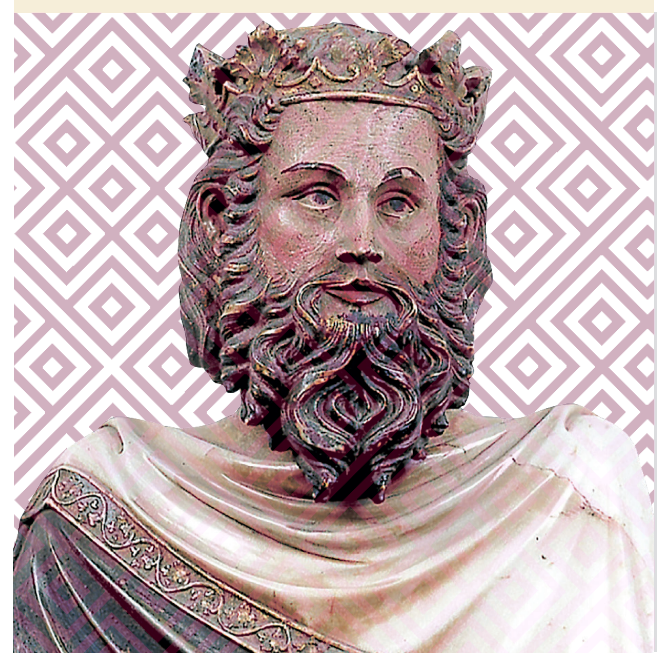

\section{VOCABULARIO DE LA CRÓNICA DE SAN JUAN DE LA PEÑA Versión aragonesa, s. XIV}




\section{VOCABULARIO DE LA CRÓNICA \\ DE SAN JUAN DE LA PEÑA}

Versión aragonesa, s. XIV 
Francho Nagore Laín

\section{VOCABULARIO DE LA CRÓNICA DE SAN JUAN DE LA PEÑA \\ Versión aragonesa, s. XIV}


Cualquier forma de reproducción, distribución, comunicación pública o transformación de esta obra solo puede ser realizada con la autorización de sus titulares, salvo excepción prevista por la ley. Diríjase a CEDRO (Centro Español de Derechos Reprográficos, www.cedro.org) si necesita fotocopiar o escanear algún fragmento de esta obra.

(C) Francho Nagore Laín

(C) De la presente edición, Prensas de la Universidad de Zaragoza

(Vicerrectorado de Cultura y Proyección Social)

1. ${ }^{\mathrm{a}}$ edición, 2021

Colección Papers d'Avignon, n. ${ }^{\circ} 6$

Director de la colección: José Domingo Dueñas Lorente

http://catedrajohanferrandezdheredia.lenguasdearagon.org/publicaciones/

Prensas de la Universidad de Zaragoza. Edificio de Ciencias Geológicas, c/ Pedro Cerbuna, 12 50009 Zaragoza, España. Tel.: 976761330.

puz@unizar.es http://puz.unizar.es

Uithe Esta editorial es miembro de la UNE, lo que garantiza la difusión y comercialización de sus publicaciones a nivel nacional e internacional. 


\section{INTRODUCCIÓN}

\section{La «Crónica de San Juan de la Peña»*}

El texto conocido como Crónica de San Juan de la Peña es una narración histórica notable por diferentes motivos: el hecho de haberse conservado en versión aragonesa, catalana y latina; su gran extensión; su importancia desde el punto de vista historiográfico. Se trata de un texto propio de la cancillería de la Corona de Aragón, como demuestra el hecho de que se redactase a instancias de Pedro IV, posiblemente para servir de preámbulo a la crónica de su reinado. Es también indicativo el hecho de que se redactase primero en latín para traducirse casi simultáneamente al aragonés y al catalán, tal como era costumbre en la cancillería real de la Corona de Aragón (cfr. Orcástegui, 1986: 5).

Por eso, la lengua del texto de la versión aragonesa presente una similitud básica con respecto al aragonés cancilleresco usado a lo largo de los siglos XIII, XIV y XV en los diversos documentos administrativos y diplomáticos, así como cartas personales, etc., emanados de los propios monarcas de la Corona de Aragón y redactados en su mayoría por escribanos oficiales que dominaban suficientemente tanto el catalán como el aragonés (cfr. COLÓN, 1989: 237-270).

También coincide básicamente con la lengua utilizada en las actas de las Cortes de Aragón, así como en obras jurídicas ( $v$ gr., Vidal Mayor, del siglo XIII) y en obras históricas ( $v$ gr., compilaciones de Juan Fernández de Heredia, del siglo XIV), aunque en estas se pueden encontrar pequeñas diferencias

*Esta parte de la introducción sobre la Crónica de San Juan de la Peña es una adaptación de NAGORE (2003a: 35-61). 
que se explican por la diferente cronología de su redacción así como por la procedencia del autor, copista o traductor. En este sentido, la mayoría de las obras atribuidas al scriptorium de Juan Fernández de Heredia (Johan Ferrández d'Eredia) presentan un aragonés propio de las Serranías Ibéricas (es decir, con algunos tratamientos fonéticos semejantes al castellano), o al menos con muchos elementos comunes a este tipo de aragonés de las zonas suroccidentales de Aragón, tal como se manifiesta tanto en obras jurídicas (por ejemplo, el Fuero de Teruel: vid. la ed. de M. Gorosch, 1950; vid. también NAGore, 2007) como en documentos notariales (véase TERRADO, 1991) o cronísticos (véanse las Crónicas de los Jueces de Teruel, ed. de López RAJADEL).

\subsection{Contenido, autor y fecha de redacción}

La Crónica de San Juan de la Peña fue conocida en la Edad Media como Coronicas de los senyores reyes d'A ragón o Cròniques dels reys d'A ragó e comtes de Barchinona, o Cronice Regum Aragonum et Comitum Barchinone.

A partir de Zurita viene siendo tradicional nombrarla como Crónica de San Juan de la Peña, y siguiendo esa tradición, Tomás Ximénez de Embún respetó ese título como subtítulo en su edición de 1876 (generalmente conocida como Crónica de San Juan de la Peña), aunque añadió como título principal Historia de la Corona de Aragón. Las ediciones posteriores han conservado la denominación de Crónica de San Juan de la Peña: así, la que realizó en 1961 Antonio Ubieto de la versión latina y la edición crítica de la versión aragonesa publicada en 1986 por Carmen Orcástegui. Sin embargo, también se han propuesto otros títulos: Crònica General de Catalunya y Aragó, Crònica General de Pere III el Cerimoniós o Crónica General de la Corona de Aragón.

\subsubsection{Contenido}

Por su contenido es, efectivamente, una historia general de la Corona de Aragón, con la única excepción de los tres primeros capítulos, que tratan de los pobladores de España antes de la invasión de los árabes. Pero se centra enseguida en el núcleo de resistencia al Islam que los cristianos constituyen en el Pirineo, en torno a San Juan de la Peña. Recoge luego la historia de los reyes aragoneses, aunque en la época condal da primacía a los reyes de Pamplona y, en cambio, a partir de la formación del reino de Aragón independiza la historia centrándose únicamente en los reyes propiamente aragoneses. El hilo conduc- 
tor del relato se quiebra, para incluir el relato de los condes catalanes desde sus orígenes. Ambas historias confluyen en la creación de la Corona de Aragón, a partir de la cual se sigue una sola línea narrativa desde Alfonso II hasta Alfonso IV el Benigno, con cuya muerte termina el relato en 1335 (si bien añade tres líneas para nombrar el traslado de sus restos a Lérida, hecho que se produjo en 1369).

Así pues, y siguiendo a Antonio Ubieto Arteta (1950) y Antonio DuRÁN GUdIol (1988), pueden distinguirse claramente cuatro partes, que de acuerdo con la extensión y por lo tanto la atención que la narración dedica a cada una de ellas, podemos esquematizar así:

Introducción. Es una breve descripción de la historia de la Península Ibérica hasta la invasión musulmana. Ocupa los capítulos 1 a 3, que suponen 157 líneas, es decir el 3,65\% del contenido total del texto.

$1^{a}$ parte. Narración de los hechos de los reyes de Pamplona, de los condes de Aragón y de los reyes de la dinastía aragonesa. Caps. 4-21. Número total de líneas: 1.301, equivalente al 30,4\% de la extensión total. Se podría desglosar en dos subpartes: 1) Capítulos 4 al 14, referente a los reyes de Pamplona y a los condes de Aragón; 2) Capítulos 15 al 21, referente a los reyes de la dinastía aragonesa.

$2^{a}$ parte. Narración de las gestas de los condes catalanes y en especial de la historia del condado de Barcelona. Ocupa los capítulos 22 a 32. Ocupa 419 líneas, que representan el 9,72\%.

$3^{a}$ parte. Trata de los reyes de Aragón y condes de Barcelona, es decir de los monarcas de la Corona de Aragón desde Alfonso II hasta Alfonso IV. Ocupa los capítulos 33 a 39. El número total de líneas es de 2.432, que supone el $56,90 \%$ del total.

Vemos que hay una evidente desproporción respecto al interés que el cronista dedica a cada parte y en consecuencia la extensión es muy desigual. En efecto, los siete capítulos finales constituyen más de la mitad del texto. Esto ya ha sido hecho notar por diversos autores, destacando el esquematismo de las dos primeras partes, propio de los cronicones antiguos, frente a la prosa más elaborada y la narración más minuciosa y extensa de la última, en especial a partir del capítulo 35, que trata de Jaime I el Conquistador. Muy probablemente, la extensión de cada parte estaba en relación con los materiales que pudo manejar el cronista. 
Para redactar la introducción el cronista se basó principalmente en De rebus Hispanice de Ximénez de Rada. El capítulo primero habla de los ybers, cetubals y griegos; el segundo de los romanos, vándalos y alanos; el tercero de los godos, especificando su genealogía, terminando con don Rodrigo y su derrota por los musulmanes con la consiguiente ocupación de estos de toda la Península.

Para los capítulos 4 al 21 la fuente principal fue la Crónica de los Estados Peninsulares o Crónica navarro-aragonesa, hasta el punto de copiar algunos párrafos literalmente, que amplió con relatos épico-legendarios, como el de la Campana de Huesca. También parece que el cronista utilizó documentos del archivo del monasterio de San Juan de la Peña. Además para la parte relativa al siglo x (capítulos 10-13) utilizó posiblemente el Liber Regum o una fuente común a este y a la Crón. SJP. También se basó en el Libro de San Voto (cfr. UBieto, 1950).

Antonio Durán (1988: 315-323) denomina “Crónica 1 de San Juan de la Peña" a un breve texto en latín titulado Privilegium Sancti Iohannis de Pinna, que narra los acontecimientos de los años 711 a 959. Este texto, redactado por un anónimo monje de San Juan de la Peña a finales del siglo XII, sería aprovechado a fondo, según Durán, para la redacción de los capítulos IV-VI de la Crón. SJP., justo a partir del momento en que dice: Porque aqui solament de los reyes de Aragón y de Navarra entendemos tractar, porque muytos tiempos fueron unos, segunt veredes. 4.10-12. De manera que los capítulos XII-XXI serían una continuación de la llamada por Durán "Crónica 1 de San Juan de la Peña". Según este autor, solo la primera parte, capítulos IV-XXI, merecen con propiedad el título de Crónica de San Juan de la Peña, ya que es el monasterio pinatense el eje conductor de la narración y su archivo la principal fuente de información del cronista.

Según Antonio Ubieto (1981: 43) también se utilizó la Vita Sanctorum Voti et Felicis, atribuida a un monje de San Juan de la Peña llamado Macario, para el capítulo 4, y las líneas 17.58-102 (págs. 56-58 de la VL) coinciden "textualmente con unos Anales procedentes del monasterio de San Juan de la Peña."

El capítulo 4 narra la derrota de los cristianos y su refugio en el monte Uruel, junto a Jaca. El cap. 5 trata de la edificación del monasterio de San Juan de la Peña, llegando al año 778 (ms. B) o 888 (ms. N y VL), en que dice que en Aragón sennyoriava el comte Azunar 5.19. Es, pues, la última fecha la que parece acercarse más a la realidad.

En los siguientes capítulos, brevísimos, habla de los reyes de Pamplona García Ximenez y García Ennego (cap. 6), Fortunnyo García (cap. 7) y el Conde Galindo (Aznárez) de Aragón (cap. 8). El cap. 9, algo más extenso, se centra en el rey de Pamplona Sancho García; el 10 en Exemen García y el 11 en García 
Enneguez: El cap. 12 recoge el nacimiento legendario de Sancho García (Sancho Garcés II Abarca, 970-994) y su entronización como rey. El cap. 13 trata del rey García tiemblador (994-1000). Y el cap. 14 reseña los hechos de Sancho Garcés III, el Mayor (1000-1035).

El capítulo 15 es un simple enlace en que el narrador explica que a partir de ahora la crónica hablará sólo de los reyes de Aragón. De esta forma, el cap. 16 recoge los hechos del rey Remiro I (1035-1063); el cap. 17 de Sancho Remírez (1063-1094); el cap. 18 de Pedro I (1094-1104), con la narración de la batalla de Alcoraz y la aparición de San Jorge; el cap. 19 de Alfonso I el Batallador (1104-1134); el cap. 20 de Remiro II el Monje (1134-1137), incluyendo por extenso el episodio de la Campana de Huesca.

Hay varias referencias del redactor de la Crón. SJP. a fuentes utilizadas, aunque no siempre esté claro a cuáles se refiere. He aquí las principales referencias:

... segunt que las coronicas dizen mas largament, las de Castiella, en otro volumpne de livro et la batalla y mete. 3.93-95; Et los que fincaron en Asturias fizieron rey a Pelayo, según en el livro de las corónicas de Castiella yes contenido 4.8-10; del qual se conta mas largament en la crónica de don Sancho Remirez 20.61-62; algunas cronónicas [corónicas N] dizen que no era en sacres órdenes. 20.72.

O en el mismo capítulo 20, dedicado a Remiro II:

...cobró la dita tierra de Aragón, la qual tenía el emperador don Alfonso de Castiella a homenage, según en la su crónica yes contenido. 20.315-317; segunt la crónica de don Rodrigo que alli era. 34.95.

En esta última cita parece refererirse a Rodrigo Ximénez de Rada, autor de la crónica en latín titulada De rebus Hispaniae.

El cap. 21 es un simple enlace: el narrador explica que a partir de ahora relatará la vida y sucesión de los condes de Barcelona.

Los capítulos 22-32, breves y esquemáticos, narran las gestas de los condes de Barcelona, con numerosas referencias a otros condes dependientes de éste, con lo que el relato se enmaraña de tal forma que es difícil de seguir. Resumiendo al máximo, el cap. 22 trata del conde Guiffre; el 23 de Guiffre (o Iuffre) Pelloso (+912); el 24 del conde Mir (+929); el 25 de Guiffre (o Sifre) (+964); el 26 del conde Borrel (+993); el 27 de Remón Burrel (+1017); el 28 de Berenguer (1034); el 29 de Remón Berenguer (I), Viello (+1076); el 30 de Remón Berenguer (II), Cap d'Estopa (+1082); el 31 de Remón Berenguer (III) (+1131); el 32 de Remon Berenguer (IV) (1131-1162), capítulo en el cual se vuelve a enlazar con la dinastía aragonesa, al casar este último conde con doña Petronila en 1137. 
Esta parte está basada en una versión catalana de las Gesta Comitum Barchinonensium (OrCástegui, 1986: 5). Aquí coinciden plenamente con la VA tanto la VC como la VL.

La última parte es, como hemos dicho, la más amplia. El cap. 33 recoge la vida de Alfonso (II) el Casto (1162-1196); el cap. 34 trata de Pero (II) el Católico, hasta su muerte en Murel (Muret) en 1213; el cap. 35 recoge la vida y hechos de Jayme el Venturoso (Jaime I el Conquistador, 1113-1276), siendo de destacar las palabras de despedida a su hijo Pedro y las oraciones antes de su muerte, párrafos en estilo directo (35.235-300) que unen a su interés lingüístico, una honda emoción contenida y un cuidado estilo literario. El extensísimo cap. 36 trata del reinado de Pedro el Grant (Pedro III, 1276-1285), con detalladas descripciones de las guerras de Sicilia y con Francia. El cap. 37 trata de Alfonso III el Franco (1285-1291). El cap. 38, también muy extenso, se refiere al reinado de Jayme (II) (1291-1327). Y, por último, el cap. 39 recoge muy brevemente el reinado de Alfonso (IV) el Benigno (1327-1336).

Para la redacción de los caps. 33 al 35, ambos inclusive, se utilizaron, según Antonio Ubieto, noticias mezcladas procedentes tanto de las Gesta Comitum como de la Crónica de los Estados Peninsulares, pero desde el cap. 36 hasta el final, opina Ubieto (1950: 488; 1961: 12-13), se emplearon «otras crónicas», en especial la historia de los reyes de Sicilia. Indica: «Es natural que los acontecimientos más cercanos al cronista fuesen mejor conocidos por él y que las fuentes disponibles fuesen mayores... Esta parte es la que Pedro IV o la persona por él designada, escribió de una forma más personal». Esta persona designada por Pedro IV es, según Rubió i Lluch (1909-1910: 545 y 547), Tomás de Canyellas, secretario real, quien redactaría, entre otros, el cap. 38 dedicado a Jaime II y terminaría la obra.

\subsubsection{Autor}

Es unánime entre los historiadores la opinión de que la Crón. SJP. se escribió a instancias de Pedro IV (Balaguer, 1319-Barcelona 1387, rey desde 1336), para servir de preámbulo a la Crónica de su reinado (la conocida como «Crónica catalana de Pedro IV»). Pero, por un lado, se tardó mucho tiempo en llegar a esta conclusión, y, por otro, hay discrepancias a la hora de valorar exactamente la labor personal del rey y la intervención de ciertos colaboradores.

El primer autor que emitió una opinión al respecto, si bien vaga, fue $\mathrm{Zu}$ rita, al escribir en el propio manuscrito de la VL de la Crón. SJP. que poseía en 
su biblioteca: «Esta es la historia más antigua que se halla del reino de Aragón, que parece ser ordenada por algún monje de San Juan de la Peña». Blancas, en el mismo manuscrito, que también utilizó, concretaba que este monje era un tal Petrus Marfilus. De esta forma se perpetuó durante mucho tiempo no sólo la atribución de un autor supuesto sino también la de un lugar concreto de redacción igualmente hipotético.

Así, según indica Soberanas (1961, VL introducción, p. 7), fue aceptada por Dormer, Abarca, Marca, Briz Martínez, Nicolás Antonio, Pellicer, Moret, Latassa y Abad y Lasierra. Tomás Ximénez de Embún, en su edición de la Crón. SJP. de 1876, sigue aceptando que fue escrita en San Juan de la Peña por un monje llamado Marfilus, aunque ya a finales del siglo XvIII Joaquín Traggia había desestimado tal suposición gratuita (SOBERANAS, 1961: 7).

Cuando el mismo ms. manejado por Blancas y luego guardado en San Juan de la Peña (de donde salió hacia paradero desconocido a finales del s. XVIII o comienzos del xix) fue adquirido por la Biblioteca Nacional de París (en la 2. ${ }^{a}$ mitad del s. XIX), se registró con el n. ${ }^{\circ} 1684$ de Nuevas adquisiciones latinas bajo el título de "Chronicon regum Aragonum, auctore Petro Marfilo, monacho S. Joannis Pinnatensis» (Morel-Fatio, 1893: 97).

Fue ya a principios del siglo xx cuando la situación cambió radicalmente: Gabriel Llabrés (1903), atribuye la Crón. SJP. a Bernat Dezcoll, cronista de Pedro IV y uno de los que intervino con seguridad en la Crónica catalana de este rey. Posteriormente Pagés (1889), González Hurtebise (1904) y Massó Torrents (1906) llegan a la conclusión de que Pedro iv es el único autor de la Crón. SJP.

Finalmente, Rubió y Lluch, aportando nueva documentación, demuestra que el autor no es de forma absoluta el rey Pedro IV, si bien hay «intervenció personal del rey en les dugues obres històriques nacionals del seu regnat [es decir, la crónica particular y la general], i la participació continuada o intermitent de diferents y experts colaboradors». De manera que «les cròniques dels nostres monarques, al menys les del XIV segle, son com una extensió de la cancilleria reyal». Y por lo tanto: «La iniciativa, l'impuls parteix del rey, que's reserva també la direcció i inspecció continuades del treball, y fins la llibertat de retocarlo personalment; els colaboradors son els secretaris o cancillers o l'escrivà de ració que guardava les escriptures, en una paraula, la cancilleria reyal». Añade: «Els colaboradors del rey Pere, que fins ara coneixem, son Tomàs Canyelles y Bernat Dezcoll». (Rubió I Lluch, 1909-1910: 524-225). 
Más adelante explica cómo varios documentos recién descubiertos y publicados en su colección, le han llevado al «ferm convenciment de que'l monarca fou l'iniciador i l'autor, si's vol, d'una part d'aquella obra, per la que mostrà sempre'l major interès e per la qual arreplegà o feu arreplegar importants materials bibliogràfichs i diplomàtichs, però no l'autor únich i material de tota ella».

En concreto parece probado por una carta datada en Perpiñán el 16 de noviembre de 1355 que el rey encarga de la continuación de la Crón. SJP. a su escribano Tomás de Canyelles (Rubió I Luuch, 1909-1910: 545-546; 19081920, I, doc. $n^{\circ} 169$ ). Y de paso prueba también que en la obra intervinieron diversas manos. Entre los escribanos o secretarios de la cancillería de Pedro IV son conocidos los nombres de Francesch de Prohomne, Matheu Adrià, Jaume Conesa, Ferrer Sayol, Bernat de Torre, Bernat de Bonastre y Joan de Barbastro (Rubió I Lluch, 1909-1910; 530-531, 543-544 y 547). Por diferentes razones, Rubió (ibídem, p. 547) cree que al menos el capítulo 38 de la Crón. SJP. lo redactó Tomás de Canyelles. Antonio Ubieto (1950: 488; 1981: 54) acepta la intervención de este en la Crónica.

Por lo demás, todos o algunos de los escribanos citados pudieron colaborar con el rey en alguna parte. Y resulta fácil suponer que el aragonés Joan de Barbastro se encargase, en todo o en parte, de la traducción al aragonés. López Molina afirma a este respecto: «esta crónica fue vertida al aragonés por Juan de Barbastro, de orden del mismo rey, a fin de que Heredia la utilizase más fácilmente». Sabemos que a Joan de Barbastro le fue encargada por Pedro IV la traducción en aragonés de la Suma de las istorias en francés. En carta de 16 de mayo de 1371 escribe Pedro IV a Fernández de Heredia:

segund vos havemos prometido fazemos la dita summa de istorias transladar en aragones, e enviar vos hemos el dito translado logo que sea fecho.

El 13 de septiembre de 1371 Pedro IV escribe a Joan de Barbastro pidiéndole la traducción de «aquells llibres franceses». En enero de 1372 le vuelve a escribir enojado por su tardanza:

Muyto nos maravellamos que del tiempo entaqua que vos tenedes aquellos libros los quales vos havemos mandados que transladedes, no los havedes transladados, mas creemos que mas curades de fazer otros afferes que no de transladar los ditos libros e assin, pus tan mala cura endavedes de transladar los ditos libros, mandamos vos que, vista la present, los nos enviedes con lo que transladado ende havedes, e fazer los hemos transladar a otri quende haura mayor cura que no havedes havida vos tro al dia de buey.

Por último, en carta de 8 de febrero de 1372, Pedro IV rechaza la solicitud de Joan de Barbastro para una escribanía diciendo que no la merece por no haber concluido la traducción de «el libro francés». Pero en 1384 Pedro IV 
paga a Joan de Barbastro por la realización de una copia de la Ordinación de la casa reyal, por lo que es muy probable que siguiese trabajando como escribano para Pedro iv (Rubió i Lluch, 1908-1921, I, docs. nº 236, 238 y 239; Gilkison, 1984: XVIII-XIX y n. 62).

\subsubsection{Fecha de redacción}

La génesis de la Crón. SJP. hay que situarla hacia 1342 ó 1345, aunque posiblemente por esos años no se inicia todavía la redacción, sino solamente la recopilación de materiales.

Como puede deducirse del contenido de varias cartas de Pedro IV en que solicita crónicas sobre gestas y hechos antiguos, se ocupó del estudio y lectura de viejas crónicas durante su larga estancia en Perpiñán en 1345, y durante su permanencia en Valencia desde finales de 1348 a abril de 1350 aprovechó para consagrarse a trabajos históricos (RuBió I Lluch, 1908-1920, I, docs. no 125 , 139, 142 y 143; 1909-1910: 543-544). Poco después, a causa de las turbulencias interiores y las complicaciones exteriores de la guerra con Génova y la rebelión de Cerdeña, que ocuparon la atención del rey durante algunos años, debió encargar la continuación de la Crónica a su secretario, Tomás de Canyellas, que probablemente trabajó en la parte de los reyes posteriores a la unión (RuBIó I Luuch, 1908-1920, I, doc. no 169; 1909-1910: 545). Finalmente, en 1359, parece que ya estaba terminada la redacción en latín y la envía al monasterio de Poblet para que se guardara en su biblioteca. Por otro lado, el 10 de noviembre de 1366 envía una copia en catalán al monasterio de Ripoll (Rubió I Lluch, 1908-1920, I, doc. no 189).

El 10 de febrero de 1372 Pedro IV escribe una carta a Juan Fernández de Heredia a propósito de una traducción en aragonés de la Suma de las istorias en francés y al mismo tiempo le promete enviar una traducción de la Crónica (Rubió I Lluch, 1908-1920, I, doc. nº 248; Gilkison, 1984: XIX).

...e otrossi faremos translatar las coronicas que demandedes de los senyores reyes dAragon nuestros predecessores, e vos enviaremos el translat, por que lo fagades continuar en las coronicas d'espanya, segunt nos havedes fecho saber que lo entendedes fazer...

Así, pues, en resumen: en 1359 estaba ya terminada la redacción en latín; en 1366 la redacción en catalán; en 1372 se encarga la traducción al aragonés.

Dado que en el cap. 39 de la Crón. SJP. se narran hechos ocurridos en 1369, en concreto el traslado de los restos de Alfonso IV a Lérida, que se 
realizó el 17 de abril de 1369, fecha comprobada documentalmente, Antonio UBIETO piensa que el texto latino se escribió entre 1369 y 1372, fecha esta última en que Pedro IV envía un códice de la Crónica, escrito en latín, a la catedral de Valencia.

Hay, efectivamente, contradicción entre el año que diversos autores admiten como fecha de terminación (1359) y los hechos narrados en el último capítulo, que datan de 1369. Esto sólo puede explicarse proponiendo, como hace UBIETO, una fecha de terminación posterior o suponiendo — como otros autores apuntan - una añadidura ulterior. Sin embargo, también hay que tener en cuenta que, en el conjunto de los textos en catalán, en latín y en aragonés, hay dos versiones diferentes, según Jordi RuBió (1936: 347): una más breve, representada por dos ms. en catalán (los de la Biblioteca del Palacio Real —hoy en la Univ. de Salamanca - y de la Biblioteca Universitaria de Valencia); otra más extensa, representada por los códices latinos, aragoneses y el catalán de la Biblioteca Nacional de Madrid. De aquí deduce J. RuBió, entre otras cosas, que quizá la primitiva versión latina era más reducida, y que hoy está perdida, mientras que la versión latina que conocemos sería una traducción del catalán, más extensa.

Por su parte, Antonio Ubieto (1950: 488) afirma que, si bien «el texto definitivo oficial debía ser el redactado en latín, idioma oficial de los estados que componían la Corona de Aragón», sin embargo, «la redacción de las partes primitivas que constituyen $\mathrm{CP}$ estaba en aragonés y catalán».

No obstante, la mayoría de los autores admiten que la Crón. SJP. fue primeramente redactada en latín.

Limitándonos a la versión aragonesa, lo único seguro que se puede afirmar es que se tradujo no antes de 1372. Y que en el inventario de la librería de Martín I el Humano realizado en 1410 figura, además de un ejemplar en latín («un altre libre appellat Cronice Regum Aragonum et Comitum Barchinone, en lati,...»), un ejemplar de la Crón. SJP. en aragonés (LlabrÉs, 1903: 10; Massó TORRENTS, 1905):

«Item un altre llibre appellat Croniques del Rey Darago en aragonés scrit en pergamins ab posts de fust cubert de cuyro vermell lo qual comença «Segunt que havemos leído» e feneix «El Rey D. Pedro.» 


\subsection{Versiones latina y catalana: manuscritos y ediciones}

La versión latina (VL) se conserva en seis manuscritos, tres de ellos fundamentales:

1. Códice núm. 198 de la Biblioteca Capitular de la Catedral de Valencia, con letra del siglo XIV.

2. Manuscrito 18.080 de la Biblioteca Nacional, fol. 179-228v, con letra del siglo XIV.

3. Manuscrito núm. 1.684 de la Biblioteca Nacional de París. Es de finales del siglo XIV o principios del XV. Estuvo en el monasterio de San Juan de la Peña hasta el siglo XVIII. Lleva como título Cronica general de los Reyes de Aragón y fue el manuscrito utilizado por los historiadores aragoneses Zurita y Blancas, quienes hicieron en él algunas anotaciones.

Los otros tres manuscritos son copias tardías, y al parecer poco solventes, del manuscrito anterior:

4. Copia de la colección Abbad y Lasierra (tomo xxII, sign. 12-23-1: A-17), conservada en la Biblioteca de la Academia de la Historia de Madrid.

5. Copia hecha sobre el manuscrito anterior, en la colección Traggia (tomo VII, sign. B-141), también en la Biblioteca de la Academia de la Historia.

6. Manuscrito núm. 1.297 de la Biblioteca Nacional de Madrid, que contiene una copia hecha en 1681 por el Cronista Mayor de Castilla, don Juan de Baños Velasco.

La edición de Tomás Ximénez de Embún, publicada en Zaragoza en 1876 utilizó para el texto latino este último manuscrito. Era la primera vez que la Crón. SJP. se publicaba impresa.

Antonio Ubieto Arteta utilizó para su edición ya citada (Valencia, 1961) el manuscrito reseñado en primer lugar (o sea, el conservado en la Biblioteca de la Catedral de Valencia). Dado que consta documentalmente que el año 1372 el rey Pedro IV entregó a la catedral de Valencia un códice escrito en latín de la Crón. SJP., UBieto deduce, en consecuencia, que el códice de Valencia «responde exactamente al texto primitivo: es una primera edición».

En cuanto a la fecha de redacción del texto latino, el mismo autor cree evidente que se escribió entre los años 1369 y 1372. Después de 1369, porque 
la Crón. SJP. termina con la noticia del traslado de los restos de Alfonso IV a Lérida (VL, p. 233), que se produce, según fecha comprobada documentalmente, el 17 de abril de 1369. Antes de 1372 porque ese año se enviaba el códice desde la casa real a la catedral de Valencia.

Sin embargo, RuBió I LLUCH ha aportado documentación que demuestra que la redacción en latín estaba ya termianda en 1359, por lo que es posible que las últimas líneas, que mencionan el traslado de los restos de Alfonso Iv, fuesen añadidas posteriormente (RUBió I LLUCH, 1909-1910: 545).

La edición de la versión latina que nosotros utilizamos, y que nombramos como VL, es la de Antonio Ubieto.

La versión catalana (VC) es conocida también con los títulos de Crónica General de Pere III el Cerimoniós [Se refiere a Pedro IV de Aragón], y de Crónica dels reys d'Aragó e comtes de Barcelona. En ambos casos, no obstante, suele incluirse como subtítulo el de Crónica de San Juan de la Peña (o de Sant Joan de la Penya).

Así, Martín de Riquer, al referirse a esta Crónica, señala que al rey Pedro, III como conde de Barcelona y IV como rey de Aragón, llamado el Ceremonioso o el del Punyalet - «hombre de gran cultura, instigador y protector del saber, poeta ingenioso circunstancialmente, y un gran entusiasta de la historia» - se debe la inspiración de «una historia general titulada Crónica dels reys d'Aragó e comtes de Barcelona, más conocida por Crónica de San Juan de la Peña» (Riquer, 1985: 395).

Por otro lado, la única edición impresa que existe de la VC, debida a A. J. Soberanas (1961), lleva en portada el título siguiente: Crónica general de Pere III el Cerimoniós dita comunament Crònica de Sant Joan de la Penya.

Sin embargo, en el «Prefaci», las primeras palabras del autor son: «L'anomenada Crònica de Sant Joan de la Penya y que nosaltres titulem Crònica General de Pere III el Cerimoniós, va merèixer l'honor, que comparteix només amb la de Jaume el Conqueridor, d'ésser escrita en tres idiomes: llatí, aragonès i català». Así, pues, parece que el título más habitual es el de Crónica de Sant Joan de la Penya.

$\mathrm{Al}$ parecer, según algunos datos aducidos por Soberanas, la redacción en catalán estaba ya terminada en 1366. Aunque otros datos apuntan a 1369 como año más probable de la terminación, ya que el traslado de los restos de Alfonso IV a Lérida, hecho histórico fechado en abril de 1369, se hace constar en la Crónica. En realidad, esto es aplicable a todas las versiones, también a la latina, que termina igualmente indicando ese hecho producido en 1369. 
La versión catalana se encuentra en diversos manuscritos. Dos de ellos son del siglo XIV y coetáneos del rey Pedro IV el Ceremonioso:

A. Ms. 2664 de la Biblioteca de la Universidad de Salamanca. Hasta hace poco había estado en la Biblioteca del Palacio Real de Madrid (signatura 2-12). La Crónica ocupa los folios 6 al 71 del ms., en pergamino. La letra es de mediados del siglo XIV, a excepción de los dos últimos capítulos (40 y 41), cuya letra es de finales del siglo xIV. Estos dos capítulos finales, que tratan del rey Pedro IV el Ceremonioso (1336-1387) y del rey Juan I (1387-1395), respectivamente, no constan en otros ms. de la versión catalana ni tampoco en la VL ni en la VA. Lógicamente, ya que terminan hablando de la muerte y enterramiento de Juan I, debieron ser añadidos después de 1395. El texto de este ms. es el transcrito en la edición de A. J. Soberanas.

B. Ms. 1811 de la Biblioteca Nacional de Madrid (signatura antigua: G.120). Consta de 64 folios en pergamino y la letra es de finales del siglo xIV. Termina con la muerte de Alfonso IV el Benigno (1327-1336).

Otros manuscritos importantes, aunque ya del siglo xv, son los siguientes:

C. Ms. de la Biblioteca del Seminario Conciliar de Barcelona. Se trata de un ms. de 124 folios; los 84 primeros los ocupa la Crónica, que termina también con la muerte de Alfonso IV el Benigno (1327-1336). La letra es del siglo XV.

D. Ms. 212 de la Biblioteca Universitaria de Valencia (antigua signatura: 92-6-12). Letra de finales del s. xv, 296 folios (la Crónica ocupa los fol. XIVLXXI).

E. Ms. 3066 de la Biblioteca del Palacio Real de Madrid (sigla anterior 2-LI-I). Ms. en papel de 65 hojas. Es trad. catalana, hecha después de 1490, de una versión latina realizada hacia 1375 por Guillem Nicolau (Capellán de Pedro IV) de una versión catalana.

Otros manuscritos secundarios son:

F. Ms. 1814 de la Biblioteca Nacional de Madrid. En papel, letra del siglo Xv, 207 folios, de los cuales, hasta el 180 en castellano; de ahí al final en catalán.

G. Ms. 2639 de la Biblioteca Nacional de Madrid. Del siglo XvI.

H. Ms. 1609 de la Biblioteca Nacional de Madrid. Año 1600. copia realizada por Jaume Ramón Vila. 
I. Ms. 2013 de la Biblioteca Nacional de Madrid. Copia realizada por el mismo Jaume Ramón Vila.

J. Ms. de la Biblioteca de la Real Academia de la Historia de Madrid (vol. xxiII de la colección del Marqués de Valdeflores).

Como ya se ha dicho, la única edición moderna de la VC es la de Amadeus J. Soberanas Lleó (1961) y es la que utilizamos en este estudio. La transcripción de esta edición está normalizada ortográficamente, tal como advierte el autor; a ella nos atenemos. Conviene advertir que el texto del ms. en el que se basa la ed. de Soberanas es una versión abreviada, en la que está muy resumida la parte referente a la historia puramente aragonesa, es decir los capítulos 16 a 20.

\subsection{Versión aragonesa: manuscritos y ediciones}

La versión aragonesa (VA) de la Crón. SJP. se conserva en tres manuscritos:

- Ms. L-II-13 de la Biblioteca de El Escorial, copia casi coetánea a la redacción de la crónica, de fines del siglo XIv. Está incompleta: conserva sólo desde 34.73 hasta el final. Es el ms. que C. Orcástegui denomina E.

— Ms. n. 2078 de la Biblioteca Nacional de Madrid. La letra es del siglo XVI. Tiene varias lagunas de algunos capítulos casi enteros y de párrafos y líneas (que incluso se quedan a mitad, dejando cortada una frase). En concreto, las lagunas más importantes son las que corresponden a los siguientes fragmentos: 11.9-41, 18.82-88, 18.99-127, 19.1-169, 32.25-73, 33.1-127 (este capítulo, entero), 34.1-8 y 34.21-25. En el resto solo falta alguna línea o alguna palabra suelta. Es el ms. denominado B.

- Ms. N-I-13 de la Biblioteca de El Escorial. Es de letra del siglo XVI y está firmado por Martín de Larraya (documentado como secretario real el 6 de octubre de 1526 en Tudela). Divide el texto en capítulos con encabezamientos que resumen su contenido (que coinciden en gran parte con los de la VL). Es el ms. denominado N. Según indica C. OrĆ́stegui, «esta copia presenta algunas deficiencias, un gran desorden en los folios, es muy variable en las grafías y contiene muchos errores propios del copista; incluye algunas adiciones de gran extensión». (OrCÁstegui, 1986: 4). Su texto es el más castellanizado.

Del cotejo de las tres copias dedujo Antonio Ubieto (1969: 310) la independencia entre ellas y su relación con un texto original perdido (o no conocido), del cual proceden separadamente. Gráficamente lo expuso en este esquema: 
ORIGINAL

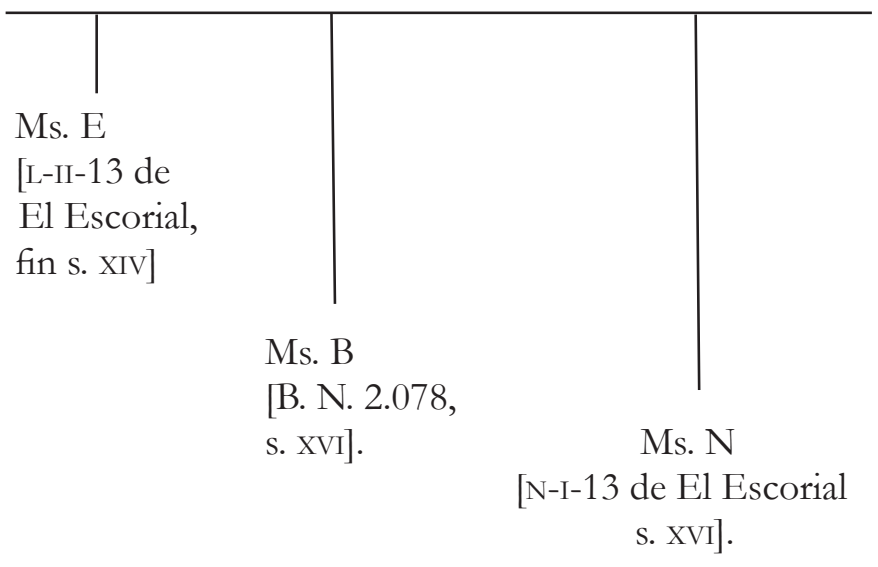

La única edición existente durante mucho tiempo fue la de Tomás XIMÉNEZ DE Embún, Historia de la Corona de Aragón. (La más antigua de que se tiene noticia), conocida generalmente con el nombre de Crónica de San Juan de la Peña, Zaragoza, Diputación Provincial, 1876, XXIII+252 págs. En esta edición se publicaban a dos columnas los textos latino y aragonés, el primero basado en una copia de 1681 (ms. 1297 de la Biblioteca Nacional de Madrid), el segundo en el ms. B (n. ${ }^{\circ} 2078$ de la Biblioteca Nacional de Madrid), cuyos huecos se rellenaron con la traducción castellana, hecha por el mismo Ximénez de EmBún, del texto latino. Por otro lado, la transcripción tenía bastantes errores.

La edición de Carmen Orcástegui, Crónica de San Juan de la Peña (versión aragonesa). Edición crítica, Zaragoza I.F.C., 1986, siguiendo los criterios señalados por Antonio Ubieto (1969), utiliza los tres manuscritos. Toma como base para la primera parte (hasta 34.73) el ms. B, cotejándolo con el ms. N, cuyas diferencias señala en nota, y completando los huecos del B con el N (que transcribe en cursiva). Para la parte que va desde 34.73 hasta el final (es decir, 39.48), toma como base el ms. E, cotejándolo con $\mathrm{B}$ y $\mathrm{N}$, cuyas diferencias señala en nota. También señala en nota variantes de contenido de la VL.

Indica la autora en la presentación que «se ha modernizado la puntuación para una mejor lectura del contenido». Esto es comprensible, además de usual, y se ha respetado generalmente. Pero también se ha procedido a colocar tildes para señalar la acentuación (que por supuesto, salvo contadísimos casos, no aparecen en el ms. original) y no siempre se ha hecho con criterios acertados a nuestro juicio, ni con total coherencia. 
Así, por ejemplo, día y avía pueden verse escritos con tilde o sin ella, de forma indiscriminada; avies o podies van regularmente sin tilde, cuando es evidente que hay que interpretarlos como [abjés] y [podjés]. Los demostrativos con función de pronombre se han acentuado unas veces sí y otras veces no. La forma mas aparece con tilde en ocasiones, pero no siempre que la lleva es adverbio, ni siempre que carece de ella es conjunción.

En fin, con frecuencia vemos sin tilde palabras cuya acentuación no ofrece duda (por ejemplo, ansi 38.127, abbadia 28.28, etc.), mientras que se acentúan como esdrújulas ciertas voces de las que es arriesgado suponer que se pronunciasen de tal forma. Hay casos en que la colocación de la tilde es contraria a la acentuación que lógica y razonablemente se puede suponer: por ejemplo, encontramos varios casos de misó y vidó, por miso y vido (perfectos fuertes), y con mucha frecuencia tenié, avie por tenié, avié (perfectos y no imperfectos), etc.

Por todo lo dicho, y aun respetando en general el texto de la edición crítica, nos hemos tomado la libertad de:

a) Corregir algunas acentuaciones, cuando nos ha parecido evidente que eran incorrectas.

b) Aplicar una acentuación sistemática cuando el acento podía ser relevante para distinguir distintas funciones o categorías gramaticales (así, en el caso de aquel-aquél, el - él, este - éste, etc.).

El hecho de acentuar un texto medieval en una edición crítica puede ser muy discutible en sí mismo, puesto que altera en cierto modo el texto original. Claro que los criterios de los historiadores y de los lingüistas no coinciden, porque también son distintos sus intereses. En este sentido, nos parece que ha primado la idea de hacer accesible, comprensible y de cómoda lectura un texto que, por su importancia en la historiografía medieval aragonesa, va más dirigido a los intereses de los historiadores que de los lingüistas. Ahora bien, el hecho de que manifestemos nuestro desacuerdo en el tema de la acentuación no es óbice para que la consideremos en general como una excelente edición, rigurosa y fiable. Nuestro estudio lingüístico (NAGore, 2003a) se basó en el texto de la edición crítica de Carmen Orcástegui. Asimismo, el vocabulario se atiene en general, tanto en los lemas como en las citas, al texto de esa edición, con escasas salvedades que se comentan más adelante (vid. el apartado 2.3). 


\subsection{Importancia histórica}

El historiador Antonio Ubieto Arteta (1961: 5) comienza la introducción a su edición de la versión latina de esta manera:

«La Crónica de San Juan de la Peña gozó de gran autoridad desde la Edad Media, siendo utilizada por cuantos han escrito sobre Historia de la Corona de Aragón. El mismo Zurita la recogió en sus Anales frecuentemente, no atreviéndose a contradecir cuanto en el texto pinatense se decía, aunque el genial cronista en algún caso no lo creyera».

RuBió I LluCH (1909-1910: 541) afirma de la Crón. SJP.: «pera nosaltres un dels més interesants llibres de la nostra historiografia». El mismo autor hace una serie de consideraciones y puntualizaciones de las que se deduce la gran valoración de la Crón. SJP., no ya hoy, sino en la misma Edad Media, en vida de Pedro Iv: «De lo que no cal dubtar es de la predilecció que sempre sentíl rey Pere per aquest text, que venia a esser pera ell com una mena de llibre oficial de l'historia d'Aragó, els exemplars del qual distribuí a tots els arxius y llochs religiosos més importants de la nostra terra». Igualmente para demostrar el gran aprecio en que entonces se le tuvo, aduce el hecho de que fuese escrita «en tres diferents idiomes, en llatí, català y aragonès, honor que no ha assolit en la nostra historiografia més que un altre llibre, també d'atribució reyal: la crónica del Conqueridor». (Rubió I Lluch (1909-1910: 542).

La utilización que de la Crón. SJP. hizo Jerónimo Zurita en el siglo XVI, confirma para este autor su valor e importancia: «Un dels elogis més grans que's poden fer d'aquest llibre, tan discutit, es el cabal gran que'n feu en Zurita, que en això de flairar l'importancia de les fonts històriques tenia molta traça. Desde'l principi dels seus Anales, se pot dir que la segueix continuament». (RuBió I Lluch (1909-1910: 542).

Se puede añadir a este respecto que Zurita no había sido el primero en utilizarla. Inmediatamente después de ser traducida al aragonés fue remitida por Pedro IV a Juan Fernández de Heredia, quien la utilizó como fuente básica para redactar la segunda parte (hoy, por desgracia, perdida) de la Grant Crónica de Espanya.

Juan I escribe a Fernández de Heredia una carta, fechada el 26 de diciembre de 1388, diciéndole:

...otrossi ya vos hemos scripto como hemos acabado de leir la primera part del libro de la grand canonica d Espanya, porque vos rogamos que nos embiedes con cierta persona la segunda part de la dita cronica.

Esto parece indicar que dicha segunda parte estaba ya acabada a finales de 1388 y, consecuentemente, que hacía algún tiempo, quizá algunos años, estaría terminada la VA de la Crón. SJP, de la que se sirvió Fernández de Heredia. 
Es también conocido que la parte inicial de la Crón. SJP, es decir la referida a los reyes de Navarra y de Aragón (hasta el cap. 20), fue «fuente indispensable para algunas composiciones navarras de gran importancia por el pasado común de ambos territorios, como la Crónica de los Reyes de Navarra del Príncipe don Carlos de Viana». (G. Orcástegui y G. Redondo, en Viñaza, 1986 [1904], introducción, p. 32, n. 55).

Por otro lado, la valoración actual desde el punto de vista historiográfico es unánimemente positiva, destacando la novedad que supone frente a las anteriores como intento de configurar una historia nacional del Estado aragonés. Es decir, ya no se trata de una suma, más o menos inconexa, de la historia de los diferentes reinos o Estados peninsulares (como pueden ser el Liber Regum o la Crónica navarro-aragonesa o Crónica de los Estados Peninsulares), en donde se incluye como uno más Aragón, sino que trata con exclusividad de éste, entendiendo como tal no sólo el Reino de Aragón, sino también Navarra durante las épocas en que Aragón fue una dependencia condal del rey de Pamplona o en que Aragón y Navarra estuvieron unidos en una misma monarquía, así como el resto de las tierras de la Corona de Aragón (condados catalanes, Valencia, Baleares, Rosellón, Provenza, Córcega, Cerdeña, Sicilia), a partir de la unión en 1137 de doña Petronila (1137-1164) y Ramón Berenguer IV de Barcelona (1131-1162).

De ahí que, de manera clara y concisa, pueda afirmar Antonio UBIETO ARTETA (1950: 463): «La denominada Crónica de San Juan de la Peña es el resultado del primer intento habido en la Corona de Aragón para componer su Historia General».

De forma semejante C. ORCÁstegui y G. ReDOndo consideran, desde el punto de vista específico aragonés, a la Crónica de San Juan de la Peña como «la Historia de Aragón más autónoma y completa del período medieval», pues «representa un gran paso hacia lo que, sin prejuicio alguno, podemos entender ya como historiografía nacional aragonesa, con independencia de la procedencia de su desconocido autor o de su finalidad... de ahí la importancia de dicho texto cronístico como testimonio trascendental de la memoria histórica de Aragón». El juicio es tajante, pues excepto esta y la de Vagad, «el resto son biografías o relatos de reinados concretos que centran el énfasis de los acontecimientos recogidos en los biografiados» (C. OrCÁstegui y G. Redondo, en ViÑAZA, 1986 [1904], introducción, p. 31; Fernández Clemente, 1989: 150).

En resumen, como dice OrCÁstegui (1986: 5) en frase definitoria: «constituye la fuente narrativa más completa e importante de la historiografía me- 
dieval aragonesa». No creemos que pueda decirse mucho más, después de esto, sobre su importancia e interés desde el punto de vista histórico.

\subsection{Interés lingüístico de la versión aragonesa}

Ya G. W. Umphrey, uno de los iniciadores del estudio del aragonés, indicaba en su trabajo titulado «The Aragonese Dialect», publicado en 1911, al referirse a la Crónica de San Juan de la Peña: «A very important document for old Aragonese» (UMPhreY: AD, 1911: 6-7). El mismo autor vuelve a referirse en ese trabajo a la Crónica de San Juan de la Peña: como «one of the purest Old Aragonese documents» (UMPHREY: AD, 1911: 37).

Por otro lado, Alwin Kunn, en su fundamental estudio titulado Der Hocharagonesische Dialekt (1935) utiliza continua y sistemáticamente la Crón. SJP. (en la edición de XIMÉNEZ DE EMBúN, única disponible entonces) para documentar en el aragonés medieval muchas de las formas que había ido recogiendo en los pueblos del Alto Aragón a lo largo de 1932. Esto, implícitamente, demuestra el alto valor que A. KuHN concedía al texto de la versión aragonesa de la Crón. SJP. como representante genuino del aragonés medieval.

En contraste con lo anterior, son escasas o hechas muy de pasada las menciones que se encuentran en otros estudios sobre el aragonés. Sin duda, el descuido con que se le trata debe explicarse por la existencia únicamente de una edición antigua, considerada como defectuosa, bien conocida por los historiadores, aunque escasamente por los lingüistas, a excepción de los citados UMPHREY Y KUHN.

Manuel Alvar, al referirse a los textos y documentos útiles para el estudio del aragonés medieval, tras mencionar algunos textos literarios del siglo xiII, con escasos rasgos lingüísticos aragoneses, añade: «Al mismo siglo pertenece algún texto jurídico importante como Los Fueros de Aragón de J. L. Lacruz, El Fuero de Teruel de M. Gorosch, Los Fueros de la Novenera, los aragoneses de Tilander y algún texto histórico de interés como la Crónica de San Juan de la Peña y el Liber Regum o Cronicón Villarensè (ALvar, DA, 1953: 112-113). Como no podía ser de otra manera, Alvar se refería a la edición de XIMÉnez de EMBúN (1876), pero — dejando aparte el lapsus de atribuir la Crón. SJP. al s. XIII— aunque la nombra, no la destaca especialmente.

La edición crítica de la Crón. SJP. publicada por C. OrCÁstegui en 1986 cambió la situación, tanto por hacer más accesible el texto como por ofrecer una edición esmerada y rigurosa. 
Vicente LAGÜENS, en la reseña que sobre ella publicó en el $A F A$, afirmaba: «Esta edición crítica merece un detallado estudio lingüístico». Y más adelante destacaba cómo un simple espigueo proporciona gran cantidad de formas lingüísticamente aragonesas, de manera que «podríamos seguir acumulando datos sobre el aragonesismo del texto u otras cuestiones lingüísticas de interés como, por ejemplo, las que sugiere la sintaxis...»Y Y terminaba caracterizando el libro como «un trabajo valioso de la profesora Orcástegui que, se ha dicho ya, ofrece a los filólogos un material más que estimable» (LAGÜENs, 1988: 393-394).

A estas observaciones sobre la importancia lingüística que algunos especialistas en el aragonés han atribuido al texto, podemos añadir algunos argumentos basados en una somera comparación con otros textos históricos en el ámbito navarroaragonés.

Algunos capítulos de la Crónica de los Reyes de Navarra del Príncipe de Viana, que data de h. 1453-1455 (ed. de C. OrCÁstegui, 1978) están casi literalmente copiados, o adaptados, de la Cron. SJP., lo que permite un análisis lingǘstico detallado. La comparación, por ejemplo, del fragmento 14.58-105 de la Crón. SJP. con el paralelo de la Crónica de los Reyes de Navarra, cap. 12, lin. 5-41, permite observar el alto interés lingüístico de la Crón. SJP. Por supuesto que es lógico, o esperable por lo que conocemos, que un texto navarro de mediados del siglo xv esté más castellanizado que uno aragonés de la segunda mitad del xIv. Pero lo mismo ocurre si lo comparamos con otros textos históricos en aragonés, tanto posteriores, como coetáneos o incluso anteriores. En todos los casos observamos cómo los otros textos están generalmente plagados de castellanismos, en especial fonéticos, o que formas fonéticamente castellanizadas conviven con formas fonéticamente aragonesas, contrastando con la mayor homogeneidad y pureza del aragonés de la Crón. SJP.

Tomemos por ejemplo un texto de la segunda mitad del siglo xv, la Crónica aragonesa del tiempo de Juan II (ed. de M. de RiQuer, 1944). A pesar de que todavía puede considerarse plenamente como texto escrito en aragonés relativamente puro, de modo que son habituales formas como fillos, muller, millor, etc., sin embargo se encuentran a menudo las formas castellanizadas fjo, fechos, aducho, derecho, satisfecho, etc., alguna vez mucher (por muller), y continuamente muncho (por muyto), inencontrables en la Crón. SJP (o en todo caso, alguna vez esporádica y excepcionalmente). Véase por ejemplo: «Munchos estranyos fechos se fizieron en aquel sitio»(lín. 374, p. 21, de la Crón. de Juan II).

Si esto es lógico, por la fecha más tardía de redacción de la Crón. de Juan II, no lo será tanto encontrar prácticamente el mismo contraste con obras coetáneas o anteriores. 
Tomemos, por ejemplo, los «Aragonese texts» editados por G. W. UMPHREY (1907) y pertenecientes a los libros $8^{\circ}, 13^{\circ}$ y $17^{\circ}$ de la Grant Coronica de los Conquiridores de Juan Fernández de Heredia. Vemos ahí muchos, fechas, abun, derrocaron (UMPHREY, 2007: 263) en lugar de muytos, feytas, encara, derrocoron; o mesclaron, fechos, muchas, mataron, escaparon, aún, mucho (UMPHREY, 2007: 270), etc. El mismo UMPHREY confirma en su estudio que las formas que halla son dicho, fecho, pecho, lecho, echar, noche, de las que lógicamente dice que «manifiestan influencia castellana» (UMPHREY, $A D, 1911: 18)$. Con ligeras variaciones, esto es lo que generalmente encontramos en las obras de Fernández de Heredia, coetáneas de la Crón. SJP., muchas de las cuales se pueden leer ahora (la mayoría en la colección «Larumbe» de Textos Aragoneses), en ediciones recientes y muy rigurosas de Adelino Álvarez Rodríguez o de colaboradores y discípulos suyos. Y es que, con escasas excepciones (Libro de los Emperadores [véase la ed. de Adelino Álvarez Rodríguez, 2006), Secreto Secretorum y, en parte, Rams de flores o Libro de Actoridades [véase la ed. de Conrado GuARdiola AlcoVER, 1998]), las obras del scriptorium de este autor (que, no olvidemos, era de Munébrega, Comunidad de Calatayud) reflejan en gran manera lo que hemos dado en llamar "aragonés de las Serranías Ibéricas" (con ciertos resultados fonéticos y morfológicos semejantes a los del castellano), frente al "aragonés propiamente dicho" (cfr. NAGORE, 2020b: 71-73).

Tomemos ahora otro texto representante de la prosa histórica en aragonés, anterior en unos 70 años a la Crón. SJP., la llamada Crónica de los Estados Peninsulares o Crónica navarro-aragonesa (ed. de Antonio Ubieto, 1955). Ahí, junto a soluciones fonéticas típicamente aragonesas (como feytos, fuella, yera, dito, dreyto, gito, nueytes, etc.) encontramos era, muger, fijo, fecho, derecho, dicho, consejaron, echo, etc. Posiblemente - si no se trata de un intento de escribir en castellano, como opina Ángel CanelLas (GEA, iv, p. 997) - ciertos rasgos y la mayor castellanización se deban explicar por estar redactada en «navarro», la tercera gran variedad dentro del dominio lingüístico románico navarroaragonés en la Edad Media.

Insistimos que en otros muchos aspectos hay coincidencia, pero lo que aquí interesa destacar es que esas fluctuaciones entre formas castellanizadas y formas puramente aragonesas, frecuentes tanto en textos posteriores como coetáneos o anteriores, apenas existen en la Crón. SJP., donde son prácticamente exclusivas las formas fonéticamente aragonesas. De ahí que esto nos permita afirmar la importancia lingüística de este texto y el gran interés que manifiesta para el conocimiento de la scripta aragonesa del siglo XIV. Naturalmente, el vocabulario que se registra en la Crón. SJP. es también reflejo bastan- 
te fiel del léxico comúnmente utilizado en el aragonés escrito de la época, en especial en el aragonés cancilleresco.

\section{Estudio del léxico de la Crónica de San Juan de la Peña}

Nuestra tesis doctoral, defendida en enero de 1992, consistió en un estudio lingüístico completo de la lengua aragonesa utilizada en la versión aragonesa de la Crón. SJP., teniendo como base la edición crítica mencionada de C. Orcástegui (1986), si bien, considerando también las variantes de los tres manuscritos, y teniendo como referencia las ediciones de las versiones en latín y en catalán. Se publicó con el título de El aragonés del siglo XIV. Según el texto de la Crónica de San Juan de la Peña (Huesca, IEA, 2003; 655 pp.). Ese libro comprende el estudio pormenorizado de las grafías, de la fonética histórica, de la morfología y de la sintaxis, así como de la formación de palabras. Pero quedó fuera el estudio relativo al vocabulario, que ocupaba dos tomos de nuestra tesis doctoral, y que ahora se recupera, se revisa, se pone al día y se completa.

La confección del vocabulario de la Crónica de San Juan de la Peña se ha llevado a cabo siguiendo una metodología sistemática en la que conviene distinguir tres fases: 1) la realización del índice de frecuencias; 2) a partir de este, la realización del índice de lemas; 3 ) finalmente, la construcción del vocabulario. No es posible entender una fase sin la precedente, que le sirve de base. Por eso, nos parece conveniente explicar por separado en qué ha consistido cada fase, cuáles han sido los trabajos necesarios y los resultados obtenidos, así como las dificultades que ha habido que superar.

\subsection{El índice de frecuencias}

El índice de frecuencias indica el número de apariciones de cada voz (palabra o forma textual) en el texto. El índice de frecuencias muestra tanto las frecuencias absolutas, es decir, el número de veces que una palabra aparece en el corpus de referencia, como las frecuencias relativas, expresadas en porcentajes (o sea, tanto por ciento que supone una forma respeto al total de palabras que se contabilizan en el texto).

Para confeccionar el índice de frecuencias se partió del texto de la edición crítica de la Crónica de San Juan de la Peña (Orcástegui, 1986): ese es el corpus textual, respecto del cual se hallaron: 1) el número total de palabras de que consta el corpus: 43.996; 2) el número total de formas distintas, que es de 5.363 ; 3) el número de veces, en cifras absolutas, que se halla cada palabra 
(forma textual distinta) en el texto (frecuencia absoluta); 3) el porcentaje, expresado con cinco decimales, que supone cada forma textual distinta respecto del total de palabras que aparecen en el corpus (frecuencia relativa).

Para la realización del índice de frecuencias se hubo de descomponer el texto total, considerado como un bloque o corpus, en cada una de las unidades textuales, que se ordenaron en primer lugar por orden alfabético. Esto, al mismo tiempo que preparaba el terreno para obtener el índice lematizado, permitía contabilizar las formas iguales; es decir, el número absoluto de veces que aparece cada palabra, expresado en una cifra. Esa cifra, multiplicada por 100 y dividida entre 43.996 para cada una de las palabras distintas, nos dio como resultado el índice de frecuencias relativas.

A partir de estos datos asociados a cada palabra se realizó: a) por un lado, el índice alfabético de frecuencias, que consta de todas y cada una de las palabras del corpus textual ordenadas por orden alfabético y con indicación de su frecuencia absoluta y de su frecuencia relativa; b) por otro lado, el índice decreciente de frecuencias, organizado de tal manera que las palabras o formas distintas aparecen ordenadas en orden decreciente según su número de apariciones, es decir, de mayor a menor número de apariciones (y por tanto, igualmente, de mayor a menor índice relativo de frecuencia).

Son destacables, y muy significativas, las frecuencias de algunas palabras. Por supuesto, como es de esperar, las palabras que podríamos denominar "gramaticales», como artículos y otros determinantes, pronombres, adverbios, preposiciones, conjunciones, etc., son las que sin duda tienen una mayor frecuencia de aparición. Véanse, por ejemplo, las preposiciones a (717: 1,62969), con (538: 1,22284), de (2.860: 6,50059), en (1.143: 2,59796), por (672:1,52741); los artículos el (1.635: 3,71625), la (1.159: 2,63433), las (263: 0,59778), lo (135: 0,30685), los (638: 1,450013); los demostrativos aquesti (178: 0,40458), aquesto (93: 0,21138), aquella (50: 0,11365); los pronombres relativos qual (258: 0,58642), que (972: 2,20909), qui (145: 0,32958), etc.); el adverbio de tiempo depues (206: 0,46822), el de negación non (209: 0,47504) o el de lugar aquí (80: 0,18183); la conjunción copulativa et (2.976: 6,76425) o e (277: 0,62960), o la conjunción adversativa mas (121: 0,27503).

Pero, con independencia de esas, hay otras palabras que aparecen también gran número de veces, ya sean sustantivos, adjetivos o verbos. Se trata de palabras clave que nos revelan las constantes temáticas y las ideas fuerza que dominan el texto de la Crón. SJP. Es decir, que constituyen auténticas referencias en las que se reincide continuamente. Véanse las que aparecen de forma más frecuente (fuera de las palabras «gramaticales»), ordenadas de mayor a menor frecuencia (incluimos entre paréntesis la frecuencia absoluta y tras dos puntos la relativa): 


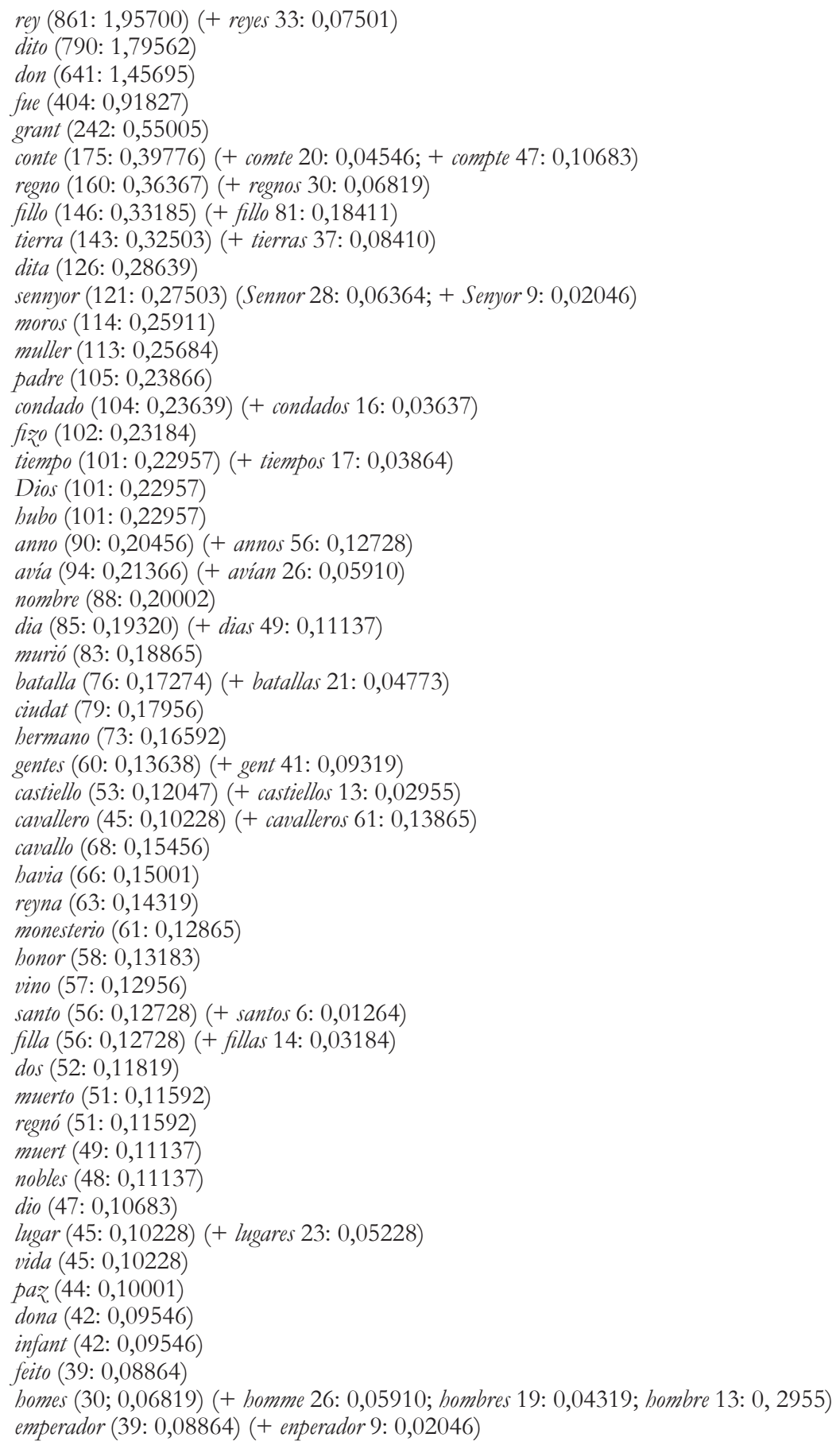




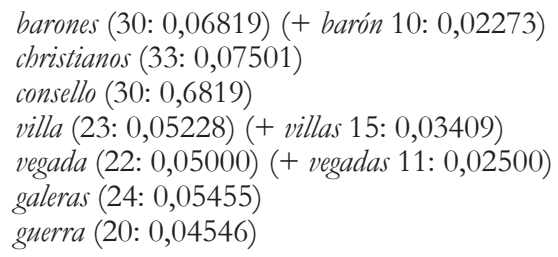

También la frecuencia de los nombres propios es sintomática. De entre ellos, ${ }^{1}$ los más frecuentes son:

Aragón (186: 0,42277)

Alfonso (153: 0,34776)

Jayme (122: 0,277730)

Castiella $(107: 0,24320)$ (+ Castilla 28: 0,06364)

Sancho (76: 0,17274)

Remón (67: 0,15229)

Navarra (55: 0,12501)

Remiro (51: 0,11592)

Barçalona (20: 0,04546) (+ Barcalona 5: 0,01136; Barchinona 42: 0,09546)

Carlos (54: 0,12274)

García (52: 0,11819)

Berenguer (47: 0,10683)

Johan (41: 0,09319)

Mallorquas (33: 0,07501)

Catalunnya (24: 0,05455) (+ Catalunna 2: 0,00455; Cataluenna 1: 0,00227; Cataluennya 2: 0,00455; Catalunya 2: 0,00455; Cathalunnya 1: 0,00227)

Pero (35: 0,07955)

Huesca (29: 0,06592)

Urgel (27: 0,06137) (+ Urgell 4: 0,00909)

Secilia (25: 0,05682) (+ Seçilia 8: 0,01818; Sicilia 2: 0,00455; Sicillia 1: 0,00227)

Caragoça (14: 0,03182) (+ Caragoşa 9: 0,02046; Caragoça 6: 0,01364)

Valencia (25: 0,05682)

Tolosa (24: 0,05455)

Pamplona (21: 0,04773)

Cerdennya (11: 0,02500) (+ Cerdenna 9: 0,02046; Cerdeyna 1: 0,00227; Cerdenya 1: 0,00227; Cerdeynna 1: 0,00227)

Espanna (13: 0,02955) (+ Espaynna 6: 0,01364; Espannya 5: 0,01137; Espanya 4: 0,00909; Espana 1: 0,00227; España 1: 0,00227; Spannya 6: 0,01364; Spanya 2: $0,00455)$.

Girona (18: 0,04091)

Ponz. (18: 0,04091)

Ripol (17: 0,03864)

Toledo (12: 0,02728)

1 Los índices onomásticos de la Crón. SJP fueron publicados: vid. F. NAGORE, «Índices onomásticos de la Crónica de San Juan de la Peña (versión aragonesa, siglo XIV)», Alaz̨et, 15 (2003), pp. 297-342. 


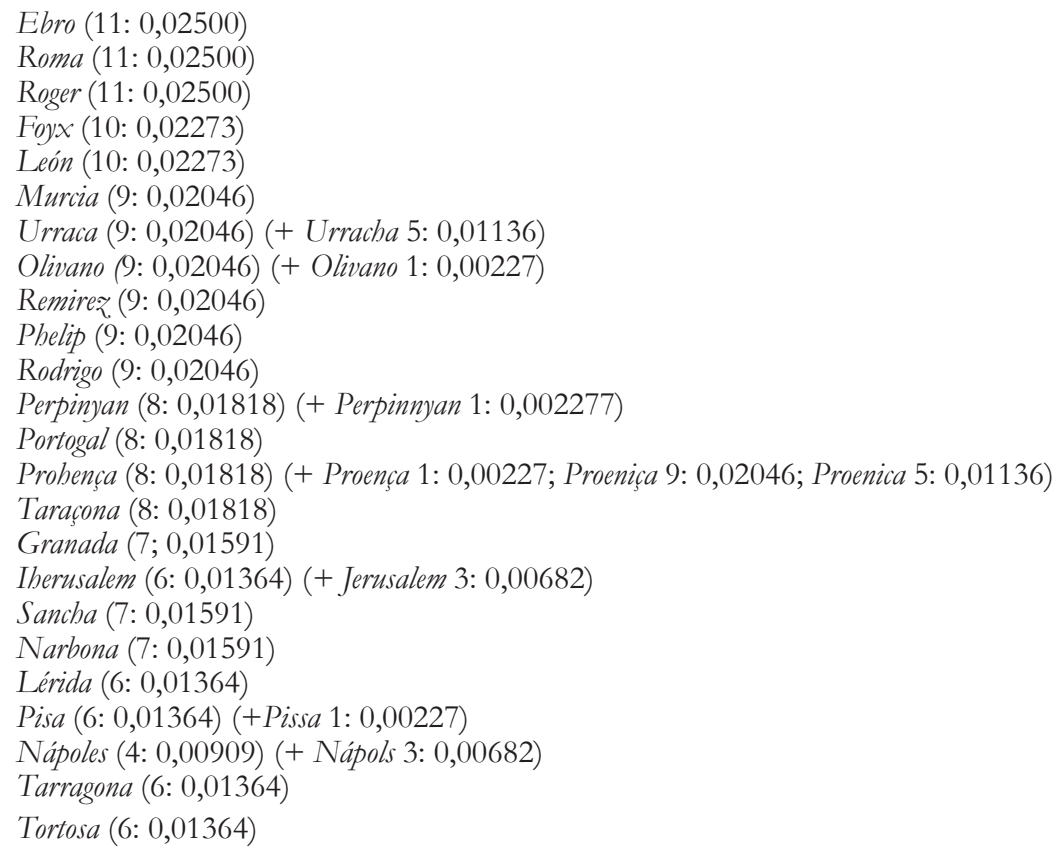

\subsection{El índice lematizado}

El índice lematizado es un índice alfabético de formas lematizadas o lemas. Entendemos por lema la entrada léxica o forma tipo bajo la que se agrupan todas las series de formas flexionadas y de variantes diversas, con sus correspondientes localizaciones en el texto, que corresponden a esa entrada léxica.

El lema, o lemma, es en realidad, de acuerdo con Marcos Marín y Sánchez LOBATO:

«la unidad de la metalengua lexicográfica, forma determinada arbitraria (pero coherentemente) a partir del lexema y elegida para figurar, no sólo como entrada principal, sino como criterio de ordenación: todas las formas que corresponden a combinaciones de cada lexema con distintos elementos se ordenan en relación con un lemma único, se lematizan» (Francisco Marcos Marín y Jesús Sánchez Lobato, Lingüística Aplicada, Madrid, Síntesis, 1988, p. 123).

El término lematización es explicado así en el Diccionario de Lingüistica dirigido por Georges Mounin:

«En lexicografía y principalmente en lexicografía automática: operación que consiste en agrupar las formas que ocurren en un texto o que integran una lista, por entradas léxicas» (Georges Mounin, Diccionario de Lingüística, Barcelona, Labor, 1979, p. 112, s. v.; el artículo está firmado por D. V. = Daniel VeroniQue). 
Como afirma Rodríguez Barcia (2016: 198-199), «el lema es la unidad mínima en lexicografía [...], ligada al artículo lexicográfico o entrada. [...]. En el lema se aglutinan todas las variantes flexivas de las unidades lingüísticas que registra un diccionario». Y, por otro lado, «lematizar no es otra cosa que reducir a lemas o formas canónicas las diferentes unidades léxicas que se quieren recoger en un repertorio lexicográfico para que en una una única converjan todas sus variantes flexivas» (Rodríguez BARCiA, 2016: 200).

La lematización se realizó manualmente, partiendo de la lista alfabética de palabras-texto o formas textuales del corpus (Crón. S.J.P.). Una vez que fueron llevadas a cabo las agrupaciones pertinentes, sobre el papel, se realizaron las oportunas manipulaciones en el ordenador: primeramente, en pantalla, sobre el mismo fichero inicial de que se partió para la realización de los índices de frecuencias y con el mismo programa de base de datos; posteriormente, para ultimar detalles, hacer las correcciones y dar el formato definitivo al texto, se vertió todo el contenido a un programa de tratamiento de textos.

Después de obtenida una impresión en borrador de los resultados, se procedió a realizar dos correcciones exhaustivas: una, para localizar posibles erratas en el texto, principalmente en los lemas, y en la adscripción de formas a determinados lemas; otra, para controlar el número de ocurrencias atribuido a cada forma textual y su coincidencia con el número de localizaciones dadas para cada una de ellas. De esta forma, al final se obtuvo un índice lematizado en el que se encuentran todas y cada una de las formas textuales, incluidas bajo uno u otro lema.

En un trabajo de esta envergadura es imposible asegurar que no habrá ningún error, de cualquier tipo que este sea. No obstante, se procuró llevar a cabo correcciones concienzudas en todas las fases, confrontando con el texto en caso de duda o de simple sospecha, por mínima que fuera.

Ahora bien, si la manipulación de un volumen de datos realmente grande fue dificultosa y compleja, simplemente como proceso técnico — pues no olvidemos que el ordenador sólo realiza aquellas operaciones que se le indican—, mucho más difícil resultó decidir en cada caso cuál debería ser el lema bajo el que había que agrupar determinadas formas. Y este trabajo, previo a la introducción de los datos en el ordenador, ha sido uno de los que más tiempo consumió y más vacilaciones produjo. ${ }^{2}$

2 Sobre dificultades que se presentan en el proceso de lematización y las particularidades a las que se debe atender en ese proceso, puede verse RodríguEZ BARCIA (2016: 200-208). 
Como se ha dicho, bajo cada lema se colocaron todas las formas correspondientes a ese lema que aparecen en el corpus. Los lemas se pusieron en negrita, mientras que las diversas formas en redonda y con sangrado. A continuación de cada una de éstas se señaló entre paréntesis el número de veces que aparece, y seguidamente todas las localizaciones en el texto (capítulo y línea, separadas ambas cifras por un punto). En trabajos de esta índole suele indicarse a veces la frecuencia absoluta total (es decir, número de apariciones u ocurrencias) detrás de cada lema. ${ }^{3}$ No nos ha parecido oportuno hacerlo así, ya que es fácilmente calculable sumando las frecuencias absolutas de cada una de las formas incluidas bajo ese lema.

Los criterios seguidos para determinar los distintos lemas, y las formas que deberían incluirse bajo cada lema, han sido los que exponemos pormenorizadamente a continuación.

En principio, se ha tomado como entrada representativa de cada vocablo la correspondiente a:

— el singular en los sustantivos.

— el masculino singular en los adjetivos.

— el infinitivo en los verbos.

De esta manera queda determinado el lema bajo el que se agruparán diversas formas y variantes.

Cuando la forma del lema no aparece literalmente en el texto la ponemos seguida de un corchete. Así, por ejemplo, prohismar], porque lo que aparece en el texto es prohismó, o fazienda] porque lo que aparece como forma textual es faziendas.

Debajo de la entrada se colocaron, con pequeño sangrado, todas las formas que corresponden a ese lema (o, dicho de otra manera, las distintas formas que puede adoptar cada lema). Y a continuación de cada forma se indicaba la localización exacta del texto donde se encuentra esa unidad léxica.

Como se ha dicho antes, «todas las formas que corresponden a combinaciones de cada lexema con distintos elementos [flexionales] se ordenan

3 Así, por ejemplo, en Manuel Alvar Ezquerra, «Concordancias e índices léxicos del Libro de la infancia y muerte de Jesús», AFA, XXVI-XXVII (1980), pp. 421-460. Véase especialmente el apartado «Concordancias», pp. 433-444. 
en relación con un lemma único» (Marcos Marín y Sanchez Lobato, 1988: 123). Pero las formas que se colocan bajo cada lema no son sólo las variantes flexionales (femenino, plural, formas personales y no personales del verbo, etc.). También se agrupan bajo el mismo lema las variantes gráficas, puesto que en realidad pertenecen a la misma unidad léxica, y las variantes fonéticas, por idéntica razón. En realidad, siempre que se trata del mismo tipo léxico, aunque se manifieste mediante variantes fonéticas diversas, hay que entender que corresponde al mismo lema. Así, por ejemplo, bajo el lema muyto aparece muito, pero también mucho (porque no deja de ser una variante fonética de la anterior, por más que sea un castellanismo). Ahora bien, en algunos casos creímos conveniente dar entrada también a determinadas variantes (quizá más esperables o más comunes) y desde ellas remitir al lema correspondiente. $\mathrm{O}$ incluso, en algún caso extremo, dar dos entradas distintas, cuando nos hemos encontrado ante variantes bastante alejadas tanto fonética como gráficamente. Un ejemplo es el de huey y oy: decidimos que aparecieran ambas.

Las decisiones al respecto han sido difíciles, y quizá no habremos acertado en todos los casos con la mejor y más coherente. ¿Cuál ha sido el criterio seguido en el caso de variantes gráficas o fonéticas? ¿qué forma se ha escogido como lema? Como norma general, la variante que aparece mayor número de veces (o dicho de otra forma, con mayor frecuencia). Es lo que nos ha parecido más científico, más neutro y más coherente. Y, con algunas excepciones inevitables que a continuación señalaremos, creemos que lo hemos seguido de manera sistemática. No siempre, al parecer, se siguen los mismos criterios. Así, Manuel Alvar EzQuerra indica:

«Para el lema se escogía la forma actual de la voz, estuviera o no documentada en el texto, [...]. En el caso de que el término no se haya conservado, se pone en el lema la forma más moderna (por ejemplo, entre dos soluciones, una con - $t$ y otra con $-d$, se elige la segunda)» (Manuel ALVAR EZQUERRA, 1980: 23).

Y el mismo autor señala en otro lugar el comportamiento seguido en la lematización, diciendo: «Cuando hay variantes el lema refleja la forma más moderna, siendo varios los casos en que lo actualizo totalmente» (M. Alvar EzQuerra, 1981: 421-422). ${ }^{4}$ Pese a ese y otros precedentes, no nos ha parecido un criterio suficientemente científico y hemos optado por aceptar como lema la forma que con mayor frecuencia aparece en el corpus. De esta forma, el criterio se fundamenta en datos objetivos, que tienen como referencia el propio texto.

4 De manera parecida se expresa el mismo autor en su libro Proyecto de lexicografía española, Barcelona, 1976, pág. 223 y sigs. 
Cuando hay variantes que no son sólo gráficas, sino también fonéticas (por ejemplo: poblicar — publicar, buey — buoy — oy, mellor - millor - mejor), por lo general se agrupan todas las formas bajo la que aparece mayor número de veces. No obstante, en alguna ocasión, si se trata de formas bastante alejadas entre sí, formalmente, o interesantes, se les da entrada por separado (por ejemplo: buey, buoy, oy).

En el caso de que aparezcan sólo dos variantes — gráficas o fonéticasde una misma palabra, se toma como lema, por lo general, la que aparece por primera vez en el orden alfabético (sólo en algún caso excepcional la otra, si presenta una grafía o forma que parece más conocida o identificable). El mismo criterio se sigue cuando aparecen el mismo número de veces diversas variantes. Cualquier otra solución nos parecía en este caso arbitraria; la solución adoptada es, cuando menos, objetiva.

Hemos evitado los lemas dobles (del tipo «X o Y»). Si acaso, se indican depués del lema, entre paréntesis, las variantes, ya sean fonéticas o grafemáticas), coincidiendo en esto con la tendencia actual en lexicografía (RoDríguez BARCIA, 2016: 203).

En algunos casos se ha dejado como lema la forma plural, cuando es la única que aparece en el texto y se sospecha que solo se utilizaba con ese sentido en plural (por ejemplo: algos, ordinaciones), o bien en algunas voces que tienen solamente una aparición en plural y cuya forma singular es arriesgado establecer (por ejemplo: robices, çafires).

En los verbos se toma como lema la variante gráfica que más veces aparece, teniendo en cuenta no sólo el infinitivo, sino el conjunto de las formas verbales. Normalmente el lema de cualquier verbo es el infinitivo (que aparece seguido de corchete si no aparece como forma textual). En los lemas correspondientes a verbos se ha prescindido de los pronombres enclíticos tras los infinitivos.

Dudamos bastante a la hora de ordenar los participios. Si además del participio aparece alguna forma personal conjugada, aquél se ordena siempre bajo el infinitivo del verbo que aparece como lema. Si sólo aparece el participio de un verbo ( $\mathrm{y}$ ninguna forma personal conjugada de ese verbo) nos pareció en principio más oportuno indicar como lema el participio. Pero luego, tras reconsiderar esta cuestión, nos inclinamos por ordenar en todos los casos los participios bajo los infinitivos, siempre y cuando dichos participios tengan efectivamente un valor y uso como formas verbales. Solamente en el caso de que aparezca sólo un par- 
ticipio y con valor y uso de adjetivo, entonces hemos considerado más oportuno que aparezca él mismo como lema. Así, por ejemplo, se verán como lemas los infinitivos cullir], emplir] o acollir] porque los participios — cullidos, emplidos, acollido - correspondientes a dichos lemas — que son, por otra parte, las únicas formas que aparecen en el corpus - tienen uso verbal. Por el contrario, aparece como lema allegado], y no allegar], porque el único participio que bajo él aparece es allegadas y tiene carácter adjetivo: los dreitos et razones allegadas de cada una part (20.159). En casos dudosos o no muy claros hemos optado por dar entrada propia al participio y además recogerlo bajo el lema del verbo correspondiente.

Cuando tras una palabra se indica una variante de otro ms., esta va entre corchetes seguida de la mayúscula identificadora del ms. Así, por ejemplo: entalscando (38.149) [et tardando N]. Por el contrario, cuando una palabra necesita a nuestro juicio una aclaración, explicación, corrección o reescritura, estas van a continuación de la palabra entre paréntesis. Así, por ejemplo, enuntió (39.119) (error por renuntió).

En algunas ocasiones la especificación de la categoría gramatical de la voz ha permitido diferenciar, y separar por bloques dentro de un mismo lema, palabras homógrafas. Así, por ej.: muyto adj. / adv. de cantidad. También los acentos han servido alguna vez para esto. Por ej.: aquél (pron. demostr.) / aquel (adj. demostr.); el art. / él pron. pers. Pero no siempre ha sido posible esta discriminación; así, en el caso de partículas que son siempre átonas, con indepedencia de su función gramatical: véase, por ejemplo, el caso de que (conj. completiva) y que (pron. rel.). La enorme frecuencia de aparición de estas partículas hacía muy costoso un análisis, una por una, para distinguirlas, y además resultaba un asunto no especialmente relevante: por esa razón se da conjuntamente la frecuencia, tanto absoluta como relativa.

Con respecto a la ordenación alfabética es necesario advertir que la $c h$ se ordena dentro de la $c$ (entre $c e$ y $c$ ), lo mismo que la $c$. No hay ningún lema que comience por $l l$.

Por último, también conviene advertir que las formas enclíticas de los pronombres (le, lo, se, etc.) aparecen bajo el lema correspondiente al pronombre de que se trate, en un bloque separado, indicando que se trata de forma enclítica (para lo que fue necesario señalar manualmente una a una en el listado alfabético inicial y luego introducirlas en el ordenador con una indicación especial de enclisis), pero también unido al verbo al que acompañe, bajo el lema correspondiente a ese verbo. Así, por ejemplo, el lo de diolo puede encontrarse bajo el lema dar, en la forma textual diolo, y además bajo el lema lo, 
en este caso separado y con una indicación entre paréntesis de que se trata de una forma enclítica. Como en ambos lugares aparece la localización, pueden confrontarse si hay alguna duda.

También las formas de algunas preposiciones fundidas gráficamente a la palabra siguiente, especialmente las preposiciones $a$ y de en las contracciones al y del, dellos, etc. pueden encontrarse en dos o tres lugares del índice lematizado. Nos ha parecido conveniente hacerlo así porque de esta manera aparecen en todos los sitios donde podrían estar y donde se le podría ocurrir a alguien buscar.

Así, por ejemplo, la forma contracta del se incluye bajo el lema del. Pero, por otro lado, parecía que no debería faltar bajo el lema de ni tampoco bajo el lema el. Así que se encuentra en los tres sitios. Naturalmente estos desdoblamientos en el índice lematizado se han hecho después de dar por concluidos los índices de frecuencias, de manera que estos últimos no han sufrido manipulación de ningún tipo que alterara o desdoblara las formas textuales.

Todos estos criterios, expuestos aquí pormenorizadamente, se han intentado seguir coherente y sistemáticamente en todo momento. Con todo, se puede encontrar alguna excepción en la aplicación de estos criterios generales. Así, por poner un ejemplo, el lema del topónimo Biel debería ser Viel (aparece Viel dos veces, frente a Biel una vez), pero ha parecido justificado en este caso dar primacía (aun yendo contra los criterios generales) a la forma gráfica a la que hoy estamos habituados.

En el índice lematizado no incluíamos el contexto correspondiente a la localización de cada forma. En primer lugar, porque se puede consultar en el texto de la edición crítica de la Crónica de San Juan de la Peña. En segundo lugar, porque hubiera significado ocupar un espacio mucho más amplio del ya extenso utilizado por el índice; además, prescindir del contexto es una práctica «que empieza a ser habitual en este tipo de trabajo». ${ }^{4} \mathrm{Y}$, por otra parte, como se indica después, en el Vocabulario se incluyen ejemplos de cada unidad léxica con el contexto completo o frase en la que aparece (y naturalmente, con la indicación de capítulo y línea).

4 M. Alvar Ezquerra, «Concordancias e índices léxicos del Libro de la infancia y muerte de Jesús», AFA, xxVI - xxVII (1980), p. 422. Precisamente, este autor no incluye el contexto en este trabajo ni tampoco en sus Concondancias e indices léxicos de la "Vida de San Ildefonso» (Málaga, 1980). Tampoco lo incluye, por ejemplo, René Pellen en «Poema de mío Cid». Dictionnaire lemmatisé des formes et des références (París, 1979). 


\subsection{El vocabulario}

El índice lematizado sirvió de base para la confección del vocabulario de la Crónica de San Juan de la Peña y constituyó una ayuda inapreciable para el estudio de multitud de cuestiones morfológicas. Como se ha indicado, el número total de formas es de 43.996: estas aparecen en el índice de frecuencias. Una vez agrupadas por bloques las formas iguales repetidas, el número total de formas distintas es de 5.363: estas constituyen la base del índice lematizado. Después de llevar a cabo la lematización, el número total de lemas es de 2.237: estos lemas constituyen las entradas del vocabulario.

El término entrada viene definido como «palabra destacada al comienzo de cada artículo de un diccionario» en el Diccionario de Lingüística de Mounin $(1979$, s. v.). Indica luego que «la agrupación de las formas flexivas por referencia a una entrada y la elección de ésta son fijados, en general, por el uso» (ibídem). Sobre el concepto de lema puede verse una amplia discusión teórica en Reinhold Werner, «La unidad léxica y el lema», en Günther HaEnsch y otros, La lexicografía. De la lingüistica teórica a la lexicografía práctica, Madrid, Gredos, 1982, pp. 188-232.

Tradicionalmente se ha considera la entrada como equivalente al lema, y en ese sentido usamos aquí el término. Téngase en cuenta, sin embargo, que recientemente ciertos autores tienden a identificar la entrada con el artículo lexicográfico completo, reservando el término lema para designar solamente el encabezamiento del artículo (Rodríguez BarCia, 2016: 199).

En el repaso y actualización del vocabulario llevados a cabo en el período octubre-diciembre de 2020, se han realizado algunos reajustes, dando como entradas algunas variantes que anteriormente solo aparecían citadas dentro de otro lema. Debido a esto, el número total de entradas del vocabulario es ligeramente superior al que inicialmente tenía (2.285).

La actualización del vocabulario ha servido, en primer lugar, para corregir erratas y para mejorar la maquetación, de manera que se han colocado en VERSALITAS todas las etimologías de las palabras, así como los apellidos de los autores citados (que inicialmente estaban en mayúsculas). Se han repuesto las cursivas (pues se habían perdido): las citas del texto de la Crón. SJC. aparecen precisamente en cursiva. En cambio, las citas de otros textos van entre comillas latinas «", destacando en cursiva las formas que interesan. Se han puesto en negrita las entradas. También se han repasado los espacios, las comas y, en fin, todos los aspectos referentes a la ortotipografía. 
Pero la actualización del vocabulario ha servido también para incluir nuevas referencias bibliográficas en algunos casos, así como nuevos datos que pueden ofrecer un contraste comparativo, ya sea en relación con el aragonés medieval (arag. med.), ya sea en relación con el aragonés moderno (arag. mod.). Así, por ejemplo, se han revisado las etimologías de palabras procedentes del árabe, teniendo en cuenta el Diccionario de arabismos y voces afines en iberorromance, de Federico Corriente (segunda edición ampliada, 2003). Y de la misma forma se han tenido en cuenta obras de referencia que en el otoño de 1991, cuando se dio por finalizada la redacción de la tesis doctoral, no se habían publicado. Por ejemplo, la referencia al DRAE (1970) se ha completado con la consulta del DLE (2014), última edición publicada del Diccionario de la Real Academia Española (y además, en este caso, de la Asociación de Academias de la Lengua Española). También se ha consultado y citado en bastantes casos el EBA (1999), obra que entonces (en 1991) no teníamos todavía, para acreditar el uso y documentación de voces en el aragonés moderno. En el caso de palabras sufijadas, si se hace algún comentario sobre la derivación, se ha consultado el Diccionario etimológico de los sufjos españoles de David Pharies (2002), si bien hay que tener en cuenta que no se ha entrado en profundidad en estas cuestiones, ya que en el estudio lingüístico se trata sistemáticamente todo lo relacionado con la morfología léxica o formación de palabras (NAGORE, 2003a: 571-611). Igualmente se han podido consultar otras obras que en 1991 no se habían publicado todavía, o bien que entonces no estaban a nuestro alcance. Así, por el ejemplo, el Dicionário etimológico Nova Fronteira da língua portuguesa (CunHA, 1986), el Nuevo diccionario etimológico latin-español y de las voces derivadas (SEGURA, 2001) o el Léxico hispánico primitivo (siglos VIII a XII) (Versión primera del Glosario del primitivo léxico iberorrománico), publicado en 2004 (LHP).

La actualización del vocabulario se ha aprovechado también para incluir, al final de cada entrada, los datos referidos a la frecuencia de las palabras. Para cada voz distinta (y cada forma distinta) se indica la frecuencia absoluta (es decir, el número de veces que aparece en el texto de la Crón. SJP.) y luego, tras dos puntos, la frecuencia relativa (expresada en un porcentaje que indica el tanto por ciento que supone respecto del total de formas que aparecen en la Crón. de SJP., que son 43.996). Así, por ejemplo, la preposición entro (cast. 'hasta') aparece 50 veces (esta es la frecuencia absoluta). Esa cifra aparece en primer lugar; después, tras dos puntos, se indica: 0,11365 (es la frecuencia relativa). De esta manera se puede clasificar cada voz (y cada forma distinta) en rangos, según su frecuencia relativa de aparición en el texto. La mayoría de las voces están en el rango 0,00 (hay muchas que aparecen una sola vez y tienen un índice de frecuencia relativa de 0,00227 ); solo algunas llegan al rango 0,1 ; y muy pocas al 1. 
El resultado es un estudio completo, revisado y actualizado del vocabulario de la Crón. SJP. En él aparecen todas las formas distintas que se hallan en el corpus textual, si bien lematizadas, de manera que cada lema constituye la entrada o unidad léxica. Para cada unidad léxica se da en primer lugar la categoría gramatical (mediante abreviaturas) y a continuación el significado (entre comillas simples). Después se incluyen uno o varios ejemplos en donde se puede ver el contexto (cada ejemplo se localiza mediante capítulo y línea). Si hay varias acepciones se separan mediante barras inclinadas $(/ /)$ y se colocan ejemplos pertinentes. Luego se presenta la etimología, de acuerdo con la consulta de diferentes obras de referencia. Además, cuando la primera documentación en castellano de la voz correspondiente es posterior al testimonio que nos proporciona la Crón. SJP., lo que ocurre en bastantes casos, nos ha parecido procedente indicarlo.

Más adelante, si es el caso, se citan formas semejantes o del mismo origen en otras lenguas románicas, principalmente catalán (cat.), occitano (occ.) y castellano (cast.), pero también en muchos casos francés (fr.), italiano (it.) y otras, así como testimonios del uso de la palabra en cuestión en aragonés medieval y en aragonés moderno. Lo primero nos parece fundamental para situar el vocablo aragonés en el contexto de las lenguas románicas circundantes; lo segundo, para ver tanto la amplitud de uso en el aragonés medieval (arag. med.) como la continuidad, o no, en el aragonés moderno (arag. mod.). Por supuesto, hay muchos vocablos comunes a la mayoría de las lenguas románicas y son suficientemente conocidos; por otro lado, también hay numerosos cultismos que tienen un interés relativo, en todo caso menor que las palabras patrimoniales. En estos casos podrían parecer superfluas las referencias a otros romances, por lo que se han reducido o incluso evitado del todo.

Finalmente, se indica, para cada forma distinta vinculada al lema o entrada, la frecuencia absoluta y la relativa, dato estadístico que nos parece relevante y que dota de valor añadido a este vocbulario.

Por lo que respecta a las referencias bibliográficas, pueden verse todas ellas en la Bibliografía que se incluye en las páginas finales de este libro. Muchas de las obras se citan habitualmente mediante siglas: pueden consultarse estas en las páginas previas al Vocabulario, donde también se relacionan las abreviaturas empleadas.

De esta manera se aprovecha por un lado el índice lematizado, que constituye el armazón sobre el que se construye el vocabulario, y por otro lado se integran en él los datos del índice de frecuencias, pero añadiendo otros datos 
fundamentales en lexicografía, como son la categoría gramatical y el significado. Además se proporcionan citas del texto en que aparece la palabra en cuestión, para que se pueda apreciar su uso en su contexto.

Como se ha dicho anteriormente, nos hemos atenido generalmente al texto de la edición crítica de C. ORCÁsTEguI (1986), que nos parece una edición magnífica, muy bien trabajada y de una gran solvencia, por cuanto se tienen en cuenta los tres manuscritos hoy conocidos de la Crón SJP. y se indica en todo momento a qué manuscrito corresponde cada parte, incluso cada capítulo o párrafo. Ahora bien, también hemos indicado que nos hemos permitido algunas excepciones al respecto.

La primera se refiere a la corrección de la numeración de la líneas de cada capítulo. Ya hemos inicado que cada palabra y cada frase lleva a continuación dos cifras que señalan su ubicación en el texto: la primera indica el capítulo; la segunda, la línea. Pues bien, al proceder así de manera sistemática, observamos que en algunos casos la localización indicada mediante las cifras no conducía al lugar exacto en el texto: esto se debía a que la numeración de las líneas, señalada de cinco en cinco como suele hacerse habitualmente, a veces tenía algunos errores, pues se saltaba alguna línea o bloques de cinco líneas, por ejemplo, pasando del 10 al 20 sin señalar la línea 15, etc. El repaso sistemático de la numeración de las líneas nos llevó a una corrección completa. En las citas de fragmentos textuales que se hacen en el vocabulario señalamos la localización de acuerdo con las correcciones pertinenentes.

La segunda se refiere a las correcciones al texto que hacemos tras la lectura del ms. B, que es el que ha merecido nuestra atención por razones obvias: el ms. N ofrece una lengua más castellanizada y un gran desorden, lo que dificulta el cotejo de los fragmentos; el ms. E es muy incompleto, pues contiene solo el texto desde la mitad del capítulo 34 hasta el capítulo 39. En total hemos realizado 380 enmiendas (se relacionan en el tomo III, pp. 78-87 de nuestra tesis doctoral). Muchas de ellas no son relevantes, pues afectan a la separación de palabras (por ejemplo, en la ed. crítica se transcribe ad aquellos, en antes, cada uno, en continent y vino sende; nosotros leemos en el ms. adquellos, enantes, cadauno, encontinent y vinosende) o a aspectos gráficos (en la ed. crítica se lee avíe y nosotros leemos en el ms. auie; en lugar de vispe, leemos bispe; ayuda: aiuda; priso: prisso; yglesia: iglesia; leyto: leito; honrada: honrrada; muytos: muitos, etc.). Algunas parecen simples erratas de transcripción (como remenmbrant. remembrant, crabantada: crebantada; semblaca: semblanca, monestero: monesterio; acordado: acordando; etc.). No son muchas las que afectan a la fonética (traballavan: nosotros leemos treballauan; estrella: estrela; fijo: fillo; tractamiento: tratamiento) o a la morfología (acordaron: nosotros leemos acordoron; querien: querian; entre: entro; fues: fuesse; consquistó: conquisso; etc.). 
Sin embargo, muy pocas de estas correcciones afectan al léxico. Por otro lado, nuestra intención ha sido guardar la máxima fidelidad al texto de la edición crítica. Por ello, solamente hemos señalado algunas de estas correcciones en las citas de los fragmentos textuales cuando nos ha parecido que podían ser relevantes, y siempre mencionando lo que aparece en la edición crítica.

Conviene indicar que en el vocabulario no se incluyen los nombres propios (con la única excepción de algunos sobrenombres que funcionan como sustantivos — veáse, por ejemplo, abarca o cabreta — o como adjetivos — véase, por ejemplo, batallador o tiemblador-). Tanto los antropónimos como los topónimos están publicados en un completo índice y pueden consultarse (NAGORE, 2003b). Fuera de los nombres propios, se han incluido todas las voces presentes en la Crón. SJP. Pensamos que la práctica, todavía bastante común, de incluir en los vocabularios - ya sean de hablas vivas, ya sean de textossolamente los elementos léxicos que se consideran diferenciales con respecto al castellano, dificulta la tarea de comparación del aragonés con otras lenguas.

Para definir el aragonés (en este caso, el aragonés medieval del siglo xIV) frente a las demás lenguas románicas (y no solo frente al castellano), en todos los aspectos, no solo en los fonéticos, es necesario contar con repertorios léxicos completos, pues solo eso posibilita una comparación de todos los elementos léxicos con los de otras lenguas románicas. Tanto las discrepancias como los elementos comunes forman parte de la definición del aragonés en el plano léxico. Y lo que pueden ser diferencias con respecto a una lengua o a unas lenguas determinadas, pueden ser hechos comunes respecto a otras, o viceversa. De manera que solo teniendo en cuenta todos los elementos léxicos podemos encarar trabajos rigurosos y completos de análisis léxicos que nos permitan una caracterización exacta del aragonés.

Finalmente indicaremos que concebimos nuestro trabajo como una contribución al conocimiento del léxico del aragonés medieval a partir del vocabulario de una obra emblemática, tanto histórica como lingüísticamente, como es la Crónica de San Juan de la Peña, de Pedro iv el Ceremonioso.

Huesca, enero de 2021

Francho Nagore Laín 



\title{
ABREVIATURAS Y SIGLAS BIBLIOGRÁFICAS
}

\author{
ABREVIATURAS
}

\begin{tabular}{|c|c|c|c|}
\hline 1 & primera persona de singular & Crón. SJP. & Crónica de San Juan de la Peña \\
\hline 2 & segunda persona de singular & dem. & demostrativo \\
\hline 3 & tercera persona de singular & deriv. & derivado \\
\hline 4 & primera persona de plural & dim. & diminutivo \\
\hline 5 & segunda persona de plural & distr. & distributiva \\
\hline 6 & tercera persona de plural & doc. & documento \\
\hline acep. & acepción & docs. & documentos \\
\hline acus. & acusativo & $\mathrm{E}$ & ms. E \\
\hline adj. & adjetivo & ej. & ejemplo \\
\hline adv. & adverbio & ejs. & ejemplos \\
\hline advers. & adversativa & encl. & enclítico \\
\hline ant. & antiguo & etim. & etimología \\
\hline ár. & árabe & expr. & expresión \\
\hline arag. & aragonés & f. & femenimo \\
\hline arag. med. & aragonés medieval & fr. & francés \\
\hline arag. mod. & aragonés moderno & fut. & futuro \\
\hline art. & artículo & gall. & gallego \\
\hline ast. & asturiano & gasc. & gascón \\
\hline B & ms. B & ger. & gerundio \\
\hline c.d. & complemento directo & germ. & germánico \\
\hline c.i. & complemento indirecto & gr. & griego \\
\hline cap. & capítulo & h. & hacia \\
\hline card. & cardinal & imp. & impersonal \\
\hline cast. & castellano & imper. & imperativo \\
\hline cat. & catalán & imperf. & imperfecto \\
\hline cfr. & confróntese & ind. & indicativo \\
\hline cl. & clásico & indef. & pret. indefinido, perf. simple \\
\hline comp. & compárese & inf. & infinitivo \\
\hline compl. & complemento & interrog. & interrogativa \\
\hline cond. & condicional & intr. & intransitivo \\
\hline conj. & conjunción & it. & italiano \\
\hline consecut. & consecutiva & lang. & languedociano \\
\hline contr. & contracción & lat. & latín \\
\hline cop. & copulativa & lat. cl. & latín clásico \\
\hline cpt. & compuesto & lat. vg. & latín vulgar \\
\hline
\end{tabular}




\begin{tabular}{|c|c|c|c|}
\hline lín. & línea & provi. & provincia \\
\hline lit. & literalmente & refl. & reflexivo \\
\hline loc. adv. & locución adverbial & relat. & relativo \\
\hline loc. cit. & en el lugar citado & retorrom. & retorrománico \\
\hline loc. conj. & locución conjuntiva & rum. & rumano \\
\hline loc. prep. & locución prepositiva & s. & sustantivo \\
\hline $\mathrm{m}$. & masculino & s. a. & $\sin$ año, sin fecha. \\
\hline med. & medieval & s. $v$. & sub verbum (bajo la palabra) \\
\hline mod. & moderno & sigs. & siguientes \\
\hline ms. & manuscrito & $\sin$. & sinónimo \\
\hline mss. & manuscritos & sing. & singular \\
\hline $\mathrm{N}$ & ms. N & subj. & subjuntivo \\
\hline n. & neutro & suf. & sufijo \\
\hline nav. & navarro, romance navarro & top. & topónimo \\
\hline neg. & negación & tr. & transitivo \\
\hline num. & numeral & u. l. p. & unidad léxica pluriverbal \\
\hline occ. & occitano & v. & verbo \\
\hline op. cit. & opus citatus, obra citada & vg. & vulgar \\
\hline ord. & ordinal & VA & versión aragonesa \\
\hline p. p. & participio pasado, part. pasivo & var. & variante \\
\hline p. pres. & participio presente & vasc. & vasco, vascuence \\
\hline p., pág. & página & $\mathrm{VC}$ & versión catalana \\
\hline part. & participio & vid. & véase \\
\hline partit. & partitivo & VL & versión latina \\
\hline pl. & plural & & \\
\hline pop. & popular & & \\
\hline port. & portugués & & \\
\hline poses. & posesivo & & \\
\hline pref. & prefijo & & \\
\hline prep. & preposición & & \\
\hline pres. & presente & & \\
\hline pret. & pretérito & & \\
\hline prnl. & pronominal & & \\
\hline prnl.-adv. & pronominalo-adverbial & & \\
\hline prob. & probablemente & & \\
\hline procl. & proclítico & & \\
\hline pron. & pronombre & & \\
\hline pron. pers. & pron. personal & & \\
\hline pron. relat. & pron. relativo & & \\
\hline prov. & provenzal & & \\
\hline
\end{tabular}




\section{SIGLAS BIBLIOGRÁFICAS}

ACA = Archivo de la Corona de Aragón.

ACR $A=$ Acta Curiarum Regem Aragonum.

$A D=$ The Aragonese Dialect, RHi, xxIv (1911), pp. 5-45 (trad. cast.: AFA, xxxIx, 1987, pp. 163-201), de G. W. Umphrey.

$A D A=$ Anuario de Derecho Aragonés (Zaragoza).

$A E F=$ Anuario de Estudios Filológicos (Cáceres).

AFA = Archivo de Filología Aragonesa. (Zaragoza, I.F.C.).

ALEANR = Atlas Lingüístico y Etnográfico de Aragón, Navarra y Rioja, de Manuel Alvar, Tomás Buesa, Antonio Llorente.

BDELC $=$ Breve Diccionario Etimológico de la Lengua Castellana, de Joan Corominas.

$\mathrm{BH} i=$ Bulletin Hispanique.

BHS = Bulletin of Hispanic Studies.

$B R A E=$ Boletín de la Real Academia Española .

$C A C=$ Compromis i Sentencia Arbritral sobre Derechos del Azud i Acequia de Candeclaus, 1406; en Miguel Ángel Gargallo \& Manuel Tomeo, Los riegos en Villamayor de Gállego, Villamayor de Gállego, Asociación Cultural «Aljez», 2011.

C.N.R.S. = Centre National de la Recherche Scientifique, París.

C.S.I.C. $=$ Centro Superior de Investigaciones Científicas, Madrid.

CLHM = Cabiers de Linguistique Hispanique Médieval. Publiés par le Séminaire d’Études Médievales Hispaniques de l'Université de Paris-XIII, sous la direction de Jean RoudiL. Paris, Klincksieck.

$\mathrm{CP}=$ Crónica Pinatense, denominación que a veces utilizan algunos autores para referirse a la Crónica de San Juan de Peña.

CPRA = Cartas de población del Reino de Aragón (Zargoza, I.F.C., 1991), de María Luisa LEDEsma Rubio.

Crón. SJP. = Crónica de San Juan de la Peña. [Las diferentes versiones se indican mediante las siguientes siglas: $\mathrm{VA}=$ versión aragonesa; $\mathrm{VC}=$ versión catalana; $\mathrm{VL}=$ versión latina. Si no se indica expresamente otra cosa nos referimos a la VA, cuyos manuscritos se nombran por B, N y E.]

$C T=$ Cortes de Tamarite (1375). [Estudio: Ma Rosa ForT CañEllas, "Estudio de 60 documentos del Proceso de las Cortes de Tamarite de Litera del año 1375, según el manuscrito 2", AFA, xx-XXI (1977), pp. 141-262].

$D A=$ El dialecto aragonés (Madrid, Gredos, 1953), de Manuel Alvar.

DCECH = Diccionario Crítico Etimológico Castellano e Hispánico (Madrid, 1980), de Joan Corominas y José Antonio Pascual.

DCELC = Diccionario Crítico Etimológico de la Lengua Castellana (Madrid, Gredos, 19541957), de Joan Corominas.

DCVB = Diccionari Català-Valencià-Balear (Palma de Mallorca, 1930-1962), de Antoni M ${ }^{a}$ ALCOVER, y Francesc de B. Moll.

DDPA = Diccionario Dialectal del Pirineo Aragonés (Zaragoza, I.F.C. 1985), de Gerhard RoHLFs. 
$D E=$ Dialectología española (Madrid, Gredos, 1967), de Alonso Zamora VicenTE.

DECL/C = Diccionari Etimologic i Complementari de la Llengua Catalana (Barcelona, Curial, 19801991), de Joan Coromines.

DEEH = Diccionario etimológico español e hispánico (Madrid, Espasa-Calpe, 1985), de V. GARCIA DE Diego.

DGL/C = Diccionari general de la llengua catalana (Barcelona, Edhasa, 12. ${ }^{\text {a }}$ edición, 1980), de Pompeu FABra.

DHLE = Diccionario Histórico de la Lengua Española, de la REAL ACADEMIA ESPAÑola, Tomo I (a-alâ), Madrid, 1972. Fascículos 11. a 16. (álaba-amenazar), Madrid 1974-1984.

DJ = Documentos de Jaca (1362-1502), [Estudio lingüístico y edición de M. AlvAR: AFA, X-XI (1958-59), pp. 195-276 y 327-366, y EDA, II, pp. 139-266].

DLAA = Documentos lingüísticos del Alto Aragón. (Documentos notariales de entre los años 1258-1495). [Edición: T. Navarro Tomás, Documentos lingüísticos del Alto Aragón, Syracuse (New York), Syracuse University Press, 1957. Estudios: J. ReIDY Fritz, Documentos notariales aragoneses, 1258-1495. Estudio lingüistico, Pamplona, I.P.V., 1977. L. CoOper, On the Language of Upper Aragon (1258-1495), HR, 28 (1960), pp. 262-275; trad. en cast. en AFA, XLI (1988), pp. 211-229; V. LAGÜENS Gracia, Léxico jurídico en documentos notariales aragoneses de la Edad Media (siglos XIV y XV), Zaragoza, I.F.C., 1992; etc.].

DLE $=$ Real Academia Española: Diccionario de la lengua española. Vigesimotercera edición. Barcelona, Espasa Libros, 2014.

DL/C = Institut D’Estudis Catalans: Diccionari de la llengua catalana. Barcelona / Palma / València, Edicions 3 i 4 / Edicions 62 / Editorial Moll / Enciclopèdia Catalan / Publicacions de l'Abadia de Montserrat, 1995.

$D M E=$ Diccionario Medieval Español. Desde las Glosas Emilianenses y Silenses (s. X) hasta el siglo XV (2 tomos, Salamanca, Universidad Pontificia, 1986), de Martín Alonso Pedraz.

DNT, $I=$ VÁzQUEZ OBRADOR, 2009

DNT, $I I=$ VÁZQUEZ OBRADOR, 2010

DNT, $I I I=$ VÁZQUEZ OBRADOR, 2011

DNT, $I V=$ VÁZqUEZ OBRADOR, 2012

DNT, $V=$ VÁzQUEZ OBRADOR, 2013

DR = El Dialecto riojano (Madrid, Gredos, 1976), de Manuel Alvar.

DRAE Manual, 1979 = Diccionario manual e ilustrado de la Lengua Española (Madrid, Espasa-Calpe, 1979, 2. a ed.), de la Real ACAdemia Española.

DRAE Manual, 1989 = Diccionario manual e ilustrado de la Lengua Española (Madrid, Espasa-Calpe, 1989, 3. a ed.), de la Real Academia Española.

DRAE, 1970 = Diccionario de la lengua española (19. ${ }^{\text {a }}$ ed., Madrid, Espasa-Calpe, 1970), de la Real ACAdemia Española.

DRAE, 1984 = Diccionario de la lengua española (20. ${ }^{a}$ ed., Madrid, Espasa-Calpe, 1984), de la Real Academia Española. 
EAMJM = Gómez de VALEnzuela, Manuel (2000a): Estatutos y Actos Municipales de Jaca y sus montañas (1417-1698). Zaragoza, Institución «Fernando el Católico». [= EAMJM]

EBA = Nagore Laín, Francho (coord.): Endize de bocables de l'aragonés seguntes os repertorios lesicos de lugars y redoladas de l'Alto Aragón. 4 tomos. Uesca, Instituto de Estudios Altoaragoneses, 1999.

EDA = Estudios sobre el dialecto aragonés. I y II (Zaragoza, I.F.C., I, 1973; II, 1978), de Manuel ALVAR.

EEMCA = Estudios de Edad Media de la Corona de Aragón (Zaragoza).

EFA = Estudios Filológicos Aragoneses (Zaragoza, P.U.Z., 1989), de Tomás Buesa Oliver.

ELH = Enciclopedia Lingüística Hispánica (Madrid, C.S.I.C., Tomo I, 1960, Tomo II 1967 y Suplemento al tomo I, 1962).

$E L I A=$ «Etude lexicologique sur les Inventaires Aragonais» (VR, x (1948-1949), pp. 87219), por B. РотTIER.

ETA = Enciclopedia Temática de Aragón (dir.: Antonio Beltrán Martínez, Guillermo Fatás Cabeza y Guillermo Redondo Veintemillas), 10 tomos, Zaragoza, ediciones Moncayo, 1986-1989.

EVT = Gómez de VAlenzuela, Manuel (2000b): Los Estatutos del Valle de Tena (14291699), Zaragoza, Real y Excma. Sociedad Económica Aragonesa de Amigos del País, 2000.

FA = Fueros de Aragón (principios del siglo XIv), según el manuscrito 458 de la Biblioteca Nacional de Madrid. Edición y estudio de G. Tilander (Lund, 1937).

FA de 1265 a 1381 = Fueros de Aragón de 165 a 1381. Edición de Jesús Bergua Camón (ADA, v, 1949-1950, pp. 457-575.

FA de 1350 = Tilander, Gunnar, «Fueros aragoneses desconocidos promulgados a consecuencia de la gran peste de 1348», RFE, XxII (1935), pp. 1-33 y 113-152.

FA hasta $1265=$ Fueros de Aragón hasta 1265. Edición de José Luis Lacruz Berdejo (ADA, II, 1947, pp. 223-362).

FAM = Gargallo Moya, Antonio (1992): Los Fueros de Aragón según el ms. del Archivo Municipal de Miravete de la Sierra (Teruel)], Zaragoza, Anubar Ediciones ("Textos Medievales", 89).

FGN = Fuero Antiguo del Fuero General de Navarra, (s. XIV), El Romance Navarro en los Manuscritos del-, (Pamplona, I.P.V., 1977), de Mª Ángeles LíBAnO ZumalacÁrRegui.

FJ = Fuero de Jaca. (Textos de los siglos XIII y XIV en latín, en occitano y en aragonés). Edición de M. MolHo (Zaragoza, 1964).

FLV $=$ Fontes Lingvae Vasconum. Stvdia et docvmenta. (Pamplona, I.P.V.).

$F N=$ Fueros de la Novenera . Edición y estudio de G. Tilander (Uppsala, 1951).

$F T=$ Fuero de Teruel (Texto en aragonés escrito en la segunda mitad del siglo XIII). Edición y estudio de Max Gorosch (Estocolmo, 1950).

GEA = Gran Enciclopedia Aragonesa, xII vols., Zaragoza, Unión Aragonesa del Libro (Unali), 1980-1982. Más cinco apéndices: Zaragoza, Unali, 1983 (apéndice I); Zargoza, Comercial Aragonesa del Libro, 1987 (apéndice ir); Zaragoza, Aragonali, 1997 (apéndice III); Zaragoza, Urusaragón, 2001 (apéndice IV), 2007 (apéndice v). 
GLA = Gramática de la lengua aragonesa (Zaragoza, Mira editores, 5ª ed., 1989), de Francho Nagore Laín.

GVAM = Glosario de voces aljamiado-moriscas (Gijón, Ediciones Trea, 2015), de Álvaro GALmés de Fuentes, Mercedes Sánchez Álvarez, Antonio Vespertino Rodríguez y Juan Carlos Villaverde Amieva.

$H A D=$ Der Hocharagonesische Dialekt, RLiR, xI (1935), 1-312, de Alwin KuHN.

$H J=$ El habla del campo de Jaca (Salamanca, 1948), de Manuel ALvar.

$H R=$ Hispanic Review

I.E.A. = Instituto de Estudios Altoaragoneses (Huesca).

I.E.O. = Institut d'Etudes Occitans (Toulouse).

I.F.C. = Institución «Fernando el Católico» (Zaragoza).

I.P.V. = Institución «Príncipe de Viana» (Pamplona).

Inv. arag. = Inventarios aragoneses (1330-1499). [Edición: M. SERRANO y SANZ, Inventarios aragoneses de los siglos XIV y XV, BRAE, II (1915), III (1916), IV (1917), VI (1919) y IX (1922). Estudios: B. РотTIER, «Etude lexicoloxique sur les Inventaires aragonais», VR, x (19481949), pp. 87-219. B. PotTier, «L'évolution de la langue aragonaise a la fin du moyen age», $B H i$, LIV (1952), pp. 184-199; trad. en cast. en $A F A$, 38 (1986), pp. 225-240.

LA $=$ Libro de Actoridades, también conocido como Rams de flores. [Edición de C. GuARDioLA Alcover, Zaragoza, IFC, 1998].

LCMA = Léxico del Comercio Medieval en Aragón (siglo XV) (Zaragoza, I.F.C., 1982), por J. Ángel Sesma y Ángeles Líbano.

LDA = López Susín, José Ignacio (2006): Léxico del Derecho aragonés. Zaragoza, El Justicia de Aragón, 2006.

LEA = Lingüistica Española Actual.

LHP = Léxico hispánico primitivo (siglos VIII al XII). Edición al cuidado de Manuel SECO. Madrid, Editorial Espasa Calpe, 2004.

$L M=$ Libro de los muros. Vid. Iranzo Muñío, María Teresa, La muralla de Huesca en la Edad Media, Huesca, Ayuntamiento de Huesca, 1986, pp. 53-122. [Texto escrito en Huesca en 1444-1465].

$L M M=$ Libro de las Maravillas del Mundo (texto escrito en aragonés en los últimos años del siglo xiv). Edición y estudio de Pilar Liria Montañés (Zaragoza, Publ. de la Caja de Ahorros de Zaragoza, Aragón y Rioja, 1979).

LR = Liber Regum (h. 1194-1211). Edición y estudio de L. Cooper (Zaragoza, I.F.C., 1960). $L R D M A=$ Léxico romance en documentos medievales aragoneses (siglos XI y XII), de María Rosa Fort Cañellas, Zaragoza, Diputación General de Aragón, 1994.

LVA $=$ Libro Verde de Aragón (1507). Estudio de M. Alvar, 1947. (EDA, II, pp. 105-138).

MGHE = Manual de gramática bistórica española (Madrid, 1968, 13. ${ }^{a}$ ed.), de R. MENÉNDEZ PIDAL NRFH $=$ Nueva Revista de Filología Hispánica.

$O B=$ Ordinaciones y paramientos de la ciudad de Barbastro publicados por D. Mariano de Pano. Aspectos lingüísticos por D. Jesús Vázquez Obrador. Barbastro, Ayuntamiento de Barbastro, 2011. (Textos de 1396 a 1521). 
P.U.Z. $=$ Prensas de la Universidad de Zaragoza.

$P V=$ Príncipe de Viana (Pamplona).

$P Y=$ Poema de Yúcuf (h. 1300). Edición y estudio por R. Menéndez Pidal (RABM, viI, 1902; $2^{a}$ ed., Granada, 1952; reprod. en TME, pp. 421-519).

$\mathrm{R} A B M=$ Revista de Arcbivos, Bibliotecas y Museos.

RDTP $=$ Revista de Dialectologia y Tradiciones Populares.

$R E W=$ Romanisches Etymologisches Wörterbuch (Heidelberg, 1935; reimpresión, Heidelberg, Carl Winter-Universitätsverlag, 1972), por W. MEYER-LüBKE.

RFDE $=$ Refrans, frases feitas, ditos y esprisions de l'Alto Aragón (Sezión de Lenguas de o Rolde de Estudios Aragoneses, Zaragoza, 2004).

RFE $=$ Revista de Filología Española .

$\mathrm{RH} i=$ Revue Hispanique.

RIEV = Revista Internacional de Estudios Vascos.

$R L i R=$ Revue de Linguistique Romane.

$\mathrm{RPh}=$ Romance Pbilology.

TLME = Textos lingüisticos del medievo español (Segunda edición corregida, Oxford, The Dolphin Book, 1966). Preparados con Introducciones y Glosario por D. J. GifFord y F. W. Hodcroft.

TLN = Textos lingüisticos navarros (Pamplona, I.P.V., 1970) de Fernando GonzáLEz OlLé.

TME $=$ Textos medievales españoles. Ediciones criticas y estudios (Madrid, Espasa Calpe, 1976) de R. MenÉndez Pidal. [Aquí se encuentran, entre otros: Roncesvalles, pp. 7-102; Razón feyta d'amor, pp. 103-117; PY, pp. 421-519].

$V M=$ Vidal Mayor (Texto en aragonés de h. 1260). Edición facsímil del único manuscrito conservado del Vidal Mayor, acompañada de un volumen de estudios introductorios: Diputación Provincial de Huesca, I.E.A. Madrid, R. Díaz Casariego, Editor, 1989. Edición y estudio de G. Tilander (Lund, 3 vols., 1956).

VMC = Vocabulario Medieval Castellano, Madrid, 1929 (reimpresión: Madrid, Visor, 1990). de Julio Cejador y Frauca. .

$V R=V o x$ Romanica.

$Z R P h=$ Zeitscbrift für Romanische Pbilologie. 



\title{
VOCABULARIO
}

\author{
A
}

a prep. 'a': que fuessen a cortes a Huesca 20.125; vinos'ende a Castellón 36.503; que se estuvies de fer enoyo et dannyo a las ditas hermanas suyas 34.130. // 'en': Et estando a Mallorquas [Mallorcas N], 37.7; El dessus dito don Jayme d'Aragón, a las Cortes Generales que tuvo a Girona, citó [sacó N] el dessus nombrado rey don Sancho de Mallorquas 38.460-461; ...paró el estendart a Barçalona 38.483; et el mas avinent [avenient $\mathrm{N}$ ] a los sus sozmesos que otro rey que al mundo fues 39.4; si al mundo havía buen cavallero, él lo era 13.6. / / En ocasiones vale por 'por', 'para', 'con', 'de': a honor dél 35.193; fue grant honor a la casa d'Aragón 36.213; el rey murió a grant selepnidad 11.65-66; et movido a gran ira 14.51. Etim.: del lat. AD 'a' 'hacia, para', (mismo origen que ad). Frec.: 717: 1,62969.

abarca] (var.: avarcha, avarca, abarcha) s. f. 'abarca': tantost firo vestir la dita criatura assín como a pastor et fizole calcar abarcas. 12.22. También sobrenombre de Sancho Garcés II: Et por aquesto, como vino vestido et calcado como pastor, clamaronlo [clamoronlo en el ms. B, original] Sancho Abarcha 12.42. Etim.: de origen desconocido, seguramente prerromano (DCECH, I, pp. 7-9). Frec.: abarcas 1: 0,00227; Abarcha 1: 0,00227; avarchas 2: 0,00455; Avarca 1: 0,00227; Avarcha 6: 0,01364.

abastamiento s. m. 'abundancia, copiosidad, abastecimiento, provisión'. ...et en el lugar que dizen Alcaçar tenieron la Nadal con gran goyo et abastamiento de viandas 19.200. Deriv. de bastar 'abastecer'. Frec.: 1: 0,00227.

abat (var.: abad, abat, abbad, abbat) s. m. 'abad'. En 20.235 aparece como s. f.: pora la qual redempción la abbat de Sant Salvador de Leyre vendie el trasoro de su monesterio. Etim.: lat. ABBATE (DCECH, s. v.). En cast. se doc. abbat desde los orígenes del idioma (DCECH, s. v.). En cat. abat, grafía ant. abbat. (DCVB, s. v.). Frec.: abat 8: 0,01818; abad 7: 0,01591; abbad 1: 0,00227; abbat 4: 0,00909.

abbadia s. f. 'abadía, iglesia o monasterio regido por un abad': ... et fue prior de Sant Benedit de Bages, qui la ora no yera abbadia 28.28. Deriv. de abat. Comp. arag. mod. abadía 'casa del cura párroco' (Andolz, 1992: 3). Frec.: 1: 0,00227.

abito (var.: hábito) s. m. 'hábito'; 'vestidura religiosa': tornó al abito de San Benedito 20.301; Et en antes quel se visties el ábito, fizo venir en la villa de Aljacira, do la ora iazía enfermo, su fillo don Pedro 35.251; recibió muyt devotament hábito de la santa religión 35.249. Del lat. HABITUS. Frec.: abito 4: 0,00909: hábito 2: 0,00455. 
abivado adj. 'avivado; animado; lleno de vida o de vivacidad': E en tanto abivado et encorajado de haver batallas continuament con los moros que apenas estava un dia seguro 10.15. En el ms. se lee abinado, quizá error de escritura. frec.: 1: 0,00227.

abrir] v. tr. 'abrir': et abrió la dita reyna por el vientre 12.9; las puertas heran aviertas 19.38. Del lat. APERIRE (DCECH, I, p. 22). Frec.: abrió 2: 0,00455; aviertas 1: 0,00227 .

abrivadament (var. aprivadament) adv. 'rápidamente, impetuosamente, fugazmente, audazmente, velozmente, con fuerza, con brío’: ...passó las montannas que yeran cubiertas de nieve et de ora del alva, muyt abrivadament [abreviadament $\mathrm{N}$ ] et podroso 12.56. Catalanismo según GeIjerstam (cfr. GILKISON, s. v.). Está documentado en cat. por primera vez en Llull con el significado de 'audazmente, sin vacilar' (DECLIC, II, p. 244). Corominas lo deriva de briu 'energía, animación' < céltico *BRIGOs. El DCVB, s. v., tomo 1, pp. 57-58) registra el cat. abrivadament 'amb força, violentament', 'veloçment' y lo deriva de abrivar 'donar força, impuls o coratge', verbo formado sobre el galo *BRIVOs 'fuerza, coraje'. Están relacionados: prov. abrivar, it. abbrivare, y los sust. cast. brío, prov. briu, fr. brif, it. brio Frec.: 1: 0,00227.

absentar] v. prnl. 'ausentar': temiendose que por semblant iudicio que firo de su padre non passas, absentos del dicto regno et vino sende en Valencia 17.12. Etim.: del lat. eclesiástico ABSENTARE, deriv. de ABSENS, -TIS 'ausente'. Documenta ausentar el BDELC h. 1460; igualmente el DCECH, I, p. 414. La Crón. SJP. adelanta la $1^{\text {a }}$ doc. casi un siglo. Frec.: absentos 1: 0,00227.

absolver] v. tr. 'absolver': ... los ditos arcevispos poblicoron la paz dessuso dita et non res menos absolvieron el dito rey don Jayme et todos aquellos qui con él eran en toda la tierra del su escomulgamiento en que estavan $38.107 ; \ldots$ mas de depués de algún tiempo todos los absolvió de las presones et lures tierras les rendió graciossamient. 36.148. Tomado del lat. ABSOLVERE. Frec.: absolvieron 1: 0,00227; absolvió 1: 0,00227.

abstener v. tr. 'abstener': Et como por todas aquestas inducciones el rey Federich non se quiso abstener de su propósito... 38.259. Etim.: Adaptación culta del lat. ABSTINERE (BDELC, p. 563 , s. v. tener). La $1^{a}$. doc. en el $2^{\circ}$ cuarto del s. XV. La Crón. SJP. la adelanta unos 60 años. El DCECH da la misma fecha indicando que se documenta en J. de Mena y en Díaz de Gámiz (DCECH, V, p. 462, s. v. tener). Frec.: 1: 0,00227.

abundoso] adj. 'abundante; copioso': indueytos de mas abundosa et acostumbrada devoción 9.28. Deriv. de ABUNDARE, propiamente 'salirse las ondas, rebosar', formado de AB y UNDARE (DCECH, IV, p. 283, s. v. onda). Frec.: abundosa 1: 0,00227 .

acabado p.p. y adj. 'acabado, terminado, finalizado': en el castiello de Perpinyan, qui la ora non era obrado nin acabado assí como buey yes 36.413. // 'completo, total': 
assí como si en plena et acabada possesión fues 36.466. Frec.: acabada 1: 0,00227; acabadas 2: 0,00455; acabado 1: 0,00227.

acabamiento s. m. 'acuerdo': viendo quel su entendimiento no avía podido aver acabamiento (en la ed. crítica acabamient) trató por otra manera verdadera que la dita paz se fizies en Catalunnya 38.69. // 'consumación, terminación, fin, término'. Aparece en la loc. verbonominal venir a acabamiento 'consumarse': ... mas por tal como el dito infant renunció a la priomogenitura et se se metió en Orden, el dito matrimonio non pudo venir a acabamiento 39.13. Deriv. de acabar. Comp. acabamiento 'terminación, conclusión'; 'muerte, fallecimiento' en Fernández de Heredia (GILKISON s. v.). El DHLE, s. v., p. 264, recoge como 1a acep.: 'efecto, realización, consumación, cumplimiento, consecución de alguna cosa', con documentación en cast. med. a lo largo de los siglos XIII-XV. Cita también un ejemplo aragonés, de FA, p. 136: «Qui ensayare crebantar con acabamiento palacio de infançón [...] será tormentado por pena d'aquel crebantamiento». Frec.: acabamiento 6: 0,01364; acabamient 1: 0,00227.

acabar] 'conseguir, lograr, obtener; recabar': ruegote que acabes con el rey de Aragón que me alargue la tregua por otros cinquo annos 36.394-395; puniava encuvierto de aver amor de la reyna et eso mismo acavó lo que quiso 19.108. Etim.: deriv. de cabo, del lat. CAPUT 'cabeza' (DCECH, I, 714), quizá a través de la formación de un verbo lat. vg. *ACCAPARE, (DCVB, t. I, pp. 76-77, s. v. acabar,). Vid. también $R E W, \mathrm{n}^{\circ}$ 1668. Comp. port., cast., cat., occ. acabar, fr. achever. El DCVB, tomo I, pp. 76-77, recoge acabar con el significado de 'dur o arribar a terme', y añade: con la idea fundamental de 'dur alguna cosa a son terme'; recoge también el significado de 'conseguir, obtener', cast. recabar, acabar. Dice que "s'usava molt acabar amb aquesta accepció en la llengua antiga, i el nom de la persona, de qui s'obtenia la cosa, anava precedit de la preposició amb: Aquells vuit probomens se'n tornaren sens que ab lo rey res no acabassen (Llull), etc.". Frec.: acabaría 1: 0,00227; acabes 1: 0,00227; acavó 1: 0,00227.

acaeçer] v. prnl. 'acaecer, concurrir, coincidi': El quoal feito se usa en Espaynna a los que se acaescen en tal feyto 19.95 (ms. N). Etim.: del lat. vg. *ACCADERE, (lat. cl. ACCIDERE), deriv. de CADERE (DCECH, I, p. 734). Frec.: acaeçen 1: 0,00227.

acallar] v. tr. 'acallar': la discordia de sus vasallos fue acallada. 38.616. Etim.: deriv. de callar y este del lat. vg. *CALLARE 'bajar la voz' (DCECH, I, p. 771). Frec.: 1: 0,00227 .

accident s. m. 'accidente': por cada una part vet [et veyet $\mathrm{N}]$ que accident vino cuytado al dito rey 37.83; et como los prometimientos dessuso ditos, algunos accidentes entrevenientes [veniesen al $\mathrm{N}$ ] el dito Padre Santo non pudies adozir a acabamiento... 38.160. Tomado del lat. ACCIDENS, -TIS, part. presente de ACCIDERE 'caer (en algo)', 'llegar (hasta algo)', 'suceder' (DCECH, I, p. 735, s. v. caer). Frec.: 2: 0,00455. 
acerca adv. 'cerca', 'de cerca': que en ninguna manera non le parecies delant, más que tenies acerca su tierra et bien establida 38.236. Del lat. AD CIRCA (DCECH, II, p. 42, s. v. cerco). Comp. acerca, acerqua 'cerca' en Fernández de Heredia (Gilkison, s. v.). Frec.: 1: 0,00227.

acollir] v. tr. 'acoger': et entrando por el palacio do se delebrava el dito parellamiento, fue bien acollido et recebido por el dito general 12.26. Deriv. de collir < lat. COLLIGERE 'recoger, allegar' (DCECH, II, p. 120-121). Comp. cat. acollir, fr. accueillir, it. accogliere, occ. aculhir $\sim$ acolhir (ALIBERT, s. v.). En arag. med. se encuentra tanto acollir como acullir: así, en las obras de Fernández de Heredia (GILKIson, s. v.). Frec.: acollido 1: 0,00227.

acomendar] v. tr. 'encomendar'; 'confiar, dejar al cuidado de': «et assi yo te livro et do el regno que Dios me avía acomendado» 35.255; A la ora el rey recibió el dito moco et acomendolo al conte de Flandres 23.6. Deriv. del lat. COMMENDARE 'confiar (algo)', 'recomendar' (DCECH, III, p. 800, s. v. mandar). Comp. en Fernández de Heredia: acomendar acomandar 'confiar algo a uno', 'encomendarse' (Gilkison, s. v.); acomandar 'encomendar' en la Epístola de San Bernardo (s. $\mathrm{XV}$ ): "que mas te acomandes a Dios que al fillo; a los qui aman el mundo o su persona no acomandes tu anima, mas a los qui aman su anima acomanda tu anima." (RIERA, 1982: 134). Frec.: acomendado 1: 0,00227; acomendolo 1: 0,00227 .

acompannyado] adj. 'acompañado': la sennyoría del del dito don Alfonso, noblement acompannyada de honrada cavallería, entró en el dito castiello 38.572; e un dia, bien aconpaynado de sus vasallos, romeage faziendo, metióse en camino por visitiar el dito santo logar 11.14. Deriv. de compannya, del lat. vg. *COMPania (DCECH, II, p. 161). Frec.: acompannyada 1: 0,00227; aconpaynado 1: 0,00227.

acordar] v. gtr. 'acordar, pactar, determinar, resolver de común acuerdo lo que se ha de ejecutar'; 'concordar, convenir': fue por su consello acordado que fues redimido 20.228; e acordaron que él avía feito lo que devía 19.90. Del lat. *ACCORDARE 'poner de acuerdo' (DCECH, I, p. 41). Frec.: acordado 4: 0,00909; acordaron 4: 0,00909 .

acorrer v. tr. 'socorrer, auxiliar, ayudar': Et el rey de Huesca Abderramen demandó ayuda ad Almoģaben rey de Caragosa que le acorriesse 18.9-18.10; Et sediendo dellos muy affrontando dellos emvió a rogar al rey don Pedro de Aragón que le fues a acorrer 18.98; et el rey assimismo avía verguença porque no le avía podido acorrer 36.348-349; non les podía aver acorrido de viandas et de otra ayuda 36.684; que viniessen con todo su poder a acorrerle et servirlo 18.14. Etim.: deriv. de correr < lat. CURRERE (DCECH, II, pp. 208210). // v. prnl. 'ir, marchar', 'acogerse, refugiarse', 'acudir': assí que los mesquinos non sabian a qualparte se acorriessen 36.641. Frec.: acorrer 2: 0,00455; acorrerle 1: 0,00227; acorrido 1: 0,00227; acorriese 1: 0,00227; acorriessen 1: 0,00227. 
acorrimiento s. m. 'ayuda, socorro, auxilio': vino grant acorrimiento a los francesses de complimiento de viandas 36.521; et de otros vaxiellos diversos sin el qual acorrimiento non podian lur voluntat complir 36.524. Deriv. de acorrer. Frec.: 2: 0.0455.

acostamiento s. m. 'acercamiento, aproximación, cercanía': Et porque aquesti matrimonio fue trobado [consumado E] fuert en acostamiento de grant parentesco et sin peccado non se podía sostener, Johan vispe de Savina, cardenal de Roma, separó et departió aquéll 35.55. Deriv. de acostar. Comp. acostamiento 'aproximación' en la Grant. Cronica de Espanya de Fernández de Heredia (GILKISON, s. v.). Frec.: 1: 0,0227. acostar] v. intr. y prnl. 'acercarse': Vehet [veyet $\mathrm{N}$ ] quel tiempo de la paga del sueldo se acostó 38.308; Depués de la muert de aquesti rey et antes por un anno por tal que la su fin se acostava, toda Spannya fizo grant duelo 35.309; et avian por capdiello un moro clamado Alacrant, al qual todos los moros se acostavan 36.63. Etim.: deriv. del lat. COSTA 'costilla, costado' (DECLIC, II, p. 1000, s. v. costa). En las Ordenanzas de la ciudad de Huesca (1284): «antes de redrar a ellos et a otros que se les acostarian o se le son ia acostados» (en TLME, doc. 100, lín. 4, pág. 186 y en R. del Arco, 1913: 115; en Laliena, 1988, p. 77, doc. no 48). En Fernández de Heredia: acostar 'traer cerca, aproximar, acercar' (GILKIsON, s. v.). Comp. cat. $\operatorname{acostar}(D C V B$, s. v.), occ. acostar (AlibERT, s. v.). Frec.: acostava 1: 0,00227; acostavan 1: 0,00227; acostó 5: 0,01136; acostoron 2: 0,00455.

acostumbrado (var.: acostupnado, acostumpnado) adj. y p. p. 'acostumbrado': Et subsiguientment los ditos christianos, indueytos de mas abundosa et acostumbrada devoción, hedificaron hi dos altares 9.28; Et aqui el dito rey don Jayme de Secilia fue untado et coronado rey d'Aragón, feyta fiesta honrada assi como yes acostupnado en semblant caso 38.22; porque pellos havia en lugares do homes non dan acostumpnado de haver, et por aquesto fue nombrado Peloso 23.25. Deriv. de costumbre costumpne. Frec.: acostumbrada 1: 0,00227; acostumbrado 3: 0,00682; acostumpnadas 1: 0,00227; acostumpnado 1: 0,00227; acostupnado 1: 0,00227.

acto s. m. 'acto, actividad, hecho, acción': non demostrando esto a don Per Atares, ni escusándolo en el acto que estava, de continen dizieron que non podian entrar a verlo 20.32; como aquell que no yera seydo usado en armas ni en actos de caballería 20.52. Frec.: acto 1: 0,00227; actos 4: 0,00909.

acuerdo s. m. 'acuerdo': et havieron acuerdo quel rey se partiesse d'alli 20.194. Postverbal de acordar. Frec.: 8: 0,01818.

acusador] s. m. 'acusador': De la qual cosa, los ditos dos hermanos no quisieron ser principales acusadores 14.56. Deriv. del v. acusar, con sufijo derivativo -dor, que expresa agente (PHARIEs, 2002: 168). Frec.: acusadores 1: 0,00227.

acusar] v. tr. 'acusar': «Sennor, si la reyna yes acusada a tuerto queredes la delivarar» 14.72; Et aconselló a sus hermanos Ferrando et Gonçalvo que acusassen la reyna 14.52; aquesti acusava et diffamava en muytas cosas al dito rey don Pedro, hermano suyo, estando infant 
36.36. Del lat. ACCuSARE, deriv. de CAusa (DCECH, I, p. 47). Frec.: acusada 2: 0,00455; acusassen 1: 0,00227; acusava 1: 0,00227.

ad prep. 'a' (ante vocal a-): et el dito rey de Castiella assí mismo sitió ad Aliazira de Alphadra 38.355; et dio ad [a N] Alvaro, hermano del dito Armengou [don Armengon $\mathrm{N}]$, el vizzcondado de Ager et de Castelbón [Castellón N] 35.99-35.101; depués fueron ad'Almería, que la clamavan en aquel tiempo Urcia 19.197; albirando que ningún homme millor non la podría dar por muller que ad aquel qui la havía conocido carnalment 23.18; que sia mas plazient de leyr ad aquellos que la leyeran et a los qui lo escuitaran 2.2; dar perdón a éll et ad aquellos que con él eran,36.175.

adaquella 'a aquella': et pobló una ciudad a la qual puso nombre Burgos et adaquella ennobleció de honrrados barones 14.10

adaquellos 'a aquellos': como era muy piadoso, adaquellos que len demandaban gracia respondió que si antes aquesto buvies feito non contrario ni enemigo le sería seydo, mas amigo verdadero 19.178 .

Etim.: del lat. AD 'a' 'hacia, para'. Para los diferentes valores, vid. el estudio lingüístico, 5.12.1. (NAGORE, 2003a: 444-446). Es habitual en textos en aragonés medieval, e incluso hasta el s. XVI en textos escritos en Aragón. Comp. con it. $a d$, variante eufónica de la prep. $a$ ante vocal $a$ que subsiste en it. mod. (cfr. Migliorini, il, 377). Frec.: ad 13: 0,2955; ad' 1: 0,00227; adaquella 1: 0,00227; adaquellos 1; 0,00227.

adelant adv. 'adelante': segunt que mas largament en vida de cada uno de los dessudo ditos infantees pora adelant recontaremos 38.426. Deriv. de delant $<$ de + lat. IN ANTE, con disimilación $n \ldots n>$ l...n. Comp. adevant. Frec.: 8: 0,01818.

adelantar] v. intr. 'adelantar': et con el conte de Pallares y con don Remón Folch et con otros cavalleros adelantóronse por otro camino 36.631. Deriv. de delant. Frec.: adelantóronse $1 ; 0,00227$.

adentro adv. 'adentro': el dito rey don Jayme con su muller la reyna dona Blanca vino sende en Catalunnya bien adentro 38.165. Deriv. de dentro < lat. DE INTRO. Frec.: 1: 0,00227.

adevant adv. 'adelante': de aqui adevant por tal como murió en aquesta batalla fue nombrado Emengou de Cordova. 27.10 'de aquí en adelante" (Vid. tb. adelant, devant). Etim.: de la prep. a más lat. DE ABANTE (DECLIC, I, pp. 323-324). En arag. moderno, adebán (ANDOLz, 1992: 10; EBA, 1999: 94 y 95). Frec.: 0,00227.

adiado adj. '(día) fijado, determinado, señalado, para un acontecimiento prefijado en cuanto a la fecha': et fue y día adiado de la batalla 36.277. Comp. arag. mod. día diau 'un día preciso correspondiente a un hecho preciso que no puede diferirse' (ANDOlz, 1992: 101). Deriv. de día. Frec.: 1: 0,00227.

adición s. f. 'adición': porque razonable cosa yes que de aquestiy de sus succedidores [...] coronicas fagamos sin ninguna otra adición 15.9. Etim.: cultismo tomado del lat. ADDITIO, -ONIS 'íd.', deriv. de ADDERE 'añadir' (DCECH, I, p. 55). Frec.: 1: 0,00227. 
adiesso adv. de tiempo 'en ese momento', 'al instante': et el dito rey don Pedro qui no les era luent adiesso et fuert a menudo firía en ellos... 36.624. // conj. distributiva 'ora...ora; ya ....ya': todos días en la huest fería adiesso aquá adiesso allá 36.576; [Lo dit rey En Pere, tots jorns en la host feria, adés ça, adés lla. (VC, p. 144); VL: modo buc, modo illuc, bostilem exercitum exicialiter inuadebat]. Etim.: AliberT, s. v., propone para el occ. adés la etim. lat. AD + ID + IPsum. Devoto, s. v., p. 6, propone para el it. adesso la etim. lat. AD IPSUM (TEMPUS), bajo la influencia de AD PRESSUM 'después'. Tilander (1964) examina y rechaza las diferentes etimologías propuestas $\left(*_{\mathrm{AD}}\right.$ IPSUM, $*_{\mathrm{AD}}$ eUM IPSUM, $*_{\mathrm{AD}}$ ID IPSUM, $*_{\mathrm{AD}} \mathrm{DE}$ IPSUM, $*_{\mathrm{AD}}$ IN IPSUM, etc.) y propone ADDERSUM, part. de AD-DERIGERE, que empleado como adverbio tenía el sentido de 'directamente', de donde 'enseguida'. Coromines, en $D E C L / C$, I, pp. 44-50, rechaza todas las etim. propuestas y sugiere que ha de provenir de una forma del lat. vg. como *ADDESSO o *ATESSO, de etimología muy incierta, pero que podría proceder de una base prerromana. Se registra adiesso, adieso adv. 'ahora' en el arag. de Fernández de Heredia (GILKison, s. v.). En DLAA (Reidy Fritz, 1977: 102, s. v.) aparece adieso en doc. 79 (de Jaca, 1302), lín. 11 («equeriendo usar de lo ofiçio, ael acomendado aproueyto de lagientes \& aserucio del senyor rey, adieso encontinent miso encorporal posesión ado frayre Brun Lopez, espitalero de Santa Christina, enel campo de lapadul de Palyons»); adies en doc. 96 (de Huesca, 1313), lín. 9 («do adies de present $\&$ asigno a uos otros perpetual ment $\&$ a uestra natura $\&$ todos los uestros vna sepoltura en la claustra de la gllesia de san Per») y en doc. 97 (de Huesca, 1314), lín. 11 («E a los quales .v. solidos de niuesaryo do \& asigno adies de present que seyan \& yescan dalli»). En Alex. adieso 'luego, enseguida' y adieso que 'tan pronto como' (SAs, Voc. del Libro de Alexandre, s. v., pp. 27-28). Comp. it. adesso (cfr. Migliorini), cat. adès (cfr. DECL/C, DCVB, s. v.), occ. adés adv. 'toujours' y ades-ades 'tantôt-tantôt' (LEVY, s. v.), adés adv. 'a l'instant, à présent'; adés-adés 'toujours, sans relâche' (AliberT, s. v.). El DCECH, s. $v$., recoge adieso como arag. ant. y riojano ant., con el significado de 'luego, al punto', del mismo origen incierto que el cat. adés, occ. adès 'hace poco', 'dentro de poco', 'ahora', it. adesso 'ahora'. Se documenta por primera vez en Berceo. Frec.: 3: 0,00682.

administrador s. m. 'administrador': el qual fue buen bomme et buen administrador 38.444. Deriv. del v. administrar, con sufijo -dor, que expresa agente. En arag. mod., alministrar y alministrador (ANDOLZ, 1992: 22; GARCÉs, 2005: 39; EBA, 1999: 152). También amenistradora, amenistrar (EBA, 1999: 163, lo registra en la Plana de Uesca). Se trata de un cultimo. Sobre administrador y administrar en los DLAA vid. LAGÜENS (1992: 49-50). Frec.: 1: 0,00227.

adobar] v. tr. 'preparar, arreglar, componer', 'disponer': de manera que pensó que quanto havian adobado que sería destorbado 20.200-201. Etim.: del fráncico 
*DUBBAn 'empujar', 'golpear', quizá, como apunta el DCECH (I, p. 56), través del fr. ant. adober 'armar caballero', 'preparar'. Frec.: adobado 1: 0,00227 .

adorar] v. tr. 'adorar': «Sennyor Dios, entraré a la tu casa et adoraré la tu santa casa, el templo santo tuyo» 35.293. Del lat. ADORARE. Frec.: adoraré 1, 0,00227.

adozir (var.: aduzir) v. tr. 'llevar, traer, conducir; portar': que avía de subiugar la nasción morisma et aduzir la tierra a la fe christiana 35.120; sacó la criatura viva del vientre de su madre et ansí se lo adozió 12.11; Et depués con grant honrament adozieronlo al monasterio de Santo Johan de la Penna 17.134; por levar las agras nuevas de la muert del dito rey don Alfonso et por adozirs'ende el rey don Jayme 38.5; el qual havía nombre Fortunno, con CCC $^{\text {s. }}$ peones et aduzía diez cargas de maças de Gascunna 18.29; et los otros pressos con si se los aduxo a Barçalona 36.418. Etim.: del lat. ADDUCERE 'conducir a', derivado de DUCERE 'conducir' (BDELC, p. 29; DCECH, I, p. 61). Frec.: adozir 5: 0,01136; adozieronlo 1: 0,00227; adozió 1: 0,00227; adozirs' 1: 0,00227; aduxo 4: 0,00909; aduzir 1: 0,00227; aduze 1: 0,00227; aduzía 3: 0,00682; aduzían 1: 0,00227; aduzieron 2: 0,00455.

adquirir] v. tr. 'adquirir': que su hermano el rey don Alfonso Sánchez havía nuevamente adquirido la ciudat de Caragoca, Calatayud, Daroca, Taraçona... 20.211; fue concordado entre ellos que por tal que la tierra sobredita de nuevo adquirida por don Alfonso erey de Aragon no se perdies quue fues livrada al emperador 20.246. Cultismo tomado del lat. ACQUIRERE. La $1^{\mathrm{a}}$ documentación que el DCECH, IV, p. 719, s.v. querer, es de princ. del s. XV en Villena. La de la Crón. SJP. es anterior en unos 50 o 60 años. Frec.: adquirida 2: 0,00455; adquirido 1: 0,00227.

adueyto p. p. de adozir. Se trata de un participio fuerte, irregular. Tb. adueito, adueyto, aduyto 'conducido, llevado, traído': Muerto el dito emperador et el departimiento de las tierras et [será error por ad] acabamiento adueyto, sennoriá [seynorió $\mathrm{N}$ ] el dito rey Remiro en el regno de Aragón 16.1-16.3 [VC, p.57: Mort lo dit emperador e lo departiment de les terres a acabament perduit, senyorejà lo dit rei Remiro en lo regne d'Aragó.]. [perduit 'portat' en el Glossari de la VC]; el cuerpo de San Indaleci [...] fue adueyto por relequias en Sant Johan de la Pennya por el rey Sancho Remirez.17.75-78; el dito rey don Pedro le restituyó la dita reyna et su fillo al dito rey Alfonso de Castiella porque non se le avía adueyto por razón de reternérselas. 36.115-116; et murió en el anno de Nuestro Senyor mil XX, et fue adueito el su cuerpo al monesterio de Ripol et aqui se soterró, 28.6. Etim.: De ADDUCTU, pp. del lat. ADDUCERE 'conducir a', derivado de DUCERE 'conducir' (BDELC, p. 29). Frec.: adueito 1: 0,00227; adueyto 3: 0,00682; aduyto 1: 0,00227.

advenidero adj. 'venidero, futuro', 'que está por venir, que sobrevendrá, que llegará': et dixo el dito rey que gran pérdida podía ser de su regno en el tiempo advenidero. 23.5. Etim.: Del lat. AD VENIRE 'venir a, llegar, sobrevenir'. En el ms. se lee auenidero. Frec.: 1: 0,00227. 
afazendado adj. 'solícito, hacendoso, diligente, activo': et la hora cada uno fizose afazendado de recebir los dessafiamientos. 38.331. Deriv. del lat. FACIENDA 'cosas por hacer', pl. neutro del part. de fut. pasivo de FACERE. Frec.: 1: 0,00227.

afer (13.3., 13.4). Se trata de la perífrasis verbal aver a fer/haver a fer: et por tal que quando havía d'entrar en batalla o havía afer cavalgada o qualesque otros afferes periglosos quel avies afer con los moros toda vegada tiembblava 13.3-4. Vid. fer.

affer (var. afer) s. m. 'quehacer, asunto, negocio': Et passados los dos aynnos, algunos aferes se crecieron en el condado 33.15; como el comte Julian, sosmeso del dito rey Rodrigo, fues ydo por mesagería al rey Aboali moro por afferes del dito rey, et el dito rey huvo affer con la muller, segunt algunos dizen, o con la villa del dito comte 3.82. Etim. deriv. de fer < lat. FACERE. Comp. cat. afer, occ. afar, fr. affaire, it. affare (DECLIC, III, pp. 959-960, s. v. fer). Es habitual en arag. med.: véase afer, affer en Fernández de Heredia (GILKISON, s. v.); aferes 'asuntos, negocios' en VILA (1990: 138); afer 'asunto, quehacer' en LMM, p. 152; etc. El EBA (1999: 100) registra afer 'sunto, negocio' en aragonés moderno (en Bal de Bielsa). Frec.: afer 2: 0,00455; aferes 1: 0,00227; affer 2: 0,00455; afferes 14; 0,03182 .

affillar] v. tr. 'adoptar un hijo, prohijar': et affilló et heredó al dito Remiro, su fillastro en Aragón 14.91. Deriv. de fillo < lat. FILIUM. Frec.: affilló 1: 0,00227.

affrontado adj. 'ultrajado, afrentado, ofendido': et sediendo dellos muy affrontado dellos emvió a rogar al rey don Pedro que le fues a acorrer 18.97. Deriv. del lat. FRONS, -TIS (DCECH, II, p. 954). Frec.: 1: 0,00227.

affruento s. m. 'ultraje, afrenta, ofensa': et teniendo a grant affruento los castellanos que remedio no podian dar, el rey de Castiella envió rogar al reye Abderramen de Huesca que crebantas la tregua al rey de Aragón 17.44. Postverbal de affrontar 'ultrajar'. Se registra afruento 'ultraje, afrenta' en el arag. de Fernández de Heredia (GILKIsON, s. v.). Frec.: 1: 0,00227.

afincadament adv. 'prontamente, con prisa, con diligencia': con grant verguença en un cavallo fuyó muy afincadament con pocos de los suyos 17.38. Comp. afincadament 'seriamente, diligentemente' en Fernández de Heredia (Gilkison, s. v.). Frec.: 1: 0,00227.

afogar v. tr. 'ahogar': et aquéll en el rio de Cinqua fizo afogar por prender vengança 36.46. Con un sentido más amplio, 'asfixiar, oprimir, estrangular, arrasar': pasó por la tierra del dito compt de Tolosa cremando e afogando aquélla, et senblament se atendó de la dita ciudat 33.71; et toda aquélla corries, quemas et affogas [cremase e afogase $\mathrm{N}$ ] 4.29. Comp. afogar 'ahogar, anegar, asfixiar, estrangular, abrasar' en el arag. de Fernández de Heredia (GIlkison, s. v.). Etim.: del lat. OfFocare 'sofocar, ahogar' (DCECH, I, p. 87). Frec.: afogar 1: 0,00227; afogó 1: 0,00227; afogas 1: 0,00227; afogando 1: 0,00227. 
agora adv. 'ahora': mas non lo han agora de nuevo porque por privilegio lo han antigament 38.396. Del lat. HAC HORA 'en esta hora' (DCECH, III, p. 387). Comp. cat. y occ. ara, fr. ore. Frec.: 15: 0,03409.

agosto s. m. 'agosto': VI meses, es assaber, mayo, junio, julio, agosto, setiembre et octobre, 18.8. Del lat. Augustus, nombre puesto en memoria del emperador Octavio Augusto (BDELC, s. v.). Frec.: 3: 0,00682.

agradable adj. 'agradable': lo que ellos farian ni ordenarian cada una part havies por firme et agradable 20.157. Deriv. del v. agradar, y este del lat. tardío GRATUM 'agradeciminento'. Frec.: 2: 0,00455.

agrament adv. 'agriamente, ásperamente, amargamente': de los ploros et lágrimas et dolores que los ditos secilianos gitavan agrament et sofrían. 36.206. Adverbio formado sobre el adj. agro, en femenino. Frec.: 1: 0,00227.

agro] adj. 'agrio, amargo, áspero, duro; desagradable, molesto': con soberbia les denegó todo quanto demandavan et fizoles fuert agra respuesta 36.180; con dos galeras et un leyen [leynno $\mathrm{N}]$ armado fuessen en Seçilia por levar las agras nuevas de la muert del dito rey 38.4. Etim.: del lat. vg. ACER, ACRA, ACRUM 'agudo, penetrante' (lat. cl. ACER, ACRIS, ACRE). De la misma forma latina vulgar proceden: it. agro, cat. agre, agra, fr. aigre, port. agro, rum. acru. (DCECH, I, p. 77). En cast. se utilizó agro hasta el s. XVII; la $1^{\text {a }}$. documentación de agrio que dan Corominas-Pascual es de 1604. Frec.: agra 1: 0,00227; agras 1: 0,00227.

agua s. f. 'agua': passando el rio del Royne, por gran desaventura cayó en el agua et murió 28.5. Del lat. AQUA. Frec.: 2: 0,00455.

aguait s. m. 'guardia, retén o cuerpo de vigilancia, grupo de personas que acechan, gente emboscada': passando la dita reyna por la val d'Ayvar, aguait de moros dieronle salto et mataron toda la compañia qui con ella era, 12.3. Etim.: germ. (fráncico) *WAHTA 'guardia, vigía, centinela'. Cfr. DCECH, I, p. 81, s. v. aguaitar, DEEH, p. 1077 , s. v. wabta. KuHn, $H A D$, p. 15, cita de la Crón. SJP. aguait' 'rebate, ataque brusco y repentino', aguaitas 'rebatos, sorpresa', comparándolo con aguaitar por la finestra 'mirar por la ventana' (Echo); ant. nav. goaitar, gasc. agaytà, gaytà, agoeytà, goeytà 'guetter, regarder' (PALAY); en aranés, agoeità 'mirar, seguir amb la mirada, cat. guaitar' (Coromines, 1990: 265); ant. nav. el goai 'vigilante', ant. prov. guaité 'sentinelle'. Según CEJADOR, VMC, aguaitas "es sorpresa preparada con celada"; recoge también aguaite 'celada' y aguait 'asechanza, emboscada', precisamente tomado este último término de la Crón. SJP. El DLE (2014) recoge como voces en desuso aguaitador y aguaitamiento, mientras que registra sin ninguna notación especial: aguaite 'acción de aguaitar' y aguaitar con varias acepciones: 'cuidar, guardar', 'acechar', 'mirar' y 'atisbar, espiar'; también guaita 'soldado que estaba en acecho durante la noche' (sin marca diatópica ni de uso), guaitar 'acechar, vigilar' (como desusado). Las mismas palabras y 
otras más pueden verse en el DEEH, p. 1077. Recoge aguaitar CovarRuBias, añadiendo: : «aguaytador, aguaytadora, aguaytamento no están en uso». Aut. lo da como voz anticuada. Según Corominas-Pascual (DCECH, I, p. 81) aguaitar y deriv. en cast. provienen del cat. aguaitar, está doc. en Asturias, como ant. o vulgar en Portugal y parece que se usó en Andalucía (lo recoge Nebrija). Pero «en realidad nunca fue voz de uso general». En cambio, afirma: “"En Aragón y Navarra es donde el vocablo ha tenido siempre mayor vitalidad». En efecto, aparece ya en FA, h. 1300 (Tilander, FA, p. 238). En Fernández de Heredia se registra: aguayta (var.: eguayt, aguayt, aguyt, heguayt, aguait), guayta, aguaytador, aguaytamiento, aguayto, aguaytar (cfr. Gilkison, s. v.). Peralta, s. v., ya recoge aguaitar 'acechar'. Lo mismo BorAo, que cita además goaitar y goai 'vigilante' en docs. antiguos de Navarra. PARDO incluye aguaitar (tomado de Borao). Andolz recoge como voces de uso (en zonas orientales de Aragón) aguaita 'vistazo, ojeada', aguaitá 'asomarse', aguaitar 'acechar'. El EBA (1999: 109) registra aguaitar en Echo y Bal de Broto, y además en Uncastillo (con la significación de 'asomar') y en Biello Sobrarbe (con el significado de 'divisar, otear'). Para el navarro, en cambio, por más que se suele citar como palabra propia, sólo encontramos goaitar 'vigilar, rondar de noche, estar de vela, centinela, etcétera' en Yanguas (1964 [1840], t. I, p. 441). No hay referencias de aguait, guayta, aguaitar, ni nada semejante en Induráin, Contribución; Ciervide, Primeros documentos; Saralegui, Irache; Líbano, FGN; González Ollé, TLN; Iribarren, Vocabulario. Para el cat. vid. DCVB, s. v. aguaitar y guaita; DECLIC, s. v. guaita. Frec.: 1: 0,00227.

aguayta] s. f. 'acecho, acechanza', 'emboscada', 'espera vigilante': con sus geniossos tractamientos, con aguaytas et en otra manera tantos mató, que del col de Panizares entre a Girona non trobariades sino homes muertos. 36.571. Comp. aguayta 'vigilancia; traición, complot, emboscada' en Fernández de Heredia (GILKISON, s. v.). Vid. aguait. Frec.: aguaytas 1: 0,00227.

aguelo s. m. 'abuelo': et todas las tierras que su aguelo Sancho Avarcha sennorió et conquirió 14.20. Según Corominas-Pascual provendría del lat. vg. *aVIOLus, sacado del fem. lat. vg. aviola, dim. de avia (DCECH, I, p. 24). Pero como no hay rastro de -BY- en la forma romance no puede proceder de AVIOLU, sino de una forma reducida *AVOLu. También aguelo en navarro medieval (LíBANO, FGN, p. 107) y moderno (IribarRen, s. v.). Igualmente se documente en arag. med. (Gilkison, s. v. aguela, -lo y abuela, -lo) y mod. (ANDolz, 1992: 15; EBA, 1999: 112; si bien estas mismas fuentes atestiguan también güelo, güela y lolo, lola). Frec.: 1: 0,00227.

ahontadament adv. 'afrentosamente, vergonzosamente, deshonrosamente': ...et en el dito contrast un cavallero francés ahontadament posó la mano en la barba del dito 
conte, et el dito conte, de grant ira movido, sacó la espada et mató el dito cavallero. 22.1113. Etim.: adv. formado sobre el p. p. adjetivado ahontada, del v. ahontar, y éste derivado de ONTA 'afrenta'. En provenzal: aontar (y aontiry antar) 'deshonorer, honnir', onta (y anta, ancta) 'honte', 'parties honteuses du corps', 'injure, invective'. (Levy, s. v., p. 22). Vid. onta. Frec.: 1: 0,00227.

aiusto s. m. 'agrupación, reunión, grupo, congregación, cantidad de gente congregada': grant innumerable aiusto [ajusto $\mathrm{B}$, aiuntamiento $\mathrm{N}]$ de moros por semblanment manera que dessuso havemos recontado 38.371. Etim.: es postverbal de ajustar. Frec.: 1: 0,00227.

aiutorio s. m. 'ayuda': el qual amava muyto et se fiava en él como en aiutorio de vida, 14.3839 [e lo qual amava molt, e es fiava en ell aixi com en ajutori de vida, VC, p. 52]. Etim.: del lat. ADJUTORIUM 'ayuda, socorro, amparo, asistencia' (cfr. BLÁNQUEZ, s. v.). Se registra ya esta voz en el que es, posiblemente, el primer testimonio escrito del aragonés: conoajutorio de nuestro dueno, dueno Christo, Glosas Emilianenses (s. X), Glosa núm. 89 (Menéndez Pidal, Orígenes, p. 7; ahora también en Origen aragonés de las Glosas Emilianenses, 2020: 105). Es decir, aquí tenemos: con o ajutorio 'con la ayuda'. Aparece también en un documento de 1425 en el que Alfonso $V$ da permiso para la constitución de una sociedad de judíos en Zaragoza (Archivo de la Corona de Aragón, Registro núm. 2593, fol. 127: vid. en GIFFORD y HodCroft, TLME pág. 203, doc. n 117, lín. 7: «por mantener los pobres vergonyantes e casar e fazer aiutorjo a casar guerfanas miserables». Se encuentra adjutorio 'ayuda' en las Crónicas de los jueces de Teruel (1176-1532): «En esti año en las cortes de Caragoça fue demandado adjutorio por el señor rey de Navarra» (1453; López Rajadel, 1994: 255). Comp. it. aiuto 'ayuda', cat. ajut 'acció d'ajudar; allò que serveix per a ajudar' (FABRA, Dic., s. v.; DL/C del IEC, 2007, s. v.), el origen de los cuales está en el lat. ADJUTUS 'ayuda, asistencia' (DECLIC, I, p. 117). El DCECH, s. v. ayudar, t. I, p. 428, recoge la forma ayudorio, con las variantes adjutorio, adyutorio y ayodoro (DHLE, vols. 1 y 2, A-CE, Madrid, 1933-6) entre los deriv. de ayudar < lat. ADJUTARE, frecuentativo de ADJUVARE, deriv. de JUVARE 'ayudar'. Comp. aiutoria 'socorro, ayuda' en la Cronica de los Emperadores de Fernández de Heredia (GILKIsOn, s. v.). Frec.: 1: 0,00227.

ajuntamiento] s. m. 'reunión, agrupamiento, aglomeración', sin. de ajustamiento: et firo grandes ajuntamientos de compaynnas de cavallo e de pie 33.79. Sólo aparece una vez en el ms. N. Frec.: ajuntamientos 1: 0,00227.

ajuntar v. tr. 'juntar, reunir, congregar'; 'unir'. Sin. de ajustar y de justar: firo ajuntar los barrones [sic] et nobles de toda su tierra 23.27; et quando todos fueron ajuntados, el dito moço sacó la espada et mató al conde Salamón delant todos. 23.37; él ajuntó [ajustó N] grant multitud de gentes de la tierra del rey de Francia 23.67-68.; et huvo por muller Ena Dolza, filla de don Gižbert conte de Prohença et de Milan, et 
ajuntolos al condado de Barchinona 31.5. Del lat. JUNCTUS, -A, -UM 'unido, junto', adj. procedente del p. p. de JUNGERE 'unir, juntar, reunir' (BLÁNQUEZ, s. v.; DECL/C, IV, p. 923, s. v. junyir, DCECH, III, p. 539, s. v. junto. Comp. arag. mod. achuntar 'juntar, unir' (ANDolz, s. v.; RoHLFs, DDPA, s. v.). Frec.: ajuntar 1: 0,00227 ; ajuntó 2: 0,00455; ajuntolos 1; 0,00227 .

ajustamiento [ayuntamiento N] s. m. 'reunión, acto de juntar o juntarse', 'recolección, agrupación, unión, aglomeración': et, estando en el dito lugar asitiado, el rey don Sancho de Castiella, nieto del dito rey Remiro, con gran ajustamiento de moros et con el Cit Rui Diaz, por mala voluntad quel havia, et porque ayudava a los navarros, vino a correr et destruir la tierra de su tio el rey Remiro 16.53. Etim.: Deriv. de ajustar 'juntar, congregar', con sufijo -miento < lat. -MENTU(M). Frec.: 4: 0,00909.

ajustar v. tr. 'juntar, reunir, congregar': mandó su muller ser pressa bien guardada en el castiello de Anagera; et pus firo ajustar sobre aquesto cort general 14.62; vino a la ciudat de Girona do fueron ya ajustados 38.464. // v. pron. 'juntarse, reunirse': ellos se ajustoron [ayuntaron B] et por mantener lurs fueros, privilegios et libertades fizieron unión 36.672, et ajustóronse en el castiello de Balaguer por fer lures tractamientos 36.131. Etim.: del lat. vg. *JUXTARE 'juntar', deriv. de juXTA 'junto a, al lado de'. Corominas-PASCUAL opinan que el término justar 'pelear o combatir en las justas' entraría seguramente en el castellano por conducto del cat. justar o del occ. ant. jostar, la $u$ se debe a influjo de justo. El cat. justar (ajustar) y el fr. jouter (ajouter) conservan la acepción general 'juntar, añadir', por lo que consideran que son autóctonos (DCECH, III, p. 542). Para el arag. se puede pensar que el término es también es autóctono, ya que conserva la significación 'juntar', y proviene directamente del lat. *JUXTARE. También justar (vid.). En el arag. de Fernández de Heredia, con la misma significación: aiustar (var. menos frecuentes: aiusstar, ayustar, ajustar). Cfr. GILKISON, s. v. Frec.: ajustar 2: 0,00455; ajustó 6: 0,001364; ajustoron 3: 0,00682; ajustóronse 2: 0,00455.

al contr. de prep. a + art. el: un moro qui de aquesta paz era tractador, con XXX ginetes, vino al dito rey guiando et díxole que con él quería favlar 38.386 // Abrev. de alias, adv. lat. 'de otro modo, por otro nombre': et quando el tiempo de la batalla asignada se apropinquó, el dito rey fuert secretament con Jayme / al Domingo / de la Figuera, mercadero de Calatayut de cavallos... 36.272. Frec.: 269: 0,61142 (dato referido a ambas formas: contracción de prep. $a+$ art. $e$, y 'de otro modo, por otro nombre', así como también con la significación 'otra cosa').

ál (var.: als) pron. indef. 'otra cosa': «et qui al by querra dezir, entre al campo et conocierrrigelo he» 12.35. También en la forma als: a los que puyavan quando als no les podia tirar, les tiró la cappellina et todas las armas que tenía 36.343; Et el dito rey, queriendo que millor fues escusado si als se esdevenía, envió sus mesageros al Padre Santo 34.134. Etim.: del lat. vg. ALID (cl. ALIUD). Cfr. DCECH, I, p. 99, MGHE, p. 264; BADÍA, Gram. bist. cat., p. 325; DECLIC, I, pp. 237-238. Corresponde al 
cat. ant. als, cast. y port. $a l$, fr. ant. el, occ. ant. au, al, als (mod. als). Comp. en el Cancionero de Pedro de Santafé (s. Xv): «Lo peor que me desvía / no eres una ni ál / y señora desigual / sin pensar matar, me matas» (Vid. AFA, xxXxI, p. 119, poema XxI, verso 18). Frec.: vid. al.

alanos adj. y s. gentilicio (pueblo que habitó en la Península Ibérica): nin de los vándalos nin de los alanos, nin de los suevos 2.8-9. Frec.: 2: 0,00455.

alargar] v. tr. 'alargar, extender'; 'demorar, prorrogar': et prendieron manera los castellanos que se alargasse entro al día siguiente 37.59; «ruegote que acabes con el rey de Aragón que me alargue la tregua por otros cinquo annos» 36.395. Frec.: alargasse 1: 0,00227; alargue 1: 0,00227.

albellón s. m. 'albañal, agujero de desagüe en un muro': Et el rey don Jayme, non queriendo seer presso, por una claveguera o albellon que es en el castiello de Perpinyan, qui la ora non era obrado nin acabado assí como buey yes, fuyó et escapó a gran su desonor. 36.412. Etim.: del ár. al ballu'a 'cloaca', que según CorominasPascual (DCECH, I, p. 113) da origen al cat. albelló y al arag. albellón, así como a las formas del arag. y del cast. oriental ant. albullón, albollón, arbollón (esta la registra en un doc. de Guadalajara de 1496; actualmente en Checa —Guadalajara, partido judicial de Molina de Aragón— arbollón se utiliza con el significado de 'abertura circular en la parte inferior de las puertas para que entren y salgan el gato y las gallinas'; información proporcionada por Benita Laguía Sánchez). Corriente (2003: 122, s. v. albello) duda de que el étimo sea el ár. ballu'ah, pues no está documentado en los dialectos árabes occidentales, en los que se encuentra solamente ballac $a b$ 'tragadera', por lo que propone una hibridación árabe-románica *al + ballă $b+$-ón. El DRAE, 1970 y 1984, s. v., recoge albellón, albollón 'desaguadero de estanques, corrales, patios, que da salida a las aguas inmundas' (dice que proviene del lat. ALveOlus). El DLE (2014) registra albellón, de donde remite a albollón, para el que da como significado 'desaguadero de estanques, corrales, patios, etc.' y como segunda acepción 'albañal, conducto de aguas residuales'; por otro lado, propone como etimología el mozárabe *balla'ón < ár. cl. balla'ah. Comp. en arag. med.: albullón 'conducto para despedir las aguas' en FA, p. 241; albellón aparece continuamente en el Libro de los Muros (Huesca, 14441465); vid., por ejemplo: «costo el albellon de sconbrar de cerca casa de don Ferrando Villamana, cinco peones, a XX dineros por peon» ( $L M$, p. 79$)$; «fizie hun albellon a vintetres del mes de agosto» ( $L M$, p. 112); «logue un peon pora limpiar un albellon» (LM, p. 119). Para el nav. YANGUAS (1854, s. v.) registra aibullon. En los textos med. cat. es frecuente el doblete claveguera o albelló (DECLIC, I, p. 142). Pero no parece que sean sin.: albelló es el 'agujero de desagüe'; la claveguera 'alcantarilla o conducto por donde se va el agua caída por el albello’. Frec.: 1: 0,00227. 
albergar v. intr. 'convivir, alojarse con': ...este ovo mala sospeyta de su muller dona Urraca e no quería albergar con ella 19.62. Del gótico *HARIBAírgôn 'alojar' (DCECH, I, p. 118). Frec.: 1: 0,00227.

albirar v. tr. 'imaginar, pensar, considerar': non podía homme albirar la mortaldat que en aquesti día fue feita de los franceses 36.657; otro consello non se podía dar, albirando que a ningún homme millor non la podría dar por muller, 23.17. Etim.: del lat. ARBITRARI (DEEH, p. 15 y 474; DECLIC, I, pp. 150-153). Comp. cat. albirar 'formar judici (sobre una cosa), imaginar com. és, com pot executar-se, etc.'; 'veure de lluny (alguna cosa) sense distinguirla bé' (FABRA, s. v.; DL/C del IEC, 2007, s. v.). Posible catalanismo, pues no aparece ni en GILKISON, ni en $L M M$, ni en el $L R$, ni en LT, ni en Tilander, FA, ni en $V M$, ni en $D L A A$. En cat. albirar tiene hoy el significado de 'percibir o ver desde lejos', 'columbrar', pero antiguamente se empleó con el sentido de 'pensar, considerar'. Viene del lat. ARBITRARI 'pensar, considerar' (DCVB, s. v., t. I, p. 436; DECLIC, s. v., t. I, p. 150-153). El DEEH, p. 15, cita albidrar 'juzgar' como forma del mismo origen en cast. ant. y port. ant. Ximénez de Embún, Vocabulario, explica albirando como 'meditando, arbitrando'. Frec.: albirar 2: 0,00455; albirando 1: 0,00227.

alborada s. f. 'alba, amanecer': Los franceses, viendose muertos, yxieron en el alborada, 34.162. Deriv. de albor y éste del lat. ALBus 'blanco’ (DCECH, I, p. 118). Frec.: 1: 00227.

alçanz s. m. 'seguimiento, persecución'; 'alcance', 'acción de perseguir de cerca, pisando los talones': de manera que al dia siguient cuydando haver otra batalla no vieron de los moros sino los feridos e los muertos que dieron en alcanz entro Almudebar, et quantos troboron matoron. 18.53. Etim.: deriv. de alcançar < lat. vg. *INCALCIARE 'pisar los talones, perseguir de cerca' (DCECH, I, p. 130). Sin embargo, en la Crón. SJP. no se documenta el verbo alcançar, sino la forma propia del arag. encalçar (vid.). MENÉndez PIDAL (MGHE, p. 188) explica alcanzar como

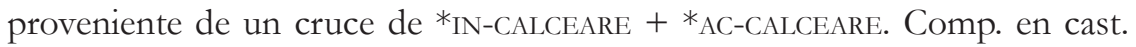
med. alcanza, alcanço con el mismo significado (VMC, s. v.). Frec.: 1: 0,00227.

alçar v. tr. 'levantar, elevar, alzar': et alçando el braço dreyto estrennyó la mano et dixo...

38.301 / / 'levantar una rebelión, retirarse, cesar en una sublevación': et los que eran seydos contrarios al alçar fueronse a Teruel 35.45. / / 'erigir, instituir': alçáronlo rey de los de la tierra 19.164; mandó cort general plegar en la ciudat de Caragoca et aquí muyt honradament el dito rey don Alfonso fue coronado et alçado rey 37.13. / / v. prnl. 'levantarse, alzarse, rebelarse, sublevarse': se levantoron et se alcoron contra el dito santo rey 36.51; que le demandas al rey de Aragon que le soltas el homenage que feito le havia por aquellos lugares, et quando le havies aquello suelto que se le alças 20.188. Etim.: del lat vg. *altiare, deriv. del lat. Altus (DCECH, I, p. 224). Comp. alçar 'acumular, guardar', 'quitar, llevarse' en el aragonés de Fernández de 
Heredia (GILKIsON, s. v.). Comp. el significado actual en arag. alzar 'guardar, recoger' (ANDolz, s. v.; EBA, 1999: 158): «Qui alza, troba»' 'el que guarda, encuentra' (RFDE, 2004: 50). Frec.: alçar 1: 0,00227; alçáronlo 1: 0,00227; alças 1: 0,00227; alçado 1: 0,00227; alçando 1: 0,00227.

alcayde (var.: alcayt) s. m. alcaide, jefe de una fortaleza': et el alcayde entendiólo bien et conosciço quel dito rey le signó que non lo rendies. 38.303; et dixieron al rey que otro castiello se rendría si su presencia vidia [vedía $\mathrm{N}$ ] el alcayt [alcayde $\mathrm{N}$ ] de aquel castiello 38.300. Etim.: del ár. AL QÂ'ID 'capitán, gobernador de una ciudad' (DCECH, p. 126). Confirma esta etimología, con algún matiz, CoRRIENTE (2003: 130): del ár. andalusí alqáy(i)d < ár. cl. qa?id 'conductor (de tropas)'. Frec.: alcayde 4: 0,00909; alcayt 1: 0,00227.

alegrament adv. 'alegremente': tornose alegrament et pagada en Catalunnya con grant victoria 35.139. Adverbio con morfema de modo -ment formado sobre el adj. alegre en su forma femenina. Frec.: 1: 0,00227.

alegre adj. 'alegre': de la quoal cosa el dito rey García Yneguiz fue muy pagado e alegre 11.35; et cuando lo vieron fueron ne muyt pagados et alegres 23.30. Del lat. vg. *ALICER, genitivo *aleCris (cl. alaCER, ALACRIS) 'vivo, animado' (DCECH, I, p. 141). Frec.: alegre 6: 0,01364; alegres 1: 0,00227.

alegría s. m. 'alegría': et fue en Barçalona el segundo día de agosto, do fue recebido por el rey don Jayme su padre, et por los otros qui aqui eran, muyt honradament et con grant goyo et alegría 38.586. Deriv. de alegre. Frec.: 7: 0,01591.

algo pron. indef. 'algo': que pues él erra padre y él fillo, que le dies algo de lo suyo que heredas, assí como fillo dever heredar a padre 20.178. Del lat. ALIQUOD, neutro de ALIQUIS 'alguno' (DCECH, I, p. 163). Frec.: 2: 0,00455.

algos s. m. pl. 'bienes, propiedades, riquezas': que podian seer $D C^{\text {ss }}$ bommes et mulleres et fillos et todos sus algos 9.15; et tiráveles todos sus algos que avían pero dioles a los sus parientes 38.284. Cfr. DCECH, III, p. 359, s. v. bijo. Frec.: 2: 0,00455.

alguno adj. indef. 'alguno'. Se apocopa en la forma algún ante sust. masc. sing.: Et depués de algún tiempo, el rey de Portogal don Dionis, cobdiciando quel rey Jayme et el rey don Ferrando de Castiella fuesen amigos et bien querientes et paz et amor fuesse entre ellos... 38.335; por tal como era hombre furioso algunos varons matoronlo 29.43; algunas conpannyas 38.289. // Tras el sust. adquiere significación negativa, 'ninguno, -a': porque de part alguna non les ossava venir vianda alguna por miedo del dito rey 36.621; et que no mandás Dios que en Aragon hi avies traydor alguno nin en su regno 38.283. // pron. indef. 'alguien': Et quando alguno judgava a muert, de grant piedad que avia, plorava 35.197; que si alguno metía cabanna de qualquier linage de ganado 11.58-60. Del lat. vg. *ALICUnus, contracción de AliQuis 'alguno' con UNUS 'uno' (DCECH, I, p. 163). Frec.: alguno 7: 0,01591; algún 19: 0,04319; algunos 38: 0,08637; alguna 10: 0,02273; algunas 10:0,02273. 
allá adv. 'allá': que lo avian allá foydo en tiempo que escapó de la batalla 19.163. Del lat. ILLAC 'por allá' (DCECH, I, p. 225). Frec.: 4: 0,0909.

allegado] adj. 'alegado, expuesto, aducido': los dreitos et razones allegadas de cada una part, convinieron en ciertos capitoles 20.159. Del p.p. de alegar, cultismo tomado del lat. ALLEGARE. Frec.: allegadas 1: 0,00227.

allenar v. tr. 'enajenar, ceder a otro los derechos de propiedad': et que por caso ninguno no podies allenar el regno de Aragón en personas algunas sino en los fillos 20.261. Etim.: del lat. ALIENARE 'enajenar', deriv. de ALIENus 'ajeno, que pertenece a otro' (DCECH, I, p. 95). Frec.: 1: 0,00227.

allí adv. 'allí: partiose de alli et vino sende al castiello 38.294. Del lat. ILLIC 'allí'. (DCECH, I, p. 225). Frec.: 39: 0,08864.

almirant s. m. 'almirante', 'jefe de la flota o armada': et aquí vino el noble don Francisco Carroz almirant con vint galeras qui se armoron en Valencia 38.500. Etim.: Según Corominas, del ant. amirate, que viene del árabe 'amîr 'jefe, emir' (deriv. de 'ámar 'mandar'), probablemente por conducto del gr. bizantino amirás, -ádos, y del bajo lat. amiratus (BDELC, p. 43; Primera doc.: mitad s. X (Glosas de Sílos); amirate en docs. arag. de 1062, 1085 y 1091 (DCECH, I, p. 193; LRDMA, p. 177, n. ${ }^{\circ}$ 764). Vid. también DECLIC. I, p. 215, s. v. almirall. Comp. fr. amiral (Roland, 1080: amiralt), de l'ár. 'amir al-bahr 'prince de la mer' (DAUZAT-DUBOISMITTERAND, s. v.). CoRRIENTE (2003: 194) cree que no hace falta suponer el ár. amiru lbahr 'almirante (de una escuadra)', sino que se puede explicar desde el ár. amir 'jefe', sin ninguna otra adición particularizadora, pero a esa forma se le habría aplicado por ultracorrección el artículo árabe al- y un sufijo, de manera que en bajo griego se habría formado amirás, -ádos, de donde el bajo lat. amiratus; y de ahí provendrían las distintas formas romances, como el cast. y port. almirante o el cat. almirall. La terminación -ant habrá de explicarse por analogía con los part. de pres. en -nt (al ser un hecho meramente gráfico, tenemos aquí una muestra más de que esa $-t$ final no se pronunciaba). Frec.: 6: 0,01364 .

almogávar] s. m. 'almogávar, soldado mercenario de una tropa escogida, propia de las zonas fronterizas': pobló el Castellar sobre Caragoşa de almogavares 19.21; fue enviada a la ciudat de Mecina alguna conpannya de almogavares o servientes por ayudar et deffender aquélla de los conbatientes. 36.223-225. Etim. del árabe MUGÂWIR 'incursor, el que toma parte en una algara', participio activo de gâwar 'realizar una expedición' (del mismo origen que algara). Cat. almugàver, almogàver (de ahí it. ant. mugàvero), port. ant. almogávar y almogavre (CORRIENTE, 2003: 198-199; DCECH, s. v., t. I, p. 199). Para el cat. cfr. Alcover-MolL: almogàver 'rústic guerrer que en l'Edat Mitjana servia com a soldat d'infanteria principalment per fer incursions dins terra d'enemics' $(D C V B$, s. v.). El cronista Desclot (S. XIV) en el cap. 79 de la Crónica hace una descripción de los almogávares: 
«aquestes gents qui han nom Almugavers son gents que no viven sino de fet de armes, ne no stan en viles ne en ciutats, sino en muntanyes e en boschs.» (DCVB, ibid. t.I, p. 532). Quizá esta descripción pueda explicar el sentido que parece tener el término en la Crón. SJP. En Andolz (1999: 23) almogabar 'tropa irregular, famosa en Aragón durante la Reconquista. Luego se extendió a otras regiones'. Frec.: almogavares 2: 0,00455.

almosna] s. f. 'limosna': et grandes almosnas firo por la ánima de su padre el rey don Pedro 38.16. Etim.: Del lat. eleEmosyna (pronunciado usualmente Elimosyna),

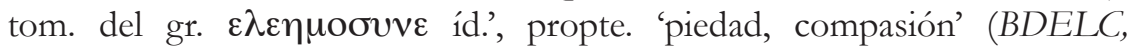
DCHCH, s. v. limosna). Comp. cat. almoina (FABRA, s. v.; DL/C del IEC, 2007, s. v.). El $D C V B$, s. v., t. I, p. 536, recoge almosna como forma antigua de almoina 'limosna': qui dona almosna a son proxme (Homilies d'Organyâ). De igual forma lo explica Coromines: «Almoina, evolució fonética de l'antic almosna, i aquest, provinent del 1l. tardà alemósina id., forma que prengué el terme greco-llatí ELeEmosyna...» (DECLIC, t. I, p. 217). Cast. limosna «del antiguo alimosna, descendiente semiculto de elimosyna». Se documenta almosna en doc. de 1200 y en Berceo; alimosna, s. XIII; limosna en Apolonio. Es forma coincidente con el cat. almoina, oc. almosna, fr. aumône, alem. almosen, gall. y port. esmolda (< esmolna $<$ elmosna). La falta de diptongación de la ŏ se debe a tratamiento semiculto, igual que la conservación de la pretónica interna (DCECH, s. v. limosna, t. III, p. 658). En arag. med. es común almosna: en DLAA (Reidy, 1977: 106), en el arag. de Fernández de Heredia (GILKIsON, 1984: 8), Frec.: almosnas 1: 0,00227.

als pron. indef. 'otra cosa', 'alguna otra cosa': que millor fues escussado si als se esdevenía 34.133-134. Tiene la misma etimología que ál, con -s adverbial. En el Glosario de Nonell (Soberanas, p. 187) para la VC, se indica: àls 'altra cosa'. Es frecuente en textos catalanes medievales: que àls no fan mas carrejar ab viandes moltes (Cronica de Ramon Muntaner, Barcelona, Barcino, 1927-1952, pág. 129); que per als bi baja tant durat com per dues coses... (ibídem, p. 1). En el arag. de Fernández de Heredia: al, alre, als 'otra cosa' (GiLkison, s. v.). Vid. al. Frec. 2: 0,00455.

altament adv. 'en voz alta, en alto': Et ditas aquestas paraulas, levantoronse todos et dixieron altament: «Viva, viva, que aquesti yes sennor nuestro et non otro» 12.38 . Adverbio con terminación -ment, que indica modo, formado a partir del femenino del adj. alto. Frec.: 3: 0,00682.

altar s. m. 'altar': soterraronlo denant el altar de Sant Johan, 17.135; la quoal tomba fue metida entre tres altares 9.24. Etim.: del lat. ALTAR 'íd.'. Frec.: altar 4: 0,0909; altares 2: 0,00455.

alteza] s. f. 'alteza': poso en su corazon de visar [visitar B, N] las altezas de los Apóstoles 38.170. Deriv. del lat. ALtus 'alto' (DCECH, I, p. 220). Frec.: altezas 1: 0,00227 . 
alva s. f. 'alba, amanecer': pasó las montannas que yeran cubiertas de nieve et de ora del alva, muy abrivadament et podroso [vigorosa $\mathrm{N}$ ], comendándose a Dios, firió tan fuertmente en el sitio de los moros... 12.56. Deriv. del lat. ALBus 'blanco' (DCECH, I, p. 118). Frec.: 1: 0,00227.

amador adj. 'amador, amante': et fue homme de grant justicia et amador de paz, et regnó L annos 31.48. Frec.: 2: 0,00455.

amar v. tr. 'amar': «Priégote, fillo, que tu devyes amar tu hermano» 35.270; «Et mando vos a entramos que vos [nos N] amedes assi como yo vos he amados» 35.272-273. Frec.: amar 1: 0,00227; ámalos 1: 00,227; amados 1: 0,00227; amava 1: 0,00227; amedes 1: 0,00227; amen 1: 0,0027; ames 1: 0,00227.

amado adj. y p. p. 'amado': Et por aquesto era amado de sus vasallos 12.69. Frec.: 3: 0,00682 .

amargor s. f. 'amargura': et todos ensemble fiesta de grant dolor et amargor [amarga N] dolorosament celebroron 37.9. Deriv. de amargo < lat. AMARUs, con influjo de amargar < lat. vg. AMARICARE (DCECH, I, p. 233). Frec.: 1: 0,00227.

amargossa adj. 'amarga': Por qual muyt dolorosa muert et muyt amargossa, la reyan su muller et sus fillos que en Sezilia eran fincados e todo el regno ensemble fizieron duelo et planto 36.716. Frec.: 1: 0,00277.

amigablement adv. 'amistosamente, con amistad': por tal que paz et concordia fues entrellos quei todos tiempos yeran seydos unos en fortunas et en prosperidades, aplegoronse amigablement 20.152. Frec.: 3: 0,00682.

amigo s. m.: Et don Caxal fue redemido por grandes quantias pora la qual redempción la abbat de Sant Salvador de Leyre vendie el trasaro de su monesterio porque era grant su amigo. 20.237. Del lat. AMICUs. Frec.: amigo 3: 0,00682; amigos 4: 0,00909.

amiztat (var.: amiztad) s. f. 'amistad': algunos reyes avian feyto paz e tregoa e amiztad con los moros 33.98; aqueste conte Guiffre havies la gracia del rey de Francia et la suya amiztat 23.52. Etim.: lat. vg. *AMiCiTAs, -ATIS (BDELC, s. v. amar, DCECH, I, p. 232). [Es normal que lleve z sonora, ya que lo habitual es que -CI- tras vocal dé $z=$ fricativa alveolar sonora /z/]. Frec.: amiztat 6: 0,01364; amiztad 1: 0,00227.

amonestamientos s. m. 'amonestaciones': las quales pregarias et amonestamientos el dito conte non quiso obedecer, 34.131. Deriv. del v. amonestar, con sufijo -miento < lat. -Mentum, que indica resultado de una acción (PHARIEs, 2002: 403). Frec.: amonestamientos 1: 0,00227.

amonestar] v. tr. 'amonestar, advertir, prevenir; exhortar': el dito rey pregó et amonestó al dito Simón que se estuvies de fer enoyo et dannyo 34.129; «priégote, fillo mio, et amoniéstote por Dios Ihesu Christo que en ti aya dreyta [dreitura B; dreytura N] et misericoridda et ayas amor et caridat a las tus gentes» 35.256. Del lat. ADMONERE, quizá con cruce de MOLESTARE (DCECH, I, p. 245). Frec.: amonestó 1: 0,00227; amoniéstote 1: 0,00227 . 
amor s. f. 'amor': por la qual cosa buvo paz. et amor entre sus gentes en toda su vida 38.627. Frec.: 11: 0,02500.

amos adj. pl. 'ambos': et amos a dos destragoron [estragaron $\mathrm{BN}$ ] el regno de León 34.79. Etim.: del lat. AMBO, -AE, -O. Se documenta ya amos en las Glosas Emilianenses y es la forma común en cast. ant. También era común la expresión amos a dos (DCECH, I, p. 238). Frec.: 2: 0,00455.

anca] s. f. 'anca': que en la batalla de anthiocbia do andava apeado prisolo San Jorge en las ancas del cavallo, 18.58; vinose San Jorge con el caballero a la batalla de Huesca et vidieronlo visiblement con el cavallero en las ancas 18.60. Del fráncico *HANKA 'cadera' (DCECH, I, p. 253). Hoy en arag. mod. anca 'cadera' (RoHLFs, DDPA, s. v.; Andolz, s. v.; EBA, 1999: 171). Comp., del mismo origen: fr. banche 'cadera', it. y port. anca. En cambio: ast. cadril; cat. maluc, gall. anca, cadeira, cadril. Frec.: ancas 2: 0,00455 .

anciano] s. m. 'anciano': fueron en Pisa por prender homenage de los ancianos del común de Pisa, 38.577. Etim.: deriv. del ant. adv. romance anæi 'antes', procedente del lat. ANTE 'antes'. Pero como en la Península Ibérica no hay huellas de anzৃ $i<$ ANTE ante palabras iniciadas por vocal (sí, en cambio, en it. anzi, fr. ant. ainz, occ. y cat. ans), debe admitirse, según COROMINAs-PASCUAL, que el cast. anciano vino muy antiguamente del francés o del occitano (DCECH, I, p. 253). La misma explicación valdrá para el aragonés. Comp. cat. ancià, port. ancião, gall. ancián, vasco aintzin 'antiguo, viejo' (SEgura, 2001, s. v. ante). Frec.: ancianos 3: 0,00682 .

andar v. intr. 'andar, caminar': eran vezados de adozir dardos et andar de pie los de cavallo 12.64; et un cavallero de Alemanna fue entramas las batallas de Anthiochía et de Aragón, que en la batalla de Anthiochía do andava apeado prisolo San Jorge en las ancas del cavallo, vencida aquella batalla, vinose San Jorge con el cavallero a la batalla de Huesca 18.58. Del lat. AMBULARE, por medio de una pronunciación descuidada *amlare (DCECH, I, p. 256). / / 'ir': Et quando fue aquesto que la su anima devía andar a Dios... 35.291. Frec.: 3: 0.00682.

angustia s. f. 'angustia': ya sea que toda la tierra fincas por la muert del virtuoso rey don Pero en grant tribulación, angustia et con grant guerra con la yglesia, 36.708. Etim.: tomado del lat. Angustia 'estrechez'. La $1^{\text {a }}$ doc. que dan Corominas-Pascual es de la $1^{\mathrm{a}}$ mitad del siglo XV, en el Marqués de Santillana (DCECH, I, p. 270). Frec.: 1: 0,00227.

ani $[$ avi $\mathrm{B}]$ que a dos dias hi ani fueron doblados 36.563. En el ms. B leemos auj o a uj; por la VL y la VC deducimos que ani es mala escritura del ms. E por $i i i$, es decir, tres. La redacción correcta sería: que a dos días o a iii [tres] fueron doblados.

ánima s. f. 'alma': Et depués, assí como rey cathólico, en hedat de XXX VII annos, rendió su anima a Dios en la ciudat de Barchinona 39.42; Et aquesto feito, la dita reyna finó 
aqui sus días et devotament et bumil rendió la su ánima a Dios 34.68. Frec.: ánima 5: 0,01136; anima 2: 0,00455.

animar] v. tr. 'animar': induyeron [supieron $\mathrm{N}$ ] et animoron [avinioron B; induzieron $\mathrm{N}$ ] el rey Federich que esforçadament le deffendiessen [los defendies $\mathrm{N}$ ], 38.240. Frec.: animoron 1: 0,00227.

anno (tb. annyo, ano, año, aynno, ayno) s. m. 'año': en el anno de Nuestro Sennyor 38.418. Del lat. AnNus 'año'. Frec.: anno 90: 0,20456; annos 56: 0,12728; annyo 6: 0,01364; annyos 1: 0,00227; anos 1: 0,00227; años 1: 0,00227.

anotadero] adj. 'anotable, digno de ser anotado'; 'que se anota, consigna, escribe o señala': de muytas notables mulleres et de otras fembras avies procriados muytos fillos qui por engendramente de dreyta linea non son anotaderos nin cal fer memoria nin mención de aquellos, 36.33. Etim.: deriv. del verbo anotar y este de nota, tomado del lat. NOTA 'mancha', 'signo', 'señal', o del lat. NOTARE 'señalar, designar, escribir, anotar'. El DCECH (IV, p. 240) documenta por $1^{\mathrm{a}}$ vez anotar en 1605, en el Quijote. Frec.: anotaderos 1: 0,00227.

ansí (var.: anssí) adv. 'así'. Vid. assí.

ante prep. 'ante, delante de': pareşiole ant'él vestido d'escarlata en un cavallo blanco 19.84 // adv. 'antes': como ante hera fablado 19.101 // conj. advers. 'antes bien, antes por el contrario'; 'sino que': indueyto de mal consello, non recibió assí como devía benignament los ditos mesageros, ante con soberbia les denegó todo quanto demandavan 36.177-179. Etim.: lat. ANTE 'delante de, antes de'. Comp. ante 'más bien’ en $L M M$, p. 154. Frec.: ante 11: 0,02500; ant' 1: 0,00227.

antes adv. 'antes, anteriormente, en otro tiempo': Depués de la muert de aquesti rey et antes por un año, por tal que la su fin se acostava, toda Spannya fizo grant duelo 35.308 // conj. advers. 'antes bien, por el contrario'; 'sino que': no quisieron esleir rey, antes se sozmetieron a la sennoria del imperio 3.25. Con esta última acepción, tb. ante. Del mismo origen que ante, pero con añadidura de la llamada $-s$ adverbial (BDELC, s. v.). Vid. en antes y en antes que. Frec.: 26: 0,05910 .

antigament adv. 'antiguamente': en antes los moros lo havian tenido antigament 36.88. Frec.: 2: 0,00455.

antigo adj. 'antiguo': En el tiempo antigo fue un cavallero clamado Guiffre 22.3. Del lat. ANTIQUUs. Frec.: 1: 0,00227.

apagar] v. tr. 'apagar, extinguir', 'aplacar, apaciguar': por tal que aquesta discordia se apagas, el dito don Phelip tractó que la filla de don Alfonso havies por muller el dito don Jayme 38.613; si quiere se fues por la grant savieça de su padre el rey don Jayme qui con buenas et bellas maneras la apagó 39.27. Deriv. de pagar 'contentar, satisfacer' < lat. PACARE 'pacificar', deriv. de PAX, PACIS (DCECH, I, p. 290). Frec.: apagas 1: 0,00227; apagó 1: 0,00227. 
apalatiz. Debe interpretarse a palatiz 'a escaramuza: Et todos días los de la ciudat exian les apalatiz [exian los apalaciz B] escondidament et paladinament matoron ne sin nombre 36.573-574. [Et tot jorns los de la ciudat eixien-los a palatic amagadament e a palesa mataven-ne sens nombre e contínuament los tollien cavalls e altres coses, a pesar llur e a fastig VC, p.144]. El Glossari de la VC da palatiç 'escaramussa'. Según Coromines el cat. ant. palatís se encuentra bastante en textos de fines del s. XIV: dos veces en Eixemenis, y más en la Crón. del Cerimoniós (es decir, Pedro IV): e tots dies haviem palatiçes entre ls nostres e.ls llur, ...y estant dellà lo riu, los de Valencia fahien lavors $p<a>$ latic ab ell; e staven-se strets, que aquest dia no exiren a palatiz de nenguna part. Indica que no debía ser autóctono en catalán, donde no se encuentra más que este sustantivo derivado, mientras que en francés existía el verbo paleter de donde aquél deriva por medio del sufijo francés postverbal -eїz > -is (= cat. -dis, -adissa). El fr. ant. paleter'combatir o luchar ante un fuerte, realizar una escaramuza, escaramuzar' y palet(e)iis 'escaramuza, lucha en forma de escaramuza' están relacionados con fr. ant. palice 'empalizada que defiende un fuerte, palenque, valla de madera o estacas', todos ellos procedentes del lat. PALus. El fr. ant. palet(e)ïs fue tomado en préstamo por el cat. ant. palatís (DECLIC, VI, p. 179, nota 1, s.v. pal). Parece evidente, pues, que apalatir. debe interpretarse como a palatir 'a escaramuza' y el pasaje completo se traduciría así: «y todos los días los de la ciudad salíanles a escaramuza a escondidas y paladinamente (públicamente, manifiestamente) mataron (de ello) sin número». La variante apalaciz de B se explica por las numerosas confusiones entre $c$ y $t$ (tanto en el ms. E como en el B; cfr. escolt $\sim$ estolt). En Fernández de Heredia está documentado palicada 'empalizada' (Gilkison, 1984, s. v.), pero palatiz es forma no documentada en textos aragoneses. En la Crón. SJP. parece que se trata de una simple adaptación del cat. ant. palatiç. Frec.: apalatiz 1: 0,00227.

aparamientos s. m. 'instrumentos, aparatos': et muyto otro navilio por levar cavallos et cavalleros et homes de pie et aparamientos [aparellament $\mathrm{N}$ ] de combatir 38.505. Deriv. de aparar 'preparar, disponer, aparejar', del lat. PARARE 'preparar, disponer' (DCECH, IV, p. 393). Frec.: 1: 0,00227.

aparecer] v. intr. 'aparecer': por la feridura que la dita reyna avía en el vientre aparecía una mano de criatura 12.9; Et esdevinose que una vegada quel estando enfermo en Montpesler de grant malautia, la Virgen gloriosa Madre de Dios li apareció [le pareçió $\mathrm{N}]$ con grant goyo et díxole que se levantas del leyto sin todo mal 35.220; Aquesti rey Sancho Remirez. fue muyt buen rey et aventurado et virtuoso et apareciose bien entre las otras cosas, por las conquistas siguientes. 17.66 (Tb. parecer). Del lat. tardío APPARESCERE, deriv. de PARERE 'aparecer, parecer' (DCECH, IV, p. 400). Frec.: aparecía 1: 0,00227; apareció 2: 0,00455; apareciose 1: 0,00227. 
aparellado adj. y p. p. 'preparado, dispuesto, aparejado': et pues gracia le demandava, yera aparellado de fazer lend. 19.181 ('estaba dispuesto a hacérsela'). Tb. apparellado. Comp. parellado. Frec.: aparellado 3: 0,00682; apparellada 1: 0,00227; apparellado 2: 0,00455; apparellados 1: 0,00227.

aparellamiento (var. apparellamiento) s. m. 'preparativo': El día de la batalla se acostó et el dito rey ningún aparellamiento non firo de hir hi, 36.267; Et depués de algunos días, cada uno fizo su pertreyto et aparellamiento por complir los enprendimientos dessuso ditos 38.351-352. Comp. cat. aparellament 'acte i efecte d'aparellar' y aparellar 'preparar' (DCVB, s. v.). En un caso aparellamiento es error por parlamento: en el dia assignado al dito aparellamiento [parlament $\mathrm{N}]$ fue present et, entrando por el palacio do se celebrava el dito parellamiento [parlament $\mathrm{N}$ ], 12.24-26. Deriv. de aparellar. Frec.: aparellamiento 3: 0,000682; apparellamiento 1: 0,00227.

aparellar] (var.: apparellar) v. tr. 'preparar; disponer, aparejar', 'aprestar': con grant poder de gent de su regno metiosse en las galeras que avía feitas apparellar 38.244; pora el rey de Castiella que se apparellava pora entrar en Aragón 36.361. // 'hostigar, vapulear, golpear, doblegar': et todo el día conbatió la dita ciudat fuertment, más los de dentro apparellaron en tal manera los de fuera que depués non si acostoron con buen corazón 36.559-561; firió tan fuertment en el sitio de los moros que todos los desbarató et los aparelló 12.58. Etim.: deriv. de parello < lat. vg. *PARICUlus, dim. de PAR 'igual, semejante', 'par' (DCECH, IV, p. 387). Se registra la forma aragonesa aparellar 'preparar' en Alex. (SAS, Voc. del Libro de Alexandre, s. v., p. 59). Frec.: aparelló 1: 0,00227; apparellar 1: 0,00227; apparellaron 1: 0,00227; apparellava 1: 0,00227.

apeado adj. 'apeado, de pie, caído del caballo': Et un cavallero de Alemanna fue entramas las batallas de Anthiochía et de Aragón, que en la batalla de Anthiochía do andava apeado prisolo San Jorge en las ancas del cavallo 18.58. Frec.: 1: 0,00227.

apeiar] v. intr. 'apearse, bajarse del caballo, desmontar': vido por la feridura que la dita reyna avía en el vientre aparecía una mano de criatura, et tantost apeió [aparexó $\mathrm{N}$ ] et abrió la dita reyna por el vientre et muy cortesament sacó la criatura 12.9. Deriv. de PES, PEDIS 'pie' (DCECH, IV, p. 530). Frec.: apeió 1: 0,00227.

apenas adv. 'apenas; casi no': que apenas estava un dia seguro 10.16. Etim.: compuesto de prep. a más sust. pena < lat. POENA. En arag. med. se usó también envidas 'apenas': «e las collidas vienen como a Dios place, de manera que las bestias de lavor envidas se pueden sostener e por el poco termino que la dita Ciudat tiene» (doc. de Jaca de 1461; en Gómez de Valenzuela, 2000: 88). Frec.: 1: 0,00227 .

aplegado adj. y p. p. 'reunido, recogido, juntado': Et en continent el dito rey, aplegado complimiento de navilio con muyt noble cavallería... vino a sitiar la ciudat 35.127 ; el qual, aplegado grant navilio armado con muyto honrado barón, ribó al puerto de Roma 
38.171 // 'acercado, arrimado': porque assin como la ariesta aplegada cerca el fuego en un moment crema... 10.18. Frec.: aplegada 1: 0,00227; aplegado 2: 0,00455; aplegados 1: 0,00227.

aplegar v. tr. 'reunir; congregar, juntar' // v. intr. 'reunirse, juntarse': et todas aquestas < cosas>feytas, el dito rey don Pedro firo aplegar grant navilio 36.261; firo aplegar Cortes generales do fueron aplegados arçebispos, vispos, prelados... 35.122; feyta la sepultura de su padre, aplegó grandes cortes a Caragoca 39.6; aplegoronse amigablement 20.152. Etim.: del lat. APPLICARE 'acercar' (BDELC, p. 370; DCECH, III, pp. 729-730). Frec.: aplegar 3: 0,00682; aplegó 5: 0,91136; aplegando 1: 0,00227; aplegoronse 1: 0,00227.

applicar] v. tr. 'aplicar, dedicar, destinar, adjudicar': et fuera gitó [priso e gitó fuera $\mathrm{N}]$ de aquell los enemigos de la fe applicando aquell a la christiandat. 36.89-90; dius pena de perder las ditas tierras guanyadas et aplicadas [ganaderas e aplicaderas $\mathrm{N}$ ] al dito donador, 16.36. Etim.: cultismo tomado del lat. APPLICARE 'íd.' (BDELC, p. $463 ; D C E C H, I V, 580$, s. v. plegar). La primera documentación que da el $D C E C H$ es de 1438, de manera que la Crón. SJP. la adelanta en unos 70 años. Frec.: aplicadas 1: 0,00227; applicando 1: 0,00227.

apóstol s. m. 'apóstol': el día de Sant Bartholomeu apóstol 38.367; visitando los santuarios de los Apóstoles 34.32 (en el ms. B, fol. 47r, se ve aplos con una línea curva superpuesta; a nuestro juicio esta escritura abreviada debe interpretarse apostolos). Comp. apostolos, apostolus en Fernández de Heredia (Gilkison, s. v. aposto); apostols en LR (CoOper, pp. 82 y 115). También apostolos en la Crónica de García de Eugui (GonzÁlez Ollé, TLN, pp. 144 y 202). Igualmente, apostolos en Alex (SAS, s. v., p. 61). Frec.: apóstol 1: 0,00227; apóstoles 2: 0,00455 .

apostolical adj. 'apostólico': Et el dito rey don Alfonso, reçevido el dito maestro apostolical, propuso en su coraçón que a onor de Dios fue a Sant Jayme firiendo romeage 33.103. Frec.: 3: 0,00682.

apparellar v. tr. 'preparar; disponer, aparejar; aprestar'. Vid. aparellar. Frec.: 1: 0,00227 .

appropriadament adv. 'propiamente': et sobre todas las eglesias parrochiales, e mas appropriadament sobre San Per de Ciresa, 20.291. Formado sobre el cultismo proprio. Frec.: 1: 0,00227.

apres prep. 'después de; tras': El qual Ispan, apres dias de Ercules, fue rey de Espanna 1.43; vino a sitiar la ciudat de Mallorquas et aquella, apres [apres de $\mathrm{B}$; a cavo $\mathrm{N}$ ] algún tiempo priso a fuerça de armas 35.130 // adv. 'después': aprés de aquesto, el dito rey Remiro... 20.251. Etim.: del bajo lat. AD PRESSUM, forma reforzada de PRESSUM 'cerca, junto a', que reemplazó a Post en el sentido de 'después de' (DAUZaTDubois-Mitterand, s. v. après). Comp. fr. après (ya en Roland, 1080) (ibídem); 
cat. aprés adv. 'després' (FABRA, DGLIC, s. v.); cast. med. aprés < APPRESUM (MGHE, p. 336, \128.4); occ. après adv. y prep. 'después de' (AliberT, s. v.). El DME recoge aprés 'cerca' (Cid, Berceo, Canc. de Baena) y aprés 'después' (Fuero de Avilés, 1155; Alex.). Vid. también DECLIC, VI, p. 795, s. v. prés. En la Crón. SJP. es mucho más abundante depués (vid.). Frec.: apres 2: 0,00455; aprés 1: 0,00227.

apretar] v. tr. 'apretar, estrechar', 'oprimir, presionar': tanto apretó el rey don Sancho Huesca quel rey moro prometie de dar parias a él 17.103-104. Etim.: del lat. tardío APPECTORARe 'estrechar contra el pecho', deriv. de peCtus, PECTORIs 'pecho' (DCECH, I, p. 302). Frec.: apretó 1: 0,00227.

aprilis lat. 'de abril': Kalendas aprilis 17.61. Es forma latina. Frec.: 2: 0,00455.

aprivadament adv. 'rápidamente, impetuosamente': et dio tan aprivadament batalla con las suyas que eran XII a las contrarias que finalment todas las desbarató et prisso, 36.540. Vid. abrivadament. Frec.: 1: 0,00227.

aprohismar v. tr. 'aproximar, acercar': quando sintieron aprohismar [aproximar $\mathrm{N}$ ] a la fin del dito gloriosso rey, 35.311. Tb. prohismar. Etim. deriv. del lat. PROXIMus 'el más cercano, muy cercano', de PROPE 'cerca' Comp. apropinquar, deriv. del lat. PROPINQUUS 'cercano' (BDELC, s. v. próximo). En cast. tanto próximo como prójimo son cultismos. Existe tratamiento popular en cat. prui $(x)$ me, proïsme, occ. ant. prue(i)sme, fr. ant. prueisme. Adviértase que aproximar no se documenta en cast. hasta 1770 (DCECH, IV, pp. 664-665.). Sobre las formas catalanas ant. proxme, proixme, pruixme, probisme, pruyxme, pruyme, y cat. mod. proïsme (sólo literario), vid. DECLIC, VI, pp. 827-829, s. v. prop. Comp. en arag. del s. XIV: proismo, proisme 'próximo, cercano', 'prójimo' en Fernández de Heredia (GILKIsON, 1984, s. v.). Quizá aprohismar sea derivado de este adjetivo romance y no del lat. Proximus. Comp. también el adj. deriv. prosmano 'próximo' en el Fuero de Navarra (cfr. Indurárn, Contribución, p. 109). Sin embargo, Líbano (FGN, p. 178) registra proximano 'próximo'. Frec.: 1: 0,00227.

apropiant adj. 'cercano, próximo': Et apropiant el día de la batalla, un monge, muy sancto varón, vino al dito emperador 14.71. Etim.: deriv. prefijado del lat. PROPE 'cerca'. Comp. arag. ant. prueb 'cerca' < PROPE, en el LR: prueb de Carrion, prueb de Pamplona (Cooper, LR, p. 145). En Fernández de Heredia, prop 'cerca' (GILKISON, s. v.). Comp. apropinquar. Podría pensarse en un verbo *apropiar 'acercar' no documentado, del que apropiant sería el part. presente en función de adjetivo. Pero apropiar sólo está documentado como variante de apropriar 'apropiarse, tomar posesión de algo' (GiLkison, s. v.), o 'ganar, obtener', 'atribuir, aplicar' (TILANDER, VM, III, p. 28). Frec.: 1: 0,00227.

apropinquar] v. 'acercar': et quando el tiempo de la batalla asignada se apropinquó... 36.272. Etim.: deriv. del cultismo propinquo 'cercano', tomado del lat. 
PROPINQUUS 'cercano', deriv. de PROPE 'cerca'. Se registra apropincuar en Sta. $M^{a}$. Egipciaca. (DCECH, IV, p. 665, s. v. próximo). En la Crón. SJP. se documenta tb. propincuo 'allegado, cercano, próximo' (38.196). Comp. aprohismar. Se documenta propinquo 'cercano' y propinquidat 'cercanía' en el arag. de Fernández de Heredia (GiLkison, s. v.). En FGN, propinco y propincano 'cercano’ (LíBANo, FGN, pp. 177-178). Frec.: apropinquó 1: 0,00227.

aproteros: E ovo por muller a dona [Agnetem VL] aproteros della un fillo clamado Pedro 18.117. Forma textual que aparece en un fragmento del ms. N. Es evidente que se trata de una mala transcripción. En la ed. de XimÉnEz de Embún se lee: E ovo por muller a dona [Ines], a proterot della un fillo clamado Pero. Será, por lo tanto, e procreó. En la VL: Habuit uxorem vocatam Agnetem, ex qua procreavit unun filium vocatum Petrum VL, p. 67. En la VC: E hac per muller Dona Agnès e procreà d'ella un fill nomenat Pedro VC, p. 66. Por tanto, la VA debería decir: E ovo por muller a dona [Inés o Agnés] e procreó della un fillo clamado Pero. Frec.: 1: 0,00227.

aprovar (var.: aprobar) v. tr. 'aprobar, autorizar, aceptar': más por fuerza que por grado, ficiéronle aprovar la unión que avían feita 37.16; La qual avinienca concordada et en escripto perpetua memoria metida publicoron [...] et aquélla looron et aproboron 20.170. Deriv. de PROBARE 'probar, ensayar' (DCECH, IV, pp. 657-658). Frec.: aprovar 1: 0,00227; aproboron 1: 0,00227.

aquá adv. 'acá, aquí, este lado': et con los moros de la tierra de aquá cercaron al Cit en Valencia, 18.96; Et el dito rey don Pedro todos los días en la huest fería adiesso aquá adiesso allá 36.576. Del lat. vg. ECCUM HAC (DCECH, I, p. 306). Vid. entaqua. Frec.: 2: 0,00455.

aquel (var.: aquell) adj. dem. de 3. ${ }^{\text {er }}$ término: Et enderrocó los muros et los fundamientos de aquel lugar 4.38; et todo aquesto fizieron por tal que Dios et los sanctos de aquell lugar los preservasen de las grandes persecuciones moriscas 9.35; et la mayor ciudad d'aquella provincia Yspalis, la qual hoy a nombre Sivilia 1.20; Et las gentes de Aragón e de Navarra eran en Huesca et en aquellas partidas que avía toda la tierra puesta a lur mano e tirada a los moros 18.100; El rey don Pedro con todos aquellos nobles cavalleros aragoness e navarros que yeran seydos en la batalla de Huesca 18.102. Etim.: del lat. ECCUM ILLE. Frec.: aquel 42: 0,09546; aquell 29: 0,06592; aquella 50: 0,11365; aquellas 15: 0,03409; aquello 8: 0,01818; aquellos 32: 0,07273

aquél (var.: aquéll) pron. dem. de 3 er $^{\mathrm{e}}$ término: Et yo so aquél qui de mientre passava por la val do murió, vi la criatura 12.32; el uno a honor de San Miguel et a invocación de aquéll, y el otro, de Sant Climent. 9.30; mandó que en continent fues con gran poder de hombres a cavallo i de pie enta las partes d'Aragón, et toda aquélla corries, quemas et affogas 4.29; et digela con tal condición las ditas tierras que aquéllas tenies en feu [feudo $\mathrm{N}]$ en dreita sennoría por el rey Remiro 16.33; atorgó a los moros aquello et embió el conde don Sancho con todo su poder 17.110; por tal que sia mas plazient ad aquéllos que 
la leyeran, 2.2. Vid. aquel. La frecuencia se da conjuntamente de aquel, y sus variantes flexivas, como adjetivo y como pronombre.

aquello pron. dem. neutro de 3. ${ }^{\text {er }}$ término 'aquello'. Vid. aquél.

aquesti (var.: aqueste) adj. y pron. dem. de $1{ }^{\mathrm{er}}$. término 'este': et depués de aquesta nación, vino Ercules por senyoriar Espana 1.12; En aquesta isla de Estancia habitaban aquestas naciones... 3.1; Et depués de aqueste regnó Zueca 3.9; Et después de aquesti regnó su fillo 3.9; assí como aquesto dizen 1.3; Et aquestos cetubals se poblaron en la ribera d'Ebro 1.7. Et por aquest era muy amado de sus gents 12.72. (aquest es la forma que se da en la ed. crítica, pero debe de ser una errata de transcripción, pues en el ms. B, que es el que se sigue en el capítulo 12, leemos claramente aquesto). Del lat. lat. ECCUM ISTE (DCECH, II, p. 781). Frec.: aquesti 178: 0,40458; aquesto 93: 0,21138; aquesta 29; 0,06592; aquestas 17: 0,03864; aquestos 11: 0,02500; aqueste 12: 0,02728; aquest 3: 0,00682.

aquesto, aquesta pron. dem. de 1 . $^{\text {er }}$ término 'esto, $-\mathrm{a}$ '. Vid. aquesti.

aquexo pron. dem. 'eso'. No aparece en la ed. crítica, pero se registra alguna vez en el ms. B: todo homme que aquesto diga [aquexo dira B] 38.320. (Obsérvese la forma más genuinamente aragonesa del ms. B, frente al E, no sólo por el dem., sino también por el uso del modo verbal). Comp.: «en aquexe lugan» (doc. de 1424, ACA, Reg. Canc. 2572; Lleal, 1997a: 78). Etim.: es compuesto de ECCU(M) IPSU(M). Comp. exo.

aquí adv. de lugar 'aquí': vino Ercules por senyorior Espana et aqui buvo batalla con un gtant princep que havia nombre Girión 1.13. Del lat. vg. ECUM HIC (DCECH, I, p. 306). Frec.: 80: 0,18183.

arabe] s. m. y adj. gent. 'árabe': Et el termino [camino N] de San Jayme qui por medio [miedo $\mathrm{N}]$ de los arabes passava por Alava et por Asturias, mudó el dito Diago conte et fizo passar por Anagera 14.13. Según Corriente (2003: 219), tanto el cat. àrab como el cast., gall. y port. árabe son voces transmitidas por el latín y el griego «y sólo remotamente derivadas del ár. 'arabí, a través del semítico noroccidental o del acadio». Lo mismo valdrá para el arag. arabe. Frec.: arabes 2: 0,00455.

aragonés] s. m. y adj. gent. 'aragonés': por estas razones con los aragoneses et navarros fue volenterosament cuentra el rey de Castiella 17.33. Frec.: aragoneses 21: 0,04773.

arbitrio s. m. 'arbitrio'; en la expr. a arbitrio de 'a juicio de, a discreción de': todo lo que se fazía en la tierra se judgava a arbitrio de los presidentes en aquella 14.5. / / 'juicio u opinión sobre alguna cosa': et segunt arbitrio comin murieron aquell día entre de cavallo et de pie VI mill moros, 38,365-366. [E segons albir común, moriren-hi aquell dia entre de cavall e de peu VI milia moros, VC, p. 168]. Arbitrio es un cultismo < lat. ARBITRIUm. La forma popular correspondiente es en cast. albedrio, en cat. albir (que es la forma usada en la VC) y en occ. ant. albire. Cat. albir 'acció d'albirar, judici, facultat $i$ acte de conèixer i comparar una cosa amb una altra', 
'parer, manera subjetiva de veure una cosa' (DCV B, s. v.). Aunque cat. albir es deriv. de albirar 'pensar, considerar' ant. (hoy más bien 'percebre des de lluny, arribar a veure al lluny') < lat. ARBITRARI 'juzgar, apreciar' (DECLIC, s. v., t. I, pp. 150-153; FABRA, s. v.; DCECH, s. v. albedrío, t. I, p. 116). Vid. albirar. Frec.: 2: 0,00455.

árbitro] s. m. 'árbitro, persona que actúa como juez en un conflicto': Assí fue feito que los ditos árbitros se plegoron en Vedadoluengo et, los dreitos et razones allegadas de cada una part, convinieron en ciertos capitoles 20.158. Frec.: árbitros 1: 0,00227.

arcas s. y adj. nombre de un pueblo antiguo de la "isla de Estancia": En aquesta isla de Estancia habitaban aquestas naciones: godos, vesegodos, estargodos, davirugis, arcas et tanis, 3.2. Frec.: 1: 0,00227.

arcevispo (variantes: arcevispe, arçevispo, arçobispe) s. m. 'arzobispo': El noble varón en Arnau, arcevispo [arçobispo N] de Narbona, 34.121; don Nuch arçobispe de Caragoça 33.39; con grant conpannya de arcevispes, vispes et prelados 36.93. En el 85\% de los casos la forma empleada es arcevispo arçevispo. Del lat. ARCHIEPISCOPus (DCECH, IV, p. 258). Frec.: arcevispo 8: 0,01818; arçervispo 1: 0,00227; arcevispos 3: 0,00682; arçevispos 1: 0,00227; arcevispes 1: 0,00227.

architofel s. m. 'canciller' (?): que en todas maneras que havies a sus manos preso don Caxal, et que sería perdido el consello de los aragoneses, porque era architofel [arthitofelis $\mathrm{N}$ ] 20.222. En la VL: “quia ille erat architofel”. XimÉnez dE Embún, Vocabulario, lo traduce por 'canciller ó guardasellos'. Frec.: 1: 0,00227.

ardido adj. 'valiente, hábil; intrépido; endurecido, curtido': el qual varón fue noble et muyt ardido en armas 30.2 [lo qual fo baró molt noble e molt ardit en armes, VC, p. 95]. Tomado conjuntamente del fr. hardi y del cat. ardit 'id'., derivados

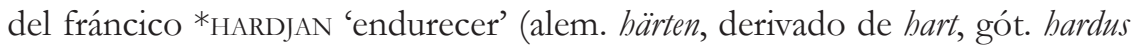
‘duro', inglés hard) (DCECH, s. v. ardido, t. I, p. 318-319, donde también se hace notar el uso de ardido 'valiente' por el aragonés Zurita). Frec.: 5: 0,01136.

ardit s. m. 'aviso, información, noticia'. Se usa en la expresión aver ardit o aver en ardit 'tener noticia, tener información': Et huvo acuerdo que por tal como havía en ardit quel [del N] común de Pisa enviava conpannya de cavallo et de pie en la isla de Cerdennya... 38.512; fue a Cap de Sant Marcho, cerca Oristan, en la isla de Cerdennya; et aqui huvo ardit del judge de Arborea que los nobles vizconte de Rocaberti et los otros qui primeros eran passados con las III naves, eran en un lugar que avía nombre Quart 38.519-522; huvo ardit que los moros treballauan [traballavan en la ed. crítica] la su tierra 23.55. Comp. cat. ardit 'noticia dels fets d'altri, comunicada por un tercer' (DCVB, t. I, p. 843, s. v. ardit (2), 3. a acepción). Según AlcoverMoll se explica por el uso de la loc. dir l'ardit o fer saber l'ardit = 'revelar els plans guerrers de l'enemic': «fàcilment dir l'ardit prengué el sentit de dir la noticia». Por lo tanto tendría la misma etim. que ardit en el sentido de 'treta, 
engaño, estratagema' (cast. ardid), el cual sería una sustantivación del adj. ardit 'atrevido'. Básicamente la misma explicación da Coromines (DECLIC, I, p. 369): en el sentido de 'estratagema, acto astuto, intento, propósito' fue sustantivación del adj., con el matiz de 'acto emprendedor, audaz, decidido'; de ahí 'empresa guerrera' y 'planes u operaciones militares' o 'planes en general' o incluso 'propósito, intención', de donde puede entenderse el paso a 'aviso, noticia'. Comp. ardit 'treta' 'estratagema', 'bravura' en Fernández de Heredia (gilkison, s. v.). Igualmente en VCA (p. 43): ardit 'ardid, artificio, astucia'. Pero en la Crón. SJP. el significado evidente es 'información, noticia'. Frec.: 3: 0,00682.

arga s. f.? 'río, en el sentido de afluente, corriente de agua que afluye a otro río': et se justa un Arga et caye en Ebro 20.279. Con artículo, luego parece que funciona como sustantivo apelativo común. Cfr. en las Cinco Villas: Arba de Luesia, Arba de Biel, etc. Andolz $(1992$, s. v.) registra arba 'río' en Cinco Villas. Estaríamos ante una raíz ar-, de origen prerromano, que indica 'corriente de agua'. Frec.: 1: 0,00227.

argent s. m. 'plata': E por otra part y offreció a honor de Dios e de los sanctos del dito lugar $D^{\text {os }}$ dineros de argent 11.41-43. Etim.: del lat. ARGENTUM 'metal, moneda, riquezas' (Dauzat-Dubois-Mitterand, p. 45). Comp. fr. argent, 'plata; dinero' (PRobert, s. v.); occ. argent 'plata; dinero' (ALIBERT, s. v.); cat. argent 'plata' (FABRA, DGLIC, s. v.; DL/C del IEC, 2007, s. v.). Vid. también el artículo argent en DECLIC, I, p. 381. En la Crón. SJP. aparece también plata 18.116 (aunque en un fragmento sólo conservado en el ms. N). Frec.: 1: 0,00227.

ariesta s. f. 'arista (filamento de la espiga de los cereales)': etpor esto metieronle sobrenombre Ariesta, porque assín como la ariesta aplegada cerca el fuego, en un moment crema, assin el dito don Ennego, sabiendo que los moros deviessen haver batallas con él, en un moment era con ellos; assin de las oras entaqua bubo nombre Ennego Ariesta. 10.17-20. Del lat. vg. *aresta, lat. cl. ARISTA (DECLIC, I, p. 373; DCECH, I, p. 334, donde cita esta forma de la Crón. SJP.). En cast. arista; cat. aresta; fr. arête. En arag. mod. ariesta, liestra, liastra, ariscla (RoHLFs, DDPA, s. v.; ANDOLZ, s. v.; EBA, 1999, s. v.). Frec.: ariesta 1: 0,00227; Ariesta 5: 0,01136.

arma s. f. 'arma': las quales gents, por luenga paz, oblidoron el uso de las armas 1.39; gentes de pie muy valerosas et spiertos en armas 36.533. Frec.: armas 18: 0,04091.

armado adj. y p. p. del v. armar, 'armado, provisto de arma(s)': fizo el rey parellar ciertos et secretos hombres en su cambra armados 20.131; don Pedro entró dentro en Castiella mano armada bien por VII jornadas 36.111. / / 'referido a una embarcación: provista de de todos los aparejos necesarios para su funcionamiento': con XX galeras que eran armadas en las marinas suyas 38.503; et lexó un lennyo armado por denunciar a las naves et al otro navilio que firiessen aquella misma via. 38.526; Frec.: armada 4: 0,00909; armadas 2: 0,00455; armado 8: 0,01818; armados 2: 0,00455. 
armar] v. tr. 'armar': et aquí vino el noble don Francisco Carroz almirant con vint galeras qui se armoron en Valencia 38.500-501. Frec.: armoron 1: 0,00227.

arras s. f. 'arras (matrimoniales)': et affilló et herdeó al dito Remiro, su fillastro, en Aragón, el qual era de la reyna por razón de su casamiento obligado en arras 14.93. Del lat. ARRAE 'lo que se da en prenda de un contrato' (DCECH, I, p. 349). Frec.: 1: 0,00227 .

arredicar v. tr. 'erradicar', 'desarraigar', 'despachar, desplazar': queriendo él de toda Calabria erradicar et remover, et todo home que su reclamo huvies 36.245-246. Etim.: cultismo, del lat. E(x)-RADICARI (BDELC, p. 490). Quizá el cambio vocálico, si no es una simple metátesis $e-a>a$-e, está influido por el verbo arrancar/ arrencar. Frec.: 1: 0,00227.

arriano] adj. 'arriano, relativo al arrianismo': Pero depués, por enganno et por fuerça del emperador Valient, qui era de la secta arriana, tornaron ereges en la error arriana 3.23. Frec.: arriana 3: 0,00682.

arribar] v. intr. 'arribar, llegar a puerto, llegar a la orilla' (de los dos casos en que aparece no puede deducirse la acepción de 'llegar en general'): partió del Alcoy con todo su escolt, do huvieron gran goyo los moros que yas tenían por consumados, et arribó en la ciudat de Palermo 36.215-217; del grau de la mar do arribó entro a la ciudat 36.219. Etim.: del lat. tardío ARRIPARE 'llegar'. Según apunta el DCECH (V, p. 7, s. v. riba), la acepción 'llegar en general' es propia del cat. y del galo e italorrománico; en cast. se encuentra en textos antiguos (aparece ya en el Cantar de Mio Cid) y americanos. Comp. cat. arribar 'venir a trobar-se en un indret per moció progressiva, tocar al terme del seu camí' (FABRA, DGLIC, s. v.; DL/C del IEC, 2007, s. v.); occ. arribar 'arriver, gagner la rive. Atteindre. Advenir, survenir' (ALIBERT, s. v.); fr. arriver 'toucher la rive, le bord', 'parvenir près du port, au port' (acep. antigua); 'toucher au terme de son voyage; parvenir au lieu aù l'on voulait aller' (acepción moderna, desde el s. XII) (Petit Robert, s. v.). En el arag. de Fernández de Heredia arribar 'arrive, come into port, dock' (GILKISON, s. v.). Comp. ribar. Frec.: arribó 2: 0,00455.

asemblant s. m. 'gesto, mueca, semblante, ademán': nos mudó el pie ni firo asemblant [fue senblant N] que fues ferido 38.277. Comp. semblant 'semejante, parecido'. Frec.: 1: 0,00227.

asentar] v. tr. 'acordar, asentar, decidir': Et depués muytos et varios tractamientos, fue asentado quel dito rey don Alfonso soltas el rey Carlos qui tenía presso 37.69-70. Frec: asentado 1: 0,00227.

asignado (var.: assignado) adj. 'asignado, indicado, señalado': et cuando el tiempo de la batalla asignada se apropinquó, 36.271; el dito don Alfonso partió de la ciudat de Barçalona con XX galeras et con muyto de otro navilio de naves, coquas et otros vaxiellos por venir a Port Fangos, do avia asignado dia de recullir todas sus compannyas 38.497. 
Frec.: asignado 4: 0,0909; asignada 1: 0,00227; assignado 1: 0,00227; assignadas 1: 0,00227.

asitiar] (var.: assitiar) v. tr. 'sitiar, poner cerco': supo que los moros tenían asitiada la ciudad de Pamplona 12.51; el dito rey Remiro asitió un lugar de moros clamado Grados et, estando en el dito lugar asitiado... 16.51-52; por esto, en el anno MXCIIII assitió la ciudad de Huesca 17.115. Etim.: deriv. de sitio 'asedio, cerco que se pone a una ciudad' (DCECH, V, pp. 265-268). También se emplea con el mismo significado sitiar: el dito rey don Pedro sitió el dito castiello de Albarrazín, 36.323. Frec.: asitió 1: 0,00227; asitiado 1: 0,00227; assitió 1: 0,00227.

assaber (var.: asaber), en la expresión es asaber que funciona como loc. conj. explicativa 'o sea, es decir': et quoando fuerment fue convatida, prisola en aquel mismo día en el otro aynno siguient, es asaber en el ochen dia en las kalendas de noviembre 32.30-31; Et fue assi enpresso entre entramos los ditos reyes que el uno, es assaber el rey de Aragón, sitias la ciudat de Almaría, et el otro, es assaber el rey de Castiella, sitias Aliazira de Alfadra 38.346-348. Frec.: assaber 20: 0,04546; asaber 3: 0,00782. assí (var.: ansí, anssí, así, asin, assín) adv. 'asî́: etyvan ansívestidos como cavalleros,3.51; Et anssi la dita reyna, conociendo el consello del cavallero sano et proveitoso, revocó el atorgamiento que havia feito de dito cavallo a su fillo García 14.48; su fillo don Pedro el Grant et hovo asi nombre porque él emperaró muyt grandes afferes contra muytos reyes 36.3; "porque bien sabedes vosotros que quando la reyna su madre murió asin por grant desastre, prennyada era) 12.31; grant multitut de gent morisca assi de cavallo como de pie 38.359. // assín mismo loc. adv. 'igualmente, también’: et assín mismo era conte de Cerdenna Guiffre su hermano 27.17. También se registra, con el mismo significado, assímismo. // assí que loc. conj. 'así que, de manera que': Assí quel dito don Pedro, haviendo guerra con él, le tollió su tierra et sus castiellos 36.43. Del lat. SIC 'id.'. La $a$ - es una mera ampliación del cuerpo del adverbio, analógica de muchos adverbios y frases adverbiales. Asín es frecuente en el aragonés de Fernández de Heredia, así como las variantes: assin, assyn, ansi, assi, etc. (GILkison, s. v.). Actualmente, en el arag. mod., asina, asinas (EBA, 1999: 221-222). Frec.: assí 107: 9,24320; assin 19: 0,04319; así 1: 0,00227; asin 1: 0,00227; ansí 4: 0,00909; anssí 1: 0,00455.

assignado adj. 'señalado, indicado': en el dia assignado al dito aparellamiento 12.24 // 'asignado, concedido': et en las otras tierras a ell por el dito emperador, su padre, dadas et assignadas 16.14. Frec.: assignado 1: 0,00227; assignadas 1: 0,00227. assímismo adv. 'asimismo, también': et assimismo el dito rey con sus vassallos yva a vegadas a pie et a vegadas a cavallo, 12.65-66. Frec.: 1: 0,00227.

astragar] v. tr. 'destrozar, dañar, asolar, causar ruina o destrucción': prendiendo et astragando la tierra de su enemigo, 17.42. Vid. estragar. Frec.: astragando 1: 0,00227 . 
atendar] (var.: attendar) v. tr. e intr. 'acampar, instalar un campamento': vino sende a la dita fuerça et, atendado [atendó $\mathrm{N}$ ] en el dito lugar clamado de Panno 4.34; qui estava attendado en el dito coll de Panizares 36.490-491; alli attendó [sitió con $\mathrm{N}]$ su buest et asitió la dita ciudad, 18.6. Deriv. del bajo lat. ant. TENDA 'tienda' (DCECH, V, p. 459). Frec.: atendado 1: 0,00227; atendó 2: 0,00455; attendado 1: 0,00227; attendó 1: 0,00227.

atender] v. tr. 'atender', 'esperar', 'aguardar': todas sus gentes yvan a él, et no los antendió 17.112-113 (antendió es la lectura clara del ms. B; quizá sea lapsus por atendio); et havieron acuerdo quel rey se partiesse d'alli, que no atendies el trato ordenado 20.195; Et el rey don Pedro fuesse pora Taraşona que los daría batalla et non lo atendieron 36.334. Etim.: del lat. ATTENDERE 'tender hacia', deriv. de tendere 'tender' (Dauzat-Dubois-Mitterand, s. v. attendre, p. 55). También en cast. med. valía a veces por 'aguardar', según el $D C E C H$ (V, p. 459, s. v. tender). Frec.: atendies 1: 0,00227; atendió 1: 0,00227; atendieron 1: 0,00227; antendió (por atendió) 1: 0,00227.

atorgamiento s. m. 'concesión': revocó el atorgamiento que bavía feito de dito cavallo a su fillo [fjo N] García, 14.50. Comp. cat. atorgament 'acció d'atorgar' (DCVB, s. v.; DL/C del IEC, 2007, s. v.). Frec.: 2: 0,00455.

atorgar (var.: actorgar, otorgar) v. tr. 'otorgar, conceder': más non de querie [queriendo B] atorgar res el rey de Francia 36.161; como aquél que lo podía fazer por el privillegio papal ganado... actorgólo por el dito monesterio 19.16-18; demandoron tregua por soterrar los lures muertos, la qual les fue atorgada 38.556; que le diessen el trasoro de la iglesia de Pamplona et que faría parellar CCC $^{\circ}$ de cavallo pora la dita guerra et pora deffender el su regno; et fuele atorgado 20.234; et assín como puro homme et vasallo suyo obedeciesse et atorgás él [otorgase a él $\mathrm{N}$ ] por sennyor, 16.35; respondióle que no le podía ayudar de res, empero atorgogele que si él lo podía conquerir.. 23.60-61; el qual havía bien menester el rey et atorgóle lo que demandava 36.400-401. En el 90\% de los casos aparece la forma atorgar. Etim.: del lat. vg. *AuCtORicare, propiamente 'autorizar', deriv. del lat. AuCTOR, -Oris (DECLIC, I, p. 475). Como indica Coromines, el arag. atorgar y el cat. atorgar tienen la misma procedencia que el occ. ant. autorgar, cast. otorgar, port. outorgar, sardo otorigare. En arag. mod. se registra atorgar en el Somontano (Mostolay, 2007: 89; Nagore, 2000: 538; Ríos, 1997; Andolz, 1992). Comp. también atorgar 'otorgar' y 'aceptar, dar el consentimiento' en Huesca y su comarca (NAGore, 2020a: 74). Frec.: atorgar 1: 0,00227 ; atorgás 1: 0,00227 ; atorgó $3: 0,00682$; atorgogele 1 : 0,00227; atorgóle 1: 0,00227.

atrevimiento s. m. 'atrevimiento, osadía': fue vencido por su grant atrevimiento de sobra locanía 19.222. Deriv. de atreverse < lat. TRIBUERE SIBI 'atribuirse (la capacidad de hacer algo)' (DCECH, I, p. 404). Frec.: 1: 0,00227. 
aturar] v. intr. 'parar, detenerse': no aturó ni posó fasta que fue cerca de los enemigos 33.84. Del lat. vg. *ATTURARE, probablemente alteración del cl. obTURARE 'tapar, cerrar estrechamente' (DECLIC, I, p. 484). Comp. cat. aturar 'detener'; occ. aturar 'arrêter' (AliberT, s. v.). Comp. arag. mod. aturar 'detener' (RoHLFs, DDPA, s. v. Andolz, s. v.). El EBA (1999: 231) permite ver que es prácticamente general en todo el territorio propio del arag., con el significado de 'parar' o 'detener'. Frec.: aturó 1: 0,00227.

audacia s. f. 'audacia, atrevimiento': prendiendo mayor audacia, pasando el mont Pirineus, conquirió entro a la ciudad de Tolosa 9.8. Etim.: palabra culta, tomada del lat. AUDACIA. $1^{\text {a }}$. doc. en cast.: princ. s. Xv, en el cancionero de Baena (DCECH, I, p. 409, s. v.). Es anterior la doc. de la Crón. SJP. Frec.: 1: 0,00227.

aulement adv. 'malvadamente, perversamente': «Si Dios me salve, todo homme que aquesto diga miente aulement et falsa por media de la barba» 38.320. Etim.: lat. HABILE MENTE. Aunque probablemente se trate de una formación adverbial ya romance, sobre el adj. aule 'malo, malvado, perverso', que procede del lat. HABILIs. Comp. occ. aul, aule (ALiberT, s. v. aul, p. 131); occ. ant. aul, avol (LEVY, s. v.); cat. àvol 'dolent' (FABRA, DGLIC, s. v.; DL/C del IEC, 2007, s. v.); arag. ant. avol 'malo', auleza 'maldad' (LR, p. 116), auleza, ableza 'vileza', ávol 'vil malo' (VM, III, pp. 8, 35 y 36); aule 'persona maligna', auleza 'vileza, maldad'; avoll, avol 'malo, perverso' en Fernández de Heredia (GILKISON, s. v.). Según Corominas àvol es palabra común al cat. y al occ., de origen discutido pero probablemente del lat. HABILIs. En cat. existieron tb. las formas primitivas àvel, ául e incluso àl. Las formas vascas aul, ahul, abol, arol, txaul 'débil, flojo, poco fértil' son atribuidas a préstamo románico (DECLIC, $I$, pp. 520-523). Vid. también para el vasco Michelena, Fonética histórica vasca, 2. ${ }^{a}$ ed., 1977, p. 94: aultu 'debilitado' (roncalés de Uztárroz), a(h)ul 'débil, flojo' (ábül en suletino), guipuzcoano y vizcaíno abol, arol. Para el DCECH (I, p. 426), el cast. ant. ávol 'vil, ruin' «es palabra frecuente en todo el s. XIII, que después desaparece, como tantos extranjerismos de esta época temprana», pues considera que, sin ninguna duda, es (en cast.) préstamo del cat. o del occ. ant. La única reminiscencia que encontramos actualmente en Aragón, de acuerdo con los repertorios léxicos publicados, es aule 'lelo' en Caspe y Pina de Ebro (Andolz, s. v.). No obstante, podríamos añadir un dato no publicado: en Santolaria de Galligo (Alto Aragón, pero provincia de Zaragoza) se usa able 'inútil' (informante: Rosa Arbués). Frec.: 1: 0,00227.

aún adv. 'aún': Encara más, que empués días del rey don García de Navarra cobras aún [Ronzal VL] Calasanz, Cadreyta et Valtierra 20.282. Debe de ser error del ms. Es la única vez que se registra; lo habitual es encara (vid.). Frec.: 1: 0,00227.

avant adv. 'adelante; en adelante': ordenó que assín como el monesterio sancto lugar era ordenado de clerigos seglares, fuesse ordenado de aqui avant [adelant $\mathrm{N}]$ et ennoblecido de monges negros 14.97. Tb. adelant. Del lat. AB ANTE. Frec.: 2: 0,00455. 
avarcha s. f. 'abarca': yva con ellos et se metía en ygual dellos en todos afferes d'armas et calcava a vegadas avarchas 12.71. Comp. abarca, abarcha. Comp. cat. avarca. De una base ABARKA prerromana común a las diversas lenguas preindoeuropeas de la Península (DECLIC, I, p. 505). Frec.: avarchas 2: 0,00455 (además, como nombre propio: Avarca 1: 0,00227; Avarcha 6: 0,01364).

avençado adj. 'aventajado': no trobavan mas valient ni mas avençado cavallero como el noble varón 10.6. Comp. cat. avençar 'avançar, progressar' (segunda acepción en FABRA, s. v., primera en el DL/C del IEC, 2007, s. v.); 'progresar, adelantar' (Miracle, 1973, s. v.). De abante se deriva ya en lat. vg. *abantiare que da directamente it. avanzare, fr. avancer, occ. avansar, cat. avançar (de aquí lo toma probablemente el cast.). La variante avençar es propia modernamente sobre todo de las islas y del cat. or., pero ya se encuentra en textos medievales, y hoy se tiende a emplear en la lengua mod. con preferencia (DECLIC, t. I, p. 324 a, s. v. ans). KuHn, $H A D$, p. 104, cita arag. ant. avenzado Peña, 26 "avezado (geeignet)". Pero a nuestro juicio no puede interpretarse ni como 'avezado (acostumbrado, habituado)', ni como 'idoneo, apropiado' (alemán geeignet). En la VL dice: magis strenuo et fortunato, VL, p. 32; en la VC: pus valent ne pus aventurat cavaller, VC, p. 39. Por lo tanto, hay que interpretarlo como adj. proveniente del p. p. de avençar (var. de avançar) en el sentido de 'aventajado, avanzado, adelantado'. Entre las diferentes acepciones del cat. avançar avençar vemos en $D C V B$, s. v., t. 2, p. 163, con marca de ant. 'aventajar' y 'dar preferencia, anteponer'. Frec.: 1: 0,00227.

avenimiento s. m. 'venida': e por piedat de lur pobreza e por esgoart del su nuevo avenimiento, le plazies enrriquecer el dito monesterio del algunas honores 11.23. Comp. cat. ant. aveniment 'acto de venir, advenimiento' (DCVB, t. 2, p. 171). Deriv. de avenir 'llegar', o de venir. Frec.: 1: 0,00227.

avenir] v. tr. y prnl. 'ponerse de acuerdo, acordar'; 'concordar': et esti don Goncalvo no y vino, mas embió sus compannyas et avino mellor en ello 18.16; et finalment fue assí avenido 38.567; mandó al dito rey don Alfonso e a los otros reyes de Espayna que no oviesen tregua con los moros, mas que todos amigablement se aveniesen e fuesen contra ellos 33.102. / / 'acontecer, suceder, ocurrir': et los porteros como locos et de poco bien, lo que muytas vezes les avien [contece N] 20.31. Del lat. ADVENIRE. Frec.: avenido 1: 0,00227; aveniessen 1: 0,00227; avino 1: 0,00227.

aventurado adj. 'afortunado, venturoso, lleno de ventura, es decir, dotado de felicidad, suerte o fortuna': Aquesti rey Sancho Remirezfue muyt buen rey et aventurado et virtuosso 17.65. El DLE (2014) da aventurado 'venturoso, afortunado' con marca de desusado. Frec.: aventurado 2: 0,00455; aventurada 1: 0,00227.

aver v. tr. 'tener' y v. auxiliar para los tiempos compuestos de los verbos transitivos: bien avedes entendido cómo por buen dreyto que avía el dito rey en el regno de Sezilia... 
36.453; el primero avie nombre Sancho 16.25; et de otras duennyas avié a Ferrant Sanchez de Castro et a Pedro Ferrandez de Ixar 35.79; todo el regno fue alegre et pagado, mayorment como simient de virtuosso princep avien elegido [esleydo $\mathrm{N}$ ] por sennyor lur. 36.725; et como el dito letrado no avies complimento de meneda...38.309; de aquesto avrian gran infamia 20.192; «Sennyor, por la tu merce, que non ayamos temor de las contrariedades de aquesti mundo» 35.239; et todo quanto avies avido que lo avies a tornar 36.446; et que non avies miedo de res 38.237; eran en un lugar que avía nombre Quart 38.521-522. Del lat. HABERE 'tener, poseer'. El DLE (2014) registra baber 'poseer, tener en su poder' con marca de desusado. En arag. aber conserva actualmente todavía la significación de 'poseer, tener' en el aragonés del valle de Echo (Nagore, 2013: 102). También haver. Frec.: aver 28: 0,06364; avía 94: 0,21366; avían 26: 0,05910 ; avianlo 1: 0,00227 ; aviase $1: 0,00227$; avida 2: 0,00455 ; avidas 1: 0,00227 ; avido $3: 0,00682$; avié $7: 0,01591$; avíen 1 : 0,00227 ; aviendo 3: 0,00682; avieron 10: 0,02273 ; avies 25: 0,05682; aviessen 2: 0,00455 ; avrá 1: 0,00227; avría 7: 0,01591; avrían 1: 0,00227; axuar 1: 0,00227 ; aya 5: 0,01136; ayamos $1: 0,00227$; ayas $3: 0,00682$.

avillar] v. tr. 'envilecer; degradar; rebajar; vilipendiar, denigrar, ultrajar, menospreciar': et recontóronle como los avía avillado el dito Padre Santo, 36.181 [como los havía acollits VC]. XIMÉNEZ DE EMBún lee aviltado, pero en el ms. B se ve claramente los auia auillado. Etim.: Está relacionado con vil < lat. VILE(M) 'sin valor'. Probabl. del lat. VIlitare 'envilecer' (cfr. DEEH, 1064). En el Poema de Yúçuf se registra abilar (ms. A) y abillar (ms. B), con el mismo sentido: Abilaban lox ermanox/diriendole: axt ${ }^{\circ}$ roxo, balate lox tux fadox (ms. A. estrofa 19) (Menéndez Pidal, Poema de Yúcuf, pp. 291 y 122, quien además cita como vocablo relacionado el cast. ant. aviltar). Se registra abiltar en Menéndez Pidal, Cid, 2732. En Covarrubias (1611) todavía encontramos: "aviltar. Vale apocar, menospreciar, hazer vil alguna cosa o persona. Aviltado, el infame y abatido". En el arag. de Fernández de Heredia: aviltar, avilar 'degradar, envilecer, vilipendiar' (GILKISON, s. v.). En VM auiltar 'envilecer, menospreciar' (TILANDER, VM, III, p. 35). En cat. ant. avilar, luego sustituido por la forma moderna envilir, deriv. de vil (DECLIC, IX, p. 278, s. v. vil). En cast. ant. aviltar 'afrentar' ( $V M C$, s. v.), 'envilecer, menospreciar, afrentar' (DME, s. v., con ejemplos de los siglos XII —Mio Cid—al xv). El GVAM, p. 9 , recoge en los textos aljamiados abilar y abillar, así como abiltado, pero remite a aviltar 'rebajar, envilecer' y a aviltado 'envilecido, menospreciado, afrentado' (ib., p. 142). Frec.: avillado 1: 0,00227.

avinença (var.: avinençia, avinienca) s. f. 'acuerdo, concordancia': con grant voluntat que havia de complir las avinenças 20.179-180; et por la dita avinencia, firole donación el desus dito rey Remiro de Ruesta et de Pitiella 16.43. Deriv. de avenir < lat. ADVENIRE. En el arag. de Fernández de Heredia: auinencia, aminença (GILKISON, 
s. v.). Frec.: avinenças 1: 0,00227; avinencia 1: 0,00227; avinençia 1: 0,00227; avinienca 1: 0,00227.

avinent adj. 'afable, fácil de tratar': porque fue el más cortés de palavra et el más familiar et el más avinent [avenient $\mathrm{N}$ ] a los sus sozmesos 39.3-4. Del lat. ADVENIENTE, part. presente de ADVEniRE. Por la forma, debe de ser catalanismo. Comp. cat. avinent con el mismo sentido $(D C V B, s . v$.). Comp. arag. avinient'conveniente' (Savall y Penén, s. v.). Frec.: 1: 0,00227.

avistados: et avistados [ajustados N] todos sus parientes et amigos et vassallos, bien et honrradament aparellado en el día assignado al dito aparellameinto fue present 12.23. Nosotros leemos en el ms. B aiustados (lo que además concuerda con el ms. N), es decir 'reunidos'. Cfr. ajustar. Frec.; 1: 0,00227 (pero súmese a ajustados).

axuar s. m. o f.? 'dote; ajuar, bienes que aporta la esposa al matrimonio': et depués fue nombrada Urracha, con la qual priso el dito regno en axuar en el anno de Nuestro Sennyor MCXXXVII, 32.11-32.13. Etim.: ár. SUWAR 'ajuar de novia' (BDELC, s. v.; DCECH, I, p. 98). Comp. axobar 'la heredad que, además de su dote, recibía la esposa por parte de su padre ó marido, y era perpetuamente, para ella y los suyos: llamábase, antiguamente, excrex' (BORAO, s. v.); 'donación que además de la dote recibía la esposa. Antes se llamaba excrex' (PArdo, s. v.). Arag. ant. axuar 'ajuar, bienes que los padres de la esposa dan a ésta al contraer matrimonio' (TILANDER, FA, p. 259); aixonar 'ajuar, bienes que la esposa, u otro por ella, da al marido al contraer matrimonio', eixouar, axuar 'bienes que los padres dan al fillo o a la filla para el matrimonio', aixuar 'equipo, ajuar' (Tilander, VM, III, p. 18). En Fernández de Heredia axumar 'dote' (GILKISON, s. v.). Arag. mod. registra ANDolz $(1992$, s. v.) con el significado de 'ajuar': ajobar (Bajo Aragón), jobar (Alquézar), jobá (Campo, Fonz); jovar f. 'ajuar, ropa de la dote que se da a la novia' (Alquézar; ArNAL, 1944, s. v.). El EBA (1999: 1102-1103) registra jobar en Salas Altas, Biello Sobrarbe, Somontano y Graus. Gall. axoar, axuar (FrAnco, s. v.); port. enxoval (FERnAndes, s. v.); cat. med. exouar (en Usatjes de Barcelona, Costumbres de Tortosa; cit. por Tilander, FA pp. 261-262); cast. med. axunar (Menéndez PidAl, Cid, Voc.). Frec.: 1: 0,00227.

ayrado p. p. de ayrar 'expulsado, desterrado por haber provocado la cólera del rey'; 'privado de la gracia y amistad'. Comp. yrado. Vid. ayrar.

ayrar] v. tr. 'desairar, apartar, extrañar, desterrar'; 'declarar a una persona non grata por haber provocado la cólera del rey': un vasallo suyo que yera ayrado et fuera del regno 18.27; et aquesta jura prendió el Cit et desplazió depués al rey muito. Et por esto lo ayró et vínose a meter en comanda del rey... 18.89; Et en aquel tiempo el Cit era ayrado del rey don Alfonso de Castiella 18.78-79; don Alfonso ayrado de su hermano... 18.83. en todos los casos ayrar tiene el significado de 'desterrar, expulsar'; en cambio yrado es más bien ‘enojado, encolerizado, irritado’. Comp., en cambio 
airar, ayrar 'enojar, indignar, encolerizar', lo mismo que irar, en Fernández de Heredia (GILKISON, s. v.). Frec.: ayró 1: 0,00227; ayrado 3: 0,00682.

ayuda s. f. 'ayuda': que ningún socorro ni ayuda non avría 38.383. Deriv. de ayudar. Frec.: 32: 0,07273.

ayudador] s. m. 'persona que ayuda, colaborador, cooperador, cómplice': tornose de Castilla, destruyendo los ayudadores del compte don Pedro 19.155. Frec.: ayudadores 1: 0,00227 .

ayudar v. tr. 'ayudar': «si Dios me ayude, grant deshonor es de mí et de vosotros.» 38.333 ('me ayuda' o quizá 'me ayude', pres. de subj.); que en todas necessidades havies ayndar e valer al dito rey Remiro 16.43; «ayúdanos Dios, que es salut nuestra et gita la yra de nos» 35.246. Del lat. ADJuTARE, frecuentativo de ADjuvare, y éste deriv. de juvare 'ayudar' (DCECH, I, p. 428). Frec.: ayudar 9: 02046; ayudava 4: 0,00227; ayudavan 2: 0,00455; ayudó 2: 0,00455; ayudarían 1: 0,00227 ; ayudas 1 : 0,00227; ayude 1: 0,00; ayúdanos 1: 0,00227; ayudando 2: 0,00455.

ayuntar] v. prnl. 'juntar, reunir': et depués todos los barones... se ayuntoron en un lugar [un día $\mathrm{N}$ ] 23.34. Aparece sólo en esta ocasión; generalmente ajustar (vid.). Frec.: ayuntoron 1: 0,00227.

ayuso adv. 'abajo; hacia abajo': Et seyendo en el sitio de Caragoca, los moros de Tudela fazían a los de la buest todos días que aduzían viandas por Ebro ayuso e de Castilla por tierra, grandes dyynos e grandes cavalgadas.19.29. Etim.: del lat. AD DEORSUM 'hacia abajo' (DCELC, IV, p. 784). Frec.: 1: 0,00227.

azes s. f. pl. 'tropas', 'líneas de combate', 'cuerpos de ejército': sallieron los aragoneses e hordenaron sus azes 19.114-115. Etim.: lat. ACIES 'línea de combate' (DCELC, s. v. haz II, t. 2, p. 889. id. en DCECH, t. III, p. 329). Comp. cast. ant. az, azes (cfr. Menéndez Pidal, Cid, II, 491-492); port. ant. az azes; cat. ant. atzes, azes 'cuerpos de ejército' empleados en los siglos XIII, XIV y XV (cfr. Colón, El léxico catalán en la Romania, pp. 199-200). El DRAE, 1970, s. v., recoge haz 'tropa ordenada, o formada en trozos o divisiones'; 'tropa formada en filas'. El DLE (2014) ya solo recoge como definición de baz 'tropa ordenada o formada en unidades' con marca de desusado. Pero ya Aut. hace notar que es voz poco usada, y hoy en cast. "debe considerarse anticuada del todo" (DCECH, III, p. 329). La $b$ - antietimológica se ve ya en Alex.: hazes (ms. P), azes (ms. O) (cfr. SAS, s. v. haz, p. 320). En el arag. de Fernández de Heredia: ac, $a \approx$, ha₹, haç, pl. azes, azez (GILKIsON, s. v.). Frec.: azes 3: 0,00682. 


\section{B}

bacallar s. m. 'villano, bellaco, rufián'. XIMÉNEZ de EMBÚN, Vocabulario, da 'traidor, pícaro'. En la ed. crítica de OrCástegui, batallar: (38.302): et alçando el braço dreyto estrennyó la mano et dixo: "Batallar, rendeme el castiello si no yo te enforcaré» 38.301-303. Pero en el ms. B, fol 84 r., se lee claramente bacallar y esta es la lectura que da XIMÉNEZ dE EMBún. También bacallar en la VC: Bacallar, rit-me lo castell si no penjar t'he. VC, p. 166. Tanto en la VA como en la VC aparece con mayúscula. Por esa razón se consideró inicialmente como nombre propio y se incluyó en el índice de antropónimos. No obstante, está claro que va con mayúscula por iniciar una frase en estilo directo. En el Glossari de la VC se indica: bacallar 'mot despectiu, usat com a insult'. Efectivamente, la voz bacallar se utilizó en cat. med. con dos sentidos: 1) 'pagès que no tenia mas ni parell de bous'; 2) 'vilà, home de costums baixes o delictives; cast. villano'; 'usat com a insult (equivalent al cast. villano, bellaco)' (DCVB, II, 193). Relacionado al parecer con el fr. bachelier 'joven que aspira a ser caballero', y cast. bachiller, tendría como origen etimológico una voz celta *BACALACOS (ibídem), o *BAKKaLLakos 'pastor, campesino, palurdo' (DCELC, I, 440), a través del lat. vg. * BaCCALLARus (BDELC, p. 79, s. v. bachiller, p. 92, s. v. bellaco). Según indican Corominas-PASCUAL, «Bacallar, no es propiamente castellano sino voz puramente catalana. 1. ${ }^{a}$ doc. empleada por el cronista valenciano Beuter, 1547» (DCECH, I, 445-6). CoROMINES en el DECL/C, I, p. 735, s. v. batxiller, relaciona el cat. ant. bacallar 'hombre vil' con el occ. bacalar 'hombre que no es caballero, villano' y con el fr. ant. bacheler 'joven que aún no es caballero y quiere serlo', que supone un original *BAKKALLAROS que por su terminación parece ser céltico. En cat. se usó en la E. M. con un sentido gravemente injurioso; entró en decadencia a fines de la Edad Media. Frec.: 1: 0,00227 .

baldonada adj. 'abandonada, desamparada', 'dejada en poder de alguien': que del grieu cativerio et oprissión a qui era baldonada, la devies preservar et delibrar 36.197. [que del gren catiu e opressió a què era abaldonada, la degués preservar e alliberar VC, p. 133]. Etim.: deriv. de baldón 'injuria', 'tratamiento soberbio o arbitrario', descendiente del fráncico BANN 'mando, jurisdicción'. De ahí surgió el verbo baldonarse 'entregar su cuerpo (una mujer)', que aparece en $S t^{a}$. $M^{a}$ Egipcíaca, v. 312. Por lo tanto, de baldonar 'injuriar' se pasó a 'entregar, exponer' y a 'abandonar', también empleado con el sentido de 'envilecer, deshonrar' (DCECH, I, p. 476). En el Glossari de la VC: abaldonada 'afrontada'. En el DGL/C de FABRA no aparece abaldonada; sí, en cambio, abandonar. Comp. 
baldonado 'denostado', en cast. med., del s. XIII al XV (citas de las Siete Partidas y de la Celestina); baldonar 'despreciar, desdeñar', del s. XIII al xv, de baldón 'ofensa o palabra afrentosa, injuria, oprobio' (DME, s. v., t. I, p. 485). Según el DME, baldón vendría del fr. ant. bandon 'tratamiento arbitrario', del fráncico bann 'mando, jurisdicción'. Por otra parte, abandonar viene, según el DLE (2014), s. $v$., del fr. abandonner, y éste del germ. *banna 'orden'. Así que baldonar y abandonar tendrían igual origen. Comp. arag. mod. abaldonar, abaldonau, abaldono (ANDOLz, s. v., las recoge en Loarre; el EBA [1999: 67] registra abaldonau 'abandonado, dejado' en Sobrepuerto). El BDELC: registra abandonar, h. 1420 (abaldonar ya h. 1270). Del fr. abandonner 'íd.', deriv. de laisser à bandon 'dejar en poder de alguien', bandon 'poder, autoridad', y éste del fráncico BANN 'mando, jurisdicción' (hoy alemán bann). Comp. cast. baldón. Frec.: 1; 0,00227.

balient adj. 'valiente': Et depués el dito balient rey, queriendose vengar de las injurias que el compte de Tolosa le avía feytas, ajutó grant gent assí de cavallo como de pie 33.62. Procede del part. presente del lat. VALERE 'ser fuerte, vigoroso', 'tener tal o cual valor' (DCECH, V, p. 733). Frec.: 2: 0,00455.

ballesta] s. f. 'ballesta': el alcayde firo desparar muytas ballestas 38.307. Etim.: del lat. BALLISTA 'balista, máquina de guerra para arrojar grandes piedras' (DCECH, I, p. 482). Frec.: ballestas 1; 0,00227.

ballestero s. m. 'ballestero': et un moro ballestero que estava en aquel lugar con una sayeta por la manga de la loriga firiolo en el costado. 17.120; bomes a cavallo et II mill ballesteros 38.533. Etim.: deriv. de ballesta sufijado con -ARIU > -ero. Frec.: ballestero 1; 0,00227; ballesteros Frec.: 1; 0,00227.

banno s. m. 'baño o aseo': Et sabiéndolo don Pero Tiçón que don Per Atares era en el banno... 20.28. Etim.: del lat. vg. BANEUM, lat. cl. BALNEUM (DCECH, I, p. 491). Frec.: 1; 00227.

baptismo s. m. 'bautismo': nombrada Hermissenda et por baptismo Gelberda 16.25. Comp. bautismo. Frec.: 1; 0,00227.

barba s. f. 'barba': posó la mano en la barba del dito conte 22.13; prisso el rey moro por la barba en una carrera de la dita ciudat, 35.134. Etim.: del lat. BARBA 'pelo de la barba' (DCECH, I, p. 504). Frec.: 3: 0,00682.

barch: Aquesti Remón ... regnó XXX dos aynnos e finó en el barch de Sant Dalmau cerca de Tenua 32.64. Se trata de una mala escritura del propio ms. por borch 'burgo, barrio'. En la VC: ... e morí en edat de L anys en el borc de Sant Dalmau, costa la ciudat de Gènoa, VC, p. 103. Se trata de la localidad cuya denominación oficial en italiano es actualmente Borgo San Dalmazzo, situada a $12 \mathrm{~km}$ al suroeste de Cuneo, provincia de Cuneo, región del Piamonte, en Italia; la denominación tradicional y popular es Borg de Sant Dalmau, ya que está situada en zona de lengua occitana (NAGORE, 2003b: 327). Frec.: 1; 0,00227. 
barcha (var. barca) s. f. 'barca': et trobó la una de las IX barcas, de las quales las ocho ribaron en Gallicia, et la novena en el ribage de Celtiberia 1.33; la qual clamó Barchanonna et hoi es clamada Barcelona, por tal como fue poblda de las gents de la dita novena barcha. 1.36. Etim.: del lat. tard. BARCA, quizá de origen hispánico (DCECH, I, p. 507, s. v.). Frec.: barcas 1: 0,00227; barcha 2: 0,00455.

bariella] s. f. 'quijada, mandíbula': dixo un día que con el su punnyo daría en las bariellas del dito conte 36.434. Etim.: deriv. del lat. VARA 'travesaño en forma de puente', 'horcón para sostener algo' (BDELC, p. 597, s. v. vara; DCECH, V, p. 739). Quizá es alteración de barriella, deriv. de BARRA, palabra prerromana de etim. incierta, probablemente proveniente del centro de Europa, que está en la base del cat. barres 'mandíbulas'; pero no es seguro (DECLIC, I, p. 663). Con todo, puede pensarse en una confusión previa entre VARA y BARRA. Comp. barót 'barrote' en Bielsa (BADíA, Bielsa, p. 231), barote 'barrote' en el Somontano de Barbastro (Mostolay, 2007: 101). Comp. en cast. med. variella 'cada uno de los dos huesos largos que forman la quijada y se unen por debajo de la barba', s. XIII, refiriéndose a las de los caballos (DME, s. v., p. 1615). Cast. mod. varilla 'íd.' en lenguaje familiar (DRAE, 1970, s. v.; el DLE, 2014, la da también, con la misma acepción, como coloquial). En arag. mod. bariella, barilla, barillas 'quijada' la mandíbula inferior, nombre usado habitualmente en plural pero con sentido singular' (Andolz, s. v.); Rohlfs (DDPA, s. v.) registra barilla (Bisaurri, Litera), bariella (Echo) 'mandíbula, quijada', barrilla 'mandíbula' (Valle del Isábena). El EBA (1999: 270) registra

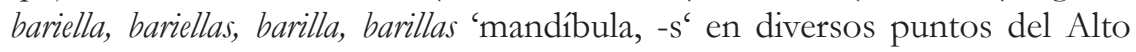
Aragón. En cat. barra 'mandíbula' (FABRA, DGLIC, s. v.). Occ. (gasc.) barro 'mâchoire' occ. (prov.) li barro 'les barres d'un cheval' (RoHLFs, Le gascon, p. 89, \310). Rohlfs dice que evidentemente se trata de la misma palabra que el fr. barre 'barra, tranca, palanca' < lat. pop. *BARRA, cercano al galo *BARRO 'extremidad, cumbre'; y que en Aragón ha sufrido la influencia del cast. vara $<$ lat. vara. Comp. gasc. barre dou cot 'muscle de la nuque' (PALAY, s. v.). En el occitano gascón del Valle de Arán, barra 'mandíbula' (Coromines, 1991: 321). Cfr. también Dauzat-Dubois-Mitterand, p. 75, s. v. barre. El DCECH (V, p. 740, s. v. vara) documenta la forma varilla por primera vez en 1495, en Nebrija, es decir más de un siglo después de la mención de bariellas en la Crón. SJP. Frec.: 1: 0,00277.

barón (var.: varón) s. m. 'hombre noble', 'título nobiliario': el dito barón establiópor si mismo dreytos qui son agora clamados Usages 29.11; aquesti valient baró [n] procreó de su muller III fillos 29.14. / / barones s. m. pl. 'conjunto de hombres principales de una población': et adaquella ennobleció de honrrados barones richos homes e cavalleros, 14.10; fizo fer los ditos barones et universidades jurar de servar feldat al dito infant 35.31-32; en la qual fue Nuch cardenal et legado de Roma, bispes et prelados, barons 
et nobles de Cataluenna 29.10; la madre firo ajuntar los barrones et nobles de toda su tierra 23.27 (errata por barones). Tb. varón: con consello de los nobles et varones et

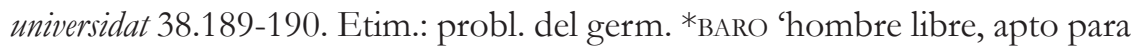
la lucha', emparentado con el escandinavo antiguo beriask 'pelear'. En la Edad Media castellana barón significa en general 'hombre noble', desde el Cid y ya en docs. de fines del s. XI. Se escribe a menudo con $v$ - Idéntico a barón es por su origen el cast. varón, que ya aparece con el sentido de 'persona de sexo masculino' desde princ. s. XIII, pero escrito normalmente con $b$-. También en otras lenguas romances que distinguen más constantemente la $b$ - de la $v$ - el vocablo aparece escrito siempre con $b$ aun en el sentido del lat. vir, cat. baró (DCECH, I, pp. 514-515, s. v. barón). Por eso piensa CoROMINAS en una fusión de la voz germánica con el lat. popular BARO, -ONIS 'hombre brutal, robusto'. En cat. es frecuente en la Edad Media en el sentido de 'hombre de alta posición' (DECLIC, I, p. 658). Comp. en arag. med. baron 'varón' en $L R$, p. 116. Es posible que en la Crón SJP. se emplee en algunos casos con el sentido de 'persona de sexo masculino', pero no es fácil especificar en cuáles, porque aparece indistintamente con $b$ o con $v$ y el contexto es insuficiente para decidirlo. Vid. varón. Frec.: barón 10: 0,02273; barones 30; 0,06819; barons 1: 0,00227.

baronía s. f. 'territorio en que ejerce jurisdicción un barón'; por aquesti ajustamiento matrimonial pervino la baronía de Montpellier a rey de Aragón 34.30. Etim.: deriv. de barón. Frec.: 3: 0,00682.

baronil adj. 'esforzado, valeroso, firme', aquí con función adverbial 'esforzadamente': vigorosament et baronil firió en los franceses 36.654. Etim.: deriv. de barón, en el sentido de 'persona de sexo masculino', con sufijo -il< lat. -ILIS, que forma sobre bases sustantivas adjetivos de pertenencia (PHARIES, 2002: 326). Obsérvese la construcción, vigorosament et baronil, que refleja el orden habitual en aragonés medieval cuando se acumulan dos adjetivos de modo en -ment: en primer lugar, el adverbio que lleva formalmente el morfema -ment, en segundo lugar, el adverbio que debería llevar el mismo morfema, pero que, con objeto de evitar la repetición, por economía lingüística, se elide. Justamente lo contrario es lo habitual en castellano, pues traduciríamos esa construcción por 'vigorosa y varonilmente'. Frec.: 1: 0,00227.

baronilment (var.: varonilment) adv. 'de manera varonil, esforzadamente': et todo el regno conquistó baronilment [valerosament $\mathrm{N}$ ] 35.158; e industrió al dito rey a regir la tierra al millor que pudo varonilment 33.14. Frec.: baronilment 3: 0,00682; varonilment 1: 0.00227.

bastar v. tr. 'proveer, abastecer' (o quizá 'alcanzar, llegar a'): con LX galeras, XXIII naves et muytos de otros navilios menudos, tantos de qui bastó a ccc vellas et mas. 38.509 . 
Etim.: de un lat. vg. *BASTARE y éste del gr. $\beta \alpha \sigma \tau \alpha \xi \varepsilon \iota v$ 'llevar, sostener (un peso)'. Port., cat., occ. bastar, it. bastare. Además de la acepción moderna, en la Edad Media se hallan otras más próximas a la griega: 'resistir', 'dar de sí', 'ser capaz de dar', 'vivir (cierta cantidad de tiempo)', en castellano; 'soportar (un peso)', 'llegar (hasta cierto lugar o cantidad)' en catalán; 'durar', 'dar de sí, alcanzar' en italiano. Corominas cita entre los deriv.: bastante (adj.) (como adv. su uso no es anterior a 1800); abastar 'ser bastante, abastecer' [1140 - s. XVII] (DCECH, I, p. 537; DECLIC, I, p. 716). Frec.: bastó 1: 0,00227.

bastar bastir v. tr. 'construir': et él possa y las primeras piedras Dios loando et a honor dél dava y de los sus trasoros por bastar [bastecerer B; bastir $\mathrm{N}$ ] aquellas 35.193-194; dio grant trasoro por bastar [bastir $\mathrm{B}$; bestir $\mathrm{N}$ ] la yglesia de Valverde 35.190. Hay confusión entre bastar 'proveer' y bastir 'construir': de ahí las variantes de los tres manuscritos. Pero resulta evidente por el contexto que se trata del v. bastir 'construir', que proviene del germ. *BASTJAN 'tejer, trenzar'. Comp. cat. bastir, fr. ant. bastir (mod. bâtir), occ. ant. bastir. La confusión entre bastir y bastar también se produjo en cat. ant. «por el hecho de que bastir ('construir') un castillo para un pueblo venía a ser poco más o menos 'proveerlo de un castillo’» (DECLIC, I, p. 721). Frec.: bastar 2: 0,00455.

bastecer] v. 'abastecer', 'proveer suficientemente'; 'construir': et tantost entró en la provincia de Celtiberia et aquí basteció una tierra la qual clamó Urgel 1.29; et specialment basteció [establió N] Benifaça 35.190; porque basteció un castiello que yes cerca Ballaguer 29.30. La confusión producida entre bastary bastir ha llevado a emplear bastecer tanto con el sentido de 'proveer' como con el de 'construir'. Etim.: deriv. de bastar. Frec.: basteció 5: 0,01136.

bastecida adj. 'abastecida': lexada la çiudat de Huesca bastecida... 18.104. Frec.: 2: 0,00455 .

bastedor adj. y sust. 'proveedor, abastecedor', o bien 'constructor, fundador': [bastador B; bastidor $\mathrm{N}$ ]; aquesti noble barón fue bastedor de muytos monesterios, 35.189. Parece que se produce un cruce entre bastar 'proveer' y bastir 'construir': de ahí la fluctuación entre los tres manuscritos. Vid. bastar $\sim$ bastir. Frec.: 1: 0,00227 .

bastir v. tr. 'construir'; 'abastecer'. Vid. bastar bastir. Vid. bastecer.

bastón] s. m. 'bastón, palo, barra; lista': mudó las armas e seynnales de Aragón e prendió bastones 33.32. Etim.: deriv. del lat. tardío BASTUM (BDELC, p. 89; DCECH, t. I, p. 539). El lat. BASTUm se halla una sola vez, en texto del s. IV d. C., pero todos los romances tienen formas correspondientes a *BASTONEM: it. bastone, fr. bâton, occ. y cat. bastó, port. bastão. Se duda del origen, aunque la opinión más general es que se trata de un derivado de * Bastare ( $>$ bastar). Corominas piensa que es de origen prerromano y relacionado con el lat. pop. BATTUERE 
'batir, golpear, sacudir', de origen celta (DECLIC, I, p. 722). Frec.: bastones 1: 0,00227 .

batalla s. f. 'batalla': et aqui buvo batalla con un grant princep que havía nombre Girión 1.13; abivado et encorajado de haver batallas continuament con los moros que apenas estava un dia seguro. 10.15. Etim.: del lat. tardío BATTUALIA 'esgrima', antiguo neutro pl. de un adj. BATTUALIS deriv. de BATTUERE 'batir, golpear, sacudir', a través del occ. ant. batalha o del bajo latín galicano battalia (DCECH, I, p. 541). Frec.: batalla 76: 0,17274; batallas 21: 0,04773 .

batallador adj. y sust. 'batallador': clamabanlo don Alfonso batallador porque en Espayna no ovo tan buen caballero que veynte nueve batallas venció 19.3. [Se trata de un fragmento en el que el ms. B presenta una laguna, que va desde 18.98 a 19.168, y que en la edición crítica de Orcástegui se ha suplido con el texto del ms. N, el que presenta una versión más castellanizada lingüísticamente]. Comp. con batallero. Frec.: 2: 0,00455 .

batallar v. tr. 'combatir': et començó de batallar [travallar N] fuerment los moros,12.43-44. Etim.: deriv. de batalla. Aunque batalla es una palabra habitual en la Crón. SJP. (aparece 97 veces), batallar sólo aparece una vez; se prefiere conbatir. Frec.: 1: 0,00277 .

batallar 38.302 'villano, bellaco'. Es mala escritura por bacallar. Vid. bacallar.

batallero s. m. y adj. 'batallador, guerreador': El primer rey con qui exieron los ditos godos de la dita isla buvo nombre Virig, el qual fue buen batallero 3.7. Deriv. de batalla. Frec.: 5: 0,01136.

batiar] v. tr. 'bautizar': Et tantost lo batió et pusole nombre Sancho García 12.11-12; [babtizari fecit VL]. Etim.: del lat. vg. BAPTIDIARE, variante de BAPTIZARE. Cfr. ALVAR-POTTIER, Morf. hist., \311, p. 399. Vid. también DCECH, I, p. 547: cita baptear en Berceo. En Alex. batear 'bautizar' (cfr. SAS, s. v.). En Fernández de Heredia: batear, batiar, bateyar (GILKIsON, s. v.). En cambio, en otros textos arag. med. se prefiere la forma culta: baptizar en LR, p. 116; babtizar en LMM, p. 157. Comp.: vn manual de batiar en $D L A A$ (doc. no 120, de Panzano, año 1360; p. 176, lín. 29). Frec.: batió 1: 0,00227 .

baurches gentilicio [Bausencis VL]: et tollió XXX castillos a los Baurches que heran sus enemigos 32.49. Frec.: 1: 0,00277.

bautismo s. m. 'bautismo': a la qual deyan por bautismo don Payronella, porque nasció en dia de Sant Peyro 20.256. Del lat. BAPTISMus. Frec.: 1: 0,00277.

beldat (var:: belldat, veldat) s. f. 'belleza': dotado sobre todos los otros reyes en beldat et probeza de cavallería 34.120; assi ninguna belldat ni ningún bien non le fallia 32.8; un su cavallo, el qual de bondad, veldat et de otras virtudes cavallinas todos otros cavallos sobrepuyava 14.37. Etim.: tomado del occ. ant. beldat, deriv. de bel 'bello' < lat. BELLus 'bonito' (DCECH, I, p. 562). Frec.: beldat 1: 0,00227; belldat 1: 0,00227; veldat 1: 0,00227 . 
bello adj. 'bello, hermoso, bonito': et soterraronlo en una muyt bella tomba 9.22 ; si quiere se fues por la grant savieça de su padre el rey don Jayme qui con buenas et bellas maneras la apagó 39.26-27; et fue homme benigno, dulz et piadoso et alegre er proz et fue muyt bello de cuerpo 30.4. Del lat. BELLus ‘bonito’ (DCECH, I, p. 562). Según se observa, la forma regular del adjetivo es masc. bello, fem. bella. // adj. indef. en la construcción un bell 'un, algún, cierto': et fizieron alli un bell castiello 36.355. La forma bell, con apócope de -o final, aparece en situación proclítica, cuando va situado inmediatamente antes del sustantivo masculino. Por otro lado, en la construcción un bell castiello (36.355) encontramos un antecedente del adjetivo indefinido bel, bella 'algún, -a' utilizado en el arag. moderno (cfr. EBA, 1999: 291; NAgore, 1989: 123-124). Borau (1908: 177) ya recogía en su Diccionario: bello, bella 'alguno, alguna' (con la indicación: es voz local), y en la misma entrada indicaba: «En Ordinación de Pedro IV sobre Coronaciones se lee: é allí esté un vel rato mostrándose á sus gentes». En efecto, y en ese mismo texto encontramos otros ejemplos: el arcenispo o el metropolitano con .I. bell trapo de lino limpie los lugares untados (Ceremonial de Consagración de los Reyes de Aragón, 1992, p. 30); e después limpieli los lugares unctados con un vell trapo de lino (Ceremonial de Consagración de los Reyes de Aragón, 1992, p. 48). También hay ejemplos en textos notariales. Así: primerament en la camenya que nos ditos conjuges dormimos, dentro la ciudat de Jacca, yes hun almadrach, vna bella cozna, dos traneseros, bun par de lincuelos, huna liytera, bun sobreleyto... (doc. de Jaca de 1435; DLAA, doc. 140, p. 205). Esta construcción todavía puede registrarse en el aragonés del s. Xx: si una bella vez se viene por aqui, ya sabe la casa (en Orlato, Sierra de Guara; SAROÏHANDY, 2005: 367). Frec.: bello 2: 0,00455; bella 3: 0,00682; bellas 1; 0,00227; bell 1, 0,00227.

benedito adj. 'bendito': «et sin periglio vivo lo saqué, benedito sea Dios» 12.34; Et fue acordado et deliberado que en el nombre de Ihesu Christo et la suya benedita Madre fues a conquerir el regno de Mallorquas 35.125. Semicultismo, del lat. BENEDICTUM (Bustos, Contrib., p. 352). Frec.: benedito 1: 0,00227; benedita 4: 0,00909. [Además, como nombre propio de persona: Benedito 4: 0,00909; Beneditto 1: 0,00227; Benedit 1: 0,00227].

benedizir] v. tr. 'bendecir': «al verdadero Dios vos comando que me clama a la su gloria, benediga [benditho N] vos Dios, el Padre, el Fillo et el Sant Spiritu» 35.278; Et pagado et alegre, Dios lohando et benediziendo [bendeziendo N], el dito rey con su compannya, sin que ninún mal non prisso, tornose a sitiar la dita ciudat de Almaria. 38.368. Del lat. BENEDICERE. Frec.: benediga 1: 0,00227; benediziendo 1: 0,00227

beneficiado] s. m. 'beneficiado, cargo eclesiástico': ordenolos perpetualment seer beneficiados en la iglesia, 20.303. Frec.: beneficiados 2: 0,00455.

benignament adv. 'benignamente, con afabilidad, con benignidad': inclinado benignament a las ditas pregarias 11.26. Frec.: 3: 0,00682. 
benignidat s. f. 'afabilidad, benevolencia': si quiere por la grant benignidat de aquesti rey don Alfonso qui res de lures privilegios nin libertades non les crebantó 39.27. Cultismo tomado del lat. Benignitatem (Bustos, Contrib. p. 353). Frec.: 1: 0,00227.

benigno adj. 'benigno, de buen natural, afable': fue muy bueno et piadoso, ordido et benigno 13.8. Cultismo tomado del lat. BENIGnus. Frec.: 5: 0,01136. [Además, como nombre propio de persona: Benigno 2: 0,00455].

bestia s. f. 'bestia, animal': que tantost que cavallo o otra bestia tocavan, en continent murían 36.599-600. Etim.: semicultismo, tomado del lat. BESTIA 'íd.' (DCECH, I, p. 575). Vid. Bustos (1974: 354), con abundante documentación en textos medievales. Frec.: 1: 0,00227.

bien s. m. 'bien, beneficio': Aquesti rey Sancho Avarca edificó muytos monesterios et iglesias et firo muyto de bien al sancto monesterio de San Johan de la Penna. 12.82; Aquesti conte Berenguer de Barchinona fue homme que non fizo res de bien 28.30. / / adj. 'correcto; bueno, justo': «que fagades dellos la justiçia que tenrredes por bien» 19.88 // adv. de modo: bien et honrradament aparellado, en el dia assignado al dito aparellamoento fue present 12.23; et entrando por el palacio do se celebrava el dito parellamiento, fue bien acollido por el dito general 12.26; et vehet como començavan lures afferes bien que todas quantas yglesias trobavan todas las robavan 36.492. // adv. partícula ponderativa de cantidad 'bien, por lo menos': de los romanos que la sennoriaron bien trezientos annos 2.7. Etim.: del lat. BENE (DCECH, I, p. 582). Frec.: 70: 0,15911.

bienes s. m. pl. 'bienes, riquezas': El estando en sana sanidat en su buen entendimiento renunció a los bienes temporales 31.49. Frec.: 2: 0,00455.

bispe (var.: vispe, vispo) s. m. 'obispo': bispes et prelados, barons et nobles de Cataluenna 29.10; et un dia, con sus ricos ommes e cavalleros e con el bispe de Aragón 11.37. Vid. vispo. Sobre las designaciones de 'obispo' en la Romania y, en general, en las lenguas europeas, puede verse Helmut LÜDTKE, Historia del léxico románico, Madrid, Gredos, 1974, pp. 198-204. Cat. bispe 'prelat de l'Esglesia, cap d'una diòcesi' (DCVB, s.v., t. 2, p. 496). Etim: lat. EPISCOPU. Frec.: bispe 2: 0,00455; bispes 1: 0,00227.

biudo] (var.: viudo) adj. y sust. 'viudo': fue padre de fillos huerfanos, guarda et deffendedor de biudas 35.177; con el quoal avía seydo fablado casamiento con dona Urraca enel tiempo del rey don Alfonso su padre, que no hera viuda [Tunc vidue existentis VL, p. 74] non la quiso dar su padre a este compte. 19.99. Etim.: del lat. viduA y viduUs, de igual significado (DCECH, V, p. 832). Frec.: biudas 2: 0,00455; viuda 1: 0,00227.

bivir v. intr. 'vivir' (var.: vivir): metiendo escusa que parientes heran que no querian vivir en peccado 19.67; Et feytas todas las sobreditas cosas, el dito rey vivie algún tiempo en buena et sancta vida como rey. 20.294; que por res del mundo no consintiesse o diesse el dito cavallo a hombre vivient 14.47; «porque, fillo, te priego que en ti sean aquestas cosas porque Dios sea con ti, el qual fillo bivas perdurablement» 35.260; et el dito rey, queriendo 
mas morir con honor que non bivir con desonor, por tal porque [como $\mathrm{N}]$ ningún tiempo en batalla que fues non giró cara, murió en aquella. 34.146. Del lat. VIVERE (DCECH, V, p. 835). Frec.: bivir 3: 0,00682; bivas 1: 0,00227; bivía 1: 0,00227; bivió 1 : 0,00227 ; vivir $1: 0,00227$; vivía $1: 0,00227$; vivie $1: 0,00227$; vivió 6 : 0,01364 ; viviendo 1: 0,00227 ; vivient $2: 0,00455$.

blanco adj. 'blanco': pareçiole ant'él vestido d'escarlata en un cavallo blanco e una soga en la mano 19.84; vistiosse el ábito de monges blancos de Poblet 35.283. Etim.: del germ. BLANK 'brillante, blanco' (DCECH, I, p. 598). Frec.: blanco 2: 0,00455; blancos 1: 0,00227.

bofordar v. intr. 'jugar a un juego de caballería consistente en arrojar lanzas (bofordos) contra un tablado': et li fues apparellado su cavallo, ensellado et bien honrado de diversos hornamentes, et fues puyado en él por bofordar por la dita ciudat con muytos otros cavalleros 37.90. [vifordar N]. Etim.: Según CoRominAs, el cast. bohordar procede del fr. bohorder 'lanzar bohordos en los juegos de caballería' y 'combatir en torneo', proced. del fráncico *BIHORDAN 'hacer un cercado' y luego 'tomar parte en un torneo' (DCECH, I, p. 613). La -b- aspirada germánica explicaría la -f- en arag. Comp. cast. ant. bohordar 'tirar o arrojar bohordos en los juegos de caballería'; bofordo, ant. bohordo 'lanza arrojadiza usada en los juegos de caballería' (DRAE, $20^{a}$ ed., s. v.; DLE, 2014, s. v.]. Arag. bofort 'juego de caballería...' en los FA de h. 1300 publ. por Tilander, \250.2, 253.1. Bofordo, befordo, biforto, en la versión latina de los mismos (1247) (cfr. Tilander, FA, p. 276). En un Inv. arag. de 1374, bofordar, con el sentido general de 'combatir' (ELIA, s. v., p. 112). No lo encontramos documentado en cat. (ni en el DCVB ni en el DECLIC). Frec.: 1: 0,00227.

bondat (var. bondad) s. f. 'bondad': un su cavallo, el qual de bondad, veldat et de otras virtudes cavallinas todos otros cavallos sobrepuyava 14.37; Et el rey, conosciendo la bondat que avía feito en que su sennyor non perdies la tierra, firole mercé et dixole: «yt emala ora» 36.380. Del lat. Bonitate(M). Frec.: bondat 1: 00,227; bondad 1: 0,00227.

bort adj. 'bastardo, ilegítimo': Et de otra part engendró un fillo bort [nombrado Bort N] nombrado Sancho 16.30. Etim.: según Corominas-Pascual, del cat. bord 'bastardo' y éste del lat. tardío BuRDus 'mulo'. En cast. se documenta en 1464, pero en arag. aparece ya bort en los FA, hacia 1300 (DCECH, I, p. 625). Tilander (FA, pp. 278-279) aporta más documentación de bort y borde en arag. med. En Fernández de Heredia: bort 'bastardo; individuo miserable' (GILKIson, s. v.). Corresponde al actual arag. borde 'bastardo', 'hijo ilegítimo, hospiciano' (Andolz, s. v.; Rohlfs, DDPA, s. v.). PARDo no lo recoge, aunque sí bordizo 'retoño': tampoco lo recogen ni Borao ni Peralta. Comp. cat. bord 'bastard, nascut d'un pare i d'una mare que no están casats', 'nascut de pares desconeguts, expósit' (FABRA, DGLLC, s. v.); occ. bòrd 'bâtard, faux, de 
mauvaise qualité ou de mauvaise race' (ALIBERT, s. v.); occ. gasc. bord 'bâtard' en la región de Burdeos (PALAY, s. v.), aunque Forx (2003) no la registra. Frec.: 1: 0,00227

braço s. m. 'brazo': quel dito rey fues braço et deffendedor de la dita Eglesia 38.179; las manos talladas, con los braços tenía la seynna clamando «Olea, Olea» 19.125. Etim.: del lat. BRACCHIUM. Se advierte la grafía $c$ en lugar de z en situación intervocálica, cosa que también ocurría en cast. medival: «Tenía $\_$sorda en cast. ant. (Nebrija, etc.)"» (DCECH, I, 657). Frec.: braço 2: 0,00455; braços 2: 0,00455 .

breu adj. 'breve, corto': podamos mellor tratar e más verdaderament e breu 2.2. // breus 'pocos': et depués de breus [breves N] de días murió 37.95. Etim.: del lat. BREvIS 'íd.'. Comp. arag. breu 'breve, corto', en Fernández de Heredia (GILkISON, s. v.). Comp. cat. y occ. breu, fr. brief (DCECH, I, p. 662). Frec.: 2: 0,00455.

breument adv. 'brevemente, en resumen, resumidamente': dotado sobre todos los otros reyes en beldat et probeza de cavallería et breument en toda laudor 34.120. // 'de forma breve, de manera rápida': Et breument aquestas cosas ordenadas... 38.86. Comp. arag. breument 'brevemente' en Fernández de Heredia (GILKison, s. v.). Frec.: 2: 0,00455.

brocar v. tr. 'espolear, picar el caballo con las espuelas para que vaya deprisa': et començas a brocar su cavallo grieument 37.91; brotó [errata por brocó]: el dito rey brotó su cavallo, 36.292. [Son numerosos los errores por confusión de $t$ por $c$, o viceversa, ya que en los manuscritos medievales eran letras de forma muy parecida]. Etim.: tanto el $D C V B$ como el DECLIC lo consideran deriv. de broca 'punta, púa, punta de espuela', y éste procedente del lat. BROCCA, fem. de Broccus 'dientes que sobresalen mucho'. Corominas añade que posiblemente sería una voz regional del lat. vg. procedente del celta BROKKOS (irlandés brocc, galés y bretón brocb 'tejón', por su morro prominente). En occ. (prov.) brocar 'piquer, blesser (d'un épieu); 'piquer de l'éperon, éperonner', 'courir, aller à toute bride, s'élancer' (LEVY, s. v.). Cat. ant. 'ferir dels esperons el cavall; cast. espolear' (DCVB, t. 2, s. v.). Comp. en el arag. de Fernández de Heredia brocar, broquar 'espolear, picar el caballo con las espuelas', 'ir deprisa', 'acelerar' (GILKIson, s. v.). Los FA de 1350 dan también testimonio del uso en el arag. del s. XIV tanto de brocar como de broca: de un par de spueras doradas, planas, con broqua... de vn par de spueras doradas francesas de rodeta en que aya VI o VIII broquas...; de spueras argentadas de broquar... (TILANDER, RFE, XXII, p. 23, \26; vid. tb. en el vocabulario; broqua 'punta', broquar 'picar', p. 119). Frec.: brocar 1: 0,00227; brotó [brocó] 1: 0,00227.

bueno adj. 'buen': fue muyt franco varón, bueno et volenteroso 11.3; buen (apócope de bueno ante sust. masc.): El primer rey con qui exieron los ditos godos de la dita isla 
huvo nombre Virig, el qual fue buen batallero. 3.7. Del lat. BONus 'íd.'. Frec.: bueno 14: 0,03182 ; buena 10: 0,02273; buenas 7: 001591; buenos 11: 0,02500; buen 31: 0,07046 .

bulla s.f. 'bula; sello': con privilegio bullado con bulla de plomo 37.17. Cultismo tomado del lat. BULLA 'bola' (DCECH, I, p. 694). Con el mismo significado se registra en Fernández de Heredia (GILKIsOn, s. v.). Frec.: 1: 0,00227.

bullado adj. 'sellado, precintado': con privilegio bullado con bulla de plomo 37.17. Con el mismo significado en Fernández de Heredia (GiLkison, s. v.). Frec.: 1: 0,00227 .

buscage s. m. 'bosque': et dioles un buscage Averico [Avetito VL] do pudiesen fer paxer su ganado 11.40; bustages [errata por buscages]: et dotó de muitas terras, assin bustages [buscages $\mathrm{N}$ ] como otros, de do los monges del dito monasterio pudiessen haver vida. 8.7. Etim.: deriv. de bosque, que procede del germ. Bosk, del mismo significado (DCV B, t. 2, p. 607, que se basa en Wartburg, FEW, I, p. 453). Para Coromines hay que suponer un tipo primitivo *BOSKO-, común al cat. y a las lenguas rom. de Francia y N. de Italia y algunas germánicas occidentales, que sería prelatino y pregermánico, proveniente de alguna lengua indígena de la zona (DECLIC, II, p. 143). En Fernández de Heredia buscage y boscage, así como el primitivo bosch (Gilkison, s. v.). Según Ximénez de Embún, Vocabulario, en la Crón. SJP. significa 'escritura en que se hacía constar la propiedad de un bosque'. Pero por el contexto parece claro que se refiere a 'terreno poblado de árboles' (avetito es 'sitio abundante en abetos'). Comp. cast. boscaje 'bosque de corta extensión' (DRAE, 1970, s. v.; DLE, 2014, s. v.). Comp. cat. boscatge 'bosque' (DCVB, s. v.). Frec.: buscage 1: 0,00227; bustages [buscages] 1: 0,00227.

bustages [buscages $\mathrm{N}$ ] [boscatges VC, p. 35]. Es mala escritura por buscages. Vid. buscage.

cabanna s. f. 'cabaña (de ganado), rebaño grande': grant enoyo et treballo soffrían por los montes qui por él et del comte d'Aragón les eran estados dados, por tal como no podían defender ni contrastar que alguno non poniesse su cabanna de ganado 11.58. Del lat. tardío CAPANNA 'cabaña' (DCECH, I, pp. 708-709). En FA, p. 283: cabanna 'rebaño de ovejas o de otro ganado con perros, tiendas y el apero necesario'; cabaynna, con la misma significación, en VM, III, p. 42. Frec.: 2: 0,00455. 
cabeça s. f. 'cabeza': por tal como havía grant espesseza de cabellos a la cabeça fue clamado Cap de Estopa 30.5. Del lat. CAPITIA, forma del lat. vg. hispánico en lugar del cl. CAPUT (DCECH, I, p. 711). Frec.: 2: 0,00455.

cabello] s. m. 'cabello': por tal como havía grant espesseza de cabellos a la cabeça fue clamado Cap de Esotpa 30.4. Del lat. CAPILLus íd. (DCECH, I, p. 710). Frec.: cabellos 1: 0,00227.

cabo s. m. 'capital'; 'cabeza o ciudad principal de un Estado': e firo cabo de su tierra la ciudad de Toledo, 3.55 [e féu cap de sa terra la ciutat de Toledo VC, p.25] // 'caudillo, jefe, capitán o comandante de una tropa': qui eran mas de mill CCC homes a cavallo et II mill ballesteros, de los quales era cabo Mamfre de Norotico [Manfre de Norocito N; de Noratico B], 38.532-534. Comp. cabo de deyta en DLAA: «Johan de Gonbres, ciudadano Jacce, propuso \& dixo que como el dito Johanes asi como cabo de deyta que fue de ciertos hombres enuiados \& otros de la ciudat en lanyo pasado, enseruicio del senyor rey...» (doc. n ${ }^{\circ} 138$, de Jaca, 1430, $D L A A$, pág. 202, lín. 56). Borao (1908: p. 184, s. v.) registra cabo de guayta 'el encargado de ejecutar las prisiones ó detenciones en nombre de los jurados de Zaragoza: era, por lo visto, el jefe de la guardia municipal ó de los miembros de ese justicia'. // 'extremo, fin, final': Et entrado el dito rey poderosament por la ciudat, prisso el rey moro por la barba en una carrera de la dita ciudat qui non avía cabo [sallida N] et tantost subingó la isla. 35.133-135. // 'parte, lado' en la expr. de su cabo 'por su parte': Asimismo de su cabo los aragoneses tractoron que enviassen por don Remiro el monge 20.66-67. / / a cabo de loc. adv. de tiempo 'al cabo de, al final de, después de': Et a cabo de un tiempo, Golcalvo, fillo del dito emperador... 16.12; A cavo de tiempo e veyendo don Alfonso la mala carrera que la reyna tenía... 19.65. / / de cabo loc. adv. 'otra vez, de nuevo': depués que buvo recebida aquesta muller çaguera, non fizo afferes de cabo [ningunos $\mathrm{N}$ ] ni [buenos ni $\mathrm{N}$ ] cominales porque toda vegada ho quayx estuvo enfermo 39.14-15. Cfr. en el Fuero de Teruel decabo, de cabo loc. adv. 'otra vez, de nuevo'; conj. de transición 'también, además' (Gorosch, FT, p. 492). También en los DLAA: «Et como de cabo aquell dia mismo trobo el dito Gonçalbo, procurador del dito prior, la casa de Domingo Balarin crebantada et abierta» (DLAA, p. 127, doc. $\mathrm{n}^{\circ} 87$, de 1306, del Valle de Sarrablo, p. j. de Boltaña). En FA decabo 'de nuevo' y 'entre tanto, mientras tanto' (TILANDER, FA, p. 341). También en textos castellanos: de cabo 'de nuevo' en la Historia Troyana (TME, p. 406). Comp. com de cabo 'otra vez' en LR (CoOper, LR, p. 119). Etim.: del lat. CAPUt 'cabeza' (DCECH, I, 714). Según Corominas- Pascual, todas las acepciones se explican bien a partir de la latina. La loc. de cabo la explica porque los trabajos deben hacerse empezando por la extremidad de un objeto; en ellos, 'empezar de nuevo' es empezar de cabo. Frec.: cabo 13: 0,02955. 
cabreta dim. de cabra; sobrenombre del conde Olivano de Besalú: fue posado sobrenombre al dito Olivano, Cabreta, como en continent quél favlava sanosament con alguno nin dalguna cosa fues yrado siempre movía el pie en senblança de cabreta qui quier cavar, et por exo la gent lo nombrava Olivano Cabreta. 25.25. También crabeta. Frec.: 1: 0,00227; Cabreta 4: 0,00909.

caça s. f. 'caza': un dia él yendo a caça, un cavallero suyo, clamado Ramón de Gasconna, matólo a gran trayción 16.14-16. Etim.: es postverbal de caçar, procedente del lat. vg. *CAPtiare 'cazar', deriv. de CAPERE 'coger' (DCECH, I, p. 932). Frec.: 1: 0,00227 .

cada adj. distributivo 'cada': segunt que mas largament en vida de cada uno de los dessuso ditos infantes pora adelant recontaremos 38.425. Es frecuente el sintagma cada un, cada una: empero que cada un rey conocies sus tierras assi como don Sancho el Mayor las avía departidas 20.165; fer observar por cada una part 37.82; por cada un lugar do de los franceses estaban muyt grant diffinidat ne matoron 36.513. Frec.: 25: 0,05682.

cadena] s. f. 'cadena': el dito conte de Foyx estuvo preso en el castiello de Siurana con grosas cadenas 36.146. Del lat. CATENA. Frec.: cadenas 2: 0,0455.

cagaria s. m. 'final' // en la expresión adv. a la cagaria 'al final, a lo último': Et non res menos a la cagaria [cagueria $\mathrm{N}$ ] el dito rey don Pedro juroles et confirmoles aquello que justament demandaron et dioles el privilegio general clamado en Aragón que yes fuero 36.677-680. Se registra muy frecuentemente çagueri'a 'postrimería' en textos aljamiados moriscos (GVAM, p. 165). Deriv. de çaguero. Frec.: 1: 0,00227

çaguero] adj. 'último' (ante sust. masc. adopta la forma apocopada çaguer, igual que ocurre hoy en el arag. mod.): aquestos dos hermanos çagueros cambioron lures condados el uno al otro 38.421-422; porque el çaguer rey de los godos fue don Rodrigo 2.11-12 procreó de aquesta çaguera muller dos fillos 39.16. Deriv. de çaga y éste del ár. andalusí sáqa < ár. cl. saqah 'parte trasera de un ejército', 'retaguardia de un ejército' (CORRIENTE, 2003: 472; DCELC, IV, p. 795). Es general en arag. med. tanto çaga como çaguero, e igualmente en arag. mod. (zaga, zaguero). Se registra çaga 'detrás' en VILA, 1990, glosario, s. v., p. 138. Se emplea a çaga 'atrás' en un refrán arag. del s. XIV: «qui adelant non guarda, a çaga caye» (Rius, 1926: 369). En el arag. de Fernández de Heredia: çaguero, çagero, çaguer 'último' (GILKIsON, s.v.). Es frecuentísima esta voz en textos arag. medievales. Véanse algunos ejemplos: «el caguero lunes de abril» (LM: 109). «Ffeyto fue aquesto en el lugar de Pandicosa, caguero dia del mes de deziembre» (DNT, IV, 1428: 74.44). «xxv florjnes que mj padre me ljxo en su çaguera fin» (DNT, V, 1431: 92.27). Con apocope de la -o final: «por tiempo de guerra que passe a otro anyo los xij florjnes el caguer anyo» (DNT, IV, 1427: 35.15). Con colocación del ordinal tras el nombre sustantivo: «se gasto en la semana caguera del mes de agosto» (LM: 59). «Fincan por pagar la media tanda caguera de la paga» 
(LM: 95). Es habitual çaguero 'postrero, último' en textos aljamiados (GVAM, p. 165). Arag. mod. zaguero, zaguer (en posición proclítica ante sust. masc.) 'último' (Andolz, s. v.; Rohlfs, DDPA, s. v.; NAgore, Panticosa, pp. 38 y 102; EBA, 1999: 1883-1885, s. v., etc.). Frec.: çaguera 4: 0,00909; caguera 1: 0,00227; çagueros 2: 0,00455; çaguer 1: 0,00227.

çaguera s. f. 'última línea de combate, última línea de un cuerpo de ejército': sallieron los aragoneses e hordenaron sus azes, la primera dieron al compte don Pedro de Lara con la seyna del regno et en la çaguera, assí como mayor, el compte don Gómez. 19.11419.117. Para la etim. vid. çaguero. Comp. reçaguera 'retaguardia'. Frec.: 4: 0,00909 (incluyendo el adj. femenino).

caladament adv. 'calladamente, sigilosamente, en secreto': et los moros caladament enviaron a don Alfonso rey de Castiella, el que prisso Toledo, que les ayudasse a defender contra el rey de Aragón 17.105. El adv. se construye sobre el adj. femenino calla$d a$, procedente del p. p. del v. callar (vid.), por lo que hay que suponer que la grafía $<1>$ vale por $<1 l>$, fonéticamente $[\lambda]$. Frec.: 1: 0,00227.

calçadament adv. 'fuertemente': que pues a non res quaixi eran venidos francesses et pues que eran en la dessexida de su tierra, entendía calçadament a ferir en los francesses 36.650. [en la VC: entenia a ferir calcadament en los francesos. VC, p. 146]. En el Glossari de la VC se da la equivalencia calcadament 'fortament'. Frec.: 1: 0,00227.

calçar v. tr. 'calzar': Et por aquesto, como vino vestido et calcado como pastor, clamoronlo Sancho Abarca 12.41; tantost firo vestir la dita criatura assin como a pastor et firole calçar abarcas 12.22; et se metía en ygual dellos en todos afferes d'armas et calçava a vegadas avarchas 12.71. Del lat. CALCEARE, deriv. de CALCEUs 'zapato' (DCECH, I, p. 770; LHP, p. 109). Frec.: calçar 1: 0,00227; calçado 1: 0,00227; calçava 2: 0,00455 .

calentura] s. f. 'calor': seyendo en Pamplona por las grandes calentas [calenturas N], 19.210. El pasaje no aparece en la VC. En la VL: dum ipse rex propter inmensos calores Pampilone moram traheret VL, p. 80. En el ms. B debe de faltar la abreviatura de -ur. Frec.: calentas [calenturas] 1: 0,00227.

caler] v. impersonal 'ser necesario, hacer falta'; 'ser muy conveniente': et de otras fembras avies procriados muytos fillos qui por engendrament de dreyta linea no son anotaderos nin cal fer memoria nin mención de aquellos 36.33. Del lat. CALERE 'ser o estar caliente', de donde 'encontrarse en actividad', 'ser urgente' (DCELIC, II, pp. 426-427). Comp. cat. ant. caler (mod. caldre, calguer, caler). Cfr. DCVB, t. 2, pp. 852-853. Occ. caler (Alibert, s. v.). Arag. mod. caler (ANDolz, s. v.; Rohlfs, DDPA, s. v:; EBA, 1999: 401; MonEva, 2004 [1924]: 124), general en el Alto Aragón y usual incluso en zonas del centro de Aragón. Frec.: cal 1: 0,00227. caliz s. m. 'cáliz': que oy en día lo claman el caliz del compte Alperche 19.51. Del lat. CALIX (LHP, p. 107). Frec.: 1: 0,00227. 
callar] v. intr. 'callar': En aquesta isla de Estancia habitaban aquestas naciones: godos, vesegodos, estargodos, davirugis, arcas et tanis. De las quales naciones nos callaremos sino tan solament de los godos porque aquestos fueron los que tollieron Espanya a los romanos 3.3; Et en la ora de su muert sallió el ladrón de su cueva et el rovador se demostró et el pobre se escondió e la clerizia calló 32.69. Etim.: del lat. vg. *CALLARE 'bajar', 'bajar la voz'. Comp. port. calar, cast. y cat. callar, occ. calar (occ. gasc. carà), etc. (DCECH, I, p. 771; CunHA, 1986: 138). Frec.: callaremos 1: 0,00227; calló 1: 0,00227.

calongía s. f. 'canonjía': el dito rey edificó el monesterio de Montaragón et la calongía de Jaca et de Fanlo 17.89-90. Deriv. del occ. ant. canonge 'canónigo' < bajo lat. CANONICUS 'clérigo', 'canónigo'. Comp. en arag. mod. canonche: «U todos monches u todos canonches» (Arnal Cavero, 1953: 248). Comp. calonge en DLAA, doc. $\mathrm{n}^{\mathrm{o}} 28$, junto a canonge en ocho documentos (REIDY FrITZ, 1977: 123). En Fernández de Heredia también se registran canonge y calonge (GILKIsON, s. v.). Frec.: 1: 0,00227.

calor s. f. 'calor': non tenía frio nin calor 36.248; non temian fridores ni calores 12.54 . Del lat. CALOR, -ORIS. Frec.: calor 1: 0,00227; calores 1: 0,00227.

cama] s. f. 'pierna': et tomó [tovo N] la criatura entre sus camas et dixo cuytadament:... 12.27. Etim.: del lat. vg. CAMBA, de origen incierto, seguramente prerromano. Según Coromines no será de origen griego, itálico ni céltico, sino posiblemente sorotáptico, con una base *KANMA adaptada como KANBA por el románico (DECLIC II, p. 444). MEYER-LÜBKE, REW, n 1539, propone una base CAMBA procedente del griego KAMPE (К $\alpha \mu \pi \eta)$ 'curvadura', 'articulación de un miembro’. Rohlfs, Estudios sobre el léxico románico, S 71, pp. 151-153, indica que el térnimo lo tomó el lat. del griego $\kappa \alpha \mu \pi \eta$, pero señala en nota: «Más bien hay que suponer que el grecismo se ha reacuñado bajo el influjo de la raíz celta CAMBO 'curvo' < CAMBA (GAMBA)» (ibídem, p. 152, nota 295). Comp. cat. cama 'pierna' (FABRA, DGLIC, s. v.; DL/C del IEC, 2007: s. v.); occ. camba, cama 'jambe' (Alibert, s. v., quien da como etim. el galo camba). El fr. jambe proviene, según Dauzat-Dubois-MitTerand, p. 400, del bajo lat. GAMBA 'pata de caballo, corvejón', tomado prestado al gr. kampê 'articulación, corvadura', etim. que acepta el PRobert. Sea griego, celta o sorotáptico, lo que se admite unánimemente es un origen común, a partir de una raíz indoeuropea kamer'doblar, curvar' (RoBERTS \& PASTOR, 2007: 74), para el fr. jambe y para cat. cama, occ. camba, occ. (prov. ant.) gambaut 'zancada', camba 'pierna' (LEVY, s. v.), it. gamba 'pierna'. En arag. mod. se usa garra 'pierna', pero comp. arag. mod. camal 'rama gruesa de árbol', camaliga, camilega, camilera 'liga para sujetar las medias', gambada 'paseo', escamalar 'arrancar ramas gruesas', escamallo 'cansancio grande; marcha o caminata precipitada', voces todas ellas deriv. de la misma base etimológica (Andolz, s. v.; EBA, 1999, s. v.). Comp. en romance 
navarro medieval: canbas 'piernas' (Induráin, Contribución, p. 97); camba 'pierna' en FN (Tilander, FN, p. 127). Para el cast. ant. el DME, s. v., p. 594, recoge camas 'piernas' como usual desde el s. XII hasta el s. Xv, con ejemplos de Cid, Alex., Gran Conquista de Ultramar, etc. En Fernández de Heredia: cama, camba, gamba 'pierna' (cfr. GILKISON, s. v.). Frec.: camas 1: 0,00227.

cambiar] v. tr. 'cambiar': aquestos dos hermanos çagueros cambioron lures condados el uno al otro 38.422. Del lat. tardío CAMBiARE 'trocar', de origen céltico (DCECH, I, p. 782). También camiar. Frec.: cambioron 1; 0,00227.

cambra s. f. 'habitación, sala': firo el rey parellar ciertos et secretos hombres en su cambra armados 20.131; por miedo de los arabes, todo hombre tenies [tovies $\mathrm{N}$ ] sus cavallos en las cambras o palacios do lurs mullers estavan 14.31-33. Del lat. CAMERA, vg. CAMARA (DECL/C, II, p. 450). Comp. cat. cambra, occ. cambra, fr. chambre. Es habitual en arag. ant., tanto con el significado de 'sala, habitación, cámara' ( $V M$, III, p. 46; Gilkison, s. v.; etc.), como con el de 'depósito o almacén de grano': «furtaron a el de una cambra que tenia en lalmodi viellyo VI kafizes de trigo grosal» (Ordenanzas de Huesca del año 1349, R. del Arco, RABM, 1913, p. 429); «aduecta la dita çeuera \& treudo en las nuastras canbras, en laçiudat dUesca» (DLA $A$, doc. no 76 , de Santa Cruz de As Serors, año 1300; p. 112, lín. 58); «...que affrontat... \& con cambra de Montaragon que tiene Johan dOla» (DLAA, doc. n ${ }^{\circ} 25$, de Huesca, año 1273; p. 33, lín. 11). Según el ALEANR, mapa no 919, cambra 'cámara entre el cielo raso y el tejado' en Noguera y Arcos de las Salinas (Teruel); según el mapa no 916: cambra 'desván' en La Codoñera, Noguera, Masegoso, Riodeva (Teruel) y Santa Cruz de Moya (Cuenca); según el mapa no 782, cambra 'granero' en Riodeva (Teruel). Cfr. CASTAÑer, 1990: 65, 284 y 309. En el cat. bajoaragonés de La Codoñera: «El tercer pis és per als 'mals endreços' (trastes); hi guarden també la collita; és anomenat la cambra» (QuintanA, 1980: 142). RoHLFs, DDPA, s. v., recoge cambra 'cocina, lugar donde se prepara la comida' en Ansó. ANDOLZ, s. v., cambra 'montepío para préstamos de trigo'; cambreta 'alacena en el hueco de la escalera' en Aragüés; 'pequeña habitación que hay en el desván de las casas y en la que se recogen las herramientas' en Orante (Campo de Jaca). El EBA (1999: 409) registra cambra 'sala de la casa que sirve de almacén' en A Fueba; 'especie de antesala que da acceso a la cocina' en Ansó; 'habitación' en Uncastillo. Frec.: cambra 2: 0,0455; cambras 1: 0,00227.

camiar] (var.: cambiar) v.tr. 'cambiar': aquestos dos hermanos çagueros cambioron lures condados el uno al otro, porque don Pero camió el su condado de Ampurias con el infant don Remón... 38.423. Como se ve, aparecen en dos líneas inmediatamente seguidas formas con - mb- y con - $m$-. Indican Corominas-PAscual que "predomina en castellano arcaico la forma camiar (más raramente camear), hasta 
principios del s. XIV" (DCECH, I, p. 782). En arag. med. alternan cambiar y camiar. Así, por ej., en $D L A A$ es prácticamente exclusivo camiar: «camjamos e por via decamjo permutamos, a saber...» (DLAA, doc. 150, de Coscojuela de Sobrarbe, de 1495; p. 221, lín. 9); pero en el mismo documento encontramos: «et yo dita Betrina sant Pietro camjo e por via de cambio permuto avos dito fray Benet Castel...» (ibídem, p. 221, lín. 12); y para mayor abundamiento: «renunciantes a toda e qualquiere excepción defrau et denganyo e de no hauer cambiado, siquiere permutado, las heredades suso dichas» (ibídem, doc. nº 150, de 1495; p. 222, lín. 27 (ReIdy, 1977: 122). En Fernández de Heredia se registra mayoritariamente cambiar, pero también camear, camiar (GILKISON, s. v.). En arag. mod. KuHN (HAD, p. 70), recoge camio en Echo y en Aineto pero lo general hoy es cambiar. Vid. cambiar. Frec.: camió 1: 0,00227; cambioron 1: 0,009227 .

camino s. m. 'camino': e un día, bien aconpaynado de sus vasallos, romeage faziendo, metiose en camino por visitar el dito santo logar 11.14-16 // camino de San Jayme 'camino de Santiago': Et el término [camino N; iter VL] de San Jayme qui por medio [miedo $\mathrm{N}]$ de los arabes passaba por Alava et por Asturias, mudó el dito Diago et firo passar por Anagera 14.12-14. Del lat. vg. CAmminus 'íd.', de origen céltico (DCECH, I, p. 787). Frec.: 5: 0,01136.

campal adj. 'campal, relativo al campo': et offreciose a entrar en batalla campal contra todo homme quien el contrario tenies 16.9. Deriv. de campo. Frec.: 1: 0,00227.

campana s. f. 'campana': metiendo fama que una campana quería fazer en Huesca que de todo su regno se oyesse 20.126. Del lat. tardío CAMPANA 'íd.', abrev. de VASA CAMPANA 'recipientes de Campania' (DCECH, I, p. 790; SEgura, 2001: 92). Frec.: 1: 0,00227 .

campo s. m. 'campo', en el sentido de 'sitio que se elige para un desafío': et qui al by querra dezir, entre al campo et conocierrigelo [conbatergelo $\mathrm{N}]$ he, 12.36 [E qui als bi vulla dir, entre en el camp e combater-li-ho he VC, p. 46]. Del lat. CAMPus 'llanura', 'terreno extenso fuera de poblado' (DCECH, I, p. 791). Frec.: 12: 0,02728.

canpanal s. m. 'campanario': et la otra sennyera fue possada en el canpanal de la eglesia mayor 38.574. Deriv. del sust. canpana con sufijo -al, que expresa pertenencia o relación con la base sustantiva; en este caso, 'lugar donde se sitúan las campanas' (Pharies, 2002: 57; Colomina, 2017). Comp. arag. mod. campanal 'campanario' (ANDOLZ, s. v.; EBA, 1999: 412, s. v.). Frec.: 1: 0,00227.

cansado] adj. 'cansado': Et los christianos fueron muy cansados 18.50. Del p. p. de cansar, del lat. CAMPSARE (DCECH, I, p. 809). Frec.: cansados 2: 0,00455.

cantano, en la lexía compuesta de tipo parasintético missa cantano 'clérigo que está ordenado de todas órdenes y celebra misa': otros dizen que yera missa cantano 20.86. Frec.: 1: 0,00227. 
cantar] v. tr. 'cantar': humilment et cantando un canto o ymno que comiença "Veni Creator Spiritus etc.» vistiosse el ábito de monges blancos de Poblet que eran all' 35.282. Del lat. CANTARE. Según Roberts \& Pastor (2007: 74), la raíz kan- 'cantar' es común a las lenguas indoeuropeas. Frec.: cantando 1: 0,00227.

canto s. m. 'canto': et cantando un canto o ymno 35.282; et con grandes cantos et melodias divinales 9.19. Etim.: del lat. CANTUS 'canto, canción, melodía, poesía' (BLÁNQUEZ, s. v., p. 283). Frec.: canto 1: 0,00227; cantos 1: 0,00227.

capdiello s. m. 'caudillo': et avían por capdiello [capdillo N] un moro clamado Alacrant 36.62. Etim.: lat. CApitellum 'cabecilla' (SEgura, 2001, s. v.). Vemos que se conserva la sorda - $p$ - aun después de perderse la vocal protónica. En cast. cabdiello, cabdillo antes del siglo XIV, luego caudillo (BDELC, p. 140). En el arag. de Fernández de Heredia capdiello y caudillo (GILKISON). La forma más propia del arag. sería capitiello, que podemos observar en el top. Os Capitiellos, al suroeste de Sabiñanigo, entre la Bal Ancha y la Bal Estrecha. Frec.: 2: 0,00455.

capellan] s. m. 'capellán, eclesiástico, sacerdote': Pero recibió et tornó al abito de San Benedito a la muert en el qual era professo en el monesterio de San Ponz de Tomeras, et los sus capellanes ordenolos perpetualment seer beneficiados en la iglesia de San Pedro de Huesca 20.303. Etim.: del bajo lat. CAPpELLANus, pero, según DCECH (I, p. 833), probablemente a través del occ. ant. capelan con -ll-por influjo de capilla. Frec.: capellanes 1: 0,00227.

capilla s. f. 'capilla': et fue enterrado en la dita iglesia de San Pedro, en la capilla de San Bartholomeu 20.307. Etim.: del lat. tardío CAPpĚLLA (DCECH, I, p. 833). Se trata de una forma castellanizada fonéticamente: ya que hay una Ĕ breve tónica se esperaría una forma capiella, en consonancia con la forma capdiello. Frec.: 1: 0,00227 .

capitán s. m. 'capitán': Rodrigo Vižcarra, cavallero et capitán del regno de Murcia 36.384385. Tomado del bajo lat. capitanus 'jefe' (DCECH, I, p. 834), de la misma raíz que CAPUT 'cabeza'. Frec.: 1: 0,00227.

capitol s. m. 'capítulo o división de un libro': assín como en el mas çerca precedient capitol [monesterio N] yes mas largament contenido. 16.11. // 'cabildo': aduzieron el cuerpo del infant don Pedro et soterraronlo en el capitol de los freyres menores de Caragoça 38.205-206. // pl. 'capítulos de paz', 'estipulaciones', 'cada uno de los artículos de que consta un acuerdo de paz': por tal como él hi avía a firmar et a conferir [et consentir $\mathrm{N}$ ]; los quales capitoles vistos et reconoscidos, el dito rey don Jayme sus solempnes mesageros envió al Padre Santo 38.77. Etim.: del bajo lat. CAPITULum 'reunión de monjes o canónigos'. El significado de 'división o capítulo de un libro' lo tomó de la idea de cabecera ('adorno que encabezaba un capítulo'), y de ahí pasó a 'lectura que se hacía durante el oficio divino', y luego 'reunión de los monjes destinada a una de estas lecturas', de donde, finalmente, 'cual- 
quier reunión monacal' (DCECH, I, p. 713). Comp. cat. capitol 1) 'cadascuna de les parts, de tema determinat, en què es divideix un escrit. Especialment: a) cadascuna de les ordenacions que es feien en cort o dictades per l'autoritat. b) pl. l'articulat d'una estipulació, i la mateixa escriptura on consta aquesta estipulació. Capitols matrimonials 'els pactes que es fan en escriptura pública en tractarse de fer un casament'; cast. capitulo (DCVB, s. v., t. II, p. 975). 2) 'Assemblea de canonges, religiosos, confrares o altres persones reunides en comunitat, per deliberar i pendre acords pertinents als interessos d'aquesta'; 'Lloc on es reuneix la dita asamblea'; 'Comunitat de canonges d'una catedral o col.legiata; cast. cabildo (ibídem). Frec.: capitol 2: 0,00455; capitoles 6: 0,01364 .

caplevar v. tr. 'entregar una fianza para liberar a un preso'; 'liberar bajo fianza': dexó el dito conte a Barchinona et depués lo dio a caplevar que dentro en XXX días él avies a tornar en poder suyo 36.451-452. Según COROMINAS-PASCUAL (DCECH, I, 714) es voz aragonesa deriv. del cat. capllevar, y éste de llevar 'sacar', con el prefijo cap-; así que propiamente cat. capllevar era 'sacar a alguien (de aprieto)'. No lo recoge el $D R A E$ ni el $D L E$. Sí recogen ambos, en cambio, cablieva como ant. con el significado de 'fianza de saneamiento'. El DRAE (1970, s. v.) lo hace proceder del bajo latín CAPLEVARE 'fiar', mientras que el DLE (2014) dice que deriva del arag. cablevar 'entregar una prenda'. Se documenta capleuar y cableuar en FA, explicado como 'entregar en depósito (una prenda) a la fianza, al deudor o a otra persona' (TiLANDER, p. 287). Cat. capllevar 'donar caplleuta per alliberar (algú) d'ésser tingut pres' (FABRA, DGLIC, s. v.; DL/C del IEC, 2007, s. v.). Frec.: 1: 0,00227.

cappellina s. f. 'capacete, pieza de la armadura que cubría la cabeza': et el dito Exemen d'Artieda a los que puyavan quando als no les podía tirar, les tiró la cappellina et todas las armas que tenía 36.344. El Dicc. de Aut., s. v., recoge capellina «la armadura de acero, que cubría antiguamente la parte superior de la cabeza y lo mismo que Yelmo o Capacete. Su etimología parece venir del lat. CAPUT». Y añade: «Se llama también la cubierta que se ponen los rústicos en la cabeza a modo de capucho, para defenderse del agua y del frío» (Ibídem). El cast. capellina sería derivado del lat. * CAPPELLA, que a su vez deriva de CAPPA 'capa', según el DRAE (1970, s. v.), si bien el DLE (2014, s. v.) apunta que es deriv. del lat. vulgar CAPPELLus 'vestidura de la cabeza'. CoROMINAS (BDELC, p. 129) lo deriva de capillo 'capacete de la armadura', del lat. vg. CAPpellus 'vestidura de la cabeza', deriv. dim. de CAPPA 'capa'. Y lo mismo en DCECH (I, 833), donde documenta capellina por vez primera en Fernán González, 1250-71. En cat. capellina 'peça de l'armadura antiga que cobria la part superior del cap' (FABRA, s. v.). El DCVB (tomo 2, p. 967 s. v.) lo deriva de capell < CAPELLU y recoge dos acepciones en cat.: 'peça de l'armadura, de ferro, de malla o de roba 
gruixada, que s'adaptava al cap del guerrer i servia per guardar-lo de cops', cast. capellina', y 'peça de vestit que cobreix el cap i les galtes', cast. rostrillo, capellina. Según COROMINEs hay conexión entre capellina y capell 'sombrero' < CAPPELLU, y ambas se relacionan con cat. capa $<$ lat. tardío CAPPA, de origen incierto (DECLIC, s. v. capa, t. II, p. 525-531). Comp. occ. (lang.) capelina 'capeline' (cast. 'capellina'), 'béguin' ('capillo de niño', 'toca religiosa') (AliberT, p. 204b, s. v. capè̇); occ. (prov.) capelina 'capeline, sorte de casque' ('casco') y capel 'chapeau, chapeau de fer, heaume' ('yelmo') (LevY, s. v.); fr. capeline, s. XIV 'armure de tête' (Petit Robert, s. v.); it. cappellina, de cappello 'chapeau'. El cast. capacete procede del fr. cabasset (DLE, 2014). Arag. med. capellina 'pieza de la armadura que cubría la parte superior de la cabeza' en Fueros de 1350 (TILANDER, 1935: 121). Con el mismo significado en Invent. arag. de 1331 y 1374 (PotTier, ELIA, p. 123, s. v.). Comp. arag. mod. capellera 'parte anterior y más elevada de la albarda', capilada 'íd.' (Alvar, 1948: 195, en varios pueblos del Campo de Jaca); capellada 'parte superior de la albarda' en los valles de Echo, Aragüés y Aísa, y capellera 'gavilla que cubre el conjunto de haces de trigo en forma de almiar' en el valle de Chistau (EBA, 1999: 429); capilera 'cada una de las tejas de pizarra (losas) que alternan, de una y otra vertiente del tejado, en el caballete' en el valle de Bielsa (EBA, 1999: 430). En el arag. de Fernández de Heredia capellina 'headpiece of armor' (= 'pieza de la cabeza de la armadura') (GILKISON). Frec.: 1: 0,00227.

captivar] (var.: cativar) v. tr. 'capturar': captivaron ne IIII", e todo lo que avian les tolló e les prendió 33.87-88; et los christianos matando et cativando sin merçé 4.31. Del lat. tardío CAPTIVARE (DCECH, I, p. 929). Frec.: captivaron 1: 0,00227; cativando 1: 0,00227.

capturado p. p. del v. capturar, 'capturado, aprehendido, apresado': de manera que no y fincó ningún moro que no fues muerto o capturado 19.41. Etim.: Es un cultismo, derivado del lat. CAPTURA 'captura, acción de coger'. El BDELC da la $1^{\text {a }}$ doc. de capturar en 1626. La de la Crón. SJP. la adelanta en dos siglos y medio (aparece en un fragmento sólo conservado en el ms. N, que es del s. XvI; en cualquier caso, aun cuando consideráramos que es propio del copista del xvi y no de la redacción aragonesa original del s. XIV, es anterior a la documentación dada por Corominas). Vid. también DCECH, I, p. 837, s. v. captar. Comp. captivar. Frec.: capturado 1: 0,00227.

cara s. f. 'cara'. En la expresión: non giró cara 34.148 'no se echó para atrás, no retrocedió no se acobardó, no dio la espalda': por tal porque ningún tiempo en batalla que fues non giró cara, murió en aquella. 34.148. Voz de origen incierto, quizá prerromano, o bien del griego arcaico KarA 'cabeza' (DCECH, I, p. 839). MEYER-LÜBKE, REW, no 1670, da como segura la etim. griega. Frec.: 1: 0,00227. 
carament adv. 'encarecidamente; con gran insistencia': Et oyda su missa devotament, pregó carament los ditos abad et clerezía del dito monasterio que lures oraciones et buenas obras lo deviessen haver por recomendado 11.43-45. Comp. cat. carament con el mismo significado (DCVB, t. 2, p. 1014). Adv. formado sobre cara, fem. del adj. caro 'caro, de gran precio' < lat. CaRus. Frec.: 2: 0,00455.

carboncle] s. m. pl. 'nombre de una piedra preciosa, quizá una variedad de granate rojo oscuro con un brillo muy vivo, quizá rubí': safires, robices et carboneles et otras piedras preciosas. 28.22. [En la ed. crítica carboneles, pero en el ms. B se ve claramente carboncles]. Etim.: del lat. CARBunculus 'carboncillo', 'rubí'; dimin. de CARBO, -ONIS 'carbón' (DCECH, I, p. 857; PRobert, p. 686, s. v. escarboucle; DCVB, t. 2, p. 1020; DECLIC, II, p. 563, s. v. carbô). En cat. carboncle 'robí' (FABRA, DGLIC, s. v.), que también se registra en las formas antiguas carbonclo, carblonco, carvoncle, carbuncle (DCVB, DECLIC). El DCVB define el término como 'piedra preciosa vermella, a la qual els antics atribuien suficient lluentor per a brillar en la nit com una brasa'. En fr. ant. carbuncle, escarbuncle, fr. mod. escarboucle (PRobert, p. 686, que lo define como 'nom donné autrefois à une varieté de grenat rouge foncé d'un vif 'eclat'). En occ. carboncle 'escarboucle' (AliberT, s. v.; Levy, s. v.). En cast. se registra carbunco, carbunclo y carbúnculo con el significado de 'rubí' (DRAE, 1970, s. v.). COROMINAS-PASCUAL registran como variantes antiguas en cast. carboncla (Cid), carbunclo, carbúncol, carbúnculo, carbonclo, carbóncol, carbunco (DCECH, I, p. 857). Covarruvias, Tesoro, s. v. carbón, dice: «...y assí se dixo carbunco, latine carbunculus, graece $\alpha v \theta \rho \alpha \kappa ı$, una piedra preciosa que tomó nombre del carbón encendido, por tener color de fuego y echar de sí llamas y resplandor, que sin otra alguna luz se puede con ella leer de noche». El pasaje de la Crón. SJP. no da pie para considerar carboncle como sinónimo de 'rubí', puesto que dice: robices et carboncles. En arag. med. se registra carboncles en Fernández de Heredia, con el significado de 'carbunclo' (GiLkison, s. v.); escarboncle, escarbunclas y carbuncla 'rubí' en $L M M$, pp. 159 y 170. En el $L T$, carbunclo, carbonclo 'bariedá de granate royo fusco de brilo bibo' (VIDALLER, 2020: 84). No se registra en LCMA ni en ELIA. Frec.: 1: 0.00227.

carboneles, lectura de la ed. crítica por carboncles. Vid. carboncle.

carçel s. f. 'cárcel': estuvo preso por mandamiento de su padre en carcel, en la qual murió sin fillos 34.19. Etim.: del lat. CARCER, -ERIS (DCECH, I, p. 862). Frec.: 1: 0,00227 .

cardenal s. m. 'cardenal': fue Nuch [Enut N] cardenal et legado de Roma 29.9; con todos los cardenales et ciudadanos de Roma 38.173. Es, según el BDELC, descendiente semiculto del lat. cardinalis 'cardinal, principal'. Frec.: cardenal 14: 0,03182; cardenales 5: 011136. 
cárdeno] adj. 'de color amoratado': et eran de tal natura que de la una part eran cárdenas et de la otra verdes 36.598. Etim.: del lat. tardío CARDINus 'azulado', deriv. de CARDus 'cardo', por el color de las flores de esta planta (BDELC, p. 132; DCECH, I 865). Se registra cardeno 'cárdeno, de color amoratado' como general en los aranceles de peajes y libros de collidas del s. XV en Aragón (LCMA, p. 140, s. v.). Frec.: cárdenas 1: 0,00227.

carestia s. f. 'carencia, escasez': tornose en su tierra, en la quoal él avía grant carestia e las gentes murian de fanbre 33.113. Del bajo lat. CARISTIA 'escasez de víveres' de origen incierto, probablemente sin relación etimológica con caro (BDELC, p. 133). Anota el DCECH (I, p. 868) que esta voz se registra en docs. arag. de 1365, 1376. Proceden de la misma etimología: it. carestía, occ. carestía, cat. carestía, port. carestía. Las formas gasconas son carèsti, carèstie (PALAY, 1974, p. 204, s. v.), cariste (Forx, 2003: 148). Comp. occ. ant. carestia (LeVY, s. v.). Es forma documentada en la mayoría de las obras atribuidas a Fernández de Heredia (GILKIsON, s. v. carestia). Comp. freytura. Frec.: 1: 0,00227.

carga] s. f. 'medida de peso': et aduría diez cargas de maças de Gascunna 18.29. La carga aragonesa equivalía a tres quintales, es decir, aproximadamente 151,5 kg (cfr. GLA, p. 112). Frec.: cargas 1: 0,00227.

caridat s. f. 'caridad': et ayas amor et caridat a las tus gentes 35.257-258. Tomado del lat. caritas, -atis 'amor, cariño' (BDELC, s. v.). Frec.: 2: 0,00455.

carnal adj. 'carnal': et a honor et a reverencia de Dios et de los sanctos que aquí iazían, renunciaron a los deleites carnales et mundanales 9.34. // carnal copula 'unión sexual': Onde como la dita reyna en días et annos de hedat non fues, carnal copula non fue seguida entre los ditos rey et reyna 38.56; Frec.: carnal 2: 0,00455; carnales 1: 0,00227 .

carnalment adv. 'carnalmente': que ningún homme millor non la podría dar por muller que ad aquél qui la havía conocido carnalment 23.18. Frec.: 1: 0,00227.

carne s. f. 'carne': pero quando contó la manera que havía visto, pensó en si mesmo quel buerto podia seer el su regno, las colles yeran las gentes del su regno, et dixo: «Por fer buenas colles, carne y a menester» 20.123. Del lat. CARO, CARNIS, acus. CARNE(M). Frec.: 1: 0,00227 .

caro adj. 'querido': Et rogó al su caro amigo esti don Pero rey d'Aragón que le fues ad ayudar 34.77. Del lat. CARUs. Frec.: 1: 0,00227.

carrera s. f. 'calle, camino': prisso el rey moro por la barba en una carrera de la cita ciudat 35.134; ; entro a la cindat et por las carreras de la do home yva sobre trapos d'oro et de seda 36.220. // 'curso, marcha, camino que sigue uno en sus acciones': e veyendo don Alfonso la mala carrera que la reina tenía... 19.66. // a la carrera loc. advl. 'con la máxima ligereza, rápidamente': como mellor e mas onrradament pudo, con todos sus clérigos procession faziendo, ixiol a la carrera 11.18; ribó al puerto de 
Roma al qual yxió [sallió $\mathrm{N}$ ] a la carrera el rey Carlos con todos los cardenals 38.173. Del lat. vg. *CARRARia, abrev. de via CaRraria 'camino para carros', deriv. del lat. CARrus, de origen galo (DCECH, I, p. 896). Frec.: carrera 5: 0,01136; carreras 1: 0,00227 .

carta s. f. 'documento', 'escritura notarial, de un decreto real, de un pacto o acuerdo diplomático, etc.'. En el sintagma carta pública 'escritura o documento público; documento notarial': Et de aquesto el dito rey requirió seer feita carta pública 36.291; requiriendo al notario que allí era que de aquellas et del comparecimiento suyo et de la fadiga et contumacia del dito rey Carlos le devies fer carta o cartas públicas a memoria perdurable. 36.298-300. También se emplea la voz sin el adj. pública: Et fizieron cartas entramos los reyes et los regnos de Castiella et de Navarra, et cada uno prendie sus cartas muyt bien firmadas et seguradas. 19.186-188; et el dito rey dixo quel su dreito avia renunciado et non de los nobles et cavalleros; et fizieron sus cartas et protestaciones. 34.46-47; et envió por toda Navarra et Aragón cartas que todos sus vassallos viniessen a Fraga 19.213. Etim.: del lat. CHARTA 'papel, escrito' (BDELC, p. 136). La voz es muy frecuente en textos notariales y jurídicos, y pueden encontrarse diferentes tipos o variedades según las figuras jurídicas de las que tratan o dan fe, tal como señala LAGÜEns (1992: 75). Para el concepto actual de 'carta' se emplea letra (vid.). Frec.: carta 2: 0,00455; cartas 6: 0,01364.

casa (var.: cassa) s. f. 'casa': passó desta vida en la casa de los pobres de Barçalona 31.54. // casa de Aragón 'linaje o familia real'; 'dinastía familiar de los reyes y sus herederos': que por tal que la tierra sobredita non se perdies que fue livrada al emperador, el qual yera muy poderoso et la podia bien defender et sennoriar, et fuele con homenage livrada a vida suya solament et depués dias suyas [sic] tornás a la casa de Aragón et fue feito assí. 20.246-250; et que depués sus días, dando el rey d'Aragón casamiento su filla, quel condado de Tolosa fincas en la cassa de Aragón. 34.154. Etim.: Del lat. CASA 'choza, cabaña'. Frec.: casa 9: 0,02046; cassa 1: 0,00227.

casamiento (var.: cassamiento) s. m. 'casamiento': et affilló et heredó al dito Remiro, su fillastro, en Aragón, el qual era de la reyna por razón de su casamiento obligado en arras. 14.92-93; El cassamiento de la reyna dona Blanca, filla del dito rey Carlos, fue celebrada [sic] entre el dito rey don Jayme et la dita rena dona Blanca 38.66. Deriv. postverbal del v. casar, con sufijo -miento, que expresa resultado de la acción significada por la base. Frec.: casamiento 14: 0,03182; cassamiento 1: 0,00227 .

casar (var.: cassar) v. intr. 'casar, contraer matrimonio': et porque el compte don Pedro yva ya escuvriendo la su mala obra con la reyna cuydando casar con ella 19.157-158; et la otra Teresa et casóla con el conte de Prohença, clamado Guillem Bertran.16.28; et diolo en casamiento a su filla Violant que cassó con fillo del rey de Castiella 35.165-166. Etim.: deriv. antiguo de casa, con derivación directa (BDELC, s. v.). Frec.: casar 2: 0,00455; casó 6: 0,01364; casola 4: 0,00909; cassó 1: 0,00227. 
caso s. m. 'caso': et que por caso ninguno no podies allenar el regno de Aragón en personas algunas sino en los fillos 20.260. Tomado del lat. CASus 'caída, caso fortuito, accidente’. La $1^{\text {a }}$ documentación que da el DCECH, I, p. 909, es de principios del s. xv en Santillana. Frec.: 3: 0,00682.

castell s. m. 'castillo': Et depués de aquesto, vino sitiar castell de Callar 38.541. Esta forma es fonéticamente catalana: se explica por el hecho de que, en realidad, se trata de un topónimo, Cagliari, la actual capital de la isla de Cerdeña (vid. Nagore, 2003: 329), denominada en catalán Castell de Callar y en sardo Casteddu< castellu. Vid. castiell, castiello. Frec. 3: 0,00682.

castellano] adj. gent. y s.: et Dios que no falle a la verdad ni fallirá fueron vencidos los castellanos y el rey de Castiella con grant verguença en un cavallo fuyó muy afincadament con pocos de los suyos. 17.36-37. Frec.: 7: 0,01591.

castiell s. m. 'castillo': entroron en castiell de Callar con los enemigos 38.553. Se trata de una forma de compromiso entre la forma fonéticamente catalana, castell, y la forma fonéticamente aragonesa, castiello. Vid. castiello. Frec.: 1: 0,00227.

castiello (var.: castillo, castell, castiell) s. m. 'castillo': En el anno de Nuestro Sennor de MLXXx priso el castiello de Corvino [Monclus N] 17.68; mientre que todo homme dormía et non se talayavan de res, todo el poder del dito castiello de Callar vino a ferir en la buest del dito don Alfonso. 38.544; el qual firo fer un castillo qui ha nombre Atharres [Atares N] 8.2. Del lat. CASTELLU(M). Se registra en la forma propiamente aragonesa (con diptongación) castiello(s) 66 veces; en la forma castellanizada (sin diptongación) castillo(s) 14 veces (todas menos una en el ms. N); castiell una vez y castell tres veces. Vid. castell, castiell. Frec.: castiello 53: 0,12047; castiellos 13: 0,02955; castillo 10: 0,02273; castillos 4: 0,00909.

catalán adj. gentilicio 'de Cataluña': «O cavalleros jet non vos yes verguença que delant vosotros aquesti cavallero catalán aya desmentido a mi et de vosotros ninguno non le aya respondido» 38.328. Frec.: 1: 0,00227.

catar] v. tr. 'observar, guardar, respetar una ley', 'atender, tener en cuenta': Et ellos como quiere que la tuviesen por el enperador don Alfonso de Aragón, pero catando dreyto de naturaleza todos comunment la rendieron a la dita reyna. 19.80; En aquesti tiempo, por razón quel dito rey don Pedro non catava [servava $\mathrm{N}$ ] privilegios, libertades et fueros a los de Aragón... 36.669. / / v. prnl. 'darse cuenta, caer en la cuenta': Et don Per Ateres quando se cató, fincó engannado [envergoynido N] por su locura et relación de malos porteros. 20.41. Etim.: del lat. CAPTARE 'tratar de coger', frecuentativo de CAPERE 'coger'. La primera documentación es de h. 950, en las Glosas Emilianenses, glosa 65: «Adtendat [katet] unusquisque [quiscataqui] ne munera accipiendo alterius causam malam faciat suam penam si jnjuste judicauerit." (LHP, p. 130; Origen aragonés de la Glosas Emilianenses, p. 103). Según indica el $D C E C H$, ya en lat. era frecuente emplear el vocablo en el sentido de 'tratar de percibir por los sentidos', especialmente el oído o la vista; desde Apuleyo 
aparece muchas veces en el sentido 'tratar de ver'. San Isidoro de Sevilla (Etym. XII, ii.38), empleando la forma ya romance dice que significa 'ver'. De la idea de 'tratar de ver' vienen las acepciones más usuales en la Edad Media: 'mirar, ver', 'observar, atender, examinar'; de ahí la acepción más común 'probar, gustar', y 'guardar', que es por lo común aragonesa (FA, tilander, 196.3; Fuero de la Novenera, p. 587; Poema de Yúcuf A, 12d, 13d; Fuero de Navarra...); en sardo logudorés accatare 'darse cuenta', quizá sea castellanismo (o aragonesismo) (DCECH, I, 920-921). Comp. catar 'ver, mirar', 'observar', 'examinar, indagar', 'considerar', 'preservar, guardar', 'guardarse, precaverse' en VM (Tilander, VM, III, p. 50); catar 'prender, capturar, captar', 'tener cuidado de', en Fernández de Heredia (GILKison, s. v.); catarán 'verán', caten 'vean, miren', catándose 'mirándose, informándose' en Ordinaciones de Barbastro (VÁzquez Obrador, 2011c: 33). En arag. mod. catar 'mirar', 'observar, darse cuenta de algo' se usa mucho en el valle de Tena y en otras zonas del Alto Aragón (Cfr. Nagore, Orós, pp. 344 y 358). El EBA (1999: 462) registra catar 'mirar' en Plana de Uesca, Orós Alto, Bal de Broto, Luesia y Uncastillo. Frec.: catando 1: 0,00227; catava 1: 0,00227 ; cató 1: 0,00227 .

catedral s. f. 'catedral': según yes contenido en privilegio que yes en la yglesia catedral de Lerida 20.74. Etim.: deriv. del cultismo cátedra, tomado del lat. cathědra, en el sentido de 'trono del obispo'. Frec.: 1: 0,00227.

cativerio s. m. 'cautiverio': porque la tierra se plorava et senglores [songlotes B] de grenges sospiros gitavan a Dios et al dito rey don Pedro que del grieu cativerio et oprissión a qui era baldonada, la devies preservar et delibrar 36.196-197. Deriv. de cativo. Frec.: 1: 0,00227 .

cativo] adj. y s. 'cautivo, preso, prisionero': entre cativos et muertos ningún christiano non pudo escapar 4.36; do murieron muytos moros et entre muertos et cativos ninguno non de escapó 35.132. Especialmente adecuado al contexto de 4.36 es el significado que todavía recoge el DRAE (1970) para cautivo 'aprisionado en la guerra. Aplícase más particularmente a los cristianos hechos prisioneros por los infieles'. Pero, como se ve en 35.132, también son cativos los moros hechos prisioneros por los cristianos. Etim.: tomado del lat. CAPTIVus 'cautivo, preso', deriv. de CAPERE 'coger' (DCECH, I, 929). La forma cativo se usó en cast. hasta el s. XVI. Frec.: cativos 2: 0,00455.

catolico (var.: catholico) adj. 'católico': Et depués de la muert de aquesti regnó el rey Bamba, el qual fue muy catholico rey et virtuoso 3.71; por los quales non tan solament ala dito regno en antes encara toda Espannya se cuydó seer exposada a grandes periglos et encara toda la fe catolica. 36.66. Frec.: catolico 3: 0,00682; catolica 1: 0,00227; catholico 2: 0,00455; catholica 2: 0,00455. 
cautela s. f. 'actuación precavida y taimada', 'cautela, precaución', en la loc. adv. a cautela 'taimadamente, astutamente, con espíritu de engaño': et dixose que a cautela el condado de Ampurias obedió al rey de Francia 36.510-511. [Diu-se emperò que a cautela lo comtat d'Empúries obei al rei de França VC, p. 142]. En el Glossari de la VC, p. 187, dice: cautela (a), 'amb esperit d'engany'; cat. cautela 'prudencia davant un perill probable' (FABRA, DGLIC, s. v.; DLlC del IEC, 2007, s. v.). Etim.: del lat. CAUTELA íd. (BDELC, p. 141, s. v. cauto; Corominas da la 1. documentación en cast. en 1438 en el Corbacho. La Crón. SJP. la adelanta en algo más de 60 años. Vid. también DCECH, I, p. 929, s. v. cauto. Frec.: 1: 0,00227.

cavalgada s. f. 'cabalgada, incursión de tropa a caballo en tierras del enemigo': quando havía d'entrar en batalla o havía afer cavalgada o qualesque otros afferes periglosos quel avies afer con los moros toda vegada tiemblava 13.3; los moros de Tudela fazían a los de la huest todos días que adurían viandas por Ebro ayuso e de Castilla por tierra, grandes daynos e muytas cavalgadas 19.28-30. Deriv. de cavalgar. Frec.: cavalgada 1: 0,00227; cavalgadas 1: 0,00227.

cavalgar] v. intr. 'acción de cabalgar montado sobre el caballo', 'montar a caballo; andar a caballo': vio flaco lugar en el muro forano et cavalgado sobre su cavallo con la mano dreita designando con el dedo dixo: 〈por aqui se puede entrar Huescca»17.118; con su tercero cavalgando cuytadament vino al dito lugar, es assaber en Bordeu, do se devian fer las ditas batallas 36.275. Del lat. vg. CABALLICARE (DCECH, I, p. 708). Frec.: cavalgado 1: 0,00227; cavalgando 2: 0,00455.

cavalleria s. f. 'cavallería', en el sentido de 'acción o empresa propia de un caballero', 'servicio de armas a caballo': et dupdavan que don Remiro el monge non lo sabies deffender como aquell que no yera seydo usado en armas ni en actos de cavalleria, la qual yes muyt necessaria para rey et princep que regnas 20.52; Empero en el tiempo de su fillo don Alfonso el que primero se intitulo rey de Aragón conte de Barchinona, noble persona en todos actos de cavalleria, cobró la dita tierra de Aragón 20.315. Frec.: 11: 0,02500.

cavallero s. m. 'caballero': çercando a qui esleyrian por sennor lur et defendedor, no trobavan [non trovaron $\mathrm{N}]$ más valient ni mas avençado cavallero como el noble varón, natural del condado de Vigorra, clamado Ennego 10.6-7; porque en antes todos los reyes se posavan en lur taula con cavalleros et havian [yvan $\mathrm{N}$ ] ansi vestidos como cavalleros 3.50-52; si fuera esto esdevenido a cavaleros del rey de Aragón, certas non 38.330. Del lat. tardío CABALLARIUS (DCECH, I, p. 708). Frec.: cavallero 45: 0,10228; cavalleros 61: 0,13865; cavaleros 1: 0,00227.

cavallino] adj. 'relativo al caballo, propio del caballo': el dito emperador se comandó [si comendó $\mathrm{N}$ ] a su muller tenedor et conservador [tenedera e conservadera $\mathrm{N}$ ] por ella en el castiello de Nágera un su cavallo, el qual de bondad, veldat et de otras virtudes cavallinas [e cavallerias $\mathrm{N}$ ] todos otros cavallos sobrepuyana 14.38. Del lat. CABALLINus 'de caballo' (BLÁNQUEZ, s. v.). Frec.: cavallinas 1: 0,00227. 
cavallo s. m. 'caballo': mandó que en continent fues con gran poder de hombres a cavallo $i$ de pie enta las partes d'Aragón 4.28; con XX galeras que eran armadas en las marinas por levar cavallos et cavalleros et homes de pie et aparamientos de combatir 38.504. Etim.: del lat. CABALLUS 'caballo malo, castrado, o de trabajo', palabra de origen extranjero en lat., quizá céltico, quizá oriental (DCECH, I, p. 708). Frec.: cavallo 68: 0,15456; cavallos 4: 0,00909.

cavar v. tr. 'cavar': como en continet quél favlava sanosament con alguno nin dalguna cosa fues yrado movía el pie en semblança de cabreta qui quier cavar 25.26. Etim.: del lat. CAVARE 'ahuecar', 'cavar', deriv. de CAvus 'hueco' (DCECH, I, 929). Frec.: 1: 0,00227.

cayer] v. intr. 'caer': Tornose a sitiar la dita ciudad, la qual, sabiendo la victoria de los moros cayda en desperación, trista et dolenta, depués de ocho dias rendiose sueltament al dito rey don Pedro 18.74; assí como va el agua de Sarasaz et caye en el rio de Yda et parte Navarra et Aragón et se justa un Arga et caye en Ebro 20.278-279; Bernart Trenchaforte conte de Bisuldu, passando el rio del Royne, por gran desaventura cayó en el agua et murió 28.4. Del lat. CADERE 'íd.' (DCECH, I, p. 734). Frec.: caye 2: 0,00455; cayda 1: 0,00227; cayó 1: 0,00227.

çelada (var.: celada) s. f. 'emboscada; trampa; celada': de manera que el conde se gitó en çelada cerca de Tudela et invió XXX de cavallo e cient peones que corriesen a los ganados e a los omnes que trovasen. 19.32. Deriv. del lat. CELARE 'encubrir, ocultar'. Frec.: çelada 2: 0,00455; celada 1: 0,00227.

celadament adv. 'encubiertamente, ocultamente, disimuladamente' o quizá 'cuidadosamente, con celo': como millor pudo, cubrió celadament el prennado de su filla, que ningún homme non lo conoció res. 23.15. Frec.: 1: 0,00227.

celebrar v. tr. 'celebrar': Aquesti noble varón, queriendo divulgar et ennoblecer la suya fama et justicia, fizo celebrar concilio general en la ciudat de Barcalona 29.8; El cassamiento de la reyna Blanca, filla del dito rey Carlos fue [fues $\mathrm{N}$ ] celebrada entre el dito rey don Jayme et la dita reyna dona Blanca 38.67; entrando por el palacio do se celebrava el dito parellamiento [parlament N] 12.25; et todos ensemble fiesta de grant dolor et amargor dolorosament celebroron [celebraron N] 37.9. Tomado del lat. CELEBRARE 'asistir en gran multitud a un lugar, visitar a uno mucha gente' (SEGURA, 2001: 109, s. v. celebro). Frec.: celebrar 2: 0,00455; celebrava 1: 0,00227; celebrada 1: 0,00227; celebroron 1: 0,00227.

celestial adj. 'celestial': et con firma fe catholica sirviendo a Dios estuvieron luengo tiempo entro que Dios los clamó al regno celestial 5.10. Deriv. de celeste, tomado del lat. caelestis. Frec.: 1: 0,00227.

celtiberos] adj. y s. gentilicio: Et por aquesta manera tollió toda Espanna a los celtiberos 1.37; et prendieron el nombre del dito rio, el qual dizen Ebro, et avieron nombre celtiberos; et yes dita Celtiberia la tierra que yes entre los montes Pyreneos et el río d'Ebro 1.10. Frec.: 2: 0,00455. 
cena s. f. 'cena': fue adueyto por reliquias en Sant Johan de la Pennya [...] con gran honor en el dia de la cena de Nuestro Senyor 17.80. Etim.: del lat. CENA 'comida de las tres de la tarde' (BDELC, p. 144). Frec.: 1: 0,00227.

cenisa s. f. 'ceniza': el dito don Alfonso hubo grant et sobrera batalla con los enemigos, el Miercoles de la Cenisa en el anno de Nuestro Sennyor M CCC XXIII 38.532. Del lat. vg. ${ }^{*}$ CINISIA (DCECH, II, p. 29). Hoy continúa empleándose en arag.: zenisa 'ceniza' (Andolz, s. v., quien lo localiza en Bielsa, Echo, Panticosa y valle de Chistau); el EBA (1999: 470, s. v. cenisa, y 1896, s. v. zenisa) localiza la voz en Bal de Chistau, Ansó, Echo y Bal de Bielsa, así como en A Fueba, Biello Sobrarbe, A Espuña y Sobrarbe en general. Frec.: 1: 0,00227.

cerca (var.: çerca, scerca) adv. 'cerca' y prep. 'cerca de': basteció un castiello qui es clamado Arquas [Archas N], el qual yes cerca el castiello de Tripol 31.34. Del lat. CIRCA 'alrededor de, cerca de'. Comp. cat. ant. cerca prep. y adv. 'prop' (DCVB, t. 3, p. 120). Frec.: cerca 22: 0,05000; çerca 7: 0,01591; scerca 1: 0,00227 .

cercano adj. 'cercano': et el regno del qual era mas cercano a ellos que ningún otro 16.22. Es deriv. de cerca, con sufijo -ano < lat. -ANus, que forma adjetivos gentilicios y de pertenencia a partir de bases sustantivas (PHARIES, 2002: 80-81); en este caso, a partir de un adverbio. Frec.: 2: 0,00455.

cercar v. tr. 'sitiar, rodear', 'poner cerco a una ciudad o fortaleza': el rey d'A ragón fuelo cercar con el conte de Foyx et otros contes de Basconnya [Gasconna B, Gascueyna $\mathrm{N}$; 34.158; et con los moros de la tierra de aquá cercaron al Cit en Valencia 18.96; seyendo el rey de Castilla en grant cuyta que los moros le tenían Cuenca cercada, enbiole a rogar al rey don Alfonso de Aragón e que le fuese a decercar aquella 33.28. Del lat. tardío CIRCARE 'dar una vuelta, recorrer' (DCECH, II, p. 42). El antónimo es decercar (vid.). Frec.: cercar 1: 0,00227; cercaron 1: 0,00227; cercó; 1: 0,00227; çercó 1: 0,0227; cercada 3: 0,00682; cerquó 1: 0,00227 .

çercar] v. tr. 'buscar': fueron çercando a qui esleyrian por sennor lur et defendedor 10.5. Etim.: lat. CIRCARE 'rodear, recorrer' (DECLIC, II, p. 674). En todos los demás casos cercar 'sitiar, rodear con gente armada una ciudad o una fortaleza, cercar'. Obsérvese que no aparece buscar ni una sola vez. Tampoco mirar, ni con el sentido de 'buscar' ni con el valor de 'mirar'. Con este último sentido tampoco aparece catar: tiene otros valores: 'observar, respetar una ley' en 36.669 o en 19.80; en 20.41 catar-se 'darse cuenta'. Comp. en la Epístola de San Bernardo (s. XV): «Cerca el suenyo mas que el colloquio» (RIERA, 1982: 133). Comp. cat. cercar, fr. chercher, it. cercare, occ. cercar, rumano cercà. Para el cat. cercar cfr. DCVB, t. 3, p. 121; FABRA, DGLIC, s. v. En Fernández de Heredia se registra cercar, cerquar, tanto con el sentido de 'cercar' como con el de 'buscar' (GILKISON, s. v.). Frec.: çercando 1: 0,00227. 
cerrado] adj. 'cerrado': los quales capitoles, cerrados et sellados con los siellos de cada un rey, el dito rey Carlos sende levó al Padre Santo 38.74. Del lat. tardío SERARE 'cerrar', con -rr- por influencia de SERRARE 'aserrar' (DCECH, II, p. 51). Frec.: cerra$\operatorname{dos} 1: 0,00227$.

certas adv. 'ciertamente, seguramente'; 'con seguridad, sin duda': certas non podia homme albirar la mortaldat que en aquesti día fue feita de los franceses 36.657. [Cert és que no es poria hom albirar...VC, p. 144]; «si fuera esto esdevenido a cavaleros del rey de Aragón, certas non» 38.330. Etim.: del lat. vg. CERTAS, aunque quizá a través del occ. o del cat. Según Corominas, del fr. certes (o del occ. ant. certas, cat. ant. certes). (DCECH, II, 70 y DCELC, I, 795, s. v. cierto). En fr. certes, documentado ya en Roland, 1080; del lat. pop. certas, del lat. CERTO 'con seguridad, sin duda, seguramente' (DauZAT-Dubois-MitTerand, s. v. certain, p. 148). En cast. med. se documenta ciertas (Alex., 347 d O) o, más comúnmente, certas (fines del s. XII, y ss. XIII-XV) (DCELC, I, 795). Certas aparece con el mismo significado en la versión aragonesa del Libro de Marco Polo hecha por Fernández de Heredia (NITTI, Voc., p. 93; un ejemplo del texto: «Certas, yo me faria antes pieças que le envias mi filla», pág. 11, lín. 20). Para otras obras de Fernández de Heredia, vid. GILKISON, s. v. certas 'ciertamente'. Es muy frecuente en VM (TILANDER, VM, III, p. 54). Igualmente se registra su uso en el LT (PrInCE, 1995: 220; RodÉs, 2016: 700). Para el cat. ant. certes vid. DCVB, t. 3, p. 132. Frec.: 2: 0,00455 .

certificación s. f. 'comprobación de que una cosa es cierta': et el dito rey, inclinado mas a creyença que a certificación, mandó su muller ser pressa 14,60-61. Deriv. del lat. CERTIFICARE. Frec.: 1: 0,00227.

cessar v. tr. 'cesar, dejar de hacer': non querían cessar aquesto 20.99. Del lat. CESSARE 'cesar, pasarse', 'entretenerse, descansar' (DCECH, II, p. 12). Frec.: 1: 0,00227 .

cetubals s. y adj. gentilicio 'pueblo antiguo de la península ibérica': Et fueron nombrados por el nombre de Tubal, cetubals [cetubales N] 1.4. Frec.: 2: 0,00455.

chico (var.: chiquo) adj. 'pequeño': el quoal fue fincado muy chico 33.4; quando fue en edat chica por su padre el rey don Sancho fue metido en el monesterio de San Ponz. de Tomeras 20.74; talló todas las colles mayores que yeran en el buerto et fincoron las solas chicas 20.115; porque murió sin fillos pervino el condado de Proeniça al rey don Alfonso qui encara era muy chiquo 33.21. Etim.: Vid. chigueza. Frec.: chica 2: 0,00455; chicas 1: 0,00227; chico 1: 0,00227; chiquo 1: 0,00227 .

chigueza s. f. [debe de ser error por chiqueza 'minoría de edad, pequeñez']: Et estando el rey en esta chigueza, el compt Remón de Tolosa firole muytas injurias 33.22. Etim.: Deriv. de chico, «vOz común al castellano con el vasco, el catalán, el sardo y algunos dialectos italianos, de creación expresiva, sólo indirectamente 
relacionada con el lat. CICCUM 'membrana que separa los granos de la granada', 'cosa insignificante, pizca'» (DCECH, s. v. chico, vol II, p. 350). Según el DEEH, p. 579, del lat. *CICUs, de donde procederían también el cat. xic y el vasc. txiki con idéntica significación de 'pequeño'. Para la -g-, que no obstante nosotros interpretamos como errata por - $q$-, comp. chiguito (Burgos), chiguín (Rioja), que cita García de Diego (DEEH, p. 579). En arag. med. se documenta chiqueza 'pequeñez, escasez, corta edad' en TILANDER, VM, III, p. 55 (tb. lo cita Andolz, s. v.). También chiqueza 'pequeñez' en Fernández de Heredia (Gilkison, s. v.), en LMM (Liria, p. 164), etc. En cambio, en FA, chiquenes, chiqueneza (Tilander, FA, p. 306). Frec.: 1: 0,00227.

christiandat s. f. 'cristiandad': Et mudólos by del monesterio de Clunyego de la orden de San Beneditto, qui a la ora pululiva et floriva en toda la christiandat 14.99; Et en tiempo de aquesti, la christiandad buvo prendido grant reformamiento et gran crecimiento 11.5 . Frec.: christiandat 4: 0,00909; christiandad 1: 0,00227.

christiano adj. 'cristiano': En tiempo de aquestos recibieron la fe christiana los godos. 3.21; et entre cativos et muertos ningún christiano non pudo escapar [ninguno non di escapó de los christianos N] 4.37. Frec.: christiano 7: 0,01591; christianos 33: 0,07501.

cielo s. m. 'cielo': él reguardó el cielo [lado B] plorando et dixo:... 35.292. Del lat. CAELUM. Frec.: 1: 0,00227.

cient adj. num. cardinal 'cien': et invió XXX de cavallo e cient peones 19.33. Del lat. CĔNTUM. Frec.: 4: 0,00909.

cierto adj. indef. 'cierto': firo el rey parellar ciertos et secretos hombres en su cambra armados 20.131. // de cierto loc. adv. 'ciertamente': porque aquesti de cierto yes nuestro [vuestro N] sennor 12.29. Del lat. CERTUS. Comp. certas. Frec.: cierto 8: 0,01818; ciertos 3: 0,00682.

cinquo adj. num. 'cinco': Et regnó el dito noble rey, bien et noblement, vint e cinquo annos 13.15. Del lat. vg. CINQUE, cl. QUINQUE (DCECH, II, p. 84). Frec.: 2: 0,00455. circa (lat.). prep. 'hacia', 'en torno a', 'alrededor de': soterraronlo en el dito monasterio que oy en dia es nombrado de San Johan de la Pennya circa annos Domini DCCCCLXI 11.67. Frec.: 1: 0,00227.

citar] v. tr. 'citar, convocar': el dessus dito don Jayme d'Aragón, a las Cortes Generales que tuvo a Girona, citó [sacó N] el dessus nombrado rey don Sancho 38.461. Del lat. CITARE 'hacer acudir', 'llamar, convocar' (DCECH, II, p. 92). Frec.: citó 1: 0,00227.

ciudadano s. m. 'ciudadano': vino don Remón Marquet, ciudadano de Barçalona, almirant de XII galeras 36.538; con cavalleros et con ciudadanos de Catalunnya et de Aragón 36.42. Deriv. de ciudat. Frec.: ciudadano 2: 0,00455; ciudadanos 2: 0,00455 .

ciudat (var.: ciudad) s. f. 'ciudad': Fue un tiempo quel dito compte fue a la ciudad de Narbona con su fillo 22.8; et fue soterrado en el monesterio de los freyres menores de la 
dita ciudat 39.47; lexada la çiudat de Huesca bastecida 18.104. Del lat. CIVITATE(M). Frec.: ciudat 79: 0,17965; çiudat 1: 0,00227; ciudad 18: 0,04091.

clamar v. tr. 'llamar', 'denominar': de aqui adelant non se quiere clamar emperador, sino rey de Aragón 19.190; et se clamava princep de Aragón et conte de Barçelona, que non quisieron consentir los aragoneses que se clamasse rey 32.17; depués fueron a d'Almeria, que la clamavan en aquel tiempo Urcia 19.198; hedificó el dito Hercules al pie del dito mont, de las gentes que vinieron con él de Tirus et de Ausonia, una ciudad que clamó Tirasona 1.28. // 'suplicar, pedir, solicitar': misose ell et la tierra sueltament en poder del dito rey clamando mercé humilment 36.443-444. / / En un caso parece que tiene el sentido de 'aclamar': Et seyendo aqui electo, non por codicia de honor mas por necessidat del regno, fue clamado por rey de Aragón por los del regno 20.84-86. Del lat. CLAMARE 'gritar, llamar, exclamar', 'nombrar' (DECLIC, II, p. 729). Clamar es habitual en arag. med. y hoy se conserva en el arag. mod. (ANDOLz, s. v.; RoHLFs, DDPA, s. v.; EBA, 1999: 555). Frec.: clama 4: 0,00909; clamabanlo 1: 0,00227; clamada 6: 0,03637; clamado 75: 0,17047; clamados 3: 0,00682; claman 2: 0,00455; clamando 3: 0,00682; clamar 3: 0,00682; clamaronlo 1: 0,00227 ; clamasse 1: 0,00227 ; clamava 2: 0,00455; clamavan 2: 0,00455; clamávanlo 1: 0,00227; clamo 1: 0,00227; clamó 8: 0,01818 ; clamote 1 : $0,00227$.

clamo] s. m. 'queja, reclamación, demanda': et por aquesta razón la dita reyna fue en Roma et delant del Padre Santo propuso sus clamos la dita reyna 34.63-64. Deriv. de clamar. Se registra clamos en FJ (Redacción D, en navarro-aragonés): por clamos que aian d'el (Molho, p. 405, \ 175). En el arag. de Fernández de Heredia: clamo 'claim' ('demanda, reclamación; derecho, pretensión'), 'complaint' ('queja, lamento; demanda'), 'acusation' ('acusación, denuncia') (GILKIsON, s. v.). Vid. también clamo ‘queja, acusación’ en FA, p. 307; en FT, p. 472; VM; III, p. 58. Para el navarro, cfr. FN, p. 134; TLN, p. 212; YANGUAS, 1854, s. $v$. Frec.: clamo 1: 0,00227; clamos 0,00227.

claro adj. 'claro': et quanto fue día claro, los franceses partieron de la Junquera 36.652. Del lat. CLARUS 'íd.'. Frec.: 1: 0,00227.

claveguera s. f. 'alcantarilla, cloaca', 'conducto para salida de aguas residuales, agujero en la pared para salida del agua de lluvia'; 'arbellón, albollón, albañal': et el rey don Jayme non queriendo seer presso, por una claveguera o albellon que es en el castiello de Perpinyan, qui la ora non era obrado nin acabado assí como huey yes, fuyó et escapó a grant su desonor 36.410-414. [E lo rei En Jacme, no volent estar pres, per una claveguera o albelló qui és en lo castell de Perpenyà, qui llavors no era acabat ni obrat, aixi con hui és, fugi e escapà a gran deshonor VC, p.138]. Comp. cat. claveguera 'conducte, generalment subterrani, per on s'escorren les immundícies, les aigües brutes i les aigës plujanes d'una ciutat' $\mathrm{y}$ 'forat que hi ha a les parets dels horts perquè hi passi l'aigua quan plou' (FABRA, s. v.; en el DL/C del IEC, 2007, s. 
v., acepciones 1 y 3 ). Es interesante hacer notar que se repiten dos voces sinónimas, unidas por la conj. o: claveguera o albellón. Y que lo mismo ocurre en la VC: claveguera o albelló. ¿Se puede deducir de aquí que ninguna de las dos voces por separado sería suficientemente clara y representativa para el autor? Quizá es que se utiliza el término cat. (o bien literario, pero tomado del cat.) y el término arag. o más popular. Etim.: del lat. vg. *CLAVACARiA, cruce de CLAVACA y CLUACARIA, resultantes ambas de una variante del lat. cl. ClOACA. Cfr. it. chiavica $<{ }^{*}$ ClaviCA, afín a ClavaCA (DECLIC, II, p. 749). Para el cat. claveguera vid. también DCVB, t. 3, p. 203. El DRAE (1970) y el DLE (2014) recogen clavijera 'abertura hecha en las tapias de los huertos para que entre el agua', con marca diatópica de Aragón. Con idéntico significado viene ya en Borao y en Pardo. En Andolz, tomado de estos, clabijera. Frec.: 1: 0,00227.

clerezía (var.: clerizía) s. f. 'conjunto de clérigos', 'conjunto de personas que componen el clero': Et oyda su missa devotament, pregó carament los ditos abad et clerezía del dito monasterio que lures oraciones et buenas obras lo deviessen baver por recomendado 11.44; et el rovador se demostró et el pobre se escondió e la clerizia calló 32.69. Frec.: clerezía 1: 0,00227; clerizia 1: 0,00227.

clérigo] s. m. 'clérigo': et aquesti rey mandó que todos los clerigos et vispos de su tierra prendiesen et tuviessen drudas 3.75; con todos sus clérigos processión faziendo 11.17. Del lat. tardío CLERICUS (DCECH, II, p. 100). Frec.: clerigos 7: 0,01591.

cobdicia (var. codicia) s. f. 'codicia': et seyendo aquí electo, non por codicia de honor mas por necessidat del regno... 20.84; inhonesta cobdicia de meneda [moneda B, N] 38.378. Tomado del bajo latín CUPIDITIA (DCECH, II, p. 117). Frec.: cobdicia 1: 0,00227 ; codicia 1: 0,00227 .

cobdiciar] v.tr. 'codiciar': copdiciando mas el servicio de Dios et exalçamiento de la fe que no dudando el temor de los infieles 18.25; el compt don Pedro de Lara, lexada la seynna a los primeros colpes, e cobdiciando la reyna, lexólos en el campo e fuese para la reyna que hera en Burgos 19.119. Deriv. de cobdicia. Frec.: cobdiciando 4: 0,00909; copdiciando 1: 0,00227.

cobrar v. tr. 'cobrar', 'recuperar, adquirir'; 'recobrar, tomar': et tierras ha deffender et las perdidas cobrar o ganar de nuevo 20.54; Et el dito conte Burrel depués que hovo cobrada la ciudat de Barchinona governó el dito condado XXVII annos 26.28; dentro el dito tiempo, avieron la dita ciudat desenparar et rendieronla al dito don Alfonso, el qual, quando la huvo cobrado, fizo reparar et endrecer [endrecar $\mathrm{N}$ ] aquella 36.690; et amos a dos destragoron el regno de León et cobroron lo que havían perdido 34.80. Etim.: formado como seudo-primitivo a partir de recobrar $<$ lat. RECUPERARE. Es VOz común al cast., port., cat. y occ. (DCECH, IV, 826); en vasco tb. como préstamo romance, kuperatu 'cobrar' en Suletino (AzKUE, 1969: 508). Frec.: cobrar 2: 0,00455 ; cobrada 1: 0,00227 ; cobrado 1: 0,00227 ; cobrando 1: 0,00227 ; 
cobras 1: 0,00227 ; cobrava 2: 0,00455 ; cobre 1: 0,00227 ; cobró 2: 0,00455 ; cobroron 1: 0,00227 .

coffre] s. m. 'cofre': el dito santo rey se fizo adozir delant sí la santa verdadera [vera $\mathrm{N}$ ] Cruz de Ihesu Christo quel avía en uno de los sus coffres 35.276. Del fr. coffre 'íd.', y este del lat. Cophinus 'cesta', tomado del griego Kopıvos 'íd.' (DCECH, II, p. 120; DECLIC, II, p. 806). La $1^{\text {a }}$ doc. que da Corominas en cat. es de fin del s. XIII en Desclot; en cast., 1495 (Nebrija), pues anteriormente sólo aparece en documentación de procedencia aragonesa (hacia 1400, Glosarios de Palacio y del Escorial: vid. CASTRO, 1991: 175, s. v. basterna). La Crón. SJP. adelanta a esta última en unos 30 años. Frec.: coffres 1: 0,00227.

col] (var.: coll) s. m. 'col, hortaliza': clamó el mensagero al buerto en el qual havía muytas coles 20.113; et teniendo la letra en la mano et leyendo, talló todas las colles mayores que yeran en el huerto et fincoron las solas chicas 20.115; pensó en si mesmo quel huerto podía seer el su regno, las colles yeran las gentes del su regno 20.122; et dixo: «por fer buenas colles, carne y a menestery 20.123. Del lat. CAuLIS. Frec.: coles 1: 0,00227; colles 3: 0,00682 .

coll (var.: col) s. m. 'collado, paso elevado entre montañas más altas': el dito rey don Pedro con aquel poco poder que avía, vinos'ende al col de Panizars et aqui él se atendó por contrastar al dito rey de Francia 36.481; Et por miedo que avían del dito rey don Pedro qui estava attendado en el dito coll de Panizares, convinoles pasar por la villa de Bannyules 36.491. Etim.: del lat. Collum 'cuello', o más bien del lat. Collis 'colina, cerro', sumada y confundida con la anterior (DECLIC, II, p. 821). En cat. tiene el sentido de 'pas elevat entre muntanyes més altes', pero en cat. ant. se empleó con la acepción de 'muntanyola, turó baix'. En cat. moderno: coll 'depressió pronunciada a la carena d'una serra o d'un contrafort' (FABRA, DGL/C, p. 407); 'depressió a la carena d'una serralada o d'un contrafort, per la qual se sol passar per anar d'un vessant a l'altre', 'turó' (DL/C del IEC, 2007, s. v.). Vid. también diferentes acepciones en cat. en DCVB (t. 3, pp. 286-289). Es evidentemente un catalanismo, por la falta de diptongación, por la caída de la -o final y porque siempre se aplica a topónimos catalanes. Frec.: col 3: 0,00682; coll 4: 0,00909.

collocado] (var.: colocado) p.p. y adj. 'colocado, puesto': collocados todos sus fillos 38.417; «Sennyor, que la mi ánima sia colocada en perdurable lumbre delant tú 35.299. Cultismo tomado del lat. collocare 'íd.'. Frec.: collocados 1: 0,00227; colocada 1: 0,00227 .

colloquio s. m. 'coloquio, entrevista, conversación, plática': Et el rey de Castiella, corronpido de grandes prometimientos de moneda por el rey Carlos, secretament a manera de convidar o de aver colloquio con él o en qualque manera entendía a prender el dito rey don Jayme 38.45-46. Es cultismo tomado del lat. colloquium. La 1. a documentación 
que citan el BDELC y el DCECH (III, p. 686, s. v. locuaz) para el cast. coloquio es de 1444. La Crón. SJP. permite adelantarla en unos 70 años. Frec.: 1: 0,00227.

collor s. m. 'color': et eran de tan natura, figura et collor que de la una part eran cárdenas et de la otra verdes 36.597. Del lat. COLORE(M). Frec.: 1: 0,00227.

colpe] s. m. 'golpe': et de los colpes de las maças trobaron [fallaron $\mathrm{N}$ ] muytos muertos 18.69. Del lat. vg. *Colupus, lat. Colaphus 'puñetazo' (DECLIC, II, p. 898, s. v. cop; DCECH, III, p. 166, s. v. golpe). Según indica Corominas en este último la forma colpe se utilizó en Aragón por lo menos hasta 1400, y está documentada ya en Berceo y en Alex. (cfr. SAS, p. 310). Se ha tenido por occitanismo el cast. golpe (MGHE, p. 82, donde se sugiere explicarlo como postverbal de

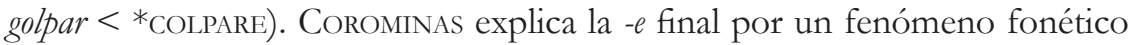
de disimilación (lo mismo que en doble, cobre, etc.). Para el arag. colpe valdrían ambas explicaciones. La forma colpar (doc. en Alex., vid. SAS, p. 310) podría haber originado un postverbal colpe. Pero tampoco parece descartable la evolución $*_{\text {COLUPus }}>*_{\text {COLPO }}>$ colpe. En Fernández de Heredia se registra colpe, golpe y colp (GiLKison, s. v.). En el LMM, colpe: «e los menasçan en l'aire e en tierra de colpes de truenos e de tempesta» (LMM; LiRIA, 1979: 128). También colpe en el arag. de la $2^{\mathrm{a}}$ mitad del s. XV: «El uno alzo la mano et vale a dar buen colpe» (Crón. de Juan II, p. 15, lín. 16). Frec.: colpes 2: 0,00455.

comanda s. f. 'petición, pedido, solicitud, encargo'; 'mandato, encomienda'; 'amparo, patrocinio, custodia, depósito'. Aparece en la loc. en comanda 'al servicio de', 'bajo el patrocinio de', 'bajo la autoridad de', 'bajo la protección de': Aquesti rey don Pedro recibió al Cit Ruy Diaz en comanda et prometiole de ayudar do lo buvies menester. 18.77; et aquesta jura prendió el Cit et desplazió depués al rey muito. Et por esto lo ayró et vínose a meter en comanda del rey don Pedro de Aragón 18.89. Como se ve por los ejemplos, la loc. en comanda alude a cierto tipo de vasallaje que significa tanto ponerse bajo la protección de un rey o un señor como, al mismo tiempo, estar al servicio de este. Etim.: deriv. postverbal de comandar < lat. COMmandare (DEEH, p. 592, s. v. commendare). Según indica Lagüens (1992: 81), el verbo commandare, «seguramente con vocalismo reconstruido sobre el simple mandare, está ampliamente registrado en el bajo latín y en el latín medieval, a menudo junto al clásico commendarè. Se registra comanda en los $D L A A$ : «quel seynor rey dAragon sia tenido de recebir en comanda su muller \& sus fillos \& todos sus bienes \& sus uassallos \& encara las mulleres \& los fillos \& todos los bienes de todos aquellos uassallos que yran con el.» (doc. n55, de Huesca, de 1283, copia del Privilegio de la Unión; DLAA, p. 81, lín. 83-85). Se registra también comanda en $F A$, tanto en el sentido de 'depósito' como en el de 'protección': «asi como aquel qui no a guerra es en nuestra custodia e comanda con todos sos bienes» (Tilander, FA, p. 153, \$263.12); «por que, quantas uegadas aquel infançón quisiere lexar el bien feito al rey si'n 
tiene, puede se espedir d'él e lexar en la fe del rey et en comanda so muller e sos fillos e todos sos bienes» (Tilander, FA, p. 134, \$240.8); comanda 'depósito' en VM (Tilander, VM, III, p. 59). En el arag. de Fernández de Heredia: comanda 'command, authority', esto es 'orden, mandato, autoridad' (GILKIson, 1984, s. v.). También en cat. comanda 'encomienda' (DCVB; DECL/C, s. v. manar; DL/C del IEC, 2007, s. v.). Frec.: 2: 0,00455.

comarca (var.: comarcha) s. f. 'comarca, territorio circundante': Otrosí Caragoca, Calatayud, Darocha et sus comarchas dio al emperador don. Alfonso de Castiella a su vida tan solament 20.271; el qual era monge en el monesterio de Sant Ponz de Tomeras en Francia, en la comarca de Besses 20.19. Deriv. de marca 'frontera', y este de un tipo germánico, seguramente longobardo *MARKAN 'anotar, señalar', reducción de *MARKJAN. La evolución semántica se entiende partiendo de 'señal que marca un límite'. Cfr. DCECH, III, pp. 842-845, donde se sitúa la primera documentación de comarca hacia 1540. La Crón. SJP. adelanta la fecha en unos 170 años. Véase también comarca en Fernández de Heredia (GILKISON, s. v.). Frec.: comarca 1: 0,00227; comarcas 1: 0,00227; comarcha 1: 0,00227; comarchas 1: 0,00227 .

comedir] v. tr. 'pensar, reflexionar'; 'calcular, buscar, tantear': Et un día, él andando en derredor de la ciudad, comidiendo por do se podría entrar, vio flaco lugar en el muro forano 17.116-118. Etim.: del lat. COMMETIRI 'medir un conjunto de cosas, confrontar' y de ahí 'moderar, pensar' (deriv. de METIRI 'medir') (BDELC, s. v. comedido, p. 161; DCECH, IV, p. 17). Frec.: comidiendo 1: 0,00227.

comencamiento (var.: començamiento) s. m. 'comienzo': Agora tractemos del comencamiento del linage de los contes de Barchinona 22.1; «et ámalos porque ellos te amen et ayas paciencia et bumildat que es començamiento de todos los bienes» 35.269. Deriv. del v. començar, con sufijo -miento, que forma sustantivos que indican el nombre de la acción significada por el verbo (PHARIES, 2002: 403). Frec.: comencamiento 2: 0,00455; començamiento 1: 0,00227.

començar] (var.: comencar) v. tr. 'comenzar, empezar': et vehet como començavan lures afferes bien, que todas quantas yglesias trobavan todas las robaban et destruyvan 36.492; et aquesti fue el primero rey que començó entrar en Espannya. 3.36; Et dolentes [dolens $\mathrm{B}]$ et vencidos plorosament comencoron partir de aqui 36.622-623; el dito santo rey se despulló los vestidos reales bumilment et cantando un canto o ymno que comienç «Veni Creator Spiritus etc.» vistiose el ábito de monges blancos 35.282. Se usa también en la perífrasis verbal comencar de + inf. 'comenzar a + inf.': E quoando comencaron de darse los unos con los otros... 19.117. Del lat. vg. *COMinitiare, deriv. de intTiare 'iniciar, instruir', y luego 'empezar' (DCECH, II, p. 157). Frec.: començaron 2: 0,00455; comencaron 1: 0,00227; començas 1: 0,00227 ; començavan 1: 0,00227; començó 6: 0,001364; comencó 1: 0,00227; comencoron 2: 0,00455; començoron 1: 0,00227 . 
comendar (var.: comandar) v. tr. y prnl. 'encomendar': el dito emperador se comandó [si comendó $\mathrm{N}$ ] a su muller tenedor et conservador por ella en el castiello de Nágera un su cavallo 14.35; passó las montannas que yeran cubiertas de nieve et de ora del alva, muyt abrivadament et podroso [vigorosaN], comendandose a Dios, firió tan fuertment en el sitio de los moros que todos los desbarató e los aparelló 12.57; Et continent, el dito rey Carlos envió a dezir al Padre Santo que pues el dito cardenal era muerto, a otro devies comendar sus vezes 38.96-98; Entro aquesti tiempo ningún varón no buvo el condado de Barcbinona perdurablement, sinon quel rey de Francia lo comendava a qui se quería a cierto tiempo 23.64; et delant dellos comendó el dito infant por criar al dito don Sancho, tio suyo 35.26. Etim.: Del lat. COMMENDARE 'confiar algo', 'recomendar'; cast. encomendar 1495, antes comendar 1220-50 (BDELC, s. v. mandar, p. 377; DCECH, III, p. 800). Se registra en el s. XIII en las obras de Berceo (ÁlvVAREZ, 1991: 172). En el arag. de Fernández de Heredia comandar comendar 'encargar', 'recomendar', 'confiar (algo a uno)', y comandarse 'recomendarse uno mismo' (GILKISON, s. v.). Vid. comanda. Frec.: comendar 1: 0,00227; comandó 1: 0,00227; comando 2: 0,00455; comendandose 1: 0,00227 ; comendava 1 : 0,00227 ; comendó 1: 0,00227 .

comer v. intr. 'comer': et muy indignados fueron a comer. 20.37; pero clamava aquellos que yeran culpables, de guisa que XIII [XII $\mathrm{N}]$ richos hombres et otros cavalleros escabegó ante que comies 20.136; levantose et con gran alegría et honra recibió los navarros et conbidoles que comiessen con él. 20.27. Del lat. COMEDERE. Frec.: comer 3: 0,0682; comies 1: 0,00227; comiessen 1: 0,00227.

cometer] v. tr. 'cometer': Et prególa el dito emperador que devies perdonar a sus fillos el defallimiento que havian cometido contra ella 14.82; todas quantas yglesias trobavan todas las robaban et destruyvan et de otros grieves crimines cometian et farian 36.494. Del lat. COMMitTere (DCECH, IV, p. 60). Frec.: cometían 1; 0,00227; cometido 1: 0,00227 .

cominales adj. pl. 'corrientes, comunes, no excepcionales': Aquesti rey don Alfonso, depués que buvo recebida aquesta muller çaguera, non firo afferes de cabo [ningunos $\mathrm{N}$ ] ni [buenos ni $\mathrm{N}$ ] cominales porque toda vegada ho quayx estuvo enfermo. 39.14-15. Etim.: lat. COMmunalis 'común' (DEEH, p. 105), con cambio de la $u$ en $i$ atribuible quizá a ser una palabra tomada del provenzal, según opinión de Fouché (DCV B, s. v. cominal, tomo 3, pp. 323-324). Comp. cat. ant. cominal'pertanyent a la majoria o a tothom'; cast. común. Sentit cominal: 'sentit comú'. De cominal consentiment: 'de comú acord'; 'que no s'alça per damunt el nivell ordinari; que és del tipus corrent o mitjà, que es troba amb més freqüencia'; cast. común, corriente, regular (DCV B, s. v.). COROMINES (DECLIC, II, pp. 861-864), a propósito de los derivados del cat. comú < lat. communis, cita el adj. comunal (hoy vivo sobre todo en los Pirineos y aplicado a las tierras del municipio), y 
añade: «Antigament s'usà més aviat una variant cominal [cap a l'any 1200]: ...; $i$ amb tots els matisos derivats o secundaris, i romanent adjetiu o substantivat: 'públic, (element) popular', 'corrent, ordinari', 'neutral'; per cominal 'en públic'. [...] És mort avui quasi pertot, no del tot en rossellonés... És molt corrent i resta viva en llengua d'oc: cominal 'commun, public, vulgaire, bas', etc.; de l'oc. ant. pogué ser manlleu l'hapax aragonès ant. cominal 'común, igual' en el Libro de Apolonio (25)». Coromines (ibídem, p. 863) acepta en principio que sea occitanismo en cat., pero cree que ha podido intervenir algún factor auxiliar, como el modelo de los adjetivos en -inal (final, veïnal, ordinal, etc.), muy numerosos. En occ. ant. cominal (Levy, 1980, p. 85, lo da como sinónimo de comunal 'commun, public, vulgar, bas'). Comp. comunal 'común' en DLAA: «E feita la dita presentacion \& fe el dito procurador dixo \& propuso que como las mesuras de Vielsa, segunt fama comunal, auuissen necesario reparación \& examinación, por tal que fuesen concordes con la de Ainsa...» (doc. de Bielsa de 1349; DLAA, doc. no 113, p. 164, lín. 38). Para el paso [u] > [ü] > [i] por influencia del occitano, vid. pupillar. Frec.: cominales 1: 0,00227.

comissión s. f. 'cosa encomendada, orden, encargo': mandó a los arecevispos de Anbrunm et de Alerat, que segunt la comissión feita al cardenal deviessen exseguir la paz. dessuso dita. 38.100. El DLE (2014) da como segunda acepción de comisión 'orden y facultad que alguien da por escrito a otra persona para que ejecute algún encargo o entienda en algún negocio'; y como $3^{\text {a }}$ : 'encargo que alguien da a otra para que haga algo'. Tomado del lat. comissio, -onis, deriv. de comittere 'confiar, encargar' (BDELC, s. v.). Frec.: 1: 0,00227.

como adv. de modo 'como': assí como aquesto dizen Ysidoro et Jeronimo 1.3. // adv. interrg. 'cómo, de qué manera': el quoal recontó el romeage que avía feyto a la dita sancta cueba, e cómo por la dita santidat d'ella e por su devotion que y avía, les avía dado el dito término 11.33. / / conj. 'ya que, puesto que': murmuriavan et es complanyan muyto et non sin razón, como non se pensavan que beredero fues fincado en la tierra. 12.15-17. Del lat. QUOMODO > lat. vulgar QUOMO (BDECL, s. v.; LHP, p. 535). Frec.: 190: 0,43186.

como quiere que (var.: como quier que) loc. conj. concesiva 'aunque': Et ellos como quiere que la tuviesen por el enperador don Alfonso de Aragón, pero catando dreyto de naturaleza todos comunment la rendieron a la dita reyna. 19.79-81.

compannar] v. tr. 'acompañar': et, compannando los dos sobreditos de Navarra, fue preso el dito Caxal 20.223. Deriv. de companna. Frec.: compannando 1: 0,00227.

companna] (var.: compannia, compannya, compaynna, conpannya, conpanya) s. f. 'compañía, formación militar de gente armada': Et otro dia mañana supo como los moros eran cerca, firo parellar sus compannas 18.33. Del lat. vg. *Compannia 'compañía', formado al mismo tiempo que el lat. merovingio 
COMPANIO, -ONIS 'compañero', calco del gótico GaHLAibA, de HLAIFS 'pan' y GA- que expresa compañía (DCECH, II, p. 161). En port. ant. ya se documenta companha en el s. XIII; en port. mod. companbia (Cunha, 1986: 200). Frec.: compannas 1: 0,0027; compañía 2: 0,00455; compannya 1: 0,00227; compannyas 4: 0,00909 ; compaynnas $1: 0,00227$; conpannya 8: 0,01818 ; conpannyas $7 ; 0,01591$; conpanyas $1: 0,00227$.

compannero (var.: conpanyero) s. m. 'compañero': et por aquesto era amado de sus vassallos, porque assin como a compannero yva con ellos et se metía en ygual dellos en todos afferes d'armas 12.68-70; et el mas familiar et el mas avinent a los sus sozmesos que oro rey que al mundo fues, que assí les fue como a conpanyero 39.5. Deriv. de companna. Frec.: compannero 2: 0,00455; conpanyero 1: 0,00227.

comparecimiento s. m. 'acto o acción de comparecer, comparecencia': requiriendo al notario que alli era que de aquéllas et del comparecimiento suyo, et de la fadiga et contumacia del dito rey Carlos le devies fer carta o cartas públicas a memoria perdurable 36.298. Deriv. de conparecer (vid.). Frec.: 1: 0,00227.

complanyer] v. prnl. 'lamentarse': murmuriavan et es complanyan muyto 12.15. Etim.: deriv. de planyer < lat. Plangere (DCECH, III, p. 724, s. v. llanto), o del lat. COM+PLANGere. Comp. occ. complànher (se) 'se plaindre, se lamenter' (ALIBERT, s. v.); complanher 'se plaindre, lamenter' (LevY, s. v.); cat. complànyer 'compadir; condoldre's; plorar ensems amb un altre o d'altres' (FABRA; DL/C del IEC, 2007; DECLIC, VI, p. 591, s. v. plànyer). En Fernández de Heredia: complanyr 'bemoan, cry' ('lamentarse, llorar, gritar'), complanymiento 'bemoaning, bewailing' ('lamento') (GILKIsON, s. v.); en docs. aragoneses del s. XV: complanyir 'lamentarse' (VILA, 1990: 138). En arag. mod. plañer-se, plañir-se (ANDOLZ, 1992, s. v.; EBA, 1999: 1483). Frec.: complanyan 1: 0,00227.

complazer v. tr. 'complacer': Et aquesto fizo porque pudies complazer a Dios e al maestro apostolical ovedir 33.108-109. Del lat. COMPLACERE 'gustar conjuntamente a varios’ (DCECH, IV, p. 572). Frec.: 1: 0,00227.

complido adj. 'cabal, perfecto, abundante, exacto, acabado completo': et havía todos los feytos muit complidos 32.5-6. Del p. p. del v. complir. Frec.: complidos 1: 0,00227 .

complimiento (var.: complimento) s. m. 'provisión, acopio, remanente', 'aprovisionamiento': Et en continent el dito rey, aplegado complimiento de navilio con muyt noble cavallería de Catalunya et de Aragón et gent valerosa de pie, vino a sitiar la ciudat de Mallorquas 35.127 (complimiento de navilio 'equipo naval, acopio de naves', aprovisionamiento de buques'); vino grant acorrimiento a los franceses de complimiento de viandas 36.522; Vehet quel tiempo de la paga del sueldo se acostó, et como el dito letrado [legado B] no avies complimento de meneda [moneda B]...38.309 (complimento de moneda 'provisión de dinero'). Deriv. del v. complir con sufijo -miento. 
complir v. tr. 'cumplir': et que complies todo lo que avía ordenado en su testament 35.288; de manera que assí complió el rey don Pedro, 18.43; con grant voluntat que havía de complir las avinenças 20.180; et quoando lo ovo complido su prometimiento e voto, los demás de los reyes de Espaynna inclinados e indutos a paz e concordia, tornose en su tierra 33.110. // 'ejecutar, llevar a cabo, realizar, efectuar': entroron por Val de Pintano et complieron a Vaylo et ad'Arbues et cremoronlos 36.352-353. Etim.: del lat. COMPLERE 'llenar', 'completar', deriv. del lat. arcaico PLERE 'llenar'. Es corriente en cast. med. la variante complir, aunque cumplir ya se halla en el Cid (DCECH, II, p. 290, s. v. cumplir). También en port. ant. se documenta la variante con vocal -o-, comprir (s. XIII), pero hoy cumprir (Cunha, 1986: 233). Frec.: complir 5: 0,01136; complió 2: 0,00455; complido 3: 0,00682; complieron 1: 0: 0,00227; complies 1: 0,00227 .

compra s. f. 'compra': Et lexó heredero del condado de Ribagorça et Ampurias, el qual por compra huvo don Pedro 38.637. Es deriv. postverbal del v. comprar. Frec.: 1: 0,00227 .

comprar] v. tr. 'comprar': el rey de Huesca lo compró 17.48. Del lat. vg. *COMPERARE (BDELC, p. 163; MGHE, p. 63). Frec.: 1: 0,00227.

compto s. m. 'cuenta, cómputo, cálculo, número': con grandes gentes de moros que no avian compto. 19.56. (El DRAE, 1970, da 'número, porción, cantidad' como acepción ant. de cuenta). Del lat. Computus 'cálculo, cuenta' (BlÁNQueZ, s. v.). Comp. nav. compto 'cuenta', cámara de comptos 'tribunal de hacienda de Navarra' (Yanguas, 1854, s. v.; Yanguas, 1964, s. v. cámara de comptos; Iribarren, s. v.). En arag. med.: compto y conto 'cuenta' (VCA, pp. 85 y 98); conto 'cuenta' en DLAA (Reidy, 1977: 138), en el arag. de Fernández de Heredia (GILKISON, 1984: 34), etc. Frec.: 1: 0,00227.

común adj. 'común': et segunt arbitrio común murieron aquell día entre de cavallo et de pie VI mill moros 38.365. Comp. cominal. // s. m. 'comunidad': por tal como el común de Pisa avía enviado conpannya de cavallo et de pie 38.491; por prender homenage de los ancianos del común de Pisa. 38.577. Del lat. communis 'íd.'. Con el mismo valor se registra en TLME, en un documento del año 1229 de la provincia de Santander, redactado en asturiano-leonés antiguo (doc. no 42, lín. 4, pág. 89). En arag. med.: comin 'comunidad, todos' en $V \mathrm{M}$ : «quar cosa conuenible es que los iuegos nozibles et malos et locos sean esquiuados, si al no, por pena de dineros, et esto es a pro del común (TILANDER, VM, II, p. 272; \IV,12.32; y VM, III, p. 61). En los DLAA: «Scripta en Aynsa, dios el siello de nuestro comun» (doc. de Aínsa de 1352; $D L A A$, doc. no 116, p. 171, lín. 18). En arag. mod. existe un refrán, localizado en el valle de Chistau, que dice: «Serbir al común ye como serbir a no nengún» 'servir a la comunidad es como no servir a nadie' (vid. en GLA, p. 126). Frec.: 5: 0,01136 (como adj. y como sustantivo). 
comunment adv. 'de común acuerdo': pero catando dreyto de naturaleza todos comunment la rendieron a la dita reyna 19.80-81. Frec.: 1: 0,00227.

con prep. 'con': buvo affer con la muller, según algunos dizen, o con la filla del dito comte 3.82; la Virgen gloriosa Madre de Dios li apareció con grant goyo 35.225. Del lat. CuM. Frec.: 538: 1,22284.

conbatiente s. m. 'combatiente, persona que combate': por ayudar et deffender aquélla de los conbatientes 36.225. Frec.: 1: 0,00227.

conbatimiento] (var.: convatimiento) s. m. 'combate': por muytas batallas et conbatimientos 36.24; e los que fincaron de dentro, como desesperados vida, enpués muytos convatimientos, rendieron la ciudat. 19.45-47. Deriv. de conbatir. Frec.: combatimientos 1: 0,00227; convatimientos 1: 0,00227.

conbatir (var.: combatir, convatir) v. tr. e intr. 'combatir': le deffendiessen el regno et se conbatiessen [convaties N] con su hermano en la mar 38.242; conbatió fuertment et poderosa la dita fuerça et finalment prendiola 4.35; Et por esto la part contraria se pensó que por miedo sende estuvies de conbatirse con él 36.271; sitió Tortosa con genoveses, con II ${ }^{m}$ omes d'armas, convatiendo fuerment la cita ciudat 32.26. Etim.: del lat. COMBATUERE 'combatir con', deriv. de BATUERE o BATTUERE 'golpear' 'batirse' (BLÁNQUEZ, s. v., pp. 241 y 365; DCECH, I, p. 545, s. v. batir). También conbater. conocierrigelo be [conbatergelo be $\mathrm{N}] 12.36$ (= 'se lo combatiré'). Según KuHN, HAD, p. 164, conocieréigelo be 'se lo haré reconocer, se lo probaré'. Pero la lectura correcta es conbatergelo be (vid. NAGORE, 2003: p. 379, \5.10.4.4.), es decir, futuro del verbo conbater. Frec.: conbatir 1: 0,00227; conbatirse 2: 0,00455; conbatian 1: 0,00227; conbatiessen 1: 0,00227; conbatió 4: 0,00909; combatir 1: 0,00227 ; combatida 1: 0,00227 ; convatida 1: 0,00227 ; convatiendo 1 : 0,00227 .

conbidar] v. tr. 'convidar, invitar': Assí como él aviés conbidado muyto honrado barón et muyto honrado prelado et otras gentes de diversos stamientos... 37.84; levantose et con grant alegría et honra recibió los navarros et conbidoles que comiessen con él. 20.27. Del lat. vg. *CONVITARE, variante de InVITARE (DCECH, III, p. 461). Frec.: conbidado 1: 0,00227; conbidoles 1: 0,00227.

concessión s. f. 'concesión, acción y efecto de conceder [alguna cosa]': por tal como la conquista del dito regno se pertannya al dito rey de Castiella por concessión apostolical. 35.169. Cultismo tomado del lat. concessio, -onis. El BDELC (p. 142, s. v. ceder) fecha la 1. a documentación en cast. de concesión en 1604. Frec.: 1: 0,00227.

concilio s. m. 'concilio, congreso, junta o reunión': Aquesti noble varón, queriendo divulgar et ennoblecer la suya fama et justicia, fizo celebrar concilio general en la ciudat de Barcalona 29.8. Tomado del lat. concilium. Frec.: 1: 0,00227.

concordante] adj. y p. de pres. del v. concordar, 'acorde con otra u otras personas'. Vid. concordar. 
concordar] v. tr. 'acordar entre sí, ponerse de acuerdo varias personas': las gentes de la tierra ensemble, concordantes con Fortunno Ximenez comte d'A ragón, eslieron el dito Ennego en rey de Pamplona 10.12-13; et todos ensemble concordoron et eslieron [esleyeron $\mathrm{N}$ ] en rey et sennyor lur al dito Frederich 38.145-146. Del lat. CONCORDARE. Frec.: concordada 1: 0,00227 ; concordado 1: 0,00227 ; concordantes 4: 0,00909; concordavan 2. 0,00455; concordaron 2: 0,00455 ; concordoron 1: 0,00227 .

concordia s. f. 'concordia': Et depués, los prelados, nobles e cavalleros et gentes populares del un regno et del otro, por tal que paz et concordia fues entrellos qui todos tiempos yeran seydos unos en fortunas et prosperidades, aplegoronse amigablement 20.151. Cultismo tomado del lat. concordia, deriv. del lat. COR, CORDIs ‘corazón'. Frec.: 3: 0,00682.

condado s. m. 'condado': no trobavan mas valient ni mas avençado cavallero como el noble varón, natural del condado de Vigorra, clamado Ennego 10.7; el uno huvo nombre Guiffre et aquesti fue primogénito et succedió después dél en el dito condado, el el otro Olviano, et huvo por heredat los condados de Bisuldu, et de Cerdenna, et Miro succedió a éll en el condado de Girona 25.2-4; aquestos dos hermnos çagueros cambioron lures condados el uno al otro, porque don Pero camió el su condado de Ampurias con el infant don Remon Belenguer su hermano por el condado de Pradas 38.422-424. Deriv. de conde. Frec.: condado 104: 0,23639; condados 16: 0,03637.

condal adj. 'perteneciente o relativo al conde': Et de otra part engendró un fillo bort nombrado Sancho, al qual dio Ayvar et Xavierre Alatre [Latre N] con todas lurs villas, et aquí lo insignó de titol condal 16.32. Deriv. de conde, con el sufijo adjetivo -al. La 1. ' documentación que da el DCECH es de 1843 (Dicc. de la RAE); el BDELC, la da en 1780. La Crón. SJP. la adelanta en casi cinco siglos en el primer caso y unos cuatro en el segundo. Frec.: 1: 0,00227.

conde s. m. 'conde, persona que ostenta el título nobiliario inmediatamente inferior al de marqués': las quales naciones los godos echaron de Espannya et despues estaron en ella fasta la traición del conde don Yllan, quasi CCCC annos 2.11. Del lat. COMES, -ITis ‘compañero', que en el Bajo Imperio se aplicó a los nobles que vivían en el palacio imperial y acompañaban al soberano en sus expediciones, de manera que acabó designando un escalón determinado en la jerarquía feudal (BDELC, p. 165, s. v.). Frec.: 11: 0,02500. Vid. conte.

condessa s. f. 'condesa': Et tantost la condessa vistió el moço con vestiment de peregrino et con una muller viella ella lo envió a su madre en la ciudat de Barchinona. 23.21; Onde como el dito Simón quisiesse las condessas de Tolossa hermanas del dito rey don Pedro deheredar... 34.128. Femenino de conde, con morfema de género -essa, de carácter irregular. Frec.: condessa 1: 0,00227; condessas 1: 0,00227.

condestable s.m. 'título de suprema autoridad militar': el rey de Francia envió el condestable et senestara senescal de Tolosa 36.331. Etim.: del lat. COMES STABULI 
'conde encargado del establo real' (DCECH, II, p. 170; BDELC, p. 165). Para cat. conestable vid. DCVB, t. 3, p. 384, y DECLIC, II, p. 861, s. v. comte. Se documenta en cat. a pric. del s. XIV (Muntaner; Consolat del Mar). Comp. fr. connétable, oc. ant. comestable; cast. condestable, adaptación, por influjo de conde, del cat. conestable. En francés está documentado ya en el s. XII. Esta dignidad se introdujo en Castilla en 1382, y el vocablo puede documentarse en el s. XV en el Marqués de Santillana; luego en Nebrija (DCECH, II, p. 170). Parece evidente que en Aragón se empleó antes. Frec.: 1: 0,00227.

condición s. f. 'condición': Et ella respondió quel plazía muito, con tal condición que su fillo no regnas en Castiella, qui por succesión, según que de suso yes dito, li era provenido. 14.83; et diogela con tal condición las ditas tierras, que aquéllas tenies en feu [feudo N] en dreita sennoria por el rey Remiro 16,32; Todo esti regno dio en casamiento con su filla con las condiciones sobreditas. 20.285. Cultismo tomado del lat. condicio, -onis 'condición, estipulación' (SEguRA, 2002: 148). Frec.: condición 4: 0,00909; condiciones 1: 0,00227.

confederación s. f. 'alianza, pacto, acuerdo, tratado': Et depués, por tal como el poder de los moros era grant et poderoso, fizo confederación et avinençia aquesti rey con el rey don Sancho de Navarra 16.41. Etim. deriv. de CONFOEDERARE 'unir por tratado,

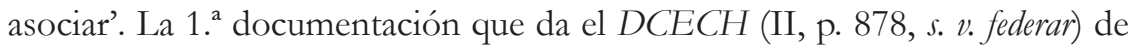
esta voz en cast. es 1469. Frec.: 1: 0,00227.

conferir v. tr. 'autorizar', 'conceder': los quales capitoles, cerrados et sellados con los siellos de cada un rey, el dito rey Carlos sende [sen $\mathrm{N}]$ levó al Padre Santo, et aquéllos en pleno consistorio al Padre Santo mostró por tal como él hi avía a firmar et a conferir [consentir $\mathrm{N}]$, 38.74-77. Etim.: del lat. CONFERRE, íd., propte. 'llevar junto con', deriv. de FERRE 'llevar' (BDELC, s. v.; DCECH, IV, p. 632). Frec.: 1: 0,00227.

confessar] (var.: confesar]) v. tr. y prnl. 'confesar': Et tantost los ditos infamadores confesaron et dixeron al sancto varón que falsament e iniqua havian a lur madra infamada 14.76; Et estando el rey en hedat de LV annos devotament et bumil penedido et confessado con grant contricción de sus peccados, al verdadero Dios envió el sus spiritu 36.703; «adoraré la tu santa casa, el templo santo tuyo, et me confessaré al tu nombre» 35.294. Cultismo tomado del bajo lat. confessare. Frec.: confesaron 1: 0,00227; confessado 1: 0,00227; confessados 1: 0,00227; conffesaré 1: 0,00227.

confiar] v. prnl. 'confiarse': estando daquá de las montannas, supo que los moros tenían asitiada la ciudad de Pamplona muyt destreytament en tiempo de yvierno et, confiandose de la gracia de Dios, con las gentes de Cantabria e de su regno... 12.52. Deriv. de fiar, del lat. vg. *FIDARE, modif. del lat. Fidere. Cfr. DCECH, II, p. 885, donde se documenta confiar en cast. por primera vez hacia 1440 . En cambio, cat. confiar e it. confidare a fin del s. XIII; occ. ant. confizar a principios del s. XIII; fr. confier en el s. Xv. Conviene anotar que rige prep. de. Frec.: confiandose 1: 0,00227. 
confirmar (var.: conffirmar) v. 'corroborar', 'ratificar lo expresado en una escritura', 'revalidar lo ya aprobado': vino visitar el dito santo lugar e fue reçevido muy onrradament e maravellosa, e conffirmó la donatión que el compt d'Aragón avía feyta 11.39; Et aquesto fizo confirmar al emperador su marido. 14.93; Mas finalment el dito Padre Santo por dreyto pronuncio quel dito matrimonio non se podía desemparar, et a mayor firmeza confirmó el dito matrimonio. 34.66; el dito rey don Pedro juroles et confirmoles aquello que justament [injustament $\mathrm{N}$ ] demandaron et dioles el privilegio general clamado en Aragón que yes fuero. 36.678. Etim.: Voz culta prodecente del lat. CONFIRMARE 'íd.' (DCECH, s. v. firme). Hay numerosos ejemplos en los DLAA: «la qual uendicion por mj lodo \& sienes negun retenemjento atorgo \& confirmo \& quiero que atodos tjempos sia firme \& ualedera» (doc. de Bespén de 1275; $D L A A$, doc. $n^{\circ} 33$, p. 49, lín. 16); «E nos donna Sancha Marrtineç, abbadesa, esta carta lodamos \& confirmamos, \& este signal y ffemos [...] \& yo donna Graçia Xemeneç, priora, por mj \& por todo el conuento, esta carta lodo \& confirmo, \& est signal y ffago; eyo don Vraca Pereç, en ffermarera, esta carta lodo \& confirmo [...]: e yo donna Maria Xemeneç, sagristana, esta carta lodo \& confirmo [...]; eyo dona Mayor Marrtineç, almosnera, esta carta lodo \& confirmo» (doc. de Santa Cruz de As Serors; DLAA, doc. no 76, p. 112, lín. 87-93); «El otro preuilegio yes del sinyor rey dAragon don Pedro [...], hen el cual el dito sinyor rey les atorga \& co[n]firma a los de Ainsa todos preuilegios \& libertades que ellos han» (doc. de Bielsa de 1349; DLAA, no 113, p. 164, lín. 26). Es término muy frecuente en ordenamientos jurídicos: se registra en $F A$, $V M, F T, F G N$, etc. Cfr. TLME, Bustos, Contrib., DME. Sobre las diferentes acepciones de este término en los documentos notariales del Alto Aragón y en general en documentos de los siglos XIV y XV, vid. LAGÜENS (1992: 90). Frec.: confirmar 1: 0,00227; confirmó 3: 0,00682; confirmoles 1: 0,00227; conffirmó 1: 0,00227 .

confusso] p. p. y adj. 'confuso, confundido, desconcertado': Confussos, vencidos et consumados los franceses, la ciudat de Girona fincó stablida de la gent francessa 36.681. Del p. p. de CONFundere. Frec.: confussos 1: 0,00227.

conocer (var.: conoscer, conascer) v. tr. 'conocer': Otros dizen que a tiempo vino en Aragón et favló con algunos que sabian de sus poridades; otros que allí se perdió, que no fue conascido. 19.221; quiso entrar en el condado de Proenica por visitar aquél e conocer 33.38; empero que cada un rey conocies sus tierras assí como don Sancho el Mayor las avía departidas 20.165-166; cubrió celadament el prennado de su filla que ningún bomme non lo conosció res 23.16; et el rey, conosciendo la bondat que avía feito en que su sennyor non perdies la tierra... 35.206. Del lat. vg. CONOSCERE, lat. COGNOSCERE (DCECH, II, p. 176). La forma genuina en arag. es conoxer [konolér], con prepalatal fricativa sorda, y así se documenta en numerosos textos medievales. Así, por ejemplo, en $D L A A$ : «\& con el dito huerto en cluden \& departen por anda- 
miento adarredor, con en tradas \& exidas \& con todos melloramientos suyos, conoxidos o por conoxers (doc. de Miranda, aldea de Sariñena, 1299; DLAA, doc. $n^{\circ} 73$, p. 106, lín. 41-42). Igualmente, en documentos de la Cancillería de Aragón del s. Xv: «E nos de otra parte vos prometemos que de los primeros beneficios qui vagaran en exe bispado u otro qualquier deuant todos otros lo beneficiaremos en tal manera que conoxera que sera stado mas proueyto suyo» (carta de Alfonso V de Aragón a su primo el arzobispo de Zaragoza, de 31 de marzo de 1424; Lleal, 1997a: 74). En los Fueros de Aragón, versión romanceada de principios del s. Xv (ms. 207 de la BUZ): «et aya tienpo conuinient en el qual pueda alli star a demandar sus testimonios, que los aduga deuant la iusticia que conoxe de aquel pleito» (fol. 17v.; Lacruz, 1947: 261, lín. 216). En el arag. de Fernández de Heredia, junto a conocer o conoscer, también se registra conoxer en ocho obras (GILKISON, 1984: 32). En el arag. mod., junto a la forma fonéticamente castellanizada, conozer (Biello Sobrarbe, Echo, Pandicosa...), se registra conoxé en Ansó, conoixer en Bal de Bielsa y en Bal de Chistau (EBA, 1999: 582); koneixé en Benás (EBA, 1999: 1128). Frec.: conocer 1: 0,00227; conocía 1: 0,00227 ; conocido 2: 0,00455 ; conociendo 2: 0,00455 ; conocies 1: 0,00227 ; conoció 3: 0,00682 ; conoscido 1: 0,00227 ; conosciendo 2 : 0,00455; conosció 3: 0,00682; conascido 1: 0,00227.

conortar] v. tr. 'consolar, confortar': diziéndole muytas cosas quel havien de venir, et conortando su buest, fízose sacar la sayeta et murió 17.126. Etim.: del lat. vg. CONHORTARE, lat. cl. COHORTARI 'exhortar, animar', deriv. del lat. HORTARI 'animar, estimular, exhortar' (DECLIC, s. v. conhortar, tomo II, pp. 881-882). Ahí comenta Coromines: «En castellà d'ús bastant general des del s. XII fins al XVI, hasta Cervantes, i va seguir usant-se en judeo-castellà. Avui sol mirar-se com un aragonesisme, i en efecte conortarse és d'ús popular a Binèfar (Coll i Altabàs), pero Menéndez Pidal (Rev. de Aragón) comenta que també és corrent aconortarse 'consolarse' a Rubielos de Mora i Titaguas, "y fue usual en Castilla, lo cita Covarrubias y de seguro se seguirá usando en provincias castellanas". El fet és, de tota manera, que avui no pertany a la llengua literària veïna.» Se registra en el s. XIII en las obras de Berceo (Álvarez, 1991: 173). Comp. arag. mod.: aconortarse 'consolarse' (en Alquézar, ARNAL Cavero, 1944, s. v.); aconohortar 'acostumbrar, habituar' (en Orante; ANDolz, 1992, s. v., seguramente tomado de Alvar, HJ); akonortásen 'conformarse, consolarse, resignarse' (en el valle de Benasque, BaLlarín, s. v.). El EBA (1999: 582) registra conortarse 'conformarse' solamente en Binéfar (tomado de Coll y Altabás, 1902), pero aconortar o aconortarse 'consolar(se), conformar(se)' en A Fueba, Biello Sobrarbe, Bal de Benás, Semontano, Sobrepuerto, Bal de Bielsa, Orante, Salas Altas. Arag. med. conortar 'confortar, consolar' (TILANDER, FA, p. 316); 'alentar, fortalecer, dar ánimo' en Fernández de Heredia (GILKISON, s. v.). También conortar 'con- 
fortar, dar ánimo' en el LT (PrInce, 1995: 220). Se usa ya en el Roncesvalles: «Porque más me conuerto por que perdoneste a Roldáne» (Roncesvalles, verso 91. Vid. MenÉndez Pidal, TME, p. 20). Vid. también aconortar 'confortar, animar' en en el arag. del s. XV (VILA, p. 138). Frec.: conortando 1: 0,00227. conoscencia s. f. 'conocimiento': dius aquesta condición le dexó el dito regno por tal como el dito rey don Jayme con voluntat et conoscencia [conocencia $\mathrm{N}$ ] de dos hombres buenos de Mallorquas et de otros dos de Perpinyan et otros dos de Puycerdan et de su consello le fues dado curador fasta que por si mismo pudies regir su tierra. 38.604. Tomado del lat. cognoscentia. En los FA: conoxença 'conocimiento' (Tilander, FA, p. 317). Frec.: 1: 0,00227.

conoscimiento s. m. 'conocimiento': Et don Alfonso de Aragón rendie gracias a Dios del consello et conoscimiento quel havía dado a su fillo 19.177. Frec.: 1: 0,00227.

conpannya (var.: compannia, conpannya, conpanya, compaynna, companna) s. f. 'compañía, formación militar, grupo de gente armada': supo como los moros eran cerca, firo parellar sus compannas et dio la delantera a su hermano 18.33; el dito rey con su compannya sin que ningún mal non prisso tornose a sitiar la dita ciudat 38.368-370; et firo grandes ajuntamientos de compaynnas de cavallo e de pie 33.78-79. Para el etim. vid. companna. Frec.: conpannya 8: 0,01818; conpannyas 7: 0,01591 ; conpanyas $1: 0,00227$; compannia $2: 0,00455$; compannya 1 : 0,00227 ; compannyas 4: 0,00909 ; compaynnas 1 : 0,00227 ; compannas 1 : 0,00227 .

conparecer v. intr. 'comparecer, hacer acto de presencia': «yo so el rey don Pedro d'Aragón qui vengo a conparecer al día de la batalla delant vos» 36.284-285. Etim.: deriv. de parecer < lat. vg. * PARESCERe, deriv. incoativo de parere 'aparecer', 'parecer'. COROMINAS documenta por 1. ${ }^{a}$ vez comparecer h. 1600 (BDELC, p. 441; DCECH, IV, p. 400, s. v. parecer). La Crón. SJP. adelanta esa documentación en más de dos siglos. Frec.: 1: 0,00227.

conpresso p. p. de conprender 'comprendido, entendido', quizá en el sentido de 'acordado, pactado': el rey Alfonso fue conpresso entre [él et $\mathrm{N}]$ el dito rey de Inglaterra de veyerse entramos cierto día et lugar 37.66. Frec.: 1: 0,00227.

conque prep. con + pron. rel. que 'con que, con la que': consello et ayuda conque pudies gitar los moros de la su tierra 23.57. Frec.: 1: 0,00227.

conquerir v. tr. 'conquistar': atorgogele que si él lo podía conquerir la tierra que havía perdida et deffender la otra que le havía fincado 23.60; la qual fue conquiesta en el anno de Nuestro Sennyor MCXLVII. 32.23; el dito rey Ordonyo prendiendo mayor audacia, passando el mont Pireneus, conquirió entro a la ciudad de Tolosa 9.8-9. Del lat. CONQUIRERE. Es cultismo según indica Bustos, Contribución, p. 388. Fue usual hasta el s. XVI (DCECH, IV, p. 719). Frec.: conquerir 7: 0,01591; conquiesta 1: 0,00227; conquirieron 1: 0,00227 ; conquirió 3: 0,00682 . 
conquiesta participio fuerte de conquerir (vid.), 'conquistada'. Frec.: 1: 0,00227. conquista s. m. 'conquista': aquesti varón fue a la conquista de Almaría 32.14; et por aquesto fue clamado venturosso, porque tantas conquistas et tan grandes et con tan pocas batallas non fueron feitas depués que Ihesu Christo fue venido en la Virgen Santa María. 35.3. Del p. p. fem. de conquerir, sustantivado. Véase que, en cambio como participio se usa conquiesta: la qual fue conquiesta en el anno de Nuestro Sennyor MCXLVII. 32.23. Frec.: conquista 10: 0,02273; conquistas 4: 0,00909.

conquistar] v. tr. 'conquistar': bubo ardit que los moros traballavan la su tierra et que la havian quasi conquistada 23.56. Verbo rehecho sobre conquista (DCECH, IV, p. 719, s. v. querer). Vid. conquerir. Frec.: conquistada 2: 0,00455.

consagrar] v. tr. 'consagrar': e res no menos fizieron consignar [consagrar $\mathrm{N}$ ] al dito monasterio por el vispo d'Aragón, nombrado Ennego, el dia de Sancta Agatha 9.38-40, (consignar: error por consagrar, en el ms. B leemos consagnar, aunque reescrito sobre consignar). Del lat. tardío consaCrare, lat. COnSECrare (DCECH, V, p. 127). Frec.: 1: 0,00227.

consanguinidat s. f. 'consanguinidad': empero el dito rey de Castiella la dita dispensación de consanguinidat no bubo al dia asignado 38.60. Deriv. del lat. SANGUIS, -INIS

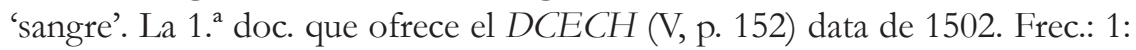
0,00227 .

consecución s. f. 'consecución, acción y efecto de conseguir': Et rendidas gracias a Dios et a la suya santificada Madre de las victorias que todos tiempos avía obtenidas contra moros et de la present consecución [conquista $\mathrm{N}$ ], edificó en la dita ciudat yglesia episcopal 35.161. Frec.: 1: 0,00227.

consellar] v. tr. 'aconsejar': e consellaronle los ricos ommes que le fizies bien e mercet, e assí lo fizo 19.93-94; rogándole que le consellasse lo que faría 20.110; pensó que sería irregular si le consellava que firies justicia 20.112; et sus vassallos conselloronlo que se parties dalli 35.171. Deriv. de consello. Frec.: consellaronle 1: 0,00227; consellasse 1: 0,00227 ; consellava 1: 0,00227 ; consellavan 2: 0,00455 ; conselló 2: 0,00455 ; conselloronlo 1: 0,00455.

consellero] s. m. 'consejero': et clamó don Caxal et dos otros conselleros et havieron acuerdo quel rey partiesse d'alli 20.194-195. Deriv. de consello. Frec.: conselleros 2: 0,00455 .

consello s. m. 'consejo': demandó de consello si lo mataría o lo faria redimir 20.226-227. / / 'conocimiento, connivencia, confabulación': el Cit era ayrado del rey don Alfonso de Castiella porque priso la jura el Cit, la qual ninguno de Castiella no ossó prender del rey don Alfonso que no fues en consello de la muert de su hermano el rey don Sancho 18.80-81. // 'órgano de deliberación que aconseja al rey': et fue por su consello acordado que fues redimido 20.228. Etim.: del lat. ConsiLium 'deliberación, consulta', 'asamblea consultiva', 'consejo, parecer' (DCECH, II, p. 177). Frec.: 30: 0,06819. 
consentimiento s. m. 'consentimiento': et con voluntat et consentimiento del dito rey Fortunyo García, el dito monasterio ennoblesció 8.6. Deriv. del v. consentir con sufijo -miento < lat. -MENTUM, que forma derivados de verbos que designan el resultado de una acción (Pharies, 2002: 403). Frec.: 3: 0,00682.

consentir v. tr. 'permitir una cosa o condescender en que se haga', 'otorgar, obligarse': et se clamava princep de Aragón et conte de Barçelona, que non quisieron consentir los aragoneses que se clamasse rey 32.17; juró a los del regno que no estado consintient en la dita muert de su hermano 18.86-87; conselló a la dita reyna que por res del mundo no consintiesse o diesse [consinties e dies $\mathrm{N}$ ] el dito cavallo a hombre vivient 14.46-47. Etim.: del lat. CONSENTIRE 'estar de acuerdo', 'decidir de común acuerdo'; la forma romance está registrada desde orígenes. Documentación en textos aragoneses: en $D L A A, F A, V M, F T, D J$. Para el castellano medieval vid. DME. Frec.: consentir 1: 0,00227; consintient 1: 0,00227; consintieron 2: 0,00455; consintiesse 1: 0,00227; consintiessen 1: 0,00227.

conservado] p. p. 'conservado': et la división destos regnos fue metida en el monesterio de Sant Johan de la Pennya que alli fues perpétuo [perpetualment $\mathrm{N}$ ] conservada [observada N] 20.172. Frec.: conservada 1: 0,00227.

conservador adj. 'conservador': el dito emperador se comandó a su muller tenedor et conservador [conservadera $\mathrm{N}$ ] por ella en el castiello de Nágera un su cavallo 14.35-37. Frec.: 1: 0,00227.

consistorio s. m. 'junta o consejo que celebra el papa con asistencia de los cardenales de la iglesia católica': los quales capitoles, cerrados et sellados con los siellos de cada un rey, el dito rey Carlos sende levó al Padre Santo, et aquéllos en pleno consistorio al Padre Santo mostró por tal como él hi avía a firmar et a conferir [et consentir N], 38.7577. Etim.: cultismo tomado del lat. consistorium 'lugar de reunión' (DCECH, II, p. 824). Vid. Bustos, Contribución, p. 389. Frec.: 2: 0,00455.

constitución] s. f. 'constitución'; 'ley, ordenanza, estatuto': fueron hi feitas constituciones a proveyto et utilidat de la tierra 38.24. Es cultismo tomado del lat. CONSTITUTIO, -ONIS. Frec.: constituciones 1: 0,00227.

constituir v. tr. 'constituir': Mas por tal como los fillos eran en pupillar [pupila N] edat constituidos, fueles dado curador 25.6. / / 'formar, componer, construir': hedificaron hí dos altares mens [menos $\mathrm{N}]$ de aquéllos qui ya eran constituidos 9.29. // 'establecer, ordenar, instituir': et constituir [constituyó B, N] III procuradores en la tierra 35.33; et por aquesta donación el Padre Santo por honor de la casa de Aragón constituyó quél y todos sus successores levassen un papallón feito a sennal del rey de Aragón 34.40-42. Etim.: voz culta procedente del lat. constituere. Corominas da la 1. ${ }^{a}$ documentación de esta voz en cast. en 1438 (DCECH, s. v. estar). Todas las localizaciones de la voz en el DME son del siglo xv, al igual que las recogidas en el DCVB. Comp. constituezco en DJ (EDA, II, p. 206, y en doc. $\mathrm{n}^{\circ} 12$, de 1484). 
En DLAA, ser constituido 'comparecer' en docs. no 105 (de 1331), n’ 113 (de 1349), no 121 (de 1360) y 147 (de 1473). Frec.: constituir 1: 0,00227; constituidos 1: 0,00227; constituydos 3: 0,00682; constituyeron 1: 0,00227; constituyó 1: 0,00227.

consumar v. tr. 'consumar, llevar a cabo totalmente algo', en el sentido de 'acabar con algo, aniquilar, exterminar, destruir': el qual finalement, muertos et consumados et los demás presos, con él se los levó a Barchinona 36.549; mutilaron et distruyeron todas las otras reliquias de aqui et de las otras eglesias lançoron et vilment consumoron 36.569. // 'ratificar el matrimonio mediante la realización del acto sexual': aquesti matrimonio fue trobado consumado 35.55; quel casamiento d'él et de su filla passaría et consumarse [confirmarse N] podría sin peccado 38.34; et non quiso consumer [consumar $\mathrm{B}$ y N] el casamiento 38.409. Cultismo tomado del lat. CONSUmmare. Frec.: consumado 1: 0,00227; consumados 4: 0,00909; consumoron 1: 0,00227; consumarse 1: 0,00227; consumer [consumar] 1: 0,00227.

conta s. f. 'cuenta, recontamiento, cómputo', 'acción y efecto de contar': et morieron grandes gentes de moros que no y havía conta 19.205-206. Comp. compto: con grandes gentes de moros que no avian compto.19.56. Etim.: deriv. de contar, y este del lat. COMPUTARE 'calcular', deriv. de PUTARE 'íd.'. El DCECH (II, 180, s. $v$. contar) incluye cuenta 'acción y efecto de contar' entre los deriv. de contar. Dice de cuenta: "derivado importante que además del castellano sólo existe en el port. conta". Por lo que vemos en la Crón. SJP, también en aragonés se documenta conta (y compto). Pero además estas formas se registran en las obras de Fernández de Heredia: conta, en la Crónica Troyana; conto en siete de sus obras y comto en Rams de Flores (GILKISON, s. v.); también conto en LT (RodÉs, 2016: 706); igualmente conto en el arag. del s. XV en Teruel (Terrado, 1991: 252); conto 'cuenta' se registra en DLAA (REIDY FRITZ, 1977: 138). En el VM, cuenta y conta ('Tilander, VM, III, p. 80). Frec.: 3: 0,00682.

contar v. tr. 'contar; narrar': et a muytos d'otros semblantes gracias fizo, las quales serían luengas de contar 35.186; pero quando contó la manera que havía visto, pensó que en si mesmo quel huerto podía seer el su regno, las colles yeran las gentes del su regno 20.120. Del lat. COMPUTARE. Vid. también recontar. Frec.: contar 1: 0,00227; contó 1: 0,00227 .

conte (var.: comte, compte, compt, cuende, conde) s. m. 'conde, primer grado en la jerarquía nobiliaria': Et depués el desus dito compt Urgel, Narmegon de Castilla, murió en el aynno de MCLVII 32.38; Aquesti barón virtuoso compte de Barçalona, quoando supo que su hermano Ramón Belenguer marques de Proeniça fue muerto... 32.42. Estas formas compt y compte aparecen en el ms. N, pero lo más habitual es conte: fue feito conte de Luna por el dito rey don Pero et la hora le dio Luna 38.436-437. Las formas comte, conde y cuende son minoritarias: es asaber, como el comte Julian, 
sosmeso del dito rey Rodrigo, fues ydo por mesagería al rey Aboali moro 3.80; las quales naciones los godos echaron de Espannya et despues estaron en ella fasta la traición del conde don Yllan, quasi CCCC annos 2.11; Et el rey de Caragoça enviól por dos cuendes a Castiella 18.12. Etim.: del lat. COMES, -ITIs 'compañero', que en el Bajo Imperio se aplicó a los nobles que vivían en el palacio imperial y acompañaban al soberano en sus expediciones, y acabó por convertirse en el nombre de un escalón determinado de la jerarquía feudal. La forma más común de todas en la época arcaica del cast. es cuende (Cid; Berceo; Disputa del alma y el cuerpo). La forma no diptongada se explica por influjo de la nasal y no por atonicidad de la palabra, según Navarro Tomas, RFE, XII, 353 n. (DCECH, II, p. 170). Vid. también conde, cuende. Frec.: conte 175: 0,39776; contes 6: 0,01364; conde 11: 0,02500; comte 20: 0,04546; compt 8: 0,01818; compte 47: 0,10683; comptes 1: 0,00227; cuende 2: 0,00455.

contemplación s. f. 'contemplación, consideración, condescendencia': fue electo en ovispo de Pamplona et depués, por contemplación de su hermano el rey don Alfonso, el qual quería que fues perlado [prelado N] en Aragón, fue electo en ovispo de Barbastro et de Roda 20.81-83. Frec.: 1: 0,00227.

contenido p.p. y adj. 'contenido': et soterraronlo en una muyt bella tomba sobra la qual el nombre et la vida del dito sancto era notificada et contenida con letras muyt ricament eentretalladas 9.23; Et los que fincaron en Asturias fizieron rey a Pelayo, según en el livro de las corónicas de Castiella yes contenido. 4.10; yxieron en el alborada et no caceron [curoron $\mathrm{N}$ ] por ren entro que plegoron al rey et matoronlo et a los otros contenidos de suso. 34.163. Del p. p. del v. contener. Frec.: contenido 6: 0,01364; contenida 1: 0,00227; contenidos 1: 0,00227.

contento adj. 'contento, satisfecho': et don Ramón compte don [sic; ¿por de?] Tolosa, no contento de las injurias que ante le avía feytas, tollió el dito castillo de Albayon al dito rey. 33.40-41. Etim.: tomado del lat. contentus 'satisfecho', propiamente 'contenido', p. p. del v. CONTINERE 'contener' (BDELC, p. 168; DCECH, II, p. 181). Es un cultismo, para el cual COROMINAs da la primera documentación en castellano en 1375, es decir aproximadamente coincidente con la de la Crón. SJP. En cat. content (FABRA, DGLIC, s. v.); occ. content (ALIBERT, s. v.); fr. content (PRobert, s.v.). Frec.: 1: 0,00227.

continent adv. de tiempo 'enseguida, a continuación, inmediatamente' (aparece también en las loc. adv. en continent, de continent, con la misma significación): non demostrando esto a don Per Atares, ni escusándolo en el acto que estava, de continent dizieron que non podian entrar a verlo, que ocupado era de afferes 20.32; et dio tan grant terror al dito castillo que de continent se rendió 32.53; Et continent, el dito rey Carlos envió a dezir al Padre Santo que pues el dito cardenal era muerto, a otro devies somendar sus vezes. 38.96; envyó por un duch sosmeso suyo clamado Abdemali Abencaçan, al qual fuertment mandó que en continent fues con gran poder de hombres a 
cavallo enta las partes d'Aragón 4.27-28; por la qual cosa él sende tornó en continent en su tierra 35.210. De la expresión latina IN CONTINENTI (TEMPORE) 'en (un tiempo) continuo', y por extensión 'inmediatamente'. Cfr. PRobert, s. v. incontinent. En occ. encontenen (LEVY, s. v.); en cat. encontinent (DECLIC, VIII, p. 422, s. v. tenir). Es habitual en arag. med.: en el VCA (p. 98) se registra tanto en continent como de continent, en el arag. de Fernández de Heredia, continent 'quickly, rapidly, inmediately' (GILKISON, 1984: 34); en los DLAA, encontinent 'en seguida, al instante' (REIDY, 1977: 159); en el LT, de continent 'rápidamente, de inmediato' (RodÉs, 2016: 706); etc. Frec.: 46: 0,10455.

continuo] adj. 'continuo': En aquellos dias, el santo rey don Jayme en la su reverent vellesa fue opprimido en el dito regno de fiebre continua por la qual non podia defender el dito regno 36.68-69. Tomado del lat. continuus. Frec.: continua 1: 0,00227.

continuament adv. 'continuamente': E en tanto abivado et encorajado de haver batallas continuament con los moros que apenas estava un dia seguro. 10.15-16. Frec.: 4: 0,00909 .

continuar v. tr. 'continuar': assi que la Unión que en tiempo del rey don Pedro se era feita et continuada en tiempo del rey don Alfonso su hermano... 38.623-624; quiso continuar su propósito de conquerir et subingar regnos et tierras de moros mientre Dios vida li dasse 35.153; el dito conte non quiso obedecer, antes continuó su propósito de mal affer contra las hermanas del dito rey. 34.132. Deriv. de continuo. Frec.: continuar 2: 0,00455; continuó 1: 0,00227; continuada 1: 0,00227.

contra (var.: cuentra) prep. 'contra': por tal que las sus gentes no [no se $\mathrm{N}]$ pudiessen rebellar contra ell 3.77-78; fue volenterosament [valerosament $\mathrm{N}$ ] cuentra el rey de Castiella 17.34; el dito conte non quiso obedecer, antes continuó su propósito de mal affer contra las hermanas del dito rey. 34.132. Del lat. CŎNTRA 'frente a, contra'. La variante cuentra se registra una sola vez; sin embargo, suele aparecer con frecuencia en obras en arag. med.: se encuentra en varias obras de Johan Ferrández d'Eredia: Rams de Flores o Libro de actoridades, Libro de los Emperadores, en la CRONICA de los CONQueridores y en la Grant Cronica de Espanya (GILKISON, 1984: 38). En FA, escontra, escuentra (TILANDER, 1937, FA, pp. 390-391, quien cita cuentra en las Ordinaciones de Zaragoza: «cuentra los ditos jurados»); en el FT, escuentra, escuantra (GoROscH, 1950: 520). Frec.: contra 76: 0,17274; cuentra 1: 0,00227 .

contradezir] v. tr. 'contradecir, pronunciarse en contra de': et los poblos del regno contradezianlo [contra lo N], guardando dreyto de naturaleza por el infant don Jayme que devía seer rey 35.16-17. Del lat. CONTRADICERE, deriv. de DiCERE. Frec.: contradezianlo 1: 0,00227.

contradicción s. f. 'contradicción, oposición, objeción': que entramos los ditos reyes cada uno con cien homes a cavallo cavalleros se aviessen a conbatir ensemble, et aquell que 
obtendría en la batalla que avies sueltament sin contradicción el dito regno de Serilia 36.257. Cultismo tomado del lat. contradictione $(m)$. Frec.: 1: 0,00227.

contrafer] v. intr. 'contravenir, obrar en contra de lo dispuesto, vulnerar, incumplir': dius [diole $\mathrm{N}$ ] pena de perder las ditas tierras guanyadas et aplicadas [ganaderas e aplicaderas $\mathrm{N}]$ al dito donador et a los suyos si contrafizies en continent 16.35-37. No tiene, pues el significado que da el DLE para el cast. contrahacer 'hacer una copia de una cosa, tan parecida a esta que apenas se distingan' (DLE, 2014, s. v.). Deriv. de fer. Frec.: contrafizies 1: 0,00227.

contrariar v. intr. 'llevar la contraria, oponerse': los de la tierra e los ricos ommes enbargaron aquel casamiento e comensaron de contrariar 19.161. Deriv. de contrario < lat. CONTRARIUS. Frec.: 1: 0,00227

contrariedades s. f. pl. 'contrariedades, dificultades': «Sennyor, por la tu merce, que non ayamos temor de las contrariedades de aquesti [desti $\mathrm{N}]$ mundo» 35.240. Cultismo tomado del lat. contrarietas, -atis. Frec.: 1: 0,00227.

contrario adj. 'contrario, opuesto, discrepante, antagónico': e destruyó la ciudat de Arles, que el hera muy contraria 32.47. // 'dicho de una cosa: perjudicial, dañosa, nociva': et él tractó muytas cosas contrarias contra ell dito hermano suyo 36.41 // s. m. 'opinión opuesta, lo contrario': et offreciose a entrar en batalla campal contra todo homme quien [que en $\mathrm{N}$ ] el contrario tenies [tuvies $\mathrm{N}$ ] 16.9-10. Del lat. CONTRARIUS. Frec.: contrario 3: 0,00682; contrarios 1: 0,00227; contraria 2: 0,00455; contrarias 3: 0,00682.

contrast s. m. 'confrontación, enfrentamiento, pugna, oposición, resistencia'; 'discrepancia, desacuerdo, disensión': que los christianos se guarnian fuertment de grandes fuerças et deffensamientos en el dito lugar clamado Pannyo, et si contrast non se dava, grant dapnage se podrían seguir a los moros. 4.24. Es postverbal de contrastar. En Fernández de Heredia: contrast, contrasto, constrast 'oposición; resistencia, discrepancia, desacuerdo' (GILKISON, s. v.); en el VCA (p. 100), contraste 'oposición'. El DCECH da el voc. de A. de Palencia (1490) como la obra en que se doc. por $1 .^{a}$ vez en cast. contraste 'oposición' (DCECH, II, p. 778, s. v. estar). La Crón. SJP. testimonia que en arag. se utilizaba contrast hacía más de un siglo. Pero aún se registra un testimonio un siglo anterior, en un documento notarial de 1280: «\& conuiengo auos sobre dicto don Guillem \& auuestro fillyo Sancho, el mayor, que si por auentura en algun tiempo nengun contrast venia sobre el dito heredamiento \& muela, \& sobre todo el dreyto que nos yemos nj la dicta orden, \& si porauentura messiones nengunas uos con ueria afer, en pleytiar nj en qual quiere manera, yo sobre dicto mayestro Sancho Xemeneç uos prometo catar de dano» (doc. de Castellyon de Valdeyassa [Castejón de Valdejasa] de 1280; DLAA, doc. n 50, p. 75, lín. 21-22). Frec.: 3: 0,00682 .

contrastant p. de pres. del v. contrastar, 'que se opone, que resiste, que se enfrenta, que hace contradicción'. Se usa en la loc. conj. non contrastant loc. conj. 'no obstante, 
a pesar de': Et depués de algunos dias, el rey de Castiella dio su filla, que avía nombre María, al dito rey don Jayme por muller, non contrastant que fuessen en muyt cercano grado de parentesco 38.27. Se registra el uso de esta loc conj. en otros textos en arag. med.: «e qual quiere que faga desafiar o desafie a otro sea encorrido en pena de çient sueldos aplicadera por iguales partes al comun o a los Jurados de la dita çiudat e no contrastant la dita pena sia constreyto a asegurar el desafiado por el Justicia e Jurados de la dita çiuda๖» (OB, p. 12., lín. 16). Vid. contrastar.

contrastar v. tr. y refl. 'oponerse, pugnar, hacer contradicción; resistir, enfrentarse a, dar batalla': el dito rey don Pedro con aquel poco poder que avia, vinos'ende al col de Panizars et aquí se atendó por contrastar al dito rey de Francia et a todo el poder suyo 36.480-483; por tal como no podian defender ni contrastar que alguno non poniesse su cabanna de ganado 11.58. / / non contrastant loc. conj. 'no obstante, a pesar de': non contrastant que fuessen en muyt cercano grado de parentesco 38.27. El verbo contrastar se registra en el s. XIII en las obras de Berceo (Álvarez, 1991: 174). Con el mismo significado en Fernández de Heredia (GILKISON, 1984, s. v. contrastar). De CONTRASTARE 'Oponerse', comp. de STARE 'estar en pie', 'estar firme', 'estar inmóvil' (DCECH, II, p. 778, s. v. estar). En Fernández de Heredia contrastar, contrestar 'oppose, resist, dispute' ['oponer, oponerse a', 'resistir, resistirse a', 'disputar'] (GILKISON, 1984, s. v.). En el VCA (p. 100): contrastar 'resistir, hacer frente'. En Alex.: contrastar 'resistir', 'ponerse en contra, oponerse' y contrasto 'oposición, resistencia' (SAS, 1976: 154 y 155). Frec.: contrastar 2: 0,00455; contrastant 1: 0,00227.

contricción (var.: contrición) s. f. 'contrición': devotament et bumil penedido et confessado con grant contricción de sus peccados, al verdadero Dios envió el su spiritu 36.703; Et tantost con gran devoción penedidos et confessados fielment de lures pecados, et con grandes cantos et melodías divinales et con grant contrición de coracón, bumilmenty devota, translataron los cuerpos del desus dito Sant Johan heremita 9.20. Etim.: cultismo, del lat. Contritio, -onis. La 1. ${ }^{\text {a doc. que }}$ da el DCECH (V, p. 644, s. v. trizar) es del Corbacho (1438). Frec.: contricción 1: 0,00227; contrición 1: 0,00227.

contumacia s. f. 'rebeldía, falta de comparecencia', 'terquedad, obstinación', 'icumplimiento de un acuerdo': requiriendo al notario que allí era que de aquéllas et del comparecimiento suyo et de la fadiga et contumacia del dito rey Carlos le devies fer carta o cartas públicas a memoria perdurable 36.297-300. Etim.: Voz culta procedente del lat. CONTUMACIA, -AE 'íd.'. Debe de ser lo mismo que contumaçio, que se registra en $D L A A$, en el sintagma caer en contumaçio 'incumplir los acuerdos de un contrato' (REIDY FRITZ, 1977: 139; LAGÜÉNS, 1992: 94-95): «Son caydos en contumaçio los ditos Eximeno de Pueyo \& Johan Pereç de Latras, de VI kafices de trigo» (doc. de Liesa, de 1300; $D L A A$, doc. $\mathrm{n}^{\circ} 77$, p. 114 , lín. 25). Se registra varias veces contumatia 'falta de comparecencia' ya hacia 1250 en el VM (TILANDER, VM, III, p. 70). Véase un ejemplo: «et, feita la citatión a su casa por tres uezes por espatio de x días, será pasado contra sus bienes en todas cosas d'aqueilla manera, assí [como] 
conra los bienes d'aqueill qui es present et se absente por contumatia, segunt dito es de suso» (Tilander, VM, II, p. 121: $\$ I, 69, 93). En el LT: contumacia 'contumacia, obstinación' (RodÉs, 2016: 706). El DME de Martín Alonso (1986, tomo I, p. 779) se recoge contumacia 'tenacidad y dureza en mantener con tesón u error', con registros en las Siete Partidas (1256-63) de Alfonso X (dice «contumacia es palabra del latín, e quiere tanto decir en romance como desobediencia»), en el Universal Vocabulario (1490) de Alonso de Palencia y en el Vocabulario español latino (1495) de Nebrija. En el DRAE (1970, s. v.): contumacia 'tenacidad y dureza en mantener un error' y (como voz forense) 'rebeldía, falta de comparecencia en un juicio'. Es esta segunda acepción la que conviene al pasaje de la Crón. SJP. Comp. en arag. mod. contumanzia 'dificultad, adversidad' en A Fueba (EBA, 1999: 585); 'infortunio, adversidad, desgracia, circunstancia adversa' en Huesca y su comarca (NAGORE, 2020a: 199); 'trampa, falsedad, fraude' en el Somontano de Basrbastro (Mоsтolay, 2007: 180). Frec.: 1: 0,00227.

conuerto s. m. 'consuelo': tanto començó bien de regir, por do buvieron grant conuerto los de la buest 17.129. Deriv. postverbal de conortar. Se registra en Alex. (SAS, 1976: 155). Lo usa en varias de sus obras (Cronica de los Conqueridores, partes I y II; Grant Cronica de Espanya, parte I) Fernández de Heredia (Gilkison, p. 32, s. v. confort, da como significado 'comfort ['comodidad'], 'solace' ['consuelo']). Se documenta también en el LT: conuerto 'consuelo, ánimo' (RoDÉs, 2016: 706). Frec.: 3: 0,00682.

convenir] v. tr. 'acordar, pactar, convenir': et res non menos $<r>$ enuntió a todo dreyto et a toda demanda que en qualquiere manera avies o podies [oviesse et podiesse $\mathrm{N}$ ] aver en el regno de Secilia, assí como era convenido en los capitoles de la paz dessuso dita. 38.121; los dreitos et razones allegadas de cada una part, convinieron en ciertos capitoles 20.160. // v. prnl. 'importar, ser adecuado, ser conveniente', 'corresponder, pertenecer': et feyta el uno al otro reverencia e honor que se conviene, con grant goyo e alegría entraronse en el dito lugar 11.19; porque se convenía que de todos mescladament favlasemos 15.4. Del lat. CONVENIRE 'venir juntamente al mismo sitio'. Frec.: convenía 1: 0,00227 ; convenido $1: 0,00227$; conviene $3: 0,00682$; convinieron 2: 0,00455; convínole 1: 0,00227; convínoles 1: 0,00227.

convento s. m. 'séquito del obispo': el dito rey Remiro fue recebido según la convinença desus dita por don Sancho de la Rosa, vispo de Pamplona, con el su convento et por todo el poblo de la dita ciudad 20.173-175. Del lat. CONVENTus 'asamblea, congreso, reunión, congregación'. Frec.: 3: 0,00682.

conversión s. f. 'conversión': en día miércoles a hora de media tercia, vigilia de la conversión [conversatión $\mathrm{N}$ ] de San Paulo 39.43. Del lat. conversio, -onis 'vuelta, giro'. El BDELC (p. 604, s. v. verter) documenta este cultismo por vez primera en cast. en 1495 (Nebrija). Frec.: 1: 0,00227. 
convertir] v. tr. y prnl. 'convertir': el dito regno fue possado en tranquilidat de paz et la tempestat fue convertida specialment en prosperidat 36.77; et veet [veyet $\mathrm{N}$ ] los prometimientos del rey de Castiella en quienta manera mala se convirtieron 38.39. Tomado del lat. CONVERTERE 'íd.'. Frec.: convertida 1: 0,00227; convirtieron 1: 09,00227;

convidar v. tr. 'convidar, invitar': a manera de convidar o de aver colloquio con él 38.46. Del lat. vg. *CONVITARE. Vid. conbidar. Frec.: 1: 0,00227.

convinencia (var.: convinença) s. f. 'acuerdo, convenio': et el otro día siguient, el dito rey Remiro fue recebido según la convinença desus dita por don Sancho de la Rosa 20.173174; dio favor et ayuda contra la convinencia que avía feita con su sennyor 36.477-477. Deriv. de convenir. Frec.: convinencia 3: 0,00682; convinença 1: 0,00227.

convinient (var.: convinent) adj. 'conveniente', 'adecuado': et esperando hora convinent, firió vigorosament en la huest de los enemigos 33.85; fue feyta dentro breu tiempo convinient población 9.38. Deriv. de convenir. Frec.: convinient 2: 0,00455; convinent 1: $0,00227$.

copiosso] adj. 'numeroso, nutrido, abundante': do fueron el arcevispo de Tarragona et muytos de otros vispos [vispes N], prelados, nobles, barones, cavalleros et ciudadanos et otras gentes en multido [multitut N] copiossa. 38.20. Deriv. del lat. COPIA 'abundancia'. El DCECH (II, p. 188) lo registra por $1^{\text {a }}$ vez en 1413. Frec.: copiossa 1: 0,00227 .

copula s. f. 'unión, cópula'. En los dos casos en que se registra, en el sintagma carnal copula y copula carnal, referido a 'unión del hombre y la mujer', es decir, con valor semejante al de 'coito': Onde como la dita reyna en días et annos de hedat non fues, carnal copula non fue seguida entre los ditos rey et reyna 38.56; la dita dispensación de consanguinidat no huvo al dia asignado, segunt avia prometido, ni encara depués el dito dia, por la qual cosa el dito rey don Jayme, assí como savio sennyor, non quiso aver copula carnal con la dita reyna 38.62-63. Etim.: del lat. COPULA ‘lazo, unión'. Es un latinismo crudo. Corominas (BCELC, p. 171, y DCECH, II, p. 188) lo registra en cast. por $1^{\mathrm{a}}$ vez en 1438; aquí, el testimonio de la Crón. SJP. sería de h. 1372. Frec.: 2: 0,00455.

coqua s. f. 'embarcación alta y muy amplia, de una o varias cubiertas': el el dito rey don Jayme envió a Oristan en la isla de Cerdennya con III coquas [comptes N] los nobles don Dalmau vizconte de Rocaberti, don Guerau de Rocaberti, don Bertran de Castellot et Nuch de Santa Pau con CLXXX hombres a cavallo 38.487-490; el dito don Alfonso partió de la ciudat de Barçalona con XX galeras et con muyto de otro navilio de naves, coquas [cotas N] et otros vaxiellos 38.496. El DRAE (1970) registra coca 'cierta embarcación usada en la Edad Media' (igualmente, el DLE, 2014, s. v. coca , $3^{a}$ acepción). Lo hace proceder del lat. CŎNCHA 'concha, caparazón', pero es difícil explicar tanto la caída de la - $n$ - como la falta de diptongación de la ŏ; además sería muy raro que hubiera dado coca por un lado y cuenca por otro, con un tratamiento fonético tan distino, pues parece claro que el cast. cuenca 
$<$ lat. CŎNCHA, lo mismo que las formas aragonesas (cuenca, cuanca, cuanga). Según Corominas, es de origen incierto, quizá del lat. Caudica 'especie de nave', por conducto del fr. coque, forma normando-picarda (DCECH, II, p. 108; DECLIC, II, p. 792). Ahí atestigua el uso del cat. coca en el s. XIII; también occ. ant. coca y fr. ant. coche y la forma coque en el mismo siglo; it. cocca en el s. XIv. En efecto, Levy (1980: 81) registra en occ. ant. coca 'sorte de vaisseau rond, large à l'avant et à l'arrière'. Para el cast. sólo atestigua la voz coca en 1817 (Academia, como voz antigua). La misma etim. CAUDICA la proponen Meyer-LÜBKe (REW, no 1775) y el $D C V B$ (t. 3, p. 243). Según la descripción y las citas que para el cat. da este último, debía de ser una nave de gran tamaño. De la Crón. SJP. 38.487-490 podemos deducir lo mismo, pues el rey don Jayme envía tres coquas con "CLXXx hombres a cavallo". Sin embargo, el lat. CAUdicA no era más que una 'especie de batel o bote' (BLÁnQueZ, s. v.). Frec.: 2: 0,00455 .

corage s. m. 'coraje, valor, arrojo, valentía': fue muy buen rey, ad grant corage, et todos tiempos guerreró con moros et toda vegada venció aquéllos. 16.38-40; et fue naturalment de grant corage et ardido et proz 32.4. Quizá sea un occitanismo. AliberT, s. v. còr, registra coratge 'courage' como propio del occ. de Quercy. Según Corominas (BCELC, s. v. corazón), del fr. courage 'valentía'. En el DCECH (II, 191) se matiza: tomado del fr. ant. corages 'valentía' (hoy courage). El adj. derivado corajoso 'valiente' se registra en Alex. (SAS, 1976, s. v.). Tanto corage como corajoso son en su origen derivados del lat. COR 'corazón), lo mismo que otras formas como encorajar, corajina, encorajinarse (DCELC, 1954, s. v.). РОтTIER (ELH, II, pp. 140 y 147) da el cast. coraje 'valentía' como galicismo adoptado en el s. XIX, pero añade que en la acepción de 'enojo' fue tomado como préstamo en el s. XIv. En la Crón. SJP. designa sólo la 'valentía' o 'fortaleza de ánimo'. Por lo tanto, está más en relación con el occ. y con el cat. coratge, que se documentan con ese sentido desde época muy antigua (cfr. DECLIC, II, p. 916.). Frec.: 2: 0,00455 .

coralment adv. 'cordialmente': «et las tus fieles gentes qui han a mi amado coralment et han metido el corazón et ell aver [animo B] al servicio de Dios et mio» 35.264-266. Comp. occ. coralmen adv. 'cordialment' (Levy, s. v.) Comp. con cat. coralment, doc. a fin del s. XIII (DECLIC, II, p. 915). En Fernández de Heredia coral 'perteneciente al corazón', amigo coral 'amigo íntimo' (GILKISON, s. v.). Frec.: 1: 0,00227 .

coraznudo] adj. 'valiente, con coraje, con valentía': Et aquesti empero rey Sancho Avarcha havía vassallos buenos et bien espiertos et coraznudos [corajosos $\mathrm{N}$ ] de haver batallas et guerras 12.63. Deriv. de corazón, con sufijo -udo, el cual, como indica Pharies (2002: 513), «aplicado a bases sustantivas de sentido anatómico, sugiere que dicha parte anatómica es de forma o tamaño exagerado o exce- 
sivo. Remonta a una terminación latina -utus, - $a$, -um de función análoga». No aparece en Gilkison (1984), ni en ReIDy (1977), ni en ANDOlz (1992), ni en otros diccionarios consultados. Únicamente en MARTínez $(2008$, s. v.) se registra coraznudo 'corajudo, valiente'. Frec.: coraznudos 1: 0,00227.

corazón (var.: coraçón) s. m. 'corazón': et con grandes cantos et melodías divinales et con grant contrición de coraçón, bumilment y devota, translataron los cuerpos del desus dito Santo Johan beremita 9.20; et, queriendo demostrar todo su corazón et su siensa [piensa $\mathrm{N}]$ que avía de subiugar la nasción morisma et aduzir la tierra a la fe christiana 35.119. Etim.: derivado del lat. Cor 'corazón', que sería primitivamente un aumentativo que aludía al gran corazón del hombre valiente y de la mujer amante (BDELC, s. v.). La forma sufijada, semejante a la del cast. corazón solo se conoce en portugués (coração), gallego (corazón), asturiano (corazón) y judeo-español (korason): los demás romances han conservado el lat. COR sin más cambios que los meramente fonéticos: cat. cor, fr. coeur, franco-prov. côr, occ. còr, romanche cor, piamontés cheur, friulano cûr, it. cuore, sardo coro, siciliano cori, a excepción del rumano, inimă (VALLÉs, 2007: 197). CunHA (1986: 261) afirma que el port. coração proviene «do lat. cor, com uma terminação que talvez se possa explicar por um suf. aumentativo de reforço (cp. cast. corazón)». Para Corominas no sería imposible como étimo un lat. vg. *CORICIO, -ONIS, y que de ahí procediera corazón, pues el cambio de I > a quizá no sería obstáculo insuperable. Sin embargo, le parece menos aventurado suponer que el vocablo recibió los dos sufijos aumentativos -ACEUM y -ONEM, por efecto del concepto medieval del corazón como sede de la valentía. En cast. tenía ç sorda en la Edad Media. La ç sorda es irregular, pero podría quizá explicarse por un refuerzo de la articulación debido al énfasis con que el vocablo se pronuncia tantas veces. La forma corazón, con ₹ antigua, solo se halla en el Yúcuf, ms. B, si bien con vacilaciones; pero como notó Menéndez PidAL (1952: 119), este manuscrito, del s. XVI, confunde ya muchas veces los dos fonemas. El vocablo no aparece en el ms. A, más antiguo (DCELC, 1954, s. v., y DCECH, II, 189-190). Como se ve, también hay vacilación coracón / corazón en la Crón. SJP., lo cual parece indicar que la confusión de los fonemas que representan ambas grafías (dentoalveolar africado sordo y sonoro, respectivamente) era ya un hecho habitual en el aragonés del siglo XIV (cfr. al respeto: NAGORE, 2003: 182-186).

cormano s. m. 'primo hermano': non queriendo sofrir ni sostener las desonores que su cormano el rey don Sancho de Castiella fiziera 17.28; porque ayudava a su cormano don Sancho rey de Navarra 17.30. (Se refiere al rey Sancho Remírez de Aragón y Sobrarbe, que ayudaba a Sancho de Navarra; y efectivamente, estos eran primos). Etim.: contracción de co-hermano (BDELC, s. v. hermano, p. 318; DCECH, III, p. 347). No se registra en el arag. de Fernández de Heredia 
(GILKIsOn, 1984) ni en los DLAA (ReIDy, 1977). En FA: cormano 'pariente de la parte de la madre' (Tilander, FA, p. 326). En VM: cormano 'pariente de la parte del padre o de la madre', cormandat 'parentesco' (TILANDER, VM, III, p. 71); en general, en las versiones romanceadas de los Fueros de Aragón: cormano 'pariente, consanguíneo, primo' (Pérez Martín, 1999: 590). En nav. ant. cormano 'lo mismo que primo; palabra de distinción con que honraban los reyes a los ricoshombres y grandes señores' (Yanguas, 1964: 202). Comp. cosino hermano 26.2-3 'primo hermano'. Vid. cosino. Frec.: 3: 0,00682.

corona s. f. 'corona': Et lexado el dito regno en buena disposición, en Catalunnya sen tornó por prender la corona et dignidat real 37.11. Del lat. CORONA. Frec.: 1: 0,00227.

coronación s. f. 'coronación': Empero quel dito Frederich desenbargas el regno de Secilia a la Yglesia et no evan [heran $\mathrm{N}$ ] a la coronación de aquéll 38.159. Deriv. de corona. Frec.: 1: 0,00227.

coronar] v. tr. y prnl. 'coronar': con muyt mas bonramiento que nunca rey se coronas, fue coronado et untado en rey 39.7-8; et el Padre Santo, vidiendo la nobleza del dito rey, coronó et untó aquél con grant honor 34.34. Del lat. CORONARE. Frec.: coronado 6: 0,01364; coronas 1: 0,0227 ; coronó 1: 0,00227 .

coronica] s. f. 'crónica'. Vid. crónica.

correr v. intr. 'correr, fluir, manar': d'alli adelant como corre Ebro entro Tudela 20.280. // v. tr. 'hacer una incursión, saquear, asolar, invadir; recorrer un territorio en son de guerra': vino a correr et destruir la tierra de su tio el rey Remiro 16.55; el dito rey ajustó los barones de Prohença, con ellos ensemble corrió toda la tierra del dito conte de Folçaquer 34.55. vino y mandado quel rey moro de Lérida con grant poder de moros le havian corrido Moncón et lur tierra 19.210-212; el qual fuertment mandó que en continent fues con gran poder de hombres a cavallo $i$ de pie enta las partes d'Aragón, et toda aquélla corries 4.29. // 'acosar, perseguir': et invió XXX de cavallo e cient peones que corriesen a los ganados e a los ommes que trovasen 19.33. Del lat. CURRERE 'correr'. El DLE (2014) recoge como acepción número 25 de correr 'perseguir o acosar a alguien', y como acepción 35 'recorrer en son de guerra territorio enemigo'. En Fernández de Heredia se registra ya, además de como intr. 'correr', 'fluir', como tr. 'hacer una incursión, saquear' (GILKIson, s. v.). Actualmente se utiliza en Aragón como tr. y con una acepción muy semejante: 'correr el monte con el ganado, ir con el ganado, pastorear'. Así, por ejemplo, en el Somontano de Barbastro: «Noniler toa ra bida les corrió o ganau á os de Migalón» (Mostolay, 2007: 183). Frec.: correr 4: 0,00909; corre 1: 0,00227; corrido 1: 0,00227 ; corrieron 2: 0,00455 ; corries 1: 0,00227 ; corriese 1 : 0,00227; corriesen 1: 0,00227; corrió 1: 0,00227.

corronpido adj. y p.p. 'corrompido': et el dito rey de Castiella, corronpido de grandes prometimientos de moneda por el rey Carlos, secretament a manera de convidar o de aver 
coloquio con él o en qualque manera entendía a prender el dito rey don Jayme 38.44. Del p. p. del v. corromper < CORRUMPERE. Cfr. DCECH, V, p. 62, que registra corrompido por 1. ${ }^{a}$ vez en 1495 (Nebrija). Frec.: 1: 0,00227.

corsario] s. m. 'corsario, pirata': supo que su bermano Ramón Belenguer marques de Proeniça fue muerto, el quoal murió por corsarios de la mar en el puerto de Malguir 32.44. Etim.: del lat. cursus 'acción de correr' (DCECH, II, 209, s. v. correr, donde se documenta corssario en 1490 (Alonso Fernández de Palencia), corsario en Nebrija (1495). Pero corsario, cursario y cossario se documentan ya en Fernández de Heredia a fines del s. XIV (GILKISON, 1984, s. v.). Frec.: corsarios 1: 0,00227.

cort s. f. 'corte'; 'junta o reunión de gobierno': et pus, fizo ajustar sobre aquesto cort general 14.63. // pl. cortes 'cortes, asamblea, junta general del reino': mandoron plegar [tovieron N] Cortes Generales en el lugar de Borja 20.11. Etim.: del lat. vg. CORS, CORTIS, lat. COHORS, -ORTIS (DCECH, II, p. 213). COHORS, -ORTIS se usó en lat. con los significados de 'recinto, patio, corral'; 'cohorte, división de un campamento, tropas acampadas'; 'grupo, tropa, banda'; 'tropa auxiliar, ejército'; 'estado mayor, séquito' (SEGURA, 2001: 130). De la primera significación procede el sust. corte 'pocilga, cochiquera', usado en algunas zonas de Aragón, en especial del centro de la provincia de Teruel (vid. NAgore, 2020c, p. 77, mapa 11); de la última, probablemente, cortes 'asamblea, junta general'. Frec.: cort 11: 0,02500; Cortes 6: 0,01364; cortes 10: 0,02273

cortés adj. 'cortés, atento, afable, que se comporta con urbanidad y con buen modo': et por aquesto fue nombrado el Benigno, porque fue el mas cortés de palabra et el mas familiar et el mas avinent a los sus sozmesos que otro rey que al mundo fues 39.3. Deriv. de cort, pues en principio designaría la manera de comportarse propia de (o que se adquiere en) la corte. Frec.: 1: 0,00227.

cortesament adv. 'cortesmente, con cortesía': et muy cortesament sacó la criatura viva del vientre de su madre 12.10-11. Adv. formado con el sufijo -ment, que indica 'modo, manera' a partir del adj. femenino cortesa. Frec.: 1: 0,00227.

cortesia s. f. 'cortesía': non recibieron de buena manera a los navarros nin aquella bonra ni cortesía que devian et habian acostumbrado. 20.24. Deriv. de cort. Frec.: 1: 0,00227.

cosa pron. indef. y adv. 'nada': Et trobos que jamás en sus días non fizo cosa que desplazies a los sozmesos sinon aquesta 35.216. Etim.: del lat. CAUSA 'causa, motivo', 'asunto, cuestión', que en lat. vg., partiendo del segundo significado, se hizo sinónimo de RES 'cosa' ya en el siglo IV de nuestra era. Indica COROMINAS: «En frases negativas se hizo sinónimo de 'nada', y con este valor se halla desde Alfonso el Sabio hasta Tirso de Molina y hoy en aragonés» (DCECH, II, 219, s. v. $\cos a$ ). En arag. med., siempre en construcciones negativas, puede verse en LMM (LiRIA, 1979: 24); en el arag. de Fernández de Heredia (BADía, 1944: 188-189); en el LT (RodÉs, 2016: 707). El arag. mod. cosa 'nada' se registra en 
casi todos los diccionarios (aunque no en Peralta, Borao ni Moneva); véase, por ejemplo, en: Pardo, 1938: 105; Badía, Contribución, p. 64; ANdolz, 1992: 124; Rohlfs, DDPA, s. v.; Martínez, 2008: 67; Mostolay, 2007: 185; EBA, 1999: 598-599; NAgore, 2020a: 203; etc. Ya en el Diccionario aragonés [anónimo] de h. 1803-1815 se registra no cosa 'nada', con un interesante comentario: "En inglés se dice nothing, que traducido literalmente es no cosa" (Bernal \& NAGore eds., 1999: 106). Comp. ren, res. Frec.: 1: 0,00227.

cosa] s. f. 'cosa': de la quoal cosa el dito rey García Yneguiz fue muy pagado 11.34; et depués de todas aquestas cosas, el dito rey don Jayme de Aragón devotament murió en hedat de LXXI annos 38.628; «et tu Sennyor es sobre todos los reyes et todas cosas son subingadas al tu imperio» 35.297. Del lat. CAUSA. Frec: cosa 33: 0,07501; cosas 26: 0,05910.

coser] v. tr. 'coser': don Jayme fue ferido con passador por el pie qui lo cosió con la cubierta de la galera 38.275. Del lat. CONSUERE (DCECH, II, p. 221). Comp. arag. mod. cusir 'coser' (EBA, 1999: 641-642). Frec.: cosió 1: 0,00227.

cosino hermano u. 1. p. (m.) 'primo hermano': et el compte de Proenica cosino hermano suyo, clamado Remón Belenguer.. 33.6-7; qui según razón et dreito devía millor suceder al dito conte Sifre en el dito condado que non su cosino hermano don Borrell 26.7; En vida de aquesti conte Borrel murió Olivano Cabreta, su cosino hermano 26.23; succedió depués en el condado de Barchinona su cosino hermano, conte de Urgell, fillo de su tio don Sunner. 26.2-3. Como se ve, en todas las ocasiones aparece la lexía cosino hermano. Comp. occ. cosin german 'primo hermano' (ALIBERT, s. v.), cat. ant.

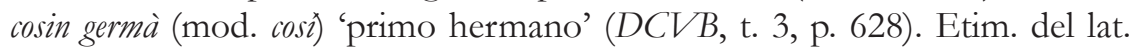
CONSOBRINUS, probablemente abrev. de CONSOBRINUS PRIMUS. En cat. se documenta cusino y cusina ya en docs. del s. XI (DECLIC, II, p. 989). Son también palabras del mismo origen it. cugino, fr. cousin, occ. cosin, franco-provenzal cusin, romanche cusrin, piamontés cusin, siciliano cucinu (Vallés, 2007: 425) En arag. sería un occitanismo, según FrAGO, pero muy antiguo y arraigado, pues, como este autor advierte, es frecuente en documentos altoaragoneses desde épocas muy tempranas: se encuentra ya en docs. altoaragoneses de 1062, 1147 y 1156 (FraGo, 1977b: 328-329). Se registra cosino 'primo' en arag. med.: en Fernández de Heredia (GILKIson, 1984: 36); en el LT (Rodés, 2016: 707); en el VCA (p. 104); en alguna de las redacciones romances de los Fueros de Aragón (Pérez Martín, 1999: 590); etc. Comp. cormano. Frec.: 4: 0,00909.

costado s. m. 'costado': con una sayeta por la manga de la loriga firiolo en el costado 17.122; los unos ferían en la delantera, los otros en la reçaguera, los otros en cada uno de los costados de la buest 36.639. Deriv. del lat. COSTA 'costilla, costado, lado' (DCECH, II, p. 278-279). Frec.: costado 1: 0,00227; costados 1: 0,00227.

costrenimiento s. m. 'constreñimiento, acción de constreñir, es decir de obligar a algo o a alguien a mantenerse dentro de ciertos límites; situación de estrechamiento o forzamiento de una ciudad, causada por el sitio o cerco de esta 
por tropas': et estando la dita ciudat en grant costrenimiento [estrenimiento B], otra vegada gran innumerable aiusto de moros por semblanment manera que dessuso havemos recontado, vino contra el dito rey et sus gentes 38.370. Etim.: es deriv. del v. costrennyr, del lat. CONSTRINGERE. Frec.: 1: 0,00227.

costrennyr (var.: costrenir) v. tr. 'oprimir, constreñir, presionar'; 'obligar'; 'agobiar, estorbar': et fizo by fer muytos castiellos et fuerças por costrennyr [estreyner N] los moros 12.48; porque más prestament et en antes los pudiessen aver et de aquéllos servir quando menester les fuesse et necessidad los costriniesse [lo costrenieron N] 14.33-35; grieu malautia lo costrennyó 38.94. Etim.: del lat. CONSTRINGERE. Se registra costrenyr en el arag. de Fernández de Heredia: costrenyr, constrenyer, costrenir, costrennyr, costrenyir 'oppress' ['oprimir, agobiarse'], como v. refl.; 'oblige, necessitate; constrain' ['constreñir, obligar'], 'impede' ['impedir, estorbar'], como v. tr. (GILkISON, s. v.); en costrenydo 'obligado' en OB (VÁzQUez, 2011c: 35) Frec.: costrennyr 1: 0,00227; costrennyó 1: 0,00227; costriniesse 1: 0,00227.

costumbre (var.: costumpne) s. f. 'costumbre; uso': porque yes costumbre et regla de monges negros que a todo novicio que era en la orden dan un monge de los ancianos por maestro 20. 104; et aqui muyt honradament el dito rey don Alfonso fue coronado et alçado rey, assí como es de costumbre et de ussança de reys todos tiempos 37.14; et confirmó todos los privilegios que avian de franquezas et todas buenas costumpnes 36.515-516; muytas et diversas injurias et dapnages que don G(uillermo) Remón de Odena havía feito et procurado al dito santo rey don Jayme su padre et a la tierra en el tiempo passado contra buenas costumpnes 36.16-19. Etim.: del lat. CONSUETUDO, -UDINIs, 'íd.', derivado de CONSUESCERE 'acostumbrar' y este de SUESCERE 'íd'. Como indican Corominas / Pascual (DCECH, II, 224-225, s. v. costumbre), «la evolución de la terminación, seguramente debida a un proceso fonético, es una alteración común a todas las lenguas hermanas y a todos los casos del sufijo -TUDO (certidumbre, mansedumbre, muchedumbre, etc.)». En cuanto al género: «El género femenino del cat. se ha conservado como en cast., en fr. coutume y parcialmente en lengua de oc. (costumna, fem., pero costum masc.) y en cat. ant. (costuma f., pero costum m., junto a algún ej. suelto de costum f.); mientras que el it. y port. costume, sardo costùmene, engad. costüm, cat. costum y el port. y gall. costume son masc., género que se oye también en Aragón según BORAO. [En la trad. castellana del De Mulieribus Claris de Boccacio, Zaragoza, Hurus 1494, y en otros incunables aragoneses aparece frecuentemente costumbre como masculino]» (DCECH, II, 224-225, s. v. costumbre). Comp. costumbre masc. en el arag. del valle de Chistau (Мотт, 1984: 40; Мотт, 2000: 101) y en otros puntos del Alto Aragón, como el Somontano de Barbastro: «En ixa casa tienen o costumbre de matar un cordero p'a fiesta» (Mostolay, 2007: 186). El EBA (1999: 602) registra costumbre como masculino en Ansó, Bal de Chistau, A Fueba, Biello Sobrarbe y Torres de lo Bispe; Romanos (2003: 169) en Orés y en Luna, en 
las Cinco Villas. Para el resultado fonético, comp. costumbrado y costumpnado 'acostumbrado' en $O B$ (Vázquez, 2011c: 35), donde vemos la misma vacilación que la Crón. SJP., circunstancia que produce igualmente en otros textos en arag. medieval. Frec.: costumbre 4: 0,00909; costumpnes 2: 0,00455.

crabeta s. f. 'cabrita, dim. de cabra'. Aparece como sobrenombre del conde Olivano de Besalú: Aquesti conte Olivano Crabeta fue varón muy poderoso 25.27. Del lat. CAPRA, con metátesis habitual en aragonés (crapa, craba). Esta metátesis se registra también en algunas lenguas románicas: así, en occ. gascón (craba), en piamontés (crava), en siciliano (crapa), en sardo (craba). No, en cambio, en la mayoría: cabra en port, gall., ast. y cast.; cabra en occ.; chiévra en franco-provenzal; chèvre en fr.; chaura en retorrom.; capra en it.; capră en rum. y en arumano (Vallés, 2007: 163). Se documenta crabito 'cabrito' en los FA de 1350 (TilanDER, 1935: 125); craba, crabitos y crabón en OB (VÁzQuez, 2011c: 35). Véase en arag. mod. craba, general en el Alto Aragón, Crabetas, crabito, crabón, crapa, crapito (EBA, 1999: 605, 607-608, 609). También Cabreta. Frec.: 1: 0,00227.

crebantar] v. tr. 'romper, quebrantar' (en el sentido de 'infringir, incumplir'): Et non res menos la tregua et paz que no quería dar al rey de Castiella, quando budió quel rey de Huesca le havía crebantada [crabantada en la ed. crítica] la tregua [tierra N], 17.51; de la qual tregua crebantada, el rey de Huesca lo compró 17.48; el rey de Castiella envió rogar al rey Abderramen de Huesca que crebantas la tregua al rey de Aragón 17.46. Deriv. del lat. CREPARE 'crujir, chasquear', aunque quizá ya existía en lat. vg. (DCECH, IV, p. 707). Es habitual en arag. med.: en el $V M$ (Tilander, $V M$, III, p. 77); en el LT (Rodés, 2016: 708); en los DLAA (REIDY, 1977: 142); en el arag. de Fernández de Heredia (GILkison, 1984: 37), en las $O B$ (VÁzQuez OBRADOR, 2011c: 35); etc. En arag. mod. el EBA (1999: 610) registra crebantau en Echo y crebar en Ansó y Echo. Frec.: crebantada 2: 0,00455; crebantas 1: 0,00227 ; crebantó 1: 0,00227 .

crecimiento s. m. 'crecimiento': la christiandad buvo prendido grant reformamiento et gran crecimiento en la tierra por los vencimientos innumerables 11.5-7. Frec.: 1: 0,00227.

crehador s. m. 'creador': «Fillo mio, sepas que yo me vo a Dios mi crehador qui me abrá merce por la su misericordia» 35.253. Aparece también el término latino en el comienzo del cántico religioso Veni Creator Spiritus 35.283. Frec.: crehador 1: 0,00227; Creator 1: 0,00227.

cremar] v. tr. 'quemar': Et por esto metierole sobrenombre Ariesta, porque como la ariesta aplegada cerca el fuego en un moment crema, assin el dito rey don Ennego, sabiendo que los moros deviessen haver batallas con él, en un momento era con ellos 10.18; quando la buvo cobrado, fizo reparar et endreçar aquella porque bien yera mester que toda era cremada et derrocada 36.691; pasó por la tierra del dito compt de Tolosa cremando e afogando aquéIla 33.70. Del lat. CREMARE 'íd.', igual que el cat. cremar. (DCECH, IV, p. 714; DECLIC, II, p. 1040). Es habitual en arag. med.: así, en los DLAA (REIDY, 
1977: 142); en el arag. de Fernández de Heredia (GiLKison, 1984: 37); en el LT (Rodés, 2016: 708); en el VM (Tilander, VM, III, p. 78); etc. Véase un ejemplo de cremar un documento notarial de Barbastro de 1394: «como él haujesse hun algaramjdero en el qual hauia de c cár $<\mathrm{r}>$ egas de lenya asuso \& de CL asuso [sic] \& aquellya algunos vezinos o habitantes en la dita ciudat le haujessen cremada por jnujdia \& malicia \& assí mateix le haujessen cremado huna casa cobierta \& le haujessen trencado muytas algaramjdas \& rejolas» (MDF, p. 189, doc. 299, lín. 9-13). En arag. mod. se conserva popularmente cremar 'quemar' en todos los altos valles, desde Ansó hasta Benasque (BADíA, Contribución, s. v.; ANDOLZ, s. v.; RoHLFs, DDPA, s. v.; EBA, 1999, p. 610, s. v. cremá, y pp. 611-612, s. v. cremar). Frec.: crema 1; 0,00227; cremada 1: 0,00227; cremando 1: 0,00227 ; cremaron 2: 0,00455 ; cremóla 1: 0,00227 ; cremoron 1 : 0,00227; cremoronlos 1: 0,00227

crexer] (var.: crecer, crescer) v. tr. 'acrecer, hacer más grande': Et depués su hermano Leovegildo, et aquesti exampló et crexió su regno en Spannya 3.48; Et depués de la muert de aquesti regnó el rey Bamba, el qual fue muy catholico rey et virutoso et batallero muy maravilloso, e exampló et creció muyto el su regno. 3.72; et a honor de Dios et de San Johan crecieron et melloraron la dita eglesia de San Johan Bautista 9.16. // v. intr. 'crecer': et pressa la dita ciudat, la maldición de las moscas quando más yva, más crecía en los franceses 36.615-617; por onde entró la podre qui a los de la establida venía de la mortaldat de los franceses et la freytura grant que sofrían grant mortaldat se cresció 36.609-610; Et quando el moco huvo estado un tiempo en la cort del dito conte et fue crexido, una filla del dito conte se enamoró del dito moço et finalment emporennola 23.9. [fue crexido 'hubo crecido']. Del lat. CRESCERE 'íd.' (DECLIC, II, p. 1036). Frec.: crexido 1: 0,00227 ; crexió 1: 0,0027 ; cresció 1: 0,00227 ; crecía 1: 0,00227; crecieron 2: 0,00455; creció 1: 0,00227.

creyença s. f. 'acreditación'; literalmente 'creencia'; 'acto de creer algo; acto de dar crédito a algo no probado': et el dito rey, inclinado mas a creyença que a certificación, mandó su muller ser pressa bien guardada en el castiello de Anagera 14.61 // letras de creyença 'cartas de presentación, de acreditación; cartas credenciales': un cavallero clamado don Pero Martinez de Bolea queriendo servir al rey et al regno, dixo quel dies letras de creyença el rey don Pedro pora el rey de Castiella que se apparellava pora entrar en Aragón 36.360 Etim.: Deriv. del verbo creyer, y éste del lat. CREDERE 'creer, dar fe (a alguno)' (DCECH, II, 235). Se documenta en otros textos en arag. med.: creyença 'creencia' en el LT (RoDÉs, 2016: 708); en Fernández de Heredia (GILKISON, 1984: 37), etc. Blancas, Indice (1641), recoge creencia 'salva'. Frec.: 3: 0,00682.

criar v. tr. 'criar, nutrir, educar': et delant dellos comendó el dito infant por criar al dito don Sancho 35.26; Et aquesti infant García yera sobrino del Cit Rui Diaz et criávalo en Valencia 20.63-64; Et en Galicia criavan a don Alfonso, fillo de dona Urraca e del 
compte Remón de Tolosa 19.130. Del lat. CREARE 'crear, procrear' (DCECH, II, p. 241). Frec.: criar 1: 0,00227; criávalo 1: 0,00227; criavan 1: 0,00227; crió 1: 0,00227 .

criatura s. f. 'criatura, niño recién nacido, o feto a punto de nacer': vido por la feridura que la dita reyna avía en el vientre aparecía una mano de criatura, et tantost apeió et abrió la dita reyna por el vientre et muy cortesament sacó la criatura viva del vientre de su madre 12.10-11. Es cultismo deriv. del lat. creatus, 'nacido de, hijo de', p. p. de CREARE (SEgura, 2001: 177). Se registra criatura 'niño que tiene pocos años' en los FA de 1350 (Tilander, 1935: 125). Frec.: 7: 0,01591.

cridar v. intr. 'gritar, dar gritos': Et depués de aquesto el dito rey brotó su cavallo assí como a valient cavallero por el campo enderredor cridando altament: "izyes aqui el rey Carlos o home por él?» 36.293. Etim.: quizá del lat. QuiRITARE, lat. vg. * CRITARE (DCECH, III, pp. 219-220). Comp. occ. y cat. cridar, it. gridare, port. y cast. gritar, fr. crier, retorrom. crider. Es habitual en arag. med.: cridado 'pregonado, anunciado', cridando 'gritando', cridará 'pregonará, anunciará' en las OB (VÁzQUEZ OBRADOR, 2011c: 35). Se registra también cridar en el arag. de Fernández de Heredia (GILKISON, 1984: 37); en los DLAA (Reidy, 1977: 142); en el LT (Rodés, 2016: 709); en el LMM (Liria, 1979: 163); en los FA (Tilander, FA, p. 334); etc. Frec.: cridando 1: 0,00227.

crido] s. m. 'grito': grant multitut de gent morisca assí de cavallo como de pie contra el poder del virtuoso rey por desuayr et desbaratar aquell si pudies, vino con grandes cridos et udulamentos 38.361. Etim.: postverbal de cridar (Vid.). Cfr. DCECH, III, pp. 219-220. La forma crido 'grito' se registra en todas las obras de Fernández de Heredia (GILKIson, 1984: 37). Igualmente, en los DLAA (REIDY, 1977: 142); en el LT (RoDÉs, 2016: 709). Frec.: cridos 1: 0,00227.

crimen s. m. 'crimen': la dio por innocent et por exempta del grieu crimen quel era levantado por sus fillos 16.7-8; todas quantas yglesias trobavan todas las robavan et destruyvan et de otros grieves crimines cometian et farían 36.494. Etim.: cultismo tomado del lat. crimen, -minis 'acusación', en la baja época 'falta, crimen' (DCECH, II, p. 243). Frec.: crimen 2: 0,00455; crimines 1: 0,00227.

crónica (var.: coronica, crononica) s. f. 'crónica': Et las oras fue vencido el dito rey Rodrigo por los moros et toda Espanna prendida entro Azlet de Provença [Arle de Proenica N] dentro XIIII meses, segunt que las coronicas dizen más largament. 3.93; del qual se conta mas largament en la crónica de don Sancho Remirez que murió en el sitio de Huesca 20.62; algunas cronónicas [corónicas $\mathrm{N}$ ] dizen que no era en sacres órdenes 20.72. Tomado del lat. CHRONICA, -ORUM 'crónicas, libros de cronologías', pl. neutro de CHRONICUs 'cronológico', tomado del griego кроvıко 'concerniente al tiempo', deriv. de крovos 'tiempo'. La variante coronica, debida a anaptixis o epéntesis vocálica, es muy común en textos aragoneses medievales. Pero también se registra en cast. $\left(1^{a}\right.$ Crón. General, Alex., Cancionero de 
Baena, Nebrija, etc.). Y ya antes, en mozárabe, en la forma qurûnica. En fr. de los ss. XIII-XIV se registra en la forma queronique, coronique (DCECH, II, p. 250). Frec.: crónica 5: 0,01136; coronicas 3: 0,00682; cronónicas [corónicas N]. cruel adj. 'cruel': Et depués regnó Euzica el qual, fue rey muy cruel 3.74. Del lat. CRUDELIS 'íd.'. Frec.: 2: 0,00455.

crueldad (var.: crueldat) s. f. 'crueldad': Et fuyendo los christianos de los lugares do habitavan por la dita terribilidad et crueldad, recullieronse en la espellunga assí como a lur refugio singular 9.12; Ennego, el qual era venido en estas partes por defender los christianos de las crueldades et terribles persecuciones de los moros 10.8-9; fue pressa la ciudat de Barchinona por moros do fue feita gran pestilencia et de grant crueldat en la tierra 26.14 . Del lat. Crudelitas, -ATIS. En VM, crueldat, pero también crueleza (Tilander, VM, III, p. 79). Frec.: crueldad 1: 0,00227; crueldades 2: 0,00455; crueldat 1: 0,00227 .

cruelment adv. 'cruelmente': le recontaron en qual manera havía estado vencido el rey $<$ de $>$ Seçilia Corrandi et en qué manera era estado escabeçado en Palermo por el rey Carlos cruelment 36.187. Frec.: 1: 0,00227.

cruz s. f. 'cruz': Et aquesto feyto, el dito santo rey se fizo adozir delant sí la santa verdadera Cruz de Ihesu Christo quel avía en uno de los sus coffres 35.275. Del lat. CRUCE(M). Frec.: Cruz 1: 0,00227; Cruçes 1: 0,00227.

cruzado] adj. 'el que toma la insignia de la cruz, alistándose para alguna cruzada': se lenvantó contra los hereges qui habitavan en provincia de Narbona con grandes gentes de Francia cruzadas 34.122-123. Frec.: cruzadas 1: 0,00227.

cubierta s. f. 'cubierta, piso superior de una nave': el dito rey don Jayme fue ferido con passador por el pie qui lo cosió con la cubierta de la galera 38.276. Frec.: 1: 0,00227.

cubierto] (var.: cuvierto) adj. y p. p. de cubrir'cubierto, que sobre un objeto se extiende una superficie de otra sustancia': passó las montannas que yeran cubiertas de nieve 12.55. // adj. 'encubierto, escondido': e no por casamiento e no por otra guisa cuvierta firo la reyna lo que él quiso 19.101-103; le envioron menazas con palauras cubiertas quel dito sitio se levantas 36.325. Etim.: del lat. COOPERTUS, p. p. de COOPERIRE. Frec.: cubierta 1: 0,00227; cubiertas 2: 0,00455; cuvierta 1: 0,00227.

cubrir] v. tr. 'ocultar, encubrir': como millor pudo, cubrió celadament el prennado de su filla 23.14. Etim.: del lat. COOPERIRE 'cubrir' (BláNQueZ, p. 440, s. v. cooperio). Frec.: cubrió 1: 0,00227.

cucjeción s. f. 'sujeción. sumisión, servidumbre': sacó el conde Guiffre el condado de Barchinona de poder de sennoria de Francia, do depués fue franco et quitio de toda cucjeción [subjitión N] 23.72. Cultismo tomado del lat. SUBJETIO, -ONIS. Frec.: 1: 0,00227.

cuende] s. m. 'conde': Et el rey de Caragoça enviól por dos cuendes a Castiella 18.12; El uno de los cuendes de dería don García de Traba de Nágera 18.14. Aparece cuendes dos veces, frente a 181 veces conte(s). Frec.: cuendes 2: 0,00455. Vid. conte. 
cuentra prep. 'contra': con los aragoneses et navarros fue volenterosament cuentra el rey de Castiella 17.34. Se documenta 76 veces la preposición contra, pero solo una vez la variante diptongada cuentra. Esta forma es habitual en los textos en arag. medieval. Se registra en cuatro obras de Fernández de Heredia (GILKISON, s. v.). En documentos notariales altoaragoneses se registra tanto quentra como quantra: «Damos en camio vnas casas que afruentan con casas de Pero dAlbella \& con via publica quentra \& salye al molino» (DLA A, p. 215, lín. 35; doc. de Boltaña de 1465); «\& atodas otras excepcionç e ajutorios que anos podesen ajudar quantra lo dito definimiento nin quentra alguna o algunas delas cossas sobre ditas» (DLAA, p. 104, lín. 33; doc. de Santa Cilia de Jaca de 1296). También cuentra en $O B$ (VÁzQUEZ, 2011c: 36): «E qui quiere que cuentra las ditas cosas o qualquiere de aquellyas vendra sea encorrido en pena de vint sueldos» (OB, p, 28, lín. 1).Vid. contra. Frec.: 1: 0,00227.

cuerda] s. f. 'cuerda': e firo el dito castillo levar por el rio con cuerdas delant el castillo de Carcataia 32.51. Del lat. CHORDA. Frec.: cuerdas 1: 0,00227.

cuerpo s. m. 'cuerpo': et las sus gentes levantaronse del sitio et levaron el cuerpo de lur sennyor a soterrar en el dito monasterio de San Johan de la Penna 16.59; et con grant contrición de coracón, bumilmenty devota, translataron los cuerpos [sic] del desus dito San Johan heremita et soterraronlo en una muyt bella tomba 9.21. Del lat. CORPus. Frec.: cuerpo 15: 0,03409; cuerpos 1: 0,00227.

cuesta prep. 'cerca de, al lado de, junto a': avía dentro en la ciudat XX mil moros, et passó [posó N] las sus tiendas cuesta los moros de la dita ciudat 32.20-21. [E posà les sues tendes costa los murs de la dita ciutat VC, p. 102] [et erant intus ciuitatem XX milia sarracenorum, et castrametatus est circa muros eiusdem civitatis. VL, p. 122]. Parece que en el texto aragonés hay una confusión de moros por muros. / / de cuesta loc. adv. 'cerca, al lado': et vino sende a un castiello en Berberia clamado Alcoll et aquel con muytos de otros qui de cuesta le estavan conquistó et priso 36.165-167. [e venc-se'n a un castell en la Barbaria apellat Alcoll, e aquell e molts d'altres qui costa ell eren, conqués e pres VC, p. 132]. Del lat. CosTA 'costilla'; 'costado, lado' (BDELC, s. v. cuesta; DCECH, II, pp. 278-279). Comp. cat. costa 'cerca, al costado de', de costa 'al lado, junto a' (DCVB, t. 3, p. 651; DECLIC, II, p. 999). Frec.: 2: 0,00455.

cueva (var.: cueba) s. f. 'cueva': en la desus dita cueva heran cullidos por el miedo 11.9; fue multiplicada la devotión en la dita cueva 11.12; el rey García Enyeguiz desus dito, el quoal recontó el romeage que avía feyto a la dita sancta cueba 11.33. Etim.: del lat. vg. *COvA 'hueca', fem. del adj. Covus, var. arcaica de CAvus 'hueco' (DCECH, II, p. 282). Comp. espelunca espellunga. Frec.: cueva 5: 0,01136; cueba 1: 0,00227 .

cueyta s. f. 'trabajo, aflicción, desventura, apuro, padecimiento': et sabia qué eran traballos et cueytas 12.71 // 'ansia, anhelo, deseo vehemente': Desque se vido la reyna partida del emperador tovo cueyta de casar con ella como ante hera 
fablado 19.100-101. Etim.: del lat. vg. Со̆СTA, fem. de состUs, lat. cl. СОАСTUS, part. de COGERE 'obligar, forzar' (BDELC, p. 184, s. v. cuita; DCECH, II, p. 285). Ambas acepciones vienen en el DRAE (1970) para el cast. cuita, la segunda como antigua (e igualmente en el DLE, 2014, que señala la segunda acepción como desusada). Cita cueytas 'padecimientos' KuHN (HAD, p. 14). En Fernández de Heredia se registra cueyta 'aflicción, cuidado, inquietud', y las variantes cuyta, cuida, cuita (GILKISON, s. v. cuyta). Vid. también la var. cuyta. Frec.: cueyta 1: 0,00227; cueytas 1. 0,00227. cullido adj. 'cogido, recogido, recluido'. Vid. cullir.

cullir] v. tr. 'coger, recoger': Et las horas, los christianos, qui en la desus dita cueva heran cullidos por el miedo e terribledat de los moros, yxieronse d'aqui e fueronse a poblar en los lugares que avían desanparados 11.9. Del lat. COLLIGERE 'recoger' (DCECH, II, p. 120). Frec.: cullidos: 1: 0,00227.

culpa s. f. 'culpa': et de otra part perdón a pena et a culpa todo christiano 36.460. Cultismo tomado del lat. culpa. Frec.: 1: 0,00227.

culpable] adj. 'culpable': pero clamava aquellos que le yeran culpables 20.135. Etim.: del lat. culpabilis, deriv. de culpa < lat. Culpa. El BDELC da la $1^{\text {a }}$ doc. de culpable en cast. a mediados del s. XVI. El DCECH (II, p. 288), en 1428. En cualquier caso, es anterior este testimonio de la Crón. SJP. Frec.: culpables 1: 0,00227.

cultivar v. tr. 'cultivar': Et por el poblo que aduxo de Cicia por cultivar la tierra et por el rio que ha nombre Beti nombra el otro regno Betica 1.18. Etim.: tomado del bajo lat. cultivare 'íd.', que es latinización del fr. ant. coutiver o del it. coltivare (BDELC, p. 185). Comp. arag. mod. cautibar (RoHLFs, 1985, DDPA, s. v.; Andolz, 1992, s. v.; EBA, 1999: 464). El DCECH (II, p. 288) registra cultivar por vez primera en cast. en 1515. Frec.: 1: 0,00227.

cunnyado s. m. 'cuñado': Otra crónica dice que su cunnyado el conde Ramón de Tolosa enviolo rogar que vinies en ayuda, que avía guerra con el rey de Francia 34.149; el qual fue desposeydo por escusación de justicia de su regno et tierras por el rey don Pedro, cunyado [cuynado N] suyo et hermano de su muller. 38.596. Etim.: del lat. COGNATUS 'pariente consanguíneo', deriv. de NATUs 'nacido' y CON- 'juntamente' (DCECH, II, p. 295). Frec.: cunnyado 3: 0,00682; cunyado 1: 0,00227 .

cupiditat s. f. 'envidia, ambición, deseo violento, afán, codicia': El qual Remón, de cupiditat inhonesta et contra Dios excitado et movido por tal que regnar pudies en el regno qui a su hermano don Sancho assin como a primogénise se pertannya, mató al dito Sancho 17.7. Tomado del lat. cupiditas, -atis. Frec.: 1: 0,00227.

cura s. f. 'cuidado': con la grant cura et consello et estrenimiento de armas del dito rey don Pedro, la ora seyendo infant... 36.24. Etim.: del lat. CURA 'cuidado, 
solicitud'. También se empleó en cast. ant. con la acepción 'cuidado', en Berceo (BDELC, p. 186; DCECH, II, p. 295). Vid. arag. med. cura 'cuidado, solicitud' en el LMM (LiRIA, 1979: 164), en el LT (RodÉs, 2016: 709), en el VCA (LLEAL, 1997: 108), etc. Es también habitual en las obras de Fernández de Heredia (GILKISON, s. v.). Frec.: 1: 0,00227.

curador s. m. 'guardador, encargado de la custodia o pupilaje', 'regente, tutor, persona encargada de tutelar o custodiar a una persona durante su minoría de edad': Mas por tal como los fillos eran en pupillar edat constituydos, fueles dado curador [goardador $\mathrm{N}$ ], 25.7. Etim.: deriv. de curar < lat. CURARE 'cuidar' (DCECH, II, p. 296; DECLIC, II, p. 1110, s. v. cura). Es habitual en arag. med.: «por la qual razón haujan mester tutor \& curador qui criás \& nudrís las personas de aquellos e demandás, procurás, regís \& mjnjstrás sus bienes» (doc. de Lanuza de 1409; VázQuez, 2017: 68). En el VM (Tilander, III: 83): curador 'persona que cuida de los bienes y de los hijos del testador': «curadores son ditos aqueillos qui reciben en su goarda los bienes et los fillos del qui faze el testament» (TILANDER, VM, II: 259; parte III, cap. 67, lín. 6). Frec.: 4: 0,00909.

curadoria s. f. 'custodia, pupilaje, tutoría, espacio de tiempo en que una persona está al cuidado de un tutor': et passados los ditos XX annos de la curadoria, los ditos fillos ... fueron en edat que cada uno pudo regir su tierra 25.12. Etim.: deriv. de curar $<$ lat. CURARE 'cuidar' (DCECH, II, p. 296, s. v. cura; DECLIC, s. v. cura, t. II, p. 1107-1111). Se pronunciaría seguramente con hiato: curadoría. Véase así interpretado en un documento de Lanuza de 1409: «por actorjdat et poder aél dado en el djto officio, dje, creó \& asignó en tutoría \& curadoría a los djtos popillos» (VÁzQuez, 2017: 68; con $j$ acentuada en el original). Frec.: 1: 0,00227.

curar] v. intr. 'preocuparse, cuidar de': Los franceses, viendose muertos, yxieron en el alborada et non caceron [curoron $\mathrm{N}$ ] por ren entro que plegoron al rey et matoronlo 34.162. Del lat. CURARE 'tener cuidado', 'cuidar'. Se registra en textos en arag. del s. XV: curar 'preocuparse, cuidar de' (VILA, 1990: 138); curar 'procurar, tener cuidado' en VCA (LLEAL, 1997: 108). Frec.: caceron [curoron] 1: 0,00227.

curial adj. 'cortés': Aquesti rey don Pero fue barón muy curial, noble, balient, largo e proz e muy espierto 34.7. Etim.: tomado del lat. curialis, deriv. de CURIA local del Senado y otras asambleas'. En la Edad Media 'corte de un príncipe', 'tribunal judicial' (DCECH, II, p. 298; DECLIC, II, p. 1111, s. v. cúria). El DCECH documenta curial por 1. ${ }^{a}$ vez en cast. en 1438. Para el arag. med. GiLKISON (1984: 38) lo da como sustantivo con el significado de 'cortesano'. En cat. curial 'cortés' (FABRA, s. v. curial); igualmente lo da como adj., con el significado de 'cortés' el DL/C del IEC (2007). En cat. ant.: 1) 'home empleat en la cort d'un príncep dins qualque ram de l'administració'; cast. curial. 2) 'Home que per la seva professió intervé en l'administració de justicia'; cast. curial, leguleyo. 3) 'cortés; que té o expressa una urbanitat extremada'; cast. cortés (DCV B, s. v., tomo 3, p. 861). Comp. cortés. Frec.: 1: 0,00227. 
curoso] adj. 'cuidadoso, solícito', forma parte del sintagma adv. diligentment et curosa: 'diligente y cuidadosamente': et acomendolo al conte de Flandres et mandóle que lo nudries muy diligentment et curosa. 23.7. Deriv. del v. curar < lat. CURARE 'cuidar de, ocuparse, velar por, preocuparse de' (SEgura, 2001: 185). Véase en el $V M$ (Tilander, $V M$, III: 83): curoso 'cuidadoso, diligente'; en el LT, curosos 'careful' [cuidadosos] (PrInce, 1995: 220). Frec.: curosa 1: 0,00227.

cuya relat. pos. 'de quien', 'de la cual' 'la cual, suya': «Seynnor, la tierra que me dieste rendí a la reyna natural mi seynora cuya hera» 19.86. Frec.: 1: 0,00227.

cuydar] v. tr. 'pensar': mas despues que fue de nueytes, cuydando que al otro día avría otra batalla 18.48; en las quales cortes cuydava seer seguro del regno 20.12; el cavallero cuydó que toda era una batalla 18.62; para la guerra que cuydava aver con el rey de Aragón. 20.229-230; era tan grant la multitud de los franceses que aquí cuydo seer desbaratado 36.582. // v. prnl. 'preocuparse': assi este compte, cuydandose deste casamiento comencó de guenrrar 19.104. Etim.: del lat. COGITARE 'pensar', de donde se pasó a 'prestar atención' y de ahí a 'asistir (a alguno)', 'poner solicitud (en algo)' (BDELC, p. 184; DCECH, II, p. 284). Frec.: cuydando 8: 0,01818; cuydandose 1: 0,00227; cuydava 2: 0,00455; cuydó 5: 0,01136.

cuyta s. f. 'aflicción, preocupación, inquietud, desventura': a la fin seyendo el rey de Castilla en gran cuyta que los moros le tenían Cuenca cercada... 33.27. Es simplemente una variante de cueyta (vid.), con el triptongo $u e y$ simplificado en $u y$. Adviértase que aparece en el ms. N (el más castellanizado de los tres). En cast. cuita deriva del v. antiguo cuitar, que es un occitanismo, tomado del occ. ant. coitar, según CoRominAs (BDELC, p. 184; DCECH, II, p. 285), aunque también admite que «podría tratarse de un aragonesismo». En arag. parece voz más genuina cueyta. Frec.: 2: 0,00455.

cuytadament adv. 'cuidadosamente, con cuidado, solícitamente, cautelosamente': con gran poder de hombres a cavallo y de pie, cuytadament, vino sende [sent $\mathrm{N}]$ a la dita fuerça 4.32-34. // 'ansiosamente, con inquietud': et tomó la critatura entre sus camas et dixo cuytadament: "Varons, prendet aquesta criatura et despullalde las vestiduras que adure et levaldo rey» 12.27. / ' 'rápidamente, aprisa, presurosamente': firió tan cuytadament con los primeros que los moros fueron en travallo 18.42. Comp. cuytosament. Frec.: 7: 0,01591.

cuytado adj. 'apresurado, con diligencia, cauteloso y rápido': mientre que la paz se tractava et non fallia sinon por el Padre Santo Nicholao IIII divulgar fer observar por cada una part, vet [et veyet $\mathrm{N}]$ que accident vino cuytado al dito rey don Alfonso 37.83. Frec.: 1: 0,00227 .

cuytar v. tr. 'asistir, guardar, cuidar': «et tu Sennyor cuyta [escuyta $\mathrm{N}$ ] a la mi flaqueça» 35.242. No parece que tenga mucho sentido la lectura del $\mathrm{ms}$. N, por lo que habrá que suponer que la lectura correcta es cuyta. La única interpretación posible en este caso es que se trata del v. cuytar en el sentido de 'poner atención, 
asistir, guardar, cuidar'. Etim.: del lat. COGITARE 'pensar' (BDELC, p. 184, s. v. (uidar). A no ser que proviniera del lat. vg. *COCTARE y tuviera el significado de 'apurar, obligar, forzar' (BDELC, p. 184, s. v. cuita). La primera etimología tiene en su contra que aparecen también en la Crón. SJP., y en 16 ocasiones, formas del verbo cuydar, con $-d$-, en todos los casos con el significado de 'pensar'. Frec.: cuyta: 2: 0,00455.

cuytar(se) v. prnl. 'darse mucha prisa': Et huvo acuerdo que por tal como havía en ardit quel comun de Pisa enviava conpannya de cavallo et de pie en la ysla de Cerdennya, se devies [buvies B] mudar en la su galera porque se cuytas con las galeras et que [porque B] en antes fues en la dita ysla, et assi fue feito 38.511-515. Etim: probabl. del lat. vg. *COCTARE, deriv. de Coctus, part. de COGERE 'obligar, forzar' (BDELC, p. 184, s. v. cuita; DCECH, II, p. 285). El DRAE (1970) recoge para cuitar como segunda acepción, con la indicación de que es antigua: 'darse mucha prisa, anhelar por alcanzar algo'. Y lo mismo consta en el DLE (2014). Estaría en relación con el sust. cueyta en la acepción 'ansia, anhelo, deseo vehemente'. Frec.: cuytas [kwitás] 1: 0,00227.

cuytosament adv. 'cuidadosamente, cautelosamente', aunque puede tener también el matiz de 'rápidamente': cuytosament de nueyt et de día vino al dito castiello de Balaguer, 36.133. No aparece en GILKIsOn, pero sí el adj. cuytoso 'cuidadoso, solícito, esmerado, cauteloso'. En el VM, cuitosament 'con apremio, con urgencia' (Tilander, VM, III: 82).. Frec.: 2: 0,00455.

\section{D}

d' forma acortada de la prep. de ante vocal. Vid. de. Frec.: d' 132: 0,00227.

daçión s. f. 'donación': el quoal le era pervenido por daçión [donation $\mathrm{N}$ ] de su madrastra, 16.3. Es cultismo tomado del lat. datio, -onis 'acción de dar', 'derecho a hacer uno cesión de sus bienes’ (BLÁnQUeZ. s. v.). Frec.: 1: 0,00227.

dallá prep. 'de más allá de’: en la tierra de Mecha et en otras tierras dallamar [dallant la mar $\mathrm{N}$ ] que agora son de moros, 3.59-60. Vid. dallent. Comp. en arag. med. dellá 'al otro lado de, allende' en LT (RodÉs, 2016: 711). Comp. en arag. mod. dellá, dillá 'más allá de': Andolz (1992, s. v.) registra dellá 'en la parte de allá' en Buerba; y dillá 'más allá' en Nobés; BADía (1948: 78), dellá 'más allá' en Buesa (valle de Broto); el EBA (1999: 680) registra dillá 'más allá' en Biello Sobrarbe, Nobés y Sobrepuerto. Etim.: posiblemente, compuesto de la prep. DE más el adv. ILLAC 'por aquella parte, por allá' (SEGURA, s. v.). Frec.: 1: 0,00227. 
dallent (var.: dallant) prep. 'de más allá de', 'de la parte de más allá de': et aquesto supieron moros dallent mar et vinieron con muy grant poder de toda Berbería 18.94-95. Etim.: del lat. ILLINC 'de allí, de allá', con la prep. de antepuesta, y la prep. de pospuesta y aglutinada (BDELC, p. 46). DE ILLIN(C)DE $>$ dellénd(e) $>$ dallent. La evolución a $a$ de la primera $e$ puede explicarse por el influjo de allá < ILLAC. La - $t$ final, por ensordecimiento de la $-d$ tras la caída de la $-e$, aunque también se ha atribuido a una falsa analogía (DCECH, I, p. 225). El DRAE, 1970, registra allent adv. de lugar. ant. 'allende', y con el mismo significado allén. Comp. cat. allèn adv. 'a l'altra banda, a la banda d'allá', allèn de loc. prep. 'ultra, a més de' (FABRA, DGLIC, s. v.). Tb. aparece la variante dallá [dallant $\mathrm{N}]$ : et en otras tierras dallamar [dallant la mar] que agora son de moros 3.60 ('de más allá del mar'). Frec.: 1: 0,00227.

dampnage (var.: dapnage) s. m. 'daño': vino sende delant Napols con las galeras armadas por desonor et dampnage fer a los enemigos del dito rey 36.306; Et por muytas et diversas injurias et dapnages que don G(uillermo) Remón de Odena bavía feito 36.16. Del lat. Damnaticu, a través del cat. o del occ. damnatge (DCVB, t. 4, p. 14). Frec.: dampnage 2: 0,00455; dampnages 2: 0,00455; dapnage 1: 0,00227; dapnages 2: 0,00455 .

dannyo (var. dayno) s. m. 'daño': que se estuvies de fer enoyo et dannyo a las ditas hermanas 34.130; los moros de Tudela farían a los de la buest todos días que adurian viandas por Ebro ayuso e de Castilla por tierra, grandes daynos e muytas calvagadas 19.29. Del lat. DAMNUM 'daño'. Frec.: dannyo 3: 0,00682; dannnyos 2: 0,0455; daynos 1: 0,00227 .

daquá adv. 'a este lado, en el lado de acá': et esdevinose una vegada, quel estando daquá de las montannas, supo que los moros tenian asitiada la ciudad de Pamplona 12.50. Del lat. DE ECCUM HAC (BDELC, s. v. aquì). Comp. con dallá. Frec.: 1: 0,00227.

dar v. tr. 'dar': et quisiessen Dios pregar et los sanctos quel dito monasterio avieron esleydo sepultura, que le dassen poder de regir su poblo dreytament et le dassen victoria todos tiempos contra los moros. 11.47; «Sennyor, datme letras de creyença» 36.387; «Sennyor, dezit nos a qui queredes que esliamos por sennyor, datnos rey pues que vos nos desenparedes» 38.136; de la qual procreó una filla la qual die por muller a Sancho 35.85; e ante del día que le prometió fue alli e dieronli batalla con el Cid 18.111; «Vete al mi sennor el rey et dile lo que has visto, que no te do otra respuesta» 20.117; et livrote la mia sennyoría con la qual te dé Dios victoria contra los tus enemigos 35.263. Del lat. DARE. Frec.: dar 21: 0,04773; daría 3: 0,00682; darían 1: 0,00227; darle 2: 0,00455; darse 1: 0,00455; dada 3: 0,00682; dadas 2: 0,00455; dado 9: 0,02046; dados 3: 0,00682 ; das 1: 0,00227 ; dasen 1: 0,00227 ; dasse 4: 0,00909; dassen 3: 0,00682 ; datme 1: 0,00227 ; datnos 1: 0,00227 ; dava 4: 0,00909 ; davan 1 : 0,00227 ; dé 1: 0,00227 ; dedes 1: 0,00227 ; die 1: 0,00227 ; diele 1: 0,00227 ; dies 4: 0,00909; diesse 4: 0,00909; diessen 1: 0,00227; dieste 1: 0,00227; 
dieron 4: 0,00909; dieronle 2: 0,00455; dieronli 2: 0,00455; dio 47: 0,10683; diogela 1: 0,00227; diól' 1: 0,00227 ; diola 6: 0,01364; diole 4: 0,00909; dioles 8: 0,01818, diolo 1: 0,00227; do 5: 0,01136.

dardo] s. m. 'dardo': eran vezados de adozir dardos 12.64. Ротtier (ELH, II, p. 132) lo da como galicismo adoptado en la Edad Media en español, procedente del fr. dard. Éste proviene del fráncico *DARO円 'íd.' (DCECH, II, p. 427). Se registra dardo en un inventario arag. de 1331 (ELLA, s. v.); también en Fernández de Heredia (GILKISON, s. v.). Frec.: dardos 1: 0,00227.

davirugis s. m. pl. 'nombre de un antiguo pueblo de la isla de Estancia': En aquesta isla de Estancia habitaban aquestas naciones: godos, vesegodos, estargodos [estragodos $\mathrm{N}$ ], davirugis, arcas et tanis [aretis et anis $\mathrm{N}]$ 3.2. Frec.: 1: 0,00227.

de prep. 'de'. Funciona como introductor de una oración subordinada (proposición) de c. d. en infinitivo: et ordenó en aquel justamiento de enviar mensageros a don Alfonso emperador de Castiella, 20.205-206. Etim.: del lat. DE 'desde arriba debajo de', 'desde', '(apartándose) de' (DCECH, s. v., t. II, p. 428). También d'+vocal, $d+$ vocal: las gentes d'alli 17.132. Pueden verse diferentes valores de la prep. $d e$ en el estudio lingüístico, 5.12 .7 (NAGORE, 2003: 450-452). Frec.: de 2.860: 650059.

de cabo loc. adv. 'otra vez, de nuevo': depués que buvo recebida aquesta muller çaguera, non firo afferes de cabo [ningunos $\mathrm{N}$ ] ni [buenos $n i \mathrm{~N}$ ] cominales porque toda vegada bo quayx estuvo enfermo 39.14-15. Cfr. en arag. med.: decabo, de cabo loc. adv. 'otra vez, de nuevo' y conj. de transición 'también, además' (Gorosch, FT, p. 492). En documentos notariales del Alto Aragón: «Et como de cabo aquell dia mismo trobo el dito Gonçalbo, procurador del dito prior, la casa de Domingo Balarin crebantada et abierta» (DLA A, p. 127, doc. $n^{\circ}$ 87, de 1306, del Valle de Sarrablo, p. j. de Boltaña). Vid. cabo.

de nantes (denantes) adv. 'antes': todo quanto avies avido que lo avies a tornar et que tornas el palacio assí como de nantes era 36.447. Del lat. IN ANTE, con añadidura de la llamada $-s$ adverbial, con lo que tenemos enantes, que con la prep. de antepuesta da denantes. Vid. denant.

de mientre adv. 'mientras, entre tanto': muytos dapnages et muytas piccadas les dieron de mientre que las gentes contrarias eran en Rosellón. 36.488-489 [dementre que les gents contràries eran en Rosselló. VC., p. 141]. Etim.: del lat. < DUM INTERIM, combinación usual en el lat. hablado de DUM 'mientras' e INTERIM 'entretanto'. De ahí surgiría la forma más antigua, domientre, de donde procede demientre (DCECH, IV, p. 70, s. v. mientras). Domientre se encuentra todavía en Alex. (SAS, s. v., p. 218); demientre en Berceo. Como señalan Corominas-Pascual: «Está claro que domientre pasó a demientre por influjo de las numerosísimas partículas que empiezan por de(debajo, defuera, detrás, denantes, de(s)pués...)». Comp. port. ant. mentre, mentres; gall. mentres; cat. mentre (cat. med. dementre, tal como aparece en la VC); it. mentre (it. med. domentre). Frec.: vid. mientre. 
decembre 'diciembre'. Es forma latina: VI kalendas decembre 18.76 Frec.: 1: 0,00227 .

decender (var.: descender) v. intr. 'descender': firose decender del cavallo, 37.93; aquesti firimiento del rey d'A ragón duró entro que buvieron decendido el coll de Panizares 36.656; por caso ninguno no podies allenar el regno de Aragón en personas algunas sino en los fillos et aquéllos que descendrían de su filla propriament 20.262. Del lat. DESCENDERE. Comp. devallar. Frec.: decender 1: 0,00227; decendido 1: 0,00227; descendrían 1: 0,00227.

decercar v. tr. 'descercar, romper o levantar el sitio o cerco': A la fin seyendo el rey de Castilla en grant cuyta que los moros le tenian Cuenca cercada, enbiole a rogar al rey don Alfonso de Aragón e que le fuese a decercar aquélla 33.29. Deriv. de cercar < lat. tardío CIRCARE. Frec.: 1: 0,00227.

décima] s. f. 'diezmo, décima parte': que todos los reyes de Aragón e los nobles e cavalleros pudiessen dar de las conquistas que farían todas las iglesias, salvant catedrales, ruegos e necesidades tener aquéllas e las décimas en tal que las yglesias feziesen servir, segunt por el privilegio parece 18.119-123. Etim.: Es forma culta, del lat. decimas. Comp. diezma. Indica Ángeles LíBANO («Consideraciones lingüísticas sobre algunos tributos medievales navarro-aragoneses y navarros», Príncipe de Viana, 154155, 1979, pp. 65-80) que «El cultismo décima resulta poco común en la Edad Media, deceno y los duplicados populares diezmo, diezma están más difundidos» El DCELC (s. v. diez, t. II, pp. 493-494) afirma igualmente que, aunque décimo se encuentra en Berceo, sin embargo, está poco extendido en la Edad Media, en que deceno era lo general, y por otro lado existían los duplicados populares diezmo, propiamente la 'décima parte de la cosecha' (en Berceo), y diezma, que es forma aragonesa. Frec.: décimas 1: 0,00227.

dedo s. m. 'dedo': con la mano dreita designando con el dedo, dixo: "spor aquí se puede entrar Huesca» 17.119. Del lat. Digitus. Frec.: 1: 0,00227.

defallimiento (var.: deffallimiento, desfallimiento) s. m. 'falta, fallo, debilidad' en el sentido de 'defecto en el obrar', 'quebrantamiento o infracción de la ley', 'mal comportamiento con alguien': que devies perdonar a sus fillos el defallimiento que havían cometido contra ella 14.82; et en redepción de los sus desfallimientos [defallimientos B] 35.289. / / 'falta, ausencia, carencia': et por tal como el dito regno en defallimiento de heredero masclo pervino a conte de Barchinona por ajustamiento matrimonial, veamos qui fue conte primo de Barcbinona 21.2; et la ora el sol sufrió deffallimiento del día [en el día $\mathrm{N}]$ de la Purificación,38.403. Comp. defallecido 'falto, necesitado, arruinado' y defallecimiento 'falta, defecto o privación de una cosa útil o necesaria', las dos con marca de antiguo (DRAE, 1970); ambas voces se mantienen en el DLE (2014) con marca de desusado. Es habitual en arag. med.: «\& non podiendo abrirla nin entrar dentro, porque era çarrada la puerta $\&$ non avia la clau, dicient que bien asi se los enparaua \& se metia en posision daquel, 
endefallimiento de clau tocando la puerta, como si dentro entras» (DLAA, doc. 91, de Huesca, de 1307; p. 131, lín. 19). En FA, defallemiento 'falta' (Tilander, 1937: 342); en OB (VÁzquez, 2011c: 36), defallimiento 'falta, escasez'; en el LT (Prince, 1995: 220), defallimjento 'error, omission'. En el arag. de Fernández de Heredia: defallimiento, desfallimiento, deffalliment 'failure' (fracaso), 'weakness' (debilidad, flaqueza) (Gilkison, s. v.). También defallimiento 'a failure' en el diccionario español-inglés de John STEVENS, de 1706 (cfr. Gili Gaya, Tesoro lexicográfico, s. v.). Deriv. de fallir. Frec.: defallimiento 3: 0,00682; deffallimiento 1: 0,00227; desfallimientos [defallimientos] 1: 0,00227.

defender (var.: deffender) v. tr. y prnl. 'defender': et non se sabieron ni podieron defender 1.40; que les ayudasse a deffender contra el rey de Aragón et que darían a él las parias dobladas 17.106; que esforçadament le deffendiessen el regno 38.241. Tomado del lat. Defendere. Frec.: defender 7: 0,01591; defendidos 1: 0,00227; defendiesen 1: 0,00227; deffender 7: 0,01591; deffendiessen 1: 0,00227; deffendióla 1: 0,00227.

deffendedor (var.: defendedor) s. m. 'defensor': fueron çercando a qui esleyrian por sennor lur et defendedor 10.6; guarda et deffendedor [et en guarda de defensión $\mathrm{N}]$ de biudas, 35.177. Deriv. de defender. Frec.: deffendedor 3: 0,00682; defendedor 1: 0,00227.

deffensamiento] s. f. 'defensa, obra de fortificación para protegerse': se guarnian fuertment de grandes fuerças et deffensamientos 4.22-23. Deriv. de defensar, sin. de defender. Frec.: deffensamientos 1: 0,00227.

deffensión s. f. 'resguardo, defensa'; 'amparo, protección': avía enviado conpannya de cavallo et de pie en la isla de Cerdennya en deffensión de aquélla. 38.493; salvant aquéllos que eran necessarios en deffensión de la ciudat, 36.526. Etim.: tomado del lat. cl. defensio, -onis 'defensa' (DCECH, II, 434). Comp. defensión 'defensa, protección’ en FA (Tilander, 1937: 343). Frec.: 2: 0.00455.

degollar v. tr. 'degollar': pudiessen fer degollar et matar vacas et qualsequier otro ganado 11.62. Del lat. Decollare 'íd.', deriv. de collum 'cuello' (DCECH, II, p. 435). Frec.: 1: 0,00227.

deiuso (var.: deiusso) adv. 'debajo': segunt que más largament deiuso recontaremos [contaremos N] 36.697. Del lat. DEORSum > Jusum, con la prep. de antepuesta. Frec.: deiuso 1: 0,00227; deiusso 1: 0,00227.

del contr. de prep. de + art. el: Et por la dita población lexaron el nombre de Tubal et prendieron el nombre del dito rio, el qual dizen Ebro, et avieron nombre celtiberos 1.9. Frec.: 422: 0,95918.

dél contr. de prep. de + pron. pers. él: E muerto el dito rey García Ennego, regnó depués del, el Fortunyo García 7.1. Frec.: 28: 0,06364. 
delant prep. 'delante de', 'ante': «O, cavalleros jet non vos yes verguença que delant vosotros aquesti caballero catalán aya desmentido a mi et de vosotros ninguno non le aya respondido?» 38.328; et delant todos en general, el dito rey don Sancho de Mallorquas reconosció tener en feu et de ius sennyoría del dito rey don Jayme el regno de Mallorquas 38.466 // adv. 'delante': porque el dito conte fue delant del rey de Francia et recibió por él el condado de Barchinona 23.52. De DE IN ANTE, o prep. de + enante < lat. tardío INANTE 'delante' (DCECH, II, p. 437). Vid. denant. Frec.: 22: 0,5000.

delantera s. f. 'delantera, línea o parte de delante o de vanguardia': fizo parellar sus compannas et dio la delantera a su hermano 18.33. Deriv. de delant. Frec.: 2: 0,00455 .

deleite] s. m. 'deleite, placer': renunciaron a los deleites carnales et mundanales, 9.34. Deriv. de deleitar, del lat. DELECTARE 'atraer, retener', 'deleitar, agradar, complacer, seducir’ (DCECH, II, p. 440). Frec.: deleites 1: 0,00227.

deliberación s. f. 'deliberación, premeditación, consideración atenta de los hechos': la qual licencia el Papa con grant deliberación et maturidad la dio, 20.71. Frec.: 3: 0,00682.

deliberado p. p. de deliberar 'considerar atenta y detenidamente una cuestión': Et fue acordado et deliberado que en el nombre de Ihesu Christo et de la suya benedita Madre fues a conquerir el regno de Mallorquas, qui la ora era de moros 35.124. Frec.: 1: 0,00227 .

delibrar v. tr. 'libertar, librar, liberar, dejar libre': que del grieu cativerio et opressión a qui era baldonada, la devies preservar et delibrar 36.196-197; mas el dito maestro [maestre $\mathrm{BN}]$ fuyendo de la presión con los guardas fue delivrado de aquélla 36.5960; un monge, muy sancto varón, vino al dito empreador et díxole: «Sennor, si la reyna yes acusada a tuerto queredes la delivrar, et que fues perdonada ad aquellos qui la han acusada» 14.72-73; de la qual cosa fue muyt pagado et delivró en continent a la dita muller suya 14.79-80; et delivró de la pressón et los fillos suyos [dos fillos suyos B] 37.77. Etim.: deriv. de librar, con un prefijo de-intensivo, del lat. DELiberare 'libertar' (BDELC, s. v. libre, p. 359). Según Corominas-Pascual es muy usual en castellano con la acepción 'librar, libertar' la forma delibrar en toda la Edad Media y hasta 1500 (DCECH, III, p. 643, s. v. libre). En el arag. de Fernández de Heredia, delibrar, dilivrar, delivrar, deslivrar, con el significado de 'finish, end' ['acabar, terminar, finalizar'] y 'deliver, free' ['libertar, librar, soltar'] (GILKIsOn, s. v., p. 41); deliurar 'liberar', 'entregar' en VCA (Lleal, 1997b: 117). Frec.: delibrar 1: 0,00227; delivrar 1: 0,00227; delivrado 1: 0,00227; delivró 2: 0,00455.

demanda s.f. 'demanda, petición legal': et non res menos $<r>$ enuntió a todo dreyto et a toda demanda que en qualquiere manera avies o podies [oviesse et podiesse $\mathrm{N}$ ] aver en el regno de Secilia 38.119. Deriv. posverbal de demandar. Frec.: 1: 0,00227. 
demandar v. tr. 'pedir, solicitar': adquellos que len demandaban gracia respondió..., 19.178; ya sia que con aquesto avies muytas vegadas por solempnes mesageros suyos demandado 38.58; no podia dir de no de res quel demandassen 13.9; et pues gracia le demandava yera aparellado de fazer lend. 19.181; porque el rey don Alfonso les atorgó por fuerça todo aquello que los de la unión le demandoron 37.28-29; entre las otras cosas le demandoron ultra otras orribles et desordenadas cosas, que si non servava los privilegios que feitoa vía a la dita unión et las ordinaciones que avían feitas ellos, que pudiessen esleyr otro rey et a ell gitar del regno 37.29-32. Del lat. DEMANDARE 'confiar, encomendar' (Segura, 2001: 202). Frec.: demandar 1: 0,00227; demandaban 1: 0,00227; demandado 1: 0,00227; demandaron 2: 0,00455; demandarole 1: 0,00227; demandás 4: 0,00909; demandasen 1: 0,00227; demandava 2: 0,00455; demandavan 4; 0,00909; demandó 5: 0,00227; demandole 1: 0,00227; demandoron 3: 0,00682.

demás adj., precedido de art. plural, 'los demás, los otros, los restantes': los demás de los reyes de Espaynna inclinados e indutos a paz e concordia, tornose en su tierra 33.111; et con aquesti tenian los demás nobles d'Aragón 35.15; muertos et consumados et los demás presos, con él se los levó a Barchinona 36.550. Compuesto de más. Frec.: 3: 0,00682.

demostrar v. tr. 'demostrar': tan sennyalado miraglo le avía feito et demostrado 38.540; fiziendo lohores a Dios et a la benedita Madre suya qui tan grandes et tan speciales gracias le demostroron 35.150. Del lat. Demonstrare. Frec.: demostrar 1: 0,00227; demostrado 1: 0,00227; demostrando 1: 0,00227; demostró 1: 0,00227; demostroron 1: 0,00227.

denant prep. 'ante, delante de': et soterraronlo denant el altar de Sant Johan 17.135 [e soterraren-lo denant l'altar de Sant Joan, VC, p. 63]. Etim.: procedente del lat. tardío INANTE 'delante, enfrente', derivado de ANTE 'delante', 'antes', con la preposición IN. Según el DCECH (II, 437, s. v. delante), denante como preposición 'delante de' se halla en varios glosarios y documentos de los siglos x y xi (documentación perteneciente a Aragón y al Este de Castilla) pero en todo el territorio de lengua cast. denante debió de existir en fecha más o menos antigua, antes de pasar a delante por disimilación. Formas similares son: cat. ant. denant (en textos de los ss. XIII y XIV), oc. ant. denan(t), it. dinanzi. Comp. denantes adv. 'antes'. Frec.: 1: 0,00227.

denantes adv. 'antes': que lo avies a tornar et que tornás el palacio assí como de nantes era 36.447 (En el texto aparece separado). Comp. antes, enantes, denant. Frec.: 1: 0,00227.

denegación s. f. 'denegación': et entendida encara la denegación que avía feita el Padre Santo al dito rey... 36.201. Derivado postverbal del verbo denegar. Frec.: 2: 0,00455. 
denegar] v. tr. 'denegar, no conceder': non recibió assí como devía los ditos mesageros, ante con soberbia les denegó todo quanto demandavan et firoles fuert agra respuesta 36.179. Etim.: del lat. DENEGARE 'negar con energía, decir que no' (BLÁNQUEZ, s. v.). Frec.: denegó 1: 0,00227.

denotar] v. prnl. 'notarse, hacerse perceptible, apreciarse, percibirse': et en cada una part vermellura se denotava 36.599. Etim.: deriv. de notar < lat. NOTARE 'señalar, anotar'. En cast. se registra denotar h. 1440 (BDELC, s. v. nota, p. 416; DCECH, IV, p. 240). Se documenta en el arag. de Fernández de Heredia, denotar 'announce, point out' ['anunciar, hacerse saber, declarar'; 'señalar, hacerse notar, indicar'] (GILKISON, s. v., p. 41). Frec.: denotava 1: 0,00227.

dentro adv. 'dentro' (generalmente aparece el sintagma dentro en): et el otro, clamado don Johan, heredero dentro en su tierra 39.40. / / prep. 'dentro de': fue feyta dentro breu tiempo 9.38. Frec.: 18: 0,04091.

denunciar v. tr. 'denunciar, avisar, notificar': et lexó un lennyo armado por denunciar a las naves et al otro navilio que fiziessen aquella misma via. 38.526; Et estando a Mallorquas, aquella muert denunció al poblo [pueblo N] de Mallorquas et a todo el regno 37.7. Frec.: denunciar 1: 0,00227; denunció 2: 0,00455.

departimiento s. m. 'división, separación, partición, reparto': et por el departimiento [departimento en la ed. crítica] de los regnos dessus ditos, el dito Remiro buvo el condado de Aragón 15.5; Muerto el dito emperador et el departimiento de las tierras et acabamiento adueyto, sennoriá [seynorió N] el dito rey Remiro en el regno de Aragón 16.1-2. // pl. 'discusiones, enfrentamiento de posturas diferentes': mandó quel dito infant fues livrado a la suya gent natural; et seyendo estos departimientos los del regno passavanlo muyt mal 35.9-11. Etim.: deriv. del v. departir 'dividir, separar', 'conversar, discutir, tratar' (DCECH, IV, p. 415, s. v. parte), y éste a su vez deriv. de partir, del lat. PARTIRI (BDELC, s. v. parte, p. 442). Frec.: departimiento 2: 0,00455; departimientos 1: 0,00227.

departir] v. tr. 'separar, dividir': et duró todo el día la batalla entro que la nueyt los departió 18.44-45: «Fillo mío, yo livro la mi spada en sennyal de dreytura con la qual tu departescas mal de bien» 35.262; empero que cada un rey conocies sus tierras assí como don Sancho el Mayor las avía departidas 20.166; Et por aquesto, el dito rey se esforçó quel casamiento dél et de su muller se departiesse 34.62. // 'conversar, comentar, debatir, discutir, tratar': et departían los aragoneses como sacassen a don Remiro de la mongía et que fuesse rey 20.38-39. Etim.: prep. de + partir < lat. PARTIRI 'dividir, repartir, separar', con el prefijo de- de carácter intensivo. De la acepción etimológica 'partir, dividir, separar' se pasó a 'explicar, declarar' y de ahí finalmente 'hablar, conversar' (cfr. DCECH, IV, p. 415, s. v. parte). Frec.: departían 1: 0,00227; departidas 1: 0,00227; departiesse 1: 0,00227; departió 2: 0,00455. 
deposar] v. tr. [con compl. preposic. regido por de] 'desposeer, deponer': et queriendo esquivar que a bombre de tan gran desonor et de tan grant infamia non fuessen sosmetidos vasallos, deposaron al dito Remon de la honor real, de la qual injustament usava 17.15-18. En María Moliner, deposar (ant.) 'deponer'. No aparece en Covarrubias (1611). Frec.: deposaron 1: 0,00227.

depués (var.: después) adv. 'después': et depués fue traslatado en el monesterio de los freyres menores de la ciudat de Lerida 39.46; Et después él partió de aqui et trobó la una de las 1.32. La var. depués se registra 206 veces, frente a sólo 13 la var. después. Del lat. vg. DЕро̆sт. Comp. port. depois, occ. depueis, fr. depuis, it. dopo, retorrom. davos (DCECH, IV, p. 684, s. v. pues). Frec.: depués 206: 0,46822; después 13 : 0,02955 .

deputado adj. 'autorizado, comisionado, delegado': et con el rey Carlos et un legado del Padre Santo, qui a pagar el sueldo al dito rey et a sus conpannyas era deputado, vino sende en Nápoles 38.232. Del lat. Deputatus 'representante de la autoridad'. Cfr. deputar 'elegir, escoger; asignar; delegar; comisionar, encargar, delegar; designar' y deputado 'diputado, representante, enviado' en el arag. de Fernández de Heredia (GIlkison, s. v.). También deputado, con ese mismo sentido, en documentos notariales aragoneses: «responden los ditos jurados de Vielsa que uerdat yes que los homnes de Vielsa o alguno deputado por ellos façen pontage a los de Ainsa, asi como a los hotros del regno» (DLA A, p. 166; doc. de Bielsa de 1349). En occ. ant. deputar 'députer, destiner’ y deputador 'qui doit être député' (LeVY, 1980: 112). Comp. deputazión 'diputación', que documenta en Huesca ANDOlz (1992: 151). Hoy se registra deputado 'deputy; officer' en el español tradicional de Nuevo México y sur de Colorado, en Estados Unidos (Cobos, 2003: 79). Cfr. député (PRobert, s. v.). Frec.: 1: 0,00227.

derramar] v. tr. 'dispersar, esparcir, diseminar, desparramar': et algunas galeras del rey de Francia fuessen derramadas por la mar 36.537 // v. prnl. 'esparcirse, dispersarse': se derramaron et fueron enta las fuercas de las montannyas 4.2. De un lat. vg. *DIRAMare 'separarse las ramas de un árbol', a través de *DisRamare $>$ * desramar. Cfr. DCECH, II, p. 446, donde se hace notar que la acepción 'dispersar, esparcir' es corriente en cast. ant. y se encuentra desde Berceo. Hay numerosos ejemplos en DME, s. v. En Fernández de Heredia se encuentra derramar, deramar y desrramar 'esparcir, desparramar', 'derramarse' (GILKISON, s. v.). Frec.: derramadas 1: 0,00227; derramaron 1: 0,00227.

derredor adv. 'alrededor': Et un día, él andando en derredor de la ciudad, comidiendo por do se podría entrar, vio flaco lugar en el muro forano 17.116. Etim.: compuesto de la prep. de más una antigua preposición redor 'detrás de'. La pronunciación proclítica, típica de las preposiciones, explicaría que la forma inicial redro (< lat. RETRO) evolucionara a redor (BDELC, p. 45, s. v. alrededor). Frec.: 2: 0,00455. 
derrocar v. tr. 'derruir, derribar': et dio tan grant terror al dito castillo que de continent se rendió e fizolo derrocar 32.53; fizo reparar et endreçar aquélla porque bien yera mester que toda era cremada et derrocada. 36.691; mandó que en continent fues con gran poder de hombre a cavallo $i$ de pie enta las partes d'Aragón, et toda aquella quemas et affogas [cremase e afogase $\mathrm{N}]$, todas las fuerças derrocando et los christianos matando 4.30; e destruyó la ciudat de Arles, que el hera muy contraria, en la qual derrocó muytas torres e fuerças 32.48; las fuercas et lugares que riba del mar de Rosas et Barcelona eran, los franceses todos los derrotoron [derrocoron B] 36.536. Deriv. de roca (DCECH, V, p. 43). Vid. ejemplos de cast. med. derrocar 'derribar, echar por tierra' en $D M E$, p. 894. Comp. enderrocar. Frec.: derrocar 1: 0,00227; derrocada 1: 0,00227; derrocando 1: 0,00227; derrocó 3: 0,00682; derrocóla 1: 0,0227; derrotoron [derrocoron] 1: 0,00227.

desastre s. m. 'desastre, desgracia': que quando la reyna su madre murió asin por grant desastre, prennyada era 12.31. Del oc. ant. desastre 'desgracia', deriv. de astre 'astro', '(buena o mala) estrella', del lat. ASTRum. Cfr. DCECH, I, p. 385, donde se da la $1^{\text {a }}$ doc. en cast. hacia 1450. Frec.: 1: 0,00227.

desavenido] adj. 'desavenido, en discordia, disconforme': et los que yeran allíplegados partieronse desavenidos de las cortes 20.90. Frec.: 1: 0,00227.

desaventura s. f. 'desventura, infortunio; suceso desgraciado o desafortunado': por gran desaventura, passando la dita reyna por la val d'Ayvar, aguait de moros dieronle salto et mataron toda la compannia qui con ella era 12.2; passando el rio del Royne, por gran desaventura cayó en el agua et murió 28.4. Deriv. de ventura 'suerte buena o mala', del lat. venturA 'lo por venir' (DCECH, V, p. 771, s. v. venir). Frec.: 2: 0,00455 .

desbaratar v. tr. 'desbaratar, deshacer, arruinar', 'desconcertar, descomponer, desordenar': et regnava en las Esturias el rey Oedonyo qui fue vencido e desbaratado por el rey de Cordova, clamado Abderramen 9.4; et aquéllos vinció e desbaratando e ultra aquéllos...33.86; por desuayr et desbaratar aquéll si pudies [podiessen $\mathrm{N}$ ], 38.361. Deriv. de desbarate 'derrota, desconcierto', deriv. de barata 'confusión, barullo', de origen desconocido (DCECH, I, pp. 501-502). Frec.: desbaratar 1: 0,00227; desbaratado 3: 0,00682; desbaratando 1: 0,00227; desbarató 2: 0,00455 .

descabeçar v. tr. 'decapitar': et avría todos los otros cavalleros assí mesmo descabeçados sinon por qual manera que fue que lo sintieron [los $\mathrm{N}]$ que yeran de fuera et fuyeron 20.137; mandavalos clamar uno a uno a consello et comonetravan, assi los mandava descabecar en su cambra 20.134. Comp. escabezar en las Crónicas de los jueces de Teruel: «en el alva fizo escabezar a los ditos Pero Lopez et micer Johan»; «La primera entrada que entro en Teruel en el olmo de la plaça de Santa Maria escabezo a micer Johan, doctor, y a Pero Lopez, notario, y enforco a Johan 
Gavara» (1400; López RAJADEL, 1994: 222 y 223). Deriv. de cabeça, con prefijo des- que indica privación. Frec.: descabeçar 1: 0,00227; descabeçados 1: 0,00227 .

descolorido adj. 'descolorido, sin color, pálido' (se refiere a la palidez de la cara): se sintió en su persona assi que en continent todo descolorido, fizose decender del cavallo et levar al palacio et posses en el leyto, del qual accident assí como bueno verdadero christiano et depués de breus de días murió en edat de XXVII annos 37.9294. Formación parasintética, a partir del sust. color, con pref. des-, que indica ausencia o privación, y sufijo -ido < lat. -ITUS, que forma adjetivos a partir de sustantivos (PHARIES, 2002: 311). Frec.: 1: 0,00227.

desconfita s. f. 'derrota, vencimiento': el dito conte se metió en celada et priso el dito Ponz Guillem et el dito castiello con muyta de gent de Torroella, en la qual desconfita murió el dito Ponz Guillem, 36.432. Etim.: del lat. DES-CONFECTA 'descompuesta, desbaratada', formado sobre lat. CONFECTUM, part. p. del verbo CONFICERE 'elaborar, componer'. Se registra esconfita, desconfita, essconfita, sconfita 'derrota, vencimiento', en Fernández de Heredia (GILKIson, p. 43, s. v.). Comp. cat. desconfir 'derrotar', desconfita 'derrota': este sust., proveniente del participio del verbo desconfir, se documenta en cat. ya en 1283 (desconfir 'derrotar' en 1316) y estuvo en uso hasta el fin de la Edad Media. Igual origen tiene el it. sconfitta 'derrota' y el fr. ant. dé(s)confire (DECLIC, II, pp. 875-876, s. v. confit). En arag. ha de ser catalanismo, pues de acuerdo con la fonética histórica aragonesa hubiera dado *esconfeita. Frec.: 1: 0,00227.

desconocençia s. f. 'desconocimiento': e no queriendo estar reposo de desconocençia por el seynnalado servicio que el dito Beltran d'Albaus le avía feyto en el tiempo pasado, encoraxóse el dito compte 33.53. Deriv. a partir del v. conocer. Frec.: 1: 0,00227.

desconortado] p. p. de desconortar] 'desconsolado': veyendo que yeran fincados desconortados de sennyor, pensaron que ningún homme del mundo no podían esleyr millor quel dito rey Remiro 16.18. Etim.: deriv. de conortado 'consolado' (con prefijo des-, que indica privación o ausencia) y este de conortar 'consolar' $<$ lat. Conhortare. Desconortado se documenta ya en Razón feyta d'amor (h. 1205): «La mia senor se va privado, / dexa a mi desconortado» (versos 142-143; Menéndez Pidal, TME, pág. 114). En Fernández de Heredia: desconuerto 'desconsuelo', pero desconsolar (Gilkison, p. 43, s. v.). Comp. conuerto 'consuelo'. Vid. conortar. Frec.: desconortados 1: 0,00227.

desconoscient adj. 'desconocedor': non queriendo seer desconoscient del amor paternal et queriendo obedecer el su mandamiento, con grant conpannya de arcevispes, vispes et prelados et otros nobles gentes, en sus proprios braços levó el cuerpo de su bien aventurado padre a soterrar al monesterio de Poblet, do le era feita sepultura muyt honrada. 36.92. Es part. pres. del v. desconoscer. Frec.: 1: 0,00227. 
desear] (var.: desseyar) v. tr. 'desear': mas el dito cardenal, deseando que paz, et amor fuesse entre ellos, pacifficó la dita discordia 35.30. Vid. deseo, desseyar. Frec.: deseando 1: 0,00227.

desemparar v. tr. 'separar' (¿error por deseparar?): Mas finalment el dito Padre Santo por dreyto pronunció quel dito matrimonio non se podía desemparar [partir ni desemparar $\mathrm{N}]$, et a mayor firmeza confirmó el dito matrimonio. 34.66. Cfr. arag. mod. deseparar 'separar' (EBA, 1999: 666; ANDolz, 1992: 153). Comp. desemparar 'abandonar, desamparar' en Fernández de Heredia (Gilkison, p. 42). Pero en este pasaje concreto de la Crón. SJP. parece que vale más bien por 'separar'. Vid. desenparar. Frec.: 1: 0,00227.

desenbargar] v. tr. 'desembargar, quitar el impedimento, alzar el embargo o secuestro': Empero quel dito Frederich desenbargas [desanparas $\mathrm{N}$ ] el regno de Secilia a la Yglesia et no evan [heran $\mathrm{N}$ ] a la coronación de aquéll. 38.158. Frec.: desenbargas 1: 0,00227 .

desenparar (var.: desanparar) v. tr. 'desamparar, abandonar': dentro el dito tiempo avieron la dita ciudat desenparar et rendieronla al dito don Alfonso 36.688; «avemos oydo dezir que muytas vegadas ses esdevenido que vassallo desenpara su sennyor, mas que sennyor desenparás jamás vassallos assí como vos Sennyor, ningún tiempo no los avemos visto nin oydo dezir sino agora.» 38.131; el dito compte avía desanparar el dito regimiento de los ditos regnos 33.16-17; «Sennyor, pues ansi es que vos nos desenparades, placia vos que nos dedes Sennyor o nos digades a quien queredes que esliamos por sennyor.» 38.127. Deriv. de emparar amparar, del lat. vg. *ANTEParare 'prevenir de antemano', 'disponer un parapeto delante de algo' (DCECH, IV, p. 394), con prefijo des- que indica privación. En Fernández de Heredia desamparar, desemparar, desemperar (GILKISON, s. v.). Frec.: desenparar 1: 0,00227; desenpara 1: 0,00227; desenparades 2: 0,00455; desenparados 1: 0,00227; desenparás 1: 0,00227 .

deseo s. m. 'deseo': e ovo grant deseo de yr a visitar la dita santa cueva 11.36. Del lat. vg. DESIDIUM 'deseo erótico', masc. del clásico DESIDIA 'indolencia, pereza'. Del mismo origen: cat. desig, occ. desieg, port. desejo, it. desio, cast. deseo (DCECH, II, p. 460). Frec.: 1: 0,00227.

deseredado (var.: desseredado) adj. 'desheredado': et devía regnar esti don Alfonso el deseredado que era fillo del infante don Ferrando promogénito; agora entendedes [entendreys $\mathrm{N}]$ por qué es dito deseredado. 37.48; sostenedor de barones deseredados a los quales dava villas et castiello 35.178; Aquesti rey Alfonso metie su amiztat con don Alfonso desseredado de Castiella por don Sancho su tio 37.41. Frec.: deseredado 3: 0,00682; deseredados 1: 0,00227; desseredado 2: 0,00455.

deseredamiento s. m. 'desheredamiento, acción y efecto de desheredar': et por el deseredamiento que demandavan injustament sufrian grant passión, pena et tribulación 
36.495-496. Deriv. del v. eredar, con pref. des-, que indica privación, y sufijo -miento < lat. -MENTUM, que designa resultado de una acción (Pharies, 2002: 403). Frec.: deseredamiento 1: 0,00227; deseredamientos 1: 0,00227.

deseredat s. f. 'indigencia, privación, abandono': sostenedor de barones deseredados a los quales dava villas et castiellos et tierras de que buviessen vida honrada por conuerto de su deseredat [e de sus deseredades N] 35.179. Deriv. de eredat, del lat. HEREDitAS, -TATIS 'herencia' (DCECH, III, p. 344). Frec.: 1: 0,00227.

desesperado] adj. 'desesperado': como desesperados vida, enpués muytos convatimientos, rendieron la ciudat 19.46. Comp. desperación. Frec.: desesperados 1: 0,00227.

desfer v. tr. 'deshacer': por la qual cosa buvo en el regno grant guerra entre el rey et los de la unión en toda su vida que nunca la pudo sobrar nin desfer 37.22. Deriv. de fer, con pref. des-, que indica privación. Frec.: 1: 0,00227.

desflorar v. tr. 'desflorar': et cómo los franceses fazian todos los días diversos males, greuges et desonores, assí como desforar virgines et desmaridar mulleres maridadas et forçar mulleres biudas 36.192. Deriv. de flor < lat. FLOS, FLORIS. Frec.: 1: 0,00227.

desheredar v. tr. 'desheredar': Onde como el dito Simón quisiesse las condessas de Tolossa hermanas del dito rey don Pedro desheredar, el rey pregó et amonestó al dito Simón que se estuvies de fer enoyo et dannyo a las ditas hermanas suyas 34.129. Comp. deseredado, deseredamiento, deseredat. Frec.: 1: 0,00227.

designar] v. tr. 'señalar': con la mano dreita designando con el dedo, dixo:... 17.119. Es cultismo, tomado del lat. designare 'íd.' (DCECH, V, 210, s. v. seña). Frec.: designando 1: 0,00227.

desmaridar v. tr. 'descasar', 'separar de su marido a la mujer': et cómo los franceses fazían todos los días diversos males, grenges et desonores, assí como desflorar virgines et desmaridar mulleres maridadas et forçar mulleres biudas 36.193. Deriv. de maridar 'casar', deriv. de MARITUS 'marido' (DECLIC, V, p. 490). Comp. cat. desmaridar 'privar del marit; separar del marit' (DCVB, s.v., t. 4, p. 288). El DRAE, 1970, s. v., incluye como antiguo 'separar de su marido a la mujer' (el DLE, 2014, da la misma acepción, pero en lugar de la marca de antiguo pone la marca de desusado). Frec.: 1: 0,00227.

desmentir v. tr. 'desmentir': «O, cavalleros jet non vos yes verguenca que delant vosotros aquesti cavallero catalán aya desmentido a mi et de vosotros ninguno non le aya respondido?» 38.329. Deriv. de mentir < lat. MENTIRI (DCECH, IV, p. 42). Frec.: desmentido 1: 0,00227.

desobedir] v. tr. 'desobedecer': Et depués de aqueste tiempo, esleyeron dos reyes por nombre Radagaiso et Alarico et desobidioron al Imperio 3.28. Etim.: deriv. prefijado con des- de obedir, y éste del lat. OBOEDIRE (DCECH, IV, 267, s. v. oirr). La $1^{\text {a }}$ doc. que da para el cast. desobedecer es de Nebrija, 1495. Cat. desobeir (DCVB, s. v.). Frec.: desobidioron 1: 0,00227. 
desolación s. f. 'desolación, aflicción, desconsuelo': Et el dito rey, entendida la desolación et la miseria de los ditos sezilianos... 36.200; do dexó grant ploro al pueblo e grant periglo a la tierra e goyo a los moros e desolation a los pobres e sospiros a los religiosos 32.67. Voz culta deriv. del v. desolar, tomado del lat. desolare 'devastar, dejar desierto', o quizá tomada directamente del lat. desolatio, -onis 'desolación, destrucción, ruina' (SEguRA, 2001: 210). El BDELC (s. v. desolar) da la 1. ${ }^{a}$ documentación de desolación en cast. en 1611 (Covarrubias, Tesoro), más de dos siglos después que el registro atestiguado para el arag. en la Crón. SJP. Frec.: desolación 1: 0,00227; desolation 1: 0,00227.

desolado] adj. 'desolado': veyendo que ellos fincavan sin governador et la tierra fincava desolada de senyor, fueron cercando a qui eslieyrian por senyor lur et defendodor 10.4. Del part. pas. de desolar, del lat. DESOLARE. El DCECH (V, p. 294, s. v. solar) señala 1520 como fecha de la $1{ }^{a}$ doc. de desolar en castellano. Frec.: desolada 1: 0,00227 .

desonor s. f. 'deshonor': non queriendo sofrir ni sostener las desonores que su cormano el rey don Sancho de Castiella fiziera [firo N] ... 17.27. Deriv. de onor, con prefijo des- de carácter privativo. Frec.: 2: 0,00455.

desordenado] adj. 'desordenado, excesivo, falto de orden y de ley': porque el rey don Alfonso les atorgó por fuerça todo aquello que los de la unión le demandoron, entre las otras cosas le demandoron, ultra otras orribles et desordenadas cosas, que si no servava los privilegios que feito avía a la dita unión... 37.30. Frec.: desordenadas 1: 0,00227.

desovidient adj. 'desobediente': el qual fue muyt desovidient [desobedient $\mathrm{B}$ ] a su hermano, 36.8. Etim.: del p. pres. del v. desobedir. Corominas (DCECH, IV, p. 267, s. v. oir) da la primera documentación en cast. de desobediente en Nebrija, 1495. Frec.: 1: 0,00227.

despagado adj. 'molesto, contrariado, insatisfecho; herido moralmente': ya sea que fues dolenta et despagada dentro en su coraçón 23.13; de la qual cosa los enemigos fueron muyt desmagados [despagados et tristos $\mathrm{N}$ ] 38.566; de la quoal cosa fue muyt despagado et movido a grant ira 14.51; et los castellanos, vidiendo que assi avian dexado lur seynnora, fueron muy despagados e movidos 19.74-76. Deriv. de pagado 'contento, satisfecho', con prefijo des- que indica privación o negación de lo significado por la base. Frec.: despagado 10: 0,02273; despagada 2: 0,00455; despagados 3: 0,00682; desmagados [despagados] 1: 0,00227.

desparar v. tr. 'disparar': el alcayde fizo desparar muytas ballestas porque se buvieron de allí partir. 38.307. Etim.: del lat. DISPARARE 'separar', tomado como negativo de PARARE 'preparar', de donde el empleo desparar la ballesta, etc., que era lo opuesto a pararla o prepararla para el tiro; voz heredada por todos los romances de Occidente, y en el sentido español propia al port., cat. (s. XIII, desparar la ballesta, Desclot) e italiano. En cast. la forma común hasta Santillana, 
Gómez Manrique y Nebrija fue desparar (DCECH, IV, pp. 393 y 394, s. v. parar). El EBA (1999: 826) registra en arag. mod. esparar 'romper, destrozar o desencajar algo' en Salas Altas y 'ocurrir algo de manera insospechada y violenta; actuar una trampa' en Fuencalderas. El EBA (1999: 671) también registra despará 'diparar el fusil' en Peralta de la Sal, en la Litera Alta, donde comienza ya la zona de habla catalana. Frec.: 1: 0,00227.

desperación s. f. 'desesperación, desesperanza': tornose a sitiar la dita ciudad, la qual, sabiendo la victoria de los moros cayda en desperación, trista et dolenta, depués de ocho días rindiose sueltament 18.73-76. Etim.: Deriv. del lat. DESPERARE 'desesperar'. Corominas no documenta desperación, aunque sí desperado en Berceo. (DCECH, II, pp. 740-741). Comp. desesperados. En GILKISON: desperacion, tb. desperation, desperación, desesperacion. Frec.: 1: 0,00227.

despeyto s. m. 'despecho, desprecio': et continuament les tollian cavallo et otras cosas a pessar lur et despeyto 36.575. En la expresión a lur despeyto 'a despecho de ellos' parece tener el sentido de 'a su pesar, contra su voluntad'. Etim. del lat. Despectus 'desprecio' (DCECH, II, p. 475). Cfr. también KuHn, HAD, p. 16. Comp. cat. despit 'desdén, desprecio, despecho' (DCVB, s. v.). Se documenta en el Libro de Alexandre: SAS (1976: 204) indica que se trata de un aragonesismo. Frec.: 1: 0,00227.

desplazer s. m. 'descontento, enfado, disgusto, ofensa, desagrado': El qual mesagero con desplazer que [ovo porque otra $\mathrm{N}$ ] respuesta non le havía dada vinose al rey et recontole que respuesta ninguna non le havia querido fazer 20.118; de la qual cosa toda la tierra buvo gran duelo et desplazer 30.16-17; aquesto le dezía porque non tomas desplazer 36.369; de la qual cosa todo homme huvo grant desplazer 38.391; por muytas injurias et desplazeres 36.13. Deriv. del s. plažer. Frec.: desplazer 4: 0,00909; desplazeres 1: 0,00227 .

desplazer] v. tr. 'desagradar, disgustar, ofender': non firo cosa que desplazies a los sozmesos 35.216; et aquesta jura prendió el Cit et desplazió depués al rey muito 18.8788; la qual cosa desplugo fuert a todos los sus sozmesos 35.214-215. Deriv. del v. plazer, con el prefijo des- que indica privación. Frec.: desplazies 1: 0,00227; desplazió 1: 0,00227; desplugo 1: 0,00227.

desplazient adj. y p. pres. 'desplaciente, desagradable, que disgusta': veyendo que el atorgamiento del dito cavallo, si acabamiento venía, sería muito desplazient al emperador... 14.45. Frec.: 1: 0,00227.

despossedido (var.: desposeydo) p. p. 'desposeído': et fue muller del rey don Jayme de Mallorquas, el qual fue desposeydo por escusación de justicia de su regno et tierras por el el rey don Pedro 38.594; et por muytas otras razones fue despossedido el rey Carlos del dito regno de Sezilia 36.455. Del v. despossedir, deriv. de possedir (vid.). Frec.: desposeydo 1: 0,00227; despossedido 3: 0,00682. 
después adv. 'después'. Et después de algún tiempo, en el anno de Nuestro Sennyor MLXII, el dito rey Remiro asitió un lugar de moros clamado Grados 16.50. Vid. depués, enpués. Frec.: 13: 0,02955.

despullar] v. tr. y prnl. 'desnudar', 'despojar': prendet aquesta criatura et despullalde las vestiduras que adurze et levaldo [levantadlo N] rey, 12.28 (despullalde: metátesis de despulladle); el dito santo rey se despulló los vestidos reales 35.281 // (con prep. de) 'desprenderse de': et en la su fin despullós del condado et metiósse a la orden de los menores 36.435-437. Etim.: del lat. DESPOLIARE 'despojar, saquear', derivado de SPOLIARE 'íd.', y este de spolium 'pellejo de los animales', 'botín'. Es voz común en todos los romances (DCECH, s. v. despojar, t. II, p. 478). Se documenta en el Libro de Alexandre (SAS, p. 204: indica que se trata de un aragonesismo). En arag. mod. despullar, espullar (RohlFs, DDPA, s. v.; ANDolz, s.v., EBA, 1999, s. v.). Frec.: despullalde 1: 0,00227; despullaronle 1: 0,00227, despulló 1: 0,00227; despullós 1: 0,00227.

desque loc. conj. 'después que, una vez que': Estonz el compte Pero Ansures, desque avié rendido la tierra a la reyna su seynora natural, fuese para el enperador de Aragón, 19.82-83 ('después que huvo entregado'); Desque se vido la reyna partida del emperador tovo cueyta de casar con ella como ante hera fablado 19.100-101. Frec.: 2: 0,00455 .

dessafiamiento s. m. 'desafío': et dessafiamientos fuessen [fuessen dados $\mathrm{N}$ ] entre el uno et el otro dados 36.106. Etim.: deriv. prefijado y sufijado de fiar y éste del lat. vg. *FIDARE, modificación del lat. FIDERE. Frec.: dessafiamientos 2: 0,00455.

dessafiar] v. tr. 'desafiar': lo enviava a éll por gitar la tregua que avian et por dessafiarlo 36.392. Etim.: deriv. prefijado de fiar, o afiar y éste del lat. vg. *Fidare, modificación del lat. FIDERE. (BDELC, s. v. fiar, p. 271). Frec.: dessafiarlo 1: 0,00227 .

dessexida s. f. 'partida, salida de un sitio al que se había entrado desde otro; acción de salir de una comarca para volver a entrar en aquella de la que se había salido', 'despedida': et pues que eran en la dessexida de su tierra, entendía calçadament a ferir en los francesses 36.649. Etim.: deriv. de exir < lat. EXIRE 'salir de, ir fuera'. Comp. desexir 'salir, partir' en Fernández de Heredia (GILKIsON, s. v.). En los $D L A A$ se emplea desexir 'desprenderse (de)': «e de mi seignoriuo e de mj poder, que yo ni los mios emos e auer deuemos sobre las ditas heredades, nos deseximos e nos despuillamos por todos tienpos» (DLAA, doc. $\mathrm{n}^{\circ} 28$, de Huesca, año 1274; p. 41, lín. 148). «del qual dito pueyo nos ditos donadores de poder \& de seynnoria nuestra \& de toda nuestra jurisdicion nos deseximos $\&$ nos astrayemos \& en present en poder uuestro \& seynnoria uuestra \& de toda jurisdccion uuestra uos enuestimus» (DLAA, doc. $\mathrm{n}^{\circ}$ 57, de Ponzano, del año 1284; p. 85, lín. 21). Frec.: 1: 0,00227. 
desseyar] (var.: desear) v. tr. 'desear': Et desseyando que nombre de traydor non buviés [fues $\mathrm{N}]$ en la tierra, encartó e gitó de todos sus regnos et tierras al dito Remón 17.21. Deriv. del sust. deseo, mediante derivación inmediata en -ar (DCECH, II, p. 460). En el arag. de Fernández de Heredia, junto a deseo, desear y deseoso, se registran las formas deseyo, deseyar y deseyoso (GILKISON, 1984: 44); también deseyo, deseyar y deseyoso en VM (Tilander, 1956, III: 93). Tienen el mismo origen: cast. desear, port. desejar, cat. desitjar, occ. desejar. Vid. también desear. Frec.: desseyando 1: 0,00227.

dessi adv. 'después, desde alli', 'de ahí': et dessi el dito Cit con trezientos cavalleros vinose para las montannas de Cuenca 18.90. Etim.: DE EX IBI (DCELC, IV, p. 770). Comp. desi 'después' en TLME: «e desi mando que fincassen las ocho allí» (TLME, doc. no 21, lín, 14, pág. 52; texto castellano de la $2^{\text {a }}$. mitad del s. XIII, Primera Crónica general); «Desi Bruto conbatio muy de recio la billa» (TLME, doc. $\mathrm{n}^{\circ}$ 81, lín. 30, pág. 161, perteneciente a un texto navarro, de princ. del s. xv, Crónica de García de Eugui, obispo de Bayona). Para el navarro desi 'después' vid. también TLN, p. 220; SARAlegui, Irache, p. 254. Ejemplos del cast. med. en DME, s. v. desí, p. 924. Es habitual en arag. med. con el significado de 'además': «Et desí en todos \& cadaúnos pleytos, demandas \& questiones ad lites» (MDF: 158.10). O bien, con la acepción de 'después, desde ahí': «assí empero que primerament los fillos hereden, et si fillos no ha, los sobrinos, et desí los quj descendieren por orden» (VM, VI, 18, 21); «quar primerament... deuen ordenar do quiere auer su sepultura... et desí emendar los tuertos» (VM, VI, 21, 3). Tilander (1956, tomo III, p. 93) registra en el Vidal Mayor en cinco ocasiones desí adv. 'después' y desí adelant 'de aquí adelante’. Lo escribe con tilde en la $i$. Frec.: 1: 0,00227.

dessuso (var.: dessus, desus, desuso, de suso) adv. y prep. 'arriba, encima'; 'sobre': fueron emplidos dos pocos con tierra que hi fue gitada dessuso 38.558; Et por el departimiento de los regnos dessus ditos, el dito Remiro bubo el condado de Aragón 15.5; contra la malvada gent quel venien dessuso, 36.529 (la malvada gent qui li venia de sobre, VC). Es frecuente en el sintagma dessuso dito 'arriba dicho, sobredicho'. En la VC aparece como dessús: el acuerdo dessuso dito VA, 38.149-150 [l'acord dessús dit VC, p. 162]. También aparece damunt. segunt que dessuso avemos dito 38.167 [segons que damunt havem dit, VC, p. 162]. Etim.: prep. de más suso < lat. sursum. 'hacia arriba'. Comp. ensuso, suso, susodito. Frec.: dessuso 36: 0,08183; dessus 5: 0,01136; desus 15: 0,03409; dususo 5: 0,01136.

destorbar (var.: estorvar) v. tr. 'desbaratar, estorbar', 'estropear': de manera que pensó que quanto havían adobado que sería destorbado 20.201; porque era de mala vida et mas al compte don Pedro que lo estorvava mas 19.166. Etim.: del lat. DISTURBARE 'dispersar'; 'demoler, destruir, deshacer'; 'arruinar, aniquilar'; 'impedir, anular, estorbar, perturbar', deriv. de TURBARE (BDELC, s. v. turbar, p. 590); cast. 
estorbar (antes destorvar), port. estorvar, cat.-oc. destorbar (DCECH, V, p. 700, s. v. turbar). Comp. arag. mod. estorbau 'desordenado, medio loco' (Uncastillo', 'persona que no está bien de la cabeza' (Luesia), 'persona rara' (Ayerbe) (EBA, 1999: 862). Frec.: destorbado 1: 0,00227; estorvava 1: 0,00227.

destragar] v. tr. 'devastar, deteriorar, destruir, arruinar, asolar, causar estragos': et fue con grant poder en ayuda suya et amos a dos destragoron [estragaron $\mathrm{B}, \mathrm{N}$ ] el regno de León et cobroron lo que havían perdido. 34.79. Se trata de un caso de confusión de prefijo, puesto que procede de *STRAGARE 'asolar, devastar' (DCECH, II, p. 798). Vid. estragar, astragar. Frec.: destragoron 1: 0,00227.

destrenimiento (var.: estrenimiento) s. m. 'acción y efecto de estrechar (un cerco, un sitio)', 'opresión, apremio, estrechamiento': et aquel sitió poderosament et destreyta por el qual destrenimiento los nobles varones qui dentro eran sufrieron grant freytura de viandas et de otros fornimientos 36.134-137; con la grant cura et consello et estrenimiento de armas del dito rey don Pedro 36.25. Etim.: deriv. de estrennyr $<$ del lat. stringere 'estrechar' (DCECH, II, 806). Comp. estrennyr. Frec.: destrinimiento 1: 0,00227; estrenimiento 1: 0,00227.

destreytament adv. 'estrechamente', 'resueltamente, amenazadoramente': tenian asitiada la ciudad de Pamplona muyt destreytament en tiempo de yvierno 12.52. Quizá podría tratarse en este caso de un derivado de destreyto; entonces el sentido sería más bien 'amenazadoramente, resueltamente'. Si no, será deriv. de estreyto 'estrecho'. En cualquier manera que sea, parece que se da una cierta confusión entre los derivados de DeSTRICtus 'resuelto', y de stRictus 'estrecho'. Frec.: 1: 0,00227 .

destreyto] (var.: districto) adj. 'resuelto, decidido', formando parte del sintagma adverbial: et aquel sitió poderosament et destreyta, por el qual destrenimiento los nobles varones qui dentro eran sufrieron grant freytura de viendas 36.135; et aquella conbatió fuermientre [fuerment $\mathrm{B}]$ et destreyta 36.485; vino sitiar Castell de Callar et mientre que lo tenia fuerment et districta [estrecha $\mathrm{N}$ ] sitiado... 38.542. Etim.: del lat. DESTRICTUS, -A, -UM 'resuelto, decidido, amenazador', p. p. de Destringere 'arrancar, cortar, coger', 'desenvainar, causar una herida; herir levemente' (BLÁNQUEZ, $s$. v.). Frec.: destreyta 2: 0,0455.

destrucción s. f. 'destrucción': Et el dito rey de Granada, viendo manifiestament la destrucción de sí mismo et de sus gentes 38.376. Cultismo tomado del lat. destructio, -onis. Frec.: 1: 0,00227.

destruir (var.: destruyr, distruyr, estruyr) v. tr. 'destruir, deshacer, arruinar', 'aniquilar': et destruytos estos dos lugares con favor de algunos cavalleros de aquella comarcha... 36.350; que todas quantas yglesias trobavan todas las robavan et destruyvan 36.493; non levando reverencia a Dios ni a los santos suyos el cuerpo de Sant Narcis, qui por reliquias en grant honor estava en la eglesia de Sant Feliu, mutilaron et distruyeron 
36.567; aquesti varón noble estruyó la ciudat de Almería con LII hommes [mil ommes $\mathrm{N}]$ a cavallo 32.18; Aquesti conte Remón Burrel por exalçar la fe christiana, por destruir la seta morisca, fue en Córdova contra moros 27.5. Del lat. DESTRUERE 'destruir, demoler, derribar'. Frec.: destruir 2: 0,00455; destruyendo 5: 0,01136; destruyó 3: 0,00682 ; destruytos 1: 0,00227 ; destruyvan 1: 0,00227 ; distruyeron 1: 0,00227; estruyó 1: 0,00227.

destruymento s. m. 'destrucción' (o más bien, si nos atenmos a la literalidad del texto, 'medios de destrucción, instrumentos de destrucción'): quando muyto la huvo opprimida por gennyos et otros destruymentos [destruimientos B] 35.144. En el arag. de Fernández de Heredia se registra destruymiento, destruimiento, estruimiento 'destrucción' (GILKISON, s. v.); en VM destruimiento, estruymiento 'tala, destrucción' (Tilander, VM, III, p. 95). Comp. cat. destrü̈ment 'destrucción' $(D C V B$, s. v.). El sentido que tiene en la Crón. SJP. parece influido por instrumentos. Frec.: destruymentos [destruimientos] 1: 0,00227.

desuayr (var.: esvayr) 'invadir, atacar, asaltar, confundir; asustar, ahuyentar; sorprender': grant multitut de gent morisca assí de cavallo como de pie contra el poder del virtuoso rey por desuayr et desbaratar aquéll si pudies, vino con grandes cridos et udulamentos, 38.360; una vegada con grant huest esvayó e destruyó grant partida de Castilla 33.77. Etim.: Según Corominas, del lat. Evadere en el sentido de 'asaltar (una muralla)', aunque influido por INVADERE 'invadir' (DCECH, II, p. 484; DECLIC, III, pp. 814-815). El DCVB (s. v., t. 5, p. 615), propone un lat. vg. *EX-VADERE que habría sustituido por cambio de prefijo a dos verbos del lat. cl.: INVADERE y EVADERE. Vid. ahí ejemplos de cat. ant. esvair 'asaltar, invadir' y 'deshacer, desbaratar'. En el arag. de Fernández de Heredia esuayr, esueyr, desuayr 'invadir, usurpar', 'asaltar, atacar', 'confundir, desconcertar', 'espantar, asombrar' (GILKISON, p. 63. s. v. esueyr. p. 63). Frec.: desuayr 1: 0,00227; esvayó 1: 0,00227.

detrás adv. 'detrás': el rey de Aragón les fue detrás et vigorosament et baronil firió en los franceses 36.654. Etim.: compuesto de las prep. de y trás < lat. TRANs 'más allá de'. (BDELC, p. 581). En arag. mod. se utiliza dezaga (ANDOLZ. s. v.; ROHLFS, $D D P A$, s. v.; GLA, pp. 249-250; $E B A, 1999:$ 676). Igualmente, en arag. med. se usó de çaga 'detrás': «hun nuestro pueyo que nos auemos \& auer deuemos de çaga el castiello de la uilla dUarta» (doc. de Ponzano, 1284; DLAA, doc. $\mathrm{n}^{\circ}$ 57, p. 85, lín. 8). En cat. darrera (DCVB, s.v.). Frec.: 1: 0,00227.

devallar] v. intr. 'bajar, caer; descender, derivar': et depués de grado en grado de cada un conte segín que devalloron el <uno> del otro, fablaremos et lur vida recontaremos 21.46 [segons que devallaren un d'altre, VC, p.73]. Etim.: del lat. valuIs 'valle'. Con la prep. AD se formó en cat. AD VALLEM $>$ avall 'abajo' y de aquí el v. avallar 'bajar'. De forma semejante, con la prep. de + avall $>$ davall 'debajo' y de aquí el v. davallar $\sim$ devallar (DECLIC, IX, pp. 30-35, s. v. valh). En arag., donde no 
existen los adv. avall y devall, habrá que pensar que es un catalanismo o bien que se ha formado por parasíntesis: de + vall $(e)+$ ar. Colón, El léxico cat., p. 88, aduce [arag. med.] devallar (cat. davallar) 'bajar' como una de las voces del arag. med. coincidentes con las soluciones del cat. En occ. davalar 'dévaler; descendre; démonter son cavalier; renverser; provenir, dériver; baisser, déchoir' (Alibert, s. v., p. 259). Etim.: lat. De + valuis + Are, según Alibert. En occ. (prov.) davalar y devalar 'descendre; descendre à un hôtel; provenir, dériver' (Levy, s. v., pp. 105 y 123). En fr. dévaler 'descender; precipitarse hacia abajo' (Gran Diccionario español-francés / francés-español LAROUSSE, 2018: 358 , s. v.). Para el gasc. mod. no lo registra PALAY. En cat. existe davallar 'anar, traslladar-se, moure's, d'un punt a un altre de més baix'; 'recórrer de dalt a baix'; 'portar de dalt a baix' (FABRA, s. v., p. 525; DL/C del IEC, 2007, s. v.). En cat. ant. también devallar (cfr. DCVB, s. v. davallar, t. 4, p. 31). Sin embargo, dudamos que pueda considerarse catalanismo, ya que en Navarra «la bajada de la montaña a la Ribera (desde los altos valles de Roncal y Salazar), a herbagar, a invernar, se llamaba deballada» (IRIBARREn, Voc. navarro, s. v. puyada, p. 435). En arag. mod. deballar 'raer con el esquiparte los costados del cauce en la limpia de las acequias' (ANDOLZ, s. v.), que quizá haya podido derivar a este significado tan concreto a través de 'rebajar'. No parece conservarse el significado original de 'descender' en el arag. moderno. En arag. med. está atestiguado devallar 'descender, bajar' en las obras de Fernández de Heredia (GILKIson, s. v. deuallar), en el s. XIv. Igualmenten en el LT (RodÉs, 2016: 715). En LMM devaillar, inf. usado como sust. 'descenso, bajada' (Liria, p. 166). También auall 'abajo', auallar 'bajar, descender', en Fernández de Heredia (GIlkison, s. v.); deuallar 'to come down, descend, dismount' en el LT (PrInCE, 1995: 221). Atestiguan también devallar 'bajar, descender' LíBANO \& Villacorta (2013: 93). Es frecuente en el arag. de los siglos XIV y XV y aun a comienzos del xvI: «por tirar scandalos, males et peleas que cada dia se seguian sobre las puyadas et devalladas enta suso et enta yuso et puyando enta la montanya et devallando enta Espanya los ganados grossos et menudos de la dita Bal de Echo. [...] quando devallaran enta part de Spanya o puyaran de Spanya enta part de la montanya...» (EAMJM, doc. n. ${ }^{\circ} 12$, de Braslavilla, de 1438; p. 71); «E assimateix por linea femenina ne deualla mossen Galcera[n] de Tarba» (Letra Intimada, 1435); «Et assí preso devalyando lo dela dita casa, et conpliendo lo a la puerta de aquella, los ditos Sancho Vidos et otros de suso nombrados li travessoron vna lança en la dita puerta» (DLAA, doc. 145, de Jaca, 1464; pág. 213, lín. 59). [En ReIDy FRITZ, 1977: 150: «devalyando, ger. de *devaluar; rebajar», lo que evidentemente es una interpretación errónea]; «et assí mismo puyan et devallan muchas fustas con mercaderias que van a las Indias et tornan» (Libro de Marco Polo, ed. NitTi, pág. 25, lín. 40); «en el 
paquo que deballa del Castillo de Grossin» (DJ, doc. de 1502, AFA, X-XI, p. 363); «E porque la salut del pueblo devalla de la salut del Princep; por aquesto la salut del Princep es fuert preciada» (Contestación al Discurso de Martín I el Humano (1398); vid. en Blancas, Comentarios, p. 352); deuallante 'derivado, resultante, que desciende': «Car nos en e sobre las ditas cosas con sus dependencias emergencias e cosas d'aquí deuallantes cometemos a vos e cadauno de vos plenerament nuestras vozes con la present» (carta de Alfonso V de Aragón a los oficiales de Zaragoza, 13 de marzo de 1425; LLEAL, 1997a: 82). El DRAE (1970, s. v.) recoge devalar (del gallego-port. devalar, o del fr. dévaler, descender, y éstos del lat. de y vallis, valle) con el significado de 'derivar, separarse del rumbo' (y con indicación que es de uso en la marina). Frec.: devalloron 1: 0,00227.

devenir v. intr. 'llegar a ser', 'sobrevenir, suceder', 'llegar a un determinado sitio, venir': Et aquesti Alarico demandó al emperador Honorio, qui a las horas emperava et sennyoriava el imperio de Roma, averpaz con él et con el Imperio et devenir [de veren $\mathrm{N}$ ] en aquél 3.32. Etim.: del lat. DEVENIRE 'venir desde arriba', 'suceder, venir a ser'. Los casos de hi devino 36.563 y de $y$ de vino 38.501 hay que interpretarlos como bide (o yde) + v. venir, es decir, 'vino allí (mismo)'. Cfr. hide. Frec.: 1: 0,00227.

dever] v. tr. 'deber': que le dies algo de lo suyo que heredás, assí como fillo deve heredar a padre 20.179; «...que mi sennyor el rey d'Aragón se yes levado lealment et assí como devía» 38.323. Etim.: del lat. DEBERE, de igual significado (DCECH, II, 429). Frec.: deve 2: 0,00455; devía 17: 0,03864; devían 3: 0,00682; devido 1: 0,00227; devies 9: 0,02946; deviessen 3: 0,00682.

devoción s. f. 'devoción': todos los christianos avian grant devoción en aquesta spelunca, 5.17; E las oras fue multiplicada la devotión en la dita cueva por los christianos, porque el compte d'A Aragón Fortún Ximeniz, qui grant devotión avía en la dita cueva... 11.12-14. Tomado del lat. devotio, -onis 'dedicacion, consagración' (SEGURA, 2001; 215). Frec.: devoción 6: 0,01364; devotión 3: 0,00682.

devotament adv. 'devotamente': el dito beremita firo una eglesia a honor de Dios y de Sant Johan Baptista et aqui sirviendo finió sus dias devotament et sancta 5.4. Frec.: 9: 0,02046 .

devoto adj. 'devoto': Et aquesti virtuoso rey era muyt devoto a Dios et a la suya benedita madre 35.235; bumilment y devota, translataron los cuerpos del desus dito Sant Johan heremita 9.20. Tomado del lat. devotus 'consagrado a, afecto a', y luego 'piadoso, devoto' (SEgura, 2001; 215). Frec.: devoto 2: 0,00455; devota 1: 0,00227.

dexar] v. tr. 'dejar': Et los castellanos, vidiendo que assí avian dexado lur seynnora, fueron muy despagados 19.74; e finó en el barch de Sant Dalmau... do dexó grant ploro al pueblo e grant periglo a la tierra 32.65; et dexolo alli, do oy en día es la eglesia de San Jorge 18.61. Etim.: procede de una alteración de lexar < lat. LAXARE 'aflojar, 
ensanchar', con $d$ - debida a influjo de otro verbo o quizá de la preposición de (DCECH, II, pp. 435-436). Es mucho más frecuente la variante lexar (vid.). Frec.: dexado 1: 0,00227; dexó 5: 0,01136; dexolo 1: 0,00227.

dezir (var. dir) v. tr. 'decir': Et tantost los ditos difamadores confesaron et dixeron al sancto varón que falsament e iniqua havian a lur madre infamada 14.76; segunt se dezía, estuvo preso por mandamiento de su padre en carçel 34.18; Et tornoron la palaura dessuso dita otra vegada: «Sennyor, dezit nos a quí queredes que esliamos por sennyor» 38.135: et tan largo et tan proz que a ninguno no podía dir de no de res quel demandassen 13.8; et dixo cuytadament: "Varons, prendet aquesta criatura et despullalde las vestiduras que aduze...»12.27; et dixieron muytas et inhonestas et non dizientes [dezideras $\mathrm{N}$ ] palavras, 38.126; «que sennyor desenparás jamás vassallos assí como vos, Sennyor, ningún tiempo no lo avemos visto nin oydo dezir sino agora» 38.132. / / v. prnl. 'llamarse': El uno de los cuendes se dezía don García de Traba de Nágera, al otro don Gonçalvo 18.14. Vid. clamar. Etim.: < lat. DICERE. Comp., en cambio, maldiciones 36.596 con $c$. Frec.: dezir 14: 0,03182; dezit 1: 0,00227; dezía 7: 0,01591; dezimos 1: 0,00227; deyan 1: 0,00227 ; dixeron 2: 0,00455 ; dixieron 5: 0,01136 ; dixiemos 2 : 0,00455; dixo 22: 0,05000; díxole 10:0,02273; dixoles 1: 0,00227 ; díxose 1 : 0,00227 ; dir 2: 0,00455; dize 2: 0,00455; dizen 17: 0,03864; dizía 1: 0,00227; diziendo 3: 0,00682 ; diziéndole 1: 0,00227 ; dizientes 1: 0,00227 ; dizieron 2: 0,00455; diziessen 1: 0,00227.

día s.m. 'día': rendió su anima a Dios en la ciudat de Barchinona, en día miércoles a hora de media tercia 39.42; et vino sende al lugar de Sant Martín do estuvo dos dias 38.583. Del lat. vg. *DIA, lat. DIES (DCECH, II, p. 486). Frec.: día 85: 0,19320; días 49; 0,01137 .

diciplo s. m. 'discípulo, alumno': el cuerpo de San Indaleci et de San Jayme diciplo de aquél... fue adueyto por reliquias en Sant Johan de la Pennya 17.76. Del lat. Discipulus. Se registra diçiplo en Alex. (SAS, p. 213). Bustos, Contribución, p. 424, registra además diçiplo en Apolonio y las formas deçiplo, disciplo, desciplo, junto a discipulo, todas ellas consideradas como cultismos. En el arag. de Fernández de Heredia: diçiplo, disciplo, diçipol, dicipulo, disçipol, desçiplo, discipulo, deçiplo (GILKIsON, 1984: 48). Véase además desciplo en un refrán arag. del s. XIV: «Qual mayestro, tal desciplo» (RIus, 1926: 370). Comp. cat. deixeble (DCVB, s. v.). Frec.: 1: 0,00227.

diezma s. f. 'diezmo, impuesto, tributo que consiste en la décima parte de los bienes'; 'la décima parte': et prisso las diezmas [décimas $\mathrm{N}$ ] de su terra, 34.155; dió la diezrma [las deçimas $\mathrm{N}$ ] de sus regnos et tierras 38.184. Además de la alternancia en estos dos casos, comp. tb. décimas 18.122, también en ms. N. La forma diezrma(s) es el resultado popular, con diptongación, del lat. DECIMAS (DCELC, s. v. diez). La forma decimas es el resultado culto. Según anota Líbano (1979: 65-80, especialmente, p. 67): «El cultismo décima resulta poco común 
en la Edad Media, deceno y los duplicados populares diežmo, diez̧ma están más difundidos». Frec.: diezma 1: 0,0027; diezmas 1: 0,00227.

difamación s. m. 'difamación, acción de difamar': los ditos dos hermanos no quisieron ser principales acusadores más consintieron que ayudarian a dar alguna favor a ell sobre la dita difamación 14.55-58; viendo la innocencia de su madrastra et la voluntaria diffamación que le era estada levantada et possada 14.67. Deriv. posverbal del v. difamar, tomado del lat. DifFAmARE, con sufijo -ción, que deriva sustantivos a partir de verbos e indica la acción correspondiente (PHARIES, 2002: 150). La 1a documentación que registra el BDELC (p. 267, s. $v$. fama) para esta voz es de 1438. Frec.: difamación 1: 0,00227; diffamación 1: 0,00227.

diffamar] v. tr. difamar': aquesti acusava et diffamava en muytas cosas al dito rey 36.36. Del lat. DIFFAMARE. Frec.: diffamava 1: 0,00227.

diffinidat s. f. 'infinidad, cantidad': por cada un lugar do de los franceses estavan muyt grant diffinidat ne matoron 36.514 [car per cascun lloc on los francesos estaven, gran infinitat n'auciren VC, p. 142]. Posiblemente se trate de un caso de confusión de prefijo (di- por in-). Frec.: 1: 0,00227.

diffinir v. tr. 'definir, concretar': et finalment fizo diffinir que ella se havies a escusar [acusar N] 14.63. Tomado del lat. diffinire, variante de definire 'limitar, circunscribir'

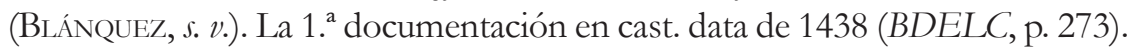
Frec.: 1: 0,00227.

dignidat s. f. 'dignidad': Etya sea que li dies el dito regno en casamiento, no empero renunciava a la dignidat real 20.287. Es cultimo tomado del lat. dignitas, -atis. Frec.: 6: 0,01364.

diligenment (var.: diligentment) adv. 'diligentemente': non les ossava venir vianda alguna por miedo del dito rey de Aragón et de las sus gentes qui diligenment lo spiavan 36.622; et mandóle que lo nudries muyt diligentment et curosa 23.7. Frec.: diligenment 1: 0,00227; diligentment 1: 0,00227.

diligent adj. 'diligente': fue muyt noble varón, largo, proz et diligent 35.90. Tomado del lat. diligens, -entis 'diligente, cuidadoso, escrupulososo, concienzudo, exacto, atento' (SEgura, 2001: 221). Frec.: 1: 0,00227.

dineros s. m. pl. 'monedas': e por otra part y offreció a bonor de Dios e de los sanctos del dito lugar $D^{\text {os }}$ dineros de argent 11.41-43. Del lat. DENARIUs. Comp. dineros 'caudal, haber monetario' en nav. med. (SAralegui, Irache, p. 167). Comp. moneda 'dinero'. Frec.: 1: 0,00227.

Dios nombre propio m. 'Dios': et de ora del alva, muyt abrivadament etpodroso, comendandose a Dios, firió tan fuertment en el sitio de los moros que todos los desbarató 12.57. Del lat. DEUS. Frec.: 101: 0,22957.

discordia s. f. 'discordia': Et tantost por la discordia que hera entre los reyes de christianos, algunos reyes avian feyto paz e tregoa e amiztad con los moros 33.97. Cultismo tomado del lat. discordia. Frec.: 12: 0,02728. 
discrección s. f. 'discernimiento': et por tal quel dito infant era sin regimiento et sin discrección natural por la su grant joventut 35.27-28. Tomado del lat. discretio, -onis 'discernimiento, selección'; discreción se halla en Berceo (DCECH, s. v. cerner, II, 48). Frec.: 1: 0,00227 .

discrybir v. tr. 'describir'. Parece error por destruir. se esdevino que con grant multitudo de franceses ydos enta Banyules por correr et discrybir [destruir B] la tierra... 36.580 [s'esdevenc que com gran multitud de francesos fossen anats vers Banyoles per còrrer e destruir la terra... VC]. Del lat. DESCRIBERE. Primera doc. de describir en cast.: princ. s. XV, en Santillana (DCECH, II, p. 711). Frec.: 1: 0,00227.

disensión (var:: dissensión, dicensión) s. f. 'disensión, oposición, discrepancia': et guardó toda aquella honor et reverencia al dito rey como fillo a padre deve fazer, tanto que nunca dicensión fue entre ellos avida 20.299; et por tal que disensión alguna non se siguiesse entre los regnos... 19.181; queriendo proveyr que enpués dias suyos dissensión alguna non avies en la successión del regno de Aragón, si fue tratado matrimonio con don Ramón Berenguer comte de Barchinona 20.252. Cultismo tomado del lat. disenssio, -onis 'disentimiento, desacuerdo, divergencia', 'división, discordia, oposición' (SEGURA, 2001, s. v.). La 1. a documentación de disensión para el cast. la registra el BDELC (p. 531, s. v. sentir) hacia 1490. Frec.: disensión 1: 0,00227; dissensión 1: 0,00227; dicensión 1: 0,00227 .

disimular] v. tr. 'disimular, encubrir, ocultar': et así como savio sennyor, disimulando el dito frau, clamada et avida la dita reyna su muller, filla del dito rey de Castiella, el dito rey don Jayme sen tornó en su tierra. 38.52. Cultismo tomado del lat. DISSIMULARE (DCECH, V, p. 198). Frec.: disimulando 1: 0,00227.

dispensación s. f. 'dispensa': empero el dito rey de Castiella la dita dispensación de consanguinidat no bubo al dia asignado 38.60. Cultismo tomado del lat. dispensatio, -onis 'distribución, reparto', 'administración, gestión' (SEGURA, 2001, s. v.). Frec.: 1: 0,00227.

disposición s. f. 'disposición': et lexado el dito regno en buena disposición, en Catalunnya sen tornó por prender la corona et dignidat real. 37.10. Cultismo tomado del lat. dispositio, -onis ‘disposición, arreglo’ (SEgurA, 2001, s. v.). Frec.: 1: 0,00227.

dito (var.: dicto) adj. y p. p. 'dicho': el dito matrimonio non pudo venir a acabamiento 39.12; temiendose que por semblant iudicio que firo de su padre non passas, absentos del dicto regno et vino sende en Valencia 17.12; deviessen exseguir la paz dessuso dita 38.101; antes que las ditas fuerças aviessen acabadas 4.20; todos los ditos homes buenos eshyeron curador suyo don Phelip su tio 38.607-608. Del lat. DICTUS, p.p. de DICERE. Es habitual en arag. med. (Tilander, FA, p. 364; Reidy Fritz, 1977: 151-152; OB, VÁzQuez, 2011c: 37; etc.), si bien en las obras de Fernández de Heredia se registra mayoritariamente dicho, dicha (GILKIson, p. 178, s. v. deziri), lo cual, junto con otros datos, es síntoma de que sus obras reflejan fundamentalmente el aragonés de las Serranías Ibéricas (cfr. NAGORE, 2020b: 72-73). Igualmente se conserva en el arag. mod.: ANDOLZ (1982: 158, s. v.) lo registra en Ansó, Bielsa y Benasque; el EBA (1999: 684-685) 
en Ayerbe, Chuseu, Torres del Obispo, Ansó, Bal de Chistau, Plana de Uesca, Mundot, valle de Bielsa. También se documenta en Panticosa (NAgore, 1986: 179). Frec.: dito 790: 1,79562; ditos 56: 0,12728; dita 126; 0,28639; ditas 14: 0,93182; dicto 1: 0,00227.

dius prep. 'bajo': las ditas tierras, que aquellas tenies en feu en dreita sennoría por el rey Remiro, et assin como puro homme et vasallo suyo obedeciesse et atorgás él por sennyor et sus succeydores dius pena de perder las ditas tierras 16.35; et dexó su regno a don Jayme, fillo de su hermano don Ferrando qui murió en Grecia, dius aquesta condición 38.603. Etim.: lat. DEORSUM 'abajo, hacia abajo' con la preposición de antepuesta (DCELC, IV, p. 784, s. v. yuso). Opina CoROMINAS respecto a la forma dius: «no creo que tengamos conservación del grupo DI- del latín vulgar, lo que sería contrario a la fonética de este idioma, sino más bien contracción de deyós, deyús» (DCELC, IV, p. 784). Se documenta dios 'bajo' en FA, diús en Inv. arag. de 1380 (DCELC, IV, 784). Es muy común en textos en arag. medieval. En Fernández de Heredia dius, dios, diuso (GILKISON, s. v.). Com. deiuso, ayuso. Actualmente se registra en la forma dichós 'debajo, bajo' en el valle de Benasque (BALLARín, 1978: 123) y en algunos otros puntos de Ribagorza como el valle de Lierp (AriÑo, 1999: 62). Frec.: 2: 0,00455.

diusmetido adj. y p. p. 'sometido': et aquesto por tal que todos tiempos conte de Aragón fue diusmetido al rey de Navarra, 15.3. Deriv. del v. meter < lat. MITTERE con la prep. dius antepuesta que funciona como prefijo. Comp. con sozmesos. Cfr. en el arag. de Fernández de Heredia diusmeter, iusmeter 'someter, someterse' (GILKISON, s. v.). Frec.: 1: 0,00227.

diverso] adj. 'diverso, distinto' // pl. 'varios': por defender los christianos de las crueldades et terribles persecuciones de los moros, el qual havía vencido et desbaratado muytas et diversas vegadas 10.10; et los otros nobles et cavalleros tuvo presos en grillones et en cadenas por diversos castiellos et lugares 36.147. Del lat. DIVERSus. Frec.: diversas 10: 0,02273; diversos 5: 0,01136 .

divinal] adj. 'divino': Et tantost con gran devoción, penedidos et confessados fielment de lures pecados, et con grandes cantos et melodias divinales et con grant contrición de coracón, bumilment et devota, translataron los cuerpos del desus dito Sant Johan heremita 9.19. Del lat. tardío DIVINALIS 'de Dios, correspodiente a Dios'. Frec.: divinales 2: 0,00455.

división s. f. 'división, separación': et aquella looron et aproboron et la división destos regnos fue metida en el monesterio de Sant Johan de la Pennya 20.170. Cultismo, tomado del lat. divisio, -onis. Frec.: 1: 0,00227.

divulgar v. tr. 'divulgar': queriendo divulgar et ennoblecer la suya fama et justicia 29.7. Tomado del lat. divulgare. Frec.: 2: 0,00455.

do adv. 'donde': et fue don Jayme en la conquista de Mallorquas, do murió como buen cavallero 35.105; et depués partió de aquí et fue en Barçalona el segundo día de agosto, do fue recebido por el rey don Jayme su padre 38.584. Formado por la prep. de más $o<$ lat. UBI (DCECH, II, p. 516). Es forma ampliamente documentada en 
arag. ant. Vid. donde, dont. Para do 'doi' vid. dar]. // por do loc. conj. consecutiva 'por donde, por lo que': tanto començó bien de regir, por do huvieron grant conuerto los de la huest. 17.129; Et el rey enpennyó muytas villas et prisso las diezmas de su tierra [en la ed. crítica, terra] et algunos trasoros de las yglesias por do avía la yra de Dios sobr'él 34.155-156. Frec.: 61: 0,15001.

doblado] adj. 'doblado, elevado al doble': que le ayudasse a deffender contra el rey de Aragón et que darian a él las parias dobladas et fincarian por suyos 17.107; tanta de gent hi devino depués que a dos días hi ani fueron doblados 36.564. Frec.: doblados 1: 0,00227; dobladas 1: 0,00227.

doble] adj. 'falso, falto de sinceridad': las dessuso malvadas palavras et dobles que dezía 36.39. Del lat. DupLus (DCECH, II, p. 519). Frec.: dobles 1: 0,00227.

dolent (var.: dolient) adj. y p. pres. 'afligido, dolido, apenado': dolent et despagado, partió del dito col 36.498; Tornose a sitiar la dita ciudad, la qual, sabiendo la victoria de los moros, cayda en desesperación, trista et dolenta... 18.74; Et dolentes [dolens B] et vencidos plorosament comencoron partir de aqui 36.622; de la quoal invasión fue el rey de Castilla muy dolient 33.78; de la qual cosa fue dolent en su corazón 38.292. [De la qual cosa fo dolent en son cor VC, p.166]. Etim.: Deriv. de doler < lat. DOLERE. Entre los deriv. de doler cita el DCECH (II, 513) doliente 'plañidero' en Berceo; 'enfermo' en J. Ruiz. Además, en relación con el diferente matiz de la voz en Castilla y en Aragón, recoge esta cita: «Doliente dize el castellano por el que tiene... enfermedad...; y en Aragón...por triste o mezquino» (vocabulario de med. s. XV, RFE, XXXV, 330). Relacionada con el cat. dolent 'malo, de mala calidad material o moral' (DCVB, s. v.). Pero Glossari de la VC da dolent'afligit'. Comp. arag. mod. dolén, dolento 'malo, endeble, débil, enfermo' (RoHLFs, DDPA, s. v.; Andolz, s. v.; EBA, 1999: 686-687). Frec.: dolent 2: 0,00455; dolenta 3: 0,00682; dolentes 2: 0,00455; dolient 2: 0,00455.

dolor s. f. 'dolor': con grant dolor et con grandes ploros 36.641; et mudólo en ayuda et socorro de los ploros et lágrimas et dolores que los ditos secilianos gitavan agrament et sofrían 36.205. Del lat. dolore (m). Frec.: dolor 3: 0,00682; dolores 3: 0,00682.

dolorosament adv. 'dolorosamente': et todos ensemble fiesta de grant dolor et amargor dolorosament celebroron 37.8-9. Frec.: 1: 0,00227.

doloroso] adj. 'doloroso': Por qual muyt dolorosa muert et muyt amargossa, la reyna su muller et sus fillos qui en Sezilia eran fincados et todo el reyno ensemble fizieron grant duelo et planto por un gran tiempo. 36.716. Deriv. de dolor, con sufijo -oso $<$ lat. -osus, con valor abundancial, que forma adjetivos a partir de bases sustantivas. Frec.: dolorosa 2: 0,00455.

dominar v. tr. 'dominar': et non podía bien aquestas tierras dominar 20.215. Tomado, como cultismo, del lat. dominare. La 1. ${ }^{a}$ documentación que da en cast. el BDELC (p. 222, s. v. dueño) es de 1423. Frec.: 1: 0,00227. 
Domini lat. 'del Señor' en la expresión: anno Domini 11.68. Frec.: 4: 0,00909.

don s. m. 'señor, tratamiento honorífico o de respeto': el mayor havia nombre don Ferrando, del marquesado de Tortosa et de la ciudat de Albarrrazín, et el otro, clamado don Johan, heredero dentro en su tierra 39.39. Apócope del lat. DOMINUS en situación proclítica. Frec.: 641: 1,45695.

don adv. de lugar? 'donde'; conj. consecut.? 'de donde, por lo que...'?: En aquella ora, por consello de algunos, los governadores fueron mesclados et mesturados con el rey [por el rey $\mathrm{N}$ ] don fue muerto don Per Ahones et los otros malgrazido [a los otros mal agradecido N] 35.49-51. Frec.: 1: 0,00227.

dona (var.: donna, donya) s. f. 'señora'; antepuesto a nombre propio fem., tratamiento de respeto: los otros dos fillos que procreó de la caguera muller clamada dona Elionor 39.37. Del lat. DǑMINA, como forma proclítica, lo que explica la falta de diptongación de la Ŏ; comp. duennya, con diptongación, por ser forma tónica. Frec.: dona 42: 0,09546; donna 6: 0,01364; donya 1: 0,00227 .

donación (var.: donaçión, donatión) s. f. 'donación': fizole donación el desus dito rey Remiro de Ruesta et de Pitiella con todas lurs villas 16.44-45. Frec.: donación 2: 0,00455; donación 1: 0,00227; donatión 1: 0,00227.

donador s. m. 'donador': dius pena de perder las ditas tierras guanyadas et aplicadas al dito donador et a los suyos si contrafizies en continent 16.36. Frec.: 1: 0,00227.

donde adv. 'donde': Aquesti rey tenía todas las órdenes de viandas en todos los lugares donde $[$ do $\mathrm{B} \mathrm{N}]$ él fues 35.196. Etim.: se crea a partir del antiguo onde 'de donde' ( $<$ lat. UNDE), reforzado mediante la preposición de. Según el $\operatorname{DCECH}$ (s. v. donde, II, pp. 516-517), «la variante dond(e) se crearía primero como mero refuerzo enfático de onde (está ya dond en Reyes Magos), después quedaría como única expresión inequívoca de la idea de procedencia, y en definitiva acabó por contaminarse del doble valor de sus sinónimos do y onde». Las variantes donde y dont aparecen una vez cada una, mientras que la variante do es la general (aparece 61 veces). Cfr. do, dont. Frec.: 1: 0,00227 .

dono] s. m. 'don, donación'; 'dote, donativo, regalo': et aquel ennobleció de grandes donos et riquezas 23.76. Del lat. DONum 'don, regalo'. Frec.: donos 2: 0,00455.

dont adv. 'donde': e con grant vitoria se tornó al lugar de dont era partido 33.88. Etim.: lat. DE UNDE. Comp., en una obra en aragonés del s. XIV traducida del francés: «Et muchas otras maneras de bestias ay en esta tierra e otra part alli entor e muy de diversas aves dont seria muy luenga cosa a Recontar» ( $L M M$, F 364, p. 131). Pero aquí dont 'de las cuales', por lo que es sin duda un galicismo, del fr. dont. (Liria, $L M M$, p. 167). Vid. do, don. Frec.: 1: 0,00227 . 
dormir] v. intr. 'dormir': un día después de comer, mientre que todo bomme dormía et non se talayavan de res... 38.543. Del lat. DORMiRE. Frec.: dormía 1: 0,00227.

dos adj. num. 'dos': los otros dos fillos que procreó de la caguera muller 39.36. Del lat. DuOs. Frec.: 52: 0,11819.

dotar] v. tr. 'dotar': el dito monasterio ennoblesció et dotó de muitas tierras [terras en la ed. crítica] 8.7. Frec.: dotó 1: 0,00227.

dotado p.p. y adj. 'dotado': En tiempo de aquesti rey don Pedro, dotado sobre todos los otros reyes en beldat et probeza de cavallería 34.119. Frec.: 1: 0,00227.

doze adj. num. 'doce': Et fue feyto que a doze días de julio del anno de M CCC XXIIII la sennyoría del dito don Alfonso, noblement acompannyada de honrada cavallería, entró en el dito castiello 38.570. Del lat. DuODECIM (SEGurA, 2001: 239). Frec.: 1: 0,00227.

dreytament adv. 'rectamente, con rectitud': et quisiessen Dios pregar et los sanctos quel dito monasterio avieron esleydo sepultura, que le dassen poder de regir su poblo dreytament 11.47 // 'directamente, derechamente': recolliose con grant poder de sus valientes varones et vassallos a Palamos et dreytament vino sende a Roma 38.225. Etim.: formación adverbial sobre el adj. DIRECTA + -MENTE 'de modo directo'. En arag. med. fue muy usado. Se registra en el LT (RodÉs, 2016: 717). En la mayoría de las obras de Fernández de Heredia se registra derechamente, derechamientre, drechament, formas que corresponden al arag. semicastellanizado de las Serranías Ibéricas; solo se registra dreytament en Secreto Secretorum y en el Libro de los Emperadores, y dereytament en la tercera parte de la Gran Coronica de Espanya (GILKISON, 1984: 42). Frec.: 2: 0,00455.

dreyto (var.: dreito) s. m. 'derecho' en el sentido de 'conjunto de facultades, acciones o privilegios legales que por propiedad, herencia, etc. corresponden a una persona sobre determinado territorio o sobre determinadas personas o cosas': pero catando dreyto de naturaleza todos comunment la rendieron a la dita reyna 19.80; los dreitos et razones allegadas de cada una part 20.159; el dito barón establió por si mismo dreytos [dreytament N] qui son agora clamados Usages 29.11; et como algunas demandas de jurisdicción et otros dreytos quel dito rey don Pedro se dezía aver sobre el condado de Urgel... 36.117-118. Etim.: Del lat. vg. DERECTUS (cl. DiReCtus) 'recto, directo', p. p. del v. DIRIGERE 'dirigir', deriv. de REGERE 'conducir, dirigir, guiar' (BDELC, p. 205; DCECH, II, p. 445, s. v. derecho). Comp. oc. (lang.) drech, oc. (gascón) dret, fr. droit, rum. drept, cat. dret, cast. derecho, port. direito, gall. dereito, ast. drechu, walón droet, franco-provenzal drêt, retorrom. dretg, friulano derit, piamontés drit, it. diritto, véneto drito, siciliano drittu, sardo deretu (VALLÉs, 2007: 216). Está muy documentada en arag. med. Se conserva en arag. mod., tanto en la forma dreito como dreto, y además es muy usual la forma castellanizada drecho (vid. Andolz, s. v., p. 103; EBA, 1999: 691). En los DLAA se documenta dreyto en más de 50 documentos: sobre los diversos valores de dreyto en documentos notariales altoaragoneses 
de los ss. XIV y XV puede verse LaGÜENs, 1992: 107. Frec.: dreyto 11: 0,02500; dreyta 4: 0,00909; dreytos 1: 0,00227; dreita 2: 0,00455; dreito 2: 0,00455; dreitos 1: 0,00227 (conjuntamente como sust. y como adj.).

dreyto adj. 'derecho (que está situado en el lado opuesto al del corazón del observador)': con la mano dreita designando con el dedo dixo... 17.118-119. // 'recto, directo': et de otras fembras avies procriados muytos fillos qui por engendrament de dreyta linea non son anotaderos 36.32-33. Etim.: Del lat. DIRECTUS 'recto', 'directo', p. p. de DIRIGERE 'dirigir' (BDELC, p. 205). Con la acepción de 'directo, recto, sin estorbo' se registra dreyto en el VCA (LLEAL, 1997: 142). / / en dreyto de loc. prep. 'frente a, delante de, en dirección a': aquesti firimiento del rey d'Aragón duró entro que huvieron decendido el coll de Panizares et fueron en dreyto de Montesquiu 36.655-656. Comp. cat. en dret de 'enfront de, davant per davant de' (DECLIC, III, p. 205). Frec.: dreyto 11: 0,02500; dreyta 4: 0,00909; dreytos 1: 0,00227 ; dreita 2: 0,00455 ; dreito 2: 0,00455 ; dreitos 1: 0,00227 (conjuntamente como sust. y como adj.).

dreytura s. f. 'rectitud, justicia': era varón de grant dreytura [dreyturera N] et de grant misericordia 35.196; «a Dios misericordioso demando quel vos faga regnar luengament segunt la suya dreytura [dreyturera $\mathrm{N}$ ] et la suya santa misericordias. 35.279-280; «priégote, fillo mío, et amoniéstote por dios Ihesu Chisto que en ti aya dreyta [dreitura $\mathrm{B}$; dreytura $\mathrm{N}]$ et misericordia 35.257. Etim.: deriv. de dreyto 'derecho, recto' $<$ lat. Directus (lat. vg. DeReCtus). Corresponde al cast. derechura, cuya primera documentación es de 1194 (DECCH, II, p. 445). El LHP (p. 190) da la primera documentación de la forma aragonesa h. 950 en las Glosas Emilianenses, en la variante fonética deritura, que traduce por 'enseñanza, doctrina', y hace remontar al lat. DIRECTURA. Véase el texto de la glosa 90: «per jntellegentiam fructum reddere doctrine [es... ela uel deritura]» (MENÉNDEZ Pidal, Origenes, 1968: 7; Origen aragonés de las Glosas Emilianenses, 2020: 104). Frec.: 4: 0,00909.

druda] s. f. 'concubina': et aquesti rey mandó que todos los clerigos et vispos de su tierra prendiessen et tuviessen drudas [tuviesen deudas $\mathrm{N}$ ] 3.74-76. Es evidente que el ms. $\mathrm{N}$ da una lectura equivocada, puesto que en la VC se lee: $e$ aquest rei manà que els clergues e bisbes de sa terra prenguessen e tenguessen drudes VC, p. 25. En el Glossari de la VC se dice: drudes 'concubines'. Esto concuerda con la VL: et iste precepit ut episcopi et clerici terre sue tenerent concubinas VL, p. 23. Se documenta escasamente en cast. med. en el s. XIII. Cfr. occ. (prov.) druda 'amante, maitresse' ['amante, querida'; 'ama, dueña; dama, manceba'] y drut s. m. 'amant, galant; fidèle, ami privé; homme courtois' (LEVY, s. v.), así como drudaria 'amour; galanterie; entente amoureuse', occ. (lang.) drud-a 'dru' ['vivo, alegre; gallardo']; 'robuste' ['robusto']; 'gaillard' ['gallardo']; luxuriant ['lozano']; fertile ['fértil']; riche ['rico'] (ALiberT, s. v.). Tb. registra, entre los 
derivados: drudariá 'gaillardise; galanterie; caresse d'amour' ['desenvoltura; galantería; caricia de amor'].

Se documenta drudo en algunos textos aragoneses. Así en FA: «por que, luego cuando casa o terrá drudo manifiesto o encara, biujendo ella casta mientre, no oviere fillos, deve perder las arras sin retenimiento nenguno» (222,6; p. 119); «maguer que case una vegada o más, o encara tan bien si oujesse drudo» (224,4; p. 123). Tilander (FA, p. 366) da el significado de 'amante'. Según documenta dicho autor, el término se traduce por 'fornicador o amigo' y por 'fornicador o adúltero' en varias versiones tardías y otras en castellano de los Fueros de Aragón. Concretamente, se traduce por 'fornicador o adúltero' en la versión romanceada de los Fueros de Aragón, de principios del siglo XV, contenida en el ms. 154 (ahora 207) de la Biblioteca Universitaria de Zaragoza. Este hecho puede ser significativo para indicarnos quizá que el vocablo drudo era raro o poco usado, o que tal vez había entrado en desuso entre finales del s. XIV y principios del s. XV. De lo que no puede dudarse es de que se trata de una palabra propiamente aragonesa, en uso al menos durante los siglos XIII y XIV, ya que al testimonio de la Crón. de SJP. (drudas), hay que añadir el citado drudo de los Fueros de Aragón, ms. 458 de la Bibl. Nac. de Madrid, cuyo texto está «escrito a principios del siglo xiv» (Tilander, FA, p. VIII). Se documenta además en el Fuero de Alfambra: «Toda muger que fara cornudo a su marido et sera provado corran la villa la muger con el drudo despullados et azotando et no les valla ninguna callonia de aver. El que sera casado et sera provado con otra muger otro tal corra la villa con su druda et quan auran corrido el baron peche LX solidos» (Fuero de Alfambra, ed. de Manuel Albareda y Herrera, Madrid, 1926, p. 28. Cit. por Tilander, FA, p. 366). Encontramos drudo y druda en los Fueros de Aragón según el ms. del Archivo Municipal de Miravete de la Sierra (GARgallo, 1992), que es de finales del s. XIII, concretamente en el vi. ${ }^{\circ}$ libro, título 234: «Por aquella misma razón, debe el varón tener e possedir su vitgüedat tanto quanto querrá seer, que no prenda otra muller o que non tienga druda públicament» (GARGALLO, 1992: 121). Y en el vi. ${ }^{\circ}$ libro, título 235: «De muller infançona: $\mathrm{La}[\mathrm{s}]$ quales dotes debe tener e posedir aprés de la muert del marido tanto quanto querrá tener vidgüedat, que no prenda otro marido ni faga drudo» (GARGALLO, 1992: 122).

Entre los refranes arag. del s. XIV publicados por Rius (1926: 371) leemos: «No sse prenga drudar / qui no sabe fen...». Parece evidente que fen... será fenbras y que drudar será mala lectura por drudas. Así que el refrán sería quizá algo así como: «No sse prenga drudas / qui no sabe fenbras tractar». El vocablo está documentado en cat.: drut, druda 'adúltero' (Labernia, Pere, Diccionari de la llengua catalana, Barcelona, 1864-1865); drut 'amant', druda 'prostituta, concubina, amancebada" (Diccionari Aguilo, Materials lexicogràfis 
aplegats per Mariàn Aguiló y Fuster, Barcelona, 1914 y sigs.). Vid. ejemplos de drut, druda en cat. ant. en $D C V B$, s. v., t. 4, pp. 607 y 608. La palabra drudo se encuentra también en portugués antiguo, según indica Tilander (FA, p. 366). En cast. ant. se registra drudo, -da 'adúltero' en la Gen Est. de Alfonso X (DME, p. 973, s. v.). Tradicionalmente se había considerado que era palabra de origen germánico o céltico. Así, MeYer-LÜBKe da el gótico DRUTHS 'querido, amante' como etim. del it. drudo 'amante ardiente', ant. fr., prov. drut 'novio, querido' (REW, 2780). En cambio, otras formas románicas, como el ant. milanés drudo 'exuberante, opulento, frondoso, sensual', ant. fr. $d r u$ 'espeso', fr. del sur drï 'exuberante', etc., las remite al galo DRUTus 'fuerte, robusto' (REW, 2779b). Devoto, s. v., indica que el it. drudo procede del lat. del s. VIII DRUDUs, palabra germánica (franco drud), que significa 'fiel, leal'. La etimología que da Alibert para el occitano drut es el galo DRUTO 'fuerte'. Para el fr. $d r u$ 'vigoroso' DaUZAT-Dubois-MitTerand remiten al galo *Druto 'fuerte'. Coromines afirma que la palabra drut no es propiamente catalana sino término occitano de los trobadores, que significó originariamente 'gallardo, lozano' aplicado a la vegetación y luego al hombre o a la mujer potentes o sensuales; indica que proviene de una palabra prerromana DRUTOS 'fuerte, vigoroso', indoeuropea y probablemente no céltica (vid. argumentos y referencias en DECLIC, III, p. 212). Frec.: drudas 1: 0,00227.

ducado s. m. 'ducado': aquesti rey Sancho sennorió Navarra et Aragón et el ducado de Cantabria 14.19. Frec.: 2: 0,00227.

duch (var.: duche) s. m. 'duque': envyó por un duch sosmeso suyo clamado Abdemalit, 4.26; El qual Enrrich quando fue grant huvo por muller la filla del duch d'Austria 34.16. También se registra la variante duche (sólo una vez, frente a 5 veces duch): la tercera fue muller la filla del duche d'Austria 38.430. Etim.: del fr. ant. duc, tomado del lat. Dux, DUCIS 'guía, conductor' (DECLIC, III, p. 215; BDELC, p. 222). РотTier lo recoge entre los galicismos hispánicos medievales (ELH, "Galicismos", pp. 127-151). Frec.: duch 5: 0,01136; duche [dúke] 1: 0,00227.

duelo s. m. 'dolor, pena, aflicción': de la qual cosa toda la tierra buvo gran duelo et desplazer mayorment como por tal razón yera muerto. 30.17; toda Spannya fizo grant duelo et non si razón, porque grant gent de moros vinieron en Spannya quando sintieron aprohismar a la fin del dito gloriosso rey 35.309; por aquesti grant vencimiento los franceses buvieron grant esmagamiento et grant duelo 36.554; los duelos, ploros, plantos et dolores que en la tierra depués de la muert suya fueron albirar ni pensar homme non los poria 36.713-715; Por qual muyt dolorosa muert et muyt amargossa, la reyna su muller et sus fillos qui en Sezilia eran fincados et todo el regno ensemble firieron grant duelo et planto 36.718. En todos los casos se usa en la acepción 'dolor', nunca de 'desafío, combate'. Etim.: proviene del lat. tardío Dolus 'dolor', que en 
lat. cl. tenía la acepción de 'dolo, engaño, fraude perfidia' (SEGURA, 2001: 233; BDELC, p. 219; DCECH, II, p. 513). Frec. duelo 8: 0,01818; duelos 1: 0,00227 .

duennya s. f. 'señora, mujer, dama (no como tratamiento, en uso proclítico, sino como nombre apelativo de uso normal; precisamente, por no ser proclítico diptonga): de dona Teresa Gil de Bidaure noble duennya havié a Jayme de Exerica et a Pedro de Ayerbe, 35.76-78; et de otras duennyas avié a Ferrant Sanchez. de Castro et a Pedro Ferrandez de Ixar 35.79. Etim.: del lat. DOMINA (DCECH, II, 530, s. v. dueño). Uno de los primeros testimonios en arag. es illa duanna donna Urraka 'la señora doña Urraca', en doc. de San Juan de la Peña, 1063, publicado por Menéndez Pidal (Orígenes, 40). Frec.: duennya 1: 0,00227; duennyas 1: 0,00227 .

dulz adj. 'dulce', fig. 'grato, apacible': et fue homme benigno, dulz et piadoso, 30.3. Etim.: $<$ lat. DULCIS. Frec.: 1: 0,00227.

dupdar] (var.: dupdar, dudar) v. tr. 'dudar'; 'temer': et díxole que agora que non dubdás del rey de Castiella, 36.368; dería que non dubdassen, que los mayores et mellores con él eran 38.250; copdiciando mas el servicio de Dios et exalçamiento de la fe que no dudando el temor de los infieles 18.26. por dos razones; la primera que dudaban que don Remiro no sabries [que no supies $\mathrm{N}$ ] regir el regno, la secunda porque los navarros se dupdavan del emperador don Alfonso de Castiella 20.45-48. El cast. dudar fue tomado en fecha antigua del lat. DUBITARE 'vacilar', 'dudar', derivado de DUBius 'vacilante, dudoso'. La $1^{\text {a }}$ doc., en la forma dubdar, está en Berceo; dudar se encuentra ya en ms. del s. XIV , pero dubdar sigue siendo usual hasta el siglo siguiente. En lat. DUBIUs podía ya significar 'crítico, difícil, peligroso', de donde DUBITARE tomó en romance el significado de 'temer', que es corriente en galorrománico (fr. ant. douter, oc. ant. dobtar, fr. redouter), y que lo fue en todo el castellano medieval y hasta principios del s. XVII (DCECH, II, 527). En arag. med. también se registra con el significado de 'temer, tener miedo', junto al de 'dudar': dubdar, duptar 'fear; doubt' en Fernández de Heredia (GILKISON, 1984: 51). Frec.: dupdavan 3: 0,00682; dubdás 1: 0,00227; dubdassen 1: 0,00227; dudaban 1: 0,00227; dudando 1: 0,00227.

dupdo s. m. 'duda', 'vacilación', 'temor': dioles privilegio que si alguno metía cabanna de qualquier linage de ganado fues en los términos de los ditos montes, que sin alguna pena et sin todo dupdo et pleito [pena $\mathrm{N}]$ real pudiessen fer degollar et matar vacas 11.59-62. Etim.: deriv. postverbal de dupdar. Esta forma se recoge para el cat. en el $D C V B$ con la anotación: «grafia ant.: v. DUBTE». Esta obra recoge numerosas acepciones en cat., entre ellas: 'qüestió dificultosa' y 'temor; por d'un perill o d'un mal possible' (ant.), assí como las expr.: esser dubte (ant.) 'haver-hi qüestió dificultosa', fer dubte (ant.) 'fer por, donar temença'. Etim.: derivado de dupdar $<$ lat. Dubitare ( $D C V B$, IV, 611; BDELC, s. v.). En cambio, en castellano 
adopta el femenino duda (dubda 'temor', 'duda', en Cid, Berceo); el postverbal masculino es el que ha predominado en otros romances: cat. dubte, oc. dopte, fr. doute (DCECH, II, 527). En el Alex. se registra dubdo, dubda, dulta, dubdança, duldança; duldo aparece en algunas ocasiones en el ms. O (SAS, pp. 220-222). Vid. también ejemplos del cast. med. dulda, dulta 'duda, temor' en VMC, $s$. v.; DME, s. v. En arag. med. se registra a menudo como masculino: dubdo 'duda' en el LT (RoDÉs, 2016: 718); dubdo 'vacilación del ánimo' en VCA (LLEal, 1997: 142). Pero, contrariamente, dubda en la mayoría de las obras de Fernández de Heredia, si bien en algunas también se registra dubdo o dupdo (GILKISON, 1984: 50-51, s. v.). Frec.: 1: 0,00227.

duradero] adj. 'duradero, que dura': con privilegio bullado con bulla de plomo por buena et duradera [verdadera N] memoria perpetualment 37.18. Deriv. de durar. Frec.: duradera 1: 0,00227.

durar] v. intr. 'durar', 'permanecer, mantenerse': el qual hi avía durado XIII annos, 38.85; et durando la dita cort, fueron hi feitas constituciones a proveyto et utilidat de la tierra, 38.23. Del lat. DURARE 'durar', 'endurecer', 'tener paciencia, perseverar'. (DCECH, II, p. 536). Comp. turaren la Crón. de Juan II: «et tirar la escomunicación que avia turado XIIII anyos» (RiQueR, p. 25, lín. 16; se corresponde con Crón. SJP. 38.85). Frec.: durado 1: 0,00227; durando 1: 0,00227; duró 3: 0,00682.

\section{$\mathbf{E}$}

e conj. cop. ' $\mathrm{y}$ ': e por aquesto que podamos mellor tratar e mas verdaderament e breu, por tal que sia mas plazient de leyr ad aquellos que la leyeran... 2.1. Del lat. Ет. Más frecuentemente et. Comp. y. Frec.: 277: 0,62960.

echar v. tr. 'echar': las quales naciones los godos echaron de Espannya 2.10. Es castellanismo fonético que aparece una sola vez. Cfr. gitar. Frec.: echaron 1: 0,00227 .

edat (var.: hedat) s. f. 'edad': Et depués de aquesti regnó su fillo Recaredo et murió moço de muy poca edat. 3.61; et al tornar, passó por el dito lugar de Grados et mató al dito rey Remiro, su tio, qui era en hedat de LXIII 16.57-58. Del lat. AETATE(M). Frec.: edat 17: 0,03864; hedat 12: 0,02728.

edificado (var.: hedificado) adj. y p. p. 'edificado, construido': en la espellunga [...], do era edificada la eglesia de Sant Johan Bautista 9.15; et yglesia episcopal [catedral $\mathrm{N}$ ] et otras [yglesias $\mathrm{N}$ ] en la dita ciudat et isla edificadas [edificó B] a honor de Dios 35.138; fue otra vegada edificado el dito monesterio de Ripol, 25.9-10; en el monesterio 
de Sixena, el qual su madre dona Sancha avía hedifficado et stablido convento de mulleres. 34.169-170; la quoal tomba fue metida entre tres altares de invocación de Sant Johan Bautista et de Sant Julián et de Sant Basilissa, ya en antes aquí hedificados. 9.24- 26. Frec.: edificada 1: 0,00227; edificadas 1: 0,00227; edificado 2: 0,00455; hedifficado 1: 0,00227; hedificado 1: 0,00227; hedificados 1: 0,00227.

edificar] (var.: hedificar) v. tr. 'edificar, construir', 'fundar': demandaron las eglesias que alli se edificarian 19.15; hedificaron bi dos altares mens [menos $\mathrm{N}]$ de aquellos qui ya eran constituidos 9.28; et vencido el dito rey Caci, hedificó el dito Hercules al pie del dito mont, de las gentes que vinieron con él de Tirus et de Ausonnia, una ciudad que clamó Tirasona 1.26. Cultismo tomado del lat. AEDIFICARE 'id.'. Todos los ejemplos documentados en el siglo XIV pertenecen a textos aragoneses, según el DCECH (II, p. 546). Es frecuente en FA (TILANDER, FA, p. 367); edifficar y hedificar en los DLAA (REIDY Fritz, 1977: 157): «\& podades bedificar \& construir molino por afarina \& por amallyos en el dito molinar» (doc. de San Victorián, 1311; DLAA, doc. n ${ }^{\circ}$ 94, p. 135, lín. 32). Frec.: edificarían 1: 0,00227; edificaron 1: 0,00227; edificó 9: 02046; hedificaron 1: 0,00227; hedificó 5: 0,01136.

eglesia (var.: yglesia, iglesia) s. f. 'iglesia, edificio consagrado al culto': do era edificada la eglesia de Sant Johan Bautista 9.15; Et ordenada la tierra et establida de buenos deffendedores et yglesia episcopal [catedral $\mathrm{N}]$ et otras [yglesias $\mathrm{N}]$ en la dita ciudat et isla edificadas... 35.138; fizo una eglesia a honor de Dios y de Sant Johan Baptista 5.3-4. // 'iglesia, institución': et le prometie que en tiempo alguno non le fallira [falliría $\mathrm{BN}$ ] con que le valies et ayudas contra la Eglesia et todos sus enemigos 38.36-37. Forma semiculta, del lat. vulgar eclesia < lat. cl. ecclesia, tomada del gr. ekklesia 'reunión, asamblea convocada' (BDELC, s. v.). Frec.: eglesia 8; 0,01818; Eglesia 4: 0,00909; eglesias 5: 0,01136; iglesia 6: 0,01364; iglesias 5: 0,01136; Yglesia 20: 0,04546; yglesias 10: 0,02273.

el (var.: ell) art. m. sing.: et prendieron el nombre del dito rio, el qual dizen Ebro 1.9; et por el su nombre fuele mudado el nombre Moncicati, el qual boy a nombre Moncayo 1.24; vencido el dito rey Caci... 1.25; et creció muyto el su regno 3,72; E muerto el dito rey Garcia Ennego, regnó depues del el Fortunyo García 7.1; soterranrolo en el dito monasterio 11.66; firole donación el desus dito rey Remiro de Ruesta et de Pitiella 16.44; el uno de los cuendes se dezía don García de Traba de Nágera, al otro don Gonçalvo 18.14-15; et dificó el monesterio de Ripol en el anno de Nuestro Sennyor DCCCCLXXVI 26.19; «et han metido el corazón et ell aver al servicio de Dios et mio» 35.266. Del lat. ILLE 'aquel', o de su acusativo ILLum, con tratamiento fonético átono. Comp. 1o. Frec.: el 1.635: 3,71625; ell 7: 0,01591.

el art. fem. (ante vocal a): por gran desaventura cayó en el agua et murió 28.5; los franceses, viendose muertos, yxieron en el alborada 34.161. Del lat. ILLA 'aquella'. Frec.: esta forma está incluida en el recuento del artículo el masculino. 
él (var.: éll) pron. pers. de $3^{a}$ pers. m. s. 'él' (fem.: ella; pl.: ellos, ellas): Él estando en sana sanidat, en su buen entendimiento, renunció a los bienes temporales 31.48; se levantó contre el dito rey don Pedro et con él guerró 36.438; las vildades et crueldades que feitas avian contra él et sus santos 36.594; et lexó mandado que de mannana todas sus gentes fuessen a éll 20.198; et que non fiziesse guerra fazer contra éll 36.365; fue feita grant fiesta ad aquell dia a honor dell 12.41; Et huvo por muller donna Felicia et engendró della III fillos 17.56; et huvo muytas batallas con moros et obtuvo todos tiempos dellas victoria 31.11; et se metía en ygual dellos en todos afferes d'armas 12.70. Fel lat. ILLE, con tratamiento fonético como forma tónica. Frec.: él 127: 0,28866; éll 23: 0,05228; ella 15: 0,03409; ellas 1: 0,00227; ello 1: 0,00227; ellos 32: 0,07273. Vid. también ella, ello, ellos.

elección s. f. 'elección': de la qual elección todo el regno fue alegre et pagado 36.723. Tomado del lat. electio, -onis. Frec.: 1: 0,00227.

electo adj. y p.p. de elegir, 'electo, elegido': fue metido en el monesterio de San Ponz de Tomeras del orden de San Benedito et, seyendo en aquell devotament, fue electo en abad del monesterio de San Fagundo et Primitivo 20.77. Cultismo tomado del lat. electus 'escogido' (SEgura, 2001: 246). Frec.: 6: 0,01364.

elegido p. p. regular de elegir, 'elegido': como simient de virtuosso princep avien elegido [esleydo $\mathrm{N}$ ] por sennyor lur 36.725. Frec.: 1: 0,00227.

ella pron. pers. de $3^{\mathrm{a}}$ pers. f.: et después estaron en ella fasta la traición del conde don Yllan 2.10; Desque se vido la reyna partida del emperador tovo cueyta de casar con ella como ante hera fablado 19.101. Frec. 15: 0,03409.

ello pron. pers. de $3^{a}$ pers. neutro: et esti don Gonçalvo no y vino, más embió sus compannyas et avino mellor en ello. 18.17. Frec. 1: 0,00227.

ellos pron. pers. de $3^{\mathrm{a}}$ pers. $\mathrm{m}$. pl.: que si no servava los privilesgios que feito avía a la dita unió et las ordinaciones que avían feitas ellos, que pudiessen esleyr otro rey et a ell gitar del regno 37.32; mas el dito cardenal, deseando que paz et amor fuesse entre ellos, pacifficó la dita discordia 35.30. Frec.: 32: 0,07273.

emala ora loc. adv. 'enhoramala': fizole mercé et dixole: «yt emala ora, que con vuestro tracto avemos perdido el regno de Aragón» 36.382. Vid. ora. Frec.: 1: 0,0027.

emendar] v. tr. 'resarcir, recompensar': Et don Caxal emendó al dito monesterio et dioles quanto havía en Tudela 20.237. Del lat. EMENDARE 'corregir, rectificar'. Ximénez de Embún, Vocabulario, traduce emendó por 'satisfizo'. Comp. emienda 'resarcimiento' en FA, p. 368. Vid. también: emendar 'resarcir, compensar, subsanar, restituir, reparar' en VM, III, p. 105. Frec.: emendó 1: 0,00227.

emparar] v. tr. 'emprender', 'mandar, ordenar', 'sostener'?: don Pedro el Grant et hovo asi nombre porque él emperaró [emparó B] muyt grandes afferes contra muytos reyes christianos et moros, et contra la yglesia et todos ensemble. 36.3-5. XIMÉNEZ DE EMBún, Vocabulario, traduce emparó por 'emprendió, llevó a cabo', que es lo 
que cuadra por el contexto. La forma emperaró parece un cruce entre emparar y emperar (vid.). El origen de emparar está en el lat. vg. *ANTEPARARE 'prevenir de antemano', según el DCECH (IV, p. 394). El DCVB propone para el cat. emparar la etim. lat. vg. *IMPARARE 'tomar posesión'. Vid. enparar. Frec.: emperaró [emparó] 1: 0,00227.

empeçar] v. tr. 'comenzar'; rige habitualmente prep. de: et por razón que sines consello de los aragoneses los navarros avían levantado rey, empeçaron de haver malquerencia unos contra otros 20.94; seyendo en edat de XVIII annos según dito es quando empeçó [començó $\mathrm{N}]$ de regnar, 17.25. Deriv. de pieça, del céltico * PETTIA 'pedazo' DCECH, s. v. empezar y s. v. pieza). Frec.: empeçaron 1: 0,00227; empeçó 5: 0,01136;

emperador (var. enperador) s. m. 'emperador': la filla del noble principe don Guillem de Montpeller [Monpesler $\mathrm{N}$ ] clamada María, nieta del emperador de Constantinnoble, de la qual procreó un fillo que fue nombrado Jayme 34.28. Frec.: 39: 0,08864; enperador 0,02046 .

emperar] v. tr. 'mandar, dominar, ejercer la autoridad máxima sobre un imperio': Et aquesti Alarico demandó al emperador Honorio, qui a las horas emperava et sennoriava el imperio de Roma... 3.30-31. Del lat. IMPERARE 'mandar'. El DCECH (III, p. 444) y el BDELC (p. 332) dan la 1. documentación de imperar en cast. en 1444. La Crón SJP la adelanta en más de medio siglo. Frec.: emperava 1: 0,00227; emperaró 1: 0,00227.

empero conj. 'aunque; sin embargo; pero': et el otro, clamado don Johan, heredero dentro en su tierra, empero sines de alguna dignidat 39.39-40. // empero que loc. conj. adversativa 'aunque': Empero quel dito Frederich desenbargas el regno de Secilia a la Yglesia et no evan [beran N] a la coronación de aquell. 38.157-38.159. Etim.: compuesto con en (de), 'de ello' y pero < lat. postclásico PER HOC 'por esto', 'por tanto' (DCECH, IV, p. 495-496). Frec.: 38: 0,08637.

emplir] v. tr. 'llenar'. No aparece el inf. [emplir] ni ninguna otra forma de este verbo, excepción hecha del p. p.: soterraron aquellos que pudieron et de los otros fueron [fueron ne $\mathrm{N}$ ] emplidos [implidos B] dos poços 38.557. Etim.: del lat. IMPLERE 'llenar' (DEEH, p. 737). Se documenta ya el arag. inplire, enplir h. 950 en las Glosas Emilianenses (Menéndez Pidal, Orígenes, pp. 6 y 8): «jpsi qui hoc predicant hoc jmplere dissimulant [tardar $\int a n$ por jnplire]》 (glosa 70); «Et repleuimur [nol enplimofamus]» (glosa 124) (pueden verse ahora también en Origen aragonés de las glosas emilianenses, 2020: 103 y 105). Según Menéndez Pidal es un ejemplo del arraigo vulgar de algunos cambios de conjugación. Comp. cast. henchir, port. y gall. encher, cat. omplir. Tanto en arag. ant. como en arag. mod, emplir está documentado (KuHn, HAD, pp. 33 y 125; BADíA, Bielsa, pp. 266; Rohlfs, DDPA, p. 113; Andolz, 1992: 166; etc.). El EBA (1999: 709) registra emplir en Aragüés de lo Puerto, Bielsa, Echo; emplí en Ansó. Para el arag. ant. vid. implir en VM, III, p. 163; emplir, implir en Fernández de Heredia 
(GIlkison, s. v.); jmplir en LMM, p. 178; etc. Comp. umplie 'llenó' (BlanCaS, Índice). Frec.: emplidos 1: 0,00227.

emprennar] v. tr. 'preñar'; 'hacer concebir': remembrose de la desonor que havía feito al conte de Flandres et a su linage por la filla suya que havía enprenyada él estando en su cort como fillo lur 23.43; una filla del dito conte se enamoró del dito moşo et finalment emprennola 23.10. Del lat. IMPRAEgnaRE. Comp. cat. emprenyar, occ. y port. emprenhar, it. impregnare (DCECH, IV, pp. 642-643). Vid. ejemplos del uso de empreñar en cast. med. en DME, s. v., p. 1001. Frec.: emprennola 1: 0,00227 .

en prep. 'en, lugar en donde': todos los reyes se posavan en lur taula con cavallaros 3.51; como buvo estado largo tiempo en la cort del dito rey 23.53-54; murió en Aragón 9.2-3; et en Aragón sennyoriava el comte Aznar, el rey Abderramen en la ciudad de Huesca 5.19-20; en el dito castiello 34.111. / / 'a, lugar a donde': el qual era venido en estas partes por defender a los christianos 10.8; fue adueyto por reliquias en Sant Johan de la Pennya 17.78; dizen que muytos se gitoron en la mar 38.253; et depués fue traslatado en el monesterio de los freyres menores 39.47. // 'en tiempo en que': en el anno de nuestro Senyor DCCCC III 7.2; en el tiempo antigo 22.3. // 'en, modo en que': et puso en buen estamiento la tierra 23.85; et valient en armas 27.17. // 'hacia, en relación a': avian grant devoción en aquesta spelunca 5.17. Del lat. IN 'en, dentro de'. Frec. 1.143: 2,59796.

en (var.: n') título de cortesía o tratamiento de respeto 'don'. Antecede a los nombres de los condes y otros altos personajes catalanes. Aparece sobre todo en la segunda parte de la Crón. SJP. (que trata de la historia de los condes catalanes): et en Berenguer Guillem 29.40; Narmengou de Barbastro 29.25 (n'Armengou); en la qual fue Nuch cardenal et legado de Roma 29.9 (n'Uch); fillo den Bernat Trencaforte 29.3; el noble varon en Arnau 34.121; entro que el dito en Oliver fue preso 35.113-114; Nolivano 28.16 (n'Olivano); Narmengou 27.2, 31.16, 34.107 (n'Armengou); etc. Etim.: de la forma latina del vocativo DOMINE 'señor' (DECLIC, III, p. 309). Vid. también para el cat. DCVB, s. v. en, t. 4, pp. 821-823. Comp. occ. en con el mismo empleo (AliberT, s. v., p. 319). Frec.: en está contabilizado conjuntamente con en prep.; n', conjuntamente con el nombre propio al que precede. Comp. ena.

ena (var.: na) trat. de respeto 'doña': et huvo por muller Ena Dolza [dona Dolca $\mathrm{N}]$ 31.4; mató la su madastra Nadalmurs [Adalmodis VL, p. 114] 29.19 (na Adalmurs). Del lat. Domina 'señora', vocativo en empleo proclítico; cat. na (DECLIC, III, pp. 309-310; DCV B, t. 4, pp. 821-823), occ. na (AliberT, s. v., p. 319). Comp. en. Frec.: Ena 1: 0,00227; Na 1: 0,00227.

enamorar] v. prnl. 'enamorar(se)': una filla del dito conte se enamoró del dito moço 23.9. Deriv. de amor. El BDELC (p. 47, s. v. amor) da la $1^{\text {a }}$ documentación de esta voz en cast en 1438. Frec.: enamoró 2: 0,00455. 
en antes loc. adv. de t. 'antes': porque se cuytas con las galeras et que en antes fues en la dita ysla 38.514. // adv. de t. 'anteriormente, en otro tiempo': porque en antes todos los reyes se posavan en lur taula 3.50 (enantes en el ms. B, original que aquí se transcribe en la ed. crítica). Vid. antes. Frec.: antes 26: 0,05910.

en antes que loc. conj. temporal 'antes que, antes de que': en antes que digamos res de sus feitos 17.3; Et en antes quel se visties el ábito firo venir en la villa de Aljacira, do la ora iazia enfermo, su fillo don Pedro 35.251; mas yes verdat que en antes quel hi fues, fue enviada a la ciudad de Mecina alguna conpannya de almogávares 36.223. En el texto aparece normalmente separado. Vid. antes. Frec.: antes 26: 0,05910.

enbargar] v. tr. 'impedir, embarazar': et teniendolo por mal los de la tierra e los ricos ommes enbargaron aquel casamiento e començaron de contrariar 19.159-160. Según Corominas, es «voz común a los romances hispánicos y a la lengua de Oc. Procede de un verbo * IMBARRicare del lat. vg. o románico primitivo de esta

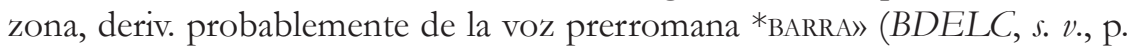
227). Frec.: enbargaron 1: 0,00227.

enbiar v. tr. 'enviar'. Frec.: enbió 1: 0,0027; enbiole 1: 0,00227; enbioles 1: 0,00227. Vid. enviar.

encalçar] v. tr. 'perseguir de cerca a alguien, ir tras alguien pisándole los talones'; 'alcanzar': do vinció Miramomoli et toda su buest, los quales encalçó por todo un dia 34.102-103; mas el dito conte de Ampurias, con grant poder de sus vassallos encalcandolo ençarró [encerró B] el dito en Oliver en un lugar clamado Ermeşera 35.111-113; et todos ensemble encalçaron tan cuytadament el dito conte de Monfort que lo fizieron encerrar en un castiello 34.142. Etim.: del lat. vg. * INCALCIARE 'pisar los talones, perseguir de cerca', deriv. del lat. CALX, -CIS 'talón' (BDELC, p. 38; DCECH, I, p. 130). Arag. ant. encalçar 'perseguir' (TILANDER, FA, p. 371); encalşar 'reach, catch up, follow; overtake, pursue', en Fernández de Heredia (GILKIsON, s. v.); encalçar 'to reach, follow; pursue' en el LT (PRINCE, 1995: 221). Arag. mod. engaliar 'correr tras una persona, animal o cosa, perseguir' (ANDOLZ, s. v., citado de Ballarín para Benasque; pero en Ballarín no se encuentra, ni el Voc. ni el Dicc.); engalzar 'correr' (PERALTA, s. v.); engalzar 'encorrer' (BORAO, s. v.); encalzar 'perseguir, ponerse en persecución' (BORAO, s. v.; pero en este caso se refiere al arag. med., pues cita «encalcen e geten de la tierra al sobredito rey», en el Códice de los Privilegios de la Unión); PARDO (s. v.) también registra encalzar 'perseguir; ponerse en persecución'; encanzar 'alcanzar' en Chistén (MотT, Dicc., s. v.); Blas/Romanos, (2008: 227) dan engalzar 'perseguir' en el valle de Chistau; engaliar 'correr tras una persona, animal, cosa' (ARNAL, s. v.); engaliar 'pillar, atrapar, perseguir, ir tras uno pisándole los talones' (MosTolay, 2007: 235). Moneva (2004 [1924]) documenta engalzáa 'encorrer' en Ribagorza y engalzar 'perseguir' en Barbastro. En los DLAA, REIDY FrITZ (1977: 159) cita arag. ant. encalcador 'que impresiona' (sic). Aparece en el doc. no 55, de 1283, 
copiado en Huesca en 1304, que recoge el Privilegio de la Unión otorgado a los aragoneses por el rey Pedro III en 1283. En la lín. 34, pág. 80 se lee: «mas los sobrejunteros que sian exsecutores de las sentencias \& encalcadores de los malfaytores». Luego, está muy claro que significa 'perseguidores'. Comp. cat. y occ. ant. encalsar 'córrer (darrera algú) per atrapar-lo' (FABRA, Dicc., s. v.; DCVB, s. v.; DL/C el IEC, 2007, s. v.); it. incalzare, fr. ant. enchaucier, port. ant. encalcar (DCECH, I, p. 130, s. v. alcan₹ar). Frec.: encalçando 1: 0,00227; encalçandolo 1: 0,00227; encalçaron 1: 0,00227; encalçó 1: 0,00227.

encara adv. de tiempo 'todavía': viviendo encara el noble varón Remón Berenguer 29.32 / / adv. 'aún, incluso': empero el dito rey de Castiella la dita dispensación de consanguinidat no huvo al dia asignado, segunt avía prometido, ni encara depués el dito día 38.59-61. Para COROMINAS, el arag. encara 'aún' fue tomado del cat. encara (DCECH, III, p. 388). No obstante, es habitual en textos medievales en aragonés. Véase, por ejemplo, en un texto de 1406 de Villamayor de Gállego, población cercana a la ciudad de Zaragoza: «Et encara, damos e atorgamos special e general, pleno e bastant poder a los ditos procuradores que puedan dar poder a los ditos arbitros arbitradores e amigables componedores» (CAC, 1406: 75). Véase también en un texto del Valle de Echo, en la zona más occidental del dominio lingüístico: «Et encara en tiempo de guerras de Reyes que puedan puyar et devallar los ditos ganados grossos et menudos por los ditos terminos de la dita Val» (doc. de Braslavilla, Valle de Echo, de 1438; EAMJM, Gómez de Valenzuela, 2000, doc. no 12, p. 72). O en documentos notariales de Barbastro: «\& cómo encara flamjaban las grandes biegas del [roto] \& encara vidieron la brasada \& lenya que allj se era cremada» (MDF: 300.82); «Quison encara más los ditos Johan de Flandina \& Martina» (MDF: 321.46). Hoy se usa en el arag. de Ribagorza y zonas de Sobrarbe. Así, por ej., el EBA (1999: 716) registra encara 'todavía' en Benás, Bal de Chistau, Bielsa, Campo, Biello Sobrarbe, Bal de Lierp, Chuseu, Torres del Obispo, Sesué, Torla, Alta Ribagorza, Graus, Bal de Bielsa. También es usual en arag. literario común. Coromines (DECLIC, I, p. 302), afirma que el cat. encara es compuesto de la partícula anc 'ìncluso' y ara 'ahora', frente a las etim. tradicionalmente admitidas HINC AD HORAM O HINC HA HORA. Comp. fr. encore, occ. encara, it. ancora. Para el italiano, Devoto (s. v.) dice que ancora proviene del fr. ant. encore; y, por su parte, DauZAT/Dubois/Mitterand (1977: 512, s. v. or ) dan como etimología del fr. encore el lat. popular binc-ad-horam 'à cette heure'. Por otra parte, existe también en occ. encara, para el que AliberT (p. 321, s. v.) da como etimología lat. HANC HORAM. Para el occ. gascón, donde se registran diversas variantes (encaro, encòro, engor, engoèro, encoèro, encoare, engouèro, dengouèro), RoHLfs (Le gascon, pp. 138 y 197) da como etimología HINC-HA-HORA. Para el arag., Alvar (DA, p. 249) propone hinc ad horam. Menéndez Pidal (TME, p. 479), refiriéndose al Poema de Yücuf, donde aparece (niy-enkara lox xunveñox ke 
biyex en los altox!, en A 19c) afirma: «También es propiamente navarro-aragonés el adverbio encara 'aún', corriente hoy en Ribagorza». La etimología y referencias para el arag ant. y mod. pueden verse más ampliamente en el estudio lingüístico (NAGORE, 2003: 410-412, apartado 5.11.2.9). Frec.: 27: 0,06137.

encartado p. p. del v. encartar y adj. 'desterrado, expulsado, proscrito': et dió al infant don Pedro de Portogal, qui era encartado de su tierra, la isla de Mallorquas en toda su vida por tal que pudies bivir con honor 35.180-182. Comp. encartado 'sujeto a un proceso. Aplicábase en lo antiguo al que era llamado por pregón para responder a una querella o acusación criminal, y al cual, por no querer venir al emplazamiento, el juez mandaba que no entrase en el lugar o tierra donde moraba o de donde era natural' (DRAE, 1970, s. v., con marca de antiguo). El $L D A$, p. 235, recoge encartado 'sujeto a un proceso', coincidiendo en la definición con el $D R A E$, pero no exactamente con la acepción con la que se emplea en la Crón. SJP. Para la etim., vid. encartar. Frec.: 2: 0,00455.

encartar] v. tr. 'desterrar, expulsar, prohibir a una persona la residencia en un determinado territorio', 'proscribir': Et desseyando que nombre de traydor non buvies [fues $\mathrm{N}]$ en la tierra, encartó et gitó de todos sus regnos et tierras al dito Remón 17.2123. Etim.: deriv. del lat. CHARTA 'papel' (y éste del griego KHARTES 'papiro', 'papel'); documentado en cast. desde el siglo XIII (BDELC, p. 136, s. v. carta; DCECH, I, pp. 898-899). Comp. encartar 'proscribir a un reo constituido en rebeldía, después de llamarle por bandos públicos' (DRAE, 1970, s. v.; DLE, 2014, con marca de desusado); semejante es la $2^{\text {a }}$ acepción que recoge el $L D A$, p. 235: 'proscribir a un reo en rebeldía, emplazar a uno por edictos'); algo distinta es la acepción que para el arag. encartar recoge (PARDO, s. v.): 'intentar acción criminal contra el obligado en instrumento en que se jura pagar y no pleitear'. La palabra y el significado están tomados de BORAO, $s$. v. quien añade entre paréntesis: «Véase á Larripa en sus Procesos forales». La misma definición recoge como primera acepción el $L D A$, p. 235. Desde luego, la significación del verbo no es la misma que la que se deduce del texto de la Crón. SJP. En Andolz, s. v., además de esa acepción, tomada de PARDO, aparecen otras: 'declarar a alguien enemigo de la sociedad' y 'desterrar', ambas citadas como antiguas y tomadas de Tilander. En $V M$, III, p. 110: encartar 'declarar alguien enemigo de la sociedad'. La explicación que da ahí Tilander es que los nombres de los encartados eran escritos en documentos públicos o bandos que se mandaban pregonar por el juez. Vid. también encartar 'citar, emplazar', 'convocar ante el tribunal' y 'proscribir' en Fernández de Heredia (GILKIsON, s. v.); encartamiento 'proscripción' (ibídem). Cat. encartar 'citar (algú) a comparèixer en judici mitjançant un edicte o ban'; 'condemnar en contumàcia' (FABRA, Dicc., s. v.; DL/C del IEC, 2007, s. v.; vid. también $D C V B$, s. v.). Frec.: encartó 1: 0,00227. 
encerrar (var.: ençarrar) v. tr. 'encerrar': lo fizieron encerrar en un castiello 34.143; mas el dito conte de Ampurias, con grant poder de sus vassallos encalçandolo ençarró [encerró B] el dito en Oliver en un lugar clamado Ermeçera et d'aqui nos movió entro [fasta $\mathrm{N}$ ] que el dito en Oliver fue preso con todos sus cavalleros. 35.112-114. Etim.: Deriv. de cerrar $<$ lat. tardío SERARE 'íd', deriv. de SERA 'cerrojo, cerradura'; la -rr-, que aparece ya en lat. vg., s. $v$, se debe a una confusión popular con SERRARE 'aserrar' (BDELC, s. v. cerrar, p. 147; DCECH, II, p. 51). La forma ençarrar se explica por un hecho fonético común, ya que el contacto con - rr- facilita la apertura de la vocal $-e->-a$ - cuando está en situación átona. Comp. arag. mod. enzarrar, registrado en Echo ( $E B A$, 1999: 753), zarrar (Echo), zarrá (Ansó), rabaño (general), tarnasco 'cordero recental' (muy común, junto a ternasco) $(E B A$, s. v.). Frec.: encerrar 1: 0,00227; ençarró [encerró] 1: 0,00227.

encondreyto adv. de modo 'en buen estado, en buenas condiciones, sin desperfectos': Et el dito rey túvolo presso algunos días et quiso et mandó que avies a tornar encondreyto la dita villa 36.444-445. Etim.: deriv. de DiRECTus, lat. vg. *DRECTUS. Comp. cat. condret (DCV B, t. 3, p. 378; DECLIC, III, pp. 204-205); tenir en condret alguna cosa 'tenir-la en bon estat, ben endreçada' (DL/C del IEC, 2007, s. $v$. condret); occ. condrech $\sim$ condreit (LEvY, s. v.), condrech $\sim$ condreit 'en bon état' (ALIBERT, s. v.). Frec.: 1: 0,00227 .

en continent locl. advl. de tiempo 'aprisa, rápidamente, inmediatamente', 'prontamente, al instante, sin dilación': Et en continent el dito Carlos se fizo nombrar rey 34.464; Et en continent mandó cort general plegar en la ciudat de Caragoca 37.11. De la expresión latina IN CONTINENTI (TEMPORE) 'en (un tiempo) continuo', y luego 'inmediatamente'. Es habitual en arag. med., tanto escrito junto, encontinent, como separado, en continent. En los DLAA (REIDY FrITZ, 1977: 159), encontinent 'en seguida, al instante’. Véase, por ejemplo: «dizimos \& mandamos al dito Bernart Gascon que la dita obra, feyta porel enel dito poço, nueuament sea deffeyta e sarrada por el encontinent o quela pueda sarrar \& deffer el dito don Gil» (DLA $A$, doc. $n^{\circ}$ 69, de Huesca, de 1293, p. 100); «segunt parescia por letra patent a el dada por el dito senyor rey, $\&$ de aquellya hauiesse feyto fer hun trasunto en la villa de Montalban en pergamino scripto \& en pendient sellyado, del qual encontinent fizo prompta fe que yes del tenor seguient...» (DLAA, doc. $\mathrm{n}^{\circ} 139$, de Jaca, de 1435, p. 204). En documentos notariales de Barbastro: «los ditos huycientos ss., precio de las ditas casas que en continent, sienes alguna tarda \& scusación, ffaré donación» (MDF: 361.21). Comp. cat. encontinent 'tot seguit (FABRA, DGLIC, s. v.; DL/C del IEC, 2007, s. v.); occ. prov. encontenen 'aussitôt, incontinent' (LEVY, s. v.), fr. incontinent 'tout de suite' (PRobert, s. v.). También de continent, continent. Frec.: en continent 41: 0,09319; de continent 3: 0,00682; continent 2: 0,00455.

encontrada s. f. 'comarca, región'; 'aledaños, alrededores': et el término [camino N] de San Jayme qui por medio de los arabes passava por Alava et por Asturias, mudó [mudólo 
N] el dito Diago conte et fizo [fizolo N] passar por Anagera, por Viruescha et por Mannya [Maya N] et por las encontradas. 14.12-15. Etim.: deriv. de contra, del lat. CONTRA 'frente a', 'contra'. Tradicionalmente se ha dado la etimología lat. vg. *COntrata (Regio-), deriv. de CONTRA, es decir 'pays en face'. Esta es la etim. propuesta por Bloch-WARTBURG ( $2^{\mathrm{a}}$ ed.) y la que asimismo aceptan para el francés contrée Dauzat-Dubois-MitTerand, s. v., y PRobert, s. v. Igualmente Devoto, s. $v$., la propone para el it. contrada. Pero Corominas rechaza la idea de que existiera un lat. vg. *CONTRATA y piensa que es más verosímil pensar en una formación derivada a partir del verbo encontrar (lo mismo que cat. avançada, enantada, davallada). Cfr. DECLIC, II, p. 892-893, s. v. contra. Occ. encontrada 'comarca, país, región' (AliberT, s. v.); contrada (LEVY, s. v.).

Vid. referencias de contrada y encontrada en cast. med. en VMC, s. v., DME, s. v. En Alex. encontrada 'territorio' (SAS, s. v.). En cast. ha de venir del cat. o del occ., según Corominas. Cat. encontrada (s. XIII), contrada (s. XIV) (DECLIC, II, p. 892-893; DCVB, s. v.). Para el cat. actual el DL/C del IEC (2007) registra encontrada como sin. de contrada 'extensió territorial determinada per límits naturals o polítics' y 'voltants, extensió de terra próxima a un lloc, a una persona, a una casa'. En arag. ant. encontrada se usa frecuentemente en el Libro de Marco Polo (citamos por la ed. de John J. NITTI): «En aquestas encontradas non ya nengunos blades nin sende faze pont» (ibídem, p. 60, lín. 14); «que quando vna nao hi viene por fortuna et surge en lur encontrada, ellos — si pueden - la toman et la roban toda» p. 53, lín. 12-14); «et guardar aquellas encontradas de Condifu» (ibídem, p. 35, lín. 9). «Et todas las encontradas son bien habitadas» (ibídem, p. 35, lín. 1); «tanto que es vn grant plazer de veyer aquellas encontradas» (ibídem, p. 26, lín. 21). «Et en aquesta encontrada se faze el gingibre et la seda» (ibídem, p. 25, lín. 41). «Las gentes destas encontradas biven de pex salado et de datiles» (Ibídem, p. 60, lín. 24). Véase también en la ed. de SANGOrRín (2016: 209): encontradas 'contornos, regiones, alrededores'. Es general en las obras de Fernández de Heredia (Gilkison, s. v.). Vid. también encontrada 'región' en FA (TILANDER, FA, p. 372); contrada 'comarca', encontradas en $L M M$ (LiRIA, $L M M$, pp. 162 y 168); encontrada 'región' en VM (TILANDER, $V M$, III, p. 112). SIESSO DE BOLEA (2008: 148) registra encontrada 'lo que contree en francés' y lo ilustra con un ejemplo del testamento del marqués de Oristán, de 1502. Frec.: encontradas 1: 0,00227.

encontrar v. prnl. 'encontrarse, topar, chocar, coincidir casualmente, tropezar con algo o alguien': el dito rey con sus conpannyas naturales en las galeras se metió por entención toda vegada de non encontrarse con su hermano si fer se pudies 38.264266. (Adviértase que no se emplea trobar 'hallar', porque encontrar tiene otro sentido: 'tropezarse, chocarse, coincidir, darse un encontronazo'). [en les galeres se mès, per intenció tota vegada de no encontrar-se ab son germà, si fer-se pogués, 
VC, p. 165]. Etim.: deriv. del lat. CONTRA 'frente a', 'contra'. Comp. cast. encontrar, documentado por 1. ${ }^{\mathrm{a}}$ vez h. 1200 en el Libre dels tres Reys d'Orient. En el sentido debilitado de mero sinónimo de 'hallar' no parece haber sido frecuente en la Edad Media (DCECH, II, p. 183, s. v. contra); cat. encontrar y encontrar-se 'topar-se amb algú inesperadament o casualment, topar-lo', se doc. en cat. desde el s. XIII. También aparece en cat. con el sentido de 'encontrar a fuerza de buscar' y 'chocar violentamente' (DECLIC, II, 892; DCV B, s. v., t. 4, pp. 888-889). El DL/C del IEC, 2007, registra encontrar 'topar (amb algú), sortir al pas (d'algú)'. Comp. trobar. Frec.: 1: 0,00227.

encoraxar] (var.: encorajar]) v. prnl. 'llenarse de valor y de ánimo'; 'encolerizarse mucho': E en tanto abivado et encorajado [corejo N] de haver batallas continuament con los moros que apenas estava un dia seguro 10.15; e no queriendo estar reposo de desconocencia por el seynnalado servicio que el dito Beltran d'Albaus le avía feyto en el tiempo pasado, encoraxóse del dito compte 33.55. Deriv. del sust. coraxe 'valentía', 'ira'. El BDELC (p. 171, s. v. corazón) considera que el cast. coraje es un préstamo del fr. courage 'valentía', deriv. del fr. coeur 'corazón'. Por lo tanto, el v. aragonés encoraxar podría tener el mismo origen. Frec.: encorajado 1: 0,00227; encoraxóse 1: 0,00227.

encuvierto p.p. del v. encuvrir y adj. (aquí en uso adverbial): Otrossí otro compte don Pero de Lara puniava encuvierto de aver amor de la reyna 19.107-108. Frec.: 1: 0,00227 .

ende (var.: end, en, ne, 'n) compl. pron. adv. 'de allí, de ahî', 'de ello': de los quales muertos ende havía los V que yeran del linage de Luna 20.139; et que len demandavan perdón 14.77; ; por esquivar vergonna et desonor que lende podría seguir 23.14; (forma enclítica): et pues gracia le demandava yera aparellado de fazer lend 19.181 ['hacérsela', 'hacerle de ello']; mas non lo quiso prender entro ha quende fues forçado por el Padre Santo 38.609. De la misma forma que se aglutina con le en lende, también con se en sende: absentós del dicto regno et vino sende en Valencia que senyorava las oras el Cit Rui Dia\%: 17.12. Igualmente puede aparecer aglutinado al adv. no en nonde, aunque se encuentra casi siempre separado non de: do murieron muytos moros et entre muertos et cativos ninguno non de escapó 35.133. Etim. del lat. INDE 'de allí', 'de esto, de eso'. La forma ende (y variante end) fue frecuente en cast. med. Cfr. DME, s. v., p. 1016; VMC, s. v., p. 169. Pero, como resumen Corominas-PASCuaL: «Desde el siglo XV el vocablo ende tendió a desaparecer del uso vivo en todo el territorio de lengua castellana, excepto en asturiano, donde se conservó con el sentido locativo 'de ahí' o 'de por ahí', y en el dialecto aragonés, donde persistió, apoyado geográficamente en el catalán y el gascón; lo mismo que en estos idiomas, en Aragón llega alguna vez a ser meramente expletivo. La ruina del uso de INDE en cast. y port., fenómeno ajeno a los demás romances, se produjo casi al mismo tiempo que la de $i$ 'alli', 
constituyendo un rasgo típico de estos dos idiomas» (DCECH, II, 604). Vid más ampliamente sobre este compl. pron.-adv. el apartado 6.2.2. del estudio lingüístico (NAGORE, 2003: 510-516). Frec.: ende 18: 0,04091; len 2: 0,00455; lend 1: 0,00227 ; lende 4: 0,00909 ; ne 12: 0,02728 ; nonde 1: 0,00227 ; sen 10: 0,02273; sende 29: 0,06592

endemedio s. m. 'período, tiempo', 'intermedio, ínterin': et en aquest endemedio [aquesti de medio N], el dito rey dio su hermana dona Violant por muller a Rubert, fillo del rey Carlos dessuso nombrado. 38.185-186. Cfr. medio en GiLkison: como $3^{\mathrm{a}}$. acepción da 'time, period'. Frec.: 1: 0,00227.

enderredor adv. 'alrededor': el dito rey brotó su cavallo assí como a valient cavallero por el campo enderredor cridando altament 36.292-293. Aunque en el texto aparece junto, podría interpretarse como separado: en derredor, donde en es una prep. Etim.: Proviene de la prep. redor, probablemente del lat. RETRO 'detrás'. Redro la cása 'detrás de la casa' se convertiría en redor la casa 'alrededor de la casa', gracias a la pronunciación proclítica de las preposiciones. El empleo como adv. es más tardío, como se ve por la circunstancia de no hallarse más que en la forma derivada de-rredor (BDELC, p. 45, s. v. alrededor, y DCECH, I, p. 213). Luego, ese adverbio se reforzaría con la prep. en: en derredor $>$ enderredor. Cfr. derredor. Frec.: 1: 0,00227.

enderrocar v. tr. 'derribar', 'derruir': et aquesti fizo enderrocar todas las fuerças de las ciudades et lugares de su regno por tal que las sus gentes no [no se $\mathrm{N}]$ pudiessen rebellar contra ell. 3.76-78; et enderrocó los muros et los fundamientos de aquel lugar 17.37-38; et que enderrocas los muros del castiello 36.448. Etim.: deriv. de roca, lo mismo que la variante derrocar (vid.). Frec.: enderrocar 1: 0,00227; enderrocás 1: 0,00227; enderrocó 1: 0,00227.

endreçar] v. tr. 'enderezar, poner derecho, levantar, arreglar': avieron la dita ciudat desenparar et rendieronla al dito don Alfonso el qual, quando la buvo cobrado, fizo reparar et endrecer [endreçar $\mathrm{N}]$ aquélla porque bien yera mester [y hera menester $\mathrm{N}]$ que toda era cremada et derrocada. (error por endreçar) 36.689-691. Etim.: de IN + lat. vg. *Directiare 'dirigir', 'poner derecho' (deriv. del lat. DiRigere 'íd.', part. DIRECTUS) (BDELC, p. 28, s. v. aderezar); DEEH, p. 154. Usual en arag. med.: endreçar, también endereçar, en el arag. de Fernández de Heredia (GILKIsON, s. v.); también en arag. mod.: endrezar 'enderezar' (Andolz, 1991: 170; EBA, 1999: 724). Frec.: 1: 0,00227.

en dreyto de loc. conj. 'frente a, enfrente de, en dirección a, cara a, a la vista de': et aquesti firimiento del rey d'Aragón duró entro que huvieron decendido el coll de Panizares et fueron en dreyto de Montesquiu 36.656 [ e foren endret Montesquiu VC, p. 147]. Etim.: del lat. IN DiRECTUM. El DCVB da esta etim. para el cat. endret, que considera grafía aglutinada de en dret. Es usual en arag. med.: «el qual dito Bernart auia foradada la tapia, baxo, enla laçez, en dreyto daquel poço, \& allí 
auia feyto obra denueuo» (DLAA, doc. nº 69, de Huesca, 1293, p. 99, lín. 8). Comp. en Benasque en endret 'delante de, en dirección de' (Andolz, s. v.); al endrét de 'enfrente, en dirección de' (Ballarín, Dicc. del benasqués, p. 135, s. v. endrét). El $D C V B$ da como tercera acepción del cat. endret o a l'endret 'enfront, davant per davant; a l'altura (d'una cosa); cast. enfrente, frente a'. Cfr. cat. endret 'dret o cara bona d'un teixit, roba, etc.' (FABRA, s. v.; DL/C del IEC, 2007, s. v.); occ. (prov.) endrech prep. 'vers, a l'égard de, devant', adv. 'droit en face', y como sust. 'endroit' (LeVY, s. v.). En occ. (lang.) moderno parece que ha mantenido sólo el significado de 'endroit, lieu, place; localité; pays; endroit du papier, d'une étoffe; côté droit d'une riviere', utilizado como sust. (AliberT, s. v. endrech $\sim$ endreit). Frec.: 1: 0,00227.

enegrir v. tr. 'ennegrecer': Et en continent, los ditos mesageros van a enegrir las velas et todas las galeras en que eran venidos et todas las xarcias [exarcias $\mathrm{N}]$ 38.140-141. [E encontinent los dits missatgers van ennegrir les veles e totes les galees en què eren vengunts e totes les eixarcies VC; Et continuo dicti nuntii omnes galeas cum quibus uenerant, et uela ac etiam omnes eoron exarcias nigro colere tincxerunt VL]. Etim.: del lat. NIGRERE 'ser oscuro' (BLÁNQUEZ, p. 1017, s. v. nigreo), prefijado con IN- > en-, o simplemente deriv. de negro < lat. NIGER, NIGRA, NIGRUM. Si comparamos el fragmento con la VC y la VL, la construcción verbal van a enegrir hace sospechar que este capítulo de la Crón. SJP. fue traducido al aragonés desde la versión catalana (al contrario de otros, que sugieren traducción de la versión latina cuando faltan en la VC). El cast. ennegrecer (< IN + NIGRESCERE) se documenta por primera vez en 1495, según Corominas (BDELC, p. 413, s. v. negro). Comp. cat. ennegrir 'tornar negro' (DECLIC, V, p. 899). Se registra ennegrir en VM, III, p. 115. Frec.: 1: 0,00227.

enemigo s. m. 'enemigo': Et el rey don Sancho vencedor, loando a Dios de la grant victoria que le dio, pasó Ebro prendiendo et astragando la tierra de su enemigo 17.43; todos tiempos tuvo el corazón contra moros et todos tiempos obtuvo victoria contra sus enemigos. 36.13. Del lat. INIMICUs. Frec.: enemigo 6: 0,01364; enemigos 27: 0,06137.

enfermedat s. f. 'enfermedad': Dios enbió enfermedat [mortaldat $\mathrm{N}$ ] sobre ellos et avieron muytos de morir 38.202. Deriv. de enfermo. Frec.: 3: 0,00682.

enfermo adj. 'enfermo': estando enfermo en Montpesler de grant malautia, la Virgen gloriossa Madre de Dios li apareció con grant goyo et díxole que se levantas del leyto sin todo mal que non sintió ren 35.218 - 221. Del lat. INFIRMus 'débil, endeble'. Cfr. dolent. Frec.: 4: 0,00909.

enforcar v. tr. 'ahorcar': el dito rey fizolo enforcar por otro crimen 38.296; «rendeme el castiello, si no yo te enforcarés 38.303. Deriv. de forca < lat. FŬRCA 'horca' (DCECH, III, p. 391). Comp. en arag. med. enforcar 'ahorcar' en FA (Tilander, 1937: 373-374), en LMM (LiRIA, 1979: 168), VCA (p. 157); enforcado 'ahorcado' en el LT (Rodés, 2006: 720), en OB (VÁzquez Obrador, 2011c: 38). Arag. mod. 
enforcar (Andolz, s. v.; Rohlfs, DDPA, s. v.; EBA, 1999: 727; Ríos, 1997: 82; GARCÉs, 2005: 138). Frec.: enforcar 1: 0,00227; enforcaré 1: 0,00227.

enformar] v. tr. 'informar'; 'enterar', 'darse cuenta de': et por la soberbia et menosprecio que don Per Atares, non seyendo encara rey, fazía a los del regno, enformaron e favlaron con muitos [en formation e tracto con los $\mathrm{N}$ ] del regno que don Remiro, hermano et fillo de su sennyor, el qual era monge en el monesterio de Sant Ponz de Tomeras en Francia, en la comarca de Besses, fiziessen que fuesse rey. 20.17. Del lat. INFORMARE 'dar forma', 'formar en el ánimo', 'describir' (DCECH, II, p. 933). Frec.: enformaron 1: 0,00227 .

engannar] v. tr. 'engañar': Et don Per Ateres quando se cató, fincó engannado [envergoynido $\mathrm{N}]$ por su locura et relación de malos porteros 20.41. Del lat. vg. *INGANNARE 'escarnecer', 'burlarse de alguien' (DEEH, p. 742; DCECH, II, p. 618). Frec.: engannado 1: 0,00227.

enganno s. m. 'engaño': pero depués, por enganno et por fuerça del emperador Valient, qui era de la secta arriana, tornaron ereges en la error arriana 3.22. Deriv. postverbal de engannar. Frec.: 1: 0,00227.

engendrament s. m. 'engendramiento': Et como el dito rey don Jayme de muytas nobles mulleres et de otras fembras avies procriados muytos fillos qui por engendrament de dreyta linea non son anotaderos nin cal fer memoria nin mención de aquellos 36.33. Deriv. de engendrar. Frec.: 1: 0,00227.

engendrar] v. tr. 'engendrar, procrear': Et de otra part engendró un fillo bort [nombrado Bort N] nombrado Sancho 16.30. // 'causar, ocasionar, producir': porque luenga paraula [palavra $\mathrm{N}$ ] engendra enoyo en leyr et en oyr 2.4. Del lat. INGENERARE 'hacer nacer, crear'. Frec.: engendra 1: 0,00227; engendró 7: 0,01591.

engenyo s. m. 'ingenio': el qual fue muyt noble varón et de grant probeça et de gran saber et de muyt grant engenyo et de grant consello 32.3. Del lat. INGENIUM. Frec.: 1: 0,00227. engenyosso adj. 'ingenioso': fue muyt noble varón, largo, proz et diligent, et muyt engenyosso 35.90. Deriv. de engenyo, con sufijo abundancial -osso. Frec.: 1: 0,00227.

ennoblecer v. tr. 'ennoblecer': Aquesti noble varón, queriendo divulgar et ennoblecer la suya fama et justicia, 29.7; el qual de manifiestas noblezas era ennoblecido 16.21; et con voluntat et consentimiento del dito rey Fortunyo García, el dito monasterio ennoblesció et dotó de muitas terras 8.5-7. Deriv. de noble. Frec.: ennoblecer 1: 0,00227; ennoblecido 2: 0,00455; ennobleció 2: 0,00455; ennoblesció 2: 0,00455.

enoyado] adj. 'enojado, enfadado': Et las gentes de Aragón e de Navarra eran en Huesca et en aquellas partidas que avía toda la tierra puesta a lur mano e tirada a los moros, enoyados, consellavan a don Pedro que no fues a Valencia 18.101. Etim.: del p. p. del v. enoyar o enuyar 'enojar'. Frec.: enoyados 1: 0,00227.

enoyo (var.: enueyo) s. m. 'enojo, enfado', 'irritación, cansancio': porque luenga paraula [palavra N] engendra enoyo en leyr et en oyr, et por aquesta razón no queremos 
más favlar del feito 2.4; El qual por discordia que huvo con la primera muller et porque la lexó, huvo muytos enueyos [enoyos N] et treballos 35.91. Etim.: postverbal de enoyar u enuyar, del lat. vg. INODIARE 'inspirar asco u horror' (DCECH, II, p. 635; MGHE, p. 236; DEEH, p. 744). Se registra enoyo, enoio en las obras de Fernández de Heredia (GILkison, 1984: 55). En cambio, en DLAA, enueyos: «E viendo el poco poder, destruymiento de personas $\&$ bienes que yes seydo hen el dito logar de Vielsa \& inquietacion de grandes messiones, trebalyos \& enueyos, que han amantener \& sostenir de necesidat muytos puentes \& fuertes \& malos \& diuersos caminos» (DLA $A$, doc. de Bielsa, 1349; p. 167, lín. 143).Frec.: enoyo 5: 0,01136; enoyos 1: 0,00227; enueyos 1: 0,00227 .

enparar] v. tr. 'amparar, sostener': avía guerra con el rey de Francia et don arcevispo de Narbona, don Arnalt, porque enparava algunos hereges 34.152. Del lat. vg. *anteparare 'prevenir de antemano' (DCECH, IV, p. 394). Comp. emparar. Frec.: enparava 1: 0,0027.

enpennyar] v. tr. 'empeñar, dejar en prenda (algo) a cambio de dinero': et el rey enpennyó muytas villas et prisso [aprisso B] las diezmas de su tierra et algunos trasoros de las yglesias 34.154-155; metió mano a los santuarios e yglesias e monesterios e prendiessen los trasoros de las eglesias, et vendia et enpeynava las heredades e posesiones de aquéllas, e pagó el sueldo de los suyos 19.147-150. Etim.: deriv. del ant. pennyo o pennyos 'prenda', del lat. PIGNus, -ORIs 'íd.' (BDELC, p. 229, s. v. empeñar, DCECH, IV, p. 638). En la Crón. SJP. no se registra pennyo, sino pennora, pero se encuentra muy abundantemente en otros textos en arag. med.: peynno, peyno, peinno en VM (Tilander, VM, III, pp. 236-237); penyo en Fernández de Heredia (Gilkison, s. v.); pennos en FA (Tilander, FA, p. 516); etc. Frec.: enpennyó 1: 0,00227.

enprendimiento s. m. 'empresa, compromiso, asunto acordado o decidido': et depués de algunos días, cada uno fizo su pertreyto [pareyt N] et aparellamiento por complir los enprendimientos dessuso ditos 38.351-352. Deriv. del v. enprender, con sufijo -miento, < lat. -MENTUM, que a partir de verbos deriva sustantivos que designan resultado de la acción indicada por la base. Frec.: enprendimientos 1: 0,00227 .

enpresso p. p. de enprender, 'decidido, comprometido'; 'resuelto, acordado': empero fue enpresso entre los franceses qui eran en la stablida fincados et el rey lur que si dentro tiempo cierto non les podía aver acorridao de viandas et de otra ayuda que pudiessen la ciudat livrar a don Alfonso 36.682; porque assí era enpresso en los capitoles de la paz dessuso dita 38.114; Et fue assi enpresso entre entramos los ditos reyes que el uno, es assaber el rey de Aragón, sitiás la ciudat de Almaría et el otro, es assaber el rey de Castiella, sitiás Aliazira de Alfrada. 38.346. Se trata del participio fuerte del v. enprender, deriv. del lat. PREHENDERE, lat. vg. PRENDERE 'coger, 
atrapar', 'sorprender' (DCECH, IV, pp. 638-640). El DCVB, s. v., t. 4, p. 811, postula como base un lat. vg. *imprehendere. Comp. en Fernández de Heredia: enprender 'emprender, acometer, comprometerse' y enpresa 'empresa, compromiso' (GILkison, s. v.). Comp. cat. emprendre 'decidir, resolver, acordar' y 'emprender' (DCVB, s. v., t. 4, p. 810). Frec.: 3: 0,00682.

enpués (var.: empués) adv. 'después': empués aquesti don Alfonso con los aragoneses pasó Duero e por Tierra de Campos fuese para Leon 19.127. // prep. 'después de, tras': enpués esto, el rey don Alfonso fue conpresso entre el dito rey de Inglaterra de veyerse entramos cierto día et lugar cada uno de los ditos reyes 37.66. Etim.: compuesto de prep. en < IN y pues < lat. PǑst (DCECH, IV, p. 684, s. v. pues). Aparece en $D L A A$ (doc. 115, de Botaya, 1351, p. 169, lín. 20): «vno en pues de vno». Comp. arag. mod. dimpués, dempués 'después' (Andolz, s. v.; RohlFs, DDPA, s. v.; BAL, 2002: 98; etc.). El EBA (1999) registra empués 'después' en Luesia (p. 711), dempués 'después' en el Baxo Alcanadre (p. 657), dimpués (pp. 680-681) en casi todo el Alto Aragón (21 registros) y dispués (p. 684) también de forma abundante (en 17 puntos). Cfr. depués. Frec.: enpués 10: 0,02273; empués 3: 0,00682 .

enrriqueçer v. tr. 'enriquecer, hacer rico, llenar de riquezas': e por esgoart del su nuevo avenimiento, le plazies enrriqueçer el dito monesterio de algunas honores 11.24. Comp. enrriquir. Frec.: 1: 0,00227.

enrriquir] v. tr. 'enriquecer': el qual edificó el monesterio de Canniego et aquél enrriquió de muytas possesiones notables 27.19. Deriv. de rico, del gótico ReIKs 'poderoso' (DCECH, V, p. 10). Frec.: enrriquió 2: 0,00455.

ensayar v. tr. 'intentar acometer, intentar atacar': luego querie ensayar Vitoria et otros lugares que yeran de Navarra 20.49. Etim.: deriv. de ensayo < lat. tardío EXAGIUM 'acto de pesar (algo)'. (DCECH, II, p. 640). Con el mismo significado se emplea en el Poema de Mio Cid (Menéndez Pidal, Cantar de Mio Cid, p. 644) y en Alex. (SAS, s. v.). Según los autores del DCECH (II, p. 640-641), ensayar se utilizó frecuentemente en cast. med. con la acep. de 'emprender'. En arag. med. se registra asayar, assayar 'intentar', 'emprender', 'probar' (GILKISON, 1984: 14), asayar, assayar 'intentar, experimentar' (VCA, p. 45). Váse un ejemplo: «que como se sea trobado en feyto de verdat que hombres recarderos e revendedores asayent e hayan asayado por diversas maneras exquisitas de comprar et fazer comprar el pan sobredito, es a saber trigo, centeno, ordio, cevada e otro grano en la comarqua...» (doc. de Jaca de 1423: Gómez de Valenzuela, EAMJM, 2000: 52). Frec. 1: 0,00227.

ensellado p. p. y adj. 'ensillado': et li fues apparellado su cavallo, ensellado et bien honrado de diversos hornamentes 37.88-89. Deriv. de siella $<$ lat. sĚLLA. El BDELC da la $1^{\text {a }}$ documentación de ensillar en cast. en 1495, es decir, más de un siglo después de la redacción en aragonés de la Crón. SJP. Frec.: 1: 0,00227. 
ensemble adv 'conjuntamente, juntamente, a la vez, todos juntos': El Padre Santo Bonifaci et Frederich dessuso dito huvieron vistas ensemble por tractar entre éll et la Yglesia 38.151. En la VC ensems: hagueren vistes ensems per tractar... VC, p. 162. Del lat. INSIMUL 'juntamente', variante reforzada de simul 'a una', 'juntamente', 'al mismo tiempo' (DCECH, II, p. 640; Dauzat-Dubois-Mitterand, s. v., p. 266; PRobert, s. v., p. 651. Comp. fr. ensemble, cat. ensems (DCVB, s. v.), occ. ensemble (Levy, s. v.). Corominas lo califica de galicismo en aragonés (DCECH, II, p. 640), pese a que ahí mismo cita su uso en docs. aragoneses y riojanos desde 1212 hasta 1519. En el DECLIC, III, p. 372, lo considera más bien un viejo occitanismo o incluso un «arcaísmo indígena». Puede verse ensemble en $D L A A$ (en docs. que van de 1268 a 1495), en FT, en $D J$, en $C T$, en $F A$, en $V M$, en Fueros de 1348, en $L M M$, en el $L T$, en Fernández de Heredia (GILKISON, s. v.), etc. Y por otra parte también es habitual en textos navarros (cfr. TLN, p. 224). Frec.: 19: 0,04319.

ensennyar] v. tr. 'enseñar': «Sennyor Dios, tu me ensennya a fer la tuya voluntat» 35.244. Etim.: del lat. vg. INSĬGNARE 'marcar', 'designar', lat. cl. INSĬGNIRE (DCECH, V, p. 210, s. v. seña). Frec.: ensennya 1: 0,00227.

ensennyoriar] (var.: ensennyorar]) v. prnl. 'dominar, hacerse dueño y señor de una cosa, apoderarse': et el dito rey ensennyoriose del dito condado mientre vivió 34.113; et en continent, ensennyorose [enseynoreose $\mathrm{N}]$ del dito condado 23.38; firo morir los ditos traydores, los quoales se heran enseynnoreado de muytas fuerças de Proeniça. 33.58-59; enseynnoreose del dito marquesado,32.45; libró al rey grant partida del dito condado de Proeniça et, en continent, enseynoirose del dito condado 33.45-47. Deriv. de sennyor. Frec.: ensennyoriose 2: 0,00455; ensennyorose 1: 0,00227; enseynnoreado 1: 0,00227; enseynnoreose 1: 0,00227; enseynoirose 1: 0,00227 .

ensuso adv. 'encima, sobre, arriba': do murieron de los enemingos bien mil cc homes entre de pie et de cavallo ensuso 38.537. Etim.: prep. en más suso, del lat. sursum 'hacia arriba, hacia lo alto' (Segura, 2001: 756). Comp. occ. ensís 'en haut'. Frec.: 1: 0,00227 .

ensuziado] p. p. 'manchado, ensuciado. contaminado' (en sentido figurado): la isla de Menorca conquistó et aquella, qui de la fé de Mabomat era ensuziada, a la fe de Ihesu Christo tornó et reduxo. 37.39. Deriv. de suz̨io, del lat. sucidus 'húmedo,

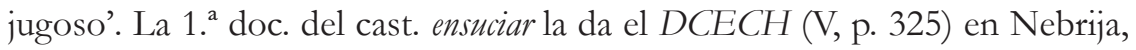
h. 1495. Frec.: ensuziada 1: 0,00227.

enta prep. 'hacia': los quales vinieron de una isla que es clamada Estancia, la qual es enta las partes de Septentrio enta la mar quel mundo environa 2.14-15; Se derramaron et fueron enta las fuerças de las montannyas de Sobrarbe 4.2-3; fues con gran poder de hombres a cavallo $i$ de pie enta las partes d'Aragón 4.28-4.29. Sistemáticamente aparece envers en la VC: anés ab gran poder d'bòmens a cavall e de peu envers la 
terra d'Aragó VC, p. 28; s'escamparen e fugiren envers les forces de les muntanyes de Sobrarbe VC, p. 27]. Es preposición habitualmente usada tanto en arag. med. como mod. Véase algún ejemplo: «stavlimos que quando venrran de enterrar et de novena, que los hommes qui seran al enterrar et a la novena, luego que las muylleres veran venir enta la casa del muerto o de la muerta, que se vayan dallí en pena de c solidos» (doc. de Huesca de fines del s. XIII; LALienA, 1988: p. 111). «como dize la buega della el couilar de Forato, en lo sarrato, tirando asuso acabo la faxa enta part de Ezeto» (DLA $A$, doc. n. ${ }^{\circ} 149$, de Panticosa, 1484; p. 219, lín. 45). Las etimologías propuestas hasta ahora no nos parecen suficientemente convincentes. Así, Corominas incluye enta entre los compuestos de ende < lat. INDE. Dice: «Enta, arag. ant. y alto arag. 'a', 'hacia' (hoy empleado desde Ansó hasta Benasque; también abreviado ta; se emplea igualmente en el gascón pirenaico y en el catalán de Huesca y del Segriá; ejs. antiguos en autores y textos aragoneses de los ss. XIV-XVI: Fuero de Tudela [Tilander, 266-7, 582], Fernández de Heredia [RH, XVI, 268.713, 272.245, 273.872], Crón. SJP. [ed. Ximénez de Embún, pp. 12, 18, 20 , etc.], ms. aragonés de Alex. 1117c, etc. Profecía aljamiada de fin s. XVI [PMLA, LII, 635, 637, 643], Recontamiento de Alixandre [RH, LXXVII, 462, 597], etc.), procede de una contracción de la forma ent arriba citada con la preposición a, Vid. Vocab. Aranés, s. v., y V. Rom., II, 160; a pesar de la semejanza casual con el umbriense ta 'a' (ZRPh, XLI, 457) que viene de INTUS $\mathrm{AD}$, la preposición pirenaica no puede tener esta etimología (como sostuvo Rohlfs, ASNSL, CLXVI, 148, y BhZRPh, LXXXV, SS 107 y 435), puesto que la -s-, que en Italia desaparece, se conserva sin excepciones en gascón, aragonés y catalán; la variante gascona ena comprueba, por lo demás, el étimo INDE AD, ya indicado por M.-L.» (DCECH, II, p. 604). Sobre la etimología INTUS AD puede verse también ROHLFs, Le gascon (1970: 201). Además de INDE AD e INTUS AD, ha sido propuesta por KONTZI (1970) la etim. árabe inda 'cerca de', 'hacia'. Pero si la etimología INTUS AD plantea el problema de la -s-, las otras etimologías propuestas no presentan menos dificultades de carácter fonético. Vid. en el estudio lingüístico (NAGore, 2003: 455-458, apartado 5.12.13). Frec.: 9: 0,02046.

en tal contracción de enta + art. el: Et el dito rey don Jayme, qui en tal [enta el $\mathrm{N}$ ] dito rey Carlos et legado se fazía a carrera 38.92. Vid. enta.

entalscar] v. tr. 'prohibir, vedar, privar, evitar': entalscando [et tardando N]; [privant l'acord VC] el acuerdo dessuso dito. 38.149. Comprobado en el ms. B, leemos entalscando, forma rara: debe de ser un lapsus del propio manuscrito. Frec.: entalscando 1: 0,00227.

entaqua adv. 'hacia aquí, hasta acá': Et por esto metieronle sobrenombre Ariesta, porque assín como la ariesta aplegada cerca el fuego en un moment crema, assin el dito rey don 
Ennego, sabiendo que los moros deviessen haver batalla con él, en un moment era con ellos; assín de las oras entaqua huvo nombre Ennego Ariesta. 10.20. Véase también en otros textos en arag. medieval: «el primo de lo rio Traviessas entaqua e del puent entaqua e de la calz de la Penya entaiuso que ba enta Trabiessas e de lo Bazato de la Ball que ba enta Salhent entaqua» (doc. de Lanuza de 1431; E $A M J M$, p. 67). Compuesto de la prep. enta y el adv. aqua. Vid. enta. Frec.: 1: 0,00227 .

entención s. f. 'intención, propósito’: et huvo todos tiempos la su entención de subiugar moros 34.88. Tomado del lat. intentio, -onis 'tensión, esfuerzo', 'atención, solicitud, diligencia', 'intención, designio, voluntad' (SEGURA, 2001: 387). Frec.: 2: 0,00227.

entender v. tr. 'entender'; 'atender': Et depués muert del padre don Alfonso de Castiella, regnó don Sancho, fillo segundo, et devía regnar esti don Alfonso el deseredado que era fillo del infante don Ferrando primogénito, agora entendedes [entendreys $\mathrm{N}$ ] por qué es dito deseredado 37.49; et por raqón que sabía gramática el cavallero, entendieron algunos en latín et recontó este miraglo 18.63-64; Et el alcayde entendiólo bien et conosció quel dito rey le signó que non lo rendies. 38.303-304. / / entender a 'acudir a': «Sennyor, entiende en la mia ayuda» 35.242. Etim. del lat. INTENDERE 'extender, dirigir hacia algo', especialmente aplicado a la mente (DCECH, V, p. 459, s. v. tender). Comp. antender. Frec.: entender 2: 0,00455: entendedes 1: 0,00227; entendemos 2: 0,00455; entendía 7: 0,001591; entendida 2: 0,000455; entendido 2: 0,00455; entendieron 1: 0,00227; entendiés 2: 0,00455 ; entendió 1 : 0,00227; entendiólo 1; 0,00227; entiende 1: 0,00227.

entendimiento s. m. 'entendimiento'; ‘juicio, raciocinio': el estando en sana sanidat en su buen entendimiento, renunció a los bienes temporables 31.49. Deriv. de entender, con sufijo -miento. Frec.: 4: 0,00909.

enterrado p. p. del v. enterrar 'inhumado, puesto bajo tierra': murió a la tornada et fue enterado [soterrado N] en los freyres predicadores de Calatayú 38.402; et fue enterrado en la dita iglesia de San Pedro, en la capilla de San Bartholomeu. 20.306. Deriv. de tierra $<$ lat. TERRA. Comp. soterrar, mucho más frecuente. Frec.: enterrado 2: 0,00455; enterado [por enterrado] 1: 0,00227.

entra contr. de la loc. prep. entro a 'hasta': no quisieron antes recevir por rey a don Alfonso entra que juró a los del regno que no <era> estado consintient en la dita muert de su hermano 18.86; et el enemigo se ergulló e vitoria fuyó entra que el rey don Sancho, su fillo, recevió el regimiento del regno suyo 32.70; la primera que havía nombre Gostança dio por muller a Fredrico rey de Sicilia, el qual fu'entra de [cerca N] poco tiempo emperador de Alemania 34.13-14. Frec.: 3: 0,00682. Vid. entro.

entramos (var.: entrambos) adj. pl. 'ambos, los dos': et un cavallero de Alemanna fue entramas las batallas de Anthiochía et de Aragón 18.56 // pron. pl. 'las dos personas', referido a personas —o cosas — mencionadas o consabidas, o 
que se van a mencionar: et depués de aquesti regnoron Federichus [Froderigus $\mathrm{N}$ ] et Acenrricus et regnoron entrambos [entramos N] ensemble 3.18-19; enpués esto, el rey don Alfonso fue conpresso entre el dito rey de Inglaterra de veyerse entramos cierto día et lugar cada uno de los ditos reyes 37.67. Compuesto de la prep. entre y el adj. amos $<$ lat. AmBO, -AE, -O 'ambos, los dos juntos, uno y otro, ambos a dos' (SEGURA, 2001: 37). En arag. med. también se registra dentramos: «do auos don Guillem de Malart, \& auuestro fillyo Sancho, el mayor que uos edes veçinos de Çuera, dedias dentramos, aquella heredat que Santa Cristina ha $\&$ auer deue setiada en la Salina, termino de Çuera» (DLA A, doc. 50, de Castejón de Valdejasa, 1280; p. 75, lín. 4); «Item pronuntiamos dius las penas que si algun official de los ditos lugares fara algun tal carnal que sera indiviso o en question que aya de benir a conoxença dentramos los lugares de Bual e de Pietrafita ante que bayan a ningun judicio dius las penas» (doc. de Piedrafita de 1445; EAMJM, p. 77). Frec.: entramos 6: 0,01364; entramas 1: 0,00227; entrambos [entramos] 1: 0,00227 .

entrar v. intr. 'penetrar' (se usa con preposición en o por): Et quando venían los richos hombres, mandavalos clamar uno a uno a consello et como entravan, assi los mandava descabeçar en su cambra 20.133; Et fueron por Navarra porque el rey de Navarra ayudava al rey de Francia et entroron por Aragón por Valdossella 36.335; el compte sallió de la çelada que no le vidieron los moros et entrose en Tudela, que las puertas heran aviertas 19.37. // v. de transitividad preposicional, 'entrar, acometer, arremeter' (rige prep. contra): non pensava que los sus naturales entrassen contra él 38.251. / / v. tr. 'acometer, atacar, conquistar, penetrar en'. Et un día, él andando en derredor de la ciudad, comidiendo por do se podría entrar, vio flaco lugar en el muro forano et cabalgado sobre su cavallo con la mano dreita designando con el dedo, dixo: «por aqui se puede [podría N] entrar Huesca» 17.119. Etim.: del lat. INTRARE 'íd.' Según el DCECH (II, 644), en la Edad Media y en los clásicos la construcción era entrar en o entrar $a$ indiferentemente, mientras que hoy se ha fijado aquella en España y esta en América. En arag. med. también se registra dentrar: «Item es concordado entre los ditos concelhos que en estas tres anyadas sobreditas del anyo mil DXVIIII y de Xx y de XXI no puedan dentrar los ganados grosos ni menudos qui a Spanya iran fasta dia e fiesta de Santa Cruz de Mayo» (doc. de Sallent de 1518; EAMJM, p. 128). Igualmente, dentrar 'entrar' en arag. mod. (ANDOLZ, 1992: 150; EBA, 1999: 659). Frec.: entrar 12: 0,02728; entrado 3: 0,00682; entrando 1: 0,00227; entraré 1: 0,00227; entrarían 1: 0,00227; entraron 2: 0,00455; entraronse 1: 0,00227; entrás 1: 0,00227; entrassen 2: 0,00455; entravan 2: 0,00455; entró 11: 0,02500; entroron 4: 0,00909; entrose 1: 0,00227.

entre prep. 'entre': et yes dita Celtiberia la tierra que yes entre los montes Pyreneos et el rio d'Ebro. 1.10. Del lat. ǏNTER 'entre, en medio de'. Frec.: 60: 0,13638. 
entrellos contr. de 'entre ellos': et depués, los prelados, nobles e cavalleros et gentes populares del un regno et del otro, por tal que paz et concordia fues entrellos... 20.151. Frec.: 2: 0,00455.

entretallado] adj. 'tallado, labrado, esculpido': et soterraronlo en una muyt bella tomba sobre la qual el nombre et la vida del dito sancto era notificada et contenida con letras muyt ricament entretalladas 9.24. Compuesto de la prep. entre y el p. p. del v. tallar < lat. vulgar TALEARE 'cortar, rajar'. Frec.: 1: 0,00227.

entreveniente] p. pres. 'que sobreviene, que se interpone'; usado en forma de ablativo absoluto: Et como los prometimientos dessuso ditos, algunos accidentes entrevenientes, el dito Pasdre Santo non pudiés adozir a acabamiento... 38.160 ['habiendo intervenido o sobrevenido algunos accidentes']. Compuesto de la prep. entre y el p. de presente del v. venir. Frec.: 1: 0,00227.

entro (var.: entro a, entro ha, entra). prep. 'hasta (tanto en sentido espacial como temporal)'. A menudo forma la loc. conj. entro a que 'hasta que': no quisieron antes recevir por rey a don Alfonso entra que juró a los del regno que no <era $>$ estado consintient en la dita muert de su hermano 18.86; Et las oras fue vencido el dito rey Rodrigo por los moros et toda Espanna prendida entro Azlet de Provença [Arle de Proenica N] 3.92; Entro a CCC christianos que fueron receptarse en la terra d'Aragón, es assaber, en un monte clamado Uruel, cerca la ciudad de Jacca 4.13; vino a la ciudat de Barcelona por suplir el defallimiento del rey sobredito entro a que por si mismo pudies regir su tierra saviament e bien 33.11; et en continent, ensonmyorose del dito condado et aquél rigió et governó de la ciudat de Narbona entro en Espanna mientre vivió 23.39; Et segunt pensamiento murieron de los moros mas de XXX mil que de pie que de cavallo, de los christianos murieron entro ba en dos mill. 18.68; todos los ditos homes buenos eshyeron curador suyo don Phelip su tio, mas non lo quiso prender entro ha quende fues forçado por el Padre Santo. 38.609; el uno de los quales havia nombre Voc et el otro Felicio, et aqui sanctament et con firma fe catholica sirviendo a Dios estuvieron luengo tiempo entro que Dios los clamó al regno celestial 5.10. Etim.: del lat. INTRO 'dentro', en abreviación de la locución INTRO USQUE 'hasta dentro de’ (DCECH, s. v. entre, t. II, p. 645). También se ha propuesto la etimología INTER HOC (RohlFs, Le gascon, p. 201, entre otros). Comenta Corominas que entrò o tro es corriente en cat. y occ. antiguos; y por otra parte afirma que entro «se halla sólo en algún antiguo texto aragonés» (ibídem). Sin embargo, por lo que conocemos, es habitual en arag. med. (cfr. Alvar, DA, p. 251; Reidy Fritz, 1977: 163; Tilander, VM, III, s. v., p. 120; Tilander, FA, s. v., p. 386; Gilkison, 1984: 57; LT, Rodés, 2016: 723; VCA, pp. 160 y 407; POTTIER, ELLA, p. 145; TERRADO, 1991: 116; etc.) y constituyen excepción los textos en que no aparece, ya sea en la forma entro ya en las variantes entro a, entroa, tro $a$. Vid. el estudio lingüístico, 5.12.15 (NAGORE, 2003: 458-461). También es habitual en navarro medieval. Para el occitano, cfr. LeVY, s. v., p. 373; Alibert, s. v., p. 345; PALAY, s. v.; Rohlfs, Le Gascon, p. 201. Vid. también entra. Frec.: 50: 0,11365. 
enueyo] s. m. 'enojo, enfado': El qual por discordia que huvo con la primera muller et porque la lexó, buvo muytos enueyos et treballos 35.91. Vid. enoyo. Frec.: enueyos 1: 0,00227 .

enuntiar]: et non res menos enuntió a todo dreyto et a toda demanda 38.119. Error por renunció, que es la lectura clara del ms. B. vid. renunciar.

enuyar] v. prnl. 'enojarse, cansarse, irritarse': envió de conpannya de cavallo et de pie la qual era tal que non tenía frio nin calor nin de levar armas continuament se enuyavan et grant partida de Calabria conquirieron 36.248. Del lat. INODIARE 'inspirar asco u horror' (DEEH, p. 744; BDELC, p. 235). Cfr. enoyado, enueyo. Frec.: enuyaban 1: 0,00227 .

envestir] v. tr. 'investir', 'conferir, conceder, asignar': et envistió el conte de Valoys, fillo del rey de Francia, de todos los regnos et tierras del dito rey don Pedro 36.462. Se usa con la prep. de. Etim.: es cultismo, tomado del lat. INVESTIRE 'revestir' (BDELC, p. 604, s. v. vestir). COROMINAS documenta investir por $1 .^{a}$ vez en cast. en 1608, más de dos siglos después que este testimonio de envestir en la Crón. SJP. (vid. DCECH, V, p. 795. La voz no aparece en el glosario de cultismos que recoge Bustos Tovar (1974) en Contribución al estudio del cultismo léxico medieval. Frec.: envistió 1: 0,00227.

enviar (var.: emviar, embiar, envyar, inbiar, inviar) v. tr. 'enviar': Et aquesti infant García yera sobrino del Cit Rui Diaz et criávalo en Valencia, et yera buen cavallero, et sines voluntad de los aragoneses embiaron por aquéll 20.63-65; emviaron por licencia al Papa 20.68; emvió a rogar al rey don Pedro de Aragón que le fues a acorrer 18.97-98; et por eso concordaron todos los navarros, con consello de [...], que enviassen por el infant don García 20.56-59; le envioron menazas con palauras cubiertas quel dito sitio se levantas 36.324-325; quando lo supo, movido de grant yra, envyó por un duch sosmeso suyo clamado Abdemalit 4.25-27; en aquella ora inbiaron a Portogal por este infant 19.161; et invió XXX de cavallo e cient peones 19.33. Del lat. tardío INVIARE 'recorrer un camino', deriv. de VIA (DCECH, V, p. 798). Frec.: emviaron 1: 0,00227; emvió 1: 0,00227; enviar 1: 0,00227; enviada 1: 0,00227; enviado 2: 0,00455 ; enviaron 1: 0,00227 ; enviassen 2: 0,00455 ; enviava 2 : 0,00455; envió 24: 0,05455; enviól 1: 0,00227; envióle 1: 0,00227; enviólo 1: 0,00227 ; envioron 1: 0,00227 ; envyó 1: 0,00227 ; inbiaron 1: 0,00227 ; invió 1: 0,00227 .

envidia (var.: invidia) s. f. 'envidia': «Priégote, fillo, que tu devyes amar tu hermano, que yes savio et bueno et de honesta vida et non te faga envidia res que yo le aya dado» 35.271; movido de grant inquidat et invidia porque lur padre havía mas honrrado que a él, un día yendo el dito conte por su camino en un lugar que yes clamado Pereita sitiado entre Girona et Sant Celoni, mató el dito conte 30.13-16. Cultismo tomado del lat. INVIDIA 'íd.' (Bustos, Contribución, pp. 447-448). Frec.: envidia 1: 0,00227; invidia 1: 0,00227 . 
environar] v. tr. 'rodear, bordear, circundar, cercar, contornear': et tratemos de los godos, los quales vinieron de una isla que es clamada Estancia, la qual es enta las partes de Septentrio enta la mar quel mundo environa 2.15. Etim.: deriv. de environ 'alrededor' y éste del ant. fr. viron 'país de alrededor, inmediaciones', formado a partir del bajo lat. *VIRARE, lat. cl. vibraRe, 'hacer rodar, dar vueltas', o del galo viria 'anillo, sortija', 'bucle, rizo', 'argolla' (DAuZAT-Dubois-Mitterand, s. v. virer, pp. 794-795). Para el DCECH (V, pp. 825-828, s. v. virar) envirón 'entorno' es un compuesto con el v. virar, al que se atribuye un origen celtolatino: *VIrare, relacionado con el galés guyro 'desviarse, inclinarse a un lado'. Documentado en las obras de Fernández de Heredia (GILKIson, s. v.: environar, enuironar 'surround'). Así, en el Libro de Marco Polo: «Et todas lures villas et castiellos son muit fuertes, car todas son environadas en torno de agua muy fonda" (NitTi, 1980: p. 36, lín. 23; SANGORRín, 2016, p. 101). En otros textos aragoneses: «Et avia fecho fazer tres fuentes beillas e nobles todas environadas de piedras de jaspre e de cristal orlados d'oro» (LMM, F, 213, p. 127); «É los Philisteus supioron, que el era entrado en la dita Ciudat; van lo environar, é pusioron guardas á la puerta de la dita Ciutad» (Discurso de Martín I el Humano, 1398; vid. en Blancas, Comentarios, p. 348; ahora puede verse también en $A C R A$, t. VI, Cortes de Martín I, p. 14); Comp. environ, enuiron 'alrededor, alrededor de' en $L M M$ (LiRIA, p. 169, s. v.); ademjron 'alrededor', que procederá de ad environ, con asimilación de $n v[\mathrm{mb}]>m$, en $D L A A$ : «Assi como estas auant ditas affrontaciones ensarran edeparten ademjron las ditas casas, cassal, canpos vinyas \& huertos" (DLAA, doc. no 104, de Jaca, año 1329; p. 150, lín. 69). Se registra en virón 'en torno' en Alex. (SAS, p. 248, lo considera galicismo). En cat. environar 'envoltar' (DL/C del IEC, 2007: s. v.). En occ. environar 'environer, entourer, être autour' (Alibert, 1988: 347, s. $v$. environ). Frec.: environa 1: 0,00227.

episcopal adj. 'episcopal, que tiene obispo, relativo al obispo': et edificó aquí yglesia episcopal 32.28; et en continent hedificó yglesias episcopales 35.148. Deriv. del lat.

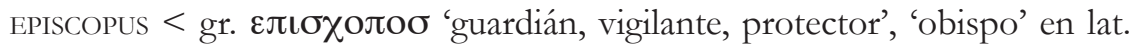
eclesiástico. Frec.: episcopal 3: 0,00682; episcopales 1: 0,00227.

ergul s. m. 'orgullo': de los quales el uno era clamado Ferrant Sanchez, el qual por potencia et por riqueza era levantado en ergul [orgul BN] 36.35-36. Etim.: del fráncico *URGOLI 'excelencia', deriv. de *URGOL 'insigne, excelente' (a. alem. ant. urguol 'íd.'). La 1. a doc. en arag., en la forma orgüello (más conforme con la fonética histórica del arag. que ergul), data de princ. del s. XIII en LR: «E fizo muitas batallas con Iudas Machabeus e con sos ermanos e priso Iherusalem; et entro en el temple con grant superbia e con grant orguello» (COOPER, 1960: 28). Para Corominas en cast. se trata de un préstamo del cat., tal como denuncia la evolución fonética (en J. Ruiz y en Juan Manuel, orgullo), pues ni la ll ni la ú son 
conformes a la fonética histórica castellana: comp. las formas de los demás romances, cat. orgull [ant. ergull, argull, s. XIII], occ. orguelh, orguolh, fr. orgueil, it. orgòglio. La comparación de estas formas revela un étimo con ŏ tónica abierta y con LI, cuyo resultado castizo en castellano habría sido *orgojo. En cambio, el orgüello aragonés del LR y el orgoioso del Alex. podrían ser autóctonas, desde un punto de vista fonético. En conclusión: «La comparación con los demás romances nos revela que el cast. orgullo hubo de tomarse del cat., único de ellos donde es normal el paso de la ŏ abierta a $u$ ante palatal: comp. $u$ ll 'ojo', cull 'coge', escull 'escollo', jull 'joyo', vull vŎLEO 'quiero', etc.» (DCECH, IV, pp. 296-297, s. v. orgullo). A tenor de lo anterior cabe considerar ergul como forma de origen catalán; mientras que serían propiamente arag. (o bien adaptadas a la fonética del arag.) formas como orgüello, ergüello o semejantes, también doc. en arag. med.: erguel en Fernández de Heredia, junto a ergull (GILKISON, s. v.); ergüello en el ms. de la Ordinación de Pedro Iv (Coronaciones), etc. Comp. en arag. mod. argüello 'orgullo' y argüelloso en el valle de Chistau (Мотт, 1984, s. v.: Мотт, 2000: 58; Blas/Romanos, 2008: 87); argüello 'orgullo, altivez' en Salas Altas (Ríos, 1997: 42; EBA, 1999: 204) y en el Somontano de Barbastro en generarl (Mostolay, 2007: 82); argullo 'orgullo' en la comarca de Huesca (NAgore, 2020: 66). Frec.: 1: 0,00227.

ergullir] v. prnl. 'enorgullecerse, crecerse en ánimo o en fuerza': et el enemigo se ergulló e vitoria fuyó entra que el rey don Sancho [Alfonso VL], su fillo, recevió el regimiento del regno suyo 32.70-71. Etim.: deriv. de ergul, orgul, posiblemente catalanismo, del cat. orgull < fráncico *URGOLI 'excelencia', deriv. de *URGOL 'insigne, excelente' (DCECH, IV, pp. 296-297). Comp. ergullar, ergullir y ergullecer en Fernández de Heredia (GILkison, s. v.); ergullecerse en el Libro de Marco Polo (NitTi, 1980: 94; SANGORRín, 2016: 210). Frec.: ergulló 1: 0,00227.

error s. f. 'error': En tiempo de aquestos recibieron la fe christiana los godos. Pero depués, por enganno et por fuerça del emperador Valient, qui era de la secta [seta $\mathrm{N}]$ arriana, tornaron ereges en la error arriana. 3.23. Es cultismo, tomado del lat. error, -oris. Frec.: 2: 0,00455.

es pron. refl. 'se': la gent de la tierra procuravase de sennor, murmuriavan et es complanyan muito et non sin razón, como non se pensaban que beredero fues fincado en la tierra. 12.15. Comp. se. Frec. 1: 0,00227.

escabeçar] v. tr. 'decapitar': Et a cabo de algunos días, vinieron al dito reyt mesageros de Secilia los quales le recontaron en qual manera havía estado vencido el rey $\langle$ de $>$ Seçilia Corrandi et en qué manera era estado escabeçado en Palermo por el rey Carlos cruelment 36.187; pero clamava aquellos que le yeran culpables, de guisa que XIII richos hombres et otros cavalleros escabeçó ante que comies 20.136. Deriv. de cabeça. Comp. en un texto de Teruel de 1348: «Senblantment prendieron a Johan Roiz de Corella et a Johan Salla et a otras personas onradas, de los cuales algunos 
fueron escabezados et otros esquarterados» (Crónicas de los Jueces de Teruel; LÓPEZ RAJADEL, 1994: 164). Comp. descabeçar. Frec.: escabeçado 1: 0,00227; escabeçó 1: 0,00227.

escalera] s. f. 'escalera': Et con escaleras puyoron en la partida que fincada era 36.342. Deriv. de escala < lat. SCALA 'escalón', 'escalera' (DCECH, II, p. 665). Frec.: escaleras 1: 0,00227.

escándalo] s. m. 'escándalo': Et aquesta fue la primera unión que aragoneses començoron, por la qual cosa muytos escándalos et malos sende siguieron 36.676. Tomado del lat.

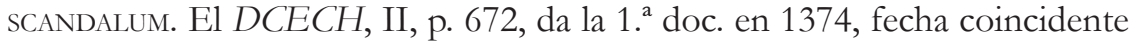
con la de la Crón. SJP. Frec.: escándalos 1: 0,00227.

escapar v. intr. 'escapar': Et aquesti conte don García embió a dezir al rey don Pedro que se levantas del sitio et si no quel ni christiano ninguno non escamparía (es la lectura que hace la ed. crítica, pero en el ms. la $m$ está tachada) 18.23; los christianos qui de la batalla o persequición podieron escapar, se derramaron et fueron enta las fuerças de las montannyas de Sobrarbe, de Ribargorza, de Aragón... 4.2; que lo avian allá foydo en tiempo que escapó de la batalla 19.164; et murió y de grant multitut de gent de franceses et todos con él se las aduxo a Barcbinona et et ninguna persona non de scapó 36.544. Del lat. vg. *eXcappare 'salirse de un estorbo', deriv. de cappa (DCECH, II, p. 674). Frec.: escapar 2: 0,00455; escapó 4: 0,00909; escamparía [escamparía] 1: 0,00227; scapó 1: 0,00227 .

escarlata adj. o sust. 'tela de color carmesí, o el propio color carmesí: Estonz el compte Pero Ansures, desque avie rendido la tierra a la reyna su seynora natural, fuese para el enperador de Aragón e paresciole ant'él vestido d'escarlata en un cavallo blanco 19.84. Etim.: Del ár. hispánico iskirlâta 'tela de color carmesí' < ár. siqirlât

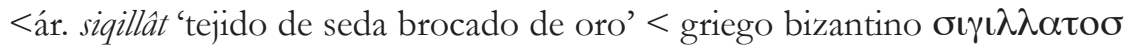
$<$ lat. (TEXTUM) sigillatum 'paño marcado' (BDELC, s. v. escarlata; DCECH, II, 683). Corriente (2003: 289, s. v. ciclatão) da la misma etimología: lat. siggillatum > (probablemente a través del bajo griego) neoár. siqlatun, pero escarlata procedería de una forma intermedia, ár. andalusí iskarláta. Del mismo origen, cita el arag. escalrata '(cierta tela) de color grana'. Moneva (2004 [1924]: 206) registra escalrata 'escarlata' en Blesa (Teruel). ELIA / (p. 146, núm. 555) se registra escarlata en doc. de 1362. Frec.: 1: 0,00227.

escolt (var.: escol, scol) s. m. 'escuadra, armada': partió del Alcoy con todo su escolt [estolt B] 36.215; valliement et spierta con las sus galeras firió en el escol [estolt B] francés, 36.549; et fue presso el almirant del dito scol [stol B], 36.551. En los ocho casos en que aparece este vocablo el ms. B dice estolt, excepto en 36.551 en que dice stol. Y estolt es la lectura que da XIMÉNEZ DE EMBÚN en su edición. La forma con $c$ es errónea y surge simplemente de una confusión de $t$ por $c$, muy parecidas en la escritura del siglo xiv. Comp. cat. ant. estol 'conjunt de naus' (DCVB, s. v., t. 5, p. 568); occ. (prov.) ant. estol 'flotte; troupe, bande' 
(Levy, s. v.). En Fernández de Heredia estol, estoll, stol (Gilkison, s. v.). Véase, por ejemplo: «non seran suffiçientes a guardar lur çiudat et a resistir al stol vuestro et fuerça marina» (Tucídides, $25 \mathrm{v}^{\mathrm{o}}$, a; López Molina, p. 89; véase ahora temién en Álvarez Rodríguez, 2007, p. 57). Proviene del lat. tardío sTolus, tomado del griego $\sigma \tau 0 \lambda$ os 'flota, escuadra', 'ejército'. En cat. se documenta ya en el siglo XIII, en la Crón. de Jaime I (vid. DECLIC, III, p. 783). Parece evidente que en arag. es un catalanismo, como otros términos del léxico marítimo. Vid. estolt. Frec.: escolt (estolt) 6: 0,01364; escol (estol) 1: 0,00227; scol (stol) 1: 0,00227.

escomengamiento s. m. 'excomunión': por manifestar la paz et tirar el escomengamiento [escomulgamiento N] de las yglesias et tierras 38.84. Parece un error por escomulgamiento, aunque también podría tratarse de una variante fonética, pues a partir del lat. EX-COMUNICARE, se explica escomungar y el cambio $u>$ $e$, si bien es raro, no deja de ser en una sílaba átona, donde el vocalismo es siempre muy inestable. Vid. escomulgamiento. Frec.: 1: 0,00227.

escomulgamiento s. m. 'excomunión': qui con él eran en toda la tierra del su escomulgamiento en que estavan 38.108. Deriv. de escomulgar < lat. EX-COMUNICARE, con sufijo -miento < lat. -MENTUM, que forma sustantivos procedentes de verbos e indica resultado de una acción. Es forma habitual en arag. med.: «los traspasadores envadidores conselleros contradizientes en contrario vinientes qualesquier singularment scomulgamiento en las universidades siquier cort sobredita, sentencia de enterdicto en aquestos scriptos damos e encara promulgamos» (Fueros de 1265 a 1381; BerguA, 1949-50, p. 536, lín. 1.325). Frec.: 1: 0,00227.

esconder] v. prnal. 'esconder(se)': Mas un cavallero clamado Villar, estarrado de las partidas de Carcasona, el qual avía estado por grant tiempo escondido en Catalunnya, escondidament furtó los ditos fillos del rey de Mallorquas 36.420; Et en la ora de su muert sallió el ladrón de su cueva et el rovador se demostró et el pobre se escondió e la clerizia calló e los lavradores fueron rovados 32.69. Del lat. ABSCONDERE 'id.'. Frec.: escondido 1: 0,00227; escondió 1: 0,00227.

escondidament adv. 'ocultamente': escondidament furtó los ditos fillos del rey de Mallorquas et levoseles a su poder 36.420. Frec.: 3: 0,00682.

escripto (var.: scripto) s. m. 'escrito': la qual avinienca concordada et en escripto perpetua memoria metida publicoron 20.167; porque assí como lo trobamos assin en scripto lo significamos 26.9. Frec.: escripto 1: 0,00227; scripto 1: 0,00227.

escudero s. m. 'escudero': el primero que puyó el muro de Ubeda fue un escudero de don Lop Ferrench de Luna 34.94. Deriv. de escudo < lat. Scutum 'escudo'. Frec.: 1: 0,00227 .

escuitar] v. tr. 'escuchar': Et por aquesto que podamos mellor tratar e mas verdaderament e breu, por tal que sia mas plazient de leyr ad aquéllos que la leyeran et a los qui lo 
escuitaran, porque luenga paraula [palavra N] engendra enoyo en leyr et en oyr 2.34. Del lat vg. *ascultare, lat. auscultare (DCECH, II, p. 713). Es forma habitual en arag. de la Edad Media. Arag. mod. escuitar, ascuitar (ANDolz, s. v.; Rohlfs, DDPA, s. v.; BadíA, Contribución, s. v.; KuHn, HAD, p. 19; etc.). El EBA (1999: 794) registra escuitar en Ansó, Aragüés de lo Puerto, Ayerbe, Biello Sobrarbe, Chasa, Echo. Los datos de Chasa [Jasa] provienen de GIL BERGÉs (1916), quien anota: «algunos ancianos dicen ascuitan». También se registra ascuitar en Echo (EBA, 1999: 220). Frec.: escuitarán 1: 0,00227.

escusa s. f. 'excusa, pretexto': veyendo don Alfonso la mala carrera que la reyna tenía, metiendo escusa que parientes heran que no querían vivir en peccado, fue con ella fasta Soria et allí rendióla a los castellanos 19.65-68. Deriv. deverbal de escusar. Frec.: 1: 0,00227 .

escusación s. f. 'excepción jurídica': el qual fue desposeydo por escusación de justica de su regno et tierras 38.594-595. Es cultismo tomado del lat. EXCUSATIO, -ONIS 'disculpa, justificación, pretexto, exención' (SEgura, 2001: 263). Comp. excusatión 'excepción jurídica’ en $V M$ (TILANDER, $V M$, III, p. 131). En $V M$ se usa mucho más frecuentemente el término exceptión. El DRAE (1970) registra como $3^{\text {a }}$ acepción de excepción: 'título o motivo jurídico que el demandado alega para hacer ineficaz la acción del demandante’. Frec.: 1: 0,00227.

escusar v. tr. 'excusar', 'evitar': ni escusándolo en el acto que estava, de continent dizieron que non podían entrar a verlo, que ocupado era de afferes 20.32; et finalment fizo diffinir que ella se havies a escusar por batalla, si no que sería judgada a meter en el fuego 14.6364; y el dito noble conte de muitos treballos en el regno lo escusava 20.296; mas Dios que provedeçe a los negocios et males, escusó que no fues la dita guerra 20.241-242; El el dito rey, queriendo que millor fues escussado si als se esdevenía, envió sus mesageros al Padre Santo 34.134. Del lat. Excusare 'excusar, disculpar' (SEgura, 2001: 263). Comp. it. scusare, fr. excuser, port. escusar. En cast., según el DCECH (I, 47, s. v. acusar), escusar, con esta grafía, es frecuente en la Edad Media (desde Aut., 1732 con $-x-$ ), con las acepciones de 'salvar' y 'evitar'. En arag. med. escusar 'exentar, eximir, dispensar' y 'evitar' (TILANDER, VM, Voc., p. 124). En arag. mod. es usual con la acepción de 'ahorrar' (ANDOLZ, 1992: 191; EBA, 1999: 797) y también de 'evitar' (NAGORE, 2020: 284). Frec.: escusar 1: 0,00227; escusava 1: 0,00227; escusó 1: 0,00227; escussado 1: 0,00227.

escuvrir] v. r. 'descubrir': et porque el compte don Pedro yva ya escuvriendo la su mala obra con la reyna cuydando casar con ella... 19.158. Deriv. de cubrir < lat. COOPERIRE, con prefijo es- que aporta la idea de 'abrir, quitar, sacar, privar' respecto de la base de derivación (NAGore, 1989: 320). En arag. mod. escubrir (Andolz, 1992: 190). Frec.: escuvriendo 1: 0,00227.

esdevenir v. intr. 'ocurrir, suceder, acaecer': Et el dito rey, queriendo que millor fues escussado si als se esdevenía [si a el esdevenía $\mathrm{N}$ ] envió sus mesageros al Padre Santo sobre 
Los deseredamientos de las hermanas 34.134; et esdevinose que en una batalla fray Pere de Moncada, maestro [maestre $\mathrm{N}$ ] de la orden de la cavallería del Temple en Spannya, fue presso en la dita batalla 36.55-57; et recontoron [recontando N] a Frederich assí [todo $\mathrm{N}]$ como les avía esdevenido 38.143-144. Deriv. de venir < lat. VENIRE. Es común en arag. medieval., por ej., en las obras de Fernández de Heredia (GILKISON, s. v. esdenenir); en el arag. del s. XV: esdenenir 'ocurrir, suceder, producirse' (VCA, p. 165). Siesso de Bolea (2008: 156, s. v.) reproduce un refrán de los Comentarios de G. de Blancas: «E los que no son malos de su natura, mas los esdeviene alguna desventura». Frec.: esdevenir 2: 0,00455; esdevenía 1: 0,00227; esdevenido 3: 0,00682; esdevino 1: 0,00455 ; esdevinose 4: 0,00909 .

esforçadament adv. 'esforzadamente, con esfuerzo, con ánimo': Los secilianos, sabiendo aquesto, induyeron et animoron el rey Federich que esforçadament le deffendiessen [los defendies $\mathrm{N}$ ] el regno, 38.241. Frec.: 1: 0,00227.

esforçado adj. 'valiente, animoso, de fuerte espíritu': este don Sancho Remirez, seyendo en edat de XVIII annos según dito es quando empeçó [començó $\mathrm{N}$ ] de regnar, fue muyt esforçado et de grant valor 17.25. Frec.: 1: 0,00227.

esforçar] v. prnl. 'esforzarse, hacer esfuerzos para conseguir algún fin': Et por aquesto, el dito rey se esforçó quel casamiento dél et de su muller se departiesse 34.62. Deriv. de fuerça < lat. FORTIA. Frec.: esforçó 1: 0,00227.

esfuerço s. m. 'esfuerzo': Et avía otras fillos et fillos sines de aquestos; de dona Teresa Gil de Bidaure, noble duennya, havie a Jayme de Exerica et a Pedro de Ayerbe, et fueron legítimos, que la madre provó aquello con grant esfuerço 35.79. Deriv. postverbal de esforçar. Frec.: 1: 0,00227.

esgoart s. m. 'vista, visión, mirada'; fig. 'miramiento, atención, respeto, consideración, deferencia': le suplicó que por honor de Dios e de la santidat del dito lugar e por piedat de lur pobreza e por esgoart del su nuevo avenimiento, le plazies enrriqueger el dito monesterio de algunas honores 11.23. En Fernández de Heredia: esguart, esguat, esguardo 'appearance, sight' ['aparición; apariencia'; 'vista, visión'] (GILKISON, s. v.); sguart 'mirada, apariencia, imagen personal' en el LT (RodÉs, 2016: 769); esguart ‘consideración, atención' en arag. del s. xv (VCA, p. 166); esguart 'consideración' en el arag. de Teruel del s. Xv (Terrado, 1991: 260). Es postverbal de esguardar. Comp. cat. esguard 'mirada'; 'aspecto'; 'atención, consideración' (DCVB, s. v.); it. sguardo 'mirada', attirare gli sguardi 'llamar la atención' (SAÑÉ \& SCHEPESI, p. 504). En arag. ant. también esguardamiento 'atención, cuidado' (Tilander, FA, p. 393). Frec.: 1: 0,00227.

esguardar] v. tr. 'mirar, observar': en continent passó por la dita val un noble varón de la montanyas d'Aragón et, esguardant la terrible mortaldad qui aqui era de christianos, vido por la feridura que la dita reyna avía en el vientre aparecía una mano de criatura 12.7. Etim.: deriv. de guardar, del lat. altomedieval GUARDARE, y éste del franco 
WARDON 'estar en guardia' (comp. alemán warten 'esperar, aguardar' (DEVOTO, s. v. guardare, p. 197; DECLIC, IV, pp. 698-701). Como en cat. esguardar 'mirar' y 'considerar, tenir en compte' (FABra, Dicc., s. v.; DL/C del IEC, 2007, s. v.). Comp. fr. regarder, it. guardare, sguardare 'mirar'. En Fernández de Heredia esguardar 'observar' (GILKISON, s. v.); sguardar 'mirar, vigilar' en el LT (RoDÉs, 2016: 769); esguardar 'considerar, atender' en arag. del s. XV (VCA, p. 166). Véase un ejemplo de esguardantes, p. pres. de esguardar 'que tienen en consideración': «Et encara nos ditos procuradores de Anso \& su vall \& de la beçiau de Borssa todos concordantes en vna et reconoxientes, considerantes \& esguardantes que los hommes de Anso \& su vall solian hauer \& han leyna de la selua deSpelunguera...» (DLA A , doc. n. ${ }^{\circ}$ 126, de Ansó, 1370; p. 183, lín. 32). En arag. mod. guardar 'observar, prevenir': «guarda que no te pille l'amo en ixa demba» (Somontano; Mostolay, 2007: 324); guarda! '¡mira!, ¡date cuenta!': «guarda si yeran caros» (Bal de Chistau; BLAs/Romanos, 2008: 320). Frec.: esguardant 1: 0,00227.

esleir v. tr. 'elegir': los ditos godos no quisieron esleir rey, antes se sozmetieron a la sennoria del imperio de Roma 3.25; fueron çercando a qui esleyrian por sennor lur et defendedor 10.5; et todos ensemble concordoron et eslieron [esleyeron $\mathrm{N}$ ] en rey et sennor lur al dito Frederich 38.146; por aquesto, todos los ditos homes buenos eslyeron curador suyo don Phelip su tio 38.608. Del lat. ELIGERE 'sacar, escoger', con confusión de la vocal inicial con el prefijo es- (DCECH, II, p. 551). En arag. med. esleir 'elegir, escoger' (TILANDER, VM, Voc., p. 125); esleysen 'eligieran' en unas ordenanzas del s. XiII del Conzello de Uesca (Fernández Ferreres, 2020: 135); esleir 'elegir, escoger' en arag. del s. XV (VCA, p. 166; Terrado, 1991: 260); esleyr 'escoger' lo registra ya Blancas (Índice, 1641). Frec.: esleir 1: 0,00227; esleydo 4: 0,00909; esleyeron 1: 0,00227; esleyessen 1: 0,00227; esleyr 2: 0,00455; esleyrian 1: 0,00227; esliamos 2: 0,00455; eslieron 6: 0,01364; eslyeron 1: 0,00227.

esmagamiento s. m. 'desaliento, desánimo, desgana'; 'desfallecimiento, desmayo, decaimiento': et por aquesti tan grant vencimiento, los francesses buvieron grant esmagamiento et grant duelo 36.554. XiménEZ dE EMBún, Vocabulario, traduce 'aflicción'. Etim.: deriv. de esmagar, del lat. vg. *EXMAGARE 'quitar las fuerzas', deriv. del germánico MAGAN 'tener fuerzas, poder'. Comp. occ. ant. esmagar 's'inquiéter, se bouleverser, perdre courage', 'se désoler, se lamenter' (LEVY, s. v.); cat. ant. esmagat 'desanimado'; it. ant. smagare 'confundir, perturbar, desconcertar', port. y gallego esmagar 'afligir, abatir', 'aplastar' (DCECH, II, p. 468 Devoto, p. 396, s. v.). Comp. esmagado 'desanimado': «mucho eran esmagados» en el Libro de Alexandre (SAS, Vocabulario del libro de Alexandre, s. v., p. 257). En el LMM esmagarse 'afligirse, turbarse' (LiRiA, p. 170). En Fernández de Heredia smaguar 'asustarse, acobardarse' (Tucídides, López 
MolinA, p. 221); también se registran las variantes esmagar, desmagar, esmayar, asmagar, smayar, desmayar (GILKIsON, s. v.). Frec.: 1: 0,00227.

esmarrido] part. adj. 'afligido, amedrentado, aterrorizado, desesperado, acongojado, despavorido; desconcertado, asustado': Tantost como fue venido con las sus gents, fue esmarrida muito la gent de la dita ciudat 32.21-23 [d'on fo espaordida molt la gent de la dita ciudat VC, p.102; tanta tristitia tantusque terror gentes civitatis invasit, quod eam demem adquisivit VL, p. 122]. XIMÉNEZ DE EMBÚN, Vocabulario, traduce 'acobardada, temerosa'. Etim.: deriv. del lat. vg. * *ARRIRE $<$ germánico occidental MARRJAN 'perturbar' (Devoto, s. v. smarrire). La misma etim. da AliberT para el occitano y el DECLIC (V, p. 501) para el catalán; PRobert concreta que MARRJAN es fráncico, igual que MEYER-LÜBKE (REW, 5373). El DCVB considera que el cat. esmarrit se ha tomado del it. smarrito. Igualmente, CunHa (1986: 320) afirma que en portugués el adj. esmarrido 'seco, resequido, desanimado' proviene del it. smarrire. Comp. occ. esmarrir 's'affliger, se désesperer'; marrimen 'aflicción, tristeza'; marrir 'affliger, attrister' (Levy, s. v., p. 168; Alibert, s. v. marrir, p. 483); cat. esmarriment 'tristeza, congoja', esmarrit 'triste acongojado' (DCV B, t. 5, p. 359); fr. ant. marrir 'affliger' (PRobert, p. 1158); it. smarrire 'perderse, extraviarse'; sardo marriu 'flaco, enjuto, delgado, miserable' (cfr. REW, 5373); cast. ant. esmarrido 'abatido, triste' (DME, s. v., VMC, s. v.) 'triste, entristecido' (SAS, Vocabulario del Libro de Alexandre, s. v., p. 257). En arag. ant.: smarimiento [sic] 'aflicción, consternación' en Fernández de Heredia, pero es palabra rara, pues solo se registra en una obra, Secreto Secretorum (GILkISON, s. v.). En cat. ant. también marrir 'afligir', marrit 'afligido', marriment 'aflicción' (DECLIC, V, pp. 500502). Frec.: esmarrida 1: 0,00227.

esmeraldes s. m.? 'esmeraldas': et ornó el altar mayor del dito monesterio et de esmeraldes et safires, robices et carboneles et otras piedras preciosas. 28.21-22. Etim.: del lat. vulgar *smaraudus, lat. cl. smaragdus < gr. smáragdos (Devoto, para el it. smeraldo, s. v.). El DCECH (II, p. 729) da también como etim. el lat. sMARAGDus, indicando que podía ser masculino o femenino. Frec.: 1: 0,00227.

esmient s. m. 'conocimiento, noticia; mención'; 'memoria, recuerdo'; en la locución haver esmient 'tener memoria, tener conocimiento o noticia de algo': E pues de aquesto, bavemos esmient [ymient $\mathrm{N}$ ] es verdad que dentro el condado [en el regnado N] de Castiella era sitiado un condado clamado Porcel [Portell N] 14.7. [e pus d'aço havem esment... VC, p. 51]. Etim.: del lat. EX MENTE, en frases latinas como PRENDERE EX MENTE, HABERE EX MENTE, literalmente 'obtener una cosa de la mente, conseguirla poniendo atención mental' (DECLIC, V, pp. 583-584, s. v. ment). La palabra está relacionada con el cast. miente o mientes < lat. MENS, MENTIS, utilizado sobre todo en frases como venir en miente, tener mientes, parar mientes, etc. (DCECH, IV, p. 41). Y especialmente con el cat. esment 'cuidado, 
atención', 'recuerdo, memoria', 'mención', 'conocimiento de un hecho' (DCVB, s. v., t. 5, p. 360; FABRA, DGLIC, s. v.; DL/C del IEC, 2007, s. v.). Según FABRA se usa en las locuciones haver esment d'alguna cosa 'venir ésta a conocimiento nuestro', tenir esment d'alguna cosa 'tener noticia de ello', etc.; el DL/C cita también fer esment, posar esment, prendre's esment, venir a esment. Según el $D C V B$ (t. 5, p. 360) el cat. esment sería deriv. postverbal de esmentar 'mentar, mencionar, recordar', que procede del lat. vg. *EX-MENTARE, deriv. de MENS 'mente'. MEYER-LÜBKE (REW, 5505) da el lat. MENTARE como etim. del cast. mentar y del cat. esmentar. Pero según COROMINAs el lat. MENTARE no ha existido nunca; lo primitivo fue esment (doc. en cat. a principios del s. XIV), de donde se formaría el verbo derivado esmentar (doc. a mediados del s. XV). Se utilizó en locuciones como prendre esment $<$ lat. PRENDERE EX MENTE, haver esment $<$ HABERE EX MENTE y otras parecidas como tenir esment, parar esment, fer esment (DECLIC, V, pp. 583-584, s. v. ment). Frec.: 1: 0,00227.

eso mismo loc. adv. 'igualmente, asimismo': Otrossí un otro compte don Pero de Lara puniava encuvierto de aver amor de la reyna et eso mismo acavó lo que quiso 19.107-108. Etim.: del lat. IPSU(M) MET-IPSI-(SSI)-MU(M) (lat. vg. *MEDIPSIMU) (DCECH, II, p. 723; MGHE, p. 259). Se documenta esso mesmo 'igualmente' en el Testamento de Carlos iII de Navarra (Saralegui, Testamento, p. 97). Véase también con el mismo sentido en Nebrija: «Porque en comienço de la palabra suenan dobladas o apretadas, como diziendo: rei, Roma, sabio, señor. Esso mesmo en medio de la palabra suenan mucho, si la sílaba precedente acaba en consonante e la siguiente comiença en una dellas...» (NeBrija, Orthografía, 1517, cap. v. Cit. por A. Alonso, De la pronunciación..., II, p. 14). Comp. exo. Frec.: 1: 0,00227.

espada s. f. 'espada': un cavallero francés ahontadament posó la mano en la barba del dito conte et el dito conte, de gran ira movido, sacó la espada et mató el dito cavallero. 22.14; «Fillo mio, yo livro [yo te livro N] la mi spada en sennyal de dreytura con la qual tu departescas mal de bien» 35.261. Del lat. SPATHA 'pala del tejedor', 'espátula' 'espada larga y ancha' (SEGURA, 2001: 723). Frec.: 3: 0,00682.

espanto s. m. 'espanto, terror': et partiendo de aqui <con> grant espanto, tornose a su tierra con gran honor 33.73. Es postverbal de espantar < lat. vg. *EXPAVENTARE 'íd.' (DCECH, II, p. 734). Frec.: 1: 0,00227.

espelunca (var.: espellunga, spelunca) s. f. 'cueva, gruta': En aqueste tiempo, un sancto hombre clamado Johan, heremita, habitava en una espelunca de ius una grant penya 5.1-2; todos los christianos avian grant devoción en aquesta spelunca 5.17; et fuyendo los christianos de los lugares do habitavan, por la dita terribilidad et crueldad, recullieronse en la espellunga assín como a lur refugio singular 9.13. Etim.: lat. SPELUNCA 'caverna, gruta, cueva'. CoROMINAs documenta la voz por 1. ${ }^{\text {a vez }}$ en cast., como cultismo, h. 1600 (DCECH, II, p. 740). La Crón. SJP adelanta la $1 .^{\text {a }}$ doc. en más de dos siglos. En arag. podría considerarse descendiente 
popular. Hoy se conserva en arag. mod.: espelunga en Ansó y Echo (KuHN, HAD, p. 71; Andolz, s. v.; RoHLFs, DDPA, s. v.; etc.); también espelunga 'cueva' en Panticosa (Mur, 2014: 31); espelunga 'cueva, caverna' en Ansó, Echo, A Fueba y Pirineo en general (EBA, 1999: 833). Además, es frecuente en toponimia: Espelungueta, en Jaca; Esplunga, en Biescas y en Yésero ( $D A$, p. 186); Espelunga y Espelungueta en Escarrilla, Valle de Tena (KuHn, HAD, p. 71); en el valle de Tena se documenta Espelunziecha, Espelunga, Espelungo, Espelungueta, Espelunguiacha, Espelunguiachas, Espeluniachas, Espluca, Espluga (Guillén, 1981: 182). La variante espluca se registra en Fanlo, Bielsa (RoHLFs, DDPA, s. v., p. 131); espluga, en Bal de Chistau, Biello Sobrarbe, A Espuña (EBA, 1999: 841). ElcOCK, De quelques affinités, p. 93, documenta espluca en Torla, Buesa, Fanlo, Sercué y Bielsa. Para esta última forma habría que partir de una etimología *speluca citada por Meyer-LÜBKe (REW, 8140). En el arag. de Fernández de Heredia: espelunca, spelunga (GILKIsON, s. v.). También en el LT: spelunca 'cave' (PRINCE, 1995: 224). En los DLAA, spluca: «Item .I. canpo alaspluca, que afruanta en canpo del seynor rey" (doc. de Torruellola de la Plana, 1309; DLAA, doc. nº 92, p. 132); y esplunga: «Encara que sobre nuyt dagua o fortuna de tienpo puedan jazer en las esplungas de las ditas penas, sien de ninguna pena» (doc. de Sardas de 1344; DLAA, doc. no 112, p. 162). Igualmente se registra como top. el deriv. Espelunguera: «han leyna de la selua deSpelunguera pora sus cabanyas de Agua Tuerta \& de Cauedallo» (DLAA, doc. 126, de Ansó, 1370; p. 183, lín. 33). Frec.: espelunca 2: 0,00455; espellunga 1: 0,00227; spelunca 1: 0,00227.

esperar] (var.: sperar) v. tr. 'esperar': et esperando hora convinent, firió vigorosament en la buest 33.85; et depués quel le ganaría el dito Imperio a mession de la Yglesia, el qual se sperava et pertannya [prometía N] I. 38.156. Del lat. SPERARE. Frec.: esperando 2: 0,00455 ; sperava 1: 0,00227 .

espesseza s. f. 'espesura': por tal como havía grant espesseza de cabellos a la cabeça fue clamado Cap de Estopa. 30.4. Deriv. de espesso < lat. SPIssus 'apretado, compacto, espeso' (DCECH, II, p. 742), con el sufijo -eza < lat. -ITIA, que forma sustantivos que indican cualidad derivados de adjetivos (PHARIES, 2002: 248). En el arag. de Fernández de Heredia se registra espeso, spesso y espessura, espesura, pero no espesseza. Igualmente, en el LT: speso, spesso, espeso, espesso y spesura (RodÉs, 2016: 724 y 772). En el VM, espessamiento (Tilander, VM, Voc., s. v., p. 126). Frec.: 1: 0,00227.

espierto adj. 'experto', 'despierto, sagaz, hábil, vivo, diligente' (parece que ambos significados se mezclan): ajuntó grant gent así de cavallo como de pie e muy vigorosament et espierto veno a la ciudat de Tolosa 33.64 [debería ser espierta, ya que funciona como adv. y este se forma sobre el adj. femenino; no se repite el sufjo -ment, pues en arag., cuando aparecen dos adverbios en -ment seguidos, 
solo se coloca esta terminación en el primero]; et aquesti empero rey Sancho Avarcha havía vassallos buenos et bien espiertos et coraznudos [corajosos $\mathrm{N}$ ] de haver batallas et guerras contra los enemigos 12.63; et, assi como valient et spierto batallador, valliement et spierta con las sus galeras firió en el escol [estolt B] francés 36.547; et prendió con él el noble don Remón d'Anglarola et Guillen de Jossa et Arnalt de Crabera con muytos de otros cavalleros et gentes de pie muy valerosas et espiertos en armas et metiósse en la dita establida. 36.533. Del lat. EXPERTus 'que tiene experiencia', participio de EXPERIRI 'experimentar' (BDELC, p. 263; DCECH, t. II, p. 825, s. $v$. experiencia). En general, en las lenguas romances se confundió el lat. vg. EXPERTUS 'despertado, despierto' (contracción de EXPERGITUS 'despierto') con el clásico EXPERTus, participio de EXPERIRI 'experimentar'. Comp. el suditaliano spierto 'intelligente, pratico, ramingo' (DCECH, t. II, p. 477, s. v. despierto). Comp. arag. med. spierto 'despierto', spiertament 'diligentemente' en el LT (RoDÉs, 2016: 772). El DCECH documenta experto por vez primera en 1438. Frec.: espierto 2: 0,00455; espiertos 1: 0,00227; spierta 1: 0.00227 ; spierto 1: 0,00227; spiertos 1: 0,00227.

esposa s. f. 'esposa': envió sus mesageros solempnes en Francia por adozir la dita filla del conte de Flandres esposa suya en Barchinona 23.47. Del lat. SPONSA 'prometida, futura esposa' (BLÁNQUEZ, s. v.). Frec.: 1: 0,00227.

esposado] p. p. 'casado': et depués prisso por muller la filla de don Ferrando, rey de Castiella, clamada Alionor, la qual era esposada con su bermano el infant don Jayme 39.9-11; envió al rey de Castiella su filla, la qual avía sposada [esposado e dado N] por muller, según que dessuso avemos dito, con convinient honor mas non real 38.166; et avie letras del rey de Inglaterra que yera quasi su padre, que era sposado con su filla 37.64. Es p. p. de esposar 'casarse, contraer matrimonio', del lat. SPONSARE 'prometer', 'prometer en matrimonio', 'contraer esponsales' (BLÁNQUEZ, p. 1479, s. v. sponso), o formación derivada sobre esposo < lat. SPONsus 'prometido' (DCECH, II, p. 752). Frec.: esposada 1: 0,00227; sposada [esposado] 1: 0,00227; sposado 1: 0,00227.

esquinçar] v. prnl. 'rasgarse, desgarrarse; cortarse, partirse (las vestiduras)': Onde como los ditos mesageros de Secilia oviessen oydo tan estrannyo mandamiento, de grant yra movidos delant éll, todos se esquinçoron [se espeçaron las vestiduras $\mathrm{N}$ ] et dixieron muytas et inhonestas et non dizientes palavras 38.123 -38.127. Etim.: del lat. vg. *EXQUINTIARE 'hacer quintas partes, partir', ant. prov. esquinsar 'partir', cast. esquinzar 'partir', cat. esquinsar 'rasgar' (GARCIA DE DIEGO, DEEH, p. 659 , s. v. exquintiare). Este autor relaciona también con la misma base etimológica ribag. esbinsarse, cast. desguince, esguince, etc., pero esbinsar, arag. esbinzar 'herniar', provienen de binza 'película, telilla', más prefijo es-. Ahora bien, para el cast., el DLE (2014) registra esquinzar, que da como sinónimo de desguinzar 'cortar el trapo con el desguince' (para desguince da el significado 
de 'cuchillo con que se corta el trapo en el molino de papel'. El DCVB, t. 5, p. 479, da para el cat. esquinçar' rompre, separar les parts d'una cosa estirantla' (cast. rasgar 'desgarrar') y la misma etim. lat. *EXQuintiare (propuesta ya por MeYer-LÜBKE, REW, 3063). También Coromines propone idéntica etimología, lat. vg. *ESQUINTIARE, deriv. de QUINTUS 'quinto', para el cat. y el occ. esquinçar (DECLIC, III, p. 702; DCECH, II, 726), si bien indica que el cast. esguince "parece ser catalanismo". En arag. med. se documenta esquinçar con el mismo significado en Fernández de Heredia (GILKIson, s. v.). Frec.: esquinçoron 1: 0,00227.

esquivar v. tr. 'esquivar, evitar, eludir': empero por esquivar vergonna et desonor que lende podría seguir, como millor pudo, cubrió celadament el prennado de su filla 23.13. Deriv. de esquivo, y éste del gótico *SKIUHS 'tímido', 'asustadizo', 'desbocado' (DCECH, II, p. 763). Según el DRAE (1970, s. v.), esquivar procedería directamente del verbo germánico skiUHAN 'tener miedo', pero el DLE (2014) matiza y dice que deriva de esquivo 'desdeñoso, áspero, huraño', el cual proviene «quizá del gót. * *kiuhs». Frec.: 3: 0,00682.

establescer] v. tr. 'establecer': et establescieron hi monesterio et constituyeron hi abad por nombre Traufirico 9.31. Deriv. de establir. Frec.: establescieron 1: 0,00227.

establida (var.: stablida): s. f. 'posición fuerte, establecimiento militar bien fortificado y defendido'; 'destacamento militar establecido en un determinado lugar: et prendió con él el noble don Remón d'Anglarola et Guillen de Jossa et Arnalt de Crabera con muytos de otros cavalleros et gentes de pie muy valerosas et espiertos en armas et metiósse en la dita establida. 36.533; Los de la stablida yxieron de la ciudat con todo lo que levar quisieron et livroron aquella a los franceses 36.613; empero fue enpresso entre los franceses qui eran en la stablida fincados et el rey lur, que si dentro tiempo cierto non les podía aver acorrido de viandas et de otra ayuda que pudiessen la ciudat livrar a don Alfonso 36.682-683; qui era enstablido en el dito castiello 34.111. (Esta última forma de la ed. crítica es muy posiblemente un error de lectura, ya que en el ms. B, fol 48v, lin. 20, se lee: qui era en stablida en el dito castiello). Etim.: procede de una sustantivación del p. p. de establir 'establecer'. Frec.: establida 4: 0,00909; stablida 4: 0,00909.

establir] (var.: stablir) v. tr. 'establecer': más aqui non podieron entrar porque el dito lugar era bien establido et toda la frontera de aquél de muyt buen batallero assí de cavallo como de pie 36.519; et con consello de los quales el dito barón establió por si mismo dreytos, qui son agora clamados Usages 29.11; confussos, vencidos et consumados los franceses, la ciudat de Girona fincó stablida de la gent francessa 36.681-82. Etim.: deriv. de estable, del lat. STABILIS 'íd.' (DCECH, II, p. 776). Frec.: establido 2: 0,00455; establió 2: 0,00455; stablido 1: 0,00227; stablida 1: 0,00227.

estajado (var.: estaja) s. f. 'residencia', 'estancia, habitáculo, sitio donde se está: Et cada uno de los ditos christianos edificó aqui su estajado [staja don $\mathrm{N}$ ], fue feyta dentro 
breu tiempo convinient población 9.37-38. Hay que interpretar este pasaje como: edificó aqui su estaja do fue feyta..., donde estaja es s. f. 'estancia, compartimento o sitio donde estar, habitáculo, residencia'. En la VC se lee: E cascú dels dits cristians edificà aqui son estatge, d'on hi fo feta dins breu temps convinent populació. VC, p. 38. Comp. cat. estatge 'habitació, lloc on hom s'está' (FABRA, DGLIC, s. v., DL/C del IEC, 2007, s. v.), 'lloc on un habita' (DCVB, t. 5, p. 525); occ. estatge 'localité, pièce d'une maison; demeure, residence; séjour'; y estatja 'séjour, lieu de séjour, demeure, domicile, maison d'habitation' (LEVY, s. v.); estatge 'demeure, résidence' (AliberT, s. v.). También se empleó en cat. ant. estatja, estadga, estaja 'lloc de residència' (DECLIC, III, p. 754). Se trata de un deriv. de estar. Para el occ. estatge Alibert postula la etim. STATicum. Coromines distingue: el m. estatge provendría de STATICUM (deriv. de STARE con el sufijo de abstracto -AтTCUM); el f. estatja del pl. neutro sтAтіCA (DECLIC, III, p. 754, s. v. estar). Comp. en arag. med.: estage, estaia 'alojamiento' (GILKISON, s. v.); estaja 'establo' (REIDY, p. 166; pero más bien parece 'alojamiento, habitáculo, habitación’: «et de obrar \& fer espital de dos suficientes estajas en el camino del dito puerto», $D L A A$, doc. no 114 , de Gistaín, año 1350; pág. 168, lín. 17); estaga 'habitación, residencia' y estagero 'habitante' en FA (TILANDER, FA, p. 398). Comp. estacha 'estancia, tiempo que se está en un sitio', en Benasque (Andolz, s. v.; Ballarin, Dicc., s. v.), estacho 'sitio donde se está, donde se espera', en Panticosa (EBA, 1999: 851). Frec.: estajado [estaja] 1: 0,00227.

estamiento (var.: stamiento) s. m. 'situación, estado': en las quales letras recontava el estamiento del su regno et mala vida que passava con los mayores del su regno 20.108; et los cardenales et el rey Carlos la dita paz firmaron et a devido stamiento [estado lo $\mathrm{N}]$ aduzieron 38.81. Comp. estamiento 'estado' en VM, III, p. 128. // s. m. 'estamento, estrato o sector de una sociedad, de acuerdo con su función o situación social': Assí como el aviés convidado muyto honrado barón et muyt honrado prelado et otras gentes de diversos stamientos queriendo tener fiesta honrada en la ciudat de Barchinona 37.85-86. Etim.: deriv. del v. estar, con sufijo -miento < -MENTU(M). En cast. Corominas documenta por 1. ${ }^{\mathrm{a}}$ vez estamento en 1604 y lo considera adaptación del cat. estament (BDELC, p. 254), aunque indica que hay variante antigua estamiento en el Cancionero de Baena (DCECH, s. v. estar, tomo II, p. 777). Frec.: estamiento 3: 0,00682; stamiento 1: 0,00227; stamientos 1: 0,00227 .

estar v intr. 'ser, estar': Está pero en verdad [empero N] que regnó el dito rey don Sancho Remirez en Aragón en antes que fues rey de Navarra 17.58; viendo la innocencia de su madrastra et la voluntaria diffamación que le era estada levantada et possada 14.67 ['le había sido levantada']; no quisieron antes recevir por rey a don Alfonso entra que juró a los del regno que no <era> estado consintient en la dita muert de su hermano 18.86; por el abbad et clérigos del dito monasterio que gran enoyo et traballo soffrian por los montes 
qui por él et del comte d'Aragón les eran estados dados, por tal como no podían defender ni contrastar que alguno non poniesse su cabanna de ganado 11.57 ['les habían sido dados']; et el quarto fillo del dito rey don Jayme de Mallorquas hubo nombre don Phelip qui fue santo hombre et murió devotament estando freyre menor. 38.452 ['siendo']; las quales naciones los godos echaron de Espannya et después estaron en ella fasta la traición del conde don Yllán, quasi CCCC ${ }^{\circ}$ annos 2.10; et estieron en batallas et en guerras bien un anno 20.148; et estovo algunos días delant la dita ciudat esperando al dito compte 33.66. Del lat. STARE 'estar de pie', 'estar inmóvil'. Frec.: estar 5: 0,01136; está 1: 0,00227; estado 9: 0,02046; estados 2: 0,00455; estada 2: 0,00455; estando 33: 0,07501; estaron 1: 0,00227 ; estava 12: 0,02728 ; estavan 5: 0,01136; estieron 2: 0,00455; estovo 1: 0,00227; estuvo 9: 0,02046; estuvieron 2: 0,00455; estuvies 1: 0,00455.

estar-se-(en[de]) v. prnl. 'abstenerse (de ello)': como el dito Simón quisiesse las condessas de Tolosssa hermanas del dito rey don Pedro desheredar, el dito rey pregó et amonestó al dito Simón que se estuvies de fer enoyo et dannyo a las ditas hermanas suyas 34.127-130; mas ya por todos aquestos remedios el dito conte Simón non se en [sen B] quiso estar. 34.137-13; Et por esto la part contraria se pensó que por miedo sende estuvies de conbatirse con él 36.270; mas non lo han agora de nuevo porque por privilegio lo han antigament et acostumbrado et pues por costumbre lo han en natura les es tornado porque non sende podrían estar. 38.398. Ya en 1904 Saroihandy (2009: 79) hizo notar «el giro aragonés estar se ende que responde al francés s'en abstenin», el cual se registra en el Poema de Yúcuf, en el ms. B, del s. Xvi: «si mandó el rrey... que ansí lo fiziesen... i que no xende estoviessen». Frec.: las formas de este verbo se incluyen s. $v$. estar.

estargodos adj. y s. 'nombre de un pueblo germánico, ostrogodos': en aquesta isla de Estancia habitaban aquestas naciones: godos, vesegodos, estargodos [estragodos N], davirugis, arcas et tanis 3.2. Del lat. tardío Ostrogothus (DLE, 2014, s. v. ostrogodo). Frec.: 1: 00227.

estarrado p.p. y adj. 'desterrado': mas un cavallero clamado Villar, estarrado de las partidas de Carcasona [...] escondidament furtó los ditos fillos del rey de Mallorquas 36.419 [esterrat VL, pág. 178]. Deriv. de tierra < lat. TERRA, con abertura de la $e>a$ por influencia de la vibrante $\operatorname{rr}[\mathrm{r}]$. Frec.: 1: 0,00227.

este (var.: esti; f. esta, n. esto) adj. y pron. dem. 'este': Este don Sancho Remirez, seyendo en hedat de XVIII annos según dito es quando empeçó de regnar 17.24; Et por tal como no es de nuestro propósico, lexemos esta materia et tornemos al dito rey Sancho 14.16; el noble varón, natural del condado de Vigorra, clamado Ennego, el qual era venido en estas partes por defender los christianos 10.8; et esti don Goncalvo no y vino, mas embió sus compannyas 18.15; Et los moros de Tudela que vidieron esto [...] sallieron a ellos de manera que pocos fincaron en el lugar andando enpués estos 19.36; porque ya otras vegadas lo avian tornado ésta el mesmo avía lexado. 19.76; et 
por esto concordaron todos los navarros [...] que enviasen por el infant don García 20.56. // Contr. prep. de + dem.: desta, deste, desti, desto, destas, destos: En aquesti mismo ayno, III kalendas, pasó desta vida el dito rey don Pedro 18.125; Et así este compte, cuydándose deste casamiento començó guenrrar por el regno contra los aragoneses 19.104; yes presuntion que desti sacrilegio que fizo en Leon et en Galicia que fue punido en la batalla de Fragos [Fraga VL] 19.152; et depués desto pobló el Castellar 19.20; et la división destos regnos fue metida en el monesterio de Sant Johan de la Pennya que alli fues perpétuo conservada 20.170; Del lat. ISTE, ISTA, ISTUD. Frec.: este 9: 0,02046; esta 6: 0,01364; ésta 1: 0,00227; estas 3: 0,00682; esti 8: 0,1818; esto 28: 0,06364; estos 3: 0,00682; desta 5: 0,01136; deste 1: 0,00227; desti 3: 0,00227; desto 2: 0,00455; destos 1: 0,00227.

estendart s. m. 'estandarte', 'insignia representativa de un ejército': En aquell mismo día, don Alfonso fillo suyo paró el estendart a Barçalona porfer el viage de Cerdennya 38.482483. En cast. estandarte 'insignia o bandera que usan los cuerpos montados y algunas corporaciones civiles o religiosas' (DRAE, Manual, 1979); 'insignia que usan los cuerpos montados, consistente en un pedazo de tela cuadrado pendiente de un asta, en el sual se bordan o sobreponen el escudo nacional y las armas del cuerpo a que pertenece' y estandarte real 'bandera que se izaba al tope mayor del buque en que se embarcaba una persona real, o a un asta en el edificio en que se alojaba' (DLE, 2014, s. v.). Tomado del fr. ant. estandart 'insignia clavada en el suelo como símbolo representativo de un ejército', 'estandarte' (РОттіER da el español estandarte como galicismo adoptado antes del s. XIV; cfr. ELH, II, p. 132). deriva del germ. STANDAN 'estar en pie, estar enhiesto', probablemente del fráncico, donde se le aplicaría como nombre la frase imperativa STAN HARD! 'manténte firme!' (cfr. it. stafermo, quizá calcado

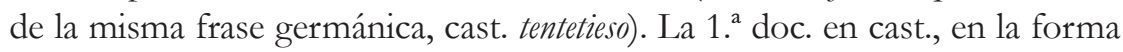
estandal, es de h. 1260 (en las Partidas; cfr. VMC), estandarte en Nebrija. Una forma stanthart 'estandarte' existe ya en alemán medio (DCECH, II, pp. 774775). La forma estendart no la cita Corominas. Aparece estendart 'estandarte' en $L M M$, p. 171: LIRIA coincide con POTTIER en considerar que procede del fr. ant. estandart. En el arag. de Fernández de Heredia: estandart, standart 'banner, standard' (GILKISON, 1984, s. v.). En el arag. del s. XV en Teruel: standarte 'estandarte' (Terrado, 1991: 307). Frec.: 1: 0,00227.

estender] v. prnl. 'extender(se)': porque la gracia del privilegio se estendía assí nobles como cavalleros 34.45; por la qual discordia muitos males et enoyos et dampnages se estendieron entre el dito rey et su muller 34.59-61. Del lat. EXTENDERE 'desplegar', 'ensanchar, alargar'. Frec.: estendía 1: 0,00227; estendieron 1: 0,00227.

esti (var.: este) pron. y adj. dem. m. sing. 'este': et esti don Gonçalvo no y vino 18.16; Todo esti regno dio en casamiento 20.285; Esti poblo Soria 19.9. Vid. este, aqueste. Frec.: 8: 0,01818. 
esto pron. dem. neutro 'esto'. Vid. este.

estolt s. m. 'escuadra, armada, conjunto de naves'. Esta es la forma que aparece sistemáticamente en el ms. B; el ms. E confunde la $t$ por $c$ y escribe escolt (vid.). Proviene del lat. tardío stolus, tomado del griego oтo $\lambda$ os 'flota, escuadra', 'ejército'. De acuerdo con esa etimología, en otros textos en arag. med. se registra estol: así en el arag. de Fernández de Heredia (Gilkison, 1984: 62). Véase también en un texto del s. XV de Teruel: «Vino el rey de Portogal sobre el estol de los moros que estaban sobre Çepta et esbaratolos» (1419; en López Rajadel, Crónicas de los Jueces de Teruel (1176-1532), 1994: 234). Igualmente, tanto en cat. ant. como en occ. ant. es estol. Por tanto, la -t adventicia y antietimológica que aparece en nuestro texto es una ultracorrección que evidencia que esa - $t$ final ya no se pronunciaba en el s. XIV. Frec.: scol (stol) 1: 0,00227; escol (estol) 1: 0,00227; escolt (estolt) 6: 0,01364.

estonz adv. 'entonces': estonz el compte Pero Ansures, desque avie rendido la tierra a la reyna su seynora natural fuese para el enperador de Aragón e pareçiole ant'él vestido d'escarlata...19.82. Etim.: del lat. vg. *EXTUNCE 'entonces', compuesto de Ex 'en' y el lat. arcaico *TUNCE, de donde salió el lat. TUNC 'entonces' (BDELC, p. 236, s. v. entonces; DCECH, II, p. 643). Comp. cast. ant. estonces (Cid) y estonce (VMC, s. v.; DME, s. v.). IrIBARREN (1984: 240) registra estonces 'entonces' en la Ribera de Navarra. Quizá no es casual el hecho de que el cap. 19 de la ed. crítica de la Crón. de SJP., donde aparece por única vez estonz, presenta una laguna en el ms. B y está tomado del ms. N, copiado en el s. XVI por el navarro Martín de Larraya. Se vea también estonz en el Roncesvalles navarro, cantar de gesta del s. XIII: «Estonz. alçó los ojos, cató cabo adelante, / vido a don Roldán acostado a un pilare» (Riquer, 1994: 399, lín. 27; Menéndez Pidal, 1976: 15, lín. 27). De todas maneras, también se registra en alguna obra en arag. medieval, como el LMM: «el diamant deue ser dado sin cobdiciar... e estonz es el de mas grant uirtu» (LIRIA, $L M M$, p. 171). En el VCA (p. 172), estonces 'en aquel tiempo'. Frec.: 1: 0,00227.

estorcido p. p. del v. estorcer, v. tr. 'hacer escapar, salvar, librar de, arrancar': et el noble varón qui la criatura havía estorcido a muert, sabiendo el nuevo parellamiento [parlament N] ques decía tener por el general de la tierra, tantost fizo vestir la dita criatura assin como a pastor et fizole calcar abarcas. 12.20. Comp. estorcer (intr.) 'escapar', 'escapar de la muerte', 'escapar, hablando del reo que es dado por libre' en FA ('Tilander, FA, p. 401). Del lat. vg. *EXtorcere, lat. eXtorquere 'arrancar, quitar de las manos, quitar por la fuerza' (Blánquez, s. v. extorqueo; DCECH, V, pp. 553-554). Comp. cat. ant. estòrcer 'salvar, treure d'un perill, d'un mal; cast. salvar, librar', y 
como intr. 'salvarse, librarse' (DCVB, s. v.); occ. ant. estorser 'tirer d'affaire, délivrer, sauver' (Levy, s. v.). Cast. med. estorcer 'librar, librarse de' (VMC, s. v.), 'libertar, sacar a alguien de un peligro o sacarle de un apuro' (DME, s. v.). En Alex. estorçer 'escapar, librar(se), salvar(se)' (SAS, s. v.). También en el arag. de Fernández de Heredia: estorcer 'free' ('soltarse, librarse'), como v. intr., aunque solo se documenta en la segunda parte de la Coronica de los Conqueridores (GILKISON, 1984: 62). Frec.: 1: 0,00227.

estorbar]: v. tr. 'poner obstáculos para la realización de algo, estorbar, desbaratar, impedir': alçáronlo rey de los de la tierra, pesando a la madre porque hera de mala vida et mas al compte don Pedro que lo estorvava mas 19.166. Del lat. Disturbare 'íd.' (DCECH, V, p. 700, s. v. turbar). Del mismo origen: cast. ant. destorvar, estorvar, port. estorvar, cat. y occ. destorbar. Vid. destorbar. Frec.: estorvava 1: 0,00227; destorbado 1: 0,00227.

estragar] (var.: destragar, astragar) v. tr. 'devastar, deteriorar, destruir, arruinar, echar a perder'; 'asolar, causar estragos, causar ruina y perjuicio': et el dito rey don Sancho vencedor, loando a Dios de la grant victoria que le dio, passó Ebro prendiendo et astragando la tierra de su enemigo et cobrando lo que se tenía de Navarra 17.42; et amos a dos destragoron [estragaron $\mathrm{B}, \mathrm{N}$ ] el regno de León, 34.79; aquesti don Alfonso con los aragoneses pasó Duero e por Tierra de Campos fuese para Leon, estragando e destruyendo la tierra 19.128; su tio don Ferrando rey de Leon et don Sancho rey de Navarra corrieron et estragoron el regno de Castiella. 34.76. Etim.: del lat. vg. *STRAGARE 'asolar, devastar', derivado de STRAGES 'ruinas', 'devastación', 'derribo, escombros', 'matanza'. En cast. med. astragar es muy frecuente en los ss. XIII y XIV. La acepción más frecuente en lo antiguo es la de 'devastar, arruinar (un país)', pero también se halla en el sentido de 'hacer matanza'. La forma con $a$ - podría explicarse por una etimología *AD-STRAGARE, pero parece más probable sea debida a influjo de astroso, astrado (DCELC, vol II, pp. 439-440, s. v. estragar, y DCECH, II, 798). En GILI GAYA, Tesoro, aparece abundantemente documentada la forma estragar, desde Nebrija (1492) hasta finales del s. XVII. Las más amplias explicaciones son las de Covarrubias (1611). El DRAE (1970) recoge como $2^{a}$ acepción de estragar 'causar estrago', lo cual se mantiene en el DLE (2014). Frec.: estragando 2: 0,00455; estragoron 1: 0,00227; destragoron 1: 0,00227; astragando 1: 0,00227 .

estrannyo (var.: estranno) adj. 'extraño': et vinció al rey de Carpitania, el qual avía nombre Caci, qui era de muyt estranna et orrible figura 1.23; mas tanta era la multitudo de la gent estrannya que ya sea que sin nombre ne matoron a malas se parecía 36.577; a las quales gentes estrannyas el rey don Jayme de Mallorquas, hermano del dito rey don Pedro, dio favor et ayuda 36.475; como los ditos mesageros de Secilia oviessen oydo tan estrannyo mandamiento... 38.124. Del lat. EXTRANEus 'exterior, ajeno, 
extranjero'. Frec.: estranna 1: 0.00227; estrannya 1: 0,00227; estrannyas 1: 0,00227; estrannyo 1: 0,00227.

estrela s. f. 'estrella': Et depués, por una estrela que ha nombre Esperus, ques pone cerca el sol et la ora es tarde, fue metido nombre a la tierra Speria. 1.5. (En la ed. crítica Orcastegui da estrella, pero en el ms. se ve claramente estrela). Etim.: del lat. STELLA. La -r- que se ve también en castellano estrella, port. estrela, se debe a un fenómeno fonético de repercusión o anticipación de la otra líquida. Tradicionalmente se admitía para explicar la - $r$ - un cruce con ASTRUM, cosa que Corominas cree inverosímil; Menéndez Pidal habla de epéntesis de $r$ tras st. Cfr. DCECH, II, 805; MGHE, \ 69, p. 190. Dice Corominas: «La forma acatalanada estrela se emplea en todo el Alto Aragón, y en el Este también el masculino estreh) (DCECH, II, 805). En efecto, estrela es forma aragonesa que se recoge en varios diccionarios: ROHLFs, DDPA, p. 135, documenta estrela en Ansó, Torla y Echo; estrel 'estrella grande', 'lucero' en Bielsa. Andolz, s. v., la documenta en Espierba, Panticosa y La Litera (y estrel 'estrella' en Bielsa y Ribagorza); estrel también se documenta en el Valle de Chistau (Mотт, 1984, s. v.). El EBA (1999: 867-868) registra estrela en Ansó, Bal de Chistau, Tardienta, Echo, Bielsa, Plana de Uesca; estrelo en A Buerda, Piarruego y Rebilla; estrel en Bal de Bielsa, Bal de Chistau y Fonz. Mostolay (2007: 276) recoge estrela en el Somontano de Barbastro; López Susín / Montaner (2000: 108) en Plasenzia (Sotonera). La forma estrela es usual incluso en Huesca y su comarca: en Nagore (2020: 301-302) pueden verse testimonios de su uso en escritores oscenses del s. xx (Luis López Allué, Pedro Lafuente, Enrique Capella, María Cruz Bescós). Frec.: 1: 0,00227.

estrella. Es lectura, incorrecta, de la ed. crítica. Vid. estrela.

estremidat s. f. 'superioridad, preeminencia, excelencia', 'ventaja, dominio': porque él con la su estremidat de armas los ditos castiellos tollio a los moros 36.73-74. Deriv. de estremo, tomado del lat. EXTREMUs. Frec.: 1: 0,00227.

estrenimiento (var.: destrenimiento) s. m. 'presión, estrechamiento': con la grant cura et consello et estrenimiento [destruymientos $\mathrm{N}$ ] de armas del dito rey don Pedro 36.25 // destrenimiento s. m. 'apremio', 'opresión', 'acción y efecto de estrechar un cerco': et aquel sitió poderosament et drestreyta, por el qual destrenimiento los nobles varones qui dentro eran sufrieron grant freytura de viandas et de otros fornimientos 36.135. Etim.: deriv., son sufijo -miento < -MENTU, del verbo estrennyr 'estrechar'. Frec.: estrenimiento 1: 0,00227; destrenimiento 1: 0,00227.

estrennyir] v. tr. 'apretar, estrechar, contraer'; 'cerrar apretando, estrechar sin llegar a cerrar del todo, entornar': el dito rey se acostó al dito castiello et alçando el braço dreyto estrennyó la mano et dixo... 38.301-302. Etim.: del lat. STRINGERE 'estrechar'. Comp. en arag. mod. estreñir 'entornar una puerta o ventana' (el $E B A, 1999:$ 869, registra la voz en Bal de Chistau, Salas Altas, Ontiñena 
y Alto Aragón en general); estreñé 'entornar (la puerta)' en el aragonés de Benasque (Ferraz, s. v.; Ballarín, 1978, s. v.); estrenhe en el Valle de Arán con el mismo significado: CoROMINES registra esta voz en El parlar de la vall d'Aran (1991: 458) con la grafía estrenye y explica: «germà del cat. estrènyer, però en aranès reduït al sentit de «ajustar una porta o finestra sense passar-hi cap mena de tancadó»; cat. estrènyer, oc. estrenher, fr. étreindre, it. stringere, con el sentido general de 'estrechar'. En cambio, en cast. estreñir desde el s. XVI sólo en la acepción de 'poner en estado de no poder evacuar el vientre' (DCECH, II, 806). Frec.: estrennyó 1: 0,00227.

estreyto adj. 'obligado, constreñido': que por vigor del homenage al qual era estreyto por razón de las tierras que tenía en fe [sic. debe decir feu 'feudo'] por el dito rey don Pedro, 36.404. Del lat. strictus, p. p. de stringere 'estrechar'. Comp. destreyto. Frec.: 1: 0,002287.

esvayr] v. tr. 'asaltar, invadir, usurpar, arrasar': con gran buest esvayó e destruyó grant partida de Castiella 33.77. Como cat. ant. esvair 'asaltar', 'atacar', 'acometer', 'saquear', 'acabar con', 'arrasar' (cat. mod. esvair 'desvanecerse', 'disipar, desaparecer'). Para la etim. vid. desuayr. Frec.: esvayó 1: 0,00227.

et (var.: e, i, y, he) conj. cop. 'y': E por aquesto que podamos mellor tratar e mas verdaderament e breu... 2.1; et non podia bien aquestas tierras dominar et quería su consello, favor e ayuda 20.215; Conviene empero que favlemos et tratemos de los godos 2.13; He oydas las rumores et federades de las gentes sin nombre que en la villa de Perpinyan se eran venidas... 36.478; al qual fuertmente mandó que en continent fues con gran poder de hombres a cavallo $i$ de pie enta las parts d'A ragón 4.28; por esto tractoron e ordenoron que esleyessen por rey a don Pedro Atares, sennor de Borja, y en aquesto quasi concordavan todos 20.6. Frec.: et 2.976: 6,76425; e 277: 0,62960; he 1: 0,00227; i 1: 0,00227; y 15: 0,03409.

etc 'abrev. de lat. et cetera': Et depués el dito santo rey se despulló los vestidos reales humilmet et cantando un canto o ymno que comiença «Veni Creator Spiritus etc.... vistiosse el ábtio de monges blancos de Poblet 35.283. Frec.: 1: 0,00227.

exalçamiento s. m. 'ensalzamiento; exaltación': copdiciando mas el servicio de Dios et exalçamiento de la fe que no dudando el temor de los infieles 18.25. Deriv. de exalçar. Se registra en Fernández de Heredia (GILKISON, s. v.). Frec.: 1: 0,00227.

exalçar v. tr. 'ensalzar', 'exaltar': aquesti conte Remón Burrel por exalçar la fe christiana, por destruir la seta morisca, fue en Córdova contra moros 27.4; Exalçó el nombre de Ihesu Christo en las tierras que conquistó 35.187. Etim.: supone un lat. vg. *EXALTIARE, deriv. de altus 'alto'. O bien, de exaltare, con cruce de alzar < lat. vg. *altiare. Frec.: exalçar 3: 0,00682; exalçó 2: 0,00455.

exaltamiento s. m. 'enaltecimiento, ensalzamiento': «et priégote, fillo mio, que tu ames los tus barones, cavalleros et las tus fieles gentes qui han a mi amado coralment et 
han metido el corazón et ell aver al servicio de Dios et mio, et al tu exaltamiento ayas merce dellos quando les será mester» 35.267. Deriv. de exaltar < EXALTARE 'levantar, ensalzar'. Vid. exalçamiento. Frec.: 1: 0,00227.

examplar] v. tr. 'ampliar, ensanchar, extender': Et depués su hermano Leovegildo, et aquesti exampló et crexió su regno en Spannya 3.48. Del lat. vg. EXAMPLARE, deriv. de Amplus, de donde proceden igualmente cat. eixamplar, occ. ant. eissamplar, fr. ant. essampler, cast. y port. ensanchar (DCECH, I, p. 254, s. v. ancho). En arag. med.: examplar 'enlarge, expand' en las obras de Fernández de Heredia (GILKISON, s. v.); exanplar 'ensanchar, aumentar la anchura de algo' en documentos del s. xv de Teruel (Terrado, 1991: 263). Comp. exanplada 'ensanchada' en DLAA: «\& ha de la otra part enta Belestar cient \& vint \& hueyto passadas; \& asi fueron las buegas ficadas en tal manera que daquellas asuso no pueye la dita cequia ni sia exanplada sienes licencia \& amor del prior de sant Per" (doc. de Huesca de 1306; DLAA, doc. no 86, p. 125, lín. 14-15). En arag. mod.: ixamplar 'ensanchar' (Biello Sobrarbe), 'desplegar las alas' (A Fueba) (EBA, 1999: 1087); en el arag. de la Alta Ribagorza, ixampll', ixampll' 'extender, aumentar la anchura de una cosa' (BALLARín, 1978: 227; Ferraz, 1934; s. v.; HAENSCH, 1960). Frec.: exampló 2: 0,00455.

excellent (var.: excellench) adj. 'excelente': et fue conte depués dél, Remón Bereguer Viello, el qual fue muyt noble varón et muy excellench 29.3; Aquesti virtuosso rey don Jayme fue princep excellent, virtuoso, valient et ardido et muy gracioso, benigno et piadoso 35.174. Tomado del lat. excellens, -entis 'que sobrepasa en altura, superior, elevado' 'distinguido, eminente, sobresaliente' (SEGURA, 2001: 261). La 1. ${ }^{a}$ documentación que da el DCECH (II, p. 821) de excelente es cast. es de 1433. La de la Crón. de SJP. para el arag. es anterior en unos 60 años. La variación -t $/$-ch $[\mathrm{k}]$ en situación final puede ser indicativa de que la $-t$ no se pronunciaba. Frec.: 2: 0,00455.

excitado p.p. y adj. 'excitado, estimulado, animado de pasión o ira': El qual Remón de cupiditat inhonesta et contra Dios excitado et movido por tal que regnar pudies en el regno qui a su hermano don Sancho assin como a promogénito se pertannnya, mató al dito Sancho 17.7. Es p. p. de excitar < lat. EXCITARE. Frec.: 1: 0,00227.

exempto] adj. 'exento, libre, no culpable': et la dio por innocent et por exempta del grien crimen 16.8. Etim.: cultismo tomado del lat. EXEMPTUS, p. p. de EXIMERE 'sacar fuera', 'eximir' (DCECH, IV, p. 832, s. v. redimir). La 1. a doc. que da CoROMINAS de exento es del Corbacho (1438) así que la Crón. SJP. la adelanta en más de 60 años. Se registra exempto 'libre, desembarazado de cargas, obligaciones, etc.' en los DLAA: «no obstant que el fuesse quito \& exempto de pagar los dreytos del dito peage» (doc. de Jaca de 1435; DLAA, doc. no 139, p. 204, lín 33). Vid. también LaGüENs (1992, p. 128), s. v. exento. Se registra exempto 'libre, exento' en el $L D A$, p. 260. Frec.: exempta 1: 0,00227. 
exir v. intr. 'salir': et todos días los de la ciudat exían les apalatiz, [apalaciz B] escondidament et paladinament 36.573; et tantost como el dito conte fue exido de la presón... 34.117; el primer rey con qui exieron los ditos godos de la dita isla huvo nombre Virig 3.6; con todo su poder ixió a dar batalla en el lugar que yes dito Azinçol 19.203; «...que en continent me yxcades del campo» 36.290 [en la edición crítica, ixtades, pero es un error por ixcades; la $t \mathrm{y} c$ son a menudo muy parecidas en el manuscrito, como ocurre en general en todos los manuscritos medievales, pero es evidente que la forma de segunda persona de plural del presente de subjuntivo de exir es ixcades]. Etim.: del lat. EXIRE 'salir' (a su vez derivado de IRE 'ir'). En cast. el verbo exir era de uso general en los siglos XII y XIII (DCECH, II, p. 549, s. v. ejido). Frec.: exir 5: 0,01136; exían 1: 0,00227; exido 1: 0,00227; exieron 1: 0,00227 ; yxieron 2: 0,00455 ; yxieronse $1: 0,00227$; yxió $3: 9,00682$; yxcades 1: 0,00227 .

exo pron. dem. 'eso': como en continen quél favlava sanosament con alguno nin dalguna cosa fues yrado siempre movía el pie en semblança de cabreta qui quier cavar, et por exo la gent lo nombrava Olivano Cabreta 25.26. Del lat. IPSUM. Se encuentra exo tanto en arag. med. como moderno, si bien lo general en arag. mod. es $i x o$, forma neutra del paradigma ixe, ixa, ixos, ixas, ixo (NAGORE, 1989: 82-83; EBA, 1999: ixa, p. 1085; ixe, p. 1089; ixo, pp. 1090-1091). Véase algún ejemplo registrado en arag. del siglo xx: «teneba fambre, por exo ploraba» (en Lobarre; SAROÏHANDY, 2005: 352). En arag. med. se encuentra en cuatro obras de Fernández de Heredia (GILKIsON, s. v.). Véanse ejemplos en otros textos en arag. med.: "por que a seudo rebel e contumaçi en est feito, por exo lo condamnamos en estos .x. soldos e encara dezimos e mandanos que el dito Guillem de Loarre que tienga e providesca illuminada la dita lanpada dia e nueit perpetualment en la glessia sobre dita» (DLAA, doc. de Huesca de 1264; doc. no 6, p. 7, lín. 32). «Enpero, si tienen tienda logada del rey, de nulla ropa que conpre delant su tienda no es tenudo de responder, mas si en otra manera la conpra, tenido es de responder sobre exa» (FAM, p. 157). También, más raramente, en la forma eyxo: «el sennor d'aquella eglesia ni d'aquel molino ni del bayno ni del forno non deve aver por eyxo calonia nenguna» (FAM, p. 178). Frec.: 1: 0,00227.

exolvidar] v. tr. 'olvidar': su grant savieza supo fer a sus vassallos exolvidarla [exolvidar $\mathrm{N}]$ por la qual cosa buvo paz et amor entre sus gentes en toda su vida. 38.625-627, [sabé fer exoblidar a sos vassalls VC, p. 176]. Etim.: lat. vg. EX-*OBLITARE. En la VC aparece exoblidar 'olvidar' (Glosario de Nonell, en Soberanas, p. 188), forma que no se encuentra en el DL/C del IEC (2007). En arag. med. se registra oblidar (TILANDER, VM, Voc., p. 216), pero también olvidar (LT, RODÉs, 2016:747). Solamente se encuentra exoblidar en una obra de Fernández de Heredia, el Eutropius; en el resto de las obras, oluidar (mayoritariamente) u oblidar (GILKIsON, s. v.). En los DLAA, olvidar: «\& en el conto se le fuessen 
oluidadas las cosas \& quantias de partes de suso contenidas, las quales por los ditos jurados le deuen seyer presas en conto» (doc. de Jaca, de 1430; DLAA, doc. $\mathrm{n}^{\circ} 138$, p. 202). En arag. mod. la forma general es olbidar (MARTínez, 2008: 275). Sin embargo, comp. arag. benasqués ixupllida(r) (BaLlarín, Dicc., p. 229). Frec.: exolvidarla 1: 0,00227.

exposado p. p. 'expuesto': por los quales non tan solament al dito regno en antes, encara toda Espannya, se cuydó seer exposada [ser delivrada $\mathrm{N}$ ] a grandes periglos et encara toda la fe catolica 36.65; et cómo el rey Carlos a diversas et crueles muertes et turmentos havía exposado los nobles varones 36.190. Es p. p. de exposar 'exponer', del lat. EXPONERE, convertido vulgarmente en *EX-PAUSARE (DCV B, t. 5, pp. 669670; DECLIC, VI, p. 744, s. v. posar). Frec.: exposado 1: 0,00227; exposada 1: 0,00227 .

exseguir v. tr. 'ejecutar, llevar a ejecución': mandó a los arcevispos de Anbrum et de Alerat que segunt la comissión feita al cardenal deviessen exseguir [seguir $\mathrm{N}]$ la paz. dessuso dita 38.100-101. Etim.: del lat. EXSEQU 'seguir hasta el final, ejecutar, cumplir' (DECLIC, VII, pp. 746, s. v. seguir). DeVoto, s. v. eseguire, sugiere un cruce del lat. EXEQUi con el it. seguire. Según COROMINAS el lat. EXSEQUI no dejó descendencia popular en cat., fuera de un uso esporádico (probablemente semi-sabio) de un verbo eixeguir medieval, sinónimo de executar (DECLIC, VII, p. 746). En la VC de la Crón. SJP. aparece este verbo: ... que segons la comissió feta al dit cardenal, deguessen exeguir la pau damunt dita. VC, p. 160. Comp. it. eseguire 'ejecutar'. En arag. med. no es muy frecuente, pero se encuentran algunos ejemplos. Comp. en FA de 1350: «non sia recebida fiança de dreyto ni appellation, ante aquéllas sian exseguidas en todas et por todas cosas iuxta su continencia» (TILANDER, RFE, XXII, p. 27; en el Glosario, ibídem, p. 130, recoge exseguir 'ejecutar, llevar a ejecución', y cita ejemplos de $F A$ y de las Ordinaciones de Zaragoza). Vid. en FA: exseguir 'ejecutar' (Tilander, FA, p. 558-559). Borao recoge "exeguir, ejecutar, voz forense". Savall y Penén: exseguir y exiguir 'ejecutar, llevar a ejecución'. Se documenta exeguir en algunas obras de Fernández de Heredia (GILKISON, s. v. exigir, p. 64, documenta exseguir en Tucídides, Crónica de los Conqueridores y Crónica General de Espanya, pero lo traduce por 'demand, order'). En DLAA, exegnido 'ejecutado': «queremos que sia exseguido \& conplido segunt aqui de la part de yuso yes scripto largament"» (DLAA, doc. no 142, de Jaca, año 1441; p. 206, lín. 9). Se registra exeguir 'ejecutar' en el $L D A$, p. 259. Frec.: 1: 0,00227. 
fabla s. f. 'conversación, acción de ejercer la palabra o la facultad de hablar': e ovo fabla con las goardas e fuesse ende a Castilla, 19.63. Etim.: del lat. FABULA 'conversación', 'relato sin garantía histórica', 'cuento, fábula', y este de FARI 'hablar'. Cast. habla, que hoy funciona como un típico postverbal de hablar, pero en lo antiguo existían acepciones más cercanas a las varias del latín: 'sentencia, refrán, consejo', 'fábula'. (DCECH, III, pp. 296-297). Vid. favla. Frec.: fabla 1: 0,00227.

fadiga s. f. 'dilación maliciosa': requiriendo al notario que alli era que de aquéllas et del comparecimiento suyo et de la fadiga et contumacia del dito rey Carlos le devies fer carta o cartas públicas a memoria perdurable 36.298-300. Etim.: Según el DEEH sería descendiente del lat. EMPHYTEUTICUs. El DCECH, s. v. fatigar, plantea un étimo distinto al de fatiga 'cansancio', postverbal de fatigar < lat. FATIGARE: «se trata en realidad de una palabra aparte, que ni siquiera es seguro que venga del lat. fatigares. Aunque en lat. med. existió fatica de directo, fatiga juris, etc. (en Du Cange, citado por tilander, FA, p. 407). En el DECLIC, s. v. fatigar, Coromines rectifica esa opinión y, a pesar de ciertas dudas, sugiere que deben de proceder de una misma etimología el cat. fadiga fatiga 'cansancio' y el término jurídico fadiga de dret, ambos relacionados con lat. FATIGARE 'agotar, extenuar'. El DRAE (1970, s. v.) registra fadiga (de fadigar) con marca diatópica de Aragón con estas definiciones: «1. Tanteo y retracto que las leyes de la Corona de Aragón reconocen a los poseedores del dominio directo en la enfiteusis, y a los señores en los feudos, cuando el enfiteuta o el vasallo enajenan sus derechos. // 2. Cantidad que en algunos casos percibirían el dueño directo o el señor por la renuncia de su derecho de prelación en las enajenaciones de enfiteusis y feudos». Además, recoge, también con marca de Aragón, el v. fadigar 'tantear el precio, calidad o valor de algún solar u otra cosa material que se desea comprar, beneficiar o labrar' (DRAE, 1970, s. v.). El DLE (2014) recoge fadiga con las mismas definiciones, pero ha suprimido la marca diatópica de Aragón y, en cambio, ha incluido la marca Der., que indica que la palabra es propia del tecnolecto del Derecho. Además, ha suprimido la voz fadigar. Se registra el uso de fadiga de dreito 'dilación maliciosa causada por la rebeldía del adversario o por la negligencia del juez’ en los FA (p. 147 en el texto; pp. 406-407, en el vocabulario); faidio de dreito en Vidal Mayor, con el mismo significado (VM, III, p. 132). Entre la documentación que cita TiLANDER en FA, cabe destacar fadiga de dret en los Usatjes de Barcelona. En doc. en latín: fatica juris, fatica de directo, 
fatiga juris, etc. Nav. fádiga 'nombre con que se conoce el derecho de tanteo en los censos, y la obligación del dueño directo de notificar el propósito de venta al enfiteuta' (IribarRen, s. v.). BoraO, s. v., da dos acepciones (y dos formas distintas, con $-d-$ y con $-t$ ): fadiga 'derecho que se paga al señor del dominio directo, siempre que se enajena la cosa dada en enfiteusis'; fatiga 'voz forense, que aunque no parece sino una de las aplicaciones de aquella palabra castellana, se ve usada en nuestros ff. en la frase fatiga de derecho, para manifestar dilación maliciosa en la administración de justicia'. No cuadran, pues, las acepciones del DRAE, ni la $1 .{ }^{a}$ de BoraO; sí en cambio la de los $F A$, la de $V M$, y la $2 .{ }^{a}$ acepción de BORAO. Sobre las voces fadiga y fatiga en los textos aragoneses, y sus diversas acepciones o interpretaciones, véase especialmente LAGÜENS, 1992: 129-130; $L D A$, pp. 268 y 270. Frec.: 1: 0,00227.

fallir v. intr. 'faltar, fallar, estar falto de, carecer': et havieron batalla muyt grant et Dios que no falle a la verdad ni fallirá fueron vencidos los castellanos 17.36; et mientre que la paz. se tractava et non fallia sinon por el Padre Santo... 37.81; mas el poder de Dios en tiempo alguno non fallió al rey de Aragón nin falliría 36.584; con grant voluntat que havía de complir las avinenças, et non fallir aquéllas 20.180; et le prometie que en tiempo alguno non le fallira [falliría B, N] 38.36. Etim.: lat. FALLERE 'engañar', 'quedar inadvertido'. Es muy frecuente en cast. en los ss. XII-XIV, en las acep. 'faltar', 'engañar', 'abandonar', 'pecar', 'errar'. Pero falta ya en Alonso Fz. de Palencia y en Nebrija. En el cast. actual sólo se emplea el adj. (ant. part.) fallido (DCECH, II, 845). Cfr. oc. falir falhirv. intr. 'faillir; manquer'. A jorn falit 'à la tombée du jour'. Der.: falbida 'faute, manquement, aillite', faliment 'manquement, faute, erreur' (ALIBERT, s. v. falir). LEVY, s. v. falhir (var.: falbire), da numerosas acepciones: 'faillir, commettre une faute', 'faire défaut, manquer', 'abandoner', 'faire défaut'. En el arag. de Fernández de Heredia fallir (faller, falir) 'acabar, terminarse', 'faltar, fallar, estar desprovisto de, errar' (GILKISON, s. v.). En FA, p. 407 y 408: fallecer 'faltar', fallir 'faltar, errar'. En VM, 133, sólo faillescer 'faltar (en hacer algo)', 'faltar, pecar', 'faltar (carecer de)'. Vid. defallimiento 'falta'. Frec.: falle 1: 0,00227; fallía 2: 0,00455; fallió 1: 0,00227; fallir 2: 0,00455; fallirá 1: 0,00227; fallira 1 : 0,00227; falliría 1: 0,00227.

falso] adj. 'falso', en el sintagma adv. malvadament e falsa: et la dio por innocent et por exempta del grieu crimen quel era levantado por sus fillos malvadament e falsa 16.9 'malvada y falsamente'. La construcción responde a la fórmula típica en aragonés; es decir, cuando se suman dos adverbios en -ment, solo el primero mantiene dicho morfema, mientras que el segundo no lo repite (si bien hay que darlo por supuesto). Frec.: falsa 2: 0,00455.

falsament adv. 'falsamente, faltando a la verdad': et tantost los ditos infamadores confesaron et dixeron al sancto varón que falsament e iniqua havian a lur madre infamada et que len demandavan perdón 14.77-78. Frec.: 1: 0,00227. 
falta s. f. 'falta', 'ausencia, inexistencia': emviaron por licencia al Papa que por rą̧ón que regnase don Remiro monge a falta de natura que le diesse licencia de sallir del Orden 20.70. Etim .: del lat. vg. *FALLITA, fem. del part. *FALLItus 'faltado', de FALLERE 'quedar inadvertido' (BDELC, p. 266). Frec.: 1: 0,00227.

fama s. f. 'fama': tanto oyó la su buena fama que en su vida no fallavan [sic: por fablavan] de otro cavallero sino desti don Alfonso 19.26. Frec.: 5: 0,01136.

fambre s. f. 'hambre': los habitadores de la dita ciudat sufriessen grant mal et fambre 36.27; e las gentes murían de fanbre 33.113. Del lat. vg. FAMIS, * FAMINIS, acus. FAMINEM (DCECH, III, p. 312). Es general en las lenguas románicas: port. fome, gall. y ast. fame, cast. hambre, cat. y occ. fam, franco-provenzal fam, famena, fr. faim, famine, romanche fom, piamontés fam, it. fame, sardo fàmine, siciliano fami, rumano foame (Vallés, 2007: 284). Frec.: fambre 3: 0,00682; fanbre 1: 0,00227.

familiar adj. 'familiar, cercano en el trato': et por aquesto fue nombrado el Benigno, porque fue el mas cortés de palavra et el mas familiar et el mas avinent, 39.3. Deriv. de familia. Frec.: 1: 0,00227.

familiaridad s. f. 'familiaridad', 'confianza mutua': et parecía verdat semblant por la grant familiaridad que era entre entramos 14.55. Del lat. FAmILIARITAS, -ATIS. Frec.: 1: 0,00227

farahón s. m. 'faraón': enbioles maldición de moscas et puedes dezir que era una de las maldiciones de farahón 36.597. Frec.: 1: 0,00227.

fartador adj. 'saciador' 'que sacia o satisface el hambre': et fue padre de fillos buerfanos, guarda et deffendedor de biudas, fartador de pobres, sostenedor de barones...35.177. Deriv. de fartar y éste de FARTUS 'relleno' (DCECH, III, p. 323). Frec.: 1: 0,00227.

fasta prep. 'hasta': e vençieron la batalla e murieron de los moros que de pie que de cavallo fasta ${ }_{L}$ mil moros, 18.113. Aparece solamente en el ms. N, copia hecha en el s. XvI por un navarro; por lo demás, entro (vid.). Frec.: 7: 0,01591.

favla s. f. 'el habla, la palabra, la facultad de hablar': por aquesti pecado el dito Berenguer Remón perdió la favla [paraula N] 30.21. Vid. fabla. Frec.: 1: 0,00227.

fablar] ( var.: favlar]) v. intr.: 'hablar': con el quoal avía seydo fablado casamiento con dona Urraca 19.98; et depués de grado en grado de cada un conte según que devalloron el $<$ uno> del otro, fablaremos et lur vida recontaremos 21.4-6; tanto oyó la su buena fama que en su vida no fallavan (error por fablavan) de otro cavallero sino desti don Alfonso 19.26; como ya en Borja con los navarros yera seido favlado de la cosa 20.68; como en continent quél favlava sanosament con alguno nin dalguna cosa fues yrado...25.24. Del lat. FABULARI 'conversar, hablar', deriv. de fabUla 'conversación', 'relato', 'cuento, fábula' (DCECH, III, p. 296). Frec.: favlar 4: 0,00909; favlaron 1: 0,00227; flavasemos 1: 0,00227; favlava 1: 0,00227 ; favlemos 1: 0,00227 ; favló 2: 0,00455; favlado 2: 0,00455; fablaremos 1: 0,00227; fabló 1: 0,00227; fablado 2: 00455 . 
favor s. f. 'favor': los ditos dos hermanos no quisieron serprincipales acusadores mas consintieron que ayudarian a dar alguna favor a ell sobre la dita difamción. 14.57. Etim.: tomado del lat. FAVOR, -ORIS 'favor, simpatía'. Frec.: 6: 0,01364.

fazienda] s. f. pl. Parece que en nuestro texto tiene el sentido de 'acciones, hechos, actuaciones, actividades, artimañas': el aquéll en el rio de Cinqua fizo afogar por prender vengança de las malvadas faziendas [maldades e paraulas $\mathrm{N}$ ] que feitas avía contra éll 36.45-47. Etim.: del lat. FACIENDA 'cosas por hacer', pl. neutro del participio de futuro pasivo de FACERE 'hacer'. Comp. hacienda, facienda en Auto de los Reyes Magos: 'asuntos, ocupación'; Berceo 'estado (de una persona)', 'importancia, prestigio', 'faena, trabajo por hacer' (acepción etimológica común con el cat. faena, port. y gall. fazenda 'trabajo, faena', 'hacienda'); de la acepción 'asuntos' se pasó a 'bienes, riquezas' (DCECH, III, p. 297-298). Comp. facienda 'hecho de armas, pelea', que recoge el $D R A E\left(1970,3^{a}\right.$ acepción), con la indicación de antiguo. Pueden verse ejemplos de distintas acepciones en cast. med. en DME, s. v. facienda; las más parecidas a la acepción de la Crón. SJP. son 'batalla, pelea' y 'obras'. Frec.: faziendas 1: 0,00227.

fe s. f. 'fe': En tiempo de aquestos recibieron la fe christiana los godos 3.21. Etim.: del lat. FIDE(M) 'fe, confianza' (Segura, 2001: 290). Frec.: 17: 0,03864.

febrero s. m. 'febrero': que home conta $X x^{\circ}$ kalendas de febrero 39.44. Etim.: del lat. FEBRUARIUS [MENSIS] (Segura, 2001: 285). Es general en arag. med. y moderno. Solo se encuentra algún caso raro con metátesis: «anno Domini millesimo $\mathrm{CCC}^{\circ}$ $\mathrm{XL}^{\circ}$ nono, dia jueues, intitulado pridie nonos de frebero, hen el logar de Vielsa, ante la eclesia mayor, do yeran personalment plegados \& constituidos...» (DLAA, doc. n. ${ }^{\circ}$ 113, de Bielsa, 1349; p. 163, lín. 2). Frec.: 1: 0,00227.

federades (feredades según nuestra lectura del ms. B) s. f. pl. 'horrores, espantos': he oydas las rumores et tabustoles et federades de las gentes sin nombre... 36.478. En el ms. B, fol. 68r., lín. 14-15, se lee feredades. En la VC: les rumors e los tabustolls e feredats de les gents VC, p. 141. Del lat. FERITATE(M) 'fiereza, ferocidad, crueldad' (DCVB, t. 5, p. 806; DECLIC, III, p. 968). Comp. cat. feredat 'horror, por intensa'; 'gran admiració barrejada d'espant' (DCVB), 'horror, impressió espantosa' (DECLIC). Comp. feredá 'miedo' en el Bajo Aragón (Andolz, 1992, s. v.); AltabA (1985: 51) recoge feredá 'miedo, temblor': «me entró una feredá al pasar por la noche junto al cementerio», que concuerda con la acepción de nuestro texto; en cambio, arag. ant. feridat, feredat 'ferocidad' (GILKIsON, s. v.) y feredat 'braveza, fiereza' ( $V M$, III, p. 137) no parece que se ajusten al significado con que se emplea en la Crón. SJP. Frec.: 1: 0,00227.

feito (var.: feyto, fecho) s. m. 'hecho' (acción, gesta; cosa, asunto; ocasión; cuestión; acto, empresa, labor, obra): Et aquesto fecho tornose en su tierra queriendo resemblar en los fechos et noblezas a sus predecessores 36.163 [en el ms. N, que sigue en esta parte la ed. crítica; sin embargo, en el ms. B leemos: Et aquesto feito tornose en su tierra, 
et queriendo resemblar en los feitos et noblezas a sus predecessores]; no queremos mas favlar del feito 2.5; en antes que digamos res de sus feitos recontaremos en qual manera fue rey de Navarra 17.3; a los que se acaeşen en tal feyto 19.95; et havía todos los feytos muit complidos 32.5. Del lat. FACTUM. Frec. (conjuntamente como sust. y como p. p. del v. fer): feito 39: 0,08864; feitos 2: 0,00455; feyto 11: 0,02500; feytos 2: 0,00455; fecho 4: 0,00909; fechos 1:0,00227. feldat s. f. 'fidelidad'. Vid. fieldat.

fembra] s. f. 'hembra, mujer, persona de sexo femenino': de muytas nobles mulleres et de otras fembras avies procriados muytos fillos 36.32. Del lat. FEMINA. Frec.: fembras 2: 0,00455.

fer v. tr. 'hacer': «a Dios misericordioso demando quel vos faga regnar luengament segunt la suya deytura» 35.279; «que fagades dellos la justiçia que tenrredes por bien»19.88; et quando aquesto fue feito, la discordia de sus vassallos fue acallada 38.616; aqui femos fin et término a los reyes de Aragón 21.1; supo fer a sus vassallos exolvidarla 38.626; «fet ne lo que von [vos $\mathrm{N}]$ pueredes [sic, por queredes] 38.139; et feyta la reverencia por el dito rey al Padre Santo... 38.175; la qual cosa et por otras que fizo a su cunnyado 38.619; las gracias que le avian fechas [feitas B] 35.206. Del lat. FACERE 'hacer'. // fer mal sus afferes tiene el sentido de 'comportarse mal, indignamente' o quizá también 'tener entendimiento amistoso o trato sexual engañando a otra persona': Et conselló a sus hermanos Ferrando et Gonçalvo que acusassen la reyna, lur madre, al rey, su padre, que ella fazía mal sus afferes [aferes N] con el dito cavallero 14.52-54. Se repite la expresión: el dito García, de grant ira movido, dixo a su padre que la reya fazía mal sus afferes con el dito cavallero 14.59. // Se utiliza en en la perífrasis verbal de obligación aver a fer 'tener que hacer': quando havía d'entrar en batalla o havía afer cabalgada o qualsque otros afferes periglosos quel avies afer con los moros, toda vegada tiemblava 13.2-4. Frec.: fer 30: 0,06819; ferle 1: 0,00227; ferlo 1: 0,00227; fernos 1: 0,00227; femos 1: 0,00227; fes 1: 0,00227; fet 2: 0,00455; feita 20: 0,04546; feitas 13: fechas: $1: 0,00227 ; 0,02955$; feyta $10: 0,02273$; feytas 4: 0,00909; fezieron 1: 0,00227; fezieronlo 1: 0,00227; feziesen 1: 0,00227; fezo 1: 0,00227; fiço 1: 0,00227 ; ficieronle 1: 0,00227 ; fazen 1: 0,00227; fazer 15: 0,03409; fazet 1: 0,00227; fazía 10:0,002273; fazían 7: 0,01519; faziendo 4: 0,00909; faga 2: 0,00455; fagades 1 : 0,00227; fagamos 1: 0,00227; fagan 1: 0,00227; fará 1: 0,00227; faré 1: 0,00227; faría 7: 0,01591; farían 5: 0,01136. [La frecuencia de feito, feyto se da teniendo en cuenta conjuntamente las formas de participio y de sustantivo: vid. feito].

fer duelo per. vnl. 'afligir', 'dolerse': toda Spannya firo grant duelo et non sin razón, porque grant gent de moros vinieron en Spannya 35.309 ('se afligió mucho').

feredades s. f. pl. 'horrores, espantos'. La ed. crítica da federades (vid.). 
feria s. f. 'cualquiera de los días de la semana, excepto el sábado y el domingo'. Se registran feria tertia 'martes', feria quinta 'jueves', feria VI 'viernes': en el dia de la cena de Nuestro Senyor, feria quinta, nonas aprilis 17.81; en la segunda semana de Quaresma, feria tertia, et ora prima 17.61; feria VI, depués Pascua, 17.82. del lat. FERIA 'día de fiesta'. Comp. en port. terça-feira 'martes', quinta-feira 'jueves', sexta-feira 'viernes' (CunHA, 1986: 352, s. v. feira). Frec.: 3: 90,00682.

ferida s.f. 'herida': qui sacó la mano por la ferida [feridura N] del vientre de su madre, 12.33; por la ferida muytos de los fuyentes murieron 36.231. De la forma femenina del p. p. de FERIRE. Comp. feridura. Frec.: 3: 0,00682.

ferido adj. 'herido': que muerta et ferida yera sobre la mar 38.270; ni fizo asemblant que fues ferido, de la qual cosa todo homme se dio a grant maravella 38.277-278 // s. m. 'persona herida': de manera que al dia siguient cuydando haver otra batalla no vieron sino los feridos et los muertow que dieron en alcanz entro Almudebar. 18.53. Del p.p. del v. FERIRE 'herir'. Frec.: ferido 4: 0,00909; feridos 2: 0,00455.

feridura s. f. 'herida': vido por la feridura que la dita reyna avía en el vientre aparecía una mano de criatura, 12.8. Deriv. de ferir. Comp. feridura 'herida', 'cuchillada', en VM, III, p. 137. Frec.: 1: 0,00227.

ferir v. intr. 'golpear, atacar, venir encima con contundencia': entendía calçadament a ferir en los francesses 36.650; todos días en la buest fería adiesso aquá adiesso allá 36.576; el rey de Aragón les fue detrás et vigorosament et baronil firió en los franceses 36.654; todo el poder del dito castiello de Callar vino a ferir en la buest del dito don Alfonso 38.544-545. // v. tr. 'causar una herida': con una sayeta por la manga de la loriga firiolo en el costado 17.121-122; et a la dita reyna firieronla con una lança por el vientre de la qual murió 12.4-5. Etim.: del lat. FERIRE 'golpear, dar con un objeto'. Esta acepción es con la que se usó en cast. en la Edad Media, junto a la de 'acometer, atacar' hasta 1490, según Corominas (BDELC, p. 317; DCECH, III, p. 346). En la Crón. SJP. se utiliza con los dos sentidos, el medieval 'golpear' y el moderno 'causar una herida'. Frec.: ferir 2: 0,00455; fería 2: 0,00455; ferían 1: 0,00227;

feu s. m. 'feudo': por razón de las tierras que tenía en fe (errata por feu) por el dito rey don Pedro 36.404; reconosció tener en feu $[f e \mathrm{~N}]$ et de ius sennyoría del dito rey don Jayme el regno de Mallorquas et islas... 38.468; et con él guerró por el fue [feudo VL] de Torrella (errata, en el ms. E por feu) 36.438. Etim.: puede provenir, igual que el cast. feudo, del bajo lat. FEuDum, latinización del fr. ant. y occ. ant.

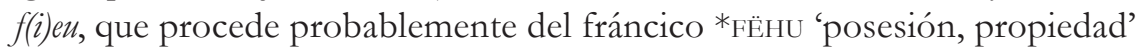
(BDELC, p. 271; DCECH, II, p. 884). Pero para la forma aragonesa feu no hace falta pensar en el bajo lat. FEUDUM, que hubiera dado regularmente feudo, sino que puede provenir del germ. *FËHU, bien directamente, bien a través del occ. ant. feu (LevY, s. v.) o del cat. feu (DGLIC, s. v.; DECLIC, s. v.; DCVB, s. v.). Frec.: 4: 0,00909. 
fiar] v. tr. y prnl. 'confiar, fiarse': el qual fiava muyto de amigos de Navarra, en special de dos que eran grandes hombres, 20.218; et se fiava en él como en aiutorio de vida 14.39. Del lat. vg. *FIDARE, modificación del lat. FIDERE (DCECH, II, p. 885). Como se ve, puede regir prep. de o prep. en. Frec.: fiava 2: 0,00455.

fidalgo] s. m. 'hidalgo': nonde murió VI homes fidalgos [Equites VL, pág. 225] et VI de pie [murieron de cavallo et de pie XI ommes N] 38.538; fue muyt buen rey et muyt francho a los fidalgos 20.96. Síntesis o contracción de fillo d'algo 'persona con bienes de fortuna' (DCECH, III, p. 359). El DME define el cast. med. fidalgo como 'nombre genérico de todos los nobles u hombres libres y exentos por linaje'. Pueden verse ahí ejemplos en cast. de los siglos XI al XV. Cfr. algos 'bienes'. Frec.: fidalgos 3: 0,00682.

fiebre s. f. 'fiebre': ho encara el rey francés ne prendió la fiebre muyt grant et fue muyt grievement enfermo 36.605-606. Del lat. FEBRIs (DCECH, II, p. 888). Frec.: 2: 0,00455 .

fiel adj. 'fiel': la fe christiana, en la qual él muyt fiel sin toda tacha estuvo et perseveró todos tiempos, 34.175; "que tu ames los tus barones, cavalleros et las tus fieles gentes qui han a mi amado coralment» 35.265. Del lat. FIDELIS, deriv. de FIDES 'fe'. Frec.: fiel 1: 0,00227; fieles 2: 0,00455.

fieldat (var.: feldat) s. f. 'fidelidad': et fizo fer los ditos barones et universidades jurar de servar feldat al dito infant, assi como a lur sennyor natural 35.32; le fizo homenage et sagrament de fieldat por si et por sus successores 38.471. Del lat. FIDELITATE(M). Se registra fieldad en cast. med. (cfr. DCECH, II, p. 877; DME, s. v., p. 1143). Frec.: fieldat 5: 0,01136; feldat 1: 0,00227.

fielment adv. 'fielmente': et el dito don Sonyer, conte de Urgell et tio lur, el qual governó los ditos condados bien et fielment XX annos. 25.8. Frec.: 2: 0,00455.

fiesta s. f. 'fiesta': feyta fiesta honrada assí como yes acostupnado en semblant caso 38.22. Del lat. FESTA. Frec.: 6: 0,01364.

figura s. f. 'figura': enbioles maldición de moscas et puedes dezir que era una de las maldiciones de farabón; et eran de tal natura, figura et collor que... 36.597; qui era de muyt estranna et orrible figura 1.23. Del lat. FIGURA 'configuración, imagen, forma'. Frec.: 2: 0,00455 .

filial adj. 'relativo o perteneciente a los hijos': veyendo et reconosciendo que de sennyor traydor ningún nascimiento filial non podría exir leal, 17.15. Cultismo tomado del lat. filialis. Frec.: 1: 0,00227.

filla s. f. 'hija': tractó que la filla de don Alfonso havies por muller 38.614; de las fillas, la primera buvo nombre Ysabel 38.452. Del lat. FILIA. Frec.: filla 56: 0,12728; fillas 14: 0,03182 .

fillastro s. m. 'hijastro': et affilló et heredó [heredero N] al dito Remiro, su fillastro, en Aragón, 14.91. Deriv. de fillo. Frec.: 2: 0,00455. 
fillo s. m. 'hijo': et de otra part engendró un fillo bort nombrado Sancho 16.30; que enviassen por el infant don García, fillo de don Remiro, fillo de don Sancho rey de Navarra 20.5969; et dexó su regno a don Jayme, fillo de su hermano, 38.602; de los quales fincoron dos fillos 38.588. Fortún Garceyz de Viel, fijo de don Castán de Viel 18.105 [La forma fijo únicamente aparece en el ms. N, copia del s. XVI muy castellanizada]. Del lat. FILIUS. Es general en arag. med. y moderno. Es también general en las lenguas románicas, con pequeñas diferencias por la evolución fonética propia de cada lengua o por la grafía: port. filho, gall. fillo, cast. hijo, gasc. hilh, cat. fill, occ. filh, franco-provenzal fily, fr. fils, romanche figl, it. figlio, siciliano figgio, sardo fiqu, rumano fiu, arumano bilju (Vallés, 2007: 287). Frec.: fillo 146: 0,33185; fillos 81: 0,18411; fijo 2: 0,00455.

fin s. f. 'fin, término, final': En la fin del dito mes de junyo vinieron en el dito sitio XX galeras 38.564. Del lat. FINIS. Frec.: 11: 0,02500.

finalment adv. 'finalmente': mas finalment por tal que aquesta discordia se apagas, el dito don Phelip tractó que la filla de don Alfonso havies por muller el dito don Jayme 38.613. Frec. 20: 0,04546.

fincar] v. intr. 'quedarse, permanecer': fincó en el sitio con toda la gent en el Pueyo clamado de Sancho 18.4; et rey francés nin las sus gentes non podian mas sofrir que fincassen alli porque de part alguna non les ossava venir vianda alguna 36.620; la segunda buvo nombre Costancia et fincó con su madre en el regno de Secilia 36.699; de los quales fincoron dos fillos et una filla 38.588; ordenó el infant quel noble don Phelip de Celuza, qui era venido de Secilia, fincás governador en la isla 38.578-579 [romasés governador en l'illa, VC, p. 175]. La VC usa en los casos correspondientes romanir. Etim.: del lat. vg. *FIGICARE, deriv. del lat. FIGERE 'clavar, hincar', 'fijar, sujetar'. Ya en la época imperial debió de cambiarse el lat. vg. *FIGICARE en *FICCARE, con síncopa muy temprana, gracias al parecido de las dos consonantes G y C. La variante castellana ficar, que aparece tb. en doc. riojano de 1044, y en otros de la época arcaica, no es ajena al Cid ni a Berceo, pero aparece sobre todo en textos leoneses y aragoneses (FA, TILANDER, \240.6). Lo cual está de acuerdo con el hecho de que esta es también la forma más usada en portugués, y de que el cat. y la lengua de oc. no conocen otra forma que ficar, de acuerdo con los demás romances (fr. ficher, engad. ficher, it. ficcare). El port. y el gall. distinguen fincar 'clavar, hincar' de ficar 'permanecer'. El ast. emplea fincar con ambas acepciones. El cast. mostró propensión a generalizar desde antiguo la variante con $n$. Pero quizá existiera en germen una tendencia similar a la portuguesa, ya que los ejemplos de ficar corresponden a la acep. intransitiva 'permanecer': ficar 'permanecer' / fincar ojo 'clavar la vista' en Alex.; ficar 'quedarse' / fincar los ynojos, en Berceo (DCECH, III, p. 363). Sin embargo, adviértase que de las once acepciones que distingue el DME, s. $v$. fincar, la que aparece con un mayor número de ejemplos es la séptima, 'quedar, permanecer'. En arag. 
mod. fincar es solamente 'hincar, clavar', no conservándose rastro de la acepción med. 'permanecer'; por otro lado, también se usa en algunas zonas ficar 'meter, introducir' (cfr. ANDOLZ, s. v.; ROHLFs, DDPA, s. v.); el EBA (1999: 931-932) confirma este uso en arag. mod., en puntos de la mitad oriental del Alto Aragón (Sobrarbe y Ribagorza). Frec.: fincada 1: 0,00227; fincado 5: 0,01136; fincados 5: 0,01136; fincarían 1: 0,00227; fincaron 9: 0,02046; fincás 3: 0,00682; fincassen 2: 0,00455 ; fincava 2: 0,00455 ; fincavan 2 : 0,00455; fincó 20: 0,04546; fincoron 8: 0,01818.

finir v. tr. 'terminar, concluir': et aquí finir loablement sus días 35.208. // v. intr. 'morir, fallecer': et finó en la ciudat de Huesca en dignidat real 20.299. Del lat. Finire (cfr. Devoto, s. v.). Comp. it. finire, con los mismos sentidos; cast. ant. finir (DME, s. v.). Fue habitual en arag. med.: Véase por ejemplo en $V M$, III, p. 143; GILKISON, s. v. Frec.: finir 1: 0,00227; finó 3: 0,00682; finió 1: 0,00227.

finido adj. y p. p. del v. finir, 'terminado, concluido': et finida la batalla... 34.99; fue firmado et finido por cada una de las partes con seguredades firmes en poder del rey 36.253. Frec.: finido 1: 0,00227; finida 1: 0,00227.

firimiento s. m. 'acción de herir o de golpear, ataque, acometimiento': et aquesti firimiento del rey d'Aragón duró entro que buvieron decendido el coll de Panizares, 36.655. Deriv. de ferir. No se registra en GiLKISON. Comp. feridura. Frec.: 1: 0,00227.

firmar v. tr. 'afirmar': «et firmo aqui de present de mantener et fer dezir a todo homme...» 38.321. // 'firmar': mostró por tal como él bi avía a firmar et a conferir 38.77. Del lat. FIRMARE 'afirmar, consolidar, dar fuerza, afianzar' (cfr. BLÁNQUEZ, s. v.). Ferc.: firmar 1: 0,00227; firmo 1: 0,00227.

firmado adj. y p. p. del v. firmar 'firmado': et cada uno prendie sus cartas muyt bien firmadas et seguradas 19.188; fue acordado et firmado 38.474. Frec.: firmado 2: 0,00455; firmadas 1: 0,00227.

firme adj. 'firme, fuerte', 'válido'; fem. firma: et aqui sanctament et con firma [confirmada $\mathrm{N}$ ] fe catholica sirviendo a Dios estuvieron luengo tiempo 5.9; lo que ellos farian ni ordenarian cada una part havies por firme et agradable 20.157; cada una de las partes con seguredades firmes en poder del rey 36.254. Del lat. vg. FIRMIS, lat. FIRMUS (DCECH, II, p. 902). Frec.: firme 2: 0,00455; firmes 1: 0,00227; firma 1: 0,00227 .

firmeza s. f. 'seguridad, consistencia': et a mayor firmeza fueron feitas cartas publicas a perpetua memoria 38.472. Etim.: deriv. de firme < lat. vg. FIRMIS, lat. FIRMUS (DCECH, II, 902), con sufijo -eza < lat. -ITIA, que forma sustantivos de cualidad sobre la base de adjetivos (Pharies, 2002: 248). Frec.: 2: 0,00455.

flaco adj. 'débil, poco resistente, endeble': comidiendo por do se podría entrar, vio flaco lugar en el muro forano 17.117-118. Etim.: del lat. FLACCus 'flojo, fláccido'. Según Corominas-Pascual es semicultismo. Se documeneta frecuentemente 
en cast. med., desde Berceo, pero con el significado de 'débil, sin fuerzas'; Nebrija recoge ya la acepción 'magro, delgado' (DCECH, II, 906). Frec.: 1: 0,00227 .

flaqueça s. f. 'debilidad': «Sennyor, entiende en la mia ayuda et tu Sennyor cuyta [escuyta $\mathrm{N}]$ a la mi flaqueça» 35.243. Etim.: deriv. de flaco. El DCECH, II, p. 906, da la 1. ${ }^{a}$ doc. de flaqueza en Alonso Fernández de Palencia (1490) y en Antonio de Nebrija (1495). La Crón. SJP. la adelanta en más de un siglo. Frec.: 1: 0,00227.

florir] v. intr. 'prosperar, florecer': Et mudólos by del monesterio de Clunyego de la orden de San Beneditto, qui a la ora pululiva et floriva en toda la christiandat 14.99. Etim.: del lat. FLORERE. Descendientes de este verbo se han conservado en todos los romances, salvo en cast. y port., que prefieren florecer $<$ lat. FLORESCERE (DCECH, II, pp. 917-918). Se registra florir 'florecer, prosperar, crecer rápidamente' en Fernández de Heredia (GILKIson, s. v.). Es interesante hacer notar que la forma verbal floriva constituye uno de los pocos ejemplos de conservación del morfema típico del aragonés para la formación del pretérito imperfecto de indicativo, [-ba]. Frec.: floriva 1: 0,00227.

forano adj. 'forastero, extraño, extranjero', si bien en el texto vale más bien por 'exterior, de fuera': vio flaco lugar en el muro forano 17.118. De lat. tardío FORANUS, deriv. del adv. FORAS (DCV B, t. 5, p. 967, s. v. forà; DCECH, II, p. 971). En el arag. de Fernández de Heredia, forano 'forastero, extraño, extranjero' (GILKIson, s. v.), así como en FA (Tilander, FA, p. 424), acepción con la que se conserva hoy en arag. mod. (cfr. ANDOLZ, s. v.). Frec.: 1: 0,00227.

forçar v. tr. 'forzar, presionar, obligar': mas non lo quiso prender entro ba quende fues forçado por el Padre Santo 38.609. // 'violentar, violar, forzar': et cómo los franceses farían todos días diversos males, grenges et desonores, assi en desflorar virgines et desmaridar mulleres maridadas et forçar mulleres biudas 36.193. Deriv. de fuerşa < lat. tardío FORTIA. Comp. forzar 'estuprar, violar una mujer' en FA, p. 425. Frec.: 1: 0,00227.

forma s. f. 'forma, modo, manera': el qual perdió su tierra en la forma siguiente 3.80. Etim.: tomado del lat. FōRMA 'forma, figura, imagen'. Frec.: 1: 0,00227.

fornido] p. p. del v. fornir, 'abastecido, aprovisionado': como tan cuytosament vino el dito rey con las buestes que non podieron seer fornidos de res 36.138. El v. fornir 'abastecer, aprovisionar, proveer de lo necesario' provendría, lo mismo que el francés fournir, de un étimo fráncico *Frumjan 'éxecuter' (DaUZAT / Dubois / MitTERAND, 1977: 318). El DCECH (t. II, p. 933, s. v. fornir) acepta esta misma etimología y documenta la primera aparición de esta palabra en un Invent. arag. de 1375. Frec.: 1: 0,00227.

fornimiento s. m. 'provisiones, aprovisionamiento, abastecimiento, suministro': et muytos de los vaxiellos con fornimiento de viandas.. 36.232; por el qual destrenimiento los nobles varones qui dentro eran sufrieron grant freytura de viandas et de otros fornimientos 
36.137. Deriv. del v. fornir. Se registra fornimiento 'provisiones' y fornir, furnir 'aprovisionar, proveer, suministrar, abastecer' en Fernández de Heredia (GILKISON, s. v.). Frec.: fornimiento 1: 0,00227; fornimientos 1: 0,00227.

fortaleza s. f. 'calidad de fuerte', 'reciedumbre, dureza': et non era de grant fortaleza pero el dito Exemen d'Artieda deffendióla 36.337. / / 'fortificación, recinto fortificado': et porque las fortalezas de la tierra se tenían por don Alfonso de Aragón plegaron uno contra otro sus gentes et sus buestes por haver batalla 19.169. Del occ. ant. fortalessa, del lat. FORTIS, con el sufijo galo -ARICIUS; en origen adj., luego sustantivado (DCECH, II, p. 972, s. v. fuerte). Frec.: fortaleza 1: 0,00227; fortalezas 2: 0,00455.

fortuna] s. f. 'fortuna': por tal que paz et concordia fues entrellos qui todos tiempos yeran seydos unos en fortunas et en prosperidades 20.152. Frec.: fortunas 1: 0,00227.

francament adv. 'libremente, con franquicia o exención': el dito rey soltó [saltó $\mathrm{N}$ ] francament et quitia [quita $\mathrm{N}]$ los fillos del dito rey Carlos et todos los otros barones que pressos tenía por rahenas del dito Carlos 38.116. Frec.: 3: 0,00682.

francés adj. y s. gentilicio 'francés': et mientre quel rey francés, su buest dolenta, partían del dito condado de Ampurias... 36.636; estando aqui, el legado y la buest francesa 38.286; la ciudat de Girona fincó stablida de la gent francessa 36.682; fue enpreso entre los franceses qui eran en la stablida fincados et el rey lur... 36.683. Frec.: francés 7: 0,01591; francesa 1: 0,00227; franceses 33: 0,07501; francessa 1: 0,00227; francesses 6: 0,01364.

franco (var.: francho) adj. 'franco, honrado, generoso, liberal': fue muyt buen rey et muyt francho a los fidalgos 20.95; su fillo primogenito don Alfonso el Franco regnó 37.3 . // 'libre, exento': et por aquesta manera [razón $\mathrm{N}]$ sacó el conde Guiffre el condado de Barchinona de poder de sennoria [de la seynoria del rey N] de Francia, do depués fue franco 23.72. Del germ. FRANK, nombre de los francos, dominadores de la Galia, que constituyeron allí la clase noble, exenta de tributos (DCECH, II, p. 945). Frec.: franco 2: 0,00455; Franco 2: 0,00455; francho 1: 0,00227.

franqueza] s. f. 'franquicias, exenciones de impuestos': et confirmó todos los privilegios que avian de franquezas et todas buenas costumpnes 36.516. Deriv. de franco. Frec.: franquezas 1: 0,00227.

fraternal adj. 'fraternal': et por su muller sennorió Castiella et León entro Portugal, porque por successión fraternal [paternal N] le era pervenido. 14.22. Deriv. de fraterno < lat. FRATERNUS. Frec.: 1: 0,00227.

frau s. m. 'fraude': et assí como savio sennyor, disimulando el dito frau... el dito rey don Jayme sen tornó en su tierra 38.52-54. Etim.: del lat. FRAUS, -DIS 'mala fe, engaño, perjuicio' (BDELC, p. 281). La primera doc. que da CoROMINAS para el cast. fraude es de 1490. La doc. de frau en la Crón. SJP. la adelanta en más de un siglo. Extrañamente, no aparece en el voc. del $V M$, ni en el de FA. Pero en Fueros de 1350 se lee la forma frau (femenina como 
en latín y en catalán antiguo): «si alguno... defraudará o fará frau a los ditos fueros, que sobre la dita frau los iurados de cadaún lugar ensemble con el ordinario de aquel lugar puedan façer provissión devida» (Fueros de 1350, Tilander, 1935: 28). Según indican Corominas-Pascual, falta fraude en los autores medievales de los cuales existe glosario, y todavía en Nebrija y C. de las Casas, pero es ya usual en los clásicos (Cervantes, Góngora, Ribadeneira) (DCECH, II, p. 950). Es una de las abundantes contradicciones que se producen entre formas castellanas y aragonesas: mientras que la forma aragonesa se usa ya en la Edad Media, la correspondiente castellana proveniente del mismo étimo, registra un uso posterior). En la Crón. SJP. es masc. Usual en arag. med. (cfr. Andolz, s. v.), se doc. en Fernández de Heredia frau, frao (GILKIsON, s. v. frao); fran 'fraude' en DLAA (docs. $\mathrm{n}^{\circ}$ 28, de 1274; 108, de 1338; 129, de 1380; 140, de 1435; 150, de 1495). La mención del doc. $\mathrm{n}^{\circ} 28$ (e todos fraus e enganos, DLAA, p. 41, lín. 158) es muy anterior a la de Fueros de 1350, ya que es un documento de Huesca de 1274; ffrau 'fraude' en $D J$, docs. de 1362 y de 1484; fran en docs. de 1435 y de 1471 (EDA, II, p. 208). Es usual en el aragonés notarial y así, por ej., se ve en un documento de 1402 del valle de Tena (VÁzquez Obrador, 2020: 99): «Huytanta florines doro dAragon, renunciantes a toda excepcion de frau, etc., los quales bos prometemos dar \& pagar daquj al dia \& fiesta de San Gil» (DNT, I; 1401: 22.6). El DRAE, 1970, recoge frau 'fraude' indicando que es ant. y utilizado en Aragón. Es forma usual en cat. (FABRA, s. v.; DCVB, s. v.; IEC, DL/C, 2007, s. v.) y en occ. (cfr. Alibert, s. v.]. Frec.: 1: 0,00227 .

fray 'título que se antepone a los hermanos de una orden, ya sea monástica, militar, etc.': et esdevinose que en una batalla fray Pere de Moncada, maestro [maestre $\mathrm{N}]$ de la orden de cavallería del Temple 36.56. Apócope (debida al empleo proclítico ante el nombre propio) de frayre o freyre 'hermano' del occ. fraire < lat. FRATRE(M). Comp. freyre. Frec.: 1: 0,00227.

frescament adv. 'frescamente, recientemente': qui con navilio de galeras era venido de Secilia frescament 36.546. Comp. «frescamente, recens, recenter» en Nebrija, Voc. esp. lat., hacia 1495 (citado en DME, s. v., p. 1171). Frec.: 1: 0,00227.

freyre (var.: frayre) s. m. 'fraile, hermano de una congregación religiosa': et murió devotament estando freyre menor 38.452; pusose en la orden de los freyres menores 38.449. Etim.: tomado del occ. fraire 'hermano', y este del lat. FRATER, -TRIS (BDELC, p. 280; DCECH, II, p. 942, s. v. fraile). Según Corominas la forma freire se explica por una mezcla de la forma occitana fraire con la forma francesa frère. Es habitual freyre en arag. med.: en VM, III, p. 146, s. v.; FA, p. 426. En Fernández de Heredia se registra frayre, frare, frayle, freyre, fraire, freyle, freyr (GILKIsON, s. v.); en $L M M$, p. 174, fraire; en DLAA: frayre, freyre, etc. (REIDY, 
1977: 176). Obsérvese el uso de la forma frayre en este refrán aragonés del s. XIV: «Amor non dura guayre, / e si dura guayre / mala por al frayre» (Ríus, 1926: 371). Andolz (1992, s. v.) registra como actual el uso metafórico de fraires 'amapola' en Biel, en las Cinco Villas alto-orientales. El EBA (1999: 969) recoge fraire 'fraile' en Plana de Uesca, Alta Ribagorza y Fonz; pero es mucho más común en el Alto Aragón la forma flaire, para la que el EBA (p. 942) registra catorce referencias. Frec.: freyre 1: 0,00227; freyres 9: 0,02046; frayres 1: 0,00227.

freytura s. f. 'escasez, falta; corte en el aprovisionamiento, desabastecimiento': por el qual destrinimiento los nobles varones qui dentro eran sufrieron grant freytura de viandas et de otros fornimientos 36.136; en la ciudat avía grant freytura de viandas et malautia fuert grant 36.609; et <por> la freytura grant que sofrían grant mortaldat se cresció 36.610. Etim.: del lat. FRACTURA 'corte, rotura, fractura, raja, grieta, ruptura, rompimiento', deriv. de FRANGERE 'romper'. Comp. cat. fretura 'mancança, necessitat', occ. ant. frachura, fraitura 'id.' (primeramente significó 'falta, pecado'). En cat. se documenta ya en el s. XIII (DECLIC, IV, p. 199, s. v. fretura). En cat. ant. se documenta tb. en las formas freitura, freytura, fraytura. En la VC, p. 145, aparece fretura. Desde el siglo xv entró en decadencia en cat. y hoy está anticuado. Afirma Coromines que no se mantuvo descendiente del lat. FRACTURA en ninguna lengua románica a excepción del cat. y el occ. Obviamente, no cita ningún ejemplo en arag. med., donde se documenta, además de en la Crón. SJP., en las obras de Fernández de Heredia (freytura, fretura 'escasez, carencia, falta, necesidad'; freyturar, freiturar, frayturar 'estar falto o carente de'; freyturoso 'necesitado'. Vid. GiLkison, p. 70, s. v.). No se conserva en arag. mod. Aparece en la Crónica de Ramón Muntaner (Barcelona, Barcino, 1927-1952), p. 194: «on havia gran freitura de vianda». Para el cat. vid. también DCVB, s. v. Frec.: 3: 0,00227.

fridor] s. f. 'frío, frialdad': non temian fridores ni calores porque yeran todos tiempos ossados 12.54. Etim.: deriv. de frido (en la Crón. SJP. frio), del lat. FRIGĬDus 'frío' (DCECH, II, p. 959). En arag. mod. se registra frior 'frío, frialdad' en el Sobrepuerto, fredor 'frío' en el valle de Chistau, fredor 'frialdad' en el valle de Biesa, fredo 'frío' en Benasque y la Alta Ribagorza, así como en el valle de Lierp, en Chuseu y en Torres de lo Bispe, en Ribagorza (EBA, 1999, p. 975, s. v.). Frec.: fridores 1: 0.00227 .

frio s. m. 'frío': envió de conpannya de cavallo et de pie la qual era tal que non tenía frio nin calor nin de levar armas continament se enuyavan 36.247. Comp. frido 'frío' en FA, p. 426. Frec.: 1: 0,00227. Etim.: del lat. FRIGIDUs ‘íd.'. Frec.: 1: 0,00227.

frontera s. f. 'límite, parte fronteriza o colindante'; 'fachada o frente principal': porque el dito lugar era bien establido et toda la frontera de aquel 36.519. Úsase también en la expresión tener frontera: et vinos'ende a tener frontera a Girona. 36.510 [tenir 
frontera VC]. La expresión vale por 'mantener fuerzas militares en el territorio extremo de un país, ante las fuerzas enemigas'. Cfr. cat. tenir frontera $(D C V B$, s. v. frontera, t. 6, p. 66). frec.: 2: 0,00455.

fuego s. m. 'fuego': et finalment fizo diffinir que ella se havies a escusarpor batalla, si no que sería judgada a meter en el fuego. 14.64. Del lat. FǑCus 'hogar', 'hoguera' (SEGURA, 2001, s. v.). Frec.: 2: 0,00455.

fuera (adv.) 'fuera; en el exterior': que yeran de fuera et fuyeron 20.138; mas los de dentro apparellaron en tal manera los de fuera que... 36.561. Del lat. FORAs. / / fuera gitar v. tr. 'expulsar': et vinció el dito rey Carlos et del regno fuera gitado, el dito vencedor rey ensennyoriose del dito regno 36.234; él prendió el dito castiello et fuera gitó [priso e gitó fuera $\mathrm{N}]$ de aquéll los enemigos, 36.89. Etim.: verbo compuesto del adv. fuera y del v. gitar 'echar', literalmente 'echar fuera'. Comp.: «Al servidor alto de corazon fuera gitalo assi como enemigo esdevenidor» (Epístola de San Bernardo; Riera, 1982: 132). En Fernández de Heredia fuera gitar, foragitar 'desterrar, exilar, expulsar' (GILKIson, s. v.). Comp. cat. foragitar 'expel-lir, llançar a fora; cast. expulsar' (DCVB, s. v., donde se indica que es palabra arcaica, no usada en el habla viva, pero reintroducida en la lengua literaria). Frec.: 7: 0,01591.

fuera gitar] v. tr. 'expulsar, echar afuera'. Verbo compuesto del adv. fuera y el v. gitar, si bien no se da todavía una fusión completa, puesto que se escriben los dos elementos separados. Vid. fuera.

fuerça s. f. 'fuerza': vino a sitiar la ciudat de Mallorquas et aquella, apres algún tiempo, priso a fuerça de armas 35.130. // En la loc. adv. por fuerça 'a la fuerza, forzadamente, en contra de la propia voluntad': et tantost respuso: «Liunyatnos [levatnos $\mathrm{B}$; luniat vos $\mathrm{N}$ ] d'aquí sino fernos [fer vos $\mathrm{N}$ ] he lunnyar [levar $\mathrm{B}$; luniar de aqui $\mathrm{N}]$ por fuerca porque, Sennyor, traydor nos avedes estado» 38.305; pero non vino a acabamiento, porque el rey don Alfonso les atorgó por fuerça todo aquello que los de la unión le demandoron 37.27-28; et aqui los aragoneses, más por fuerza que por grado, ficiéronle aprovar la unión que avían feita en tiempo de su padre el rey don Pero 37.15 // 'fortaleza, fortificación': et aquesti fizo enderrocar todas las fuerças de las ciudades et lugares de su regno 3.76; et firo grant fuerça en una penya que oy en día la claman la penya del Cit 18.91; et fizo by fer muytos castiellos et fuerças 12.47. Etim: del lat. vg. FŎRTIA 'fuerza', deriv. de FORTIS 'fuerte' (BDELC, s. v.). Frec.: fuerça 12: 0,02728; fuerca 1: 0,00227 ; fuerças 13: 0,02955 ; fuercas 2: 0,00455 .

fuero s. m. 'fuero, ley, ordenamiento jurídico': et dioles el privilegio general clamado en Aragón que yes fuero 36.680; todo bomme que vinies contra lures fueros et lures libertades 36.675. Etim.: del lat. FŏRum 'tribunales de justicia' < 'plaza pública' (BDELC, s. v.). Frec.: fuero 1: 0,00227; fueros 4: 0,00909.

fuert adj. 'fuerte': era varón bueno, armado et muyt fuert et valient en armas 27.17; tan fuert batalla bi fue feita...38.268. // adv. 'muy': tanta mortaldat se miso en la dita buest que tornó fuert a poco nombre de gent 36.603; en la ciudat avía grant freytura de viandas 
et malautia fuert grant 36.607; mas cada uno era en fuert chica edat constituydos 38.345; porque el campo do se devían fazer las ditas batallas era fuert inconvinient et sospeytoso a éll por muytas razones 36.268-269; fuert secretament 36.272; fuert a menudo firía en ellos 36.624. Etim.: del lat. FǑRTIS 'íd.'. Según indican CorOMINAS-PASCUAL, la acep. propia es frecuente en todos los tiempos; la derivada peyorativa 'difícil, duro, malo, funesto' es corriente en la Edad Media. También es corriente entonces el empleo adverbial, en cuya virtud fuert o fuerte significa 'muy, mucho' como en francés ( «fue en la abadia el baron assentado, / con la fazienda pobre era fuert enbargado», Berceo). Después del s. XIII este uso tiende a desaparecer, aunque todavía se emplea fuerte como adv. 'fuertemente' (DCECH, II, 972). Comp. cat. fort en la acepción 'muy, mucho' (DCVB, t. 6, p. 15), occ. fort 'fuerte' y 'muy, mucho' (Levy, s. v.; Alibert, s. v.). Frec. 13: 0,02955.

fuertment (var.: fuerment, fuermientre) adv. 'fuertemente': lo tenía fuerment et districta [en estrecha $\mathrm{N}$ ] sitiado 38.542; et aquélla conbatió fuermientre [fuerment $\mathrm{B}$ ] et destreyta, 36.485; los christianos se guarnian fuertment de grandes fuerças 4.23. Frec.: fuertment 8: 0,01818; fuerment 3: 0,00682; fuermientre 1: 0,00227.

fundamiento] s. m. 'cimiento': et enderrocó los muros et los fundamientos de aquel lugar 4.38. Etim. del lat. FUNDAMENTUM 'cimiento, base, fundamento'. Se documenta fondamiento en Berceo, fundamento en Apolonio 637b (DCECH, III, $381 \mathrm{y}$ 382). No aparece alazet o alacet en toda la Crónica. Curiosamente, tampoco se registra en las obras de Fernández de Heredia (cfr. Gilkison). Sin embargo, en una obra anterior, el Vidal Mayor, de mediados del s. xIII, se registra alacet 'cimiento, fundamento', aunque una sola vez (cfr. Tilander, VM, t. III, Vocabulario, s. v., p. 18): «Si alguno, abriendo el alacet en tierra aillena...» (VM, libro III, cap. 6, lín. 2; Tilander, 1956, t. II, p. 190). El correspondiente pasaje de los $F A$ dice: «Si por uentura alguno abriere fundamiento en algun casal, maguer alleno...» (Tilander, 1937: \95, p. 45). Sin embargo, en los FA hasta 1265 (ms. 7, antes 207 de la Biblioteca de la Universidad de Zaragoza) se emplea la variante alizaz: "Qualquiere omne que en algún casal biello abrirá alizaz...» (LACRUZ, 1947: \87, p. 258). También podemos encontrar alacez 'fundamento, cimiento' en los DLAA (aunque formalmente parece plural, lleva determinante singular): «el qual dito Bernart auia foradada la tapia, baxo, enla laçež en dreyto daquel poço, \& alli auia feyto obra denueuo, en manera que prendia e traya el \& los suyos agua del dito poço» (DLA $A$, doc. n. ${ }^{\circ}$ 69, de Huesca, 1293; p. 99, lín. 8). Frec.: fundamientos 1: 0,00227.

furiosso adj. 'furioso': por tal como era hombre furiosso algunos varons matoronlo 29.42. Es cultismo tomado del lat. furiosus 'loco, furioso, violento'. Frec.: 1: 0,00227.

furtar v. tr. 'robar, hurtar, quitar': lo quisies furtar et toller el castiello 36.429; escondidament furtó los ditos fillos del rey 36.421. Deriv. de furto < lat. FURTUM. Frec.: furtar 1: 0,00227; furtó 1: 0,00227. 
fusta s. f. 'madera': e basteció maravelloso castillo de fusta sobre navilio en el rio del Royne 32.50. Etim.: del lat. FUSTA, acus. neutro pl. de FUSTIS, -IS 'palo, bastón' (DEEH, p. 699). Comp. cat. fusta 'substancia dura fibrosa que forma la major part del tronc i branques dels arbres i arbustos sota l'escorça' (FABRA, DGLIC, s. v.; IEC, DL/C, 2007, s. v.), fust 'bois de construction', fusta 'íd' (AliberT, s. v.). Vid. también para el cat. DCVB, s. v.; DECLIC, s. v. En arag. med.: fusta 'madera' en VM (Tilander, 1956, III, p. 140); fusta 'madera' en los DLLA (Reidy Fritz, 1977: 177); fusta 'wood, boat' en Fernández de Heredia (Gilkison, 1984: 70); fusta 'wood' en el LT (PrInce, 1995: 221); fusta 'madera' en el LMM (LiRIA, 1979: 174); fust 'madera' y fustes 'maderos' en doc. notariales de Teruel del s. Xv (TERRADO, 1991: 269-270); fustas 'maderas' en $O B$ (VÁzQuez Obrador, 2011c: 42). En arag. mod.: fusta 'madera' en la Alta Ribagorza y en Salas Altas; fusta 'viga' en Benasque y Alta Ribagorza (EBA, 1999: 986). Frec.: 1: 0,00227.

fuyent] s. m. 'huidor, que huye': muytos de los fuyentes murieron 36.231. Procedente del part. pres. del v. fuyr. Comp. fuyent 'huidor' en VM (Tilander, 1956, III: 149). Frec.: fuyentes 1: 0,00227.

fuyr v. intr. 'huir': fuyendo de la presión con los guardas 36.59; por la qual cosa lende fuyeron muytos, 36.587 // v. tr. 'alejar, apartar': que lo avian allá foydo en tiempo que escapó de la batalla, 19.163-164. Etim.: del lat. FugERE 'íd.'. General en todas las épocas y común a todos los romances. Estos suponen en todas partes una base vulgar FUGIRE, documentada desde el s. III. La variante foír no es rara en la Edad Media (por ej., Alex., 63, 48, 1031...) (DCECH, III, 422). Comp. cat. fugir (vid. DECLIC, s. v.). Arag. moderno fuir, fuyir (ANDOLZ, s. v.; EBA, 1999, s. v.). Frec.: fuyr 1: 0,00227; fuyó 3: 0,00682; fuyeron 3: 0,00682; fuyendo 3: 0,00682; fuydos 1: 0,00227.

\section{G}

galera (var.: gallera) s. f. 'galera': se devies mudar en la su galera porque se cuytas con las galeras et que en antes fues en la dita ysla 38.514; feita primerament inbibición a todo homme que si non fues natural en todas las galleras que allí eran parelladas, las quales eran $L$, non entras porque él todo solo con sus vassallos quería aver batalla con su hermano 38.261. Del griego bizantino galea $(\gamma \alpha \lambda \varepsilon \alpha)$ 'mustela, pez selacio', empleado como nombre de la embarcación por los movimientos ágiles y rápidos de 
ésta, a semejanza del pez. Cfr. DCECH, III, p. 34. La 1. a doc. de galera que da es de 1433; anteriormente galea (Berceo), galeya (Sta. Ma Egipcíaca). Cfr. VMC y DME. En Alex. también galea (SAS, p. 302). Para el cat. galea, galera, vid. Coromines, Entre dos llenguatges, III, p. 181, y DECLIC, IV, p. 283. Frec.: galera: 2: 0,00227; galeras: 24: 0,05455; galleras: 3: 0,00682.

gallego] s. y adj. gentilicio, 'de Galicia': parelladas sus azes a batalla, e obtuvo vitoria don Alfonso con los aragoneses, vençidos, muertos e fuydos los leoneses e los gallegos 19.144. Frec.: gallegos: 2: 0,00455.

ganado s. m. 'ganado, conjunto o clase de animales que se apacientan en grupo': do pudiessen fer paxer su ganado et millor sustener lur vida 11.41; que sin alguna pena et sin todo dupdo et pleito real pudiessen fer degollar et matar vacas et cualsequier otro ganado qui dentro en los ditos términos fues entrado sin lur licencia 11.63. Deriv. de ganar, que evolucionaría desde su sentido original 'ganancia, bienes' a 'riqueza pecuaria', y de ahí 'ganado'. Frec.: ganado 4: 0,00909; ganados: 3: 0,00682.

ganado adj. 'ganado, conseguido, obtenido': lo podía fazer por el privillegio papal ganado por su hermano 19.17. Del p. p. del v. ganar. Frec.: 1: 0,00227.

ganar v tr. 'ganar, adquirir, conseguir': et tierras ha defender et las perdidas cobrar 0 ganar de nuevo 20.54; et depués quel le ganaría el dito Imperio, 38.155; et non fue rey en Espanna que tanto ganasse de moros nin corriesse nin talasse nin tanto mal les fizies 19.206. Del gótico *GANAN 'codiciar', influido en su significado por el germánico WAIDANJAN 'segar, cosechar', 'ganar' (DCECH, III, p. 65). Frec.: ganar 1: 0,00227; ganaría 1: 0,00227; ganasse 1: 0,00227.

gannivet s. m. 'cuchillo, navaja'. et sacó un gavinet que tenía et, teniendo la letra en la mano et leyendo, talló todas las colles mayores que yeran en el huerto 20.113. A nuestro juicio, la lectura correcta del ms. B es gannivet (el ms. B es el que le sirve de base a C. Orcástegui para la edición crítica de la Crón. SJP en esta parte, no conservada en el ms. E). Vid. gavinet.

gascón] s. y adj. gentilicio, 'de Gascuña': Et en aquesti mismo aynno fue a sitiar a Çaragoça con los sus naturales de Aragón e de Navarra e con don Gastón de Bearne e con los gascones 19.24. Frec.: gascones 1: 0,00227.

gavinet s. m. 'cuchillo, navaja': et sacó un gavinet que tenía et, teniendo la letra en la mano et leyendo, talló todas las colles mayores que yeran en el huerto 20.113. A nuestro juicio, la lectura correcta del ms. B es gannivet. Derivado del fráncico KNIF 'cuchillo' (com. ingl. knife, neerl. med. cniff). 1. ${ }^{a}$ doc.: canivet, h. 1300, Gran Conquista de Ultramar (DCECH, I, p. 825). El DRAE (1970) recoge cañivete 'cuchillo pequeño', como antiguo, y canivete 'navaja'. Igualmente, el DLE (2014), si bien añade en canivete 'cuchillo pequeño', como desusado. Corominas-PAscual citan diversas variantes antiguas del cast.: canavete, canivete, cañivete, cañavete, cavinete. Y diversas formas documentadas en el arag. med.: ganivet (1331), ganyvete 
(1365), gafinet (1500-1535). Añaden, además: cat. vg. gavinet 'cuchillo', arag. cañivete, fr. canif 'cortaplumas', riojano ganifete 'hoz de vendimia', vasc. guipuzcoano y suletino ganibet 'cuchillo'. Por su parte, López de Guereñu (1998) cita entre sus voces alavesas guanivet 'espada corta', como ant. en Laguardia. Para el arag. ant. ganyvet (1331) vid. ELLA, núm. 699; guanivetes, guanivyetes (LCMA, p. 226); ganinyet (DLAA, doc. no 134, de Jaca, 1412). Actualmente se utiliza, en diversas var., en Aragón: gabinete (Ateca, Calatayud y comarca; comarca de Tarazona), gabiñete (Ejea), gabiñet (Cretas, Bajo Aragón de habla catalana), gabiño (Biel, Lanuza, Caspe, Ontiñena), ganibete (Fuendejalón), ganifete (Bijuesca), gabinet (Fayón, Valderrobres, Peñarroya de Tastavins, Bajo Aragón de habla catalana), etc. (cfr. ANDOLZ, s. vi; ROHLFS, DDPA; ALEANR, mapa n ${ }^{\circ}$ 1441; AFA, 36-37, p. 503, etc.). Moneva (2004 [1924]) registra gabinete 'navaja curva' en Ateca y gaviñet 'cuchillo' en Valjunquera. Se registra ganivete, gañivete y gaviñete en Savall y Penén. Para el cat. ganivet vid. Fabra, DGLIC; DCVB. Comp. occ. ganivet (ALIBERT), ganifet, canivet (LEVY), ganibét (PALAY), etc. Vid. más ampliamente sobre esta voz el apartado 7.2.1.2, nota, del estudio lingüístico (Nagore, 2003: 584-585). Frec.: 1: 0,00227.

gele combinación de pron. pers. de $3^{a}$ pers. de c.i. + c.d., con leísmo, 'se lo': de la qual cosa todo homme buvo grant desplazer et gele tuvieron [gelo tuvieron $\mathrm{N}$ ] a grant locura por muytos periglos 38.391 // (enclítico) respondióle que no le podía ayudar de res, empero otorgogele que si él lo podía conquerir la tierra que bavía perdida... 23.60; el dito tio [curador $\mathrm{N}$ ] restituyogeles assí como lur padre avía ordenado 5.14. Sobre la confusión existente entre el complemento directo y el indirecto u otras anomalías en estas combinaciones de pronombres, puede verse NAGORE (2003: 341-342). Frec.: gele [gelo] 1: 0,00227 (como proclítico); atorgogele 1: 0,00227; restituyogeles 1: 0,00227.

gelo combinación de pron. pers. de $3^{\text {a }}$ pers. de c.i. + c.d., 'se lo': et diogela con tal condición las ditas tierras [sic]16.32; «et sin periglio vivo lo saqué, benedito sea Dios, en testimonio de mis parients et vassallos presents aqui qui aquesto vieron; et qui al by querra dezir, entre al campo et conocierrigelo [conbatergelo $\mathrm{N}]$ be» 12.36 . La lectura que parece que tiene sentido es la del m. N: conbatergelo he 'se lo combatiré'. Frec.: diogela 1: 0,00227; conocierrigelo [conbatergelo] 1: 0,00227.

generación s. f. 'generación': el primero hombre que se pobló en España havia nombre Tubal, del qual yxió la generación de los ybers 1.3. Cultismo tomado del lat. generatio, -onis 'generación, reproducción'. Frec.: 1: 0,00227.

general adj. 'general': que don Alfonso, fillo del dito rey don Jayme, comte de Urgel et general procurador suyo, fues a conquerir el regno de Ceredennya 38.476; a las Cortes Generales que tuvo a Girona 38.460 / / s. m. 'el común, la generalidad, el pueblo; el conjunto de los ciudadanos': Et el general de la tierra, veyendo que ellos fincavan sin governador... 10.3; Et tantost los nobles et general de la tierra se plogó [plegó $\mathrm{N}]$ et 
todos ensemble concordoron et eslieron en rey et sennyor lur al dito Frederich 38.145-147 // en general loc. adv. 'en general, sin especificar': do fueron ya ajustados todos los prelados, richos homes, barones, cavalleros, sindicos, procuradores de ciudades et de villas de Catalunnya, et delant todos en general [ensemble N], el dito rey don Sancho de Mallorquas reconosció tener en feu... 38.467. Del lat. GENERALIS 'íd.', derivado de género < lat. GENUS, -ERIS 'linaje', 'especie, género'. Frec.: general 16: 0,03637; generales 4: 0,00909.

generalment adv. 'generalmente, en general, de forma general': la qual avinienca concordada... publicoron aquella en Pamplona generalment a los reyes desus ditos 20.166-168. Frec.: 1: 0,00227.

geniosso] adj. 'ingenioso': et el dito rey don Pedro con sus geniossos tractamientos, con aguaytas et en otra manera tantos mató... 36.570. Cultismo deriv. de ingenium 'cualidades innatas de alguien’ (BDELC, p. 296, s. v. genio), con eliminación del prefijo. Frec.: geniosos 1: 0, 00227.

gennyo] s. m. 'ingenio, máquina de guerra': havies asitiada la ciudat de Murcia con grant multitud de hombres a cavallo et de pie, et por muytas batallas et conbatimientos et gennyos [de genos $\mathrm{N}$ ], con la grant cura et consello et estrenimiento [destruymientos $\mathrm{N}$ ] de armas ...36.24. Del lat. GENIUs, o quizá, más bien, aféresis de engennyo < lat. INGENIUM, en el sentido de 'invención ingeniosa' (cfr. BLÁNQUEZ, s. v. ingenium, última acepción). Frec.: 2: 0,00455.

genobés] s. y adj. gentilicio 'genovés, de Génova': depués quando el dito viaje fue venido, sitió Tortosa con genobeses, con II ${ }^{m}$ omes d'armas, convatiendo fuertment la dita ciudat de Tortosa et finalment prisola en el ayno de... 32.26. Frec.: genobeses 1: 0,00227.

gent s. f. 'gente': et plegada toda la su gent, recollióse et vino sende en Catalunnya 38.393; buvo paz et amor entre sus gentes 38.627; Tantost como fue venido con las sus gents, fue esmarrida muito la gent de la dita ciudat 32.22. // Se emplea tb. formando parte de la loc. adj. grant gent de 'muchos, -as', aplicada a personas: porque grant gent de moros vinieron en Spannya 35.310. Del lat. GENS, GENTIS 'raza, familia, tribu'. Frec.: gent 41: 0,09319; gentes 60: 0,13638; gents 4: 0,00909.

ginete] s. m. 'jinete, soldado moro de a caballo': un moro qui de aquesta paz era tractador con XXX ginetes, vino al dito rey guiando 38.386. Etim.: del árabe vulgar ZENETI (ár. ZANATI) 'individuo de Zeneta, tribu bereber famosa por su caballería' (DCECH, III, p. 517). CoRRIENTE (2003: 242) concuerda con esta etimología y especifica aún más: «del and. zanáti < neoár. zanati, gentilicio reflejado por el cast. cenete, de la confederación tribal bereber de Zanata, bien establecida en el Rif y famosa en el Occidente islámico por la cría de excelentes caballos y dominio de la equitación, lo que hizo que los soberanos del Alándalus los reclutaran a menudo». Frec.: 1: 0,00227.

girar] v. tr. (e intr.) 'girar, volver': ningún tiempo en batalla que fues non giró cara 34.148. Del lat. GYRARE 'girar', deriv. de GYRUs 'giro, movimiento circular', tomado del 
griego yupoo 'círculo' (DCECH, III, p. 151). La 1. a doc. que da el DCECH es de mediados del s. Xv en un autor aragonés, Juan de Tapia: girar la faz (Cancionero de Stúniga, p. 213). Advierte además que se encuentra en Mena (med. s. $\mathrm{xv}$ ) y en otros escritores latinizantes o dialectales, pero que no es voz popular en castellano. Covarrubias, 1611, dice: «girar, es rebolver. No es término usado en Castilla: úsase en la lengua catalana, vale bolver a la redonda» (cfr. ed. de M. de RIQUer, p. 641). Registra la voz A. de Palencia en su Vocabulario (1490). Pero los testimonios medievales son generalmente aragoneses: $A l$ menos no girarles la cara lingerament (Fernández de Heredia, Tucídides; cfr. López MolinA, 1960: 132). Obsérvese que las expresiones en que se emplea, girar la faz, girarles la cara, son similares a la de la Crón. SJP., girar cara. En OB (VÁzQUEZ OBRADOR, 2011c: 42) se documenta también girar: «muytas de uegadas sean uenidos a peleas escandalos e a males e apres se ayan a tornar e girar a furtar e robar el allyeno» (OB, p. 36, lín. 1). Para el cat. girar (donde se doc. ya en 1250), vid. DECLIC, IV, p. 505. En arag. mod. chirar (BADíA, Bielsa, p. 257; Andolz, s. v.). El EBA (1999: 513) registra chirar en A Fueba, Biello Sobrarbe, Bielsa, Salas Altas, A Buerda, Sobrarbe, Capella, Bal de Broto, Oto, Piarruego, Rebilla, Semontano; y en la forma chirá en Graus, Fonz, Estadilla, Campo, Bal de Chistau, Bal de Lierp. Frec.: 1: 0,00227.

gitar (var.: getar) v. tr. y prnl. 'echar, arrojar': el qual fue catolico rey e getó [ gitó $\mathrm{N}]$ toda la error arriana 3.54; tollió a los moros et gitó aquéllos de todo su regno 36.74; dizen que muytos se gitoron en la mar 38.253. En una ocasión se emplea en una acepción un tanto especial: cómo su sennyor el rey de Aragón lo enviava a éll por gitar la tregua que avian et por dessafiarlo 36.392 'echar abajo, romper, derribar' // 'derramar': en ayuda et socorro de los ploros et lagrimas et dolores que los ditos secilianos gitavan agrament et sofrían 36.205. Del lat. vg. *JECTARE, variante vulgar del lat. JACTARE 'arrojar, echar, lanzar, agitar', frecuentativo de JACERE 'echar, arrojar'. También puede explicarse por aféresis de EJECTARE 'echar fuera', deriv. de JACTARE Comp. cast. echar, ast. echar, port. y gallego deitar (ant. geitar), cat. gitar, occ. getar, fr. jeter, it. gettare, corso ghjittà, napolitano jettà, siciliano jïttari (DCECH, III, pp. 540-544; DECL/C, IV, pp. 524-515; VALLÉs, 2007: 233). En arag. med. es general gitar o itar. Se registra itar, ytar en VM, III, p. 166; itar en FA, p. 442 (ahí cita G. TILANDER gitar en FJ, gitar y chitar en Ordenanzas municipales de Estella, año 1303). En DLAA: gitar, getar, jetar, ytar (REIDY, 1977: 178). En LMM: gitar, ytar (LIRIA, pp. 175 y 178). En Fernández de Heredia generalmente gitar, en una obra bitar (GILKIson, 1984, s. v.). En el LT, gitar 'to throw' (PRINCE, 1995: 221). En arag. mod. itar en Echo y Aineto (KuHn, HAD, p. 15); itá en Ansó (VICÉN -MonCAYOlA, p. 50); chitar en Bielsa (BADíA, Bielsa, p. 258), Campo, Buesa (BADíA, Contribución), Alquézar (ARnAL, Voc.), Fanlo, Sercué... (DDPA); chetar-se en el valle de Chistau (Motт, Dicc. chist.-cast.; Blas/Romanos, 2008: 188), chetá en 
Benasque (Ballarín, Dicc.). Alvar, DA, $\ 78$, da chitar como general en el Alto Aragón. El EBA (1999: 516) recoge doce registros de chitar y diez de chitar-se 'echarse, acostarse'. Andolz. (1992: 142) registra chitar 'echar, tirar' en Alquezár y Bielsa, y chitar-se 'echarse, acostarse' en los mismos puntos. El postverbal chito 'retoño, brote' es general. Frec.: gitar 3: 0,00682; gita 1: 0,00227; gitavan 2: 0,00455; gitada 1: 0,00227; gitado 2: 0,00455; gitados 1: 0,00227; gito 6: 0,001364; gitoron 1: 0,00227; gitoronlo 1: 0,00227.

gladio s. m. 'espada' o quizá 'filo de la espada' (si no, hay redundancia): e con gladio de espada fizo morir los ditos traydores 33.58. Cultismo tomado del lat. GLADIUS 'espada'. Frec.: 1: 0,00227.

gloria s. f. 'gloria': «al verdadero Dios vos comando que me clama a la su gloria» 35.277. Cultismo tomado del lat. GLORIA. Frec.: 2: 0,00455.

glorificado adj. y p. p. de glorificar 'glorificado', 'ensalzar, alabar, glorificar': et hedificó en la dita ciudat yglesia episcopal et en el regno de aquella muytas et diveras otras en que el nombre de Ihesu Christo bi fues glorificado. 35.164. Es cultismo tomado del lat. tardío GLORIFICARE (DCECH, III, p. 156). Frec.: 1: 0,00227.

gloriosament adv. 'gloriosamente': e pasó desta vida aquí mismo gloriosament et estando en hedat de XXVII aynnos 33.124. Frec.: 1: 0,00227.

gloriosso adj. 'glorioso': porque grant gent de moros vinieron en Spannya quando sintieron aprohismar a la fin del dito gloriosso rey 35.311; la Virgen gloriossa Madre de Dios li apareció con grant goyo et díxole que se levantas del leyto 35.219. Deriv. de gloria, con morfema derivativo sufijo -oso. Frec.: gloriosso 1: 0,00227; gloriossa 1: 0,00227.

godo] s. y adj. gentilicio 'godo': en tiempo de aquesti los godos tenían lur sennoría mayor en Tolosa 3.38. Frec.: godos 10: 0,02273.

governación s. f. 'gobernación, gobierno' (pero parece error por generación): no queremos mas favlar del feito de Ercules, nin de la suya governación 2.6 [generation $\mathrm{N}$ ] [generatione VL, pág. 19]. Frec.: 1: 0,00227.

governador s. m. 'gobernador': et ordenó el infant quel noble don Phelip de Celuza, qui era venido de Secilia, fincas governador en la isla con $C^{-5}$ hombres... 38.579; por consello de algunos, los governadores fueron mesclados et mesturados con el rey 35.49. Frec.: governador 5: 0,01136; governadores 2: 0,00455.

governar v. tr. 'gobernar': El quoal compte Remón Belenguer governó los ditos regnos e condados muy bien e provechosament dos aynnos 33.12; et governólo bien segunt su poder 28.26. Etim.: del lat. GUBERnARE (DCECH, III, 156). Frec.: governó 9: 0,02046; governólo 1: 0,00227.

goyo s. m. 'gozo, alegría': ... do fue recebido por el rey don Jayme su padre et por los otros qui aqui eran muyt honradament con grant goyo et alegría 38.586. Del lat. GAUDIUM 'placer, gozo'. Es voz usual tanto en el arag. medieval (FA, Tilander, 1937: 431; Gilkison, 1984: 72; LT, Prince, 1995: 222; PY, Menéndez Pidal, 1902 : 
292), como moderno (cfr. PArdo, 1938: 190; Andolz, 1992: 237; Rohlfs, DDPA, p. 165; EBA, 1999: 1036-1037; Diccionario aragonés [Anónimo de h. 1803-1815], p. 90; Moneva, 2004 [1924]: 264); Siesso De BoleA, 2008: 175). Blancas (Índice, 1641) recoge ya goyo 'gozo'. Frec.: 16: 0,03637.

goyoso adj. 'alegre, gozoso' (se usa en un sintagma adverbial): et un dia pregó a la reyna su madre que le plaçies dar el dito cavallo, la qual cosa le atorgó [octorgó $\mathrm{N}]$ francament et goyosa 14.42. Deriv. de goyo. Se registra goyoso 'happy, pleased' en el arag. de Fernández de Heredia (GILKIson, 1984: 72). También es derivado de goyo el v. goyar 'gozar, deleitarse, alegrarse': «...que daquj adelant ellyos nj alguno dellyos nj sus descendjentes, non se goyen nj alegren nj se puedan goyar nj alegrar delos bienes suyos, nj de mobles nj de sedientes» (DLAA, doc. n. ${ }^{\circ}$ 131, de Jaca, 1391; p. 193, lín. 37-38). Frec.: 1: 0,00227.

gracia s. f. 'gracia': Et con grant victoria el dito don Alfonso levantó el campo et fizo grandes gracias et lohores a Dios 38.539. / / loc. adv. de gracia 'gratuitamente': a cabo de un tiempo, livrólos de la presón et rendió el dito condado de gracia por tal como el conte le firo lo que fer devía 36.125. Del lat. GRATIA. Frec.: 11: 0,02500.

gracioso adj. 'generoso': Et trobós que jamás en sus días non firo cosa que desplaziés a los sozmesos sinon aquesta, tanto era justo et gracioso 35.217. Deriv. de gracia. Frec.: 2: 0,00455 .

graciossament adv. 'graciosamente, gratuitamente, generosamente, sin recompensa': los absolvió de las presones et lures tierras les rendió graciossament 36.149. Es adv. formado con morfema -ment sobre el adj. gracioso. Frec.: 1: 0,00227.

grado s. m. 'voluntad, gusto'; en la loc. adv. por grado 'por propia voluntad, voluntariamente': Et aqui los aragoneses, más por fuerza que por grado, ficiéronle aprovar la unión que avian feita 37.15-16. [E aqui los aragoneses, més per força que per grat, faeren-li lloar e aprovar la unió que havien feta VC, p. 153]. Etim.: del lat. tardío GRATUM 'agradecimiento', y éste del lat. GRATUS, -A, -UM 'agradable', 'agradecido' (BDELC, p. 301; DCECH, III, p. 189, s. v. grado II ). Registra grado 'voluntad, gusto' el DRAE $(1970$, s. v.). Cat. grat 'satisfacció que hom troba en algú o en alguna cosa, que hom testimonieja al qui ha fet alguna cosa por ell, o amb què estem disposats a fer quelcom' (FABRA, DGL/C, p. 932, s. v.; la misma definición en IEC, $D L / C, 1995$, s. v.) Comp. la expresión: Mig per força migper grat (ibídem). Frec.: 5: 0,01136 (incluyendo tanto grado 'voluntad' como grado 'escalón').

grado s. m. 'grado, escalón', 'valor, situación, calidad o medida susceptibles de ser ordenados en forma creciente o decreciente'; 'relación mayor o menor de parentesco entre las personas': et don Remiro ovo fillo a don Sancho que murió en el sitio de Huesca, padre desti don Alfonso marido desta dona Hurraca, assi que hera en tercero grado 19.73; el rey de Castiella dió su filla, que avia nombre María, al dito rey don Jayme por muller, non contrastant que fuessen en muyt cercano grado de parentesco 
38.27. Con este mismo valor se emplea en la loc. adv. de grado en grado 'sucesivamente, progresivamente, por partes': et depués de grado en grado de cada un conte según que devalloron el <uno $>$ del otro, fablaremos et lur vida recontaremos 21.4-6 [e puis de grau en grau de cascun compte, segons que devallaren un d'altre, parlarem e llur vida recontarem. VC, p. 73]. Etim.: del lat. GRADUs 'paso, marcha', 'peldaño', 'graduación' (BDELC, p. 301), derivado de GRADI andar' (DCECH, III, p. 188, s. v. grado I). El DRAE, 1970, s. v., registra grado 'peldaño' y 'cada una de las generaciones que marcan el parentesco entre las personas'. También la expresión adverbial de grado en grado 'por partes, sucesivamente'. Cat. grau 'cadascun dels estats intermediaris que condueixen succesivament d'un estat a un altre' (FABRA, DGL/C, s. v.), 'qualsevol dels estats intermediaris que condueixen succesivament d'un estat a un altre' (IEC, DL/C, 1995: 972). Frec.: 5: 0,01136 (incluyendo tanto grado 'voluntad' como grado 'escalón').

gramática s. f. ' 'gramática; letras en general; lenguas': et por razón que sabía gramática el cavallero, entendieron algunos en latín et recontó este miraglo 18.63. Frec.: 1: 0,00227.

grant (var.: gran, grande) adj. 'grande': al qual fuertment mandó que en continent fues con gran poder de hombres a cavallo i de pie enta las partes d'A ragón 4.28; el dito rey todo solo con los moros estuvo et fabló una gran pieça 38.390; tornó sano et salvo de la dita batalla con grande honor 27.14; et firo grandes gracias et lohores a Dios 38.539; regió su tierra con grant justicia 38.633. // adj. indef. 'mucho, -a': et morieron grandes gentes de moros 19.205; porque era grant su amigo 20.237; havia grant espesseza de cabellos 30.4; Et ya sia quel dito rey fuesse viello et de grandes dias, empero non queriendo planyer su persona en servir Dios... 35.204. Del lat. GRANDIS 'grandioso', 'de edad avanzada'. Abrumadoramente más frecuente es la forma grant, tanto esta forma, con una -t no etimológica, como la escritura gran abonan la sospecha de que la -t final que aparece escrita tras una nasal - y lo mismo tras una vocalno se pronunciaban en aragonés medieval. Otros indicios van en la misma dirección: véase, por ej., luent. Frec.: grant: 242: 0,55005; gran 23: 0,05228; grande 3: 0,000682; grandes 33: 0,07501.

grau s. m. 'puerto natural, muelle, desembarcadero en la desembocadura de un río, paso de un estanque o puerto al mar'; 'punto de la costa que sirve de desembarcadero; paso del mar a tierra, a través de una costa abrupta': que del grau de la mar do arribó entro a la ciudat et por las carreras de la <iiudat> home yva sobre trapos d'oro et de seda 36.219. Etim.: del lat. GRADUs 'paso, marcha', 'escalón', 'graduación', deriv. de GRADI 'andar, caminar' (DECLIC, IV, p. 628 y BDELC p. 301). La acepción 'puerto en la desembocadura de un río' se desarrolló en catalán y en lengua de Oc, partiendo del escalón que forma la barra; del cat. grau se tomó el cast. grao (DCECH, III, p. 189, s. v. grado I). Comp. arag. mod. grau 'comienzo del paso estrecho de montaña ante un precipicio en serranía rocosa' (ANDOLZ, s. v.); grau 'paso natural prou furo, que gosa estar l'unico en 
un puesto inazesible; ta pasar d'una faxa enta atra más alta, puyar d'o cobaxo d'un zillo u peña ta o cobalto u en un río u barranco entre zillos, puesto por an que se puede blincar ta l'atra marguin. Cast. paso escarpado' (CASAUS y Miguel, 2008: 174). Tb. en toponimia, en el Alto Aragón: Lo Grau (nombre de la población que oficialmente se llama El Grado-Lo Grau). Con esta misma acepción Corominas-Pascual lo documentan en el Valle de Ordesa y Valle de Tena (DCECH, III, p. 189, s. v. grado I). También en catalán tiene este sentido (DECLIC, IV, p. 629). Véase la diferencia fonética entre grau con este sentido y grado 'escalón, grado', dos significantes que, según todos los indicios, proceden de la misma forma etimológica. Frec.: 1: 0,00227.

greuge s. m. 'agravio, afrenta, ofensa grave, injuria': et cómo los franceses farían todos días diversos males, grenges et desonores 36.191; porque la tierra se plorava et senglores de greuges sospiros gitavan a Dios 36.195. Etim.: del cat. grenge 'injuria, ofensa grave' sust. postverbal del v. arcaico cat. greujar < lat. vg. *GREVIARE o *AGGREVIARE (DECLIC, IV, p. 651). El arag. greuge está tomado, según Corominas-PasCUAL, DCECH, III, p. 203, de la forma catalana correspondiente greuge. Se documenta greuge 'offense, affront, injury' en el arag. de Fernández de Heredia (GILKIsOn, 1984: 73); greuge 'queja del agravio hecho a las leyes o fueros' en los DLAA (Reidy Fritz, 1977: 179). Véase en un documento notarial que firma Jayme dAnçano, «publico notario dUesca»: «et en otra manera, si contra aquesto facian, tenia se por agreugado, \& apellaua del greuge feyto \& facedero al senyor rey» (DLAA, doc. n. ${ }^{\circ} 102$, de Huesca, 1362; p. 147, lín. 36). Frec.: greuges 2: 0,00455.

griego s. y adj. gentilicio 'griego': et retuvo a la suya senyoria Espanna, et a la servitud de los griegos. 1.41; sino tan solament de los godos porque aquestos fueron los que tollieron Espanya a los romanos que senoryaron los griegos et a la nación que Ercules y avia lexado. 3.5. Frec.: griegos 2: 0,00455.

grieu (var.: greu) adj. 'grave': et la dio por innocent et por exempta del grieu crimen quel era levantado 16.8; estando el dito rey don Alfonso en la villa de Perenia fue movido de greu maulatia 33.120. El pl. es grieves: todas quantas yglesias trobavan todas las robavan et destruyvan et de otros grieves crimines cometian 36.494. Etim.: del lat. *GRĚVIS, alteración vulgar del lat. cl. GRAVIS 'pesado, grave', por influencia del contrapuesto LĔVIS. Del mismo origen son cat. greu, occ. greu, rum. greu, fr. ant. grief (Cfr. DECLIC, IV, p. 649). El cast. grave proviene del lat. GRAVIS, pero la variante grieve se documenta en cast. ant., en algunas obras del s. XIII como los Libros del Saber de Astronomía de Alfonso el Sabio o la Primera Crónica General (DCECH, III, pp. 202-203). Según POTTIER, el arag. grieu 'grave' es préstamo occitano ("Les éléments gascons et languedociens dans l'aragonais médiéval", p. 685; vid. también: Роттter, "Notas lingüísticas sobre antiguos textos aragoneses", AFA, III, pp. 225-240; p. 220). Induráin (Contrib., p. 91) 
achaca a influencia francesa la presencia de grieument en navarro medieval. PoTTIER se basa en la diptongación para afirmar que es préstamo occitano, pero a nuestro juicio el comportamiento fonético es perfectamente explicable en aragonés a partir del lat. vg. GRĚVIs. Frec.: grieu 3: 0,00682; greu 1: 0,00227; grieves 1: 0,00227.

grieument (var.: greument, grievement) adv. 'gravemente, de manera grave, de manera importante': convinole aver batalla con los ommes de Niça, en la quoal fue ferido muy greument 33.19; començas a brocar su cavallo grieument 37.92; et fue muyt grievement [grieument B] enfermo 36.606. Frec.: grieument 1: 0,00227; grievement 1: 0,00227 ; greument 1: 0,00227 .

grillones s. m. pl. 'conjunto de dos grilletes o aros de hierro que, unidos por una cadena, se colocan en los pies de los presos': et los otros nobles et cavalleros tuvo presos en grillones [grillons B] et en cadenas por diversos castiellos 36.147. Etim.: del lat. GRILLus 'grillo, insecto' > grillo, que se utilizó primero con esa misma significación y luego en la acepción 'prisión de hierro que sujeta los pies de un preso' (1335), por comparación del ruido metálico que producen los grillos al andar el preso con el sonido agudo que emite el insecto. Entre los deriv. de grillo cita CoROMINAS grillón (1817) (BDELC, p. 304a; DCECH, III, 215). Grillón 'grillete' no se registra en el DRAE Manual (1979) ni el DRAE (1970) ni en María Moliner ni en Covarrubias. Tampoco en el DLE (2014), que sin embargo sí recoge grillos 'conjunto de dos grilletes con un perno común, que se colocaban en los pies de los presos para impedirles andar' y grillete 'arco de hierro, casi semicircular, con dos agujeros, uno en cada extremo, por los cuales se pasa un perno que se afirma con una chaveta, y sirve para asegurar una cadena a la garganta del pie de un presidiario, a un punto de una embarcación'. En Inv. arag. (1397), grillos 'anneaux de fer' (ELIA, núm. 746), que se encuentra tb. en cast. (Juan Ruiz, Nebrija, Autoridades, etc.) (DCECH, III, 214). En cambio: grillon 'fetter' [grillete] en Fernández de Heredia (GILKISON, s. v.). En arag. mod. grillón sólo está documentado con el significado de 'brote que sale a los tubérculos, semillas, etc.' (vid. Andolz, s. v.). El cat. grilló es frecuente desde principios del s. XIV; oc. ant. grilhon, grelhon; fr. ant. y med. gresillons 'esposas' [s. XIII]; tb. se dijo fr. grillons en el s. XV, además de gresillons (DCECH, III, 214-215); cat. grillo' 'grillete, grillo, brete, pihuelas' (MiraCLE, 1973, s. v.); grilló 'peça de ferro en forma d'arc aproximadament semicircular que es clou passant un pern pels forats que hi ha a cada extrem de l'arc, la qual serveix per a subjectar una cadena al coll o a la cama d'una persona, penjar una campana, etc.' (DL/C del IEC, 2007, s. v.). Frec.: grillones 1: 0,00227. groso] adj. 'grueso': El dito conte de Foyx estuvo preso en el castiello de Siurana con grosas cadenas 36.146. Del lat. Grossus. Fonéticamente es forma catalana por la falta de diptongación. No obstante, es habitual en arag. med. la unidad léxica 
compleja ganados grossos 'ganado mayor': «por tirar scandalos, males et peleas que cada dia se seguian sobre las puyadas et devalladas enta suso et enta yuso et puyando enta la montanya et devallando enta Espanya los ganados grossos et menudos de la dita Bal de Echo» (doc. de Braslavilla de 1438; GómEZ DE Valenzuela, 2000: 71). Vid. también ganado grosso en Líbano y Villacorta (2013: 67, apartado 4.2.1). Frec.: grosas 1: 0,00227.

guanyar] v. tr. 'ganar': Et el dito rey don Jayme prisso el condado a su mano, el qual ya en tiempo de Ponz de Cabrera [Guerau de Cabrera N], conte desuso dito, havía guanyado por razón de dona Aurembiaya, filla de don Armengou, conte de Urgel 35.96; dius pena de perder las ditas tierras guanyadas et aplicadas [ganaderas e aplicaderas $\mathrm{N}$ ] al dito donador et a los suyos si contrafiries en continent. 16.36. Comp. ganar. Frec.: guanyadas 1: 0,00227; guanyado 1: $0,00227$.

guarda (var.: goarda) s. f. 'guardia, cuerpo de vigilantes, centinelas': e no quería albergar con ella, e puisolo en el Castellar de Caragoça e ovo fabla con las goardas 19.63; «Sennyor Dios, tu seas deffendedor et guarda del poblo» 35.241; mas el dito maestro fuyendo de la presión con las guardas fue delivrado de aquélla 36.59. Deriv. postverbal de guardar, aunque también podría provenir directamente del sustantivo germánico WARDA 'acto de buscar con la vista', 'guardia', 'atalaya', o del gótico WARDJA 'el que monta guardia, centinela, vigía' (DCECH, III, p. 246). Frec.: guarda 2: 0,00455; guardas 1: 0,00227; goardas 1: 0,00227.

guardar v. tr. 'guardar': mandó su muller ser pressa bien guardada en el castiello 14.62; los quoales guardó dentro en su regno 36.114. // 'cuidar, custodiar, preservar, vigilar': querían guardar a bien del regno et naturaleza qui devía seer rey 20.14 // 'observar, cumplir': guardando dreyto de naturaleza por el infant don Jayme que devía seer rey 35.17. Del germánico WARDÔN 'aguardar', 'buscar con la vista' (DCECH, III, p. 246). En arag. med. también se usó con el sentido de 'mirar', derivado del de 'vigilar, atender': «qui adelant non guarda a çaga caye», refrán aragonés del s. XIV (Rius, 1926: 369). Frec.: guardar 1: 0,00227; guardó 2: 00455; guardada 1: 0,00227.

guarnir] v. prnl. 'guarnecerse, dotarse, proveerse': que los christianos se guarnían fuertment de grandes fuerças et deffensamientos en el dito lugar clamado Pannyo 4.22. Etim.: del germ. occid. WARNJAN 'proveer, guarnecer, armar' (DCECH, III, 250). Frec.: guarnían 1: 0,00227.

guerra s. f. 'guerra': buvo en el regno grant guerra entre el rey et los de la unión 37.21; et estieron [estuvieron $\mathrm{N}$ ] en batallas et en guerras bien un anno, 20.149. Etim.: del germánico occid. WERRA 'discordia, pelea' (DCECH, III, 258). Frec.: guerra 20: 0,04546; guerras 6: 0,01364.

guerriar (var.: guerrerar, guenrrar) v. intr. 'guerrear, hacer guerra': comencó de guenrrar por el regno contra los aragoneses 19.105; guerreró con moros et toda vegada venció aquéllos 16.39-40; con el qual guerrió luengament por el feu del castiello de Torroella 36.428. Comp. guerriar en LR (COOPER, LR, p. 129). Frec.: guenrrar 1: 0,00227; 
guerrió 1: 0,00227 ; guerró 1: 0,00227 ; guerreró 1: 0,00227 .

guiar v. tr. 'guiar, dirigir, conducir'; 'escoltar': un moro qui de aquesta paz, era tractador, con XXX ginetes, vino al dito rey guiando [guiado B] et díxole que con él quería favlar, 38.387. Etim.: quizá del gótico *WIDAN (GAWIDAN) 'juntarse', aunque se trata de una etim. muy discutida (vid. diferentes propuestas y pros y contras en $D C E C H$, III, pp. 258-261). Frec.: guiando [guiado B] 1: 0,00227.

guisa s. f. 'manera, forma, modo': con su hermano el infant don Alfonso, el qual tenía por guisa de meter las manos por los afruentos 18.109; Aquesti rey Alfonso metie su amiztat con don Alfonso desseredado de Castiella por don Sancho su tio por esta guisa:... 37.42 ('de esta manera'); porque él faría por guisa que su regno non havría menoscabo por la su venida, 38.257. // Se usa también en la loc. de guisa que 'de manera que': de guisa que XIII richos hombres et otros cavalleros escabeçó 20.135. Etim.: del germánico occidental WISA 'modo, manera', probablemente ya tomado por el latín vulgar. En castellano fue de uso general en la Edad Media, pero, en cuanto ésta termina comienza a hacerse desusado. Es habitual en el arag. medieval (GiLKison, $s$. v.). En Inv. arag., alaguysa, a la guisa 'a la manière courante, ordinaire' ('a la moda del día') (PotTier, ELIA, no 19, p. 93): El dito pellot, con penya de guisa viella 1390; un jupon a la guysa viella 1393; una bacineta a la guysa con su bisera e camal; unos cuxares e cameras a la guysa 1474; unas cuyracas guarnidas a la guisa, en cuero blanco (BRAE, IV, 354, 520; II, 346, 351; IV, 355; cf. DCECH, III, 274-275). Frec.: 6: 0,01364.

guisado (var.: guissado) en la loc. conj. de guisado que 'de manera que': et el rey don Pedro val ad ayudar de guissado quel rey de Navarra, lexado el regno, passó la mar, 34.83; ... de guisado que estavan parellados pora lidiar 37.58; et fue con ellos don Diago de las Vizzcayas et otros de Castiella entro a CCC de cavallo, de guisado que eran con el rey d'Aragón entro a IIII ${ }^{\circ}$ mill de cavallo 37.54-55. Locución formada con el sust. guisa 'manera, modo'. También se encuentra en la forma de guisa que. Vid. guisa. Frec.: guisado 2: 0,00455; guissado 1: 0,00227.

\section{$\mathbf{H}$}

ha prep. 'a': de los christianos murieron entro ba en dos mill 18.69. Vid. a.

ha $3^{a}$ pers. de sing. del pres. de ind. del v. aver haver 'tener': por una estrela que ha nombre Esperus 1.5; fue comte de Aragón su fillo Galindo, el qual fizo fer un castillo qui ha nombre Atharres [Atares N] 8.2; con otras virtudes que ba de aver 20.54. // ni ha, 3. ${ }^{a}$ pers. de sing. del verbo aver haver en uso impersonal, con los compl. ne e $i$, 'hay (allí, de 
ello)': entre los quales lugares ni ha buoy uno clamado Sancho Avarcha 12.73. Comp. y a. / / ha + a, forma de la per. vl. aver a 'tener que': como aquell que no yera seydo usado en armas ni en actos de caballería, la qual yes muyt necessaria para rey et princep que regnas et tierras ha deffender [= ha a deffender] 20.53. Vid. aver, haver. Frec.: 8: 0,01818.

habitación s. f. 'habitación, acción y efecto de habitar': Et por la habitación de aquestos sanctos hombres todos los christianos avian grant devoción en aquesta spelunca. 5.16. / / 'sitio, lugar o territorio donde se habita': et diele por habitación pacifica Gallia, qui agora yes dita Francia, et Espanna 3.33. Cultismo tomado del lat. habitatio, -onis. Frec.: 3: 0,00682.

habitador] s. m. 'habitante, cada una de las personas que componen una población': et de otros richos hombres suyos fizo exir los habitadores de la dita villa 36.501; los habitadores de la dita ciudat sufriessen grant mal et fambre 36.26. Frec.: habitadores 3: 0,0682.

habitar] v. intr. 'habitar, vivir, morar': en aquesta isla de Estancia habitaban aquestas naciones: godos... 3.1; un sancto hombre clamado Johan, heremita, habitava en una espelunca de ius una grant penya 5.2. Cultismo tomado del lat. HABITARE. Frec.: habitaban 1: 0,00227; habitava 1: 0,00227; habitavan 2: 0,00455.

hasmamiento s. m. 'juicio, pensamiento', 'capacidad de discernir o pensar': et a hasmamiento de todo homme et, segunt que depués de cierto se suppo, de toda aquesta gent malvada non tornoron a lur tierra la XXX part 36.665. Etim.: De un derivado vulgar de Aestimare (>estimar), *ADAestimare, procede el antiguo aesmar (F. Juzgo), normalmente asmar, que ya se encuentra en el Cantar del Cid, y fue corriente hasta princ. s. Xv; osmar se halla a veces en el mismo sentido. Deriv. de asmar es asmamiento. En euskera asmatu 'inventar', y asmu 'pensamiento', 'talento, espíritu, ingeniosidad' (DCECH, II, p. 789; AzkuE, s. v.). Cfr. occ. ant. esmar 'estimer, apprécier; considérer, calculer; penser, s'imaginer'; esme 'estimation, appréciation'; esmansa 'estimation, opinion; reflexion' (LEVY, s. v.); arag. mod. esme 'facultad de orientación, tiento' en el valle de Benasque (cfr. Ferraz, Ballarín, DDPA, s. v.); esmo ‘conocimiento’ en Alquézar (Arnal CAvero, s. v.). El EBA (1999: 818) registra esmo en el valle de Chistau, A Fueba, Biello Sobrarbe, Barbastro, Campo, Salas Altas, Chuseu y Torres del Obispo. Ya Moneva (2004 [1924]: 217) recogía esmo 'orientación' en el Somontano y Ribagorza, y ‘tiento, tino’ en el Alto Aragón en general. Mostolay (2007: 262) registra para el Somontano de Barbastro esmo 'conocimiento, talento' y 'orientación, sentido'. Frec.: 1: 0,00227.

haver v. tr. 'poseer, tener' y v. auxiliar para la conjugación de los tiempos compuestos de los verbos transitivos: et havieron acuerdo quel rey se partiesse d'alli 20.194; Et tal era havido su consello, la qual cosa vino ad acabamiento 20. 222. Del lat. HABERE 'tener, poseer'. También aver (vid.). Frec.: ha 8: 0,01818; han 5: 0,01136; has 2: 0,00455; había 1: 0,00227; haver 15: 0,03408; havemos 4: 
0,00909; havia 66: 0,15001; havían 12: havido 2: 0,00455; havie 4: 0,00909; havien 2: 0,00455 ; haviendo 1: 0,00227 ; havieron 2: 0,00455 ; havies 9: 0,0246; haviessen 2: 0,00455; havría 2: 0,00455; he 5: 0,01136.

hedificar v. tr. 'edificar'. Et res non menos, hedificó, a honor de Dios e de sennor Sant Johan, un monesterio en el lugar clamado Sant Martin de Certico 8.3. Vid. edificar. Frec.: hedifficado 1: 0,00227; hedificado 1: 0,00227; hedificados 1: 0,00227; hedificaron 1: 0,00227; hedificó 5: 0,01136.

heredar v. tr. 'dejar o asignar en herencia': que le dies algo de lo suyo que heredas assí como fillo deve heredar a padre 20.178-179; et heredó del condado de Barcelona a su fillo don Remón Berenguer et del Marquesado de Probença al otro fillo Berenguer Remon 31.50-51; depués quando buvo heredado sus fillos rendiose a la orden de cavallería de Iherusalem 31.52. Del lat. tardío hereditare (BDELC, s. v.). Frec.: heredar 1: 0,00227; heredas 1: 0,00227; heredado 1: 0,00227; heredó 3: 0,00682; heredólo 1: 0,00227.

heredat s. f. 'herencia', 'bienes, posesiones, hacienda': et aquel ennoblesció de muytas heredades et bastecida la iglesia del dito monesterio 28.20; et por tal como estuvo luengo tiempo en Castiella en la heredat de su madre fue nombrado Ermengou de Castiella 31.24. Del lat. HereditAs, -ATIS 'acción de heredar, herencia'. Comp. herencia. Frec.: heredat 4: 0,0909; heredades 2: 0,00455.

heredero adj. y sust. 'persona que hereda, que sucede por testamento o por ley en una herencia': et lexó heredero del condado de Ribagorça et de Ampurias, el qual por compra bubo, don Pedro 38.636; et lexó herederos suyos en los regnos de Aragón, de Valencia, de Cerdennya et el condado de Barchinona el dito don Alfonso 38.633. Del lat. HeReditarius 'referente a una herencia' (DCECH, III, p. 344). Frec.: heredero 15: 0,03409; herederos 2: 0,00455.

hereditario adj. 'hereditario, relativo a la herencia o sucesión': et depués quel le ganaría el dito Imperio a messión de la Yglesia, el qual se sperava et pertannya a la dita muller por dreyto hereditario 38.157. Cultismo tomado del lat. HEREDITARIUS. La $1 .{ }^{a}$ doc. que dan Corominas-Pascual (DCECH, III, p. 344) es de 1600; luego la Crón. SJP la adelanta en más de dos siglos. Frec.: 1: 0,00227.

herege] (var. erege])s. m. 'hereje': Pero depués, por enganno et por fuerça del emperador Valient, qui era de la secta arriana, tornaron ereges en la error arriana 3.23; avía guerra con el rey de Francia et con arcevispo de Narbona, don Arnalt, porque enparava algunos hereges 34.152. Etim.: del occ. ant. eretge, y este del lat. tardío haERETiCus 'íd.', tomado a su vez del gr. hairetikós 'partidista', 'sectario' (BDELC, p. 317; DCECH, III, p. 344). Occ. ant. eretge 'hérétique; Cathare' (Levy, s. v.). occ. (lang.) eretge 'hérétique' (AliberT, s. v.); cat. heretge 'el qui sosté una heretgia' (FABra, DGLIC, s. v.; DL/C del IEC, 2007, s. v.). En el arag. de Fernández de Heredia: erege, eretge, herege, heretge 
(GiLKISON, 1984: 57). Frec.: hereges 2: 0,00455; ereges 1: 0,00227.

heremita s. m. 'eremita, ermitaño': translataron los cuerpos [sic] del desus dito Sant Johan heremita et soterraronlo en una muy bella tomba 9.21. Del lat. EREMITA. Frec.: 3: 0,00682.

herencia s. f. 'herencia': et lo rigió bien assín como cosa propria suya et herencia 20.297. Tomado del lat. HAERENTIA 'pertenencias' y luego 'bienes y derechos que se heredan' (BDELC, s. v.). En DCECH (III, 346), se lee: «La forma aragonesa herencio 'herencia' (Borao) es seguramente secundaria; si fuese muy antigua (pero no figura en Tilander) podría imaginarse que saliera del sinónimo latino HEREDIUM (bastante frecuente en los clásicos y en la Edad Media), con tratamiento semipopular del grupo -DI- (como en hozar < FODIARE), y con influjo posterior de -encia (tal como cansancio < cansacio y análogos); entonces herencia sería el resultado último de este influjo progresivo. Pero esto es muy complicado y totalmente hipotético». La presencia de herencia en la Crón. SJP. confirma la suposición de que herencio (o erenzio) no sea forma muy antigua y, en cambio, sea forma secundaria. En arag. med. lo común es eredamiento o heredamiento: «\& uos \& aqellos que verran apres uos qe dedes de aqellos fruytos qe Dios dara a collir en el dito eredamiento del cabomaso bien \& lial ment dieçma \& promicia a la casa de Sant Urbiç» (DLA A, doc. n. ${ }^{\circ} 43$, de Panzano, 1278; p. 66, lín. 20-21). En Fernández de Heredia, heredamiento (GILKISON, 1984: 57). Vid la forma mod. erenzio en ANDOLz (1992: 178), EBA (1999: 755), etc. Frec.: 2: 0,00455.

hermano s. m. 'hermano' (f. hermana) : prisso otra muller, la hermana del rey de Chipre clamada dona María 38.440; el dito don Alfonso et encara sennyor de sus hermanos 38.636. Etim.: del lat. GERMANU. Se registra siempre con $b$-. Lo coherente con la fonética histórica aragonesa sería encontrar germano (arag. mod. chirmano, chermano). Pero la forma con palatal inicial es rara en textos medievales arag. (cfr. PotTier, 1952). Además, compárese con lo que ocurre, contrariamente también a las leyes de evolución fonética propias, en gallego-portugués, donde tenemos irmão: gall. irmán, irmau, irmá (Franco Grande, Diccionario galego-castelán, s. v., p. 567); port. irmão (FERnANDEs, Dicc. port.español, s. v.). Quizá hay que pensar que se trata de un temprano castellanismo, tanto en arag. como en gall.-port. Sin embargo, cfr. arag. germano en el Eutropius de Fernández de Heredia (junto a hermano, ermano habituales en otras obras) (GILKISON, s. v.). En documentos notariales altoaragoneses: jermano («e a uuestra muler Maria \& a Petro uuestro jermano \& asso muler Agnes \& a Martin, jermano de uos Johanes»: DLA A, p. 3, doc. $\mathrm{n}^{\circ} 3$, de Nocito, 1262), pero hermandat («algunas cossas por anuestros negocios enla dita hermandat, et por defallimjento de labor que an mester la dita hermandatı: DLAA, p. 117, doc. nº 80, de Ansó, de 1304); etc. Frec.: hermana 7: 0,01591; hermanas 7: 0,01591; hermano 73: 0,16592; hermanos 7: 0,01591. 
hi (var.: hy, y, i) compl. pron.-adv. 'ahí, allí, en aquel sitio, en ese sitio': el qual hi [ya $\mathrm{N}]$ avía durado XIIII annos 38.85; et no y buvo ninguno que bi respondies [respondiesse $\mathrm{N}]$, 38.323-324 (' no huvo allí nadie que respondiese a ello'); del qual fillo ni filla no y fincó 16.17; ningún christiano no bi murió 35.234; fueron hi feitas constituciones 38.23. // 'a ese sitio, a aquel sitio': et mudólos by [omite N] del monesterio de Clunyego [Clunigo N], 14.97-98. // 'a eso, a ello': et no y buvo ninguno que hi respondies [respondiesse N], 38.323-324 ('que respondiese a ello'). Del lat. IBI 'aquí, allí, en ese lugar, en aquel sitio'. Frec.: hi 24: 0,05455; y 47: 0,10683; hy 3: 0,$00682 ;$ i 1: 0,00227.

hide (var.: yde) compl. pronl-adv. 'allí, ahí mismo': se rendría si el rey d'Aragón y de hiva 38.291; tanta de gent hi de vino depués... 36.563; et assi mismo y de vino Huguet de Totzo almirant del rey don Sancho de Mallorquas con XX galeras 38.501; et murió y de grant multitut de gent 36.542; et fue y de entre los barones e nobles Narmengon 32.29. Del lat. IBIDEM 'allí mismo, en el mismo lugar'. Comp. hy, hi, y. Se registra hide 'allí, allí mismo' en TLME (lín. 17, p. 200, doc. nº 113, del último tercio del s. XIV) en un fragmento de la traducción de La flor de las ystorias de orient atribuido a J. Fernández de Heredia: «Por el otro camino de la Mar Mayor no bide osarian entrar ninguno». Es frecuente en Fernández de Heredia en las variantes $i d e$, bid, yde, hide, byde (GILKIsON, s. v. ide, p. 74). También aparece frecuentemente en otros textos aragoneses medievales. Frec.: se han contabilizado por separado las formas hi, $\mathbf{y}$ (vid. hi), puesto que aparecen separadas; no obstante hi de aparece una vez $(0,00227)$ e y de 4: 0,00909.

ho partícula afirmativa intensiva, procedente del lat. HOC, usada en la combinación ho encara, literalmente 'sí todavía, eso mismo todavía', que aquí significa 'sino que también, sino que incluso': et no tan solament contes et otros barones hi murieron, ho encara el rey francés ne prendió la fiebre muyt grant et fue muyt grievement [grieument B] enfermo 36.604-605 [E no tan solament comtes e altres barons hi moriren, hoc encara lo rei francès ne pres gran febre VC, p. 145]. En el Glossari de la VC, p. 189, hoc encara se traduce por 'fins i tot'. Según Coromines, los matices que tiene el cat. ant. hoc encara son 'sinó que també' y 'àdhuc' (DECLLC, IV, pp. 797-801, s. v. ho, y esp. p. 800). El origen de ho es el mismo que el de la partícula afirmativa hòc, hò, que se usó en cat. med., concurriendo con sí (esta, afirmación más atenuada), y que hoy está restringida al dialecto rosellonés (Coromines, ibídem; $D C V B$, t. 6, p. 537). E igualmente, que el del adverbio de afirmación occ. ant. oc, o, oi (LeVY, s. v.), occ. mod. ò òc (AliberT, s. v.). Está atestiguado el uso de la partícula de afirmación intensiva hoc 'sí, ciertamente' en el aragonés de J. Fernández de Heredia, en las combinaciones certas hoc 'esto es ciertamente verdad' y hoc encara 'sino que además' (GILKISOn, s. v., p. 95; lo documenta en siete obras distintas de Fernández de Heredia). Parece que es una loc. conj. que tiene el significado aproximado de 'sino también', 
'sino que incluso' (adversativa exclusiva). Aparece con el mismo sentido hoc encara en la contestación al discurso de Martín I el Humano en las Cortes de Zaragoza de 1398 (ACRA, t. vI, vol. $1^{\circ}$, p. 17). También lo vemos en documentos notariales del Alto Aragón: «Et a esto tener \& complir obligo a vos mj pesona $\&$ todos mjs bienes mobles \& sedientes haujdos \& por hauer en todo lugar, hoc encara obligo mj persona» (MDF: 183.15). Aparece también en los Fueros de Aragón: «las ditas unión et aplegamiento por ocasión de las quales los ditos males, danyos, scandalos fueron seguidos et se speravan mayores seguir, en el tiempo adevenidero, con os clamados privillegios del rey Don Alfonso, fillo del rey Don Pedro, feytos en Caragoça (v calendas de janero), tal dia et anyo etc., hoc encara la confirmación por nos feyta el anyo primero pasado en la dita ciudat de Caragoça» (Fueros de 1265 a 1381; BERGUA, 1949-1950: 502). «et faremos a todos tienpos observar et custodir los fueros diuso scriptos, specialment dius aquesta rubrica sobredita contenidos. Hoc et encara los otros fueros, privillgios, libertades, husos et costumbres del dito regno» (Fueros de 1265 a 1381; Bergua, 1949-1950: 503). Véase también en la forma oc et encara: «et todas et cada unas cosas en los ditos privillegios et declaacion contenidos sian en Aragon fueros, et por fueros d'Aragon sigan avidos et observados, et a todos et cada unos subditos; oc et encara a los judges et oficiales del dito regno» (Fueros de1265 a 1381; Bergua, 1949-1950: 511). Como adv. de afirmación hoc 'sí' en la Crónica de Juan II ( $2^{\mathrm{a}}$ mitad s. Xv): «—Dezitme — dixo el rey— ¿el campo es fecho? Respuso el senescal: -Hoc, mas la batalla se devia facer en presencia de mi» (Riquer, 1969: vi, 262-264). Igualmente, en un texto de Calatayud de 1488 (proceso contra Fernando López, acusado de judaizante): «Hoc confessos, mas no christianos, mas qualque día vos ne poría venir mal» (VILA: 1989: 139). Puede verse también en documentos municipales del Alto Aragón: «Respusieron e dixeron todos generalment los que son en la sobredita procura nombrados de Biescas e Senegue e Betes, Yosa, Xabierre e Latas que hoch con aquellos usos e costumbres qui los antipassados havian acotumbrados» (doc. de Biescas de 1447; Gómez de Valenzuela, 2000: 81-82). Dado el empleo de hoc en estos y otros muchos textos medievales arag. de los siglos XIV y XV, hay que considerarlo como forma propia del aragonés. Si la documentación no es abundante, se explica por tratarse de una partícula propia del estilo coloquial. No obstante, es bastante más habitual que lo que a simple vista parece, pues a menudo se interpreta mal al realizar la transcripción de los textos, de manera que se transcribe por bot, lo que se explica por el gran parecido de la $c$ y la $t$ en los manuscritos medievales y, añadido a eso, por el desconocimiento del uso de la partícula hoc en aragonés. Un ejemplo lo vemos en DLAA (doc. 135, de Jaca, 1420, 
p. 198): «...\& por fuerça tiroron lis las ditas bestias, a poder de colpes, dando a las ditas bestias, ho[n]t encara diciendo todos ensenble: - Mal aquí soz venidos, car todos o en partida hi podremos fincar, mas vosotros con mal ne partirez...». Se ha transcrito bont en lugar de hoc, confudiendo la $c$ por $t$, y además ha añadido el transcriptor una - $n$ - injustificadamente. Véase otro ejemplo: «segunt las possien los vezinos \& habitadores de la dicha villa de Biescas \& del dicho luguar de Guauin bo[n]t encara por darnos algunas entradas \& patouienças pora nuestros ganados grosos e menudos (DLAA, doc. n. ${ }^{\circ}$ 149, de Panticosa, 1484; p. 219, lín. 12). Frec.: 1: 0,00227.

ho conj. disy. 'o', es mera variante gráfica de o: porque toda vegada ho quayx estuvo enfermo 39.15. Frec. 1: 0,00227.

home s. m. 'hombre' (variantes: homme, hombre, ome, omme): buvo nombre don Phelip qui fue santo hombre et murió devotament estando freyre menor. 38.452; todos los ditos homes buenos eslyeron curador suyo don Phelip su tio 38.607; murió don Sancho rey de Mallorquas, el qual fue homme simple 38.599; sitió Tortosa con genobeses, con II" omes d'armas 32.26; prendiendo e matando ommes e fenbras 33.81. // pron. indef. impers. (semejante al on francés, podría traducirse por 'se'): que home conta $X X^{\circ}$ kalendas de febrero 39.44; buvo un fillo que bomme lo clamaban Armengou de Gerb 29.28; Los duelos, ploros, plantos e dolores que en la tierra después de la muert suya fueron albirar ni pensar homme non los poria 36.715 // pron. indef. 'alguien': «iyes aqui el rey Carlos o home por él?» 36.294. / / homme ninguno, ningún homme pron. indef. 'nadie': que homme ninguno non podía ir sino sobre gent muerta 36.643; a ningún homme millor non la podría dar por muller 23.17 / / todo home, todo homme pron. indef. 'toda la gente, todos, todo el mundo': firo exir todo home de Girona 36.525; mientre que todo homme dormía 38.543. Etim.: del lat. HOMINE(M). (DCECH, III, p. 379). Los valores correspondientes a pronombres indefinidos impersonales ( $=$ fr. 'on') son frecuentes en otros textos en arag. med.: «Et partiendo daqui avant $\mathrm{v}$ iornadas por ponent, troba hombre ciudades, villas et castiellos, et troba hombre vna otra provinçia que ha nombre Letabech» (Libro de Marco Polo, ed. NitTi, p. 27, lín. 21-22; ed. de Sangorrín, 2016: 71). «Como hombre entra a man ezquerra», Inv. arag. de 1375 (BRAE, IV, 213; DCECH, III, 379). El arag. hombre con valor impersonal proviene del acusativo HOMI$\mathrm{NE}(\mathrm{M})$, mientras que el fr. on y cat. hom provienen del nominativo homo (cfr. PRobert, s. v.; Dauzat-Dubois-Mitterand, s. v.; Badía, Gram. hist. cat., p. 326; Coromines, DECLLC, IV, pp. 801-805). Sobre la no diptongación de ŏ vid. DCECH, III, p. 379a: cita la explicación que dan MeYer LÜBKe y MenéndeZ PidAL (MGHE, \13.4): una pronunciación latina rústica o romance en que la nasal cerraba el timbre de la ŏ. Antiguamente se empleó en cast. hombre o el hombre como pronombre indefinido, a semejanza del fr. on, cat. hom: este uso se registra ya en Berceo (el omne, Milagros, 91a) y en muchos textos me- 
dievales hasta la Celestina ( $« \mathrm{El}$ comienço de la salud es conoscer hombre la dolencia del enfermo», I, Clás. cast. I, 42.5), pero todavía perdura en varios autores de los siglos de Oro: hombre en Juan de Valdés (Dial. de la Lengua, 8.10), Jorge de Montemayor, etc. (Corominas-Pascual, DCECH, III, p. 379). Frec.: hombre 13: 0,02955; hombres 19: 0,04319; home 5: 0,01136; homes 30; 0,06819; homme 26: 0,05910; hommes 4: 0,00909; omes 1 : 0,00227; ommes 8: 0,01818.

homenage (var.: omenage) s. m. 'homenaje; juramento solemne de fidelidad hecho a un rey o señor': fueron en Pisa por prender homenage de los ancianos del común de Pisa 38.577; que le fizies omenage et sagrament de fieldat por las tierras que tenia por él 36.102. Etim.: tomado del occ. ant. omenatge, o del cat. homenatge, y éstos del lat. tardío *hominaticum, deriv. de homine en el sentido feudal de 'vasallo' (DCVB, t. 6, p. 541; DECLIC, IV, p. 804). Frec.: homenage 15: 0,03409; omenage 5: 0,01136.

honesto adj. 'honesto': «Priégote, fillo, que tu devyes amar tu hermano que yes savio et bueno et de honesta vida» 35.271. Frec.: honesta 1: 0,00227.

honor (var: onor) s. f. 'honor': Et veyt si fue grant honor [veyet si no con grant honor $\mathrm{N}]$ a la casa d'A ragón quel rey don Jayme tollies al rey de Castiella, mas poderoso rey que él, tal regno como es Murcia 38.213; privando aquéll de los regnos et honores suyas, possando viedo en todas las tierras suyas 36.458-459; propuso en su coraçón que a onor de dios fues a Sant Jayme fiziendo romeage 33.103-104. Del lat. HONOS, -ORIS. Frec.: honor 58: 0,13183; honores 4: 0,00909; onor 1: 0,00227.

honra (var.: honrra) s. f. 'honra': et con grant alegria et honra recibió los navarros et conbidoles que comiessen con él 20.26; et levaron el su cuerpo a Montaragón et aquí estuvo reservado VI meses et XV días, por tal que non yssen las gentes d'alli por fazer honrra al cuerpo et los moros prendiessen conuerto 17.132. Etim.: postverbal de honrar. Frec.: honra 2: 0,00455; honrra 1: 0,00227.

honrablement adv. 'honorablemente, honradamente': et con grant duelo honrablement soterrado en el monesterio de los freyres menores de Barchinona 37.98. Frec.: 1: 0,00227.

honradament (var.: honrradament, onradament) adv. 'honradamente, con honor': el dito rey don Jayme de Aragón devotament murió en hedat de LXXI annos en la ciudat de Barchinona, la vigilia de Todos Santos, et fue soterrado muyt honradament en el monesterio de Santas Cruzes 38.631; et fue soterrada muyt honrradament en la iglesia de San Pedro 34.69; vino don Beltrán d'Albaus et puyó con el dito rey don Alfonso en el cavallo e, pasado el dito rio de Royne, vinieron sende en el castillo de Arlet do fue reçevido muy onrradament. 33.45. Frec.: honradament 13: 0,02955; honrradament 6: 0,01364; onrradament 3: 0,00682.

honrado (var.: honrrado]) adj. 'honrado, honorable, digno, honesto; virtuoso, de buena reputación': la sennyoria [sennyera N] del dito don Alfonso, noblement acompannyada de honrada cavallería, entró en el dito castiello 38.572; el qual, aplegado grant 
navilio armado con muyto honrado barón, ribó al puerto de Roma 38.172; et pobló una ciudad a la qual puso nombre Burgos et adaquella ennobleció de honrrados barones 14.10. Frec.: honrado 4: 0,00909; honrada 5; 0,01136; honrrados 1: 0,00227. (Vid. también honrrar).

honrament s. m. 'honra, honor, estima y respeto': Et depués con grant honrament adozieronlo al monasterio de Sant Johan de la Penna 17.134. [E depuis, ab gran honrament aduguerenlo al monastir de Sant Joan de la Penya VC, p. 63]. Fonéticamente es forma catalana y coincide además con la forma que aparece en la versión catalana: quizá habría que pensar en que para la traducción de este capítulo se ha tenido en cuenta la VC y no la VL. Comp. honramiento. Etim.: deriv. de honra. Frec.: 1: 0,00227.

honramiento s. m. 'honra, honor, solemnidad': aplegó grandes cortes a Caragoca et aquí, con muyt mas [grant N] honramiento que nunca rey se coronas, fue coronada et untado en rey 39.7. Deriv. de honra. Esta forma obedece a fonética propia del del aragonés. Comp. honrament. Frec.: 1: 0,00227.

honrrar] v. tr. 'honrar': movido de grant inquidat et invidia porque lur padre havía mas honrrado que a él... 30.14. Etim.: del lat. HONORARE. Frec.: honrrado 1: 0,00227.

hora (var.: ora) s. f. 'hora': que fue cerca de los enemigos, et esperando hora convinent, firió vigorosament en la huest de los enemigos 33.85; en día miércoles a hora de media tercia 39.43 / / la hora (la ora, las horas, las oras, a las horas) adv. 'entonces': et era la hora vispo en Jaca García, fillo del dito Remiro rey 16.48; et la hora entró la ley romana en Sant Johan de la Penna 17.60; Et la ora regnava en Navarra el rey García Ximenez 5.18; Et la ora era conte en el condado de Ampurias Huch 35.102; et la ora el sol sufrió deffallimiento 38.403; Et aquesti Alarico demandó al emperador Honorio, qui a las horas emperava et sennyoriava el imperio de Roma, aver paz con él et con el Imperio 3.31; et las horas, la nacion morista, por la vitoria que ottuvo contra el dito rey Ordonyo, prendiendo mayor audacia, passando el mont Pireneus, conquirió entro a la ciudad de Tolosa 9.7; et las horas, los cristianos qui en la desus dita cueva heran cullidos por el miedo e terribledat de los moros, yxieronse d'aqui 11.8; Assín de las oras entaqua buvo nombre Ennego Ariesta 10.20. Vid. ora, la ora. Frec.: ora 36: 0,08183; oras 13: 0,02855; hora 7: 0,01591; horas 3: 0,00682.

hornamentes s. m. pl. 'ornamentos, adornos, aderezos': et li fues apparellado su cavallo, ensellado et bien honrado de diversos hornamentes 37.89. Frec.: 1: 0,00227.

hudió 'oyó', pret. indef. del v. oyr: quando budió [vido N] quel rey de Huesca le havía crabantada la tregua, como buen rey, quirie mas haver guerra con los moros que non con los christianos 17.51. Vid. oyr. Frec.: 1: 0,00227.

huerfano] adj. 'huérfano': et fue padre de fillos huerfanos 35.176. Etim.: del lat. tardío orphanus, y éste del gr. oppavos (DCECH, III, p. 417). Frec.: huérfanos 1: 0,00227 . 
huerto s. m. 'huerto’: pensó en si mesmo quel huerto podía seer el su regno 20.121. Del lat. HŎRTUS 'jardín, huerto’. Frec.: 3: 0,00682.

huest s. f. 'hueste, conjunto de gente armada': et soterraron aquellos que pudieron et de los otros fueron emplidos dos poços con tierra que hi fue gitada dessuso por tal que non dasen pudor en la buest 38.559; tan cuytosament vino el dito rey con las buestes que non podieron seer fornidos de res 36.138. Del lat. HŎsTIS 'enemigo' y luego 'ejército enemigo', 'ejército en general' (DCECH, III, p. 421; DECLIC, IV, p. 821). Comp. cat. ant. host, fr. ant. ost, cast. hueste, port. e it. oste. Frec.: huest 17: 0,03864; huestes 3: 0,00682.

huey (var.: oy, hoy, hoi, huoy) adv. de tiempo 'hoy': et huey en dia fazen aquel mismo officio los beneficiados que son alli 20.305; por una claveguera o albellon que es en el castiello de Perpinyan, qui la ora non era obrado nin acabado assí como buey yes 36.413; prendió muytos lugares en Cantabria, entre los quales lugares ni ba buoy uno clamado Sancho Avarca 12.73; actorgólo por el dito monesterio que yes de monges negros e oy en día lo poxedecen 19.18; dizen oy en día por Castiella «malas Urreas passen por tu casa» 38.209; el qual hoy a nombre Moncayo 1.25. Etim: lat. HŏDIE. «General en todas las épocas y común a todos los romances. De acuerdo con la fonética dialectal, en aragonés y leonés el resultado fue huey o bués (DCECH, III, p. 405). En arag. la forma propia es huey (guey, gueı), que se ve de forma habitual en los textos medievales, fuera de las obras del scriptorium de Fernández de Heredia, donde habitualmente aparece hoy, oy (solamente buey en Rams de flores y en la Coronica de los conqueridores; cfr. GILKISON, p. 98, s. v. oy). También se registra la forma sin diptongar (de la misma manera que en el Fuero de Teruel encontramos sin diptongación oio y ocho, en lugar de güello y güeyto: cfr. GoRosch, 1950: 58; Nagore, 2007) en los textos notariales de Teruel (véase oy en Terrado, 1991: 65) y de las Serranías Ibéricas en general, cuyo tipo de aragonés concuerda mayoritariamente con el de Fernández de Heredia. Véase algún ejemplo de huey, guey: «\& en otras messiones por lo officio que vos fuéssedes tenjdo entro al present dja de huej» (MDF, 96.11, doc. de 1390); «et encara que la dita vigna sia por todos tienpos entegra, assi como buey, est present dia aquesta present carta fue escripta» (DLAA, doc. de Montearagón de 1287, p. 87); «et aquellos duren et hayan plena firmeça et valor por tiempo de cient anyos de buey a devant primeros venientes» (doc. de Braslavilla, en el valle de Echo, de 1438; en Gómez de Valenzuela, 2000: 71); « $\mathrm{LV}^{\mathrm{m}}$ florines de oro de Aragon, de los quales le prometieron de dar e pagar la meytat de guey en quatro meses» ( $A C R A$, VIII, Cortes de Zaragoza de 1412, p.195). «...que todas e qualesquiere sentencias que sian seydas dadas enta al presente dia de guey entre los concelhos de Bual e Pietrafita...» (doc. de Piedrafita de 1445; EAMJM, p. 75). La forma güe es moderna y solo se registra en Bielsa y en Benasque (BADíA, 1948: 116; BA- 
LLARín, 1978: 222), zonas donde es normal la reducción del diptongo ei $>e$ (güei > güé, de la misma forma que estreito $>$ estreto o feito $>$ feto), por lo que se puede considerar una forma dialectal, frente al arag. común güei. Llama la atención el uso muy frecuente del sintagma buey en día, oy en día como loc. adv. de tiempo, perífrasis enfática creada para compensar la brevedad del vocablo. La última forma mencionada aparece habitualmente en el manuscrito como oyendia, es decir, escrita como una sola palabra, lo que explicaría la no diptongación de la ŏ al hallarse en posición átona. Frec.: huey 2: 0,00455; huoy 1: 0,00227; hoy 3: 0,00682; hoi 1: 0,00227 ; oy 10: 0,02273 .

hueyto adj. num. 'ocho': Es verdad empero quel dito rey Remiro regnó XXX bueyto annos 16.61. Etim.: del lat. Ŏсто. Es habitual en arag. med. la forma bueyto, gueyto [gwéito]: «en el anyo de nuesrtro Senyor Dios de Mil $\mathrm{CCC}^{\circ} \mathrm{xxxx}^{\mathrm{a}}$ et gueyto» (Fueros de 1265 a 1381; Bergua, 1949-1950: 500; Dezeno libro, lín. 9); «a precio de cada seys sueldos e gueyto dineros, que montan xx ss.» ( $L M$, p. 55); «quaranta gueyto cargas de agua» ( $L M$, p. 68); «el dito dia viernes gueyto cargas de agua» ( $L M$, p. 76$)$; «dia miercoles a gueyto día del mes de oztubre» ( $L M$, p. 76$)$; «de los trehudos de los albacares recebie cinquanta e gueyto sueldos» (LM, p. 112); «por precio de gueyto florjnes doro» (DNT, IV, 1427: 5.9); «por preçio de gueyto soldos dineros jaqueses» (DNT, IV, 1427: 79.9); «por precio de gueyto florines» (DNT, IV, 1428: 96.71); «en el lugar de Salljent, a gueyto dias del mes de setiembre» (DNT, V, 1431: 88.43); «gueyto dias apres de San Miguel» (DNT, V, 1431: 104.41); «et si con armas en los ditos lugares trobado no sera que en aquest caso jaga preso gueyto dias en la presion del dito Senyor Rey» (OB, p. 45, lín. 28). Hoy solo se conserva la forma güeit 'ocho' en el valle de Benasque (BALLARín, 1978: 222, s. v. gueyt). Frec.: 1: 0,00227.

huffana s. f. 'gallardía, arrogancia, ostentación', 'jactancia, soberbia, engreimiento': et con grant buffana el dito Carlos con sus galeras se acostó al dito Roger 36.311. [E ab gran ufana lo dit Carles ab les sues galeres s'acostà al dit Roger VC, p. 137]. Etim.: incierta, pero probablemente relacionada con el gótico Ufjô 'abundancia, exceso', acusativo UfJôn (DCVB, s. v. ufana, t. 10, p. 592; DECLIC, VIII, p. 955; DCECH, V, p. 708; DEEH, p. 409). El DME, p. 1608, registra ufana 'orgullo'; 'vanidad, presunción, honra'; debió quedar anticuado en el s. XVI, aunque siguió empleándose el adj. deriv. ufano, -a 'presuntuoso, arrogante'. Comp. cat. ufana 'ostentació artificiosa o per vanitat' (DCV B, 10, pp. 591592, donde pueden verse varios ejemplos en cat. med.). Según Coromines, en esta acepción de 'ostentación, presunción, vanagloria' es de uso literario; en cambio, tiene plena vitalidad la acepción 'lozanía, exuberancia' (DECLIC, VIII, p. 956). Cat. ufana 'pompa, ostentació' (FABRA, Dicc., s. v.), 'ostentació artificiosa o per vanidat' (DL/C del IEC, 2007, s. v.). En occ. ant. ufana 'osten- 
tación, arrogancia, vanidad, fanfarronería’ tiene aún más vitalidad que en cat. (LeVY, s. v.). Se registra también para el occ. mod. ufan $\sim$ ufana 'ostentación, vanidad, fasto, gloria' (AliberT, s. v.). En cast. ufana 'ostentación, pompa' se documenta ya h. 1290 (DECLIC, VIII, 956; DCECH, V, 708-711). Quizá es lo mismo que ufanía 'jactancia, vanagloria, soberbia' o bien, en segunda acepción, 'alegría, despejo, gusto, o satisfacción, con que se hace alguna cosa' (RAE, Dicc. de Aut., s. v.). Cast. ufano 'arrogante, presuntuoso, engrído', 'satisfecho, alegre, contento', voz afín al oc. ufana 'jactancia' y al cat. ufana 'lozanía, frondosidad (DLE, 2014, s. v). Frec.: 1: 00227.

humanal adj. 'humano': et que la malquerencia quel enemigo del bumanal linage havía procurada 20.163. Etim.: deriv. de humano, del lat. HUMANus 'humano'. En la Edad Media, en cast. es frecuente bumanal (por ej. en Berceo, J. Ruiz), que envejece después del s. Xv (aunque todavía se encuentra en Nebrija (DCECH, III, p. 425). El Dicc. de Aut. lo recoge con la indicación: «lo mismo que Humano. Es voz antiquada.» Pueden verse ejemplos cast. de los s. XIII al Xv en DME, p. 1244. Se registra bumanal, umanal, en Fernández de Heredia (GiLKIsON, s. v.), en $V M$ (Tilander, VM, III, p. 161), en el LT (Rodés, 2016: 733), etc. Frec.: 1: 0,00227 .

humil adj. 'humilde': Et estando el rey en hedat de LV annos, devotament et humil, penedido et confessado con grant contricción de sus peccados, al verdadero Dios envió el su spiritu 36.702. [Aquí hace oficio de adverbio, pero tal como es típico del aragonés, el sufijo adverbial -ment solo aparece en el primero cuando hay dos adverbios seguidos en -ment. Etim.: del lat. HUMILIS 'humilde' (DCECH, III, p. 426). La forma bumil 'humilde' es habitual en arag. medieval: GILKISON (1984, s. v. homilde) registra bumil en ocho obras de Fernández de Heredia; en otras se registran las variantes homilde, humill, homil, bumilde. Frec.: 3: 0,00682.

humildat s. f. 'humildad': «et ayas paciencia et bumildat que es començamiento de todos los bienes» 35.269. Del lat. HUmilitate(M). Gilkison $(1984$, s. v.) registra bumildat en diez obras de Fernández de Heredia. Frec.: 1: 0,00227.

humilment adv. 'humildemente, con humildad': humilment recebido el hábito de los freyres menores 37.97. Habitual en arag. med.: GiLKIsON $(1984$, s. v.) registra bumilment en diez obras de Fernández de Heredia. Frec.: 5: 0,01136.

huoy adv. 'hoy': entre los quales lugares ni ha buoy [en día N] uno clamado Sancho Avarcha 12.73. Vid. tb. huey, oy. Frec.: 1: 0,00227.

hy compl. pron. adv. 'ahí, aquí, alli': et qui al by querra dezir, entre al campo 12.35; et firo by fer muytos castiellos 12.47; et mudólos by del monesterio de Clunyego 14.97. Etim.: del lat. IBI 'aquí, allí, ahí, en ese lugar, en aquel sitio'. Aparece también en las formas hi, y, i. Frec.: 3: 0,00682. 
i conj. cop. 'y': envyó por un duch sosmeso suyo clamado Abdemalit Abencaçan, al qual fuertment mandó que en continent fues con gran poder de hombres a cavallo $i$ de pie enta las partes d'Aragón 4.28. Vid. et, e. Frec.: 1: 00227.

i compl. prnl.-advl. 'allí, ahí', en la secuencia ni ba $=$ ne $i$ ba 'de ello allí hay': entre los quales lugares ni ha buoy uno clamado Sancho Avarcha. 12.73. Comp. hy, hi, y. Frec.: 1: 0,00227.

iazer] v. intr. 'yacer': fizo venir en la villa de Aljacira, do la ora iazía enfermo, su fillo don Pedro 35.252; a honor et a reverencia de Dios et de los sanctos qui aquí iazían 9.33. Del lat. JACERE 'estar echado' (DCELC, IV, p. 771). Frec.: iazía 1: 0,00227; iazían 1: 0,00227.

idus s. m. pl. 'idus, el día que divide en dos partes el mes': en la villa dessuso dita IIII ${ }^{\circ}$ idus novembris, en el anno de Nuestro Sennyor 36.705. Tomado del lat. idus, de igual significado. Tb. ydus. Frec.: 1: 0,00227.

iglesia (var.: yglesia, eglesia) s. f. 'iglesia, edificio consagrado al culto': Otrosí rogó al vispo don Sancho de la Rossa et al convento de Pamplona que le diessen el trasoro de la iglesia de Pamplona et que faría parellar $C C C^{\text {ss }}$ de cavallo para la dita guerra 20.232; edificó muytos monesterios et iglesias 12.82; et fue enterrado en la dita iglesia de San Pedro, en la capilla de San Bartholemen 20.306. Frec.: iglesia 6: 0,01364; iglesias 5: 0,01136; Yglesia 20: 0,04546; yglesias 10: 0,02273 .

immensitat s. f. 'inmensidad': Et por la immensitat de tierra que possidia et sennoriava se fizo nombrar emperador 14.26. Cultismo tomado del lat. immensitate $(m)$. Frec.: 1: 0,00227.

imperio s. m. 'imperio, dominio, en el sentido concreto de territorio en el que se ejerce el mando': et depués quel le ganaría el dito imperio a messión de la Yglesia 38.156. Tomado del lat. imperium. Frec.: 7: 0,01591.

incessanment adv. 'incesantemente': matoron aquélla [hora grant gent $\mathrm{N}$ ] incessanment, et segunt arbitrio común murieron aquell día entre de cavallo et de pie [bien N] VI mil moros 38.364. Etim.: Deriv. del lat. CESSARE 'pararse, descansar' (BDELC, p. 147, s. v. cesar). De forma inmediata, el adv. se ha construido sobre el adj. incessant, part. pres. en su origen. Frec.: 1: 0,00227.

inclinado adj. 'propenso, tendente': et el dito rey, inclinado mas a creyença que a certificación, mandó su muller ser pressa 14.60; los demas de los reyes de Espaynna inclinados e indutos a paz e concordia, tornose en su tierra 33.111. Frec.: inclinado 2: 0,00455; inclinados 1: 0,00227. 
inclinar] v. prnl. 'decidirse por una opción, propender a hacer, a pensar o a hacer algo': penssando que grant ayuda et favor ende avría contra sus enemigos, inclinós [inclinose $\mathrm{N}$ ] a prender filla del rey de Castiella 38.31. Etim.: del lat. INCLINARE 'ser propenso a, estar inclinado a'. Frec. inclinós 1: 0,00227.

inconvinient adj. 'inconveniente, que no conviene': porque el campo do se devían fazer las ditas batallas era fuert inconvinient et sospeytoso a éll por muytas razones 36.269. Del lat. INCONVENIENS, -IENTIS. Frec.: 1: 0,00227.

indignado] adj.: 'indignado, lleno de indignación, ofendido': et muy indignados fueron a comer 20.37. Etim.: del p. p. del verbo indignar < lat. INDIGNARI 'considerar algo como indigno, sentir indignación, estar irritado' (SEgura, 2001: 369). Frec.: indignados 1: 0,00227.

inducción] s. f. 'instigación, acción de inducir a hacer algo o de persuadir para no hacerlo': et como por todas aquestas inducciones el rey Federich non se quiso abstener de su propósito 38.259. Cultismo tomado del lat. inductio, -onis. Frec.: inducciones 1: 0,00227.

indueyto p. p. del v. induyr]: 'inducido, instigado'. Se trata de un participio fuerte. También induto. Vid. induyr.

indulgencia] s. f. 'indulgencia': et fue y ordenado a dar las indulgencias sobreditas 36.467. Frec.: indulgencias 1: 0,00227.

industria s. f. 'maña, destreza, artificio'; 'habilidad': los ditos castiellos tollió a los moros et gitó aquéllos de todo su regno, assí que [por] la industria et valentía de aquesti rey don Pedro el dito regno fue possado en tranquilidat de paz 36.75. Cultismo tomado del lat. industria 'actividad'. (DCECH, III, p. 449). Frec.: 2: 0,00227.

industriar] v. tr. 'instruir, adiestrar': e nudrió e industrió al dito rey a regir la tierra al millor que pudo varonilment 33.14. Del lat. INDUSTRIARE. Frec.: industrió 1: 0,00227.

induyr] v. tr. 'inducir, mover, instigar': el dito Padre Santo, indueyto de mal consello, non recibió assí como devía benignament los ditos mensageros 36.177; los ditos christianos, indueytos de mas abundosa et acostumbrada devoción hedificaron bi dos altares 9.27 ; los demás de los reyes de Espaynna inclinados e indutos a paz e concordia, tornose en su tierra 33.112; Los secilianos, sabiendo aquesto, induyeron [induyoron $\mathrm{B}$, supieron $\mathrm{N}$ ] et animoron [avinioron $\mathrm{B}$; indurieron $\mathrm{N}]$ el rey Federich que esforçadament le deffendiessen el regno 38.240. En el arag. de Fernández de Heredia se registra induyr (Grant Crón. de Espanya, I parte) pero también otras variantes del mismo verbo: enduðir, induzir, endozir, ynduzir, indozir, jndu₹ir, inducir (GILKISON, s. v. enduحir). Del lat. INDUCERE (DCECH, I, p. 62, s. v. aducir). Frec.: indutos 1: 0,00227; induyeron [induyoron] 1: 0,00227; indueyto 1: 0,00227 ; indueytos 1: 0,00227 .

infamar] v. tr. 'infamar, deshonrar; declarar contra la honra o la estimación de alguien': confesaron et dixeron al sancto varón que falsament e iniqua havian a lur madre infamada [acusado a lur madre $\mathrm{N}$ ] et que len demandavan perdón 14.77. Cultismo tomado del lat. infamare. Frec.: infamada 1: 0,00227. 
infamador] adj. y sust. 'persona que infama': Et tantost los ditos infamadores confesaron et dixeron al sancto varón que falsament e iniqua havian a lur madre infamada 14.76. Der. del v. infamar con sufijo -dor, que expresa agente. Frec.: infamadores 1: 0,00227 .

infamia s. f. 'infamia, descrédito, deshonra': et que el rey et el regno de Navarra de aquesto avrian gran infamia 20.192. Tomado del lat. infamia 'mala fama, mala reputación, descrédito, infamia, deshonor’ (SEGuRA, 2001: 372). Frec.: 2: 0,00227.

infant (var.: infante) s. m. 'hijo varón y legítimo del rey nacido después del primogénito': Et ordenó el infant quel noble don Phelip de Celuza, qui era venido de Secilia, fincás gobernador en la isla 38.578; et devía regnar esti don Alfonso el deseredado que era fillo del infante don Ferrando primogénito 37.48; segunt mas largament en vida de cada uno de los dessuso ditos infantes pora adelant recontaremos 38.426. Del lat. INFANS, -TIS 'que aún no habla, niño muy pequeño' (SEGURA, 2001: 372). Frec.: infant 42: 0, 09546; infante 1: 0,00227; infantes 1: 0,00227.

infiel s. m. 'no cristiano'; se aplica generalmente a los musulmanes: non porque dasse ayuda a ningún infiel o enemigo de la fe christiana 34.174; Taraçona et sus pertinencias porque la sennoriasse que nuevament yera adquirida de infieles 20.311. Deriv. de fiel < lat. FIDELIS. Frec.: infiel 1: 0,00227; infieles 3: 0,00682.

infinido] adj. 'infinito, mucho, incontable', 'muy numeroso': El dito rey de Francia [...], con XX mil homes de cavallo et infinida gent de piet et con el dito legado, vino a Perpinyan por entrar et conquerir la tierra del dito rey don Pedro 36.473. Del lat. INFINITUS. Frec.: infinida 1: 0,00227.

infinidat s. f. 'infinidad, gran número': et matoron grant infinidat de franceses 36.635 (el uso expletivo de grant produce tautología). Del lat. INFINITAs, -ATIS. Frec.: 1: 0,00227.

inhibición s. f. 'prohibición, inhibición': feita primerament inhibición a todo homme que si non fues natural en todas las galeras que alli eran parelladas, las quales eran L, non entrás 38.260-262. Etim.: cultismo, tomado del lat. inhibitione (o bien, derivado de inhibir, tomado del lat. INHIBERE, cultismo derivado de HABERE 'tener', lo mismo que prohibir, cohibir, exhibir, etc.). La 1. ' doc. que da el DCECH (IV, p. 659, s. v. probibir), es de 1597, es decir, más de dos siglos posterior a la de la Crón. SJP. Frec.: 1: 0,00227.

inhonesto] adj. 'falto de honestidad', 'indecente, indecoroso': inhonesta cobdicia de meneda [moneda $\mathrm{B}, \mathrm{N}], 38.378$; dixieron muytas et inhonestas et non dirientes palavras 38.126. Tomado del lat. INHONESTUS. Frec.: inhonesta 2: 0,00455; inhonestas; $1 ; 0,00227$.

iniquo] adj. 'injusto, contrario a la equidad': que falsament e iniqua havian a lur madre infamada 14.77. Aquí se trata de un adj. en uso adverbial. Cultismo tomado del lat. INIQUUS. Frec.: iniqua 1: 0,00227. 
injuria] s. f. 'agravio, ultraje, injuria': et vengar el rey de Aragón de los tuertos et injurias que prendian 36.595. Tomado del lat. INIURIA injusticia, ofensa, iniquidad'. Frec.: injurias 8: 0,01818.

injustament adv. 'injustamente': et de otros grieves crimines cometian et fazian, por las quales et por el deseredamiento que demandavan injustament sufrian grant passión, pena et tribulación 36.495. Frec.: 3: 0,00682.

injusto adj. 'injusto, contrario a derecho': antes contra ell se rebellassen assí como occupador injusto de lur tierra 36.208. Del lat. INIUSTUs. Frec.: 1: 0,00227.

innocencia s. f. 'inocencia': Mas el dito Remiro, fillastro suyo [...], viendo la innocencia de su madrastra et la voluntaria diffamación que le era estada levantada... 14.66. Tomado del lat. INNOCENTIA. Frec.: 1: 0,00227.

innocent adj. 'inocente': et la dio por innocent et por exempta del grieu crimen 16.7. Tomado del lat. INNOCENS, -ENTIS. Frec.: 2: 0,00455.

innumerable adj. 'innumerable, incontable': Et estando la dita ciudat en grant costrenimiento, otra vegada grant innumerable aiusto de moros por semblant manera que dessuso havemos recontado, vino contra el dito rey et sus gentes 38.371; por los vencimientos innumerables que obtuvieron los ditos Ennego Ariesta Ariesta et su fillo García Enneguez contra los moros 11.7. Del lat. INNUMERABILIs. Frec.: innumerable 1: 0,00227; innumerables 1: 0,00227.

inportunidat s. f. 'importunidad, incomodidad o molestia causada por una solicitud o pretensión': por grandes inportunidades et prometienças quel dito rey de Castiella fazía al dito rey don Jayme 38.29. / / 'inconveniencia, ocasión inadecuada, falta de oportunidad': más el dito rey Federich a grant importunidat [su oportunidat $\mathrm{N}$ ] de los secilianos enta su hermano se acostó 38.267. Frec.: inportunidat 2: 0,00455; inportunidades 1: $0,0227$.

inquidat s. f. 'iniquidad, maldad': don Berenguer Ramón su hermano, movido de grant inquidat et invidia porque lur padre havía mas honrrado que a él [...] mató el dito conte 30.13. Etim.: del lat. INIQUiTAS, -ATIS 'iniquidad, injusticia, maldad, desigualdad' (Blánquez, s. v.). Frec.: 1: 0,00227.

insignir] v. tr. 'distinguir, señalar, adornar', 'designar, nombrar': Et depués, porque de tales donos de gracia tan maravellosament Dios le insignó [se insiguió N], quiso continuar su propósito de conquerir et subingar regnos en tierras de moros mientre Dios vida li dasse 35.153; Et de otra part engendró un fillo bort nombrado Sancho, al qual dio Ayvar et Xavierre Alatre [Latre N] con todas lurs villas, et aqui lo insignó de titol condal 16.32. Cultismo tomado del lat. insignire, con el mismo significado (cfr. BLÁNQUEZ, s. v. insignio, p. 817). El DRAE (1970, s. v.), recoge insignido 'distinguido, adornado', como ant.; con la misma significación, el DLE, 2014, s. v., pero con modificación de la abreviatura de ant. (antiguo) por desus. (desusado). Comp. cast. insigne 'señalado, distinguido', de lat. INSIGNIS. Frec.: insignó 2: 0,00455. 
instar] v. tr. 'reiterar una petición, insistir en una demanda o súplica; solicitar algo con insistencia': et el rey de Castiella por aquesto avies instado [oviese por esto ayuntado N] 38.59. Cultismo tomado del lat. INSTARE. Frec.: instado 1: 0,00227.

instancia s. f. 'insistencia', 'constancia', 'apremio', 'porfía, reiteración, súplica insistente': el dito rey don Pedro le demandó con gran instancia el vizcondado de Finoledas et el condado de Carcasona 36.155. Etim.: cultismo, tomado del lat. instantia 'presencia, proximidad, inminencia, aplicación, asiduidad, constancia', 'vehemencia, calor, vigor' (BLÁNQuez, s. v.). No recoge esta voz Bustos (1974). Frec.: 1: 0,00227 .

instituyr] v. tr. 'nombrar o establecer (heredero)': instituydo heredero primogénito en su principado don Jayme, la ora rey de Sezilia hermano suyo 37.99; et instituyó heredero suyo el tercero fillo suyo Remón Berenguer 29.56. Del lat. INSTITUERE. Frec.: instituydo 1: 0,00227; instituyó 1: 0,00227.

intitular v. tr. y prnl. 'nombrar, otorgar un título o una dignidad'; 'designar a una persona para un cargo o dignidad': Et el desus dito Remón Berenguer se firo intitular conte de Barcalona et marqués de Prohença 31.46; Empero en el tiempo de su fillo don Alfonso el que primero se intituló rey de Aragón... 20.314; Porque una vegada ya hyvan acordado que obidiessen a Carlos de Valoys, qui el Papa avía intitulado rey de Aragón 37.25. Frec.: intitulado 1: 0,00227; intitular 1: 0,00227; intituló 1: 0,002287.

invasión s. f. 'invasión': de la quoal invasión fue el rey de Castilla muy dolient 33.78. Cultismo tomado del lat. invasio, onis. Corominas-Pascual (DCECH, t. III, p. 461, s. v. invadir) dan la 1. a documentación de esta voz en Oudin (1607) y en Argensola (1562-1631). La Crón. SJP. la adelanta en más de dos siglos. Frec.: 1: 0,00227 .

invidia s. f. 'envidia': don Berenguer Ramón su hermano, movido de grant inquidat et invidia porque lur padre havia mas honrrado que a él... 30.13. Etim.: Es palabra culta, tomada del lat. invidia 'íd.' (DCECH, V, p. 773 , s. v. ver). Vid. envidia. Frec.: 1: 0,00227 .

invocación s. f. 'invocación’: Et en el dito castiello establió yglesia de invocación de Sant Pedro 36.169. Tomado del lat. invocatio, -onis. Frec.: 3: 0,00682.

ir v. intr. 'ir'. Vid. yr.

ira (var.: yra) s. f. 'ira, indignación, enojo, cólera': revocó el atorgamiento que havía feito de dito cavallo a su fillo García, de la qual cosa fue muyt despagado et movido a grant ira 14.51. Etim.: del lat. IRA 'cólera, enojo'. Comp. yrado. Frec.: ira 3: 0,00682; yra 5: 0,01136.

irregular adj. 'irregular, no regular, contrario a la regla': pensó que sería irregular si le consellava que firies justicia 20.112. Frec.: 1: 0,00227.

isla (var.: ysla) s. f. 'isla': En aquesta isla de Estancia habitaban aquestas naciones:... 3.1; el dito rey don Sancho de Mallorquas reconosció tener en feu et de ius sennyoria del dito 
rey don Jayme el regno de Mallorquas et islas de aquéll 38.469; porque se cuytas con las galeras et que en antes fues en la dita ysla 38.515. Frec.: isla 14: 0,03142; islas 1: 0,00227; ysla 4: 0,00909.

istoria s. f. 'historia'. Vid. ystoria.

ius prep. 'bajo, debajo de'; se usa siempre precedida de la prep. de: habitava en una espelunca de ius una grant penya 5.2; reconosció tener en feu et de ius sennyoría del dito rey don Jayme el regno de Mallorquas 38.468-469. Etim.: del lat. DEORSUM > Jusum 'hacia abajo' (bajo el influjo de suRsum $>$ susum 'hacia arriba' (DCECH, IV, p. 784). La contracción de de + ius da lugar a dius (vid.). Frec.: 4: 0,00909.

\section{J}

jamás (var.: ya más) adv. 'nunca': mas que sennyor desenparás jamás vassallos asi como vos Sennyor, ningún tiempo no lo avemos vistonin oydo dezir sino agora. 38.131; ya más [jamás B] en tiempo de aquesti rey nos movió ni se susctió 39.24. Etim.: del lat. JAM MAgIs. Comp. occ. ant. ja mais, de donde procede según Corominas-PASCUAL el cast. jamás (DCELC, IV, p. 771). Frec.: 3: 0,00682.

jornada] s. f. 'camino que yendo de viaje se anda regularmente en un día', 'tiempo que dura el día': et en continent, partióse de aqui et a jornadas tiradas de nueyt et día vino sende en su tierra con grant goyo et honor 36.301; entró dentro en Castiella mano armada bien por VII jornadas 36.111-112. Etim.: deriv. del lat. DIURNUS 'diurno, que ocurre durante el día'. Comp. cat. y occ. jornada, deriv. de jorn 'día' < DIURNus. El cast. jornada es para Corominas-Pascual un occitanismo (DCECH, III, p. 525). Lo mismo opina Colón (“Occitanismos”, ELH, II, p. 179). Para el cat. jornada vid. DECLIC, IV, p. 906. En arag. mod. Andolz (1992: 144) registra chornada 'jornada' en Benasque; el EBA (1999: 523), tanto en Benasque como en la Plana de Uesca. En Nagore (2020:178) también se documenta en Huesca. Veáse, por ejemplo: “Ta aquí, ta Huesca plegaban / montañeses que con garbo / en tres u cuatro chornadas / plantaban aquí su tajo." (en Pedro Lafuente, 1989: 119). Frec.: jornadas 2: 0,00455.

joventut (var.: juventud) s. f. 'juventud, edad en la que se es joven': empero non queriendo planyer su persona en servir Dios assí como avía acostumbrado en su joventut... 35.206; porque la tierra estava en grant peligro por la su grant juventud 33.5-6. Del lat. JUVENTUte(M). Frec.: joventut 2: 0,00455; juventud 1: 0,00227. 
joya] s. f. 'joya': qui quisies prender joyas en diversas maneras, a ellos se era 36.644. Del fr. ant. joie, deriv. retrógado de joiel (mod. joyau), deriv. del lat. vg. *Jocale, deriv. a su vez de jocus 'juego'. Del francés pasó al occ., it. y cat., y, quizá a través del cat. o del occ., al cast. (DCECH, III, p. 530). El arag. pudo tomarlo también del occ. o del cat. Frec.: joyas 1: 0,00227.

judgar] v. tr. 'juzgar': et delivró en continent a la dita muller suya a que era judgada 14.80; et cuando alguno judgava a muert, de grant piedat que avía, plorava 35.197. Del lat. JUDiCARE (DCECH, III, p. 536). Frec.: judgada 2: 0,00455; judgava 2: 0,00455.

judge s. m. 'juez': et aqui buvo ardit del judge [juge N] de Arborea [Arbolea N]..., 38.519.; A requerimiento del noble Nuch, judge de Arborera [Arborea B; d'Arbolea $\mathrm{N}]$ et vizzonte de Bas, et el dito rey don Jayme envió a Orisan en la isla de Cerdennya con III coquas los nobles don Dalmau vizconte de Rocaberti... 38.485-486. Etim.: del cat. jutge < lat. JUDEX, -DICIS. Por el tratamiento fonético, hay que considerarlo catalanismo. La evolución fonética en cat., oc. jutge, fr. juge, ha causado estrañeza, pues teóricamente se podría esperar un resultado como el de dotré, tretze DuOdeCim, TREDECIM. MEYER-LÜBKe hablaba de un postverbal de JUDICARE. Otros han pensado en un lat. vulg. *Judicus, o bien en influencia de MEDiCus y otros títulos profesionales semejantes. Corominas piensa que la pronunciación del latín fue JúDEÇE con una c palatal no muy diferente de la C de JUDiCARE. Habla de una especie de relación proporcional JUDICE: JUDICÁre = MEDICU: MEDICÁre. Lo que hizo que la $\mathrm{C}+\mathrm{A}$, con un grado de palatalización más leve que la C+I,E, derivara hacia el vecino C (DECLIC, IV, p. 933). Comp. cast. juez < jú(d)ez < JUDICEM (DCECH, III, p. 536). En otros textos arag. med.: inge (VM, III, p. 168); indge, jutge, inge (FA, p. 443); juge, judge (DLAA; ReIDY, p. 188); en cambio, iúdez en FT (Gorosch, p. 550). En Fernández de Heredia: iner, juez, inge, iutge, indge, juge, juytge (GILKIsON, s. v.). Frec.: 3: 0,00682.

judicio s. m. 'juicio': Et un fillo del dito don Sancho nombrado Remiro, temiendose que por semblant iudicio que fizo de su padre non passas, absentós del dicto regno et vino sende en Valencia que senyorava las oras el Cit Rui Dia: 17.11; parellado a fer et complir todo lo que conviene al judicio de la batalla 36.295. Cultismo tomado del lat. JuDicium. En otros textos med. arag.: iuditio, iuyzio (VM, III, p. 168); indirio, iudicio (FA, p. 443); judicio, jodiçio (DLAA; ReIDY, p. 188); iudicio (FT, p. 551). En Fernández de Heredia: indicio, iutzio, indiciu, indico, judicio, iuyzio, juyzio, judicion (GILKIsON., s. v.). Frec.: 1: 0,00227.

judio] adj. y sust. gentilicio 'individuo perteneciente a la raza y pueblo judío': et aquesti rey fiço vaciar por fuerça los judios 3.58. Del alt. IUDAEUs. Frec.: judios 1: 0,00227 .

julio s. m. 'julio, séptimo mes del año': Et aquesto feyto, a XVIII días de julio del dito anno el dito Alfonso partió del lugar de Bonayre con todo su escolt [estolt B] 38.581. Del lat. IULIUS (MENSIS). Frec.: 5: 0,01136. 
junii 'de junio' (es lat.): pridie nonas junii en aquest mismo anno 18.2. Frec.: 2: 0,00455. junyo (var.: junio, junnyo) 'junio': VI meses, es assaber, mayo, junio, julio..., 18.8; a IX días del mes de junnyo 38.517; en la fin del dito mes de junyo 38.564. Del lat. IUNIUS (MENSIS). Frec.: junio 1: 0,00227; junnyo 2: 0,00455; junyo 2: 0,00455.

jura s. m. 'jura, juramento': et aquesta jura prendió el Cit et desplazió depués al rey muito, 18.87. Etim.: es post verbal de jurar. Frec.: 2: 0,00455.

jurar v. tr. 'jurar': el qual fue jurado en rey o primogénito en la ciudat de Caragoca 38.589; et fizo fer los ditos barones et universidades jurar de servar feldat al dito infant, 35.31; el dito rey don Pedro juroles et confirmoles aquello que... 36.678. Etim.: del lat. JURARE 'íd.' (DCECH, III, p. 541). Frec.: jurar 2: 0,00455; jurado 2: 0,00455; jurarás 1: 0,00227 ; jurarían 2: 0,00227 ; juraron 1: 0,00227 ; juró 2: 0,00455 ; juróles 1: 0,00445 .

jurisdicción s. f. 'jurisdicción': et como algunas demandas de jurisdicción et otros dreytos quel dito rey don Pedro se dezía aver sobre el condado de Urgel... 36.117. Cultismo tomado del lat. jurisdictio, -onis. El DCECH (III, p. 541), lo documenta en castellano por primera vez en 1440, en la forma juridición. Frec.: 1: 0,00227.

justament adv. 'justamente, con justicia': fue justament despossedido de su regno et tierras 38.620. Frec.: 3: 0,00682.

justamiento s. m. 'junta, reunión': et ordenó en aquel justamiento de enviar mensageros, 20.206. Derivado de justar. Vid. también ajustamiento. Comp. en Fernández de Heredia iustamiento 'proximidad' (GILKIsON, s. v.). Frec.: 1: 0,00227.

justar] v. prnl. 'juntar, unir, agregar': et parte Navarra et Aragón et se justa un Arga et caye en Ebro 20.279. Etim.: del lat. vg. *JuXTARE 'juntar', deriv. de la prep. JUXTA 'junto a, al lado de' (DCECH, III, p. 542). Comp. cat. justar, occ. ant. jostar, fr. ajouter. Es más frecuente en la Crón. SJP. ajustar (vid.). Comp. en Fernández de Heredia iustar 'reunir', 'reunirse, juntarse', 'aproximarse' (GiLkison, s. v.). Frec.: justa 2: 0,00455; justas 1: 0,00227.

justicia (var.: justiçia) s. f. 'justicia': regió su tierra con grant justicia et misericordia, 38.633; que fagades dellos la justiçia que tenrredes por bien, 19.88. Tomado del lat. iustitia. Frec.: 9: 0,02046; justiçia 1: 0,00227.

justiciero adj. 'que observa y hace observar estrictamente la justicia': nombrado el Justiciero porque non plannya fazer [fer N] justicia, 38.6. Deriv. de justicia. Frec.: 1: 0,00227 .

justo adj. 'justo': et huvo ende justa razón 16.5; por otras razones justas [muytas $\mathrm{N}] 14.100$; tanto era justo et gracioso 35.217. Del lat. IUSTUS 'justo, conforme a derecho'. Frec.: 1: 0,00227. 
kalendas s. f. pl. 'el primer día de cada mes': en día miercoles a hora de media tercia, vigilia de la conversión de Sant Paulo que home conta $X X^{\circ}$ kalendas de febrero, en el anno de Nuestro Sennyor MCCCXXXV ${ }^{\circ}$ 39.44. ('el 20 de febrero'). Tomado del lat. CALENDAE, -ARUM 'el día primero de cada mes’ (BlánQueZ, s. v.). Frec.: 8: 0,01818.

1' art. det. m. (ante vocal o): el uno clamado Bernart [...] et l'otro Guiffre 26.25. Frec.: 3: 0,00682 .

la art. f. 'la': dió la diezma de sus regnos 38.184; entre las gentes huvo grant mal 38.612 // pron. pers. f.: don Sancho el Mayor las avia departidas 20.166; con grant deliberación et maturidad la dio 20.71. Frec.: la 1.159: 2,63433; las 263: 0,59778.

ladrón s. m. 'ladrón': sallió el ladrón de su cueva 32.68. Del lat. LATRONE(M) (DCECH, III, p. 555). Frec.: 1: 0,00227.

lagrima] s. f. 'lágrima': et mudólo en ayuda et socorro de los ploros et lagrimas et dolores que los ditos secilianos gitavan agrament et sofrían 36.204-206. Del lat. LACRIMA. Actualmente la voz usual en aragonés es glarima (EBA, 1991: 1027-1028), forma con acentuación llana, que, según se ve en el mapa 1410 del $A L E A N R$, se registra en casi todo el Alto Aragón (Echo, Bailo, Biel, Agüero, Ardisa, Bolea, Lasieso, Laguarta, Broto, Fanlo, Laspuña, Gistaín, Campo, Angüés, Pueyo de Santa Cruz), así como en algunos puntos del centro y sur de Aragón (Osera, Codo, Calcena, Bello, Barrachina, Puebla de Valverde) y del sureste de Navarra (Cáseda, Caparroso, Arguedas). Frec.: lagrimas 1: 0,00227.

lança s. f. 'lanza': et a la dita reyna firieronla con una lança por el vientre de la qual murió 12.4-5. Etim.: del lat. LANCEA 'lanza' (BDELC, s. v. lanza). Según CoromINAS-PASCUAL, «el lat. LANCEA sería oriundo de España (según Varrón), y quizá fuese voz celtibérica» (DCECH, III, p. 576). Frec.: 1: 0,00227.

lançar] v. tr. 'lanzar, echar, arrojar con fuerza': et con la ayuda de Dios lançó fuera de Barchinona et de toda la tierra vigorosament los malvados moros 26.16-18; todas las otras reliquias de aqui et de las otras eglesias langoron et vilment consumoron 36.568. Etim.: 
del lat. tardío lanCEARE 'manejar la lanza' (BDELC, s. v. lanæa). Es voz «común a todos los romances de Occidente» (DCECH, III, p. 576). Frec.: lançó 1: 0,00227; lançoron 1: 0,00227.

la ora (var.: la hora, las horas, las oras) adv. 'entonces': Et la ora era conte en el condado de Ampurias Huch 35.102 [Et tunc erat comes Impuriarum, Hugo VL, p. 148]. [E llavors era comte en lo comtat d'Empuries, N'Hug VC, p. 119]. En la VL corresponde a tunc. Sistemáticamente corresponde a llavors de la VC: el rey Ordonyo qui fue venido [vencido e N] las oras, desbaratado por el rey de Cordova 9.4 [lo rei Ordonyo, qui fo vencut llavors e desbaratat per lo rei de Còrdova VC, p. 37]; Et las horas, la nación morista... 9.7 [E llavors la nació morisca... VC, p. 37]; assin de las oras entaqua buvo nombre Ennego Ariesta 10.20 [aixi, de llavors ençá hac nom Ennec Arista. VC, p. 40]. Frec.: ora 36: 0,08183; hora 7: 0,01591; oras 13: 0,02955; horas 3: 0,00682.

largament adv. 'ampliamente, extensamente': segunt que mas largament en vida de cada uno de los dessuso ditos infantes pora adelant recontaremos 38.425; segunt que las coronicas dizen mas largament 3.94. Frec.: largament 8: 0,01818; largamente 1: 0,00227 .

largo adj. 'generoso', 'copioso', 'abundante', 'dadivoso, liberal': Aquesti empero rey fue muy bueno et piadoso, ordido (sic) et benigno, et tan largo et tan proz que a ninguno no podía dir de no de res quel demandasen. 13.7-9; el qual fue varón muyt largo, piadoso et muyt buen [sic; quizá error por bien] armado 31.3; fue muyt noble varón, largo, proz et diligent, et muyt engenyosso 35.89-90. Etim.: del lat. LARGus 'abundante, considerable', 'liberal, generoso' (BDELC, p. 354). Conserva el significado original que tenía en latín (también en cast. lo conservó hasta el s. Xv). El concepto 'largo, de gran longitud' se expresa en la Crón. SJP. por luengo. Como explica CoROMINAs: «La acepción moderna, por la que largo sustituyó a luengo, es tardía: no se puede documentar claramente hasta Nebrija, y aun éste admite todavía "largo en ancho: latus", junto a "largo en luengo: prolixus", y "largo, liberal: largus". En el Cid., Alex., Apol. y Berceo sólo hallo la acepción "copioso, abundante, grande, numeroso', o bien 'generoso', y así es todavía en los glosarios de h. 1400. [...] Pero en el Siglo de Oro ya estaba fijado el significado predominante de hoy» (DCECH III, p. 586) Cfr. largo 'ancho, extenso', 'copioso, abundante, generoso, liberal' en Fernández de Heredia (GILKIson, s. v.). Frec.: 4: 0,00909.

las oras adv. 'entonces'. Vid. la ora.

latín s. m. 'latín, lengua latina': et por razón que sabía gramática el cavallero, entendieron algunos en latín et recontó este miraglo.18.64. Frec.: 1: 0,00227.

laudor s. f. 'alabanza, loor'; 'elogio, cualidad, excelencia': dotado sobre todos los otros reyes en beldat et probeza de cavallería et breument en toda laudor, el noble varón en Arnau, arcevispo de Narbona, se levantó contra los hereges 34.121, [VC, p. 114: llausor] 
/ / laudors m. pl. 'alabanzas, loores': et fiziendo laudors a Dios con todo su escolt 38.285. [E faent llaors a Déu, ab tot son estol...VC, p. 165]. Etim.: derivado de lat. LAUS LAUDIS (acusativo LAUDEM) 'alabanza, elogio', o mejor derivado del lat. LAUDARE 'alabar' (BDELC, s. v. loar). Cast. loor 'alabanza', gall.-port. louvor, occ. lauzor, ant. cat. Ilaor, cat. lloança (DEEH, s. v. laudare). Por lo tanto, frente a la forma castellana, la correspondiente aragonesa conserva el grupo -AU- y la -D- intervocálica, pero es muy posible que sea un cultismo. Es tb. un ejemplo interesante de pl. -rs. Comp., en cambio, loar, lohor. Comp. también cast. ant. Loanza, cat. lloança, gall. louvanz̧a. Para el occitano, Alibert, p. 462, recoge laus 'alabanza' y lausar 'alabar', pero no lauzor, que sí recoge en cambio LEVY, s. $v$. En arag. laudor podría interpretarse como forma patrimonial, puesto que es característica la conservación de la $-d-$. Pero no es fácil explicar la conservación del diptongo au (pues, aunque en arag. mod. existe algún caso como auca, auco, puede explicarse por fonética sintáctica). En Fernández de Heredia: laudable, laudablement, laudadores, laudar y laudor, aunque tb. lohor, loable, loar, laor, laudor aparece en la Grant Cronica de Espanya, parte I (GILKISON, pp. 81, 83 y 84). En un texto en arag. de finales del s. XVII se registra loba 'loa, alabanza': «Mas sobre todo lo dito oyganme una loba de bravas clopas» (NAGORE, 1980: 15). Frec.: laudor 1: 0,00227; laudors 1: 0,00227.

lavar] v. refl. 'lavar': otros dizen que la cabega se lavava 20.29. Del lat. LAVARE. Frec.: lavava 1: 0,00227.

lavrador] s. m. 'labrador': e los lavradores fueron rovados 32.69. Etim.: deriv. de labrar, del lat LABORARE 'trabajar' (DCECH, III, p. 545). Frec.: lavradores 1: 0,00227.

lazerio s. m. 'sufrimiento, calamidad, miseria, padecimiento': alli attendó su huest et asitió la dita ciudad de Huesca, et aquélla tuvo asitiada con gran traballo et lazerio VI meses 18.6-7. Etim.: < lat. vg. *LACERIU(M). Es un cultismo abundantemente documentado en el cast. med. (Bustos Tovar, 1974: 528), derivado de LACERARE 'desgarrar', 'despedazar', 'torturar'. En la Edad Media se documenta lazerio en cast. (Berceo), en gall-port. ant. lazeiro (Cantigas). Tb. hoy cat. lazeria 'mezquindad, miseria, calamidad', port. y gall. lazeira 'miseria', 'desgracia', 'lepra' y especialmente 'hambre; penalidad' (DCECH, III, p. 549, s. v. lacerar). Se documenta laçerio y lazerio 'trouble, misery, hardship; lashing, flogging' en Fernández de Heredia (GILKISON, s. v.). Frec.: 1: 0,00227.

le (var.: li) pron. pers. átono de $3^{a}$ pers., de dat. (compl. ind.) 'le': et de su consello le fues dado curador 38.606; demandoron tregua por soterrar los lures muertos, la qual les fue atorgada 38.556; et ya sea que li dies el dito regno en casamiento, no empero renunciava a la dignidat real 20.286. Frec.: le 112: 0,25457; li 6: 0,01364.

leal adj. 'leal, fiel, que actúa con lealtad': la qual cosa el dito noble assí como verdadero et leal fizo et cumplió 36.529-530; et li eran estados fieles et leales 23.28-29. Del lat. LEGALIS. Frec.: 3: 0,00682. 
lealment adv. 'lealmente, fielmente, con lealtad': «mi sennyor el rey d'Aragón se yes levado lealment et assí como devía» 38.323. Frec.: 2: 0,00455.

legado s. m. 'legado, persona enviada por una suprema autoridad eclesiástica o civil para tratar un negocio': et aquesto feito, vinieron compannyas del dito legado 38.298; et fue por legado et mesagero ordenado don Caxal 20.217; con el rey Carlos et un legado del Padre Santo 38.230. // 'persona eclesiástica que por disposición del Papa hace sus veces en un concilio': en la qual fue Nuch cardenal et legado de Roma 29.9. Del lat. Legatus 'legado, embajador, diputado, comisionado' (Segura, 2001: 419). Frec.: 11: 0,02500.

legítimo] adj. 'legítimo': et fueron legítimos, que la madre provó aquello con grant esfuerço 35.78. Del lat. Legitimus 'establecido por la ley'. Frec.: legítimos 1: 0,00227.

legua s. f. 'legua': et a una legua de castell de Callar 38.522. Etim.: del lat. tardío LEUGA, de origen céltico. Comp. cast. legua, port. légoa, cat. llegua, occ. lega, fr. lieue (DCECH, III, p. 625). Frec.: 1: 0,00227.

lel combinación de pron. pers. de $3^{a}$ pers. de c.i. y de c.d., 'se lo': et si non lel queries soltar, 20.188. Comp. arag. belsetán actual: le'l trayen 'se lo traen, traen esto a él' (BADÍA, 1950: 112). Frec.: 1: 0,00227.

lende (var.: lend, len) combinación de le + ne 'le, de ello': et que len demandavan perdón 14.77; et pues gracia le demandava yera aparellado de fazer lend 19.181 ('hacérsela, hacerle de ello'); por esquivar vergonna et desonor que lende podría seguir 23.14 . Frec.: len 2: 0,00455; lend 1: 0,00227; lende 4: 0,00909.

lennyo s. m. 'nave o embarcación de pequeño tamaño', 'embarcación ligera, menor que la galera; galeota': et lexó un lennyo armado por denunciar a las naves 38.525; con dos galeras et un leyen [leynno N] armado fuessen en Seçelia 38.3 (error por lennyo). Etim.: del lat. Lignum 'leño, madero'. Con el significado de 'embarcación semejante a la galeota' la primera documentación en castellano es de 1430 (DCELC, III, p. 76a.; DCECH, III, p. 631, s. v. leña). Martín Alonso, Enciclopedia del idioma, s. v. leño, da como $3^{\mathrm{a}}$ acepción, usual del s. XVII al xx, 'embarcación semejante a las galeotas que durante la Edad Media se usó mucho, particularmente en el Mediterráneo'; en general, 'nave, embarcación' y 'bajel, barco o navío' (lo registra tanto en Cervantes como en Góngora). Para la Edad Media, documenta lenyo 'barco' en el arag. de Fernández de Heredia, y leño 'pequeño navío' en autores castellanos del s. Xv (DME, s. v.). El DRAE $\left(1970\right.$, s. v.), da como $3^{a}$ acep. de leño: 'embarcación de vela y remo, semejante a las galeotas, que durante la Edad Media se usó mucho, particularmente en el Mediterráneo'. Esta definición se ha modificado levemente en el DLE (2014, s. v.): 'embarcación medieval, de vela y remo, semejante a las galeotas'. Cfr. cat. lleny, nombre de embarcación con valor genérico, aunque normalmente forma contraste con nau y con gale(r)a, designando una embarcación más pequeña. Se usó en cat. hasta la segunda mitad del s. Xv (DECLIC, V, 
p. 155-156 s. v. llenya). El DCVB, VI, s. v., define lleny como 'vaixell marítim, embarcació' y lo traduce por cast. buque. La documentación que aporta es de los siglos XIII y XIV. Es muy frecuente en narraciones históricas catalanas medievales la voz lleny y en especial en la lexía lleny armat. Así, por ej., en la Crònica de Ramon Muntaner (Barcelona, Barcino, 1927-1952) se encuentra innumerables veces: págs. 66, 93, 96, 113, 119, 129, 141, 159, 163, 194, 225, 252, 255, 275, 282, 289, etc. (Vid. Michael Metzeltin, «La marina mediterránea en la descripción de Ramón Muntaner», en La Corona de Aragón y las lenguas románicas. Miscelánea de bomenaje para Germán Colón, Tübingen, Gunter Narr Verlag, 1989, pp. 55-67). En el arag. de Fernández de Heredia se documenta lenyo, ligno, lenno (GILKISON, s. v.). En Tucídides, lenyo 'barco': encoraron las proas de los lurs lenyos (López Molina, Tucídides, p. 210). Frec.: lennyo 1: 0,00227; leyen [leynno] 1: 0,00227.

leonés] adj. y sust. gentilicio 'natural de León': muertos e fuydos los leoneses e los gallegos 19.143. Frec.: leoneses 2: 0,00455.

letra s. f. 'carta, misiva': et, teniendo la letra en la mano et leyendo, talló todas las colles mayores que yeran en el buerto 20.114; embió un mensagero al su monasterio de Sant Ponz de Tomeras con letras al su maestro 20.103 // letras de creyença 'cartas credenciales', 'cartas de presentación': queriendo servir al rey et al regno, dixo quel dies letras de creyenca el rey don Pedro pora el rey de Castiella que se apparellava pora entrar en Aragón... 36.360. Etim.: del lat. LITTERA 'letra' (DCECH, III, p. 636). También se utilizó letra con el sentido de 'carta' en cast. med., así como lletra (letra, letres) en cat. med. (DECLIC, V, pp. 178-179). Frec.: letra 1: 0,00227; letras 11: 0,02500.

letrado s. m. 'letrado': et como el dito letrado [legado B] no avies complimento de meneda [moneda B]... 38.309. Parece una equivocación por legado, que da el ms. B y que concuerda con la VC: lo dit legat VC, p. 166. Frec.: 1: 0,00227.

levantar v. tr. y prnl. 'levantarse, ponerse en pie': et ditas aquestas paraulas, levantoronse todos et dixieron altament... 12.37. / / 'levantar, deshacer un cerco o sitio': et jurado por rey fízole prometer que non se levantasse del sitio entro que avies Huesca a su mano 17.125 // 'alzarse, sublevarse': se levantoron et se algoron contra el dito santo rey 36.51. Etim. Deriv. del lat. Levare 'levantar' (DCECH, III, 637). Tiene el mismo origen que levar 'llevar'. Frec.: levantar 2: 0,00455; levantada 1: 0,00227; levantado 5: 0,01136; levantara 1: 0,00227; levantaron 1: 0,00227; levantaronse 1: 0,00227 ; levantarse 1: 0,00227 ; levantas 4: 0,00909 ; levantasse 1: 0,00227; levantó 9: 0,2046; levantoron 2: 0,00455 ; levantoronse 1: 0,00227 ; levantose 1: 0,00227 .

levar v. tr. 'llevar, transportar': movió batalla con los franceses, qui preso se lo levavan 22.18; et prendiéronlo et levóronlo a Francia 36.346; et levósen con sí el rey d'Aragón... 38.355. // 'levantar': et que la malquerencia quel enemigo del humanal linaje habia 
procurada et metida entrellos et sus gentes, haviessen et levassen contra moros 20.164; / / 'elevar, entronizar (a una persona como rey)': prendet aquesta criatura et despullalde las vestiduras que aduze et levaldo [levantadlo $\mathrm{N}$ ] rey, porque aquesti de cierto yes nuestro sennor 12.29. // 'observar, guardar' (en el sentido de 'respetar, acatar'): los franceses, non levando reverencia a Dios ni a los santos suyos, el cuerpo de San Narcis, qui por reliquias en grant honor estava en la iglesia de San Feliu, mutilaron et destruyeron todas las otras reliquias 36.565. Etim.: del lat. LEVARE 'aliviar', 'librar', 'levantar' (DCECH, III, 731). Según indican Corominas-Pascual, la forma con $l$-fue general o poco menos en cast. med.; la forma llevar se generaliza en cast. en el s. XVI (ya está en Nebrija). La forma levar fue corriente en arag. med. y aun hoy se usa en arag. modeno. Tb. se usa levantar. Frec.: levar 9: 0,02046; levaron 4: 0,00909; levassen 2: 0,00455; levava 1: 0,00227; levavan 2: 0,00455; levó 4: 0,00909; levoronlo 1: 0,00227; levóselas 1: 0,00227; levoseles 1: 0,00227; levósen 1: 0,00227;

levarse] v. prnl. 'comportarse, conducirse, actuar': el rey d'A ragón se yes levado lealment et assi como devia 38.323; non se yes levado lealment en aquestos afferes 38.317. Frec.: levado 3: 0.00682.

lexar] v. tr. 'dejar': ... diziendo: «agora que non yes sennyor non se nos lexa veer, ¿qué fará quando seya rey?» 20.36; que les livraría la ciudat con que les lexasse yr salvos et seguros 36.612; et por tal como no es de nuestro propósito, lexemos esta materia et tornemos al dito rey 14.16; el compt don Pedro de Lara, lexada la seynna a los primeros colpes, e cobdiciando la reyna, lexólos en el campo e fuese para la reyna 19.119. Etim.: del lat. LAXARE 'ensanchar, aflojar, relajar', deriv. de LAXUS 'flojo' (DCECH, II, p. 435). Es la forma general en cast. med. hasta 1200; luego aparece la forma con $d$-. En cat. med. (l)lexar, a mitad del s. xv ya se encuentra dexar. Comp. occ. laissar, fr. laisser, it lasciare (DCECH, II, pp. 435-437). En DLAA, lexar o lixar (REIDY FriTz, 1977: 194). En la Crón. SJP. predomina lexar, aunque también aparece dexar (vid.). Algo semejante ocurre en las obras de Fernández de Heredia, donde se documenta por igual lexar y dexar (cfr. GILKIson, s. v.). Así que en el arag. de la 2. ${ }^{a}$ mitad del XIV ya había una fuerte vacilación. Actualmente, en arag. mod. es dexar, deixar o dixar, esta última predominante (ANDOLZ, s. v.; Rohlfs, DDPA, s. v.; en el EBA, 1999, s. v., se encuentra tres registros de dexar, dos de deixar, uno de deixá, ocho de dixar, diez de dixâ). Frec.: lexa 1: 0,00227; lexada 4: 0,00909; lexado 5: 0,01136; lexando 1: 0,00227; lexaron 1: 0,00227; lexas 1: 0,00227 ; lexasse 1: 0,00227 ; lexemos 1: 0,00227 ; lexó 12: 0,02728; lexoles 1: 0,00227; lexólos 1: 0,00227.

ley s. f. 'ley'; 'norma, regla'; 'rito': et de aqui adelant twieron la ley romana 17.63. Del lat. LEGE(M). Frec.: 2: 0,00455.

leyr v. tr. 'leer': segunt que havemos leydo en muitos libros 1.1; et, teniendo la letra en la mano et leyendo, talló todas las colles mayores que yeran en el huerto et fincoron las solas chicas 
20.114; ad aquéllos que la leyeran et a los qui lo escuitaran 2.3; porque luenga paraula engendra enoyo en leyr et en oyr 2.4. Del lat. LEGERE 'recoger, escoger', y luego, de ahí, 'leer' (DCECH, III, p. 619). Es común a todos los romances, excepto en rumano: port. y gall. ler, ast. lleer, cat. llegir, occ. legir, francoprovenzal lière, fr. lire, romanche leger, piamontés lese, véneto lèsar, it. leggere, siciliano leggiri, sardo lezer (VALLÉs, 2007: 312). En arag. med. se registra leyer (GILKISON, s. v.), igual que en arag. mod. (MARTínez, 2008: 116; Andolz, 1992: 260). Frec.: leyr 2: 0,00455; leyeran [futuro] 1: 0,00227; leyen 1: 0,00227; leydo 1: 0,00227; leyendo 1: 0,00227.

leyto s. m. 'lecho, cama': firose decender del cavallo et levar al palacio et posses [posose N] en el leyto 37.94. Etim.: del lat. LECTUs 'cama'. (DCECH, III, p. 617, s. v. lecho). Conservado en casi todos los romances, excepto el rumano: port. y gall. leito, ast. llechu, cast. lecho, cat. llit, occ. lang. lièch, occ. gasc. lhèit, francoprovenczal liét, fr. lit, romanche letg, piamontés let, véneto leto, it. letto, siciliano lettu, sardo letu. En arag. mod. apenas se conserva leito 'lecho, cama' en el arag. popular hablado de algún punto aislado: así, en Echo (LERA, 2004: 132). Además, en el valle de Gistau, leito 'placenta' (Blas/Romanos, 2008: 345). Por otro lado, sin embargo, se registra el deriv. leitera 'sábana' (RoHLFs, DDPA, lo documenta en Panticosa y en Lanuza; Andolz, s. $v$., en Biescas, Panticosa, Sallent y Torla; el EBA, 1999: 1154, en Lanuza y Sallén). En arag. med. está abundantemente documentado: leyto 'cama' en el Índice de BLANCAS (1641); leito 'cama' en VM (Tilander, VM, III, p. 174); también leyto en algunas obras de Fernández de Heredia (Secreto Secretorum, Libro de los Emperadores, Rams de flores o Libro de actoridades), pero en las demás se encuentra el castellanismo lecho (GILKison, 1984: 81, s. v. lecho). Frec.: 3: 0,00682.

li pron. pers. de $3^{a}$ pers. dativo (c. i.) 'le': qui por succesión, según que de suso yes dito, li era provenido 14.84; la Virgen gloriossa Madre de Dios li apareció [le pareçió N] con grant goyo et díxole que [quiso N] se levantas del leyto sin todo mal que non sintió ren 35.219-221. También le. Frec.: 6: 0,01364.

libertades s. f. pl. 'libertades, derechos', 'privilegios políticos, independencia': qui res de lures privilegios nin libertades non les crebantó 39.28. Frec.: 5: 0,01136.

libralment adv. 'con liberalidad': el quoal regió mientre vivió muy libralment e poderosa 33.48. Frec.: 1: 0,00227.

licencia s. f. 'licencia, autorización': por razon que regnasse don Remiro monge a falta de natura que le diesse licencia de sallir del Orden 20.70. Frec.: 4: 0,00909.

lidiar v. intr. 'combatir, luchar': de guisado que estavan parellados pora lidiar et prendieron manera los castellanos que se alargasse entro al dia siguiente 37.58; estieron en la batalla e lidiaron quoanto pudieron 19.122. Etim.: del lat. LITIGARE 'disputar, pelearse con palabras' (DCECH, III, p. 645). 
limitar] v. tr. 'limitar, poner límites': encara mas, diole limitado el regno de Aragón 20.263; Otrosi de part de Navarra limitra et Sancta Engracia del Puerto entro Broçal con todo Roncal que yes honor de Ruesta 20.276. Cultismo tomado del lat. LIMITARE (DCECH, III, p. 656). Frec.: limitado 1: 0,00227, limitra [futuro] 1: 0,00227.

linada s. f. 'linaje, descendencia': yxió linada [ineada $\mathrm{N}$ ] real et muyt noble 31.8. Etim.: deriv. del lat. Linea. XimÉneZ de Embún, Vocabulario, recoge linada 'descendencia, linaje'. Comp. linada 'linaje familiar', 'clase, categoría' en VM (TilanDER, VM, p. 177), aunque también linaje. Comp. linage. Frec.: 1: 0,00227.

linage s. m. 'clase, raza': cabanna de qualquier linage de ganado 11.60. // 'linaje, ascendencia familiar': que aquell mismo linage fincavan en el su regno et en su servicio 38.282; Agora tractemos del comencamiento del linage de los contes de Barchinona 22.1. Etim.: es deriv. de linea, con el sufijo derivativo -age. Para el cast. linaje hay acuerdo en su procedencia extranjera: tomado del cat. llinatge, llinyatge (CoromINAS, DCECH, III, p. 662) o del occ. linhatge o del fr. lignage (Colón, ELH, II, p. 235). En arag. puede ser también un préstamo, bien del occitano, bien del catalán, pero en todo caso es voz arraigada desde antiguo: lignage en LR, p. 132; linatge en $F A$, p. 456; linage en $V M$, III, pp. 177-178; lignage, linyage, linage en DLAA (ReIDy, 1977: 194); linage, linatge, licnage, lignage, linnage, linagna en Fernández de Heredia (Gilkison, s. v.). Comp., no obstante, linada, forma que no vemos documentada en cast. ni en otros idiomas. Frec.: 8: 0,01818.

linea s. f. 'línea': muytos fillos qui por engendrament de dreyta linea non son anotaderos 36.33; assi como a quis pertannya por dreyta linea et successión 36.198. Cultismo tomado del lat. linèa 'línea, hilo de lino; cuerda; cordel; raya'. El BDELC (p. 362, s. v.) da la 1. a documentación en castellano en 1490, es decir, un siglo y pico después que la Crón. SJP., si bien h. 1250 en la forma liña. Frec.: 2: 0,00455.

livrar (var. librar) v. tr. 'entregar': el quoal Beltran d'Albus libró al rey grant partida 33.45; et mandó el rey Carlos que le fues livrada la reyna de Aragón 38.324; recibió el dito infant por livrarlo a los suyos sozmezos 35.21; et livroron aquélla a los francesses 36.614; «Fillo mio, yo livro la mi spada en sennyal de dreytura con la qual tu departescas mal de bien, et livrote la mia sennyoría con la qual te dé Dios vistoria contra los tus enemigos» 35.262. Etim.: del lat. LIBERARE 'libertar'. Cfr. cat. lliurar, fr. livrer con el mismo significado de 'entregar' (DCECH, III, pp. 642-643). Frec.: libró 1: 0,00227; livrada 3: 0,00682; livrado 4: 0,00909; livrarlo 1: 0,00227; livro 1: 0,00227; livroron 1: 0,00227; lívrote 1: 0,00227.

livro (var.: libro) s. m. 'libro': segunt que havemos leydo en muytos libros 1.1; según en el livro de las corónicas de Castiella yes contenido 4.9. Frec.: livro 3: 0,00682; libros 1: 0,00227 .

lo art. n. 'lo': Et quando el dito cavallero fue al rey Carlos et huvo dito lo que deziir le devia... 38.315 // pron. pers. átono de $3^{\mathrm{a}}$ persona, $\mathrm{m}$. sing. 'lo': mas non lo quiso prender... 38.608; con conpannya del dito judge los avía livrado por vedar que viandas 
non entrassen en el dito castiello 38.523. / / art. m. sing. 'el': et el uno buvo nombre Gifrre et lo otro Olibano 24.4. Comp. el. Frec.: lo 135: 0,30685 [incluye las tres funciones].

loablement adv. 'loablemente, de una manera digna de alabanza': et aquí finir loablement sus días 35.208. Frec.: 1: 0,00227.

loar] v. tr. 'alabar', 'ensalzar, elogiar': et loado el nombre de Dios, fizo aplegar Cortes generales 35.121; et él possa y las primeras piedras Dios loando 35.193; Dios lohando et benediziendo, el dito rey con su compannya sin que ningún mal no prisso tornose a sitiar la dida ciudat de Almaría 38.368; et aquélla looron et aproboron 20.170. Etim.: del lat. LAUDARE 'alabar' (DCECH, III, p. 674). En castellano la forma castiza fue alabar, loar quizá sea forma tomada en la Edad. Media del fr. o del cat. La forma loar se halla en algunas poesías de Berceo, pero más a menudo laudar (ÁlvarEZ, 1991:185, indica que este verbo tiene tres formas en las obras de Berceo: /laud-/, /láud-/ y /lo-/). La misma forma en Fernán González. Aparece loa en el Apol., de lenguaje aragonesizante y catalanizante. Como no es muy probable que el latinismo laudar se hubiera introducido en un vocabulario tan estrictamente romance como el del Cid si loar fuese corriente, cabe sospechar que el castellano tomó esta forma del francés ant. loer (hoy louer) o del cat. ant. Loar (hoy lloar). Puede ser uno de tantos vocablos de gente de iglesia introducidos por el movimiento cluniacense. Frente a cast. loar existen cat. lloar y gall. y port. louvar, laudar se doc. ya en el Poema del Cid, h. 1250 y luego en Berceo, Alex., Apol., etc. (DCECH, III, p. 674; Bustos, Contribución, pp. 301 y 530: éste llama la atención sobre la aparición del doblete laudar/loar en Berceo). Se registra laudar 'alabar' y laudable 'digno de alabanza' en VM, III, p. 173, s. v.; laudar 'alabar, celebrar' en FA, p. 450, s. v. Se documenta lauzar en el Rams de Flores de Fernández de Heredia, pero son más abundantes en sus obras laudar y loar lohar (GILKISON, s. v.). Comp. lohor. Frec.: looron 1: 0,00227; loado 1: 0,00227; loando 3: 0,00682; lohando 2: 0,00455.

loçanía s. f. 'lozanía': por su grant atrevimiento de sobra loçanía de corazón 19.222. Etim.: deriv. de loçano y éste de un lat. vg. *LAUTIANus, a su vez deriv. de LAUTia 'ajuar proporcionado al huésped' (DCECH, III, pp. 700-704). Frec.: 1: 0,00227.

loco] adj. 'loco, sin juicio'; 'tonto, imprudente': et los porteros como locos et de poco bien... 20.30. Etim.: de origen incierto, quizá de un tipo ${ }^{*}$ LAUCU, quizá del árabe LÁUQA, LAUQ, fem. y pl. de álwaq 'tonto, loco' (DCECH, III, p. 683). El DEEH, s. v., p. 244, propone el lat. OLUCCus 'mochuelo, lechuza', étimo que hubiera dado, a nuestro entender, *olco. Corriente (2003: 365) comparte la idea de que procede del árabe, aunque matiza la propuesta del DCECH: «más bien que del ár. ***lawq sugerido por Coromines, error por **lawaq 'locura', con dificultad fonética y cambio inexplicado de categoría morfológica, podría derivar de lawqā? 'loca', suponiendo hubiera existido un no documenta- 
do and. láwqa, fem. de alwáq 'estúpido', derivación a través del fem.». Frec.: locos 1: 0,00227.

locura s. f. 'locura, acto propio de locos': Et aquesto oyeren los nobles et cavalleros dixeron: "Vayamos a veer aquella locura que nuestro rey quiere fazer» 20.129. Deriv. de loco. Frec.: 1: 0,00227.

lohor] s. f. 'alabanza, loa, loor': et firo grandes gracias et lohores a Dios 38.539; recontando loores a Dios et a los ditos sanctos de las victorias que havía obtenido 11.53. Etim.: deriv. de loar < lat. LAUDARE. entre los derivados de loar están: cast. loa; gall. Louva; loor (Berceo). En cambio, en occ. lauzor, cat. llaor, port y gall. lawvor. Comp. laudor. Frec.: lohores 3: 0,00682; loores 1; 0,00227.

loriga s. f. 'armadura para defensa del cuerpo, hecha de pequeñas láminas de acero imbricadas': et un moro ballestero que estava en aquel lugar con una sayeta por la manga de la loriga firiolo en el costado 17.122. [fo nafrat lo dit rei ab sageta per la mànega de l'asberc o camisol, VC, p. 63]. Del lat. LORICA 'coraza', deriv. del lat. LORUM 'cuerpo', 'correa'. 1. ${ }^{a}$ doc.: lorika, doc. arag. de 1029. Del mismo origen cast. y port. loriga y cat. ant. (I)loriga (DCECH, III, p. 696). Frec.: 2: 0,00455 .

los art. det. m. pl. 'los': de las quales naciones nos callaremos, sino tan solamente de los godos 3.3.; et fizo by fer muytos castiellos et fuerças por costrennyr los moros 12.48; de la qual respuesta los de Navarra fueron muy despagados 20.34; entre los quales morieron Aznar Pardo et Pero Pardo su fillo 34.164. Frec.: 638: 1,45013.

luego adv. de tiempo 'luego': aparellado luego tantost con gran poder de hombres 4.32; luego querie ensayar Vitoria et otros lugares que yeran de Navarra 20.49. Etim.: del lat. LOCO, abreviación de ILICO 'inmediatamente', formado de IN LOCO 'en el lugar, allí mismo'. Comp. cast. luego, port. logo, fr. ant. lues. Cfr. DCECH, III, p. 710, s. v. lugar. En arag. mod., luego y lugo (cfr. ANDOLZ, s. v.; RoHLFS, $D D P A$, s. v.). Frec.: 8: 0,01818.

luengament adv. 'largamente, por mucho tiempo'; 'durante largo tiempo': el qual regió su tierra con grant justicia et misericordia luengament et lexó herederos suyos 38.633. Deriv. de luengo. Frec.: 5: 0,01136.

luengo adj. 'largo, amplio, extenso': las quales gents, por luenga paz, oblidoron el uso de las armas 1.38; las quales serían luengas de contar 35.186; Luengo tiempo havia por tal quel dito regno de Secilia fues mas segurament preservado de poder de los enemigos 36.264. Etim.: del lat. LŎNGus 'largo'. Fue de uso general en toda la Edad Media. En el s. Xvi ya pasa a ser vocablo anticuado, aunque no de un modo brusco (DCECH, III, p. 708). Es habitual en arag. med. Véase por ej. en Fernández de Heredia (Gilkison, s. v.), en FA (Tilander, 1937: 461), etc. En arag. mod. se usa generalmente largo, pero algún vocabulario recoge luengo como antónimo de curto (LERA, 2004: 132, en Echo). Se encuentra 
también en toponimia: Barluenga ( $<$ VALLE LŎNGA), Billalangua ( $<$ Billaluanga $<$ vILLA LŎNGA). Frec.: luengo 5: 0,01136; luenga 2: 0,00455; luengas 1 : 0,00227 .

luent adv. 'lejos': et el dito rey don Pedro qui no les era luent adiesso et fuert a menudo firía en ellos 36.624. Entre los deriv. de LŎNGUS > luengo 'largo', citan COROMINAS-PASCUAL lueñe [orígenes del idioma: Glosas de Silos, escrito luenge; Berceo luen, lueñe, etc. frecuente en toda la Edad Media, por ej. en $S t^{a}$. $M^{a}$. Egipcíaca, 338; Alex., 486, 1271; lueñes, Nebr.; alueñe, Calila: hoy todavía conservado en Asturias, lloñi en Colunga, llonxi y tsuenxi en el Oeste de esta región (Vigón), formas que a su vez se dan la mano con el port. longe, gall. lonxe], del lat. LŎNGE 'lejos', más tarde sustituido en castellano por lejos. En ast. la forma de referencia es lloñe (Academia de la Llingua Asturiana, Diccionario de la Llingua Asturiana, 2000: 756). En otras lenguas románicas: cat. lluny, occ. luenh, francoprovenzal luen, fr. loin, romanche lunsch, piamontés lontan, véneto lontan, it. lontano, siciliano luntanu (VALLÉs, 2007: 312). La forma aragonesa luent (TILANDER, FA, pp. 460, 542, con su deriv. lonteza 'lejanía') enlaza con el cat. dial. llunt (Castellón de la Plana, etc.), en lugar del cat. lluny (DCECH, III, pp. 708-709, s. v. luengo). La forma luent 'lejos' es común en textos arag. med., con diversas variantes. Véase, por ej., luent en el Índice de Blancas (1641); luein, lueing, lueint en $L M M$, p. 180; lueyn, luein en VM, III, p. 180; luent y luen en FA, p. 460. En el LT, luente (Prince, 1995: 222). En Fernández de Heredia GiLKIson, s. v. recoge luent, luente, lueynt y, además, luennes, luenye con un significado semejante. La forma luent, con - $t$ final supone una ultracorrección que deja en evidencia que esa - $t$ gráfica no se pronunciaba. En arag. mod. se registra luen en la Fueba, luẽẽes en Sercué (Bal de Bio), lluen en Benasque (Andolz, s. v.; DDPA, s. v.; Ferraz, s. v.; Ballarín, s. v.). El EBA (1999: 1190) registra también luen 'lejos' en Jasa; lluen en Sesué, Bal de Lierp, Chuseu, Torres de lo Bispe. Moneva (2004 [1924]: 297) registra luen ‘lejos’ en Jaca y Aragüés del Puerto. Frec.: 1: 0,00227.

lugar (var.: logar) s. m. 'pueblo, entidad de población menor que la ciudad'; 'lugar, sitio': salieron entre Estroga e Leon, en el logar clamado Via Anguis 19.141; diole Sarasanz [Sarrazas N], Roncal, Cadreta et Valetra [Valtierra N] a vida suya con tal pero condición que depués muert suy a los ditos lugares tornassen al rey de Aragón 20.181183; que le soltas el homenage que feito le havía por aquellos lugares 20.187; et vino sende [vinose $\mathrm{N}$ ] al lugar de Sant Martín, do estuvo dos días 38.583. Etim.: del lat. LOCALIS 'del lugar', deriv. de LŎCus 'lugar' (DCECH, III, p. 710). Frec.: lugar 45: 0,10228; lugares 23: 0,05228; logar 2: 0,00455.

lumbre s. f. 'luz': «Sennyor, que la mi ánima sia colocada en perdurable lumbre delant tú» 35.300. Del lat. LUMEN, -INIS 'cuerpo que despide luz' (DCECH, III, p. 712). Frec.: 1: 0,00227. 
lunes s. m. 'lunes': día lunes a XII días de setiembre 38.417. Del lat. LUNAE (DIES) 'día consagrado a la luna' (DCECH, III, p. 713). Frec.: 3: 0,00682.

lunnyar v. intr. 'alejar': et tantost respuso: «liunyatnos [levatnos B; luniat vos $\mathrm{N}$ ] d'aquí sino fernos [fer vos $\mathrm{N}$ ] he lunnyar [levar $\mathrm{B}$; luniar de aqui $\mathrm{N}$ ] por fuerca porque, Sennyor, traydor nos avedes estado» 38.304-306. Etim.: deriv. del adv. luent 'lejos'. Pero hay que suponer que se ha partido de la forma con nasal palatal [lwén] o, aún mejor, de [lún]; en este último caso sería un catalanismo. Más fácil resulta pensar que se trata de un préstamo del cat. ant. (l)lunyar. El Índice de BlanCAS (1641) recoge lunense 'apartense'. Frec.: 1: 0,00227.

lur adj. poses. 'su, de ellos' (en pl. lurs/lures 'sus, de ellos'): et eslieron en rey et sennyor lur al dito Frederich 38.146; demandoron tregua por soterrar los lures muertos 38.556; et ellos assi mismo vestidos de negro et lurs conpannyas partieron d'aquí 38.142. Etim.: del lat. ILLŌRum, genitivo plural de ILLE, 'de aquellos, de ellos', con influencia del dativo singular LUI, que cambia la $o$ en $u$. Cfr. DECLIC, V, pp. 309-310. Es constante el uso de lur, lur(e)s en los textos en arag. med. Comp. con cat. llur, occ. lor, ant. fr. lor (mod. leur), it. loro, rum. lor, retorrom. lur (cfr. BOURCIEz, Eléments de ling. rom., pp. 355, 525, 584, 678; LAUSBERG, Ling. rom., II, pp. 232-233; AliberT, s. v:; BADíA, Gram. hist. cat., p. 306.). Sobre la forma lur, lurs en la Crón. SJP. y en aragonés medieval puede verse, más ampliamente, NAGOrE (2003: 261-267). Frec.: lur 36: 0,08183; lures 14: 0,03182; lurs 7: 0,01591.

\section{$\mathbf{M}$}

maça] s. f. 'maza': Et de los colpes de las maças trobaron [fallaron $\mathrm{N}$ ] muytos muertos 18.69. Etim.: del lat. vg. * MATTEA, que parece ser deriv. retrógrado del lat. MATEOLA íd. (DCECH, III, p. 893). Frec.: maças 3: 0,00682.

madrastra (var.: madastra) s. f. 'madrastra': et porque el dito Pedro Remón mató la su madastra Nadalmurs por el qual pecado el dito Pedro Remón murió en Espanna sins fillos 29.18; el qual le era pervenido por daçión [donación $\mathrm{N}$ ] de su madrastra 16.3. Deriv. de madre. Frec.: madastra 1: 0,00227; madrastra 2: 0,00455.

madre s. f. 'madre': et fincó con su madre en el regno de Secilia 36.700; assí como a viprias [vipras $\mathrm{N}$ ] que naturalment quando naxen matan lurs madres 29.18. Del lat. MATER, MATRIS. Frec.: madre 26: 0,05910; madres 1: 0,00227.

maestro s. m. 'maestro': embió un mensagero al su monasterio de Sant Ponz de Tomeras con letras al su maestro, clamado Forçado 20.103; ... metiendo fama que una campana 
quería fazer en Huesca que de todo su regno se oyesse, que maestros havía en Francia que la farían 20.127. Del lat. MAGISTER, -TRI. Frec.: maestro 8: 0,01818; maestros 1: 0,00227 .

maguera conj. concesiva 'aunque, no obstante', 'si bien, aun cuando', 'a pesar de que': dirziendo estas paraulas: "Maguera yo dé a tu el regno pero la mi dignidat real non lexo» 20.292; el qual, maguera fues abbat, él [omite N] yva como cavallero, 35.13. Etim.: del griego $\mu \alpha \chi \alpha \rho \iota \varepsilon$ 'feliz, bienaventurado', vocativo de $\mu \alpha \chi \alpha \rho \iota \sigma^{\prime}$, adj. de este signif.; maguer significó primitivamente 'ojalá', acepción que todavía conserva en algún texto arcaico y en it. magari, y de ahí pasó a tomar valor concesivo. La 1. ${ }^{a}$ doc., en la forma macare, se encuentra en las Glosas Silenses (h. 950-1000): macare ke siegat [= maguer que sea], traduciendo el lat. quamvis (LHP, p. 351). La forma maguer es frecuentísima en cast. med., especialmente hasta el s. XIv. La variante maguera es tb. antigua, pues ya aparece alguna vez en Berceo y en otros autores de los ss. XIII y XIV, y después conserva mayor vitalidad que la otra variante en textos del s. Xv y xvI. Es la única forma que registra Nebrija. Comp. magari 'ojalá, 'aunque fuese', 'aunque' en it. común., rum. macar 'por lo menos' (DCECH, III, pp. 764-768). En ladino (judeoespañol escrito) está documentado makaré 'aunque, a pesar' (PAscual Recuero, 1977: 93). García de Diego, DEEH, 253, relaciona el cast. ant. y port. maguer 'aunque' con la voz magar 'aunque', usual en serbio, turco y griego («griego moderno macarie 'aunque', de origen eslavo»: ibídem, p. 789). También Rohlfs y MeYer-LÜBKe (REW, $\mathrm{n}^{\circ}$ 5224) suponen que proviene de mägär (serbio y turco). Para CoROMINAS «es posible que sea esta palabra turca [méger o méjer 'si no', 'salvo', 'sólo que', 'quizá, casualmente'] la que viene del griego, o bien que no tenga nada que ver con las voces romances, griegas y eslavas en cuestión (albanés, búlgaro, serbocroata makar 'aunque'], pero que éstas son de origen griego no puede caber duda. Que el vocablo en toda la Romania desciende directamente del latín vulgar, el cual lo adoptó del griego coloquial, está fuera de toda duda» (DCECH, III, pp. 764-768). En arag. med. se registra maguera 'sin embargo': «Maguera en algunos logares ay buena tierra mas no en muchos logares« ( $L M M$, C.142, p. 77); maguera que 'aunque': «do \& lexo a Martin Lopeç, criado mio, c solldos de jaqueses, daquell deudo que don Johan de Graç deuia a Marin Lopeç sobre dicto, con carta publica, elqual deudo, maguera quela carta del deudo deçiese aldicto Martin Lopeç, era mio» (DLAA, doc. n. ${ }^{\circ}$ 49, de Huesca, 1279; p. 74, lín. 9); también se encuentra maguer que, mager que 'aunque': «E si la asta passará más adelant, mager que no'l toque en carne ni poco ni muyto, deve peytar por calonia...» (FAM; Gargallo, 1992: 172); «Segunt las razones de los razonadores deue seer dado el iudizio, e non puede reuocar so dito, diziendo de no, maguer que aya errado» (FA, 61.1; Tilander, 1937: 33). Es muy frecuente maguer como conj. 
concesiva con subjuntivo en VM (TILANDER, 1956, III: 181). Comp. empero: 'sin embargo, no obstante': Empero quando buvo conquisto [conquistado N] el dito regno de Murcia... 35.164-165. Frec.: 3: 0,00682.

mal s. m. 'mal': entre las gentes huvo grant mal et grant treballo 38.612; et como los franceses fazían todos días diversos males, grenges et desonores... 36.192; et teniendolo por mal los de la tierra e los ricos omnes enbargaron aquel casamiento 19.159. // adj. (apócope de malo): et el dito Padre Santo, indueyto de mal consello, non recibió assí como devía benignament los ditos mesageros 36.177; más empero non quisieron estar de continuar lur mal proposito 36.555. // adv. 'mal, malamente, de mala manera': que acusassen la reyna, lur madre, al rey, su padre, que ella faría mal sus afferes con el dito cavallero 14.53. Vid. malament. Del adv. lat. MALE 'mal'. Frec.: mal 20: 0,04546; males 3: 0,00682 .

malament adv. 'de mala manera': depués, como Alfonso de Castiella tractas malament [a añade B] su muller, hermana del rey dito don Pedro... 36.105. Frec.: 1: 0,00227.

malas s. f. 'manojos, bultos, fardos': mas tanta era la multitudo de la gent estrannya que ya sea que sin nombre ne matoron a malas se parecía 36.578. El pasaje es oscuro. En la VC: ...que, ja sia que sens nombre n'occissen a males, envides s'bi parien. (VC, p. 144). En la VL: Sed multitudo gentis, que illuc confluxerat erat in numero sic prodigaliter excessivo, quod licet ex ea caderent infiniti, non videbatur suspicere detrimentum. (VL, p. 186). La idea está clara: «era tanta la gente que a pesar de que mataron innumerables (de ellos), apenas parecía que disminuyeran». Una posible interpretación sería: a malas 'apenas', en relación con el arag. mod. malas que 'apenas, nada más que'. Pero esta loc. conj. se usa sólo en sentido temporal, por lo que no parece convincente. Otra interpretación posible: mala 'baúl, maleta', 'bulto, fardo', 'manojo'. Cfr. malas 'bultos, fardos, legajos, haces' en Fernández de Heredia (GiLKIsOn: mala 'bundle'). Cfr. también cat. ant. mala 'baúl, saco de viaje' < fráncico * MALHA 'saco o morral de viaje' (DECLIC, V, p. 392). Podría ser, por tanto: a malas 'a sacos, a zurrones, a baúles', loc. adv. de cantidad equivalente a 'en gran cantidad'. Es más verosímil, pero no encaja con la VC envides 'apenas', ni con a males si ésta se interpreta como loc. 'por fuerza, violentamente' (cfr. DCVB, t. 7, p. 139). Frec.: 1: 0,00227.

malautia s. f. 'enfermedad': es verdat empero que grant fambre et grant malautia se metió en la buest del dito rey 38.399; estando el dito rey don Alfonso en la villa de Perenia, fue movido de greu maulatia e hordenó su testament e restituyó heredero en el regno de Aragón 33.120; grieu malautia lo costrennyó; por la qual muert del dito cardenal et malautia del dito rey la publicación de la dita paz se bubo a prolongar. 38.93-96. Etim.: Según Garcia de Diego, DEEH, pp. 253 y 792, de male habitus 'enfermo' $>$ malauto, y de aquí deriv. malautía. Comp. malatia 'enfermedad' en Fazienda de Ultramar, 116.8. y maletia < lat. MALITIAM 'enfermedad, dolencia', en Apolonio, 199 d. (cit. por Bustos, 1974: 542 y 543). Comp. arag. med. malaudo 'enfermo' 
en DLA $A$, doc. n'. 138, lín. 9; cat. malalt 'enfermo' < MALE HABITU (Colón, 1976: 24, 66 y 89); cat. malaut adj., var. ant. de malalt, (DCVB, 7, p. 146). Cat. malalt 'mancat de salut', cast. 'enfermo' ( $D C V B$, t. 7, p. 142) y malaltia 'qualitat de malalt; pertorbació de l'estat de salut; alteració que interromp o pertorba les funcions vitals'; cast. 'enfermedad', con la variante malautia (Crón. de Jaime I, Llull) (DCVB, t. 7, p. 143). Corominas: cat. malalt, primeramente malaute, malalte < lat. vg. MALE HABITUS 'el qui es troba malament'. De aquí proviene tb. oc. malaute o malaude, fr. malade; it. malato. «Ja des del XIV la forma malalt es va imposar pertot» (DECL/C, V, 385-386). Como deriv. de malalt cita malaltia, que es tan antiguo literariamente com malalt y que, aunque no se crea en latín, debe remontarse al latín vulgar tardío, ya que es común con el it. malatia, el fr. maladie y el oc. malautia. Cita luego como formas relacionadas: malotía (<-autía) 'enfermedad que no obliga a guardar cama', en Caspe y Alborge (Puyoles-Larrosa; también en Andolz, 1992: 277; y en Moneva, 2004: 308), malatía en Olocau del Rey, maletía en Murcia (GArCía Soriano) (DECLIC, V, pp. 386-387). La forma maletia del cast. ant. (cfr. Alex, SAS, p. 366) podría venir según COROMINAs de MALE(D)ICTA 'maldición'. En cambio, malautia en Alex., ms. O (SAS, p. 366) piensa que ha de ser occitanismo (DCECH, III, p. 784). En arag. mod. se registra malautía 'enfermedad indeterminada' en Sesué y Benás, malantía y malotía 'enfermedad, dolencia' en A Fueba (EBA, 1999: 1205 y 1211). Frec.: 7: 0,01591.

maldat s. f. 'maldad': veyendo la maldat, et que el rey et el regno de Navarra de aquesto avrían gran infamia... 20.191. Del lat. tardío MALITAS, -ATIS 'maldad' (SEGURA, 2001: 442). Frec.: 1: 0,00227.

maldición s. f. 'maldición': et pressa la dita ciudat, la maldición de las moscas quanto más yva, más crecía en los franceses 36.616; enbioles maldición de moscas et puedes dezir que era una de las maldiciones de farahón 36.596. Del lat. MALEDiCTIO, -ONIS. Frec.: maldición 2: 0,00455; maldiciones 1: 0,00227.

maleza s. f. 'malicia, maldad': et pensaronse con quanta maleza era estado muerto su padre 23.31. Etim.: del lat. MALITIA 'maldad, malignidad, mala naturaleza' (DCECH, III, p. 785). Comp. maldat. Frec.: 1: 0,00227.

maleztat s. f. 'acto vil y malvado, daño, mal, maldad': et sabiendo la maleztat [malveztad $\mathrm{N}]$ que su sennyor le havía feita 3.85. Etim. Podría venir de un lat. vg. *MALECITATE, formado a semejanza de lat. vg. *Aмicitate > amiz̧tat 36.425. El DCVB (t. 7, p. 168) documenta malvestat 'maldad' en Llull, Crón. de Pere IV, Metge, y actualmente en Eivissa. El DECLIC, entre los deriv. de malvat (<lat. vg. MALIFATIUS) cita malvestat en R. LuLL, en occ. ant. malvastat, malvestat, derivado del arcaico y occidental malvatź, en catalán ant. se encuentra tanto en el sentido abstracto de 'cualidad o naturaleza malvada' como en el concreto de 'acción malvada'. Con este sentido concreto está vivo en catalán central («no 
facis malvestats»), si bien como abstracto solo se encuentra en cat. medieval (DECLIC, V, 403, s. v. malvat). Frec.: 1: 0,00227.

malgrazido adj. 'mal agradecido', 'desagradecido', 'desplaciente': en aquella ora, por consello de algunos, los governadores fueron mesclados et mesturados con el rey [por el rey $\mathrm{N}$ ] don fue muerto don Per Ahones et los otros malgrazido [a los otros mal agradecido $\mathrm{N}] 35.51$. Comp. cat. malgraciós 'áspero al trato', malgraciosament 'con desplacer' (DCVB, t. 7 , p. 158). Frec.: 1: 0,00227.

malo] adj. 'malo': et veet los prometimientos del rey de Castiella en quienta manera mala se convirtieron 38.39; algunos davan de consello al rey que diesse por malos a los sus naturales que yeran seydos en la batalla 38.280. Del lat. MALUS, -A, -UM. Vid. también mal, forma apocopada del masc. malo ante sustantivo. Frec.: malos 3: 0,00682; mala 9: 0,02064; malas 2: 0,00455.

malquerencia s. f. 'malquerencia, mala voluntad a una persona, odio': et que la malquerencia quel enemigo del humanal linage havía procurada et metida entrellos et sus gentes, haviessen et levassen contra moros 20.163. Palabra compuesta del adj. mala y del sust. querencia, deriv. del v. querer. Frec.: 2: 0,00455.

malvadament adv. 'malvadamente, con maldad, con injusticia': et la dio por innocent et por exempta del grieu crimen quel era levantado por sus fillos malvadament e falsa 16.9. Frec.: 1: 0,00227.

malvado] adj. 'malvado': Et a hasmamiento de todo bomme et, segunt que después de cierto se suppo, de toda aquesta gent malvada non tornoron a lur tierra la XXX part 36.666; fizo afogar por prender vengança de las malvadas faziendas que feitas avía contra éll 36.46; et con la ayuda de Dios lançó fuera de Barchinona et de toda la tierra vigorosament los malvados moros 26.17. Del lat. vg. MALIFATIUs 'malhadado, desgraciado', compuesto de maLus 'malo' y fatum 'destino' (DCECH, III, p. 788). Frec.: malvada 3: 0,00682; malvadas 2: 0,00455; malvados 1: 0,00227.

mancebo s. m. 'joven muchacho': Muerto el dito rey don Remiro, regnó su fillo Sancho que era mancebo de XVIII ${ }^{\circ}$ annos 17.2. Etim.: lat. vg. hispánico *MANCIPUs, nominativo sacado secundariamente del lat. HOMO MANCIPI, genitivo de MANCIPIUM 'propiedad', 'esclavo', compuesto de MANUS 'mano' y CAPERE 'coger' (DCECH, III, p. 818, s. v. mano). Indica Corominas que en Apol. es todavía 'esclavo'; luego 'criado', y posteriormente 'joven muchacho'. En cat. y occ. macip 'criado, ganapán'; cast. mancebo. Frec.: 1: 0,00227.

mandamiento s. m. 'mandato': et por mandamiento del Padre Santo envió al rey de Castiella su filla, la qual avía sposada 38.165; et ningún tiempo non quiso seer enemigo de la casa de Aragón, ante [antes B] a los mandamientos de aquélla, mientre vivió, obedeció 38.600. Etim.: deriv. de mandar < lat. MANDARE 'encargar, dar una misión', 'confiar algo, encomendar' (DCECH, III, 800), con sufijo -miento que deriva sustantivos de verbos e indica el resultado o el nombre de una acción 
(PhARIES, 2002: 403). Frec.: mandamiento 6: 0,01364; mandamientos 1: 0,00227 .

mandado s. m. 'encargo, mandato', 'orden': et lexó mandado que de mannana todas sus gentes fuessen a éll 20.197. Del p. p. del v. mandar. Frec.: 3: 0,00682.

mandar] v. tr. 'mandar, ordenar': «mando vos de part del rey de Inglaterra que en continent me yxtades del campo» 36.289; Et en continent, el dito rey mandó a todos sus cavalleros que les firiessen lugar 38.389; et mandoron plegar Cortes Generales en el lugar de Borja 20.10. Del lat. MANDARE 'encargar, encomendar'. Frec.: mandaría 1: 0,00227; mandás 2: 0,00455; mandava 2: 0,00455; mandavalos 1: 0,00227; mandó 15: 0,03409; mando 2: 0,00455; mandóla 1: 0,00227; mandóle 1: 0,00227; mandoron 1: $0,00227$.

manera s. f. 'manera, forma, modo': otra vegada grant innumerable aiusto de moros por semblanment [senblant $\mathrm{N}]$ manera que dessuso havemos recontado, vino contra el dito rey 38.372; con los quales favló el rey don García de Navarra que en todas maneras que havies a sus manos preso don Caxal 20.220. Del lat. vg. MANUARIA 'manera', fem. de MANUARIUS 'manejable' (DCECH, III, p. 806). Frec.: manera 36: 0,08183; maneras 4: 0,00909.

manga s. f. 'manga': et la manga de la loriga se abrió, et un moro ballestero que estava en aquel lugar con una sayeta por la manga de la loriga firiolo en el costado 17.121. Del lat. MANICA 'manga', deriv. de MANUS 'mano' (DCECH, III, p. 807). Frec.: 2: 0,00455 .

manifestar v. tr. 'manifestar', 'declarar': vinies en Catalunna et en las otras tierras del dito rey por manifestar la paz 38.84; Et en continent, el dito sancto varón manifestólo al dito emperador 14.79. / / 'revelar': et en esto manifestó miraglo Nuestro Sennyor Dios al dito don Alfosno 38.545. Cultismo tomado del lat. MANIFESTARE. Frec.: manifestar 1: 0,00227; manifestó 1: 0,00227; manifestólo 1: 0,00227.

manifiestament adv. 'claramente, de forma evidente': Et el dito rey de Granada, viendo manifiestament la destrucción de si mismo et de sus gentes... 38.376. Frec.: 1: 0,00227 .

manifiesto] adj. 'patente, evidente, manifiesto': pensaron que ningún homme del mundo no podian esleyr millor quel dito rey Remiro, el qual de manifiestas noblezas era ennoblecido 16.20. Del lat. MANIFESTUS. Frec.: manifiestas 1: 0,00227.

mannana s. f. 'la mañana, parte del día hasta el mediodía': toda la nueyt et la mannyana 36.559; et buena manyna a la qual podemos dezir dolorosa et despagada por las cosas subsiguientes 37.87 (forma errónea en el ms. E) [maynnana N]. // otro día mannana loc. adv. 'el día siguiente por la mañana': et a otro día mannana, supo como los moros eran çerca 18.32; pora conbatirse otro día manyana con los franceses 36.651. // de mannana loc. adv. 'por la mañana, temprano, al amanecer': et lexó mandado que de mannana todas sus gentes fuessen a éll 20.197. Etim.: del lat. 
vulgar *MANEANA, abrev. de HORA * MANEANA 'en hora temprana', deriv. del adv. MANE 'por la mañana' (BDELC, s. v.). Frec.: mannana 2: 0,00455; mannyana 1: 0,00227 ; manyana 1: 0,00227 ; manyna $1: 0,00227$.

mano s. f. 'mano': et alçando el braço dreyto estrennyó la mano et dixo... 38.302 // a su mano loc. adv. de modo 'en su poder': fizole prometer que non se levantasse del sitio entro que avies Huesca a su mano [priso por su mano N] 17.125; Et depués de grant honrament adozieronlo al monasterio de San Johan de la Penna, prendida Huesca a su mano, et soterroronlo denant el altar de San Johan. 17.133-136 ['tomada Huesca en su poder']; que en todas maneras que havies a sus manos preso don Caxal 20.220; asitió el dito castiello et aquél priso et huvo a su mano 36.15. GILKIsON $(1984$, s. v.) registra mano en Fernández de Heredia, que traduce por 'hand, power' ['mano, poder']. Del lat. MANus, -Us. Frec.: mano 16: 0,03637; manos 5: 0,01136.

mantener v. tr. 'mantener, sostener, sustentar': et firmo aqui de present de mantener et fer dezir [dir $\mathrm{N}]$ a todo homme uno depués otro que mi sennyor el rey d'Aragón se yes levado lealment 38.321; que avía de suingar la nasción morisma et aduzir la tierra a la fe chiristiana, por tal que fues mantenido et loado el nombre de Dios 35.121; el dito rey Remiro, delant de su marido et de sus fillos en la cort general sobre aquesto clamada, la mantuvo et la dio por innocent et por exempta del grieu crimen quel era levantado por sus fillos 16.7 . Compuesto de mano y tener (lat. vg. MANU TENERE). Frec.: mantener 3: 0,00682; mantenido 1: 0,00227; mantuvo 1: 0,00227.

mar s. f. 'mar': el dito rey don Jayme con grant et maravellosa armada, por mar et por tierra sitió la dita ciudad de Almaría 38.353; tan fuert batalla bi fue feita que la mar vermelliana [vermellava $\mathrm{N}$ ] de la sangre de la gent que muerta et ferida yera sobre la mar 38.269 (error por vermelliava). Del lat. MARE 'mar'. Frec.: 16: 0,03637.

maravella s. f. 'maravilla': et mientre duró la batalla sol nos mudó el pie ni firo asemblant que fues ferido, de la qual cosa todo homme se dio a grant maravella 38.278. Etim.: es descendiente semiculto del lat. MIRABILIA, pl. neutro del adj. MIRABILIS 'extraño, notable'. General en todos los romances de occidente, con algunas disimilaciones y asimilaciones vocálicas: cast. maravilla, fr. merveille, cat. meravella, port. maravilha, it. maravighia $\sim$ meraviglia, sardo maraviza, occ. meravelha $\sim$ meravilha, retorrom. (sobreselvano) marveglia, retorrom. (engadino) müravaglia. Cfr. DCECH, IV, pp. 84-85, BDELC, p. 381, s. v. mirar, DECLIC, V, pp. 701-703. Frec.: 3: 0,00682.

maravellado adj. 'maravillado, sorprendido, admirado': el rey de Castiella envió al rey d'Aragón que le dasse a Calatayú et sus pertinencias como le avía prometido si non que faría guerra contre éll. Et fue de aquesto maravellado el rey 36.373. Vid. maravillar. Frec.: 1: 0,00227 .

maravellosament (var:: maravellossament) adv. 'maravillosamente, de un modo maravilloso': Et depués, porque de tales donos de gracia tan maravellosament Dios le insignó, quiso continuar su propósito de conqueir et subingar regnos et tierras de moros mientre Dios vida li dasse 35.152; armado muyt maravellosament assí como si devies entrar en batalla 
36.281; et regnó muyt maravellossament todas vegadas 36.712. Frec.: maravellosament 2: 0,00455; maravellossament 1: 0,00227.

maravelloso (var.: maravilloso) adj. 'maravilloso, admirable, excelente': Aquesti virtuoso rey don Jayme fue princep excellent, virtuoso, valient e ardido et muy gracioso, benigno et piadoso et muyt maravelloso batallero 35.176; con grant et maravellosa armada, por mar et por tierra, sitió la dita ciudat de Almaría 38.353; et havía muyt bella persona et grant et los miembros suyos muy maravellosos et concordantes et muy bello de persona 32.7; Et fue con él vencedor en la grant batalla de Húbeda, en la qual fue muyto maravilloso batallero 34.88. Deriv. de maravella. Frec.: maravelloso 2: 0,00455; maravellosos 1: 0,00227; maravellosa 4: 0,00909; maravilloso 3: 0,00682.

maravillar] v. pron. 'admirarse, quedarse asombrados o maravillados': non dixo res, mas fuesse por la buest et fizo jurar a su fillo don Pedro por rey, et las gentes se maravilloron de aquesto 17.124. Etim.: deriv. de maravella. Frec.: maravilloron 1: 0,00227.

maridada] adj. f. 'casada': et cómo los franceses fazían todos días diversos males, grenges et desonores, assi en desflorar virgines et desmaridar mulleres maridadas et forçar mullers biudas 36.193. Etim.: del lat. MARITARE 'casar'. Comp. cat. y occ. (prov.) maridar 'casar' (FABra; Levy, s. v.), prov. maridado (Mistral, Tresor, t. II, p. 279), gasc. maridá 'marier' (FoIx, p. 418, s. v.), fr. marier 'casar', marié 'casado' (Petit Robert, s. v.); cast. ant. maridado 'casado' en Berceo, Calila, J. Ruiz, y en el Romancero; Aut. advierte que sólo se emplea festivamente (DCECH, III, 853; DME, p. 1361). Comp. cat. maridar 'casar a una mujer, darle marido': dona maridada 'mujer casada' en doc. en cat. de 1381 (DECLIC, V, p. 490; DCVB, t. 7, pp. 248249). El DRAE, 1970, recoge maridar 'casar o unir en matrimonio'. Véase un ejemplo de maridada 'casada' en arag. med.: «La madre por ventura cobdicia seyer maridada〉 (Epístola de San Bernardo, s. XV; RIERA, 1982: 135). Frec.: maridadas 1: 0,00227.

marido s. m. 'marido': la quinta bubo nombre dona Violant et fue muller del fillo del princep de la Morera [Morea N] et de Taranto, la qual prisso otro marido depués de aquéll 38.434. Del lat. MARITUS. Frec.: 8: 0,01818.

marina] s. f. 'astillero, atarazana', 'zona costera, terreno junto al mar'?: con XX galeras que eran armadas en las marinas suyas 38.503. En la VC: ab XX galeras qui eren armades en les marines sues, VC p. 172. Etim.: del adj. lat. MARINUs, -A, -UM 'propio del mar, relativo al mar, marino, marítimo’. Comp.: «que quatre derassenals ordenàs en les sues marines, qui fossen daressenals Sabuts» (Crònica de Ramón Muntaner, Barcelona, Barcino, 1927-1952, p. 36). Pero aquí parece que tiene el sentido de 'costas'. Y en general ese es el sentido que tiene tanto en cat. como en cast. Cfr. cat. marinatge 'art de navegar' (FABRA, Dicc., s. v.); cat. la marina 'zona al llarg de la costa', 'país al llarg del mar'; cat. ant. amarinar 'guarnir de tripulació, proveir-la de navegants' (DECLLC, V, 461, 462). El DCVB, t. 7, p. 250, s. v. marina, da entre otros los siguientes significados: «1. 'ofici de mariner; art de navegar, i conjunt 
de vaixells i dels homes que hi treballen'; cast. marina. / 2. 'extensió de terra contigua a la mar'; cast. marina, costa». Frec.: marinas 1: 0,00227.

marqués s. m. 'marqués': el uno bubo nombre don Ferrando, qui fue marqués de Tortosa 39.17. Etim.: deriv. de marca, aunque posiblemente tomado del occ. ant. marqués, originariamente 'jefe de un territorio fronterizo' (DCECH, III, p. 845). Sobre la etim. de marca vid. comarca. Frec.: 4: 0,00909.

marquesado s. m. 'título o dignidad y territorio que corresponde a un marqués': el mayor, havía nombre don Ferrando, del marquesado de Tortosa et de la ciudat de Albarrazin 39.38. Deriv. de marqués. Frec.: 4: 0,00909.

mas conj. advers. 'mas, pero, sino': el qual regió su tierra / non/ assí como rey mas assí como a tirano 38.618; vino grant [contra $\mathrm{N}]$ el dito rey et sus gentes, mas Dios ayudando [a los christianos añade $\mathrm{N}$ ], con grant deshonor et vinció et con más mortaldat que la primera vegada, tristos et dolentes sen tornoron. 38.373. Frec.: 121: 0,27503.

más adv. de cantidad 'más': por tal que sia más plazient de leyr 2.2; porque más dio en su vida que rey del mundo 37.3; Encara más, que empués días del rey don García de Navarra cobrás aún Calasanæ, Cadreyta et Valtierra 20.281. Del lat. MAGIs 'más'. Frec.: 12: 0,02728.

masclo adj. 'masculino, macho, de sexo masculino': et por tal como el dito regno en defallimiento de heredero masclo pervino a conte de Barchinona por ajustamiento matrimonial 21.2-3. Etim.: del lat. MASCulus 'íd.', propiamente diminutivo de MAS, MARIS 'macho, carnero padre' (BDELC, p. 372; DCECH, III, p. 747, s. v. macho). En cast. macho. En arag. mod. masclo (ANDOLZ, s. v.; RoHLFS, DDPA, s. v.). El EBA (1999: 1239) registra masclo en Bal de Chistau, Bal de Bielsa, Caspe, Puebla de Hijar y Binéfar; mascllo en Fonz, Alta Ribagorza, Chuseu y Torres del Obispo. Cat. mascle (FABRA, DGLIC, s. v.), occ. mascle (Alibert, s. v.). También existe en arag. mod. la variante masto 'animal macho' (Andolz, s. v), que según Rohlfs (DDPA, s. v.) es variante fonética de macho. El EBA (1999: 1241) registra masto en el Bajo Alcanadre, Sobremón, Borrés, Fuencalderas, Plasencia, Berdún, Ansó, A Buerda, Biel, Mundot, Luesia, Campo, Uncastillo, Bal d'Esca, Bielsa, Echo, Pandicosa, Plana de Uesca, Orós Alto, Guara Meridional, Buerba, Salas Altas, A Fueba, Biello Sobrarbe y Monflorite; o sea, es prácticamente general en el dominio lingüístico del aragonés. Para CoROMINAS (DCECH, III, 747) en el arag. masto ha habido despalatalización mascho $>$ mast,o $>$ masto. En el arag. de Fernández de Heredia lo más frecuente es masclo (s. 'male; adj. 'masculine'), pero también se registra mascho, masco (GiLkison, s. v.). Es habitual masclo 'macho, de sexo masculino' en arag. medieval. Así, por ejemplo, puede verse en $L M M$ (LIRIA, 1979: 181), en el VM (Tilander, 1956, III, p. 191), en el LT (Prince, 1995: 223; RodÉs, 2016: 740). Obsérvense también otros ejemplos: "Lexo de su generacion fillos masclos"; "El qual morio sin fillos masclos" (Letra intimada, 
1435). Directamente de MAS, MARIS proviene el arag. mardano 'macho de la oveja, carnero padre'. Frec.: 1: 0,00227.

matar v. tr. 'matar': et matólo porque el dito Pon₹ Guillem dixo un dia que con el su punnyo daría en las bariellas del dito conte 36.433; mas el dito virutoso rey con su valiente gent todos tiempo vincié aquella morisma baronilment et por todo un dia encalçando matoron aquella [hora grant gent añade N] incessanment 38.364. Etim.: probablemente, según Corominas-Pascual, de un lat. vg. *Mattare, deriv. de MATTUS 'estúpido, embrutecido', aunque se han propuesto otras etimologías (DCECH, III, pp. 878-879). García de Diego, en su DEEH (p. 261 y 788) propone como etimología el lat. MACTARE 'sacrificar', siguiendo al lingüista alemán F. Diez, Etymologisches Wörterbuch der romanischen Sprachen (Bonn, 1878). Frec.: matar 4: 0,00909; matan 1: 0,00227; matando 2: 0,00455; mataría 1: 0,00227 ; matarlo 1: 0,00227 ; mataron 1: 0,00227 ; matava 1: 0,00227 ; matavan 2: 0,00455; mató 10: 0,02273; matólo 2: 0,00455; matoron 7: 0,01591; matoronlo 4: 0,00909.

materia s. f. 'materia, tema': Et por tal como no es de nuestro propósito, lexemos esta materia et tornemos al dito rey Sancho 14.16. Cultismo tomado del lat. MATERIA. Frec.: 1: 0,00227.

matrimonial adj. 'matrimonial': etpor aquesti ajustamiento [ajuntamiento $\mathrm{N}]$ matrimonial [natural N] pervino la baronía de Montpeller a rey de Aragón 34.29. Deriv. de matrimonio con sufijo -al que forma adjetivos a partir de bases nominales, los cuales expresan pertenencia o relación con la base (PhARIEs, 2002: 57; Colomina, 2017: 15-20). Frec.: 2: 0,00455.

matrimonio s. m. 'matrimonio': el dito rey don Remiro, queriendo proveyr que enpués días suyos dissensión alguna non avies en la succesión del regno de Aragón, si fue tratado matrimonio con don Ramón Berenguer comte de Barchinona 20.253. Tomado del lat. matrimonium. Frec.: 5: 0,01136.

maturidad s. f. 'madurez, buen juicio, prudencia, sazón o buen punto que se logra por la meditación y la reflexión sobre un asunto o idea'; o quizá 'celeridad, prontitud': ... que le diesse licencia de salir del Orden, la qual licencia el Papa con grant deliberación et maturidad la dio 20.71. Etim.: deriv. del lat. MATURUs 'maduro' (DCECH, IV, 760). MATURITAS, -ATIS 'madurez, sazón, perfección'; 'prontitud, celeridad' (BLÁNQUEZ, s. v.). Frec.: 1: 0,00227.

mayo s. m. 'mayo, mes de mayo': et aquesti mismo mes de mayo, el dito don Alfonso partió de la ciudat de Barçalona con XX galeras 38.494. Del lat. (MENSIS) MAIUS. Frec.: 4: 0,00909 .

mayor (var.: maior) adj. 'mayor': et la maior ciudad d'aquella provincia [es clamada añade N] Yspalis, la qual boy a nombre Sivilia 1.19; assi como don Sancho el Mayor las avia departidas 20.166; pero él, queriendo seguir lo que avía prometido dezía que non 
dubdassen, que los mayorales [mayores $\mathrm{N}$ ] et mellores con él eran 38.250; talló todas las colles mayores que yeran en el huerto 20.115. Del lat. MAJOR, -ORIS. Frec.: mayor 22: 0,05000; maior 1: 0,00227; mayores 6: 0,01364; mayorales 1: 0,00227.

mayorment adv. 'mayormente, principalmente, especialmente': de la qual elección todo el regno fue alegre et pagado mayorment como [supieron que añade $\mathrm{N}$ ] simient de virtuosso princep avíen elegido por sennyor lur 36.724; como buen rey, quirie mas haver guerra con los moros que non con los christianos, maiorment pues con grant honor et victoria aviase vengado del rey de Castiella, fizo paz et tregua con él. 17.53. Frec.: mayorment 2: 0,00455; maoirment 1: 0,00227.

me pron. pers. átono de $1 .^{a}$ pers. caso dat. y acus. 'me': «Agora yes ora quando se yes partido; si Dios me ayude, grant desonor es de mi et de vosotros» 38.333; «Sennyor Dios, tu seas deffendedor et guarda del poblo que mas [me has $\mathrm{N}$ ] livrado por regin» 35.241. «Sennyor, datme letras de creyença pora el rey de Granada» 36. 387. Frec.: 12: 0,02728.

meanero adj. 'intermediario; mediador': la qual cosa el dito rey don Jayme, meanero Nuestro Sennyor Dios, conosció sotilment 38.51; porque razonable cosa yes que de aquesti y de sus succedidores que sin meano [meanero N] regnaron en Aragón, coronicas fagamos sin ninguna otra adición 15.8. Deriv. de meano < lat. MEDIANus 'que está en medio'. Comp. meado 'mediado' en FA, p. 473; meiano, meyano 'mediano', 'intermedio' en VM, III, p. 199. En cambio, medianero en Fernández de Heredia (GiLkison, s. v.). Comp. nav. mejana 'isla que se forma en medio del río’ (IrIBARREN, 1984: 343; aunque dice que es «voz árabe», procederá del lat. MEDIANA). Frec.: meanero 1: 0,00227; meano [meanero] 1: 0,00227.

medio] adj. 'medio': a media nueit partióse de Pamplona et fuesse al monesterio de San Salvador de Leyre 20.196 // media, medio adv. 'en medio': «todo homme que aquesto diga miente aulement et falsa por media [medio B] de la barba» 38.320; fizo parellar sus compannas et dio la delantera a su hermano... et en la de medio fue don Ferriz. 18.35. Del lat. MEDIUs 'medio'. Frec.: medio 2: 0,00455; media 3: 0,00682.

mellor (var.: millor) adj. 'mejor': et dioles un buscage Averico [avetito VL] do pudiesen fer paxer lur ganado e millor sostener lur vida 11.41; porque assi era enpresso en los capitoles de la paz dessuso dita por mellor aquélla observar 38.114; pero él, queriendo seguir lo que avía prometido dezía que non dubdassen, que los mayorales [mayores $\mathrm{N}$ ] et mellores con él eran 38.250; et seyendo electo de bueno en millor puyando según merecía, fue electo en ovispo de Burgos 20.79. Del lat. MELIOR, -ORIs. Las formas mellor y millor son habituales en arag. med.: véase en $\operatorname{los} D L A A$ (REIDy FriTz, 1977: 199, s. v. mellor), en el arag. de Fernández de Heredia (GILKIson, p. 90, s. v. millor), en el $V C A$ (p. 247 y 253), etc. Véase en este ejemolo: «por via e manera de esquesta o secreta informacion o como millor visto lis sera» (doc. de Jaca de 1417; EAMJM, p. 51). Se conservan en el arag. mod.: MonEva (2004 [1924]): registra milló en Ribagorza; el EBA (1999: 1271) documenta millor en Pandicosa, Plana de Uesca, Casbas, Biello Sobrarbe, Bal de Bielsa, Mundot, 
Torres del Obispo; Andolz (1992), mellor en Panticosa y milló en Benasque y Campo. GonzÁlez Guzmán (1953: 36), refiéndose a la evolución lat. -LI$>$ arag. -ll-, comenta: «En el barranco del Estarrún [es decir: valle de Aísa] domina la solución castellana, aunque no falta la solución palatalizada y en palabras de tan abundante comercio lingüístico como mellor $<\mathrm{m}$ e $\mathrm{l}$ i o o r e y cullar < c o c h 1 e a r e». Frec.: mellor 8: 0,01818; millor 9: 0,02046.

mellorar] (var.: millorar) v. tr. 'mejorar': et a honor de Dios et de San Johan Bautista crecieron et melloraron la dita eglesia 9.16; et milloró su patrimonio bien por las dos partes 38.445. Deriv. de mellor millor. Frec.: melloraron 1: 0,00227; milloró 1: 0,00027 .

melodía] s. f. 'melodía': et con grandes cantos et melodias divinales et con grant contrición de coraçón, bumilmenty devota, translataron los cuerpos del desus dito Sant Johan beremita 9.19. Cultismo tomado del lat. tardío MELODIA, y éste del griego $\mu \varepsilon \lambda \omega \delta\llcorner\alpha$. La 1. ${ }^{a}$ doc. en castellano que da el DCECH, IV, p. 26, es de 1449 en Santillana. La Crón. SJP. la adelanta en casi 70 años. Frec.: melodias 1: 0,00227.

memoria s. f. 'memoria': la qual avinienca concordada et en escripto perpetua memoria metida publicoron 20.167; et pregó a su fillo don Pedro que avies memoria de la suya ánima 35.287. Frec.: 6: 0,001364.

menacar] v. tr. 'amenazar': menacando quel dito rey de Castiella se levantara [se levantas N] del dito sitio et sen tornás a su tierra 38.378. Deriv. de menaza. Frec.: menacando 1: 0,00227 .

menaza] s. f. 'amenaza': mas el dito rey por menazas de ninguno ni en otra manera non se quiso levantar del dito sitio 36.326. Etim.: del lat. vg. MINACIA, deriv. del lat. MINAE, -ARUM 'amenazas' (DCECH, I, p. 242; BDELC, s. v. amenaza). Comp. fr. menacer, it. minacciare (DCECH, I, 242). Se documenta menaza 'amenaza' menazar 'amenazar' en Fernández de Heredia (Tucídides, p. 211; GILkison, p. 88); también en el LT (RoDÉs, 2016: 741). En arag. mod. se documenta menazar en el Somontano (NAGore, 2000: 557) y en la Sotonera (GARCÉs, 2005: 230). En cat., en cambio, amenaçar y amenaça, aunque tb. se doc. como formas antiguas menaça y menaçar (DCVB, s. v., t. I, p. 616).

mención s. f. 'mención', en la per. vnl. fer mención 'mencionar': muytos fillos que por engendrament de dreyta linea non son anotaderos nin cal fer memoria nin mención de aquéllos 36.34. Cultismo tomado del lat. MENTIO, -ONIS. Frec.: 1: 0,00227.

menester (var.: mester) s. m. 'necesidad' // adj. 'necesario, preciso'; se usa en las loc. verbonominales aver menester 'necesitar' (tr.) y seer menester 'hacer falta, ser necesario' (impers.): prometiole de ayudar do lo buvies menester 18.78; que defendiesen bien el regno de Castilla que lo avía grant menester de los moros 19.139; pero quando contó la manera que havía visto, pensó en si mesmo quel huerto podía seer el su regno, las colles yeran las gentes del su regno, et dixo: «Por fer buenas colles, carne y a menester». 
20.123; et enantes los pudiessen aver et de aquellos servir quando menester les fuesse 14.34; ayas merce dellos quando les será mester [menester B N], 35.267; fizo reparar et endreçar aquella porque bien yera mester [y hera menester $\mathrm{N}]$, que toda era cremada et derrocada. 36.690-691. Etim. del lat. MINISTERIUM 'servicio', 'empleo', 'oficio', derivado de MINISTER, -TRI 'servidor', 'oficial'. Como indica COROMINAS, en lo antiguo es común la forma mester (por ej. en Berceo, Alex., etc.), debida a la confusión de los parónimos MINISTERIUM y MYSTERIUM. La génesis semántica es fácil de comprender: es menester valía propiamente 'es servicio', 'es útil' y de ahí 'es preciso'; a base de ella se creó haver menester, que ya aparece en el Cid (DCECH, IV, p. 37). Frec.: menester 5: 0,01136; mester 2: 0,00455.

menor adj. 'menor': et murió devotament estando freyre menor. 38.452; et todos los monesterios de los menores et de los predicadores de todos sus regnos 35.191. Del lat. MINOR, -ORIs. Aquí, en los dos ejemplos, parece que se refiere a "franciscano", es decir, 'integrante de la Orden de los Hermanos Menores o Franciscanos'. El DLE (2014: 1445, s. v. menor), da como quinta acepción 'franciscano'. Frec.: menor 1: 0,00227; menores 10: 0,02273.

menos adv. 'menos'. Se utiliza exclusivamente formando parte de las siguientes loc: menos de loc. prep. que tiene un matiz de resta o exclusión, aproximadamente equivalente a 'sin' o 'sin contar': porque se tornoron menos de recaudo al dito rey en Berbería 36.180 [menys de recapte VC, p. 133]; hedificaron hi dos altares mens [menos $\mathrm{N}$ ] de aquéllos qui ya eran constituidos 9.29. [menys d'aquells VC, p. 38]. Se trata de una locución usual en arag. med.: «E si el homenage será feyto con carta publica, bien puede seer demandado e destreyto e pendrado e, si es feyto menos de carta e puede seer provado con dos leales testimonias, bien puede seer demandando e estreyto e pendrado» (FAM, $\mathbb{S}$ 272, p. 142). «Et los ditos sotzcolljdós requerjón a mj, notario, que no carrase la carta menos de su respuesta» (MDF, 355.19). Igualmente se registra en el arag. de Ferrández d'Eredia (GILKISON, 1984: 88) // non res menos res non menos 'asimismo, también, además, igualmente': que avies sueltament sin contradicción el dito regno de Sezilia et res non menos que por ningún tiempo non se nombrasse rey 36.257-258; los ditos arcevispos poblicoron la paz dessuso dita et non res menos absolvieron el dito rey don Jayme 38.106-107. También esta locución es de uso habitual en aragonés medieval: «Et res no menos damos poder al dito procurador» (CAC, 1406; p. 71). En las obras de Ferrández d'Eredia: no res menos 'nonetheless, even, what is more' (GILKISON, 1984, s. v. menos). La loc. no res menys está bien atestiguada en cat. med. (DECLIC, VII, p. 273). Frec.: menos 9: 0,02046.

menoscabo s. m. 'merma, detrimento', 'disminución, deterioro, descrédito'; 'perjuicio, daño’: porque él faría por guisa que su regno non havría [algún añade N] menoscabo por la su venida 38.258. Etim.: compuesto sobre menos < lat. MINUs. 
Parece ser postverbal de menoscabar, que supone un lat. vg. *MinusCapare, deriv. de MINUS CAPU(T) 'persona privada de los derechos civiles' (en lat. cl. MINOR CAPITE) (DCECH, IV, p. 40, s. v. menos). Se doc. menoscabo ya en Berceo. En cat. menys capte < MINUS CAPITE (ibídem). Frec.: 1: 0,00227.

menospreciar v. tr. 'menospreciar, despreciar, desdeñar': «Sennyor verdadero todo poderoso, fet hi nos menospreciar las prosperidades d'aquesti mundo» 35.238. Es compuesto de menos y preciar. Frec.: 1: 0,00227.

menosprecio s. m. 'menosprecio, desprecio': et por la soberbia et menosprecio que don Per Artarés, non seyendo encara rey, fazía a los del regno 20.15. Postverbal de menospreciar. Frec.: 2: 0,00455.

mentir] v. intr. 'mentir': «todo homme que aquesto diga miente aulement [vilment $\mathrm{N}$ »], 38.320. Del lat. MENTIRI. Frec.: miente 1: 0,00227.

menudo adj. 'pequeño', 'de poca importancia': con LX galeras, XXIII naves et muytos de otros navilios menudos 38.508. // En el sintagma gent menuda 'gente modesta, sencilla, humilde, común, plebeya, no perteneciente a la nobleza': et firo muyto de bien a la gent menuda 36.237; et la ora todos los nobles et cavalleros et la gent menuda del dito condado obedieron al poder del rey de Francia. 36.507. Del lat. MINUTUS, p. p. de MINUERE 'rebajar, disminuir' (DEEH, p. 814; BDELC, p. 391). Recoge el $D R A E$ (1970), s. v. menudo, 3. acepción: 'plebeyo o vulgar'; el DLE (2014) registra como 3. acepción de menudo 'despreciable, de poca o ninguna importancia' y como $4 .^{a}$ acepción 'plebeyo o vulgar'. // Se encuentra también una vez en la loc. adv. a menudo 'muchas veces, frecuentemente y de forma continuada': et el dito rey don Pedro qui no les era luent adiesso et fuert a menudo firía en ellos et matava ende tantos que era maravella 36.624. Frec.: menudo 1: 0,00227; menudos 1: 0,00227; menuda 2: 0,00455 .

mercadero s. m.'mercader, tratante, negociante': el dito rey fuert secretament con Jayme alias Domingo de la Figuera, mercadero de Calatayut de cavallos [...], cuytadament vino al dito lugar, es assaber en Bordeu 36.273. Deriv. de mercar < lat. MERCARI 'comprar'. Frec.: 2: 0,00455.

mercado s. m. 'mercado, sitio público destinado al comercio': de la part de la val de Aragón cumplieron entro Verdún et cremoron el mercado 36.354. Del lat.

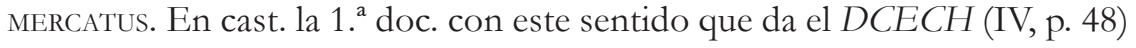
es de 1495 (Nebrija). Frec.: 1: 0,00227.

merce (var.: mercet) s. f. 'merced, gracia, tratamiento especial, favor, misericordia, compasión': «sepas que yo me vo a Dios mi crehador qui me avrá merce por la su misericordia» 35.254; con consello de algunos barones misose ell et la tierra sueltament en poder del dito rey clamando mercé bumilment. 36.444; e consellaronle los ricos ommes que le fizies bien e mercet, e assí lo fizo 19.94 // a merçé 'a merced, a voluntad, 
dependiendo de una fuerza ajena': de los moros a merçé ninguno non prendían 18.47 // sin mercé 'sin remisión, sin compasión': todas las fuerças derrocando et los christianos matando et cativando sin mercé. 4.31. Etim.: del lat. MERCES, -EDIS 'paga, recompensa', deriv. de MERX, -CIs 'mercancía'. Según explica Corominas en el DCECH (IV, 48), fue «de uso general desde los orígenes del idioma literario, pero su empleo en la fraseología religiosa y cortesana hizo que el vocablo pasara al castellano en forma semiculta; de otro modo la - $d$ se habría perdido, como en pie o fe. La forma mercé sólo la conozco en aragonés antiguo (vid. Tilander), a no ser en hablas vulgares modernas, donde es reducción fonética de tipo general». En efecto se encuentra mercé en $V M$ (III, p. 196), pero también en el arag. de Fernández de Heredia (GILKIISON, s. v.), en FA, p. 478, en los DLAA (Reidy Fritz, 1977: 200), en el LT (Prince, 1995: 223; RoDÉs, 2016: 742), en el VCA (p. 250), etc., de manera que puede decirse que es forma general en aragonés medieval. Frec.: merce 11: 0,02500; merçé 1: 0,00227; mercet 2: 0,00227.

merecer] v. intr. 'merecer': et seyendo electo de bueno en millor puyando según merecía, fue electo en ovispo de Burgos 20.80. Del hispano-lat. * MERESCERE, deriv. del lat. MERERE (DCECH, IV, p. 49). Frec.: merecía 2: 0,00455.

mérito s. m. 'mérito': et por mérito de aquesta reyna Dios le fizo muytas gracias 34.70. Tomado del lat. MERITUM. Frec.: 1: 0,00227.

mes s. m. 'mes': En el anno de Nuestro Sennyor M LXXXVIII', en el mes de mayo, el dito rey edificó el monesterio de Montaragón 17.88; et asitió la dita diudad de Huesca, et aquella tuvo asitiada con gran traballo et lazerio VI meses, es assaber, mayo, junio, julio, agosto, setiembre et octobre. 18.7. Del lat. MENSIs. Frec.: mes 10: 0,02273; meses 3: 0,00682.

mesagería s. f. 'mensaje, embajada', 'acto de transmitir un mensaje por medio de un mensajero'; 'comisión, encargo': envió otro mensagero al emperador don Alfonso de Castiella por la dita mesagería que yva don Caxal 20.245; como el comte Julian, sosmeso del sito rey Rodrigo, fues ydo por mesagería al rey Aboali moro por afferes del dito rey 3.81. Deriv. de mesage, del occ. messatge < lat. Missaticu(M). Frec.: 3: 0,00682.

mesagero (var.: mensagero, misagero) s. m. 'mensajero': Enpués esto, el rey don Remiro de Aragón envió otro mensagero al emperador don Alfonso de Castiella 20.244; et fue por legado et mesagero ordenado don Caxal 20.217; denunció el rey de Castiella con sus misageros al rey de Aragón 38.381. Etim.: deriv. de mesage, del occ. messatge, que procede del lat. vg. *MISSATICU 'mensaje', deriv. de missus 'enviado', p. p. de mitTERe 'enviar', 'soltar', 'arrojar, lanzar'. Podría provenir igualmente del fr. message o del cat. missatge. Comp. it. messaggio. En arag. mod. perdura esta voz en la forma mesache, misache con el significado de 'muchacho, mozo, hombre joven', y en fem. mesacha, misacha 'muchacha, chica, mujer joven'. Es prácticamente general en el Alto Aragón: vid. Andolz, s. v.; RoHLFs, DDPA, s. v.; DECLIC, V, p. 654; EBA, 1999: 1261-1262 y 1278. Se explica porque el vocablo medieval 
mesage se aplicó por metonimia además de al 'mensaje' al 'mensajero'; de ahí 'mozo (que lleva mensajes, encargos)', que se generalizó con el significado de 'muchacho' en aragonés. Pero, por otro lado, surgió ya en arag. med. el deriv. mesagero, que también existe en otras lenguas románicas: fr. messager, occ. mesatgier (LEVY, s. v.), cat. missatger. En cast. ya desde muy pronto se propaga la nasalidad y se crea mensaje (ya en Cid) y mensajero (vid. para todo esto DECLIC, V, pp. 653-654; DCECH, IV, p. 60). Frec.: mesagero 3: 0,00682; mesageros 14: 0,03184; misageros 1: 0,00227.

mescladament adv. de modo: 'mezcladamente, de forma mezclada': porque se convenía que de todos mescladament favlasemos entro [troa $\mathrm{N}$ ] agora 15.4. [per què es convenia que de tots més clarament parlàssem entrò ara. VC, p. 55]. Teniendo en cuenta la redacción de la VL: vnde congrumm fuit quod de ommibus mixtim loquti fuerimus usque modo (VL, p. 48), donde mixtim 'en mezcolanza', y teniendo también en cuenta el contexto (hasta entonces en la Crón. SJP. se ha hablado de los reyes de Navarra y de los condes de Aragón conjunta y mezcladamente), hay que concluir que el error está en la VC y que este error demuestra que al menos el capítulo xv se tradujo al catalán desde la versión aragonesa, y no desde la versión latina: el error sólo se puede explicar a partir de mescladament (a més clarament), no de mixtim. Frec.: 1: 0,00227.

mesclar] v. tr. 'mezclar': et mescladas las unas galeras con las otras, tan fuert batalla bi fue feita... 38.268; por consello de algunos, los governadores fueron mesclados et mesturados con el rey 35.50; el dito Carlos se firo nombrar rey de Aragón et mescló su sennyal con el del rey de Aragón 36.465. Etim.: del lat. vg. *MISCUlare, deriv. del lat. misCere 'mezclar' (BDELC, p. 395, s. v. mezclar, DCECH, IV, p. 9). Tb. mesclar en cast. ant., port. y cat. (DEEH, p. 815). La forma mesclar es habitual en arag. med.: así se encuentra en FA, p. 479; VM, III, p. 197; en Fernández de Heredia (GILKISON, s. v.), etc. También en cast. med. (vid. DCECH, V, p. 9; DME, p. 1387). Para el cat. mesclar vid. $D C V B$ (t. 7, p. 382). Frec.: mescladas 1: 0,00227; mesclados 1: 0,00227; mescló 1: 0,00227.

mesmo adj. 'mismo'. Vid. mismo.

mesquino] adj. 'pobre, desgraciado, infeliz, miserable, desdichado': assí que los mesquinos non sabian a qual parte se acorriessen 36.640. Etim.: del árabe MISKIN 'pobre, indigente' (BDELC, p. 395; CORRIENTE, 2003: 389). Se registra mesquino 'miserable, mezquino', 'pobre' en TILANDER (FA, p. 479); mesquinadament 'mezquinamente, avariciosamente' en VM (III, p. 197); mesquino, mesquino, mezquino y misquino 'miserable, pobre, infeliz, ruín' en Fernández de Heredia (GILKISON, s. v.). En la Crón. SJP. el sentido es 'infeliz, desgraciado'. Pero en el arag. del siglo XIV es todavía usual con el sentido de 'pobre, indigente': «qui fues adevino non sería mesquino» (refrán arag. del s. XIV; Rius, 1926: 372). El sentido etimológico es 'pobre indigente' (se doc. hasta el s. XIII o xIV, tanto en cast. como en arag.). Pronto pasa a 'desgraciado, miserable'. La acepción moderna 'escaso, miserable, 
avariento' se documenta desde med. del s. XvI (en el Lazarillo; normal desde el Siglo de Oro). Es arabismo común a todos los romances de Occidente (fr., occ., cat., it.) (DCECH, IV, p. 63). El DRAE (1984) aún recoge mesquino como forma ant. equivalente a merquino, e igualmente el DLE (2014), que da mesquino como desusado y remite a mezquino. Frec.: mesquinos 1: 0,00227.

mester. Vid. menester.

mesturado] adj. 'mezclado': por consello de algunos, los governadores fueron mesclados et mesturados con el rey 35.50. Adj. procedente del part. del v. mesturar 'mezclar', deriv. del lat. mixtura 'mezcla', deriv. de mixtus (p. p. de miscere). Comp. cat. mestura 'mestall' (= 'mescla de blat i sègol'), mesturar 'mestallar' (= 'mesclar, barrejar') (FABRA, Dicc., s. v.); arag. mod. mestura 'trigo mezclado con centeno' (Andolz, s. v.), mistura 'centeno' (Arnal Cavero, s. v.; Andolz, s. v.). El EBA (1999: 1263 y 1279) registra mestura 'centeno' en Sobrarbe, Sobremón, Biescas, Panzano y 'mezcla de trigo y centeno' (o 'pan hecho con esa mezcla') en 'Tardienta, Uncastillo, Bal de Chistau, Bielsa, Monflorite, Benás; mistura ‘centeno’ en Radiquero, Uncastillo, Semontano, Angüés; en el valle de Bielsa mistura 'pan hecho con trigo mezclado con centeno'. El DLE (2014) registra mestura 'mezcla rara de cosas muy diferentes' con marca diatópica de Aragón. En occ. (lang.) mestura 'mixture, mélange; méteil; pain de méteil' (Alibert, s. v.). En fr. méteil 'seigle et froment mêlés qu'on sème et qu'on recolte ensemble', del lat. pop. *MisTiLium, del lat. MiXTus 'mezcla' (Petit Robert, s. v.). En cast. ant. mestura. Se registra mestura, mesturar y mesturador en Alex. (SAs, p. 398). Igualmente, mesturar en Berceo. Parece que de 'mezclar' pasó a 'calumniar' y de ahí a 'revelar, denunciar'; la misma evoluc. en el sentido de halla en el fr. ant. mesler, oc. mesclar (DCECH, IV, p. 10). ANDOLZ cita mesturar (ant. doc.) 'delatar a alguien; acusarle de haber cometido algún agravio contra el monarca'. Pero no registramos este significado en FA, ni en $V M$, ni en LT. En definitiva, mesturados no es sino p. p. de mesturar 'mezlar'. Frec.: mesturados 1: 0,00227.

meter v. tr. 'poner': et la división destos regnos fue metida en el monesterio de Sant Johan de la Pennya 20.170; aquesti rey Alfonso metie su amiztat con don Alfonso 37.41; con consello de algunos barones misose éll et la tierra sueltament en poder del dito rey 36.443. / / v. prnl. 'meterse, entrar': et metiósse a la orden de los menores et lexó el condado a su fillo 36.436. / / Úsase además en las locuciones verbonominales meter mano 'hurtar, desvalijar, despojar': metió mano a los santuarios e yglesias e monesterios 19.147-148) y meter fama 'divulgar, hacer correr un rumor': metiendo fama que una campana quería fazer en Huesca 20.125. Etim.: del lat. MITTERE 'enviar', 'soltar', 'arrojar', 'lanzar' (BDELC, s. v.). Véase algún ejemplo en arag. med.: «Encara se deven catar de más los ricos omnes que en las honores que tienen que no y metan fueros nuevos ny costunpnes ni no fagan fuerças 
ni destrectos ni pedidos» (FAM, \271, 271, p. 142). «me obligo de meter dozientos soldos dineros jacceses de mellyora» (MDF, 167.10). El uso de meter 'poner' continúa hoy vivo en el Alto Aragón (ANDolz, s. v.; DDPA, s. v.; EBA, 1999, s. v.). Frec.: mete 1: 0,00227; meter 4: 0,00909; meterlo 1: 0,00227; metía 2: 0,00455; metíanse 1: 0,00227; metida 4: 0,00909; metido 4: 0,00909; metié 1: 0,00227; metiendo 2: 0,00455 ; metieron 1: 0,00227 ; metieronla 1: 0,00227 ; metieronle 1: 0,00227 , metió $8: 0,01818$; metiose 2: 0,00455; metiosse 2: 0,00455; miso 2: 0,00455; misose 2: 0,00455.

meytat s. f. 'mitad': et tiroron ne la meytat de la torre et en la otra meytat, fincó el alcayde 36.340. Del lat Medietate(M). Frec.: 2: 0,00455.

mi pron. pers. de $1^{a}$ pers. con prep.: «que tu ames los tus barones, cavalleros et las tus fieles gentes qui han a mi amado coralment» 35.265; «si Dios me ayude, grant desonor es de mi et de vosotros» 38.333 // adj. poses. de $1^{a}$ pers. y un solo poseedor: a la reyna natural mi seynora cuya hera, 19.86; que mi sennyor el rey d'Aragón se yes levado lealment et assí como devía 38.322; en testimonio de mis parients et vasallos presents aqui qui aquesto vieron 12.34. Frec.: mi 14: 0,03182; mí 2: 0,00455.

miedo s. m. 'miedo': qui por medio [miedo $\mathrm{N}$ ] de los arabes passava por Alava (error por miedo) 14.13; et que non avies miedo de res porque non yva por occuparle su tierra 38.237. Del lat. METUs 'íd'. Frec.: 8: 0,01818.

miembro] s. m. 'miembro': et havía muyt bella persona et grant et los miembros suyos muy maravellosos et concordantes et muy bello de persona 32.6. Del lat. MEMBRUM 'íd.'. Frec.: miembros 1: 0,00227.

mientre adv. 'mientras': et mientre que de la tutoría el dito don Phelip ussava, en la tierra suya se movió grant discordia 38.610 (usualmente aparece en la loc: mientre que). // de mientre 'mientras': yo so aquel qui de mientre passava por la val do murió, vi la criatura qui sacó la mano por la ferida del vientre de su madre 12.32. De la combinación del lat. hablado DUM 'mientras' + INTERIM 'entretanto'. Actualmente, arag. mientres (Andolz, 1992: 291; EBA, 1999: 1369). Véase en este refrán: «Marzelo, mientres lo mandas, fe-lo» (RFDE, p. 91). Frec.: 27: 0,06137.

miercoles s. m. 'miércoles': el dito don Alfonso buvo grant et sobrera batalla con los enemigos el Miercoles de la Cenisa en el anno de Nuestro Sennyor MCCCXXIII 38.531; rendió su anima a Dios en la ciudat de Barchinona, en día miércoles a la hora de media tercia 39.43. Abreviación de MERCuri [DiEs] 'día de Mercurio' (DCECH, IV, p. 72). Frec.: 2: 0,00455 .

milia adj. num. 'mil': Exalçó el nopmbre de Ihesu Christo en las tierras que conquistó [e edificó $\mathrm{N}]$ bien dos milia yglesias. 35.188. Del lat. MILIA, pl. de MILLE 'mil'. Cfr. mil, mill. Frec.: 1: 0,00227.

mill (var. mil) adj. num. card. 'mil': avía dentro en la ciudat XX mil moros 32.20; do murieron de los enemigos bien mill CC bomes 38.536. Del lat. MILLE 'mil'. Frec.: mill 12: 0,002728; mil 5: 0,01136. 
millessimo] adj. num. ord. 'milésimo': en el anno de Nuestro Sennyor MCCXIII, era millessima CCLII 34.168. Frec.: millesima 2: 0,00455.

millor adj. 'mejor'. Vid. mellor.

mio pron. poses. 'mío': «et livrote la mia sennyoría con la qual te dé Dios victoria» 35.262; et han metido el corazón et ell aver al servicio de Dios et mio» 35.266; «fillos otros mios, al verdadero Dios vos comando» 35.276. Frec.: mio 6: 0,01364; mios 1: 0,00227; mia 2: 0,00455.

miraglo (var.: milagro) s. m. 'milagro': por el qual milagro a honor de la bien aventurada Virgen Madre nuestra sennyora Santa María dio gran trasoro por bastar la yglesia de Valverde 35.221; et en esto manifestó miraglo Nuestro Sennyor Dios 38.545; porque miraglos firo Dios en su vida et depués su muert 34.71. Del lat. MIRACULUm 'hecho admirable'. Frec.: miraglo 3: 0,00682; miraglos 1: 0,00227.

miseria s. f. 'miseria, desgracia': et el dito rey, entendida la desolación et la miseria de los ditos sezilianos... 36.200. Cultismo tomado del lat. MISERIA 'desventura, desgracia'. Frec.: 1: 0,00227.

misericordia s. f. 'misericordia': el qual regió su tierra con grant justicia et misericordia luengament 38.633. Tomado del lat. misérícordía. Frec.: 5: 0,01136.

misericordioso adj. 'misericordioso': «a Dios misericordioso demando quel vos faga regnar luengament segunt la suya dreytura et la suya santa misericordia» 35.279. Deriv. del sustantivo misericordia, con sufijo -oso, que tiene valor abundancial. El BDELC y el DCECH (s. v. mísero) dan la 1. ${ }^{a}$ documentación de misericordioso en cast. en 1438. La presencia del vocablo en la Crón. SJP adelanta la documentación en arag. medio siglo. Frec.: 1: 0,00227.

mismo (var.: mesmo) adj.: fue electo en abad del monesterio de San Fagundo et Primitivo que yes en Castiella de aquella mesma orden de San Benedito. 20.78; de guisa que XIII richos hombres et otros cavalleros escabeçó ante que comiés, et avría todos los otros cavalleros assi mesmo descabeçados sinon por qual manera que fue que los sintieron que yeran de fuera et fuyeron 20.137; et lexó un lennyo armado por denunciar a las naves et al otro navilio que fiziessen aquella misma via 38.527; le fues dado curador fasta que por si mismo pudies regir su tierra 38.607; et fazían guerras entre si mismos 20.98. Del lat. vg. *MEDipsimus, de METipsissimus, forma enfática de IPSE 'el mismo, el propio' (DCECH, IV, p. 89; MGHE, pp. 182 y 259). Frec.: mismo 41: 0,09319; mismos 2: 0,00455; misma 1: 0,00227; mesma 1: 0,00227; mesmo 4: 0,00909.

missa s. f. 'misa': Et oyda su missa devotamente, pregó carament los ditos abad et clerezía del dito monasterio que [en $\mathrm{N}]$ lures oraciones et buenas obras lo deviessen haver por recomendado 11.43; Et tantost fizo celebrar misas por toda Catalunnya et por todos los regnos 38.15. Tomado del lat. missa, participio del v. MITTERE 'enviar', sacado de la fómula final del oficio religioso: ite, missa est. Frec.: misas 1: 0,00227; missa 2: 0,00455; 
missa cantano s. m. 'clérigo que está ordenado de todas las órdenes y celebra misa': Et seyendo aqui electo, non por codicia de honor mas por necessidat del regno, fue clamado por rey de Aragón por los del regno; otros dizen que yera missa cantano. 20.86. [Es un fragmento que sólo aparece en el ms. B; lo omite tanto la VL como el ms. $\mathrm{N}$ de la VA. En la VC no aparece porque el capítulo 20 está muy resumido]. Etim.: compuesto parasintético de missa y cantar. Con igual significado recoge el DRAE (1970) misacantano; tb. con la acepción más popular hoy: 'sacerdore que dice la primera misa', que comparte el cat. missa cantant 'el sacerdot que dice la primera missa' (FABRA, DGLIC, s. v.). Se documenta mjssacantano en FT (Gorosch, FT, p. 575). Se registra en las Ordenanzas de Huesca del año 1290 (R. del ARCo, RABM, 1913, p. 427), transcritas también por LALIENA (1988: 110): «Otrosi si moço o moça que venrra a comer et si personas foranas venrran a la boda o a la missa nueva, que ellos no paguen, et si el novio o el missacantano qui no levara los VI dineros del dia de la boda e los IIII dineros en otro dia de la boda daquellos que y comerán, que pague la dita pena de los C solidos sienes remedio ninguno». Frec.: 1: 0,00227.

missión (var.: messión) s. f. 'gasto, coste, expensas': empero todas aquestas cosas procuró Ispán vispo de Segorbe a missión suya propia et del sennyor d'Albarrazin. 35.23; et depués quel le ganaría el dito Imperio a messión de la Yglesia 38.156; don Sancho de Mallorquas le prometie ayudar con XX galeras a su missión propia, la qual cosa complió muyt bien 38.478. Del lat. missio, -onis. Es cultismo. El DRAE (1970) aún recoge misión 'gasto, costa o expensas que se hacen en una cosa' como antiguo; el DLE (2014), como desusado (acepción 10): 'gasto, costa o expensas que se hacen en algo'. Frec.: messión 1. 0,00227; missión 4: 0,00909 .

moço s. m. 'mozo, muchacho': el dito moço sacó la espada et mató al conde Salamón delant todos. 23.37 // adj. 'mozo, joven': Et después de aquesti regnó su fillo Recaredo et murió moso de muy poca edat 3.61. Etim.: Según Corominas es voz de origen incierto, quizá relacionado con el vasco motz 'rapado', palabra de creación expresiva (BDELC, s. v. mozo). La etimología propuesta por MEYERLÜBKe (REW, 5779) es el lat. Musteus adjetivo que tenía el significado de ‘dulce como el mosto' y de 'fresco, nuevo, reciente' (SEgura, 2001: 480). Pero Corominas argumenta que en ese caso el resultado fonético habría tenido que ser *moxo en Aragón (y también en gallogoportugués, donde, sin embargo, es moço): puede verse la extensa explicación en el DCECH (IV, pp. 172-175). Frec.: 9: 0,02046.

moment s. m. 'momento, instante': porque assin como la ariesta aplegada cerca el fuego en un moment crema, assin el dito rey don Ennego, sabiendo que los moros deviessen haver batalla con él, en un moment era con ellos 10.18-20. Etim.: del lat. MOMĚNTU(M) 'instante', 'movimiento' (BDELC, p. 405; DCECH, IV, p. 170). En cast. 
momento es cultismo por la no diptongación de la Ě. La $1{ }^{a}$ doc. que da Corominas para el cast. momento es de 1438. La Crón. SJP. adelanta esa doc. en unos 70 años. Aquí es, no solamente cultismo (por la no diptongación de la Ĕ), sino quizá tb. catalanismo (por la caída de la -o final). Frec.: 2: 0,00455.

moneda s. f. 'moneda', 'dinero': Et como don Alfonso avies estado grant tiempo en Castilla, mas de un ayno, fallir la moneda para pagar el sueldo a los aragoneses e navarros... 19.146; inhonesta cobdicia de meneda [moneda $\mathrm{B}, \mathrm{N}] 38.378$ (error por moneda); corronpido de grandes prometimientos de moneda por el rey Carlos 38.45. Etim. del lat. MONETA (DCECH, IV, 126). Común a todos los romances de Occidente. Comp. dineros 'monedas': y ofreció a honor de Dios e de los sanctos del dito lugar $D^{\circ s}$ dineros de argent 11.43. En dos ocasiones aparece en el ms. E meneda 38.309, 38.378 , pero en los dos casos aparece moneda en $\mathrm{B}$ y en $\mathrm{N}$, por lo que hay que entenderlo como un simple error de copia del ms. E. En ambos casos tiene el mismo significado de 'dinero': inhonesta cobdicia de meneda 38.378; como el dito letrado no avies complimiento de meneda 38.309 ('provisión de dinero'). Frec.: moneda 3: 0,00682; meneda 2: 0,00455 .

monesterio (var.: monasterio) s. m. 'monasterio': embió un mensagero al su monasterio de Sant Ponz de Tomeras 20.102; et retenía pora si la senyoría de todas las eglesias del su regno et sobre los monasterios de San Salvador de Leyre, de Sant Johan de la Penya et de San Victorián 20.289; et fue soterado muyt honradament en el monesterio de Santas Cruzes 38.631.

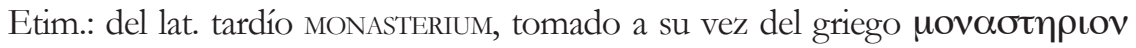
(BDELC, p. 401). De una variante vulgar MONISTERIUM (en relación con el lat. vg. MONICUS 'anacoreta, fraile') viene la variante antigua monesterio, casi general hasta el Siglo de Oro en castellano. De ahí tb. el cat. monestir, fr. ant. mostier, alem. münster, logud. ant. munister, etc. (DCECH, IV, 128, s. v. monje). En arag. generalmente es monesterio. En la Crón. SJP. aparece en 67 ocasiones con -es- y 17 con -as- (algunas de estas son erratas de imprenta de la ed. crítica que habría que corregir por monesterio). Frec.: monesterio 61: 0:13865; monesterios 6: 0,01364; monasterio 16: 0,03637; monasterios 1: 0,00227.

monge s. m. 'monje': los aragoneses tractoron que enviassen por don Remiro el monge 20.67; et que diriessen las oras a costumbre de monges negros 20.305. Etim.: tomado del oc. ant. monge 'íd.', que procede del lat. vg. MONICus, lat. tardío MONACHUs 'anacoreta,

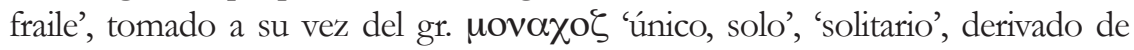

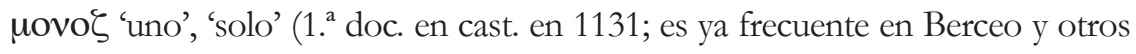
coetáneos, a veces con el sentido de 'ermitaño', como en latín). Aunque podría provenir del cat. ant. monge (hoy monje), más bien se tratará del oc. ant. monge traído por los de Cluny, formas que como el fr. moine se explican regularmente por la fonética de estos idiomas partiendo del lat. vg. MONICus (DCECH, IV, 128). Colón (1967: 181) considera el cast. monje como occitanismo tomado del occ. ant. monge, forma traída por los cluniacenses. Vid. también monche 'monje' en 
aragonés mod., considerado como occitanismo (NAGORE, 1994b: 147). Véase en este refrán: «U toz monches u toz canonches» (RFDE, p. 98; vid. también el mismo refrán en el Somontano, recogido por ARNAL CAVERO, 1953: 107). Frec.: monge 13: 0,02955; monges 7:0,01591.

mongía s. f. 'monacato', 'estado de monje': et departían los aragoneses como sacassen a don Remiro de la mongía et que fuesse rey 20.39. Deriv. de monge. Se documenta ya en el LR: e ssacharon a so ermano don Remiro de la mongia e fizieron lo rey (LR, 17.36; COOPER, LR, p. 135). Frec.: mongía 1: 0,00227.

mont (var.: monte) s. m. 'monte': Et las horas, la nación morista, por la victoria que ottuvo contre el dito rey Ordonyo, prendiendo mayo audacia, passando el mont Pireneus, conquiró entro a la ciudad de Tolosa 9.9; Entro a CCC christianos que fueron receptarse en la tierra ad'Aragon, es assaber, en un monte clamado Uruel cerca la ciudad de Jacca 4.14; dioles privilegio que si alguno metía cabanna de qualquier linaje de ganado fues en los términos de los ditos montes... 11.61. Del lat. MONS, MONTIS, acus. MONTE(M). Frec.: mont 3: 0,00682; monte 1: 0,00227; montes 3: 0,00682.

montanna (var.: montanya, muntania, muntannya) s. f. 'montaña': et a la raiz de una sierra et montanna fincaron sus tiendas 19.199; et fueron enta las fuerças de las montannyas de Sobrarbe 4.3; passó por la dita val un noble varón de las montanyas d'Aragón 12.6; et depués conquistó Siurana muy maravellosa fuerça e toda la muntania, e muytos de otros castillos e fuercas que son la ribera de Ebro 32.35; et constituir III procuradores en la tierra, yes assaber, en Catalunnya uno, l'otro de las muntannyas de Aragón entro a Ebro, l'otro de Ebro entro a Castiella 35.34. Del lat. vg. *MONTANEA, pl. n. del adj. * montaneus (DCECH, IV, p. 131). Frec.: Montanna 1: 0,00227; montanna 1: 0,00227 ; montannas 4: 0,00909 ; montannyas 1: 0,00227 ; montanyas 1 : 0,00227; muntania 1: 0,00227; muntannyas 1: 0,00227.

montar] v. intr. 'sumar, ascender, valer'; 'ser una cosa de importancia, consideración o entidad': que quasi en poder montava tanto como el su regno de Aragón 20.214. Etim.: Es deriv. de mont < lat. MONS, MONTIS, pero no directamente, sino tomado del fr. monter en calidad de vocablo cetrero y financiero, acepciones con las que se utiliza en la Edad Media. Desde el fr. el vocablo se extendió a todos los demás romances, ninguno de los cuales lo emplea en el sentido propio; del it., o más bien del fr., pasó luego, como término militar, en la acep. 'subirse encima de un animal', quizá ya en el s. XVI, pero en realidad no aparece hasta 1728. Para Corominas tiene poco fundamento el lat. vg. *MONTARE supuesto por MEYERLÜBKE, y es erróneo sacar de ahí las formas hispánicas, que vendrían del fr. monter (DCECH, IV, pp. 132-133, s. v. monte). El PRobert propone para el fr. monter el lat. pop. *MONTARE, deriv. de MONS. Tb. lo proponen DAUZAT-DUBOIS-MITTERAND, p. 474 , s. v.). Comp. en $L M M$ (p. 183) montança 'subida', aunque aquí puede ser galicismo (pues son abundantísimos en el $L M M$ ). En arag. mod. amontato, figura del carnaval de Bielsa, «consistía en vestir de paja la mitad delantera del 
cuerpo, de modo que un hombre, de pie, parecía ir montado sobre una persona vieja» (BADÍA, Bielsa, p. 223). Andolz (1992, s. v.) registra amontar 'montar' en el Valle del Jiloca; montar 'cubrir el macho a la hembra', en Santa Eulalia de Gállego. GiLKison, s. v., registra en el léxico de Fernández de Heredia: montar, muntar 'montarse, subir (en un caballo)' y 'sumar, aumentar'; amontar 'acumular, recaudar, amontonar'. Es raro, si como dice Corominas, en la Edad Media sólo se utilizó montar en el sentido financiero ('ascender, subir', 'hacer una suma, sumar') y de ahí 'valer' (tanto monta 'tanto vale'). Frec.: montava 1: 0,00227.

morir v. intr.: 'morir': es verdad empero quel dito rey Remiro regno XXX bueyto annos, mori anno Domini MLXII 16.61; et murieron con él muytos barones d'Aragón entre los quales morieron... 34.164; Dios enbió enfermedat sobre ellos et avieron muytos de morir, specialment murie de enfermedat el infant don Pedro de Aragón 38.202; et assí eran veninossas que tantost que cavallo o otra bestia tocavan, en continent murian 36.600. Del lat. vg. MORIRE, lat. MORI 'íd.'. Frec.: morir 5: 0,01136; morieron 2: 0,00455; mori 1: 0,00227 ; murían 2: 0,00455 ; murie $3: 0,00682$; murieron 17: 0,03864 ; muries 2: 0,00455; murió 83: 0,18865.

morisco] adj. 'morisco, relativo a los moros': Aquesti conte Remón Burrel por exalçar la fe christiana, por destruir la seta morisca, fue a Cordova contra moros 27.5; que Dios et los sanctos de aquell lugar los preservassen de las grandes persecuciones moriscas 9.36; Et las horas, la nación morista, por la victoria que ottuvo contra el dito rey Ordonyo... 9.7 (quizá errata por morisca, explicable por la gran semejanza entre $t \mathrm{y} c$ en el manuscrito). Etim.: Deriv. de moro < lat. MAURus 'habitante de Mauritania', forma hermana del cat. morisc, de uso general desde el s. XIV por lo menos (DCECH, IV, p. 151). Frec.: morisca 2: 0,00455; moriscas 1: 0,00227; morista 1: 0,00227.

morisma s. f. 'conjunto de moros': et fuesen en un pueyo qui agora es clamado Santa María del Puyg et toda la morisma vinies contra ellos en la batalla $35.231 / /$ adj. $\mathrm{f}$. 'relativa a los moros', 'mora, morisca, árabe': queriendo demostrar todo su corazón et su siensa [piensa $\mathrm{N}]$ que avía de subiugar la nasción morisma et aduzir la tierra a la fe christiana 35.120. Sin embargo, con este valor se usa tb. morisca. Deriv. de moro, con sufijo sugerido por marisma, de matiz también colectivo (DCECH, IV, p. 151). Hoy se conserva como sust. en el título de la pieza de teatro popular y tradicional "A morisma de L'Aínsa" que se desarrolla cada dos años en L'Aínsa para conmemorar un acontecimiento histórico-legendario (sobre

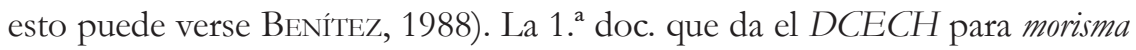
en cast. es 1444 (en J. de Mena). Frec.: 3: 0,00682.

moro s. m. 'moro, musulmán, árabe': Aquesti conte Remón Burrel por exalcar la fe christiana, por destruir la seta morisca, fue a Cordova contra moros 27.5; Et un día, mientre ques tractava aquesta paz, un moro qui de aquesta paz, era tractador, con XXX ginetes vino al dito rey 38.385; et el dito rey todo sólo con los moros estuvo et fabló una gran piesca 38.390. Del lat. MAURus. Frec.: moro 9: 0,02046; moros 114; 0,25911. 
mortaldat (var.: mortaldad) s. f. 'mortandad': et esguardant la terrible mortaldad qui aqui era de christianos, vido por la feridura que la dita reuna avía en el vietre aparaceía una mano de criatura 12.7; et con mas mortaldat que la primera vegada, tristos et dolentes sen tornoron 38.374. Del lat. MORTALITATE(M). Se documenta ya en el LR (COOPER, LR, p. 136). Y es usual a lo largo de la Edad Media. Véase un ejemplo del s. $\mathrm{XV}$ : «Item, yes condicion que si por la ventura las ouellyas, por guerra o por mortaldat se menoniuan, que menonescan pora todos, assí adaquell que prende muyto como aqui prende poco» (DLAA, doc. 142, de Jaca, 1441; p. 208, lín. 62). También se encuentra mortaldá 'mortandad' en arag. mod.: el EBA (1999: 1301) lo registra en Adagüesca (si bien, es más frecuente mortalera, con la misma significación). Frec. 1: 0,00227.

mortero s. m. 'mortero, argamasa, mezcla de cal y arena': et que tornás el palacio assí como denantes era et que personalment hi avies a levar piedra et mortero a la obra 36.448. Etim.: del lat. morTarium. En la acep. de 'argamasa', la 1.' doc. en Alex., hacia 1250 (DCECH, IV, p. 157). Vid. tb. SAs, p. 412: morter (ms. O), mortero (ms. P). Frec.: 1: 0,00227.

mosca] s. f. 'mosca': Et pressa la dita ciudat, la maldición de las moscas quanto más yva, más crecía en los franceses. 36.616. Etim. < del lat. MŬsCA. Frec.: 2: 0,00455.

mostrar] v. tr. 'mostrar, enseñar': e, mostrando al dito compte por el dito abat las reliquias et el monesterio... 11.20; et mostroles su fillo, et quando lo vieron fueron ne muyt pagados et alegres 23.29. / / 'demostrar, indicar': et los christianos fueron muy cansados pero con la victoria que havien non lo mostraban [no les parecia res N] 18.51. Del lat. MONSTRARE. Frec.: mostraban 1: 0,00227; mostrando 1: 0,00227; mostró 0,00227.

movedor] s. m. 'impulsor, promotor', 'movedor, incitador': et encara que aquellos que fueron movedores de la Unión quaxi eran muertos 39.29. Etim.: deriv. del verbo mover < lat. MOVERE. El DRAE (1970) y el DLE (2014) recogen, como s. y como adj., movedor 'que mueve'. Frec.: movedores 1: 0,00227.

mover v. tr. y pron. 'mover', 'moverse, partir, ponerse en movimiento'; 'iniciar, promover', 'excitar, agitar': queriendo resemblar a sus predecessores, començó de mover guerra et batallas contra moros 35.118; siempre movía el pie en semblança de cabreta 25.25; que la unión que en tiempo de los predecessores de aquesti rey era movida et succedida, ya más en tiempo de aquesti rey nos movió ni se suscitó 39.24; oydo tan estrannyo mandamiento, de grant yra movidos delant éll, todos se esquinçoron 38.125; moviosse grant discordia entre los barones et las ciudades et villas de la tierra 35.28. Etim.: del lat. MOVERE, de igual significado. Común a todos los romances occidentales (DCECH, IV, 169). Frec.: mover 1: 0,00227; movía 1: 0,00227; movida 1: 0,00227; movido 9: 0,2046; movidos 2: 0,00455; movieron 1: 0,00227; movió 4: 0,00909; moviose 1: 0,00227; moviosse 1: 0,00227.

mudar v. tr. 'cambiar': a la qual deyan por bautismo don Payronella, porque nasció en dia de San Peyro, et depués fue mudado nombre donna Urracha 20.257; fueron muyt despagados 
et su voluntat et su propósito mudóseles diziendo: «agora que non yes sennyor non se nos lexa veer, ¿qué fará quando seya rey?» 20.35; e mudó las armas e seynnales de Aragón e prendió bastones 33.32; lexó el propósito que avía contra los moros et mudólo en ayuda et socorro 36.204; // v. pron. 'mover': et mientre duró la batalla sol nos mudó el pie ni fizo asemblant que fues ferido 38.276; se devies mudar en la su galera 38.513. Etim.: del lat. mutAre 'cambiar'. Común a todos los romances (DCECH, IV, p. 178). Frec.: mudar 1: 0,00227; mudado 2: 0,00455; mudó 3: 0,00682; mudólo 1: 0,00227; mudólos 1: 0,00227; mudóseles 1: 0,00227.

muert s. f. 'muerte': diole Sarasanz, Roncal, Cadreta et Valetra [Valtierra N], a vida suya con tal pero condición que depués muert suya los ditos lugares tornassen al rey de Aragón 20.182; et cómo el rey Carlos a diversas et crueles muertes et turmentos havía exposado los nobles varones 36.190. Del lat. MORTE(M). Frec.: muert 49: 0,11137; muertes 1: 0,00227 .

muerto adj. 'muerto': et muerto el dito rey don Jayme de Mallorquas, regnó depués él en el su regno et tierras el segundo fillo suyo don Sancho 38.456; tan fuert batalla hi fue feita que la mar vermellava de sangre de la gent que muerta et ferida yera sobre la mar. 38.270. Del lat. MORTUUS. Frec.: muerto 51: 0,11592; muertos 17: 0,03864; muerta 2. 0,00455.

muller 'mujer; esposa': La filla huvo nombre Constancia [Gostança N] et fue muller del rey don Jayme de Mallorquas 38.593; et desmaridar mulleres maridadas 36.193; por miedo de los arabes, todo hombre tenies sus cavallos en las cambras o palacios do lurs mullers estavan 14.33. Del lat. MULIER, -ERIS. La 1. ${ }^{a}$ doc. de muller que da Corominas es de un doc. arag. de 1025 (DCECH, IV, p. 185). El LHP, p. 405. s. v. mugier, cita muller en un documento de San Juan de la Peña de 1023 (que había sido publicado por Menéndez Pidal en Orígenes, p. 54). Es forma habitual en el arag. med. (vid. GILKISON, p. 92, s. v.; REIDY FriTZ, 1977: 206; VCA, p. 259) y usual en el arag. mod.: Andolz (p. 302, s. v.) registra muller en Almudévar, Ayerbe, Agüero, Bielsa, A Fueba, Echo y Cinco Villas; mullé en Campo, Estadilla y Fonz; Siesso de Bolea (2008, p. 205) ya indicaba: «muller antiq. Mujer. Dícenlo oy montañeses y en aldeas»; el EBA (1999, pp. 13151316) registra muller o mullé en 45 puntos del Alto Aragón. Frec.: muller 113: 025684; mulleres 6: 0,01364; mullers 1: 0,00227

multiplicado] adj. 'multiplicado, aumentado notablemente': e las oras fue multiplicada la devotión en la dita cueva 11.12. Frec.: 1: 0,00227.

multitudo (var.: multitut, multitud) s. f. 'multitud': era tan grant la multitud de los franceses que aqui cuydó seer desbaratado 36.582; et otras gentes en multido [multitut $\mathrm{N]}$ copiossa 38.20; grant multitut de gent morisca 38.359; mas tanta era la multitudo de la gent estrannya que ya sea que sin nombre ne matoron a malas se parecía 36.578 . Es cultismo tomado del lat. MULTITUDO, -INIs. Frec.: multitudo 7: 0,01591; multitud 5: 0,01136; multitut 2: 0,00455; multido 1: 0,00227. 
mundanal] adj. 'mundanal, relativo al mundo': renunciaron a los deleites carnales et mundanales 9.34. Deriv. de mundo. Frec.: mundanales 1: 0,00227.

mundo s.m. 'mundo': que en ningún caso del mundo non quisies aver batalla con él 38.256; et tratemos de los godos, los quales vinieron de una isla que es clamada Estancia, la qual es enta las partes de Septentrio, enta la mar que el mundo environa 2.15. Del lat. MUNDUs. Frec.: 13: 0,02955

murmuriar] v. intr. 'murmurar, manifestar disgusto': la gent de la tierra procuravase de sennor, murmuriavan et es complanyan muyto et non sin razón 12.15. Es cultismo, tomado del lat. mURMURARE 'íd.', con - $i$ - debida al influjo de murmurio < lat. tardío MURMURIUM (DCECH, IV, p. 193). Frec.: murmuriavan 1: 0,00227.

muro s. m. 'muralla': comidiendo por do se podría entrar, vio flaco lugar en el muro forano 17.117-118 ('en la muralla exterior'); viendo que dito regno se perdía, opposándose por muro por la fe en la yglesia de Dios... 36.71; [oposant si mateix per murper la fe en l'Esglesia de Déu, VC, p. 129]; et que enderrocas los muros del castiello 36.448; avía dentro en la ciudat XX mil moros, etpassó [posó N] las sus tiendas cuesta los moros [sic] de la dita ciudat. 32.20-21. [Es evidente error o despiste del copista, influenciado por el anterior moros, por muros. En la VC se lee: E posà les sues tendes costa los murs de la dita ciutat, VC, p. 102]. Etim.: del lat. Mūrus 'muralla', 'muro de una ciudad', 'pared'. La 1. a aparición se documenta en Berceo. Desde el principio se especializa en iberorromance en la acep. 'muralla', 'pared gruesa y externa, especialmente la que defiende un lugar fortificado'. Es de uso general en la Edad Media y hasta más tarde; ha dejado descendencia en todos los romances (DCECH, IV, p. 193, s. $v$. muro). En arag. med. es habitual muros por 'murallas'. Así, por ejemplo, en el Libro de los muros: «fueron tres piqueros a la dita obra de los muros», «fueron ad athemar los ditos dos piqueros el troz del dito muro», «fueron passados los contos de la obra de los muros de la dita ciudat», "primerament obroron en el muro del corral de Johan de Xiar e de Martin de Bolea» ( $L M$, pp. 59, 78, 92, 100 y passim). Frec.: muro 3: 0,00682; muros 3: 0,00682.

mutilar] v. tr. 'mutilar'; 'cortar o quitar una parte de una cosa': mutilaron et distruyeron todas las otras reliquias et de las otras eglesias lancoron... 36.567. Etim.: tomado del lat. mutILARE íd. (BDELC, p. 409). Por el tratamiento fonético, se trata claramente de un cultismo. No lo recoge, sin embargo, Bustos Tovar en su Contribución al estudio del cultismo léxico medieval (1974). Corominas (BDELC, p. 409) lo documenta por primera vez en cast. en 1553. Vid. también DCECH, IV, p. 198. El testimonio de la Crón. SJP. adelanta la documentación en casi dos siglos. Frec.: mutilaron 1: 0,00227.

muyt (var.: muit, muy) adv. 'muy' (apócope de muyto): de la qual cosa el rey fue muit despagado 20.120; el qual fue rey muy cruel 3.74; que fuessen en muyt cercano grado de parentesco 38.27. Vid. muyto. Frec.: muyt 98: 0,22375; muit 3: 0,00682; muy 62: 0,014092 . 
muyto (var.: muito, mucho) adj. 'mucho': en aquel annyo mismo murieron muytos christianos en Rueda et pobló Ayerve 17.72; Y el dito noble conte de muitos treballos en el regno lo escusava 20.296; el dito monasterio ennoblesció et dotó de muitas tierras 8.7; el dito conte se metió en celada et priso el dito Ponz. Guillem et el dito castiello con muyta de gent de Torroella 36.431; con XX galeras que eran armadas en la marinas suyas et muyto otro navilio, 38.504; et muytos de otros navilios menudos 38.508. // adv. de cantidad 'muy, mucho': encara non seyendo esleydo por rey, empecó muito a levantarse mas en orgul que no primero. 20.8; e exampló et crecio muyto el su regno 3.72; en la qual fue muyto maravilloso batallero 34.87-88. Se encuentra muchos christianos en 18.18. El resto de las veces (144 formas plenas y 163 apocopadas) la solución es /uit/. Del lat. мuLtus, -A, -TUM. El arag. muito se documenta ya en el siglo X, Glosas Emilianenses: muitas (glosa 54), muitos (glosa 71). Cfr. Menéndez Pidal, Orígenes, pp. 5 y 6 (ahora también se puede consultar en Origen aragonés de las Glosas Emilianenses, 2020: 102 y 103). Es de uso habitual en el arag. medieval. En arag. moderno continúa empleándose la forma muito (AnDolz, s. v., p. 302; DDPA, p. 214; EBA, s. v., p. 1324). Frec.: muyto 17: 0,02864; muytos 61: 0,12865; muyta 4: 0,00909; muytas 52: 0,11819.

\section{$\mathbf{N}$}

nación (var.: nasción]) s. f. 'nación', 'pueblo', 'nacionalidad': la nación morista 9.7; habitaban aquestas naciones 3.1; la nasción morisma 35.120. Etim.: cultismo tomado del latín NATIO, -ONIS 'nacimiento', 'raza', 'nación'. La primera documentación que dan Corominas-Pascual (DCECH, IV, p. 202) en cast. es del s. Xv. Frec.: nación 4: 0,00909; naciones 3: 0,00682; nasción 1: 0,0027.

Nadal s. f. 'Navidad': et firo batalla en Piedra pissada con moros en el día de Nadal, 17.74; en el lugar que dizen Alcaçar tenieron la Nadal con gran goyo et abastamiento de viandas, 19.200; el día de Nadal en el anno de Nuestro Sennyor MCCCXXII, 38.481. Como se ve, en dos ocasiones aparece sin artículo, en el sintagma el día de Nadal. La única vez que va precedido de artículo, este es femenino, lo que nos indica que el sustantivo también lo es: la Nadal. Etim.: del lat. (DIES) NATALIS 'día del nacimiento', acus. natale(M) (Corominas, DECL/C). En arag. ant. se documenta nadal en el Vidal Mayor, VII, 23.8 (Tilander, VM, tomo 3, p. 208); nadal y natal en Fernández de Heredia (GILKISON, s. v.). En cambio, natividat del Sennor en FA (Tilander, FA, p. 490). En DLAA (doc. núm. 144, de Alqué- 
zar, año 1445; p. 209, lín. 25: «Item, diomos a los jouenes a Nadal por fer los juegos... v ss.». En el arag. del s. XVII lo encontramos en Ana Abarca de Bolea: «Toz la claman buena noche, / dirálo la colación / y lo tizón de Nadal / que ye nombrado tizón» (ABARCA DE BolEA, Obra en aragonés, p. 30). En arag. mod., si bien se ha recuperado en el uso literario, no es de uso popular como sustantivo (Andolz, s. v., lo localiza en Peralta de la Sal, localidad de habla catalana), aunque PARDo, s. v. navidal, recoge nadal como adjetivo sinónimo de éste y con el significado de 'navideño'. El EBA (1999: 1322) registra Nadal en Noals, Valle de Barrabés, Peralta de la Sal, Ardanui, Bonansa, Castanesa y Espés (todas, localidades de Ribagorza de habla catalana ribagorzana), y además en Casbas de Uesca (dato que se refiere al uso que de esta voz hace Ana Abarca de Bolea) y en Chistén (dato que procede de Antonio Plaza Boya, El mundo religioso del Alto Ésera, Huesca, IEA, 1986). Debió de ser voz tradicional en la Ribagorza baja, pues allí recogió CosTA (2010: 46) este refrán: «Nadal sin lluna, de cien güellas en torna una». También procede de Ribagorza este otro refrán: «Por Nadal cada güella a su corral» (Moneva, 2004 [1924]: 343). Nadal es voz usual en cat. (FABRA, s. v.), en occ. prov. (Levy, s. v.), en occ. langued. (Alibert, s. v.), así como en asturiano y gallego: Nadal 'navidad' se atestigua ya en las Cantigas (DCECH, IV, pp. 204, s. v. nacer). El fr. Noël, el it. Natale, el port. Natal, proceden también de la misma etimología: NATALIS (DIES) o NATALE(M) (DIEM) 'el día del nacimiento de (Jesucristo)', mientras que el cast. Navidad tiene como base etimológica el lat. nativitate(M). El DCV B, s. v., t. 7, p. 687, da nadal como masculino, pero una de las citas dice: E tenguem la Nadal a Alcanic e l Aninou en Tortosa (Crón. de Jaime I). El DECLIC, V, p. 903, s. v. néixer, lo da también como masculino y añade que usualmente aparece sin artículo. Comp. natividat. Frec.: 3: 0,00682.

nariz s. f. 'nariz': Guillem Croy [Troy N] qui buvo la nariz tuerta et plana 29.39 // pl. 'orificios de la nariz'. et metianse por las orellas et por las narizes de la gent et de las bestias 36.601. Etim.: del lat. *NARICAE (BDELC, p. 411). Según indican Corominas-PASCuAl a propósito del significado: «Lo común, sobre todo en lo antiguo, es que narizes aparezca en plural. A. Pal[encia] distingue entre nariz, significado moderno, y narizes 'orificios de la nariz'. Comp. cat. nariu (ant. tb. naril) 'ventana de la nariz', frente a nas (< lat. NASUs), 'conjunto del órgano'; it. le narici 'las ventanas de la nariz', frente a il naso 'la nariz, el órgano en su conjunto'. Esta distinción semántica abarcaría primitivamente los idiomas iberorromances, pero éstos perdieron posteriormente naso, generalizando el uso de narizes, que sin embargo siguieron empleando en plural, aun cuando se refería a todo el órgano. NARICES se encuentra ya en lat. vg. aplicado a las ventanas de la nariz. Esta forma resulta de una nueva 
pluralización del nominativo plural NARICAE, que se tomó por un singular (= NARICE)» (DCECH, IV, p. 213, s. v. nariz). En la Crón. SJP parece claro que se distingue entre nariz 29.39 como órgano en su conjunto y narizes 36.601 'orificios de la nariz'. Frec.: nariz 1: 0,00227; narizes 1: 0,00227.

nascer] v. intr. 'nacer': assí como aquel qui era nascido de virtuoso rey padre et virtuosa madre 36.10; porque nasció en día de San Peyro 20.256. Vid. naxer. Frec.: nascido 1: 0,00227 ; nasció 1: 0,00227 .

nascimiento s. m. 'nacimiento': que de sennyor traydor ningún nascimiento filial non podría exir leal 17.15. Deriv. de nascer. Frec.: 1: 0,00227.

natividat s. f. 'natividad': en el anno de la natividat de Nuestro Sennyor 37.96. Comp. Nadal. Frec.: 1: 0,00227.

natura s. f. 'naturaleza, esencia de las cosas, linaje': e fue seynnor de tres regnos, de Navarra e de Aragón por natura et de Castilla por la muller 19.6. En arag. mod. se documenta natura, al menos en la paremiología popular. Así, Arnal CAVEro (1953: 117) recoge este refrán: «O que no viene de natura, tararura». Y al respecto hace el siguiente comentario: «Se dice que el que no tiene condiciones heredadas, innatas, para una aptitud, para una manera de ser, difícilmente se adquieren sólo con voluntad y buen deseo». Frec.: 4: 0,00909.

natural adj. y s. 'natural, nativo', 'del país', 'ciudadano oriundo de la Corona de Aragón': feita primerament inbibición a todo bomme que si non fues natural...non entrás 38.261; davan de consello al rey que diesse por malos a los sus naturales que yeran seydos en la batalla 38.280. Frec.: natural 10: 0,02273; naturales 4: 0,00909.

naturaleza s. f. 'naturaleza, linaje, parentesco': guardando dreyto de naturaleza por el infant don Jayme que devía seer rey 35.17. El sintagma dreyto de naturaleza se refiere al 'derecho adquirido por el linaje'. Cfr. natura. El DLE (2014), s. v., recoge como acepción número 17 'parentesco, linaje' (con marca de desusado). Frec.: 3: 0,00682.

naturalment adv. 'por naturaleza, de nacimiento': et fue naturalment de grant corage et ardido et proz et sotil 32.4. Frec.: 2: 0,00455.

navarro] s. y adj. gentilicio '[persona] natural o procedente de Navarra': et por razón que sines consello de los aragoneses los navarros avian levantado rey... 20.93. Frec.: navarros 15: 0,03409.

nave] 'nave, barco': et lexó un lennyo armado por denunciar a las naves et al otro navilio que fiziessen aquella misma via. 38.526. Del lat. NAvis 'barco, nave'. Frec.: 5: 0,01136 .

navilio s. m. 'barco, embarcación, nave', 'tipo o clase de embarcación en general'. con LX galeras, XXIIII naves et muytos de otros navilios menudos 38.508. // 'conjunto de embarcaciones de diversas clases y tipos': por denunciar a las naves et al otro navilio que fiziessen aquella misma vía. 38.526. Etim.: tomado del bajo lat. 
*NAVILIUM, alteración de NAVIGIUM ‘embarcación, navío’ en el sentido no habitual; lo normal es que signifique 'navío'- de 'flota, conjunto de naves', como en cat. ant. navili, fr. ant. navoi, it. navilie, etc. (DCECH, IV, p. 219, s. v. nave). Comp. cat. navili 'nau gran, esp. de guerra' y 'conjunt de naus' (FABrA, DGLIC, s. v.); "'vaixell per a navegar, i especialment el de grans dimensions'; cast. navio // ant. 'conjunt de vaixells'; cast. armada, escuadra...» (DCVB, t. 7, p. 720). Según Coromines (DECLIC, V, pp. 886-887, s. v. nau), el cat. navili (doc. desde 1274) supone un lat. tardío

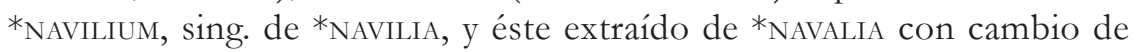
sufijo. En Fernández de Heredia nabilio, navilio 'ship, boat, fleet' (GILKISON, s. v.). De este mismo origen son el fr. ant. navilie, fr. medio (s. XIV) navire (DAUZAT-Dubois-MitTERAND, s. v. navire, p. 489) y occ. ant. navili, naveli, con el sentido de 'flota' o 'nave'. En arag. med. quizá fuera un catalanismo (lógico, por otra parte, en un término marítimo); podría tratarse de un cultismo directamente tomado del latín, favorecido por el uso de navili en catalán. En cualquier caso, fue un término habitual en los textos aragoneses del s. XIV. Frec.: 12: 0,02728.

naxer] v. intr. 'nacer': que naturalment quando naxen matan lurs madres. 29.17. Etim.: del lat. vg. NASCERE, que dio descendientes en todos los romances (DCECH, IV, p. 201). Vid. tb. nascer, con grafía similar a la latina, quizá por inercia cultista. Frec.: naxen 1: 0,00227.

ne compl. prnl.-adv. 'de ello': et quando lo vieron fueron ne muyt pagados et alegres 23.30; matoron ne sin nombre 36.574; quando el cavallero ne fues partido... 38.325. Del lat. ǏNDE 'de allí, desde allí, de esto'. Sobre el compl. pronominal-adverbial procedente de este adv. latino y sus diferentes alomorfos (ende, end, en, ne) en la Crón. SJP. vid. más ampliamente NaGore (2003: 510-516). Cfr. ende. Frec.: 12: 0,02728.

necessario] adj. 'necesario': la qual yes muyt necessaria 20.52; viendo esto, fizo exir todo home de Girona salvant aquéllos que eran necessarios en deffensión de la ciudat de Girona 36.526. Del lat. NECESSARIUS. Frec.: necessaria 1: 0,00227; necessarios 1: 0,00227.

necessidat (var.: necessidad) s. f. 'necesidad': ruegos e necessidades 18.121; et de aquellos servir quando menester les fuesse et necessidad los costriniesse 14.35; et lo sirvió en todas sus necessidades 36.425; non por codicia de honor mas por necessidat del regno, fue clamado por rey 20.85. Tomado del lat. NECESSITAS, -ATIS. Frec.: necessidad 1: 0,00227; necessidades 2: 0,00455; necessidat 1: 00227.

negar] v. tr. 'negar': con el qual guerrió luengament por el feu del castiello de Torroella que le negava 36.429. Del lat. NEGARE. Frec.: negava 1: 0,00227.

negocio] s. m. 'negocio, asunto, empresa': mas Dios que provedeçe a los negocios et males... 20.241. Del lat. Negotium. Frec.: negocios 1: 0,00227. 
negro adj. 'negro': et ellos assí mismo vestidos de negro 38.142; et que diziessen las oras a costumbre de monges negros 20.305. Del lat. NIGER, NIGRA, NIGRUM. Frec.: negro 1: 0,00227; negros 4: 0,00909.

ni (var.: nin) conj. cop. 'ni': nin aquella honra ni cortesía que devian 20.24; ni que ayuda nin favor le dasse 36.461; qui res de lures privilegios nin libertades non les crebantó 39.28; et por aquesta razón no queremos mas favlar del feito de Ercules, nin de la suya governación [generation N] nin de la nación que de él pobló Espanna... nin de los romanos... nin de los vándalos nin de los alanos, nin de los suevos nin de los ugones et sanicos 2.5-2.9 / / A veces vale por ' $y$ ' o por una suma simultánea de 'y' + 'o': lo que ellos farian ni ordenarian 20.156. Frec.: ni 35: 0,07955; $\operatorname{nin} 29: 0,06592$.

ni ha (= en $i$ ha) 'hay de ello allí': entre los quales lugares ni ha buoy uno clamado Sancho Avarca 12.73. Las forma i es una de las que adopta el compl. pronominal-adeverbial procedende del lat. ǏBI 'allí, ahí, en ese sitio'. Otras son: hi, hy, y. La construcción hi ha para indicar existencia impersonal en un sitio dado es habitual en arag. med.: «Item qui ha vino pora vender, sea tenido de manifestar a los rendadores, quando dello requerido sera, quantas cubas entro a e quanto vino hi ha en cada una» (doc. por el que Pedro IV el Ceremonioso autoriza a los judíos de la aljama de Huesca el establecimiento de un nuevo impuesto sobre el pan, la carne y el vino; BLAsco, 1995: 121). Actualmente, en arag. mod., bi ha, b’ha, $i$ ha, y en combinación con el compl. ne, en bi ha o bi'n ha, ne b'ha, i'n ha (cfr. GLA, pp. 105 y 238-239). Vid. y.

nieta s. f. 'sobrina': Et tantost fizo por manera que el emperador de Alamanya dio su nieta por muller al nieto de aquesti noble varón, et ovo el ducado de Proenica del dito emperador para todos tiempos 32.54-56; ... o ovo por muller la nieta del compte de Folcalquer 34.5; prometió el dito Padre Santo a Frederich de darle en muller la filla del [duch N] de Constantinnoble, nieta del rey Carlos dessuso dito 38.153. Cfr. nieto. Del lat. vg. * ${ }_{\mathrm{NEPTA}}$ cl. NEPTIS, que tenía los dos significados de 'nieta' y 'sobrina' (cfr. BLÁNQUEZ, s. v.). Comp. fr. nièce 'sobrina' (PRobert, s. v.); inglés niece 'sobrina', tomado del normando. Frec.: 6: 0,01364.

nieto s. m. 'sobrino': el rey don Sancho de Castiella, nieto [cosino N] del dito rey Remiro 16.53 (luego se dice por dos veces, en 16.56 y 16.57, que el rey Remiro era tío de Sancho de Castiella); el dito don Jayme, nieto del dito don Phelip, 38.615; enseynnoreose del dito marquesado et recevió un fillo del dito marqués e nieto suyo por nodrirlo 32.45-46 (está hablando de Ramón Berenguer IV conde de Barcelona; el marqués de Provenza era su hermano Berenguer Remón, luego efectivamente nieto es aquí 'sobrino'). Etim.: En lat. NEPOs, -OTIS 'nieto' y 'sobrino'. Pero, según indican Corominas-PASCuA, nieto se sacó secundariamente de nieta; es innovación común a los romances ibéricos y algunas hablas occitanas. Señalan, igualmente, que la acepción de ‘sobrino' se conservó en navarro-arago- 
nés hasta el siglo Xv (DCECH, IV, p. 226, s. v. nieto). Comp. nieto 'sobrino' y nieta 'sobrina' en LR (COOPER, LR, pp. 137-138, da una extensa explicación sobre la cuestión); nieto 'sobrino' y 'nieto', nieta 'sobrina' en Fernández de Heredia (Gilkison, s. v.). También ANDolz, s. v., recoge nieto como 'sobrino (hasta el siglo Xv)'. Frec.: 6: 0,01364.

nieve s. f. 'nieve': passó las montannas que yeran cubiertas de nieve 12.56. Etim.: del lat. NIX, NIVIIS (acus. NIVEm). Se ha especulado con la posibilidad de que ya en lat. vg. hubiera una forma con $e$ abierta, *NĔVEM (DCECH, IV, p. 227; MGHE, p. 288). En arag. med. se documenta nieu: «que si por fortuna de nieu o de poca yerba que los ganados possaran mal o dapnage...» (doc. de Sallent de 1427; EAMJM, p. 57). Comp. arag. mod. nieu (ANDolz, s. v., lo registra en los valles de Bielsa, Echo y Chistau; Rohlfs, DDPA, s. v., en Echo, Bielsa; neu en Benasque; ñeu en Ansó). El EBA (1999) también registra nieu en los valles de Echo, Bielsa y Chistau, así como ñeu en Ansó. Frec.: 1: 0,00227.

ninguno adj. y pron. indef. 'ninguno': envió a dezir secretament a su hermano el rey don Frederich de Secilia que en ninguna manera non le parecies delant 38.235. // pron. indef. 'nadie': et non osava aquesto revelar a ninguno 20.101; «O cavalleros jet non vos yes verguença que delant vosotros aquesti cavallero catalán aya desmentido a mi et de vosotros ninguno non le aya respondido?» 38.329. Es habitual la doble negación, tanto en arag. med. como moderno. Comp.: «...que ninguno no encubra», en las Ordenanzas de la ciudad de Huesca (1284). Vid. en TLME, doc. 100, lín. 23, pág. 186. Frec.: ninguno 16: 0,03637; ninguna 10: 0,03637.

ningún tiempo loc. adv. 'nunca': que ningún tiempo moros non las pudieron possedir, 4.8; por tal porque [como en $\mathrm{N}$ ] ningún tiempo en batalla que fues non giró cara, murió en aquélla, 34.147-148. Comp. todos tiempos 'siempre' 34.176, pássim. Frec.: ningún 24: 0,05455.

ninnyo s. m. 'niño': «qui a ninnyo sierve, pierde su tiempo», 35.52. Según CoromINAS-PASCUAL procedería de un tipo *NINNUS, de creación expresiva, común al cast., al cat. y a muchas hablas occitanas e italianas. No en cambio al fr. enfant (DCECH, IV, p. 228). La grafía indica una pronunciación con nasal palatal [níno], frente al arag. mod. con nasal alveolar nino [níno] (ninno en Bielsa, con nn geminada; nirno en Echo). Frec.: 1: 0,00227.

no adv. de neg. 'no': respondiole que con él no se podía veer sin batalla 38.562. // nos aglutinación de no + s(e) 'no se': por tal como nos podían deffender 36.502; et mientre duró la batalla sol nos [no se $\mathrm{N}$ ] mudó el pie ni fizo asemblant que fues ferido 38.276; nos movió ni se suscitó 39.25. Tb. non. Frec.: 101: 0,22957.

noble s. m. 'noble, hombre noble', 'título de honor': et ordenó el infant quel noble don Phelip de Celuza, qui era venido de Secilia... 38.578; que los nobles vizconte de Rocaberti et los otros... 38.520. El DRAE (1970, s. v.) recoge como sexta acepción: 'título de honor que daba el rey de Aragón, como el de duque o marqués, 
subrogado desde el año 1390 al título de ricohombre'. // adj. 'noble, preclaro, ilustre, principal, de nacimiento noble': no trobavan más valient ni más avençado cavallero como el noble varón, natural del condado de Vigorra, clamado Ennego. 10.7. Del lat. NOBILIS. Frec.: noble 49: 0,11137; nobles 48: 0,10910.

noblement adv. 'noblemente': noblement acompannyada de honrada cavallería 38.572. Frec.: 3: 0,00682.

nobleza s. f. 'nobleza': feyta solepnidat fiesta et honor por la su nobleza cavallería 35.43; queriendo resemblar en los fechos et noblezas a sus predecessores 36.163. Frec.: 4: 0,00909.

nodrido s. m. 'criado, persona que ha sido cuidada, criada o cultivada por otra': fuesse et lexoles por governador un su nodrido [criado $\mathrm{N}$ ] el qual havía nombre Ispan, 1.42. Etim.: p. p. sustantivado del v. nodrir (vid.). Frec.: 2: 0,00455.

nodrir v. tr. 'criar, cuidar': a la ora el rey recibió el dito moco et acomendolo al conte de Flandres et mandóle que lo nudriés muyt diligentment et curosa 23.7; e nudrió e industrió al dito rey a regir la tierra al millor que pudo varonilment 33.13; el qual se era nodrido en cort del valeroso rey, 36.263. Etim.: del lat. NUTRIRE (DCECH, IV, p. 253). Se ve que conserva el sentido etimológico de 'cuidar, criar, atender' más que el de 'alimentar'. El desarrollo popular nodrir se doc. en Berceo. Frec.: nodrir 1: 0,00227; nodrirlo 1: 0,00227 ; nodrido 2: 0,00455 ; nudriés 1: 0,00227 ; nudrió 1: 0,00227.

nombrar (var.: nonbrar) 'nombrar, llamar, designar': et por el rio que ba nombre Beti nombra el otro regno Betica 1.19; citó el dessus nombrado rey don Sancho 38.461; et por aquesto fue nonbrado el Franco 37.3. Del lat. NOMINARE. Frec.: nombrar 2: 0,00455; nombra 1: 0,00227; nombrada 4: 0,00909 ; nombrado 21: 0,04773 ; nombrados 5: 0,01136 ; nombrasse 1: 0,00227 ; nombrava 1: 0,00227 ; nombró 1: 0,00227; nonbrado 1: 0,00227.

nombre s. m. 'nombre': en nombre de Ihesu Christo 33.94; la filla buvo nombre Costancia [Gostança N] 38.593. Del lat. NOMEN, -INIS, acus. NOMINEM. // 'número, cantidad': et de otras gentes en grant nombre 35.124; tornó fuert a poco nombre de gent 36.603. Se emplea especialmente en la locución sin nombre infinidad, incontables, innumerables': las gentes sin nombre que en la villa de Perpinyan se eran venidas 36.479; escondidament et paladinament matoron ne sin nombre 36.574; que ya sea que sin nombre ne matoron 36.578. Etim.: cat. nombre < lat. NUMERUS (DCECH, IV, p. 251, s. v. número). Frec.: 88: 0,20002 (sumando ambos significados del significante nombre).

non adv. de neg.: 'no': que ningún tiempo moros non las pudieron possedir 4.8; et si no quel ni christiano ninguno non esca[n]paría 18.23; de los moros a merçé ninguno non prendían 18.47. Tb. no. Frec.: 209: 0,47504.

nonas] s. f. pl. 'el día 5 de cada mes y el día 7 en los meses de marzo, mayo, julio y octubre': feria quinta, nonas aprilis 17.81. Tomado del lat. NONAE (cfr. BLÁNQUEZ, s. v. nonae, p. 1024). Frec.: 3: 0,00682. 
nonde aglutinación de no + ende 'no de ello': do murieron de los enemigos bien mill cC homes entre de pie et de cavallo ensuso, et de la part del dito don Alfonso nonde murió ИI homes fidalgos et VI de pie 38.537. Parece que, para completar la construcción sintáctica, faltaría que o sino que, dado que la idea que quiere expresar es que 'de los hombres de don Alfonso no murieron — de ellos — sino seis hidalgos y seis de a pie'. Frec.: 1: 0,00227.

non res menos (y res non menos) loc. adv. 'asimismo, también, además, igualmente': et non res menos a la cagaria [cagueria N] el dito rey don Pedro juroles et confirmoles aquello 36.677-678. Etim.: lat. NON RES MINUS, literalmente 'no cosa menos' o 'nada menos'. En la forma no res menys es locución atestiguada en cat. ant. con igual significado (cfr. DECL/C, VII, p. 273). Se registra en la VC de la Crón. SJP abundantemente, en casi todos los fragmentos correspondientes a los de la VA en que aparece; pero hay fragmentos de la VA en que aparece la loc. non res menos que se han eliminado en la VC. Para una comparación de los párrafos paralelos con esta loc. adv., véase el apartado 5.6.2.5. del estudio lingüístico (NAgORE, 2003: 296). La locución non res menos es habitual en los textos en arag. medieval. Para la frecuencia, vid. menos.

nos aglutinación de no + es 'no se' (adv. de negación + pron. refl.). Vid. no.

nos pron. pers. átono de $1^{a}$ pers. pl. dativo o acusativo 'nos': «agora que non yes sennyor non se nos lexa veer» 20.36; «¿vos podedes nos tener seguro?» 36.287; «porque, Sennyor, traydor nos avedes estado» 38.306. Frec.: 18: 0,04091.

nós pron. pers. tónico de $1^{\mathrm{a}}$ pers. pl. caso preposicional 'nosotros': «ayudanos Dios, que es salut nuestra, et gita la yra de nos». 35.247.

notable] adj. 'notable', 'señalado, distinguido': et de otras gentes notables 14.11. Del lat. NOTABILIS. Frec.: notables 2: 0,00455.

notario s. m. 'notario': requiriendo al notario que allí era que de aquéllas. . . le devies fer carta o cartas públicas a memoria perdurable 36.297. Es cultismo, tomado del lat. notarius 'copista, escriba, estenógrafo'. Frec.: 1: 0,00227.

notificado] adj. y p. p. 'notificado': sobre la qual el nombre et la vida del dito sancto era notificada et contenida 9.23. Es p. p. de notificar < lat. NOTIFICARE. Frec.: notificada 1: 0,00227.

novembris lat. 'de noviembre': en la expr. lat. IIII ${ }^{\circ}$ idus novembris 36.705. Frec.: 1: 0,00227 .

noveno] adj. num. ordinal 'noveno': fue poblada de las gents de la dita novena barcha 1.36. Del lat. NOVENUS, -A, -UM. Frec.: novena 2: 0,00455.

novicio s. m. 'novicio, que aún no ha profesado en la orden religiosa, sino que se está preparando para ello': que a todo novicio que era en la orden dan un monge de los ancianos por maestro 20.105. Tomado del lat. NOVICIUS, -A, -UM 'nuevo, reciente'. Frec.: 1: 0,00227. 
noviembre s. m. 'undécimo mes del año': XI dias de noviembre, en el tercero anno del regimiento del dito rey 3.87; en el ochen día en las kalendas de novienbre 32.32. Del lat. NOVEMBER, -BRIS. Frec.: noviembre 1: 0,00227; novienbre 1: 0,00227.

nuestro adj. poses. de 1. a pers. pl. 'nuestro': Nuestra Sennyora Santa María 38.404; en el anno de Nuestro Sennyor M CCC XXVII. 38.632; en el anno de Nuestro Sennyor M CCC XXXV 39.45. Del lat. NǑSTER, NŎSTRA, NŎSTRUM. Frec.: nuestro 80: 0,18183; nuestra 3: 0,00682.

nuevament (var.: nuebament) adv. 'nuevamente': el fue aduyto el su cuerpo al monesterio de Poblet, el quoal nuebament avía hedificado, 33.126; que la tierra <que> aquesti rey don Remiro dio a homenage al emperador de Castiella [...], porque la sennoriasse, que nuevament yera adquirida de infieles, ya non quería rendir aquélla al dito conte de Barchinona 20.311. Frec.: nuebament 1: 0,00227; nuevament 2: 0,00455.

nuevas s. f. pl. 'noticias, novedades': por levar las agras nuevas de la muert del dito rey 38.4; 'sucesos, asuntos': por algunas nuevas et questiones et demandas quel dito rey fazía a los nobles de Cataluennya, la mayor partida de aquellos, ensemble con el conte de Urgel et con el conte de Foyx, movieron guerra contra el dito rey 36.127; Etim.: deriv. del adj. nuevo < lat. NŎvum. Comp. ardit 'información, noticia'. Frec.: 2: 0,00455.

nueve adj. num. 'nueve': que veynte nueve batallas vençió, 19.4. Contrasta esta forma, que presenta la -e final conservada, con la genuina del arag., nueu, habitual en los textos en arag. medieval (junto a la forma sin diptongación, nou, que muestra influencia del catalán). Del lat. NŎvEM. Frec.: 2: 0,00455.

nuevo adj. 'nuevo': que la tierra sobredita de nuevo adquirida por don Alfonso, 20.246. Etim.: del lat. NǑvUs, -A, -UM. Frec.: 5: 0,01136.

nueyt (var.: nueit) s. f. 'noche': a media nueit, partióse de Pamplona et fuesse aal monesterio 20.196; et toda la nueyt éll firo su parellament como mellor pudo pora conbatirse otro día manyana con los franceses 36.650; fuesse de nueytes a la possada del rey de Aragón et recontole esto, 20.192; de nueyt ni de dia no aturó ni posó fasta que fue cerca de los enemigos, 33.83-84 (mueyt en ms. N; error por nueyt). Del lat. NŎстE(M), acus. de NŎx, NŎстіs 'noche'. Es forma habitual en arag. medieval: «ordenamos e mandamos que en bedado del Puerto que aya de dia pena por cada estallo x sueldos e de nueytes xx sueldos» (Estatuto Municipal de Asso de Sobremonte, 1446; EAM$J M$, p. 79); «clamadas o no clamadas, una vegada o muytas, de dia o de nueytes» (CAC, 1406, p. 89); «dezimos e mandamos que el dito Guillem de Loarre que tienga e providesca illuminada la dita lanpada, dia e nueit perpetualmente en la glessia sobre dita, sotz la pena auant dita, asi que dia e nueit no çesse de cremar» (DLAA, doc. n. ${ }^{\circ}$ 6, de Huesca, 1264; p. 7, lín.35-36); «si lo firiere de nueits (FA, vIII, $\int 325$, p. 190). Hoy, en la forma nuei se conserva en el aragonés del valle de Echo y en la forma nuet en el del valle de Bielsa (EBA, 1999: 1338; Andolz, 1992: 308). Frec.: nueyt 7: 0,01591; nueytes 3: 0,00682. 
número s. m. 'número': et con otros reyes moros por número XXV 3.91; las quales eran por numero LX 38.245. Etim.: tomado del lat. numerus (BDELC, p. 417). La 1.a doc. que da el BDELC es de 1433 (también el DCECH, IV, p. 251). La de la Crón. SJP. la adelanta en algo más de medio siglo. Vid. tb. nombre. Frec.: 2: 0,00455.

nunca adv. de tiempo 'nunca': pero nunca lo troboron ni muerto ni vivo 19.218; nunca dicensión fue entre ellos avida 20.299; que nunca la pudo sobrar nin desfer 37.22; etc. Etim.: del lat. NUMQUAM, compuesto de NE y UMQUAM 'alguna vez' (DCECH, IV, p. 232, s. v. no). Comp. occ. ant. nonca 'jamais' (LevY, s. v.). Vid. ningún tiempo. Frec.: 5: 0,01136.

\section{$\mathbf{O}$}

o conj. disyunt. 'o': en el tiempo o comencamiento del dito rey don Jayme, 38.625. Siempre o, excepto una vez ho: porque toda vegada ho quayx estuvo enfermo, 39.15. Del lat. AUT. Frec.: o 35: 0,07955; ho 1: 0,00227.

o interj. '¡oh!': $\because O$ cavalleros jet non vos yes verguença que delant vosotros aquesti cavallero catalán aya desmentido a mi et de vosotros ninguno non le aya respondido?» 38.327 . Frec.: 1: 0,00227.

obedecer v. tr. 'obeceder': et queriendo obedecer el su mandamiento... 36.92; a las requestas el dito rey don Jayme de Mallorcas non quiso obedeger 36.408; et assin como puro homme et vasallo suyo obedeciesse 16.34; a los mandamientos de aquélla, mientre vivió, obedeció 38.601. Etim.: del lat. OBOEDIRE 'íd.', antiguo derivado de AUDIRE, con evolución fonética latina (DCECH, IV, p. 267, s. v. oir). Tb. obedir. Frec.: obedecer 3: 0,00682; obedeçer 1: 0,00227; obedeciesse 1: 0,00227; obedeció 1: 0,00227.

obedir (var.: ovedir) v. tr. 'obedecer': et la hora todos los nobles et cavalleros et la gent menuda del dito condado obedieron al poder del rey 36.508; que d'aqui adelant obediessen a la Yglesia 38.123; el condado de Ampurias obedió al rey de Francia por tal que escondidament dasse dampanage a éll et a sus gentes 36.511; ya hyvan acordado [avian otorgado N] que obidiessen [ovedeçiesen N] a Carlos de Valoys 37.24; porque pudies complazer a Dios e al maestro apostolical ovedir 33.109. Etim.: del lat. OBOEDIRE íd., antiguo deriv. de AUDIRE (DCECH, IV, 267, s. v. oir). Tb. obedecer. Frec.: obedir: 2: 0,00455 ; obedió 1: 0,00227 ; obedieron 1: 0,00227 ; obediessen 1 : 0,00227; obidiessen 1: 0,00227 ; ovedir 1: 0,00227 . 
oblidar] v. tr. 'olvidar': las quales gents, por luenga paz, oblidoron [olvidaron $\mathrm{N}$ ] el uso de las armas 1.39. Etim.: del lat. vg. *OBLITARE, deriv. de OBLITUS, p. p. de OBLIVISCI 'olvidar'. En Berceo se halla también la forma etimológica oblidar (ÁLvarez, 1991: 188; DCECH, IV, p. 281). Comp. cat. oblidar (FABRA, DGLIC, s. v.); occ. oblidar (AliberT, s. v.); fr. oublier (PRobert, s. v.); etc. Comp. exolvidar que supone *EX-OBLITARE. Frec.: oblidoron 1: 0,00227.

obligado adj. 'obligado': et affilló et heredó al dito Remiro, su fillastro, en Aragón, el qual era de la reyna por razón de su casamiento obligado en arras 14.92. Frec.: 1: 0,00227.

obligar] v. tr. 'obligar': et todo quanto podía aver en qualquier manera todo lo dava, en tanto que obligó et metió pennoras [peynoras $\mathrm{N}]$ castillos, villas et rendas suyas porque pudies complir lo que havía en coracón et en voluntad 34.9. Etim.: cultismo del lat. OBLIGARE deriv. latino de LIGARE 'atar' (DCECH, III, 647). Frec.: obligó 1: 0,00227.

obra s. f. 'obra, acción': el compte don Pedro yva ya escuvriendo la su mala obra con la reyna 19.158; pregando al dito abat e a los ditos clerigos del dito monesterio que en lures oraciones e buenas obras deviesen aver a él e a su tierra por recomendados 11.29. Del lat. ŎPERA. Frec.: obra 3: 0,00682; obras 2: 0,00455.

obrado p. p. del v. obrar. Vid. obrar.

obrar] v. tr. 'obrar, elaborar', 'construir, hacer una obra': qui la ora non era obrado nin acabado 36.413. Del lat. OPERARE. Frec.: obrado 1: 0,00227.

observar v. tr. 'observar, cumplir': assí como es de costumbre et de ussança de reys todos tiempos observada 37.15; porque assi era enpresso en los capitoles de la paz. dessuso dita por mellor aquélla observar 38.115. Del lat. OBSERVARE. Frec.: observar 3: 0,00682; observada 2: 0,00455.

obtener] (var.: optener], ottener]) v. tr. 'obtener, alcanzar, conseguir, lograr': et aquéll que obtendría en la batalla que avies sueltament sin contradiccion el dito regno de Sezilia 36.256; et obtenida de victoria de tan grant batalla, rendió gracias a Dios et tornose con grant honor a su tierra 34.104; vinció et obtuvo victoria contra los enemigos 38.535; El dito don Roger optuvo palma de grant victoria 36.313; por la victoria que ottuvo contra el dito rey Ordonyo 9.7. Del lat. OBTINERE. Frec.: obtenía 1: 0,00227; obtendría 1: 0,00227 ; obtenida 2: 0,00455 ; obtenidas 2: 0,00455 ; obtenido 1: 0,00227 ; obtuvieron 1: 0,00227 ; obtuvo 5: 0,01136 .

occupador s. m. 'ocupador, el que ocupa, toma posesión o se apodera de algo': como occupador injusto de lur tierra 36.208. Deriv. del v. occupar con morfema derivativo -dor. Frec.: 1: 0,00227.

occupar (var.: ocupar) v. tr. 'ocupar, apoderarse (de una tierra)': non yva por occuparle su tierra 38.238; la tierra por los moros ocupada 26.19 // v. prnl. 'emplearse en un trabajo, dedicarse a un asunto o tarea': que non podian entrar a verlo, que ocupado era de afferes 20.33. Cultismo tomado del lat. OCCUPARE. Frec.: occuparle 1: 0,00227; ocupada 1: 0,00227 ; ocupado 1: 0,00227 . 
ochen num. ord. 'octavo': en el ochen día en las kalendas de noviembre 32.32. Con apócope de -o debido a que se encuentra en situación proclítica ante el sustantivo y, extrañamente, con fonética castellana del grupo latino -CT- > -ch-en lugar del resultado aragonés -it-. Vid. ocho, hueyto. Frec.: 1: 0,00227. ocho num. card. 'ocho': depués de ocho días rendiose sueltament al dito rey don Pedro 18.75. Es castellanismo por hueyto (vid.). Frec.: 2: 0,00455.

octobre s. m. 'octubre': en el mes de octobre entraron en la tierra de los moros, tallando et destruyendo plegoron a Valencia 19.194. Cultismo tomado del lat. octobris. Frec.: 2: 0,00455 .

odio (var. hodio) s. m. 'odio': Mas antes que las ditas fuerças aviessen acabadas, vino en hodio [oyda N] del Almaçor de Cordova 4.21. Se usa en la expresión aver en odio 'tener aversión o antipatía hacia una persona': el padre buvo en odio su fillo 36.40. Cultismo tomado del lat. odium 'aborrecimiento, aversión contra alguien o algo' (SEgura, 2001: 512). Frec.: odio 1: 0,00227; hodio 1: 0,00227.

odir] (var. hudir]) v. tr. 'oír': quando budió [vido N] quel rey de Huesca le havía crebantada la tregua [tierra $\mathrm{N}]$ 17.51; segunt que odiredes pora [poco $\mathrm{B}]$ avant 36.496. Del lat. AUDIRE. Comp.: port. y gall. owvir, cat. oir, occ. auzir, ausir, fr. ouir, francoprovenzal aouir, romanche udir, it. udire, rum. auæi (SEGURA, 2001: 67; Alibert, 1988: 132; Levy, 1980: 35; Vallés, 2007: 379). En arag. mod. se usa generalmente, con este mismo significado, sentir, atestiguado también en la Crón. SJP. Tb. oyr, sentir. Frec.: odiredes 1: 0,00227; hudió 1: 0,00227.

official] s. m. 'oficial': et aqui vicarios et officiales constituydos... 38.215. Tomado del lat. OFFICIALIS. Frec.: officiales 1: 0,00227.

officio s. m. 'oficio religioso, rezo diario de los eclesiásticos': et buey en día fazen aquel mismo officio 20.305. Frec.: 1: 0,00227.

offrecer] v. tr. 'ofrecer': $y$ offreció a honor de Dios e de los sanctos del dito lugar $D^{0 s}$ dineros de argent 11.42; et offrecióse a entrar en batalla 16.9. Del lat. OFFERRE > lat. vg. OFFERIRE (BDELC, p. 422). Frec.: ofreció 1: 0,00227; offrecióse 2: 0,00455.

omenage s. m. 'homenaje, juramento solemne de fidelidad hecho a un rey o señor': que le fizies omenage et sagrament de fieldat por las tierras que tenía por él 36.102. Etim.: tomado del ant. occ. omenatge y este del lat. *Hominaticum, deriv. de HOMINE en el sentido de 'vasallo'. Tb. homenage. Frec.: 5: 0,01136. ome] (var. omme]) s. m. 'hombre': sitió Tortosa con genobeses, con II" omes d'armas 32.26; prendiendo e matando ommes e fenbras 33.81. El sintagma omes d'armas vale por 'soldados, guerreros'. Del lat. HǑMINE. Vid. home. Frec.: omes 1: 0,00227; ommes 8: 0,01818.

onda] s. f. 'ola': en las ondas de la mar lo afogó 36.19. Etim.: del lat. ǓNDA 'ola, onda, remolino'. Fue general en cast. hasta fines de la Edad Media (DCECH, IV, p. 283). Frec.: ondas 1: 0,00227. 
onde conj. consecutiva 'donde'; por onde 'por donde, por lo cual': por onde entró la podre 36.607 // 'así pues, por tanto': onde [ent $\mathrm{N}$ ] como el dito Simón quisiesse las condessas de Tolossa hermanas del dito rey don Pedro desheredar, el dito rey pregó et amonestó al dito Simón 34.127. Del lat. UNDE 'de donde' (DCECH, II, p. 516). Comp. onde, ond, on 'de donde, por lo cual' en Fernández de Heredia (GILKIson, s. v.). Frec.: 5: 0,01136.

onor s. f. 'honor': propuso en su coracón que a onor de Dios fue a Sant Jayme fiziendo romeage 33.104. Obsérvese la constr:: a onor de 'en honor de'. Del lat. HONOS, HONORIS (acus. HONOREM) 'honor, honra, respeto, consideración' (SEGURA, 2001: 340). Tb. honor. Frec.: 1: 0,00227.

onrradament adv. 'honradamente': vinieron sende en el castillo de Arlet do fue reçevido muy onrradament 33.45. Tb. honradament (vid.). Frec.: 3: 0,00682.

onta s. f. 'afrenta'; 'deshonor, humillación, vergüenza, deshonra, injuria': queriendose vengar de la onta de la prisont, movió batalla con los franceses 22.17 . Etim.: del fráncico *haunitha. Cfr. Dauzat-dubois-mitterand, p. 374, $s$. v. honnir, Lausberg, I, p. 329; PRobert, s. v., p. 937; DECLIC, VI, p. 77. Comp. occ. onta (AliberT, s. v.), onta, anta, ancta (LEVY, s.v.); cat. ant. onta, honta (DCVB, s. v.); fr. honte (PRobert, s. v.). Comp. con el mismo significado onta, honta, hont, bontamiento en Fernández de Heredia (Gilkison, s. v.). Véase también onta 'injuria' en FA (voc. p. 497): «peite por calonia DCCCC sueldos a la eglesia a qui aurá feita la onta» $(F A, \mathbb{1} 1,3, \mathrm{p}$. 10). También se utilizó en it. onta y en cast. med. onta, honta, fonta (cfr. VMC, s. v. honta), aunque en estos idiomas tomado del fr. ant. honte (cfr. Devoto, s. v. onta). Frec.: 1: 0,00227.

opposar] v. prnl. 'oponer(se)': viendo quel dito regno se perdía, opposándose por muro por la fe en la yglesia de Dios... 36.70. Del lat. Opponere (DECLIC, VI, p. 744, s. v. posar). Hay que suponer que el v. se rehizo sobre el tema de perfecto. Comp. opposar, oposar y opponer en Fernández de Heredia (GILKison, s. v.). Frec.: opposándose 1: 0,00227.

oppresso p. p. del v. opprimir, 'oprimido': de grant malautia fue oppresso 38.90. Se trata del participio fuerte, que es irregular. También se registra el participio regular, opprimido, -a. Vid. oprimir. Frec.: 1: 0,00227.

opprimir] v. tr. 'oprimir'; 'afligir': de grant malautia fue oppresso 38.90; quando muyto la buvo opprimida 35.144; el santo rey don Jayme en la su reverent vellesa fue opprimido en el dito regno de fiebre continua 36.68. Del lat. OPPRIMERE. Frec.: opprimida 1: 0,00227; opprimido 1: 0,00227.

oprissión s. f. 'opresión', 'aflicción': que del grieu cativerio et oprissión a qui era baldonada, la devies preservar et delibrar 36.196. Del lat. Oppressio, -ONIS. Frec.: 1: 0,00227. 
or 35.92 de la ed. crítica, es error por por: buvo muytos enueyos [enoyos $\mathrm{N}$ ] et treballos, et or tesegueza [tisiguera N] murió en Foyx en el anno de Nuestro Sennyor MCC XLVII, 35.91-92. En el ms. B, fol. 52r, se lee: por tessegueza. Vid. por. Frec.: 1: 0,00227 .

ora s. f. 'hora'; 'tiempo oportuno y determinado para una cosa': «iagora yes ora quando se yes partido?» 38.332. // pl. 'oficio religioso en que se recitan diversas partes del breviario en distintos momentos del día', 'esas partes del breviario': et que diriessen las oras a costumbre de monges negros 20.304 / / la ora, las oras, a la ora, a las oras loc. adv. 'entonces': qui a la ora pululiva et floriva en toda la christiandat 14.99; porque entro a las oras todo lo que se fazia en la tierra se judgava a arbitrio de los presidentes en aquella 14.4; et murieron la ora de los enemigos mas de CCC hommes 38.550; et las oras era conte de Bisuldu Bernart Trenchaforte 27.15. Vid. sobre esta loc. adv. GILI GAYA, «A la hora», Misc. Griera, t. I, pp. 281-288. Las loc. adv. la ora, las oras o semejantes son comunes en arag. medieval. Actualmente, allora 'entonces' en el valle de Echo, alora en Ansó, aloras en Jasa (EBA, 1999: 149 y 154). Frec.: ora: 36: 0,08183; oras: 13: 0,02955.

oración] s. f. 'oración': por las quales palauras et oraciones lo firo Dios bivir luengament al su servicio 35.247. Del lat. ORATIONE(M). Frec.: oraciones 3: 0,00682.

orden s. f. 'orden; institución monástica religiosa que sigue unas reglas establecidas; norma, guía o regla por la que se rige': del monesterio de San Fagundo et Primitivo que yes en Castiella de aquella mesma orden de San Benedito 20.77-79 // 'orden sacerdotal, sacramento de la Iglesia por el cual son instituidos los sacerdotes': algunas cronónicas dizen que no era en sacres órdenes 20.72 // s. m.: que le diesse licencia de sallir del Orden 20.70; fue metido en el monesterio de San Ponz de Tomeras del orden de San Benedito 20.75-76. Etim.: descendiente semiculto del lat. ORDO, -INIS (masculino) 'orden'. Frec.: orden 16: 0,03637; órdenes 2: 00455.

ordenar] (var.: hordenar) v. tr. 'ordenar, poner en orden': e hordenaron sus azes 19.115; e bordenó su testament e restituyó beredero 33.120. // 'mandar, prevenir que se haga una cosa': et los sus capellanes ordenolos perpetualment seer beneficiados en la iglesia 20.303; lo que ellos farian ni ordenarian cada una part havies por firme et agradable 20.156. Frec.: ordenada 1: 0,00227; ordenadas 1: 0,00227 ; ordenado 11: 0,02500 ; ordenados 1: 0,00227 ; ordenarían 1: 0,00227 ; ordenava 1: 0,00227 ; ordenó 7: 0,01591; ordenolos 1: 0,00227; ordenoron 3: 0,00682.

ordido adj. 'intrépido, arrojado': fue muy bueno et piadoso, ordido et benigno 13.7. Comprobado en el ms., aparece con o-, pero debe de ser error de escritura por ardido (vid.). Frec.: 1: 0,00227.

ordinaciones s. f. pl. 'ordenación, disposición, regulación, reglamento'. Úsase en pl. en las dos apariciones: que si no servava los privilegios que feito avía a la dita unión et las ordinaciones que avian feitas ellos 37.30-31; et que semblant pena fues possada a 
los sus succedidores si las ditas ordinaciones [ordenanças $\mathrm{N}$ ] passavan 37.34. Etim.: del lat. ORDINATIO, -ONIS. Se trata de un cultismo. No lo registra Bustos Tovar en Contribución al estudio del cultismo léxico medieval; sí, en cambio, ordenamiento, p. 593. Corominas (BDELC, p. 425) documenta ordenación por primera vez en 1490. Vid. también DCECH (IV, p. 291, s. v. orden). La Crón. SJP. adelanta en algo más de un siglo la 1. ${ }^{a}$ documentación (naturalmente, de la variante aragonesa y en pl. ordinaciones). Frec.: 2: 0,00455.

orella] s. f. 'oreja': et metianse por las orellas et por las narizes de la gent 36.600. Etim.: del lat. AURICULA, dim de AuRIS 'oreja' (DCECH, IV, p. 293). Se conserva en arag. moderno: vid. ANDolz (1992: 313), EBA (1999: 1354). Es voz común a las lenguas románicas. Comp. port. orelha, gall. orella, ast. oreya, cat. orella, cast. oreja, occ. aurelha, fr. oreille, francoprovenzal orelye, retorrom. ureglia, friulano orele, piamontés orija, véneto recia, it. orecchio, sardo origra, siciliano ariccbia, rum. ureche (VALLÉs, 2007: 382). Frec.: orellas: 1: 0,00227.

orgul s. m. 'orgullo': el dito don Pedro Atares, encara non seyendo esleydo por rey, empeçó muito a levantarse mas en orgul que no primero [orguyl mas que no de primero $\mathrm{N}$ ], 20.8. Etim.: del fráncico *URGOLI 'excelencia' (BDELC, p. 426; DECLIC, VI, p. 112; $D C E C H, I V$, p. 296). En arag. med. existió la forma diptongada orgüello. Puede verse, por ej., en $L R$, fol 10, lín. 2, pp. 28 y 45 . Aunque también se documenta la forma sin diptongar: orguill en $L M M$, p. 185, s. v. En el arag. de Fernández de Heredia, orgull, ergull, erguyll, ergul, erguel (GILKIsON, pp. 57 y 98). Estas últimas formas con $e$ - pueden explicar el arag. mod. argïello (ANDolz, s. v.; MотT, 2000: 58), con apertura vocálica $e$ - $>a$ - propiciada por la vibrante siguiente. En cat. orgull (FABRA, DGLIC, s. v.; DCVB, s. v.); occ. ant. ergolh, orgolh, orgul, orgulh (LEVY, s. v.), occ. mod. orguèlh, orgulh (ALiBerT, s. v.), it. orgoglio (Devoto, p. 293, s. v.). Este vocablo se encuentra también en la toponimia de origen occitano de San Sebastián: Monte Urgul. El cast. orgullo procede del cat. orgull según CoROMINAS (BDELC, s. v.). El arag. orgul puede también proceder de la forma catalana (Motт, 2000: 58) o bien de la occitana. Según Devoto (p. 293, s. v.) el it. orgoglio proviene del provenzal orgolh. Comp. ergul, ergullar. Frec.: 1. 0,00227.

orifany s. m. 'elefante': et fue possada [en la torre $\mathrm{N}$ ] sobre lapeire del Orifany [poyre del orisani N] 38.573-574. Tomado del cat. ant. orifany 'elefante' y éste del lat. ELEPHAS, -ANTIS, procedente del griego $\varepsilon \lambda \varepsilon \varphi \alpha \varsigma,-\alpha \nu \tau O \varsigma$. En cat. med. se documenta aurifany, aurifan, orifan, orifany, olifant. Comp. oc. ant. olifan, orifan, aurifan; fr. ant. oliphant (DECLIC, III, p. 265). En arag. med.: orifant, orifan, horifant, oriflan, helefant, elefant, elifant en Fernández de Heredia (GILKison, p. 98, s. v. orifant); oriflans, oriphantes, oriffantes en $L M M$, p. 185. Frec.: 1: 0,00227.

original adj. 'original': El traslat del qual privilegio yes en el monesterio de Sant Johan de la Penya, que lo retinieron [reçevieron $\mathrm{N}$ ], que alli era el privilegio original 34.50. Cultismo tomado del lat. originalis. Frec.: 1: 0,00227. 
ornar] v. tr. 'ornar, adornar': et enrriquió et ornó el altar mayor del dito monesterio et de esmeraldes et safires, robices et carboneles et otras piedras preciosas 28.21. Tomado del lat. ORNARE. La 1. ${ }^{a}$ doc. en cast. que da Corominas es de 1438, en el Corbacho (DCECH, IV, p. 302). Frec.: ornó 1: 0,00227.

oro s. m. 'oro': El qual se redimió por grant quantía de moneda d'oro 36.553. Del lat. AURUM. Frec.: 3: 0,00682.

orrible adj. 'horrible, que causa horror': el qual avia nombre Caci qui era de muyt estranna et orrible figura 1.23; le demandoron ultra otras orribles [terribles B] et desordenadas cosas que si no servava los privilegios que feito avía a la dita unión et las ordinaciones que avian feitas ellos, que pudiessen esleyr otro rey et a ell gitar el regno 37.30. Del lat. HORRIBILIS. Frec.: orrible 1: 0,00227; orribles 1: 0,00227.

ossado] adj. 'osado, atrevido': qui non temían fridores ni calores porque yeran todos tiempos ossados [usados N] 12.55. Frec.: ossados: 1: 0,00227.

ossar] v. tr. 'soler, acostumbrar': non les ossava venir vianda alguna 36.621 // 'osar, atreverse': ninguno de Castiella no ossó prender del rey 18.80; et non osava aquesto revelar a ninguno 20.101. Del lat. AUSARE, frecuentativo de AUDERE, part. AUSUS (DCECH, IV, p. 317). Comp. arag. mod. gosar, también con los dos sentidos 'soler, acostumbrar' y 'atreverse a' (ANDOLZ, 1992, s. v.). Frec.: ossava 1: 0,00227; osava 1: 0,00227 ; ossó 1: 0,00227 .

otri pron. indef. 'otra persona': el rey don Jayme de Secilia nombrado el Justiciero porque non plannya fazer justicia de si mismo a otri, ni de part a part en Catalunnya 38.7. Etim.: del dativo lat. ALTERI 'para otro', según Corominas (DCECH, IV, p. 323, s. v. otro). Para Menéndez Pidal, MGHE, p. 265, la -i de otri procede de la $-i$ final de qui. Lo mismo opina Garcia de Diego, Gram. hist., pp. 103, 214, 219, quien en la pág. 200 escribe: «Las formas otri, otre de ALTERI perduran en Aragón, Navarra, Rioja, Soria y Cuenca». Según Menéndez Pidal (ibídem, p. 265), aún es usual en Navarra y Álava; Corominas (ibídem) añade que es usual en pueblos de Soria y Logroño, además de Navarra. Aporta tb. doc. en cast. med., desde el s. XIII al XV (última cita en La Celestina). Iribarren, Vocabulario navarro, cita, s. v. otri, p. 384, de otri y pa utri. Y aporta varias citas del Fuero General de Navarra: «en heredad qui otri tiene, de omne que prenda a otri... ni por sí ni por otri». No se registra en Tucídides; GILKIsON (1984) lo recoge s. v. otro (como si fuera una variante de este, lo que puede ocasionar confusión). Es voz común en arag. mod. Andolz (1992, s. v.) la registra en los valles de Echo y de Chistau; Alvar (DA, p. 215) dice que la forma otri parece propia del Somontano (Huesca, Barbastro) y que llega también al límite oriental del Campo de Jaca (Sabiñánigo). Añade que era forma «conocida desde el s. XIII tanto en los documentos jurídicos navarros como en los aragoneses». Ya registra otri el Diccionario aragonés [anónimo de h. 1803-1815] (BERNAL 
\& Nagore ed., 1999: 107). También registran otri Pardo, Borao y Peralta. Podrían añadirse otras muchas referencias en arag. moderno; véanse, entre otras: otri 'otra persona' en el Valle de Tena (NAgore, 1986: 97), en el Valle de Chistau (Мотт, 2000: 185; Blas \& Romanos, 2008: 397); en Ansó (Mendiara et al., 2003: 64); en Murillo de Gállego (Palacios \& Baos, 2010: 108); otri 'otro; se usa sólo precedida de las prep. para y de' (Fuencalderas; en Arbués Possat, 1980: 172; 2012: 188). Otras referencias de otri en diversos puntos del Alto Aragón — desde la Plana de Uesca hasta el Biello Sobrarbe, desde el Somontano de Barbastro a la Fueba o al valle de Broto- pueden verse en el EBA (1999: 1359). Del mismo origen y empleo análogo, cat., occ., e it. altri; el fr. autrui viene del dativo vulgar ALTERUI (DCECH, IV, p. 323). Vid. más documentación en el estudio lingüístico, 5.6.1.10 (NAGORE, 2003: 288-289). Frec.: 1: 0,00227. otro pron. y adj. indef. 'otro': et la otra sennyera fue possada en el canpanal, 38.574; la qual cosa et por otras que fizo a su cunnyado... 38.619; de dos hombres buenos de Mallorquas et de otros dos de Perpinyan, 38.605. / / el otro día loc. advl. 'el día siguiente': en el otro día, aquellos del castiello demandoron tregua 38.555. Etim.: del lat. ALTER, -ERA, -ERUM 'el otro entre dos'. 1. ${ }^{a}$ doc.: orig. del idioma. Testimonio del arag. en la forma altro en Glosas Emilianenses (h. 950): Dicit denuo [altra] anima (glosa 116; LHP, p. 44; Origen aragonés de las Glosas Emilianenses, p. 105). Testimonio del cast.: otro, en Cid. Según hacen notar Corominas-Pascual, el cast. (y también bastante el port.) se apartan de los idiomas hermanos en no admitir el empleo del artículo indefinido un en combinación con otro; sin embargo, en aragonés es frecuente: así, vemos un otro en arag. ant. en Invent. arag. de 1379 (BRAE, II, 711) y en otros de esta colección (DCECH, IV, p. 323). Véase en la Crón. SJP: Otrossí un otro compte don Pero de Lara puniava encubierto de aver amor de la reyna 19.107. También está registrado en arag. moderno: «pero tos quiere’spllicá / un otra segunda parte» (Cleto TORRODELlas, Versos y romances en ribagorzano, p. 64). Frec.: otra 46: 0,10455; otras 44: 0,10001; otro 73: 0,16592: otros 83: 0,18865.

otrosí (var.: otrossí) adv. 'además, asimismo'; ‘también, de igual modo’: Otrossí un otro compte don Pero de Lara puniava encuvierto de aver amor de la reyna 19.107; otrosí fueron con ellos 38.199. Etim.: cpt. con si' 'así' (del lat. SIC): formación común con los demás romances, port. outrosim, cat. ant., oc. ant., it. altresí, fr. aussi. Ya Aut. nota que ha pasado a ser característico del lenguaje forense, único donde se emplea en la actualidad en castellano (DCECH, IV, p. 323b, s. v. otro). Frec.: otrosí 4: 0,00909; otrossí 1: 0,00227.

oy (var.: hoi, hoy) adv. 'hoy': et hoi es clamada Barcelona 1.35; et hoy es clamada Vich, 1.31; et la división destos regnos fue metida en el monesterio de San Joan de 
la Pennya que alli fues perpertuo [perpetualment $\mathrm{N}$ ] conservada et yes oy en dia 20.172; et oyo [oy $\mathrm{N}]$ en dia lo recivie de Navarra 34.86. Vid. huey. Frec.: hoi 1: 0,00227 ; hoy 3: 0,0682 ; oy 10: 0,02273 .

oyr (var.: odir) v. tr. 'oír': quando budió [vido N] quel rey de Huesca le bavía crebantada la tregua [tierra N] 17.51; segunt que odiredes pora [poco B] avant 36.496; et oyda su missa devotament, pregó carament los ditos abad et clerezía del dito monasterio que lures oraciones et buenas obras lo deviessen haver por recomendado 11.43; no lo avemos visto nin oydo dezir sino agora 38.132; una campana quería fazer en Huesca que de todo su regno se oyesse 20.127; mas depués por convinencia lende rendió part segunt adelant oyredes. 38.212. Etim.: del lat. AUDIRE (DCECH, IV, p. 266). Vid. odir. Frec.: hudió 1: 0,00227; odiredes 1: 0,00227 ; oyr 1 : 0,00227 ; oyredes 3 : 0,00682 ; oyda $1: 0,00227$; oydo $3: 0,00682$; oyo 1: 00227 ; oyó 2: 0,00455 ; oyeron 1:0,00227; oyesse 1: 0,00227 .

\section{$\mathbf{P}$}

paciencia s. f. 'paciencia': «et ámalos porque ellos te amen et ayas paciencia et humildat que es començamiento de todos los bienes» 35.269. Cultismo tomado del lat. patientia. Frec.: 1: 0,00227.

pacifficar] v. tr. 'pacificar': deseando que paz et amor fuesse entre ellos, pacifficó la dita discordia 35.30. Cultismo tomado del lat. pacificare 'tratar de paz', 'apaciguar' (DCECH, IV, p. 445). Frec.: pacifficó 1: 0,00227.

paçificadament adv. 'pacíficamente, en paz': et en continent recobró toda la tierra e aquella tovo mientre vivió paçificadament 33.61. Frec.: 1: 0,00227.

pacífico] adj. 'pacífico': et diele por habitación [herençia N] pacifica Gallia, qui agora yes dita Francia 3.33. Cutlismo tomado sel lat. pacificus, -a, -um. Frec.: pacífica 1: 0,00227 .

pacto s. m. 'pacto': tractó pacto con los franceses que les livraría la ciudat con que les lexasse yr salvos 36.611. Cultismo tomado el lat. pactum 'acuerdo, convenio'. En arag. mod. es pauto, con evolución -ct- $>$-ut- propia de semicultismos. Se registra pauto 'pacto' en La Puebla de Castro (Bruballa, 2009: 85), Binéfar (EBA, 1999: 1496; Coll, 1902), Huesca y la Litera (ANDOLz, 1992: 326), A Sotonera (GArCÉs, 2005: 255), Somontano de Barbastro (Mostolay, 2007: 425), Bal de Chistau (Blas/Romanos, 2008: 409), Bal d'Echo (Lera, 2004: 159), etc. Para Huesca, vid. ejemplos en NAgore (2020: 487). Frec.: 1: 0,00227. 
padre 'padre' s. m.: en las otras tierras a ell por el dito emperador, su padre, dadas et assignadas, 16.13; mas non lo quiso prender entro ha quende fues forçado por el Padre Santo. 38.609. Del lat. PATRE(M), acus. de PATER, -TRIs. Frec.: 105: 0,23866.

paga s. f. 'acción de pagar': quel tiempo de la paga del sueldo se acostó 38.308. Deriv. postverbal de pagar. Frec.: 1: 0,00227.

pagadament adv. 'con satisfacción': en Catalunnya sen tornó pagadament [pagado $\mathrm{N}$ ] et alegre 38.216. Frec.: 1: 0,00227.

pagado adj. 'satisfecho, contento', 'complacido, ufano': Et quando la madre lo vido fue muyt pagada et alegre et conosció que era su fillo 23.24; de la quoal cosa el dito rey García Yneguiz fue muy pagado e alegre 11.35; et mostroles su fillo; et quando lo vieron fueron ne muyt pagados et alegres 23.30. Del p. p. del v. pagar, usado con el sentido de 'satisfacer, contentar'. Frec.: pagado 6: 0,01364; pagada 2: 0,00455; pagados 1: 0,00227.

pagamiento (var.: pagament) s. m. 'satisfacción, contento, gusto': el dito rey don Pedro cuytadament vino sende a la ciudat de Mecina do fue recebido con grant goyo et pagament 36.223; el legado et la buest francesa qui en Napoles eran fincados passoronse en secilia con grant goyo et pagamiento. 38.288. Etim.: deriv. del v. pagar(se) 'estar satisfecho', del lat. cl. PACARE, que sólo se empleaba para 'apaciguar, someter', pero en la baja época ya se encuentra en la acepción 'apaciguar, calmar, aquietar'. Todos los romances presentan desde el principio el sentido 'contentar, satisfacer', de donde pasa a 'satisfacer al acreedor, pagarle' y finalmente 'pagar una cantidad' (ya doc. en Cid) (DCECH, IV, p. 337). Comp. cast. ant. pagamiento en Berceo, Alex., etc. (DME, s. v.). La variante pagament responde a fonética catalana; el resultado fonético pagamiento es tanto castellano como aragonés. Frec.: pagamiento 2: 0,00455; pagament 1: 0,00227.

pagar v. tr. 'pagar, abonar una cantidad, satisfacer al acreedor': la moneda para pagar el sueldo a los aragoneses, 19.146; e pagó el sueldo de los suyos 19.150; et pagóle luego tantost el sueldo 36.397. Del lat. PACARE 'satisfacer, contentar', y luego 'satisfacer al acreedor' (BDELC, s. v.). Frec.: pagar 2: 0,00455; pagó 1: 0,00227; pagóle 1: 0,00227 .

palacio s. m. 'habitación, sala, cuarto de una casa': fizose decender del cavallo et levar al palacio et posses [posose $\mathrm{N}$ ] en el leyto 37.93; Et como en aquel tiempo, por miedo de los árabes, todo hombre tenies sus cavallos en las cambras o palacios do lurs mullers estavan... 14.32. // 'palacio, edificio grande y lujoso destinado a residencia de reyes o altos personajes': porque el dito conte destruyó et derrocó una vegada la villa de Figueras et el palacio de aquella, el qual avía feito el dito rey 36.440. Cfr. palacio 'habitación de una casa, sala de reunión' en el arag. del s. XV (VILA, 1990: 139). Cultismo tomado del lat. palatium 'palacio'. CorominAs hace notar la acepción 'habitación, sala' en Invent. arag. de 1379 y 1497 (DCECH, IV, p. 346). El DEA recoge 
con marca de regional palacio 'sala principal de una casa'. Frec.: palacio 4: 0,00909; palacios 1: 0,00227.

paladinament adv. 'públicamente, manifiestamente, palmariamente': Et todos días los de la ciudat exian les apalatiz, [apalaciz B] escondidament et paladinament matoron ne sin nombre 36.574. Corresponde a la loc. adv. a palesa en la VC y a palam en la VL. Deriv. de paladino 'claro, público, manifiesto' < lat. Palatinus 'de palacio' y de ahí luego 'público' (DCECH, IV, p. 347). Este adv. es de uso habitual en arag. med.: «de alli no salliremos nj nos partiremos nj salliran o partiran de dia nj de nueyt paladinament publica nj scondida» (ACA, Fondo de Sástago, pergamino 192; en LLEAL [dir.], 2007; doc. 35, p. 187). Frec.: 1: 0,00227.

palaura (var.: paraula, palavra) s. f. 'palabra': Et muytas palavras dixieron assí como desenparados contra el dito rey don Jayme reptándolo de fe. Et tornoron la palaura dessuso dita otra vegada: «Sennyor, dezit nos a qui queredes que esliamos por sennyon» 38.135; aplegó todos los cavalleros et la otra gent qui a las palavras dessuso ditas eran presentes 38.326; porque luenga paraula [palavra N] engendra enoyo en leyr et en oyr 2.3. Del lat. PARABOLA 'comparación' (tomado del griego $\pi \alpha \rho \alpha \beta o \lambda \eta$ 'alegoría'), que en romance adquirió el sentido de 'frase' y luego 'vocablo' (DCECH, IV, p. 345). Seguramente, las formas palaura y palavra son solo variantes gráficas de lo que fonéticamente sería [paláßra]; en la forma paraula no se ha producido la metátesis $r-l>l-r$. Comp. a este respecto parola, paroliar, parolería y parolero en arag. mod. (EBA, 1999: 1392-1393). Frec.: palaura 1: 0,00227; palauras 4: 0,00909; palavra 1: 0,00227; palavras 4: 0,00909; paraula 1: 0,00227; paraulas 2: 0,00455 .

palma s. f. 'palma, emblema de la victoria': El dito don Roger optuvo palma de grant victoria 36.313. Tomado del lat. PALMA 'palma, emblema de la victoria', 'victoria'. Frec.: 1: 0,00227.

pan s. m. 'pan': et por aquesta plaga et por fambre grant que sufrian de pan, de vino et todas viandas 36.618. Del lat. PANE(M), acus. de PAN, PANIS 'íd.'. Frec.: 1: 0,00227.

papa s. m. 'papa': e ovo un privillegio del papa Urvano II ${ }^{\circ}$ 18.119; el dito rey Jayme poso en su corrazón de visar [visitar $\mathrm{BN}$ ] las altezas de los Apóstoles de presentarse delant el Papa 38.171. Del lat. PAP(P)A 'padre, término de respeto dirigido a obispos y otros dignatarios eclesiásticos', del griego $\pi \alpha \pi \pi \alpha \varsigma$ 'papá' (DCECH, IV, p. 382; Segura, 2001: 532). Frec.: 9: 0,02046.

papal adj. 'papal, del papa o relativo al papa': que lo podía fazer por el privillegio papal ganado por su bermano el rey don Pedro 19.17. Deriv. de papa < lat. PAP(P)A 'padre', del griego $\pi \alpha \pi \pi \alpha \varsigma$ 'papá' (DCECH, IV, p. 382). Frec.: 1: 0,00227

papallón s. m. 'pabellón', en el sentido de 'colgadura', 'bandera', 'estandarte', 'enseña militar': et por aquesta donación el Padre Santo por honor de la casa de Aragón constituyó quély todos sus succesores levassen un papallón feito a sennal del rey de Aragón 
34.40-42. [...constitui que ell et tots sos succeidors portassen un papallol feit a senyal del rei d'Aragó. VC, p. 112; uexillum VL, p. 135.]. Etim.: del lat. PAPILIO, -ONIS 'mariposa', y más tarde 'tienda de campaña'. Comp. cat. papalló < PAPILIONE (MolL, Gram. hist. cat., p. 97). El Glossari de la VC traduce papallol por 'estendard'. El cast. pabellón es un galicismo procedente del fr. ant. paveillon 'tienda de campaña' (hoy pavillon) y este del lat. PAPILIO, -ONIs 'mariposa' (DLE, 2014, s. $v$; BDELC, s. v.). Corominas lo documenta por $1 .^{\mathrm{a}}$ vez con el sentido de 'tienda de campaña' en 1490; con el de 'glorieta, emparrado' en 1641; con el de 'dosel que cubre una cama, un trono' en 1495; y con el sentido de 'bandera con las armas de la Corona’ en 1737 (DCECH, IV, 329). Así que la Crón. SJP. adelanta en tres siglos y medio la $1 .^{a}$ doc. con este último sentido (aunque, evidentemente, no en la forma pabellón, sino papallón). En cat. mod. se utiliza con este sentido pavelló, mientras que papalló tiene únicamente el valor de 'mariposa' (FABra, DGLIC, s. v.). Pero cat. ant. papalló 'tienda militar', 'dosel', con las var.: pavelló, pavalló, paballó (DECLIC, VI, pp. 248-249, s. v. papallona). Comp. occ. ant. pabalhon, pabalhol, papalhon 'pabellón', 'tienda', 'palio' (Levy, s. v.). En Fernández de Heredia no se registra papallón, pero sí pauellon, pauallon 'pabellón, tienda'. Se registra papallón, pavallon, pabillon 'tour de lit' en invent. arag. de 1487 (ELIA, núm. 981). Véase también en la Crón. de Juan II (IV, 16): «ordeno que todos sus sucesores levasen hun papallon a senyales del rey de Aragón» (RiQuer, 1944: 9). La forma catalanizada fonéticamente papallo 'pabellón, colgadura plegadiza que cobija y adorna el altar' en LCMA, p. 279. РоттіER da el español pabellón como galicismo adoptado en el s. Xv, procedente del fr. ant. paveillon (cfr. ELH, II, p. 133). Para el port. pavilhão 'bandeira', 'construção leve, de madeira ou de outro material' también se postula un préstamo del fr. pavillon < lat. papilio, -onis (CunHA, 1986: 588). Frec.: 1: 0,00227.

para prep. 'para', 'hacia': lexólos en el campo e fuese para la reyna que hera en Burgos 19.120; e fuyendo con la reyna en Tormón cerca Palentia se entraron e tornose para Aragón 19.157. Etim.: < lat. PRO AD, «probablemente alteración del antiguo pora, compuesto de por y a, alteración facilitada por el influjo de la antigua preposición par, que se empleaba en juramentos, procedente de la lat. PER. Al cambio de pora en para además de la fonética contribuyó el influjo de la otra preposición par, que se empleaba casi generalmente en fórmulas de exclamación y juramento como par Dios, par Sant Esidre [Cid, etc.], etc., y que según indicó MENÉNDEZ PIDAL no es galicismo sino prolongación autóctona de la prep. latina PER. El caso es que más tarde este par es asimismo sustituido por para. Hoy para sustituye a hacia en el uso común americano (como en portugués), uso del cual ya abundan los antecedentes medievales y clásicos: "que se fuesen para allá e que quería fablar con ellos” (Caballero Zifar)» (DCECH, IV, pp. 388-389). Conviene hacer notar que la forma para no se registra ni una sola vez en el ms. E y solo excepcional- 
mente (5 veces) en el ms. B; el resto de los ejemplos pertenece a fragmentos solo conservados en el ms. N, el más castellanizado. Vid. pora. Comp. enta. Frec.: 12: 0,00227.

parada s. f. 'parada, formación de tropas': en un pueyo qui agora es clamado Santa María del Puyg et toda la morisma viniés contra ellos en la batalla, qui entre ellos fue muyt grant, les apareció Sant Jorge con muytos cavalleros de parada [paradiso $\mathrm{N}]$ qui los ayudó a vencer la batalla 35.233. Deriv. de parar < lat. PARARE 'preparar, disponer'. Frec.: 1: 0,00227 .

paradiso s. m. 'paraíso': les apareció Sant Jorge con muytos cavalleros de parada [paradiso $\mathrm{N}]$ qui los ayudó a vencer la batalla 35.233. Del lat. PARADIsus. Aparece solo en el ms. N, pues en el ms. B se lee parada. Es voz habitual en arag. med.: «...estando en nuestro buen seso \& sana memorja \& paraula, temjendo las penas jnfernales, copdiciando yr a la santa glorja de paradiso, ffemos nuestro vltimo testament» (MDF, p. 172, lín. 5). Se registra en el arag. de Ferrández d'Eredia (GILKISON, 1984: 99). Frec.: 1: 0,00227.

parar] v. tr. 'preparar, disponer, aprestar': el rey de Caragoca con todo su poder paró sus az̧es et començó la batalla 18.41; En aquell mismo día, don Alfonso fillo suyo paró el estendart a Barçalona por fer el viage de Cerdennya. 38.483. Etim.: del lat. PARARE 'preparar, aprestar, aparejar, disponer, arreglar, decidir, concertar, dejar al cuidado de, procurarse, resolver' (BLÁNQuEZ, p. 1102, s. v. paro); 'preparar, disponer' (DCECH, IV, p. 393). Esta acepción se ha conservado en aragonés moderno. Corominas cita de TORRES Fornés parar la mesa 'poner la mesa' en el arag. residual de Segorbe (Castellón), que también se registra en el Alto Aragón: así, en la Baja Ribagorza (Arnal Purroy, 2003: 144); parar a mesa en el Somontano de Barbastro (Mostolay, 2007: 419), en Huesca y su entorno (NAGore, 2020: 479), etc. En el arag. mod. sigue utilizándose parar 'preparar', 'disponer'. ANDolz, s. v., lo documenta con el significado de 'armar una cosa desarmada' en Magallón; pero es un significado muy extendido. Es general la expresión parar cuenta 'darse cuenta, fijarse, poner atención' (ANDOLZ, s. v. parar, BADÍA, Bielsa, p. 312; GARCÉs, 2005: 253; Ríos, 1997: 128; EBA, 1999: 1387-1388) y muy habitual también parar o colchón 'varear el colchón': GARCÉs (2005: 253) la registra en A Sotonera; Ríos (1997: 128) en el Somontano de Balbastro; Olano (1994, s. v. parar) en Uncastillo; Compaired (1996, s. v.) en Luesia; etc. Frec.: paró 2: 0,00455.

paraula s. f. 'palabra'. Vid. palaura.

parece] v. intr. 'aparecer': et enderrocó los muros et los fundamientos de aquel lugar, assí como pareçe oy en dia 4.37-39; que todo los reyes de Aragón e los nobles e cavalleros pudiesen dar de las conquistas que farian todas las iglesias, salvant catedrales, ruegos e necesidades tener aquellas e las décimas en tal que las ygleisas feziesen servir, segunt por el privilegio parece 18.123; que en ninguna manera non le parecies delant, mas que tenies 
acerca su tierra 38.236; e pareçiole ant'él vestido d'escarlata en un cavallo blanco 19.84. mas tanta era la multitudo de la gent estrannya que ya sea que sin nombre ne matoron a malas se parecía 36.578. ['que aunque sin número mataron de ello [gente], a montones se aparecía']. Del lat. vg. *PARESCERE, deriv. de PARERE 'aparecer, parecer' (DCECH, IV, p. 400). Frec.: parece 1: 0,00227; parece 1: 0,00217; parecía 2: 0,00455; parecies 1: 0,00227; pareçiole 1: 0,00227.

parellado adj. 'preparado, dispuesto': porque él paraellado [sic] era de ayudar et seguir [a servir $\mathrm{N}]$ como fillo a padre 19.175; todas las galleras que alli eran parelladas 38.261; «yo so el rey de Aragón parellado a fer et complir todo lo que conviene al judicio de la batalla». 36.295; que le diessen el trasoro de la iglesia de Pamplona et que faría parellar CCC $^{o s}$ de cavallo pora la dita guerra et por defender el su regno; et fuele atorgado et fueron aquéllos parellados. 20.234; por la qual rebellión el dito rey Carlos, qui [con] grant poder de homes a cavallo et a pie avía perellado [parellado B] contra el enperador de Costantinnoble 36.213. Del p. p. de parellar (vid.). Frec.: parelladas 2: 0,00455; parellado 1: 0,00224; parellados 2: 0,00227; perellado [parellado B] 1: 0,00227; paraellado 1: 0,00227 (sin duda, error del copista, en el propio ms., por parellado).

parellament (var.: parellamiento). En todos los ejemplos que se citan parece error por parlament parlamiento 'parlamento', 'conversación', en el sentido de 'asamblea donde se parlamenta', 'acto de reunirse para parlamentar', 'asamblea de gente que delibera': et un dia, clamados ensemble los nobles cavalleros con la gent popular et de la tierra por levantar rey qualque noble varón, quisieron tenerparellament [parlament N], 12.17-19; et el noble varon que la critatura havía estorcido a muert, sabiendo el nuevo parellamiento [parlament $\mathrm{N}$ ] ques decía tener por el general de la tierra... 12.20; en el dia assignado al dito aparellamiento [parlament $\mathrm{N}$ ] fue present et, entrando por el palacio do se celebrava el dito parellamiento [parlament N], 12.24-26. Como se ve, en todos los casos se registra parlament en el ms. N. Igualmente, en todos los casos la VC tiene parlament y la VL generale colloquium (12.19), colloquium. Cfr. VC, p. 46; VL, p. 38. Tanto parellament como parlament obedecen a fonética catalana, frente a las formas propias del aragonés, parellamiento y parlamiento. Vid. parlament. Frec.: parellament 2: 0,00455; parellamiento 2: 0,00455; aparellamiento [parlament] 1: 0,00227.

parellamiento s. m. 'preparación, disposición'. Pero en todos los casos, en el ms. B, parece error por parlament parlamiento. Vid. parellament.

parellar v. tr. 'disponer, preparar': fizo el rey parellar ciertos et secretos hombres en su cambra armados que fiziessen lo quél les mandaría 20.130. Etim.: deriv. de parello < lat. vg. *PARICUlus, dim. de PAR, PARIS 'igual, semejante', 'pareja' (DECLIC, VI, p. 225). Comp. con aparellar (que aparece habitualmente). Frec.: parellar 4: 0,00909 .

parentesco (var.: parentezco) s. m. 'relación o vínculo entre parientes': el rey de Castiella dio su filla, que avía nombre María, al dito rey don Jayme por muller, non con- 
trastant que fuessen en muyt cercano grado de parentesco 38.27; et aquesto hera el parentezco: el rey don Sancho clamado mayor avie dos fillos... 19.68. Etim.: Deriv. del lat. PARENTES 'padre y madre', y a su vez éste deriv. del lat. PARERE 'dar a luz, engendrar'. Con un sufijo -esco que en este caso no forma adj. sino sust. Comp. cast. parientes 'padre y madre' ant. (Berceo; Apol.; J. Ruiz, etc.); pariente 'perteneciente a la familia' ( $C i d$; Nebrija, etc.). Ya en la baja época PARENTES toma el sentido de 'parientes', único conservado modernamente en iberorromance e italiano; parentesco (h. 1275, 1'. Crón. Gral;; J. Ruiz). Es rara la formación en -esco para un sustantivo abstracto. Según Corominas, parece probable que el cast. parentesco sea un occitanismo, que entraría a través del aragonés gracias a la importancia de los textos jurídicos y forales tan copiosos e importantes en Navarra y Aragón por este tiempo y cuajados de occitanismos (o incluso escritos en occitano; cfr. el Fuero de Jaca, el Fuero de Estella, etc.). En occ. ant. era parentés, con un sufijo -és < -etæ;, pero por influjo del sufijo más frecuente -esc, se comprende que tendiera a cambiarse en parentesc (DCECH, IV, p. 404, s. v. parir). Pharies (2002: 236) llama la atención sobre dos diferencias importantes de parentesco con respecto a los demás derivados en -esco en español: a) es el único sustantivo, frente a todos los demás, que son adjetivos; b) aparece tempranamente, en el siglo XIII, mientras los demás aparecen ya en el s. Xv. Estas discrepancias sugieren un origen foráneo: dado que el vocablo parentesco se documenta en italiano en el s. XIV, es probable que sea un italianismo. Ahora bien, ¿cómo se transmitió al castellano? PHARIES (ibídem) expresa de forma literal: «Lógicamente, el italianismo pudo ser transmitido al castellano a través del catalano-aragonés». $\mathrm{Al}$ respecto cabe decir que se documenta parentesc en cat. ya en el s. XIII (DCVB, s. v.) y que parentesco aparece en 94 ejemplos recogidos por NitTI y KASTEN (1997) en textos medievales aragoneses. Según Pharies, el sufijo -esco habría sido tomado del italiano -esco y este a su vez procedería del lat. -iscus $<$ gr. iskos. No obstante, según RoHLFS (Grammatica storica della lingua italiana e dei suoi dialetti. III. Sintassi e formazione delle parole, Turín, 1969: 437-439, citado por Pharies) podría haber sufrido el influjo de un sufijo -iscus proveniente del ilirio y del sufijo germánico -isk (que aparece, por ejemplo, en francesco 'francés'). Frec.: parentesco 2: 0,00455; parentezco 1: 0,00227.

parias s. f. 'parias, impuestos, tributos': tanto apretó el rey don Sancho Huesca quel rey moro prometie de dar parias a él. 17.104; que les ayudasse a deffender contra el rey de Aragón et que daría a él las parias dobladas 17.107. Deriv. de un ant. *pariar (< lat. PARIARE, deriv. de PAR) 'igualar', 'saldar (una cuenta)' (DCECH, IV, p. 387, s. v. par). Frec.: 2: 0,00455.

parient s. m. 'pariente': el dito Manfre demandó que se pudies veer con el dito don Alfonso por tal como era su parient 38.561; et tiráveles todos sus algos que avían pero dioles a los 
sus parientes. 38.285; en testimonio de mis parients et vassallos presents aqui qui aquesto vieron 12.35. Del lat. PARENTES. Frec.: parient 1: 0,00227; parientes 4: 0,00909; parients 1: 0,00227.

parir] v. tr. 'parir': vino sende en Napoles do la reyna don Blanca, muller del dito rey, parió un infant que huvo nombre don Alfonso 38.233. Del lat. PARERE. Frec.: parió 1: 0,00227 .

parlament (var.: parlamento], parlamiento) s. m. 'parlamento, conversación, entrevista'; 'asamblea de gente que delibera': Fue un tiempo quel dito compte fue a la ciudad de Narbona, con su fillo que havia nombre Guiffre Pelloso, por [fer añade N] parlament con algunos mesageros del rey de Francia 22.9; et por muytos parlamentos que avieron, el dito rey don Pedro le demandó con grant instancia el vizzcondado de Finoledas 36.154; Et visidandose assi la su tierra, vinose en la villa de Perynia [Perpiniani VL] en la quoal tuvo parlamiento con los de Proeniça 33.115. Etim. Deriv. de parlar. Según el DCECH (IV, p. 346), está tomado del occ. parlar 'hablar' (¿O del cat. o del fr.?), que procede del lat. vg. PARABOLARI 'hacer comparaciones, frases'. El vocablo parlamento se registra en cast. h. 1520 (DCECH, IV, p. 346). Parlament 'discurso, comentario' está en el Tucídides del aragonés Fernández de Heredia (ed. de López Molina, p. 213); también parlamento, con el mismo sentido, en otras obras del mismo autor (Cfr. GiLKISON, s. v.). Frec.: parlament 1: 0,002; parlamentos 1: 0,00227; parlamiento 1: 0,002297.

parrochial] adj. 'parroquial, relacionado con o pertenenciente a la parroquia': et reternia pora si la senyoría de todas las eglesias del su regno et sobre los monasterios de San Salvador de Leyre, de San Johan de la Penya et de San Victorián, et sobre todas las eglesias parrochiales 20.291. Deriv. de parroquia. Frec.: parrochiales 1: 0,00227.

parroquia s. f. 'parroquia': dio a don Gastón de Bearn por herencia suya toda la parroquia de Santa María del Pilar 19.49. Del lat. tardío PAROCHIA 'íd.' (DCECH, IV, 413). Frec.: 1: 0,0’0227.

part (var.: parte) s. f. 'parte, lado': Et por esto la part contraria se pensó que por miedo sende estuvies de conbatirse con él 36.270; de la part de la val de Aragón cumplieron entro Verdin et cremoron el mercado 36.353; et era de tal natura, figura et collor que de la una part eran cardenas et de la otra verdes et en cada una part vermellura se denotava 36.597; porque de part alguna non les ossava venir vianda alguna 36.620-621; milloró su patrimonio bien por las dos partes 38.445. Del lat. PARS, PARTIS 'íd.'. Se emplea con un sentido de aproximación geográfica u orientación, frente a partida 'parte, trozo, fragmento de una cosa que se divide'. Comp. con partida. Arag. mod. enta par de 'hacia, hacia la parte de, en dirección de' (NAGORE, 1989: 285). Frec.: part 28: 0,06364; parte 2: 0,00455; partes 6: 0,01364.

partida s. f. 'parte, trozo, porción, fragmento en que se divide una cosa': por algunas nuevas et cuestiones et demandas quel dito rey fazía a los nobles de Cataluennya, la mayor partida de aquellos ensemble con el conte de Urgel et con el conte de Foyx, mo- 
vieron guerra contra el dito rey 36.128; et metieronla en pias et tiroron ne la meytat de la torre [...]. Et con escaleras puyoron en la partida que fincada era 36.342 // pl. 'paraje, territorio, distrito, comarca, región': mas un cavallero clamado Villar, estarrado de las partidas de Carcasona 36.419. Etim.: del lat. PARTiTA, fem. del p. p. PARTITUS 'partido'. Es usual en arag. med.: «no porian passar la dita agua por dos leguas o mas si no hen bien pocas partidas del anno» (DLAA, doc. no 113, de Bielsa, año 1349; p. 167, lín. 139); «asi de los habitantes de Aynsa como de las otras partidas (ibídem, lín. 147-148); «hen nenguna partida del regno» (ibídem, p. 166, lín. 96). El DRAE (1970, s. v.) recoge como acepción número 14 de partida 'parte o lugar' (acepción núm. 15 en el DLE, 2014, s. v.). ReIDy FriTz (1977: 219) indica para los $D L A A$ las acepciones 'parte; región; distrito; facción; grupo'. En Fernández de Heredia partida 'parte, porción', 'región', 'grupo' (Gilkison, s. v.). Frec.: partida 10: 0,02273; partidas 6: 0,01364.

partimiento s. m. 'separación, partida, retirada': Es verdat empero que grant frambre et gran malautia se metió en la huest del dito rey don Jayme en la fin del partimiento de Almaría 38.400. Deriv. de partir. Frec.: 1: 0,00227.

partir v. prnl. 'irse, marcharse': et sus vassallos conselloronlo que se parties d'alli que non $[n o \mathrm{~N}]$ la podie [podrie $\mathrm{N}]$ aver 35.171; et fue muyt turbado et clamó don Caxal et dos otros conselleros et havieron acuerdo quel rey se partiesse d'alli 20.195; a media nueit, partióse de Pamplona et fuesse al monesterio de San Salvador de Leyre 20.196. / / v. tr. 'partir, dividir': assí como va el agua de Sarasaz et caye en el río de Yda et parte Navarra et Aragón 20.279. Del lat. PARTIRI 'dividir, partir'. La acepción 'irse' se explica desde 'separarse' (DCECH, IV, p. 414). Frec.: partir 2: 0,00455; partían 1: 0,00227; partido 5: 0,01136; partiendo 1: 0,00227; partieron 2: 0,00455; partieronse 2: 0,00455; parties 1: 0,00227; partiesse 1: 0,00227; partió 12: 0,00227; partióse 7: 0,01591.

pasado (var.: passado) adj. 'pasado': por reverencia de su padre, del quoal avía reçevido muytas gracias e honores en el tiempo pasado 33.9; Et por muytas et diversas injurias et dapnages que $G$ Remón d'Odena havía feito et procurado al dito santo rey don Jayme su padre et a la tierra en el tiempo passado contra buenas costumbres 36.18. Del p. p. del v. passar. Frec.: pasado 3: 0,00682: passado 3: 0,00682.

pascua (var.: pascoa) s. f. 'pascua, fiesta solemne que celebra la resurrección de Jesucristo': El dito Beltran d'Albaus murió por algunos traydores en el dia de Pascoa e fue levado el su cuerpo a soterrar a la eglesia de Magalona. Del lat. PASCHA, que por conducto del griego, procede de una variante del hebreo PESACH 'paso, tránsito', fiesta con que los judíos conmemoraban la salida de Egipto. El vocablo sufrió el influjo de PASCUA, pl. de PASCUUm 'alimento de los animales' (BDELC, s. v.). Frec.: Pascua 1: 0,00227; Pascoa 1: 0,00227. 
passador s. m. 'pasador, flecha, saeta, dardo': en la qual batalla, el dito rey don Jayme fue ferido con passador por el pie qui lo cosió con la cubierta de la galera 38.275. Etim.: Deriv. de passar < lat. vg. PASSARE. Comp. occ. (lang.) passador 'flèche, dard' (Alibert, s. v. passar, p. 529). En Fernández de Heredia passador 'type of arrow' ['tipo de flecha'] (GILKIson, s. v.). Frec.: 1: 0,00227.

passar v. intr. 'pasar': que por manera de dezir mal, dizen oy en día por Castiella «malas Urreas passen por tu casa» 38.210; Aquesti santo rey passó desta vida en hedat de LXXII annos 35.305. // v. prnl. 'trasladarse, cruzar': el legado et la buest francesa qui en Nápoles eran fincados passoronse en Secilia con grant goyo et pagamiento 38.287; Otros dizen que de verguença que era vencido el que todos tiempos era seydo vencedor, passosse a Jherusalem, pero nunca lo troboron ni muerto ni vivo. 19.218. // v. tr. 'transgredir': et que semblant pena fues possada a los sus succedidores [sucessores $\mathrm{N}$ ] si las ditas ordinaciones [ordenancas $\mathrm{N}$ ] passavan 37.33-34. // v. tr. 'sufrir, tolerar': en las quales letras recontava el estamiento del su regno et mala vida que passava con los mayores del su regno 20.109. Etim.: del lat. vg. * Passare (DCECH, IV, p. 420). Frec.: passar 3: 0,00682; passados 6: 0,01364; passando 4: 0,00909; passaría 1: 0,00227 , passaron 1: 0,00227 ; passas $1: 0,00227$; passava 3 : 0,00455; passavan 2: 0,00455; passavanlo 1: 0,00227; passen 1: 0,00227; passó 12: 0,02728; passoron 2: 0,00455; passoronse 1: 0,00227; passose 1: 0,00227 .

passatge s. m. 'viaje', 'travesía marítima'; 'pasaje, acción de pasar de una parte a otra': el qual passatge non plazie a Dios que por la christiandat fues complido aquella vegada 35.208; porque la ora se tractava et se ordenava que los christianos fiziessen passatge contra moros en la Tierra Santa. 35.202. Del occ. ant. pasatge 'paso, pasaje', 'viaje de ultramar, cruzada' (Levy, s. v.). Comp. occ. (lang.) passatge 'passage, défilé, couloir, chose qui passe' ('paso, desfiladero, desfile, pasillo, corredor') (Alibert, s. v. passar, p. 529); fr. passage 'acción de pasar', 'travesía en un navío' (PRobert, s. v.); cat. passatge 'acción de pasar, pasaje'; cat. ant. 'acción de pasar a ultramar' (DCVB, t. 8, p. 300). Es deriv. de passar, con el sufijo-atge $<$ lat. -ATICUM. Frec.: passatge 2: 0,00455.

passión s. f. 'pasión, padecimiento': injustament sufrian grant passión, pena et tribulación 36.496. Cultismo tomado del lat. passio, -onis (BDELC, p. 432, s. v. padecer). Frec.: 1: 0,00227.

pastor s. m. 'pastor': tantost fizo vestir la dita criatura assin como a pastor et fizole calcar abarcas 12.22. Etpor aquesto, como vino vestido et calcado como pastor, clamoronlo Sancho Abarca. 12.42. Del lat. PASTOR, -ORIS, acus. PASTORE(M). Frec.: 2: 0,00455.

paternal adj. 'paternal, de padre': el dito rey, non queriendo seer desconoscient del amor paternal et queriendo obedecer el su mandamiento... 36.92. Deriv. de paterno, tomado del lat. paternus. El BDELC, s. v. da la 1. a documentación en cast. de 
paternal en 1438, es decir, unos 70 años después que el testimonio que aporta la Crón. SJP. Frec.: 2: 0,00455.

patriarcha s. m. 'patriarca': el tercero don Johan et fue arcevispo de Toledo et depués

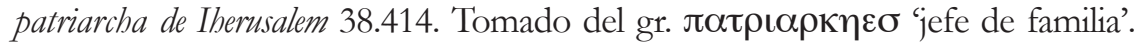
Frec.: 1: 0,00227.

patrimonio s. m. 'patrimonio, hacienda, bienes': fue buen bomme et buen administrador et milloró su patrimonio bien por las dos partes 38.445. Cultismo tomado del lat. patrimonium 'bienes heredados de los padres'. Frec.: 1: 0,00227.

patronado s. m. 'patronato', en la lexía ius patronado 'derecho de patronato' o 'privilegios y facultades del patrono, según el estatuto de fundación, y principalmente el poder o facultad de presentar personas hábiles para los beneficios y capellanías vacantes' (definición de derecho de patronato que da el DRAE (1970, s. v. derecho): dio el ius patronado que havía en todas las iglesias de toda su sennoría 34.36-37. El DLE (2014, s. v. derecho), reduce la definición de derecho de patronato a 'privilegios y facultades del patrono, según el estatuto de la fundación'. Patronado y patronato los recoge el DCECH, IV, p. 325, entre los deriv. cultos de PATRONUS 'defensor, protector' Frec.: 1: 0,00227.

paxer v. tr. 'pacer': le plazies enrriqueçer el dito monesterio de algunas honores do pudiesen fer paxer sus ganados 11.25. Etim.: del lat. PASCERE 'apacentar, pacer', verbo heredado por todos los romances (DCECH, IV, p. 331). Es forma que se conserva en arag. mod.: paxer 'salir los caracoles con la lluvia' (en Longás, Agüero y Santolaria de Galligo (Romanos, 2003: 223), así como el deriv. paxentar 'apacentar' en Sobrarbe, en A Galliguera y Plana de Uesca (EBA: 1999: 1407; Romanos, 2003: 223; Nagore, 2020: 486), pachentar en el Somontano y en A Galliguera (Mostolay, 2007: 409; Palacios \& Baos, 2010: 112). Andolz (1992: 326) registra paxentar 'pacer' en Agüero, Ayerbe, Biscarrués, Losanglis, Loscorrales y Morán. Frec.: 2: 0,00455.

paz s. f. 'paz': los demás de los reyes de Espaynna inclinados e indutos a paz e concordia, tornose en su tierra 33. 112; por la qual cosa buvo paz et amor entre sus gentes 38.627; el dito regno fue possado en tranquilidat de paz 36.77. Del lat. PACE(M), acus. de PAX, PACIS. Frec.: 44: 0,10001.

peada] s. f. 'huella, pisada': los quales siguieron las peadas [vias $\mathrm{N}$ ] de los otros sanctos hombres qui avian servido a Dios 5.14. Etim.: deriv. del lat. PES, PEDIS 'pie'. Cfr.: piada 'huella, pisada' en occ. (AliberT, s. v.); peada 'pisada' en gall. (DCECH, IV, p. 530); cat. ant. peada 'petjada', es decir 'pisada' (DCVB, t. 8, p. 344), que lo deriva del lat. PEDATA). Frec.: peadas 1: 0,00227.

peccado (var.: pecado) s. m. 'pecado': por aquesti pecado el dito Berenguer Remón perdió la favla [paraula $\mathrm{N}$ ] et fue muyt vituperado et yrado por todo el mundo 30.20; quel casamiento d'él et de su filla passaría et consumarse [confirmarse $\mathrm{N}$ ] podría sin 
peccado 38.35. Del lat. PECCATUM 'acción culpable, delito'. Frec.: peccado 3: 0,00682; peccados 1: 0,00227; pecado 2: 0,00455; pecados 1: 0,00227.

peire s. f. 'piedra': et fue possada [en la torre añade $\mathrm{N}$ ] sobre la peire del Orifany [poyre del orisani $\mathrm{N}], 38.573-574$. Del lat. PETRA, con tratamiento fonético occitano, pero adoptado desde muy temprano en arag., y ya arraigado incluso en toponimia: cfr. monte Peiro (entre Arguis y Rasal), posiblemente del lat. PETREus. En la Crón. SJP. aparece también el antropónimo Peyro 'Pedro': por bautismo don Payronella, porque nasció en dia de San Peyro 20.256. Comp. piedra. Frec. 1: 0,00227.

peligro s. m. 'peligro': porque la tierra estava en grant peligro por la su grant juventud del dito rey don Alfonso 33.5. Frec.: 1: 0,00227 [esta única aparición se encuentra en el cap. 33, que está tomado del ms. N, el más castellanizado de los tres, ya que hay un espacio en blanco en el m. B]. Vid. periglo.

pello] s. m. 'pelo': et conosció que era su fillo porque pellos havía en lugares do bomes non dan acostumpnado de haver, et por aquesto fue nombrado Peloso 23.24. Del lat. PILus. Frec.: 1: 0,00227.

peloso (var.: pelloso) adj. 'peludo, con abundancia de pelo': et conosció que era su fillo porque pellos havia en lugares do bomes non dan acostumpnado de baver, et por aquesto fue nombrado Peloso 23.24. Deriv. de pelo, con suf. -oso que a partir de sustantivos produce adjetivos con valor abundancial. Frec.: peloso 1: 0,00227; pelloso 1: 0,00227 .

pena s. f. 'pena'; 'castigo': et que semblant pena fues possada a los sus succedidores si las ditas ordinaciones passavan 37.33. Del lat. POENA. Este vocablo se halla ya en los primeros testimonios escritos del aragonés: así, en las Glosas Emilianeses: «ubi erit fletus et stridor dentium et multitudo tormentorum [penas]》 (glosa 104; LHP, p. 470; puede verse ahora también en Origen aragonés de las Glosas Emilianeses, 2020: 105). Frec.: 5: 0,01136.

pendient adj. y p. pres. 'pendiente': et pendient el tracto et término de las cortes, los navarros entre si acordaron .. 20.43. Es participio presente de pender $<$ lat. PENDERE 'estar colgado'. Frec.: 1: 0,00227.

pendón s. m. 'pendón, bandera o estandarte militar': et un cavallero de los de Olea, que tenía un pendón del compte muerto, en el cavallo, las manos talladas, con los braços tenía la seynna clamando: «Olea, Olea». 19.124. Tomado del fr. ant. u occ. ant. pennon, del lat. PINNA 'pluma, penacho', con influencia del verbo pender (DCECH, IV, p. 479). Frec.: 1: 0,00227.

penedido adj. y p. p. 'arrepentido': devotament et humil penedido et confessado con grant contricción de sus peccados 36.703; con grant devoción penedidos et confessados fielment de lures pecados 9.18. Es p. p. de penedir 'arrepentir(se)' del lat. PAENITERE (DECLIC, VI, 421). Comp. cat. penedir-se 'arrepentirse' (FABRA, DGLIC, s. v.); occ. 
penedir 'se repentir' (Levy, s. v.). En Fernández de Heredia penedir 'arrepentirse' (GILKISON, s. v.). Frec.: penedido 1: 0,00227; penedidos 1: 0,00227.

penitencia s. f. 'penitencia': et estando el rey en esta chiqueza, el compt Remón de Tolosa firole muytas injurias de las quoales estuvo en penitencia 33.23. Cultismo tomado del lat. paenitentia. Frec.: 1: 0,00227.

pennora] s. f. 'prenda': aquesti rey don Pero fue barón muy curial, noble, balient, largo e proz. e muy espierto, et todo quanto podía aver en qualquier manera todo lo dava, en tanto que obligó et metió pennoras [peynoras $\mathrm{N}$ ], castillos, villas et rendas suyas porque pudies complir lo que havía [avies $\mathrm{N}$ ] en coraçón et en voluntad. 34.7-11 (metió pennoras 'empeñó') [e mès penyora castells...VC, p. 111]. Etim.: del lat. PIGNORA, pl. de PIGNUS, -ORIS 'prenda' (DCECH, IV, p. 638, s. v. prenda). En FA, pendra (h. 1300); pengnora está documentado en un doc. de Huesca de 1148 (GILI GaYA, 1925: 117). En arag. med.: penyorar 'dar en prenda', pero pendra 'prenda' en los DLAA (REIDY FRITZ, 1977: 221); penyora 'debt; pawned goods' en tres obras de Fernández de Heredia (GILKIson, 1984, s. v.); penyos 'lo que se deja en prenda' en OB (VÁzQUEZ, 2011c: 48); pennos en ms. Az del FJ (Molho, 1964: 100); penyora 'lo que se deja en prenda' en VCA, p. 291. Comp. cat. penyorar, occ. penhorar, port y gall. penhorar, cat. penyora; occ. penhora, gall. peñor 'prenda', ast. pindra 'prenda' (DCECH, IV, p. 638). Frec.: pennoras [peynoras N] 1: 0,00227.

pensamiento s. m. 'pensamiento': et segunt pensamiento murieron de los moros mas de XXX mill que de pie que de cavallo 18.67. Deriv. de pensar. Frec.: 1: 0,00227.

pensar v. tr. 'pensar': assí como se lo ovo pensado, assí lo miso en obra 33.106; et pensaronse con quanta maleza era muerto su padre 23.30; que non pensava que los sus naturales entrassen contra él 38.251; assí mismo penssando que grant ayuda et favor ende avría contra sus enemigos 38.30. Del lat. PENSARE íd., intensivo de PENDERE 'pesar' (DCECH, IV, p. 503). Frec.: pensar 1: 0,00227; pensando 1: 0,00227; pensado 1: 0,00227; pensaron 1: 0,00227 ; pensaronse 1: 0,00227 ; pensava 1: 0,00227 ; pensavan 1: 0,00227; pensó 5: 0,01136; penssando 1: 0,00227.

penya s. f. 'peña, roca': un sancto hombre clamado Johan, heremita, habitava en una espelunca de ius una grant penya 5.2. Del lat. PINNA 'almena' (DCECH, IV, p. 477). Frec.: 3: 0,006982. [Además, como parte del nombre propio, Sant Johan de la -: Penna 13: 0,02955; Penya 2: 0,00682; Pennya 3: 0,00682; Peyna 3: 0,0682].

peón] s. m. 'peón, soldado de a pie': con $C C^{\text {ss }}$ bombres a cavallo [ommes de pie $\mathrm{N}$ ] et con $D^{o s}$ peones. 38.580. Del lat. vg. PEDO, -ONIS (DCECH, IV, p. 531). Frec.: peones 4: 0,00909 .

peor adj. 'peor': e por esto dizen que peor fue que la de Cuntada 19.56. Del lat. PEJOR, -ORIS. Frec.: 1: 0,00227.

perder v. tr. 'perder': et atorgas a él por sennyor et sus succeydores, dius [diole $\mathrm{N}]$ pena de perder las ditas tierras 16.36; et a tiempo fue suelto et non osava tornar en Aragón de 
verguença que avía perdida la torre 36.348; et que sería perdido el consello de los aragoneses, porque era architofel 20.221; tornado de la mesagería et sabiendo la maleztat que su sennyor le havía feita, tractó que su sennyor perdiesse su regno 3.86; por aquesti pecado el dito Berenguer Remón perdió la favla 30.20. Del lat. PERDERE 'íd.'. Frec.: perder 1: 0,00227; perdía 1: 0,00227; perdida 1: 0,00227; perdido 7:0,01591; perdieron 1: 0,00227; perdies 2: 0,00455; perdió 3: 0,00682.

perdición s. f. 'perdición, ruina o daño grave', 'situación de desarreglo en las costumbres': et fue puesto en gran perplexidat cómo daría remedio a tanta perdición del su regno 20.101. / / 'pérdida': E feita la dita perdición [persecution $\mathrm{N}$ ] o conquista... 4.1. Cultismo tomado del lat. perditio, -onis. Frec.: 2: 0,00455.

pérdida s. f. 'pérdida': et dixo el dito rey que gran pérdida podia ser de su regno en el tiempo advenidero 23.5. Del lat. PERDITA, p.p. de PERDERE. Frec.: 1: 0,00227.

perdón s. m. 'perdón': por el perdón quel Padre Santo havia dado 36.562; et fue y ordenado a dar las indulgencias sobreditas et perdones, un cardenal legado del Padre Santo clamado Cardet 36.468. Deriv. postverbal de perdonar. Frec.: perdón 7: 0,01591; perdones 1: 0,00227.

perdonar v. tr. 'perdonar': et no perdonava a ningún travallo que ningún hombre podies sufrir 12.66; Depués a tiempo perdonoles el rey et tornoron a la tierra del rey 35.48; et havie gran plazer et perdonolo 18.30. Del lat. tardío PERDONARE (DCECH, II, p. 515, s. v. donar). Frec.: perdonar 1: 0,00227; perdonada 1: 0,00227; perdonava 1: 0,00227; perdonoles 1: 0,00227; perdonolo 1: 0,00227.

perdurable adj. 'perdurable': requiriendo al notario que alli era que de aquellas et del comparecimiento suyo et de la fadiga et contumacia del dito rey Carlos le devies fer carta o cartas públicas a memoria perdurable. 36.300. Del lat. PERDURABILIS. Frec.: 2: 0,00455.

perdurablement adv. 'perdurablemente, perennemente': «fillo, te priego que en ti sean aquestas cosas porque Dios sea con ti el qual fillo bivas perdurablement» 35.260. Frec.: 2: 0,00455 .

peregrinage s. m. 'peregrinaje': et este día mismo fue la batalla de Antiochia del gran peregrinage 18.55. Deriv. de peregrino. Frec.: 1: 0,00227.

peregrino (var.: pelegrino) s. m. 'peregrino': et fuessen en Iherusalem et murió pelegrino 30.22; et la hora era conte de Urgel en Aymegou Perigri [Narmengon e Peregrin N] [Ermengaudus Peregrini VL] et por tal fue assi clamado porque murió peregrino en la ciudat de Jherusalem, 29.22. Tomado del lat. Peregrinus 'extranjero' (DCECH, I, p. 78). Frec.: peregrino 2: 0,00455; pelegrino 1: 0,00227.

periglo (var.: periglio, peligro): fue preservada la dita ciudad del grant periglio [peligro $\mathrm{N}]$ que estava 12.61; el qual pensando que sin grant periglo non podía estar en el dito sitio, pensando encara que ningún socorro ni ayuda non avría del rey de Castiella, tractó paz entre si mismo et el rey de Granada. 38.382; et el dito rey todo solo con los moros estuvo et fabló una gran pieça, de la qual cosa todo homme buvo grant desplazer et gele 
tuvieron a grant locura por muytos periglos que se podian esdevenir. 38.392. Del lat. Periculum. Vid. tb. peligro. Frec.: periglo 3: 0,00682; periglos 2: 0,00455; periglio; 2: 0,00455; peligro 1: 0,00227.

perigloso] adj. 'peligroso': quando havia d'entrar en batalla o havía afer cavalgada o qualesque otros afferes periglosos [qualesquier cosas peligrosas N], 13.3. Deriv. de periglo. Frec.: periglosos 1: 0,00227.

pero conj. advers. 'pero, aunque', 'sin embargo': el qual fue jurado en rey o primogénito en la ciudat de Caragoça antes que la dita dona Teresa muries, tantost pero aquel [enpero que el dito N] don Alfonso fue coronado [tornado N] de Cerdennya, 38.591. Véase la colocación en las siguientes citas: con tal pero condición 20.181-20.182 ('pero con tal condición'); Está pero en verdad que regnó el dito rey don Sancho Remirez, 17.58. Etim.: del lat. postclásico PER HOC 'por esto', 'por tanto', que empleado de preferencia en frases negativas, tomó el sentido adversativo de 'sin embargo', conservado en la Edad Media, y más tarde atenuado hasta hacerse equivalente de mas. En el romance primitivo pero conserva todavía un valor adversativo más fuerte que el de mas, muchas veces equivalente a 'sin embargo'; esto es general en lengua de oc., cat. e it., y es tb. frecuente en cast., por lo menos hasta el s. XIV; en este idioma tiende, sin embargo, a adquirir otros valores: a veces es ya equivalente de mas, y sobre todo es muy frecuente el empleo con el valor de 'aunque' (DCECH, IV, p. 495). Frec.: 17: 0,03864.

perpetualment adv. 'perpetuamente': et los sus capellanes ordenolos perpetualment seer beneficiados en la iglesia de San Pedro en Huesca 20.303. Frec.: 3: 0,00682.

perpetuo adj. 'perpetuo, perdurable': et en escripto perpetua memoria metida publicoron aquélla en Pamplona 20.167; en el monesterio de Sant Johan de la Pennya que alli fues perpétuo [perpetualment $\mathrm{N}$ ] conservada [observada $\mathrm{N}$ ] et yes oy en dia 20.171. Cultismo tomado del lat. perpetuus 'continuo, sin interrupción'. Frec.: perpetuo 2: 0,00455; perpetua 1: 0,00227.

perplexidat s. f. 'perplejidad': fue puesto en gran perplexidat cómo daría remedio a tanta perdición del su regno 20.100. Etim.: deriv. del lat. PERPLExus 'entrelazado, sinuoso, embrollado'. La 1. a documentación de perplejidad que da Corominas es de la Celestina (DCECH, II, p. 162, s. v. complejo), luego la Crón. SJP, la adelanta en más de un siglo. Frec.: 1: 0,00227.

persecución] (var.: persequción) s. f. 'persecución': por defender los christianos de las crueldades et terribles persecuciones de los moros 10.9; E feita la dita perdición [persecution N] o conquista, los christianos qui de la batalla o persequión podieron escapar se derramaron et fueron enta las fuerças de la montannyas de Sobrarbe, de Ribagorça, de Aragón... 4.2. Frec.: persecuciones 12: 0,00455; persequción 1: 0,00227. 
perseverar] v. intr. 'perseverar, mantenerse constante, persistir': ... de la fe christiana, en la qual él muyt fiel sin toda [ninguna $\mathrm{N}$ ] tacha estuvo et perseveró todos tiempos enta Nuestro Sennyor Dios 34.175-177. Frec.: perseveró 1: 0,00227.

persona s. f. 'persona': et de todos dannyos et dampnages que en qualquiere manera fuesen feitos por el dito rey et sus sozmesos a la Yglesia o al rey de Francia o qualquiere otro rey o persona por la razón sobre dita 38.111; et estando aqui por retraher [recrear $\mathrm{N}]$ et repossar lures personas, el dito cardenal de grant malautia fue opresso 38.89. Etim.: cultismo tomado del lat. persona, propiamente 'máscara de actor', 'personaje teatral' (BDELC, s. v.; SEGURA, 2001: 557). Frec.: persona 9: 0,02046; personas 3: 0,00682 .

personalment adv. 'personalmente': por venir a Port Fangos, do avía asignado dia de recullir todas sus compannyas, do el rey don Jayme personalment et todos sus fillos et muytos prelados et richos homes de Catalunnya et de Aragón et del regno de Valencia 38.498. Frec.: 4: 0,00909.

pertannyer] v. prnl. y tr. 'pertenecer', 'corresponder': con convinient honor mas non real [con real $\mathrm{N}$ ] assí como a filla de rey se pertannya [pertenía $\mathrm{N}$ ], 38.168; el dito rey don Jayme, assi como savio sennyor, non quiso aver copula carnal con la dita reyna, mas tuvo et trató aquélla con honor real, segunt que del se pertanya 38.64; et por otras tierras que possedia, las quales pretannyan [pertannia B] al condado de Barchinona 36.160. Del lat. PERTINGERE 'obtener, alcanzar', 'extenderse hasta', si bien con cruzamiento con cat. ant. tànyer < lat. TANGERE 'tocar' (DCVB, t. 8, p. 501), o simplemente deriv. de este último (DECLIC, VIII, pp. 284-285). En la forma pertenir podría igualmente proceder de PERTINERE 'extenderse hasta, llegar a, prolongarse'. Es muy probablemente un catalanismo, tomado del cat. pertànyer 'corresponder, pertenecer', o un occitanismo. En Fernández de Heredia pertanyir, pertannir, partanyir (GILKISON, s. v.); en VM pertaynnescer (TILANDER, VM, III, p. 235). Comp. occ. pertanher, partanher 'appartenir, convenir', también usado como prnl. (LeVY, s. v.). Frec.: pertannya 6: 0,01364; pertanya 1: 0,00227; pretannyan [pertannia] 1: 0,00227.

pertinencias s. f. 'pertinencias': et a Gonçalvo todo Sobrarbe et de Troncedo entro a Matirero, et Loarre et Sant Emeteri [Martin $\mathrm{N}$ ] con todas sus villas et pertinencias 14.90. Deriv. culto de PERTINERE 'extenderse hasta', 'pertenecer a'. Frec.: 5: 0,01136.

pertreyto s. m. 'pertrecho, toda clase de útiles, adminículos, objetos, provisiones, suministros, etc.': cada uno fizo su pertreyto [pareyt $\mathrm{N}$ ] et aparellamiento por complir los enprendimientos dessuso ditos 38.351. Etim.: probablemente del lat. PROTRACTUM, p. p. de PROTRAHERE 'hacer salir, producir' (DCECH, V, p. 577, s. v. traer, BDELC, p. 454). El DRAE (1970, s. v.) propone PERTRACTUs 'lo acarreado, lo que se trae'; GARCIA DE DiEgo (DEEH, p. 307 y 869) se adhiere a esta última etimología. La 1. ${ }^{a}$ doc. que da Corominas del cast. pertrecho es de 1490. Cita también arag. ant. petreyt o pertrey 'adminículos' en un invent. de 1492 (Рот- 
TIER, ELLA, p. 190, da pertreyt y pertrey, luego petreyt es errata en el DCECH). La forma pertreyto de la Crón. SJP. adelanta la 1. ${ }^{a}$ doc., tanto de la forma cast. como de la arag. en más de un siglo. También es anterior a la $1 .^{a}$ doc. del cat. pertret (en J. Roig, s. xv). Comp. occ. pertrach 'attirail, matériaux, attirail de guerre; provisión; marchandises' (Levy, s. v.); fr. ant. partrait. Comp. cast. pertrechos 'municiones, armas y demás instrumentos, máquinas, etc., necesarios para el uso de los soldados y defensa de las fortificaciones o de los buques de guerra' (DRAE, 1970, s. v.; DLE, 2014, s. v.). Frec.: 3: 0,00682.

pervenir] v. intr. 'llegar una cosa a propiedad de una persona, a través de otra': sennoriá [seynorió $\mathrm{N}$ ] el dito rey Remiro en el regno de Aragón, el qual le era pervenido por daçión de su madrastra 16.3; et por aquesti ajustamiento [ajuntamiento $\mathrm{N}$ ] matrimonial $[$ natural $\mathrm{N}]$ pervino la baronía de Montpeller a rey de Aragón 34.30; et pervinole el dito condado por successión del tio suyo 34.106. Del lat. PERVENIRE 'llegar hasta un término', 'llegar a un estado'. Comp. fr. parvenir 'arriver à destination (choses)' (PRobert, s. v.), parvenir 'llegar a' (Gran Diccionario español-francés / francés-español Larousse, s. v.); cat. pervenir 'pasar a esser propiedat d'algú una cosa' (DCVB, t. 8, p. 504, s. v., $2^{\mathrm{a}}$ acepción). Frec.: 3: 0,00682.

pesar] v. intr. 'causar dolor, pena o disgusto': alçaronlo rey de los de la tierra, pesando a la madre porque hera de mala vida 19.164. Del lat. PENSARE, intensivo de PENDERE 'pesar'. / / a pessar loc. conj. 'a pesar de, contra la voluntad de': et continuament les tollian [collian B] cavallo et otras cosas a pessar lur et despeyto 36.575. ['a su pesar, contra la voluntad de ellos']. Frec.: pesando 1: 0,00227; pessar 1: 0,00227.

pestilencia s. f. 'pestilencia', 'peste, epidemia contagiosa': et en tiempo de aquesti conte Borrel fue presa la ciudat de Barchinona por moros do fue feita gran pestilencia et de grant crueldat en la tierra... 26.13. Cultismo tomado del lat. PESTILENTiA. Frec.: 1: 0,00227 .

pia] s. f. 'cuña': et avía una torre en Ull... deffendióla muyt bien en manera que no la querie render, et metieronla en pias et tiroron ne la meytat de la torre et en la otra meytat fincó el alcayde... 36.339. Comp. arag. pía 'traba de piedra o madera que se pone al carro o al coche' (ANDolz, s. v., que lo localiza en el Bajo Aragón, pero es voz muy general). Posiblemente relacionado con arag. mod. piá(r) 'atar' (Benasque; Ballarín, Dicc., s. v.; Ferraz, s. v.; y general en Ribagorza; cfr. Andolz, s. v.). El EBA (1999: 1451) registra pía 'piedra o cuña para dejar frenado el carro' en Luesia y en Uncastillo; piá 'atar, trabar' en Campo, Bal de Lierp, Alta Rigorza, Chuseu, Torres del Obispo, Benás; también se registra en la Baja Ribagorza (Arnal Purroy, 2003: 149). En A Sotonera: pia 'piedra u otro objeto que se coloca delante o detrás de la rueda del carro o del coche [para evitar que éste se mueva]' y piar 'poner un obstáculo (la pía) delante o detrás de la rueda al estar parado, ya en subida, ya en bajada' (GARCÉs, 2005: 260). Comp. cat. occ. piar 'atar' (Sopeira, Benabarre, Valle de Bohí, valle de Barrabés; cfr. DCVB, 
s. v., t. 8, p. 550), gascón pia 'entraver; enrayer, en parlant d'un véhicule; fixer un objet de façon à l'empêcher de se mouvoir' (PALAY, s. v.). Es probable que pía sea una formación postverbal de piar. Según García de Diego, DEEH, p. 861, pía procedería de * PEDA o $^{*}$ PEDIA 'traba o calce', para lo que hay dificultades fonéticas. También sugiere PEDARE 'trabar' (aunque en lat. era 'poner guías o rodrigones a las plantas'); de este verbo, deriv. de PES, PEDIS, podría proceder piar 'calzar, trabar', y de aquí, como formación regresiva, pía. No obstante, es difícil de aceptar este planteamiento, ya que lo normal es que en arag. se hubiera conservado la -D- intervocálica. Frec.: pias 1: 0,00227.

piadoso adj. 'piadoso': Aquesti virtuoso rey don Jayme fue princep excellent, virutoso, valient et ardido et muyt gracioso, benigno et piadoso et muy marevelloso batallero 35.175. Deriv. de piedat < lat. PIETAS, -ATIS. Frec.: 8: 0,01818.

piccada] s. f. 'picotazo', con el sentido de 'pequeño golpe', 'punzada', 'pequeño ataque': mas las gentes del dito rey don Pedro muytos dapnages et muytas piccadas les dieron de mientre que las gentes contrarias eran en Rosellón 36.488 [molts damnatges e moltes picades los donaren dementre que les gents contraries eren en Rosselló. VC, p. 141]. Etim.: Deriv. de la onomatopeya PICC, sobre la que se crearía ya en lat. vg. el v. *PICCARE (DEEH, p. 872; DauZat-Dubois-MitTerand, s. v. piquer, p. 569; García DE Diego, Diccionario de voces naturales, 1968, p. 531.). Comp. cast. picada (de picar) 'acción y efecto de picar un ave, un reptil o un insecto' (DRAE, 1970, s. v.; reducido a 'acción y efecto de picar' en el DLE, 2014, s. v. picado, da), cat. picada 'acció de picar; l'efecte' (FABRA, DGLIC, s. v.; DL/C del IEC, 2007, s. v.). Según el DCECH (IV, p. 518-519), picar es voz común a todos los romances de Occidente, de creación expresiva. La 1. a documentación se encuentra en el Poema del Cid, con la acep. de 'herir con instrumento punzante'. Existe, con mayor o menor extensión semántica, picar en port., cat., occ., fr. e it. (piccare, picchiare). La forma francesa piquer, sin alteración de la -K-, prueba el carácter expresivo u onomatopéyico del vocablo. Se trata de la misma raíz que ya se encuentra en lat. en PICUs 'pico (pájaro)', alusiva al golpeteo a que este pájaro se dedica. En romance se creó de nuevo esta onomatopeya, aplicándola a cualquier golpeteo, y de la idea de 'golpear' se pasó fácilmente a la de 'herir' o 'punzar'. En ast., también picar 'golpiar, dar golpes' y un amplio número de acepciones (ACADEmia de la Llingua Asturiana, Diccionariu de la Llingua Asturiana, 2000: 941); en romanche piclar 'becqueter, picorer' (FURER, Vocabulari romontsch sursilvan-franzos, 2002: 355). Frec.: piccadas 1: 0,00227.

pie s. m. 'pie': et murieron la ora de los enemigos mas de CCC hommes solament de cavallo, ultra aquellos que y murieron de pie. 38.551; con XX mill homes de cavallo et infinida gent de piet et con el dito legado, vino a Perpinyan 36.473. Del lat. PES, PEDIs. Frec.: 39: 0,08864.

pieça s. f. 'rato, espacio de tiempo': et el dito rey todo sólo con los moros estuvo et fabló [con ellos N] una grant pię̧a 38.390 [peça VC, 'estona' en el Glossar]. Etim.: del célt. 
* LHP, pp. 483-484, registra pieza 'porción de tierra' en un documento riojano de 958, piaça en un documento de Sos de 1059. Probablemente, aragonesismo en cast., según CuERVO, pues se encuentran ejemplos en docs. navarros, riojanos y aragoneses de los siglos X-XII, pero no en Castilla y León antes del siglo XIII. En efecto, el vocablo falta en el Cid, y el primer autor literario que lo emplea es el riojano Berceo. Luego es probable el supuesto de Cuervo de que pieza sea un aragonesismo en castellano, aunque pronto generalizado, pues ya es corriente en J. Ruiz y Juan Manuel. Enrique de Villena a princ. del s. XV cita pieça por pedaço, y además pieça por 'espacio de tiempo' (Corominas, DCECH, IV, p. 539, s. v. pieza). Se registra pieça 'pedazo de qualquiera cosa' en Covarrubias, quien no recoge específicamente la acepción de 'espacio de tiempo'. El DRAE (1970) recoge como acepción 8 a de pieza: 'espacio de tiempo o lugar' (el DLE, 2014, igualmente, como acepción 9ª). El LRDMA registra pieza (aunque solamente en la acepción de 'porción de terreno') en un doc. de 1076, si bien antes ya registra piaza (en 1059), peça (en 1073) y peza (en 1056) (FORT, 1994: 37, \ 87). Frec.: 1: 0,00227.

piedat s. f. 'piedad': et el dito rey don Pedro, aviendo piedat de los ditos secilianos... 36.215. Del lat. PIETAS, -ATIS 'íd.'. Frec.: 4: 0,00909.

piedra s. f. 'piedra': et que personalment hi havies a levar piedra et mortero a la obra 36.448; et enrriquió et ornó el altar mayor del dito monesterio et de esmeraldes et safires, robices et carboneles et otras piedras preciosas. 28.21-22. Del lat. PĔTRA. Comp. peire. Frec.: piedra 1: 0,00227; piedras 2: 0,00455.

piensa s. f. 'pensamiento, intención', 'mente': et queriendo demostrar todo su corazón et su siensa [piensa $\mathrm{N}]$ que avía de subiugar la nasción morisma... 35.119-120. [E volent mostrar tot son cor e sa pensa que havía de subjugar la nació morisca VC, p. 120]. [Et volens pandere intentionem quam habebat ad pessundandum sarracenicam nationem VL p. 148]. Etim.: postverbal de pensar < lat. PENSARE. Según COROMINAS piensa y pienso se documentan, preferentemente en textos orientales: catalán y occitano antiguo pensa, oc. ant. pe(n)s, con el significado de 'mente' (DCECH, IV, p. 504, s. v. pesar). Es común en textos aragoneses medievales: piensa 'pensamiento' en FA (TILANDER, FA, p. 520) y en FT: seer poderoso de su piensa 'estar en su juicio' (Gorosch, FT, p. 596). En Fernández de Heredia pienso 'inquietud, preocupación' (GILKIsOn, s. v.). Véase también en los Fueros de Aragón de 1265 a 1381: "por la qual cosa en nuestra piensa muytas vegadas dizimos que el dito regno en todas cosas buenament fues regido» (Bergua, 1949-50, p. 522, lín. 816). Comp. cat. pensa 'facultat de pensar' (FABrA, s. v.; DLlC del IEC, 2007, s. v.); occ. (lang.) pensa 'penseé, souci' (ALIBERT, s. $v$. pensar, p. 539); occ. (prov.) pensa 'pensée; esprit, raison' (LEVY, s. v.). Hay que tener en cuenta que siensa es la forma que aparece en los mss. 
E y B; con todo, es la forma piensa la que parece conforme al original. Vid. siensa. Frec.: 1: 0,00227.

pissada adj. 'pisada', 'machacada': et fizo batalla en Piedra pissada con moros en el dia de Nadal 17.73. En realidad se trata de un topónimo. El castillo de Piedra-Pisada (Petra Pisata, Petram Pisadam, Piedra-Pissada, Petra-Piza, Piedra-Pisa) se ha identificado y localizado en un cerro cercano a la localidad de Naval. El paraje se denomina Pisa (el topónimo se conserva plenamente en Naval) y la documentación medieval atestigua que allí hubo una aldea del mismo nombre (cfr. Fuster Santaliestra, «Arqueología e Historia de los castillos de Naval (Huesca)», en I Congreso de Arqueología Medieval Española (Huesca, 1985), Zaragoza, DGA, 1987, pp. 164-179). El top. podría interpretarse como 'piedra machacada', de PISATA, p. p. de PISARE 'machacar'. Frec.: 1: 0,00227 .

placer s. m. 'placer': Et los aragoneses hovieron gran placer quando vengaron assí la muert del rey Remiro 17.39. Frec.: 1: 0,00227. Vid. plazer.

plaga s. f. 'plaga, peste, calamidad, azote': de la qual plaga tanta mortaldat se miso en la dita buest que tornó fuert a poco nombre de gent 36.602. Del lat. PLAGA 'herida'. Según indica el DCECH (III, p. 720), el cast. plaga 'calamidad, azote' es cultismo empleado a principios del s. XVII. En efecto, Covarrubias, en su Tesoro de la lengua castellana, o española (1611) explica, s. v. plaga: «La llaga o herida, latine plaga, del nombre griego $\pi \lambda \eta \gamma \eta$. Plaga, la persecución o calamidad, como las plagas de Egipto». Es decir, recoge tanto la acepción etimológica y popular como la más culta y nueva. Pero en aragonés no se puede considerar que plaga sea un cultismo, sino que responde a la fonética histórica propia de esta lengua, con conservación del grupo consonántico inicial PL-. Y, como vemos, se registra su uso en la Crón SJP con la acepción de 'calamidad' más de dos siglos antes que en castellano. Pero casi un siglo antes ya se utiliza con este sentido en un documento notarial en aragonés: «perdonamos, quitamos \& difinimos alos homnes e atoda lla vniversidat dela villa de Ciella, presentes \& qui son por venir, por nos $\&$ por todos nuestros suscesores, todas plagas \& todas enjurias \& desonras \& todos otros dannos \& males que los homnes \& lla vniversidat dela villa de Ciella ayan feytos alos homnes \& ala vniuersidat dela uilla de Bralauilla, atoç en general o quiscuno en especial» (DLAA, doc. $n^{\circ}$ 72, de Santa Cilia de Jaca, 1296; p. 103, lín. 12). Frec.: 2: 0,00455.

plana s. f. 'cuenca, llano, hoya': Et conquirió de Cantabria entro a Nagera et entro a Monti d'Ocha et entro a Tudela et toda la plana de Pamplona et gran partida de las montannas d'Aragón et de Sobrarbe 12.45. Sustantivación del adj. plana < lat. PLANA 'llana'. Frec.: 1: 0,00227.

planeza s. f. 'llanura, llano': En una planeza [un plano N] cerca el castiello de Montroyg [Mont roch N], 38.71. Etim.: del lat. PLANITIA 'llanura', deriv. de plano < lat. 
PLANus 'llano'. Corominas sólo cita planicie, cultismo tomado del lat. PLANITIES 'íd.' (DCECH, III, p. 722). Frec.: 1: 0,00227.

plano] adj. 'llano', en el texto más bien 'aplanado, achatado': Aquesti conte Berenguer Guillem Gordo engendró en su muller dos fillos, Guillen Croy qui buvo la nariz, tuerta et plana et en Berenguer Guillem qui succidió en el dito condado de Bisuldu 29.40. Del lat. PLANus, -A, -UM. Frec.: 1: 0,00227.

planto s. m. 'llanto, lloro, lamentación': et avies recontado la muert de don Alfonso... toda la tierra fizo grant duelo et planto 38.10; et todo el regno ensemble fizieron grant duelo et planto por un grant tiempo 36.718; los duelos, ploros, plantos et dolores que en la tierra depués de la muert suya fueron albirar ni pensar homme non los poria. 36.714. Etim.: del lat. PlANCTUS, -US, derivado de PLANGERE 'golpear', 'golpearse en señal de dolor', 'lamentarse'. Se documenta planto h. 1200 en el Libre dels Tres Reys d'Orient y en Sta. María Egipc.; también planto en Berceo; pero llanto en Calila, 1251. Todos los textos antiguos que contienen la forma en $p l$ - presentan formas de tipo aragonés (comp. ploro por lloro en el ms. bíblico I-j-8 del s. XIII). Por eso dice Corominas: «no creo que deba darse importancia a la escasez de testimonios viejos de la forma $l l-$, que en realidad sería muy antigua». En port. chanto, cat. plant, fr. plaint se anticuaron pronto (BDELC, p. 369 y DCECH, III, 724, s. v.). Frec.: planto 2: 0,00455; plantos 1; 0,00227.

planyer v. tr. 'ahorrar, excusar; eximir, rehusar'; 'escatimar, regatear': nombrado el Justiciero porque non plannya fazer [fer $\mathrm{N}$ ] justicia 38.6; empero non queriendo planyer [planir $\mathrm{N}$ ] su persona en servir [en servicio de N] Dios, 35.204 [emperò no volent plànyer la sua persona en servir així con havia acostumat en son jovent VC, p. 123]. Etim.: del lat. PLANGERE 'golpear', 'golpearse en señal de dolor', 'lamentarse' (DCECH, III, 724 , s. $v$. llanto). Pero el significado no parece tener nada que ver con el cast. plañir 'gemir y llorar, sollozando y clamando' (DRAE, 1970, s. v.; DLE, 2014, s. v.), que además, según Corominas (DCECH, III, 724), es un arcaísmo que procede de Berceo y que nunca ha salido de la lengua literaria; la forma popular cast. que se encuentra alguna vez es llaner, quizá disimilado de llañer. En el texto de la Crón. SJP. parece que cuadra la $2^{\mathrm{a}}$. acepción del cat. plànyer que da FABRA, DGLIC, s. v.: 'estalviar (un esforç, un mitjà, etc.)', que también recoge el DL/C del IEC, 2017, s. v.: plànyer 'estalviar esforços (a algú)'. Y con la $4^{\mathrm{a}}$ acepción del $D C V B$ (t. 8, p. 648): 'escatimar, regatear'. Este valor de 'ahorrar, excusar' puede entenderse a partir del de 'lamentar': 'no lamentar (tal cosa)' > 'no ahorrar (tal cosa)'. En arag. mod. plañer-se tiene uso popular con el sentido de 'lamentarse, quejarse': Andolz (1992: 342) registra plañer 'acusar una persona el mucho peso que lleva sobre sus espaldas («se plañe»= no puede más)’ en Bolea, Loarre y Murillo de Gállego; en el mismo sentido, plañer 'encorvarse [una persona] por el peso que lleva en las espaldas' en A Sotonera 
(GARCÉs, 2005: 265); PARDO (1938, s. v.) registra plañir '(de plangere, doler) sentir, deplorar' y 'resentir un peso o trabajo'; el EBA (1999: 1483) recoge plañer 'compadecer, tener consideración' en Binéfar; 'gemir, llorar, quejarse' en Bal de Chistau'; en Nagore (2020: 513) se registra para Huesca y su comarca: plañer-se 'quejarse, lamentarse'. Frec.: planyer 1: 0,00227; plannya 1: 0,00227.

plata s. f. 'plata': e todo quoanto pudo aver de oro e de plata le dio todo a monesterios e a cavalleros 18.116. Del bajo lat. PLATA 'lámina de metal' (DCECH, II, p. 347). Comp. argent. Frec.: 1: 0,00227.

plazer s. m. 'placer': el maestro, con grant plazer que havía, recebidas las letras, pensó que sería irregular si le consellava que firies justicia 20.111; et los aragoneses hovieron gran placer quando vengaron assi la muert del rey Remiro 17.39; Et estando el dito rey con con grant plazer et goyo en el dito castiello, envió sus mensageros al Padre Santo 36.171. Sustantivación del infinitivo plazerer. También placer. Frec.: plazer 7: 0,01591; placer 1: 0,00227;

plazer] (var.: plaçer]) v. tr. 'placer, agradar', 'aprobar, parecer bien': et un dia pregó a la reyna su madre que le plaçies dar el dito cavallo, la qual cosa le atorgó francament et goyosa 14.41; et el rey de Castiella díxole que le plazia 36.366; porque no hera plazient el dito compt Remón de Tolosa al suegro de Castilla 19.133; que le plazies dar perdón a éll et ad aquéllos que con él eran 36.175. Del lat. PLACERE 'íd.'. Frec.: plaze 3: 0,00682; plazía 2: 0,0455; plazie 1: 0,00227; plazient 2: 0,00455; plazies 2: 0,00455; placia 2: 0,00455 ; plaçies 1: 0,00227 .

plazient adj. y p. de pres. del v. plazer, 'agradable, que place, que parece bien': porque no hera plazient el dito compt Remón de Tolosa al suegro de Castilla 19.133. Frec. 2: 0,00455.

plegar v. prnl. 'juntarse'; 'congregarse, reunirse': et plegada toda la su gent, rocoliosse et vino sende en Catalunnya 38.393; Et plegado [aplegado N] todo el escolt [estolt $\mathrm{B}$; estol $\mathrm{N}]$, el dito don Alfonso sitió la villa de Yglesias 38.527; Et los moros acordaron que mas valia con aquellos dar la batalla antes que mas gentes se plegassen a él 19.216; Assí fue feito que los ditos árbitros se plegoron en Vedadoluengo 20.158; Et tantost los nobles et general de la tierra se plogó $[$ plegó $\mathrm{B}, \mathrm{N}]$ et todos ensemble concordoron et eslieron en rey et sennyor lur al dito Frederich 38.145. // v. intr. 'llegar': et envió por toda Navarra et Aragón cartas que todos sus vassallos viniessen a Fraga, et plegó alli con CCC de cavallo. 19.214; en el mes de octubre entraron en la tierra de los moros, tallando et destruyendo plegoron a Valencia 19.196; Los franceses, viendose muertos, yxieron en el alborada et no caceron [curoron B] por ren entro que plegoron al rey et matoronlo 34.162. Del lat. PLǏCARE. Hoy en arag. mod. continúa vivo como intr. 'llegar' y como tr. 'recoger' (Rohlfs, DDPA, s. v.; ANDolz, s. v.; EBA, 1999: 1485). Frec.: plegar 3: 0,00682; plegada 1: 0,00227; plegadas 1: 0,00227; plegado 1; 0,00227; plegados 2: 0,00455; plegaron 1: 0,00227; plegaronse 2: 0,00455; plegassen 2: 0,00455; plegó 4: 0,00909; plegoron 3: 0,00682; plogó [plegó] 1: 0,00227. 
pleito s. m. 'proceso legal', 'litigio judicial': que sin alguna pena et sin todo dupdo et pleito [pena $\mathrm{N}]$ real pudiessen fer degollar et matar vacas et qualseguier otro ganado 11.62. Etim.: del bajo lat. PLACITUM 'decreto, sentencia' (DRAE, 1970, s. v.; DCECH, IV, p. 577, s. v. plazo). CoROMINAS considera que pleito en cast. procede del fr. ant. plait, lo mismo que el cat. plet y el occ. ant. plag. Ahora bien, dice: «Al cast. hubo de llegar pleito a través de Aragón, lo cual nos explica el restablecimiento de la sorda por adaptación a la fonética de este dialecto. Pero no es admisible suponer con M. P. un *PLACTU tomado por el primitivo romance aragonés al latín galicano, ya que tal forma * PLACTU no existió en Francia, y tampoco lo sería admitir un lat. vg. *PLACTu, propio y exclusivo de Aragón, e inexistente en el Sur y Norte de Francia, en Cataluña y en Castilla-León-Portugal... Verdad es que este galicismo hubo de ser muy antiguo (plecto, pleitu, pleito, ya se halla en docs. arag. de 1054, 1060, 1062, Oelschl.), lo cual nos explica que el diptongo ai evolucionara en $e i$, según la tendencia aragonesa, y no quedara en $a i$, como en galicismos posteriores (fontaina, laido, etc.)» (CorominAs, ibídem, p. 578). Para Menéndez Pidal, pleito < PLACITU es un aragonesismo introducido en Castilla hacia el siglo XII (MGHE, p. 162, \$ 60.2; Orígenes, \$17, págs. 85-86). Dice que «se trata de un derivado normal de la síncopa PLACTU; esta vOz así sincopada pertenece al lat. de la Galia, donde la pérdida de la vocal postónica fue, en general, anterior a la sonorización». Puntualiza, en nota que «se trata, sin duda, de un galicismo; pero muy antiguo, tomado del lat. galicano y no del francés o del provenzal» (Orígenes, pág. 85, nota). En cualquier caso, proceda del fr. ant. plait (Corominas) o del latín galicano * Plactu (Menéndez Pidal), tuvo que adoptarse en época muy antigua, pues está plenamente adaptado al arag. en el s. XI, de donde pasaría, con la fonética propia aragonesa, al cast. en el s. XII. El LHP (p. 490, s. v. pleito) nos permite comprobar que todas las citas de pleito (o formas intermedias como placito, plecto, pleto...) proceden de documentos del s. XI y XII de Aragón y de algunos del s. XII de Navarra. La primera vez que se ve propiamente en la forma pleito es un documento de San Juan de la Peña de 1060: «fuit illo pleito facto de ista allodem in Atares, denante rex domno Ranimiro». Por su parte, el LRDMA registra pletos en un doc. de 1035, pleito y pleyto en 1060, pleicto en un doc. de 893, pleito en varios docs. de 1062 , etc. (FORT, 1994: 193-194). Frec.: 1: 0,00227.

pleno adj. 'lleno, pleno, completo': se firo nombrar rey de Aragón et mescló su sennyal con el del rey de Aragón, assí como si en plena et acabada possesión fues de los regnos del dito rey don Pedro 36.466; et aquéllos en pleno consistorio al Padre Santo mostró por tal como él hi avía a firmar 38.76. Del lat. Plenus 'íd.'. Frec.: pleno 3: 0,00682; plena 1; 0,00227 .

plomo s. m. 'plomo': Et aqui los aragoneses, más por fuerza que por grado, ficiéronle aprobar la unión que avían feita en tiempo de su padre el rey don Pero, con privilegio bullado 
con bulla de plomo por buena et duradera memoria perpetualment. 37.17. Etim.: del lat. PLumbum (DCECH, s. v., IV, p. 582). La conservación del grupo PL- responde a la fonética histórica aragonesa típica. En cast. se conserva el grupo PL- de forma irregular (tratamiento regular se da en el port. chumbo). Según Meyer-LübKe (REW, 6615) se debe a que es un catalanismo. Cuervo admite la posibilidad de que sea aragonesismo. Corominas cree posibles ambos préstamos, y apunta que «la temprana aparición en el Apol. no les es desfavorable». Pero termina diciendo: «De todos modos no se puede descartar del todo la posibilidad de un predominio de la pronunciación conservadora de las clases elevadas, tratándose del nombre de un metal» (DCECH, IV, p. 582). Frec.: 1: 0,00227.

plorar] v. intr. 'llorar': Et quando fue aquesto que la su anima devía andar a Dios, él reguardó el cielo plorando et dixo: «Sennyor Dios, entraré a la tu casa et adoraré la tu santa casa» 35.292. // v. prnl. 'quejarse, clamar': porque la tierra se plorava et senglores [songlotes B] de greuges sospiros gitavan a Dios et al dito rey don Pedro 36.195. Etim.: del lat. PLORARE. La forma plorar, con conservación del grupo inicial PL-, obedece fielmente a la fonética histórica aragonesa y continúa usándose en arag. mod. (ANDolz, 1992; DDPA; KuHN, HAD, p. 33; EBA, 1999: 1490; etc.). Frec.: plorando 1: 0,00227; plorava 2: 0,00455.

ploro s. m. 'llanto, lloro': do dexó grant ploro al pueblo e grant periglo a la tierra e goyo a los moros 32.66; los duelos, ploros, plantos et dolores que en la tierra depués de la muert suya fueron albirar ni pensar homme non los poria 36.713. Deriv. postverbal de plorar. Frec.: ploro 1: 0,00227; ploros 4; 0,00909.

plorosament adv. 'llorosamente, con lloro, con lamentaciones': Et dolentes [dolens B] et vencidos plorosament comencoron partir de aqui 36.623. Adverbio construido a partir del adj. fem. plorosa, deriv. del sust. ploro. Frec.: 1: 0,00227.

población s. f. 'poblamiento, población': et cada uno de los ditos christianos edificó aquí su estaja do [staja don $\mathrm{N}$ ] fue feyta dentro breu tiempo convinient población. 9.38. Frec.: 2: 0,00455 .

poblador] s. m. 'poblador': Aquesti don Alfonso en el aynno de mil CX priso Exea de moros e dioles buenos privillegios a los pobladores de alli 19.12. Deriv. postverbal del v. poblar, con sufijo -dor, que forma sustantivos con significado de agente. Frec.: pobladores 1: 0,00227.

poblar v. tr. 'poblar': et specialment basteció Benifaça, que es cerca de Moriella, et lo pobló de los monges de Poblet, 35.190; ... de las IX barcas, de las quales ocho ribaron en Gallicia et la novena en el ribage de Celtiberia, do el edificó una ciudad la qual clamó Barchanona et hoi es clamada Barcelona, por tal como fue poblada de las gents de la dita novena barcha 1.36. // v. prnl. 'establecerse': Et aquestos cetubals se poblaron en la ribera d'Ebro. 1.7. // ser poblado 'habitar, residir': mandó a un cavallero que avía 
nombre Bertran Canyellas, qui era poblado en Penedes 38.312-313. Etim.: Es deriv. de populus 'pueblo’ (DCECH, IV, 673). Frec.: poblar 1: 0,00227; poblada 1: 0,00227 ; poblado 2: 0,00455 ; poblaron 1: 0,00227 ; poblaronse 1 : 0,00227; pobló 17: 0,03864.

poblicación s. f. 'publicación': por la qual muert del dito cardenal et malautia del dito rey la poblicación de la dita paz se huvo a prolongar 38.95. Deriv. de poblicar. Frec.: 1: 0,00227.

poblicar v. tr. 'publicar, hacer pública una cosa': el dito rey Carlos con su filla dona Blanca et con el dito legado, vinientes pora poblicar la dita paz, fueron en la villa de Perpinnyan 38.87; los ditos arcevispos poblicoron [publicaron N] la paz dessuso dita 38.106; La qual avinienca concordada et en escripto perpetua memoria metida publicoron aquélla en Pamplona 20.167. Del lat. PūBLICARE 'hacer público'. Frec.: poblicar 1: 0,00227; poblicoron 1: 0,00227; publicoron 1: 0,00227.

poblo (var.: pueblo) s. m. 'pueblo': que le dassen poder de regir su poblo dreytament 11.47; quel rey Remiro tuvies por fillo al rey García et el rey Remiro que fues sobre todo el poblo et el rey García sobre todos los cavalleros 20.162 [en la ed. crítica, pueblo, pero en el ms. se lee poblo]; et verdaderament podian dezir los pueblos que buen padre, mellor fillo a los regnos et a la tierra fue dado. 36.82. / / 'población, parte poblada o zona urbana de una ciudad': et por todo el poblo de la dita ciudad honrradament proffessión faziendo... 20.175. La forma sin diptongación puede deberse a catalanismo, pero también podría explicarse por influencia analógica del v. poblar. Vid. pueblo. Frec.: poblo 5: 0,01136; poblos 1: 0,00227; Frec.: pueblo 2: 0,00455; pueblos 1: 0,00455.

pobre s. m. 'pobre': el pobre se escondió e la clerizia calló 32.69; et fue padre de fillos buerfanos, guarda et defendedor de biudas, fartador de pobres 35.177. Del lat. PAUPER, -ERIS 'íd.'. Frec.: pobre 1: 0,00227; pobres 4: 0,00909.

pobreza s. f. 'pobreza': le suplicó que por honor de Dios e de la santidat del dito lugar e por piedat de lur pobreza e por esgoart del su nuevo avenimiento, le plazies enrriqueçer el dito monesterio de algunas honores 11.23. Deriv. de pobre. Frec.: 1: 0,00227.

poco (var.: pocho) adj. y adv. 'poco': el dito rey don Pedro, con aquella poca de conpannya que tenía, firió en ellos 36.581; las galeras de los secilianos se vincieron et fueron muytas pressas, salvant aquélla do era el rey Federich et pocas otras 38.273; como buen cavallero, todo aquello preció pocho, copdiciando mas el servicio de Dios 18.25; la hermana del rey de Chipre clamada dona María, de la qual non procreó fillos nin fillas por tal como era de muytos días et bivió poco tiempo con el dito rey don Jayme 38.442; Et el dito rey don Pedro aplegó sus conpanyas et reconociolas et trobó que muy pocos de los suyos hi avian presso mal nin dannyo 36.659. Del lat. PAUCUS. Frec.: poco 8: 0,01818; pocho 1: 0,00227 ; pocos 4: 0,00909 ; poca 2: 0,00455 ; pocas 2: 0,00455 . 
poço] s. m. 'pozo': et de los otros fueron [ne $\mathrm{N}$ ] emplidos [implidos B] dos poços [los pozos $\mathrm{N}]$ con tierra que hi fue gitada dessuso por tal que non dasen pudor en la buest. 38.558. Del lat. PǓTEUs 'hoyo, pozo’. Frec.: poços 1: 0,00227.

poder s. m. 'pertenencia, posesión, propiedad, dominio': todas aquestas tierras fincaron en poder de christianos 4.7. // 'capacidad, facultad, posibilidad': et governolo bien segunt su poder 28.26 // 'fuerza militar': todo el poder del dito castiello de Callar vino a ferir en la buest del dito don Alfonso. 38.544. / / 'imperio, dominio, poderío': et uvo tanto de poder entre los los barones de Espanna et entre los moros que XII reyes de Espanna le fizieron tributo cada un anno mientre que vivió. 29.4. Sustantivación del v. poder. Frec.: 51: 0,11592 [sumando tanto sustantivo como infinitivo].

poder] v. tr. 'poder': do fizieron muytos castiellos et muytas otras fuerças do se pudiessen reçeptar et defender de los moros. 4.6; «ivos podedes nos tener seguro?» 36.287; queriendo tener fiesta bonrada en la ciudat de Barchinona [Barcalona $\mathrm{N}]$ et buena manyna [maynnana $\mathrm{N}]$ a la qual podemos dezir dolorosa et despagada por las cosas subsiguientes. 37.87; respondiole que con él no se podía veer sin batalla 38.562; La qual ciudat de Murcia el infant don Alfonso de Castiella la tenie luengo tiempo cercada et sus vassallos conselloronlo que se parties dallí que non la podie [podrie B] aver. 35.171; et fue por su consello acordado que fues redimido et que poria haver CC o CCC hombres de cavallo de la su rendempción para la guerra que cuydava aver con el rey de Aragón. 20.228; et de su consello le fues dado curador fasta que por si mismo pudies regir su tierra. 38.607. Del lat. vg. *POTERE. Frec.: poder 51: 0,11592 [sumando tanto sustantivo como infinitivo]; podamos 1: 0,00227 ; podedes 1: 0,00227 ; podemos 1: 0,00227 ; podía 23: 0,05228 ; podían 12: 0,02728 ; podido 2: 0,00455 ; podie 1: 0,00227 ; podieron 5: 0,01136 ; podies 3: 0,00682 ; podré 1 : 0,00227 ; podría $8: 0,01818$; podrían 2: 0,00455 ; poria 2: 0,00455 ; pudie 1: 0,00227 ; pudieron 3: 0,00682; pudies 14: 0,03182; pudiesen 3: 0,00682; pudiesse 1: 0,00227 ; pudiessen 10: 0,02273; pudo 15: 0,03409.

poderosament adv. 'poderosamente', 'con poder': et con grant poder de homes a cavallo et de pie poderosament aplegó et el regno de Murcia conquistó et prisso. 38.191. Frec.: 3: 0,00682 .

poderoso (var.: podroso) adj. 'poderoso': el quoal rigió mientre vivió muy libralment e poderosa 33.48; Et veyt si fue grant honor a la casa d'Aragón quel rey don Jayme tollies al rey de Castiella, más poderoso rey que él, tal regno como es Murcia 38.214; et de ora del alva, muyt abrivadament [abreviadament $\mathrm{N}$ ] et podroso [vigorosa $\mathrm{N}$ ] comendandose a Dios, firió tan fuertment en el sitio de los moros...12.56. Deriv. de poder. Frec.: poderoso 6: 0,01364 ; poderosos 2: 0,00455 ; poderosa 2: 0,00455 ; podroso 1: 0,00227 .

podre s. f. 'peste, putrefacción, pestilencia': en la ciudat avía grant freytura de viandas et malautia fuert grant, por onde entró la podre qui a los de la establida venía de la mortaldat de los franceses 36.606-609 [En la VC, p. 145: la pudor]. Etim.: del lat. PUTRIS 
'podrido' (DRAE, 1970, s. v.), o lat. PUTER, -RIs, 'podrido', de la misma raíz que putrere 'pudrirse'. La 1. a documentación que da el DCECH (IV, p. 673, s. v. pudrir) es de h. 1335, con el valor de 'pus'. El DRAE (1970, s. v.), registra podre 'putrefacción de algunas cosas' y en segunda acepción 'pus', también como femenino (ambas se mantienen en el DLE, 204). Con el signif. de 'pus' lo recoge el DME, p. 1505. No se registra en GILKIsON, aunque sí podrecer. Frec.: 1: 0,00227.

poner] v. tr. 'poner, colocar': por tal como no podía defender ni contrastar que alguno non poniesse su cabanna de ganado 11.58; et fue puesto en gran perplexidat cómo daría remedio a tanta perdición del su regno 20.100; et depués los buenos ommes de Castilla pusieronlo en paz con su marido 19.64. // v. prnl. 'meterse': en vida de su padre renunció el regno et pusose en la orden de los freyres menores 38.448. // 'ponerse, meterse, ocultarse (el sol)': por una estrella que ha nombre Esperus, ques pone cerca el sol et la ora es tarde 1.6. Etim.: del lat. PONERE 'colocar, poner'. Frec.: pone 1: 0,00227 ; poniesse 1: 0,00227 ; poso 2: 0,00227 ; puesta 1: 0,00227 ; puesto 1 : 0,00227; puestos 1: 0,00227 ; pus 1: 0,00227 ; pusieronolo 1: 0,00227 ; puso 3: 0,00682; pusole 1: 0,00227; púsolo 1: 0,00227; pusose 1: 0,00227.

popular (var.: pupullar) adj. 'popular, del pueblo': et un dia, clamados ensemble los nobles, cavalleros con la gent popular et de la tierra por levantar rey qualque noble varón... 12.18; Et depués, los prelados, nobles e cavalleros e gentes populares del un regno et del otro 20.150; Et depués la dita reyna con todos los nobles et barones et la gent pupullar [pupillar $\mathrm{B}$; el popular $\mathrm{N}$ ] del dito regno ensemble... 36.720. Del lat. POPULARIS 'íd.'. Vid. pupillar. Frec.: popular 1: 0,00227; populares 1: 0,00227; pupullar 1: 0,00227 .

por prep. 'por': Et lexó heredero del condado de Ribagorça et de Ampurias, el qual por compra buvo, don Pedro 38.637; actorgólo por el dito monesterio que yes de monges negros 19.18. // prep. 'para': 〈por fer buenas colles, carne y a menester» 20.123; el rey de Aragón lo enviava a éll por gitar la tregua que avian 36.391 // por do loc. conj. "por lo cual, por lo que': tanto començó bien de regir, por do buvieron grant conuerto los de la buest 17.129. // por razón que loc. conj. 'debido a que, a causa de que': En aquesti tiempo, por razón quel dito rey don Pedro non catava privilegios, libertades et fueros a los de Aragón [...] ellos se ajustoron et por mantener lurs fueros, privilegios et libertades fizieron unión 36.668. // por tal como loc. conj. causal 'a causa de que, puesto que, ya que': Et buvo acuerdo que por tal como bavía en ardit quel comín de Pisa enviava conpannya de cavallo et de pie en la ysla de Cerdennya, se devies mudar en la su galera... 38.511-513; depués muert de la dita reyna dona Blanca, prisso otra muller, la hermana del rey de Chipre clamada dona María, de la qual non procreó fillos nin fillas por tal como era de muytos días et vivió poco tiempo con el dito rey don Jayme. 38.441 // por tal que loc. conj. final 'para que, a fin de que': Luengo tiempo havía por tal quel dito regno de Secilia fues mas segurament preservado de poder de los enemigos 36.264; E 
por aquesto que podamos mellor tratar e mas verdaderment e breu por tal que sia más plazient de leyr ad aquellos que la leyeran et a los qui lo escuitaran 2.2; et soterraron aquellos que pudieron et de los otros fueron emplidos dos poços con tierra que hi fue gitada dessuso por tal que non dasen pudor en la huest. 38.558. Etim.: Del lat. vg. POR, alteración del lat. cl. PRO 'por', 'para' (DCECH, IV, p. 611). Frec.: 672: 1,52741.

pora prep. 'para': el dito rey Carlos con su filla dona Blanca et con el dito legado, vinientes pora poblicar la dita paz, fueron en la villa de Perpinnyan 38.87; dixo quel dies letras de creyença el rey don Pedro pora el rey de Castiella que se apparellava pora entrar en Aragón 36.361. Comp. por. / / 'hacia': et pagóle luego tantost el sueldo et fuesse poral rey, et avie grant alegría et plazer con él 36.398; et en aquella ora los aragoneses con los fillos de don Ferrando tornoron pora Aragón 38.205. Etim.: compuesto de por y a. En cast. se documenta desde origen del idioma (Cid, etc.). Normalmente se halla pora en el s. XII y en el s. XIII (Berceo; Alex., etc.). La combinación latina PRO AD aparece ya en docs. port. de fines del s. Ix, leoneses de 932, etc. Esta sería, pues, la etimología (DCECH, IV, p. 388). Se documenta habitualmente pora 'para', en el arag. de los ss. XIII-XV: «logue hun hombre con huna bestia, que carrio agua pora fer bardo»; "Item, pague a hun hombre con hun asno pora trayer arena pora la dita obra» (Libro de los muros, 1444-1465, Iranzo, 1986: 55 y 116); «sían partidos la tercera part del sennyor rey e las dos partes pora los alcaualeros» (Ordinaciones de la alcabala judía de Huesca del año 1389; Motis, 1990: 36); «et I leyto de los millores pannos que sean trobados en casa et una mula pora caualgar e ir bestias de arar» (FA, 222.8; Tilander, FA, 1937, p. 120); «El dito senyor uispe, entendida la raçon de su part, dioles vna carta pora nos otros» (DLA A, doc. núm 110, de Alquézar de 1341; p. 160). Frec.: pora 19: 0,04319; poral 3: 0,00682.

poridades s. f. pl. 'secretos, asuntos íntimos o confidencias': Otros dizen que a tiempo vino en Aragón et favló con algunos que sabian de sus poridades 19.220. Etim.: deriv. del lat. Purus 'puro'. Puridad y poridad se usaron con el significado de 'secreto' en cast. ant., en la Edad Media e incluso hasta el Siglo de Oro (DCECH, IV, p. 698). En el arag. de Fernández de Heredia se registra puridat y poridat 'purity' ('pureza') (GILKISON, 1984, p. 111, s. v.). Frec.: poridades 1: 0,00227 .

porque conj. causal 'porque': se movió grant discordia porque algunos non querian obedir al tutor 38.611; et non querían matarlo porquel capdiello mandava que tan bueno et leal era que non muries 36.345 [porque + el]. / / Equivale en algunos casos a 'por lo que' (conj. consec.): el alcayde fizo desparar muytas ballestas porque se huvieron d'alli partir. 38.306-307. Frec.: porque 130: 0,29548; porquel 1: 0,00227.

portero] s. m. 'portero, encargado de vigilar la puerta': et los porteros como locos et de poco bien [...], de continent dizieron que non podian entrar a verlo 20.30. Deriv. de puerta. Frec.: porteros 2: 0,00455. 
posar v. intr. 'alojarse': et fuese en el castillo de Albayón do era venido a posar don Nuch arçobispe de Caragoça 33.39. / / 'reposar, descansar', 'parar': de nueyt ni de dia no aturó ni posó fasta que fue cerca de los enemigos 33.84. / / v. prnl. 'sentarse': porque en antes todos los reyes se posavan en lur taula con cavalleros 3.51. // 'posarse, echarse, recostarse': firose decender del cavallo et levar al palacio et posses [posose $\mathrm{N}$ ] en el leyto 37.94. // v. tr. 'poner, colocar': et él possa y las primeras piedras 35.192; et la otra sennyera fue possada en el canpanal de la eglesia mayor 38.574; fue posado sobrenombre al dito Olivano, Cabreta 25.23; un cavallero francés ahontadament posó la mano en la barba del dito conte 22.12-13. Etim.: del lat. PAUSARE 'detenerse, reposar' (que en lat. vg. adquirió también el significado de 'posar', 'poner'). Comp. poner. Frec.: posar 1: 0,00227; posado 1: 0,00227 ; posase 1: 0,00227 ; posavan 1: 0,00227; posó 2: 0,00455 ; possa 1: 0,00227 ; possada 5: 0,01136 ; possado 2: 0,00455; possando 1: 0,00227; posses [posose] 1: 0,00227.

possedir v. tr. 'poseer': e cuydando ser e posedir Castilla por suya 19.147; por razón de la sennyoría de Montpesler et por otras tierras que possedía 36.160; el rey don Pedro su fillo possidie los regnos de Aragón et de Valencia et el condado de Barçalona 36.81; actorgólo por el dito monesterio que yes de monges negros e oy en día lo poxedecen 19.19. Etim.: del lat. POSSIDERE 'poseer' (DCECH, V, p. 206). Frec.: possedir 1: 0,00227; posedir 1: 0,00227; possedía 1: 0,00227 ; possidía 1: 0,00227 ; possidie 1 : 0,00227; poxedecen1: 0,00227 [error del ms. $\mathrm{N}$ original por posedexen].

possesión (var.: posesión) s. f. 'posesión': metio mano a los santuarios e yglesias e monesterios e prendiesen los trasoros de las eglesias, et vendía et enpeynava las heredades e posesiones de aquellas 19.149; et fueronse pora Castiella a meterlo en possesión del regno 37.53. Del lat. POSSESIO, -ONIS. Frec.: possesión 2: 0,00455; possesiones 1: 0,00227; posesiones 1: 0,00227.

postremero] adj. 'último, posterior': et dio la delantera a su hermano... et en la de medio fue don Ferriz, ... en la postremera el rey con don Ladrón 18.37. Etim. deriv. de postremo < lat. POSTREmus 'último' (DCECH, IV, p. 621). Comp. çaguero. Frec.: postremera 1: 0,00227.

postura] s. f. 'pacto, ajuste, convenio', 'condiciones': Otrosi Caragoca, Calatayud, Darocha et sus comarchas dio al emperador don Alfonso de Castiella a su vida tan solament, con homenage que le faría et otras posturas 20.273. Frec.: posturas 1: 0,00227 .

potencia s. f. 'potencia, poder': el qual por potencia et por riqueza era levantado en ergul [orgul B, N], 36.35. Cultismo tomado directamente del lat. potentia. Frec.: 1: 0,00227 .

precedient adj. 'precedente, que precede': assín como en el mas çerca [cercano N] precedient capitol yes mas largament contenido 16.11. Del p. de pres. del v. preceder. Frec.: 1: 0,00227. 
preciar] v. tr. 'apreciar, estimar': et aquesto oyeron los nobles et cavalleros dixeron: "Vayamos a veer aquella locura que nuestro rey quiere fazer», como aquéllos que lo preciavan [preciamos N] poco 20.130; como buen cavallero, todo aquello preció pocho, copdiciando mas el servicio de Dios 18.25; Et aquesti don Remiro fue muyt buen rey et muyt franco a los fidalgos, de manera que. muytos de los lugares del regno dio a nobles et cavalleros; et por esto no lo precioron res 20.97. Del lat. tardío PRETIARE 'íd'. Frec.: preciaban 1: 0,00227; preció 1: 0,00227; precioron 1: 0,00227.

precioso] adj. 'de gran valor y precio, de gran finura y lujo'; en la lexía piedras preciosas: de esmeraldes, et safires, robices et carboneles et otras piedras preciosas 28.22. Frec.: preciosas 1: 0,00227.

predecessor] (var.: predecesor) s. m. 'antecesor, antepasado': queriendo resemblar a sus predecesores, comencó de mover guerra et batallas contra moros 35.118; es verdat enpero que la unión que en tiempo de los predecessores de aquesti rey era movida et succedida, ya más en tiempo de aquesti rey nos movió ni se suscitó 39.23. Cultismo tomado del lat. praedecessor, -oris 'el que murió antes, antepasado', deriv. de decedere 'fallecer'. El BDELC (p. 473, s. v.) da la 1. a documentación en cast. en 1438, unos setenta años después de la redacción de la Crón. SJP. Frec.: predecessores 3: 0,00682; predecesores 1: 0,00227.

predicador] adj. y s. m. 'predicador': Don Johan Ximenez. d'Urrea, sennyor de Montagudo et murió a la tornada et fue enterado [soterrado N] en los freyres predicadores de Calatayú 38.403. Frec.: 2: 0,00455.

predicar v. tr. 'predicar': en tiempo de aquesti començó a predicar Mahomat la suya malvada secta [seta N] 3.58. Del lat. PRAEDICARE. Frec.: 1: 0,00227.

pregar v. tr. 'rogar; suplicar': pregó carament los ditos abad et clerezía del dito monasterio... et quisiessen Dios pregar et los sanctos... que le dassen poder de regir su poblo dreytament 11.43-47; pregando et suplicando quel dito Padre Santo le quisies scrivir al dito Simón 34.135; et prególa el dito emperador que devies perdonar a sus fillos el defallimiento que babian cometido contra ella 14.81; «fillo, te priego que en ti sean aquestas cosas porque Dios sea con ti» 35.259; «priégote, fillo, que tu devyes amar tu hermano» 35.270. Etim.: bajo lat. PRECARE (lat. cl. PRECARI) 'rogar, suplicar, pedir'. (PRobert, p. 1527, s. v. prier, Devoto, s. v. pregare). Dice Corominas: «El verbo pregar 'rogar', tan vivo en otros romances, no puede decirse propiamente que haya existido en castellano. Conozco un solo ej. en doc. riojano de 1206 (M.P., DL, 83.5), donde quizá no es más que un romanceamiento ocasional de la voz latina» (DCECH, IV, p. 631, s. v. preces). Cfr., no obstante: pregar 'rogar, suplicar' en Alex. (SAs, s. v., p. 503). El DME cita, además del Alex. un ejemplo de Berceo, San Millán, 186, y otro de Alfonso X, en el Libro de la Aqafeha (Libros del saber de Astronomía), pero en este último pregaremos equivale a plegaremos. Comp. fr. prier 's'adresser à Dieu', 'demander par grâce, avec humilité ou 
déférence' (Dauzat-Dubois- Mitterand, p. 601; PRobert, p. 1527); it. pregare 'rezar', 'rogar' (SAÑ̃é/Schepisi, s. v.); occ. pregar 'prier' (AliberT, p. 562, s. v. prèc); cat. pregar v. tr. 'demandar zelosament, humilment (a algú) de concedir alguna cosa; demanar (a Déu) la concessió d'una gracia' (FABRA, DGLlC, $s$. v.); 'demanar respectuosament [alguna cosa] a algú' (DL/C del IEC, 2007, s. v.). En arag. med.: pregar 'orar', 'rogar' (LR, p. 143); pregar algo a alguien 'pedir, rogar' (FA, p. 528; VM, III, p. 248); pregar 'suplicar, rogar' (DLAA; REIDY FRITZ, 1997: 230); pregar, preguar, pregrar 'rogar, suplicar, solicitar', 'orar' en Fernández de Heredia (GILKISON, s. v.); pregar 'rogar, suplicar' en el LT (Rodés, 2016: 755); pregar 'rogar' en VCA (p. 305). No se usa hoy en el arag. mod., si no es como forma literaria. Frec.: pregar 1: 0,00227; pregando 1: 0,00455; pregándolo 1: 0,00227; pregó 5: 0,01136; prególa 1: 0,00227.

pregaria] s. f. 'plegaria, ruego, súplica, solicitud' (en los dos casos documentados se emplea en $\mathrm{pl}$.): las quales pregarias et amonestamientos el dito conte non quiso obedecer 34.131 ['los cuales ruegos y advertencias'); inclinado begninament a las ditas pregarias justament suplicadas 11.26. Etim.: del bajo latín PRECARIA 'íd.' (DCECH, IV, p. 631, s. v. preces), fem. de PreCARIus 'referente al ruego', 'que se obtiene por complacencia, por súplicas' (Dauzat-Dubois-MitTerand, p. 601, s. v. prier). Se documenta pregaria en arag. med. abundantemente: 'ruego que se hace a Dios' (LR, p. 143); 'súplica, plegaria' (FA, p. 528; VM, III, p. 248); pregaria, preguaria, pregaria, precaria 'ruego, súplica, solicitud, petición', en Fernández de Heredia (GILKIsON, s. v.); pregaria 'plegaria, ruego' en DLAA (REIDY FritZ, 1977: 230); pregaria 'plegaria, súplica' en LT (RodÉs, 2016: 755). Comp. occ. ant. preguiera 'prière' (LevY, s. v.); occ. (lang.) pregària, preguièra 'prière' (AliberT, p. 562, s. v. prèc); port. pregárias; it. preghiera; cat. pregària 'acció de pregar Déu, oració' (FABRA, DGL/C, s. v.; DL/C del IEC, 2007, s. v.); fr. prière (PRobert); cast. med. pregaria (Berceo, Santillana, y en otros autores de los ss. XIV y Xv); tb. en el Voc. de A. de Palencia (1490) y en Nebrija (DCECH, IV, p. 631; DME, II, p. 1516). Frec. pregarias 2: 0,00455.

prelado (var.: perlado) s. m.: el qual quería que fues perlado [prelado N] en Aragón, fue electo en ovispo de Barbastro et de Roda 20.83; Assí como el aviés conbidado muyto honrado barón et muyto honrado prelado et otras gentes 37.85; do el rey don Jayme personalment et todos sus fillos et muytos prelados et richos homes de Catalunnya et de Aragón et del regno de Valencia 38.499. Del lat. PRAELATUS, pp. de PRAEFERO 'llevar delante, anteponer, preferir'. Frec.: prelado 2: 0,00455; prelados 9: 0,02046; perlado [prelado] 1: 0,00227.

prender v. tr. 'tomar, capturar': yes assí quel rey don Alfonso, hermano suyo, la prendie de moros et diola al conte Alperche 20.267; et partido de alli esti rey don Jayme fuela a sitiar et prendióla [prisola $\mathrm{N}]$ segunt dessuso dito yes 35.173; envió el condestable et se- 
nestara senescal de Tolosa con don Johan Munioz del Ara que prendría Aragón 36.332; Feria VI, depués Pascua, prendió el dito rey Arguedas, x kalendas junii pres [priso N] Setcastella 17.83; fue presa la ciudat de Barchinona por moros 26.12; et aquellas assí mismo fueron presas 38.273; et aquesti prese [priso N] en Espanna la provincia de Tarragona 3.43; Et pressa la dita ciudat, la maldición de las moscas quanto más yva, más crecía en los franceses 36.615; el dito don Alfonso sitió villa de Yglesias, la qual con grandes traballos et enoyo prisso 38.529; sitio la ciudat de Mallorquas con navilio de Pissa et finalment prissola 31.10. / / 'tomar, coger, agarrar': "Varons, prendet aquesta criatura et despullalde las vestiduras» 12.28. / / 'tomar, recibir': el dito rey, assí como aquél qui non podía sostener ni devía que mal prendiessen sus hermanas, vino con grant poder en ayuda del conte de Tolosa 34.139; et trobó que muy pocos de los suyos hi avian presso mal nin dannyo 36.660. Del lat. vg. PRENDERE 'coger, atrapar'. Frec.: prender 10: 0,02273; prendet 1: 0,00227; prendía 2: 0,00455; prendían 3: 0,00682 ; prendida 2: 0,00455 , prendido 1: 0,00227 ; prendie 3: 0,00682; prendiendo 5: 0,01136; prendieron 6: 0,01364; prediéronlo 1: 0,00227; prendiesen 1: 0,00227; prendiessen 3: 0,00682; prendió 22: 0,05000; prendiola 2: 0,00455 ; prendría 2: 0,00455; pres [priso] 1: 0,00227; priso 16: 0,03637 ; prisola 2: 0,00455 ; prisolo 1: 0,00227 ; prisso 18: 0,04091 ; prissola 1: 0,00227 ; presa 1: 0,00227 ; presas 1: 0,00227 ; prese [priso] 1: 0,00227; pressa 2: 0,00455 ; pressas 1: 0,00227 ; preso 11: 0,02500 ; presos 3: 0,00682; pressos 5: 0,01136. [En las formas de p. p. se suman también las formas del sustantivo preso, $-a /$ presso, $-a]$.

prennado s. m. 'preñado, preñez, estado de la mujer preñada': empero por esquivar vergonna et desonor que lende podría seguir, como millor pudo, cubrió celadament el prennado de su filla 23.15. Del lat. tardío PRAEGNATus 'gestación'. El DCECH (IV, p. 643) da la 1. a doc. del cast. preñado 'preñez' hacia 1600. Frec.: 1: 0,00227.

prennyada adj. f. y p. p. 'preñada': porque bien sabedes vosotros que quando la reyna su madre murió asin por grant desastre prennyada era 12.31; soterrado el dito rey, fincó donna Ennega su muller prenyada 12.1. Del lat. vg. PRAEGNATA (DCECH, IV, p. 642). Comp. enprenyada. Frec.: prennyada 1: 0,00227; prenyada 1: 0,00227.

presa p. p. f. del v. prender, 'tomada, capturada'. Vid. prender.

presencia s. f. 'presencia': et dixieron al rey que otro castiello se rendría si su presencia vidia [vedia $\mathrm{N}$ ] el alcayt de aquel castiello 38.299. Es cultismo tomado del lat. praesentia. Frec.: 1: 0,00227.

present adj. 'presente': aplegó todos los cavalleros et la otra gent qui a las palavras dessuso ditas eran presentes et dixoles: ... 38.327; en testimonio de mis parients et vassallos presents aqui qui aquesto vieron 12.35. / / de present loc. advl. de t. 'en el momento presente': et firmo aqui de present de mantener et fer dezir a todo homme uno depués otro que mi sennyor el rey de Aragón se yes levado lealment 38.321. Del lat. PRAESENS, -TIS 
'que está presente'. Es muy frecuente esta loc. en el arag. med.: «vendemos \& de present ljuramos a vos, Martín Boyl, vezino de la dita cjudat, yes a saber vna vjnya nuestra setiada en la Corona de Figaruela» (MDF, 41.3). Frec.: present 7: 0,01591; presentes 2: 0,00455; presents 1: 0,00227.

presentar] v. prnl. 'presentarse, ponerse o hacerse presente': Et depués de todas aquestas cosas, el dito rey don Jayme poso en su corazón de visar [visitar $\mathrm{BN}$ ] las altezas de los apóstoles de presentarse delant el Papa 38.170. Del lat. PRAESENTARe. Frec.: presentarse 1: 0,00227.

preservar v. tr. 'preservar, proteger': Et con grant victoria, loando Dios et sus sanctos, levantó el campo porque fue preservada [perseverada restravada $\mathrm{N}$ ] la dita ciudad del grant periglio que estava 12.60; et todo aquesto firieron por tal que Dios et los sanctos de aquell lugar los preservassen de las grandes persecuciones moriscas 9.36. Frec.: preservar 1: 0,00227 ; preservada 1: 0,00227 ; preservado 1: 0,00227 ; preservasen 1 : 0,00227 ; preservó 1: 0,00227 .

president] s. m. 'presidente', 'que preside': todo lo que se faría en la tierra se judgava a arbitrio de los presidentes en aquélla 14.5. Del lat. PRAESIDENS, -TIS (p. pres. de PRAESIDERE) 'el que preside, gobernador de una provincia'. Frec.: presidentes 1: 0,00227 .

preso (var.: presso) s. m. 'preso, cautivo': empero los otros pressos antes que salliessen de la pressón se huvieron redemir 36.422 // adj. y p.p. de prender. El dito conte de Foyx estuvo preso [prisso B] en el castiello de Siurana con grosas cadenas et los otros nobles et cavalleros tuvo presos en grillones 36.145-147; mandó su muller ser pressa bien guardada en el castiello de Anagera [Nagera $\mathrm{N}]$ 14.61; el dito rey soltó francament et quitia los fillos del dito rey Carlos et todos los otros barones que pressos tenía [havía N] 38.118. Del p. p. de prender 'coger, asir, tomar', 'capturar' < PREHENDERE. Frec.: preso 11: 0,02500 ; presos 3; 0,00682 ; pressa 2: 0,00455 ; pressas 1: 0,00227 ; presso 10: 0,22273; pressos 5: 0,01136.

presón (var.: pressón, presión, prisont) s. f. 'prisión': mas el dito maestro [maestre $\mathrm{BN}]$ fuyendo de la presión con las guardas fue delivrado de aquélla 36.59; et los otros barones quel dito rey don Jayme tenía presos pudiessen exir [sallir $\mathrm{N}]$ de la presón 38.50; et los otros nobles et cavalleros tuvo presos en grillones et en cadenas por diversos castiellos et lugares de su tierra, mas depués de algún tiempo todos los absolvió de las presones 36.149; et los fillos suyos et los barones dessuso ditos por rahenes dados del dito don Carlos en pressón del dito rey don Alfonso... 37.78; el dito conte, queriendose vengar de la onta de la prisont, movió batalla con los franceses 22.17. Del lat. PREHENSIO, -ONIS (DCECH, IV, p. 640). Frec.: presón 3: 0,00682; presones 1: 0,00227; pressón 3: 0,00682; presión 1: 0,00227 ; prisont 1: $0,00227$.

prestament adv. 'rápidamente': por miedo de los arabes, todo hombre tenies sus cavallos en las cambras o palacios do lurs mullers estavan, et aquesto porque mas prestament et en 
antes los pudiessen aver et de aquéllos servir quando menester les fuesse 14.33. Deriv. del lat. tardío PRAESTUS, -A, -TUM 'pronto dispuesto' (DCECH, IV, p. 646). Frec.: 1: 0,00227 .

presuntion s. f. 'presunción, creencia, conjetura': yes presuntion que desti sacrilegio que fizo en Leon et en Galiçia que fue punido en la batalla de Fragos [Fraga VL] 19.152. Es cultimo tomado directamente del lat. praesuntio, -onis 'antipación', 'presunción, conjetura, presentimiento', 'concepción anticipada' (SEGURA, 2001: 592). Frec.: 1: 0,00227.

pridie es un adverbio latino 'el día de antes, la víspera': pridie nonas junii en aquest mismo anno 18.2. Frec.: 1: 0,00227.

priessa s. f. 'prisa, rapidez, prontitud': de manera que assi complió el rey don Pedro con la çaguera en la mayor priessa como los primeros 18.44. // 'aprieto', 'situación comprometida que necesita urgente remedio': viendo como el rey de todas partidas estava en grant priessa, si dixo al rey: "Sennyor, datme letras de creyença pora el rey de Granada» 36.386. Etim.: del lat. PRESSA 'aprieto', 'apretada', part. de PREMERE 'apretar'. Antes significaba 'tropel agitado de gente', 'rebato, alarma' (BDELC, p. 476). GiLkison, s. v., lo registra en el vocabulario de Fernández de Heredia con las acepciones 'multitud, gentío' y 'prisa, presteza, precipitación'. Frec.: 2: 0,00455.

primerament adv. 'primeramente': Mas primerament mandó a un cavallero que avía nombre Bertran Canyellas 38.311. Adv. en -ment formado sobre el adj. numeral femenino primera. Frec.: 5: 0,01136.

primero adj. num. ord. 'primero': de las fillas, la primera huvo nombre Ysabel 38.453; et el possa y las primeras piedras Dios loando 35.193; de los quales fincoron dos fillos et una filla: el primero uvo nombre don Pedro 38.589; et los otros qui primeros eran pasados con las III naves, eran en un lugar que avía nombre Quart 38.521. / / primer 'primero', forma apocopada de m. s. ante sust.: et aquesti fue el primer conte que jamas fues en Urgell 23.82. Frec.: primero 22: 0,5000; primeros 5: 0,01136; primera 11: 0,02500; primeras 1: 0,00227; primer 2: 0,00455.

primo adj. num. ord. 'primero': XI kalendas aprilis en la segunda semana de Quaresma, feria tertia, ora prima et III fue toledana, ora vi fue romana 17.62; veamos qui fue conte primo de Barchinona 21.4. Cultismo tomado del lat. primus 'el primero, el que está más adelante', superlativo correspondiente al comparativo prior (SEGURA, 2001: 597). Vid. primero. Frec.: primo 1: 0,00227; prima 1: 0,00227.

primogénito s. y adj. 'primogénito': el primero uvo nombre don Pedro, el qual fue jurado en rey o primogénito en la ciudat de Caragoça 38.590. Cultismo tomado del lat. primogenitus 'primeramente nacido'. Frec.: 14: 0,03182.

primogenitura s. f. 'primogenitura': por tal como el primero fillo suyo renunció a la primogenitura et se metió en Orden 38.458. Deriv. de primogénito. La 1. ${ }^{\text {a documen- }}$ 
tación en cast. la da el BDELC (p. 234, s. v. engendrar) en 1490, más de un siglo después que el testimonio de la Crón. SJP. para el aragonés. Frec.: 2: 0,00455.

princep (var.: príncipe) s. m. 'príncipe': la quinta huvo nombre dona Violant et fue muller del fillo del princep de la Morera [Morea $\mathrm{N}]$ et de Taranto 38.433; conquistó muytos castiellos, fuercas et noblezas de moros et buvo tributo de los princeps de Valencia, de Tortosa et de Lérida. 31.13; Fortún Garceyz. de Viel, fjo de don Castán de Viel, buen cavallaro, el que primero firo seynal de tornellas e fue clamado príncipe de Huesca 18.107. Tomado del lat. princeps, -cipis 'el primero, el principal', 'jefe, soberano'. Frec.: princep 9: 0,02046; princeps 1: 0,00227; príncipe 1; 0,00227; príncipes 2 : 0,00455 .

principado s. m. 'principado': instituydo heredero primogénito en su principado don Jayme, la ora rey de Sezilia, hermano suyo 37.100. Deriv. de princep. La 1. ${ }^{a}$ documentación en cast. que da el BDELC (p. 475, s. v. príncipe) es de 1490, más de un siglo después de la que ofrece la Crón. SJP. Frec.: 2: 0,00455.

principal] adj. 'principal': la qual yes muyt necessaria para rey et princep que regnas et tierras ha deffender et las perdidas cobrar o ganar de nuevo con otras virtudes que ha de aver et una de aquéllas esta precipua [es principal $\mathrm{N}$ ] 20.52-55; no quisieron serprincipales acusadores 14.56. Deriv. de princep. Frec.: principales 1: 0,00227; precipua [principal] 1: 0,00227 .

prior s. m. 'prior': et el otro Guillem Berenguer et fue prior de Sant Benedit de Bages 28.27. Tomado del lat. prior, prius 'primero entre dos, superior' (BDELC, p. 475, s. v. primo). Frec.: 1: 0,00227.

prioressa s. f. 'priora, superiora de un monasterio': la quarta buvo nombre don Blancha et fue prioressa de Xixena 38.432. Frec.: 1: 0,00227.

privar] v. tr. 'privar, desposeer': dio sentencia contra éll, privando aquéll de los regnos et honores 36.458. Etim. del lat. PRIVARE 'apartar (de algo)', 'privar, despojar' (DCECH, IV, p. 655). Del lat. PRIVARE 'privar, despojar'. Frec.: privando 1: 0,00227 .

privilegio (var.: privillegio) s. m. 'privilegio': mas non lo han agora de nuevo porque por privilegio lo han antigament 38.396; como aquel que lo podia fazer por el privillegio papal ganado por su hermano el rey don Pedro 19.17. Cultismo tomado del lat. privilegium 'ley privada'. Frec.: privilegio 10: 0,02273; privilegios 7: 0,01591; privillegio 2: 0,00455; privillegios 1: 0,00227.

proçessión s. f. 'procesión': el el abat, saviendo la venida de su sennor, como mellor e mas onrradament pudo, con todos sus clérigos processión faziendo, ixiol a la carrera 11.17. Tomado del lat. processio, -onis 'acción de adelantarse', 'salida solemne' (DCECH, II, p. 13, s. v. ceder). Frec.: 1: 0,00227.

procrear] (var.: procrehar) v. tr. 'procrear': Aquesti rey don Alfonso regnó sin que no buvo muller nin procrehó fillos 37.102; depués muert de la dita reyna dona Blanca, prisso 
otra muller, la bermana del rey de Chipre clamada dona María, de la qual non procreó fillos nin fillas 38.441; et de otras fembras avies [ne avía N] procriados muytos fillos 36.32. Frec.: procreó 24: 0,05455; procrehó 2: 0,00455; procriados 1: 0,00227.

procuración s. f. 'procuración, comisión o poder que una persona delega en otra para que ejecute algo en su nombre': et todos ensemble concordoron et eslieron en rey et sennyor lur al dito Frederich, hermano del dito rey don Jayme, el qual se retuvo acuerdo sobre la procuración que regía del dito regno por su hermano el dito rey don Jayme 38.148. Deriv. de procurar. Frec.: 1: 0,00227.

procurador s. m. 'procurador, persona que tiene poder delgado de otra para ejecutar algo en su nombre': fue acordado et firmado aqui mismo que don Alfonso, fillo del dito rey don Jayme, comte de Urgel et general procurador suyo, fues a conquerir el regno de Cerdennya et de Corcega. 38.476; procuradores de ciudades et de villas de Catalunnya 38.466. Deriv. de procurar. Frec.: procurador 2: 0,00455; procuradores 3: 0,00682 .

procurar] v. tr. 'producir, causar': et que la malquerencia quel enemigo del bumanal linage havía procurada et metida entrellos et sus gentes 20.163; et por muytas et diversas injurias et dapnages que don Guillermo Remón d'Odena havía feito et procurado al dito santo rey 36.17. Los amigos de la muller procuraron que aqueste conte Giffre havies la gracia del rey 23.50. / / 'procurar, hacer diligencias y esfuerzos para conseguir algo': Et depués de algunos días et annos la gent de la tierra procuravase de sennor 12.15; porque el dito infant don Pedro queriendo dar reverencia a su padre non los quiso recebir mas procuró que al dito padre suyo se rendiessen 36.30. Tomado del lat. procurare. Frec.: procurada 1: 0,00227 ; procurado 1: 0,00227 ; procuraron 1: 0,00227 ; procuravase 1: 0,00227; procuró 2: $0,00455$.

prodeza s. f. 'magnanimidad, grandeza de espíritu'. Vid. proheza.

professo adj. 'profeso, que ha profesado en una orden religiosa': recibió et tornó al abito de San Benedito a la muert en el qual era professo en el monesterio de San Ponz de Tomeras 20.302. Frec.: 1: 0,00227.

proffessión s. f. 'profesión' (?); parece error por proçessión: el dito rey Remiro fue recebido según la convinença desus dita por don Sancho de la Rosa, vispo de Pamplona, con el su convento et todo el poblo de la dita ciudad honrradament proffessión faziendo et por el rey et todo su regno 20.176. Comp. proçessión. Frec.: 1: 0,00227.

proheza (var.: prodeza, proheça) s. f. 'magnanimidad, grandeza de espíritu'; 'rectitud, bondad, valentía, bizarría, destreza, excelencia'. Se refiere en todos los casos a una virtud de un rey o un personaje de gran categoría. En ningún caso tiene el significado de 'hazaña o acción valerosa': el qual fue muyt noble varón et de grant proheça et de grant saber et de muyt grant engenyo et de grant consello 32.2-2; Et por la su proheza et virtud que en él era, Gasconna [Gascueyna N] se sozmetió al su principado 14.23-24; dotado sobre todos los otros reyes en beldat et proheza 
de cavallería et breument en toda laudor 34.119-121; et por la su nobleza et prodeza buvo del rey de Francia el condado de Barchinona 22.6-7. Etim.: del lat. vg. tardío PRODiTiA (DCV B , t. 8, p. 902), que sería deriv. del lat. vg. PRODE 'provecho' y estaría relacionado con el v. PRODEO, -IRE 'adelantarse, avanzar, sobresalir, ser prominente'. Sin embargo, a juicio de Coromines, no existió en latín el derivado PRODITIA (ni en el vulgar ni el clásico), así que el cat. proesa sería un deriv. de prou < lat. vg. PRODE 'provecho', extraído del lat. cl. PRODEST, que vulgarmente se convirtió en PRODE EST (DECLIC, VI, p. 834; DCECH, IV, pp. 656-657). Comp. proeza, proheza, prodeza, prodeça en Fernández de Heredia con el significado de 'valor, bizarría, destreza'; 'habilidad, maña'; 'valor, valentía'; 'excelencia'; 'beneficio, favor, bien, utilidad'; 'ventaja, provecho' (GILKISON s. v. proeza, p. 109). Comp. cat. ant. proesa 'qualitat de pros; valor moral d'una persona' (DCV B, t. 8, p. 902), aunque en cat. mod. se define como 'acte de valor' (DL/C del IEC, 1995, s. v.); cast. proeza 'hazaña, valentía o acción valerosa' (DRAE, 1970); fr. prouesse 'acte de courage' (PRobert, s. v.); occ. proesa 'prouesse' (Alibert, s. v. pros, p. 566). Pero, como se ve, en estas lenguas romances el significado es distinto, pues se refiere a 'hazaña', mientras que en la Crón. SJP. está relacionado con el 'valor moral de una persona', acepción que solo se encuentra en cat. antiguo. Comp. proz. Frec.: proheza 2: 0,00455; proheça 1: 0,00227; prodeza 1: 0,00227.

prohismar] v. prnl. 'aproximar, acercar': et depués el dito santo rey se prohismó [proximo $\mathrm{N}$ ] a la su fin 35.290. Comp. cat. ant. pruixme, pruxme < lat. PROXIMU 'muy cercano', 'el más cercano' (BADIA, Gram. hist. cat., p. 147). Así que hay que explicarlo como vocalización de la $[\mathrm{k}]$ en -KS- $>$-is-; es decir: PROXIMUS $>$ PROKS(I)MU $>$ proismo. Quizá en arag. luego hay una transformación del diptongo oi [ói] en hiato obi [o1́] (la - $b$ - parece precisamente indicarlo). BADíA, refiriéndose a las palabras pruixme, pruxme indica: «La primera forma llegida de manera que $i$ es consideri en hiatus (quan, en realitat, tota la grafia ix correspon al so [j]), ha pogut donar la paraula mod. proïsme, tot i que molt menys emprada que la culta pròxim, presa directament de la forma llatina» (Gram. bist. cat., p. 147, nota 5). Se documenta proisme, proismo 'cercano, próximo, inmediato' como adjetivo y 'vecino, prójimo' como sustantivo en Fernández de Heredia (GILKISON, s. v., p. 109). Según Corominas, apenas hubo en cast. huellas de un tratamiento fonético popular del vocablo (ya que tanto en próximo como prójimo el tratamiento es netamente culto), como el que existe en cat. prui $(x) m e$, prö̈sme, oc. ant. prue(i)sme, fr. ant. prueisme. Comp. parientes prosmanos 'próximos' en el Fuero de Navarra; cat. ant. pruixma(n) 'próximo, siguiente' (DCECH, IV, p. 665, s. v. próximo). Vid. aprohismar. Frec.: prohismó 1: 0,00227.

prolongar v. tr. 'dilatar, demorar': por la qual muert del dito cardenal et malautia del dito rey la poblicación de la dita paz, se huvo a prolongar. 38.96. Del lat. PROLONGARE. Frec.: 1: 0,00227 . 
prometer v. tr. 'prometer': et jurado por rey fízole prometer que non se levantasse del sitio entro que avies Huesca a su mano 17.124; por vigor de la convinencia entre el Padre Santo et él feita et prometida 38.219; pero él, queriendo seguir [tener $\mathrm{N}$ ] lo que avía prometido, dezía que non dubdassen, que los mayores et mellores con él eran 38.249; Et Rodrigo Viscarra prometielo de ferlo et pagólo luego tantost el sueldo 36.397. Del lat. PROMITTERE. Frec.: prometer 1: 0,00227: prometida 1: 0,00227; prometido 4: 0,00909; prometie 6: 0,01364 ; prometielo 1: 0,00227 ; prometió 2: 0,00455 ; prometiole 1: 0,00227 .

prometiença] s. f. 'promesa': mas por grandes inportunidades et prometienças [prometimientos $\mathrm{N}$ ] quel dito rey de Castiella fazía al dito rey don Jayme... 38.29. Deriv. de prometer. Frec.: prometienças 1: 0,00227.

prometimiento s. m. 'promesa': et aquesti prometimiento devía seer feito et complido 38.154; por el tractamiento de los prometimientos quel dito rey de Castiella le avía feito 38.395. Deriv. de prometer. Frec.: prometimiento 2: 0,00455; prometimientos 4: 0,00909.

promoción s. f. 'promoción', 'acción de promover, acción de ascender a alguien a un cargo o categoría superior': Et quando los navarros vinieron a las cortes de Borja con voluntat et propósito que fiziessen rey a don Per Atares, su promoción [promotivo N] del regno non recibieron [fezieron $\mathrm{N}$ ] de buena manera a los navarros 20.23. Etim.: cultismo, tomado de promotio, -onis, deriv. del lat. PROMOVERE, y éste deriv. de MOVERE 'mover'. (DCECH, IV, p. 170, s. v. mover). La 1. a doc. en cast. que da Corominas es de h. 1578. Por tanto, la Crón. SJP. la adelanta en unos dos siglos. Frec.: 1: 0,00227.

pronunciar] v. tr. 'pronunciar, dar un veredicto, hacer pública una decisión': el dito Padre Santo por dreyto pronunció quel dito matrimonio non se podía [partir ni añade N] desemparar, et a mayor firmeza confirmó el dito matrimonio. 34.65. Cultismo, del lat. pronuntiare 'anunciar públicamente, exponer'. Frec.: pronunció 1: 0,00227.

propinquo adj. 'próximo, cercano': en ayuda de don Alfonso el deseredado que dixiemos [diximos $\mathrm{N}$ ] en la crónica [coronica $\mathrm{N}]$ de don Alfonso d'Aragón más propinquo [próximo N] dessuso dito 38.195-197. Etim.: Es cultismo, tomado del lat. PROPINQUUS 'cercano, próximo, inmediato, vecino, situado cerca' (BLÁNQUEZ, s. v., p. 1251), deriv. del lat. PRŎPE. Comp. arag. ant. prueb 'cerca' < lat. PRŎPE 'cerca', con evolución popular, en LR: «E pues a la Cumberri, prueb de Pamplona, firieronla d'una lança e murie la madre, e naxie el fillo biuo por la plaga de la lançada» (CoOper, 1960: 145). Aparece propincuo o propinco, «en forma enteramente culta» en Las Partidas, h. 1260; en A. Palencia; en Cervantes... (DCECH, IV, p. 665, s. v. próximo). Para el cat. propinc, documentado desde mediados del siglo XIV, vid. DECLIC (VI, p. 827). En arag. ant. propinquo 'cercano', propinquidat 'cercanía' en Fernández de Heredia (GILkison, s. v.); 
también propinquo 'próximo' en el LT (RoDÉs, 2016: 757). Comp. apropinquar. Frec.: 1: 0,00227.

proponer] v. tr. 'proponer': et delant del Padre Santo propuso sus clamos la dita reyna 34.64. Del lat. PROPONERE 'poner delante, presentar'. Frec.: propuso 2: 0,00455.

propósito s. m. 'propósito': el rey Federich non se quiso abstener de su propósito 38.259. Del lat. PRopositum 'plan, intención, designio'. Frec.: 10: 0,02273.

propriament adv. 'propiamente': por caso ninguno no podies allenar el regno de Aragón en personas algunas sino en los fillos et aquellos que descendrian de su filla propriament 20.262. Adv. formado sobre el adj. proprio. Frec.: 1: 0,00227.

proprio s. m. 'riquezas propias, propiedades': et conoció et sabió [supo N] el dia de la su muert, et queriendo sin proprio passó desta vida en la casa de los pobres de Barçalona en edat de LXX annos 31.54. Etim.: Es cultismo, del sust. lat. proprium 'propiedad, lo propio de cada uno, lo que uno posee' (Blánquez, s. v., p. 1253). Con el mismo significado lo recoge en Berceo Bustos Tovar, Contribución al estudio del cultismo léxico medieval, p. 639. Comp. cat. propi: sustantivado y en pl. se encuentra en la acepción 'las propiedades, les pertanyences (d'algú)': que han hagut de deixà/sos propis y sas casas, en un romance de 1790 (DECLIC, VI, p. 830, s. v. propi). // proprio (var.: propio) adj. 'propio, perteneciente a uno, peculiar de cada persona, relativo a la misma persona de que se habla': el rey don Sancho de Mallorquas le prometie ayudar con XX galeras a su missión propria 38.479; en sus proprios bracos levó el cuerpo de su bien aventurado padre 36.94; qui por la lur propia voluntat e a honor et a reverencia de Dios et de los sanctos qui aquí iazían, renunciaron a los deleites carnales et mundanales 9.32. Etim.: del adj. lat. PROpRIus 'propio, perteneciente a alguno o a alguna cosa'. La variante proprio se encuentra hasta en Nebrija; sin embargo, este emplea ya propio en sus definiciones, y esta es la forma que se halla constantemente en el Quijote, Covarrubias, etc. (DCECH, IV, p. 662, s. v. propio). En los DLAA es abundante el uso del adj. propria (REIDY FrITZ, 1977: 233). Frec.: proprio 1: 0,00227; proprios 1: 0,00227; propria 4: 0,00909; propia 1: 0,00227 .

prosperidat s. f. 'prosperidad': «Sennyor verdadero todo poderoso, fet hi nos menospreciar las prosperidades [prospidades $\mathrm{N}$ ], 35.238; el dito regno fue possado en tranquilidat de paz et la tempestat fue convertida specialment en prosperidat [prospiedat $\mathrm{N}$ ] et fueron gitados [echados $\mathrm{N}$ ] los enemigos del dito regno 36.77. Etim.: Tomado del lat. prosperitate $(m)$. Lo recoge Bustos (Contribución al estudio del cultismo léxico medieval, p. 641) en Alex. (h. 1250). Frec.: prosperidat 1: 0,00227; prosperidades 2: 0,00455 .

protestación] s. f. 'declaración, atestado, protesta, queja o reclamaciones': et fizieron sus cartas et protestaciones 34.47. Etim.: Tomado del lat. protestatione 
(protestatio, -onis), deriv. de protestar < lat. protestari 'declarar en alta voz, afirmar' (DCECH, V, p. 478). La 1. a doc. que da Conominas es del Corbacho (1438). Comp. protestación de la fe 'declaración, confesión pública que uno hace de la religión verdadera o de la creencia que profesa' (DRAE, 1992, s. v.). Frec.: protestaciones 1: 0,00227.

provar] v. intr. 'mostrarse, lucirse, destacar, resultar, ser a propósito, producir un efecto, demostrar que se es apto': en esta batalla provó muyt bien el buen cavallero don Gomez de Luna. 19.224; fue a sitiar a Çaragoça con los sus naturales de Aragón e de Navarra e con don Gastón de Bearne e con los gascones que y provaron muy bien 19.24. // v. tr. 'hacer ver que algo es cierto, hacer patente la verdad, justificar, demostrar': et avía otras fillos et fillas sines de aquestos; de dona Teresa Gil de Bidaure noble duennya... et fueron legítimos, que la madre provó a quello con grant esfuerço 35.78. Etim.: del lat. PROBARE 'probar, ensayar, comprobar'. Común a todos los romances de Occidente (DCECH, IV, p. 657). Frec.: provaron 2: 0,00455; provó 2: 0,00455.

provechosament adv. 'provechosamente': governó los ditos regnos e condados muy bien e provechosament dos aynnos 33.13. Aparece una sola vez en el ms. N, que es el más castellanizado. Comp. proveyto, proveitoso. Frec.: 1: 0,00227.

provedir (var.: proveyr) v. tr. 'proveer', 'procurar': mas Dios que provedece a los negocios et males, escusó que non fues la dita guerra 20.241; ... plegó sus gentes en Huesca non con propósito de fazer guerra a Navarra mas por provedir al buen estamiento del su regno 20.205; Aprés de aquesto, el dito rey don Remiro queriendo proveyr que enpués dias suyos dissensión alguna non avies en la successión del regno de Aragón, si fue tratado matrimonio con..., 20.251. Etim.: del lat. PRovidere, deriv. de videre (DCECH, V, p. 773). Frec.: provedir 1: 0,00227; provedeçe 1: 0,00227; proveyr 1: 0,00227;

proveitoso adj. 'provechoso': et anssí la dita reyna, conociendo el consello del cavallero sano et proveitoso, revocó el atorgamiento que havía feito de dito cavallo a su fillo García 14.49. Deriv. de proveyto. Frec.: 1: 0,00227.

provenir] v. intr. 'corresponder, venir a parar a propiedad de una persona, llegar a corresponder a uno': con tal condición que su fillo no regnas en Castiella, qui por successión, según que de suso yes dito, li era provenido. 14.85. Quizá se trate de una confusión del texto original, por pervenir (vid.). Frec.: provenido 1: 0,00227.

proveyto s. m. 'provecho': fueron hi feitas constituciones a proveyto et utilidat de la tierra 38.24. Etim.: del lat. PROFECTUS, -us 'adelanto, progreso, provecho, utilidad', deriv. de proficere 'adelantar, prosperar, ser útil' (DCECH, IV, p. 664). Comp. cat. profit, fr. profit, occ. profiech, port. proveito, cast. provecho. KuHN (HAD, p. 16), cita esta forma de la Crón. SJP., al analizar el comportamiento lat. -СT- $>$ arag. -it-, y la compara con otras voces recogidas modernamente en el Alto Aragón, como peito, dreito y estreito. Se registra proueito y proueitoso, 
proveyto y proveytoso en arag. med. (Reidy Fritz, 1977: 234; Tilander, FA, p. 532; VÁzquez, OB, 2011: 50; VCA, p. 322; etc.). En el arag. de Fernández de Heredia, si bien se registra proueyto y proueytoso en algunas obras, son mayoritarias las formas prouecho y prouechoso (GILKISON, 1984: 110), en consonancia con el tipo de aragonés de las Serranías Ibéricas predominante en los escritos del taller Herediano. En arag. mod. probeito y probeitoso (Andolz, 1992: 351). Frec.: 1: 0,00227.

provincia s. f. 'provincia': Beti nombra el otro regno Betica, et la maior ciudad d'aquella provincia [es clamada $\mathrm{N}$ ] Yspalis, la qual hoy a nombre Sivilia 1.20. Etim.: voz culta, tomada del lat. provincia (DCECH, IV, p. 664). Frec.: 5: 0,01136.

proz adj. 'bueno, excelente, valiente; hábil, inteligente, experto': fue muyt noble varón, largo, proz et diligent 35.89. Etim.: Para CoRominas es una var. de prou, del lat. vg. PRODE 'provecho', extraído de las expresiones PRODEST 'es útil', PROFICIT 'íd.' del lat. clásico, cambiadas vulgarmente en PRODE EST, PRODE FACIT. Comp. cat. ant. pros, prous 'noble, generoso, virtuoso' (DCVB, t. 8, p. 828 , donde se considera préstamo del prov. pros). Quizá haya también influencia del lat. PROCER, -ERIS 'personaje eminente'. Comp. occ. pro, pros 'bon, excellent, qui a la de la valeur, du mérite' (Levy, s. v.); pros 'preux, valereux, généreux' (AliberT, s. v.); fr. preux 'brave, vaillant' (prod en 1080, proz en el s. XiI) (PRobert, s.v.; Dauzat / Dubois / Mitterand, p. 600). En el arag. de Fernández de Heredia se registra pros, proz, proç (GILkison, s. v.). Frec.: 6: 0,01364.

publicar] v. tr. 'publicar, hacer público algo'. La qual avinienca concordada et en escripto perpetua memoria metida publicoron aquélla en Pamplona 20.167. Frec.: publicoron 1: 0,00227. Vid. poblicar.

público] adj. 'público'; en los tres casos en que se registra forma parte de la lexía carta(s) pública(s) 'documento o certificación notarial', 'escritura, instrumento público, documento en que justifica o prueba alguna cosa': Et de aquesto el dito rey requirió seer feita carta pública. 36.291; Et a mayor firmez̧a fueron feitas cartas publicas a perpetua memoria. 38.472; et del comparecimiento suyo et de la fadiga et contumacia del dito rey Carlos le devies fer carta o cartas públicas a memoria perdurable. 36.300. Vocablo culto, tomado del lat. publicus. Como indica LAGÜENS (1992: 224), «se trata de un término frecuentísimo en los documentos notariales, donde se suele hallar junto a los nombres carta y notario». Frec.: pública 1: 0,00227; públicas 2: 0,00227.

pudor s. f. 'hedor, mal olor, hediondez, fetidez': soterraron aquellos que pudieron et de los otros fueron emplidos dos pocos con tierra que hi fue gitada dessuso por tal que non dasen pudor en la huest 38.559. Etim.: lat. PUTOR, -ORIS, acus. PUTORE(M) 'mal olor, hedor'. Doc. en arag. med. y mod. (hoy en arag. es fem. a pudor). En 
cat. pudor 'mala olor' (FABRA, DGLIC, p. 1401). El DRAE (1984) lo registra como antiguo, con el significado de 'mal olor, hedor' — como masculino-, y lo mismo el DLE $(2014$, s. v.). Pero conviene tener en cuenta que a menudo en el DRAE, y mucho más en el DLE, se consignan como anticuados vocablos de uso en el aragonés actual. Para el arag. ant. pudor 'hedor' y pudir 'heder' vid. GiLKISON (1984: 111, s. v.); igualmente se registran en el LT (RoDÉs, 2016: 757). Comp. arag. mod. pudor 'hedor' (sust. femenino) у empudir, emputir, putir, pudir 'heder' (ANDolz, 1992: 166, 352 y 354; EBA, 1999: 711, 1524 y 1535). Frec.: 1: 0,00227.

pueblo s. m. 'pueblo, conjunto de los ciudadanos; gente, conjunto de personas': yes assaber: quel rey Remiro tuvies por fillo al rey García et el rey Remiro que fues sobre todo el pueblo et el rey García sobre todos los cavalleros 20.162; et verdaderament podian dezir los pueblos que buen padre, mellor fillo a los regnos et a la tierra fue dado. 36.82. Etim.: del lat. Pŏpulus 'pueblo, conjunto de ciudadanos' (DCECH, IV, p. 673). Comp. poblo. Frec.: pueblo 2: 0,00455; pueblos 1: 0,00455.

puent s. m. 'puente': un dia él yendo a caça, un cavallero suyo, clamado Ramón de Gasconna, matólo a gran trayción en el puent de Monclús 16.16. Del lat. PǑNS, -TIS. Es habitual en arag. med.: así, por ejemplo, en los DLAA (REIDY Fritz, 1977: 235). Comp. arag. mod. puen (KuHN, HAD, p. 86; BADÍA, Contribución, p. 163; Rohlfs, DDPA; Andolz; EBA, 1999: 1524-1525). Frec.: 1: 0,00228 [y Puent 1: 0,00227$]$.

puerta] s. f. 'puerta'; en los tres casos en que se registra aparece en pl. refiriéndose a 'puertas de la muralla de una ciudad': Et en continent, los franceses corrieron entro a las puertas de Bisuldu 36.518. Del lat. PǑRTA. Frec.: puertas 3: 0,00682.

puerto s. m. 'puerto de mar, lugar protegido de la costa donde fondean naves': et aqui huvo de consello que sende fues al puerto de Palma de Sols 38.525. // 'puerto de montaña', 'paso entre montañas', 'collado de una sierra': passó con todos sus cavalleros et con su gent ultra los puertos de Muladar 34.101. Etim. del lat. PŎRTUS, -us 'paso, puerto, fondeadero'. Pero la 2. a acepción procede, según CoroMINAS, «del sorotáptico PORTUS, de igual etimología indoeuropea que la voz latina, pero con un significado más semejante al de sus hermanos proétnicos» (DCECH, IV, 682). Cfr. puerto 'paso entre montañas' y en general referido a los Pirineos en FGN (Líbano, FGN, p. 178). En Fernández de Heredia se registra puerto 'port, harbor' y también 'mountain pass' (GILKIsON, 1984: 111). Igualmente, en los DLAA: puerto 'puerto' y 'paso' (ReIDy Fritz, 1977: 235). Frec.: puerto 8: 0,01818; puertos 1: 0,00227.

pues conj. causal 'pues, así pues, puesto que, ya que': Et depués rogó el dito rey García al dito rey Remiro que pues él era padre y él fillo que le dies algo de lo suyo que heredas, assí como fillo deve heredar a padre 20.177-20.179. // adv. 'después': E pues de aquesto 
havemos esmient es verdad que dentro el condado [en el regnado $\mathrm{N}$ ] de Castiella era sitiado un condado clamado Porcel 14.7. Etim.: Del lat. РǑsт 'después, detrás, después de, detrás de' que en la Baja época tomó el valor de PostQuam 'después que, como, puesto que' (BDELC, p. 481; DCECH, IV, p. 683). Es común en arag. medieval. Véase, por ejemplo, en el LR: «E ovo pues Adam otro fillo» (CooPER, 1960: 145). Vid. depués. Comp. pus. Frec.: 15: 0,03409.

pueyo (var.: pueio) s. m. 'colina', 'otero': en el anno MXCIII priso Nabal et el Pueio don Sancho sobre Huesca 17.101; fincó en el sitio con toda la gent en el Pueyo clamado de Sancho 18.5; et fuessen en un pueyo qui agora es clamado Santa María del Puyg 35.230. Del lat. PǑDIUm 'grada', 'colina, pequeña eminencia del terreno' (BLÁnQuez, s. v.). Pero, a partir de ahí, es evidente la diferente evolución semántica en cast. y en aragonés y catalán. Comp. cast. poyo 'banco de piedra' (DCECH, IV, 628), cat. puig (DCV B, t. 8, p. 967; DECLIC, VI, pp. 853-854). El DL/C (IEC, 1995, s. v.) define puig como 'elevació del terreny, més o menys rosta i formant cim que sobresurt del terreny circumdant, sia una plana, sia un massís muntanyós'. En Fernández de Heredia se registra pueyo 'elevated piece of land, hill' (GILKISON, 1984: 107), pero también poyo, que es la forma — de fonética castellana - que aparece en los textos en arag. de Teruel y en general de las Serranías Ibéricas, así como pug, puyg y puy, formas de fonética catalana (Gilkison, 1984: 107 y 111). En los DLAA se registra la forma pueyo: «hun nuestro pueyo que nos auemos... de çaga el castiello dUarta... el qual dito pueyo afronta...» (DLAA, doc. no 57, de Ponzano, año 1284; p. 85, lín. 7-9). Y es habitual en textos en arag. med.: «damos a poblar un pueyo nuestro que yes clamado Alcala» (doc. de Veruela de 1238; CPRA, p. 220). Se registra igualmente en arag. mod. (ANDolz, 1992: 353; EBA, 1999: 1526; NAgore, 2020: 533; etc.). Frec.: pueyo 1: 0,00227; Pueyo 1: 0,00227; Pueio 1: 0,00227.

pugnar] (var. puniar]) v. intr. 'batallar, contender': et avie grant alegría et plazer con él porque en todas maneras pugnava en su servicio et honor 36.399 // fig. "procurar, solicitar, porfiar con ahínco': Otrossí un otro compte don Pero de Lara puniava encuvierto de aver amor de la reyna 19.107. Tomado del lat. PUGNARE 'pelear, luchar'. Frec.: pugnava 1: 0,00227; puniava 1: 0,00227.

pululir] v. intr. 'pulular', 'multiplicarse, abundar': Et mudólos by del monesterio de Clunyego de la orden de San Beneditto, qui a la ora pululiva et floriva en toda la christiandat 14.99. Del lat. PULlulare 'echar brotes, multiplicarse, extenderse', que da en cast. pulular 'abundar y bullir en un lugar', 'dicho de los insectos y sabandijas: abundar, multiplicarse rápidamente en un lugar', 'dicho de un vegetal: empezar a brotar y echar renuevos o vástagos' y también 'dicho de una cosa: originarse, provenir o nacer de otra' (DLE, 2014, s. v.). En el texto de la Crón. SJP. merecen destacarse dos cosas: 1) que el verbo, que sería inicialmente 
pulular, pues es la solución regular a partir del lat. pullulare, ha pasado de la primera a la tercera conjugación, quizá por influencia del v. florir, que se encuentra a continuación; 2) que aparece el genuino morfema de pretérito imperfecto de indicativo del aragonés, $-b a$, en las conjugaciones segunda y tercera, lo cual ocurre en pocas ocasiones, tanto en general en los textos medievales en aragonés como en particular en la Crón. SJP. (en esta se registra cinco veces, con los v. pululir, florir, destruyr y aver, más otras doce con el v. yr, cf. NAGOre, 2003: 363). Frec.: pululiva 1: 0,00227.

punnyo s. m. 'puño': dixo un dia que con el su punnyo daría en las bariellas del dito conte 36.434. Del lat. PUGNus. Frec.: 1: 0,00227.

punyr (var.: punir) v. tr. 'castigar': yes presuntion que desti sacrilegio que fizo en Leon et en Galicia que fue punido en la batalla de Fragos [Fraga VL], 19.153; queriendo punyr el rey de Francia et sus gentes de las vildades et crueldades que feitas avian 36.592. Del lat. PUNIRE 'íd.'. El DCECH (IV, p. 471) documenta por 1. ${ }^{a}$ vez punir, «palabra siempre rara en castellano», en el siglo XV. En $V M$ se registra a menudo este verbo con dos grafías distintas, puinnir y puynnir (TILANDER, 1956, III, p. 257). En el VCA, p. 325, se registra tanto punir como punyir' castigar al culpable de un delito'. Frec.: punyr 1: 0,00227; punido 1: 0,00227.

pupillar adj. 'propio de los pupilos, infantes o menores de edad': Mas por tal como los fillos eran en pupillar edat constituidos, fueles dado curador [goardador $\mathrm{N}]$ 25.6. Etim.: tomado del lat. pupillaris 'del pupilo, del menor'. El DRAE (1970) registra el cultismo pupilar 'perteneciente o relativo al pupilo o a la menor edad'. Frec.: 1: 0,00227.

pupillar s. f. 'gente común, clase popular, pueblo': et cómo el rey Carlos a diversas et crueles muertes et turmentos havía exposado los nobles varones et la pupillar de la tierra de Seçilia 36.191. Etim. del sust. lat. POPULARIS, -IS 'paisano, compatriota, compañero', o bien del adj. POPULARIS, -E 'popular, relativo al pueblo', sustantivado a través del empleo «la (gente) popular». La $i$ se deberá a influjo de pupilo, o a haber sido tomada la palabra del occitano con pronunciación [ü]. Comp. occ. ant. popular 'homme du peuple, gens du peuple' como sustantivo masculino singular (LEVY, s. v.). Vid. popular, pupullar. Frec.: 1: 0,00227.

pupullar adj. 'popular'. Vid. popular.

puro adj. 'puro, libre y exento de otra cosa', 'mero': et diogela con tal condición las ditas tierras que aquellas tenies en feu en dreita sennoría por el rey Remiro, et assin como puro homme et vasallo suyo obedeciesse et atorgás a él por sennyor et sus succeydores 16.34. Del lat. PURUS, -A, -UM 'limpio, sin mancha'. Frec.: 1: 0,00227.

pus adv. 'después': Et el dito rey, inclinado mas a creyença que a certificación, mandó su muller ser pressa bien guardada en el castiello de Anager [Nagera $\mathrm{N}$ ]; et pus, fizo ajustar sobre aquesto cort general 14.62. Etim.: del lat. РО̆sт 'después' (BDELC, p. 481). 
Más que en falta de diptongación habrá que pensar aquí en una reducción del diptongo $u e>u$. Si no es una simple errata del copista, pues otras veces aparece pues: E pues de aquesto, havemos esmient... 14.7. No puede descartarse que se trate de pus < plus 'más' < lat. Plus, pero sería la única que vez que aparece en la Crón. SJP. Vid. pues, depués, enpués. Frec.: 1: 0,00227.

puyar] v. intr. 'subir': El se levantas et li fues apparellado su cavallo, ensellado et bien honrado de diversos hornamentes, et fues puyado en él por bofordar [vifordar $\mathrm{N}]$ 37.90; et seyendo electo de bueno en millor puyando según merecía, fue electo en ovispo 20.79; et el dito Exemén d'Artieda a los que puyavan, quando als no les podía tirar, les tiró la cappellina et todas las armas que tenía et fería a los que puyavan 36.345; el primero que puyó el muro de Ubeda fue un escudero 34.93; Et con escaleras puyoron en la partida que fincada era 36.342. Del lat. vg. *Podiare, deriv. de Podium 'grada', 'colina'. De uso general en arag. med.: «Et la vegada el dito Sancho se aparto, \& el dito Miguel, jurado, con el dito su hermano entro en la dita casa, \& puyoron alto en aquelya, \& aly troboron al puyant de la scalera a Espanyol de Vidos» (DLAA, doc. 145, de Jaca, 1464; p. 213, lín. 49); «Item hordenamos que los ganados o cabanyas que deuallyaran de la montanya o puyaran ad aquellya por erbagar e pasaran por el termino de la çiudat grosso o menudo puedan pasar por cualesquiere caminos o uieros publicos» (OB, p. 20, lín. 9); «et puyando enta la montanya et devallando enta Espanya los ganados grossos et menudos de la dita Bal de Echo» (doc. de Braslavilla de 1438; EAMJM, p. 71). Continúa vivo en arag. moderno: vid. Andolz; DDPA; $H A D$, p. 116; EBA, 1999: 1535-1536; etc. Comp. cat. pujar, del mismo origen. Frec.: puyado 1: 0,00227; puyando 1: 0,00227; puyavan 2: 0,00455; puyó 2: 0,00455; puyoron 1: 0,00227 .

\section{Q}

quaixi vid. quasi.

qual (var.: quoal) pron. relat. 'cual': Et lexó heredero del condado de Ribagorça et de Ampurias, el qual por compra buvo 38.637; dona Teresa, muller del dito don Alfonso, murió; de los quales [de la qual $\mathrm{N}$ ] fincoron dos fillos et una filla 38.588; establió por si mismo dreytos qui son agora clamados Usages, por las [sic] quals fue et es regido el dito condado 29.12; e procreó della una filla, la quoal fue muller de Alfonso 34.22; fizo 
morir los ditos traydores, los quoales se heran enseynnoreado de muytas fuerças 33.59 . Etim.: del lat. QUALIS (DCECH, II, p. 257). Frec.: qual 258: 0,58642; quoal 28: 0,06364; quals 1: 0,00227; quales 52: 0,11819; quoales 5: 0,01136.

qualesque adj. indef. 'cualesquiera', 'algunos': quando havia d'entrar en batalla o havía afer cavalgada o qualesque otros afferes periglosos 13.3. Es pl. de qualque. Frec.: 1: 0,00227.

qualque adj. indef. 'algún, -a', 'uno(a) cualquiera': a manera de convidar o de aver colloquio con él o en qualque [qual $\mathrm{N}]$ manera entendía a prender el dito rey don Jayme 38.46; por levantar rey cualque noble varón 12.18. Etim.: compuesto de qual y que. Comp. cat. qualque 'alguno', hoy de uso literario, a excepción de Baleares y Rosellón, donde se mantiene su uso popular (DECLIC, VI, p. 888889); occ. qualque cuanque 'quelque' (ALIBERT, s. v.); fr. quelque 'alguno' (cfr. PRobert, s. v.); arag. mod. cualque 'alguno' en los valles de Bielsa y de Chistau (BADía, Bielsa, p. 253; Мотт, 2000: 103; el EBA, s. v., p. 619, lo registra para Bielsa). Frec.: 2: 00455.

qualquiere (var.: qualquier) pron. indef. 'cualquier': cabanna de qualquier linage, 11.60; et todo quanto podía aver en qualquier manera todo lo dava 34.8; a todo dreyto et a toda demanda que en qualquiere manera avies o podies [oviesse et podiesse $\mathrm{N}$ ] aver en el regno 38.119; que en cualquiere manera fuessen feitos 38.109. Frec.: qualquiere 3: 0,00682; qualquier 2: 0,00455.

qualsequier pron. indef. 'cualquier, cualquiera': pudiessen fer degollar et matar vacas et qualsequier otro ganado qui dentro en los ditos terminos fues entrado sin lur licencia 11.63. Comp. arag. mod. cualsiquiera 'cualquiera, quienquiera' (PARDO, s. v.); cualsiquier 'cualquiera' en Biello Sobrarbe, cualsiquiera 'cualquiera' en Echo (EBA: 1999: 619); cualsiquiera, cualsiquier en Huesca y comarca (es usual en las obras de López Allué; NAGORe, 2020: 213). Frec. 1: 0,00227.

quando (var.: quoando) adv. 'cuando': et quando aquesto fue feito, la discordia de sus vassallos fue acallada 38.615; et quoando lo ovo complido su prometimiento e voto... 33.110. Del lat. QUANDO 'íd.' (DCECH, II, p. 258). Frec.: quando 63: 0,14319; quoando 8: 0,01818.

quantía s. f. 'suma o cantidad de dinero': el qual se redimió por grant quantía de moneda d'oro 36.552; Et don Caxal fue redemido por grandes quantias 20.235. Etim.: deriv. de quanto con sufijo -ía para la formación de abstractos (DCECH, II, p. 259). Frec.: quantía 1: 0,00227; quantías 1: 0,00227.

quanto (var. quoanto) pron. relat. e interrog. 'cuanto, cuánto': et pensaronse con quanta maleza era muerto su padre 23.30; et todos quantos dentro eran fizo morir a mala muert 36.486; prendiendo e matando ommes e fenbras e ganados et todo quoanto rovar el continent. 33.81; e fueron vençidos él e quoantos sallieron con él 19.45. Del lat. QUANTus (DCECH, II, p. 258). Frec.: quanto 6: 0,01364; quoanto 3: 0,00682. 
quaresma s. f. 'cuaresma': en la segunda semana de Quaresma 17.61. Etim.: del lat. tardío QUADRAGESIMA (DIES) (DCECH, II, p. 259). Frec.: 1: 0,00227.

quarto adj. num. ord. 'cuarto': la quarta buvo nombre dona Blancha 38.431; et el quarto fillo del dito rey don Jayme 38.450. Frec.: quarto 2: 0,00455; quarta 3: 0,00682.

quasi (var.: quaxi, quaixi, quayx) adv. 'casi': que pues a non res quaixi eran venidos franceses 36.648; et avie letras del rey de Inglaterra que yera quasi su padre 37.63; et encara que aquéllos que fueron movedores de la Unión quaxi [cerca todos $\mathrm{N}]$ eran muertos 39.30; porque toda vegada ho quayx estuvo enfermo 39.15. Tanto quaxi, quayx, quaixi, como quasi son formas todas ellas provenientes del lat. QUASI 'como si' (cfr. BDELC, p. 137; DECLIC, VI, p. 898). Corominas-Pascual dan la 1. a doc. de casi en cast. en 1406-12 (DCECH, I, p. 908, s. v. casi). La Crón. SJP adelanta la $1^{\text {a }}$ doc. (claro que no del cast. casi, sino del arag. cuasi, gráficamente quasi) en unos 30-40 años. En arag. popular moderno es general cuasi (cfr. Andolz, s. v.; Rohlfs, DDPA, s. v.; EBA, 1999: 622; etc.). Comp. cat. ant. quaix (semejante a la forma quayx de la Crón. SJP), cat. mod. quasi, occ. ant. cais, it. quasi, cast. casi. Frec.: quasi 5: 0,01136; quaxi 1: 0,00227; quayx 1: $0,00227$.

quatro adj. num. 'cuatro': Et huvo por muller la reyna dona Urracha, de la qual buvo un fillo, clamado García, et quatro fillas 12.76. Etim.: del lat. QUATTUOR (DCECH, II, p. 261). Frec.: 1: 0,00227.

quaxi vid. quasi.

quayx vid. quasi.

que pron. relat. (con antecente de cosas y personas) 'que', 'el que, la que, los que, las que': los quales vinieron de una isla que es clamada Estancia 2.14; et $\langle$ de $>$ la freytura grant que sofrían grant mortaldat se crescio 36.609; Muerto el dito rey don Remiro, regnó su fillo Sancho que era mancebo de XVIII annos 17.1; en ayuda et socorro de los ploros et lagrimas et dolores que los ditos secilianos gitavan agrament et sofrían. 36.205; por una estrela [estrella en la ed. crítica] que ha nombre Esperus, ques pone cerca el sol 1.5. (ques = que+se). Etim.: del lat. QUEM, acusativo masc. de QUI, QUAE, QUOD 'el que, la que, lo que' (DCECH, IV, pp. 703705). Frec.: que (pron. rel.) + que (conj. compl.): 972: 2,20929; ques 3: 0,00682 .

qué pron. interrog. (referido a cosas) 'qué': et se metía en ygual dellos en todos afferes d'armas et calçava a vegadas avarchas et sabia qué eran treballos et cueytas 12.71; et mientre estava en acuerdo qué farian, algunas conpannyas... 38.289. Etim.: del lat. QUID, pron. interrog. neutro (DCECH, IV, p. 705). Frec.: 65: 0,01136.

que conj. completiva 'que': dixole que agora que non dubdas del rey de Castiella 36.368; los nobles et cavalleros de Aragón dizieron que aquel renunciamiento non vallía 34.43-44. // conj. consecutiva 'de tal manera que': cubrió celadament el 
prennado de su filla que ningún homme non lo conoció res 23.15. // Forma parte tb. de la loc. conjuntiva final por tal que 'para, con el fin de que' (vid. por). Etim.: del lat. QUID, interrog. neutro latino, con la aportación de ciertos usos vulgares de QUIA (DCECH, IV, p. 703). Frec.: que (pron. rel.) + que (conj. compl.): 972: 2,20929.

quel (conj. que + art. el): et ordenó el infant quel noble don Phelip de Celuza, qui era venido de Secilia..., 38.578 // (conj. que + pron. pers. átono el = 'le'): et por tal quel das [que dasse $\mathrm{N}$ ] a entender al legado el dito rey... 38.292 // (conj. que + pron. pers. tónico él): et depués quél le ganaría el dito Imperio a messión de la Yglesia, 38.155. Frec.: quel 96: 0,21820; quél 2: 0,00455; quella 1: 0,00227. quende = que+ende 'que de ello; que a ello': mas non lo quiso prender entro ba quende fues forçado por el Padre Santo 38.609. Comp. en Fernández de Heredia: por la muy grant mercaderia quende passa, la qual va entro a India. (Libro de Marco Polo, ed. NitII, p. 27, lín. 10). Vid. ende. Frec.: 1: 0,00227.

querer v. tr. 'querer': Sennyor, dęit nos a qui queredes que esliamos por sennyor 38.136; fuessen amigos et bien querientes et paz et amor fuesse entre ellos, 38.337; con muytos otros christianos que no querieron matar 18.47; et si non lel queries soltar, pues en su poder yera, que retenies al rey de Aragón por preso 20.188; siempre movía el pie en semblança de cabreta qui quier cavar, 25.25; quirie mas haver guerra con los moros que non con los christianos 17.52; se quirieron [quisieron $\mathrm{N}$ ] render al dito infant 36.28; que lures oraciones et buenas obras lo deviessen haver por recomendado, et quisiessen Dios pregar et los sanctos quel dito monasterio... 11.45. Etim.: del lat. QUAERERE 'buscar, inquirir, pedir" (DCECH, IV, p. 717). Frec.: querer 1: 0,00227; queredes 3: 0,00682; queremos 1: 0,00227; quería 16: 0,03637; querían 6: 0,01364; querido 1 : 0,00227; querie 3: 0,00682; querien 1: 0,00227 ; queriendo 29: 0,06592 ; queriéndolo 1: 0,00227; queriendose 2: 0,00455 ; querientes 1: 0,00227 ; querieron 1: 0,00227 ; queries $1 ; 0,00227$; querra $1: 0,00227$; querriase 1 : 0,00227 ; quier 2: 0,00455 ; quiere 5: 0,01136 ; quirie 1: 0,00227 ; quirieron 1 : 0,00227 ; quis 1: 0,00227 ; quisieron 7:0,01591; quisies 5: 0,01136 ; quisiesse 2: 0,00455; quisiessen 1: 0,00227; quiso 21: 0,04773.

question] s. f. 'cuestión': por algunas nuevas et questiones et demandas quel dito rey fazía a los nobles 36.127. Etim.: Es cultismo tomado del lat. quaestio, -onis 'búsqueda, interrogatorio, problema' (DCECH, IV, p. 719, s. v. querer). Frec.: questiones 1: 0,00227 .

qui pron. interrog. 'quién' (referido a personas): «Sennyor, dezit nos a qui queredes que esliamos por sennyor» 38.135. // pron. relat. de generalización 'quien, el que, aquel que': et qui al by querra dezir, entre al campo... 12.35. // pron. relat. con antecedente (de persona o de cosa) 'que, el cual, la cual, los cuales, las cuales': el otro don Jayme qui fue comte de Urgel 38.592; toda la compannia qui con ella era 
12.4; un fillo qui fue clamado García Inneguez.10.23; con vint galeras qui se armoron en Valencia 38.501. Etim.: del lat. QUI, nominativo masc. del pron. relat. QUI, QUAE, QUOD 'el que, la que, lo que' (DCECH, IV, p. 705). Para los usos de qui, véase más ampliamente el apartado 5.8.1.2. del estudio lingüístico (NAGORE, 2003: 308-309). Frec.: 145: 0,32958.

quien pron. interrog. 'quién': «placia vos que nos dedes Sennyor o nos digades a quien queredes que esliamos por sennyor» 38.128. Solo aparece dos veces, frente a la forma habitual qui (vid.). Frec.: 2: 0,00455.

quienta pron. interrog. f. 'qué, cuál' (referido a cosas, objetos o conceptos): et veet los prometimientos del rey de Castiella en quienta manera mala se convirtieron, 38.38-39; nin quienta respuesta les avia feita 36.182 [ne quina resposta los havia feta, VC]. Funciona en ambos casos como interrogativo indirecto. Comp. en occ. (prov.) quinh pron. adj. interrog. 'quel, de quelle sorte' (Levy, s.v.); en occ. (langued.) quin, quina pron. o adj. 'lequel?’ (Alibert, s. v.); cat. quin, $-a$ adj. 'un (o uns) d'un grup o nombre de persones o coses sobre el qual (o els quals) recau una interrogació directa o indirecta / adjectiu exclamatiu' (FABra, Dicc., s. v.). Se documenta en el arag. de Fernández de Heredia quiento, -a, quientos, -as (GILKISON, s. v., p. 112). Con gran profusión aparece en el Rams de flores o Libro de actoridades, de Fernández de Heredia (ed. de Guardiola Alcover, 1998), con el sentido de 'cómo' o de 'quién, cuál': «Veylat porque non sabedes en quiénta ora deue venir Nuestro senyor» ( $L A$, p. 160, lín. 18); «Sant Paullo apostol, en la primera epistula ad Corinthios, capitulo XII, declara quiéntas deuen seyer las moças» ( $L A$, p. 178, lín. 10). CoromiNAS cita en quienta guisa 'en quina manera' en una versión aragonesa inédita de la Crónica de Lucas de Tuy, ms. de finales del s. XIII o comienzos del XIV (DCEL/C, VI, p. 961). Para el arag. mod. Andolz da quiento 'icómo!', 'de qué manera', y tal y quiento 'tal y cual', pero lo toma de MONEva y de PARDO, de quienes copia los ejemplos. Según Moneva, quiento se usa en Zaragoza, pero debemos confesar que nosotros no lo hemos oído nunca. En la VC de la Crón. SJP a quienta corresponde cat. quina. Etim.: Podría proceder de un cruce entre lat. QUEM 'quien' y QUANTUM 'cuanto', o de QUI y QUANTUM; o quizá del adv. interrog. QUEM AD MODUM 'cómo, de qué modo' (cfr. BlánqueZ, s. v.), aunque en todo caso habría que pensar en un cruce con QUANTum. Para el occ. quin AliberT propone lat. QUID unus. Para explicar la forma arag. quiento CoROMINAS propone partir de la misma base QUINA (< QUINAM, pron. interrog. neutro indefinido) que propone para el cat. quin, $-a$. Pero añade que debió de haber una contaminación de QUANTUS y de quien $<$ QUEM, de manera que primero se formaría quin(o), - a y de ahí *quien(o), que daría quiento, - a por influencia de cuanto (DECL/C, VI, p. 961). Frec.: 2: 0,00455 . 
quiere Úsase en la loc. conj. concesiva como quiere que, como quier que 'aunque': el emperador como quier que de sayna fuese movido... 19.89; et ellos como quiere que la tuviesen por el enperador... 19.79. Vid. querer.

quinto num. ord. 'quinto': la quinta buvo nombre dona Violant, 38.432; el quinto don Remón Berenguer, 38.420. Etim.: del lat. Quintus (DCECH, II, p. 84). Frec.: quinto 1: 0,00227; quinta 2: 0,00455.

quis contr. de qui 'quien' + pron. refl. es 'se': assí como a quis pertannya por dreyta linea et successión [= qui + se] 36.198. Vid. qui. Frec.: 1: 0,00227.

quitar] v. tr. 'quitar', 'liberar', 'eximir': soltóle e quitóle el omenage e los lugares que él e los lugares le heran tenidos 33.29. Etim.: podría proceder del lat. tardío QUIETARE 'apaciguar, tranquilizar', alterado en QUITARE. La etim. está relacionada con la de quitio, y no está claro si este es postverbal de quitar o por el contrario el verbo procede de él. Cfr. DCECH, IV, pp. 735-7737; DauZAT-Dubois-MiтTERAND, p. 624, s. v. quitte; MEYER-LÜBKE, REW, no 6957. Comp. tirar, toller. Frec.: quitóle 1: 0,00227.

quitio adj. 'libre, franco, exento', 'ileso, incólume': aquestas cosas feitas, el dito rey soltó francament et quitia [quita $\mathrm{N}$ ] los fillos del dito rey Carlos 38.116; do depués fue franco et quitio de toda cucjeción [subjitión N] 23.72. Etim.: del lat. QUIETUS 'tranquilo, libre de guerra', por vía semiculta. O quizá del verbo lat. tardío QuieTARe, 'eximir de una obligación', luego 'libertar', y por fin 'quitar', por medio de una metátesis: quietar > quitear $>$ quitiar, y de ahí quitio. $\mathrm{O}$ bien quietar $>$ quetiar $>$ quitiar (DCECH, IV, p. 735-737). Comp. cat. y occ. quiti 'libre de obligación'. Frec.: quitio 1: 0,00227; quitia 1: 0,00227.

\section{$\mathbf{R}$}

rahenes (var.: rahenas) s. m. 'rehenes': et todos los otros barones que pressos tenía por rahenas del dito Carlos 38.118; et delivró de la pressón, et los fillos suyos et los barones dessuso ditos por rahenes dados [renas N] del dito don Carlos 37.78. Etim.: Según el DCECH, IV, p. 855, del ár. vg. RAHÁn (ár. RAHN) 'prenda'. Pero, según Corriente (2003: 424), del ár. andalusí RiHÁN, pl. de RÁHN 'prenda; rehén', aunque con contaminación del prefijo romance re-. En Fernández de Heredia: rahena, rehena, reena, raena, rafena, refena, rephena, reffena, rebena (GILKISON, s. v. rehena). En Zonaras, refenas (Álvarez, 2006: 399). Frec.: rahenas 1: 0,00227; rahenes 2: 0,00455. 
raiz s. f. 'raíz', fig. 'pie, somontano': et a la raiz, de una sierra et montanna fincaron sus tiendas 19.198. Del lat. RADIX, - ICIS 'raíz'. Frec.: 1: 0,00227.

ratificar] v. tr. 'ratificar': et aquestas palauras et otras por retificar [ratificar B] su dreyto dixo una et diversas vegadas 36.296. Es un cultismo tomado del bajo lat. ratificare. La 1. ${ }^{a}$ doc. que dan Corominas-Pascual es de 1604 en el Guzmán de Alfarache (DCECH, IV, p. 802, s. v. razón).

razón s. f. 'razón', 'argumentación', 'motivo, causa': por la rąón sobre dita 38.111; los dreitos et razones allegadas de cada una part 20.159. Aparece tb. en la expresión de razón 'en derecho, con sujeción a razones', 'de acuerdo a razones': envió a don Alfonso de Aragón a rogar como a padre quel diesse su regno et non le quisiesse aquell tirar por fuerça, pues de razón non podía, porque él par [a] ellado era de ayudar et seguir [a servir $\mathrm{N}$ ] como fillo a padre. 19.172-176. Del lat. RATIO, -IONIS. Frec.: razón 30: 0,06819; razones 10: 0,02273.

razonable adj. 'razonable': porque razonable cosa yes que de aquestiy de sus succedidores que sin meano regnaron en Aragón coronicas fagamos sin ninguna otra adición. 15.7. Deriv. de razón. El DCECH, IV, p. 802, da la 1. a doc. de esta voz a finales del s. XIv. Frec.: 1: 0,00227.

real adj. 'real, relativo o perteneciente al rey': con convinient honor mas non real [con real N] 38.168; el dito santo rey se despulló los vestidos reales 35.281. Del lat. REGaLIS. En otros textos en arag. med. es frecuente encontrar la forma reyal. Así, por ejemplo, en varias obras atribuidas a Fernández de Heredia; al menos, en la Cronica troyana, Eutropius, Grant Cronica de Espanya y Orosio, si bien en otras obras se registra real (GILKISON, s. v. real). También aparece reyal en el Ceremonial de Consagración y Coronación de los reyes de Aragón: «E todas las ditas cosas feytas e acabadas el rey seyendo en el sitio reyal con las insignias reyales..." (p. 37); «E depues la reyna en meyo de dos uispes ira delant laltar mayor e alli siali apparellado un sitio reyal ornado de panyo doro» (ibídem, p. 45). Frec.: real 9: 0,02046; reales 3: 0,00682.

rebellar v. intr. y prnl. 'rebelarse': por tal que las sus gentes no pudiessen rebellar contra ell 3.78; antes contra éll se rebellassen assí como occupador injusto de lur tierra 36.208; contra el dito rey Carlos se rebelloron 36.211. Etim.: cultismo, tomado del lat. rebellare 'renovar la guerra', 'rebelarse', deriv. de BELLum 'guerra' (DCECH, I, p. 558). Muy posiblemente la grafía - $l l$ - valdría por $l$ geminada (y no por palatal lateral). Frec.: rebellar 1: 0,00227; rebellassen 1: 0,00227; rebelloron 1: 0,00227 .

rebellión s. f. 'rebelión': contra el dito rey Carlos se rebelloron, por la qual rebellión el dito rey Carlos, qui grant poder de homes a cavallo et a pie avía perellado contra el enperador de Costantinnoble, con el mismo poder sitió la ciudat de Mençina 36.211-214. Etim.: cultismo tomado del lat. REBELLIO, -ONIS (DCECH, I, p. 558). Igual que rebe- 
llar, se registra con - ll, grafía que valga posiblemente por $l$ geminada y no por lateral palatal (cfr. DCECH, I, p. 558b). En Fernández de Heredia: rebellion, rebillion (también rebelion), rebellamiento 'rebelión', rebelle 'rebelde' (tb. rebeldia 'rebelión'), rebellar 'rebelar', etc. (GiLkison, p. 113). Frec.: 2: 0,00455.

reçaga s. f. 'retaguardia': firió en la reçaga de los enemigos 36.230. Deriv. de çaga, del ár. SÂQA 'retaguardia de un ejército' (DCELC, IV, p. 795). Idéntica etimología propone CORRIENTE (2003: 472, s. v. zaga): del ár. andalusí SÁQA 'parte trasera (de un ejército), retaguardia'. En Fernández de Heredia reşaga, reşagua 'retaguardia, parte trasera' (GILKISON, s. v.). Frec.: 1: 0,00227.

reçaguera s. f. 'parte trasera, retaguardia (de un ejército)': los unos ferían en la delantera, los otros en la reçaguera, los otros en cada uno de los costados de la buest 36.639. Etim.: deriv. del árabe SÂQA 'retaguardia de un ejército', de la raíz SÂQ 'rebaño', 'conducir o empujar un rebaño' (DCECH; CoRRIENTE, s. v. zaga). En cast. se documenta rezaga 'retaguardia' h. 1300 (BDELC, p. 618). Con un prefijo re- y un sufijo -era. De la misma base etimológica: cagueria, cagaria 36.677, çaguera 19.116. En Fz. de Heredia reçaga 'reaguard; rear' (GILKISON, s. v.). En el DRAE (1984) no se registra rezaguera; sí, en cambio, rezaga 'cuerpo militar que va el último, retaguardia’. Lo mismo vemos en el DLE (2014). Frec.: 1: 0,00227 .

recaudo s. m. 'recado', 'mensaje' o quizá 'contestación, resultado de una entrevista o consulta': les denegó todo quanto demandavan et fizoles fuert agra respuesta, porque se tornoron menos de recaudo al dito rey en Berbería 36.180. [menys de recapte VC, p. 133]. La traducción sería: ' $\ldots$ por lo que se volvieron sin resultado...'. Es deriv. postverbal de un v. recaudar < lat. vg. RECAPITARE, probablemente modificación de RECEPTARE > RECAPTAR 'acoger', 'recuperar' (DCECH, IV, p. 817). Comp. cast. ant. recaudo 'noticia, mensaje', en el s. Xv (DME, s. v. recaudo, p. 1546). Frec.: 1: 0,00227.

recebir (var.: recevir) v. tr. 'recibir': Aquesti rey don Alfonso, depués que buvo recebida aquesta muller çaguera, non firo afferes de cabo ni cominales 39.14; del quoal avía reçebido muytas gracias e honores 33.8; et non quiso el rey recebielo [recebirlo B] 34.161; et el enemigo se ergulló e vitoria fuyó entra que el rey don Sancho, su fillo, recevió el regimiento del regno suyo; e fue enterrado el su cuerpo 32.71; no quisieron antes recevir por rey a don Alfonso entra que juró a los del regno que no <yera> estado consintient en la dita muert de su hermano 18.85. Del lat. RECIPERE 'tomar, coger, recibir'. Frec.: recebir 2: 0,00455 ; recebida 3: 0,00682 ; recebidas $1: 0,00227$; recebido 1 : 0,00227 ; recebielo [recebirlo B] 1: 0,00227 ; recevir 1: 0,00227 ; recevido 3 : 0,00682 ; recevió 2: 0,00455 ; recivie $1: 0,00227$; recibida $1: 0,00227$; recibie 1: 0,00227; recibieron 4: 0,00909; recibió 11: 02500; recibirían 1: 0,00227; recibo 1: 0,00227 . 
receptar v. prnl. 'acogerse, guarecerse, refugiarse, ocultarse, esconderse': do fizieron muytos castiellos et muytas otras fuerças do se pudiessen reçeptar et defender de los moros 4.6; entro a CCC christianos que fueron receptarse en la terra [abreviatura tra en el ms. B, original] d'Aragón 4.13. Etim.: del lat. ReCEPTARe 'recibir, acoger', RECEPTAR SE 'retirarse, replegarse' (DCECH, IV, p. 817-818; BDELC, p. 496, s. v. recaudar). En Fernández de Heredia reçeptar 'ocultar, esconder' (GILKISON, s. v.). Frec.: receptar 1: 0,00227; receptarse 1: 0,00227.

reclamo s. m. 'oposición': queriendo él de toda Calabria erradicar et remover et todo home que su reclamo huvies 36.246. Deriv. del v. reclamar, del lat. RECLAMARE 'gritar contra, protestar contra, oponerse gritando' (BLÁnqueZ, s. v.). Comp. en el arag. de Fz. de Heredia reclamar 'oponer, resistir, oponerse a' (GILKIsOn, s. v.). Frec.: 1: 0,00227.

recobrar] v. tr. 'recuperar, recobrar': et quando el dito conte huvo recobrada la dita ciudat et la tierra por los moros ocupada 26.18; et finalment recobró el dito conte de Probença a su querer [poder N] 34.56; mas quando fue muerto, los nobles de Catalunnya recobroron [recabaron $\mathrm{N}$ ] de los procuradores del dito regno [se refiere a Aragón] el dito Guerau et su muller et sus fillos. 34.115. Del lat. ReCuperare. Comp. cobrar. Frec.: recobrada 1: 0,00227; recobró 2: 0,00455; recobroron 1: 0,00227 .

recomendado adj. y p. p. 'recomendado': que lures oraciones et buenas obras lo deviessen haver por recomendado 11.45; que en lures oraciones e buenas obras deviesen aver a él e a su tierra [terra en la ed. crítica] por recomendados 11.30. Es p. p. del v. recomendar. Frec.: recomendado 1: 0,002287; recomendados 1: 0,00227.

recomendatión s. f. 'recomendación': et feyta la recomendatión, vinose el dito compt a su sennor el rey García 11.31. Etim.: deriv. de recomendar y éste del ant. comendar $<$ lat. COMMENDARE 'confiar (algo)', 'recomendar', 'alabar' (DCECH, III, 800). CoRominas (BDELC, p. 377 , s. v. mandar) fecha la primera aparición de recomendación en cast. en 1438. En el DCECH, h. 1460. Es anterior, por lo tanto, en aragonés (si bien se trata de un cultismo, no solo fonético, sino también gráfico). No aparece en Bustos (1974). Frec.: 1: 0,00227.

reconocer] (var.: reconoscer) v. tr. 'reconocer, examinar con cuidado': los quales capitoles, vistos et reconoscidos.. 38.77. // 'advertir, considerar, reparar, observar': veyendo et reconosciendo que de sennyor traydor ningún nascimiento filial non podría exir leal... 17.14. / / 'aceptar': et lo reconocieron por sennyor 14.25. Deriv. de conocer. Frec.: reconocieron 2: 0,00455; reconociolas 1: 0,00227; reconoscidos 1: 0,00227; reconosciendo 1: 0,00227; reconosció 1: 0,00227.

recontamiento s. m. 'relato, narración': de los quales recontamiento otro non trobamos 10.2. Deriv. de recontar, con sufijo - miento < lat. -MENTUM, «sufijo latino que sirve para derivar sustantivos deverbativos que designan en la mayoría de 
los casos un instrumento, el resultado y a veces también el nombre de una acción» (Pharies, 2002: 403). Frec.: 1: 0,00227.

recontar] v. tr. 'contar, narrar, relatar, referir': otra vegada grant innumerable aiusto [aiuntamiento $\mathrm{N}$ ] de moros por semblanment [senblant $\mathrm{N}$ ] manera que dessuso bavemos recontado 38.372; et lurs conpannyas partieron d'aquí et tornoron sende en Secilia et recontoron [recontando $\mathrm{N}]$ a Frederich assi como les avía esdevenido. 38.143; segunt recuenta en la ystoria del rey Remiro el Monge. 33.26; et recuéntase que algunos davan de consello al rey que diesse por malos a los sus naturales 38.279; segunt que mas largament en vida de cada uno de los dessuso ditos infantes pora adelant recontaremos 38.425. Etim.: Deriv. prefijado con re- de contar, del lat. COMPuTARe (DauZAT-Dubois-MitTERAnd, pp. 185 y 194). Se documenta en arag. med.: «Et lo que vido vos recontará d'aquí avant» (Marco Polo, cap. 20; ed. Sangorrín, 2016: 61). E igualmente, en otras obras de Fernández de Heredia (GILKIson, s. v.). Comp. recomptar en cat. med.: recomptaràs, recomptes, en la Crònica de Ramon Muntaner (Barcelona, Barcino, 1927-1952). En el DRAE (1970): 'dar a conocer o referir un hecho', como 2. acepción. El DGL/C de FABRA incluye recomptar sólo con el sentido de 'comptar de nou'. Sin embargo, el DL/C del IEC (2007) registra también recontar 'contar'. En fr. recompter 'volver a contar', raconter 'referir' (son dos formas que proceden de compter $\sim$ conter, del mismo origen; conservan diferencia gráfica sólo para distinguir los sentidos, cfr. Dauzat-Dubois-Mitterand, p. 194). PRobert, s. v: raconter 'exposer par un récit'; recompter 'compter de nouveau'. Frec.: recontado 3: 0,00682; recontando 1: 0,00227; recontaremos 6: 0,01364 ; recontaron 1: 0.00227 ; recontava 1: 0,00227 ; recontó 3: 0,00682 ; recontole 3: 0,00682 ; recontólo $1: 0,00227$; recontoron $1: 0,00227$; recontoronle 2: 0,00455 ; recuenta 1: 0,00227 ; recuéntase 1: 0,00227 .

recullir (var.: recollir) v. tr. 'acoger', 'recibir': fue muyt esforçado et de grant valor et recullie bien los fidalgos et las otras gentes sosmessas a él 17.25-27. // v. prnl. 'cobiajrse, recogerse, acogerse a un refugio o sitio protegido': Et Simón de Monfort que tenía la guerra por el rey de Francia recolliesse con sus gentes en Murel, el rey d'A Aragón fuelo cercar 34.157. vino a sitiar un castillo do los traydores que avían muerto el dito Beltran se heran recullidos, clamado Mocuel 33.57. / / 'retirarse': satifeito [satisfeito B] et pagado primerament a éll et a sus cavalleros et conpannyas recolliose con grant poder de sus valientes varones et vassallos a Palamos 38.224; et plegada toda la su gent, rocoliosse [reculliose $\mathrm{N}$ ] et vino sende en Catalunnya 38.393. / / 'embarcarse': encontinent, se levantó del dito sitio suyo por recullirse en mar et fuyr al poder del dito rey don Pedro. Et mientre se recollia, el dito rey don Pedro, a manera de relampago, firió en la reşaga de los enemigos 36.228. Etim.: del lat. RECOLLigere (BDELC, p. 157, s. v. coger). Comp. cat. collir, del lat. COLLiGERE 'recollir', 'aplegar', deriv. de LEGERE 'agafar', 'escollir', 'llegir' (DECL/C, II, pp. 831-834). Entre los deriv. en cat.: acollir, encollir (cast. 'encoger'), escollir (cast. escoger), recollir. Advierte COROMINES sobre recollir (DECLIC, II, 833) que 
es frecuente en la lengua antigua en el sentido de 'donar alberg' ('dar albergue') y tb. 'arreplegar, aplegar' ('recoger'). Acepción muy viva en la Edad Media fue: recollir-se 'embarcar-se'. Otra acep. medieval: recollir-se 'retirar-se en un lloc defensat, en temps de guerra' [Desclot]. En cuanto al cast. recoger, el DCECH, II, p. 121, lo doc. por $1^{\text {a }}$ vez en 1495 (Nebrija). Comp. recullir, recollir 'acoger, recibir' (tr.), 'reunirse, unirse' (intr.), 'retroceder, cobijarse' (prnl.), en Fz. de Heredia (GILKISON, s. v.). Frec.: recullir 1: 0,00227; recullirse 1: 0,00227; recullidos 1: 0,00227 ; recullie $1 ; 0,00227$; recullieronse $1: 0,00227$; recullios 1: 0,00227 ; recollir 1: 0,00227 ; recolliose 1: 0,00227 ; recolliesse 1: 0,00227 ; recollidos 1: 0,00227; recollía 1: 0,00227 .

redemir (var.: redimir) v. tr. y prnl. 'redimir(se)': et don Caxal fue redemido por grandes quantias 20.234; empero los otros pressos antes que salliessen de la pressón se buvieron redemir 36.423; et fue por su consello acordado que fues redimido 20.228; el qual se redimió por grant quantía de moneda d'oro 36.552; demandó de consello si lo mataría o lo faría redimir 20.227. Tomado del lat. REDIMERE 'rescatar, volver a comprar'. Frec.: redemir 1: 0,00227; redemido 2: 0,00455; redimir 1: 0,00227; redimió 1: 0,00227 ; redimido 1: 0,00227 .

redempción (var.: redepción) s. f. 'redención': pora la qual redempción la abbat de Sant Salvador de Leyre vendie el trasoro de su monesterio porque era grant su amigo 20.235; et pregó a su fillo don Pedro [...] que complies todo lo que avía ordenado en su testament en toda manera a honor de Dios et en redepción de los sus desfallimientos 35.289 (en el ms. $\mathrm{B}$ : en redempcion de sus defallimientos). Etim.: cultismo, tomado del lat. REDEMPTIO, -ONIS (DCECH, IV, p. 832). Frec.: redempción 2: 0,00455; redepción (redempcion) 1: 0,00227.

reduzir] v. tr. 'reducir, devolver, volver una cosa al estado en que estaba, cambiar, reconducir': la isla de Menorca conquistó et aquella qui de la fe de Mahomat era ensuriada, a la fe de Ihesu Christo tornó et reduxo. 37.40. Del lat. REDUCERE. Frec.: reduxo 1: 0,00227 .

reformamiento s. m. 'reforma, renovación, restablecimiento, reconstitución, restauración': et en tiempo de aquesti, la christiandad buvo prendido grant reformamiento [enformamiento $\mathrm{N}]$ et gran crecimiento en la tierra 11.6. Deriv. de reformar $<$ lat. REFORMARE 'volver a su primitiva forma, rehacer'. Frec.: 1: 0,00227.

refugio s. m. 'refugio': avies aver refugio et socorro singlar [singular B] 36.199. Cultismo tomado del lat. REFUGIUM. Frec.: 2: 0,00455.

regidor s. m. 'regidor; gobernante, soberano': et depués vispe de Vich et regidor del monesterio de Sant Miguel de Cuxá 26.27; et de los regnos metieron regidores et governadores en los regnos et non podían ser bien defendidos 20.3. Deriv. de regir, con sufijo -dor que sirve para derivar, a partir de una base verbal, sustantivos que expresan agente, instrumento y lugar (PhARIES, 2002: 169). Aquí aporta la significación 
de 'agente'. En Fz. de Heredia regidor 'dirigente, gobernante' (GILKIson, s. v.). Frec.: regidor 2: 0,00455; regidores 1: 0,00227

regimiento s. m. 'gobierno, administración', 'regencia, gestión, acción de regir': et lexada su tierra con buen regimiento... 36.707; noble hombre en todos actos de cavalleria et regimientos de tierras et de gentes 20.255. Deriv. de regir. Se registra con el mismo sentido en Fz. de Heredia (GILKISON, s. v.). Frec.: regimiento 5: 0,01136: regimientos 1: 0,00227.

regir v. tr. 'regir, gobernar, administrar': el qual se retwvo acuerdo sobre la procuración que regia del dito regno 38.148; et assí yo te livro et do el regno que Dios me avía acomendado, el qual he yo regido con el su poder 35.255; e rigió el dito marquesado muy bien 32.46. Del lat. Regere 'íd.'. Con el mismo sentido en Fz. de Heredia (Gilkison, s. v.). Frec.: regir 10: 0,02273; regía 1: 0,00227 ; regido 2: 0,00455 ; regió 12 : 0,02728 ; rigió 2: 0,00455 .

regla s. f. 'regla; norma, precepto': porque yes costumbre et regla de monges negros que a todo novicio que era en la orden dan un monge de los ancianos por maestro 20.104. Del lat. Regula. Frec.: 1: 0,00227.

regnar v. intr. 'reinar': Et depués regnando el dito rey... 33.49; porque más dio en su vida que rey del mundo que la ora regnas 37.4; que por razón que regnasse don Remiro monge a falta de natura que le diesse licencia de sallir del Orden 20.69; Goncalvo, fillo del dito emperador, el qual regnava en Sobrarve et en Ribagorza 16.13; regnó depués él en el su regno et tierras el segundo fillo suyo 38.456; et regnoron entrambos [entramos $\mathrm{N}$ ] ensemble 3.19. Tomado del lat. REGNARE. Frec.: regnar 4: 0,00909; regnando 2: 0,00455; regnaron 2; 0,00455 ; regnas $3: 0,00682$; regnase $1: 0,00227$; regnasse 1 : 0,00227; regnava 3: 0,00682; regnó 51: 0,11592; regnoron 2: 0,00455.

regno s. m. 'reino': fue justament despossedido de su regno et tierras 38.621; et la división destos regnos fue metida en el monesterio de Sant Johan de la Pennya, que allí fues perpétuo conservada et yes oy en dia 20.170; fue grant honor a la casa d'A Aragón quel rey don Jayme tollies al rey de Castiella, mas poderoso rey que él, tal regno como es Murcia 38.215. Frec.: regno 160: 0,36367; regnos 30: 0,06819.

reguardar] v. tr. 'mirar': et quando fue aquesto que la su anima devía andar a Dios, él reguardó el cielo plorando et dixo: «Sennyor... 35.292. Etim.: deriv. del fránc. *WARDÔN 'velar, estar en guardia' > fr. garder, cast. guardar, cat. guardar, occ. gardar, it. guardare 'mirar'. Comp. cat. reguardar 'mirar (algú o alguna cosa) amb reguard' y reguard 'temor, desconfiança, per quelcom que ens sembla oferir un perill' (FABRA, s. v.; las mismas definiciones en el DL/C del IEC, 2007). Cfr. occ. regardar (etim.: occ. re + gardar, AlibeRT, s. v.); fr. regarder (reguarder, 1080), de re- et garder 'velar, estar en guardia' (PRobert, s. v., p. 1642). Comp. cast. esguardar ant. 'mirar', tomado del cat. esguardar 'íd.', así como reguardar 'mirar con cuidado o vigilancia' reguarda 'mirada cuidadosa', reguardo 'mirada 
cuidadosa', todos con marca de «desusado» (DLE, 2014). Todos son deriv. del germ. *WARDÔN (deriv. de WARDA 'acto de buscar con la vista', 'guardia, guarda', 'atalaya', 'garita'), tomado por el latín vg. al germánico occidental común (DCECH, III, p. 246-247). En el arag. de Fz. de Heredia reguardar 'mirar, considerar, mostrar', reguart 'mirada, apariencia, guardia, vigilancia' (GILKIsOn, s. v.). Frec.: reguardó 1: 0,00227.

relación s. f. 'relación', 'trato': quando se cató, fincó engannado [envergoynido N] por su locura et relación de malos porteros 20.42. Del lat. RELATIO, -ONIS. Frec.: 1: 0,00227.

relampago s. m. 'relámpago': el dito rey don Pedro, a manera de relampago, firió en la reçaga de los enemigos 36.230. Etim.: Según Corominas-PASCUAL está relacionado con el griego $\lambda \alpha \mu \pi \varepsilon \iota v$, lat. tardío LAMPARE 'brillar', más que con LAMPAS, -ADIS 'antorcha', 'meteoro brillante', a pesar del port. ant. relâmpado. Comp. cat. llampec, occ. lampec, it. lampo. (DCECH, IV, p. 864). Pero comp. arag. mod. lampadear 'relampaguear' (Andolz, 1992, s. v.), llampadiá en Benasque (DDPA), llampit 'relámpago, rayo' en la Alta Ribagorza (DDPA), relampado, relampago y relampiu (MARTíNEZ, 2008: 153). El EBA (1999: 1588) registra relampadiar en A Fueba y Bal de Chistau. Además, la forma relampado se registra, junto con relampago, en Fernández de Heredia (GILKIson, s. v.). Frec.: 1: 0,00227.

religión s. f. 'religión': recibió muyt devotament hábito de la santa religión de Dios 35.249 // 'orden religiosa, disciplina o comunidad religiosa deteminada': aquesti noble barón fue bastedor de muytos monesterios de diversas religiones 35.189. Es cultismo, tomado del lat. RELIGIO, -ONIS. Frec.: religión 1: 0,00227; religiones 1: 0,00227.

religioso] s. m. 'religioso, persona que profesa en una orden religiosa regular': do dexó grant ploro al pueblo e grant periglo a la tierra e goyo a los moros e desolation a los pobres e sospiros a los religiosos 32.67. Frec.: religiosos 2: 0,0455.

reliquia] s. f. 'reliquia': mutilaron et distruyeron todas las otras reliquias de aqui et de las otras eglesias 36.568. Etim.: cultismo, tomado del lat. reliquiae, -arum, 'restos, residuos', deriv. de RELIQuUs 'restante' (BDELC, s. v.). Frec.: reliquias 4: 0,00909 .

remediar] v. tr. 'remediar', 'dar remedio, auxilio', 'socorrer': seyendo el rey de Castilla en grant cuyta que los moros le tenían Cuenca cercada, enbiole a rogar al rey don Alfonso de Aragón [e] que le fuese a decercar aquella, soltóle e quitóle el omenage e los lugares que él e los lugares le heran tenidos, et como buen cavallero remedió al sitio 33.31. Es cultismo, del lat. remediare 'poner remedio, curar'. Frec.: remedió 1: 0,00227.

remedio s. m. 'remedio': et por dar remedio al su regno embió un mensagero al su monasterio 20.102; mas ya por todos aquestos remedios el dito conte Simón non se en quiso estar. 34.137. Forma culta tomada del lat. remedium 'remedio, medio curativo, medicamento’ (SEgura, 2001: 651). Frec.: remedio 3: 0,00682; remedios 1: 0,00227 . 
remembrar] v. tr. 'recordar': firo batalla en Moriella et remembrandose quel Cit Rui Diaz yera seido en la muert de su padre... 17.85; remembrose [remenbrandose $\mathrm{N}$ ] de la desonor que havía feito al conte 23.41; mal remenmbrant [mal remembrant $\mathrm{N}$ ] de la ayuda quel fižo el rey de Aragón 17.108. Etim.: Deriv. del ant. membrar 'íd.', del lat. MEMORARE 'recordar (algo a alguno)', deriv. de MEMOR 'el que se acuerda de algo' (BDELC, p. 502, s. v. remembrar). Frec.: remembrandose 1: 0,00227; remembrose 1: 0,00227 ; remenmbrant 1: 0,00227 .

remover v. tr. 'remover, apartar': queriendo él de toda Calabria arredicar et remover et todo home que su reclamo buvies... 36.246. Del lat. REMOvere. Frec.: 1: 0,00227.

ren pron. indef. 'nada': et dixole que se levantas del leyto sin todo mal que non sintió ren [e no sintió $\mathrm{N}$ ] por el qual milagro a honor de la bien aventurada Virgen Madre nuestra sennyora Santa Maria dio grant trasoro 35.221; et non caceron [curoron B] por ren entro que plegoron 34.162. Etim.: del lat. REM, acusativo de RES 'cosa'. Comp. cat. y occ. ant. ren, re, mod. res (DECL/C, VII, p. 269). Es frecuente ren en los textos de de Fz. de Heredia: «car sin navilios no aurie fecho ren» (Libro de Marco Polo, ed. NitTi, p. 36, lín. 34); «et respondieron que no farien res» (ibídem, p. 36, lín. 36). Gilkison, s. v., registra en la lengua de este autor las variantes rem, res, rex y re. En los DLAA encontramos tanto ren como res: «que no turbassen en ren al dito prior de San Urbeç, nin asu procurador en ren de sus possesiones» (DLAA, doc. 87, de Valle de Sarrablo, 1305; p. 127, lín. 33-34); «Present el dito Miguel d'Artho, jurado... el qual no dixo res» (DLAA, doc. 148, de Jaca, 1476; p. 218, lín. 32). Vid. res. Frec.: 2: 0,00455.

renda] s. f. 'renta': él yva como cavallero et prendía las rendas [rentas B] de Montaragón, 35.14. Etim.: del lat. vg. *RĔNDITA, participio de RĚNDERE, por REDDERE 'devolver, restituir'. De la misma etim.: cat., port. y occ. renda, fr. rente, it. réndita (BDELC, p. 503). Según Corominas el cast. renta, dada la falta de diptongación, debió de tomarse del francés (DCECH, IV, p. 874; DECLIC, VII, p. 294). Consecuentemente, habrá de atribuirse a influjo catalán u occitano la forma del aragonés que se registra en la Crón SJP. En cat. renda 'profit periòdic, esp. en diner, que ret una cosa' (FABra, DGLIC, s. v.), 'profit periòdic, especialment en diner, que ret un actiu material o financer' ( $D L / C$ del IEC, 2007); occ. renda 'rente, fermage; loyer; récolte; revenu' (AliberT, s. v.). Se registra renda en Fz. de Heredia (GILKISON, s. v.). Frec.: rendas 2: 0,00455 .

render (var.: rendir) v. tr. 'rendir; dar, entregar': et dixo: «Batallar, rendeme el castiello si no yo te enforcaré» 38.302; por tal como francament se eran rendidos 36.517; recibo de ti el regno el qual te rendo 35.298; et dixieron al rey que otro castiello se rendría si su presencia vidia el alcayt de aquel castiello. 38.299; "la tierra que me dieste rendí a la reyna natural mi seynora cuya hera, e riendo vos las manos, la voca et el cuerpo que vos 
fizieron omenage por ella que fagades dellos la justicia que tenrredes por bien». 19.86; el compte Pero Ansures, desque avie rendido la tierra a la reyna su seynora natural, fuese para el enperador de Aragón 19.82. Etim.: del lat. vg. *RĚNDERE, alteración del lat. RĔDDERE 'devolver', bajo el influjo de PRENDĚRE 'tomar' (DCECH, IV, p. 873). Frec.: render 6: 0,01364; rendeme 1: 0,00227; renderla 1: 0,00227; rendí 1: 0,00227 ; rendida $1: 0,00227$; rendidas $1: 0,00227$; rendido 2 : 0,00455; rendidos 1: 0,00227; rendie 1: 0,00227 ; rendieron 2: 0,00455 ; rendieronla 1: 0,00227 ; rendieronse $1: 0,00227$; rendies $1: 0,00227$; rendiesen 1: 0,00227 ; rendiessen 1: 0,00227 ; rendió 10 : 0,02273 ; rendiola 1 : 0,00227; rendiose 4:,00909; rendir 2: 0,00455; rendo 1:0,00227; rendría 2: 0,00455 .

renunciamiento s. m. 'renuncia': dizieron que aquel renunciamiento non vallia porque la gracia del privilegio se estendía assí nobles como cavalleros 34.44. Deriv. de renunciar. Frec.: 1: 0,00227.

renunciar] v. tr. 'renunciar': et el dito rey dixo quel su dreito avía renunciado et non de los nobles et cavalleros 34.46; clerigos qui por la lur propia voluntat et a honor et a reverencia de Dios et de los sanctos qui aquí iazían, renunciaron a los deleites carnales et mundanales 9.34; et de otra part lo requirió que renuncias a todas demandas que avies contra su bermano 36.157; no empero renunciava a la dignidat real 20.287; por tal como el primero fillo suyo renunció a la primogenitura et se metió en Orden 38.458. Del lat. RENUNTIARE 'anunciar', 'dar cuenta de, avisar', 'desdecirse', 'renunciar a'. Frec.: renunciaron 1: 0,00227 ; renuncias $1: 0,00227$; renunciava $1: 0,00227$; renunció 5 : 0,01136 .

reparar v. tr. 'arreglar, reparar, volver a disponer correcta y ordenadamente': fizo reparar et endrecer [endregar $\mathrm{N}$ ] aquélla porque bien yera mester [y hera menester $\mathrm{N}$ ] que toda era cremada et derrocada 36.690. Etim.: del lat. REPARARE 'preparar o disponer de nuevo', deriv. de PARARE 'preparar, disponer' (BDELC, p. 440, s. v. parar, DCECH, IV, p. 395). Frec.: 1: 0,00227.

reposo adj. 'sosegado, quieto, tranquilo, calmado': e no queriendo estar reposo de desconocençia por el seynnalado servicio 33.53. Deriv. de repossar < lat. REPAUSARE 'reposar, descansar' (SEgura, 2001, s. v.). Frec.: 1: 0,00227.

repossar v. tr. 'reposar, descansar, calmar, sosegar': et, estando aqui por retraher [recrear $\mathrm{N}]$ et repossar lures personas, el dito cardenal de grant malautia fue opresso 38.89. Del lat. Repausare 'reposar, descansar' (Segura, 2001, s. v.). Frec.: 1: 0,00227.

reptamiento] s. m. 'acusación, reproche', 'desafío': et estando assí, reptamientos el un rey al otro feytos por la razón dessus dita, fue firmado et finido por cada una de las partes con seguredades firmes en poder del rey de Ynglaterra que entramos los ditos reyes... 36.252. Etim. deriv. de reptar 'acusar', 'desafiar' < del lat. REPUTARE (BDELC, pp. 505-506). Comp.: «repto 'acusación que pone un hidalgo contra otro de 
alevosía; y porque le haze culpado y reo se dixo reptar, y la tal acusación repto. Es término castellano antiguo, de que usan nuestras corónicas y las leyes de la partida, las quales le dan otra etymología'; riepto 'es, según la ley de partida "acusamiento que faze un fidalgo a otro por corte, profaçandol [sic] de la traición o del aleve que le hizo; e tomó este nombre de riepto, que es una palabra de latín que quiere dezir recontar otra vez la cosa, diziendo la manera como la fizo, etc." Demanera que la ley le da la etymología del verbo repeto, is.» (Covarrubias, s. v. repto y riepto). Se registra reptamiento 'acusación' en Fz. de Heredia (GiLkison, s. v.). En VM reptador 'acusador', reptorio 'acusación' (Tilander, VM, III, p. 271); reptamiento 'acusación' en FA (Tilander, FA, p. 545). Frec.: reptamientos 1: 0,00227.

reptar] v. tr. 'acusar', 'censurar', 'echar en cara una falta, desafiar': et muytas palavras dixieron assí como desenparados contra el dito rey don Jayme reptándolo de fe. 38.134 [reptant lo de fe, VC]. Etim.: del lat. REPUTARE 'calcular, considerar, reflexionar', que en bajo lat. tomó el sentido de 'hacer un reproche' (BDELC, pp. 505506; DCECH, IV, p. 890). Se usó en cast. ant. (actualm. cast. retar). Vid. en DME, p. 1557: reptar 'increpar', 'citar a juicio', 'reprender, inculpar' en cast. de los siglos XIII a XV. Corominas lo cree en cast. un préstamo del cat. o del occ. (DCECH, IV, p. 890); cat. reptar 'echar en cara una falta, desafiar' (FABRA, s. v.), 'reprendre (algú) tirant-li en cara una falta, un error, etc.' (DL/C del IEC, 2007). Vid. arag. reptar 'acusar, desafiar' en VM, FA, Fz. de Heredia (GILKISON), etc. Frec.: reptándolo 1: 0,00227.

requerimiento s. m. 'requerimiento': et venido de Barchinona, a requerimiento del noble Nuch 38.485. Deriv. de requerir. Frec.: 1: 0,00227.

requerir] v. tr. 'requerir, solicitar': envió sus mesageros a éll requiriendo [requerido $\mathrm{N}$ ] que por vigor de la convinencia entre el Padre Santo et él feita et prometida... 38.218; pregándolo et requiriéndolo que como él entendies a subiugar con la ayuda de Dios Africa et sembrar el nombre de Dios et la fe christiana... 36.173. Del lat. REQUIRERE. Frec.: requiriendo 2: 0,00455; requiriéndolo 1: 0,00227.

requesta] s. f. 'demanda, ruego, solicitud, requerimiento': a las requestas el dito rey don Jayme de Mallorquas non quiso obedecer 36.407 [en VC requestes]. Etim.: del lat. vg. REQUAERERE, deriv. de QUAERERE (BDELC, p. 28, s. v. adquirir). O del lat. REQUiRERe 'buscar, investigar con diligencia' (Dauzat-Dubois-MitTERAnd, p. 622, s. v. quérir, DECL/C, VI, pp. 945-947). Comp. requesta 'demanda' en el arag. ribagorzano de Campo (MasCaray, 1984: 121; 2013: 315). El EBA (1999: 1602) registra requesta 'demanda' en Fonz, Bal de Bielsa, Biello Sobrarbe, Campo y Graus). Comp. inglés request 'ruego, solicitud', 'demanda, salida': in request 'en boga, solicitado', del fr. ant. requeste, fr. mod. requête 'demanda, requerimiento', 'petición, solicitud' (PRobert, s. v.). En it. richiesta 'solicitud', 'petición, instancia' (SAÑé \& SCHEPISI, 2002, s. v.). Comp. cat. requesta 'deman- 
da, instancia, requerimiento, petición' (DCVB, s. v.; FABRA, DGL/C, s. v.). En arag. del siglo XIV está documentado requesta 'demanda, solicitud', en Fz. de Heredia (GILKIsON, s. v., p. 117). También en el LT: requesta 'petition, request' (Prince, 1995: 224). Frec.: 1: 0,00227.

res pron. indef. / adv. 'nada': et él non dixo res 17.122; mientre que todo homme dormía et non se talayavan de res, todo el poder del dito castiello de Callar vino a ferir en la buest del dito don Alfonso. 38.544; tan largo et tan proz, que a ninguno no podía dir de no de res quel demandassen 13.9. Del lat. RES 'cosa' (DECL/C, VII, p. 269). Es de uso corriente en arag. med.: «los quales dictos dineros nos deuos aujemos erecebiemos en nuestras manos contantes el dia que aquesta carta fue feyta, enon romanje res apagar delos dictos dineros» (doc. de Huesca de 1275; DLAA, doc. 36, p. 54, lín. 23); «yeguas bueyes e de so natura dos dineros por cabeça empero a la puyada de la montanya los corderos crabitos pollynos ni terneros aquel anyo naxidos no paguen res» (OB, p. 20, lín. 37). Se conserva en arag. mod.: ANDOLz (1992: 374) lo registra en Benasque; el EBA (1999: 1602) en Bal de Chistau, Zanui, Peralta de la Sal, Biello Sobrarbe, Chuseu, Torres de lo Bispe, Benás, Fonz, Estadilla, Sesué, Alta Ribagorza; Mascaray (2013: 315) en Campo con la marca de «inusitado»; BLAS \& Romanos (2008: 455) en el valle de Chistau; $n i$ res 'nada de nada' en Orés, Cinco Villas (Romanos, 2003: 234) y en Pandicosa (NAGore, 1986: 125, con la anotación... «muy poco usada»). // Se emplea también en las locuciones res non menos, non res menos 'asimismo, igualmente, también, además': et res non menos que por ningún tiempo non se nombrase rey 38.258. Esta fórmula es habitual en el arag med.: «Et no res menos, renunciamos a qualesquiere fueros e dreytos» (doc. de Jaca de 1471; en DJ, Alvar, EDA, II, p. 258, lín. 53). «Et no res menos se hauja cremado muytos artefficios \& ropas en la dita casa (MDF: 300.17). Vid. non res menos, ren. Frec.: 24: 0,05455.

resemblar v. intr. 'parecerse, imitar, asemejarse': aquesti rey Alfonso, depués de algún tiempo, queriendo resemblar a los sus predecessores, con grant poder de homes a cavallo et de pie, la isla de Menorca conquistó 37.37; Et porque resemblava a su padre assin en andar de pie con los de pie et a cavallo con los de cavallo, et era assin como a compannero con sus vasallos, et calçava a vegadas avarchas, et fuele metido nombre García Avarca. 13.912. Deriv. de semblar, del lat. SIMILARE 'ser semejante'. Comp. fr. ressembler (s. XVI, de re- et sembler) 'avoir des traits communs avec, presenter des caractères identiques à (ceux d'un autre objet)' (PRobert, p. 1689, s. v.). Cat. semblar 'ésser en aparença, oferir-se als ulls o a la imaginació com si fos; tenir l'aparença d'alguna cosa essent-la o no; aparèixer com a probable, ver, just, convenient' (FABRA, s. v.; las mimas definiciones en el DL/C del IEC, 2007). Con la misma significación que en la Crón. SJP. se registra en varias obras del taller de Ferrández d'Eredia (GILKIson, 1984: 117), así como en el LT (RoDÉs, 2016: 762). Frec.: 4: 0,00909. 
reservado adj. y p.p. 'guardado, encubierto, oculto, conservado, reservado': et levaron el su cuerpo a Montaragón et aqui estuvo reservado VI meses et XV días 17.131. Etim.: es p. p. del verbo reservar, cultismo procedente del lat. RESERVARE 'conservar', cuya primera documentación para el cast. es de h. 1525 (DCECH, II, p. 178, s. v.). Frec.: 1: 0,00227.

resistencia s. f. 'resistencia': ninguno hombre no les pudo fer resistencia 9.11. Deriv. del v. resistir con sufijo -encia < lat. -ENTIA, de carácter culto, que deriva sustantivos que expresan un estado duradero resultante de una acción verbal (РHARIES, 2002: 202). Frec.: 1: 0,00227.

responder] v. tr. 'responder': et de vosotros ninguno non le aya respondido 38.329; et no y huvo ninguno que hi respondies [respondiesse $\mathrm{N}$ ] 38.324; et la hora cada uno fizose afazendado de recebir los dessafiamientos et él les respuso 38.332. Del lat. RESPONDERE. Frec.: respondido 1: 0,00227; respondies 1: 0,00227; respondió 8: 0,01818; respondióle 1: 0,00227 ; respondioles 1: 0,00227 ; 6: 0,01364; respuso 3: 0,00682.

respuesta s. f. 'respuesta': El qual mesagero con desplazer que respuesta non le havia dada, vinose al rey et recontole que respuesta ninguna non le bavia querido fazer 20.119 . Sustantivación del p. p. fuerte de responder. Frec.: 6: 0,01364.

restituyr v. tr. 'restituir, devolver a quien lo tuvo antes': et depués de algún tiempo, el rey don Pedro le restituyó la dita reyna et su fillo al dito rey Alfonso de Castiella 36.115; el dito tio [curador $\mathrm{N}$ ] restituyogeles assí como lur padre avía ordenado 25.14; et que fues contra Secilia, et por prender aquélla et restituyrla a la dita Eglesia 38.181. Del lat. RESTITUERE 'íd.'. Frec.: restituyó 4: 0,00909; restituyogeles 1: 0,00227; restituyrla 1: 0,00227 .

retener v. tr. 'retener': porque non se le avía adueyto por razón de retenérselas 36.116; pues en su poder yera, que retenies al rey de Aragón por preso 20.189; el traslat del qual privilegio yes en el monesterio de Sant Johan de la Penya, que lo retinieron, que alli era el privilegio original 34.49; el rey de Castiella retúvoselo todo en aquella paz et oyo [oy $\mathrm{N}]$ en dia lo recivie [se lo tiene $\mathrm{N}]$ de Navarra 34.85. Del lat. RETINERE. Frec.: retenérselas 1: 0,00227 ; retenía 1: 0,00227 ; retenida 1: 0,00227; retenies 1: 0,00227 ; retinieron 1: 0,00227 ; retuvo 2 : 0,00455 ; retuvose $2: 0,00455$; retúvoselo $1: 0,00227$.

retraher v. tr. 'apartar, retirar, refugiar': et, estando aqui por retraher [recrear $\mathrm{N}]$ et repossar lures personas, el dito cardenal de grant malautia fue oppresso 38.89. el lat. RETRAHERE. Frec.: 1: 0,00227.

revelar v. tr. 'revelar, dar a conocer': et non osava aquesto revelar a ninguno 20.101; et non lo quiso revelar a ninguno 36.329. Etim.: cultismo tomado del lat. REVELARE 'quitar el velo', 'revelar'. La 1. a doc. que dan Corominas-Pascual es 1436 (DCECH, V, p. 761). Frec.: 2: 0,00455. 
reverencia s. f. 'reverencia': et feita la reverencia por el dito rey al Padre Santo... 38.175. Etim.: es voz culta, del lat. REVERENTIA (DCECH, V, p. 789, s. v. vergüenza). Frec.: 9: 0,02046.

reverent adj. 'reverente, venerable': En aquellos dias, el santo rey don Jayme en la su reverent vellesa fue opprimido en el dito regno de fiebre continua 36.67. Tomado del lat, REVERENS, -TIS 'respetuoso, reverente'. Frec.: 1: 0,00227.

revocar] v. tr. 'revocar, dejar sin efecto una concesión': revocó el atorgamiento que havía feito de dito cavallo a su fillo 14.49. Etim.: deriv. culto del lat. REVOCARE 'llamar a uno', 'hacer retirar', deriv. de vOCARE 'llamar' (DCECH, V, pp. 845-846). Frec.: revocó 1: 0,00227.

rey s. m. 'rey': En la qual villa el dito rey don Jayme prisso por muller dona Blanca, filla del dito rey Carlos 38.113; cada uno de los ditos reyes sen tornoron en su tierra 38.349; el dito rey don Alfonso fue coronado et alçado rey, assí como es de costumbre et de ussança de reys todos tiempos observada 37.14. Del lat. REX, -REGIS, acusat. REGE(M). Frec.: rey 861: 1,95700; reyes 33: 0,07501; reys 1: 0,00227.

reyna s. f. 'reina': et por aquesta razón la dita reyna fue en Roma et delant del Padre Santo propuso sus clamos la dita reyna. 34.63-64; depués muert de la dita reyna dona Blanca, prisso otra muller 38.439. Del lat. REGINA. Frec.: 63: 0,14319.

riba s. f. 'orilla, costa' / / riba de loc. adv. 'en la orilla de': de las fuercas et lugares que riba del mar de Rosas et Barcelona eran 36.535. Etim.: del lat. RIPA 'margen de un río', 'orilla, ribera' (BDELC, p. 508; DCECH, V, p. 7). La loc. prepositiva en riba de la mar 'a orillas del mar' se encuentra en Berceo, Milagros de N. Señora, 47. Comp. riba de, o simplemente riba como preposición, en catalán medieval, muy frecuente. En cat. mod. se regista como sust.: riba 'vora del mar, d'un riu' y en la loc. riba mar 'a la riba del mar' (DL/C, IEC, 1995: 1601). En cast. la 1. a acep. que da el DRAE (1970) es 'porción de tierra con alguna elevación y declive, ribazo’. Con este valor, y también con el de 'montón grande de tierra', 'montón grande de cosas, en general', se emplea hoy en el Alto Aragón ripa, con la sorda conservada. Es de uso general. Rohlfs, DDPA, s. v., la recoge con el significado 'montón de piedras, paja o patatas' en Fanlo, Alquézar; Elcock, De quelques affinités, p. 85, atestigua el uso de ripa 'gran cantidad' en prácticamente todo el Alto Aragón. Andolz, s. v., con la significación de 'montón' en Alquézar; 'ribazo' en Bielsa, Valle de Chistau, Zaragoza. El EBA (1999: 1616-1617) recoge 23 registros de ripa en el Alto Aragón, además de doce de ripazo. La 3. a acep. del DRAE (1970), 'tierra cercana a los ríos. Sólo en composición: Ribagorza, Ribadavia', quizá convenga aquí. La expr. riba del mar valdría por 'en la tierra cercana al mar', o 'sobre la tierra cercana al mar' (DCECH, V, p. 7, s. v. riba). En Fz. de Heredia riba 'orilla, costa, playa, ribera'; 'ribazo, talud; margen, orilla' y riba mar ‘a lo largo de la orilla o costa del mar' (GILKISON, s. v.). También 
riba 'orilla' en $L M M$ (LiRIA, $L M M$, p. 191); riba 'orilla de un río, lago o mar' en el LT (Rodés, 2016: 763). Frec.: 1: 0,00227.

ribage s. m. 'orilla, costa': et trobó la una de las IX barcas, de las cuales las ocho ribaron en Gallicia et la novena en el ribage de Celtiberia, do él edificó una ciudad la qual clamó Barchanona 1.34. Deriv. de riba. Frec.: 1: 0,00227.

ribar] v. intr. 'arribar; llegar a la orilla o a puerto': trobó la una de las IX barcas, de las quales las ocho ribaron en Gallicia 1.33; el qual, aplegado grant navilio armado con muyto honrado barón, ribó al puerto de Roma 38.172. Derv. de riba. Con el mismo significado, ribar en Fz. de Heredia (GILKIson, s. v.). Frec.: ribaron 1: 0,00227 ; ribó 1: 0,00227 .

ribera s. f. 'ribera, orilla': e muytos de otros castillos e fuercas que son la ribera de Ebro 32.35. Deriv. de riba < lat. RIPA. Comp. ribage. Frec.: 2: 0,00455.

ricament adv. 'ricamente': una muyt bella tomba sobre la qual el nombre et la vida del dito sancto era notificada et contenida con letras muyt ricament entretalladas 9.23; el qual crió muy ricamente [ricament en el original, ms. B] 12.13. Frec.: ricament 1: 0,00227; ricamente [ricament] 1:0,00227.

richo (var.: rico) adj. 'rico', 'noble', 'poderoso'. Sólo aparece formando parte de la lexía rico home: aquesti cavallero era muyt richo homme 22.5; et todos sus fillos et muytos prelados et richos homes 38.499; de ricos homes, don García Romeu, don Exemén Cornel, don Miguel de Luesia... 34.90. Del gótico REIKs, fon. [riiks] 'poderoso' (DCECH, V, p. 10). Frec.: richo 1: 0,00227; richos 8: 0,01818; ricos 4: 0,00909.

rio s. m. 'río': et se justa un Arga et caye en Ebro, rio grande 20.280. Etim.: del lat. RIVUS 'arroyo, canal'. Ya aparece reducido a RIUS en inscripciones y otros textos vulgares latinos (DCECH, V, p. 28), por lo que no extraña la pérdida de -V-. Frec.: 13: 0,02955.

riqueza s. f. 'riqueza': el quoal por potencia et por riqueza era levantado en ergul [orgul BN] 36.35; edifició el monesterio de Ripol en el anno de Nuestro Sennyor DCCC LXXX VIII et aquel ennobleció de grandes donos et riquezas 23.76. Deriv. de richo, rico. Frec.: riqueza 1: 0,00227; riquezas 1. 0,00227.

robices s. m. pl. 'piedras preciosas', 'rubíes': et enrriquió et ornó el altar mayor del dito monesterio et de esmeraldes et safires, robices et carboneles et otras piedras preciosas 28.22. En LCMA se documenta robius 'rubíes, piedras preciosas de color rojo encendido', que parece a simple vista (a no ser que valga por robins) la solución catalana correspondiente a robices. Pero precisamente el cast. rubi proviene del cat. robi (doc. muchas veces en el s. Xv), procedente del bajo lat. Rubinus (deriv. de Rubeus), que ha dado también occ. rubi (de donde fr. rubis), it. rubino. En cast. se documenta rubi en 1495 (Nebrija). Cfr. DCECH, V, p. 81. El DECL/C, VII, p. 403, s. v. roig, registra entre 
otras formas del cat. ant.: rubiçes (pl.), rubiç (sing.) (1319). El DCVB, s. v. robi, registra las siguientes variantes antiguas: rubir, robis, robic (sing.), robiz. (sing.), robiços (pl.), 1356, robits (pl.), 1356. En cat. actual es robi (FABRA, s. v.). Como indican Alcover-Moll, t. 9, p. 515, la forma robi es un singular analógico formado sobre la forma de pl. robis interpretada como si fuese singular. Las formas cat. rubiçes y robiços, las más cercanas a la de nuestro texto, son claramente plurares duplicados. La forma robices sólo se puede explicar sobre un pl., tomado como sing., robits $>$ robiç + morfema de pl. -es. El paso -ts $>$-z. está atestiguado en arag. mod. (todas las segundas personas de pl. de los verbos: tenez, fébaz, etc.; los plurales en -z: mozet, pl. mozez, etc.). Además, la forma rubiz, tomada como sing. se documenta en arag. med., en $L M M$ (E.423; LiRIA, 1979: 192) y en invent. arag. de 1402 (ELIA, n $\mathrm{n}^{\circ}$ 1148; el contexto es: «hun otro aniello d'oro con un rubiz bermello», cfr. BRAE, II, p. 221). Luego se explica perfectamente el plural duplicado robices. Frec.: 1: 0,00227.

rogar v. tr. 'rogar': rogándole que le consellasse lo que faría 20.110; enviolo [inviole a N] rogar que vinies en ayuda 34.150; Et depués rogó el dito rey García al dito rey Remiro que pues él era padre y él fillo, que le dies algo de lo suyo que heredás 20.177; «ruegote que acabes con el rey de Aragón que me alargue la tregua por otros cinquo annos» 36.394. Del lat. ROGARE. Comp. pregar. Frec.: rogar 5: 0,01136; rogándole 1: 0,00227; rogó 3: 0,00682; ruegote 1: 0,00227.

romano] adj. 'romano', 'peculiar de Roma, relativo a Roma': de aqui adelant tuvieron la ley romana 17.64. / / s. y adj. gentilicio: e aquesti tollió las tierras todas et ciudades et lugares que los romanos sennyoriavan en Spanya 3.64. Frec.: romana 3: 0,00682; romanos 3: 0,00682.

romeage s. m. 'peregrinaje': e faziendo romeage, fizo concordia e paz 33.106. Deriv. de romeo (< bajo lat. ROMAEUS) 'peregrino' (DCECH, V, p. 58). Se registra romeage 'peregrinación' en $L M M$, p. 191. En Sta. $M^{a}$ Egipciaca, romeatge (cfr. VMC, s. v.). Frec.: 4: 0,00909.

roquero] adj. 'roquero, edificado sobre rocas': et muytos de otros castiellos roqueros 38.343. Deriv. de roca. Frec.: 1: 0,00227.

rovador s. m. 'ladró': Et en la ora de su muert salió el ladrón de su cueva et el rovador se demostró 32.68. Deriv. de rovar. También robador 'ladrón' en DLAA (REIDY, 1977: 247). Comp. ladrón. Frec.: 1: 0,00227.

rovar (var.: robar) v. tr. 'robar': et matavan et robavan las gentes del regno 20.98; e los lavradores fueron rovados 32.70; et todo quoanto rovar el continent 33.82. Etim.: del lat. vg. *RAubare, tomado del germ. RAubôn 'saquear' (DCECH, V, 40). Comp. arag. ant. ropado 'robado', ropar, ropadas en Rams de Flores (en las demás obras de Fernández de Heredia, robar). Cfr. Gilkison, p. 219, s. v. robar. Según indi- 
ca el DCECH, V, 41, ropar 'robar' es frecuente en arag. ant. Pero esta forma derivará del gót. RAUPJAN 'pelar, arrancar', de una raíz emparentada con el germ. RAUBÔN. Aparece ropar 'robar' en FA, así como roparia 'robo', ropador 'robador' (pero tb. robador, robar y robaria). Vid. Tilander, FA, pp. 552-553. Frec.: rovar 1: 0,00227; rovados 1: 0,00227; robavan 2: 0,00455.

ruego] s. m. 'ruego, petición': que farian todas las iglesias, salvant catedrales, ruegos e necesidades tener aquéllas 18.121. Derivado deverbal de rogar. Comp. pregraria. Frec.: ruegos 1: 0,00227.

rumor] s. f. 'rumor': He oydas las rumores et tabustoles et federades de las genetes sin nombre que en la villa de Perpunyan se eran venidas... 36.478. Del lat. RUMOR, -ORIS 'ruido, rumor'. Frec.: rumores 1: 0,00227.

\section{S}

sabado s. m. 'sábado': Feria VI, depués Pascua, prendió el dito rey Arguedas, X kalendas junii pres [priso N] Setcastella, el sabado depués siguient firo batalla en Tudela 17.83. Del lat. SAвватUm y éste del hebreo sabbath 'descanso semanal' (DCECH, V, p. 102). Frec.: 1: 0,00227.

saber v. tr. 'saber': porque bien sabedes vosotros que quando la reyna su madre murió asin por grant desastre, prenyada era. 12.30; et non se sabieron ni podieron [se pudieron ni supieron $\mathrm{N}$ ] defender 1.39; et dupdavan que don Remiro el monge non lo sabies [supies $\mathrm{N}]$ deffender 20.51; et conoció et sabió [supo $\mathrm{N}$ ] el dia de la su muert 31.53; et acordaron que no por dos razones: la primera que dudaban que don Remiro no sabries [que no supies $\mathrm{N}]$ regir el regno, 20.46; et súpolo el rey de Aragón, et con sus fillos Pedro et Alfonso et todas sus gentes yvan a él 17.111; segunt que depués de cierto se suppo, de toda aquesta gent malvada non tornoron a lur tierra la XXX part 36.666. Del lat. SAPERE. Frec.: saber 1: 0,00227 ; sabedes 1: 0,00227; sabemos 1: 0,00227; sabía 3: 0,00682; sabían 3: 0,00682; sabida 1: 0,00227; sabiendo 10: 0,02273; sabiendolo 1: 0,00227; sabieron 1: 0,00227; sabies 1: 0,00227 ; sabió 1: 0,00227 ; sabries 1 : 0,00227; saviendo 2: 0,00455 ; sepas 1: 0,00227 ; supieron 2: 0,00455 ; supo 11: 0,02500; súpolo 1: 0,00227; suppo 2: 0,00682.

sacar v. tr. 'sacar': et departian los aragoneses como sacassen a don Remiro de la mongía et que fuesse rey 20.38; vi la criatura qui sacó la mano por la ferida del vientre de su madre et sin periglio vivo lo saqué, benedito sea Dios 12.34. Probablemente del gótico SAKAN 'pleitear' y luego 'extraer; quitar' (DCECH, V, p. 116). Frec.: sacar 1: 0,00227; sacassen 1: 0,00227; sacó 6: 0,01364; saqué 1: 0,00227 . 
sacres] adj. y f. pl. 'sagradas': algunas crononicas [coronicas $\mathrm{N}$ ] dizen que no era en sacres ordenes 20.72. Del lat. SACER, SACRA, SACRUM 'sagrado'. La forma sacres solo puede explicarse suponiendo que se ha construido sobre el genitivo (o nominativo pl.) sacrae. Frec.: 1: 0,00227.

sacrilegio s. m. 'sacrilegio': yes presuntion que desti sacrilegio que firo en Leon et en Galicia que fue punido en la batalla de Fragos 19.152. Tomado del lat. sacrilegium. Frec.: 1: 0,00227.

safires s. m. pl. 'zafiros, piedras preciosas de corindón cristalizado de color azul': enrriquió et ornó el altar mayor del dito monesterio et de esmeraldes et safires, robices et carboneles et otras piedras preciosas 28.22. En cast. se doc. çafir en 1335. Parece haberse tomado del ár. safirr. Aunque posteriormente sufrió el influjo del lat. SAPPHIRUS, tom. del gr. $\sigma \alpha \pi \pi \eta \varepsilon \iota \rho O \sigma$, que a su vez parece ser voz de origen oriental, emparentada con dicha palabra arábiga (BDELC, s. v. zafiro; DCELC, IV, p. 793.). CORRIENTE (2003: 471) afirma igualmente que el origen de esta voz es el ár. andalusí safir < gr. sáppheiros, que a su vez deriva de una lengua asitática no determinada.Está claro pues que estamos ante el pl. de la forma antigua çafir 'zafiro'. Comp. cat. safir (DECLIC, VII, p. 581; CoROMINES, en este caso, supone que la voz catalana procede directamente del lat. SAPPHIRUS < gr. $\sigma \alpha \pi \varphi \varepsilon \rho \varsigma^{\prime}$ 'íd.'). Se documenta safir, çafi en invent. arag. (ELIA, $\mathrm{n}^{\circ}$ 1156); safires en Fernández de Heredia (GILKIson, 1984: 120). En el LMM, saphires, saphirs: "primerament hombre los ensaya a tallar en saphirs o en otras piedras preciosas», D.221; «la forma de su lecho es toda de saphires finos bandados d'oro, car los saphires fazen bien dormir e si Restriynnen la luxuria», F.192 (LMM, p. 89 y 126). Frec.: 1: 0,00227.

sagrado adj. 'sagrado': recibió muyt benignament et bumil el santo cuerpo de Dios sagrado et todos los otros sagramentos con grant devoción 35.285. Del lat. SACRATUs. Comp. sacres. Frec.: 1: 0,00227.

sagrament s. m. 'juramento, promesa sagrada': le fizo homenage et sagrament de fieldat por si et por sus successores 38.471. / / 'sacramento': recibió muyt benignament et bumil el santo cuerpo de Dios sagrado et todos los otros sagramentos con grant devoción, 35.286. Etim.: < lat. SACramentum. Según Corominas, la acepción 'juramento' se da en la Edad Media tanto en textos aragoneses como castellanos (DCECH, V, p. 127, s. v. sagrado). Vid. también DEEH, p. 944. En Alex.: sagramente con la misma acepción (SAS, s. v.). En Fernández de Heredia: sagrament 'juramento' y otras variantes (Gilkison, s. v.). Aparece en FT, Savall y Penén, Yanguas, GIFFORD. En otros sitios, con el valor propio del lenguaje eclesiástico. Vid. Aut., 4. ${ }^{a}$ acepción de sacramento: «se toma también por la obligación y vínculo del juramento». El DRAE (1984) recoge como 5. acepción de sacramento (con marca de desusado): «Afirmación o negación de algo poniendo por 
testigo a Dios en sí o en sus criaturas». Frec.: sagrament 5: 0,01136; sagramentos 1: 0,00227.

sallir v. intr. 'salir del interior de un sitio, aparecer': et metíanse por las orellas et por las narizes de la gent et de las bestias que en algún tiempo no ende sallian entro que eran muertos 36.600-603; con los leoneses e gallegos sallieron entre Estroga [Astorgam VL] $e$ Leon 19.140-141; empero los otros pressos antes que salliessen de la pressón se buvieron redemir 36.422; en el lugar clamado d'Espina scerca de Sepulvega sallieron los aragoneses e hordenaron sus azes 19.114-115. Etim.: del lat. SALIRE 'saltar'. Según explica Corominas, en el Poema del Cid es ya corriente con el sentido actual 'pasar de dentro afuera'. En este sentido es de uso general desde el lenguaje más arcaico (Berceo, Juan Manuel, etc.), sentido que han conservado los descendientes de SALIRE en port., cast. y en algunas hablas del sur de Francia y Piamonte. La forma sallir, fue corriente en cast. desde los orígenes hasta el siglo XVI. La palatización se explica a partir de formas como salió, saliera, saliendo (DCECH, V, p. 139). Comp. exir, que se emplea con el significado de 'salir de una ciudad, irse de un país, de una tierra', mientras que sallir tiene un sentido más restringido 'aparecer a la vista, salir del interior de un hueco'. Comp. saillir en $V M$; sallir en PY, en Fernández de Heredia (GILKIson, s. v.), en $L M M$, etc. Se emplea todavía en el arag. del s. XVII: salleron, salliva, sallón en Ana Abarca de Bolea (Alvar, Estudios sobre el «Octavario», p. 36; ABARCA DE BOLEA, 1980: 37, 43, 50). Frec.: sallir 2: 0,00455; sallían 1: 0,00227; sallieron 4: 0,00909; salliesen 1: 0,00227; salliessen 1: 0,00227; sallió 4: 0,00909.

salto s. m. 'asalto, ataque': aguait de moros dieronle salto et mataron toda la compannia qui con ella era 12.3. Del lat. SALTus 'salto, acción de saltar'; el cast. asalto, tomado del it. assalto, se doc. en 1570 (DCECH, V, 142). Frec.: 1: 0,00227.

salut s. f. 'salud': «ayúdanos Dios, que es salut nuestra» 35.246. Del lat. SALus, -UTis. Frec.: 1: 0,00227 .

salvant prep. 'excepto, a excepción de, con excepción de, fuera de, menos': et el dito rey don Pedro, viendo esto, fizo exir todo bome de Girona salvant aquellos que eran necessarios en deffensión de la ciudat de Girona 36.524-527; las galeras de los secilianos se vincieron et fueron muytas pressas, salvant aquella do era el rey Federich et pocas otras 38.271-273. Etim.: del del part. pres. del v. salvar, utilizado como adv. o prep. Comp. cat. salvant y salvat, preposiciones, 'deixant intacte, de banda; exceptuant' (FABRA, DG$L / C$, p. 1523). El $D C V B$ (t. 9, p. 710) recoge salvant 'salvat, excepte, cast. salvo'. El DRAE (2001, s. v.) da para salvar como 4. a acepción: 'exceptuar, dejar aparte, excluir una cosa de lo que se dice o se hace de otra u otras'. Frec.: 3: 0,00682.

salvar] v. tr. 'salvar': El el dito cavallero respondió [respuso N]: «Si Dios me salve, todo bomme que aquesto diga miente aulement et falsa por media de la barba 38.319. Del lat. SALVARE 'íd.'. Frec.: salve 1: 0,00227. 
salvo adj. 'salvo', 'ileso, libre': El dito conte Borrel tornó sano et salvo de la dita batalla con grande honor 27.13; que les libraría la ciudat con que les lexasse yr salvos et seguros con todo lo que se podrian levar 36.612. Del lat. SALvus 'sano', 'salvo'. Frec.: salvo 1: 0,00227; salvos 1: 0,00227.

san adj. 'santo', apócope de santo en situación proclítica: a honor de Dios et de San Johan crecieron et melloraron la dita eglesia 9.15-17. Tb. sant. Frec.: 41: 0,09319.

sanctament adv. 'santamente': et aqui sanctament et con firma [confirmada N] fe catholica sirviendo a Dios estuvieron luengo tiempo 5.8. Frec.: 1: 0,00227.

sangre s. f. 'sangre': tan fuert batalla hi fue feita que la mar vermelliana [vermellava $\mathrm{N}$ ] de la sangre de la gent que muerta et ferida yera sobre la mar 38.269. Del lat. SANGUIS, -INIS. Frec.: 1: 0,00227.

sanicos gentilicio 'nombre de un pueblo que habitó en España': ... nin de los vándalos nin de los alanos, nin de los suevos nin de los ugones et sanicos; las quales naciones los godos echaron de Espannya 2.9. Frec.: 1: 0,00227.

sanidat s. f. 'salud': el estando en sana sanidat en su buen entendimiento, renunció a los bienes temporales 31.48. Del lat. SANITAS, -ATIS. Frec.: 1: 0,00227.

sano adj. 'san': el estando en sana sanidat 31.48; tornó sano et salvo de la dita batalla con grande honor 27.13. Del lat. sANus. Frec.: sano 2: 0,00455; sana 1: 0,00227.

sanosament adv. de modo 'con saña, con enojo, airadamente': como en continent quél favlava sanosament con alguno nin dalguna cosa fues yrado siempre movía el pie en semblança de cabreta qui quier cavar 25.24. Etim.: deriv. del sustantivo saña, probablemente del lat. INSANIA 'locura furiosa', o quizá sacado del verbo ensañar < lat. insaniare (DCECH, V, p. 155). Según García de Diego, y otros, del lat. SANNA 'mueca', 'escarnio' (DEEH, p. 365, 744 y 951), cosa que rechaza Corominas. Se documenta sanyosament 'con saña' en LT (Rodés, 2016: 766) y en alguna obra del taller de Ferrández d'Eredia (GILkison, 1984: 121). Frec.: 1: 0,00227 .

sant adj. 'santo', apócope de santo: el dito heremita fizo una eglesia a honor de Dios y de Sant Johan Baptista 5.4 Tb. san. Frec.: 45: 0,10228.

santidat s. f. 'santidad': el quoal recontó el romeage que avia feyto a la dita sancta cueba, $e$ cómo por la dita santidat d'ella e por su devotión que y avía, les avía dado el dito termino 11.33. Del lat. sanctitas, -ATis. Frec.: 2: 0,00455.

santificado] adj. 'santificado': et rendidas gracias a Dios et a la suya santificada Madre de las victorias que todos tiempos avía obtenidas contra moros... 35.159. Del p. p. del v. santificar. Frec.: santificada 1: 0,00227.

santo (var.: sancto) adj. y s. 'santo': E res no menos fizieron consignar [fizo consagrar $\mathrm{N}]$ al dito monasterio por el vispo d'A ragón, nombrado Ennego, el dia de sancta Agatha 9.40; ordenó que assín como el monesterio sancto lugar era ordenado de clérigos seglares, fuesse ordenado de aqui avant et ennoblecido de monges negros. 14.95-96; Et con grant 
victoria, loando Dios et sus sanctos, levantó el campo 12.59-60; buvo nombre don Phelip qui fue santo hombre 38.451; el dito rey don Jayme de Aragón devotament murió en hedat de LXXI annos en la ciudat de Barchinona, la vigilia de Todos Santos 38.630. Del lat. SANCTUS. Frec.: santo 56: 0,12728; santa 17: 0,03864; santos 6: 0,01364; santas 2: 0,00455; sancto 8: 0,01818; sancta 7: 0,01591; sanctos 10: 0,02273.

santuario] s. m. 'santuario': visitando los santuarios de los Apóstoles muy devotament 34.32. Del lat. SANCTUARIUM. Frec.: santuarios 2: 0,00455.

satisfeito B [satifeito E] adj. 'satisfecho': devies conquerir el regno de Secilia segunt las convinencias de la paz dessuso dita, satifeito [satisfeito B] et pagado [el sueldo $\mathrm{N}$ ] primerament a éll et a sus cavalleros et conpannyas, recollioso con grant poder de sus valientes varones et vasallos a Palamos 38.222. Debe de ser error por satisfeito (ms. B, fol. 82v., lín.4). Del lat. satisfactum, p. p. de satisfacere 'hacer lo suficiente, llenar cumplidamente, satisfacer' (BLÁNQUEZ, p. 1394). De uso habitual en arag. med.: «Item, seynor, como el nos aya adar en cada carga .I. rouo de trigo de mas, por ordinacion uuestra $\&$ del vispo, \& aquello no nos aya conplido, que sia la vuestra merce que aquello nos sia satisfeytor (DLAA, doc. de Jaca de 1317; p. 141, ringl. 46); «certificantes uos que d'aquesto nos faredes singular plazer vltra que a la justicia crehemos por esto sera satisfeyto» (carta de la Cancillería Real de 29 de mayo de 1424, ACA, Reg. Canc. 2575, f. 9r; en LLEAL, 1997a: 76). Puede verse satisfer 'sastisfacer' y satisfeyto 'satifecho' en DJ (Alvar, EDA, II, p. 214); en los DLAA (Reidy, 1977: 250); en el LT (Rodés, 2016: 766); en $O B$ (VÁzQuez Obrador, 2011c: 52); en Ferrández d'Eredia, satisfer — solo en Secreto secretorum, Cronica de los conqueridores y Grant Cronica de Espanya-, pero no satisfeyto. Comp. en arag. mod.: satisfer 'satisfacer' en Salas Altas (Ríos, 1997: 146) y Somontano de Barbastro en general (Mostolay, 2007: 498); satisfeito en el valle de Chistau (BLAs / Romanos, 2008: 469), en el valle de Echo (LerA, 2004: 190), etc. Frec.: 1: 0,00227.

saviament adv. 'saviamente': Et la ora era conte en el condado de Ampurias Huch qui fue muyt noble cavallero et regió el dito condado muyt saviament 35.104. Frec.: 3: 0,00682.

savieça (var.: savieza) s. f. 'sabiduría': ya más [jamás B] en tiempo de aquesti rey nos movió ni se suscitó, si quiere se fues por la grant savieça de su padre 39.24-26; con grant savieza supo [fizo B] fer a sus vassallos exolvidarla 38.626. Etim.: deriv. de savio < lat. SAPIDUS 'que tiene sabor', y en la baja época 'prudente, juicioso'. COROMINAS dice que es raro sabieza por sabiduría en la lengua antigua $(D C E C H, \mathrm{~V}, \mathrm{p}$. 113, s. v. saber). Se doc. en Alex., h. 1250 (SAS, s. v.). En VM, samieza (Tilander, 1956, III, 279). En Fernández de Heredia: sabieza, sanieça, sauieza, sauiençia, saniedat (GILKISON, 1984, s. v.). Frec.: savieça 1: 0,00227; savieza 1: 0,00227.

savio (var.: sabio) adj. 'sabio': Aquesti cavallero era muy rico bomme et muy bien armado et muyt sabio 22.6; et aquesti rey don Jayme de Aragón fue muyt savio varón 38.622. Etim.: del lat. sApIDus 'que tiene sabor, sabroso', y en la baja época 'prudente, 
juicioso' (BDELC, s. v. saber). Muestra una evolución fonética propia del castellano: comp. arag. mod. saputo 'sabio', 'sabiondo', registrado en Almudébar, Pandicosa, Plana de Uesca, Salas Altas, Uesca (EBA, 1999: 1662; Ríos, 1997: 146; NAGore, 2020: 590). En Ardisa: saputo 'listo, inteligente' (Romanos, 2003: 237). Frec.: sabio 1: 00227; savio 8: 0,01818.

sayeta s. f. 'flecha, saeta': Et aquesti conte Guillem Jordan basteció un castiello qui es clamado Arquas, el qual yes cerca el castiello de Tripol, et aquí fue ferido con sayeta 31.35; et la manga de la loriga se abrió et un moro ballestero que estava en aquel lugar con una sayeta por la manga de la loriga firiolo en el costado 17.121; et conortando su buest fizose sacar la sayeta et murió. 17.127. Etim.: del lat. SAGITTA (DCECH, V, p. 124). Habitual en arag. med.: sayeta 'arrow' ['flecha'] en el arag. de Fernández de Heredia (GILKIson, 1984, s. v.), en el LT (Rodés, 21016: 766), etc. Véase un ejemplo en el Libro de Marco Polo: «et como fueron descavalgados començaron a ferir en los orifantes con lures sayetas, que ivan tan spessas que apenas vidie hombre l'aire» (NiTTI, 1980: 31; SANGORRín, 2016: 85). En arag. del s. XVI: sayeta 'saeta, manecilla del reloj' (Mostolay, 2007: 498). Comp. en arag. mod.: sayeta 'saeta, aguja del reloj' en Campo (Mascaray, 2013: 327); en Ardisa (Romanos, 2003: 238); en A Buerda, Bal de Bielsa, Bal de Benás (EBA, 1999: 1669). Rohlfs (DDPA, 1985: 282) registra sayeta 'aguja del reloj' en Bielsa. Frec.: 3: 0,00682. sayna s. f. 'saña, cólera, ira': El enperador como quier que de sayna fuese movido luego por dar sentencia contra él... 19.88-90. Probablemente del lat. INSANIA 'locura furiosa' (DCECH, V, p. 155); otra etim. propuesta es lat. sANNA 'mueca burlona' (DEEH, p. 951). Comp. sanosament. Frec.: 1: 0,00227.

scripturas s. f. pl. 'escrituras, la Biblia': Aquesti conte fue devoto christiano et entendía en las divinales scripturas 36.435. Frec.: 1: 0,00227.

scrivir v. tr. 'escribir': suplicando quel dito Padre Santo le quisies scrivir al dito Simón 34.136. Del lat. SCRIBERE. Frec.: scrivir 1: 0,00227; scripto 1: 0,00227.

se pron. refl. 'se' (tanto con uso propiamente reflexivo como impersonal): de los quales dizen que quando la batalla se dio, dizen que muytos se gitoron en la mar 38.252; muytas vegadas ses esdevenido que vassallo desenpara su sennyor 38.130 . Vid. también es. Frec.: 239: 0,54323.

seciliano] (var.: seciliano], seziliano]) adj. gentilicio 'de Sicilia': et forçar mulleres biudas como en otra manera a los seçilianos 36.194; A la fin, la mano dreyta de Dios ayudando, las galeras de los secilianos se vincieron 38.271; Et como los prometimientos dessuso ditos, algunos accidentes entrevenientes, el dito Padre Santo non pudies adozir a acabamiento a grant inportunidat de los sezilianos... 38.161. Frec.: secilianos 5: 0,01136; seçilianos 1: 0,00227; sezilianos 3: 0,00682.

secretament adv. 'secretamente': et díxole que con él quería fablar et su conpannya por tractar de la paz secretament. 38.388. Frec.: 6: 0,01364. 
secreto] adj. 'secreto', 'oculto': fizo el rey parellar ciertos et secretos hombres en su cambra armados 20.131. Del lat. SECRETus 'íd.'. Frec.: secretos 1: 0,00227.

secta (var.: seta) s. f. 'secta': et en tiempo de aquesti comencó a predicar Mahomat la suya malvada secta [seta N] en la tierra de Mecha et en otras tierras dallamar, que agora son de moros. 3.58-60; por destruir la seta morisca, fue en Córdova contra moros 27.5. Cultismo, del lat. seCTA 'línea de conducta', 'partido, bando', 'escuela filosófica', etc. (DCECH, V, p. 192, s. v. seguir). Frec.: secta 2: 0,00455; seta 1: 0,00227.

secundo adj. ordinal 'segundo': el secundo don Alfonso qui fue conte de Urgel 38.410; La secunda hermana, Elionor, dio por muller a Remón conte de Tolosa 34.20. Del lat. SECUNDUS. Comp. segundo. Frec.: secundo 4: 0,0909; secunda 2: 0,05455.

seda s. f. 'seda': yva sobre trapos d'oro et de seda 36.220. Del lat. SAETA 'cerda de puerco', 'sedal de pescar' (DCECH, V, p. 186). Frec.: 1: 0,00227.

seer v. copulativo 'ser': ... a Fredrico rey de Sicilia, el qual fu'entra de poco tiempo emperador de Alemanna 34.13; ¿qué fará quando seya rey? 20.36; ya sia que con aquesto avies muytas vegadas 38.57; mas non lo quiso prender entro ha quende [fasta que $\mathrm{N}$ ] fues forçado por el Padre Santo 38.609; quel rey don Jayme et el rey don Ferrando de CastieIla fuessen amigos et bien querientes 38.337; et la ora hera compte d'Urgel Narmengon 33.116; el dito rey que volentaroso yera de conquerir el regno de Secilia 38.293; el qual fue homme simple es ningún tiempo non quiso seer enemigo de la casa de Aragón 38.600. / / v. auxiliar: como ya en Borja con los navarros yera seido favlado de la cosa 20.68; agora yes ora quando se yes partido [el es ydo N] 38.332; et quando fue ante el rey «yo, dixo, yo so venido ante vos»... 36.375. / / v. intr. 'haber, existir': et paz. et amor fuesse [fues $\mathrm{N}$ ] entre ellos 38.337. / / v. intr. 'estar': et sediendo dellos muy affrontado dellos emvió a rogar al rey don Pedro de Aragón que le fues a acorrer 18.97; et recuéntase que algunos davan de consello al rey que diesse por malos a los sus naturales que yeran seydos en la batalla con el rey Federich 38.280; et a cabo de III días, seyendo en Pamplona el dito don Remiro 20.184; Etim.: de una fusión de los v. latinos ESSE 'ser' (lat. vg. *ESSERE) y SEDERE 'estar sentado’ (DCECH, V, 213). Frec.: seer 19: 0,04319; ser 8: 0,01818; será 1: 0,00227; sería 8: 0,01818; serían 1: 0,00227; sea 9:0,02046; sean 1: 0,00227 ; seas 1: 0,00227 ; sediendo 1: 0,00227 ; seido 2: 0,00455 ; seya 1: 0,00227; seydo 5: 0,01136; seydos 4: 0,00909; seyendo 15: 0,03409; sia 8: 0,01818 ; hera 14: 0,03182 ; heran 8: 0,01818 ; yera 20: 0,004546 ; yeran 19: 0,04319; es 'eres' 3: 0,00682 (35.246, 35.296, 35.297); eres 'eres' 2: 0,00455 (35.245, 35.295); yes 'es' 58: 0,13183; es 'es' 53: 0,12047.

seglar] adj. 'seglar', 'secular, no perteneciente a una orden o regla monástica': por la grant devoción que havía en San Johan de la Penna, ordenó que assín como el monesterio sancto lugar era ordenado de clérigos seglares, fuesse ordenado de aqui avant et ennoblecido de monges negros. 14.96. Etim.: deriv. del lat. sAECulum 'generación', 'época', ‘siglo’ (DCECH, V, p. 245, s. v. siglo). El significado con que se usa en la Crón. SJP. no coincide con los que da el $\operatorname{DRAE}(1970$, s. v.): 'perteneciente a la vida, 
estado o costumbre del siglo o mundo', ‘que no tiene órdenes clericales'. Frec.: seglares 1: 0,00227.

seguir v. intr. y prnl. 'suceder', 'ocurrir', 'originarse, producirse': carnal copula / non/ fue seguida [subseguida $\mathrm{N}$ ] entre los ditos rey et reyna 38.56-57; et despues siguies [siguios $\mathrm{N}]$ quel dito Manfre vínole enfermedat de la qual murió. 38.563; et por tal que disensión alguna non se siguiesse entre los regnos, reconocieron la tierra que yera de Navarra, yes assaber, d'Ebro entro tierra Burgos 19.182. Del lat. SEQUI, luego sustituido por SEQUERE, que adoptó la terminación -IRE (DCECH, V, p. 191). Frec.: seguir 4: 0,00909; seguida 1: 0,00227; seguidas 1: 0,00227; siguieron 2: 0,00455; siguies 1: 0,00227 ; siguiesse 1: 0,00227 ; siguen 1: 0,00227 ; siguiendo 1 : 0,00227; siguient 5: 0,01136; siguiente 2: 0,00455; siguientes 1: 0,00227.

segundo (var: secundo) adj. ordin. 'segundo': et acordaron que no por dos razones; la primera que dudaban..., la secunda porque los navarros se dupdavan del emperador 20.47; et depués partió de aqui et fue en Barçalona el segundo dia de agosto 38.584. Del lat. SECundus 'el siguiente', 'segundo'. Comp. secundo. Frec.: secundo 4: 0,0909; secunda 2: 0,05455; segundo 6: 0,01364; segunda 3: 0,00682.

segunt (var.: según) prep. 'según': cobró la dita tierra de Aragón, la qual tenía el emperador don Alfonso de Castiella a homenage, según en la su crónica yes contenido 20.317; et depués de grado en grado de cada un conte según que devalloron el <uno> del otro, fablaremos et lur vida recontaremos 21.5; et por otras que fizo a su cunnyado el rey don Pedro de Aragón, segunt que deiusso recontaremos 38.619. Del lat. SECundum 'según'. En arag. mod., seguntes es la forma general (EBA, 1999: 1673; ANDOLZ, 1992: 392; Rohlfs, DDPA, 1985: 283), si bien en Pandicosa se registra segunte (Mur, 2014: 41). Frec.: segunt 36: 0,08183; según 10: 02273.

segurado] adj. 'asegurado': cada uno prendie sus cartas muyt bien firmadas et seguradas 19.188. Del p. p. de segurar'asegurar'. Frec.: seguradas 1: 0,00227.

segurament adv. 'de forma segura, de modo seguro', 'con seguridad': Luengo tiempo havia por tal quel dito regno de Secilia fues más segurament preservado de poder de los enemigos 36.264-265; et depués tuvo toda la tierra segurament a la suya voluntad. 23.69-70. Frec.: 2: 0,00455.

seguredades s. f. pl. 'seguridades, garantías': fue firmado et finido por cada una de las partes con seguredades firmes en poder del rey 36.253. Del lat. SECURITAS, -ATIS. Frec.: 2: 0,00455 .

seguro adj. 'seguro': Et el dito senescal respondió: «yo non vos puedo tener el campo seguro» 36.288; Assimismo de su cabo los aragoneses tractoron que enviassen por don Remiro el monge et cuydando seer seguros... 20.66-67. Del lat. SECURUS, -A, -UM. Frec.: seguro 5: 0,01136; seguros 2: 0,00455.

sellado] adj. y p. p. 'sellado, con sello': los quales capitoles, cerrados et sellados con los siellos de cada un rey, el dito rey Carlos sende levó al Padre Santo, et aquellos en pleno 
consistorio al Padre Santo mostró 38.74. Del lat. Sigillatus 'grabado', de SIgILLARE 'marcar, sellar, estampar'. Frec.: sellados 1: 0,00227.

semana s. f. 'semana': et la ora entró la ley romana en Sant Johan de la Penna, XI kalendas aprilis en la segunda semana de Quaresma, feria tertia et ora prima 17.61. Del lat. SEPTIMANA. Frec.: 1: 0,00227.

semblança (var.: semblanca) s. f. 'semejanza': como en continet quél favlava sanosament con alguno nin dalguna cosa fues yrado siempre movía el pie en semblança [semblaça en la ed. crítica; pero el ms. se lee claramente semblança] de cabreta qui quier cavar 25.25; que yera conoscido en aquellas partidas, a semblanca de mercadero 36.274. Etim.: deriv. sufijado con -ANTIA > -ança de semblar 'parecer, semejar' < lat. SIMILARE. El DCECH

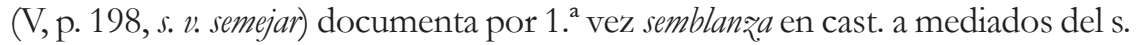
xv, así que la Crón. SJP. la adelanta en unos 80 años. Por otro lado, para los autores de esta obra, semblar, semblante y semblanza serían en castellano catalanismos, tomados del cat. semblar, semblant y semblança. Para el arag. no parece necesario suponer eso: cfr. Vidas semblantes, título de la obra de Plutarco traducida al aragonés por Fernández de Heredia (vid. la ed. de Adelino Álvarez RodríguEz, 2000). Se registra semblança en FA, en Fernández de Heredia (GILKIson, 1984, s. v.); semblança ‘imitación’ en el Índice de Blancas (1641). En cambio, semeillança en VM, III, p. 283. Frec.: semblança 1: 0,00227; semblanca 1: 0,00227.

semblanment (var.: semblantment, senblament) adv. 'semejantemente, parecidamente'; 'igualmente', 'de la misma o semejante manera': (S)abida semblament la muert del excellent rey, su fillo promogenito don Alfonso el Franco regnó 37.1; por semblanment [senblant $\mathrm{N}]$ manera que dessuso havemos recontado 38.372; el dito rey don Jayme firo el homenage et sagrament de fieldat et senblament lo firo fer a sus vassallos et sozmesos 36.104. Frec.: semblament 1: 0,00227; semblanment 2: 0,00455; semblantment 1: 0,00227; senblament 2: 0,00455.

semblant adj. 'semejante, parecido', 'que semeja, parece o imita': temiendose que por semblant iudicio que firo de su padre non passas 17.11; et mientre duró la batalla sol nos mudó el pie ni fizo asemblant [fue senblant $\mathrm{N}$ ] que fues ferido, de la qual cosa todo homme se dio a grant maravella 38.276-278; de que yes semblant de lo que fizieron 38.210; et a muytos d'otros [et muitos dones B] semblantes gracias firo 35.185-186. // verdat semblant 'verosímil': ... que acusassen la reyna, lur madre, al rey, su padre, que ella fazía mal sus afferes con el dito cavallero; et parecía verdat semblant por la gran familiaridad que era entre entramos. 14.54-55. Del part. pres. del v. semblar 'parecer' < lat. SIMILARE 'ser semejante'. Es muy común en arag. med. Vid. semblar 'parecer, semejar', semblant'semejante', en Fernández de Heredia (GILKISON, s. v.). Frec.: semblant 5: 0,01136; semblantes 2: 0,00455.

sembrar v. tr. 'sembrar, esparcir, difundir': que como él entendies a subiugar con la ayuda de Dios Africa et et sembrar el nombre de Dios et la fe christiana... 36.174. Del lat. SEMINARE. Frec.: 1: 0,00227. 
senaladamente adv. 'señaladamente, singularmente': et plegados a las cortes de Monçón, los navaros no vinieron alli, senaladamente don Az̧nar d'Oteyça et don Fernan [Fortún N] Enneguez de Let 20.87-88. Esta es una de las escasas excepciones en que se registra la forma en -mente: en la Crón. SJP. es general la forma en -ment. De los 272 adverbios de este tipo que aparecen en el texto, solamente tres son en -mente; todos los demás, en -ment. Frec.: 1: 0,00227 .

sende contr. de se + ende. Frec.: 29: 0,06572. Vid. ende.

senescal s. m. 'senescal, jefe o cabeza principal de la nobleza': Enpués esto, el rey de Francia envió el condestable et senestara senescal de Tolosa con don Johan Munioz del Ara que prendría Aragón 36.332. Etim.: del occ. senescal, y éste del fráncico SINISKALK 'mayordomo, criado anciano', de SKALK 'criado' y una forma germánica afín del lat. SENEX, SENIs 'viejo' (DCECH, V, p. 212, s. v. señor). Se registra senescal 'seneschal, leader' (GILKIson, 1984, s. v.) en tres obras de Fernández de Heredia. Comp. cat. senescal 'mayordom d'un gran senyor medieval' (FABRA, DGLIC, s. v., p. 1542; DLlC del IEC, 2007, s. v.). Frec.: 4: 0,00909.

senestara (?): Enpués esto, el rey de Francia envió el condestable et senestara [senescara B] senescal de Tolosa con don Johan Munioz del Ara que prendría Aragón 36.331. Debe de tratarse de una forma errónea. En el ms. B leemos senescara, pero carece igualmente de sentido. La redacción no se resiente si se suprime esta forma: envió el condestable et senescal de Tolosa... Frec.: 1: 0,00227.

senglor] (songlot]) s. m. 'sollozo': porque la tierra se plorava et senglores [songlotes B] de grenges sospiros gitavan a Dios 36.195. Etim.: del lat. vg. *singlutTus, alteración del lat. cl. SINGULtus 'hipo', por influencia del GLUTTIRE 'tragar' (DEEH, p. 974; PRobert, s. v. sanglot, DECL/C, VII, p. 661; DCECH, V, p. 297; Dauzat - Dubois - Mitterand, s. v. sanglot). Comp. cat. senglot $\sim$ sanglot singlot, occ. sanglot, fr. sanglot. En la Alta Ribagorza sanlluc 'hipo' (Ferraz, s. v.; Ballarín, Dicc., p. 449, s. v. sanllúk). En cambio, cast. sollozo < lat. vg. SugGluttium, alteración del cl. singultus. Frec.: senglores [songlotes] 1: ',00227.

sennoriar (var.: sennyoriar, senyoriar, senoryar) v. tr. 'gobernar, regir, dominar': Muerto el dito emperador et el departimiento de las tierras et acabamiento adueyto, sennoriá [seynorió $\mathrm{N}$ ] el dito rey Remiro en el regno de Aragón 16.2; et en Aragón sennoryava el comte Aznar 5.19; Et aqueste Alarico demandó al emperador Honorio, qui a las horas emperava et sennyoriava el imperio de Roma, aver paz con él 3.31; aquestos fueron los que tollieron Espanya a los romanos, que senoryaron los griegos et a la nación que Ercules y avía lexado. 3.5; Et depués de aquesta nación, vino Ercules por senyoriar Espana 1.12. Deriv. de sennyor. Frec.: sennoriar 1: 0,00227 ; sennoriase 1: 0,00227 ; sennoriava 1: 0,00227 ; sennoriavan 
1: 0,00227; sennorió 3: 0,00682 ; sennoryava 1: 0,00227 ; senyoriar 1 : 0,00227 ; sennyoriava 2: 0,00455 ; sennyoriavan $1: 0,00227$; senoryaron 1: 0,00227 ; senyorava 1: 0,00227 .

sennyal (var. sennal, seynal, seynnal) s. m. 'enseña real', 'insignia', 'escudo de armas': Et por aquesta donación el Padre Santo por honor de la casa de Aragón constituyó quély todos sus successores levassen un papallón feito a sennal del rey de Aragón 34.42; Et en continent el dito Carlos se firo nombrar rey de Aragón et mescló su sennyal con el del rey de Aragón 36.465; en la quoal fincaron Fortún de Viel, fillo de don Castán de Viel, buen cavallero, el que primero fizo de seynal de tornellas e fue clamado principe de Huesca 18.106; e mudó las armas e seynnales de Aragón e prendió bastones. 33.32. Del lat. SIGNALIS. Frec.: sennal 1: 0,00227; sennyal 2: 0,00455; seynal 1: 0,00227; seynnales 1: 0,00227.

sennyalado adj. 'señalado, destacado', 'distinguido': et aquestos fueron muit sennalados en la batalla 18.31; qui tan sennyalado miraglo le avia feito 38.540; por el seynnalado servicio que el dito Beltran d'Albaus le avía feyto en el tiempo pasado 33.54. Deriv. de sennyal. Frec.: sennyalado 2: 0,00455; sennalados 1: 0,00227; seynnalado 1: 0,00227 .

sennyalero s. m. 'porta estandarte', 'alférez, abanderado', 'portador de la bandera': et fue ordenado por el Padre Santo et por todos cardenales que dito rey fues brasgo et deffendedor de la dita Eglesia de Roma et sennyalero et almirant de la armada de aquélla et que fues contra Secilia 38.177-179. Deriv. de sennyal. Comp. cat. senyaler 'portador de la senyera o bandera' (DCVB, t. 9, p. 842). Frec.: 1: 0,00227 .

sennyera s. f. 'estandarte, bandera': et la otra sennyera fue possada en el canpanal de la eglesia mayor 38.574. del lat. SIGNARIA, deriv. de SIGNUM 'marca, signo, señal'. Frec.: 1: 0,00227.

sennyor (var.: sennor, senyor, seynnor) s. m. 'señor': él murió en el anno de Nuestro Sennor MCXI 31.42; et aqui prisso muller Hatlesen de Moncada, el día de Nadal en el anno de Nuestro Sennyor MCCCXXII. 38.482; passando el rio del Royne, por gran desaventura cayó en el agua et murió en el anno de Nuestro Senyor mil XX 28.5; et dixole assi: «Seynnor, la tierra que me dieste rendi a la reyna...»19.85; et aquesti fue sennyor de toda Spanya 3.65. Del lat. SENIOR, -ORIS. Frec.: sennyor 121: 0,27503; Sennor 28: 0,06364; Senyor 9: 0,02046; seynnor 2: 0,00455.

sennyora (var.: seynnora, seynora) s. f. 'señora': et la ora el sol sufrió deffallimiento del día [en el día $\mathrm{N}$ ] de la Purificación de Nuestra Sennyora Santa María, en el anno de Nuestro Sennyor MCCCIX 38.404; matoronlo cerca de la villa de Senyora Sancta María del Puch 22.18; et los castellanos, vidiendo que assi avían dexado lur seynnora, fueron muy despagados e movidos 19.74; "la tierra que me dieste rendí a la reyna natural mi seynora» 19.86 . Femenino creado a partir de sennyor. Frec.: sennyora 4: 0,00909; seynnora 1: 0,00227; seynora 2: 0,00455; Senyora 1: 0,00227. 
sennyoria s. f. 'señoría, dominio': el dito rey a bornor de Dios et de la santa eglesia de Roma dio el ius patronado que havia en todas las iglesias de toda su sennoria [su tierra $\mathrm{N}$ ], 34.37; Et fue feyto [puesto N] que a doze dias de julio... la sennyoria [seynnera $\mathrm{N}]$ del dito don Alfonso, noblement acompannyada de honrada cavallería, entró en el dito castiello et fue possada [en la torre añade N] sobre la peire del Orifany 38.571; et retenía pora si la senyoria de todas las eglesias del su regno 20.288. Deriv. de sennyor. Frec.: sennyoria 7: 0,01591; sennoria 6: 0,01364; senyoria 2: 0,00455.

sentencia s. f. 'sentencia': Por aquesto el Padre Santo, santo papa Martín, natural de Francia, en pleno consistorio, non clamado el dito rey don Pedro, dio sentencia contra éll, privando aquél de los regnos et honores suyas 36.457. Cultismo tomado del lat. sententia. Frec.: 2: 0,00455.

sentir] v. tr. 'oír, presentir, advertir': et avría todos los otros cavalleros assí mesmo descabeçados sinon por qual manera que fue que lo sintieron [los que añade N] que yeran de fuera et fuyeron 20.136-138. / / 'sentir, experimentar dolor': la Virgen gloriossa Madre de Dios li apareció con grant goyo et díxole que se levantas del leyto sin todo mal que non sintió ren [e no sintió N] 35.221. Del lat. SENTIRE, que ya en lat. podía emplearse con varias acepciones, entre otras: 'percibir con los sentidos, darse cuenta', 'percibir los efectos de algo, sufrir' (SEGURA, 2001: 701-702). Frec.: sintieron 2: 0,00455; sintió 2: 0,00455.

separar]: v. tr. 'separar': et porque aquesti matrimonio fue trobado consumado fuert en acostamiento de grant parentesco et sin peccado non se podia sostener, Johan vispe de Savina, cardenal de Roma, separó et departió aquéll 35.54-57. Tomado del lat. separare 'íd.' La 1. ${ }^{a}$ documentación en cast. es de 1515 (BDELC, s. v.); en arag. se adelanta casi siglo y medio, de acuerdo con esta cita de la Crón. SJP. Frec.: separó 1: 0,00227 .

Septentrio s. m. 'septentrión, Norte': los quales vinieron de una isla que es clamada Estancia, la qual es enta las partes de Septentrio [Septentenio N] enta la mar quel mundo environa 2.15. Es forma latina. Frec.: 1: 0,00227.

sepultura s. f. 'sepultura'; 'exequias, funeral', 'entierro': El qual, feyta la sepultura de su padre, aplegó grandes cortes a Caragoca 39.6; Feita la honor de la sepultura, las gentes levantoron rey don Pedro 18.1. Frec.: 4: 0,00909.

servar v. tr. 'respetar, conservar, guardar, mantener': et fizo fer [fazer a N] los ditos barones et universidades jurar de servar feldat al dito infant 35.31-32. / / 'observar, cumplir': que si non servava los privilegios que feito avía a la dita unión et las ordinaciones que avían feitas ellos, que pudiessen esleyr otro rey et a ell gitar el regno 37.30. Etim.: del lat. SERVARE (DCECH, II, p. 178, s. v. conservar). El DRAE (2001, s. v.) recoge como ant. servar 'observar', 'guardar'. Cfr. servar 'guardar, conservar' en arag. del s. XV (VILA, 1990: 139). Frec.: servar 2: 0,00455; servava 1: 0,00227.

servicio s. m. 'servicio': que aquell mismo linage fincavan en el su regno et en su servicio 38.281-282. Cultismo tomado del lat. servitium. Frec.: 10: 0,02273. 
servidor s. m. 'servidor': «et placia a ti Sennyor que yo sia th servidor [servient $\mathrm{N}$ ]) 35.245-246. Deriv. de servir. Frec.: 1: 0,00227.

servient s. m. 'sirviente, servidor': placia a ti Sennyor que yo sia th servidor [servient $\mathrm{N}]$ 35.245-246. alguna conpannya de almogávares o servientes por ayudar et deffender 36.225. Etim.: del lat. SERVIENS, -ENTIS (de SERVIRE 'ser esclavo' > servir) (DCECH, V, p. 244, s. v. siervo). Frec.: servient [N] 1: 0,00227; servientes 1: 0,00227

servir v. tr. 'servir': et por esto dizen: «qui a ninnyo sierve, pierde su tiempo». 35.52; et aqui sactament et con firma fe catholica sirviendo a Dios estuvieron luengo tiempo 5.9; fue en grant amizrtat con aquesti rey don Pedro et lo sirvió en todas sus necessidades. 36.425. Del lat. SERVIRE 'ser esclavo, servir'. Frec.: servir 9: 0,02046; servirlo 1: 0,00227 ; servido 1: 0,00227 ; sierve 1: 0,00227 ; sirviendo 2: 0,00455 ; sirvió 1: 0,00227 .

servitud s. f. 'trabajo propio de un siervo', 'servidumbre', 'servilismo', 'obediencia': et tantost mandó a los mesageros que sen tornassen et ninguna servitud non fiziessen al dito Carlos 36.206-207. Del lat. SERVITUS, -UTIS. Frec.: 2: 0,00455.

setiembre (var.: septiembre) s. m. 'septiembre': a XIX kalendas septiembre firo bataIla en Moriella 17.84; día lunes a XII días de setiembre en el anno de Nuestro Sennyor M CСC LVIII 38.418. Frec.: setiembre 4: 0,00909; septiembre 1: 0,00227.

seycientos adj. num. 'seiscientos': Et esti emperador vençió la grant batalla de Cuntada, en la quoal fue el compte Opiqueus bueno, que era all' con seycientos de cavallo 19.54. Frec.: 1: 0,00227.

seynna s. f. 'enseña; estandarte': e hordenaron sus az̧es, la primera dieron al compte don Pedro de Lara con la seyna del regno 19.116; e muy vigorosament et espierto veno a la ciudat de Tolosa, seynna tendida, talando, destruyendo villas 33.64-65. Del lat. SIGNA, pl. de signum 'señal, marca', 'insignia, bandera'. Comp. sennyal, sennyera. Frec.: 3: 0,00682.

sí adv. de afirmación 'sî': Et dixo el rey: «jurarás aquesto seer assì», et respuso: «sí, fazet de mi lo que vos plazee» 36.379-380. Etim.: lat. SIC 'así'. Frec.: 1: 0,00227. // partícula expletiva-continuativa, que en algunos casos puede valer por adv. de modo 'así': Et entre las otras honores que le fizieron sí le fizieron una 36.218; viendo como el rey de todas partidas estava en grant priessa, si [asi $\mathrm{B}]$ dixo al rey: «Sennyor, datme letras de creyença pora el rey de Granada si [así B] podré fazer algún tracto con éli 36.385-388; el dito rey Remiro, queriendo proveyr que enpués dias suyos dissensión alguna non avies en la successión del regno de Aragón, si fue tratado matrimonio con don Ramón Berenguer comte de Barchinona 20.253. Con este uso se registra a menudo en otros textos en arag. med. como el $L M M$ (LiRIA, $L M M$, p. 194). Véase un ejemplo de este texto: «si ende ouiemos grant repression a los coraçones» (LMM, B.138, p. 61). También es frecuente en el Libro de Marco Polo: «Et como el rey vido las huestes de los tartres, si huvo muy grant miedo, car no era husado de fecho 
de armas» (NiTTI, 1980: 36; en la ed. de SANGORRín, 2016: 102: «s’j uvo muy gran miedo»). Etim.: del lat. sic 'así'. Frec.: 5: 0,01136. // pron. pers. refl. de $3^{a}$. pers. tras prep.: et aduxo con si la dita reyna 36.112; se fizo adozir delant si la santa verdadera Cruz 35.274; fasta que por si mismo pudies regir su tierra 38.606. Del lat. SIBI, dativo del pron. refl. de $3^{a}$ persona. Frec.: 14: 0,03182.

si conj. cond. 'si': «Sennor, si la reyna yes acusada a tuerto queredes la delivrar» 14.72; «si fuera esto esdevenido a cavaleros del rey de Aragón, certas non» 38.330; por desuayr et desbaratar aquéll si pudies [podiessen N], 38.361. Etim.: del lat. sI 'si, a condición de que, siempre que'. Frec.: 32: 0,07274. // aglutinación de se + y: que depués non si acostoron con buen corazón 36.561. ['no se acercaron allí]. Frec.: 1: 0,00227.

si quiere conj. distr. 'ya... ya', 'bien... bien': Es verdat enpero que la unión que en tiempo de los predecessores de aquesti rey era movida et succedida, ya más en tiempo de aquesti rey nos movió ni se suscitó, si quiere se fues por la grant savieça de su padre el rey don Jayme qui con buenas et bellas maneras la apagó, si quiere por la grant benignidat de aquesti rey don Alfonso qui res de lures privilegios nin libertades non les crebantó 39.25-29. El $D R A E$ (1970) indica s. v. siquier o siquiera: "Úsase como conjunción distributiva, equivaliendo a o, ya u otra semejante". El DLE (2014) da siquier, con marca de desusado, como sinónimo de siquiera, conjunción distributiva que vale por ya. Comp. adiesso. Frec.: 1: 0,00227.

siello] s. m. 'sello': et aqui en ciertos capitoles amigablement se convinieron de la dita paz; los quales capitoles, cerrados et sellados con los siellos de cada un rey... 38.74. Del lat. SIGILLUM 'señal impresa', 'sello'. Frec.: siellos 1: 0,00227.

siempre adv. 'siempre': como en continent quél favlava sanosament con alguno nin dalguna cosa fues yrado siempre movía el pie en semblança de cabreta qui quier cavar 25.25. Del lat. š̌MPER. Comp. todos tiempos, toda vegada. Frec.: 2: 0,00455.

siensa s. f. 'pensamiento, intención': et queriendo demostrar todo su corazón et su siensa [piensa $\mathrm{N}]$ que avia de subiugar la nasción morisma 35.119-120. [e volent mostrar tot son cor e sa pensa que havia de subjugar la nació morisca VC, p. 120]. [Et volens pandere intentionem quam habebat ad pessundandum sarracenicam nationem VL, p. 148]. Seguramemente se trata de un error por piensa (y así lo interpreta el ms. N). Etim.: si la forma correcta es siensa, provendría del lat. SENSA 'pensamientos', 'sentimientos, juicios', del participio pl. de SENTIRE 'percibir por los sentidos', 'darse cuenta', 'pensar, opinar' (BLÁnquez, s. v.; DCECH, V, pp. 208-209). Cfr. piensa. Frec.: 1: 0,00227.

sierra s. f. 'sierra, accidente montañoso': et a la raiz de una sierra et montanna fincaron sus tiendas 19.198. Del lat. SĔRRA 'sierra de aserrar' (DCECH, V, p. 242). Frec.: 1: 0,00227.

siet adj. num. 'siete': él enpero que tenies en poder suyo por rabenes dos fillos suyos, es assaber, Rubert et Loys et siet barones de los más nobles que fuesen en Prohença et en 
Nápoles 37.72. Del lat. sĚPTEM. Frec.: 1: 0,00227.

signar] v. tr. 'señalar, indicar', 'mostrar con un gesto': et el alcayde entendiólo bien et conosció quel dito rey le signó que non lo rendies 38.303-304. Es cultismo tomado del lat. š́gnare. Comp. el tratamiento fonético popular en el arag. mod. zeñar 'hacer señas' (ANDolz, s. v., que lo localiza en el Somontano de Huesca; EBA, 1999: 1897, que lo documenta en el Somontano de Barbastro, A Buerda, Tardienta, A Fueba, Biello Sobrarbe, Monflorite, Salas Altas; Nagore, 2020, que lo registra en Huesca y alrededores). Frec.: signó 1: 0,00227 .

significar] v. tr. 'expresar, manifestar': empero non sabemos la razón porqué se firo, porque assí como lo trobamos assin en scripto lo significamos 26.9. Cultismo tomado del lat. significare. Frec.: significamos 1: 0,00227.

siguient (var.: siguiente) adj. 'siguiente': et el otro día siguient, el dito rey Remiro fue recebido según la convinença desus dita por don Sancho de la Rosa, vispo de Pamplona 20.173; et prendieron manera los castellanos que se alargasse entro al día siguiente 37.59-60; et apareciose bien entre las otras cosas por las conquistas siguientes.17.67. Del lat. SEQUENS, SEQUENTIS 'que sigue'. Frec.: siguient 5: 0,01136; siguiente 2: 0,00455; siguientes 1:0,00227.

simient s. f. 'simiente': de la qual elección todo el regno fue alegre et pagado mayorment como simient de virtuosso princep avien elegido por sennyor lur. 36.724. Del lat. SEMENTIS 'semilla sembrada', 'siembra, sementera' (SEGURA, 2001: 699). Frec.: 1: 0,00227.

simple adj. 'sencillo, llano, ingenuo': el qual fue homme simple et ningún tiempo non quiso seer enemigo de la casa de Aragón 38.599. Etim.: del lat. SIMPLus; la -e se explicaría por analogía fonética con doble < lat. DuPLEx o, más probablemente, del lat. DupLus $>$ doblo $>$ doble, con disimilación vocálica (DCECH, II, p. 519; V, p. 254). Frec.: 1: 0,002287.

simplement adv. 'de manera sencilla, sin complicaciones': regió el dito condado simplement et bien 24.2. Frec.: 1: 0,00227.

sin (var.: sines, sins) prep. 'sin': respondiole que con él no se podía veer sin batalla 38.562; etpor si havian levantado rey sins voluntat de los aragoneses, 20.148; el dito lur fillo murió sines [sins B] de fillos 35.58. Etim.: del lat. š̃Ne 'íd.'. Según indica Corominas, «el resultado normal sería sen, tal como port. sem, cat. ant. sens (sense modernamente), occ. sens o senes, fr. ant. senz, etc. La forma sen no es rara en la lengua medieval, especialmente en textos leoneses y aragoneses: Alex., Invent. arag. de $1369 . .$. Hay también, con $-s$ adverbial, senes, Alex., Apol., etc. La variante con $i$ y $-s$ adverbial, es más común todavía: Cid, Auto de los R.M., Tres Reys d'Orient, Berceo, Apol., y hasta muy modernamente en Aragón, sobre todo en la combinación sines de: una guitarra sines de tavla Invent. de 1373» (DCECH, V, 254-255). Afirma además Corominas (ibídem) que * SINES con $-s$ adverbial ya debió de pertecener al latín vulgar, pues de otra manera no se explicaría la 
conservación de la segunda $e$ en el oc. ant. y cat. ant. senes, que en cambio es natural si combinaciones como SINES TERRA ya son antiguas. Ahora bien, una prep. se pronuncia rápidamente y así sines pudo contraerse en sens, senz, aun en italiano (luego senza). También se encuentra en arag. med. sien, sienes en FA; en $D J$; etc. En los $D L A A$ encontramos tanto sines (forma mayoritaria) como sienes, sien, siens, senes, sine, sin, etc. (REIDY, 1977: 260). Vid. tb. sines. Frec.: sin 38: 0,08637; sines 7: 0,01591; sins 4: 0,00909.

síndico] s. m. 'síndico', 'persona elegida por una comunidad para cuidar de sus intereses': vino a la ciudat de Girona do fueron ya ajustados [ayuntados N] todos los prelados, richos homes, barones, cavalleros, sindicos, procuradores de cindades et de villas 38.465. Etim.: del lat. sYNDicus 'abogado y representante de una ciudad', to-

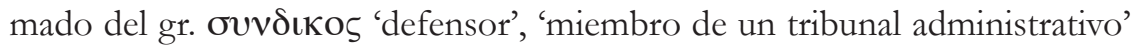
(BDELC, p. 537, donde se documenta por primera vez en cast. en 1607). Igualmente, en DCECH (V, p. 256). Frec.: síndicos 1: 0,00227.

sines (var.: sins) prep. 'sin': muerto el rey don Alfonso, o perdido en la batalla, los regnos de Aragón et de Navarra fincoron sines heredero bien un anno 20.1-3; por si havian levantado rey sins voluntat de los aragoneses 20.148. Vid. sin. Frec.: sines 7: 0,01591; sins 4: 0,00909.

singlar (var.: singular) adj. 'singular', 'preeminente, único, destacado': assí como a quis pertannya por dreyta linea et successión, avies aver refugio et socorro singlar [singular B] 36.198-199; recullieronse en la espellunga assín como a lur refugio singular 9.13. Del lat. SINGULARIS 'único, solo, aislado'. Se documenta también singlar en el Tucidides de Fernández de Heredia: «los quales, si prosperan, lur provecho no sera singlar mas comun a los otros» (López MolinA, p. 90; voc., s. v., p. 221). Vid. también la ed. de Álvarez Rodríguez (2007, p. 58), quien afirma en nota a pie de página que se trata de un catalanismo; si tenemos en cuenta voces del arag. como ungla, zingla, zingliello, no parece que haya de considerarse catalanismo. Frec.: singlar 1: 0,00227; singular 1: 0,00227.

singularmente adv. 'específicamente, expresamente': et en los condados ya desuso singularmente nombrados 34.2. Frec.: 1: 0,00227.

sino conj. 'nada más que'; 'sino': no vieron de los moros sino los feridos et los muertos 18.53-54; murieron la ora de los enemigos mas de CCC hommes solament de cavallo, ultra aquellos que y murieron de pie. Et de la part del dito don Alfonso no y murieron sino dos homes de cavallo 38.552 // sino tan solament 'excepto': De las quales naciones nos callaremos sino tan solament de los godos porque aquestos fueron los que tollieron Espannya a los romanos 3.3. Etim.: de la conj. $s i+\mathrm{el} \mathrm{adv.} \mathrm{no(n)}(D C E C H, \mathrm{~V}, \mathrm{p}$. 237). Frec.: 12: 0,02728.

sinon contr. de si (conj. cond.) + non (adv. de neg.), conj. 'si no, de no ser porque, salvo que, excepto que': et avría todos los otros cavalleros assí mesmo descabeçados 
sinon por qual manera que fue que lo sintieron que yeran de fuera et fuyeron 20.137 // sino que loc. conj. 'si no es porque, de no ser porque': et aquellas assí mismo fueron [fueran B] presas sino quel vencedor rey mandó que sende fues 38.273. Vid. sino. Frec.: 7: 0,01591.

sins prep. 'sin'. Forma que aparece en el ms. B. Comp. sines, sin. Frec.: 4: 0,00909 .

sitiado adj. 'situado, enclavado, ubicado': es verdad que dentro el condado [en el regnado $\mathrm{N}]$ de Castiella era sitiado un condado, clamado Porcel [Portell $\mathrm{N}]$ 14.8; qui fue de la villa d'Arria, sitiada en la tierra de Conflent 22.4. En otras ocasiones tiene el significado de 'sitiado', p. p. del v. sitiar 'sitiar, cercar, hacer cerco militar a una ciudad o fortaleza'. Comp. occ. ant. asetïar 'asseoir, placer, établir' (p. p. asetiat 'situé') y sitar 'placer' (LeVY, s. v.). CoROMINAS alega las formas del occ. assetiar y sitiar, de las que dice que no se pueden separar del cultismo situs y de su derivado situare, frecuente en bajo latín: «es natural que el cultismo situare, pronunciado sitïar en lengua de Oc, se convirtiera en sitiar, setiar, y que éste a su vez influyera en el lat. situs, convirtiéndolo en seti [en occ. y cat.], con el influjo auxiliar de assetar < AD-SEDITARE. Que el vocablo pudo comunicarse desde tierras de Oc, pasando por Cataluña, hasta Castilla y Portugal, no ofrece dificultad alguna, y de hecho esto es lo que indican las fechas de las primeras documentaciones respectivas. Realmente lo que primero encontramos en Castilla es el latinismo puro sito, y sólo más tarde, y primeramente sólo en Aragón, aparece la variante sitio con la $i$ postónica como en Cataluña y Occitania» (DCECH, V, p, 267). En resumen: sitiado es p. p. del v. sitiar, «que se explica como adaptación occitana del bajo latín SITUARE» (DCECH, V, 265). En arag. med. también se documenta setiado 'situado': «vnas casas \& vna vjna quenos \& nuestro monesterio emos \& auer devemos en la cipdat de Vesca, las quales casas son setiadas en la pelicaria» (DLAA, núm. 115, de Botaya, 1351; p. 169, lín. 12); «la qual thorre de Buesa, con la thorre del Puyal \& con sus terminos \& pertinencias son setiadas et setiados en Sobrarbe, cerqua de la dita villya de Ajnsa» (DLAA, núm. 123, de Aínsa, 1362; p. 180, lín. 14-15). Frec.: sitiado 3: 0,00682; sitiada 3: 0,00682.

sitiar v. tr. 'sitiar, asediar, poner cerco a una ciudad o fortaleza': et luego fue a sitiar a Huesca 17.114; Tornose a sitiar la dita ciudad 18.73; el dito rey don Pedro sitió el dito castiello de Albarrazin , 36.323; Et fue assí enpresso entre entramos los ditos reyes, que el uno, es assaber el rey de Aragón, sitias la ciudat de Almaría et el otro, es assaber el rey de Castiella, sitiada [sitias N] Aliazira de Alfrada 38.347-348; vino a sitiar castell de Callar et mientre que lo tenía fuerment et districta [en estrecha $\mathrm{N}$ ] sitiado... 38.542; el dito don Alfonso sitió villa de Yglesias, la qual con grandes traballos et enoyo prisso 38.528. Etim.: del bajo lat. SITUARE, a través de una adaptación occitana, sitüar > sitiar (DCECH, V, pp. 265-268). Se documenta sitiar, 
tanto en el sentido de 'situar' como de 'asediar' en Fernández de Heredia, y también assitiar y asitiar con ambos sentidos (GILKISON, s. v.). Comp. asitiar. Frec.: sitiar 9: 0,02046; sitias 1: 0,00227; sitió 14: 0,03182.

sitio s. m. 'asedio, cerco que se pone a una ciudad': firió tan fuertment en el sitio de los moros que todos los desbarató 12.57; et las sus gentes levantaronse del sitio et levaron el cuerpo de lur sennyor a soterrar 16.58; Mas fincó un fillo dél, qui fue Narmengou de Barbastro et por tal fue assí clamado como [porque N] fue en el sitio de Barbastro do fizo muy bien sus afferes 29.26; menacando quel dito rey de Castiella se levantara [se levantas $\mathrm{N}]$ del dito sitio et sen tornas a su tierra 38.379; el dito rey don Pedro sitió el dito castiello de Albarrazín. Et mientre el dito sitio se tenía et los reyes de Francia et de Castiella le envioron menazas con palauras cubiertas quel dito sitio se levantas...non se quiso levantar del dito sitio entro que lo huvo presso 36.323-327. Etim.: de origen incierto; parece que se trata de una alteración semiculta del lat. siTus, -Us, 'íd.'; la terminación -io podría ser debida al influjo de asedio (lat. OBSIDIO) o a la del verbo sitiar, que se explica como adaptación occitana del bajo lat. SITUARE. En castellano sitio 'asedio' no se encuentra hasta Nebrija, 1495. En occ. ya se encuentra seti con este sentido desde la Cansó de la Crozada, comienzo del s. XIII (DCECH, V, pp. 265-268). Vid. prov. ant. seti 'siège, place; situation; siège d'une ville; armée assiégeante’ (LEVY, s. v.). Frec.: 20: 0,04546.

soberbia s. f. 'soberbia': et por la soberbia et menosprecio que don Per Atares, non seyendo encara rey, fazía a los del regno... 20.15. Del lat. sŭperBiA 'íd.' Frec.: 2: 0,00455.

sobra sust. 'exceso, sobra, demasía': Et qui siempre fue vencedor fue vencido por su grant atrevimiento de sobra loçania de corazón et menosprecio de los enemigos 19.222. Aquí parece funcionar como adj. 'excesiva, demasiada'. Comp. sobras 'demasía' en el Índice de BlanCAs. La forma sobra será postverbal del v. sobrar. Frec.: 1: 0,00227.

sobrar v. tr. 'superar', 'sobrepujar, vencer': por la qual cosa buvo en el regno grant guerra entre el rey et los de la unión en toda su vida que nunca la pudo sobrar nin desfer 37.22. Etim.: del lat. < SUPERARE 'ser superior, abundar', 'sobrepujar, vencer' (BDELC, p. 539). Superare con el valor de 'ser sobrante' (hoy el más común en cast.), ya se encuentra alguna vez en el latín tardío; pero el empleo transitivo con el valor de 'sobrepujar, vencer', muy clásico en latín, también subsistió en cast., sobre todo en la Edad Media y algo en el Siglo de Oro, aunque J. de Valdés dice que ya sólo se tolera en poesía. (DCECH, V, p. 277 , s. v. sobre). Frec.: 1: 0,00227.

sobre prep. 'sobre, encima de, por encima de': Et el rey enpennyó muytas villas et prisso las diezmas de su terra et algunos trasoros de las yglesias por do avía la yra de dios sobr'él 34.156; la sennyoria del dito don Alfonso, noblement acompannyada de honrada cavallería, entró en el dito castiello et fue possada [en la torre añade N] sobre la peire del Orifany 38.573. Del lat. SŬPER. Frec.: sobre 38: 0,08637; sobr' 1: 0,00227. 
sobredito adj. 'sobredicho, dicho arriba o antes': por tal que la tierra sobredita de nuevo adquirida por don Alfonso rey de Aragón non se perdies 20.246; et fue y ordenado a dar las indulgencias sobreditas et perdones un cardenal legado del Padre Santo clamado Cardet 36.467; fue nombrado el Benigno, porque fue el mas cortés de palabra et el mas familiar et el mas avinent a los sus sozmesos que otro rey que al mundo fues, que assi les fue como a conpanyero, fillo suyo sobredito. 39.5. Es formación deriv. de dito, p. p. de dežir, con la prep. sobre; si bien puede pensarse en una continuidad del lat. sUPRADICTUS 'arriba dicho, susodicho', con influencia de la prep. sobre. Este adjetivo es frecuentísimo en escritos en arag. med. y puede decirse que tiene un carácter cuasideterminativo. Véase, por ejemplo: «que el dito senyor abbat e monges den e dan luego de present con los capitoles e con las condiciones sobreditas e infrascriptas sobreditos e infrascriptos e no en otra manera, a los sobreditos pobladores del dito lugar de Piniello e a sus succesores...» (doc. de Veruela de 1451; CPR A, p. 326). Comp. dessuso dito, dessus dito (vid. dessuso). Frec.: sobredito 4: 0,00909; sobredita 1: 0,00227; sobreditos 1: 0,00227; sobreditas 4: 0,00909.

sobrenombre s. m. 'sobrenombre': fue posado sobrenombre al dito Olivano, Cabreta, como en continent quél favlava sanosament con alguno nin dalguna cosa fues yrado siempre movía el pie en semblança de cabreta qui quier cavar, et por exo la gent lo nombrava Olivano Cabreta. 25.23. Deriv. de nombre. Frec.: 2: 0,00455.

sobrepuyar] v. tr. 'sobrepujar, aventajar, superar, sobrepasar': el qual de bondad, veldat et de otras virtudes cavallinas todos otros cavallos sobrepuyna 14.38 (error por sobrepuyava). Deriv. de puyar. Comp. sobrepuyar 'aventajar, superar, exceder' en Fernández de Heredia (GILKISON, s. v.); vid. también sobrepuyar 'sobrepujar, vencer, superar' en Tucídides (LÓPEZ MOLINA, p. 221); sobrepuyar 'superar, sobrepasar' en el LT (RoDÉs, 2016: 770). Frec.: sobrepuyua (sobrepuyava) 1: 0,00227.

sobrero] adj. 'excesivo, abundante, superior', 'soberbio': huvo grant et sobrera batalla con los enemigos 38.531. Deriv. de sobrar, o bien del lat. SUPERARIUs 'de encima' (DCVB, t. 9, p. 956). Se documenta sobrero en el cancionero de Pedro de Santafé (poeta de la Corte de Alfonso v el Magnánimo, siglo xv): «a tan sobrero adversario», poema XIII, verso 19; «m'es familiar et sobrero», poema X, verso 12. (Vid. M. De Andrés Gutiérrez, «Edición crítica del Cancionero de Pedro de Santafé», AFA, XX-XXI (1977), pp. 79-139 [pág. 111]). Comp. sobrancero 'excesivo' (Alex.), sobranzano 'grande, excesivo' (Berceo), port. sobranceiro 'soberbio, que abusa con violencia', 'que sobrepuja a otro' (cfr. DCECH, V, p. 278, s. v. sobre; DME, p. 1585). En arag. med.: sobrero 'superior' en Fernández de Heredia (GILKIson, s. v.); cat. ant. sobrer 'superior en fuerza, que supera o domina' (DCVB, t.9, p. 956). Frec.: sobrera 1: 0,00227.

sobrevivir] v. intr. 'sobrevivir, vivir uno después de la muerte de otro': et regnoron entrambos ensemble. Mas Acenarricus sobrevivió et regnó todo solo. 3.19. Del lat. SUPERVIVERE. Frec.: sobrevivió 1: 0,00227. Frec.: sobrevivió 1: 0,00227. 
sobrino s. m. 'nieto': et aquesti infant García yera sobrino del Cit Rui Diaz 20.63. Del lat. SOBRINUs 'primo hermano' y luego 'primo segundo'. En arag. ant. se registra sobrino 'nieto' en FA (Tilander, FA, p. 574), en VM ('Tilander, VM, III, p. 294), etc. Con el mismo significado se registra en las obras de Fernández de Heredia (GILKISON, 1984, p. 126, s. v.). Comp. aguelo, cormano, cosino, fillo, tio. Frec.: 1: 0,00227.

socorro s. m. 'socorro, auxilio': pensando encara que ningún socorro ni ayuda non avría del rey 38.383. Deriv. posverbal de socorrer, del lat. SUCCURRERE 'correr hacia, ir en auxilio'. Frec. 5: 0,01136.

sofrir (var.: sufrir) v. tr. 'sufrir, padecer, soportar': que grant enoyo et traballo soffrian por los montes qui por él et del comte d'Aragón les eran estados dados 11.56; los ploros et lagrimas et dolores que los ditos secilianos gitavan agrament et sofrían 36.206; sinon que eran todos cansados del treballo que avian sofrido en aquel día 36.661; por las quales et por el deseredameinto que demandavan injustament sufrian grant passión, pena et tribulación 36.495. Del lat. SUFFERRE 'soportar', lat. vg. *'sufFERIRE (DCECH, V, p. 333). Frec.: sofrir 3: 0,00682; soffrían 1: 0,00227; sofrían 2: 0,00455; sofrido 1: 0,00227 ; sufrir 1: 0,00227 ; sufrían 2: 0,00455 ; sufrieron 1: 0,00227 ; sufriessen 1: 0,00227; sufrió 1: 0,00227.

soga s. f. 'soga, cuerda': e pareçiole ant'él vestido d'escarlata en un cavallo blanco e una soga en la mano 19.85. Etim.: del lat. tardío soca 'íd.', quizá de origen céltico (DCECH, V, p. 291). Frec.: 1: 0,00227.

sol s. m. 'sol': por una estrela que ha nombre Esperus, ques pone cerca el sol et la ora es tarde 1.6; et la ora el sol sufrió deffallimiento del día [en el día N] de la Purificación de Nuestra Sennyora Santa María, en el anno de Nuestro Sennyor M CCC IX. 38.403. Del lat. sol, SOLIS, acus. SOLE(M) 'íd.'. Frec.: 2: 0,00455.

sol adv. 'sólo, solamente': et mientre duró la batalla sol nos [no se N] mudó el pie ni fizo asemblant [fue semblant $\mathrm{N}$ ] que fues ferido 38.276-277. Parece que hay que entender aquí: 'no sólo no se movió el pie...'. Frec.: 1: 0,00227.

solament adv. 'sólo, solamente': et a XIIII días del mes dessuso dito tan solament con las galeras fue a Cap de Sant Marcho, cerca Oristan, en la isla de Cerdennya 38.518. / / sino tan solament loc. prep. 'excepto': De las quales naciones nos callaremos, sino tan solament de los godos porque aquestos fueron los que tollieron Espanya a los romanos 3.3. Frc.: 11: 02500.

solempne adj. 'solemne': cort general et solempne tenia [tenida $\mathrm{N}]$ en la ciudat de Palermo 36.721; envió sus mesageros solempnes en Francia 23.46. Etim.: Tomado del lat. sollemnis 'consagrado, que se celebra en fechas fijas', aplicado a las fiestas y demás costumbres. Se documenta por 1. ${ }^{a}$ vez en cast. (en la forma solepme) en 1399 (BDELC y DCECH, s. v. solemne). Por lo tanto, la Crón. SJP. adelanta la 1. ' documentación en casi 30 años. Solepme resultó de un compromiso entre 
solepne (reducción de solempne) y soleme. La más usual antiguamente es la grafía solene. Pero Covarrubias ya latiniza solemne, lo mismo que el Dic. Aut. (cfr. DCECH, s. v. solemne). Frec.: solempne 1: 0,00227; solempnes 4: 0,00909.

solepnidat (var.: solepnidad, solempnidad) s. f. 'solemnidad': soterraronlo en el dito monasterio con grant honor et solempnidad 13.17; el rey murió a grant solepnidad et honor 11.66; feyta solepnidat fiesta et honor por la su nobleza 35.43. Tomado del lat. SOLLEMNITAS, -ATIS. Frec.: solempnidad 1: 0,00227; solepnidad 1: 0,00227; solepnidat 2: 0,00455 .

soler] v. tr. 'soler, acostumbrar': et todas las comarcas cerca aquellas que solían ser infieles moros 20.213. Del lat. SOLERE 'tener costumbre’. Frec.: solían 1: 0,00227.

solo adj. 'solo': talló todas las colles mayores que yeran en el buerto et fincoron las solas chicas ['solamente las pequeñas'] 20.115 // todo solo loc. adj. 'totalmente solo, completamente solo': Mas Acenarricus sobrevivió et regnó todo solo ['totalmente solo'] 3.20; et el dito rey todo solo con los moros estuvo et fabló una gran pieça ['completamente solo'] 38.390. Del lat. solus, -A, -UM. Frec.: solo 5: 0,01136; solas 1: 0,00227.

soltar v. tr. 'absolver', 'anular, quitar', 'liberar', 'relevar de un cumplimiento': le demandás al rey de Aragón que le soltás el homenage que feito le havía por aquellos lugares 20.186; et quando le havies aquello suelto que le alças, et si no lel queries soltar, pues en su poder yera, que retenies al rey de Aragón por preso 20.187. Etim.: deriv. de suelto, procedente del p. p. de solvere 'desatar, soltar'. Frec.: soltar 1: 0,00227; soltas 2: 0,00455; soltó 2: 0,00455 ; soltóle 1: 0,00227 .

songlot] s. m. 'sollozo'. Vid. senglor.

sosegar] v. tr. 'sosegar, apaciguar, calmar': Et aquellos muertos, no podieron los otros haver que yeran foydos, sosegó su regno en paz. 20.144. Etim.: del lat. vg. *sessicare 'hacer reposar' (DCECH, V, p. 316). Frec.: sosegó 1: 0,00227.

sosmetido] adj. 'sometido'. Et queriendo esquivar que a hombre de tan gran desonor et de tan grant infamia non fuesen sosmetidos vasallos, deposaron el dito Remon de la honor real de la qual injustament usava 17.17. Del p. p. del v. sosmeter, variante fonética de sozmeter < lat. SUBMITTERE 'colocar debajo', con remplazmiento del prefijo sub- por el prefijo soz- < suBTus 'debajo, por debajo de’ (DECL/C, V, p. 652). Vid. sozmeter. Frec.: sosmetidos 1: 0,00227.

sospeyta s. f. 'sospecha': et empués, este ovo mala sospeyta de su muller dona Urraca e no quería albergar con ella 19.61. Es postverbal de sospeytar, del lat. susPECTARE (y antes suspicARI, SUSPICERE) (DCECH, II, s. v. espectáculo). Es habitual en arag. medieval. Cfr. sospeita, suspeita en $V M$, en $F A$; sospeyta en los DLAA (REIDY Fritz, 1977: 262), en el LT (Rodés, 2016: 771), etc. Frec.: 1: 0,00227. 
sospeytoso adj. 'sospechoso': porque el campo do se devian fazer las ditas batallas era fuert inconvinient et sospeytoso a éll por muytas razones 36.269. Deriv. de sospeyta. Cfr. KuHn, HAD, p. 16. Comp. sospeitoso, suspeitoso en VM, en FA; sospeytosa en los DLAA (REIDy Fritz, 1977: 262); sospeytoso en el LT (RodÉs, 2016: 771), etc. En arag. mod. registra LERA (2004: 195) sospeitar y sospeitoso en arag. del valle de Echo. Frec.: 1: 0,00227.

sospiro] s. m. 'suspiro': porque la tierra se plorava et senglores de grenges sospiros gitavan a Dios et al dito rey 36.195. Es postverbal de sospirar < lat. SUSPIRARE 'respirar hondo' (CDECH, II, p. 748). Se documenta tanto en arag. med. (GILKISON, 1984: 127) como mod. (ANDOLZ, 1992: 401; EBA, 1999: 1706). Frec.: sospiros 2: 0,00455.

sostenedor adj. 'sostenedor, sustentador, que sostiene': et fue padre de fillos huérfanos, guarda et deffendedor de biudas, fartador de pobres, sostenedor de barones deseredados, 35.177. Deriv. de sostener. Frec.: 1: 0,00227.

sostener v. tr. 'mantener': aquesti matrimonio fue trobado consumado fuert en acostamiento de grant parentesco et sin peccado non se podía sostener 35.56. / / v. tr. 'tolerar, aguantar': et non queriendo sofrir ni sostener las desonores que su cormano el rey don Sancho de Castiella fiziera... 17.27; assí como aquel qui non podía sostener ni devía que mal prendiessen sus hermanas 34.139. Del lat. SUSTINERE 'sostener'. Comp. sustener. Frec.: 4: 0,00909.

soterrar v. tr. 'enterrar': la dita reyna finó aqui sus días et devotament et humil rendió la su ánima a Dios; et fue soterrada muyt honrradament en la iglesia de San Pedro, 34.68; et aduzieron el cuerpo del infant don Pedro et soterraronlo en el capitol [monesterio N] de los freyres menores de Caragoca 38.206; et fue adueito el su cuerpo al monesterio de Ripol et aquí se soterró 28.6. Etim. del lat. SUB-TERRA-ARE 'poner algo debajo de tierra', deriv. del lat. TERRA 'tierra' (DCECH, V, p. 489, s. $v$. tierra). Esta es una de las palabras que no coincide con la correspondiente de la VC, donde se prefiere sebellir (cat. mod. sebollir), forma que no se documenta en la VA. Sin embargo, en la VC también se utiliza alguna vez soterrar (cat. mod. soterrar; cfr. FABRA, DGLIC, s. v.; DCVB, s. v.; DLlC del IEC, 2007 , s. v.), coincidiendo con lo habitual en VA. La forma soterrar la recoge el DRAE (1970, s. v.), indicando que proviene del lat. suB 'debajo', y TERRA 'tierra', y con el significado 'enterrar, poner una cosa debajo de tierra'; el DLE (2014; s. v.) consigna la voz con leves modificaciones. Frec.: soterrado 25: 0,05682; soterrada 1: 0,00227; soterrar 4: 0,00909; soterraron 1: 0,00227 ; soterró 1: 0,00227 .

sotil adj. 'sutil, agudo, perspicaz, astuto': et fue naturalment de grant corage et ardido et proz et sotil et muy firme en su entendimiento 32.4. Del lat. SUBTILIS. Frec.: 2: 0,00455 . 
sotilment adv. 'de manera sutil, ingeniosa, perspicaz': la qual cosa el dito rey don Jayme, meanero Nuestro Sennyor Dios, conosció sotilment [el tracto que fecho avía añade N], 38.51. Frec.: 2: 0,00455.

sozmeso] (var.: sosmeso) s. m. 'súbdito': quando lo supo, movido de grant yra, envyó por un duch sosmeso suyo clamado Abdemalit 4.26; et de todos dannyos et dampnages que en qualquiere manera fuessen feitos por el dito rey et sus sozmesos [sezmesos $\mathrm{N}$ ] a la Yglesia o al rey de Francia 38.110. // adj. 'sometido': et recullie bien los fidalgos et las otras gentes sosmessas a él 17.26. Etim.: SUB (o SUBTUS) MISsus, part. del lat. MITTERE 'enviar', 'soltar', 'arrojar, lanzar', empleado en lugar de PONERE ya en el siglo V (literalmente, pues, 'sometido, puesto bajo [el poder]'). Podría proceder también directamente de submissus, p. p. de submitTere 'poner debajo', con cambio de prefijo sub- por soz- < subtus. Cfr. Dauzat-Dubois-Mitterand, s. v. mettre; DCECH, IV, p. 61; DCVB, s. v. sots y sotmès; DECL/C, V, p. 625. Frec.: sozmesos 7: 0,01591; sozmezos 1: 0,00227; sosmeso 2: 0,00455: sosmessas 1: 0,00227.

sozmeter] (var.: sosmeter]) v. tr. 'someter': Et queriendo esquivar que a bombre de tan gran desonor et de tan grant infamia non fuesen sosmetidos vasallos, deposaron el dito Remon de la honor real de la qual injustament usava 17.17; los ditos godos no quisieron esleir rey, antes se sozmetieron a la sennoria del imperio de Roma 3.25; et por la su proheza et virtud que en él era, Gasconna [Gascueyna N] se sozmetió al su principado 14.24. Del lat. submittere 'colocar debajo', con remplazmiento del prefijo suB- por el prefijo soz- < suBTus 'debajo, por debajo de' (DECL/C, V, p. 652). Frec.: sozmetió 1: 0,00227; sozmetieron 1: 0,00227.

spavoramiento s. m. 'espanto; amedrentamiento, acción y efecto de tomar miedo, de espantarse; miedo, pavor': conquirió entro a la ciudad de Tolosa, assí que por la terribilidad et spavoramiento de los moros ninguno hombre no les pudo fer resistencia. 9.9-11. [conqueri entrò en la ciudat de Tolosa aixi que per la terribilitat e espaordiment dels moros null hom no els poc resistència fer. VC, p.37]. Etim.: deriv. pre- y sufijado del lat. PAVOR, -ORIS 'pavor, miedo'. Cfr. cat. espaordiment 'acció d'espaordir o d'espaordir-se; l'efecte' (FABRA, s. v.; DL/C del IEC, 1995, s. v.); espaordir 'despavorir, aterrorizar' < lat. vg. *EX-PAVORitiRe, formado sobre PAVOR, según el DCVB (t. 5, p. 380). Vid. también DECL/C, VI, p. 700, s. v. por. Comp. en Fernández de Heredia espauordimiento, espaordimiento, espanordir, espanorir, espaordir 'espantar, asustar, aterrorizar' (GILKIsON, s. v., p. 60). Frec.: 1: 0,00227 .

special adj. 'especial': el qual fiava muyto de amigos de Navarra, en special de dos que eran grandes hombres 20.218; firiendo lohores a Dios et a la benedita Madre suya qui tan grandes et tan speciales gracias le demostroron visiblement 35.150. Tomado del lat. specialis. Frec.: special 3: 0,00682; speciales 1: 0,00227. 
specialment adv. 'especialmente, particularmente': Et el de Portogal fuesse por a su regno et tanto fizieron specialment [firo semblant $\mathrm{N}$ ] don Exemén de Urrea que por manera de dęir mal, dizen oy en día por Castiella «malas Urreas passen por tu casa» 38.208. Frec.: 6: 0,01364 .

spelunca s. f. 'cueva'. Vid. espelunca. Frec.: 1: 0,00227.

spiar] v. tr. 'espiar': porque de part alguna non les ossava venir vianda alguna por miedo del dito rey de Aragón et de las sus gentes qui diligenment lo spiavan. 36.622. Del gótico *SPAíHÔN 'acechar, atisbar, espiar', según el DCECH (II, p. 742), que proporciona la 1. a documentación para el cast. espiar en 1480 (Alonso de Palencia). En arag. se registra ya en Fernández de Heredia, segunda mitad del s. XIV (vid. espiar, spiar en GILKISON), así como en otros textos en arag. del s. XIV, como el LT (RoDÉs, 2016: 724 y 772), lo que corrobora el empleo de este verbo en la Crón. SJP. Frec.: spiavan 1: 0,00227.

spierto adj. 'experto, experimentado', 'despierto, sagaz, hábil, diligente'. Vid. espierto. Frec.: spierto 1: 0,00227; espierta 1: 0,00227; spiertos 1: 0,00227.

spíritu s. m. 'espíritu': «Gloria sia al Padre et al Fillo et al Sant Spiritu por todos tiempos.» 35.243; Et estando rey en hedat de LV annos devotament et humil, penedido et confessado con grant contricción de sus peccados, al verdadero Dios envió el su spiritu en la villa dessuso dita 36.704. Tomado del lat. spiritus. Frec.: 4: 0,00909.

Spíritus: forma latina que aparece en: «Veni Creator Spiritus...» 35.283. (Iniciación de un cántico en latín). Frec.: 1: 0,00227.

spital s. m. 'hospital': su madre dona Sancha avía hedifficado et stablido convento de mulleres de la orden del Spital [ospital N] de Iherusalem. 34.171. Del lat. (CUBICUlum) hospitale 'habitación para huésped'. Es habitual en arag. med.: espital 'albergue, posada' y espitalero 'hospedador, persona que hospeda' en los DLAA (REIDy FrITZ, 1977: 165). Véase algún ejemplo: «elas otras tres tiendas setienen todas tres ensenble, $\&$ afrontan en casas del espital de la sanoga mayor, \& en via publiga \& en tienda de don Alaçar Aujnardut" (DLAA, no 48, de Huesca, 1279; p. 72, lín. 9-10); «et de obrar \& fer espital de dos suficientes estajas en el camino del dito puerto» (DLAA, no 114, de Gistaín, 1350; p. 168, lín. 17). Frec.: 1: 0,00227.

stamiento (var.: estamiento) s. m. 'estamento, clase social': como él aviés conbidado muyto honrado barón et muyto honrado prelado et otras gentes de diversos stamientos 37.84-85. // 'estado, situación': la dita paz firmaron et a devido stamiento [estado lo N] aduzieron. 38.81; en las quales letras recontava el estamiento del su regno 20.108; por provedir al buen estamiento del su regno 20.205. Deriv. de estar. El DCECH, II, p. 777 , da la $1 .{ }^{a}$ doc. de estamento en cast. a mediados del siglo XVII, donde advierte que proviene del cat. estament, aunque hay variante antigua estamiento (Cancionero de Baena, princ. s. Xv). Frec.: stamiento 1: 0,00227; stamientos 1: 0,00227; estamiento 3: 0,0682. 
su adj. poses. m. y f. 'su': envió a dezir secretament a su hermano el rey don Frederich de Seçilia que en ninguna manera non les parecies delant, mas que tenies acerca su tierra et bien establida 38.234; Aquesti rey don Remiro, tornado de Pamplona, plegó sus gentes en Huesca non con propósito de fazer guerra a Navarra mas por provedir al buen estamiento del su regno 20.203. Comp. suyo, lur. Frec.: su 505: 1,14783; sus 162: 0,36822 .

subiugación s. f. 'sumisión', 'subyugación', 'dependencia de vasallaje': el dito Remiro buvo el condado de Aragón sueltament et sin ninguna subingación, do fue feito rey 15.6. Tomado del lat. sujugatio, -onis 'acción de subyugar, sumisión'. Frec.: 1: 0,00227 .

subiugar v. tr. 'subyugar, sojuzgar', 'dominar, avasallar': «Sennyor Dios, th es el poder et tu es el regno et tu Sennyor es sobre todos los reyes et todas cosas son subingadas al tu imperio» 35.297; et cómo el rey Carlos avía injustament subingado assí a Secilia qui al dito rey se pertannya por buen dreyto 36.188; pregándolo et requiriéndolo que como él entendies a subingar con la ayuda de Dios Africa... 36.173; Et depués todo el regno con gran enoyo et treballo conquistó et subingó al su imperio 35.147. Tomado del lat. subjugare 'hacer pasar bajo el yugo', 'someter'. Frec.: subiugadas 1: 0,00227; subiugado 1: 0,00227; subiugar 4: 0,00909; subiugó 4: 0,00909.

subsiguiente] adj. 'subsiguiente, subsecuente, que sigue o se encuentra a continuación': et buena manyna [maynnana $\mathrm{N}$ ] a la qual podemos dezir dolorosa et despagada por las cosas subsignientes 37.88. Del lat. SUBSEQUENS, ENTIS. Frec.: subsiguientes 1: $0,00227$.

subsiguientment adv. 'subsiguientemente', 'inmediatamente después': et subsiguientment los ditos christianos, ... hedificaron hi dos altares 9.27-28. Frec.: 1: 0,00227 .

succeder (var.: suçeder) v. intr. 'suceder, venir tras otro a ocupar el mismo cargo que él': que succediessen en aquello los fillos que avría de la dita su filla 20.259; et depués él succedió en aquel condado su fillo clamado en Armengou 31.18; et muerto el dito don Pedro rey sines fillos, suçedió este don Alfonso 19.1; el qual sucidió en el dito condado d'Urgel 32.40. // 'suceder, ocurrir, producirse': es verdat enpero que la unión que en tiempo de los predecessores de aquesti rey era movida et succedida, ya más en tiempo de aquesti rey nos movió ni se suscitó 39.24. Etim.: del lat. SUCCEDERE 'suceder' (DCECH, II, p. 13 s. v. ceder). Se trata muy probablemente de un cultismo. Frec.: succeder 1: 0,00227; succedida 1: 0,00227; succedió 10: 0,02273; succidió 6: 0,01364; suçedió 1: 0,00227 ; sucedió 3: 0,00682; suçidió 1 : 0,00227; sucidió 2: 0,00455; succediessen 1: 0,00227.

succedidor] (var.: succeydor) s. m. 'sucesor': et que semblant pena fues possada a los sus succedidores [suçessores N] 37.33; Aquesti rey don Alfonso lexó heredero et succeydor [sucesor $\mathrm{N}]$ en los regnos de Aragón, de Valencia, de Cerdennya, en el condado de 
Barçalona, Pedro fillo suyo 39.31; et assín como puro homme et vasallo suyo obedeciesse et atorgas él por sennyor et sus succeydores [a los sus creydores $\mathrm{N}]$ dius [diole $\mathrm{N}]$ pena de perder las ditas tierras guanyadas 16.35. Deriv. de succeder, aunque supone como base un infinitivo succeyr o succedir, que no se registra expresamente en la Crón. SJP., si bien es frecuente en otros textos arag. med. Cfr. succedir, succeir, succeyr en Fernández de Heredia (GILkison, s. v.). En cambio, en los DLAA, succesor (REIDY, 1977: 264). Frec.: succedidores 2: 0,00455; succeydor 1: 0,00227; succeydores 1: 0,00227.

successión (var.: sucessión) s. f. 'sucesión': Et la ora era conte de Urgel Guerau de Crabera et pervinole el dito condado por successión del tio suyo Narmengou, qui murió sin fillos 34.107; la devies preservar et delibrar como al dito rey don Pedro, assí como a quis pertannya por dreyta linea et successión 36.198. Cultismo tomado del lat. SUCCESIO, -ONIS. Frec.: successión 4: 0,00909; sucessión 1: 0,00227.

succesivament (var.: successivament) adv. 'sucesivamente, uno tras otro': que succediessen en aquello los fillos que avría de la dita su filla succesivament 20.260; lexemos esta materia et tornemos al dito rey Sancho del qual et de los otros qui successivament regnaron en navarra et en Aragón entendemos a favlar. 14.17. Construido sobre el adj. succesivo < lat. SUCCESIVUS. Frec.: 1: 0,00227.

successor] s. m. 'sucesor': et por aquesta donación el Padre Santo por honor de la casa de Aragón constituyó quély todos sus successores levassen un papallón feito a sennal del rey de Aragón. 34.41. Tomado del lat. suCCESSOR, -ORIs 'íd.'. Vid. succedidor. Frec.: successores 2: 0,00455.

suegro s. m. 'suegro: Porque no hera plazient el dito compt Remón de Tolosa al suegro de Castilla 19.134. Se forma a partir del femenino suegra < lat. vg. sŎCRA (cl. soCERA). (DCECH, V, p. 325). Frec.: 1: 0,00227.

sueldo s. m. 'sueldo, paga, salario': vehet [veyet $\mathrm{N}]$ quel tiempo de la paga del sueldo se acostó, et como el dito letrado no avies complimento de meneda [moneda N]... 38.308. Del lat. tardío sŏLĬDus 'cierta moneda de oro'. Frec.: 7: 0,01591.

sueltament adv. 'libremente, voluntariamente', 'sin ninguna condición': misose éll et la tierra sueltament en poder del dito rey clamando mercé bumilment 36.443. Formado sobre suelto, p. p. de soltar (vid.). Frec.: 6: 0,01364.

suevos adj. y s. gentilicio 'suevos' (pueblo germánico que se estableció en España): nin de los vándalos nin de los alanos, nin de los suevos nin de los ugones et sanicos; las quales naciones los godos echaron de Espannya 2.9. Frec.: 1: 0,00227.

suplicar] (var.: supplicar]) v. tr. 'suplicar': et en continent, el dito compte, inclinado benignament a las ditas pregarias justament suplicadas, dioles e otorgoles un término clamado Espelunca de Gaçellos de cerca d'Olool11.26 [Guallons, circa d'OrolVL]; envió sus mesageros al Padre Santo sobre los desheredamientos de las hermanas, pregando et suplicando quel dito Padre Santo le quisies scrivir al dito Simón 34.136; el dito abat con sus clérigos 
le suplicó que por honor de Dios e de la santidat del dito lugar e por piedat de lurpobreza e por esgoart del su nuevo avenimiento, le pląies enrriqueger el dito monesterio de algunas honores 11.21; recontando loores a Dios et a los ditos sanctos de las victorias que havía obtenido contra los moros et supplicando bumilment por el abbad et clerigos del dito monasterio... 11.54. Cultimo tomado del lat. supplicare 'rogar, suplicar humildemente'. Frec.: suplicadas 1: 0,00227; suplicando 1: 0,00227; suplicó 1: 0,00227; supplicando 1: 0,00227.

suplir v. tr. 'suplir, remediar la carencia o falta de algo; ponerse en lugar de alguien': vino a la ciudat de Barcelona por suplir el defallimiento del rey sobredito entro a que por si mismo pudies regir su tierra saviament e bien. 33.10. Etim.: Cultismo tomado del lat. supplere 'completar, suplementar', deriv. de PLERE 'llenar' (BDELC, p. 548. s. v.). La 1. a documentación que da Corominas es de 1574 (ibídem). Lo mismo en DCECH (II, p. 290, s. v. cumplir). La de la Crón. SJP. la adelanta en dos siglos. Frec.: 1: 0,00227.

suscitar] v. prnl. 'suscitar(se)', 'promover(se)', 'levantar(se)', 'avivar(se)': que la unión que en tiempo de los predecessores de aquesti rey era movida et succedida, ya más en tiempo de aquesti rey nos movió ni se suscitó, si quiere se fues por la grant saviegca de su padre el rey don Jayme qui con buenas et bellas maneras la apagó, si quiere por la gran benignidat de aquesti rey don Alfonso 39.25. Cultismo tomado del lat. suscitare 'levantar, alzar, resucitar, reanimar, avivar'. El DCECH (II, p. 92) da la 1. documentación de suscitar en cast. en 1612. La de la Crón. SJP. La adelante en más de dos siglos. Frec.: suscitó 1: 0,00227.

suso adv. 'encima, arriba', en la loc. adv. de suso 'arriba, encima': Et ella respondio quel plaría muito, con tal condición que su fillo no regnás en Castiella, qui por succesión, según que de suso yes dito, li era provenido. 14.84. Etim.: del lat. vg. susum, reducción del lat. SURSUM 'hacia arriba'. Palabra usual en cast. en los ss. XIII y XIV (DCECH, V, p. 345, s. v. suso; DME, p. 1587, s. v. suso). Y también en arag. med.: suso 'arriba' en los DLAA (Reidy Fritz, 1977: 265), en los FA (Tilander, FA, 1937: 580), en las obras del taller de Fernández de Heredia (GILKISON, 1984: 130), etc. Vid. dessuso. Frec.: 7: 0,01591.

susodito adj. 'susodicho, antedicho, citado, mencionado': depués de la muert del susodito rey García 14.1. Compuesto de dito y suso 'sobre, encima' < lat. sursum. Frec.: 1: 0,00227 .

sustener v. tr. 'sostener, sustentar, mantener': e conffirmó la donatión que el conte d'A ragón avia feyta et dioles un buscage Averico [Avetito VL] do pudiesen fer paxer lur ganado e millor sustener [sostener $\mathrm{N}$ ] lur vida 11.41. Comp. sostener. Frec.: 1: 0,00227.

suyo adj. y pron. poses. 'suyo' (de un solo poseedor: 'de él, de ella'): en la tierra suya se movió grant discordia 38.611; con XX galeras que eran armadas en las marinas suyas 38.503; comte de Urgel et general procurador suyo 38.476; herederos suyos en los regnos de Aragón, de Valencia, de de Cerdennya et en el condado de Barcbinona 38.634. Del lat. suus. Comp. lur (referido a varios poseedores). Frec.: suyo 49: 0,11137; suya 45: 0,10228; suyos 25: 0,05682; suyas 9: 0,02046. 


\section{$\mathbf{T}$}

tabustol] s. m 'alboroto, griterío, tumulto': he oydas las rumores et tabustoles et federades de las gentes sin nombre que en la villa de Perpinyan se eran venidas... 36.478. Comp. arag. ant. (Fernández de Heredia, siglo XIV): tabustol, tabustoll, tebustoll 'uproar, commotion' ['griterío, albototo, tumulto'; 'conmoción, agitación'] (GILKISON, s. v.). En cat. tabust 'tabustol; terrabastall'; cat. tabustol o tabustoll 'esvalot, soroll de crits' ['griterío, ruido de gritos'] (FABRA, s. v., DL/C del IEC, 2007, s. v.); occ. (prov.) tabust 'trouble' ['turbación, desorden, confusión' pl.: 'turbulencias, disturbios']; tabustar 'frapper; faire du tapage' ['golpear; hacer ruido']; tabustol 'bruit, tapage' ['ruido, alboroto'] (LEvy, s. v.); occ. (lang.) tabust 'tapage, vacarme, querelle' ['ruido, ruido tumultuoso, querella'] (ALIBERT, s. v.). Etim.: para AliberT procede del ant. occ. tabustar. También Corominas opina que tabustol sería derivado del v. tabustar 'producir alboroto, hacer ruido' y añade que éste provendría de un cruce de taburar (verbo que no aparece en el $D C V B$ ) y su sinónimo tustar 'golpear fuertemente' (DECLIC, VIII, pp. 183-186). Da toda la impresión de ser un catalanismo en el arag. medieval. Frec.: tabustoles 1: 0,00227.

tacha s. f. 'falta, defecto': non porque dasse ayuda a ningún infiel o enemigo de la fe christiana, en la qual él muyt fiel sin toda tacha estuvo et perseveró todos tiempos enta Nuestro Sennyor Dios 34.176. Etim.: No está claro si ha de interpretarse como / táka/ o como / tát $\mathrm{a} /$, pues la grafía ch se usa a menudo por / $\mathrm{k} /$ (por ej.: richo, duche, etc.). Por el significado cabrían las dos interpretaciones. En cualquier caso, el origen es común: lat. vg. *TACCA, latinización del germ. TAIKN 'señal' (DCECH, V, p. 371, s. v. tacha; DECLIC, VIII, p. 190, s. v. taca). El arag. taca 'mancha' corresponde a occ. y cat. taca, it. tacca, retorrom. tacca, fr. tache, todas con el sentido de 'mancha' o 'marca, señal'. Cfr. en retorrom. tacca 'tache, marque' y fig. 'tache, défaut' (FURER, 2002: 542). En cat. se ha usado mucho en sentido figurado y moral («immaculada e neta de tota taca de pecat», en B. Metge), que es el que cuadra en la Crón. SJP. El vocablo sólo es ajeno al cast. y al port., que no lo tienen más que como galicismo. Cfr. en port.: «tacha 'mancha, nódoa, mácula', do fr. tache» (CuÑA, 1986: 749). Hoy se admite generalmente que se trata de uno de los préstamos del germánico hechos por el latín vulgar. El cast. tacha se tomó, como término caballeresco, del fr. ant. tache, que además de 'mancha' ha significado 'mancilla, tacha' figuradamente; la - ch- es correspondencia regular en francés de la -c- o - cc- de los demás romances. El sentido es igualmente válido para nuestro texto. Por tanto, si se 
interpreta como / tát $\int_{a} /$ no cabe duda que se trata de un galicismo tomado del cast., pues taca se conserva hoy en arag. con el sentido de 'mancha'. Vid. tacau, tacada 'manchado, -a' en DDPA, s. v.; taca 'mancha', tacada, tacadura, tacata en ANDolz, s. v. Para el arag. ant. cfr.: tacha 'error' (GILkison, s. v.), tacón 'señal' (FA, pp. 583 y 564); tacha 'mancha, señal' ( $L M M$, p. 195), etc. Frec.: 1: 0,00227 .

tal adj. 'tal': et depués, porque de tales donos de gracia tan maravellosament Dios le insignó, quiso continuar su propósito de conquerir et subingar regnos e tierras de moros 35.152; firió tan fuertment en el sitio de los moros que todos los desbarató et los aparelló, tales que no pudo tornar ninguno en lur tierra 12.57-59; con tal condición que su fillo no regnas en Castiella 14.83; et eran de tal natura, figura et color que de la una part eran cárdenas et de la otra verdes et en cada una part vermellura se denotava 36.597 . Se usa a menudo en la loc. conj. por tal como 'a causa de que, puesto que, por la razón de que': et por tal como el rey de Ungría murió luego, la dita Gostança se tornó en Aragón 33.94-95; et aquesta vinción se cuydó esdevenir por tal como la su gent no era bien apparellada 36. 586587; le dexó el dito regno por tal como el dito rey don Jayme con voluntat et conoscencia de dos hombres buenos de Mallorquas... 38.603. Con significado semejante, aparece la loc. conj. por tal que 'debido a que, a causa de que': et por tal que cuando bavía d'entrar en batalla o havía afer cabalgada $[. .$.$] toda vegada tiemblaba, et [por aquesto \mathrm{N}]$ la gent lo clama García tiemblador 13.2-5; Et por tal que ayudar nos pudies el dito rey don Pedro de las fuerças et lugares que riba del mar de Rosas et Barcelona eran, los franceses todos los derrotoron [derrocoron B] 36.533-536. Etim.: del lat. TALIS. Es común a todos los romances. Frec.: tal 70: 0,15911; tales 2; 0,00455. [En sing. casi siempre forma parte de las locuciones conjuntivas por tal que -23 veces- $\mathrm{y}$ por tal como - 32 veces-].

talar] v. tr. 'arrasar, arruinar, asolar, devastar': enpués esto fueron a Granada et, talando et destruyendo, depués cercó Cordova 19.201; et non fue rey en Espanna que tanto ganasse de moros nin corriesse nin talasse nin tanto mal les firies 19.207. Etim.: del bajo lat. TALARE, probablemente recibido del germ. occid. *TALON 'arrebatar, arrancar', 'rapiñar, robar' (DECLIC, VIII, p. 224, s. v. talar). Se documenta talar 'arrasar, destruir' en $V C A$, p. 394. Frec.: talando 2: 0,00455; talasse 1: 0,00227.

talayar] v. tr. 'otear, observar, vigilar' // v. refl. 'percatarse, observar, darse cuenta': se utiliza con régimen pronominal de, talayarse de: mientre que todo homme dormía et non se talayavan de res, todo el poder del dito castiello de Callar vino a ferir en la buest del dito don Alfonso 38.543. Derivado de atalaya, procedente del árabe andalusí attaláyac < ár. cl. talayz 'avanzada [de un ejército]' (CORRIENTE, 2003: 237). El DLE (2014) define atalaya 'torre hecha comúnmente en lugar alto, para registrar desde ella el campo o el mar y dar aviso de lo que se descubre' y atalayar 'registrar el campo o el mar desde una atalaya o altura, para dar aviso de lo que se descubre' y 'observar o espiar las acciones de otros'. El cast. atalayar se 
documenta ya en las Partidas; en cat. talaiar 'guardar (ganado)', talaiar-se 'darse cuenta' (DCECH, I, 388). Se emplea talayar en el Cancionero de Pedro Santafé: «Antes partidos, muy turbados, / fueron asaz mis sentidos, / mas estaban muy movidos / sospechosos talayados» (Cancionero de Pedro de Santafé, poema XxII, verso 30; vid. De ANDRES, 1977: 121). Cfr. talayar (intr.) 'guardarse, protegerse, vigilar', atalayar 'mirar, observar', talaya y atalaya 'torre de vigilancia' en Fernández de Heredia (GIlkison, s. v.). También en arag. moderno: talayar 'divisar, contemplar a lo lejos' (NAGORE, 2020: 613). Frec.: talayavan 1: 0,00227.

tallado] adj. y p. p. del v. tallar, 'cortado': tenía un pendón del compte muerto, en el cavallo, las manos talladas, con los bracos tenía la seynna clamando: «Olea, Olea».19.125. Vid. tallar.

tallar] v. tr. 'cortar'; 'tajar, 'rajar': tenía un pendón del compte muerto, en el cavallo, las manos talladas, con los braços tenía la seynna clamando: «Olea, Olea».19.125; talló todas las colles mayores que yeran en el huerto et fincoron las solas chicas 20.114. // 'azotar, machacar, arrasar': entraron en la tierra de los moros, tallando et destruyendo plegoron a Valencia 19.195; et depués passaron Xucar et talloron Dennya, depués passoron Murcia 19.196. Etim.: del lat. vg. TALEARE 'cortar', 'rajar', deriv. del lat. TALEA 'retoño, hijuelo que se trasplanta' (DCECH, V, p. 381). En la 2. acepción probablemente es lo mismo que talar y la grafía $l l$, por tanto, valdrá por l. En cuanto a la etimología, será la misma que la de talar o bien habrá que pensar en un cruce, tanto formal como semántico, entre talar y tallar. Cfr. tallar 'cortar' en el Índice de Blancas. También tallar 'cortar en FA (TiLANDER, FA, p. 583). En Fernández de Heredia tallar 'cut, slash' ['cortar, rasgar, azotar, machacar'] (GILKISON, s. v.). Con la misma significación se registra en el LT (Prince, 1995: 225). En VM, taillar 'cortar' (TILANDER, VM, Voc., p. 300). En los DLAA se registra talladores, referido a 'instrumento de cocina con el que se corta' o bien 'tabla gruesa para cortar sobre él la carne': «vna cobertera crebada, vna brumadera, .x. escudiellas, .v. talladores.» (doc. de Panzano de 1360; DLAA, p. 176). En DJ (Alvar, EDA, II, p. 216) vemos tallar 'cortar' y tallados 'tajadores', pl. de tallador (talladors), el cual nos muestra que ya en la Edad Media la - $r$ - $[r]$ se hacía muda en el grupo final -rs: «Item carga de tallados, xij dineros. Barzol de tallados, viiij dineros» (doc. de Jaca de 1437; Alvar, EDA, II, p. 245, lín. 221). También se registra en arag. moderno: tallá en Campo, Benás, Bisagorri, Chuséu, Torres del Obispo; tallar en Sobrarbe, Bal de Bielsa, A Fueba; y el compuesto: tallabarzas 'podadora, hoz con mango largo para cortar ramaje' en A Fueba y Bal de Chistau (EBA, 1999: 1728); además, el derivado talladera 'compuerta para contener las corrientes de agua' en Ribagorza (Moneva, 2004 [1924]: 430). Andolz (1992: 406) registra talladera con el mismo significado en Estadilla y Fonz; tallada 'tajada' y tallador 'gruesa tabla con un pequeño mango para cortar sobre ella la carne' en Benasque; tallá 
'cortar' en Ribagorza y tallar 'cortar, tajar' en Echo. En la mayor parte del dominio lingüístico del aragonés este verbo está hoy castellanizado fonéticamente, de manera que se usa ya tajar y los derivados tajadera 'compuerta', tajador 'sacapuntas', etc. (cfr. NAGORE, 2020: 612). Frec.: talladas 1: 0,00227; tallando 1: 0,00227; talló 1: 0,00227; talloron 1: 0,00227.

tan adj. apócope de tanto: Et con grant victoria el dito don Alfonso levantó el campo et firo grandes gracias et lohores a Dios qui tan sennyalado miraglo le avía feito et demostrado 38.540 . Frec.: 31: 0,07046.

tanis gentilicio (nombre de una de las naciones que habitaban la isla de Estancia): en aquesta isla de Estancia habitaban aquestas naciones: godos, vesegodos, estargodos, davirugis, arcas et tanis [aretis et anis $\mathrm{N}$ ] 3.2. Frec.: 1: 0,0227.

tanto adj. 'tanto': fue puesto en gran perplexidat cómo daría remedio a tanta perdición del su regno 20.100; et por aquesto fue clamado venturoso, porque tantas conquistas et tan grandes et con tan pocas batallas non fueron feitas depués que Ihesu Christo fue venido en la Virgen Santa María. 35.3. // pron. 'tanto': et muytos de otros navilios menudos, tantos de qui bastó a CCC vellas et mas 38.508. // adv. 'tanto; pondera la intensidad, duración o frecuencia de la acción expresada por el verbo': et tanto fizieron specialment [fizo semblant $\mathrm{N}$ ] don Exemén de Urrea que por manera de dezir mal dizen oy por Castiella «malas Urreas passen por tu casa» 38.208. Del lat. TANTUS, -A, -UM. Frec.: tanto 16: 0,03637; tantos 4: 0,00909; tanta 6: 0,01364; tantas 2: 0,00455.

tantost adv. 'enseguida, inmediatamente, prontamente, rápidamente, aprisa': el qual fue jurado en rey o primogénito en la ciudat de Caragoça antes que la dita dona Teresa muries, tantost pero aquel don Alfonso fue coronado [tornado $\mathrm{N}$ ] de Cerdennya 38.591; et depués tantost fue rey d'Aragón 38.413. // tantost que loc. conj. 'tan pronto como', 'en cuanto, en cuanto que': et assi eran veninossas que tantost que cavallo o otra bestia tocavan, en continent murian 36.599-36.600; mas tantost quel fue sennyor del condado, remembrose de la desonor que havía feito 23.41. Etim. comp. de tan < TANTU(M) y tost < lat. pop. TOSTUM, neutro, empleado como adv., de tostus 'tostado, quemado', p. p. de TORRERE, primero tendría el significado de 'calientemente' y luego 'prontamente'. En fr. tôt 'temprano, pronto', tantôt ... tantôt 'tan pronto... tan pronto' (cfr. DAUzat-Dubois-Mitterand, s. v. tôt, p. 753). Comp. occ. tantòst 'bientôt' (AliberT, $s$. v.); cat. tantost 'tot seguit, immediatament' (FABRA, DGLLC, p. 1608); it. tantosto; arag. ant. tantost 'immediately, quickly' en el Libro de Marco Polo, versión arag. de J. Fernández de Heredia (NiтTi, Voc., s. v., p. 100). Con el mismo significado 'rápidamente, inmediatamente' en la mayoría de las obras de Fernández de Heredia (GILkison, s. v.). Vid. tb. en continent que. Frec.: 4: 0,07728.

tarde adv. de tiempo 'tarde': por una estrela que ha nombre Esperus, ques pone cerca el sol et la ora es tarde, fue metido nombre a la tierra Speria 1.6. Del adv. lat. TARDE 'íd.'. Frec.: 1: 0,00227 . 
taula s. f. 'mesa': fue el primer rey que se posó a taula todo solo 3.49; porque en antes todos los reyes se posavan en lur taula con cavalleros et havian [yvan $\mathrm{N}$ ] ansí vestidos como cavalleros 3.51. Del lat. TABula 'tabla' (DECLIC, VIII, p. 349). Comp. cat. taula. En el arag. de Fernández de Heredia taula y, con menos frecuencia tabla, taulo 'mesa'. En el Índice de BLANCAS, taula 'mesa'. Frec.: 2: 0,00455.

te pron. pers. átono de $2^{a}$ pers. 'te': «rendeme el castiello, si no yo te enforcaré» 38.302. Frec.: 8: 0,01818.

temer] v. tr. 'temer': con las gentes de Cantabria e de su regno qui non temian fridores ni calores 12.54. // v. prnl. 'recelar, sospechar': temiendose que por semblant iudicio que fizo de su padre non passás, absentós del dicto regno et vino sende en Valencia 17.11. Del lat. TIMERE. Frec.: temían 1: 0,00227; temiendose 1: 0,00227.

temor s. m. 'temor', 'miedo': «et fes nos, Sennyor, por la tu mercé, que non ayamos temor de las contrariedades de aquesti mundo» 35.239; copdiciando mas el servicio de Dios et exalçamiento de la fe que no dudando el temor de los infieles. 18.26. Del lat. TIMOR, -ORIS. Frec.: 2: 0,00455.

tempestat s. f. 'tempestad': el dito regno fue possado en tranquilidat de par et la tempestat fue convertida specialment en prosperidat 36.76. Tomado del lat. TEMPESTAS, -ATIS 'mal tiempo'. Frec.: 1: 0,00227.

templo s. m. 'templo': et dixo: «Sennyor Dios, entraré a la tu casa et adoraré la tu santa casa, el templo santo tuyo, et me confessaré al tu nombre» 35.293. Del lat. TEMPLUM. Frec.: 1: 0,00227.

temporal adj. 'temporal, que dura un tiempo limitado'; 'secular, profano, del mundo'; 'relativo a las necesidades humanas o físicas, no espirituales': le plazies enrriqueçer el dito monesterio de algunas honores do pudiesen fer paxer sus ganados et ellos aver vida temporal 11.25; El estando en sana sanidat en su buen entendimiento, renunció a los bienes temporales 31.49. Del lat. TEMPORALIS. Frec.: temporal 1: 0,00227; temporales 1: 0,00227.

tendida pp. y adj. 'extendida, desplegada': veno a la ciudat de Tolosa, seynna tendida, talando, destruyendo villas, lugares e tierras del dito compte de Tolosa. 33.65. Es p. p. de tender < lat. TENDERE 'íd.'. Frec.: 1: 0,00227.

tenedor adj. 'que tiene o posee': el dito emperador se comandó a su muller tenedor et conservador [tenedera e conservadera N] por ella en el castiello de Nágera, un su cavallo 14.36. Deriv. de tener. Frec.: 1: 0,00227.

tener v. tr. 'tener', 'mantener', 'sostener', 'retener': et sacó un gavinet que tenía, et teniendo la letra en la mano et leyendo, talló todas las colles mayores que yeran en el huerto 20.113-114; reconosció tener en feu [fe N] et de ius sennyoría del dito rey don Jayme el regno de Mallorquas 38.468; la qual ciudat de Murcia el infant don Alfonso de Castiella la tenie [tuvo N] luengo tiempo cercada 35.170 [se lea/tenié/: es pret. indef.]; et lo tuvieron los franceses entro que fue feita la paz, et tenienlo [tenianlo B] por el rey, 36.356; 
et finalment fue assí avenido quel comun de Pisa livraría todas las fuerças que avía en la isla et terrian [ternia $\mathrm{N}]$ castell de Callar en se [fe $\mathrm{B}, \mathrm{N}]$ [en feu VC, p. 175] por el rey d'Aragón 38.568; et con grant desonor tinieron lur camino enta Perpinyan 36.663; et en continent recobró toda la tierra e aquella tovo mientre vivió paçificadament 33.60; et tuvolos presos [tuvolo preso $\mathrm{N}$ ] en el castiello de Loarre en Aragón 34.112 // 'sostener' (frente a aver 'tener'): et un cavallero de los de Olea, que tenía un pendón del compte muerto, en el cavallo, las manos talladas, con los braços tenía la seynna clamando: "Olea, Olea».19.123-125. // 'mantener': et aquella tuvo asitiada con traballo et lazerio VI meses 18.7. // tener por 'considerar, juzgar': «que fagades dellos la justicia que tenrredes por bienı 19.88; et fue muyt tovido por cruel por los turcos et por los moros 31.31. Etim.: del lat. TENERE 'tener asido u ocupado', 'mantener', 'retener'. La 1. ${ }^{\mathrm{a}}$ doc. es de mediados del s. x, en las Glosas Emilianenses (DCECH, V, pp. 461-462, s. v. tener): «qui sacerdotibus honorem jnpendit [tienet]» (glosa 49); «cum Dei adjutorio jmplere contendite [tenete]» (glosa 63); «[equal duenno tienet ela mandatjone cono Patre]» (glosa 89). Vid. en LHP, p. 616; Menéndez Pidal, Orígenes, 1968: 5, 6 y 7; ahora también puede verse en Origen aragonés de las Glosas Emilianenses, 2020: 102, 103 y 104. La posesión pura y simple se expresa preferentemente con aver (vid.). Frec.: tener 9: 0,02046; tenía 25; 0,05682; tenían 10:0,02273; tenidas 1: 0,00227; tenido 2: 0,00455 ; tenidos 1: 0,00227 ; tenie 1: 0,00227 ; teniendo 2: 0,00455 ; teniendolo 1: 0,00227 ; tenientes 1: 0,00227 ; tenieron 1: 0,00228 , tenies 5: 0,01136; tenrredes 1: 0,00227; terrían [ternía] 1: 0,00227; tienen 1: 0,00227 ; tinieron 1: 0,00227 ; tovido 1 : 0,00227 ; tovo $4: 0,00909$; tuvieron 3: 0,00682 ; tuvies 1 : 0,00227 ; tuviessen $1: 0,00227$; tuvo 15: 0,03409 ; túvolo 1: 0,00227; tuvolos 1: 0,00227. Puede verse la conjugación de este verbo en el estudio lingüístico de la Crón. SJP. (NAGORE, 2003: 397).

teniente p. de presente del v. tener y adj. 'tenedor, sostenedor, que tiene, que mantiene, que retiene': en el dito regno fincassen muytos moros tenientes castiellos en aquéll 36.50. Vid. tener. Frec.: tenientes 1: 0,00227.

tercero num. ord. 'tercero': et la terçera, Sancha, dio al fillo del dito compte de Tolosa e procreó della una filla 34.21; la tercera fue muller del duche d'Austria 38.430; el tercero don Johan et fue arcevispo de Toledo 38.413. Del lat. TERTIARIUS 'que contiene una tercera parte’. La 1. a documentación se da en arag. h. 950 en las Glosas Emilianenses: «Et tertius ueniens [elo terzero diabolo uenot]» (glosa 9: LHP, p. 617; MeNÉNDEZ Pidal, Origenes, p. 4; Origen aragonés de las Glosas Emilianenses, 2020: 100). Frec.: tercero 10: 0,02273; tercera 1: 0,00227 ; terçera 1: 0,00227 .

tercia s. f. 'segunda de las cuatro partes iguales en que según el cómputo romano se dividía el día: desde las seis de la mañana hasta las doce del mediodía, es decir, desde el fin de la tercera hora temporal hasta el fin de la sexta': en dia miércoles a hora de media tercia 39.43. Del lat. TERTIA 'tercera'. Frec.: 1: 0,00227. 
término s. m. 'término, fin': aqui femos fin et término a los reyes de Aragón 21.1. / / 'término, límite, lindero'; 'paraje señalado o limitado': et qualsequier otro ganado qui dentro en los ditos términos fues entrado sin lur licencia 11.63. Tomado del lat. terminus 'mojón, linde'. Frec.: término 5: 0,01136; términos 2: 0,00455.

terribilidad s. f. 'calidad de terrible', 'aspecto espantoso, terrible': et fuyendo los christianos de los lugares do habitavan por la dita terribilidad et crueldad, recullieronse en la espellunga 9.12. Del lat. TERRIBILITAS, -ATIS. Frec.: 2: 0,00455.

terrible adj. 'terrible, que causa espanto o terror': esguardant la terrible mortaldad que aqui era de christianos... 12.7; por defender los christianos de las crueldades et terribles persecuciones de los moros 10.9. Etim.: tomado del lat. TERRIBILIS (BDELC, p. 565; DCECH, V, p. 473, s. v. terror). La 1. a doc. que da CoROMINAS para la voz terrible en castellano es de h. 1400. La de la Crón. SJP. la adelanta unos años. Frec.: terrible 1: 0,00227; terribles 1: 0,00227.

terribledat s. f. 'cualidad de terrible': qui en la desus dita cueva heran cullidos por el miedo e terribledat de los moros 11.10. Deriv. de terrible. Comp. el cultismo terribilidad. Frec.: 1: 0,00227.

terror s. m. 'terror, miedo, espanto': et dio tan grant terror al dito castillo que de continent se rendió e fizolo derrocar 32.52. Etim.: Tomado del lat. terror, -oris. La 1. a doc. en cast. que da Corominas (BDELC, s. v.) es h. 1440: la de la Crón. de SJP. la adelanta en más de medio siglo. Frec.: 1: 0,00227.

tertia en la lexía compleja feria tertia 'martes': en la segunda semana de Quaresma, feria tertia, et ora prima 17.61. De manera semejante, feria quinta 'jueves', feria sexta 'viernes'. Vid. feria. Frec.: 1: 0,00227.

tesegueza s. f. 'enfermedad de tisis; tuberculosis pulmonar': buvo muytos enueyos [enoyos N] et treballos, et por tesegueza [tisiguera N] murió en Foyx en el anno de Nuestro Sennyor мССLII 35.92. Etim.: lat. PHTHISICUS, mediante derivación con el sufijo -eza (o -era). Comp. en la VC tisiguea 'tisi' (Glossari de la VC), que supone la forma tesegueza (y no -era) en aragonés. Efectivamente, en cat. «el nom de la malaltia fou llarg temps la tísica...; també es digué tisique(s)a o tisigue(s)a, i la variant tesic o teic es troba en algun text antic» (DECLIC, t. VIII, p. 517). El cat. tísic está tomado del lat. PHTHISICus, y este del gr. $\varphi \theta ı \sigma \iota \chi 0 \varsigma$ ‘id.', deriv. de $\varphi \theta ı \sigma \iota \varsigma$ 'extinción, decadencia', 'consunción, tisis' (ibídem). (Cfr. también BDELC, s. v. tísico). Frec.: 1: 0,00227.

testament s. m. 'testamento': e hordenó su testament e restituyó heredero 33.121. Cultismo tomado del lat. testamentum 'toma de testigos, acto de testar'. Frec.: 2: 0,00455.

testimonio s. m. 'testimonio': et sin periglio [peligro N] vivo lo saqué, benedito sea Dios, en testimonio de mis parients et vassallos presents aqui qui aquesto vieron 12.34. Del lat. TESTIMONIUM. Frec.: 1: 0,00227. 
ti pron. pers. tónico de $2^{\mathrm{a}}$ pers. con prep. 'ti': «et placia a ti Sennyor que yo sia tu servidor» 35.298. Del lat. TIBI, dat. de TU. Comp. tu, también empleado con prep. Frec.: 5: 0,01136.

tiemblador adj. 'temblón, temblador' (sobrenombre de García II rey de Pamplona): toda vegada tiemblava, et la gent lo clama García tiemblador 13.5. Deriv. de tiemblar. Frec.: 1: 0,00227.

tiemblar] v. intr. 'temblar': et por tal que quando bavía d'entrar en batalla o bavía a fer cabalgada o qualesque otros afferes periglosos quel avies afer con con los moros, toda vegada tiemblava, et la gent lo clama García tiemblador 13.4. Del lat. TREMULARE 'íd.'. Frec.: 1: 0,00227 .

tiempo s. m. 'tiempo': et en tiempo de aquesti los godos tenían lur sennoría mayor en Tolosa 3.38; et encara en el tiempo o comencamiento del dito rey don Jayme, su gran savieza supo fer a sus vassallos exolvidarla 38.625; et aqui sanctament et con firma fe catholica sirviendo a Dios estwvieron luengo tiempo 5.9. // 'temporada, época': supo que los moros tenian asitiada la ciudad de Pamplona muy destreytament en tiempo de yvierno 12.52. // todos tiempos loc. adv. 'siempre': el dito virtuoso rey con su valient gent todos tiempos vincie aquella morisma 38.363. // ningún tiempo loc. adv. 'nunca': todas aquestas tierras fincaron en poder de christianos, que ningún tiempo moros non las pudieron possedir. 4.8. Del lat. TEMPUs. Frec.: tiempo 101: 0,22957; tiempos 17: 0,03864 .

tienda] s. f. 'tienda (de campamento de guerra)': et a la raiz de una sierra et montanna fincaron sus tiendas 19.199. Del bajo lat. TENDA, deriv. de TENDERE 'desplegar'. Frec.: tiendas 2: 0,00455.

tierra s. f. 'tierra': et el rey enpennyó muytas villas et prisso las diezmas de su tierra [terra en la ed. crítica] 34.155; el dito monasterio ennoblesció et dotó de muitas tierras 8.7 ; el qual regió su tierra con grant justicia et misericordia luengament et lexó [dexó B] herederos suyos en los regnos de Aragón, de Valencia, de Cerdennya et en el condado de Barchinona el dito Alfonso 38.632; fue justament despossedido de su regno et tierras 38.621. Del lat. TERRA. Frec.: tierra 143: 0,32503; tierras 37: 0,08410.

tio s. m. 'tío': todos los ditos homes buenos eslyeron curador suyo don Phelip su tio 38.608.

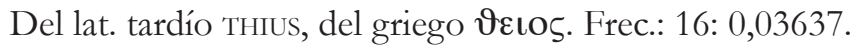

tirado] adj. 'continuado, seguido': Et en continent, partióse de aquí et a jornadas tiradas de nueyt et de día vino sende en su tierra con grant goyo et honor. 36.301. Frec.: tirada 3: 0,00682; tiradas 1: 0,00227; tirado 1:0,00227.

tirano s. m. 'tirano': el qual regnó su tierra non assí como rey mas assí como a tirano 38.618. Tomado del lat. tyranus, y este a su vez del griego $\tau \psi \rho \alpha v v o \sigma$ 'reyezuelo, soberano local' (BDELC, s. v.). Frec.: 1: 0,00227.

tirar v. tr. 'quitar': porque el dito rey de Castiella avía tirado a don Sancho rey de Navarra gran partida de sus regnos 17.32; quando buvies tirada [tullida N] su tierra a él 18.10 
(como se ve en este ejemplo, el ms. $\mathrm{N}$ usa otro verbo que es prácticamente sinónimo: toller); et tiráveles todos sus algos que avían pero dioles a los sus parientes 38.284; et tiroron ne la meytat de la torre 36.339. Etim.: de origen incierto. Es voz común a todos los romances. La etim. propuesta por DiEZ, el germ. TERAN 'desgarrar, destrozar', le parece escasamente verosímil a CoROMINAs, quien ve dificultades de orden semántico sobre todo. Le parece más verosímil que la palabra se formara en la jerga latina de los legionarios, derivada por estos del pártico *TIR 'flecha'. Usa ya este verbo Berceo con la acepción de 'quitar' (cfr. DCECH, V, 505-507, donde pueden verse numerosos ejemplos de este uso en cast. med.; vid. también ÁLVAREz, 1991:197). En arag. med. es habitual tirar 'quitar' (vid. REIDY, 1977: 269): «Et assi preso, deualyando lo dela dita casa, \& conpliendo lo a la puerta de aquella, los ditos Sancho Vidos \& otros de suso nonbrados li trauessoron vna lança en la dita puerta \& cuydo cayer sobre aquella, \& assi tiroron le el dito preso violentment» (DLAA, doc. 145, de Jaca, 1464; p. 213, lín. 59-62). En arag. mod. conserva el sentido de 'quitar', al menos, en los valles de Ansó y Echo (Andolz, 1992: 415, s. v., lo registra en Echo, Embún y Siresa con esa significación; con la de 'pegar en el sentido de castigar', en Bielsa; BADíA, 1948: 184, registra tirá a teta 'quitar la teta, retirar la teta, destetar' en Ansó; en el EBA, 1999: 1767, vemos tamién tirar 'quitar' en Echo). Es también 'sacar, quitar, echar fuera' el sentido fundamental del francés tirer (cfr. PRobert, el cual, siguiendo a BLOCH y WARTBURG, Dictionnaire Étymologique de la langue française, dice que es reducción del ant. fr. MARTIRIER 'torturar', que provendría de un supuesto lat. *MARTYRARE, idea desautorizada por COROMINAS). En port. tirar tiene varias acepciones, entre ellas, 'tirar', 'extraer', 'separar', 'quitar, usurpar', 'eliminar' y 'arrojar' (cfr. FernANDES, 1966: 794, s. v.). CunHa (1986: 771) dice que el port. tirar es «de origem desconhecida». Comp. toller. Frec.: tirar 3: 0,00682; tirada 3: 0,00682; tiradas 1: 0,00227; tirado 1; 0,00227; tiráveles 1: 0,00227; tiró 1: 0,00227; tiroron 1: 0,00227 .

titol s. m. 'título': segunt adelant lo oyredes en el titol del rey don Pedro 17.49. Tomado del lat. titulus 'inscripción, rótulo, título'. Comp. cat. títol (DCVB, t. 10, p. 317), cast. tilde (duplicado semipopular de titulo). Cfr. DCECH, V, 512. Aparece titol, junto a titulo en obras de Fernández de Heredia (GiLkison, s. v.). Registra titol el Índice de Blancas (1641). Frec.: 2: 0,00455.

tocar] v. tr. 'tocar': et assí eran veninossas que tantost que cavallo o otra bestia tocavan, en continent murian 36.600. Etim.: Según parece procede de una onomatopeya común a todos los romances y ya heredada del lat. vg. (DCECH, V, p. 520; GARCía DE Diego, Dicc. de voces naturales, 1968, p. 627, s. v. TOK). Frec.: tocavan 1: 0,00227.

todo adj. y pron. indef. 'todo': buvo paz et amor entre sus gentes en toda su vida 38.627; et depués de todas aquestas cosas, el dito rey don Jayme de Aragón devotament murió en hedat de LXXI annos en la ciudat de Barchinona 38.628; el dito Alfonso partió del 
lugar de Bonayre con todo su escolt [estolt B] 38.582; la vigilia de Todos Santos 38.630. // adv. 'totalmente, completamente': regnó todo solo en todo el regno 3.29; et aqueste fue el primero rey que se poso a taula todo solo et se vistió de vestiduras reales 3.49-50; Mas Acenarricus sobrevivió et regnó todo solo 3.20. Etim.: del lat. TOTUs 'todo entero' (DCECH, V, p. 528). // todos días loc. adv. 'siempre, todos los días': Et el dito rey don Pedro todos días en la huest fería adiesso aquá adiesso allá 36.576. / / todos tiempos loc. adv. 'siempre': todos tiempos tuvo el corazón contra moros et todos tiempos obtuvo victoria contra sus enemigos 36.11. Comp.: «que la present renunciacion et revocacion romanga en su firmeza et vallor pora todos tiempos", en Estatuto de la aljama de Zaragoza, de 1331 (TLME, doc. $\mathrm{n}^{\circ} 103$, lín. 38, pág. 190). Comp. occ. tostemps adv. 'en tout temps; toujours' (ALIBERT, s. v.); cat. totstemps (es la forma que traduce en la VC de la Crón. SJP. a todos tiempos de la VA). / / toda vegada loc. adv. 'siempre': toda vegada ho quayx estuvo enfermo 39.15. Frec.: todo 85: 0,19320; toda 71: 0,16138; todos 108: 0,24548 ; todas 54: 0,12274 .

toledano] adj. 'de 'Toledo' (se refiere a la ley, es decir, al rito litúrgico): et la hora entró la ley romana en Sant Johan de la Penna, XI kalendas aprilis en la segunda semana de Quaresma, feria tertia, et ora prima et III fue toledana, ora vi fue romana 17.62. Frec.: 1: 0,00227.

toller v. tr. 'quitar': et como don Ponz. Guillem lo quisies furtar et toller el castiello de Verges... 36.429. Etim.: del lat. TOLLERE 'levantar, sacar, quitar'. Se documenta toller 'quitar' ya en las Glosas Silenses, h. 950-1000 (LHP, p. 626). Se empleó comúnmente en cast. con esta acepción hasta el siglo XIV (DCECH, V, p. 689). También en arag. med.: toller 'quitar, llevar', 'robar, hurtar', en FA, p. 594; toller 'quitar' en DLAA (ReIDY, p. 269); también en Fernández de Heredia (GILKISON, s. v.); tollyer 'quitar, robar' en las Ordinaciones de Barbastro (VÁzQuEz OBRADOR, 2011c: 54), etc. Comp. it. togliere 'quitar' (Migliorini, II, 274, la cita entre las "variantes que los gramáticos catalogan como antiguas o poéticas", en la primera mitad del ochocientos). Comp. tirar. Frec.: toller 1: 0,00227; tollería 1: 0,00227; tollían 1: 0,00227 ; tollido 1 : 0,00227 ; tollieron 1 : 0,00227 ; tollies 1 : 0,00227 ; tollió 7 : 0,01591; tolló 1: 0,00227.

tomar] v. tr. 'tomar, coger, asir': et tomó [tovo N] la criatura entre sus camas 12.27. / / 'recibir, adquirir': aquesto le dezía porque non tomás desplaz̧er 36.369. Etim.: de origen incierto. García de Diego (DEEH, p. 395), propone como etim. el lat. MUTUARE 'tomar prestado', lo que requiriría una metátesis muy forzada y otros cambios difíciles de explicar. Corominas (DCECH, V, p. 539) cree verosímil que venga del lat. AUTUMARE 'afirmar', en el sentido de 'proclamar el derecho de uno a un objeto', que se pronunciaría en el lat. hispánico en la forma *TUMARE. Frec.: tomás 1: 0,00227; tomó 1: 0,00227.

tomba s. f. 'tumba': la quoal tomba fue metida entre tres altares 9.24. Etim.: del lat. tardío

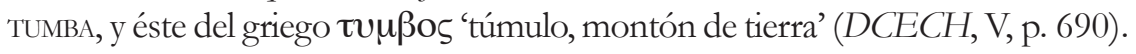
Frec.: 2. 0,00455. 
tornada s. f. 'vuelta, regreso': Don Johan Ximenez d'Urrea, sennyor de Montagudo et murió a la tornada et fue enterado [soterrado $\mathrm{N}$ ] en los freyres predicadores de Calatayú 38.402. Procede de la sustantivación del p. p. fem. del v. tornar. Frec.: 2: 0,00455 .

tornar v. intr. y prnl. 'volver, regresar': et a grant desonor et vituperio sende tornoron muertos et consumados 38.549; et aquesto feito, tornos'ende en su tierra 37.76. // v. tr. 'devolver': et pues por costumbre lo ban en natura les es tornado porque non sende podrían estar 38.398; porque ya otras vegadas lo avían tornado 19.75-76; el rey d'Aragón tornó lo que presso avía 34.84-85; que avies a tornar encondreyto la dita villa 36.445; et todo quanto avies avido que lo avies a tornar et que tornás el palacio assí como de nantes era 36.446-447; que dentro en xxx dias el avies a tornar en poder suyo 36.452. Del lat. TORNARE 'tornear, dar vueltas al torno', de donde pasaría a 'girar' y luego a 'volver'. Es un verbo habitual tanto en arag. med. como moderno. Cfr. en arag. mod.: "torna-me las camilegas / si las me has a tornar...» 'devuélveme las ligas / si me las has de devolver...' (en GASTÓN, Flexión, p. 43). En el EBA (1999: 1783) se encuentran diecisietee referencias de tornar 'volver'. Para el arag. med., GILKISON (1984: 133) registra tornar 'turn, become; return, go back'; tornar 'devolver' en los DLAA (REIDY, 1977: 270); en OB, tornar(se) 'volver(se)' (VÁzQuez OBRADOR, 2011c: 54). Frec.: tornar 6: 0,01364 ; tornado 5: 0,01136 ; tornada 2: 0,00455 ; tornaron 1: 0,00227 ; tornaronlo $1: 0,00227$; tornás $3: 0,00682$; tornassen $2: 0,0455$; tornava 1 : 0,00227 ; tornavan 1: 0,00227 ; tornellas $1: 0,0227$; tornemos 2 : 0,00455 ; tornó 15: 0,03409 ; tornoron 10: 0,02273 ; tornós 2 : 0,00455 ; tornose 14 : 0,03182; tornósende 1: 0,00227.

torre s. f. 'torre': et non osava tornar en Aragón de verguença que avía perdida la torre 36.348; e destruyó la ciudat de Arles, que el hera muy contraria, en la quoal derrocó muytas torres e fuerças 32.48. Del lat. TURRIS 'íd.'. Frec.: torre 3: 0,0682; torres 2: 0,00455 .

traballar]: que los moros traballavan la su tierra 23.55. Es trebellavan en el ms. Posiblemente será un error de imprenta. Vid. trebellar.

tractador adj. 'tratador, negociador, que trata un asunto': Et un día, mientre ques tractaba aquesta paz, un moro qui de aquesta paz, era tractador, con XXX ginetes, vino al dito rey 38.386. Del lat. TRACTATOR, -ORIS. Frec.: 1: 0,00227.

tractar (var.: tratar) v. tr. 'tratar sobre un asunto, comentar': Asimismo de su cabo los aragoneses tractoron que enviassen por don Remiro el monge 20.66; a demandar consello et ayuda sobre aquello que el rey de Navarra le havia tractado. 20.210. // 'cuidar (mal o bien)', 'proceder (mal o bien) con una persona': depués, como Alfonso de Castiella tractás malament su muller, hermana del rey dito don Pedro, et dessafiamientos fuessen entre el uno et el otro dados, el dito rey don Pedro, sabiendo quel rey Alfonso de Castiella non tractava con aquella honor que devía la reyna muller suya... 36.105-109. 
Del lat. TRACTARE. Frec.: tractar 5: 0,01136; tractan 1: 0,00227; tractás 1: 0,00227; tractava 4: 0,00909; tractavan 1: 0,00227 ; tractavas 1: 0,00227 ; tractó 5: 0,01136 ; tractoron 2: 0,00455 ; tratar 1: 0,00227 ; tratemos 1 : 0,00227; trató 2: 0,00455 .

tracto (var.: trato) s. m. 'trato, acuerdo, pacto': «Sennyor, datme letras de creyença pora el rey de Granada si podré fazer algún tracto con él’ 36.388; et havieron acuerdo quel rey se partiesse d'alli, que no atendies el trato ordenado 20.195. Es derivado postverbal de tractar. Frec.: tracto 3: 0,00682; trato 2: 0,00455.

traición (var.: trayción) s. f. 'traición': et passo por la tierra de Proença, do oyo dir quel conde de Folçaquer tenía preso al conte de Prohença, hermano del dito rey de Aragón, a grant traición 34.54; un dia él yendo a caça, un caballero suyo, clamado Ramón de Gasconna, matólo a gran trayción en el puent de Monclús 16.16. Del lat. TRADITIO, -ONIS 'acción de entregar, entrega, rendición'. Frec.: traición 2: 0,00455; trayción 1: 0,00227.

tranquilidat s. f. 'tranquilidad, calma': el dito regno fue possado en tranquilidat de paz 36.76. Deriv. del adj. tranquilo. El BDELC, p. 580, s. v. tranquilo, da la 1. ${ }^{a}$ documentación h. 1440 (e igualmente el DCECH, t. IV, p. 709, s. v. quedo). La Crón. de SJP. la adelanta en más de medio siglo. Frec.: 2: 0,00455.

translatar] (var.: traslatar) v. tr. 'trasladar': et con grant contrición de coraçón, bumilment y devota, translataron los cuerpos del desus dito Sant Johan heremita 9.20; mas depués fue traslatado al monesterio de Poblet, assí como él lo avía mandado 35.303. Formado sobre el p. p. de transferre, TRANSLATUS 'transportado'. Frec.: translataron 1: 0,00227; traslatado 2: 0,00455

trapo] s. m. 'trapo': que del grau de la mar do arribó entro a la ciudat et por las carreras de la do home yva sobre trapos d'oro et de seda 36.220. Etim.: del lat. tardío DRAppus (DCECH, V, p. 604). Frec.: trapos 1: 0,00227.

traslat s. m. 'copia por escrito': et firieron sus cartas et protestaciones. El traslat del qual privilegio yes en el monesterio de Sant Johan de la Penya 34.48. Etim.: puede ser sust. postverbal de traslatar, aunque sin vocal de apoyo. Cfr. el apartado 7.2.2.4 del estudio lingüístico (NAGOre, 2003: 609). Aunque quizá proceda del lat. TRAnslatus (cfr. DCECH, IV, p. 634). En Fernández de Heredia translat 'versión' y translatar, trasladar, transladar 'traducir; copiar' (GILKIsOn, s. v.); Reidy Fritz (1977: 270) da para los DLAA, traslat 'traducción', si bien vale también por 'copia de una escritura', tal como se puede ver: «et ante ellos asi como ante honrradas personas mostro \& leyr fiço vn traslat publico, el qual deçia seer sacado de hun priuilegio original del senyor rey don Jayme, de clara memoria... E dixo que por el dito traslat del priuilegio \& por la dita letra del senyor rey se manifiesta que los hommes de Aynsa han priuilegio que no son tenidos alguna cossa dar ho pagar por peyta ni por redenpcion de huast ni por alguna otra exaccion» (doc. 102, firmado 
por Jayme d'Ançano, notario de Uesca, en 1326; DLA A, p. 146, lín. 1014). Frec.: 1: 0,00227.

traslatar. Vid. translatar.

trasoro s. m. 'tesoro': Otrosí rogó al vispo don Sancho de la Rossa et al convento de Pamplona que le diessen el trasoro de la iglesia de Pamplona 20.231; metió mano a los santuarios e yglesias e monesterios e prendiesen los trasoros de las eglesias 19.148. Etim.: del lat.

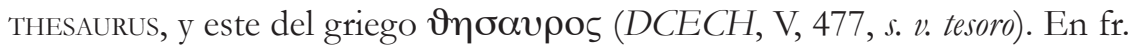
trésor: DAUzAT-Dubois-MitTERAND (p. 764) explican la - $r$ - como debida a una anticipación fonética. En la forma de la Crón. SJP. hay además apertura $e>$ $a$ facilitada por el contacto con $r$ y quizá por identificación con el prefijo tras- < TRANS-. En arag. med.: trasoro, trassoro, tresoro, thesoro y trasor en Fernández de Heredia (Gilkison, s. v., p. 135). Vid. un ejemplo del Libro de Marco Polo: «Aquesti rey es muy rico et ha grant trasoro» (NiTTi, p. 53, lín. 17). En $L M M$, p. 197, tresoro; pero en LT, trasoro (RodÉs, 2016: 779). En los DLA A, tressoro: «Item, seynor, quando el sagristan morie, el dito spitalero recebie las claues delas arcas del tressoro equellas arcas el abriesse las ditas arcas menos de mandamjento uuestro \& del conuento» (doc. $\mathrm{n}^{\circ}$ 98, de Jaca, de 1317; DLAA, p. 141, lín. 64). Frec.: trasoro 3: 0,00682; trasoros 3: 0,00682.

tratamiento (var.: tractamiento, tractament) s. m. 'trato, acuerdo'; 'negociación': et los fillos suyos et los barones dessuso ditos por rabenes dados del dito don Carlos en pressón del dito rey don Alfonso por tractamiento del dito Carlos envió sus mesageros solempnes por tractament [tractamiento N] 37.78-80; et depués de muytos tractamientos, prometió el dito Padre Santo a Frederich de darle en muller la filla del [duch N] de Constantinnoble 38.152; et vino [buvo N] por tratamiento de algunos nobles cavalleros de Aragón qui fueron en su servicio contra la unión 37.19. Deriv. de tractar. Frec.: tratamiento 2: 0,00455; tractamiento 4: 0,00909; tractamientos 5: 0,01136; tractament 1: 0,00227.

trato s. m. 'trato': et havieron acuerdo quel rey se partiesse d'alli, que no atendies el trato ordenado 20.195. Vid. tracto. Frec.: 1: 0,00227.

traballo (var.: travallo) s. m. 'penalidad, tribulación', 'dificultad', 'contratiempo difícil de superar', 'sufrimiento', 'esfuerzo': et no perdonava a ningún travallo que ningún hombre podies sufrir 12.66-67; et asitió la dita ciudad de Huesca, et aquélla tuvo asitiada con gran traballo et lazerio VI meses 18.7; el infant don Alfonso firió tan cuytadament con los primeros que los moros fueron en travallo 18.41-43. Es postverbal de traballar, del lat. vg. *TRIPALIARE 'torturar'. De la idea de 'sufrir' se pasó a 'esforzarse' y 'laborar' (DCECH, V, p. 571). Es forma común en arag. med., manteniendo la acepción de 'esfuerzo, penalidad': treballyo y trabayllo en $\operatorname{los} D L A A$ (REIDY FRITZ, 1977: 271): «etodo 
treballyo que ellos sufriran, Dios lesen rieda buen gualardon enest segle \& vida perdurable ellotro" (doc. 49, de Huesca, año 1279; $D L A A$, p. 74, lín. 40); treballo, traballo y triballo en Fernández de Heredia (GiLKison, p. 135, s. v.); treballos, trebayllos en VCA, p. 404. En arag. mod., ya con el sentido de 'labor' y 'laborar': treballo y treballar (Ansó, Ayerbe, Loarre), triballo y triballar (Echo, Lanuza, Ipiés) (KuHn, HAD, p. 25); traballo, treballo, triballo, troballo (Andolz, 1992, s. v.; DDPA, s. v.; EBA, s. v.). Las variantes treballo y triballo son formas etimológicas de *Tripaliare; la variante traballo se explica por asimilación vocálica. En el cast. trabajo también se produjo la asimilación de las vocales. En la Crón. SJP. aparecen dos formas: con tre(mayoritaria) y con tra-. Frec.: traballo 2: 0,00455; traballos 2: 0,00455; travallo 2: 0,00455. Vid. treballo.

trayción s. f. 'traición'. Vid. traición.

traydor s. m. y adj. 'traidor': «fer vos he lunnyar por fuerca porque, Sennyor, traydor nos avedes estado» 38.306; e con gladio de espada fizo morir los ditos traydores 33.59. Del lat. TRADITOR, -ORIS. Frec.: traydor 4: 0,00909; traydores 3: 0,00682.

treballo s. m. 'esfuerzo, dificultad, contratiempo dificil de superar', 'penalidad', 'sufrimiento': Y el dito noble conte de muitos treballos en el regno lo escusava 20.295296; entre las gentes huvo grant mal et grant treballo 38.612; eran todos cansados del treballo que avían sofrido en aquel día 36.661. Etim.: deriv. de treballar y este del lat. vg. *Tripaliare 'torturar', deriv. de tripalium 'especie de cepo o instrumento de tortura', compuesto de tres y PALus. Aquí se conserva el sentido etimológico de 'sufrimiento, dolor'. Y esa la acepción fundamental en aragonés medieval (vid. traballo). No obstante, también puede documentarse el sentido de 'labor, quehacer propio de un oficio': «Empero si a persona senyalada e que a los Jurados o a la mayor partida de aquellos placia fazer toquar nueyt e dia é muytos toques que le den los parientes buena ayuda o se auiengan con el canpanero de so salario del más treballyo» (OB, p. 9); «E los jurados de la dita çiudat que son e por tiempo seran por los treballyos qui han del oficio reziban segunt que antiguamente yes acostupnado» (OB, p. 20). En arag. mod. casi siempre se usa en el sentido de 'quehacer, ya sea retribuido o no; esfuerzo humano aplicado a la producción de bienes; acción y efecto de trabajar'. Véase un ejemplo en arag. de Arguis: «En estos días de siega / pa todos treballo abeba: / yera o pan de cada día, / y mui agusto lo feban» (CEBOLLERo, 2009, \809, p. 131). El EBA (1999: 1796, 1810, 1818, 1824) registra traballo (en Lanuza, Pandicosa, A Fueba, Aineto, Aragüés de los Puerto), treballo (en Adagüesca, Mundot, Sobrepuerto, Ansó, Benás, Biello Sobrarbe, Ayerbe, Lobarre), triballo (en Echo), troballo (en los valles de Bielsa y de Chistau), junto a la forma castellanizada fonéticamente trebajo. Frec.: treballo 5: 0,01136; treballos 2: 0,00455. Vid. también traballo. 
trebellar] v. tr. 'pisotear, patear', 'andar de un sitio a otro, recorrer un territorio pisoteándolo': et por tal como el dito rey buvo a yr a Valencia porque los moros le trebellavan la tierra 36.450; buvo ardit que los moros traballavan la su tierra 23.55 [en el ms. treballauan, que muy posiblemente es error del copista por trebellauan]. Etim.: Según Corominas sólo podría venir de una base *TripeLIARE, propuesta que no acepta por su carácter hipotético. Propone en cambio la posibilidad de que sea un verbo derivado del sust. trebejo 'chanza, juego, escarnio, mala pasada' en cast. med. (en port. trebelho 'brinco, juego, retozo', en gall. trebellos 'trebejos, trastos o utensilios para hacer algo; juguetes, chanzas'), que se pregunta si no podría ser un diminutivo-despectivo de trébe $(d e)<$ TripeDEm. Es decir: trebe(d)ejo. No acepta Corominas ni *trepidulare (Meyer-LÜBKE), ni deriv. de trabiCula 'viga pequeña' (RAE) (DCECH, V, 613-616). En port. trebelhar 'jugar' («de origen incerta», CUNHA, 1986: 785). En ast. trebeyar 'enredar, entretenerse [moviéndose, corriendo, blincando]' (ACADEMIA DE LA Llingua Asturiana, 2000: 1210). En gall. trebellar 'facer cousas que sirven de diversión e entretenemento, como brincar, correr un detrás dos outros, etc.' y 'realizar xogos mozos de distinto sexo ou facerse uns a outros bromas de carácter sexual' (Real Academia Galega / Instituto da Lingua GALEGA, 1990: 764, s. v.). En cast. trebejar intr. 'travesear, enredar, juguetear, retozar' (DRAE, 1970, s. v.). En port. trebelhar 'brincar ou bulir com varias cousas e correr de hua parte para outra' (cit. por DCECH, V, p. 613). En arag. med. se documenta trebeillo 'diversión, entretenimiento' y trebeillar 'divertirse, jugar' (ANDolz, s. v.; VM, III, p. 313; véase, por ej. en IV, 12, 29: «que el uno de los qui luytan dixiere que non quiere más trebeillar o luytar»); trebellar en Fernández de Heredia, Tucídides (Gilkison, s. v. treballar, p. 135; parece que confunde ambos verbos). El DCEL/C (IV, p. 557, s. v.), recoge trebejo 'juego', 'objeto para jugar', en port. trebelho, origen incierto, quizá diminutivo de trebe (variante de trébede) 'trípode'. $\mathrm{Y}$ añade que el verbo trebejar, con el sentido de 'jugar', es casi tan antiguo como trebejo (se documenta trebejar en Berceo, en Alex,...); en un texto en aragonés de h. 1220 también parece tener ese sentido: «el rey D. Enric trebelló con sus mozos e feriéronlo con una piedra en la cabeza e murió» (BRAE, VI, 218). En épocas posteriores ya sólo queda la acep. 'retozar, juguetear' y trebejarse 'hacer travesuras'. Aut. lo reconoce como anticuado, y Covarrubias lo confunde con trabajar. Seguramente ya sería poco usual en el s. xv, puesto que falta en los glosarios de h. 1400 y en A. Palencia, y Nebrija tampoco lo registra. En cat. se documenta trebeyl en la Crón. de Jaime I: «e ab un trebeyl que feya ab uns moços...». Corominas cree que o será arcaísmo pronto olvidado en cat. o será aragonesismo, porque no conoce otro ejemplo en catalán. El sustantivo tuvo una vida más duradera que el verbo. Es frecuente la acepción 
figurada 'broma pesada, mala pasada'; o de 'intriga, manejo'... y luego ya trebejos 'piezas del ajedrez', hoy anticuado incluso en esta acepción. Piensa Corominas que «el sustantivo trebejo es básico, y anterior al verbo trebejan», porque en el Libro del Ajedrez de Alfonso X se documenta el sust. y no el verbo, y lo mismo ocurre en los textos más antiguos. En port. trebelho 'juego', 'burla' y aceps. análogas, en doc. ant.; trebello 'chanza, escarnio' en las Cantigas de Alfonso x (de ahí luego 'copla satírica'). Otro sentido en port. 'torneo amistoso entre caballeros'. «Hoy verbo y sust. están más o menos anticuados en el portugués normal mientras que en gallego siguen siendo usuales trebellar 'travesear, enredar, juguetear' y trebellos 'trebejos, trastos, utensilios para hacer algo; juguetes; chanzas'» (DCECH, V, pp. 612-616). Frec. trebellavan 1: 0,00227; treballavan (posible error por trebellauan) 1: 0,00227 .

tregua (var.: tregoa) s. f. 'tregua': mandó al dito rey don Alfonso e a los otros reyes de Espayna que no oviesen tregoa con los moros 33.101; demandoron tregua por soterrar los lures muertos, la qual les fue atorgada 38.556. Del gótico TRIGGWA 'tratado' (DCECH, V, p. 618). Frec.: tregua 8: 0,01818; tregoa 2: 0,00455.

Trenchaforte sobrenombre de Bernat o Bernart, conde de Besalú, literalmente 'rompe fuerte', con tratamiento fonético cat. por la falta de dipt. de la $o$. Et las oras era conte de Bisuldu Bernart Trenchaforte, et por aquesto era assí clamado, porque era varón bueno, armado et muy fuert et valient en armas 27.15-17; Viviendo encara el noble varón Remón Berenguer, conte de Barçalona, era conte en Bisuldu Berenguer Guillem Gordo, fillo den Bernat Trenchaforte 29.32-34. Para el arag. mod. Andolz (1992: 424) registra trencar 'romper, fracturar' en Bielsa y en Benasque; trencá 'hacer leña, cortar leña' en Ribagorza; trencadura 'fractura, rotura de un hueso' en Benasque. El EBA (1999: 1813) confirma que es palabra usada en zonas orientales del aragonés: Bal de Lierp, Alta Ribagorza, aunque también la recoge en el Biello Sobrarbe y en Bielsa (frente a crebar, que con el mismo significado se registra en zonas occidentales: el EBA, p. 610, documenta este verbo en Ansó y en Echo). Frec.: 3: 0,00682.

tres num. card. 'tres': Et fuele dada otra muller al dito rey don Jayme, es assaber, la filla del rey d'Ongaria nombrada Ardeura, la qual depués hubo nombre Violant, nieta del enperador de Costantinnoble, de la qual procreó tres fillos 35.62. Del lat. TRES. Frec.: 6: 01364.

trezientos num. card. 'trescientos': con trezientos cavalleros vinose para las montannas de Cuenca et de Albarrazin 18.90. Etim.: del lat. TRECENTI 'íd.' (DCECH, V, p. 625, s. v. tres). Frec.: 3: 0,00682.

triado] adj. 'escogido': muytos nobles cavalleros et otra gent triada la mellor en armas de Napols 36.309. Etim.: de origen incierto, según CoROMINAs el verbo triar 
supone una base ${ }^{*}$ TRIARE, acaso extraída secundariamente del fr. ant. destrier, occ. y cat. destriar 'separar, discernir' lat. vg. *DESTRIARE 'separar con un surco', deriv. de STRIA 'surco', STRIARE 'formar estrías o arrugas' (DCECH, V, p. 627). Pero ya indica que se trata de una suposición verosímil, aunque incierta (DECLIC, VIII, p. 818). Comp. cat. y occ. triar y fr. trier 'escoger'. En el arag. de Fernández de Heredia: triar 'escoger, elegir' (documentado apenas en dos obras); además triga 'dilación, demora' y trigar 'tardar, demorarse, retrasar' (GILKISON, s. v.). La segunda acepción, que coincide con cat. y occ. trigar(se) 'entretenerse, tardar', proviene del lat. TRICARE 'entretener, buscar excusas para una dilación', por lo que no tiene relación. En arag. mod. recoge $A_{N}-$ DOLz, s. v.: triá 'clasificar, seleccionar' (Benasque), tría 'separación de las ovejas de cada dueño’ (Ribagorza), 'separación, elección’ (Huesca), triar 'elegir, escoger, seleccionar' (general), triga 'separación de las ovejas' (Bielsa), trigar 'hacer la triga' (Bielsa), trigare 'elegir' (valle de Chistau), trigau 'elegido' (ib.). Además: trigar 'separar', en Gistaín y Serveto (Мотт, Dicc. chist-cast., s. v.); trigar 'separar' en Plan y trigare 'escoger' en Gistaín (CASACuberTA-Coromines, $s$. v.). En Alquézar triador 'plazuela, entrada del pueblo, etc. donde se reúne el ganado por la mañana y desde donde se distribuye por la noche a todas las casas' (Arnal Cavero, s. v.). El EBA (1999: 1818) registra triá 'clasificar, seleccionar, elegir' en Benás y Bal de Lierp, y triar, con la misma significación en Salas Altas, Biello Sobrarbe, Monflorite, Bajo Alcanadere, Adagüesca, Echo, A Buerda, Balbastro, Torres del Obispo, Sobrepuerto y A Fueba. Frec.: triada 1: 0,00227.

tribulación s. f. 'tribulación, aflicción, inquietud': ya sea que toda la tierra fincas por la muert del virtuoso rey don Pero en grant tribulación, angustia et con grant guerra con la yglesia 36.708; et huvo grandes guerras et tribulaciones [terribles N] 35.108. Etim.: es cultismo tomado del lat. tribulatione $(m)$. Frec.: tribulación 3: 0,00682; tribulaciones 1: 0,00227.

tributo s. m. 'tributo': et encara subingó la isla de Menorquas a tributo 35.136. Etim.: es cultimo tomado del lat. tributu $(m)$. Es más común en arag. med. treudo: en los $D L A A$ se registra tributo una vez, pero treudo aparece en ventidós documentos, treundo en dieciocho, trehudo en once, y además una sola vez formas intermedias como treunto y trevudo (REIDY, 1977: 271). En el VM, trebudo (TILANDER, 1956, III, p. 313); en FA, treúdo (TILANDer, 1937: 601). Frec.: 4: 0,00909.

tristo] adj. m. 'triste'; fem. trista: tornose a sitiar la dita ciudad, la qual, sabiendo la victoria de los moros cayda en desperación, trista et dolenta... 18.74; et con mas mortaldat que la primera vegada, tristos et dolentes sen tornoron. 38.375. Del lat. TRISTIS 'íd.' (DCECH, V, p. 643). Se produce una regularización, de acuerdo con los más habituales morfemas de género masculino $(-o)$ y femenino $(-a)$, como con- 
secuencia de la tendencia típica del aragonés a dotar de flexión de género a adjetivos. Frec.: trista 1: 0,00227; tristos 1. 0,00227.

trobar] v. tr. 'encontrar, hallar': Et el dito rey don Pedro con sus geniossos tractamientos, con aguaytas et en otra manera tantos mató, que del col de Panizares entro a Girona non trobariades sino homes muertos 36.572; passosse a Jherusalem, pero nunca lo troboron ni muerto ni vivo 19.219. // v. prnl. fig. 'suceder, ocurrir, acaecer': et se troba que muytos santos de Paraysso non tan solament ayudavan a él quando avía batallas con los moros, mas encara ayudavan a sus vassallos 35.224; et trobos [trovose $\mathrm{N}$ ] que jamás en sus días non firo cosa que desplazies a los sozmesos 35.215. Etim.: probablemente de un lat. vg. *Tropare, variante del lat. tardío contropare 'hablar figuradamente, hacer comparaciones'. Comp. occ. trobar, fr. trowver, it. trovare, cat. trobar. Es habitual en arag. ant.: así, por ej. en Fernández de Heredia, trobar 'encontrar' (GILKIsOn, s. v.); en $L M M$, p. 197; en FA, p. 603; en los DLAA (ReIDy Fritz, 1977: 272); en $O B$ (VÁzquez Obrador, 2011c: 55); en el $V C A$, p. 407, etc. En arag. mod. es general en todos los altos valles, desde Ansó hasta Benasque, y en Ribagorza (Andolz, s. v.; DDPA, s. v.; EBA, 1999: 1825), etc. En cambio, en el Somontano ha sido sustituido casi totalmente por alcontrar (vid. Andolz, s. v.; Ríos, 1997: 37; Nagore, 2000: 535; Castillo, 2001: 21; Mostolay, 2007: 65), igual que en la Sotonera (GArCÉs, 2005: 36) y en general en todas las zonas meridionales del dominio lingüístico ( $E B A, 1999$ : 136; NAgore, 2020: 41). No obstante, también se registra un uso residual de trobar en algunos puntos de estas zonas (Mostolay, 2007: 549, registra trobar 'encontrar': «se lo trobón espiazau y muerto»), en especial en frases proverbiales («Qui alza, troba» es un refrán conocido en bastantes pueblos del somontano altoaragonés). Por otro lado, se registra su uso en escritores populares de Huesca (NAGore, 2020: 653, si bien se indica que se utiliza más el v. alcontrar). Frec.: troba 1: 0,00227 ; trobado 1: 0,00227 ; trobamos 2: 0,00455 ; trobariades 1: 0,00227 ; trobaron 1: 0,00227 ; trobavan 2: 0,00455 ; trobó 3: 0,00682 ; troboron 1: 0,00227; trovos 1: 0,00227 .

tu pron. poses. 'tu': que por manera de dezir mal, dizen oy en día por Castiella «malas Urreas passen por tu casa» 38.210 // pron.pers. de $2^{\mathrm{a}}$ pers. con prep.: «ruegote que acabes con el rey de Aragón que me alargue la tregua por otros cinquo annos como avemos et darle sueldo pora $C^{0} C^{\circ}$ hombres a cavallo pora un anno et faré a tu bien et mercés 36.396 // pron.pers.suj. de $2^{a}$ pers.: «tu es el poder et tu es el regno et tu Sennyor es sobre todos los reyes» 35.296; "priégote, fillo mio, que tu ames los tus barones, cavalleros et las tus fieles gentes que han a mi amado coralment» 35.265. Frec.: 24: 0,05455.

tuerto] adj. 'torcido': Guillem Croy qui buvo la nariz, tuerta et plana 29.40. Aparece además en el sobrenombre Barbatuerta 18.31, 18.34, lit. 'barba torcida'. // s. m. 'agravio, daño, injusticia, error, hecho contra razón y justicia, acto falto de 
rectitud': queriendo punyr el rey de Francia et sus gentes de las vildades et crueldades que feitas avian contra El et sus santos, et vengar el rey de Aragón de los tuertos et injurias que prendian 36.595. / / a tuerto loc. adv. 'equivocadamente, torcidamente, erróneamente, injustamente': "Sennor, si la reyna yes acusada a tuerto queredes la delivrar, et que fues perdonada...» 14.73. Etim.: del lat. TORCTUs, TORTUs, part. del lat. Torquere, vg. ${ }^{\text {Torcere }}$ (BDELC, p. 574). Vid. tb. DECLIC, VIII, pp. 583-584. Es un p. p. de torcer (tuerto, part. fuerte, de carácter irregular, frente al regular torcido), sustantivado (< lat. TORTUs, DEEH, p. 1028). De tuerto 'torcido’ se pasó a ‘injusto’, h. 1250, y sustantivado, 'injusticia’ h. 1140 (BDELC, p. 574). Se usó en cast. med. con el mismo sentido, aunque a partir del s. XVI se generalizó entuerto. Lo recoge el DRAE, 1970, acep. 4ª , con el significado de 'agravio, sinrazón o injuria que se hace a uno' y entuerto m. 'tuerto o agravio'. El DLE (2014, s. v. tuerto) registra la loc. adv. a tuerto 'contra razón, injustamente'. En cat. tort adj. 'no dret; que fa corva o s'inclina més a un costat que a l'altre' (FABrA, DGLIC, s. v.; DL/C del IEC, 2007, s. v.). En arag. mod. aparece, con el sentido originario de 'torcido' en varios compuestos populares como aguatuerta, aguatuarta 'meandro', garrituerto 'estevado' (ANDOLZ, s. v.). Además, en fem. tuerta 'hierba seca recogida en forma de madeja' (RoHLFs, $s$. v.; Arnal Cavero, s. v.; EBA, 1999: 1836; Castillo, 2001: 225); tuerto 'torcido' (ANDOlz, s. v.; EBA, 1999: 1836; Ríos, 1997: 157). Comp. fr. tort 'injusticia agravio, culpa, prejuicio, falta', especialmente en la construcción avoir tort 'no tener razón' (cfr. PRobert, s. v.). Es común en arag. med.: cfr. tuerto 'torcido’ en $L M M$, p. 198. También tuerto 'agravio': en $D L A A$ : «et quiero et mando que todas mis debdas \& todos mios tuertos que prouados seran con uerdat, aquí yo so tenuda segunt Dios, que sian pagados de mis bienes» (doc. $\mathrm{n}^{\circ} 38$, de Huesca, año 1276; DLAA, p. 57); VM, III, p. 315; GILKIson, s. v.; FA, p. 604; tuerto 'injuria, agravio’ en $O B$ (VÁzQUEZ OBRADOR, 2011c: 55). Cfr. a tuerto 'injustamente' en nav. (TLN, p. 265, en un texto del s. XIII). Frec.: tuerto 1: 0,00227; tuerta 1: 0,00227; tuertos 1:0,00227.

turbado adj. y p. p. 'alterado, conmovido, aturdido, sorprendido': fuesse de nueytes a la possada del rey de Aragón et recontole esto; et fue muyt turbado et clamó don Caxal et dos otros conselleros et havieron acuerdo quel rey se partiesse d'alli 20.193. Del p. p. de turbar < lat. TURBARE. Frec.: 1: 0,00227.

turco] adj. gentilicio 'turco': et fue muyt tovido por cruel por los turcos et por los moros 31.32. Frec.: turcos 1: 0,00227.

turmento] s. m. 'tormento, suplicio, tortura': a diversas et crueles, muertes et turmentos havía exposado los nobles varones 36.190. Etim.: del lat. TORMENTum íd. Cfr. DECLIC, VIII, pp. 590-592. Se doc. turmento (junto a tormento, turmiento, turment, torment, turmient) y turmentar (junto a tormentar) en el arag. de Fernández de Heredia (GILKison, s. v.). Comp. cat. turment, occ. tourment (Mistral, Tresor). 
occ. gasc. tourmén, turmén (PALAY, s. v.), occ. lang. torment (AliberT, s. v.). Frec.: 1: 0,00227 .

tutor s. m. 'tutor; regente provisional durante la minoría de edad del rey': en la tierra suya se movió grant discordia porque algunos non querian obedir al tutor 38.612. Del lat. TUTOR, -ORIS. Frec.: 1: 0,00227.

tutoría s. f. 'tutoría; regencia provisional por menor edad del rey': et mientre que de la tutoría el dito don Phelip ussava... 38.610. Deriv. de tutor. Frec.: 1: 0,00227.

tuyo, -a, -os, -as pron. poses. 'tuyo, -a'. Se registra la construcción <art. det. + pron. pos. + sust.>, típica del aragonés, equivalente al cast. 'tu, tus': «Sennyor Dios, tu me ensennya a fer la tuya voluntat 35.244; «Sennyor, en las tuyas manos comando mi spiritu» 35.294. También puede ir el posesivo, en su forma plena, detrás del sustantivo: «et adoraré la tu santa casa, el templo santo tuyo» 35.293. Frec.: tuyo 1: 0,00227 ; tuya 1: 0,00227 ; tuyas $1: 0,00227$.

\section{$\mathbf{U}$}

udulamento] s. m. 'aullido', 'alarido': vino con grandes cridos et udulamentos [Iulamientos $\mathrm{N}]$ 38.361. Etim.: deriv. del verbo udular, y este del lat. vg. HULULARE (según Alibert, s. v.); del lat. vg. ululare, lat. cl. Ululare según el $D C V B, 10$, p. 591; DEEH, p. 1044; DECLIC, VIII, p. 953. Comp. occ. udolar idolar 'aullar, dar alaridos', 'gimotear'; udòl olut 'aullido, alarido', udolament 'acción de aullar' (Alibert, s. v.). También en gascón: udoulà 'aullar', 'gimotear, quejarse, hablando del perro', 'ulular', udoulado 'alarido o grito semejante' (PALAY, s. v.). cat. udolament 'acció d'udolar' y udolar 'fer udols'; cast. aullar (DCV B, 10, p. 591). No encontramos en COROMINAs (ni en DCECH ni en DECL/C) referencia a las formas aragonesas modernas, con -t. Cfr. arag. mod. otular, otilar. De ser correcta la etimología, las formas aragonesas supondrían una ultracorrección; o bien hay que pensar en otra base etimológica con -T-, *UTULARE, como propone ELCOCK: «Vu la presence du $t$ dans notre région, à côté de $d$ ailleurs, nous ne pouvons croire qu'à une autre forme primitive *UTULARE. Mais d'où viendrait la $t$ de cette forme? Une influence possible que se présente à l'esprit est celle d'un type *GuTtulaRe. Certaines formes aragonaises, botilár, gotilár, semblent en effet accuser une provenance directe de ce type. Cependant les formes catalane et provençale exigent une base avec un $t$ intervocalique, le $d$ 
intervocalique ayant passé dans ces parlers à ₹: Les autres formes aragonaises pourraient donc représentar soit *UTTULARE, soit *UtUlaRE. Mais, étant donné que le maintien du $t$ intervocalique est usuel dans cette région, et que le mot est essentiellement du terroir, il semble très probable que la même base, *UtUlare, est commune au provençal, au catalan, et à l'aragonais» (De quelques affinités, p. 51). Efectivamente, parece evidente que si en aragonés se encuentran formas con la consonante oclusiva dental sorda $-t$ - y en aragonés oriental y en catalán esta aparece sonorizada en $-d-$, la forma etimológica de la que ambas proceden ha de poseer -T-. Se trata de un caso semejante al de lat. ${ }^{*}$ MUTULONE (deriv. de MUTULUS) > arag. motolón; arag. or. modolón, mogolón, mologón; cat. occ. modoló, mogoló. ROHLFs, (DDPA, s. v.) recoge otilar 'aullar' en Biescas; utilar en Buesa; utilá en Ansó; uludá en Espés y en Benasque; ulurá en Bisaurri (y además, las formas tular, botilar, gotilar, tomadas de ElcOCK, 1938); además, están registradas las siguientes formas: utilius 'aullidos' en Alquézar (ARNAL CAVERO, s. v.); otilar 'aullar el lobo' (BORAO, con la indicación: «en pueblos del Somontano»); otilar 'ulular, aullar el lobo, el perro, lastimosamente' y otilidos 'aullidos, alaridos' en PARDO, s. v. ElCOCK (De quelques affinités, p. 51 y mapa 8), documenta las formas tular, otilar, utilar, cautilar, botilar, gotilar, utilá, en una zona que va desde Ansó hasta Plan y por el Sur hasta Ayerbe y Alquézar. En concreto utilá (en Ansó), botilar (en Echo, Osia y Ayerbe), gotilar (en Agüero y Lasieso), cautilar (en Yésero), utilar (en Linás de Broto, Buesa, Basarán, Sobás, Gésera, Gillué, Morcat y Bierge), otilar (en Torla, Fanlo, Burgasé, Yeba, Berroy, Cámpol y Ascaso), tular (en Sercué, Bestué, Tella, Bielsa, Plan, Laspuña y Banastón). Andolz (1992, s. v.) registra: otilar (sin marca diatópica), otilido (tomado de PARDo, 1938), otular (en Panticosa), utilar y utilius (en Alquézar). El EBA (1999) confirma confirma algunos de estos datos y los completa con otros: así, registra botilar en Echo y Fuencalderas; otilar en Salas Altas, Biescas, Semontano, Bal de Broto, Otiñena; otiliu en Biello Sobrarbe; tular en A Fueba, A Espuña y Bal de Bielsa; utilá en Ansó; utilar en Ontiñena; utilius 'aullidos de los lobos hambrientos' en el Semontano; uludá en Benás y en Castanesa: ulurá en Bisagorri. Quizá el verbo de donde procede otular otilar podría ser un derivado del lat. ŌTUS 'nombre de un ave nocturna, el mochuelo' (BLÁNQUEZ, s. v.), para referirse a su forma de gritar o aullar: *ōtulare. En relación con esa posibilidad póngase esta copla recogida en Pandicosa [Panticosa]: «Qué paxarraco ye aquel / qu'esgramuca en aquel ramizo?; / anda, dile que no otule, / que si puyo lo'scornizo» (Latas \& NAGORE, eds., 2007: 56). La forma de nuestro texto, udulamento, refleja sin duda una fonética catalana o, al menos, oriental. Frec.: 1: 0,00227.

ugones s. m. 'nombre de un pueblo o nación (tribu)': nin de los alanos, nin de los suevos nin de los ugones 2.9. Frec.: 1: 0,00227. 
ultra prep. 'más allá de, además de': mas de ccc hommes solament de cavallo, ultra [menos de N] aquéllos que y murieron de pie 38.551. Teniendo en cuenta que menos de se emplea con el sentido de 'sin, sin contar', parece que aquí vale por 'además de'. Del lat. ultra 'más allá'. Frec.: 5: 0,01136.

unión s. f. 'unión', 'acción de unir varias fuerzas en una': et unión fizieron contra el rey de Granada 38.339. // En todos los demás casos se emplea en el sentido específico de 'unión de los ricos hombres, nobles, cavalleros, ciudades y villas de Aragón para mantener sus fueros, privilegios y libertades' (cfr. 36.670-673): por mantener lurs fueros, privilegios et libertades fizieron union 36.673; Et aquesta fue la primera unión que aragoneses comencoron 36.375; buvo en el regno grant guerra entre el rey et los de la unión 37.21-22; que si non servava los privilegios que feito avía a la dita unión... 37.31; la Unión que en tiempo del rey don Pedro se era feita 38.623; aquellos que fueron movedores de la Unión quaxi eran muertos 39.30; etc. Frec. 11: 0,02500.

universal adj. 'universal; aplicado a la herencia, que comprende todos los bienes, derechos, acciones, obligaciones o responsabilidades del difunto': fincó heredero universal en el dito condado 28.1. Frec.: 1: 0,00227.

universidat s. f. 'corporación municipal'. Se usa casi siempre en plural: et assí a cavalleros como a universidades lures privilegios et libertades les confirmó 36.235; con consello de los nobles et varones et universidat [universidades B] et con grant poder de homes 38.190; prelados, barones, universidades de ciudades et de villas 35.123. El Glossari de la VC da universitats 'corporacions municipals'. Etim.: del lat. UNIVERSITAS, -ATIS 'universidad, totalidad', 'compañía de gente, comunidad'; tenía en latín el sentido de 'colectividad, gremio' (DCECH, V, p. 794, s. v. verter). La 1. ${ }^{a}$ documentación en cast. es de 1490, en Alonso de Palencia, con el sentido de 'totalidad'; Pedro de Alcalá, en 1505, ya emplea la voz con el sentido de 'Universidad de estudio'. Así que, aunque con otro sentido (que no se cita en el $D C E C H)$, la Crón. SJP. se adelanta en más de un siglo en el uso del vocablo. Comp. en DLAA: 'conjunto de poblaciones o de barrios que estaban unidos por intereses comunes, bajo una misma representación jurídica' (REIDY FrITZ, s. v., p. 281). Frec.: universidat 1: 0,00227; universidades 4: 0,00909.

uno (un ante sust., en posición proclítica), una, unos, unas art. indef. 'uno, -a, -os, -as'. Et buvo en otro fillo de una muller noble (error: en por un) 14.29; un día depués de comer 38.542; et fabló [con ellos $\mathrm{N}$ ] una gran pieşa 38.390 // num.: todo un día encalçando 38.364; de los quales fincoron dos fillos et una filla 38.588. Etim: del lat. UNUS, -A, -UM. Es difícil separar claramente los usos como art. indefinido (o indeterminado) y como numeral. Frec. (teniendo en cuenta, conjuntamente, tanto las formas que funcionan como artículo indefinido, como numeral y como pronombre indefinido): un 124: 0,28184 ; una 61: 0,13865 ; unas 1 : 0,00227; uno 41: 0,09319; unos 8: 0,01818. 
uno, una, unos, unas pron. indef. 'uno, -a, -os, -as': et puedes dezir que era una de las maldiciones de farahón 36.596; mescladas las unas galeras con las otras 38.268; en vida de cada uno de los dessuso ditos infantes 38.425. Vid. uno (un) art. indef.

untar] v. tr. 'ungir': el dito rey don Jayme de Secilia fue untado et coronado rey d'Aragón 38.21; et el Padre Santo, vidiendo la nobleza del dito rey, coronó et untó aquél con grant honor 34.34. Etim.: del lat. vg. UNCTARE, derivado del lat. UNGERE 'untar', 'ungir' (DCECH, V, p. 715). Comp. port. y cat. untar, occ. ant. onchar y onher, it. untare y ùngere. Frec.: untó 1: 0,00227; untado 3: 0,00682.

usar] v. prnl. 'acostumbrar, ser habitual, ser costumbre': el quoal feito se usa en Espaynna 19.94 / / v. tr. 'usar, disfrutar, ejercer': deposaron el dito Remón de la honor real de la qual injustament usava 17.18; et mientre que de la tutoría el dito don Phelip ussava, en la tierra suya se movió grant discordia 38.610. / / v. intr. 'tener costumbre estar acostumbrado, ejercitado, entrenado': que no yera seydo usado en armas ni en actos de cavaIlería 20.51. Etim. del lat. vg. *USARE, frecuentativo del lat. UTI 'usar' (DCECH, V, p. 724). Frec.: usa 1: 0,00227; usado 1: 0,00227 ; usados 1: 0,00227; usava 1: 0,00227 ; ussava 1: 0,00227 .

uso s. m. 'uso, práctica, ejercicio, empleo, trato habitual': las quales gents, por luenga par, oblidoron el uso de las armas 1.39. Del lat. usus 'íd.' (DCECH, V, p. 724). uso 1: 0,00227 .

ussança s. f. 'usanza, uso o práctica que está en boga': assí como es de costumbre et de ussança de reys todos tiempos observada 37.14. Etim. deriv. de uso < lat. usus, deriv. de UTI 'usar'. El DCECH da la 1.' doc. del cast. usança en 1490 (en Alonso Fz. de Palencia y Nebrija), más de un siglo después de la Crón. SJP. Frec.: 1: 0,00227.

utilidat s. f. 'utilidad, provecho, interés, disfrute': et durando la dita cort, fueron hi feitas constituciones a proveyto et utilidat de la tierra 38.24. Frec.: 1: 0,00227.

\section{V}

vaca] s. f. 'vaca': que sin alguna pena et sin todo dupdo et pleito real pudiessen degollar et matar vacas et qualsequier otro ganado qui dentro en los ditos términos fues entrado si lur licencia 11.62. Del lat. VACCA. Es habitual en documentos medievales en aragonés el término baca, bacas, a veces con las especificaciones bacas pello bermeyllas ("vacas 
de color rojizo'), bacas betelleras ('vacas preñadas, con betiellos, es decir, terneros'). Vid. Líbano \& VildacorTA, 2013: 73. He aquí un ejemplo: «Encara vos damos siet houellyas \& una gegua, pello negra, \& hun polltro, pello bermellyo, \& dos roçines, launo pello negro, laotro pello bermellyo; ítem dos bacas, pello bermellyas» (DLAA, doc. no 104, de Jaca, 1329; p. 150, lín. 65-67). Frec.: vacas 1: 0,00227 .

vaciar v. tr. 'evacuar, echar, arrojar': Et depués de aquesti Sisabuch, et aquesti rey fiço vaciar por fuerça los judios 3.57. Etim.: deriv. de vacio < lat. vg. vaCIvus 'íd.' (DCECH, V, p. 728 , s. v. vagar). El significado 'evacuar, echar, arrojar' se documenta en varios textos medievales, entre otros el PY (versos 18b y 58b; cfr. MenÉndez Pidal, TME, pp. 458 y 462). Frec.: 1: 0,00227.

val s. f. 'valle': passando la dita reyna por la val d'Aybar, aguait de moros dieronle salto 12.2; de la part de la val de Aragón 36.353. Del lat. vaLLIS, acus. valLE(M). El término, ya sea escrito con $v$-como, más frecuentemente, con $b$-, es habitual en arag. medieval. Así, por ejemplo: «como lo camjno de Caragoca dize de Jacca entasuso, la bal de Cebollera \& enta part de Tena» (MDF: 99.15). «tem, un oljuar setiado a la bal de lo Cauagero» (MDF: 234.13). «Presentes testimonios fueron a las sobreditas cosas los honrados Domingo Brun notario Fuertes Manche bayle de la Bal de Echo" (doc. de Braslabilla, de 1438; EAMJM, p. 74). «Eadem die en el verdeguero de la Yglesia de Sant Miguel en el lugar de lo Pueyo ante la presentia del magnifico Johan de Lanuça lugarteniente de Justicia de la Bal de Thena» (doc. de El Pueyo, de 1498; EAMJM, p. 119). «no sia tan osado ningún bezino o habitador de la dita Bal de bender pan assi como trigo o centeno de ninguna manera ni natura que sia a ningún hombre estrangero fuera de la dita Bal) (doc. de 1431, de El Pueyo de Tena; EVT, p. 46). Continúa vigente en arag. mod., como femenino: bal 'valle', 'hondonada' (ANDolz, 1992, s. v.), bal 'valle', 'vaguada' (EBA, 1999; s. v., p. 252, también ball, balle, val, generalmente como femenino). Frec.: 7: 0,01591.

valentia s. f. 'valentía': assí que la industria et valentia de aquesti rey don Pedro el dito regno fue possado en tranquilidat de paz 36.75. Del lat. VALENTIA 'poder, facultad, capacidad' (SEgura, 2001: 819). Frec.: 1: 0,00227.

valer (var. valler]) v. tr. 'amparar, proteger, ser útil': que en todas necessidades havies ayudar e valer al dito rey 16.43; non le fallira [falliría $\mathrm{N}]$ con que [aunque $\mathrm{N}]$ le valies et ayudas contra la Eglesia et todos sus enemigos 38.36. // v. intr. 'valer, importar, convenir': et los moros acordaron que mas valía con aquéllos dar la batalla antes que mas gentes se plegassen a él 19.215. / / 'tener validez o valor, ser válido': los nobles et cavalleros de Aragón dizieron que aquel renunciamiento non vallía porque la gracia del privilegio se estendía assí sobles como cavalleros 34.44. Del lat. VALERE 'estar fuerte, ser vigoroso, tener fuerza, ser capaz de, poder', 'ser eficaz', 'prevalecer, dominar', 'tener un valor o precio determinado', 'tener buena salud' (SEGURA, 
2001: 819). Frec.: valer 1: 0,00227 ; valía 1: 0,00227 ; valies 1: 0,00227 ; vallía 1: 0,00227 .

valeroso (var.: valleroso) adj. 'valeroso, que tiene valor': el dito rey, aplegado complimiento de navilio con muyt noble cavallería de Catalunya et de Aragón et gent valerosa de pie, vino a sitiar la ciudat de Mallorquas 35.129; con muytos de otros cavalleros et gentes de pie muy valerosas et spiertos en armas 36.532; que pudiessen la ciudat livrar a don Alfonso, fillo primogénito del valeroso rey don Pedro. 36.686; Et aquesti conde Guifre fue muyt buen hombre et valleroso et benigno 23.84. Deriv. de valor (con disimilación valoroso > valeroso) o del inf. valer sustantivado (DCECH, V, p. 733). Frec.: valeroso 4: 0,00909; valerosa 1: 0,00227 ; valerosas 1: 0,00227 ; valleroso 1: 0,002287 .

valient (var.: balient) adj. 'valiente': Et depués el dito balient rey, queriendose vengar de las injurias que el compte de Tolosa le avia feytas, ajuntó grant gent... 33.62; Aquesti rey don Pero fue barón muy curial, noble, balient, largo e proz. e muy espierto 34.7; mas el dito virtuoso rey con su valient gent todos tiempos vincie aquella morisma 38.362; con grant poder de sus valientes varones 38.224. Del lat. VALENS, -NTIS, acus. VALENTE(M) 'fuerte, robusto, vigoroso' (SEGURA, 2001: 819). Frec.: valient 12: 0,02728; valientes 1: 0,00227; balient 2: 0,00455.

valla] s. f. 'valla, empalizada, muralla de tierra o de piedra': començaron a fer grandes fortalezas de castiellos, de muros, de vallas [valles $\mathrm{N}$ ] porque se pudiessen defender de los enemigos 4.18. Etim.: del lat. valda, pl. de valLum 'empalizada', 'muralla de tierra o de piedra' (DCECH, V, 736). La 1. ' doc. que da el DCECH es la de COVArrubias (vid. Tesoro, p. 991). Así que en cast. se doc. en 1611 por vez $1^{\mathrm{a}}$, mientras que en arag. se documenta ya h. 1372, es decir más de dos siglos antes que en cast. Cfr. GiLkison, s. v. val, vall 'empalizada, defensa, fortificación'. Comp. vallado 'cerca' en DLAA: «entro al vallado et el rigo dela cassa de Lilia enta aca» (DLAA, doc. $n^{\circ}$ 80, de Ansó, año 1304; p. 117, lín. 27). Frec.: vallas 1: 0,00227.

valliement adv. 'valientemente': assí como valient et spierto batallador, valliement et spierta con las sus galeras firió en el escol [estolt B] francés, 36.548. Adv. en -ment sobre el adj. valient (vid.). Luego se ha producido un acortamiento valient-ment $>$ valienment $>$ valiement, por aglutinamiento de las dos nasales en una, lo que implica que la - $t$ final del grupo - $n t$ no se pronunciaba. Frec.: 1: 0,00227.

valor s. f.(?) 'valor, entereza de ánimo, firmeza': Este don Sancho Remirez [...] fue muyt esforçado et de grant valor 17.26. Del lat. tardío vALOR, -ORIS. Frec.: 1: 0,00227.

vándalos (var.: vandellos) adj. y s. gentilicio 'individuos pertenecientes al pueblo vándalo': nin de los vándalos nin de los alanos 2.8; prendió las tierras de Bética et de $G a$ licia, las quales tenían los vandellos [vandalos $\mathrm{N}$ ] et los alanos, 3.40. Frec.: vándalos 1: 0,00227; vandellos (vandalos) 1: 0,00227.

varios adj. 'diversos, diferentes, variados' (quizá indef. 'más de uno, unos cuantos'; pero no está claro): et depués muytos et varios [diversos $\mathrm{N}]$ tractamientos 37.69. Etim.: es 
cultismo tomado del lat. varIUs 'de colores variados', 'variado, diverso'. La 1. ${ }^{\text {' doc. }}$ de vario que da Corominas es de hacia 1440 (en Juan de Mena). Además anota que «el plural varios en su valor gramaticalizado de 'más de uno, unos cuantos' es todavía poco usual en los clásicos» (DCECH, V, p. 747). Efectivamente, aún no está en el Tesoro de CovarRubias (ni con valor gramaticalizado, ni como simple adjetivo). Aun cuando no sea como indefinido sino como adjetivo calificativo, hay que hacer notar que la Crón. SJP adelanta la 1. a doc. dada por el DCECH en unos 70 años. Frec.: 1: 0,00227.

varón s. m. 'hombre, persona de sexo masculino': Et aquesti rey don Jayme fue muyt savio varón 38.622. // 'hombre noble': recolliose con grant poder de sus valientes varones a Palamos 38.224; Muerto el dito Remón Berenguer Cap d'estopa, los nobles varons de Catalunna por conte eslieron don Ramón Berenguer fillo suyo 31.2. Etim.: Según Corominas la etim. de varón 'hombre, persona de sexo masc.' es la misma que la de barón 'hombre noble'. Durante la Edad Media no hay distinción gráfica ni semántica entre un vocablo y otro (DCECH, p. 515, s. v. barón). En la Crón $S J P$. es difícil determinar con qué sentido se emplea en cada caso, aunque la mayor parte de las veces — sea con $b$-, sea con $v$ - — parece que es el de 'hombre noble'. Vid. barón. Frec.: varón 32: 0,07273; varones 6: 0,01364; varons 3: 0,00682.

varonilment adv. de modo 'de forma varonil'. e nudrió e industrió al dito rey a regir la tierra al millor que pudo varonilment. 33.14. Es más frecuente con b-: vid. baronilment. Frec.: 1: 0,00227.

varrio s. m. 'barrio': assí mismo al compte Alperche dio un varrio do posase que oy en día lo claman el caliz del compte Alperche, 19.51. Del árabe BARR 'afueras (de una ciudad)' o de su deriv. BARRî 'exterior', ár. vg. BÁRRI (DCECH, I, p. 527). CORRIENTE (2003: 120) explica que el cast. barrio procede del ár. andalusí bárri, neoár. barrî ‘exterior', alomorfo del arameo **bârrâ ‘tierra [exterior]'. En arag. se documenta también la forma bario, al menos en Ansó y en Chistén (EBA, 1999; 270; CASACUBerTa-Coromines, 1936, s.v.), y por lo que nosotros conocemos, también en el Somontano de Barbastro. Frec.: 1: 0,0227.

vassallo (var.: vasallo) s. m. 'vasallo, siervo, súbdito': et diogela con tal condición las ditas tierras que aquellas tenies en feu en dreita sennoria por el rey Remiro, et assin como puro homme et vasallo suyo obedeciesse 16.34; queriendo esquivar que a hombre de tan gran desonor et de tan grant infamia non fuessen sosmetidos vasallos 17.17; et avemos oydo dezir que muytas vegadas ses esdevenido que vassallo desenpara su sennyor 38.130. Etim.: del célt. *VASSALlos 'semejante a un criado', deriv. del galo vassos 'servidor', a través de su generalización en latín vulgar tardío, ya que ha tenido continuidad en casi todas las lenguas románicas: fr. y occ. vassal, it. vassallo, port. vassalo, cat. vassall, cast. vasallo (DCECH, V, p. 748). Indica COROMINAS 
que predomina desde el Cid la grafía vassallo con -ss-, y no hay duda de que la sibilante fue siempre sorda. Añade que no hay razón para suponer que el vocablo se tomó de Francia, porque el vasallaje tenía arraigo, profundo y lejano ya, en la vida castellana de los s. XI y XII. En todo caso, si hubo préstamo, este debió arrancar de la época del Bajo Imperio: la voz vassALLus se documenta en bajo latín desde el s. viII. Si se hubiese tomado del fr. u occ. vassal — como afirmaron MEYER-LÜBKE (REW, 9166), BLOCH y otros-, no se habría cambiado en cast. la terminación del vocablo galorrománico, pues el sufijo -al es frecuentísimo en iberorromance. También son antiguos y bien arraigados el port. vasalo, el cat. vassally el it. vassallo, y sus formas se corresponden regularmente según la fonética histórica: luego se trata de una palabra heredada en todas partes del latín vulgar, quizá en una fase del mismo algo tardía. Frec.: vassallo 3: 0,00682 ; vassallos 18: 0,04091 ; vasallo 2: 0,00455 ; vasallos 2 : 0,00455 .

vasso s. m. 'urna, recipiente, hornacina o hueco para enterramiento en una iglesia': fue soterrado en el monesterio de Ripol en el vasso de su padre 29.38. Etim.: lat. vg. VASU(M) 'vaso, vasija', lat. vAS, -IS 'vasija' (DCECH, V, 749, s. v. vaso). «Desde Berceo es frecuentísimo como denominación de recipientes litúrgicos y otros. En valenciano vaso significa 'colmena'». (Ibídem). Con el mismo significado de 'recipiente o hueco para enterramiento en una iglesia' en DLAA (doc. no 96, de Huesca, 1313; p. 138, lín. 14): el doc. asigna «vna sepoltura dentro en la claustra de la gllesia de San Per» y autoriza «que podades fer alli vuelta de piedra picada \& fer carnal \& meter vaso de piedra o toma pora vos $\&$ vuestra natura qual vos mas querredes, \& vos podades enterrar alli vos \& todos los vuestros». Frec.: 1: 0,00227.

vaxiello] s. m. 'bajel, nave, barco': Partió el dito don Alfonso con todo su escolt [estolt B; estol $\mathrm{N}]$ de galeras et de naves et de otros vaxiellos del dito puerto 38.516. Etim.: lat. VASCELLum 'vaso' (DEEH, s. v. vaxiello, p. 412). Comp. cat. vaixell (FABRA, s. v.; DL/C del IEC, 2007: vaixell 'nau de guerra gran', en 2. acepción); cast. bajel, «del cat. vaixell, y lo mismo el port. vaixel» (DRAE, 1970, s. v.); arag. vaxiello (DEEH, s. v., p. 412 y s. v. vascellum, p. 1053). La palabra aragonesa responde tb. a esta etim., por lo que parece voz patrimonial, derivada no del cat. sino directamente del lat. Comp. vaxiello 'chest, box'; 'boat', en el Libro de Marco Polo, versión arag. de J. Fernández de Heredia (ed. de NitTi, Voc., s. v., p. 100; vid. también en la ed. de SANGorRín, 2016, p. 246: vaxiello 'bajel, buque, barco'). Igualmente en el LT (RodÉs, 2016: 780). En GILKISON, s. v.: vaxiello, vaxiello, baxiello 'box, chest; boat; glass, cup, vessel'. En Blancas, Índice: vaxiellos 'vasos', significado con que también aparece en textos en arag. medieval. Así, en los DLAA: baxiellyo 'dim. de vaso; vasija; conjunto de cubas o tinajas en las bodegas' (REIDY, 1977: 117). Véase este ejemplo: «vna vendicion que el 
enel dito nombre procuratorjo hauia feyta al dito don Blasco Ximenez, sagristan, del dito palacio, siquiere casas, con todos los baxiellyos bjnarios, arcas, arqujbanques, \& ostillas otras que dentro aquel fuessen» (doc. de Jaca de 1412; $D L A A$, p. 196, lin. 16). Frec.: vaxiellos 4: 0,00909.

vedar 'evitar': los avía livrado por vedar que viandas non entrassen en el dito castiello 38.523. Del lat. VETARE 'prohibir, vetar'. Frec.: 1: 00227.

veer (var.: veyer) v. tr. 'ver': el dito Manfre demandó que se pudies veer con el dito don Alfonso por tal como era su pariente, et el dito don Alfonso respondiole que con él no se podía veer sin batalla. 38.562; Et veet [veyet $\mathrm{N}$ ] los prometimientos del rey de Castiella en quienta manera mala se conviertieron. 38.38; vehet [veyet $\mathrm{N}]$ quel tiempo de la paga del sueldo se acostó 38.308; porque muytos tiempos fueron unos, segunt veredes 4.12; et vidieronlo visiblement con el cavallero en las ancas 18.60. Del lat. VIDERE. En el Índice de BLANCAS (1641): veyendo 'viendo', veygan 'vean'. En arag. mod. se registran las formas beyer, bier, bijer (EBA, 1999: 304, 307, 316). Frec.: veer 4: 0,00909: veet [veyet] 1: 0,00227 ; vehet [veyet] $2: 0,00455$; vet $1: 0,00227$; veredes $1: 0,00227$; verlo 1: 0,00227 ; veyendo $7: 0,01591$; veyerse $1: 0,00227$; veyt $1: 0,00227$; vi 1 ; 0,00227 ; vidía $1: 0,00227$; vidiendo 2 : 0,00455 ; vidieron 3 : 0,00682 ; vidieronlo 1: 0,00227 ; vido 3: 0,00682 ; viendo $6: 0,01364$; viendose $1: 0,00227$; vieron 3: 0,00682 ; vio 1: 0,00027 ; visto 4: 0,00909 ; vistos $1: 0,00909$.

vegada s. f. 'vez', 'tiempo u ocasión determinada en que se ejecuta una acción': el qual havía vencido et desbaratado muytas et diversas vegadas aquellos 10.10; que la primera vegada tristos et dolentes sen tornoron 38.375; Et estando la dita ciudat de Almaría sitiada por el poder del dito rey, la qual muytas vegadas era estada fuerment combatida por aquel mismo poder... 38.358. // En la expresión todas vegadas o toda vegada 'siempre, en todas las ocasiones', es semejante a todos tiempos: et firo muytas et diversas batallas con ellos et toda vegada fue vençedor 12.49. Etim.: del lat. vg. *VICATA (DCECH, V, p. 796, s. v. very). Vegada se usó en cast. med. (Berceo, Alex., etc.), y también en port. ant. Actualmente, en cat. y occ. (DECLIC, IX, p. 72. En la Crón. SJP. no se puede considerar catalanismo, ya que vegada fue muy usual en el arag. med. (véase, por ejemplo, en GILKISON, 1984: 137; en ReIDy Fritz, 1977: 274; etc.). Veánse ejemplos en arag. med.: «que aya de pena x sueldos por cada begada» (doc. de El Pueyo de Jaca de 1432; EVT, p. 47); «todos los canonges dela dita seu residentes la vegada en la dita ciudat de jacca enel qual capitol fuemos presentes et jnteruenjemos» (doc. de Jaca de 1465; ALvar, EDA, II, p. 254, lín. 12). Blancas (Índice, 1641) recoge vegadas 'vezes'. Tb. se utiliza vezes en la Crón. SJP, pero generalmente con otro sentido, 'funciones inherentes a un cargo'. En arag. mod.: begada 'vez' en Biello Sobrarbe, Sesué, Benás, begata 'vez' en Bal de Bio, vegada 'vez' en la Alta Ribagorza (EBA, 1999: 291 y 1858). En Pardo (1938: 372), vegada 'racha, redada'. Sin embargo, el mismo autor cita también vegata: «Así decían cuando deseaban bailar con una: Yo, que te embreco; y ella con- 
testaba: Y yo que me doy por embrecata pa ésta y pa otra vegata» (PARDO, 1938, p. 134, s. v. embrecar). Frec.: vegada 22: 0,05000; vegadas 11: 0,02500.

vela] (var. vella]) s. f. 'vela (de los barcos)': los ditos mesageros van a enegrir las velas et [de $\mathrm{N}]$ todas las galeras en que eran venidos, 38.140; con LX galeras, XXIII naves et muytos de otros navilios menudos, tantos de qui bastó a CCC vellas et mas, 38.509. Del lat. VELA, pl. de velum 'vela de un navío'. Frec. velas 1: 0,00227; vellas 1: 0,00227.

veldat s. f. 'belleza': un su cavallo, el qual de bondad, veldat et de otras virtudes cavallinas todos otros cavallos sobrepuyua [sic, por sobrepuyana] 14.37. Deriv. del lat. BELLus 'bonito', aunque quizá tomado del occ. ant. beltat, deriv. de bel 'bello'. Cfr. DCECH, I, p. 562. También beldat. Frec.: 1: 0,0027.

vellesa s. f. 'vejez': el santo rey don Jayme en la su reverent vellesa fue opprimido en el dito regno de fiebre continua 36.68. [en la sua reverent vellesa VC, p. 129]. Etim.: deriv. con suf. -ITIA $>-e z a$, de viello < veTUlus. La $-s$ - se deberá a catalanismo. Comp. cat. vellesa 'edat avançada, qualitat de vell' (FABrA, Dicc., s. v.). En cambio, en el arag. de Fernández de Heredia: vellę, velleza (GILKison, s. v.). En arag. mod. biellera 'vejez' (Andolz, 1992, s. v., lo documenta en Echo). El EBA (1999: 397) registra biellera 'vejez' en Orós Alto y en Linars de Marcuello. Comp. viello. Frec.: 1: 0,00227.

vencedor adj. y s. m. 'vencedor': sino quel vencedor rey mandó que sende fues 38.274; et fizo by fer muytos castiellos et fuerças por costrennyr los moros, et fizo muytas et diversas batallas con ellos et toda vegada fue vençedor 12.49. Deriv. de vencer, con sufijo -dor que indica agente. Frec.: vencedor 9: 0,02046; vençedor 1: 0,0227.

vencer v. tr. 'vencer': vencida aquella batalla, vinose San Jorge con el caballero a la batalla de Huesca 18.58; e obtuvo vitoria don Alfonso con los aragoneses, vençidos, muertos e fuydos los leoneses 19.143; e fizo muytas batallas con moros et toda vegada vinçió aquéllos 18.115. Del lat. vINCERE 'íd.'. Frec.: vencer 1: 0,00227; vencida 1: 0,00227; vencidas 1: 0,00227 ; vencido 8: 0,01818 ; vençidos 3: 0,00682 ; vencidos 5 : 0,01136 ; vencieron $1: 0,00227$; vençieron $1: 0,00227$; vençió 2: 0,00455 ; venció 1 : 0,00227 ; vincie $1: 0,00227$; vincieron 2 : 0,00455 ; vinció 9: 0,02046; vinçió 1: 0,00227.

vencimiento s. m. 'victoria, vencimiento': et por aquesti tan grant vencimiento, los francesses huvieron grant esmagamiento et grant duelo 36.553; la christianadad hubo prendido grant reformamiento et gran crecimiento en la tierra por los vencimientos innumerables que obtuvieron los ditos Ennego Ariesta et su fillo García Enneguez, contra los moros. 11.6. Deriv. posverbal de vencer, con sufijo -miento que indica resultado de una acción (PHARIES, 2002: 403). Frec.: vencimiento 1: 0,00227; vencimientos 1: 0,00227.

vención (var.: vinción) s. f. 'vencimiento; acto de vencer o ser vencido': le ayudó et preservó de la vención 36.585; et aquesta vinción se cuydó esdevenir por tal como la su 
gent no era bien apparellada 36.586. Del lat. vg. *VINCIONE, deformación analógica de * viCTione (cfr. DCVB, t. 10, p. 697). Se utilizan como sinónimos en la Crón. SJP:: vencimiento, victoria vitoria. Frec.: vención 1: 0,00227; vinción 1: 0,00227.

vender] v. tr. 'vender': metió mano a los santuarios e yglesias e monesterios e prendiesen los trasoros de las eglesias, et vendía et enpeynava las heredades e posesiones de aquellas 19.149; pora la qual redempción la abbat de Sant Salvador de Leyre vendie el trasoro de su monesterio 20.236. Del lat. VENDERE 'íd.'. Frec.: vendía 1: 0,00227;

vendición s. f. 'bendición': Et recebida vendición por el dito abad, partiose de aquí et tornose en Pamplona. 11.49. Comp. bennedezir. Frec.: 1: 0,00227.

vengança s. f. 'venganza': et aquéll en el rio de Cinqua firo afogar por prender vengança de las malvadas faziendas [maldades e paraulas $\mathrm{N}$ ] que feitas avía contra éll 36.46. Deriv. de vengar. Frec.: 1: 0,00227.

vengar (var.: bengar) v. tr. 'vengar': Et depués el dito balient rey, queriendose bengar de las injurias que el compte de Tolosa le avía feytas... 33.62; como buen rey, quirie mas haver guerra con los moros que non con los christianos, maiorment pues con grant honor et victoria aviase vengado del rey de Castiella, fizo paz et tregua con él. 17.54. Etim.: del lat. vINDICARE 'reivindicar, reclamar', 'librar', 'vengar'. Común a todos los romances (DCECH, V, p. 770). Frec.: vengar 2: 0,00455; vengaron 1: 0,00227.

Veni: Comienzo de un cántico religioso en lat.: et cantando un canto o ymno que comiença «Veni Creator Spiritus...» 35.283. Frec.: 1: 0,00227.

venida s. f. 'venida': et el abat, saviendo la venida de su sennor, como mellor e mas onrradament pudo, con todos sus clérigos proçessión faziendo, ixiol a la carrera 11.16; porque él faría por guisa que su regno non havría menoscabo por la su venida. 38.258. Sustantivación del p. p. fem. del v. venir. Frec.: 2: 0,00455.

venino s. m. 'veneno': et el otro Guifre et murió con venino et fue soterrado en el monasterio de Ripol 23.79. Del lat. VENENUM 'droga, veneno'. La forma venino fue general en cast. en la Edad Media. Se explica por la gran frecuencia del sufijo -INUM (cfr. $D C E C H, \mathrm{~V}$, p. 769). También en arag. med.: venino 'veneno' en Fernández de Heredia (Gilkison, s. v.), en $V M$ (Tilander, $V M$, III, p. 318), en FA (TilanDER, FA, p. 608). Comp., en cambio, bereno en arag. mod. (KUHN, HAD, pp. 106 y 230; Rohlfs, DDPA, s. v.; ANDolz, s. v:; EBA, 1999: 298). Frec.: 1: 0,00227.

veninosso] adj. 'venenoso': enbioles maldición de moscas... et eran de tal natura,... et assí eran veninossas que tantost que cavallo o otra bestia tocavan, en continent murian 36.599. Deriv. de venino. Se registra en Fernández de Heredia (GILKIsOn, s. v.). En arag. mod. berenoso (ANDOLZ, 1992: 62; KuHN, HAD, pp. 106 y 230; EBA, 1999: 298). Frec.: veninossas 1: 0,00227.

venir v. intr. y prnl. 'venir': pregó carament al noble don Ramón Folch, viz̨comte de Girona, que aquellos que deffendedores la dita ciudat contra la malvada gent quel venien dessuso... 36.529; vinole enfermedat de la qual murió 38.563; el qual mesagero con desplazer que 
respuesta non le havía dada, vinose al rey et recontole... 20.118. // venir a acabamiento loc. verbo-nominal, 'consumarse': mas por tal como el dito infant renunció a la primogenitura et se metió en Orden, el dito matrimonio non pudo venir a acabamiento 39.13; Mas un cavallero qui servía a la dita reyna, veyendo quel atorgamiento del dito cavallo, si $\langle a\rangle$ acabamiento venía, sería muyt desplaziente al emperador...14.44. Del lat. VENIRE. Frec.: venir 7: 0,01591; vengo 1: 0,00227; venía 4: 0,00909; venían 1: 0,00227 ; venidas $1: 0,00227$; venido 12 : 0,02728 ; venidos $3: 0,00682$; venien 1: 0,00227 ; veniessen 1: 0,00227 ; veno 1 : 0,00227 ; vinían $1: 0,00227$; viniendo 1: 0,00228; vinientes 1: 000227; vinieron 16: 0,03637; vinies 6: 0,01364; viniessen 2: 0,00455 ; vino 57: 0,12956; vínole 1: 0,00227 ; vinose 7: 0,01591; vinos' 5: $0,01136$.

venturosso adj. 'venturoso': et por aquesto fue clamado venturosso, porque tantas conquistas et tan grandes et con tan pocas batallas non fueron feitas depués que Ihesu Christo fue venido en la Virgen Santa María. 35.2. Deriv. de ventura, con sufijo abundancial -osso. Frec.: 2: 0,00455.

verdaderament adv. 'verdaderamente': por tal que escondidament dassen dampnage a éll et a sus gentes assí como verdaderament fizieron 36.512. Frec.: 4: 0,00909.

verdadero adj. 'verdadero': trató por otra manera verdadera que la dita paz se fizies en Catalunnya 38.70; del qual accident, assí como bueno verdadero christiano et depués de breus [de] dias murió en hedat de XXVII annos 37.94. Deriv. de verdat. Frec.: verdadero 6: 0,01364; verdadera 2: 0,00455.

verdat (var.: verdad) s. f. 'verdad': está pero en verdad [empero $\mathrm{N}]$ que regnó el dito rey don Sancho Remirez en Aragón en antes que fues rey de Navarra ИI annos 17.58; Es verdat empero que grant fambre et gran malautia se metió en la buest del dito rey 38.398. Del lat. VERITAS, -ATIS. Frec.: verdat 11: 0,02500; verdad 6: 0,01364.

verde] s. f. 'verde, de color verde': et eran de tal natura, figura et collor que de la una part eran cárdenas et de la otra verdes 36.598. Del lat. VǏRǏDIS 'verde', 'vigoroso, vivo'. Frec.: verdes 1: 0,00227.

vergonna s. f. 'vergüenza': empero, por esquivar vergonna et desonor que lende podría seguir, como millor pudo, cubrió celadament el prennado de su filla 23.13. Del mismo origen y con igual resultado que en cat. vergonya (DL/C del IEC, 2007, s. v.) y en it. vergogna < lat. verecundia (Devoto, s. v.). También verguença (vid.). Curiosamente, en port. aparece igualmente este doble resultado, pues en el siglo XIII se documentan tanto vergonha como vergonça (CunHA, 1986: 817). Frec.: 1: 0,00227.

verguença s. f. 'vergüenza': ¿et non vos yes verguença [es vergoyna $\mathrm{N}$ ] que delant vosotros aquesti cavallero catalán aya desmentido a mí...? 38.328. Del lat. verECundiA. Frec.: 5: 0,01136.

vermelliar] v. intr. 'enrojecer, teñirse o mancharse de rojo': tan fuert batalla hi fue feita que la mar vermelliana [vermellava $\mathrm{N}$ ] de la sangre de la gent que muerta et ferida yera 
sobre la mar 38.269 (error por vermelliava): Deriv. de vermello < lat. VERMICULUS 'gusanillo', 'cochinilla', empleado para producir el color grana (DCECH, I, p. 567). Comp. port. vermelho 'da cor do sangue', s. XIII; avermelhar, s. XVIII (CuNHA, 1986: 817). Frec.: vermelliana [vermellava] 1: 0,00227.

vermellura s.f. 'rojez, cualidad de rojo o bermejo': et eran de tal natura, figura et collor que de la una part eran cardenas et de la otra verdes et en cada una part vermellura se denotava 36.598. Deriv. de vermello 'bermejo, rojo'. Comp. cat. vermellor 'qualitat de vermell' (FABRA, s. v.; DL/C del IEC, 20017, s. v.). El DLE (2014) registra bermejor como sinónimo de bermejura, con la marca de «muy poco usado» y bermejura 'cualidad de bermejo' como «desusado». Frec.: 1: 0,00227.

vesegodos adj. y s. 'visigodos': En aquesta isla de Estancia habitaban aquestas naciones: godos, vesegodos, estargodos, davirugis, arcas et tanis. 3.2. Frec.: 1: 0,00227.

vestido s. m. 'vestido, prenda de vestir, ropa con que se cubre el cuerpo': Et depués el dito santo rey se despulló de los vestidos reales bumilment et [...] vistiosse el ábito de monges de Poblet 35.283. Frec.: vestidos 1: 0,00227.

vestido adj. y p. p. del v. vestir, 'vestido, cubierto de ropa': fuese para el enperador de Aragón e pareçiole ant'él vestido d'escarlata en un cavallo blanco 19.84; porque en antes todos los reyes se posavan en lur taula con cavalleros et havian [yvan $\mathrm{N}$ ] ansí vestidos como cavalleros 3.52. Vid. vestir. Frec.: vestido 2: 0,00455; vestidos 2: 0,00455.

vestiduras s. f. 'vestiduras': Et tantost despullaronle las vestiduras que aduæía et vistieronle reales 12.39 . Frec.: 3: 0,00682.

vestiment $\mathrm{s}$. m. 'vestidos, vestimenta, ropa': Et tantost la condessa vistió el moso con vestiment de peregrino 23.22. Del lat. vestimentum, con tratamiento fonético catalanizante. Frec.: 1: 0,00227.

vestir v. prnl. 'vestirse': Et en antes quel se visties el ábito, firo venir en la villa de Aljacira, do la ora iazía enfermo, su fillo don Pedro 35.251; Et depués el dito santo rey se despulló de los vestidos reales humilment et [...] vistiosse el ábito de monges de Poblet 35.283 . Del lat. VESTIRE 'íd.'. Frec.: vestir 1: 0,00227; vistieronle 1: 0,00227; visties 1: 0,00227; vistió 2: 0,00455; vistiosse 1: 0,00227 .

veynte (var.: vint) adj. num. 'veinte': veynte nueve batallas vençió 19.4; Et regnó el dito noble rey, bien et noblement, vint e cinquo annos 13.15. Etim.: lat. VIGǏNTI > viinte > veinte, vint(e) (DCECH, V, p. 756). Las formas veynte y vint obedecen a una evolución fonética distinta, pero sería arriesgado afirmar que la segunda forma es de origen catalán o de influencia catalana. En este texto predomina vint, pero también es más abundante en otros textos en arag. med. Así, en Yúcuf, vinte; en los DLAA, vint (ReIDy Fritz, 1977: 279), e igualmente vint en OB (VÁzQuez Obrador, 2011c: 56). Véanse algunos ejemplos: «fiz trayer el dito dia vint cargas de agua» (LM: 85); «cient cabeças de ouellas de fillos, cinquanta de carneros \& vint borregos» (DNT, III, 1425: 30.65-66). Vid. PоTTIER, AFA, 
II, 1947, pp. 145-149, sobre los numerales en arag. med. y en especial sobre vint veynt veyent, pp. 147-148. En arag. mod. es general bente en todo el dominio lingüístico del arag. (la única excepción la constituye Benasque, donde se registra vint), e incluso se extiende el área de bente por puntos de la zona centro-oriental de la provincia de Zaragoza y algunos puntos del norte de la de Teruel, mientras que en la franja oriental, de lengua catalana, se registra vint (ALEANR, mapa 1588). Frec.: veynte 1: 0,00227; vint 2: 0,00682.

vezes s. f. pl. 'funciones, autoridad o jurisdicción que una persona ejerce en un puesto o cargo': queriendo resemblar a su padre et siguiendo aquestos actos et las vezes de su padre 36.71-73; que pues el dito cardenal era muerto, a otro devies comendar sus vezes 38.97-98. Aquí conviene la 7. ${ }^{a}$ acep. del DRAE (1970, s. v. ver), $8^{a}$ acep. en el DLE (2014, s. v.): «pl. ministerio, autoridad o jurisdicción que una persona ejerce supliendo a otra o representándola. Ú m. con el verbo hacer. Hacer uno las veces de otro; hacer uno con otro veces de padre». // s. f. 'vez, tiempo u ocasión en que se hace u ocurre algo': et los porteros como locos et de poco bien, lo que muytas vezes les avien [contece $\mathrm{N}$ ] 'lo que muchas veces les ocurre', 20.31. Aquí tiene el sentido habitual del cast. veces 'tiempo u ocasión determinada en que se ejecuta una acción' (DRAE, s. v. vez, 2. acep.; DLE, 2014, s. v.). En esta 2. acep. es mucho más frecuente vegada (vid.). Etim.: del lat. vicis ‘turno en el ejercicio de una función' (DCECH, V, 796). Frec.: 3: 0,00682 .

vezado] adj. 'acostumbrado, habituado, experimentado': eran vezados de adozir dardos et andar de pie los de cavallo 12.64. Etim.: deriv. de vezo 'costumbre' < lat. VǏTIUum 'defecto, falta, vicio, tara, imperfección' (DCECH, I, p. 421, s. v. avezar). Comp. arag. mod. abezar(-se) 'aficionarse, engolosinarse', amalbezau 'dado a malos vicios', eshezar 'destetar' (Andolz, 1992: 5, 25 y 180). Comp. acostumbrado (35.207). Frec.: vezados 1: 0,00227.

via s. f. 'vía, itinerario': por denunciar a las naves et al otro navilio que fiziessen aquella misma via 38.527. Del lat. VIA. Frec.: via 1: 0,00227; Via 1: 0,00227.

viage (var.: viaje) s. m. 'viaje': quería passar en el dito viage personalment 35.207; et depués quando el dito viaje fue venido, sitió Tortosa 32.25. Del occ. viatge < lat. VIATICUM 'provisiones para el viaje' (DCECH, V, 797). Parece un préstamo muy temprano, perfectamente asimilado, como otros términos con terminación en -age o -atge, que en arag. mod. es -ache, como por ejemplo: mesache, orache, etc. Frec.: viage 2: 0,00455; viaje 1: 0,00227.

vianda s. f. 'comida, provisiones, alimento, comestibles': por fambre grant que sufrian de pan, de vino et todas viandas et por grant mortaldat que en ellos era 36.618; los avia livrado por vedar que viandas non entrassen en el dito castiello 38.523. Del fr. viande ant. 'conjunto de alimentos' < lat. vg. *VIVANDA, lat. cl. vivendA 
(de vivere 'vivir') 'lo que es necesario para vivir' (Dauzat/Dubois/MitteRAND, 1977: 791; DCECH, V, 835). Se registra vianda en Fernández de Heredia (GiLkison, s. v.). Véase un ejemplo en los DLAA: «do haura bueno \& suficient domicilio por recoyllir a caminantes \& mercadarias, do habitaran estagero ho estageros suficientes $\&$ aptos, qui venderan viandas a los viandantes continuament, al menos pan \& vino» (DLAA, doc. $\mathrm{n}^{\circ} 114$, de Gistaín, 1350; p. 168. lín. 21). Frec.: vianda 1: 0,00227; viandas 11: 0,02500.

vicario] s. m. 'lugarteniente, autoridad militar en zona de frontera': et aquí vicarios et officiales constituydos, en Catalunnya sen tornó pagadament et alegre. 38.215. Del lat. vicarius 'sustituto, lugarteniente'. Comp. en Fernández de Heredia vicario 'military rank' (GILKISON, s. v.). Frec.: vicarios 1: 0,00227.

victoria (var.: vitoria) s. f. 'victoria': et con grant victoria el dito don Alfonso levantó el campo et firo grandes gracias et lohores a Dios 38.538; et avidas aquestas dos vitorias tornose de Castilla 19.154; e obtuvo vitoria don Alfonso con los aragoneses, vençidos, muertos e fuydos los leoneses 19.143 Tomado del lat. VICTORIA. Frec.: victoria 21: 0,04773; victorias 2: 0,00455 ; vitoria 6: 0,01364 ; vitorias 1: 0,00227 .

vida s. f. 'vida': su grant savieza supo fer a sus vassallos exolvidarla; por la qual cosa buvo paz et amor entre sus gentes en toda su vida 38.627. Aparece varias veces la locución: a vida suya 'de por vida, de forma vitalicia': diole Sarasanz, Roncal, Cadreta et Valetra a vida suya con tal pero condición que depués muert suya los ditos lugares tornassen al rey de Aragón, 20.181-20.183; et fuele con homenage livrada a vida suya solament et depués dias suyas tornás a la casa de Aragón, 20.249-250. Etim.: del lat. vITA 'íd.' (DCECH, V, p. 835). Frec.: 45: 0,10225.

viedo s. m. 'veto, prohibición', 'censura eclesiástica': dio sentencia contra éll, privando aquéll de los regnos et honores suyas, possando viedo [Ecclesiastico interdicto VL, pág. 180] en todas las tierras suyas 36.459. Etim.: del lat. VӖTO, primera pers. del pres. de ind. de VĔTARE 'prohibir, vetar' (DCECH, V, 752, s. v. vedar). Aunque ya en Berceo se doc. deviedo, forma que recoge como ant. el DRAE (deviedo ant. 'acción y efecto de devedar' / 2. ant. 'vedado' / 3. ant. 'entredicho, censura eclesiástica', en $D R A E, 1970$, s. v.). La forma veto se registra a partir del s. XIX (en el $D R A E$ ) y parece que se tomó del lat. por conducto del fr. veto (1718) (DCECH, V, 752). En la Crón. SJP. viedo parece una forma popular del mismo origen, que por tanto adelanta la doc. en tres siglos y medio (si no se tiene en cuenta la forma deviedo). Comp. arag. mod. bieda 'prohibición de sacar ganados, granos y otras mercancías fuera del reino' (ANDOLz, 1992: 65; PARDO, 1938, s. v. vieda). Frec.: 1: 0,00227.

viello adj. 'viejo': et con una muller viella ella lo envió a su madre, 23.22; et ya sia quel dito rey fuesse viello et de grandes dias, 35.204. Etim.: del lat. VĚTuLus, dim. de VĔTus, -ERIS (DCECH, V, p. 805, s. v. viejo). Es forma habitual en los textos aragone- 
ses medievales, muy a menudo con $b$-. Véase algún ejemplo: «Item, en la canbra baxa otro leyto de tablas, con vn almadrac biello, .I. trauesero, .II. literas...» (doc. de Panzano de 1360; DLAA, doc. no 120, p. 176, lín. 12). Blancas (Índice, 1641) recoge viello 'viejo'. Se conserva en arag. mod.: ANDOLZ (1992: 65) registra biello en Echo; el EBA (1999: 307), en Ansó, Pandicosa, Plana de Uesca, Biello Sobrarbe, Echo, Lobarre, Bal de Broto, Bal de Chistau, Oto, Bal de Bio, Sallén, Mundot, Benás, A Buerda, A Fueba, Orós Alto, Linars de Marcuello. Es voz común a todas las lenguas románicas. Comp.: port. velho, gall. vello, ast. vieyu, cat. vell, occ. vièlh, francoprovenzal viely, fr. vieux, romanche $v e g l$, friulano vieri, piamontés vej, milanés vegg, véneto vecio, it. vecchio, siciliano vecchiu, sardo betzi, rum. vechi, arrumano veclju (VALLÉs, 2007: 520). Frec.: viello 3: 0,00682; viella 1: 0,00227.

vientre s. m. 'vientre, seno materno': «vi la criatura qui sacó la mano por la ferida del vientre de su madre et sin periglio vivo los saqué»12.33. Del lat. VĔNTER, -TRIS, acus. VĔNTRE(M). Frec.: 5: 0,01136.

vigilia s. f. 'vigilia, en el sentido de día que antecede, víspera de una festividad': el dito rey don Jayme de Aragón devotament murió en hedat de LXXI annos en la ciudad de Barchinona, la vigilia de Todos Santos 38.630. Tomado del lat. vigilia 'vigilia, vela, acción de velar'. Frec.: 4: 0,00909.

vigor 'vigencia', 'vigor, fuerza legal': el Padre Santo envió sus mesagueros a éll requiriendo que por vigor de la convinencia entre el padre Santo et él feita et promedida... 38.218; que por vigor del homenage al qual era estreyto por razón de las tierras que tenía en feu... 36.403. Del lat. VIGOR, -ORIS 'fuerza vital, vigor, robustez'. Frec.: 2: 0,00455.

vigorosament adv. 'vigorosamente, con fuerza': el rey de Aragón les fue detrás et vigorosament et baronil firió en los franceses 36.654. Frec.: 4: 0,00909.

vildad] s. f. 'mala acción; acción indigna o infame, vileza': queriendo punyr el rey de Francia et sus gentes de las vildades et crueldades que feitas avian contra el 36.593. Deriv. de vil < lat. VILIS 'vil, barato, sin valor'. Frec.: vildades 1: 0,00227.

villa s. f. 'villa, ciudad'; 'agrupación urbana y entidad de población de menor categoría que la ciudad'. Así parece deducirse de la enumeración siguiente, que va encabezada por los miembros de mayor categoría o importancia: firo aplegar Cortes generales do fueron aplegados arcevispos, vispos, prelados, barones, universidades de ciudades et de villas et de otras gentes 35.122-124; cavalleros, sindicos, procuradores de ciudades et de villas de Catalunnya 38.466; Et plegado todo el escolt [estolt $\mathrm{B}$; estol $\mathrm{N}]$ el dito don Alfonso sitió villa de Yglesias 38.528. Etim. del lat. VILLA 'casa de campo, granja', 'residencia donde se recibía a los embajadores cuando no se les permitía la entrada en Roma'. La 1. a documentación se encuentra en el Poema de Mio Cid y en Berceo. En el Cid villa 'población en general', con el mismo valor de çibdat. Tb. Berceo usa villa y çibdat como sinónimos perfectos. «En los textos medievales, en general, es difícil calibrar la importancia exacta de la po- 
blación llamada villa, aunque regularmente se trata de algo mayor que una aldea. [...]. En el s. XIII cibdat es de uso algo menos frecuente [...], la lucha de los dos vocablos va concretándose en el sentido de que ciudad expresa un núcleo urbano mayor, aunque villa conserva el matiz de población con ciertos privilegios especiales, reconocidos legalmente. [...]. Más tarde, villa ha seguido perdiendo terreno, sobre todo en el uso urbano del español... Más conservador de lo antiguo, el cat. sigue empleando su vila libremente, distinguiendo ciudat, vila, poble (= pueblo o aldea) y veïnat (= aldea, caserío o cortijada) como cuatro escalones de importancia demográfica decreciente» (DCECH, V, p. 818). Frec.: villa 23: 0,05228; villas 15: 0,03409.

vilment adv. 'con alevosía': todas las otras reliquias de aqui et de las otras eglesias lançoron et vilment consumoron 36.568. Deriv. de vil. Frec.: 2: 0,00455.

vint adj. num. 'veinte': et aqui vino el noble don Francisco Carroz almirant con vint galeras qui se armoron en Valencia 38.501; Et regnó el dito noble rey, bien et noblement, vint e cinquo annos. Del lat. VIGINTI. Comp. veynte. Frec.: 2: 0,00455.

vipria] s. f. 'víbora': assí como a viprias [vipras $\mathrm{N}$ ] que naturalment quando naxen matan lurs madres 29.17. Del lat. viPERA 'íd.'. Comp. arag. mod. gripia 'serpiente venenosa', 'mujer pendenciera' (ANDOLz, 1992: 239); 'víbora pequeña', 'lución' (RohlFs, DDPA, p. 267). En el EBA (1999: 1045-1046) se encuentran 37 registros de gripia 'serpiente venenosa', 'víbora' o 'mujer pendenciera, que grita mucho' en diferentes puntos del Alto Aragón. Comp. gasc. gripo 'víbora', fr. guivre (RohlFs, 1970: 66, \$149). Frec.: viprias 1: 0,00227.

virgen adj. y s. 'Virgen, la Virgen María': por el qual milagro a honor de la bien aventurada Virgen Madre nuestra sennyora Santa María dio grant trasoro por bastar la iglesia de Valverde. 35.222. // 'virgen, muchacha virgen': et cómo los franceses fazían todos dias diversos males, greuges et desonores, assi en desflorar virgines et desmaridar mulleres maridades et forçar mulleres biudas 36.193. Cultismo tomado del lat. virgo, -inis 'muchacha, doncella, virgen'. Frec.: Virgen 3: 0,00682; virgines 1: 0,00227 .

virtud s. f. 'virtud': et por la su probeza et virtud que en él era 14.23; fue nombrado el Casto, porque sobre todas las virtudes ovo esta 33.4. Etim.: tomado por vía semiculta de VǏrTUS, -UTIS, acus. VǏRTUTE(M) 'fortaleza de carácter, virtud' (DCELC, IV, 749). Frec.: virtud 1: 0,00227; virtudes 3: 0,00682.

virtuoso (var.: virtuosso) adj. 'virtuoso': nascido de virtuoso rey padre et virtuosa madre 36.11; de la qual elección todo el regno fue alegre et pagado, mayorment como simient de virtuosso princep avien elegido por sennyor lur. 36.725. Del lat. VIRTUOSUs. Frec.: virtuoso 12: 0,02728; virtuosso 2: 0,00455; virtuosa 1: 0,00227.

visar v. tr. 'visitar'. poso en su corazón de visar [visitar $\mathrm{B}, \mathrm{N}$ ] las altez̧as de los Apóstoles 38.170 [quizá error en el ms. E por visitar]. Vid. visitar. Frec. 1: 0,00227. 
visiblement adv. 'visiblemente, patentemente': tan grandes et tan speciales gracias le demostroron visiblement 35.151. Frec.: 2: 0,00455.

visitar v. tr. y prnl. 'visitar': poso en su corazón de visar [visitar $\mathrm{B}, \mathrm{N}$ ] las altezas de los Apóstoles 38.170 [error?]; visitando los santuarios de los Apóstoles, 34.32; et visitandose assi la su tierra, vinose en la villa de Perynia, 33.114; el dito rey quiso entrar en el condado de Proenica por visitar aquél e conocer 33.38. Cultismo tomado del lat. visitare 'ir a ver', 'ver con frecuencia'. Frec.: visitar 4: 0,00909; visitando 1: 0,00227; visitandose 1: 0,00227.

vispo (var.: bispe, vispe, ovispo) s. m. 'obispo': de la qual procreó dos fillos, el primero avie nombre Sancho et el otro García qui fue bispe de Jacca, 16.26; de bueno en millor puyando según merecía, fue electo en ovispo de Burgos 20. 80; con grant conpannya de arcevispes, vispes et prelados et otros [sic] nobles gentes 36.93; et muytos de otros vispos

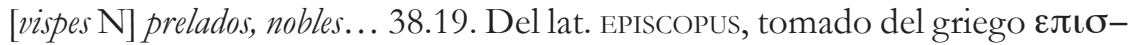

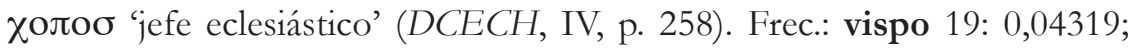
vispos 4: 0,00909 ; vispe $5: 0,01136$; vispes $1: 0,00227$; ovispo 3: 0,00682 .

vistas s. m. 'entrevista, conversaciones': El Padre Santo Bonifaci et Ferederich dessuso dito huvieron vistas ensemble por tractar entre éll et la Yglesia 38.151. Frec.: 5: 0,01136 .

vituperado adj. 'vituperado': por aquesti pecado... fue muyt vituperado et yrado por todo el mundo 30.21. Frec.: 1: 0,00227.

vituperio s. m. 'vituperio, afrenta, deshonra, oprobio': et a grant desonor et vituperio sende tornoron muertos et consumados 38.548. Cultismo tomado del lat. vituperium. En cast. se registra a partir del s. XV (BDELC, s. v. vituperar). Frec.: 1: 0,00227. viudo] s. f. 'viudo'. Vid. biudo.

vivir: Vid. bivir.

vivo adj. 'vivo': et sin periglio vivo lo saqué 12.34; pero nunca lo troboron ni muerto ni vivo 19.119; sacó la criatura viva del vientre de su madre 12.11. Etim.: del lat. VIVUs, -A, -UM. Es voz común a todos los romances (DCECH, V, p. 834). Frec.: vivo 2: 0,00455 ; viva 3: 0,00682 .

vizcondado s. m. 'vizcondado': heredero del condado de Urgel et del vizcondado d'Ager 39.34. Frec.: 3: 0,00682.

vizconte (var.: vizconde, vizcomte) s. m. 'vizconde': et pregó carament al noble don Ramón Folch, vizcomte de Cardona, que aquellos deffendedores de la dita ciudat... 36.527; et engendró dos fillas, la una muller del conte de Pallars et la otra del vizzconde de Laltres 29.52; el otro don Jayme qui fue comte de Urgel et vizconte d'Ager. 38.593. En más del 90\% de las ocasiones aparece vizconte. Frec.: vizconte 10: 0,02273; vizconde 1: 0,00227; vizcomte 1: 0,00227.

voca s. f. 'boca': «e riendo vos las manos, la voca et el cuerpo que vos firieron omenage por ella» 19.87. Del lat. BuCCA. Frec.: 1: 0,00227. 
volenterosament adv. 'de buena gana, gustosamente, de buen grado': por estas razones con los aragoneses et navarros fue volenterosament [valerosament $\mathrm{N}$ ] cuentra el rey de Castiella 17.34. Adverbio de modo en -ment formado sobre la forma femenina del adj. volenteroso. De uso frecuente en arag. med.: «Et sabet que aquellos que son del linage del Grant Can fazen parentesco volenterosament con aquellos de la casa del preste Johan por la voluntat del Grant Can» ( $\mathrm{Li}$ bro de Marco Polo; NitTi, 1980: 16, lin. 13; SANGORRín, 2016: 35). «antes queremos \& atorgamos volentarossament quel dito perdonamiento, difinimiento \& quitamiento, aya ualor efirmeça para todos tienpos jamas» (DLAA, doc. 72, de Santa Cilia de Jaca, de 1296; p. 103, lín. 19). Frec.: 1: 0,00227.

volenteroso (var.: volentaroso) adj. 'deseoso', 'gustoso', 'bien dispuesto': el dito rey que volentaroso yera de conquerir el regno de Secilia 38.293; fue muyt franco varón, bueno et volenteroso de haver batallas 11.3. En Fernández de Heredia: volunteroso, volenteroso, volentoroso, etc. (Gilkison, s. v.). Deriv. del lat. voluntarius $>$ *volontero $>$ *volentero (por influencia del adv. volenter 'de buen grado' < lat. vOLUNTARIE), con sufijo abundancial -oso. Comp. fr. volontaire, it. volenteroso, occ. volontós (ALIBERT, 1988: 698, s. v. voler). Frec.: volenteroso 1: 0,00227; volentaroso 1: 0,00227 .

volumpne s. m. 'volumen, tomo': segunt que las coronicas dizen mas largament, las de Castiella, en otro volumpne de livro 3.94. Del lat. vOLUmen, -INIS. Comp. port., it., fr. volume; cat. volum. Frec.: 1: 0,00227.

voluntario] adj. 'voluntario': et la voluntaria diffamación que le era estada levantada 14.67. Tomado del lat. voluntarius, -a, -um 'voluntario, espontáneo, libre, voluntario' (SEgura, 2001: 849). Este cultismo no se registra en cast. hasta 1438, según el BDELC. Frec.: voluntaria 1: 0,00227.

voluntat (var.: voluntad) s. f. 'voluntad': porque pudies complir lo que havía en coraçón et en voluntad 34.11; le dexó el dito regno por tal como el dito rey don Jayme con voluntat et conoscencia [conosencia $\mathrm{N}$ ] de dos hombres buenos... 38.604. Tomado del lat. voluntas, -atis acus. voluntate $(m)$ 'voluntad, intención, volición, deseo' (SEGURA, 2001: 849). Frec.: voluntad 4: 0,00909; voluntat 13: 0,012955.

vos pron. pers. átono de $2^{a}$ pers. pl. 'os': «O cavalleros jet non vos yes verguença [es vergoyna $\mathrm{N}$ ] que delant vosotros aquesti caballero catalán aya desmentido a mí...» 38.327; «benediga vos Dios, el Padre, el Fillo et el Sant Spiritu» 35.278. «Fillos otros mios, al verdadero Dios vos comando» 35.377. Frec.: 15: 0,03409.

vós forma tónica, tratamiento de respeto de $2^{\mathrm{a}}$ pers. sing., 'vos': «Sennyor, dezit nso a qui queredes que esliamos por sennyor, datnos rey pues que vos nos desenparades» 38.136; "yo so venido ante vos, lo que vos prometie por mi sennyor el rey d'Aragón» 36.376; «fet ne lo que von [vos $\mathrm{N}]$ pueredes [queredes $\mathrm{BN}]$ » 38.139. Frec.: 6: 0,01364 . 
vosotros pron. pers. sujeto 'vosotros': «grant desonor es de mí et de vosotros» 38.334; «O cavalleros jet non vos yes verguença [es vergoyna $\mathrm{N}$ ] que delant vosotros aquesti caballero catalán aya desmentido a mí...» 38.327. Frec.: 4: 0,00909.

voto s. m. 'voto, promesa': Et quoando lo ovo complido su prometimiento e voto, los demás de los reyes de Espaynna inclinados e indutos a paz e concordia, tornose en su tierra 33.111. Tomado del lat. votum 'promesa que se hace a los dioses'. Frec.: 1: 0,00227.

vuestro adj. poses. 'vuestro': «non de suppo res entro que agora recibie vuestras letras» 36.377; uyt emala ora, que con vuestro tracto avemos perdido el regno de Aragón» 36.382. Del lat. vg. VOSTER, -TRA, -TRUM. Frec.: vuestro 1: 0,00227; vuestras 1: 0,0227.

\section{$\mathbf{X}$}

xarcia] s. f. pl. 'jarcias, conjunto de aparejos y cabos de un buque': Et en continenet, los ditos mesageros van a enegrrir las velas et todas las galeras en que eran venidos et todas las xarcias [exarcias $\mathrm{N}$ ] 38.141. Etim.: según Corominas-Pascual (DCECH, t. III, p. 495, s. v. jarcia), del griego bizantino $\varepsilon \xi \alpha \rho \tau \iota \alpha$, pl. de $\varepsilon \xi \alpha \rho \tau \iota$ ' 'aparejos de un buque', deriv. del gr. $\varepsilon \xi \alpha \rho \tau \iota \xi \varepsilon \iota v$ 'equipar, aparejar un navío', y

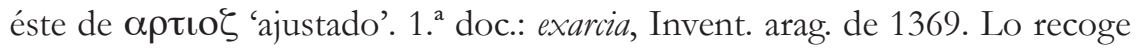
PotTier en ELIA, pág. 151, núm. 613, con el sentido de 'attirails' ['trastos, objetos, arreos, aparatos'], 'choses en désordre'. Cast. jarcia, cat. xarcia. Para Corominas-Pascual ahí tiene el sentido de 'enseres'. En otro inventario de 1374 aparece en el sentido de 'conjunto de muchas cosas desordenadas'. Pero parece que el sentido primitivo sería, como en los demás romances, el marino, ya documdentado en A. Palencia. Cervantes y Quevedo lo emplean en el sentido de 'carga de cosas distintas para cierto uso'. Del mismo origen: port. enxàrcia 'cordaje de navío', oc. ant. sàrsia [1374] o sàrtia [1390], hoy sàrtis, it. sarte o sartie 'aparejos de navio'. En cat., hoy la forma común es xarxa, pero existen las variantes xàrcia, sàrsia, xèrxa o xèrxi, sàrtia y la acep. más corriente es 'red de pescar'; en la Edad Media se halla exàrcia desde el s. XIII 'aparejo de navegación', 'cordaje' (DCECH, III, 495). Decía el DRAE (1970) que procede del ár. SARSIYA 'cuerda que sujeta el mástil'. Pero el DLE (2014) da ya la más verosímil etim. que propone el $D C E C H$. Vid. sobre xarxa y exàrcia en cat.: CoRomines, "Les relacions amb Grècia reflectides en el nostre voca- 
bulari”, en Entre dos llenguatges, III, Barcelona, Curial, 1977, pp. 178-230; pp. 201-203. Comp. el sentido en arag. moderno jarzia 'abundancia sobre todo de cosas inútiles' en el Somontano y la Hoya de Huesca (Andolz, 1992, s. v., 4. ${ }^{a}$ acepción); jarzia 'comida poco apetitosa' en el Somontano de Barbastro (Coscujuela, A lueca, Huesca, 1982, voc. s. v., p. 188); Mostolay (2007) da para el Somontano de Barbastro varias acepciones, entre ellas: 'cosa en general', 'productos que componen un guiso, condimento', 'montón, cúmulo', 'pejiguera, estorbo, enredo; trasto, cosa inútil', y agrega: «La jaræ̨ia era una red gruesa y pesada de esparto, posiblemente de aquí venga el significado actual, dado lo mucho que ocupaba y estorbaba. Ya en el siglo XVII se documenta exarçia u xarçia con el significado actual.» En Campo (Ribagorza): jarzia 'todo lo que se saca de la huerta; cantidad revuelta y heterogénea' (MASCARAY, Benas, trallo y fuellas, Huesca, 1984, voc., s. v., p. 117). También se registran acepciones más cercanas al sentido originario: 'jábrega, red gruesa' (PARDO, 1938, $s$. v. jarcia). Si bien el mismo autor registra otras acepciones: 'jauría de perros', 'abundancia', 'copia de conocimientos, sentatez, etc.' (PARDO, 1938, ibídem). Para el valle de Chistau se ha registrado la acepción más general: 'gran cantidad de cosas variadas y heterogéneas' (Blas-Romanos, 2008: 338). En las Cinco Villas alto-orientales se registran también algunas de estas acepciones (Romanos, 2003: 2007): 'verduras y productos de la huerta, 'estudios, habilidades, conocimientos'; pero también otras: una, relacionada con 'jauría de perros' es 'grupo de gente, concurrencia de personas diversas y a veces con un tono despectivo' (en Orés y Salvatierra de Esca); otra, relacionada con el significado marinero, es 'ramas verdes y flexibles utilizadas para atar los troncos de la almadía' (en Salvatierra de Esca). Es interesante también observar las acepciones que recoge Moneva (2004 [1924]: 289): 'jauría de perros' (Zaragoza), 'red de cuerda de malla más espesa que la jábrega' (Zaragoza), 'red hecha de sogas de esparto que va puesta en el carro para transportar paja' (Ribera de Jalón), 'abundancia de una cosa de poco valor' (Somontano, Ribagorza), 'provisiones de boca para comida ordinaria o banquete, en donde hay abundancia de cosas buenas' (Zaragoza). Frec.: xarcias 1: 0,00227. 


\section{Y}

y (var.: hi, hy, i) compl. pron.advl. 'ahí, allí, en ese sitio': emplidos dos pocos con tierra que hi fue gitada dessuso 38.558; et múdolos by del monesterio de Clunyego 14.97; et a la nación que Ercules y avía lexado 3.5. Del lat. ǏBI 'aquí, allí, ahí, en ese lugar, en aquel sitio’. Frec.: y 47: 0,10683 (incluyendo tanto el compl. pron.-advl. como la conj. cop.); hi 24: 05455; hy 3: 0,00682.

y (var.: e, et) conj. cop. 'y': los reyes de Aragón y de Navarra 4.11; y en aquesto quasi concordavan todos 20.6. Del lat. ET. Generalmente et, e (vid.). Frec.: 47: 0,10683 (incluyendo tanto el compl. pron.-advl. como la conj. cop.).

y a $3^{\text {a }}$ pers. del v. aver en uso impers. con el compl. y 'hay': cuando contó la manera que havía visto, pensó en si mesmo quel buerto podia seer el su regno, las colles yeran las gentes del su regno, et dixo: «Por fer buenas colles, carne y a menester» 20.123.

ya adv. 'ya': vino a la ciudat de Girona do fueron ya ajustados [ayuntados N] todos los prelados, richos homes, barones, cavalleros... 38.464; partió del Alcoy con todo su escolt, do buvieron grant goyo los moros que yas tenían por consumados, et arribó en la ciudat de Palermo 36.216. Etim.: Del lat. JAM (DCELC, IV, p. 770). Frec.: ya 26: 0,05910; yas 1: 0,00227 .

ya más adv. 'jamás': Es verdat enpero que la unión que en tiempo de los predecessores de aquesti rey era movida et succedida, ya más [jamás B] en tiempo de aquesti rey nos movió ni se suscitó 39.24. También jamás (vid.). Vid. ya.

ybero] nombre gentilicio 'pueblo perteneciente a la raza ibera; persona de este pueblo': el primero hombre que se pobló en España havia nombre Tubal, del qual yxió la generación de los ybers [yberos N] 1.3. Frec.: 1: 0,00227.

ydus (var.: idus) s. m. pl. 'idus, es decir, el día que divide en dos partes el mes: el 15 en los meses de marzo, mayo, julio y octubre y el 13 en los demás meses': al verdadero Dios envió el su spiritu en la villa dessuso dita, IIII ${ }^{\circ}$ idus novembris, en el anno de Nuestro Sennyor mil cc xxxv 36.705; e finó en barc de Sant Dalmau cerca de Tenua [in civitate Taurinis VL], en Lonbardia, en el aynno de M C LXII en los ydus de agosto 32.65. Es voz latina (aunque en lat. IDus era fem.). Procede de la voz etrusca IDUO 'dividir' (cfr. BLÁNQUEZ, s. v.). Frec.: 1: 0,00227.

yglesia (var.: iglesia, eglesia) s. f. 'iglesia, templo' (edificio): qui por reliquias en grant honor estava en la eglesia de Sant Feliu 36.567; porque la gracia del privilegio se estendía assi nobles como cavalleros de las iglesias de sus lugares 34.45 / / 'iglesia' (institución): requiriendo que por vigor de la convinencia entre el Padre Santo et él feita et prometida, con aquell mayor poder que pudies de homes a cavallo et de pie, a missión de la Yglesia, devies conquerir el regno de Secilia 38.221. Etim.: lat. ECCLESIA. Tb. eglesia (vid.). Frec.: Yglesia 20: 0,04546; yglesias 10: 0,02273. 
ygual adj. 'igual, de la misma clase o categoría', 'de la misma forma o manera'. Aparece en la loc. en ygual de 'como': porque assin como a compannero yva con ellos et se metía en ygual dellos en todos afferes d'armas 12.70. Frec.: 1: 0,00227.

ymno s. m. 'himno; cántico': depués el dito santo rey se despulló los vestidos reales bumilment et cantando un canto o ymno que comiença "Veni Creator Spiritus, etc.» vistiosse el ábito de monges blancos 35.282. Cultismo tomado del lat. HYMnus 'íd.'. Frec.: 1: 0,00227 .

yo pron. pers. $1^{\text {a }}$ pers. 'yo': «rendeme el castiello, si no yo te enforcarés 38.302 . Frec.: 17: 0,03864 .

yr (var. hir) v. intr. 'ir': tan solament, con las galeras, fue a Cap de Sant Marcho 38.518; dixeron: «vayamos a veer aquella locura que nuestro rey quiere fazer» 20.128; et dixole: «Fillo mio, sepas que yo me vo a Dios mi crehadon» 35.253; por tal que non yssen las gentes d'allí por fazer honrra al cuerpo et los moros prendiessen conuerto 17.132. Del lat. IRE 'íd.'. Frec.: yr 6: 0,01364; yría 1: 0,00227; yrían 1: 0,00227; yssen 1: 0,00227 ; yt 1: 0,00227 ; yva 9: 0,02046 ; yvan $1: 0,00227$; ydo $2: 0,00455$; ydos 1: 0,00227 ; yendo 3: 0,00682; hir 1: 0,00227 ; hiva 2: 0,00455 ; van 1: 0,00227 ; vayamos 1: 0,0227 ; vo 1: 0,00227 . Las formas del pretérito indefinido, que comienzan por $f$-, incluyen tanto las del v. yr como las del v. seer: fue 404: 0,91827; fu 3: 0,00682; fueron 53: 0,12047; fueronse 4: 0,00909; fui 1: 0,00227.

yra (var:: ira) s. f. 'ira': et el dito conte, de grant ira movido, sacó la espada et mató el dito cavallero, 22.13; oydo tan estrannyo mandamiento, de grant yra movidos, delant éll, todos se esquincoron, 38.125. Del lat. IRA 'cólera, enojo' (DCECH, III, p. 463). Frec.: yra 5: 0,01136; ira 3: 0,00682 .

yrado adj. 'airado, enojado, encolerizado': como en continent quél favlava sanosament con alguno nin dalguna cosa fues yrado siempre movía el pie en semblança de cabreta qui quier cavar 25.25; de la muert del quoal el rey fue muy yrado e despagado 33.53. / / 'expulsado, alejado, por haber retirado el señor su gracia al vasallo': et fue muyt vituperado et yrado por todo el mundo 30.21. Etim.: deriv. de yra. Comp. ayrado. Frec.: 3: 0,00682.

ysla s. f. 'isla': porque se cuytas con las galeras et que en antes fues en la dita ysla 38.515. Etim.: del lat. INSULA. Tb. isla (vid.). Frec.: 4: 0,00909.

ystoria s. f. 'historia, narración histórica': segunt recuenta en la ystoria del rey Remiro el Monge 33.26. Del lat. HiStoria (SEGuRA, 2001, s. v.). Frec.: 1: 0,00227.

yvierno s. m. 'invierno': supo que los moros tenían asitiada la ciudad de Pamplona muyt destreytament en tiempo de yvierno 12.52. Etim.: del lat. vg. HIBERNUM (TEMPUS). La forma etimológica ivierno fue también usual en cast. med. Pero es ya invierno en J. Ruiz y en Nebrija (DCECH, III, 461; DCECH, V, p. 778). En arag. continúa utilizándose hoy ibierno, y es forma muy general en el Alto Aragón. Andolz, s. v., la documenta en Echo y Nobés. El EBA (1999: 1075-1076) registra ibierno en Bal de Broto, A Buerda, Piarruego, Rebilla, Tardienta, Plana de Uesca, A Fueba, Biello 
Sobrarbe. Pero se encuentra también en otros muchos puntos, de acuerdo con repertorios léxicos no incluidos aún en el $E B A$. A modo de ejemplo: se registra en Alquezra (CASTLLlo, 2001: 136), en A Sotonera (GarCÉs, 2005: 201), en Salvatierra de Esca y Santolaria de Galligo (Romanos, 2003: 206), en Ballobar (SoLer, 20094: 123), Somontano de Barbastro (Mostolay, 2007: 329), etc. Moneva (2004[1924]: 286) lo registra incluso en Zaragoza; NAGORE (2020: 67), en Huesca. En la Alta Ribagorza es ibert (RoHLFs, DDPA, en Benasque, y Bisaúrri). Registran ya ivierno BorAO, PARDO. En arag. med. ivierno, yvierno es habitual en Fernández de Heredia (GILKIsON, s. v.); las mismas formas se registran en el LMM (LiRIA, 1979: 178). También en navarro ivierno, yvierno en el Fuero General de Navarra (IribarRen, s. v.). En todas las lenguas románicas encontramos sucesores de la misma etimología latina: occ. ivern (ALIBERT, s. v.); cat. bivern (FABRA, DGLIC, s. v.), gall. y port. inverno, ast. iviernu, fr. biver, francoprovenzal hivern, romanche enviern, piamontés invern, véneto inverno, it. inverno, friulano unvier, siciliano mmernu, rum. iarnă (VALLÉs, 2007: 297). Frec.: 1: 0,00227. 


\section{BIBLIOGRAFÍA}

Abad, Francisco: Diccionario de lingüística de la escuela española. Madrid, Gredos, 1986.

Abarca de Bolea, Ana (1980): Obra en aragonés: Albada al Nacimiento, Baile pastoril al Nacimiento, Romance a la procesión del Corpus, Introduzión, notas y comentarios de Inazio Almudébar, Chulio Brioso, Angelines Campo y Francho Nagore, Huesca, Consello d'a Fabla Aragonesa, 1980.

Abarca de Bolea, Ana (1994): Vigilia y octavario de San Juan Baptista. Edición, introducción y notas de $\mathrm{M}^{\mathrm{a}}$ Ángeles Campo Guiral. Huesca, Instituto de Estudios Altoaragoneses (col. «Larumbe», 6).

Academia de la Llingua Asturiana (2000): Diccionariu de la Llingua Asturiana. Uviéu, KRK ediciones, 2000.

Acta Curiarum Regni Aragonum. XVI tomos que recogen la trascripción y edición de las actas de las Cortes de Aragón desde el s. XIII hasta comienzos del s. XVI. Publicados en Zaragoza por el Grupo C.E.M.A. de investigación (Universidad de Zaragoza), IberCaja, Cortes de Aragón y Gobierno de Aragón desde 2005 a 2020. [ACRA]

Af Geijerstam, Regina. Vid. Geijerstam.

Agel de Mello, William (2020): Dicionário geral das línguas românicas. 4 volumes. Goiânia, Kelps Editora.

Alarcos Llorach, Emilio (1954): «Resultados de Ge,i en la Península Ibérica», Archivum, IV (Oviedo, 1954), pp. 22-30.

Alarcos Llorach, Emilio (1968): Fonología española. Madrid, Gredos, 1968.

Alarcos Llorach, Emilio (1972): Estudios de gramática funcional del español. Madrid, Gredos.

Alazet. Revista de Filología del Instituto de Estudios Altoaragoneses. Huesca, anual, desde 1988.

Albareda y Herrera, Manuel (1925): Fuero de Alfambra. Madrid, Tipografía de la Revista de Archivos, Bibliotecas y Museos.

Alcover, Antoni Ma y Moll, Francesc de B., (amb la col-laboració de M. SAnchis Guarner y A. Moll Marques): Diccionari català-valencià-balear. Inventari lexicogräfic $i$ etimologic de la llengua catalana en totes les seves formes literàries $i$ dialectals, recollides dels documents $i$ textos antics $i$ moderns, y del parlar vivent al Principat de Catalunya, al Regne de Valencia, a les Illes Balears, al departament francés dels Pirineus Orientals, a les Valls 
d'Andorra, al marge oriental d'Aragó i a la ciutat d'Alguer de Sardenya. 10 tomos, Palma de Mallorca, Editorial Moll, $1^{\text {a }}$ ed. 1951; 2. ${ }^{\text {e }}$ d. corregida y puesta al día, 1968; $6^{\text {a }}$ reimpresión, 1988. [DCVB]

Alemany Bolufer, José (1920): Tratado de la formación de palabras en la lengua castellana. La derivación y la composición. Estudio de los sufijos y prefijos empleados en una y otra. Madrid, Librería General de Victoriano Suárez, 1920.

Alex. = Libro de Alexandre (h. 1240-1250). [Para el vocabulario, vid. Louis F. SAs]

Aliaga, José Luis, y Arnal, María Luisa (1999): Textos lexicográficos aragoneses de Benito Coll (1902-1903) presentados al Estudio de Filología de Aragón. Edición y estudio. Zaragoza, Libros Pórtico.

Alibert, Louis (1988): Dictionnaire occitan-français d'aprés les parlers languedociens. Toulouse, I.E.O., 2. ${ }^{\text {e ed., }} 1988$ [1. ${ }^{\text {a }}$ ed.: I.E.O.-C.N.R.S., 1966].

Alonso Pedraz, Martín (1958): Enciclopedia del idioma. Diccionario bistórico y moderno de la lengua española (siglos XII al XX), etimológico, tecnológico, regional e hispanoamericano. 3 tomos. Madrid, Aguilar, 1958.

Alonso Pedraz, Martín (1972): Evolución sintáctica del español. Sintaxis histórica del español desde el iberromano hasta nuestros días. Madrid, Aguilar, 3. a ed., 1972.

Alonso Pedraz, Martín (1986): Diccionario medieval español. Desde las Glosas Emilianenses y Silenses (s. X) hasta el siglo XV. 2 tomos, Salamanca, Universidad Pontificia, 1986. [DME]

Alonso, Amado: De la pronunciación medieval a la moderna en español. Ultimado y dispuesto para la imprenta por Rafael Lapesa. Madrid, Gredos, Vol. I, 1955, 2a ed. $1967\left(1^{\mathrm{a}}\right.$ reimpresión, 1976); vol. II, 1969.

Alonso, Dámaso (1959a): La fragmentación fonética peninsular. Temas y problemas. Suplemento al tomo I de la ELH, Madrid, C.S.I.C., 1959.

Alonso, Dámaso (1959b): «Ensordecimiento en el norte peninsular de alveolares y palatales fricativas», en La fragmentación fonética peninsular. Temas y problemas, suplemento al tomo I de la ELH, Madrid, C.S.I.C., 1959, pp. 85-103.

Altaba Escorinuela, José (1985): Palabras locales, comarcales y regionales (más de tres mil palabras de uso popular regionalista). [Título de la 2. ${ }^{a}$ portada: Teruel. Peculiaridades de nuestro léxico popular]. Zaragoza, 1985.

Alvar EzQuerra, Manuel (1976): Proyecto de lexicografía española. Barcelona, Editorial Planeta.

Alvar EzQuerra, Manuel (1980): «La electrónica aplicada a la investigación lingüística», Arbor, núm 410, febrero 1980, pp. 15-25.

Alvar EzQuerra, Manuel (1981): «Concordancias e índices léxicos del «Libro de la infancia y muerte de Jesús», $A F A$, 36-37 (1981), pp. 421-460.

Alvar, Manuel (1945): Estudios sobre el «Octavario» de doña Ana Abarca de Bolea. Zaragoza, I.F.C., 1945. [Octavario] 
Alvar, Manuel (1947): «Noticia lingüística del Libro Verde de Aragón», AFA, II (Zaragoza, 1947), pp. 59-92. [Reproducido en EDA, II, pp. 105-138] [LVA]

Alvar, Manuel (1948): El habla del Campo de Jaca. Salamanca, 1948. [H]

Alvar, Manuel (1950): «El peaje de Jaca de 1437», en Estudios dedicados a Menéndez Pidal, Tomo II, Madrid, 1950, pp. 91-133. [Reproducido en EDA, II, 1978, pp. 57-101].

Alvar, Manuel (1952): «Grafías que representan fonemas palatales en los documentos navarro-aragoneses en la Edad Media», Argensola, núm. 11 (Huesca, 1952), p. 237248.

Alvar, Manuel (1953a): El dialecto aragonés. Madrid, Gredos, 1953. [DA]

Alvar, Manuel (1953b): «Grafías navarro-aragonesas», en Pirineos, IX (Zaragoza, 1953), pp. 56-85. [Reproducido con muy escasas rectificaciones en EDA, I, 1973, pp. 13-46. Citamos por esta última edición].

Alvar, Manuel (1958-1959): «Documentos de Jaca (1362-1502)», AFA, X-XI (195859), pp. 195-276 y 327-366. [Reproducido en EDA, II, 1978, pp. 139-266] [DЛ]

Alvar, Manuel (1973): «La formación del apellido en los antiguos documentos aragoneses», en EDA, I, Zaragoza, I.F.C., 1973, pp. 113-161.

Alvar, Manuel (1976a): Aragón, literatura y ser histórico. Zaragoza, Pórtico, 1976.

Alvar, Manuel (1976b): El dialecto riojano. 2. ${ }^{a}$ ed., Madrid, Gredos, 1976. [1. ed.: México, Universidad Nacional Autónoma de México, 1969]. [DR]

Alvar, Manuel (1984): Informática y lingüistica. Madrid, Ágora, 1984.

Alvar, Manuel: Estudios sobre el dialecto aragonés. 3 vols., Zaragoza, I.F.C., I, 1973; II, 1978; III, 1998. [EDA]

Alvar, Manuel (1990): Micelánea de estudios medievales. Vol I. Zaragoza, Diputación General de Aragón, Departamento de Cultura y Educación.

Alvar, Manuel, Alvar, Elena y Bernabé, Aurea: «Cancionero de Estúñga: Índices léxicos (I)», $A F A$, XLI ( $2^{\circ}$ semestre de 1988), pp. 253-373; (II), $A F A$, XLII-XLIII (1989), pp. 321-356; (III), AFA, XLIV-XLV (1990), pp. 257-289.

Alvar, Manuel, Buesa, Tomás y Llorente, Antonio: Atlas Lingüistico y Etnográfico de Aragón, Navarra y Rioja. 12 tomos. Madrid, Editorial La Muralla, Departamento de Geografía Lingüística del C.S.I.C - Zaragoza, Institución «Fernando el Católico», 1979-1983. [ALEANR]

Alvar, Manuel, y РОтTier, Bernard (1983): Morfología bistórica del español. Madrid, Gredos, 1983.

Álvarez Álvarez, Manuela (1991): Estudio de la flexión verbal en la Obra de Gonzalo de Berceo (siglo XIII). Bilbao, Universidad de Deusto, 1991.

Álvarez Rodríguez, Adelino (ed.) (2006): Juan Zonaras. Libro de los emperadores. Versión aragonesa del Compendio de historia universal, patrocinada por Juan Fernández de Heredia. Zaragoza, PUZ / IEA / IET / GA (col. «Larumbe», 41). [«Notas léxicas», en pp. 377-406]. 
Álvarez Rodríguez, Adelino (ed.) (2007): Tucídides. Discursos de la guerra del Peloponeso. Versión aragonesa de la Historia de la guerra del Peloponeso patrocinada por Juan Fernández de Heredia. Zaragoza, PUZ / IEA / IET / GA («Larumbe», 48). Álvarez Rodríguez, Adelino (ed.) (2009): Plutarco. Vidas semblantes. Versión aragonesa de las Vidasparalelas, patrocinada por Juan Fernández de Heredia. 2 volúmnes, Zaragoza, PUZ / IEA / IET / GA (col. «Larumbe», 59).

Andolz Canela, Rafael: Diccionario aragonés (aragonés-castellano, castellano-aragonés). Zaragoza, Librería General, 1977; 2. ed., Zaragoza, Librería General, 1979; 3. ${ }^{a}$ ed. ampliada en 2.000 voces, Zaragoza, Librería General, 1984; 4. ${ }^{a}$ edición corregida y aumentada, Zaragoza, Mira editores, 1992. [Aumentada en 8.000 voces respecto a la 3. ${ }^{a}$ edición, con un total de unas 40.000 entradas].

Andrés GutiérRez, M. de - (1977): «Edición crítica del Cancionero de Pedro de Santafé», Archivo de Filología Aragonesa, xx-xxi (1977), pp. 79-139.

Anglade, J. (1977): Grammaire de l'Ancien Provençal ou ancienne langue d'oc. París, éditions Klincksieck, 1977. [Reimpresión de la edición de 1921]

Arbués Possat, José (1980): Fuencalderas en mi recuerdo. Gerona, 1980.

Arbués Possat, José (2012): Tradiciones, costumbres y lengua en Fuencalderas (Cinco Villas, Zaragoza). Zaragoza, Prensas de la Universidad de Zaragoza / Xordica Editorial. Archivo de Filología Aragonesa [AFA]. Zaragoza, Institución «Fernando el Católico».

Arco, Ricardo del (1913): «Ordenanzas inéditas dictadas por el concejo de Huesca (1284 a 1456)», RABM, xxIx (1913), pp. 112-126 y 427-452.

ArCo, Ricardo del (1943): Notas de folk-lore altoaragonés. Madrid, Consejo Superior de Investigaciones Científicas.

Ariño Castel, José María (1999): La bal de Lierp. Geografía y léxico. Uesca, Publicazions d'o Consello d'a Fabla Aragonesa (col. «Puens enta ra parola», 10).

Ariza Viguera, Manuel (1989): «La preposición A de objeto. Teorías y panorama», Lexis, vol. xIII, no 2 (1989), pp. 203-222.

Ariza Viguera, Manuel (1989): Manual de Fonología Histórica del Español. Madrid, Síntesis, 1989.

Arnal Cavero, Pedro (1944): Vocabulario del Alto-aragonés (de Alquézar y pueblos próximos). Madrid, C.S.I.C., 1944.

Arnal Cavero, Pedro (1953): Refranes, Dichos, Mazadas... en el Somontano y montaña oscense. Zaragoza, I.F.C., 1953.

Arnal Purroy, M. ${ }^{a}$ Luisa (2003): Diccionario del habla de la Baja Ribagorza occidental (Huesca). Zaragoza, Gara d'Edizions / Institución «Fernando el Católico»-

Asín Palacios, Miguel (1944): Contribución a la toponimia árabe de España. 2. edición, Madrid, C.S.I.C., 1944.

Ayala castro, Marta Concepción (1983): «Índices léxicos de la Egloga de Calisto y Melibea de Ximénez de Urrea», AFA, XxII-XXIII (1983), pp. 379-411. 
Azkue, Resurrección María de- (1969): Diccionario vasco-español-francés. Dictionnaire basque-espagnol-français. 2 tomos. Bilbao, La Gran Enciclopedia Vasca, 1969. Reproducción facsímil de la primera edición: Bilbao, 1905-1906.

Badía Margarit, Antonio (1947a): Los complementos pronominalo-adverbiales derivados de IBI e INDE en la Península Ibérica. Anejo XXXVIII de la RFE, Madrid, 1947.

Badía Margarit, Antonio (1947b): «Morfología dialectal aragonesa», Boletín de la Academia de Buenas Letras de Barcelona, xx (1947), pp. 60-123.

Badía Margarit, Antonio (1948): Contribución al vocabulario aragonés moderno. Zaragoza, Monografías de la Estación de Estudios Pirenaicos (C.S.I.C). [BADíA, Contribución]

Badía Margarit, Antonio (1950): El habla del valle de Bielsa. Barcelona, Instituto de Estudios Pirenaicos. [BADíA, Bielsa]

Badía Margarit, Antonio (1951): «Sobre ibi e inde en las lenguas de la Península Ibérica», Revista de Filología Española, XXXV (1951), pp. 62-74.

Badía Margarit, Antonio (1963): «Tres notas de sintaxis medieval aragonesa», Weltoffene Romanistik: Festschrift Alwin Kuhn, Innsbruck, 1963, pp. 325-332.

Badía Margarit, Antonio M. (1944): «Algunas notas sobre la lengua de Juan Fernández de Heredia», Revista de Filología Española, XXVIII (1944), pp. 177-189.

Badía Margarit, Antonio M. (1954): «Sobre los extranjerismos léxicos en el aragonés de Juan Fernández de Heredia», en Homenaje a Fritz. Krüger, tomo II, Mendoza (Argentina), Universidad Nacional de Cuyo, 1954, pp. 193-197.

Badía Margarit, Antonio M. (1962): Gramática catalana. 2 vols. Madrid, Gredos, 1962.

Badía Margarit, Antoni (1964): Llengua i cultura als Països Catalans. Barcelona, Edicions 62, 1964.

Badía Margarit, Antoni M. (1984): Gramática històrica catalana. Valencia, Tres i Quatre (Biblioteca d'estudis i investigacions, núm. 4), 2. ${ }^{a}$ ed. en catalán, 1984. [1. ${ }^{\mathrm{a}}$ ed. en castellano: Barcelona, Noguer, 1951].

Bal Palazios, Santiago (2002): Dizionario breu de a luenga aragonesa. Zaragoza, Diputación General de Aragón, Departamento de Educación y Ciencia.

BAldinger, Kurt (1962): «La langue des documents en ancien gascon», Revue de Linguistique Romane, XXVI (1962), pp. 331-347.

Baldinger, Kurt (1972): La formación de los dominios lingüísticos en la Peninsula Ibérica. Versión española de Emilio Lledó y Montserrat Macau, 2. ${ }^{a}$ ed. corregida y muy aumentada. Madrid, Gredos, 1972.

Ballarín Cornel, Ángel (1976): Elementos de gramática benasquesa, Zaragoza, 1976.

Ballarín Cornel, Ángel (1978): Diccionario del benasqués, 2. edición, Zaragoza, 1978.

Bayo Bueno, María Luisa (1978): La comedia chesa "Qui bien fa nunca lo pierde», de Domingo Miral (Estudio lingüístico). Zaragoza, I.F.C., 1978. 
BEC, Pierre (1979): «Constitution de l'Occitanie littéraire et véhiculaire», en A. Armengaud y R. Lafont (dir.), Histoire d'Occitanie, París, Hachette, 1979, pp. 256-284.

BEC, Pierre (1984): «La scripta occitane entre le XIII et le XVI ${ }^{\mathrm{e}}$ siècles. 1. En Gascogne», en Colloque International d'Etudes Occitanes, Montpellier, 1984, pp. 123-133.

BEC, Pierre (1986): «Gascon et Aragonais au Moyen-Age. A propos de la langue du Cartulaire de la Vallée d'Ossau», en Actas del IV Curso de Verano de la Universidad del País Vasco, Lengua y Literatura Románica en torno al Pirineo, Bilbao, Servicio editorial Universidad del País Vasco, 1986, pp. 65-94.

Becerra Pérez, Miguel (1989): «El Léxico de los documentos navarro-aragoneses de la Crestomatía del Español medieval (Primera serie: Documentos y glosas anteriores a 1067)», AEF, xi (Cáceres, 1989), pp. 25-52.

Bello, Andrés: Gramática de la lengua castellana. Edición crítica de Ramón Trujillo, Santa Cruz de Tenerife, Instituto Universitario de Lingüística Andrés BelloCabildo Insular de Tenerife, 1981.

Benítez Marco, María Pilar (1988): Contribución al estudio de La Morisma de Ainsa. Huesca, Instituto de Estudios Altoaragoneses, Excma. Diputación Provincial de Huesca.

Benítez Marco, Ma Pilar (1989): «El verbo haber como forma no auxiliar en el ámbito aragonés», AFA, XLII-XLIII (1989), pp. 131-140.

Benítez Marco, Ma Pilar (2001): L'ansotano. Estudio del habla del Valle de Ansó. Zaragoza, Gobierno de Aragón, Departamento de Cultura y Turismo.

Bergua Camón, Jesús (transcripción y notas) (1949-50): «Fueros de Aragón de 1265 a 1381» [Versión romanceada contenida en el ms. 207 de la Biblioteca Universitaria de Zaragoza], Anuario de Derecho Aragonés, tomo V (Zaragoza, 1949-1950), pp. 457575.

Bernal, Chesús \& Nagore, Francho (eds.) (1999): Diccionario aragonés [manuscrito anónimo, de h. 1803-1815]. Edición, introducción y notas de Chesús Bernal y Francho Nagore. Zaragoza, Edizions de l'Astral (Publicaciones del Rolde de Estudios Aragoneses), 1999.

BlanCAS, Gerónimo de -: «Índice donde se declaran algvnos vocablos aragoneses antiguos que ay en las Coronaciones», en las págs. finales del libro Coronaciones de los Serenísimos Reyes de Aragón [obra escrita en 1583, aunque publicada en 1641 en Zaragoza, por don Juan Francisco Andrés de Ustarroz]. [Edición facsímil, con una nota introductoria de F. Nagore Laín, en Fuellas, 77 (mayo-junio 1990), pp. 15-23; también tirada aparte en separata, Huesca, 1990] [BLANCAS, Índice].

Blánquez Fraile, Agustín: Diccionario Latino-Español, Español-Latino. Barcelona, Editorial Ramón Sopena, 3 tomos: I, 1985; II y III, 1988.

Blas, Fernando, y Romanos, Fernando (2008): Diccionario aragonés: chistabin-castellano (Bal de Chistau). Zaragoza, Gara d'Edizions / Institución «Fernando el Católico». 
Blasco Martínez, Asunción (1995): «Normativa tributaria de la aljama de judíos de Huesca a comienzos del reinado de Pedro el Ceremonioso: la ordenanza de 1337», en Homenaje a don Antonio Durán Gudiol, Huesca, Instituto de Estudios Altoaragoneses, 1995, pp. 107-121.

Borao, Jerónimo (1908): Diccionario de voces aragonesas, precedido de una introducción filológicohistórica, 2. ${ }^{a}$ ed., aumentada con las Colecciones de voces usadas en la comarca de la Litera, autor don Benito Coll y Altabas, y las de uso en Aragón, por don Luis V. López Puyoles y don José Valenzuela Larrosa, Zaragoza, Diputación Provincial de Zaragoza, Imprenta del Hospicio Provincial, 1908. [1. ${ }^{a}$ ed., Zaragoza, 1859].

Bourciez, Édouard (1967): Éléments de linguistique romane. Cinquième Édition révisée par l' auteur et par les soins de Jean Bourciez, Paris, Librairie C. Klincksieck, 1967.

Bourciez, Jean (1986): «El perfecto latino de los verbos en a en la región pirenaica (3. ${ }^{a}$ persona)», AFA, xxxvIII (1986), pp. 221-223. [Publicado originalmente en francés en $B H i$, xxviI, 1925, pp. 226-228].

Brown, Dolores (1970): «Un caso de lis dativo», Nueva Revista de Filología Hispánica, XIX (1970), pp. 382-383.

Bruballa Angusto, Francisco (2009): Vocabulario del habla de La Puebla de Castro (Baja Ribagorza). Huesca, Instituto de Estudios Altoaragoneses.

Brunetto Latini: El libro del trasoro. 2 vols. Edición, introducción y notas de Francho Rodés Orquín. Zaragoza, PUZ / IEA / IET (col. «Larumbe», 87), 2016.

Buesa Oliver, Tomás (1986): «Habla coloquial en dos diplomas medievales altoaragoneses», Archivo de Filología Aragonesa, xxxviII (Zaragoza, 1986), pp. 49-66. [También publicado en: Pirenaico navarro-aragonés, gascón y euskera. V Curso de Verano de la Universidad del País Vasco, Bilbao, Servicio de Publicaciones de las Universidad del País Vasco, 1987, pp. 157-179].

Buesa Oliver, Tomás (1989a): Estudios Filológicos Aragoneses. Zaragoza, Prensas Universitarias de Zaragoza, 1989. [Buesa, EFA].

Buesa Oliver, Tomás (1989b): «Sistema gráfico en un documento altoaragonés de 1510», Aragón en la Edad Media, 8 (Zaragoza, 1989), pp. 139-147.

Bustos Tovar, José Jesús de - (1974): Contribución al estudio del cultismo léxico medieval. Madrid, Anejo xxviII del BRAE, 1974.

CAcho Blecua, Juan Manuel (1997): El gran maestre Juan Fernández de Heredia. Zaragoza, Caja de Ahorros de la Inmaculada de Aragón (col. «Mariano de Pano y Ruata», 12).

Calvo, Manuela (2007): Vocabulario popular navarro-aragonés. El habla de nuestros mayores. Pamplona, Sahats Servicios Editoriales.

Canellas, Ángel (1988): Diplomatario medieval de la Casa de Ganaderos de Zaragoza. Zaragoza, Real Sociedad Económica Aragonesa de Amigos del País. 
Capmany, A. de - (1974): Antiguos tratados de paces y alianzas entre algunos reyes de Aragón y diferentes principes infieles de Asia y Africa, desde el siglo XIII hasta el XV, Madrid, Imprenta Real, 1786. Reimpresión facsímil, Valencia, Anubar ediciones, 1974. [El Tratado de Paz firmado por el rey Pedro IV de Aragón con el rey de Fez en 1357 aparece en pp. 18-25].

Carrasco, Pilar (1987): Fuero de Zamora. Estudio Lingüístico. Málaga, Universidad de Málaga - Universidad de Salamanca - Colegio Universitario de Zamora, 1987.

Casacuberta, Josep M., y Corominas, Joan (1936): «Materials per a l'estudi dels parlars aragonesos. Vocabulari», Butlleti de Dialectología Catalana, xxiv (1936), pp. 158-183.

Casaus Parrilla, Chesús, y Miguel Ballestín, Pascual (2008): Dizionario aragonés de terminos cheograficos. Zaragoza, Gara d'Edizions / Institución «Fernando el Católico».

Casorrán Berges, Ester (2019): Santa María la Mayor de Zaragoza (el Pilar) a través de sus documentos (1118-1318). Historia, devoción y tradición. Vol. I. Estudio histórico. Vol. II. Apéndice documental. Zaragoza, Fundación «Teresa de Jesús» - Excmo. Cabildo Metropolitano de Zaragoza.

Castañer Martín, Rosa Ma (1983): Forma y estructura del léxico del riego en Aragón, Navarra y Rioja, Zaragoza. Zaragoza, Institución «Fernando el Católico».

Castañer Martín, Rosa Ma (1990): Estudio del léxico de la casa en Aragón, Navarra y Rioja, Zaragoza. Zaragoza, Diputación General de Aragón, Departamento de Cultura y Educación.

Castañer Martín, Rosa Ma (2009): «Afinidades léxicas en los Pirineos», en Lagüens Gracia, Vicente (ed.), Baxar para subir. Colectánea de estudios en memoria de Tomás Buesa Oliver, Zaragoza, Institución «Fernando el Católico», pp. 197-227.

Castillo Seas, Fabián (2001): Bocabulario de l'aragonés d'Alquezra y lugars d'a redolada.

Uesca, Publicazions d'o Consello d'a Fabla Aragonesa (col. «Puens enta ra parola», 12).

Castro, Américo (1991): Glosarios latino-españoles de la Edad Media. Madrid, Consejo Superior de Investigaciones Científicas.

Catalán, Diego (1989): El español. Orígenes de su diversidad. Madrid, Paraninfo, 1989.

Cebollero Ciprés, Lorenzo (1998): As cosas d'os tiempos d'antes más en Arguis y a redolada. Uesca, Publicazions d'o Consello d'a Fabla Aragonesa.

Cebollero Ciprés, Lorenzo (2009): A bida en a montaña. Uesca, Publicazions d'o Consello d'a Fabla Aragonesa.

Cejador y Frauca, Julio: Vocabulario Medieval Castellano. Madrid, 1929 (reimpresión: Madrid, Visor, 1990) [VMC]

Ceremonial de la Consagración y Coronación de los Reyes de Aragón, Zaragoza, Diputación General de Aragón, 1991 [Edición facsímil de un códice miniado, de 39 fol., 
procedente de Sádaba, del siglo xiv, que recoge el texto de Pedro iv, Ordinación...Reyes y Ordinación...Reynas]. Vid. Pedro Iv, Ordinación.

Ceremonial de la Consagración y Coronación de los Reyes de Aragón. [ms. R. 14.425 de la Biblioteca de la Fundación Lázaro Galdiano, en Madrid]. Tomo II. Transcripción y estudios. Zaragoza, Centro de Documentación Bibliográfica Aragonesa, 1992. [El texto del Ceremonial lo transcribe Ángel SANviCENTE en pp. 12-53; luego se publica un estudio lingüístico: J. M. Enguita Utrilla y V. LAGÜÉns Gracia, «Aspectos filológicos», pp. 57-84].

Ciérbide Martinena, Ricardo: El romance navarro antiguo (siglos XI-XVI). Tesis doctoral inédita, realizada bajo la dirección de D. Rafael Lapesa Melgar y presentada en abril de 1970 en la Universidad Central de Madrid.

Ciérbide Martinena (1970): «El romance navarro antiguo. Onomástica Medieval Navarra (Siglos x al xv. Estudio realizado sobre documentos originales)», Fontes Lingva Vasconvm, año II, núm. 6 (sepbre. - dicbre. 1970), pp. 269-370. Ciérbide Martinena, Ricardo (1972): Primeros documentos navarros en romance (11981230). Comentario lingüistico, Pamplona, I.P.V., 1972. [Primeros documentos]

Ciérbide Martinena, Ricardo (1973): «Comentario lingüístico del Fuero de Tafalla de 1157», Principe de Viana, 130-131 (1973), pp. 27-45.

Ciérbide Martinena, Ricardo (1974): «Notas lingüísticas a las Ordenanzas de Tafalla (1309)», Principe de Viana, 134-135 (1974), pp. 81-108.

Ciérbide Martinena, Ricardo (1978): Inventario de bienes de Olite (1496). Con la colaboración de Paul Muñoyerro Ajuriagoxeascoa, prólogo de Julio Caro Baroja. Pamplona, Institución Príncipe de Viana, 1978.

Ciérbide Martinena, Ricardo (1985): «Ordenanzas capitulares del cabildo de Santa María de Tafalla (1357). Historia y lengua», en Symbola Lvdovico Mitxelena septuagenario oblata, Pars Prior, Vitoria, 1985, pp. 773-793.

Ciérbide Martinena, Ricardo (1986): «El romance navarro antiguo», en Lengua y Literatura románica en torno al Pirineo (Iv Cursos de Verano en San Sebastián), Bilbao, Servicio editorial de la Universidad del País Vasco, 1986, pp. 125150.

Ciérbide Martinena, Ricardo (1988a): «Fonética y fonología diacrónicas de las articulaciones sibilantes en la documentación medieval navarra: estado de la cuestión», en Actas del I Congreso Internacional de Historia de la Lengua Española, vol. I, Madrid, Arco/Libros, 1988, pp. 83-90.

Ciérbide Martinena, Ricardo (1988b): Estudio lingüístico de la documentación medieval en lengua occitana de Navarra. Vitoria-Gasteiz, Servicio Editorial de la Universidad del País Vasco, 1988.

Ciérbide Martinena, Ricardo (1989): «Confusión grafemática-fonológica en las sibilantes, según documentación inédita de la Baja-Navarra (siglos XIV-Xv)», Fontes Linguae Vasconum, año xxi, núm. 53 (Pamplona, 1989), pp. 27-35. 
Ciérbide Martinena, Ricardo (1999): Estatutos antiguos de la orden de San Juan de Jerusalén. Versión original occitana y su traducción al español, según el códice navarro del AHN de Madrid (1314). Pamplona, Gobierno de Navarra, Insitutición Príncipe de Viana.

Ciérbide Martinena, Ricardo (2002): Edició crítica dels manuscrits catalans inèdits de l'orde de Sant Joan de Jerusalem (segles XIV-XV). Barcelona, Fundació Noguera, Pagès Editors.

Ciérbide Martinena, Ricardo (2004): «Comentario lingüístico al Pesah de la aljama de Huesca (siglos XII-XIII)», en Estudios e rechiras arredol d'a luenga aragonesa e a suya literatura. Autas d'a III Trobada (Uesca-Alquezra, 17-20 d'otubre de 2001), Huesca, Instituto de Estudios Altoaragoneses / Publicazions d'o Consello d'a Fabla Aragonesa, 2004, pp. 329-337.

Ciérbide Martinena, Ricardo (2008): «La scripta medieval bajonavarra y su relación con la jaquesa», Alazet, 20 (2008): 181-195.

Ciérbide Martinena, Ricardo (2012): «Aportaciones a la onomástica medieval aragonesa: Documentos de Montearagón (1058-1205)», Alazet, 23 (2011), pp. 11-28.

Ciérbide Martinena, Ricardo (2019-2020): «La onomástica histórica de Navarra», Luenga \&o fablas, 23-24 (2019-2020), pp. 5-28.

Ciprés Palacín, Ángeles (2011): «Elementos lingüísticos galorrománicos en el texto aragonés Flor de las ystorias de Orient, del scriptorium de Juan Fernández de Heredia», Alazet, 23 (2011), pp. 29-39.

Cobos, Rubén (2003): A Dictionary of New Mexico \& Southern Colorado Spanish. Revised \& expanded edition. Santa Fe [Nuevo México], Museum of New Mexico Press.

Coll y Altabás, Benito: Colección de voces usadas en la comarca de la Litera, en El Diccionario Aragonés. Colección de voces para su formación. Zaragoza, Imprenta del Hospicio Provincial, 1903. Apud Borao, 1908.

Colomina i Castanyer, Jordi (ed.) (1995): Llengües en contacte als regnes de València i de Múrcia (segles XIII-XV). Alacant, Universitat d'Alacant.

Colomina, Jordi (2017): El sufix -al / -ar amb valor col.lectiu, abundancial i augmentatiu. Un estudi de morfonologia lèxica iberoccitanoromànica. Alacant, Universitat d'Alacant, Departament de Filologia Catalana.

Colón Domenech, Germán (1967): «Occitanismos», en Enciclopedia Lingüistica Hispánica, t. II, Madrid, 1967, pp. 153-192.

Colón, Germán (1976): El léxico catalán en la Romania. Madrid, Gredos, 1976.

Colón, Germán (1989): «El aragonés cancilleresco: sociología de un idioma», en El español y el catalán, juntos y en contraste, Barcelona, Ariel, 1989, pp. 237-270.

Colón, Germán (1989): El español y el catalán, juntos y en contraste. Barcelona, Ariel, 1989.

Compaired AragüÉs, Alfredo (1996): Luesia. Su lengua aragonesa. Zaragoza, Ayuntamiento de Luesia. 
Cooper, Louis (1960): El Liber Regum. Estudio lingüístico. Zaragoza, I.F.C., 1960. [LR] Cooper, Louis (1988): «On the Language of Upper Aragón (1258-1495)», HR, 28 (1960), pp. 262-275. (= «Sobre la lengua del Alto Aragón (1258-1495)», traducción de María Luisa Arnal Purroy, AFA, xLI (Zaragoza, 2. ${ }^{\circ}$ semestre de 1988), pp. 211-229).

Corominas, Joan (1958): Reseña de Documentos lingüísticos del Alto Aragón de T. Navarro Tomás, NRFH, xiI (1958), pp. 65-75. [Reproducido después en Tópica Hespérica, I, 186-205, en el capítulo «Dos grandes fuentes de estudio del aragonés arcaico».]

Corominas, Joan (1972): Tópica Hespérica. Estudios sobre los antiguos dialectos, el substrato y la toponimia romances, 2 vols. Madrid, Gredos, 1972.

Corominas, Joan, con la colaboración de José A. Pascual: Diccionario Crítico Etimológico Castellano e Hispánico, vols. I-VI, Madrid, Gredos, 1. ed., 1980-1983, (1. eimpresión, 1984-1986). [DCECH]

Corominas, Joan: Breve Diccionario Etimológico de la lengua castellana. $3^{\text {a }}$ edición muy revisada y mejorada. Madrid, Gredos, 1973. [BDELC]

Corominas, Joan: Diccionario Crítico Etimológico de la lengua Castellana, Madrid, Gredos, I-IV, 1954-1957. [DCELC]

Coromines, Joan (1990): El parlar de la Vall d'Aran. Gramàtica, diccionari i estudis lexicals sobre el gascó. Barcelona, Curial Edicions Catalanes.

Coromines, Joan, amb la colllaboració de Joseph Gulsoy i Max CAHner: Diccionari Etimològic i Complementari de la Llengua Catalana. Vols. I-Ix Barcelona, Curial Edicions CatalanesCaixa de Pensions «La Caixa», $1^{a}$ ed., 1980-1991. [DECL/C]

Coromines, Joan (2001): Diccionari etimològic i complmentari de la llengua catalana. Amb la col. laboració de Joseph Gulsoy i Max Cahner. Volum x. Suplement. Index per Joan Ferrer, Josep Ferrer i Joan Pujadas. Barcelona, Curial Edicions Catalanes, 2001. [= DECL/C]

Coronaciones $=$ Coronaciones de los Serenísimos Reyes de Aragón, de Gerónimo de Blancas (Zaragoza, por don Juan Francisco Andrés de Ustarroz, 1641).

Corriente, Federico (2003): Diccionario de arabismos y voces afines en iberorromance. Segunda edición ampliada. Madrid, Gredos.

CosTa, Joaquín (2010): Textos sobre las lenguas de Aragón. II. Artículos y otros escritos. Introducción general: Ramón Sistac. Edición: José Ignacio López Susín. Zaragoza, Aladrada Ediciones («Biblioteca de las lenguas de Aragón», 4), 2010.

Covarrubias, Sebastián de-: Tesoro de la Lengua Castellana o Española, según la impresión de 1611, con las adiciones de Benito Remigio Noydens publicadas en la de 1674. Edición preparada por Martín de RiQuer, Barcelona, editorial Alta Fulla, 1987.

Crespo, Ángel (1997): La nueva poesía en aragonés. Ensayos y críticas. Uesca, Publicazions d'o Consello d'a Fabla Aragonesa (col. «A tefla de cuatro fuellas», 3).

Crón. SJP. = Crónica de San Juan de la Peña (versión aragonesa). Edición Crítica por Carmen OrCástegui Gros. Zaragoza, I.F.C., 1986. [La abreviatura Crón. SJP. se refiere también, 
de una manera general, a los diferentes manuscritos de la VA, que se indican con las siglas B, N y E, y a las diferentes versiones, que se nombran con las siglas VA, VC y VL]. Crónica de Juan II = Crónica aragonesa del tiempo de Juan II ( $2^{\mathrm{a}} \operatorname{mitad}$ del s. Xv). Vid. RIQUER, Martín de-, "Crónica aragonesa del tiempo de Juan II», Analecta Sacra Tarraconensia, 17, Barcelona, 1944, pp. 1-29.

Crónica de los Estados peninsulares (texto del siglo xIV). Estudio preliminar, edición e índices, por Antonio Ubieto Arteta, Colección Filológica de la Universidad de Granada, vol. XI, Granada, 1955. [Reseña de Antonio Torres en AFA, x-XI, 1958-1959, pp. 391-395].

Crònica de Ramon Muntaner. Text i notes per E. B. 9 vols., Barcelona, ed. Barcino, 1927-1952.

Cunha, Antônio Geraldo da- (1986): Diccionário etimológico Nova Fronteira da língua portuguesa. 2. edição revista e acrescida de um suplemento. Rio de Janeiro, Editora Nova Fronteira, 1986 [1. edición: 1982].

D’ANDrÉs, Ramón (1983): Vocabulario temáticu de la Llingua Asturiana. Xixón, Conceyu Bable.

Dauzat, Albert, Dubois, Jean, Mitterand, Henri (1977): Nouveau dictionnaire étimologique et historique, Quatrième édition revue et corrigée, París, Larousse, 1977.

DCECH = Corominas, Joan, con la colaboración de José A. Pascual, Diccionario Crítico Etimológico Castellano e Hispánico, vols. I-VI, Madrid, Gredos, 1. a ed., 19801983, (1. a reimpresión, 1984-1986).

De Andrés Gutiérrez, Mariano (1977): «Edición crítica del Cancionero de Pedro Santafé», Archivo de Filología Aragonesa, xx-xxi (1977), pp. 79-139.

DECLIC = Coromines, Joan, amb la col-laboració de Joseph Gulsoy i Max CAHnER, Diccionari Etimologic i Complementari de la Llengua Catalana. Vols. I-X, Barcelona, Curial Edicions Catalanes-Caixa de Pensions «La Caixa», 1. ed., 1980-1991.

Devoto, Giacomo: Avviamento alla etimologia italiana. Dizionario etimologico. Firenze, Felice Le Monnier, 2. ${ }^{a}$ ed. (1968), 8. ${ }^{a}$ reimpr., 1989.

Dic. Aut. = Diccionario de Autoridades de la Real Academia Española. Madrid, 1726; ed. facsímil: Madrid, Gredos, 1969.

Diccionario aragonés [manuscrito anónimo, de h. 1803-1815]. Edición, introducción y notas de Chesús Bernal y Francho Nagore. Zaragoza, Edizions de l'Astral (Publicaciones del Rolde de Estudios Aragoneses) (col. «Petarruego» 1), 1999. Diccionario normativo galego-castelán. $3^{\mathrm{a}}$ ed., Vigo, Editorial Galaxia, 1994.

Domínguez Bordona, J. (1923): «La primera parte de la «Crónica de los Conquiridores» de Fernández de Heredia», RFE, x (1923), pp. 380-388.

$D R A E=$ Real Academia Española: Diccionario de la lengua española .

Duarte i Montserrat, Carles, y Alsina i Keith, Àlex: Gramática històrica del català, 3 tomos, Barcelona, Curial, 1984-1986. 
Dueso Lascorz, Nieus-Luzía (1985): Leyendas de l'Alto Aragón. Huesca, Publicazions d'o Consello d'a Fabla Aragonesa.

Durán Gudiol, Antonio (1988): Los condados de Aragón y Sobrarbe. Zaragoza, Guara Editorial, 1988.

EBA = Nagore Laín, Francho (dir.): Endize de bocables de l'aragonés seguntes os repertorios lesicos de lugars y redoladas de l'Alto Aragón. Tomos I-IV, Uesca, Instituto de Estudios Altoaragoneses, 1999.

Egido, Aurora, y Enguita, José M.a (eds.) (1996): Juan Fernández de Heredia y su época. IV Curso sobre lengua y literatura en Aragón. Zaragoza, Institución «Fernando el Católico»

Eco, Umberto (1982): Cómo se hace una tesis. Técnicas y procedimientos de investigación, estudio y escritura. Barcelona, Gedisa, 1982. 3. ${ }^{a}$ edición: Buenos Aires, Editorial Celtia, 1982.

El Libro de Marco Polo, versión aragonesa del siglo XIV. Edición y estudio de Francisco Sangorrín Guallar. Zaragoza, Institución «Fernando el Católio», 2016.

ElCOCK, W. D. (1938): De quelques affinités phonétiques entre l'aragonais et le béarnais. I. La conservation des occlusives sourdes entre voyelles. II. La sonorisation des occlusives sourdes après nasale ou liquide. París, Librairie E. Droz, 1938. [Hay trad. en español: Algunas afinidades fonéticas entre el aragonés y el bearnés. Tradución de $\mathrm{M}^{\mathrm{a}}$ Esther Castrejón. Zaragoza, Prensas Universitarias de Zaragoza / Xordica Editorial, 2005].

Elvira, Javier; Fernández-Ordóñez, Inés; García GonzÁlez, Javier; Serradilla CASTAÑo, Ana (eds.) (2008): Lenguas, reinos y dialectos en la Edad Media Ibérica. La construcdión de la identidad. Homenaje a Juan Ramón Lodares. Madrid, Iberoamericana / Vervuert.

Enciclopedia Temática de Aragón (dir.: Antonio Beltrán Martínez, Guillermo Fatás Cabeza y Guillermo Redondo Veintemillas), 10 tomos, Zaragoza, Ediciones Moncayo, 1986-1989. [Especialmente interesa el tomo 7, Literatura, dirigido por M. Alvar, y dentro de este, el capítulo III, «La poesía épica», pp. 62-90, redactado por José Fradejas] [ETA]

Enguita Utrilla, José M. ${ }^{a}$ (1984): «Notas sobre los diminutivos en el espacio geográfico aragonés», $A F A$, xxxiv-xxxv (1984), pp. 229-250.

Enguita Utrilla, José M. a y LagüEns Gracia, Vicente (1989): «El dialecto aragonés a través de algunos documentos notariales del siglo xiII: una posible interpretación de variantes», Aragón en la Edad Media, 8 (Zaragoza, 1989), pp. 383-398.

Enguita Utrilla, José María, y Lagüens Gracia, Vicente (1992): «Aspectos filológicos», en Ceremonial de Consagración de los Reyes de Aragón. [ms. R. 14.425 de la Biblioteca de la Fundación Lázaro Galdiano, en Madrid]. Tomo II, Transcripción y estudios. Zaragoza, Centro de Documentación Bibliográfica Aragonesa, 1992, pp. 57-84.

Epistola de San Bernardo (siglo Xv) = RiERA SANS, Jaume, «Una versión aragonesa de la «Epístola de cura et modo rei familiaris utilius gubernande» atribuida a San 
Bernardo (siglo xv)», AFA, xxvIII-XxIx (1982), pp. 121-141. [El texto aragonés, fechable entre 1464 y 1492, ocupa las págs. 130-135].

Escudero Buil, Pedro José (1995): Léxico aragonés de Monflorite. Uesca, Publicazions d'o Consello d'a Fabla Aragonesa (col. «Puens enta ra parola», 4).

Évolution = B. POTTIER, «L'évolution de la langue aragonaise a la fin du moyen âge», BHi, LIV (1952), pp. 184-199). [Traducción al castellano: «La evolución de la lengua aragonesa a fines de la Edad Media», trad. de P. García Mouton, AFA, XXXVIII (1986), pp. 225-240].

Fabra, Pompeu (1980): Diccionari General de la Llengua Catalana. Revisat i ampliat per

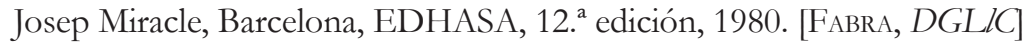

FABra, Pompeu (1979): Gramàtica catalana. Barcelona, Teide, 9. ${ }^{a}$ ed., 1979.

Fedou, René, et al. (1982): Léxico bistórico de la Edad Media. Versión castellana de Demetrio Castro Alfín, Madrid, Taurus (Col. «Textos Auxiliares», n²).

Fernandes, Júlio da Conceiçao: Diccionario portugués-español. Barcelona, ediciones Hymsa, s. a. [pero 1966].

FernÁndez Clemente, Eloy (1989-1990): «Introducción a la Historiografía Aragonesa» (I), Turia, 12 (Teruel, octubre 1989), pp. 147-158; (II), Turia, 13 (Teruel, febrero 1990), pp. 191-202.

Fernández de Heredia, Johan: La Grant Cronica de Espanya. Vid. Geijerstam.

Fernández de Heredia, Johan: Libro de Marco Polo (versión aragonesa). Vid. NitTi. Vid. SANGORRÍN.

Fernández Ferreres, Luzía (2020): «Léxico del siglo xiII en unas ordenanzas en aragonés del Conzello de Uesca», Luenga \& fablas, 23-24 (2019-2020), pp. 125150.

Ferraz y Castán, Vicente (1934): Vocabulario del dialecto que se habla en la Alta Ribagorza. Madrid, 1934.

Forx, Vincent, abbé (2003): Dictionarire Gascon-Français (Landes) suivi de son Lexique Français-Gascon et d'éléments d'un Thesaurus Gascon. Texte établi au Centre d'Études des Cultures d'Aquitaine et d'Europe du Sud sous la direction de Paule Bétérous. Bordeaux, Presses Universitarires de Bordeaux.

Folgar, Carlos (1988): «A + topónimo objeto directo en español arcaico», Verba, 15 (1988), pp. 403-420.

Formularios notariales aragoneses. Serie de vi tomos que abarca formularios notariales desde el s. XIII al XVI, publicada en Zaragoza por El Justicia de Aragón, 2001. Incluye los siguientes tomos: I. Formularios notariales de Zaragoza y de Valencia, siglos XIII-XIV. Transcripción y notas por Ángel San Vicente y Asunción Blasco Martínez. II. Formulario notarial de Gil de Borau, Zaragoza, siglo XIV. Transcripción y notas de Asunción Blasco Martínez y Ángel San Vicente Pino. III. Formulario notarial del Archivo Municipal de Barbastro. Introducción, transcripción y notas por José Ángel Sesma Muñoz. IV. Formulario zaragozano del siglo XV. Transcripción y notas por $\mathrm{M}^{\mathrm{a}}$ 
Desamparados Cabanes Pecourt y Pilar Pueyo Colomina. v. Formulario notarial zaragozano de la primera mitad del siglo ХVI. Transcripción y notas por Cristina Monterde Albiac y María Rosa Gutiérrez Iglesias. vi. Formulario notarial de Gil Abat. Mora (Teruel), siglo ХVI. Transcripción y notas por Encarnación Marín Padilla.

Fort Cañellas, María Rosa (1977): «Estudio de 60 documentos del Proceso de las Cortes de Tamarite de Litera del año 1375, según el manuscrito 2», $A F A$, xx-Xxi, pp. 141-262. [CT]

Fort Cañellas, María Rosa (1985) «Sobre onomástica aragonesa medieval», AFA, XXXIV-XXXV, pp. 553-579.

Fort Cañellas, María Rosa (1986): Relación del léxico catalán con el aragonés en documentación primitiva aragonesa. Zaragoza, Diputación General de Aragón (Colección «Estudios y Monografías», 2).

ForT CAÑellas, María Rosa (1994): Léxico romance en documentos medievales aragoneses (siglos XI y XII). Zaragoza, Diputación General de Aragón, Departamento de Educación y Cultura.

Frago Gracia, Juan Antonio (1977a) «Varias calas documentales en el aragonés antiguo», AFA, xx-xxi (Zaragoza, 1977), pp. 323-326.

Frago Gracia, Juan Antonio (1977b): «Una perspectiva histórica sobre la relación entre el léxico navarroaragonés y el del área occitana», RLiR, XLI (1977), pp. 302332.

Frago Gracia, Juan Antonio (1977c): «El punto de vista sociológico en lingüística histórica: Resultados popular y culto en el léxico aragonés antiguo derivado de étimos latinos con grupo TY», AFA, xx-Xxi (Zaragoza, 1977), pp. 57-78.

Frago Gracia, Juan Antonio (1980): «Literatura navarroaragonesa», en Diez BorQue, José M.a (coord.), Historia de las literaturas hispánicas no castellanas, Madrid, Taurus, 1980, pp. 221-276.

Frago Gracia, Juan Antonio (1980): «Sobre el léxico aragonés», en Actes del Cinquè Col. loqui Internacional de Llengua i Literatura Catalanes (Andorra, 1-6 d'octubre de 1979), publicades a cura de J. Bruguera i J. Massot i Muntaner, Publicacions de l'Abadia de Montserrat, 1980, pp. 405-440.

Frago Gracia, Juan Antonio (1989): «El marco filológico del Vidal Mayon», en Vidal Mayor. Estudios, Huesca, Diputación Provincial-Instituto de Estudios Altoaragoneses., 1989, pp. 83-112.

Frago Gracia, Juan Antonio (2001): «Las lenguas de Aragón en la Edad Media», Boletin de la Real Academia Española, tomo LXxxi (septiembre-diciembre de 2001), pp. 465-478.

Franco Grande, X. L. (1983): Diccionario galego-castelán e vocabulario castelán-galego. 8. ${ }^{a}$ edición, Vigo, Galaxia, 1983.

Fuellas. Publicazión bimestral en aragonés de cultura, luenga e literatura. Uesca, Consello d'a Fabla Aragonesa, desde 1978. 
Fuero de Alfambra. Edición de Manuel Albareda y Herrera, Madrid, 1925.

Fueros de Aragón según el ms. del Archivo Municipal de Miravete de la Sierra. Vid. Gargallo, 1992.

Fuero de Cuenca. Cuenca, Editorial Alfonsípolis, 2001. [Otorgado por Alfonso viII de Castilla en 1190. Esta edición reproduce la versión romanceada contenida en un Códice del s. xv, conservado en la Biblioteca Universitaria de Valencia, según el texto establecido por Rafael Ureña].

Fuero de Jaca. Edición crítica por Mauricio Molho, Zaragoza, Escuela de Estudios Medievales - Instituto de Estudios Pirenaicos, 1964. [Redacciones en aragonés: $\mathrm{A}^{\mathrm{P}}$ (en una curiosa mezcla de lat., occ. y arag.; redac. anterior al siglo XIII), pp. 7-9; Az (redactada en el s. XII en Aragón; en aragonés con mezcla de frases en latín), pp. 92-100; D (versión en navarro-aragonés hecha posiblemente por García Martínez, notario de Villafranca de Navarra, h. 1340), pp. 279-507; el resto de las redacciones está en occitano cispirenaico aragonés].

Fuero de Teruel. Edición y estudio: Max Gorosch, El Fuero de Teruel, Estocolmo, 1950. («Es el más extenso fuero municipal medieval en aragonés». Segunda mitad siglo XIII). [FT]

Fueros de la Novenera, publicados por Gunnar Tilander, Stockholm, 1951. Leges Hispanicæ Medii Aevi, II. [FN]

Furer, Jean-Jacques (2002): Vocabulari romontsch sursilvan-franzos / Dictionnaire romanche sursilvan-français. Glion, Fundaziun Retoromana Pader Flurin Maissen.

Fuster Santaliestra, Bizén (1985): «Arqueología e Historia de los castillos de Naval (Huesca)», en I Congreso de Arqueología Medieval Española (Huesca, 1985), Zaragoza, DGA, 1987, pp. 164-179.

Galmés de Fuentes, Álvaro / Mercedes SÁnchez Álvarez / Antonio Vespertino Rodríguez y Juan Carlos Villaverde Amieva: Glosario de voces aljamiadomoriscas. Gijón, Ediciones Trea, 2015. Reimpresión de la primera edición: Oviedo, Universidad de Oviedo, 1994. [GVAM]

GARCÉs, Agliberto (2005): Fraseología de habla popular aragonesa. [Vocabulario del aragonés popular de Bolea y la comarca de La Sotonera]. Edición a cargo de Francho Nagore Laín. 2. a edición corregida. Uesca, Publicazions d'o Consello d'a Fabla Aragonesa (col. «Puens enta ra parola», 13). [1. ${ }^{a}$ ed.: 2002].

GArCía ArIAS, Xosé Lluis (1988): Contribución a la gramática histórica de la lengua asturiana y a la caracterización etimológica de su léxico. Uviéu, Serviciu de Publicaciones Universidá d’Uviéu («Biblioteca de Filoloxía Asturiana», 3).

García de Diego, Vicente (1968): Diccionario de voces naturales. Madrid, Aguilar, 1968. García de Diego, Vicente (1970): Gramática histórica española. 3. a edición corregida, Madrid, Gredos. 
García de Diego, Vicente (1985): Diccionario etimológico español e hispánico. 2. edición considerablemente aumentada con materiales inéditos del autor a cargo de Carmen García de Diego. Madrid, Espasa-Calpe, 1985. [DEEH]

García de Diego, Vicente (1990 [1918]): «Caracteres fundamentales del dialecto aragonés», AFA, XLIV-XLV (1990), pp. 231-254. [Publicado anteriormente en Zaragoza, 1918, y en V. García De Diego, Miscelánea filológica, Madrid, s. a., pp. 1-18.]

García Soriano, Justo (1980): Vocabulario del Dialecto murciano. Con un estudio preliminar y un apéndice de documentos regionales. Murcia, 1980. [1. a ed.: 1932].

Gargallo, Miguel Ángel, y Tomeo, Manuel (2011): Los riegos en Villamayor de Gállego. Compromis i Sentencia Arbritral sobre Derechos del Azud i Acequia de Candeclaus, 1406. Villamayor de Gállego, Asociación Cultural «Aljez».

Gargallo Gil, José Enrique (1994): Les llengües romàniques. Tot un món lingüistic fet de romanços. Barcelona, Editorial Empúries.

Gargallo Gil, José Enrique (2004): Habla y cultura popular en el Rincón de Ademu₹. Madrid, Consejo Superior de Investigaciones Científicas.

Gargallo Gil, José Enrique, y Bastardas, María Reina (coords.) (2007): Manual de lingüistica románica. Barcelona, Ariel.

Gargallo Moya, Antonio (1989): «Una tradición desconocida de los "Fueros de Aragón". El códice foral del Archivo Municipal de Miravete de la Sierra (Teruel)», Turia, revista cultural, n. ${ }^{\circ} 12$ (Teruel, octubre de 1989), pp. 177-195.

Gargallo Moya, Antonio [Edición e índices] (1992): Los Fueros de Aragón [según el ms. del Archivo Municipal de Miravete de la Sierra (Teruel)]. Zaragoza, Anubar Ediciones («Textos Medievales», 89). [FAM]

Gargallo, Manuel (1985): «Notas léxicas sobre el habla de Tarazona y su comarca», AFA, xxxVI-XxxVII (1985), pp. 417-571.

Gastón Burillo, Rafael (1934): El latín en la flexión verbal del dialecto cheso. Zaragoza, 1934 (separata de la revista Zurita, II, 1934, pp. 69-114) = Universidad, XI, Zaragoza, 1934, pp. 273-318). [Reimpresión en AFA, xxx-Xxxi [1982], pp. 239289].

Gastón BuriLlo, Rafael: Gramática histórica elemental de la lengua española. Zaragoza, Librería General, s. a.

Geijerstam, Regina af (1964): Juan Fernández de Heredia, «La Grant Cronica de Espanya», Libros I-II, Uppsala, Almqvist \& Wiksells, 1964.

Geijerstam, Regina af (1980): «Sobre Heredia i el bilingüisme medieval aragonèscatalá», en Actes del Cinquè Colloqui Internacional de Llengua i Literatura Catalanes, Publicacions de l'Abadia de Montserrat, 1980, pp. 495-510.

Gifford, D. J., y Hodcroft, F. W. (1966): Textos lingüísticos del medioevo español. Preparados con Introducciones y Glosario por-, 2. a edición, corregida, Oxford, The Dolphin Book Co. Ltd., 1966 [TLME] 
Gil Bergés, Joaquín (1916): Colección de voces aragonesas. Huesca, Talleres Tipográficos de Justo Martínez, 1916. [Reed. en AFA, xxxvIII, 1986, pp. 265-278]

GIL, Antón Chusé (editor) (1999): Léxico aragonés de Sos del Rey Católico. Zaragoza, Crica d'Edizions, 1999.

GILI GAYA, Samuel (1925): «Manifestaciones del romance en documentos oscenses anteriores al siglo xIII», en Homenaje a R. Menéndez Pidal, tomo II, Madrid, 1925, pp. 99-119. [Reed. en AFA, XLII-XLIII, 1989, pp. 293-317]

GILI GAYA, Samuel (1946): «Nos-otros, vos-otros», RFE, xxx (1946), pp. 108-117.

Gili Gaya, Samuel (1960): Tesoro lexicográfico (1492-1726). Tomo primero A-E, Madrid, C.S.I.C., 1960, 1005 págs.

Gild Gaya, Samuel (1973): Curso superior de Sintaxis española. Barcelona, Vox-Bibliograf, 11. ${ }^{a}$ edición, 1973.

Gilkison Mackenzie, Jean (1984): A lexicon of the 14th-Century Aragonese Manuscripts of Juan Fernández de Heredia. Madison (Wisconsin, USA), The Hispanic Seminary of Medieval Studies, 1984.

Glossari $=$ Glosario de algunas voces catalanas que aparecen en la VC de la Crón. de SJP., realizado por Lluís Nonell y publicado en la ed. de la VC de SoBERANAS, pp. 187-190.

Gómez de Valenzuela, Manuel (1992a): Documentos del valle de Tena (siglos XIV-XV). Zaragoza, Real Sociedad Económica de Amigos del País, 1992.

Gómez de Valenzuela, Manuel (1992b): Documentos del valle de Tena (siglo XVI). Zaragoza, Real Sociedad Económica de Amigos del País, 1992.

Gómez de Valenzuela, Manuel (2000a): Estatutos y Actos Municipales de Jaca y sus montañas (1417-1698). Zaragoza, Institución «Fernando el Católico». [EAMJM]

Gómez de Valenzuela, Manuel (2000b): Los Estatutos del Valle de Tena (1429-1699).

Zaragoza, Real y Excma. Sociedad Económica Aragonesa de Amigos del País, 2000. [EVT]

Gómez de Valenzuela, Manuel (2003): Derecho municipal aragonés. Estatutos, actos de gobierno y contratos (1420-1786). Zaragoza, El Justicia de Aragón.

Gómez de VALEnZuela, Manuel (2007): Documentos sobre ganadería altoaragonesa y pirenaica (siglos ХV у ХИл). Zaragoza, El Justicia de Aragón, 2007.

Gómez Fargas, Rosa Ma (1989): «Peculiaridades lingüísticas aragonesas en «Triste deleytaçion», AFA, XLII-XLIII (1989), pp. 21-64.

Gónzález Guzmán, Pascual (1953): El habla viva del valle de Aragüés, Zaragoza, Instituto de Estudios Pirenaicos, 1953. [Hay reedición facsímil, con introducción de Alberto Gracia Trell, Zaragoza, Aladrada, 2019].

GónZÁlez Hurtebise, E. (1904): «La Crónica General escrita por Pedro IV de Aragón», Revista de Bibliografía Catalana, IV (Barcelona, 1904), pp. 188-214.

GonzÁlez Ollé, Fernando (1970a): Textos lingüísticos navarros, Pamplona, I.P.V., 1970. $[T L N]$ 
GonZÁlez Ollé, Fernando (1970b): «El romance navarro», RFE, LIII (Madrid, 1970), pp. $45-93$.

GonZÁlez Oldé, Fernando (1970c): «Vascuence y romance en la Historia lingüística de Navarra», BRAE, 50 (1970), pp. 31-76. (Publicado también como libro en tirada aparte: Pamplona, Ediciones y Libros, 1972, 58 págs.)

GonZÁlez Oldé, Fernando (1980): Lengua y Literatura españolas medievales. Textos y glosario. Barcelona, Ariel.

GonZÁLEZ OlLÉ, Fernando (1983): «Evolución y castellanización del romance navarro», PV, XLIV (1983), pp. 173-180.

GonzÁlez Oldé, Fernando (2007): «Opciones y preferencias lingüísticas del rey Pedro IV de Aragón», Revista de Filología Española, LXxxVII (2007), pp. 293-322.

Gorosch, Max (1950): El Fuero de Teruel. Estocolmo (Leges Hispanicae Medii Aevi, I), 1950. [Reedición facsímil en Tiempo de Derecho foral en el sur aragonés: Los fueros de Teruel y Albarracín, II, Zaragoza, El Justicia de Aragón, 2007] [FT]

Gran Diccionario español-francés / francés-español LAROUSSE. Barcelona, Larousse Editorial, 2018.

Gran Enciclopedia Aragonesa (dir.: Eloy Fernández Clemente), XII vols., Zaragoza, Unión Aragonesa del Libro, 1980-1982. Apéndice I, Zaragoza, Unión Aragonesa del Libro, 1983; Apéndice II (dir. y coord.: Manuel Martín Bueno), Zaragoza, Comercial Aragonesa del Libro, 1987; Apéndice III, Zaragoza, Aragonali, 1997; Apéndice IV, Zaragoza, UrusAragón, 2001; Apéndice v, Zaragoza, UrusAragón, 2007. [GEA]

Gual Camarena, Miguel (1976): Vocabulario del Comercio Medieval. Colección de aranceles aduaneros de la Corona de Aragón (Siglos XIII y XIV). Barcelona, Ediciones El Albir, 1976.

Guardiola Alcover, Conrado (ed.) (1998): Rams de flores o Libro de Actoridades. Obra compilada bajo la protección de Juan Fernández de Heredia, Maestre de la Orden del Hospital de San Juan de Jerusalem. Zaragoza, IFC, 1998. [LA]

Guillén Calvo, Juan José (1981): Toponimia del Valle de Tena. Zaragoza, Institución «Fernando el Católico».

Haensch, G., Wolf, L., Ettinger, S., y Werner, R. (1982): La lexicografía. De la lingüistica teórica a la lexicografía práctica. Madrid, Gredos.

Haensch, Günther (1960): «Las hablas de la Alta Ribagorza», AFA, x-XI (1958-59), pp. 57-193, y AFA, xII-XIII (1961-62), pp. 117-250. Publicado también como libro: Las hablas de la Alta Ribagorza (Pirineo aragonés). Zaragoza, Institución «Fernando el Católico», 1960. [Reedición facsímil: Zaragoza, Institución «Fernando el Católico» / Gara d’Edizions, 2003].

Hanssen, Federico (1896): «Estudios sobre la conjugación aragonesa», Anales de la Universidad, Santiago de Chile, tomo 93 (1896), pp. 391-409. [También como publicación separada: Santiago de Chile, 1896]. (Publicado posteriormente en $A F A$, xxvi-XxviI, Zaragoza 1981, pp. 401-418; citamos por esta 
publicación). [Como indica la nota de la relección en el $A F A$, p. 401, «algunos de los presupuestos históricos y lingüísticos que expone Hanssen, son hoy indefendibles»].

Hermandat et confrayría in honore de Sancte Marie de Transfixio. Estatutos de la Cofradía de la Transfixión de Zaragoza (1311-1508). Edición, introducción y notas de Antonio Cortijo Ocaña. Zaragoza, PUZ / IET / GA (col. «Larumbe» 29), 2004.

Hodcroft, Fred W. (1964): «Notas sobre la Crónica de Morea», AFA, xIV-Xv (196364), pp. 83-102.

Índice $=$ BlanCAS, Geronimo de - (1641): «Indice donde se declaran algvnos vocablos aragoneses antiguos que ay en las Coronaciones», en Coronaciones de los Serenísimos Reyes de Aragón (redactado en 1583, aunque publicado en 1641). [Ed. facsímil en Fuellas, 77 (mayo-junio 1990), pp. 15-23].

INDURÁIN, Francisco (1945): Contribución al estudio del dialecto navarro-aragonés antiguo. Zaragoza, I.F.C., 1945. [Induráin, Contribución]. Vid. Ynduráin.

Inventarios aragoneses (1330-1499). [Edición: M. SERRANO Y SANZ, «Inventarios aragoneses de los siglos XIV y XV», BRAE, II (1915), III (1916), IV (1917), VI (1919) y ix (1922). Estudios: B. РоттIER, «Étude lexicoloxique sur les Inventaires aragonais», VR, x (1948-1949), pp. 87-219. B. РоттIER, «L'évolution de la langue aragonaise a la fin du moyen age», $B H i$, LIV (1952), pp. 184-199; trad. en cast. en $A F A$, xxxviII, (1986), pp. 225-240].

Iordan, Iorgu, y Manoliu, Maria (1972): Manual de lingüística románica. Revisión, reelaboración parcial y notas por Manuel Alvar. 2 tomos, Madrid, Gredos.

Irache $=$ SARALEGUI, Carmen: El dialecto navarro en los documentos del monasterio de Irache (958-1397). Pamplona, I.P.V., 1977.

Iranzo Muñio, María Teresa (1986): La muralla de Huesca en la Edad Media. Huesca, Ayuntamiento (Colección «Crónica», Estudios y documentos sobre Huesca, n. 1$), 1986$. [Incluye edición de El libro de los muros (1444-1465), pp. 53-122].

Iranzo Muñío, María Teresa (2008): Politica municipal y vida pública en Huesca. Documentos (1260-1527). Zaragoza, Instituto de Estudios Altoaragones / Grupo de Investigación C.E.M.A. (Universidad de Zaragoza).

IRIBARREN, José Ma (1984): Vocabulario navarro. Segunda edición preparada y ampliada por Ricardo Ollaquindia, Pamplona, I.P.V., 1984.

Jimeno Jurío, José María (1987): Vocabulario histórico navarro (villa de Tafalla). Tafalla, Altaffaylla Kultur Taldea.

KERKHOF, M.P.A.M. (1987): «El diptongo ua y el posesivo lur en el aragonés medieval: dos formas que desaparecen tempranamente (siglo XIV) de la lengua escritas, Orbis, XXXII (1987), pp. 85-96.

Kivinarju, Jukka (2004): Colección Diplomática del Hospital de Santa Cristina de Somport, I (años 1078-1304). Saarijärvi (Finlandia), Academia Scientiarum Fennica - Suomalaisen Tiedeakatemian Toimituksia. 
Kock, Josse de- (1974): Introducción a la lingüística automática en las lenguas románicas. Con ejemplos en colaboración con Walter Bossaert, Luc Debusschere, Dirk Geens y Romana Dhanis-Zwaenepoel. Madrid, Gredos.

Kontzi, Reinhold (1970): «Ist die aragonesische Präposition enta ein Arabismus?», ZRPh, vol. 86 (1970), pp. 372-381.

Kunn, Alwin (1935): «Der Hocharagonesische Dialekt», RLiR, XI (1935), pp. 1-312. [Hay trad. en español: El Dialecto Altoaragonés. Trad. de José Antonio Saura y Xavier Frías. Zaragoza, Prensas Universitarias de Zaragoza / Xordica Editorial, 2008]. [HAD]

Kunn, Alwin (1950): El aragonés, idioma pirenaico. Zaragoza, 1950. (Separata de las Actas del Primer Congreso Internacional de Pireneístas, San Sebastián, septiembre de 1950). [Hay trad. en arag.: «L’aragonés, idioma pirenenco», Luenga \& fablas, 11 (2007), pp. 125-135].

KuHn, Alwin (1960): «Sintaxis dialectal del Alto Aragón», en Miscelánea Filológica dedicada a Mons. A. Griera, tomo II, Barcelona, Instituto Internacional de Cultura Románica, 1960, pp. 9-22.

KuHN, Alwin (1989): «El perfecto simple aragonés. Arag. -ll- > -ts-», AFA, XLIIXLIII (1989), pp. 279-291. [Traducción al castellano, por Jorge Alvar, del trabajo publicado originalmente en ZRPh, 59 (1939), pp. 73-82.]

La Corona de Aragón (dir: Guillermo Fatás Cabeza), seis tomos con texto bilingüe cast./cat., Barcelona-Zaragoza, editorial Aragó, 1988-1991.

LaCarra, José María (1972): Aragón en el pasado. Madrid, Espasa-Calpe (Colección Austral, no 1435).

Lacruz Berdejo, José Luis (1947): «Fueros de Aragón hasta 1265», ADA, II (1947), pp. 223-362. [FA hasta 1265]

LagüÉns Gracia, Vicente (1985): «Algunos aspectos de la derivación en textos altoaragoneses del siglo xV«, Archivo de Filología Aragonesa, xxxvI-XxxvII, pp. 223-254.

LagüÉns Gracia, Vicente (1988): Reseña de Crónica de San Juan de la Peña (versión aragonesa). Edición crítica por Carmen Orcástegui Gros (Zaragoza, I.F.C., 1986), Archivo de Filología Aragonesa, XLI (2 semestre de 1988), pp. 392-394.

LAGÜÉNS Gracia, Vicente (1991): «El aragonés medieval en sus fuentes documentales», en José M. ${ }^{a}$ Enguita (ed.), I Curso sobre lengua y literatura en Aragón (Edad Media), Zargoza, Institución «Fernando el Católico», 1991, pp. 83-114.

LAGÜÉNs Gracia, Vicente (1992): Léxico jurídico en documentos notariales aragoneses de la Edad Media (siglos XIV y XV). Zaragoza, Diputación General de Aragón, Departamento de Cultura y Educación.

LAGÜÉNS GRACiA, Vicente (1996): «Caracterización lingüística de la prosa herediana (a través de la Bibliografía)», en Aurora Egido y José M. ${ }^{a}$ Enguita, 1996: 285355. 
LAGÜÉns Gracia, Vicente (1999): «Estado actual de los estudios sobre el aragonés medieval», en José María Enguita (ed.), Jornadas de Filología Aragonesa en el aniversario del AFA, 2 vols., Zaragoza, Institución «Fernando el Católico», 1999, vol. II, pp. 163-264.

LAGÜÉNS GRACIA, Vicente (2009): «Contactos lingüísticos y transmisión textual: a propósito del léxico de las Coronaciones glosado por Jerónimo de Blancas» (I), AFA, 65 (2009), pp. 13-52; (II), AFA, 66 (2010), pp. 33-96.

Laliena Corbera, Carlos (ed.) (1988): Documentos municipales de Huesca, 1100-1350. Huesca, Ayuntamiento de Huesca (Colección «Crónica», nº 3).

Lapeña Paul, Ana Isabel (1989): El monasterio de San Juan de la Peña en la Edad Media (desde sus origenes hasta 1410). Zaragoza, Caja de Ahorros de la Inmaculada.

LAPESA, Rafael (1971): «Sobre el artículo ante posesivo en castellano antiguo», en Festschrift für Harri Meier, München, 1971, pp. 277-296.

LAPESA, Rafael (1985a): Historia de la lengua española. Novena edición corregida y aumentada, Madrid, Gredos, $4^{a}$ reimpresión, 1985.

LAPESA, Rafael (1985b): «Asturiano y provenzal en el Fuero de Avilés», en Estudios de bistoria lingüistica española, Madrid, Paraninfo, 1985, pp. 53-122.

LAPESA, Rafael (1985c): Estudios de bistoria lingüística española. Madrid, Paraninfo, 1985.

LatAS, Óscar, e NAGORe, Francho (editors) (2007): Foratata. Antolochía de testos en aragonés de l'Alto Galligo. Uesca, Publicazions d'o Consello d'a Fabla Aragonesa (col. «A tefla de cuatro fuellas», 6).

Lathrop, Thomas A., con la colaboración de Juan GutiérRez Cuadrado (1984): Curso de gramática histórica española. Barcelona, Ariel, 1984.

LAusBERG, Heinrich: Lingüistica románica. 2 tomos, Madrid, Gredos, tomo I, 1970; tomo II, 1973.

Lázaro Carreter, Fernando (1968): Diccionario de términos filologicos. Tercera edición corregida. Madrid, Gredos, 1968.

LCMA = SESMA, J. Ángel y LíbANO, Ángeles, Léxico del Comercio Medieval en Aragón (siglo XV), Zaragoza, Institución «Fernando el Católico», 1982.

Ledesma Rubio, María Luisa (1991): Cartas de población del Reino de Aragón. Zaragoza, Institución «Fernando el Católico». [ $=$ CPR A]

Lera Alsina, José (2004): Aplego. Dicionario de resistencia y gramatica sobre lo cheso (fabla altoaragonesa). Barcelona, edizión de l'autor.

Letra intimada $(1435)=$ «Letra intimada por mossen Johan Ximenez Cerdan á mossen Martin Diez d'Aux, Justicia de Aragón«, en Fori regni Aragonum a Gundisalvo García de Sancta María correcti, Caesaraugustæ, Paulus Hurus, 1496, ff. 49r-56r. [Se reproduce en el libro de Ángel Bonet, Esteban SaRASa y Guillermo Redondo, El Justicia de Aragón: Historia y Derecho, Zaragoza, Cortes de Aragón, 1985].

Levy, Emil: Petit dictionnaire provençal-français, Raphèle - lès - Arles, Marcel Petit, 1980. [Reimpresión de la ed. de 1909]. 
Léxico hispánico primitivo (siglos VIII al XII). Versión primera del Glosario del primitivo léxico iberorrománico. Proyectado y dirigido inicialmente por Ramón Menéndez Pidal. Redactado por Rafael Lapesa. Vid. SECO, Manuel (ed.) (2004) [LHP]

Líbano ZumalacÁrregui, Ángeles (1977): «Galicismos, occitanismos y catalanismos en el léxico del Fuero General de Navarra«, en Homenaje a D. José $M^{a}$ Lacarra, tomo II, Zaragoza, 1977, pp. 187-202.

Líbano ZumalacÁrregui, Ángeles (1977): El Romance Navarro en los Manuscritos del Fuero Antiguo del Fuero General de Navarra, Pamplona, I.P.V., 1977. [FGN]

Líbano ZumalacÁrregui, Ángeles (1979): «Consideraciones lingüísticas sobre algunos tributos medievales navarro-aragoneses y riojanos», $P V$, n. ${ }^{\circ} 154-155$ (1979), pp. 65-80.

Líbano Zumalacárregui, Ángeles (1986): «El léxico medieval aragonés: sus características», en Lengua y Literatura románica en torno al Pirineo (director: R. Ciérbide), Bilbao, Servicio editorial Universidad del País Vasco, 1986, pp. 95-123.

Líbano Zumalacárregui, Ángeles, y Villacorta Macho, Consuelo (2013): Paisaje rural y explotación agropecuaria. Léxico de los recursos naturales y de la vida cotidiana en el aragonés, navarro y romance vasco (siglos XIII-XVI). Zaragoza, Prensas de la Universidad de Zaragoza.

Líbano, Ángeles y Sesma, J. Ángel (1982): Léxico del Comercio Medieval en Aragón (Siglo XV), Zaragoza, I.F.C., Zaragoza, 1982. [LCMA]

Libro de las generaciones. Estudio preliminar, edición crítica e índices por Josefa FERRANDIS Martínez, Valencia, Anubar, 1968. [Texto copiado en el siglo Xvi por el escribano navarro don Martín de Larraya, de un original escrito entre 1258 y 1270, muy posiblemente en Navarra. Está hecho a partir del Liber Regum, pero añadiendo noticias posteriores e intercalando datos nuevos].

Libro de las Gestas de Jaime I, rey de Aragón. Compilación aragonesa patrocinada por Juan Fernández de Heredia. Edición, introducción y notas de Francisco José Martínez Roy. Zaragoza, PUZ / IEA / IET / GA (col. «Larumbe», 66), 2010.

Libro de los muros. [Libro de la obra de las murallas de la ciudad de Huesca; texto escrito en los años 1444-1465, en un excelente aragonés]. Vid. en Iranzo MuñIo, $\mathbf{M}^{\mathrm{a}}$ Teresa, La muralla de Huesca en la Edad Media, Huesca, Ayuntamiento, 1986, pp. 53-122.

Libro del Trasoro [LT]. Vid. BRunetTo Latini.

Libro Verde de Aragón (1507). [Estudio: Alvar, Manuel, «Noticia lingüística del Libro Verde de Aragón», AFA, II (Zaragoza, 1947), pp. 59-92. [Reproducido en EDA, II, pp. 105-138] [LVA].

Lindenbauer, Petrea; Metzeltin, Michael; Thir, Margit (1995): Die romanischen Sprachen. Eine einfübrende Übersicht. Wilhemsfeld, Egert Verlag. [1. ${ }^{\text {a }}$ ed.: 1994].

Liria Montañés, Pilar (1979): «Libro de las maravillas del mundo» de Juan de Mandevilla. Zaragoza, Publicaciones de la Caja de Ahorros de Zaragoza, Aragón y 
Rioja, 1979. [Traducción aragonesa, hecha a fines del siglo xiv, del libro de viajes, redactado originalmente en francés, de Johan de Mandevilla o John de Mandeville]. [LMM]

LLABréS, Gabriel (1903): «Quién es el autor de la Crónica de San Juan de la Peña», Revista de Huesca, I (1903), pp. 1-15.

LLEAL, Coloma (1997a): El castellano del siglo XV en la Corona de Aragón. Zaragoza, Institución «Fernando el Católico».

LLEAL, Coloma (1997b): Vocabulario de la Cancillería Aragonesa (siglo XV). Zaragoza, Institución «Fernando el Católico». [VCA]

LLeAL, Coloma (2011): «Aragonés y aragonesismos en el DiCCA-xv», Aląet, 23 (2011), pp. $41-53$.

Lleal Galcerán, Coloma (dir.); Arroyo Vegga, Paloma; Cruz Piñol, Mar; Forment Fernández, Mar; y Vidal Díez, Mónica (2007): Pergaminos aragoneses del Fondo de Sástago: siglo XV. Zaragoza, Institución «Fernando el Católico».

López de Guereñu Galarraga, Gerardo (1998): Voces alavesas. Segunda edición. Prólogo y edición de Henrike Knörr. Bilbo, Euskaltzaindia. [1.ª edizión: 1958].

López de MENeSES, Amada (1952): «Documentos culturales de Pedro el Ceremonioso», EEMCA, vol. v (Zaragoza, 1952), pp. 669-771.

LóPEZ MoLINA, Luis (1960): Tucídides romanceado en el siglo XIV. Madrid, anejo v del BRAE, 1960. [Tucídides]

López Puyoles, Luis V., y Valenzuela Larrosa, José: Colección de voces de uso en Aragón, en El Diccionario Aragonés. Colección de voces para su formación, Zaragoza, Imprenta del Hospicio Provincial, 1903. Apud BoraO, 1908.

López Rajadel, Fernando (1994): Crónicas de los Jueces de Teruel (1176-1532). Estudio crítico y edición. Teruel, Instituto de Estudios Turolenses.

López Susín, José Ignacio (2006): Léxico del Derecho aragonés. Zaragoza, El Justicia de Aragón, 2006. [LDA]

López Susín, José Ignacio / Montaner Susín, Ma Dolores (2000): Bocabulario de Plasenzৃia (Sotonera). Uesca, Publicazions d'o Consello d'a Fabla Aragonesa (col. «Puens enta ra parola», 11).

LÜDTKE, Helmut (1974): Historia del léxico románico. Versión española de Marcos Martínez Hernández. Madrid, Gredos.

LÜDTKE, Helmut (2004): «El aragonés en el conjunto de las lenguas románicas», en F.

NAgOre (ed.), Estudios e rechiras arredol d'a luenga aragonesa e a suya literatura. Autas d'a III Trobada [Uesca-Alquezra, 17-20 d'otubre de 2001], Huesca, Instituto de Estudios Altoaragoneses / Consello d'a Fabla Aragonesa, 2004, pp. 13-20.

Luenga \& fablas. Publicazión añal de rechiras, treballos e decumentazión arredol de l'aragonés e a suya literatura. Huesca, Consello d'a Fabla Aragonesa, desde 1997.

MackenZie, Jean Gilkison: vid. GiLkison MaCKenzie, Jean. 
Macpherson, Ian R. (1961): «Associative interference in object-pronoun combinations in Navarre and Aragon», BHS, xxxvIII (1961), pp. 28-31.

Macpherson, Ian R. (1967): «Past Participle Agreement in Old Spanish Transitive Verbs», BHS, xLIV (1967), pp. 241-254.

Magdalena Nom de Déu, Ramón, y Lleal, Coloma (1995): Aljamías hebraicoaragonesas (siglos XIV-XV). Barcelona, Universidad de Barcelona.

Marco Polo, Vid. El Libro de Marco Polo. Vid. NitTi (1980). Vid. también Sangorrín (2016).

Martin i el Humano, Discurso (1398) = Discurso pronunciado por Martín I el Humano ante las Cortes de Aragón celebradas en la Seo de Zaragoza el 29IV-1398, en Jerónimo de Blancas, Comentarios de las cosas de Aragón [edición en castellano de Manuel Hernández de Aragonensium rerum commentari, Zaragoza, 1588], Zaragoza, 1878, pp. 348-355. [Ahora se puede ver también en: $A C R A$, tomo vi, vol. 1. ${ }^{\circ}$, Cortes del reinado de Martín I. Cortes de Zaragoza de 1398-1400. Ed. a cargo de Germán Navarro Espinach. Zaragoza, Grupo CEMA / IberCaja / Cortes de Aragón / Gobierno de Aragón, 2008. Discurso de apertura de Martín I: pp. 14-16. Respuesta del arzobispo de Zaragoza: pp. 17-19].

Martinet, André (1974): Economía de los cambios fonéticos. Madrid, Gredos, 1974.

Martínez de Sousa, José (1995). Diccionario de lexicografía práctica. Barcelona, Biblograf.

Martínez Ruiz, Antonio (2008): Vocabulario básico bilingüe aragonés-castellano y castellanoaragonés. Tercera edición corregida y aumentada. Uesca, Publicazions d'o Conselo d'a Fabla Aragonesa («Puens enta ra parola«, 7).

Martínez Salazar, Ángel (2005): El habla y la cultura popular en Aguilar, la Berrueza, Valdega y Los Arcos. Vitoria-Gasteiz, Tusitala enea Ediciones.

Mascaray, Bienvenido (1984): Benas, trallo y fuellas. Poesias en ribagorzano de Campo. Uesca, Publicazions d'o Consello d'a Fabla Aragonesa. [Vocabulario en pp. 109124].

Mascaray Sin, Bienvenido (2013): Vocabulario del habla de Campo (Ribagorza, Huesca). Zaragoza, Prensas de la Universidad de Zaragoza / Xordica Editorial.

Massó Torrents, J. (1905): «Inventari dels bens mobles del rey Martí d’Aragó», RHi, XII (1905), pp. 413-590.

MeIer, Harri (1984): Notas críticas al DECH de Corominas / Pascual. Santiago de Compostela, Universidade de Santiago de Compostela (Verba, Anexo 24).

Meilán García, Antonio (1988): «Y< IBI en castellano medieval, ¿`intagma o morfema?», Verba, 15 (1988), pp. 421-432.

MÉndez CoArasa, Veremundo (1979): Añada’n la Val d'Echo. Introducción, antología y vocabulario por Tomás Buesa Oliver. Zaragoza, I.F.C., 1979.

Mendiara Ornat, Pilar; Pérez Barcos, Alicia; Mendiara Gastón, Josefina; Castán Arnal, Montse (2003): Diccionario del dialecto ansotano. Jaca, Ayto. de Ansó. 
Menéndez Pidal, Ramón (1952): Poema de Yúcuf. Materiales para su estudio, RABM, tomo vII, (1902), pp. 91-129, 276-309, 347-362. 2. edición: Universidad de Granada, 1952. (Publicado también en TME, pp. 421-519). [PY]

Menéndez Pidal, Ramón (1968): Manual de gramática histórica española. Madrid, Espasa-Calpe, 13.a ed., 1968 [1. ${ }^{a}$ ed. en 1904]. [MGHE]

Menéndez Pidal, Ramón (1968): Orígenes del español. Estado lingüístico de la Peninsula Ibérica hasta el siglo XI. Madrid, Espasa-Calpe, 6. ${ }^{a}$ ed., 1968.

Menéndez Pidal, Ramón (1976): Textos medievales españoles. Ediciones críticas y estudios (Obras completas de R. Menéndez Pidal, tomo XII). Madrid, Espasa-Calpe, 1976. [TME]

Menéndez Pidal, Ramón: Cantar de Mio Cid. Texto, gramática y vocabulario. Madrid, I, $1976^{5}$; II, $1969^{4}$; III, $1969^{4}$.

Messner, Dieter; MülLER, Hans-Joachim (1983): Ibero-romanisch. Einfürung in sprache und literatur. Darmstadt, Wissenschaftliche Buchgesellschaft.

MetzeLtin, Michael (1989): «La marina mediterránea en la descripción de Ramón Muntaner», en La Corona de Aragón y las lenguas románicas. Miscelánea de bomenaje para Germán Colón, Tübingen, Gunter Narr Verlag, 1989, pp. 55-67.

Metzeltin, Michael (1998): «Die romanischen Sprachen: eine Gesamtschau / Les langues romanes: une vue d'ensemble», en Holtus, Günter / Metzeltin, Michael / Sснмітт, Christian (eds.), Lexikon der Romanistischen Linguistik, vII, Tübingen, Max Niemeyer Verlag, 1998, pp. 1040-1085.

Metzeltin, Michael (2004): Las lenguas románicas estándar. Historia de su formación y de su uso. Uviéu, Academia de la Llingua Asturiana.

Meyer-LüBKe, Wilhelm (1972): Romanisches Etymologisches Wörterbuch [Heidelberg, 193533]. Reimpresión, Heidelberg, Carl Winter-Universitätsverlag, 1972. $[R E W]$

Michelena, Luis (1977): Fonética histórica vasca. 2. ${ }^{a}$ edición, corregida y aumentada, San Sebastián, Publicaciones del Seminario Julio de Urquijo, de la Excma. Diputación Provincial de Guipúzoa.

Migliorini, Bruno (1968): Historia de la lengua italiana. Versión española de Fr. Pedro de Alcántara Martínez, 2 tomos. Madrid, Gredos, 1968.

Miracle, Josep (1973): Vocabulari Essencial castellano-català, català-castellano. Barcelona, Selecta.

Miral, Domingo (1924): «El verbo ser en cheso», Universidad, I (Zaragoza, 1924), pp. 209-216.

Miral, Domingo (1929): «Dialectología del Pirineo. Tipos de flexión verbal en el cheso (el verbo hacer-fer)», Universidad, vi (Zaragoza, 1929), pp. 3-10.

Mistral, Frédéric: Lou tresor dón felibrige ou dictionnaire provençal - français embrassant les divers dialectes de la langue d'oc moderne. Avec un supplement etabli d'apres les notes de Jules Ronjat. 2 tomos. Tercera edición. Raphèle-lès-Arles, Marcel 
Petit (Culture Provençale et méridionale), 1979 [Depósito Legal: Barcelona, 1979]. [La primera edición es de 1878-1886].

Molno, Mauricio (1964): El Fuero de Jaca. Edición crítica por - Zaragoza, Escuela de Estudios Medievales / Instituto de Estudios Pirenaicos, 1964. [FJ] [Manuscritos: AP (en una curiosa mezcla de lat., occ. y arag.; redac. anterior al siglo XIII), pp. 7-9; $A^{Z}$ (redactada en el s. XIII en Aragón; en aragonés con mezcla de frases en latín), pp. 92-100; D (versión en navarro-aragonés hecha posiblemente por García Martínez, notario de Villafranca de Navarra, h. 1340), pp. 279-507; los demás ms. están redactados en occ.] [FJ

Moll y Casanovas, Francisco de Borja (1952): Gramática histórica catalana. Madrid, Gredos, 1952. [Reedición traducida al catalán por Ferran Fabregat: Francesc de B. Moll, Gramática històrica catalana, València, Universitat de València, Servei de Publicacions, 1991].

Moneva y Puyol, Juan (2004 [1924]): Vocabulario de Aragón. [c. 1924]. Edición y estudio de José Luis Aliaga Jiménez. Zaragoza, Prensas Universitarias de Zaragoza / Institución «Fernando el Católico« / Xordica Editorial, 2004.

Morel-Fatio, Alfred (1885): Libro de los fechos et conquistas del principado de la Morea compilado por comandamiento de don Fray Johan Fernández de Heredia, Société de l'Orient Latin, Ginebra, 1885.

Morel-Fatio, Alfred (1889): «Une version aragonaise d'Eutrope faite sous les auspices de Juan Fernández de Heredia», Romania, XVIII (1889), pp. 491-493.

Morel-Fatio, Alfred (1893): «La Chronique de San Juan de la Peña», Bibliothèque de l'École des Chartes, Revue d'érudition, París, Alphonse Picard, 1893, vol. LIV, pp. 97-100.

Moret Oliver, María Teresa, y Tomás FAci, Guillermo (2014): El pleito del guiaje ganadero de Ribagorza (1316-1319). Edición y estudio histórico-lingüístico. Zaragoza, Institución «Fernando el Católico».

Mostolay, Chesús de- (2007): El aragonés en el Somontano de Barbastro. Zaragoza, Aneto Publicaciones (col. «O Chinipro», 1).

Mотт, Brian (1984): Diccionario chistavino - castellano, Zaragoza, Caja de Ahorros de Zaragoza, Aragón y Rioja, s. a. [1984].

Mотт, Brian (1988): «La sufijación sustantiva y adjetiva en el habla de Gistaín», Alazet, Revista de Filología del I.E.A., n. ${ }^{\circ}$ 0, (1988), pp. 223-243.

Мотт, Brian (1989): El habla de Gistain, Huesca, I.E.A., 1989.

Мотт, Brian (2000): Diccionario etimológico chistabino-castellano, castellano-chistabino. Zaragoza, Institución «Fernando el Católico», 2000.

MounIn, Georges (dir.) (1979): Diccionario de lingüistica. Barcelona, Labor, 1979.

Mur SAurA, Ricardo (2014): Diccionario panticuto -con apéndice gramatical y recopilación de textos-. Sabiñánigo, Comarca Alto Gállego (col. «Pan de paxaricos», 4).

Nabarro Garzía, Chusé Inazio (2011): «Estudio lingüístico d'un capbreu de Tauste d'o sieglo xv», Alazet, 23 (2011), pp. 55-82. 
Nagore Laín, Francho (1980): «Un texto en aragonés d'o sieglo XVII», Fuellas, 18 (chulio-agosto 1980), pp. 14-17. [Texto de Huesca de 1689].

Nagore Laín, Francho (1982): «Documento ansotano de 1369 sobre l'agüegamiento feito entre Ansó e Isaba», Fuellas, 28 (marzo-abril 1982), pp. 5-8.

Nagore Laín, Francho (1986): El aragonés de Panticosa. Gramática. Huesca, Instituto de Estudios Altoaragoneses, 1986. [Panticosa]

Nagore Laín, Francho (1987): Replega de testos en aragonés dialeutal de o sieglo XX (Materials ta lo estudio de l'aragonés popular moderno). Tomo I: ansotano, ayerbense, belsetán, Zaragoza, Diputación General de Aragón, 1987. [Replega]

Nagore Laín, Francho (1989): Gramática de la lengua aragonesa. Quinta edición, Zaragoza, Mira Editores, 1989. [GLA]

Nagore Laín, Francho (1989b): «L'aragonés charrato por una familia d’Orós Alto (Tierra de Biescas) en 1977. Bellas anotazions», en Homenaje a «Amigos de Serrablo», Huesca, Instituto de Estudios Altoaragoneses, 1989, pp. 331-366.

Nagore Laín, Francho (1994a): «Los occitanismos en aragonés; inventario provisional», en Actes du IV Congrès International de l'Association Internationale d'Etudes Occitanes (Vitoria-Gasteiz, 22-28 août 1993), tomo II, Vitoria-Gasteiz, 1994, pp. 851-886.

Nagore Laín, Francho (1994b): «Los occitanismos en aragonés», Alazęt, 6 (1994), pp. 119-173.

Nagore Laín, Francho (1995): «Arredol de bel tipo chenuino de condizional aragonés», Alazet, 7 (1995), pp. 97-104.

Nagore Laín, Francho (1996): «Más sobre o condizional aragonés», Alaẓet, 8 (1996), pp. 141-147.

Nagore Laín, Francho (2000): «Bocables aragoneses en A través del Somontano altoaragonés, de Salvador María de Ayerbe», en Nagore, Francho (coord.), Homenaje a Rafael Andol\%. Estudios sobre la cultura popular, la tradición y la lengua en Aragón. Huesca, Instituto de Estudios Altoaragoneses / Consello d'a Fabla Aragonesa / Instituto Aragonés de Antropología, pp. 527-573.

Nagore Laín, Francho (2001): Os territorios lingüisticos en Aragón. Zaragoza, Publicaciones del Rolde de Estudios Aragoneses [con la colaboración del Gobierno de Aragón - Departamento de Educación y Ciencia], 2001.

Nagore Laín, Francho (2003a): El aragonés del siglo XIV según el testo de la Crónica de San Juan de la Peña. Huesca, Instituto de Estudios Altoaragoneses.

Nagore Laín, Francho (2003b): «Índices onomásticos de la Crónica de San Juan de la Peña (versión aragonesa, siglo XIv)», Alazet, 15 (2003), pp. 297-342.

Nagore Laín, Francho (2007): «Aspectos lingüísticos de la redacción romance de los Fueros de Teruel y Albarracín en comparación con otros textos medievales en aragonés», en Tiempo de Derecho foral en el sur aragonés: los fueros de Teruel y Albarracín. Tomo I: Estudios. Zaragoza, El Justicia de Aragón, pp. 419-448. 
Nagore Laín, Francho (2008): «Bels aspeutos lingüisticos en un testo en aragonés meyebal: as ordinazions d'a Cofrairía d'a Transfixión de Zaragoza (1311-1508)», Alazet, 20 (2008), pp. 207-222.

Nagore Laín, Francho (2013): Lingüistica diatopica de l'Alto Aragón. Cómo ye l'aragonés de cada puesto: carauteristias, bibliografía, testos, mapas. Uesca, Publicazions d'o Consello d'a Fabla Aragonesa («A tefla de cuatro fuellas», 8).

Nagore Laín, Francho (2016a): «Bellas anotazions sobre morfolochía e sintasis en protocolos notarials de Balbastro de 1390 a 1395«, Alazet, 28 (2016), pp. 81-134.

Nagore Laín, Francho (2016b): «Una fuen importán ta o conoximiento de l'aragonés d'a segunda metá d'o sieglo xiII: os Documentos de la colegiata de Santa María de Alquézar. Siglos XI al XIII), Luenga \& fablas, 20 (2016), pp. 157-164.

Nagore Laín, Francho (2019): «Un excelente vocabulario de la scripta navarroaragonesa del siglo XIII», en Gunnar Tilander, Vidal Mayor. Traducción aragonesa de la obra In Excelsis Dei Thesauris de Vidal de Canellas. Vocabulario, Zaragoza, Prensas de la Universidad de Zaragoza, pp. XxI-LxIx.

Nagore Laín, Francho (2020a): O charrar d'a chen de Uesca. Bocabulario e rechistro decumental de l'aragonés d'a qiudá de Uesca e a redolada. Uesca, Publicazions d'o Consello d'a Fabla Aragonesa (col. «Puens enta ra parola», 19).

Nagore Laín, Francho (2020b): «El aragonés en textos medievales no literarios: aspectos morfosintácticos», en Javier Giralt Latorre y Francho Nagore Laín (eds.), Aragonés y catalán en la historia lingüistica de Aragón. Zaragoza, Prensas de la Universidad de Zaragoza, pp. 69-123.

Nagore Laín, Francho (2020c): «Ecos del habla popular de Huesca en la obra publicada (1913-1936) de Ramón Acín», Alazet, 32 (2020), pp. 33-87.

Nagore Laín, Francho (coord.) (2000): Homenaje a Rafael Andolz. Estudios sobre la cultura popular, la tradición y la lengua en Aragón. Uesca, Instituto de Estudios Altoaragoneses - Consello d'a Fabla Aragonesa - Instituto Aragonés de Antropología, 2000.

Nagore Laín, Francho (coord.): Endize de bocables de l'aragonés seguntes os repertorios lesicos de lugars y redoladas de l'Alto Aragón. tomos I-IV, Huesca, Instituto de Estudios Altoaragoneses, 1999.

Nagore Laín, Francho \& VÁzquez Obrador, Jesús (2018): Minutas en aragonés en protocolos de los años 1390-1399 de Domingo Ferrer, notario de Barbastro. Zaragoza, Prensas Universitarias de Zaragoza, 2018. [MDF]

Nagore Laín, Francho, Rodés, Francho, VázQuez, Chesús (eds.) (1999): Estudios y rechiras arredol d'a luenga aragonesas y a suya literatura. Autas d'a I Trobada [Uesca, 2022 de febrero de 1997]. Huesca, Instituto de Estudios Altoaragoneses / Consello d'a Fabla Aragonesa, 1999.

Nagore Laín, Francho, Rodés, Francho, Vázquez, Chesús (eds.) (2001): Estudios y rechiras arredol d'a luenga aragonesas y a suya literatura. Autas d'a II Trobada [Uesca,18-20 
de nobiembre de 1999]. Uesca, Instituto de Estudios Altoaragoneses - Consello d'a Fabla Aragonesa, 2001.

Navarro Romanos, Luis (2000): Léxico de uso común en la villa de Ibdes. Tarragona, Asociación Cultural Amigos de la Villa de Ibdes, 2000.

Navarro Tomás, Tomás (1909): «El perfecto de los verbos en -ar en aragonés antiguo. Observaciones sobre el valor dialectal de los documentos notariales», Revue de Dialectologie Romane, I (1909), pp. 110-121. [Publicado posteriormente en AFA, X-XI (1950), pp. 315-324].

Navarro Tomás, Tomás (1957): Documentos lingüísticos del Alto Aragón. Syracuse (New York), Syracuse University Press, 1957. [DLAA]

Neira Martinez, Jesús (1969): «Los prefijos es-, des- en aragonés», Archivum, 19 (Oviedo, 1969), pp. 331-341.

NiтII, John J. (1980): Juan Fernández de Heredia's Aragonese version of the 'Libro de Marco Polo', edited by —. Madison, Hispanic Seminary of Medieval Studies, 1980.

NitTi, J., y Kasten, Ll. (1997): The electronic texts and concordances of Medieval navarro-aragonese manuscripts. Madison [Wisconsin, U.S.A.], The Hispanic Seminary of Medieval Studies. [CD-ROM].

Octavario = Estudios sobre el «Octavario» de doña Ana Abarca de Bolea. Zaragoza, Institución «Fernando el Católico», 1945, de M. ALVAR. [El Octavario de San Juan Baptista, de Ana Abarca de BoleA, se publicó en Zaragoza en 1679]. Vid. ed. de M. ángeles Campo Guiral, Huesca, I.E.A., 1993.

Olano Pemán, José (1994): Diccionario de palabras, voces y dichos de Uncastillo. Uncastillo, Asociación Cultural «La Lonjeta», 1994.

Orcástegui Gros, Carmen (1978): La crónica de los Reyes de Navarra del Principe de Viana. Estudio, Fuentes y Edición crítica. Pamplona, Institución «Príncipe de Viana», 1978.

Orcástegut Gros, Carmen (1986): Crónica de San Juan de la Peña (Versión aragonesa). Edición crítica, Zaragoza, Institución «Fernando el Católico».

Orcástegui Gros, Carmen, y redondo veintemildas, Guillermo (1986): «Los cronistas medievales y su culminación en Gauberto Fabricio de Vagad», en la introducción a VIÑAZA, Conde de la —, Los Cronistas de Aragón, Madrid, 1904; edición facsimilar, Zaragoza, Cortes de Aragón, 1986, pp. 11-45.

Ordinación = Ordinación de la ceremonia de coronación de los Reyes de Aragón y de la de Reynas de Aragón. Vid. Pedro iv, Ordinación... Reyes y Ordinación ... Reynas. [Edición: G. de Blancas, Coronaciones de los Serenísimos Reyes de Aragón, Zaragoza, por don Juan Francisco Andrés de Uztarroz, 1641, pp. 117-152 del Libro I y pp. 173-185 del Libro II].

Ordinaciones de Barbastro = Ordinaciones y paramientos de la Ciudad de Barbastro [1396-1521], publicados por D. Mariano de Pano. Aspectos lingüísticos por D. Jesús VÁzQuEZ Obrador. Barbastro, Ayuntamiento de Barbastro, 2011. [Vid. también VázQuez OBRADOR, 2011c]. [OB] 
Origen aragonés de las Glosas Emilianenses. Estudios y edición facsímil. Introd. de Ramón D’Andrés DíAz. Zaragoza, Aladrada Ediciones, 2020.

Orosio, Paulo: Historias contra los paganos. Versión aragonesa patrocinada por Juan Fernández de Heredia. Edición crítica, estudio y vocabulario de Ángeles Romero Cambrón. En colaboración con Ignacio J. García Pinilla. Zaragoza, PUZ / IEA / IET / GA (col. «Larumbe», 50), 2008.

PAGÉs, Amédée (1889): «Recherches sur la chronique catalane attribuée à Pierre IV d'Aragon», Romania, Vol. xVIII, (1889), pp. 233-280.

Palacios Rasal, Liena, y Baos Muñoz, Chan (2010): Bocabulario de Murillo de Galligo. Uesca, Publicazions d'o Consello d'a Fabla Aragonesa (col. «Puens enta ra parola», 18).

Palay, Simin (1974): Dictionaire du Béarnais et du Gascon modernes (Bassin Aquinain) embrassant les dialectes du Béarn, de la Bigorre, du Gers, des Landes, et de la Gascogne maritime et Garonnaise. Seconde édition complétée, Paris, Editions du C.N.R.S., 1974 [1. a ed., 1961].

Palestra Nvmerosa Avstriaca (1650). Vid. vÁzQUEZ OBRADOR.

PAR, Alfonso: «Qui y que en la Península Ibérica», «I. En castellano», RFE, XIII (1926), pp. 337-349; «II. En el dominio catalán», RFE, XVI (1929), pp. 1-34 y 113-147; «III. En aragonés», RFE, XVIII (1931), pp. 225-234.

Pardo Asso, José (1938): Nuevo diccionario etimológico aragonés. Zaragoza, Imprenta del Hogar Pignatelli.

Pascual Recuero, Pascual (1977): Diccionario básico ladino-español. Barcelona, Ameller Ediciones.

Pascual Rodríguez, José Antonio (1988): «Los aragonesismos de La visión deleitable del bachiller Alfonso de la Torre», en Actas del I Congreso Internacional de Historia de la Lengua Española, vol. I, Madrid, Arco/Libros, 1988, pp. 647-676.

Pato, Enrique (2010): «Algo más sobre la historia del posesivo lun», AFA, 66 (2010), pp. 13-32.

Pedro iv de Aragón: Ordinación ... Reynas = «Ordinacion de la manera como las

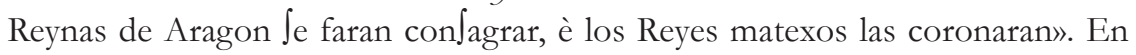
Geronimo de Blancas, Coronaciones de los Serenísimos Reyes de Aragón, Zaragoza, por don Juan Francisco Andrés de Ustarroz, 1641, Libro II, cap. v, pp. 173-185.

Pedro iv de Aragón: Ordinación... Reyes $=$ «Ordinación feyta por el muy alto, è muy excelent Princep \& Senyor, el Senyor Don Pedro el IV, Rey de Aragón

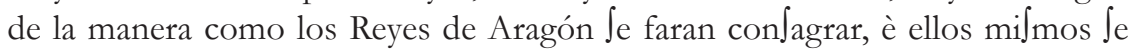
coronaran». En Geronimo de Blancas, Coronaciones de los Serenísimos Reyes de Aragón, Zaragoza, por don Juan Francisco Andrés de Ustarroz, 1641, Libro I, cap. x, pp. 117-152. Vid. también Ceremonial de la Consagración y Coronación de los Reyes de Aragón.

Pedro iv de Aragón: Tratado de Paz (1357) = «Tratado de paz y treguas entre el Rey de Aragón D. Pedro IV y el de Fez por cinco años, incluyendo baxo las mismas 
condiciones al Rey de Granada, firmado en Zaragoza á 20 de Julio del año 1357》, en Antiguos tratados de paces y alianzas entre algunos reyes de Aragón y diferentes príncipes infieles de Asia y Africa, desde el siglo XIII hasta el XV, por D. Antonio de Capmany y de Montpalau, Madrid, en la Imprenta Real, 1786. Reimpresión facsímil, Valencia, Anubar, 1974, pp. 18-25.

Pellen, René (1977): «Poema de Mio Cid. Vocabulaire réduit (vocables avec leur fréquence globale et leur fréquence par chant). Caractères statistiques généraux de ce vocabulaire. Contribution de l'informatique à la connaissance du lexique espagnol médieval», CLHM, n. 2 (París, marzo 1977), pp. 171-251.

Pellen, René, Huynh-Armanet, Véronique, y Roudil, Jean (1977): «Traitement automatique de textes espagnols du Moyen Age et analyse des données», CLHM, n. ${ }^{\circ} 2,1977$, pp. 271-274.

Pena, Jesús (1980): La derivación en español. Verbos derivados y sustantivos verbales. Anexo 16 de Verba, Anuario Galego de Filoloxia, Universidade de Santiago de Compostela, 1980.

Peralta, Mariano: Ensayo de un diccionario aragonés - castellano: Zaragoza, Imprenta Real, 1836; 2. ${ }^{a}$ ed. [reimpresión], Palma de Mallorca, Pedro José Gelabert, 1853. [Eds. facsímiles de esta última: Madrid, Ediciones El Museo Universal, 1984; Zaragoza, Ediciones Moncayo, 1986].

Pérez Martín, Antonio (1999): Los Fueros de Aragón: la Compilación de Huesca. Edición crítica de sus versiones romances. Zaragoza, El Justicia de Aragón.

Pérez-SaLAZAR, Carmela (1995): El romance navarro en documentos reales del siglo XIV (1332-1349). Pamplona, Institución «Príncipe de Viana»..

Pharies, David (2002): Diccionario etimológico de los sufjos españoles y de otros elementos finales. Madrid, Gredos.

Piel, Joseph-Maria (1989): Estudos de linguística histórica galego-portuguesa. Lisboa, Imprensa Nacional - Casa da Moeda.

Plutarco (2009): Vidas semblantes. Versión aragonesa de las Vidasparalelas, patrocinada por Juan Fernández de Heredia. Edición de Adelino Álvvarez Rodríguez. Dos volúmenes. Zaragoza, PUZ / IEA / IET / GA (col. «Larumbe« 59), 2009.

Ponsoda Sanmartín, Joan J. (1996): El català i l'aragonés en els inicis del Regne de València segons el Llibre de Cortede Justícia de Concentaina (1269-1295). Alcoi, Editorial Marfil.

Porcar Miralles, Margarita (1986): «Las formas verbales de futuro en textos medievales aragoneses», AFA, xxxvIII (1986), pp. 9-47.

Potтier, Bernard (1947): «Miscelánea de Filología Aragonesa», AFA, iI (Zaragoza, 1947), pp. 93-153.

PotтiER, Bernard (1948-1949): «Etude lexicoloxique sur les Inventaires aragonais», VR, x (1948-9), pp. 87-219. [ELLA]

POTTIER, Bernard (1950a): «Notas lingüísticas sobre antiguos textos aragoneses», AFA, III (1950), pp. 227-239. 
PotTIER, Bernard (1950b): «Un manuscrito aragonés de «Las vidas de hombres ilustres» de Plutarco», $A F A$, III (1950) pp. 241-250.

PоттіеR, Bernard (1952): «L'évolution de la langue aragonaise a la fin du Moyen Âge», BHi, LIV (1952), pp. 184-199. [Traducción al castellano por P. García Mouton: AFA, xxxvIII (1986), pp. 225-240].

PotTiER, Bernard (1955): «Les éléments gascons et languedociens dans l'aragonais médiéval», en VII Congreso Internacional de Lingüistica Románica, Barcelona 1955, pp. 679-689. [Traducción al castellano por P. García Mouton: AFA, XLVI-XLVII (1991), pp. 235-244].

PotTIER, Bernard (1960): «Problèmes relatifs aux adverbes en -ment», en Miscelánea filológica dedicada a Mons. A Griera, tomo II, Sant Cugat del Vallés, Barcelona, Instituto Internacional de Cultura Románica, 1960, pp. 189-205. [Traducción castellana en Lingüística moderna y filología hispánica, Madrid, Gredos, 1970, pp. 217 231]

Prince, Dawn E. [ed.] (1995): The Aragonese Version of Brunetto Latini's Libro del trasoro. Madison [Wisconsin, U.S.A.], The Hispanic Seminary of Medieval Studies, 1995. [Glossary, pp. 219-225].

PRobert = Dictionnaire alphabétique et analogique de la langue française (París, 1988), por P. Robert, A. Rey y J. Rey-Debove.

Quintana i Font, Artur (1980): El parlar de La Codonyera. Resultats d'unes enquestes. Barcelona, Institut d'Estudis Catalans, 1976-1980 [Extret d'Estudis Romànics, XVII].

Quintana i Font, Artur (2004): El aragonés residual del bajo valle del Merquín. Segunda edición corregida y ampliada. Torrecilla de Alcañiz, Ayuntamiento, 2004.

Quintana i Font, Artur (2007a): El aragonés nuclear de Nerín y Sercué (Valle de Vió). Zaragoza, Institución «Fernando el Católico» / Gara d'Edizions.

Quintana i Font, Artur (2007b): Xandra. Estudios aragoneses de luenga e literatura. Edizión a ro cudiau d'Hèctor Moret. Calaceit, Associació Cultural del Matarranya / Institut d'Estudis del Baix Cinca.

Ramos Remedios, Emiliana (2002): Los cartularios de Santa María de Valpuesta. Análisis lingüistico. Donostia, Eusko Ikaskuntza - Sociedad de Estudios Vascos - Societé d'Études Basques.

Rams de flores o Libro de actoridades. Obra compilada bajo la protección de Juan Fernández de Heredia, Maestre de la Orden del Hospital de San Juan de Jerusalem. Ed. de Conrado Guardiola Alcover. Zaragoza, Institución «Fernando el Católico», 1998. [LA]

Real Academia Española (1726-1739): Diccionario de Autoridades. Edición facsímil. 3 tomos. Madrid, Gredos, 1969. [Diccionario de la lengua castellana, 6 tomos, Madrid, Francisco del Hierro, 1726-1739.] [Dicc. Aut.]

Real Academia Española (1970): Diccionario de la Lengua Española, 19. a edición, Madrid, Espasa-Calpe, 1970. [DRAE, 1970] 
Real Academia Española (1973): Esbozo de una nueva gramática de la Lengua Española. Madrid, Espasa-Calpe, 1973. [Esbozo]

Real Academia Española (1979): Diccionario manual e ilustrado de la Lengua Española, $2^{a}$ edición, Madrid, Espasa-Calpe, 1950; $7^{a}$ reimpresión, 1979. [DRAE Manual, 1979]

Real Academia Española (1984): Diccionario de la Lengua Española, 20. a edición, 2 tomos, Madrid, Espasa - Calpe, 1984. [DRAE, 1984]

Real Academia Española (1989): Diccionario manual e ilustrado de la Lengua Española, 4. ${ }^{a}$ edición revisada, Madrid, Espasa - Calpe, 1989. [DRAE Manual, 1989]

Real Academia Española (Seminario de Lexicografía): Diccionario Histórico de la Lengua Española, tomo I (a-alâ), Madrid, 1972. Fascículos 11. a 16. (álaba-amenazar), Madrid, 1974-1984. [DHLE]

Real Academia Española: Diccionario de la lengua española. Vigésima segunda edición. Madrid, Editorial Espasa Calpe, 2001.

Real Academia Española: Diccionario de la lengua española. Vigesimotercera edición. Barcelona, Espasa Libros, 2014. [DLE]

Real Academia Galega / Instituto da Lingua Galega (1990): Diccionario da lingua galega. Director: Constantino García. Coordinadores: Manuel González González, Antón Santamarina Fernández. A Coruña, Real Academia Galega / Instituto da Lingua Galega, 1990.

Refrans, frases feitas, ditos y esprisions de l'Alto Aragón. Replegas orals y escritas feitas por a Sezión de Lenguas de o Rolde de Estudios Aragoneses. Zaragoza, Publicaciones de Rolde de Estudios Aragoneses, 2004. [RFDE]

ReIDY FRITZ, J. (1977): Documentos notariales aragoneses, 1258-1495. Estudio lingüistico, Pamplona, Institución «Príncipe de Viana», 1977. [Sobre el léxico jurídico de estos documentos, véase LAGÜÉNS, 1992]

Reta JanÁriz, Alfonso (1976): El habla de la zona de Eslava (Navarra). Pamplona, Institución «Príncipe de Viana».

Riba y García, Carlos (1915): Carta de población de la ciudad de Santa María de Albarracín según el códice romanceado de Castiel existente en la Biblioteca Nacional de Madrid. Zaragoza, Tipografía de Pedro Carra.

Ridruejo, Emilio (1985): «Tres catalanismos (y aragonesismos) sintácticos en «Los doze trabajos de Hércules» del Marqués de Villena», Archivo de Filología Aragonesa, 34-35 (1985), pp. 273-290.

RiERA SANS, Jaume (1982): «Una versión aragonesa de la "Epístola de cura et modo rei familiaris utilius gubernande" atribuida a San Bernardo (siglo XV)», Archivo de Filología Aragonesa, 28-29 (1982), pp. 121-141.

Ríos Nasarre, Paz (1997): Bocabulario d'o Semontano de Balbastro (de Salas Altas y a redolada). Uesca, Uesca, Publicazions d'o Consello d'a Fabla Aragonesa (col. «Puens enta ra parola», 8). 
Ríos Nasarre, Paz (1997): «Enampladura d'o Bocabulario d'o Semontano de Balbastro (de Salas Altas y a redolada)», Luenga \& fablas, 5-6 (2001-2002), pp. 9-27.

Riquer, Martín de - (1944): «Crónica aragonesa del tiempo de Juan II», Analecta Sacra Tarraconensia, 17 (Barcelona, 1944), pp. 1- 29.

Riquer, Martín de - (1969): «Medievalismo y Humanismo en la Corona de Aragón a fines del siglo xIV», vIII Congreso de Historia de la Corona de Aragón [1967], Valencia, 1969, t. II, vol. 1, pp. 221-235.

Riquer, Martín de - (1985): Historia de la literatura universal. Vol. 3, Literaturas medievales de transmisión escrita. Barcelona, Planeta, 1985.

Riquer, Martín de - (1994): Chanson de Roland (Cantar de Roldán y el Roncesvalles navarro). Barcelona, Quaderns Crema, Sirmio, 1994.

Rius SERRA, J. (1926): «Refranes del s. XIV», RFE, XIII (Madrid, 1926), pp. 364-372. [Refranes aragoneses del siglo xiv (c. 1350)].

RoBert, Paul: Dictionnaire alphabétique et analogique de la langue française (Le Petit Robert 1). Rédaction dirigée par Alain Rey et Josette Rey-Debove. Nouvelle édition revue, corrigée et mise à jour pour 1989, París, Dictionnaires Le Robert, 1988. [PRobert]

Roberts, Edward A., \& PASTor, Bárbara (2007): Diccionario etimológico indoeuropeo de la lengua española. Madrid, Alianza editorial. [Sexta reimpresión; 1. ${ }^{a}$ edición, 1996].

Rodés Orquín, Francho (1996): Bocabulario aragonés d'o botero Pedro Lafuente, Uesca, Publicazions d'o Consello d'a Fabla Aragonesa («Puens enta ra parola», 5), 1996.

Rodés Orquín, Francho (2016): «Léxico», en LT, 2016, pp. 681-783.

Rodríguez Barcia, Susana (2016): Introducción a la lexicografía. Madrid, Editorial Síntesis.

RoHLFs, Gerhard (1951): «Los sufijos en los dialectos pirenaicos», traducción de Luis Márquez Villegas, Pirineos, 19-22, 1951, pp. 467-526. Reproducido en $A F A$, xL, Zaragoza, 1988, pp. 115-170). Publicación original en alemán: «Beiträge zur Kenntnis der Pyrenäenmundarten», RLiR, vII (1933), pp. 119169. [Rohlfs, Sufjos.]

RoHLFS, Gerhard (1970): Le gascon. Études de philologie pyrénéenne. Deuxième édition, entièrement refondue, Tübingen / Pau, Max Niemeyer Verlag / Editions Marrimpouey Jeune, 1970.

RoHLFs, Gerhard (1979): Estudios sobre el léxico románico. Reelaboración parcial y notas de Manuel Alvar. Edición conjunta, revisada y aumentada, Madrid, Gredos.

RoHLfs, Gerhard (1985): Diccionario dialectal del Pirineo Aragonés. Presentación por Tomás Buesa Oliver, Zaragoza, I.F.C., 1985. [RoHLFs, DDPA]

Romanos Hernando, Fernando (2003): Al límite. La pervivencia del aragonés en las comarcas del norte de Zaragoza. Zaragoza, Diputación de Zaragoza. 
Romanos Hernando, Fernando, y Sánchez Pitarch, Fernando (1999): L'aragonés de A Fueba. Bocabulario y notas gramaticals, Uesca, Publicazions d'o Consello d'a Fabla Aragonesa (col. «Puens enta ra parola», 9), 1999.

RoudiL, Jean (1977): «Documents lexicométriques: «Poridat de las poridades» (index des formes et index des vocables)», CLHM, n. 2 (París, marzo 1977), pp. 119169.

Roudil, Jean (1979): «Index alphabétique des formes de la Primera Crónica General», CLHM, no 4 bis, 1979, pp. 205-365.

Rubio Garcia, Luis (1963): «El dialecto de Jaca a través de sus documentos (s. X-XII )», en Actas del Tercer Congreso Internacional de Estudios Pirenaicos, Zaragoza, Instituto de Estudios Pirenaicos (S.C.I.C.), 1963, pp. 75-126.

Rubió i Lluch, A. (1908-1921): Documents per l'Història de la Cultura Catalana Mig-eval. 2 vols. Barcelona, Instituto d'Estudis Catalans, 1908-1921.

Rubió i Lluch, A. (1909-1910): «Estudi sobre la elaboració de la Crònica de Pere.1 Ceremoniós», Anuari de l'Institut d'Estudis Catalans, (1909-1910), pp. 519-570.

Rubió, Jordi (1936): «La versió llatina de la Crónica General de Catalunya i Aragó», Estudis Universitaris Catalans, xxi (Barcelona, 1936), pp. 343-355.

Sangorrín Gualdar, Francisco (2016): El Libro de Marco Polo, versión aragonesa del siglo XIV. Edición y estudio de — Zaragoza, Institución «Fernando el Católio», 2016. [Glosario en pp. 185-247]. [Marco Polo]

SAÑé, Secundí \& SCHEPISI, Giovanna (2002): Dizionario spagnolo italiano / italiano spagnolo. Bologna, Zanichelli / Barcelona, Biblograf. [1. ed., 1987].

Saralegui, Carmen (1971): El testamento de Carlos III de Navarra. Edición, estudio lingüístico y vocabulario. Pamplona, I.P.V., 1971. [Testamento]

Saralegui, Carmen (1977): El dialecto navarro en los documentos del monasterio de Irache (958-1397). Pamplona, I.P.V., 1977. [Irache]

SARALEGUI, Carmen (1988): «Un fuero navarro del siglo XIV y su versión en el siglo XVI», en Actas del I Congreso Internacional de Historia de la Lengua Española, vol. II, Madrid, Arco/Libros, 1988, pp. 1557-1568.

SARAlEgui, Carmen (1992): «Aragonesisch/Navarresisch: Externe und interne Sprachgeschichte. / Evolución lingüística externa e interna», en Günter HoLTus, Michael Metzeltin, Christian Schмiтт (eds.), Lexikon der Romanistischen Linguistik (LRL), vol. vI, 1, Tübingen, Max Niemeyer Verlag, 1992, pp. 37-54.

SAROÏHANDy, Jean-Joseph (1898): «Mission de M. Saroïhandy en Espagne», Ecole Pratique des Hautes Etudes, Annuaire (París, 1898), pp. 85-94 (= «Misión de J. Saroïhandy en España [1896]», AFA, vi, Zaragoza, 1954, pp. 9-26, trad. y notas de M. Alvar. Ahora puede verse, nuevamente traducido por Óscar Latas, en SAROÏHANDY, 2009: 27-40).

SaroïHANDy, Jean-Joseph (1901): «Mission de M. Saroïhandy en Espagne», Ecole Pratique des Hautes Etudes, Annuaire (París, 1901), pp. 106-118 (= «Informe del 
Sr. Saroihandy», trad. del Sr. Laborda, con un prólogo de Joaquín Costa titulado «Dialectos aragoneses», Revista de Aragón, Zaragoza, 1902, pp. 644-654. Ahora puede verse en SAROÏHANDY, 2009: 41-59).

SARoÏHANDY, Jean-Joseph (1904): «Remarques sur le poème de Yúçuf», Bulletin Hispanique, vi (1904), pp. 182-194. (Trad. en cast. en SaroÏHANDy, 2005: 80-93, y en Saroïhandy, 2009: 60-80).

SARoÏHANDY, Jean-Joseph (1913): «Vestiges de phonétique ibérienne en territoire roman», RIEV, VII (1913), pp. 475-497 (= «Huellas de fonética ibérica en territorio románico», trad. de A. LLORENTE, AFA, vIII-IX, 1956-57, pp. 181-199. Ahora puede verse en SAROÏHANDY, 2009: 117-157).

SaroïHANDy, Jean-Joseph (2005): Misión lingüística en el Alto Aragón. Edición y estudio de Óscar Latas Alegre. Zaragoza, Prensas Universitarias de Zaragoza / Xordica Editorial.

SARoÏHANDy, Jean-Joseph (2009): Informes sobre el aragonés y el catalán de Aragón [189819167. Edición y estudio de Óscar Latas Alegre. Zaragoza, Aladrada ediciones («Biblioteca de las lenguas de Aragón», 2).

SAS, Louis F. (1976): Vocabulario del libro de Alexandre. Anejo xxxiv del BRAE, Madrid, 1976.

Satué Sanromán, José M. ${ }^{a}$ (1991): Vocabulario de Sobrepuerto (léxico comentado de una comarca despoblada del Altoaragón). Uesca, Instituto de Estudios Altoaragoneses, 1991.

Savall y Dronda, Pascual y Penén y Debesa, Santiago (1983 [1866]): «Glosario de las voces provinciales y anticuadas que se encuentran en los Fueros, Observancias y Actos de corte del Reino de Aragón», AFA, xxx-xxxi (1983), pp. 293-319. [1. ${ }^{a}$ ed. en Fueros, Observancias y Actos de Corte del Reino de Aragón, Zaragoza, 1866, pp. 191-201].

SECO, Manuel (1989): Gramática esencial del español. Introducción al estudio de la lengua. Segunda edición, revisada y aumentada, Madrid, Espasa Calpe, 1989. [1. ${ }^{a}$ ed.: Madrid, Aguilar, 1980].

SECO, Manuel (ed.) (2004): Léxico hispánico primitivo (siglos VIII al XII). Versión primera del Glosario del primitivo léxico iberorrománico. Proyectado y dirigido inicialmente por Ramón Menéndez Pidal. Redactado por Rafael Lapesa, con la colaboración de Constantino García. Madrid, Fundación Ramón Menéndez Pidal / Real Academia Española / Editorial Espasa Calpe, 2004.

Seco, Manuel, Andrés, Olimpia y Ramos, Gabino: Diccionario del español actual. 2 vols. Madrid, Aguilar (Grupo Santillana de Ediciones), 1999. [DEA]

Segura Munguía, Santiago (2001): Nuevo diccionario etimológico Latín-Español y de las voces derivadas. Bilbao, Universidad de Deusto.

Sesma, J. Ángel y Líbano, Ángeles (1982): Léxico del Comercio Medieval en Aragón (siglo XV). Zaragoza, Institución «Fernando el Católico», 1982. [LCMA]. 
Sevillano Colom, Francisco (1950): «La cancillería de Pedro IV el Ceremonioso», Anuario Histórico del Derecho Español, 20 (1950), pp. 137-241.

Sezión de Lenguas de o Rolde de Estudios Aragoneses (2004): Refrans, frases feitas, ditos y esprisions de l'Alto Aragón. Replegas orals y escritas feitas por a Sezión de Lenguas de o Rolde de Estudios Aragoneses. Zaragoza, Publicaciones de Rolde de Estudios Aragoneses. [= RFDE]

Siesso DE BOLEA, José: Borrador de un diccionario de voces aragonesas [c. 1715-1724]. Edición y estudio de José Luis Aliaga Jiménez, Zaragoza, Institución «Fernando el Católico» / Prensas Universitarias de Zaragoza / Gara d’Edizions, 2008.

Simón DíAz, José (1955): «El tema literario de «La Campana de Huesca», Revista de Literatura, núm. 13-14 (1955), pp. 30-49.

Soberanas Lleó, Amadeu-J. (ed.) (1961): Crònica General de Pere iII el Cerimoniós dita comùnament Crònica de Sant Joan de la Penya. Primera edició del seu text catalá. Transcripció, prefaci i notes per Amadeu-J. Soberanas Lleó, Barcelona, Alpha.

Soler Betés, Amparo-Ángeles (2004): Replega de bocabulario de Ballobar. Uesca, Publicazions d'o Consello d'a Fabla Aragonesa (col. «Puens enta ra parola», 14).

TABernero Sala, Cristina (1996): La configuración del vocabulario en el romance navarro. Estudio sobre documentos reales de los siglos XIII y XIV. Pamplona, Ediciones de la Universidad de Navarra.

Terrado Pablo, Javier (1991): La lengua de Teruel a fines de la Edad Media. Teruel, Instituto de Estudios Turoleneses

Testamento $=$ El testamento de Carlos III de Navarra. Edición, estudio lingüístico y vocabulario, por Carmen Saralegui (Pamplona, I.P.V., 1971).

Tiberio, Gaio E. (1972): Some Aragonese Morphophonemics: A first approximation to the main stress rule and functionally related rules. Wiesbaden, LB (Linguistiche Berichte) - Papier Nr. 26, 1972.

Tiempo de Derecho foral en el sur aragonés: los fueros de Teruel y Albarracín. I. Estudios. II. El Fuero de Teruel. Coordinación: Guillermo Redondo Veintemillas y Esteban Sarasa Sánchez. Zaragoza, El Justicia de Aragón, 2007.

Tilander, Gunnar (1935): «Fueros aragoneses desconocidos promulgados a consecuencia de la gran peste de 1348», Revista de Filología Española, XXII (1935), pp. 1-33 y 113-152. [= Fueros de 1348].

Tilander, Gunnar (1937): Los Fueros de Aragón según el manuscrito 458 de la Biblioteca Nacional de Madrid, publicados por —. Lund, C.W.K. Gleerup (Acta Reg. Societatis Humaniurum Litterarum Lundessis, Xxv), 1937. [Texto en aragonés escrito a principios del siglo XIV] [FA]

Tilander, Gunnar (1951): Los Fueros de la Novenera, publicados por —, Uppsala (Leges Hispanicæ Medii Aevi, II), 1951. [FN]

Tilander, Gunnar (1956): Vidal Mayor. Traducción aragonesa de la obra In Excelsis Dei Thesauris, de Vidal de Canellas, editada por_-, vol. I: Introducción; vol. II: Texto; 
vol. III: Vocabulario. Lund, Hakan Ohlsson Boktryckeri (Leges Hispanicae Medii Aevi, IV), 1956. [VM]

Tilander, Gunnar (1964): «Francés antiguo, provenzal, catalán ades, italiano adesso, español antiguo adieso», Archivo de Filología Aragonesa, XIv-Xv (1963-1964), pp. 315-317.

Tilander, Gunnar (2019): Vidal Mayor. Traducción aragonesa de la obra In Excelsis Dei Thesauris de Vidal de Canellas. Vocabulario. [Edición facsímil]. Textos introductorios de José Ignacio López Susín y de Francho Nagore Laín. Zaragoza, Prensas de la Universidad de Zaragoza.

Tomás Faci, Guillermo (2018): «El tratado diplomático bilingüe de 1409: edición comparada de las versiones aragonesa y castellana», Alazet, 30 (2018), pp. 167190.

Tomás FACI, Guillermo (2020): El aragonés medieval: Lengua y Estado en el reino de Aragón. Zaragoza, Prensas de la Universidad de Zaragoza.

TORRODELlas, Cleto (1988): Versos y romances en ribagorzano. Introduzión, estudio, notas y bocabulario por Francho NAgore. 2. ${ }^{a}$ edizión enamplada. Uesca, Publicazions d'o Consello d'a Fabla Aragonesa, 1988.

Tratado de Paz de Pedro IV [con el rey de Fez]. (Firmado por Pedro iv en Zaragoza el 20 de julio del año 1357). Vid. Pedro iv de Aragón.

Tucídides (2007): Discursos de la guerra del Peloponeso. Versión aragonesa de la Historia de la guerra del Peloponeso, patrocinada por Juan Fernández de Heredia. Edición de Adelino Álvarez Rodríguez. Zaragoza, PUZ / IEA / IET / GA (col. «Larumbe», 48), 2007. Vid. también López Molina.

Tucídides $=$ (Traducción al aragonés de los discursos griegos de Tucídices por Juan Fernández de Heredia, finales del s. xiv). Vid. López Molina.

Ubieto Arteta, Agustín (1972): Toponimia aragonesa medieval. Valencia, Anubar, 1972.

Ubieto Arteta, Antonio (1950): «Notas sobre la Crónica de San Juan de la Peña», Pirineos, vi (1950), pp. 463-493.

Ubieto Arteta, Antonio (1951): «La campana de Huesca», RFE, xxxv (1951), pp. 29-61.

Ubieto Arteta, Antonio (1955): Crónica de los Estados peninsulares (texto del siglo XIV). Estudio preliminar, edición e índices por - Colección Filológica de la Universidad de Granada, vol. XI, Universidad de Granada, 1955.

Ubieto Arteta, Antonio (1967): «Poesía navarro-aragonesa primitiva», EEMCA, VIII (1967), pp. 9-44.

Ubieto Arteta, Antonio (1969): «El texto aragonés de la Crónica de San Juan de la Peña», en VIII Congreso de Historia de la Corona de Aragón, Valencia, 1969, tomo II, vol. I, págs. 307-310.

Ubieto Arteta, Antonio (1979): La campana de Huesca. Colección «Alcorces», Tema Aragonés 4, Zaragoza, Anubar ediciones, 1979. 
Ubieto Arteta, Antonio (1981): Historia de Aragón. Literatura medieval, I. Zaragoza, Anubar, 1981. [Especialmente pp. 53-55 sobre la Crónica de San Juan de la Peña].

Ubieto Arteta, Antonio (ed.) (1961): Crónica de San Juan de la Peña. Versión latina e índices preparados por —, Valencia, Anubar (Textos Medievales, 4), 1961.

Umphrey, G. W. (1907): «Aragonese text now edited for the first time», RHi, xVI (1907), pp. 244-287.

Umphrey, G. W. (1911): «The aragonese dialect», RHi, xxIV (1911), pp. 5-45. [Traducción castellana por Alfredo Alvar: «El dialecto aragonés», $A F A$, xxxix, 1987, pp. 163-201] [AD]

VÄÄNÄNEM, Veikko (1968): Introducción al latín vulgar. Versión española de Manuel Carrión. Madrid, Gredos, 1968.

Vallés Giménez, Miguel (2007): Vocabulario románico (Diccionario de las lenguas románicas). 2 tomos. Segunda edición revisada, corregida, actualizada y ampliada. Barcelona, edición del autor.

VÀrvaro, Alberto (1970): «Tradizioni scrittorie e lingua parlata: il dittongamento di o breve tonica nell'Alta Aragona», Bolletino del Centro di Studi Filologici e Lingusitici Siciliani, 11 (1969), pp. 480-497. [También publicado en A. Vàrvaro, La parola nel tempo. Lingua, società e storia, Bolonia, Il Mulino, 1984, pp. 187-204. Trad. en cast. por José M. ${ }^{a}$ Enguita: «De la escritura al habla: la diptongación de o breve tónica en el Alto Aragón», $A F A$, XLXI-XLVII, pp. 245-265].

VÀrvaro, Alberto (1988): Historia, problemas y métodos de la lingüistica románica. Traducción de Anna María Mussons. Barcelona, Sirmio, 1988.

VÀrvaro, Alberto: «Storia della lingua: passato e prospettive di una categoria controversa (I)», RPh, vol. xxvi, n. ${ }^{\circ} 1$ (agosto 1972), pp. 16-51; (II), RPh, vol. XXVI, n. ${ }^{\circ} 3$ (febrero 1973), pp. 509-531.

VÁzquez obrador, Jesús (1988): «Poesías en aragonés de la Palestra Nvmerosa Avstriaca (Huesca, 1650): estudio lingüístico», Alaz̨et, Revista de Filología del I.E.A., n 0 (Huesca, 1988), pp. 153-190. [Publicado anteriormente en Argensola, tomo XXIII, n. ${ }^{\circ}$ 92, 1981, pp. 319-356].

VÁzquez Obrador, Jesús (1998): «Onomástica de Biescas en protocolos del siglo xv: documentos», Alazet, 11 (1998), pp. 153.181.

VÁzquez Obrador, Jesús (1999): «El aragonés de Tierra de Biescas y Gavín: breve caracterización», Alažet, 11, pp. 153.181.

VÁzquez Obrador, Jesús, «Soluciones romances de la geminada -LL- en la toponimia de Sobremonte, Ribera de Biescas y Sobrepuerto (Huesca). Intento de explicación fonético-fonológica», Anuario de Estudios Filológicos, XVI (Universidad de Extremadura, 1993), pp. 391-415.

VÁzquez Obrador, Jesús, Toponimia de las comarcas de Tierra de Biescas y Sobrepuerto (Huesca). Sabiñánigo, Comarca del Alto Gállego, 2002. 
Vázquez Obrador, Jesús (2009): «Documentos notariales tensinos del siglo XV redactados en aragonés (I): años 1401, 1402 y 1424», Alą̧et, 21 (2009), pp. 89-122. $[D N T, \mathrm{I}]$

VÁzquez Obrador, Jesús (2010): «Documentos notariales tensinos del siglo xv redactados en aragonés (II): años 1403-1405«, Alazet, 22 (2010), pp. 145206. [DNT, II]

VÁzquez Obrador, Jesús (2011a): «Documentos notariales tensinos del siglo xv redactados en aragonés (III)): años 1424-1426», Alazet, 23 (2011), pp. 99-218. $[D N T, \mathrm{III}]$

VÁzquez Obrador, Jesús (2011b): Sobre fonética histórica del aragonés. Uesca, Publicazions d'o Consello d'a Fabla Aragonesa (col. «A tefla de cuatro fuellas»,7).

VÁzquez Obrador, Jesús (2011c): Ordinaciones y paramientos de la ciudad de Barbastro (1396-1557), publicados por D. Mariano de Pano. Aspectos lingüísticos, por D. Jesús Vázquez Obrador Barbastro, Ayuntamiento de Barbastro. [OB]

VÁzquez Obrador, Jesús (2012): «Documentos notariales tensinos del siglo xV redactados en aragonés (IV): años 1427 y 1428», Alazet, 24 (2012), pp. 173-274. $[D N T, I V]$

VÁzquez Obrador, Jesús (2013): «Documentos notariales tensinos del siglo xv redactados en aragonés (v): año 1431», Alazet, 25 (2013), pp. 121-248. [DNT, v]

VÁzquez Obrador, Jesús (2017): «Documentación tensina en pergaminos de 1374, 1396 y 1409, reutilizados como cubierta de protocolos. Edición y notas lingüísticas», $A F A, 73$ (2017), pp. 61-98.

VÁzquez Obrador, Jesús (2019): «Léxico atestiguado en documentación medieval tensina (I); años 1318, 1374 y 1396», Alazet, 31 (2019), pp. 143-173.

VÁzQuez Obrador, Jesús (2020): «Léxico atestiguado en documentación medieval tensina (II): años1401 y 1402», Luenga \& fablas, 23-24 (2019-2020), pp. 89-113.

Vicén Pérez, Ana Cristina, y Moncayola, Santiago (1991): Bocabulario de l'ansotano. Huesca, Publicazions d'o Consello d'a Fabla Aragonesa.

Vicente DE VERA, Eduardo (1992): El aragonés: historiografía y literatura. Zaragoza, Mira Editores.

VIDALLER TRICAS, Rafel (1989): Dizionario sobre espezies animals y bexetals en o bocabulario altoaragonés. Huesca, Instituto de Estudios Altoaragoneses.

VidAlLER TRICAS, Rafel (2004): Libro de as matas y os animals. Dizionario aragonés d'espezies animals y bechetals. Zaragoza, Consejo de Protección de la Naturaleza de Aragón.

Vidaller Tricas, Rafel (2020): «As corporals cosas: o lesico d'o mundo natural en o Libro d'o Trasoro», Luenga \& fablas, 23-24 (2019-2020), pp. 73-88.

Vidos, B. E. (1977): Manual de lingüistica románica. Traducción de F. de B. Moll. 2. edición, Madrid, Aguilar. 
Vila Rubio, Ma Nieves (1989): «Aproximación a la lengua coloquial del siglo XV en el Bajo Aragón», AFA, XLII-XLIII (1989), pp. 65-81.

Vila Rubio, Ma Nieves (1990): Aspectos de sintaxis coloquial en documentos aragoneses del siglo XV. Zaragoza, Diputación General de Aragón, Departamento de Cultura y Educación (Colección de Filología y Lingüística, 3), 1990.

ViÑAZA, Conde de la- (1986 [1904]): Los cronistas de Aragón. Edición facsimilar del texto original de 1904 con una introducción a cargo de Carmen OrcÁstegui Gros y Guillermo Redondo Veintemillas, Zaragoza, Cortes de Aragón, 1986.

Viudas Camarasa, Antonio (1979): «Sobre la evolución de (PL-) a (pll-) y (CL-) a (cll-) en aragonés antiguo», AEF, II (Cáceres, 1979), pp. 355-375.

Viudas Camarasa, Antonio (1986): Dialectología hispánica y geografía lingüística en los estudios locales (1920-1984). Bibliografía crítica y comentada. Confederación Española de Centros de Estudios Locales (CSIC), Institución Cultural «El Brocense», Cáceres.

Viudas Camarasa, Antonio (1988): «Notas sobre el léxico de un inventario medieval», en Actas del I Congreso Internacional de Historia de la Lengua Española, vol. I, Madrid, Arco/Libros, 1988, pp. 1003-1006.

Vives, Josep (1927): Juan Fernández de Heredia, Gran Maestre de Rodas. Barcelona, Biblioteca Balmes, 1927.

VOX. Diccionari manual castellà-català, català-castellà, novena edició (reimpressió), Barcelona, Bibliograf, 1988.

WitTlin, Curt J. (1976): «Un inventario turolense de 1484: Los Sánchez Muñoz, herederos del Papa Clemente vIII», AFA, XVIII-XIX (1976), pp. 187-215. [En relación con el texto de este inventario, vid. el artículo de Antonio Viudas Camarasa, «Notas sobre el léxico de un inventario medieval», en Actas del I Congreso Internacional de Historia de la Lengua Española, vol. I, Madrid, Arco/libros, 1988, pp. 1003-1006.]

Ximénez de Embún, Tomás (1876): Historia de la Corona de Aragón (la más antigua de que se tiene noticia), conocida generalmente con el nombre de Crónica de San Juan de la Peña. Zaragoza, Diputación Provincial, 1876. [Contiene un breve «Vocabulario de las palabras y frases anticuadas y extrañas, contenidas en la versión aragonesa», pp. 247-252. Nos referimos a él como: Ximénez de EmBún, Vocabulario].

Yanguas y Miranda, José (1854): Diccionario de las palabras anticuadas que contienen los documentos existentes en los archivos de Navarra, y de su correspondencia con el lenguaje actual. Pamplona, Imprenta de Francisco Erasun, 1854. [Nuevamente publicado en $A F A$, XxxIX, 1987, pp. 205-241].

Yanguas y Miranda, José (1964 [1840]): Diccionario de antigüedades del Reino de Navarra. 3 tomos, Pamplona, Diputación Foral de Navarra - Institución Príncipe de Viana, 1964. [Reimpresión de la edición de 1840].

YlLERA, Alicia (1980): Sintaxis histórica del verbo español: Las perifrasis medievales. Zaragoza, Departamento de Filología Francesa, Universidad de Zaragoza, 1980. 
YNDURÁIN, Francisco (1945): Contribución al estudio del dialecto navarro-aragonés antiguo. Zaragoza, I.F.C., 1945. [INdurárn, Contribución]. Vid. Induráin.

Zamora vicente, Alonso (1967): Dialectología española. 2. ${ }^{a}$ edición muy aumentada, Madrid, Gredos.

Zonaras, Juan (2006): Libro de los emperadores (Versión aragonesa del Compendio de bistoria universal patrocinada por Juan Fernández de Heredia). Edición de Adelino Álvarez Rodríguez. Fuentes bizantinas de Francisco Martín García. Zaragoza, IEA / PUZ / GA / IFC, 2006. Vid. Álvarez Rodríguez. 


\section{ÍNDICE}

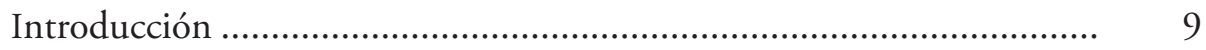

1. La Crónica de San Juan de la Peña ....................................................

1.1. Contenido, autor y fecha de redacción...................................... $\quad 10$

1.2. Versiones latina y catalana: manuscritos y ediciones ................... 19

1.3. Versión aragonesa: manuscritos y ediciones................................ 22

1.4. Importancia histórica................................................................. 25

1.5. Interés lingüístico de la versión aragonesa ................................... 27

2. Estudio del léxico de la Crónica de San Juan de la Peña .................... 30

2.1. El índice de frecuencias ......................................................... $\quad 30$

2.2. El índice lematizado .............................................................. 34

2.3. El vocabulario........................................................................ 41

Abreviaturas y siglas bibliográficas ........................................................ 47

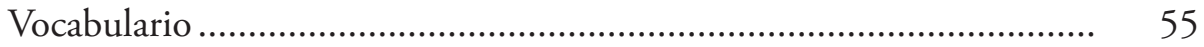

Bibliografía........................................................................................ 471 
Este libro se acabó de imprimir en los talleres del Servicio de Publicaciones de la Universidad de Zaragoza en abril de 2021

$\cos$ 
La Crónica de San Juan de la Peña, conocida también en la Edad Media como Coronicas de los senyores reyes d'Aragón, fue redactada a instancias de Pedro IV el Ceremonioso en la segunda mitad del siglo XIV. La redacción inicial fue en latín y posteriormente se tradujo al catalán y al aragonés. La versión en aragonés parece que estaría ya redactada hacia 1372. Se trata de uno de los textos en aragonés clásico más interesantes que suma a su importancia histórica su interés lingǘstico. Francho Nagore Laín publicó en 2003 un amplio estudio de los aspectos lingüísticos de este texto que incluía la grafemática, la fonética, la morfología, la sintaxis y la formación de palabras. Ahora publica en este volumen el vocabulario completo de dicho texto, que consta de 2285 entradas. Cada una de estas incluye, además del lema o encabezamiento, la categoría gramatical, su significado en castellano, ejemplos del texto para cada una de las acepciones, comentarios sobre la etimología, las palabras del mismo origen en otras lenguas románicas y la documentación sobre el registro de las voces tanto en aragonés medieval como moderno. Es, pues, una contribución al conocimiento del léxico del aragonés medieval a partir de una obra emblemática, tanto histórica como lingüísticamente.

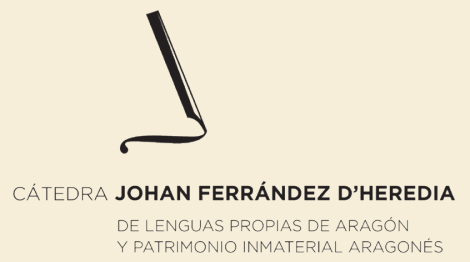

UNIVERSIDAD DE ZARAGOZA GOBIERNO DE ARAGÓN 